\title{
Wissenschaftlicher Realismus
}

Dissertation

zur Erlangung des philosophischen Doktorgrades an der Philosophischen Fakultät der Georg-August-Universität Göttingen

\author{
vorgelegt von \\ Frank Tschepke \\ aus Kassel
}

Göttingen 2003 
1. Gutachter: Prof. Dr. Felix Mühlhölzer

2. Gutachter: Prof. Dr. Ulrich Majer

Tag der mündlichen Prüfung: 


\section{Inhaltsverzeichnis}

Vorwort $\quad$ xiii

1 Einleitung: Die Realismusdebatte in der Wissenschaftstheorie und ihr $\begin{array}{lr}\text { allgemein-philosophisches Umfeld } & 1\end{array}$

1.1 Probleme des Realismus . . . . . . . . . . . . . . . . . . . . . . . 1

1.2 Realismus in allgemein-philosophischen Diskussionen: Dimensionen des Themas, Thesen und Positionen . . . . . . . . . . . . . . . . 2

1.2.1 Realistische Thesen . . . . . . . . . . . . . . . . 3

1.2.2 Gegenpositionen . . . . . . . . . . . . . . . . 9

1.3 Realismus in der Wissenschaftstheorie: Dimensionen des Themas, Thesen und Positionen . . . . . . . . . . . . . . . . . 11

1.3.1 Realistische Thesen . . . . . . . . . . . . . . . . . 11

1.3.2 Gegenpositionen ...................... 18

1.4 Realismus: Das Verhältnis von allgemein-philosophischen und wissenschaftstheoretischen Thesen, Positionen und Argumentationen . . . . . . . . . 20

1.4.1 Ein Cluster realistischer Thesen mit mehreren Teilclustern, das Thema der wissenschaftstheoretischen Realismusdebatte als "Spezialgebiet", kein Konsens über die für eine realistische Position konstitutiven Thesen . . . . . . . . . . . . . . . . . . 20

1.4.2 Strategien der Argumentation für (oder gegen) wissenschaftlichen Realismus und ihr Verhältnis zur Argumentation für (oder gegen) realistische Thesen bezüglich anderer Bereiche . . . . . . . . . . . . 21

1.4.3 Realistische Positionen im Mainstream der wissenschaftstheoretischen Debatte . . . . . . . . . . . . . . . 22

1.4 .4 Fazit . . . . . . . . . . . . . . . . . 25

I Bedeutungs-, Referenz- und Wahrheitstheorien für die Sprache der Wissenschaften

2 Verifikationistische Theorien und die "Standarddarstellung" des logischen Positivismus 31

2.1 Die Verifikationstheorie . . . . . . . . . . . . . . . . . 31

2.2 Die Erosion der Verifikationstheorie: Reduktionssätze versus Definitionen . 33

2.3 Die "Standarddarstellung" wissenschaftlicher Theorien . . . . . . . . . . . . 37

2.4 Logischer Positivismus und Wahrheits- und Referenztheorien . . . . . . . . 42

2.5 Bedeutungs-, Referenz- und Wahrheitstheorien des logischen Positivismus und semantischer Realismus . . . . . . . . . . . . . . . . . 45 
2.5.1 Die Verifikationstheorie . . . . . . . . . . . . . . 47

2.5.2 Die Standarddarstellung . . . . . . . . . . . . . . . . . . 49

2.6 Probleme und Einwände . . . . . . . . . . . . . . . . . 52

2.6.1 Die Adäquatheit der Formalisierung . . . . . . . . . . . . . . . 53

2.6.2 Die Unterscheidung Beobachtungsterme/theoretische Terme . . . . . 53

2.6.3 Die Unterscheidung analytisch/synthetisch . . . . . . . . . . . 54

2.6.4 Veränderungen der Bedeutung theoretischer Ausdrücke und die "pessimistische Induktion" . . . . . . . . . . . . . . . . . . . 55

2.6.5 Unterbestimmtheit . . . . . . . . . . . . . . . . . . 59

2.6.6 Bedeutungskonstituierende Beschreibungen, sprachliche Kompetenz und Referenzbestimmung ............... . 61

2.7 Fazit . . . . . . . . . . . . . . . . . . . 62

3 Kontextheorien $\quad 65$

3.1 Die Idee einer Kontexttheorie und ihre Varianten . . . . . . . . . . . . . . 65

3.2 Kontexttheorie und semantischer Realismus . . . . . . . . . . . . . . 67

3.3 Probleme und Einwände . . . . . . . . . . . . . . . . . . . . 69

3.3.1 Die Abgrenzung des bedeutungskonstituierenden Kontextes eines Ausdrucks . . . . . . . . . . . . . . . . . . 69

3.3.2 Veränderungen von Bedeutung und Referenz . . . . . . . . . . 71

3.3.3 Inkommensurabilitätsprobleme . . . . . . . . . . . . . . . . . 72

3.4 Fazit . . . . . . . . . . . . . . . . . . 75

4 Kausale Referenz- und Bedeutungstheorien $\quad 77$

4.1 Kripkes kausale Theorie der Referenz . . . . . . . . . . . . . . . 77

4.1 .1 Eigennamen . . . . . . . . . . . . . . . . . . 77

4.1.2 Bezeichnungen für natürliche Arten . . . . . . . . . . . . . . 78

4.2 Putnams Bedeutungstheorie . . . . . . . . . . . . . . . 80

4.2.1 Die Theorie für natürliche Arten und physikalische Größen . . . . . 80

4.2.2 Der Zusammenhang zwischen der Referenz eines Art- oder Größennamens und den Eigenschaften, die den Referenzobjekten zugeschrieben werden . . . . . . . . . . . . . . . . . . 82

4.3 Kausale Referenztheorie und Wahrheit . . . . . . . . . . . . . . . . 88

4.4 Die kausale Referenztheorie und semantischer Realismus . . . . . . . . . . . 89

4.5 Probleme und Einwände . . . . . . . . . . . . . . . . . . . . 89

4.5.1 Probleme der deskriptiven Adäquatheit des Modells von Kripke und Putnam . . . . . . . . . . . . . . . . . . 90

4.5.2 Konflikte mit vortheoretischen Intuitionen über die Referenz wissenschaftlicher Art- und Größennamen: "Zu stabile" Referenzrelationen 92

4.5.3 Generalisierungsprobleme bei der Einführung von Art- und Größennamen . . . . . . . . . . . . . . . . . . . . 94

4.5.4 Die Rolle der Kausalität in der kausalen Referenztheorie . . . . . . . 98

4.6 Fazit . . . . . . . . . . . . . . . . . . . . . . 99

5 Hybridtheorien $\quad 103$

5.1 Die Idee einer Hybridtheorie und ihre Varianten . . . . . . . . . . . . . . 103

$5.1 .1 \quad$ Die Idee . . . . . . . . . . . . . . . . . . . . . . 103

5.1.2 Die Angabe einer Kategorie als minimale Beschreibung . . . . . . . 105 
5.1.3 Die Angabe eines kausalen Mechanismus als minimale Beschreibung 105

5.1.4 Die Angabe einer explanatorischen Metapher als minimale Beschreibung . . . . . . . . . . . . . . . . . 107

5.1.5 Der Zusammenhang zwischen der Referenz eines Art- oder Größennamens und den Eigenschaften, die den Referenzobjekten zugeschrieben werden . . . . . . . . . . . . . . . . . . . . 109

5.2 Hybridtheorien, Bedeutung, Wahrheit, semantischer Realismus . . . . . . . 110

5.3 Probleme und Einwände . . . . . . . . . . . . . . . . . . . 111

5.3.1 Wie klar und wohldefiniert sind die verschiedenen Vorschläge für minimale Beschreibungen? . . . . . . . . . . . . . . . . . 111

5.3.2 Sind die Hybridtheorien frei von den Problemen der kausalen Referenztheorie? . . . . . . . . . . . . . . . . . . . . . 113

5.3.3 Sind die Hybridtheorien frei vom Problem der Referenzinstabilitäten, das Beschreibungstheorien häufig belastet? . . . . . . . . . . . 115

5.4 Fazit . . . . . . . . . . . . . . . . . . 116

6 Fazit: Bedeutungs-, Referenz- und Wahrheitstheorien für die Sprache der Wissenschaften und ihre Eignung für eine Rolle in der Realismusdebatte

II Argumente für wissenschaftlichen Realismus $\quad 121$

7 Präsuppositionsargumente $\quad \mathbf{1 2 5}$

7.1 Putnams Konjunktionsargument . . . . . . . . . . . . . . . 125

7.2 Cartwrights Generalisierungsargument . . . . . . . . . . . . . . . 130

7.3 Probleme und Kritik . . . . . . . . . . . . . . . . . 137

7.4 Fazit . . . . . . . . . . . . . . . . . . . 139

8 Kontinuitätsargumente $\quad 141$

8.1 "Destruktive" Kontinuitätsargumente . . . . . . . . . . . . . . . . . . 141

8.1.1 Zweifel, daß die Unterscheidung beobachtbar/theoretisch eine für philosophische Zwecke brauchbare Grenzziehung ergibt . . . . . . . . 141

8.1.2 Van Fraassens Replik: Eine Präzisierung des Begriffes der Beobachtbarkeit . . . . . . . . . . . . . . . . . . . 142

8.2 "Positive" Kontinuitätsargumente: vortheoretische Intuitionen über Kontinuitäten auf der Sachebene . . . . . . . . . . . . . . . . . 145

8.2.1 Die "Merkwürdigkeit" eines anthropozentrischen Weltbildes . . . . . 145

8.2.2 Zwei antirealistische Repliken . . . . . . . . . . . . . . . . . . 147

8.3 "Positive" Kontinuitätsargumente: epistemische Kontinuitätsargumente . . 149

8.3.1 Naturalistische und reliabilistische Ansätze in der Erkenntnistheorie 151

8.3.2 Kontinuität durch eine "grenzüberschreitende" Folge von Beobachtungsverfahren mit überlappendem Anwendungsbereich (Maxwell) . 157

8.3.3 Kontinuität durch ein grenzüberschreitendes kausales Beobachtungsverfahren (Salmon) . . . . . . . . . . . . . . . 158

8.3.4 Kontinuität durch ein grenzüberschreitendes kausales Inferenzprin-

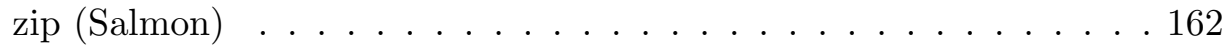

8.3.5 Kontinuität durch ein grenzüberschreitendes Inferenzprinzip des Schließens auf die beste Erklärung (Glymour) . . . . . . . . . 167 
8.3.6 Probleme und Einwände . . . . . . . . . . . . . . . . . . 171

8.4 Fazit . . . . . . . . . . . . . . . . . . . 182

9 Das Wunderargument und seine Varianten $\quad 185$

9.1 Formulierungen des Wunderarguments . . . . . . . . . . . . . . . . . 185

9.1.1 Die Idee, grob formuliert (Putnam, Smart) . . . . . . . . . . . . 185

9.1.2 Ein präzisierter Vorschlag für das Explanandum: erfolgreiche neue Prognosen und unbeabsichtigte Vereinheitlichungsleistungen . . . . . 188

9.1.3 Ein präzisierter Vorschlag für das Explanandum: die Verläßlichkeit wissenschaftlicher Methodologie (Boyd) . . . . . . . . . . . 189

9.1.4 Ein Vorschlag für ein "abgeschwächtes" Explanans: Realismus der Phänomenarten (Carrier) . . . . . . . . . . . . . . . . . . . 192

9.1.5 Ein Vorschlag für ein "abgeschwächtes" Explanans: Realismus der mathematischen Strukturen (Worrall) . . . . . . . . . . . . . 193

9.2 Die Versionen des Wunderarguments als Schlüsse auf die beste Erklärung: Die Version von Putnam und Smart und deren Varianten mit präzisiertem Explanandum (erfolgreiche neue Prognosen und unbeabsichtigte Vereinheitlichungsleistungen . . . . . . . . . . . . . . . . . . . . . . . . . . 194

9.2.1 Erfolge einzelner Theorien oder Erfolge der Gesamtheit wissenschaftlicher Theorien als Explanandum . . . . . . . . . . . . . . . 195

9.2.2 Semantische oder epistemische Antirealisten als Diskussionsgegner . 197

9.2.3 Prognoseerfolge als Explanandum . . . . . . . . . . . . . . . 199

9.2.4 Vereinheitlichungsleistungen als Explanandum . . . . . . . . . . . . 202

9.2.5 Handlungserfolge als Explanandum . . . . . . . . . . . . . . . . . 203

9.3 Die Versionen des Wunderarguments als Schlüsse auf die beste Erklärung:

Die Version von Boyd . . . . . . . . . . . . . . . . . . . . . . 210

9.4 Die Versionen des Wunderarguments als Schlüsse auf die beste Erklärung:

Die Version von Carrier . . . . . . . . . . . . . . . . . . . . . 211

9.5 Die Versionen des Wunderarguments als Schlüsse auf die beste Erklärung: Die Version von Worrall . . . . . . . . . . . . . . . . . . . . . . . 212

9.6 Die Versionen des Wunderarguments als Schlüsse auf die beste Erklärung: Explanantia des Wunderarguments und realistische Thesen . . . . . . . . 213

9.7 Die Versionen des Wunderarguments als Schlüsse auf die beste Erklärung: Probabilistische Modelle für kognitive Zustände . . . . . . . . . . . . . . . 214

9.8 Die Versionen des Wunderarguments als Schlüsse auf die beste Erklärung: Fazit . . . . . . . . . . . . . . . . . . . . . . 217

9.9 In welchem Sinn von 'erklären' wird das Explanandum des Wunderarguments durch dessen Explanans erklärt (und in welchem Sinn nicht)? . . . . 218

9.9.1 Die Erklärung einfacher Prognoseerfolge . . . . . . . . . . . . . 220

9.9.2 Die Erklärung neuer Prognoseerfolge . . . . . . . . . . . . . . . . . . 223

9.9.3 Die Erklärung von Vereinheitlichungsleistungen . . . . . . . . . . . . 225

9.9.4 Die Erklärung von Handlungserfolgen . . . . . . . . . . . . . . . . 225

9.9.5 Die Erklärung der instrumentellen Verläßlichkeit der Methodologie der Wissenschaften (Boyd) . . . . . . . . . . . . . . . 227

9.9.6 Die Erklärung neuer Prognoseerfolge durch abgeschwächte Explanantia (Carrier/Worrall) . . . . . . . . . . . . . 233

9.9 .7 Fazit . . . . . . . . . . . . . . . . . . . 235

9.10 Probleme und Einwände . . . . . . . . . . . . . . . 236 
9.10.1 Das Wunderargument im Lichte der Geschichte der Wissenschaften betrachtet . . . . . . . . . . . . . 236

9.10 .2 Unterbestimmtheit . . . . . . . . . . . . . . . . . . . . 239

9.10.3 Vorschläge für Alternativen zu den Erklärungen, auf die gemäß dem Wunderargument zu schließen ist; Kriterien für die beste Erklärung 248

9.10.4 Der Petitio-Principii-Einwand . . . . . . . . . . . . . . . . . 256

9.10.5 In welchem Sinn sind die Explananda, auf die sich das Wunderargument bezieht, erklärungsbedürftig oder "wundersam" und welche argumentative Rolle spielen die Inanspruchnahme von Erklärungsbedarf und die Rede von "Wunder"? . . . . . . . . . . . . . . . . 263

10 Bas van Fraassens konstruktiver Empirismus 295

10.1 Einleitung . . . . . . . . . . . . . . . . . . . 295

10.2 Konstruktiver Empirismus . . . . . . . . . . . . . . . . . . 295

10.2.1 Semantischer Realismus plus ontologischer, epistemischer und axiologischer Antirealismus . . . . . . . . . . . . . . . . 295

10.2.2 Die Unterscheidung beobachtbar/unbeobachtbar . . . . . . . . . 296

10.2.3 Die Unterscheidung akzeptieren/glauben . . . . . . . . . . . . . . . 297

10.2.4 Van Fraassens Ideal epistemischer Rationalität . . . . . . . . . . 297

10.3 Probleme und Kritik . . . . . . . . . . . . . . . . . . . 300

10.3.1 Die Frage nach der konsistenten Abgrenzung dessen, was ein konstruktiver Empirist glauben darf _. . . . . . . . . . . . 300

10.3.2 Epistemische Kontinuitätsargumente . . . . . . . . . . . . . 303

10.4 Fazit . . . . . . . . . . . . . . . . . . . . . . . . 304

11 Der experimentelle Realismus von Ian Hacking und Nancy Cartwright 307

11.1 Einleitung . . . . . . . . . . . . . . . . . . . 307

11.2 Terminologisches . . . . . . . . . . . . . . . . . . 308

11.3 Hacking . . . . . . . . . . . . . . . . . . . . . . . 310

11.3.1 Hackings "experimentelles Argument" für wissenschaftlichen Realis-

mus . . . . . . . . . . . . . . . . . . 310

11.3.2 Probleme und Kritik . . . . . . . . . . . . . . . . . . . . . 320

11.3.3 Hackings experimentelles Argument - eine Zwischenbilanz . . . . . . 331

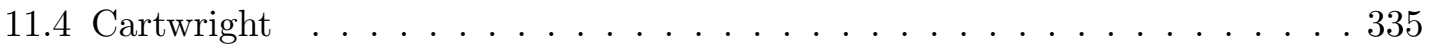

11.4.1 Cartwrights Argumentation für wissenschaftlichen Realismus . . . . 335

11.4 .2 Probleme und Kritik . . . . . . . . . . . . . . . . . . . . . . . 346

11.5 Der experimentelle Realismus von Hacking und Cartwright — Fazit . . . 352

12 Andrew Pickerings Sozialkonstruktivismus 355

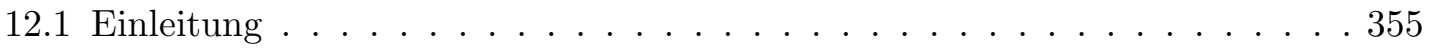

12.2 Constructing Quarks . . . . . . . . . . . . . . . . . 356

12.3 The Mangle of Practice . . . . . . . . . . . . . . . . . 360

12.4 Probleme und Kritik . . . . . . . . . . . . . . . . . . . . . . 364

12.4.1 Constructing Quarks . . . . . . . . . . . . . . . 364

12.4.2 The Mangle of Practice . . . . . . . . . . . . . . . . 373 
12.5 Fazit . . . . . . . . . . . . . . . . . . . . . . . . . . . . . . . .

IV Das Programm eines selektiven wissenschaftlichen Realismus 381

13 Der Umriß einer selektiven realistischen Position in der wissenschaftstheoretischen Realismusdebatte $\quad \mathbf{3 8 3}$

13.1 Eine Bilanz der bisherigen Debatte . . . . . . . . . . . . . . . 383

13.2 Welche Art(en) von Thesen ist (sind) konstitutiv für eine realistische Position?387

13.2.1 Ontologische oder semantische plus epistemische Thesen als Herzstück einer realistischen Position? . . . . . . . . . . . . . . . . 387

13.2.2 Erläuterungen und Ergänzungen zu ontologischen realistischen Thesen400

13.2.3 Ontologische realistische Thesen und konstruktivistische Motive . . . 411

13.2.4 Eine axiologische These als konstitutiv für eine realistische Position? 415

13.2.5 Fazit: Ontologische realistische Thesen bilden das Herzstück einer intuitiv angemessenen realistischen Position . . . . . . . . . . . 417

13.3 Welche Rolle spielen Wahrheits-, Bedeutungs- und Referenztheorien für eine realistische Position? . . . . . . . . . . . . . . . . . . . . . 418

13.3.1 Die Verträglichkeit von ontologischen realistischen Thesen und semantischen Theorien . . . . . . . . . . . . . . . . . . 418

13.3.2 Die Rolle semantischer Theorien bei der Begründung oder Verteidigung einer realistischen Position . . . . . . . . . . . . . . 421

13.4 Eine selektive realistische Position in der wissenschaftstheoretischen Realismusdebatte, deren Herzstück ontologische realistische Thesen bilden: einige Details . . . . . . . . . . . . . . . . . . . . . . . 424

13.4.1 Natur, Herkunft und Inhalt ontologischer realistischer Thesen . . . . 424

13.4.2 "Epistemisch vorsichtige" ontologische realistische Thesen . . . . . . 426

13.4.3 Die Struktur der Gesamtheit der ontologischen realistischen Thesen, die eine selektive realistische Position konstituieren . . . . . . . . . . 429

\section{Rechtfertigungsgründe und Argumente für ontologische realistische The-}

14.1 Die Argumentation gegen instrumentalistische Diskussionsgegner . . . . . . 432

14.1.1 Die argumentative Konstellation in der Diskussion zwischen Realisten und Instrumentalisten . . . . . . . . . . . . . . . . . 432

14.1.2 Eine Argumentationsstrategie für konziliante Realisten und Instrumentalisten: Die Verlagerung der Debatte auf die epistemische Ebene 436

14.1.3 Ein kausales Kriterium im Anschluß an Hacking und Cartwright . . 439

14.1.4 Argumente für epistemische Zugänglichkeit . . . . . . . . . . . . . . 442

14.1.5 Fazit . . . . . . . . . . . . . . . . . . . . . . . . 446

14.2 Epistemische Rechtfertigungsgründe und Argumente für ontologische realistische Thesen . . . . . . . . . . . . . . . . . . . . 448

14.2.1 Eine naturalistische und reliabilistische Perspektive . . . . . . . . . . 448

14.2.2 Der Zusammenhang zwischen der Eigenschaft einer Überzeugung, daß $P$, gerechtfertigt zu sein, Rechtfertigungsgründen und Argumenten für die Überzeugung, daß $P$, und der Überzeugung (zweiter Ordnung), daß die Überzeugung, daß $P$, gerechtfertigt ist . . . . . . 455 
14.2.3 Rechtfertigungsgründe und Argumente für ontologische realistische Thesen über Beobachtbares . . . . . . . . . . . . . . . . . 458

14.2.4 Rechtfertigungsgründe und Argumente für ontologische realistische Thesen über Unbeobachtbares . . . . . . . . . . . . . . . . . . 494

14.2 .5 Fazit . . . . . . . . . . . . . . . . . . . 520

15 Ein Baustein für die Realisierung des Programms eines selektiven wissenschaftlichen Realismus

15.1 Elektrische Ströme und Spannungen . . . . . . . . . . . . . . . . . . . 524

Zusammenfassung und Fazit 
Für Lorenz Krüger 



\section{Vorwort}

Eine Aufzählung der äusseren Umstände, durch die sich das Erscheinen dieser Schrift so lange verzögert hat, wäre ohne Interesse für den Leser; der innere Grund der Verzögerung lag in der Schwierigkeit eines Theiles der zu behandelnden Probleme und der gerechten Scheu, zu Fragen, die den Meisten für transcendent gelten, eine Meinung zu äussern, ehe dieselbe nicht nach den verschiedensten Seiten gekehrt und zu einem wenigstens subjectiv befriedigenden Abschluss gebracht war. ${ }^{1}$

Gegenstand dieser Arbeit sind der wissenschaftliche Realismus und die Debatte, die in der Wissenschaftstheorie um realistische und andere, alternative Positionen geführt wird. Es wird untersucht, wie in dieser Debatte realistische Positionen formuliert werden, es werden die für und gegen wissenschaftlichen Realismus vorgebrachten Argumente analysiert, und es wird im Anschluß daran untersucht, wie im Lichte der bisherigen Debatte eine intuitiv angemessene und haltbare realistische Position zu formulieren ist, und was sich für sie an Rechtfertigungsgründen und an überzeugungskräftigen Argumenten angeben läßt.

Das Resultat ist der Umriß einer moderaten realistischen Position, der auszufüllen ist durch eine Vielzahl von Einzelthesen über unbeobachtbare Gegenstände und Sachverhalte aus den Themenbereichen der Wissenschaften, außerdem eine Analyse der Möglichkeiten und der Grenzen der Möglichkeiten, für eine solche realistische Position erfolgreich zu argumentieren, sowie ein umfangreiches Programm für die Suche nach den Einzelthesen, die konstitutiv für eine solche realistische Position sind, und nach den für sie im einzelnen zur Verfügung stehenden Rechtfertigungsgründen und Argumenten.

Das Thema "wissenschaftlicher Realismus" ist zu groß und die Realismusdebatte in der Wissenschaftstheorie inzwischen viel zu umfangreich, um sie in einer Arbeit, selbst einer vergleichsweise langen wie dieser, auch nur annähernd vollständig und erschöpfend zu diskutieren. Die folgenden Kapitel spiegeln daher notwendigerweise eine Perspektive wieder, die durch meinen Zugang zu dieser Debatte geprägt ist, und aus der diese Debatte nicht vollständig erfaßt wird, auch wenn das Ziel ist, wenigstens die systematisch wichtigsten Positionen und Argumente in den Blick zu nehmen. Der Gang der Untersuchung ist der Folgende.

\footnotetext{
${ }^{1}$ Alois Riehl; Der philosophische Kriticismus und seine Bedeutung für die positive Wissenschaft, zweiter Band, zweiter Theil, Leipzig, 1887, S.III.
} 
In der Einleitung wird eine systematisierende Übersicht über die verschiedenen, vielfach nicht präzise formulierten Thesen gegeben, die in der wissenschaftstheoretischen Realismusdebatte unter dem Stichwort "Realismus" vertreten und bestritten werden, und damit auch über die diversen, durch verschiedene solcher Thesen konstituierten realistischen Positionen und ihre wichtigsten Gegenpositionen in dieser Debatte. Noch zuvor wird eine entsprechende systematisierende Übersicht über die Thesen, Positionen und Gegenpositionen gegeben, die in allgemein-philosophischen, also nicht auf den Bereich der Wissenschaftstheorie beschränkten Debatten unter dem Stichwort "Realismus" diskutiert werden. Man gewinnt auf diese Weise zum einen präzise Formulierungen für verschiedene, deutlich voneinander unterscheidbare realistische Thesen, zum anderen ein Bild vom Verhältnis der wissenschaftstheoretischen Realismusdebatte zu ihrem allgemein-philosophischen Umfeld und den dort zum Thema "Realismus" geführten Debatten. Beides erweist sich als wichtig für die folgenden Untersuchungen.

Die Kapitel 2 bis 6 sind Bedeutungs-, Referenz- und Wahrheitstheorien für die Sprache der Wissenschaften gewidmet. Diese Theorien sind für die Realismusdebatte in zweierlei Weise relevant: Zum einen zählen sie zum Inhalt einiger realistischer Positionen, zum anderen spielen sie bei der Argumentation für und gegen realistische Positionen an mehreren Stellen eine wichtige Rolle. Im Hinblick auf ihre Eignung für diese Rollen in der Realismusdebatte werden die wichtigsten derzeit vorliegenden semantischen Theorien für die Sprache der Wissenschaften untersucht.

In den folgenden Kapiteln 7 bis 9 werden die Argumente, die in der Realismusdebatte für wissenschaftlichen Realismus vorgebracht werden, nach drei Arten klassifiziert und hinsichtlich ihrer Struktur, ihrer Vorzüge und ihrer Mängel eingehend analysiert. Diskutiert werden nacheinander Präsuppositionsargumente, Kontinuitätsargumente und das Wunderargument und seine Varianten.

Gegenstand der Kapitel 10 bis 12 sind drei neuere Positionen in der Realismusdebatte, die (in unterschiedlichem Maß) als Konkurrenten realistischer Positionen auftreten. Diskutiert werden im Hinblick auf ihre Beiträge zur Realismusdebatte Bas van Fraassens konstruktiver Empirismus, der experimentelle Realismus von Ian Hacking und Nancy Cartwright und schließlich Andrew Pickerings Sozialkonstruktivismus.

In den letzten Kapiteln der Arbeit wird, im Anschluß an eine Bilanz des bis dahin gewonnenen Bildes vom Stand der Dinge in der wissenschaftstheoretischen Realismusdebatte, eine moderate, im dort erläuterten Sinn selektive realistische Position umrissen. Außerdem wird ein Programm skizziert, was zu tun ist, um diesen Umriß einer realistischen Position mit konkreten Thesen auszufüllen und sich alles an Rechtfertigungsgründen und Argumenten für diese Thesen zu verschaffen, was der Natur der Sache nach zu haben ist. In Kapitel 13 wird erörtert, welche der diversen, in der Realismusdebatte diskutierten Thesen konstitutiv für eine intuitiv angemessene realistische Position sind. In Kapitel 14 wird untersucht, welche Rechtfertigungsgründe und Argumente für eine solche Position vorgebracht werden können, und zwar zum einen, was der realistischen Seite in einer Diskussion mit instrumentalistischen Gegnern an Argumenten zur Verfügung steht, zum anderen, was sich von realistischer Seite an epistemischen Rechtfertigungsgründen und Argumenten für die eigene Position ins Feld führen läßt, etwa in einer Diskussion mit antirealistischen Gegnern wie van Fraassen. In Kapitel 15 schließlich wird an einem Fallbeispiel gezeigt, was zu tun wäre, um das skizzierte Programm umzusetzen.

Wenn die angestellten Überlegungen richtig sind, ist die Umsetzung dieses Programms das, was man tun kann, um zu einer plausiblen und haltbaren realistischen Position in der wissenschaftstheoretischen Realismusdebatte zu gelangen, und das, was einem auf realisti- 
scher Seite nach Umsetzung dieses Programms an Argumenten für die eigene Position zur Verfügung steht, ist der Natur der Sache nach das beste, was an argumentativen Mitteln zu haben ist, obwohl dadurch, wie die Diskussion zeigen wird, nicht alle Diskussionsgegner vom wissenschaftlichen Realismus überzeugt werden können.

Obwohl die Argumentation in den folgenden Kapiteln natürlich für sich spricht, ist es vielleicht nützlich anzudeuten, auf welchem Weg ich zu der Position gelangt bin, die am Ende dieser Arbeit steht. Als ich begann, mich mit dem Thema "wissenschaftlicher Realismus" zu beschäftigen, neigte ich, wie viele, die in den Naturwissenschaften sozialisiert worden sind, intuitiv zu einer realistischen Position, ohne jedoch dafür einigermaßen zufriedenstellende Rechtfertigungsgründe oder Argumente nennen zu können und auch ohne ein wirklich präzises Bild davon zu haben, was eigentlich wissenschaftlichen Realismus ausmacht. Meine Versuche, mich auf dem Feld der Realismusdebatte zu orientieren und meine wenig reflektierten realistischen Intuitionen zu einer systematischen, durch Argumente gestützten Position zu entwickeln, brachten zunächst die Erfahrung, daß eine frustrierende Diskrepanz besteht zwischen hartnäckigen realistischen Intuitionen einerseits und der zunächst sehr unbefriedigenden Bilanz der Suche nach Argumenten für eine realistische Position andererseits: Die Argumente, die sich in der Literatur finden, sehen bei etwas genauerer Betrachtung meistens mehr oder weniger skizzenhaft formuliert und unzufriedenstellend aus (auch wenn sie von ihren Anhängern gelegentlich im Brustton der Überzeugung vorgetragen werden), und selbst die Argumente, die noch am griffigsten und plausibelsten aussehen, erweisen sich in der Diskussion mit konsequenten Diskussionsgegnern als kraftlos und scheinen gleichsam unter der Hand ihre Überzeugungskraft einzubüßen. Realistische Intuitionen (meine jedenfalls) werden von diesem Befund jedoch eigenartigerweise kaum berührt.

Zur Auflösung dieser frustrierenden Diskrepanz führt die Einsicht (oder hat sie zumindest für mich geführt), daß in der wissenschaftstheoretischen Realismusdebatte häufig unter unausgesprochenen Voraussetzungen argumentiert wird, die sich, wenn man sie explizit macht, als wenig plausibel und jedenfalls nicht unkontrovers erweisen, und die deutlich an intuitiver Plausibilität einbüßen, wenn man sie in allgemein-philosophische, über die wissenschaftstheoretische Debatte hinausreichende Diskussionszusammenhänge rückt. Die "Unsichtbarkeit" dieser Voraussetzungen wird dadurch zumindest begünstigt, daß die wissenschaftstheoretische Debatte üblicherweise von allgemein-philosophischen, insbesondere von erkenntnistheoretischen Debatten abgekoppelt geführt wird, und die Voraussetzungen werden leichter sichtbar, wenn man die "Entkoppelung" der Debatten rückgängig macht. Eine solche Voraussetzung, die für die Argumentation in dieser Arbeit eine wichtige Rolle spielt, ist die, daß in der wissenschaftstheoretischen Realismusdebatte häufig eine Art empiristische und/oder fundamentalistische Konzeption von epistemischer Rechtfertigung vorausgesetzt wird: Durch direkte Beobachtung mit dem bloßen Auge gewonnene Überzeugungen gelten danach als in epistemischer Hinsicht "unproblematisch", ebenso durch deduktive Schlüsse daraus gewonnene Überzeugungen, alles andere ist dagegen in epistemischer Hinsicht "problematisch" und muß auf der Basis "unproblematischer" Überzeugungen durch deduktive Schlüsse gerechtfertigt werden. Eine zweite solche Voraussetzung ist die Annahme, daß man dann und nur dann zufriedenstellende Rechtfertigungsgründe für eine Überzeugung hat, wenn man über ein (im Prinzip) für jedermann überzeugungskräftiges Argument für diese Überzeugung verfügt. Wenn man diese Voraussetzungen fallenläßt - und dafür spricht einiges - , dann erscheinen zumindest ein Teil der Argumente, die für realistische Positionen vorgebracht werden, in einem deutlich günstigeren Licht, und die Aussichten, eine intuitiv plausible realistische Position zu entwickeln und in einer der 
Natur der Sache angemessenen Weise zu rechtfertigen und durch Argumente zu stützen, werden deutlich besser.

Im Anschluß an ein Kolloquium mit Michael Friedman in Göttingen, auf dem er seine "zeitgemäß erneuerte" neukantianische Wissenschaftsphilosophie vorgestellt hat, bin ich auf die Frage gestoßen, wo die Position, die am Ende dieser Arbeit anvisiert wird, auf einer "philosophischen Landkarte" anzusiedeln wäre, und diese Frage liegt auch nahe, wenn man, wie es in dieser Arbeit für das Thema "Realismus" getan wird, dafür plädiert, wissenschaftstheoretische Debatten stärker in allgemein-philosophische Debatten einzurücken, als es in der Wissenschaftstheorie noch immer üblich ist. Wo die anvisierte Position nicht anzusiedeln ist — nämlich z.B. nicht in der Nähe empiristischer Positionen (wie die von van Fraassen) und nicht in der Nähe kantianischer Positionen (wie die von Friedman) - , ist leichter zu sagen als sie "positiv" zu verorten, und generell haben solche Etikettierungen ohnehin nur sehr begrenzten Gehalt, aber wenn die anvisierte Position zu einer sehr groben Orientierung einem Bereich der "philosophischen Landkarte" zugeordnet werden muß, dann sollte dies der Bereich sein, in dem so etwas wie ein naturalistischer Common-sense-Realismus liegt ${ }^{2}$, also eine Position, wie sie von den zeitgenössischen Philosophen "außerhalb der Wissenschaftstheorie" etwa Ernest Sosa vertritt, und wenn dieser Bereich durch den Namen eines philosophischen Klassikers gekennzeichnet werden muß, dann müßte dies am ehesten der von Thomas Reid sein.

Einige entschuldigende Bemerkungen: Ich verwende bei Berufsbezeichnungen etc., von denen es eine weibliche und eine männliche Form gibt, aus Gewohnheit und Bequemlichkeit in der Regel die letztere, also etwa "Philosophen" und "Physiker", natürlich ohne damit irgendjemanden ausschließen oder gar emanzipatorische Errungenschaften bestreiten zu wollen; ich habe dies im Text beibehalten, da ich hinreichend viele Philosophinnen und Physikerinnen kenne, die dem keinerlei Bedeutung beimessen.

Von den diversen Disziplinen und Fachgebieten, die gewöhnlich den Wissenschaften zugerechnet werden, spielt im folgenden, wenn es um Fallbeispiele etc. geht, die Physik die zentrale Rolle, obwohl sich die Realismusdebatte natürlich nicht nur auf die Physik bezieht und auch die von mir am Ende skizzierte realistische Position nicht, wie im Verlauf der Diskussion klar werden sollte. Dies hat damit zu tun, daß ich mich in der Physik am besten auskenne, und soll keinerlei Annahmen über einen irgendwie privilegierten Status der Physik o.ä. implizieren oder zum Ausdruck bringen.

Schließlich sollen drei neuere Arbeiten zum Thema "wissenschaftlicher Realismus" genannt werden, auf die ich leider zu spät aufmerksam geworden bin, um mich in angemessener Weise mit ihnen auseinanderzusetzen und sie über die Erwähnung in einigen wenigen Fußnoten hinausgehend zu berücksichtigen, nämlich die Bücher von Jarrett Leplin und von Stathis Psillos ${ }^{3}$, und auch, was ich besonders bedauere, das Buch von Philip Kitcher ${ }^{4}$.

Zu den erfreulichen Dingen, die mit dem Abschluß dieser Arbeit verbunden sind, zählt die Gelegenheit, mich bei all denen zu bedanken, denen ich dankbar bin für ihre Unterstützung oder Hilfe auf dem etwas unebenen Weg, der zu dem geführt hat, was ich damit fertiggestellt habe.

Diese Dissertation wurde durch mehrere Institutionen gefördert, denen ich dafür Dank schulde: Begonnen habe ich diese Arbeit als Mitarbeiter am Forschungsschwerpunkt Wissenschaftsgeschichte und Wissenschaftstheorie der Förderungsgesellschaft Wissenschaftli-

\footnotetext{
${ }^{2}$ Nicht zu verwechseln mit dem, was in der wissenschaftstheoretischen Realismusdebatte gewöhnlich als Common-sense-Realismus bezeichnet wird; siehe S.24.

${ }^{3}$ [Lepl97, Psil99].

${ }^{4}$ [Kitc93].
} 
che Neuvorhaben m.b.H. in Berlin. Sie wurde außerdem gefördert durch ein Stipendium des Deutschen Akademischen Austauschdienstes und durch ein Stipendium der Landesgraduiertenförderung des Landes Baden-Württemberg. Dem Center for Philosophy and History of Science der Boston University und insbesondere seinem Leiter, Professor Alfred Tauber, bin ich zu Dank verpflichtet für eine Einladung als Visiting Scholar im akademischen Jahr 1995/96.

Annabel Falkenhagen und Klaus Tschepke haben Teile des Manuskripts gelesen und hilfreiche Verbesserungsvorschläge gemacht. Ihnen sei hiermit für ihre Mühen herzlich gedankt.

Für Förderung und Anregungen während meiner Berliner Zeit danke ich Professor Michael Heidelberger und Professor Jürgen Renn, außerdem allen Mitarbeitern des Forschungsschwerpunkts Wissenschaftsgeschichte und Wissenschaftstheorie. Für Diskussionen mit oder ohne Kaffeetasse danke ich Malte Grunwald, Ed Jurkowitz, Niels Loesch und Heike Wiese.

In meiner Zeit in Boston verdanke ich den Diskussionen und Gesprächen mit Jordi Cat, Professor Ulrich Majer und Professor Sam Schweber wichtige Anregungen. Außerordentlich hilfreich für mich war dort außerdem eine Physik-Vorlesung von Professor Gerald Gabrielse. Besonders herzlich bedanken möchte ich mich bei Professor Peter Galison für Vorlesungen, Seminare und Diskussionen in seinem inspirierenden, von seinem ansteckenden Engagement geprägten Zirkel.

Auf meiner nächsten Station in Heidelberg waren Diskussionen mit Andreas Hüttemann, Jesse Kraai, Jutta Rockmann, Marcus Schulte und Orestis Terzidis hilfreich und anregend. Zu Dank verpflichtet bin ich ferner Professor Martin Carrier, der eine Zeitlang offizieller Betreuer meines Dissertationsprojektes war.

Ein großer und herzlicher Dank geht an Professor Felix Mühlhölzer, der die Betreuung meiner Dissertation zu einem Zeitpunkt übernommen hat, zu dem es für mich wichtig war, obwohl er dafür eigentlich kaum gute Gründe haben konnte, und der diese Arbeit dann mit großer Unterstützung und Geduld begleitet und gefördert hat.

Mein größter Dank erreicht seinen Adressaten nicht mehr: Er geht an Professor Lorenz Krüger, der mir einen Weg zur Philosophie gezeigt hat und der auch diese Arbeit angeregt und in ihrer Anfangsphase gefördert hat. 
xviii 


\section{Kapitel 1}

\section{Einleitung: Die Realismusdebatte in der Wissenschaftstheorie und ihr allgemein-philosophisches Umfeld}

\subsection{Probleme des Realismus}

Innerhalb der Wissenschaftstheorie, die sich mit einem ganzen Spektrum von Orientierungsfragen zu den modernen Wissenschaften, ihren Zielen, Methoden und Praktiken, ihren Erkenntnisleistungen und ihrem Beitrag zu unserem Weltbild beschäftigt, behandelt die Debatte, die über das Thema Realismus geführt wird, in vieler Hinsicht ein Kernproblem. Im Schnittpunkt zahlreicher Fragestellungen aus den genannten Bereichen liegt das Problem, ob und wenn ja in welchem Sinn genau die "kognitiven Produkte" wissenschaftlicher Forschung, also Theorien, Erklärungen, Modelle, Gesetze etc., als Erkenntnisse über die Natur, die Welt o.ä. zu verstehen sind und wie solche Erkenntnisansprüche gegebenenfalls zu bewerten sind.

In der wissenschaftstheoretischen Realismusdebatte werden also für den Bereich der Wissenschaften Fragen verhandelt, die prima facie zu den allgemeineren, umfassenderen Themenbereichen gehören, die traditionell der theoretischen Philosophie, sprich: der allgemeinen Erkenntnistheorie, Sprachphilosophie und Metaphysik, zugerechnet werden. Dennoch zeigt ein Blick auf die "philosophische Praxis", daß die wissenschaftstheoretische Realismusdebatte weitgehend abgekoppelt von den allgemeineren erkenntnistheoretischen, sprachphilosophischen und metaphysischen Debatten geführt wird, oder wenigstens ohne explizite Bezugnahme auf sie. Da zudem das Stichwort "Realismus" in den allgemeinen wie in den spezielleren Diskussionen jeweils mehrere verschiedene Thesen und Positionen bezeichnet, die von den Beteiligten nur zum Teil aufeinander bezogen und präzise voneinander abgegrenzt werden, ist es zur ersten Orientierung nützlich, ein grobes Bild von den beiden Debattenfeldern und ihrem Verhältnis zueinander zu gewinnen, bevor man die Thesen und Argumente der wissenschaftstheoretischen Debatte genauer in den Blick nimmt.

Im folgenden soll zunächst in beiden Debattenfeldern eine systematisierende Übersicht über die wichtigsten realistischen Thesen und Positionen sowie auch über das Spektrum der Gegenthesen und -positionen gewonnen werden. Anschließend soll untersucht werden, 
in welcher Beziehung die beiden Debattenfelder zueinander stehen.

\subsection{Realismus in allgemein-philosophischen Diskussionen: Dimensionen des Themas, Thesen und Positionen}

In allgemein-philosophischen, also nicht auf die Wissenschaftstheorie beschränkten Diskussionen wird unter Realismus eine Vielzahl von Thesen und daraus kombinierten Positionen verstanden, hinter denen sich aber vielleicht so etwas wie eine sie verbindende, allgemeinere Intuition erkennen läßt. ${ }^{1}$ Thomas Nagel formuliert diese wie folgt:

"In simple terms [realism ...] is the view that the world is independent of our minds, but the problem is to explain this claim in a nontrivial way which cannot be easily admitted by everyone." 2

Crispin Wright beschreibt diese Intuition etwas ausführlicher und streicht dabei heraus, daß sie zwei "Komponenten" hat:

"A reasonable pretheoretical characterisation of realism about, say, the external world seems to me that it is a fusion of two kinds of thoughts, one kind expressing a certain modesty, the other more presumptuous. The modest kind of thought concerns the independence of the external world - for example, that the external world exists independently of us, that it is as it is independently of the conceptual vocabulary in terms of which we think about it, and that it is as it is independently of the beliefs about it which we do, will or ever would form $[\ldots]$. The presumptuous thought, by contrast, is that $[\ldots]$ we are nevertheless, in favourable circumstances, capable of conceiving the world aright, and, often, of knowing the truth about it." 3

Typischerweise geht es in den allgemeinen Diskussionen pro und contra Realismus zunächst um materielle Gegenstände der Alltagswelt (Tische, Bratpfannen, Papageien, Wolken u.ä.) und ihre Eigenschaften bzw. entsprechende Sachverhalte oder Sätze. Dinge dieser Art liefern die paradigmatischen Beispiele, anhand derer realistische und antirealistische ${ }^{4}$ Thesen entwickelt und diskutiert werden. Debatten über realistische oder

\footnotetext{
${ }^{1}$ Mit "Intuitionen" oder auch "vortheoretischen Intuitionen" sind hier und im folgenden (für den jeweiligen Kontext relevante) Überzeugungen gemeint, die man zu Beginn einer philosophischen Untersuchung hat, die also den Ausgangspunkt der Argumentation bilden. Dies können in sehr unterschiedlichem Grad reflektierte und auch bisher noch gar nicht artikulierte Überzeugungen sein. Was in diesem Sinn "intuitiv plausibel" erscheint, ist keineswegs unrevidierbar, man wird eine entsprechende Überzeugung jedoch auch nicht ohne Grund aufgeben. (Zu dieser Verwendung von "Intuition" vgl. [Sosa91a], Kap.15.)

Ein Appell an "Intuitionen" in diesem Sinn ist daher von anderen in der Philosophie geläufigen Verwendungsweisen dieses Ausdrucks abzugrenzen: Es wird nicht auf so etwas wie ein Vermögen "rationaler Intuition" Bezug genommen, wie es von Anhängern rationalistischer Positionen in Anspruch genommen wird, und es geht i.a. auch nicht um sprachliche Intuitionen, also um die Bedeutung von Begriffen, Ausdrücken o.̈̈., die (bestimmten sprachphilosophischen Positionen zufolge) jedem kompetenten Sprecher einer Sprache "intuitiv" zugänglich ist.

${ }^{2}$ [Nage86], S.90.

${ }^{3}$ [Wrig92], S.1/2.

4'Antirealismus' bzw. 'antirealistisch' wird in dieser Arbeit als Bezeichnung für Thesen und Positionen verwendet, die realistischen Thesen und Positionen entgegengestellt werden. Dies entspricht dem Sprachgebrauch, der in der zeitgenössischen philosophischen Literatur vorherrscht und der weiter ist als die in Teilen der sprachphilosophischen Literatur im Anschluß an Dummett übliche Verwendung dieser Ausdrücke zur Bezeichnung speziellerer semantischer Thesen und Positionen (vgl. S.10).
} 
antirealistische Thesen werden aber auch bezüglich anderer Gegenstands- oder Diskursbereiche geführt: über Universalien ("Röte" bzw. die Farbe rot u.ä.) und natürliche Arten (Gürteltiere, Granat usw.), abstrakte Gegenstände (Sinfonien, Vereine, Nationen u.ä.), mathematische Gegenstände (Zahlen, Algebren, Mannigfaltigkeiten u.ä.), mentale Zustände und Entitäten, die Gegenstände und Sachverhalte der Ethik (Werte, ethische Urteile etc.), Sachverhalte kausaler, modaler und kontrafaktischer Art und vieles mehr. Eine differenzierte philosophische Position kann nach Gegenstands- oder Diskursbereichen unterscheiden, die groß oder klein "zugeschnitten" sein können und in bezug auf verschiedene Bereiche i.a. unterschiedliche realistische und antirealistische Thesen einschließen.

\subsubsection{Realistische Thesen}

Bei den Anhängern realistischer Positionen findet sich eine Vielzahl realistischer Thesen, teils explizit und präzise formuliert, teils eher grob skizziert, nur angedeutet oder implizit angenommen, die sich als Konkretisierung der von Nagel und Wright genannten allgemeinen Intuition auffassen lassen. Die Menge dieser Thesen ist zu umfangreich, um sie (oder auch nur wesentliche Teile davon) im einzelnen zu analysieren, es läßt sich aber eine systematisierende Übersicht über sie gewinnen, indem man drei Dimensionen dessen unterscheidet, was diese Thesen zum Inhalt haben: eine ontologische, eine semantische und eine erkenntnistheoretische. ${ }^{5}$ Für jede dieser Dimensionen lassen sich ein oder zwei Schemata für präzise formulierte realistische Thesen angeben derart, daß die meisten der von Anhängern realistischer Positionen vertretenen Thesen sich als Instantiierungen dieser Schemata auffassen lassen oder sich, wenn es sich um grob und unscharf formulierte Thesen handelt, zumindest im Sinne einer präzisierenden Explikation als Instantiierungen dieser Schemata rekonstruieren lassen. ${ }^{6}$

\section{Ontologischer Realismus}

Eine ontologische realistische These ${ }^{7}$ bezüglich eines bestimmten Gegenstandsbereiches, d.h. bezüglich eines spezifizierten Bereichs von Entitäten und deren Eigenschaften ${ }^{8}$, Sachverhalten, Gesetzen o.ä., ist eine These der Form

OR Die spezifizierten Entitäten existieren unabhängig von menschlicher Erkenntnis und haben unabhängig von menschlicher Erkenntnis die spezifizierten Eigenschaften, es

\footnotetext{
${ }^{5}$ Für Klassifikationen dieser und ähnlicher Art siehe z.B. [Earm93, Haac87, Hell83, Horw82a, Nage86] sowie [Mitt95], Bd.3, S.500ff.

${ }^{6}$ In diesem Sinn ist die Liste der im folgenden vorgeschlagenen Schemata und zugehörigen Erläuterungen zu verstehen. Sie soll möglichst viele und insbesondere die systematisch wichtigen der in der Realismusdebatte vertretenen realistischen Thesen im Sinne einer systematisierenden und präzisierenden Explikation erfassen. Um zu zeigen, daß sie dies leistet, müßte die Literatur zur Realismusdebatte vollständig aufgearbeitet und analysiert werden, was hier nicht möglich ist.

${ }^{7}$ In der Literatur werden diese häufig auch als metaphysische Thesen bezeichnet. Das Etikett 'ontologisch' hat jedoch den Vorzug, daß man terminologisch Abstand hält von Hilary Putnams Unterscheidung von "metaphysischem" und "internem" Realismus (siehe u.a. [Putn78], Teil 4, [Putn81], [Putn87a], [Putn90a], Kap.2). Die damit bezeichneten Positionen (oder, wie Putnam sich ausdrückt, "Perspektiven") verflechten Thesen und Themen verschiedener Art (Wahrheitstheorien, Bedeutungstheorien, Ontologie, Physikalismus, Unterbestimmtheit und einiges mehr) in einer zu komplizierten Weise, um sie hier entflechten und sinnvoll behandeln zu können.

${ }^{8}$ Inklusive relationaler, also "mehrstelliger" Eigenschaften; diese Erläuterung bleibt im folgenden implizit.
} 
liegen unabhängig von menschlicher Erkenntnis die spezifizierten Sachverhalte vor, es gelten unabhängig von menschlicher Erkenntnis die spezifizierten Gesetze u.ä. ${ }^{9}$

An einer solchen These lassen $\operatorname{sich}^{10}$ zwei Aspekte unterscheiden, die die beiden "Komponenten" der von Nagel und Wright genannten Intuition konkretisieren: Zum einen die Aussage, daß bestimmte Entitäten existieren und bestimmte Eigenschaften haben, daß bestimmte Sachverhalte vorliegen, bestimmte Gesetze gelten usw., zum anderen die Bestimmung, daß dies unabhängig von menschlicher Erkenntnis so ist. Erstere konkretisiert den, wie Wright sich ausdrückt, anmaßenden Gedanken, den die realistische Intuition enthält, letztere den bescheidenen. ${ }^{11}$

Aus diesem Schema wird eine präzise These, indem zum einen ein Gegenstandsbereich spezifiziert wird und zum anderen die Unabhängigkeitsaussage, d.h. die Qualifikation "unabhängig von menschlicher Erkenntnis", erläutert wird. Letzteres kann entweder in bereichsspezifischer, d.h. auf einen speziellen Gegenstandsbereich bezogener Weise geschehen, so daß für verschiedene Gegenstandsbereiche evtl. unterschiedliche Erläuterungen gegeben werden, oder in (mehr oder weniger) globaler Weise.

Eine solche Erläuterung ist eine Aussage der Form

UvmE1 Die Entitäten würden auch dann existieren und hätten auch dann die spezifizierten Eigenschaften, die Sachverhalte würden auch dann vorliegen etc., wenn es keine menschliche Erkenntnis gäbe.

Eine andere Erläuterung ist eine Aussage der Form

UvmE2 Die Entitäten und ihre Eigenschaften, die Sachverhalte etc. werden von menschlichen Erkenntnis- und Wahrnehmungszuständen, -fähigkeiten und -verfahren kausal nicht beeinflußt.

Aussagen dieser Art können noch weiter präzisiert oder eingeschränkt werden:

UvmE1a Die Entitäten würden auch dann existieren und hätten auch dann die spezifizierten Eigenschaften, die Sachverhalte würden auch dann vorliegen etc., wenn niemand von dieser Existenz, von diesen Eigenschaften, von diesen Sachverhalten etc. wüßte (in der Vergangenheit gewußt hätte oder zukünftig wissen würde), Evidenzen für oder gegen diesbezügliche Überzeugungen hätte (gehabt hätte oder zukünftig

\footnotetext{
${ }^{9}$ Dazu zählen als Grenzfälle auch Thesen, die die "blanke" Existenz bestimmter Entitäten zum Inhalt haben, ohne diesen irgendeine Eigenschaft zuzuschreiben, und Thesen, die eine generelle Aussage oder ein Gesetz formulieren, die bzw. das (möglicherweise) keine Instantiierung hat. Der Gegenstandsbereich, über den eine ontologische realistische These etwas aussagt, kann grundsätzlich jede Größe haben: Sie kann im Extremfall auch von einer einzelnen, speziellen Entität handeln oder ein völlig allgemeines Gesetz formulieren.

${ }^{10}$ Ähnlich wie Devitt es tut ([Devi84], S.12ff., [Devi91], S.44).

${ }^{11}$ Eine These, daß bestimmte Entitäten existieren und bestimmte Eigenschaften haben etc., konkretisiert den von Wright als "anmaßend" charakterisierten Gedanken nicht, wie Wrights eigene Formulierung ("we are [...] capable of conceiving the world aright, and [...] of knowing the truth about it"), indem sie vom Vorliegen von Wissen über einen unabhängigen Gegenstandsbereich oder von epistemischen Fähigkeiten handelt, sondern indem sie den Inhalt solchen Wissens formuliert, so daß jemand, der diese These vertritt und damit eine Behauptung aufstellt, dadurch einen Wissensanspruch in bezug auf den unabhängigen Gegenstandsbereich erhebt. Daß ein solcher unabhängiger Gegenstandsbereich für Menschen epistemisch zugänglich ist, wird also nicht explizit durch den Inhalt dieser These zum Ausdruck gebracht, sondern durch das Behaupten der These pragmatisch impliziert. (Die sprachphilosophische Frage, was genau eine Behauptung bzw. das Vertreten einer These involviert und impliziert, und auf welche Weise, muß an dieser Stelle beiseite bleiben.)
} 
haben würde) und/oder über die Begriffe verfügte (verfügt hätte oder zukünftig verfügen würde), diese Überzeugungen zu formulieren.

UvmE2a Die Entitäten und ihre Eigenschaften, die Sachverhalte etc. werden von den menschlichen Erkenntnis- und Wahrnehmungszuständen, -fähigkeiten und -verfahren kausal nicht beeinflußt, die menschliches Wissen von diesen Entitäten etc. konstituieren bzw. erzeugen. ${ }^{12}$

Eine dritte (zu den beiden ersten quer liegende ${ }^{13}$ ) Erläuterung ist eine Aussage der Form

UvmE3 Die Entitäten und ihre Eigenschaften, die Sachverhalte etc. werden nicht durch mentale Entitäten und Eigenschaften, Sachverhalte etc. konstituiert.

Damit wird ausgeschlossen, daß die fraglichen Entitäten etc. identisch sind mit oder zusammengesetzt aus Ideen, Überzeugungen, Wahrnehmungen, Empfindungen oder ähnlichen Typen mentaler Entitäten, deren Eigenschaften, entsprechenden Sachverhalten etc., die für menschliche Erkenntnis konstitutiv sind. Eine weiter präzisierte oder eingeschränkte Variante dieser Erläuterung ist eine Aussage der Form

UvmE3a Die Entitäten etc. werden nicht durch diejenigen mentalen Entitäten etc. konstituiert, die für menschliche Erkenntnis von ihnen konstitutiv sind, d.h. nicht durch Überzeugungen über sie, Wahrnehmungen von ihnen etc. ${ }^{14}$

Sowohl die erste als auch die dritte der genannten Erläuterungen sind erfüllt, wenn die stärkere Unabhängigkeitsaussage gilt:

\footnotetext{
${ }^{12}$ Die Qualifikation, daß es nur auf Erkenntnis- und Wahrnehmungszustände etc. ankommt, die Wissen von den fraglichen Entitäten und ihre Eigenschaften konstituieren o.ä. (im Unterschied zu sonstigen Erkenntnis- und Wahrnehmungszuständen etc.), ist wichtig, zumindest für einige Gegenstandsbereiche, z.B. wenn Artefakte (wie Bratpfannen und Fernrohre) und "soziale Objekte" (wie Institutionen, soziale Rollen u.ä.) nicht als Kandidaten für ontologische realistische Thesen ausfallen sollen; vgl. auch Kap.13.2.1 und 13.2.3.

${ }^{13} \mathrm{Daß}$ die dritte Erläuterung nicht identisch mit einer der beiden vorigen ist, kann man sich anhand von Fällen verdeutlichen, die unter die ersteren fallen, aber nicht unter die letztere: Russell spricht von "sensibilia" und versteht darunter so etwas wie potentielle Erscheinungen oder Wahrnehmungen (im Unterschied zu den aktuellen Wahrnehmungen und Sinnesdaten eines Beobachters), auf die Gegenstände wie Tische etc. reduzierbar sind ([Russ18b], bes. S.148ff.). Nach Russell wären solche Gegenstände also als unabhängig von menschlicher Erkenntnis im Sinne der ersten Erläuterung und, insofern Russell den Kausalbegriff ganz zurückweist, auch im Sinne der zweiten Erläuterung, aber (sofern "sensibilia" als mentale Entitäten zählen) nicht als unabhängig im Sinne der dritten Erläuterung aufzufassen. Kandidaten für "inverse" Fälle, also Abhängigkeit von menschlicher Erkenntnis im erst- und zweitgenannten Sinn (ohne daß das den in der vorigen Fn. erwähnten trivialen Grund hat) und Unabhängigkeit im Sinne der dritten Erläuterung sind mentale Entitäten wie Wahrnehmungen, Überzeugungen etc.; ob man diese (bzw. welche davon man) tatsächlich als einschlägige Beispielfälle akzeptiert, hängt jedoch davon ab, welche Position man in der Philosophie des Geistes vertritt. Andere unzweideutige "inverse" Fälle außerhalb von Philosophiebüchern zu finden ist nicht ganz einfach; ein Beispiel findet sich aber bei Douglas Adams: "Es gibt eine Theorie, die besagt, wenn jemals irgendwer genau rausfindet, wozu das Universum da ist und warum es da ist, dann verschwindet es auf der Stelle und wird durch etwas noch Bizarreres und Unbegreiflicheres ersetzt" ([Adam82], S.7).

${ }^{14}$ Diese Qualifikation kann relevant sein, wenn man eine realistische These in bezug auf mentale Entitäten wie Überzeugungen, Wahrnehmungen etc. formulieren möchte, insbesondere, wenn man diese nicht für unabhängig von menschlicher Erkenntnis im Sinne der ersten Erläuterung hält.
} 
UvmE Die Entitäten würden auch dann existieren und hätten auch dann die spezifizierten Eigenschaften, die Sachverhalte würden auch dann vorliegen etc., wenn es keine denkenden und wahrnehmenden Wesen, sprich: keine Menschen gäbe ${ }^{15}$.

Eine vierte (wiederum quer zu den anderen liegende ${ }^{16}$ ) Erläuterung ist eine Aussage der Form

UvmE4 Die Eigenschaften der Entitäten, die Sachverhalte etc. involvieren nicht den menschlichen kognitiven Apparat oder bestimmte seiner Züge oder Charakteristika. D.h. konkret, daß die Eigenschaften, Sachverhalte etc. keine relationalen Eigenschaften, Sachverhalte etc. sind, bei denen der menschliche kognitive Apparat ein Relationsglied ist, keine Dispositionen sind oder involvieren, zu deren Manifestationsbedingungen dieser kognitive Apparat gehört, o.ä.

Damit wird ausgeschlossen, daß die fraglichen Eigenschaften etc. sozusagen zu anthropozentrisch sind. ${ }^{17}$

Während die bisher beschriebenen Versionen ontologischer realistischer Thesen beide Komponenten der von Nagel und Wright genannten Intuition konkretisieren, sich also auf Entitäten, Sachverhalte etc. beziehen, die für Menschen kognitiv (mehr oder weniger) zugänglich sind oder jedenfalls gewöhnlich dafür gehalten werden, halten einige Anhänger realistischer Positionen nur die eine Komponente, den bescheidenen Gedanken über die Unabhängigkeit der Welt vom menschlichen Geist, für wesentlich und formulieren daher ontologische realistische Thesen, die sich auf einen Bereich beziehen, der für Menschen nicht zugänglich ist: Sie versuchen, durch Analogien eine These wie die folgende plausibel zu machen:

OR2 Es gibt Dinge und Sachverhalte in der Welt oder kann sie geben, über die Menschen nicht nur in dem Sinne nichts wissen können, daß sie über die Wahrheit oder Falschheit von Sätzen, die diese Dinge beschreiben, nicht entscheiden können, sondern darüber hinaus in dem starken Sinn, daß Menschen der konzeptionelle Apparat fehlt und, so wie sie kontingenterweise "gebaut" sind, immer fehlen wird, um diese überhaupt begrifflich erfassen zu können.

Auf Sloganform gebracht lautet der Gedanke: "Reality is bigger than us" ${ }^{18}$; eine Analogie, um ihn zu stützen, wäre etwa die zu einem Kleinkind oder einem Tier (z.B. einem Affen), denen man kognitive Fähigkeiten zuspricht, die aber die durch Theorien wie die Quantenmechanik oder die Transformationsgrammatik beschriebenen Sachverhalte begrifflich nicht erfassen können. ${ }^{19}$

\footnotetext{
${ }^{15}$ Und wenn man außerdem voraussetzen kann, daß es ohne denkende und wahrnehmende Wesen keine mentalen Entitäten, Sachverhalte etc. gäbe. Diese Annahme könnte man bestreiten; vgl. die vorletzte Fn.

${ }^{16}$ Ein Beispiel, das die Differenz zwischen dieser Erläuterung und den vorigen illustriert, wären Farben bzw. entsprechende Sachverhalte, sofern man etwa die Eigenschaft, rot zu sein, auffaßt als eine Disposition, (unter "Normalbedingungen" im Hinblick auf Beleuchtung usw.) bei Menschen eine Rotempfindung hervorzurufen. Farbeigenschaften wären demnach unabhängig von menschlicher Erkenntnis im Sinne der ersten drei Erläuterungen, aber nicht im Sinne der vierten.

${ }^{17}$ Thesen dieser Art werden vor allem im Zusammenhang mit sekundären Qualitäten, Ethik und ähnlichen Bereichen diskutiert. Siehe dazu z.B. [Krug89, Pett91].

${ }^{18}$ [Hack83a], S.274.

${ }^{19}$ Vgl. [Nage86], Kap.VI.
} 


\section{Semantischer Realismus}

Semantischer Realismus in Bezug auf eine bestimmte Menge von Sätzen ${ }^{20}$ schließt mindestens $^{21}$ eine These der Form

SR1 Die spezifizierten Sätze haben Wahrheitswerte, d.h. sind wahr oder falsch, und zwar unabhängig von menschlichen epistemischen Mitteln zum Erkennen dieser Wahrheitswerte. ${ }^{22}$

ein. Aus diesem Schema wird eine präzise These, indem zum einen eine Menge von Sätzen spezifiziert wird und zum anderen die zentralen Formulierungen "Wahrheitswerte haben" und vor allem "unabhängig von menschlichen epistemischen Mitteln" erläutert werden. Dies kann in bereichsspezifischer oder in (mehr oder weniger) globaler Weise geschehen.

Die Suche nach einer solchen Erläuterung führt auf die Frage nach einer Wahrheitstheorie und evtl. nach einer Bedeutungs- und Referenztheorie für die fraglichen Sätze, innerhalb derer die semantischen Eigenschaften und Relationen der Sätze charakterisiert werden und damit auch erläutert wird, in welchem Sinn die Eigenschaft eines Satzes, einen Wahrheitswert zu haben, bzw. die semantische Relation zwischen einem Satz und seinem Wahrheitswert unabhängig von menschlichen epistemischen Mitteln sind. Realisten plädieren an dieser Stelle meistens für eine nicht-epistemische Wahrheitstheorie, typischerweise für eine Korrespondenztheorie, und evtl. für eine Bedeutungs- und Referenztheorie, bei der Wahrheits- bzw. Erfüllungsbedingungen ${ }^{23}$ im Zentrum stehen. ${ }^{24}$ Eine Erläuterung von "unabhängig ...", die sich durch eine solche semantische Theorie ergeben kann, ist eine Aussage der Form

UvmeM1 Die Sätze hätten auch dann ihre Wahrheitswerte, d.h. wären auch dann wahr oder falsch, wenn niemand über epistemische Mittel verfügen würde, die es (wenigstens im Prinzip) ermöglichen, herauszufinden, ob die Sätze wahr sind oder falsch.

Eine andere solche Erläuterung ist eine Aussage der Form

UvmeM2 Die Eigenschaft der Sätze, einen Wahrheitswert zu haben, d.h. wahr oder falsch zu sein, involviert nicht menschliche epistemische Mittel zum Erkennen dieser Wahrheitswerte. D.h. konkret, daß die Eigenschaft, wahr oder falsch zu sein, keine relationale Eigenschaft ist, bei der epistemische Mittel ein Relationsglied sind, keine Disposition ist oder involviert, zu deren Manifestationsbedingungen diese epistemischen Mittel gehören, o.ä. ${ }^{25}$

Eine semantische realistische These vom Typ (SR1) wird, je nach Gegenstandsbereich, häufig durch eine zweite Teilthese ergänzt, die unerwünschte Interpretationen der Sätze,

\footnotetext{
${ }^{20}$ Bzw. Propositionen; ich übergehe hier diese Differenz und die damit zusammenhängenden Probleme. ${ }^{21} \mathrm{~S} . \mathrm{u}$.

${ }^{22}$ Siehe etwa [Dumm78b], S.146. Mögliche Komplikationen, die mit leeren Kennzeichnungen oder vagen Prädikaten zusammenhängen, bleiben hier beiseite.

${ }^{23}$ Im Unterschied zu Behauptbarkeitsbedingungen, Regeln des Gebrauchs u.ä.

${ }^{24}$ Die semantischen Theorien, die zur Erläuterung von (SR1) herangezogen werden können, und die Frage, ob, und wenn ja, wie sie eine Erläuterung von "unabhängig ..." liefern, können an dieser Stelle nicht diskutiert werden, dies geschieht jedoch für die Sprache der Wissenschaften in Teil I.

${ }^{25}$ Andere Erläuterungen von "unabhängig ...", die man vielleicht in Analogie zu den für ontologische realistische Thesen genannten Erläuterungen konstruieren könnte, spielen im Zusammenhang mit semantischem Realismus keine Rolle.
} 
auf die sich die These der Form (SR1) bezieht, ausschließt und den Spielraum für mögliche Reduktionen und Paraphrasierungen der Sätze und Ausdrücke auf bzw. durch andersartige Sätze und Ausdrücke einschränkt, die den "eigentlichen" Gehalt, die tatsächliche Bedeutung o.ä. der ersteren anzugeben beanspruchen. Etwas metaphorisch heißt es häufig:

SR2 Die fraglichen Sätze und Ausdrücke sind wörtlich zu nehmen oder buchstäblich zu verstehen,

im Gegensatz zu reduzierbaren Sätzen und Ausdrücken, Metaphern, stehenden Redewendungen oder sonstigen nicht-wörtlich aufzufassenden sprachlichen Gebilden. ${ }^{26}$

\section{Epistemischer Realismus}

Erkenntnistheoretischer oder epistemischer Realismus in bezug auf eine bestimmte Menge von Sätzen setzt eine Version des semantischen Realismus voraus. Eine epistemische realistische These ist eine (zu einer semantischen realistischen These hinzutretende) Aussage der Form

\section{ER Die spezifizierten Sätze sind wahr. ${ }^{27}$}

Semantische und epistemische realistische Thesen gehören im Hinblick auf die Frage, wie realistische Thesen die von Nagel und Wright genannte Intuition konkretisieren, in gewisser Weise zusammen, da sie (wie die beiden Teile einer ontologischen realistischen These der Form (OR)) je einer der beiden Komponenten dieser Intuition zuzuordnen sind: Semantische realistische Thesen konkretisieren den bescheidenen Gedanken, daß die Welt unabhängig vom menschlichen Geist und menschlicher Erkenntnis ist, epistemische realistische Thesen konkretisieren den anmaßenden Gedanken, daß Menschen dennoch Wissen haben können und tatsächlich haben. ${ }^{28}$

Sowohl ontologische realistische Thesen zu vertreten, als auch epistemische realistische Thesen zu vertreten, ist verträglich mit dem Anerkennen der prinzipiellen Fehlbarkeit menschlicher Erkenntnisfähigkeiten und -verfahren, also der Erfahrung, daß selbst die

\footnotetext{
${ }^{26}$ Siehe z.B. [Dumm93b], S.468ff., [Dumm93c], S.239. Sätze wie 'Peter hat die Nase voll von Jane-AustenVerfilmungen', 'Das Klonen von Menschen ist moralisch verwerflich' oder 'Der FSV Eppelheim hat sich aufgelöst' sind Beispiele für Sätze, die vielfach nicht wörtlich genommen werden oder sogar (der erste Satz) wörtlich genommen gar nicht verständlich sind. Dennoch lassen sich für sie Interpretationen angeben, unter denen sie (unabhängig von epistemischem Zugang) wahr oder falsch sind und daher die erste Teilthese des semantischen Realismus erfüllen, etwa indem man sie interpretiert als Sätze über Peters Dispositionen im Hinblick auf sein Freizeitverhalten, die (moralischen) Präferenzen von Menschen oder Handlungen einer bestimmten Gruppe von Personen. Der erste Satz wird danach als Metapher oder stehende Redewendung interpretiert, beim zweiten werden ethische Aussagen auf deskriptive, nicht-normative reduziert und der dritte, der wörtlich genommen von einem abstrakten Gegenstand handelt, wird als Satz über Handlungen von konkreten Personen interpretiert.

${ }^{27}$ Abweichend werden als erkenntnistheoretischer oder epistemischer Realismus gelegentlich auch Positionen bezeichnet, die als bezüglich des semantischen Realismus neutral aufgefaßt werden sollen, die also z.B. die These einschließen, daß eine bestimmte Menge von Sätzen wahr ist, dabei aber die Frage offen lassen wollen, ob die fraglichen Sätze unabhängig von menschlichen epistemischen Mitteln wahr oder falsch sind, und ebenso die Frage, welches die für diese Sätze korrekte Wahrheitstheorie ist; vgl. z.B. [Horw82a]. Weiterhin wird als konstitutiv für erkenntnistheoretischen oder epistemischen Realismus gelegentlich auch die These, daß Menschen (oder "wir") die Wahrheit über einen bestimmten Gegenstandsbereich kennen oder Wissen darüber haben können, angesehen, oder die These, daß Menschen (bzw. "wir") solches Wissen tatsächlich haben; beide Thesen werden von jemandem, der eine entsprechende These der Form (ER) vertritt bzw. als Behauptung aufstellt, pragmatisch impliziert (vgl. dazu S.4, Fn.11).

${ }^{28}$ Vgl. dazu S.4, Fn.11.
} 
besten epistemischen Fähigkeiten und Verfahren, die Menschen zur Verfügung stehen, gelegentlich Fehler und Täuschungen liefern. Ein Realist, der bestimmte Überzeugungen für tatsächlich wahr hält, die bei sorgfältigem Einsatz für den fraglichen Bereich geeigneter epistemischer Mittel und Verfahren gewonnen wurden, hält im allgemeinen die zur Gewinnung eingesetzten Mittel und Verfahren nicht für unfehlbar, d.h. er schließt nicht aus, daß ihr "Output" in Einzelfällen zu korrigieren sein könnte. ${ }^{29}$

In der Literatur gibt es keinen Konsens darüber, welche These oder Thesen der genannten Arten als "realismuskonstitutiv" zu betrachten sind, d.h., durch welche Thesen die von Nagel und Wright genannte allgemeine Intuition konkretisiert werden sollte, um zu einer intuitiv angemessenen realistischen Position zu gelangen. Die mittelgroßen materiellen Gegenstände der Alltagswelt stellen sicherlich einen Kernbereich dar, bezüglich dessen die meisten Autoren, die überhaupt "realistische Neigungen" haben, für realistische Thesen plädieren. Jedoch gehen die Meinungen auseinander, ob dort eine oder mehrere ontologische Thesen den Kern einer realistischen Position bilden sollten und welche genau, oder stattdessen eine oder mehrere semantische plus (evtl.) epistemische Thesen, ${ }^{30}$ ebenso darüber, inwieweit (gleichartige oder andere) realistische Thesen auch für andere der vorne genannten Gegenstands- oder Diskursbereiche zu formulieren und zu begründen sind. Unter dem Titel "Realismus" wird eine Vielzahl von Positionen formuliert, skizziert oder angedeutet, die verschiedene, verschiedenartige und unterschiedlich weitreichende Thesen einschließen, die zu den genannten drei Arten gehören oder sich zumindest im Sinne einer präzisierenden Explikation in dieser Weise rekonstruieren lassen.

\subsubsection{Gegenpositionen}

Den verschiedenen realistischen Positionen steht ein mindestens ebenso vielfältiges Spektrum von Gegenpositionen gegenüber, die sich dadurch unterscheiden, welche (Arten von) realistischen Thesen abgelehnt werden und durch welche Thesen sie (eventuell) ersetzt werden. Von diesen Gegenpositionen sollen einige wichtige genannt werden.

Skeptiker zeichnen sich dadurch aus, daß sie in erkenntnistheoretischer Hinsicht pessimistisch sind: Sie halten die menschlichen epistemischen Fähigkeiten und Verfahren nicht für ausreichend, um zu Wissen bzw. zu gerechtfertigten Überzeugungen (sprich: ontologischen oder epistemischen realistischen Thesen) zu gelangen, da systematische Irrtümer -

\footnotetext{
${ }^{29}$ Zwecks terminologischer Klarheit sollen hier noch zwei Unterscheidungen erwähnt werden, die innerhalb der Erkenntnistheorie im Kontext von Theorien der Wahrnehmung gängig sind: Einerseits die zwischen direktem und indirektem Realismus und andererseits die zwischen naivem Realismus und dem, was manchmal (z.B. [Danc85], S.144ff.) wissenschaftlicher Realismus genannt wird (nicht zu verwechseln mit dem wissenschaftlichen Realismus der wissenschaftstheoretischen Debatte - s.u.). Ein direkter Realist vertritt die These, daß Menschen Objekte "direkt", d.h. sozusagen ohne "zwischengeschaltete" Ebene wahrnehmen können, ein indirekter Realist dagegen die These, daß sie nur Ideen, Sinnesdaten o.ä. im eigentlichen Sinn wahrnehmen können und diese ihrerseits von den Objekten hervorgerufen werden, so daß die Objekte selbst nur "indirekt" epistemisch zugänglich sind. Die Unterscheidung zwischen naivem und wissenschaftlichem (in diesem Sinn des Terminus) Realismus hängt mit der Dichotomie von primären und sekundären Qualitäten zusammen: Ein naiver Realist schreibt den Gegenständen alle Eigenschaften zu, die er an ihnen beobachten kann, ein wissenschaftlicher Realist unterscheidet primäre Qualitäten, die den Gegenständen zukommen, und sekundäre Qualitäten, die den Gegenständen nur insofern zukommen, als Menschen sie wahrnehmen, und die mit Hilfe von primären Qualitäten zu erklären sind.

${ }^{30}$ Z.B. sieht Michael Dummett eine (bestimmte) semantische These als den wesentlichen Kern einer realistischen Position (siehe z.B. [Dumm78b, Dumm93b]). Für eine Trennung der Realismusdebatte von semantischen Fragen plädiert dagegen Michael Devitt (siehe [Devi84, Devi91]); vgl. Kap.13.2 und 13.3.
} 
global (wie im Fall der Täuschung durch Descartes bösen Dämon ${ }^{31}$ oder Hilary Putnams sinistren Wissenschaftler mit den Hirnen im Tank ${ }^{32}$ ) oder in bestimmten Gegenstandsbereichen — nicht ausgeschlossen werden können. Skeptiker können jedoch semantische Realisten sein.

Als Antirealismus werden in der sprachphilosophischen Literatur ${ }^{33}$ summarisch dieje- $^{2}$ nigen Positionen bezeichnet, die die Thesen des semantischen Realismus (für bestimmte Gegenstandsbereiche oder global) ablehnen. Darunter fällt u.a. die Position von Michael Dummett, der im Kontext systematischer sprachphilosophischer Überlegungen argumentiert, daß jede These der Form (SR1) zu unüberwindlichen Schwierigkeiten für eine Bedeutungstheorie führt. ${ }^{34}$ Eine Position, die mit Thesen der Form (SR2) in bezug auf die materiellen Gegenstände der Alltagswelt konfligiert, vertritt Alfred Ayer ${ }^{35}$, indem er für die These plädiert, daß Ausdrücke für Gegenstände und Sachverhalte dieser Art ersetzbar sind durch "logische Konstruktionen" aus Ausdrücken, die für Sinnesdaten stehen ${ }^{36}$.

Projektivismus oder expressive Theorien werden Positionen genannt, die in bezug auf einen bestimmten Diskursbereich die Ansicht vertreten, daß dort Äußerungen von Aussagesätzen nicht als "ernsthafte" Behauptungen zu verstehen sind, sondern eine andere Funktion haben, etwa die, eine normative, emotionale oder pragmatische Einstellung zum Ausdruck zu bringen. ${ }^{37}$ Dies impliziert insbesondere auch, daß die fraglichen Äußerungen nicht als "ernsthaftes" Behaupten ontologischer realistischer Thesen (oder Teilthesen) aufzufassen sind. Im Bereich der Ethik wird eine entsprechende Position als Emotivismus bezeichnet; ${ }^{38} \mathrm{ihr}$ zufolge bringen Äußerungen, die von ihrer Oberflächengestalt "ernsthafte" Behauptungen über ethische Sachverhalte zu sein scheinen, tatsächlich nur emotionale Einstellungen zu "gewöhnlichen" (d.h. ohne normatives, ethisches o.ä. Vokabular charakterisierbaren) Sachverhalten zum Ausdruck.

Idealismus ist ein Etikett, mit dem verschiedene Gegenpositionen zu verschiedenen ontologischen realistischen Thesen bezeichnet werden. Unter anderem wird George Berkeleys Position ${ }^{39}$ häufig so etikettiert, der für Alltagsgegenstände (UvmE3) bestreitet. Ebenfalls als Idealismus werden aber auch Positionen bezeichnet, die die These (OR2) für inkohärent halten. ${ }^{40}$

Keine spezifische eigene Bezeichnung tragen meist Positionen, die Thesen vom Typ (UvmE4) bestreiten, also etwa eine Position, nach der es (in bestimmten Gegenstandsbereichen) keine primären, sondern nur sekundäre Qualitäten (und entsprechende Entitäten und Sachverhalte) gibt. ${ }^{41}$

Konstruktivismus ist eine Bezeichnung für unterschiedliche, mit verschiedenen realistischen Thesen (jedenfalls prima facie) in einem Spannungsverhältnis stehende Positionen, die, für einen bestimmten Gegenstandsbereich oder global, die These vertreten, daß die Gegenstände, Sachverhalte etc., von denen menschliches Wissen handelt, nicht als unabhängig von menschlicher Erkenntnis, sondern vielmehr als durch den Erkenntnisprozeß,

\footnotetext{
${ }^{31}$ [Desc72], 1.Meditation.

${ }^{32}$ [Putn81], Kap.1.

${ }^{33}$ Siehe Fn.4.

${ }^{34} \mathrm{Vgl}$. [Dumm76].

${ }^{35}$ [Ayer36], Kap.3, 7.

${ }^{36}$ [Ayer36], S.53, 63ff.

${ }^{37}$ [Blac84], S.167ff.

${ }^{38}$ Siehe z.B. [Ayer36], Kap.6.

${ }^{39}$ [Berk88].

${ }^{40}$ Etwa die von Donald Davidson; siehe [Nage86], S.93ff.

${ }^{41}$ Vgl. z.B. [Putn81], S.61ff.
} 
die Verwendung eines Begriffsschemas o.ä. konstruiert aufzufassen sind. Konstruktivisten bestreiten jedoch ontologische realistische Thesen und insbesondere die darin enthaltenen Unabhängigkeitsaussagen i.a. nicht ${ }^{42}$, sofern 'unabhängig von menschlicher Erkenntnis' darin in einer der vorne angegebenen Weisen präzisiert wird. Soweit sie positive Erläuterungen geben, in welchem Sinn Gegenstände, Sachverhalte etc. als "konstruiert" und daher als abhängig von menschlicher Erkenntnis o.ä. aufzufassen sind, versuchen sie meistens, eine Abhängigkeit der Gegenstände, Sachverhalte etc. von den Begriffen oder Begriffssystemen $\mathrm{zu}$ identifizieren und plausibel zu machen, mittels derer die Gegenstände, Sachverhalte etc. individuiert oder identifiziert werden. ${ }^{43}$

\subsection{Realismus in der Wissenschaftstheorie: Dimensionen des Themas, Thesen und Positionen}

Die wissenschaftstheoretische Realismusdebatte wird zu einem guten Teil von den anderen oben genannten philosophischen Debatten abgekoppelt geführt. Ihr Thema sind realistische und antirealistische Thesen bezüglich der Gegenstandsbereiche und Diskurse der Wissenschaften, insbesondere insofern theoretische Entitäten involviert sind, also Gegenstände, Eigenschaften, Prozesse, Sachverhalte etc., die, anders als materielle Alltagsgegenstände und deren Eigenschaften, nicht der Beobachtung mit bloßem Auge zugänglich sind. Zwar hat man es in den Wissenschaften natürlich auch mit mittelgroßen materiellen Gegenständen wie Kristallen, Insekten, Säuren und Wolken zu tun, im Mittelpunkt des wissenschaftstheoretischen Interesses stehen jedoch Dinge wie Gene, Elektronen, Moleküle, elektromagnetische Felder, kovalente Bindungen, das Über-Ich u.ä. und die diesbezüglichen kognitiven Produkte der Wissenschaften. ${ }^{44}$

\subsubsection{Realistische Thesen}

Wie in den allgemein-philosophischen Debatten findet sich auch in der wissenschaftstheoretischen Realismusdebatte bei den Anhängern realistischer Positionen eine Vielzahl realistischer Thesen, die teils explizit und präzise formuliert, teils eher grob skizziert, nur angedeutet oder implizit angenommen werden. ${ }^{45}$ Über die Menge dieser Thesen kann man auch hier eine systematisierende Übersicht gewinnen, indem man eine ontologische, eine semantische und eine erkenntnistheoretische Dimension dessen unterscheidet, was die Thesen zum Inhalt haben; zusätzlich finden sich allerdings hier axiologische Thesen. Für diese Dimensionen lassen sich auch hier Schemata für präzise formulierte realistische Thesen angeben derart, daß die meisten der von Anhängern realistischer Positionen vertretenen Thesen sich als Instantiierungen dieser Schemata auffassen lassen oder sich, sofern es sich um grob und unscharf formulierte Thesen handelt, zumindest im Sinne einer präzisierenden Explikation als Instantiierungen dieser Schemata rekonstruieren lassen. Zwischen beiden Debattenfeldern gibt es also weitreichende Parallelen hinsichtlich der von realistischer Seite vertretenen Thesen. ${ }^{46}$

\footnotetext{
${ }^{42}$ D.h. jedenfalls nicht prinzipiell, nicht qua Konstruktivisten.

${ }^{43}$ Vgl. etwa [Putn81], [Putn87a], [Putn92], Kap.6, [Good78, Good80].

${ }^{44}$ Von den diversen Wissenschaften und ihren Gegenstands- und Diskursbereichen wird hier und generell in dieser Arbeit hauptsächlich die Physik im Zentrum der Diskussion stehen.

${ }^{45}$ Vgl. z.B. [Lepl84], [NeSm81], Kap.II, [Hack83a], Kap.1.

${ }^{46}$ Für die Frage nach der Vollständigkeit und Adäquatheit der Liste der folgenden Schemata und Erläuterungen s. Fn.6.
} 


\section{Ontologischer Realismus}

Auch in der wissenschaftstheoretischen Debatte werden ontologische realistische Thesen bezüglich bestimmter Gegenstandsbereiche diskutiert, die besagen, daß die spezifizierten Entitäten unabhängig von menschlicher Erkenntnis existieren, bestimmte Eigenschaften haben etc., also Thesen der Form (OR) oder jedenfalls Thesen, die sich in dieser Form rekonstruieren lassen. Damit aus dem Schema (OR) eine präzise These wird, muß wiederum die Qualifikation "unabhängig von menschlicher Erkenntnis" erläutert werden, und auch hier kommen dazu Aussagen der Formen (UvmE1) - (UvmE4) in Betracht.

Erläuterungen der Form (UvmE1a), (UvmE2a) und (UvmE3a), die die Qualifikation enthalten, daß es für die Unabhängigkeit bestimmter Entitäten, Eigenschaften etc. von menschlicher Erkenntnis "nur" auf die Unabhängigkeit von Erkenntniszuständen etc. ankommt, die die fraglichen Entitäten, Eigenschaften etc. zum Inhalt haben ${ }^{47}$, sind im Bereich der Wissenschaftstheorie insbesondere dann relevant, wenn ontologische realistische Thesen über Entitäten, Phänomene, Zustände usw. formuliert werden sollen, die für experimentelle Untersuchungen präpariert, hergestellt oder manipuliert werden müssen. ${ }^{48}$

Erläuterungen der Form (UvmE3) bzw. (UvmE3a), die ausschließen, daß bestimmte Entitäten, Eigenschaften etc. durch mentale Entitäten konstituiert werden, sind in der wissenschaftstheoretischen Debatte vor allem gegen phänomenalistische Positionen ${ }^{49}$ gerichtet.

Aussagen der Form (OS2) über Grenzen des menschlichen kognitiven Zugriffs auf die Welt spielen dagegen in der wissenschaftstheoretischen Debatte im allgemeinen keine Rolle.

\section{Semantischer Realismus}

Semantische realistische Thesen, die die Form (SR1) und (SR2) haben oder sich jedenfalls so rekonstruieren lassen, also Thesen, die besagen, daß eine bestimmte Theorie oder eine bestimmte Menge von Sätzen oder Theorien wahr oder falsch ist, unabhängig von menschlichen epistemischen Mitteln zum Erkennen ihres Wahrheitswertes, und außerdem wörtlich zu nehmen, finden sich ebenfalls in der wissenschaftstheoretischen Debatte. ${ }^{50}$

Zur Erläuterung dieser Thesen wird von realistischer Seite auch hier meistens eine nicht-epistemische Wahrheitstheorie ins Spiel gebracht, typischerweise eine Korrespondenztheorie $^{51}$, und evtl. eine Bedeutungs- und Referenztheorie, bei der Wahrheits- bzw. Erfüllungsbedingungen im Zentrum stehen. ${ }^{52}$ Diese können als Erläuterung von "unabhängig ..." wiederum Aussagen der Form (UvmeM1) und (UvmeM2) ergeben.

Bei semantischen Thesen der Form (SR1) liegt in der wissenschaftstheoretischen Debatte der Akzent darauf, daß die fragliche Theorie bzw. Menge von Sätzen in allen Teilen wahr oder falsch ist, d.h. in den Teilen, in denen sie von unbeobachtbaren Entitäten, Eigenschaften etc. handelt, genauso wie in den Teilen, in denen es um Beobachtbares geht. Eine solche realistische These soll für die gesamte Theorie bzw. die gesamte Menge von Sätzen gelten, nicht nur für einen Teil, der keine unbeobachtbaren Entitäten enthält. ${ }^{53}$

\footnotetext{
${ }^{47} \mathrm{Im}$ Gegensatz zu sonstigen Erkenntniszuständen etc.

${ }^{48}$ Siehe Abschnitt 12.4.1.

${ }^{49}$ S.u.

${ }^{50}$ Eine frühe Arbeit, die auf die Formulierung von semantischem Realismus in der wissenschaftstheoretischen Realismusdebatte zielt, ist [Feig50a].

${ }^{51}$ Siehe z.B. [NeSm81], S.28/29.

${ }^{52}$ Die semantischen Theorien, die zur Erläuterung von (SR1) herangezogen werden können, und die Frage, ob, und wenn ja, wie sie eine Erläuterung von "unabhängig ..." liefern, werden in Teil I diskutiert.

${ }^{53}$ Siehe aber die unten (S.15ff.) diskutierten Abschwächungen.
} 
Entsprechend liegt bei semantischen Thesen der Form (SR2) der Akzent darauf, daß die Theorie bzw. die Menge von Sätzen insgesamt, also auch in ihrem "unbeobachtbaren Teil", wörtlich zu nehmen ist. ${ }^{54}$ Damit sollen die Reduktion von Ausdrücken und Sätzen über Unbeobachtbares auf Ausdrücke und Sätze, die makroskopische Gegenstände bezeichnen, und Reduktionen auf Ausdrücke und Sätze einer Sinnesdatensprache ausgeschlossen werden, wie sie physikalistische und phänomenalistische Positionen propagieren. ${ }^{55}$ Nicht ausgeschlossen werden sollen dagegen üblicherweise Reduktionen von Ausdrücken und Sätzen auf andere Ausdrücke und Sätze über eine mikroskopischere Gegenstandsebene, etwa eine Reduktion von Ausdrücken und Sätzen über thermodynamische Größen auf solche über statistisch-mechanische Größen, von Ausdrücken und Sätzen über Chromosomen auf solche über ihre molekularen Bestandteile u.ä. ${ }^{56}$

\section{Epistemischer Realismus}

Epistemischer Realismus wird in der wissenschaftstheoretischen Debatte ebenfalls durch Thesen formuliert, die besagen, daß eine bestimmte Theorie oder eine Menge von Sätzen wahr ist, also durch Thesen, die die Form (EP) haben oder sich jedenfalls so rekonstruieren lassen, es finden sich aber auch in bestimmter Weise "abgeschwächte" epistemische realistische Thesen. ${ }^{57}$ Epistemischer Realismus setzt wiederum semantischen Realismus voraus.

Der Akzent liegt bei epistemischen realistischen Thesen in der wissenschaftstheoretischen Debatte darauf, daß die fragliche Theorie bzw. Menge von Sätzen in allen Teilen wahr ist, also in den Teilen, in denen sie von unbeobachtbaren Entitäten, Eigenschaften etc. handelt, genauso wie in den Teilen, in denen es um Beobachtbares geht. ${ }^{58}$

\section{Axiologischer Realismus}

Neben den Thesen der drei genannten Arten werden in der wissenschaftstheoretischen Debatte von realistischer Seite gelegentlich axiologische Thesen über das Unternehmen Wissenschaft oder über Teile davon (z.B. die Naturwissenschaften, die Physik) formuliert. Eine axiologische realistische These ist eine Aussage der Form

(AR) Das Ziel der Wissenschaften (oder eines spezifizierten Teils der Wissenschaften) sind wörtlich zu nehmende und wahre Theorien, Gesetze etc. ${ }^{59}$

Eine präzise These erhält man aus diesem Schema, indem man spezifiziert, für welchen Teil des Unternehmens Wissenschaft sie gelten soll, und erläutert, was genau mit "Ziel" gemeint ist, und indem man mittels einer Wahrheitstheorie (und evtl. einer Bedeutungsund Referenztheorie) erläutert, was Theorien, Gesetze etc. zu wahren Gesetzen, Theorien etc. macht. Letzteres tun Realisten meistens mit Hilfe einer nicht-epistemischen Wahrheitstheorie, typischerweise einer Korrespondenztheorie (und evtl. einer dazu passenden Bedeutungs- und Referenztheorie).

Für die Erläuterung der Redeweise von einem "Ziel der Wissenschaften" ist eine Unterscheidung zu beachten. Ein Ziel schreibt man gewöhnlich Personen und ihren Handlungen

\footnotetext{
${ }^{54}$ Siehe z.B. [Lepl84], S.2, [vFra80], S.9.

${ }^{55}$ Siehe S.18.

${ }^{56}$ Siehe [vFra80], S.10f.

${ }^{57}$ Dazu S.15ff.

${ }^{58}$ Bzw. Analoges bei abgeschwächten Thesen.

${ }^{59}$ Siehe z.B. [Musg88], S.229, [vFra80], S.8.; s.a. [Hutt96].
} 
und Praktiken zu, gemeint sein kann damit zweierlei. Daß eine Person ein bestimmtes Ziel hat, kann heißen, daß sie wünscht, daß ein bestimmter Sachverhalt eintritt. Ein solches Ziel kann bestimmte Handlungen der Person motivieren und erklären. Wenn die Person, die dieses Ziel hat, glaubt, daß die Handlungen dazu führen, daß der gewünschte Sachverhalt eintritt oder jedenfalls wahrscheinlich eintritt, daß die Handlungen eine notwendige Voraussetzung dafür schaffen, daß er eintritt, o.ä. ${ }^{60}$, besteht ein kohärenter Zusammenhang zwischen dem Wunsch, den Überzeugungen und den Handlungen dieser Person; ihre Handlungen sind in diesem Sinn rational. Man spricht in diesem Fall auch davon, daß die Handlungen das entsprechende Ziel haben. ${ }^{61}$

Daß eine Person und ihre Handlungen ein bestimmtes Ziel haben, kann jedoch auch etwas anderes heißen: Wenn sich zu bestimmten Handlungen einer Person sozusagen aus einer Außenperspektive ein Sachverhalt angeben läßt derart, daß die Handlungen dazu führen, daß dieser Sachverhalt eintritt oder jedenfalls wahrscheinlich eintritt o.ä., dann spricht man in manchen Fällen davon, daß dieser Sachverhalt das Ziel der Handlungen ist, unabhängig davon, ob die Person selbst den Wunsch hat, daß er eintritt, und unabhängig davon, ob die Person selbst der Überzeugung ist, daß die Handlungen dazu führen, daß der entsprechende Sachverhalt eintritt, wahrscheinlich eintritt o.ä. Wenn die Person diesen Wunsch und diese Überzeugung hätte, dann bestünde ein kohärenter Zusammenhang zwischen diesem Wunsch, ihren Überzeugungen und ihren Handlungen; die Handlungen wären dann rational im ersten, oben genannten Sinn. Auch wenn dies nicht der Fall ist, spricht man jedoch manchmal in einem davon verschiedenen, zweiten Sinn von rationalen Handlungen, wenn man ihnen ein Ziel im zweiten hier beschriebenen Sinn zuschreiben kann, und auch davon, daß die Handlungen durch das Ziel erklärt werden können. ${ }^{62}$

Wenn in einer axiologischen realistischen These ein "Ziel der Wissenschaft" formuliert wird, ist mit "Wissenschaft" die Gesamtheit der Handlungen und Praktiken gemeint, die Wissenschaftler qua Wissenschaftler ausführen bzw. ausüben, und von einem Ziel ist im Sinne der zweiten der beiden unterschiedenen Verwendungsweisen die Rede. Daß das Ziel z.B. der Physik wahre Theorien sind, heißt also, daß die Handlungen und Praktiken der Physiker dazu führen, daß sie wahre Theorien gewinnen, wahrscheinlich dazu führen, daß sie wahre Theorien gewinnen, eine notwendige Voraussetzung dafür schaffen, daß sie wahre Theorien gewinnen, o.ä.; jedenfalls wird gemäß einer solchen Erläuterung von "Ziel”, die zu einer präzisen axiologischen realistischen These führt, den Handlungen und Praktiken der Physiker das Ziel wahre Theorien gleichsam aus der Außenperspektive zugeschrieben. Eine axiologische realistische These der Form (AR) impliziert nicht, daß die Wissenschaftler selbst den Wunsch haben, wahre Theorien zu gewinnen, oder daß sie überzeugt sind, daß ihre Handlungen und Praktiken dazu führen, wahrscheinlich dazu führen o.ä., daß sie wahre Theorien gewinnen. Sie impliziert, daß die Handlungen und Praktiken rational im Sinne der zweiten der beiden obigen Erläuterungen sind, nicht jedoch, daß sie rational im

\footnotetext{
${ }^{60}$ Hier sind verschiedene Präzisierungen denkbar, auf deren genaue Gestalt es an dieser Stelle nicht ankommt.

${ }^{61}$ Ein Beispiel ist eine Person, die das Ziel hat, ihr Vermögen zu verdoppeln, und verschiedene Aktienkäufe tätigt, weil sie glaubt, daß dies dazu führt, das der gewünschte Sachverhalt eintritt.

${ }^{62}$ Ein Beispiel sind bestimmte Handlungen eines Fußballspielers, etwa das ständige Manndecken des gegnerischen Rechtsaußen, die das Ziel haben, daß seine Mannschaft das Spiel gewinnt, obwohl dem Spieler selbst Sieg oder Niederlage gleichgültig sind (er hat vielleicht nur den Wunsch, durch seine Leistung seinen Marktwert zu erhöhen, oder er tut gewohnheitsmäßig stets das, was der Trainer ihm vorschreibt, o.ä.) und er zudem nicht glaubt, daß seine Handlungsweise zum Sieg führt, ihn wahrscheinlich macht o.ä.
} 
Sinne der ersten Erläuterung sind. ${ }^{63}$

Nimmt man die wissenschaftstheoretische und die allgemein-philosophischen Realismusdebatten zusammen in den Blick, so stellt man also fest, daß es weitreichende Parallelen, jedoch keine vollkommene Übereinstimmung im Hinblick auf die Arten von realistischen Thesen gibt, die jeweils vertreten werden. Dasselbe gilt für die Frage, ob, und wenn ja, in welcher Weise die von Nagel und Wright genannte Intuition durch präzise realistische Thesen konkretisiert wird: Die beiden Komponenten dieser Intuition, der bescheidene Gedanke, daß die Welt unabhängig vom menschlichen Geist und menschlicher Erkenntnis ist, und der anmaßende Gedanke, daß Menschen dennoch Wissen haben können und tatsächlich haben, werden in beiden Debatten entweder durch die beiden Teile ontologischer realistischer These der Form (OR) konkretisiert, oder durch semantische und epistemische realistische Thesen zusammen. Axiologische realistische Thesen dagegen lassen sich nur in einem losen Sinn als Konkretisierung dieser Intuition auffassen. ${ }^{64}$

Realistische Thesen zu vertreten, insbesondere ontologische und epistemische, schließt in der wissenschaftstheoretischen Realismusdebatte, genau wie in den allgemein-philosophischen Debatten, die Anerkennung der prinzipiellen Fehlbarkeit menschlicher Erkenntnisverfahren nicht aus.

Welche These oder Thesen der genannten Arten eine intuitiv angemessene realistische Position ergeben, welche Thesen also konstitutiv für wissenschaftlichen Realismus sein sollten, dazu gibt es auch in der wissenschaftstheoretischen Debatte keinen Konsens. Zu der bereits im Kontext der allgemeineren Debatten genannten kontroversen Frage, ob eine oder mehrere ontologische Thesen oder eine oder mehrere semantische plus (evtl.) epistemische Thesen den Kern einer realistischen Position bilden sollten und welche genau, kommt die Frage hinzu, ob eine axiologische These Teil einer realistischen Position sein sollte. Auch in der wissenschaftstheoretischen Realismusdebatte wird unter dem Titel "Realismus" eine Vielzahl von Positionen formuliert, skizziert oder angedeutet, die verschiedene, verschiedenartige und unterschiedlich weitreichende Thesen einschließen, die zu den genannten Arten gehören oder sich zumindest im Sinne einer präzisierenden Explikation in dieser Weise rekonstruieren lassen.

\section{Differenzierungen und Abschwächungen realistischer Thesen}

Traditionell werden realistische oder antirealistische Thesen in der Wissenschaftstheorie häufig für die Theorien und Entitäten einer Naturwissenschaft insgesamt formuliert oder sogar für die Theorien und Entitäten aller Naturwissenschaften en bloc. Entsprechend läßt man die Unterscheidung zwischen innerwissenschaftlichen Argumenten (für die Etablierung von Theorien, die Existenz von Entitäten und Phänomene u.ä.) einerseits und der

\footnotetext{
${ }^{63}$ In diesem Sinn ist die gelegentlich im Zusammenhang mit axiologischen realistischen Thesen formulierte These zu verstehen, daß die Wissenschaften ein rationales Unternehmen sind.

${ }^{64}$ Axiologischer Realismus wird typischerweise zusammen mit semantischen realistischen Thesen vertreten, die dann sozusagen für die Konkretisierung des "bescheidenen Gedankens" zuständig sind. Den "anmaßenden Gedanken" konkretisieren axiologische realistische Thesen offenbar nicht wirklich, sie sind aber verträglich mit epistemischen oder ontologischen realistischen Thesen, die das tun, und legen sie vielleicht sogar nahe: Daß wahre Theorien das Ziel der Praktiken der Physik sind, impliziert nicht, daß durch diese Praktiken das Ziel tatsächlich erreicht wird (es könnte sozusagen etwas dazwischen kommen, obwohl die Methoden eigentlich geeignet sind, das Ziel zu erreichen) oder sogar schon erreicht wurde, und läßt auch offen, welches die wahren Theorien sind, ist aber mit dem Erreichen des Ziels verträglich und legt vielleicht sogar nahe, daß einige wahre Theorien bereits gefunden wurden.
} 
(wissenschafts-)philosophischen Reflexion über die Erkenntnisansprüche der Wissenschaften andererseits häufig zusammenfallen mit einer Unterscheidung zwischen spezifischen, auf die Etablierung bestimmter, einzelner Theorien, Gesetze, Entitäten usw. gerichteten Argumenten einerseits und globalen, den Status aller Theorien und Entitäten der Wissenschaften betreffenden Argumenten andererseits. ${ }^{65}$

Diese Gleichsetzung ist aber nicht allgemein akzeptiert; einige Autoren stellen sie in Frage. ${ }^{66}$ Wie an den oben angegebenen Schemata für die verschiedenen Typen realistischer Thesen ablesbar, kann der Gegenstandsbereich bzw. die Menge von Sätzen oder Theorien, für die eine realistische These gelten soll, in verschiedener Weise spezifiziert werden, insbesondere unterschiedlich weit, d.h. man kann ohne weiteres realistische Thesen formulieren, die sich "nur" auf Teile der Theorien und Entitäten der Wissenschaften beziehen. Entsprechend kann man versuchen, selektive, evtl. "bereichsspezifische" Argumente zu finden, um eine realistische These oder mehrere zu begründen, die sich "nur" auf einen Teil der Theorien und Entitäten einer Wissenschaft (oder der Wissenschaften) beziehen, und es ist keineswegs selbstverständlich oder zwangsläufig so, daß solchen Argumenten keine (wissenschafts-)philosophische Relevanz zukäme.

Ein Motiv dafür, realistische Thesen nicht en bloc zu formulieren, liegt darin, daß das, wovon eine realistische These handelt, die sich auf eine Theorie als ganze bezieht, i.a. zu mehreren der oben ${ }^{67}$ erwähnten Kategorien zählt: Eine physikalische Theorie etwa handelt von manifesten physikalischen Entitäten und Prozessen, hat jedoch (zumindest in bestimmten Lesarten) auch modale und kontrafaktische Sachverhalte zum Inhalt und involviert meistens mathematische Entitäten und Sachverhalte und (je nach Lesart) evtl. auch Universalien und natürliche Arten. Verschiedene Anhänger realistischer Positionen plädieren für eine unterschiedliche Beurteilung dieser Kategorien und daher für eine entsprechend differenzierte Formulierung realistischer Thesen.

Ein weiteres Motiv dafür, bei der Formulierung realistischer Thesen nach Gegenstandsbereichen zu differenzieren, und außerdem und gleichzeitig ein Motiv, in bestimmter Weise "abgeschwächte" realistische Thesen zu formulieren, liegt für viele Anhänger realistischer Positionen darin, daß der Status von unbeobachtbaren Entitäten und Theorien über sie wesentlich problematischer zu sein scheint als der von (in allgemein-philosophischen Debatten zentralen) materiellen Alltagsgegenständen und "Theorien" über diese. Für einen solchen problematischeren Status spricht vor allem die historische Erfahrung, daß Überzeugungen über mittelgroße Gegenstände der Alltagswelt im großen und ganzen über lange Zeiträume stabiler sind als wissenschaftliche Theorien, nicht in demselben Maße Korrekturen unterworfen.

Aus diesem Grund werden in der Wissenschaftstheorie realistische Thesen häufig in einer Weise nach ihrer Reichweite oder "Stärke" differenziert, die man in den allgemeineren Diskussionen nicht findet: Dort schließt semantischer Realismus in bezug auf eine Menge von Sätzen die These ein, daß diese Sätze unabhängig von menschlichen epistemischen Mitteln wahr oder falsch sind, und epistemischer Realismus entsprechend die These, daß sie wahr sind. Daß dies auch für die in der fraglichen Menge von Sätzen enthaltenen oder von ihr implizierten Existenzsätze gilt, wird dabei selbstverständlich vorausgesetzt. Es geht also bei den realistischen Positionen der allgemeinen Diskussion sozusagen um nicht weniger als die Wahr- oder Falschheit bzw. die Wahrheit der zur Debatte stehenden Menge von Sätzen einschließlich der in ihr enthaltenen oder von ihr implizierten Exi-

\footnotetext{
${ }^{65}$ Hacking spricht hier von realism-in-particular versus realism-in-general; [Hack83a], S.29ff.

${ }^{66}$ Z.B. [Hack83a, McMu84, McMu91, Shap69].

${ }^{67}$ S.3.
} 
stenzsätze (für ontologischen und axiologischen Realismus gilt Entsprechendes). In der wissenschaftstheoretischen Realismusdebatte dagegen ist es nach Ansicht vieler Autoren ratsam und angemessen, eine realistische Position mittels qualifizierter, in bestimmter Weise abgeschwächter realistischer Thesen $\mathrm{zu}$ formulieren.

$\mathrm{Zu}$ diesem Zweck wird zum einen (neben dem Begriff der Wahrheit bzw. der Falschheit von Theorien) häufig der Begriff der annähernden Wahrheit, Wahrheitsnähe oder Wahrheitsähnlichkeit eingeführt. Die Idee ist, eine begriffliche Möglichkeit zu schaffen, um differenzieren zu können zwischen einerseits völlig falschen Theorien und andererseits Theorien, die strenggenommen zwar falsch sind, die aber z.B. für bestimmte Größen numerische Werte angeben, die nahe bei den "wahren" Werten liegen. Weiterhin will man auf diese Weise die Idee explizieren, daß sich von einer Folge von Theorien über denselben Gegenstandsbereich, die allesamt strenggenommen falsch sind, Genaueres sagen lassen muß, nämlich, ob ein Erkenntnisfortschritt zu verzeichnen ist. Der Begriff des Erkenntnisfortschritts soll dahingehend expliziert werden, daß man von Fortschritt spricht, wenn eine Folge von Theorien der Wahrheit näher kommt. ${ }^{68}$

Zum anderen wird von einigen Autoren eine Unterscheidung eingeführt zwischen realistischen Thesen, die die Wahrheit oder Falschheit von Existenzsätzen bzw. die Existenz von theoretischen Entitäten zum Inhalt haben (Entitätenrealismus) einerseits, und andererseits realistischen Thesen, die darüber hinaus die Wahrheit oder Falschheit von theoretischen Sätzen oder Theorien bzw. das Vorliegen von Eigenschaften bei den theoretischen Entitäten, Gesetze, denen die theoretischen Entitäten unterliegen, u.ä. zum Inhalt haben (Theorienrealismus).

Entitätenrealismus kann also ontologische Thesen einschließen, die besagen, daß bestimmte, insbesondere unbeobachtbare Entitäten unabhängig von menschlicher Erkenntnis existieren, semantische Thesen, die besagen, daß Existenzaussagen über bestimmte, insbesondere unbeobachtbare Entitäten wörtlich zu nehmen und wahr oder falsch sind, und epistemische Thesen, die besagen daß diese Existenzaussagen wahr sind ${ }^{69}$. Darüber hinaus muß über etwaige Theorien, die Eigenschaften und Verhalten der Entitäten beschreiben, nichts angenommen oder impliziert werden. Theorienrealismus dagegen schließt Thesen des Entitätenrealismus ein plus weiterreichende Thesen, und zwar ontologische Thesen, die sagen, daß die fraglichen Entitäten unabhängig von menschlicher Erkenntnis die Eigenschaften haben, die ihnen bestimmte Theorien zuschreiben, den Gesetzen dieser Theorien unterliegen etc., und/oder semantische Thesen, die sagen, daß diese Theorien über die Entitäten wörtlich zu nehmen und wahr oder falsch sind, und/oder epistemische Thesen, die sagen, daß diese Theorien wahr ${ }^{70}$ sind. $^{71}$

Neben dem Entitätenrealismus sind in den letzten Jahren noch weitere Arten von abgeschwächten realistischen Thesen und mit ihrer Hilfe formulierte realistische Positionen vorgeschlagen worden, insbesondere ein Realismus der Phänomenarten und ein Realismus

\footnotetext{
${ }^{68}$ Siehe dazu [Tsch93].

${ }^{69}$ Oder wahrheitsähnlich o.ä.

${ }^{70}$ Oder wahrheitsähnlich o.ä.

${ }^{71}$ Axiologischer Realismus wird üblicherweise nur in der Form des Theorienrealismus vertreten, eine entitätenrealistische Version ist aber ebenfalls denkbar.

Bei genauerem Hinsehen ist die Unterscheidung von Entitäten- und Theorienrealismus problematisch oder jedenfalls erläuterungsbedürftig, da ihre beiden Seiten "in Reinform" wenig attraktiv aussehen und auch keine vollständige Alternative darstellen, sondern eher die beiden Enden eines Spektrums. Intendiert ist mit der Einführung dieser Unterscheidung meistens so etwas wie eine Linie zwischen Thesen, die die Existenz theoretischer Entitäten plus einige wenige "beobachtungsnahe" Eigenschaften und Gesetze zum Inhalt haben, einerseits, und andererseits Thesen, die den Entitäten "hochtheoretische" Eigenschaften zuschreiben, "hochtheoretische" Gesetze über ihr Verhalten formulieren u.ä. (vgl. Kap.11).
} 
der Strukturen. ${ }^{72}$

\subsubsection{Gegenpositionen}

Den verschiedenen realistischen Positionen steht in der wissenschaftstheoretischen Realismusdebatte - wie in den allgemeineren Debatten - eine ganze Reihe von Gegenpositionen gegenüber, die verschiedene realistische Thesen (oder Arten von realistischen Thesen) ablehnen und (eventuell) durch andere ersetzen.

Bas van Fraassen vertritt die von ihm als konstruktiver Empirismus bezeichnete Position, wissenschaftliche Theorien inklusive derjenigen ihrer Teile, die von Unbeobachtbarem handeln, als wahr oder falsch aufzufassen und wörtlich zu nehmen, gleichzeitig aber eine agnostische Haltung in bezug auf den Bereich des Unbeobachtbaren einzunehmen. ${ }^{73}$ Er verbindet also bezüglich dieses Bereichs semantischen Realismus mit der Ablehnung erkenntnistheoretischer realistischer Thesen. Außerdem lehnt er auch axiologische realistische Thesen ab.

Die als Antirealismus bezeichneten, durch bedeutungstheoretische Überlegungen motivierten allgemein-philosophischen Positionen ${ }^{74}$ schließen als Spezialfall eine antirealistische Position in der wissenschaftstheoretischen Realismusdebatte ein, die für die hier thematisierten Gegenstands- bzw. Diskursbereiche Thesen der Form (SR1) bestreitet. ${ }^{75}$

Zwei im Umkreis des logischen Positivismus vertretene Positionen stehen hinsichtlich des Bereichs des Unbeobachtbaren im Widerspruch zu Thesen der Form (SR2). Der einen dieser Positionen zufolge können theoretische Sätze bzw. Ausdrücke übersetzt werden in solche über beobachtbare Gegenstände, Sachverhalte und Ereignisse, also in eine, wie es dort gelegentlich heißt ${ }^{76}$, Dingsprache (thing-language). Andere gebräuchliche Formulierungen, die dasselbe ausdrücken sollen, sind die, daß Elektronen, Atome u.ä. "logische Konstruktionen" aus beobachtbaren Gegenständen und Ereignissen sind, ${ }^{77}$ und die, daß theoretische Ausdrücke allein durch Ausdrücke, die für Beobachtbares stehen ${ }^{78}$, definiert werden können. ${ }^{79}$ Diese Position wird von ihren Vertretern als Physikalismus bezeichnet. Die zweite der beiden Positionen, die häufig Phänomenalismus genannt wird, vertritt eine analoge These über die Übersetzbarkeit von theoretischen Sätzen und Ausdrücken in Sätze und Ausdrücke, die Wahrnehmungen oder Sinnesdaten zum Inhalt haben. ${ }^{80}$

Operationalisten lassen grundsätzlich nur solche Begriffe als sinnvoll und legitim für die Formulierung von theoretischen Sätzen und Theorien zu, für die konkrete Meß- oder Nachweisverfahren angegeben werden können, und betrachten diese Verfahren als die Bedeutung oder Definition der Begriffe. ${ }^{81}$ Semantischer Realismus ist damit ausgeschlossen.

Als Instrumentalismus werden verschiedene Positionen bezeichnet, die darin übereinstimmen, daß sie bestimmten (Mengen von) im Diskurs der Wissenschaften geäußerten Sätzen den Status von "ernsthaften" Behauptungen absprechen, insbesondere Sätzen über

\footnotetext{
${ }^{72}$ Siehe dazu Kap.9.1.4 und 9.1.5.

${ }^{73}$ Siehe Kap.10.2.

${ }^{74}$ Siehe S.10.

${ }^{75}$ Siehe z.B. [Dumm93b], S.469ff.

${ }^{76}$ Z.B. [Ca36/37], S.466.

${ }_{77}$ [Smar63], S.27.

${ }^{78}$ Plus logische Ausdrücke natürlich.

${ }^{79}$ [Nage79], S.118f.

${ }^{80}$ Siehe z.B. [Nage79], S.120, [Russ18b]. Zu den beiden genannten Positionen und deren Nachfolgepositionen siehe Kap.2.

${ }^{81}$ Z.B. [Brid27], S.5.
} 
Unbeobachtbares. ${ }^{82}$

Die traditionelle Form des Instrumentalismus tut dies aus bedeutungstheoretischen ${ }^{83}$ Gründen: Theorien und theoretische Sätze sind nach dieser Auffassung zwar sprachliche Entitäten, aber sie bzw. diejenigen ihrer Teile, die nicht von Beobachtbarem handeln, sind nicht wahr oder falsch, sondern gehören sozusagen zu einer anderen Sorte sprachlicher Gebilde als gewöhnliche Aussagesätze: Sie sind als eine Art "intellektuelle Werkzeuge" 84 , "Instrumente [...] zur Ableitung von Beobachtungssätzen aus anderen solchen Sätzen" 85, "inference tickets" 86 für das Ableiten von experimentellen Daten aus anderen experimentellen Daten, "Vorschriften, Verhaltensmaßregeln für den Forscher, sich in der Wirklichkeit zurechtzufinden, wahre Sätze aufzufinden, gewisse Ereignisse zu erwarten" ${ }^{87}$. Diese Version des Instrumentalismus lehnt also die Thesen des semantischen Realismus für den Bereich des Unbeobachtbaren ab. Theoretischen Sätzen und Theorien kommt, sofern sie von unbeobachtbaren Entitäten und Prozessen sprechen, kein Wahrheitswert zu, die entsprechenden Ausdrücke haben keinerlei Bedeutung oder Referenz, sie sind in diesem Sinn nicht "semantisch vollwertig". Daher können sie auch nicht zur Äußerung von Behauptungen verwendet werden. Die Frage nach erkenntnistheoretischem Realismus stellt sich für Instrumentalisten dieses Typs nicht.

Ebenfalls als Instrumentalismus werden häufig Positionen bezeichnet, denen zufolge bestimmte (Mengen von) Äußerungen aus epistemischen Gründen nicht als Behauptungen aufzufassen sind, nämlich (semantisch vollwertige) Sätze, für deren Wahrheit man keine hinreichenden Evidenzen hat oder (semantisch vollwertige) Sätze, für deren Falschheit man sogar gute Evidenzen hat, die aber dennoch in praktischen Kontexten verwendet bzw. geäußert werden im Sinne einer Rede von zweckmäßigen Fiktionen für die denkökonomische Organisation von Beobachtungswissen, für (in bestimmten, abgegrenzten praktischen Kontexten funktionierende) Handlungsregeln, -rezepte u.ä. ${ }^{88}$

Die oben als Idealismus bezeichneten allgemein-philosophischen Positionen und die Positionen, die Entitäten, Eigenschaften etc. generell die Unabhängigkeit von menschlicher Erkenntnis im Sinne von (UvmE4) absprechen, beziehen sich unter anderem auch auf die in der wissenschaftstheoretischen Realismusdebatte thematisierten Gegenstandsbereiche.

Als Konstruktivismus werden in der Wissenschaftstheorie verschiedene Positionen bezeichnet, u.a. die für den Gegenstandsbereich der Wissenschaften spezialisierten Versionen der Positionen, die in den allgemein-philosophischen Debatten als Konstruktivismus etikettiert werden, aber auch andere spezifisch wissenschaftstheoretische, (teilweise oder ganz) "realismuskompatible" ${ }^{89}$ Positionen. ${ }^{90}$ Zur letzteren Gruppe zählen Positionen, die Thesen vertreten wie die, daß der Geltungsbereich wissenschaftlicher Theorien auf (im Labor) konstruierte Artefakte beschränkt ist, die, daß konstruierte Artefakte, sprich: Meß-, Beobachtungs- und sonstige Instrumente, Voraussetzung jeder Theoriebildung sind, die,

\footnotetext{
${ }^{82}$ Vgl. [NeSm81], S.28ff., [Pett91], S.590f., [Wrig92], S.7.

${ }^{83}$ Verifikationistischen oder operationalistischen — siehe Kap.2.

${ }^{84}$ [Dewe88], S.166, [Nage79], S.131.

85 [Nage79], S.129; s.a. [Nage50], S.176, [Fran32], Kap.1.

${ }^{86}$ [Ryle49], S.121.

${ }^{87}$ [Schl38b], S.68.

${ }^{88}$ Siehe z.B. [Feye81d]. Von diesen gängigen Verwendungsweisen von 'Instrumentalismus' abweichend bezeichnet Arthur Fine ([Fine86b], S.156ff., 175) mit diesem Etikett eine Position, die sich im Kern um den Wahrheitsbegriff dreht, den Fine auf pragmatistischer oder deflationärer Linie erläutern will, und zwar ohne eine relevante Grenze beobachtbar/unbeobachtbar o.ä.

${ }^{89}$ Je nach Erläuterung von "unabhängig von menschlicher Erkenntnis".

${ }^{90}$ Die in der Philosophie der Mathematik als Konstruktivismus bezeichneten Positionen bleiben hier beiseite.
} 
daß der Gegenstandsbereich oder Teile des Gegenstandsbereichs einiger Wissenschaften einen ontologisch abhängigen Status haben (z.B. soziale Rollen, einige biologische Kategorien), oder die, daß wissenschaftliche Normen, Methodologien, Theorien, Modelle usw. das Produkt sozialer Entscheidungsprozesse (und in diesem Sinn "konstruiert") sind. ${ }^{91}$

\subsection{Realismus: Das Verhältnis von allgemein-philosophischen und wissenschaftstheoretischen Thesen, Positionen und Argumentationen}

\subsubsection{Ein Cluster realistischer Thesen mit mehreren Teilclustern, das Thema der wissenschaftstheoretischen Realismusdebatte als "Spe- zialgebiet", kein Konsens über die für eine realistische Position konstitutiven Thesen}

Das Verhältnis der wissenschaftstheoretischen Realismusdebatte zu den allgemein-philosophischen Debatten läßt sich, nach dem, was gesagt wurde, im Hinblick auf die zur Diskussion stehenden Inhalte folgendermaßen charakterisieren. Thema der allgemein-philosophischen Debatten ist ein Cluster von teils explizit und präzise formulierten, teils eher grob skizzierten, nur angedeuteten Thesen, die sich auf unterschiedlich große Ausschnitte aus dem von der gesamten Debatte abgedeckten weiten Feld von Gegenstands- bzw. Diskursbereichen beziehen. Bei dem, was diese Thesen beinhalten, lassen sich eine ontologische, eine semantische und eine erkenntnistheoretische Dimension unterscheiden. Für jede dieser Dimensionen lassen sich ein oder zwei Schemata für präzise formulierte realistische Thesen angeben derart, daß die meisten der von Anhängern realistischer Positionen vertretenen Thesen sich als Instantiierungen dieser Schemata auffassen lassen oder sich zumindest im Sinne einer präzisierenden Explikation als Instantiierungen dieser Schemata rekonstruieren lassen. Der Cluster von Thesen läßt sich in diesem Sinn in drei Teilcluster von präzisen realistischen Thesen zerlegen, nämlich ontologische, semantische und epistemische realistische Thesen. Die Schemata, die zu den Teilclustern gehören, bringen das zum Ausdruck, was die Thesen des jeweiligen Teilclusters verbindet. Die Thesen der Teilcluster gehen aus den Schemata hervor, indem man einen Gegenstands- bzw. Diskursbereich (Entitäten, Eigenschaften etc. bzw. Sätze, Theorien etc.) spezifiziert und die "Parameter" "unabhängig von menschlicher Erkenntnis' etc. erläutert.

Die Schemata der drei Teilcluster entsprechen zwei nicht (oder zumindest nicht notwendigerweise) konfligierenden Weisen, die von Nagel und Wright genannte allgemeine, hinter den diversen realistischen Positionen stehende Intuition zu konkretisieren: Eine Möglichkeit ist, dies durch ontologische realistische Thesen zu tun, deren zwei Aspekte den beiden Komponenten der genannten Intuition entsprechen. ${ }^{92}$ Die andere Möglichkeit ist, dies durch semantische realistische Thesen zusammen mit epistemischen realistischen Thesen zu tun, die je einer der beiden Komponenten der von Nagel und Wright beschriebenen Intuition entsprechen.

Thema der wissenschaftstheoretischen Realismusdebatte sind (größtenteils) Thesen, die sich auf die von den Wissenschaften untersuchten Gegenstandsbereiche bzw. die Diskurse der Wissenschaften beziehen und sich in derselben Weise in präzise Thesen aus drei

\footnotetext{
${ }^{91}$ Siehe z.B. [JaTe85, Sism93, Tete87] sowie Kap.12 und 13.2.3 dieser Arbeit.

${ }^{92}$ Genauer: durch ontologische realistische Thesen der Form (OR). Thesen der Form (OR2) konkretisieren, wie oben erörtert, nur eine der beiden Komponenten.
} 
Teilclustern zerlegen lassen. Hinzu kommen hier axiologische Thesen über das Ziel der Wissenschaften. Bis auf die letzteren Thesen, die eine Besonderheit der wissenschaftstheoretischen Debatte darstellen, läßt sich das Thema dieser Debatte als ein "Spezialgebiet" unter vielen auffassen, die in den anderen zum Thema Realismus geführten Debatten behandelt werden.

Weder in den allgemein-philosophischen Debatten noch in der wissenschaftstheoretischen Realismusdebatte gibt es einen Konsens zu der Frage, welche realistische These oder Gesamtheit realistischer Thesen eine intuitiv angemessene realistische Position konstituiert, d.h. wie viele Thesen, wie einheitliche und wie weitreichende, in welcher Weise erläuterte aus welchem Teilcluster (oder aus welchen Teilclustern) dazu erforderlich bzw. hinreichend sind. Es findet sich jeweils eine Reihe verschiedener, unterschiedlich differenziert und explizit ausformulierter Positionen, die jeweils von ihren Anhängern und/oder von ihren Gegnern als adäquate Formulierung dessen verstanden werden, was Realismus ausmacht.

Sofern sich eine realistische Position auf beide Debatten bezieht, d.h. realistische Thesen sowohl über die Gegenstands- bzw. Diskursbereiche der Wissenschaften, als auch über andere Bereiche einschließt, kann sie in unterschiedlichem Maß "einheitlich" sein, also bezüglich der verschiedenen Bereichen in unterschiedlichem Maß gleichartige oder ähnliche realistische Thesen einschließen.

\subsubsection{Strategien der Argumentation für (oder gegen) wissenschaftlichen Realismus und ihr Verhältnis zur Argumentation für (oder gegen) realistische Thesen bezüglich anderer Bereiche}

In dieser Arbeit können die in den allgemein-philosophischen Debatten zum Thema Realismus vorgebrachten Argumentationen nicht diskutiert werden, sondern lediglich die Argumente, die in der wissenschaftstheoretischen Debatte vorgebracht werden (oder werden können) und für die dort verhandelten Thesen relevant sind. Für die wissenschaftstheoretische Debatte wird man, gegeben das skizzierte Gesamtbild realistischer Thesen und Positionen, damit rechnen, daß sich, den unterschiedlich formulierten realistischen Positionen entsprechend, auch unterschiedliche Strategien finden, Argumente für die wissenschaftstheoretische Realismusdebatte zu konstruieren und dort zum Einsatz zu bringen: Man wird unterschiedliche Strategien erwarten, je nachdem, wie einheitlich oder wie bereichsspezifisch die Thesen sind, die für angemessene Formulierungen dessen gehalten werden, was Realismus ausmacht, d.h., ob dies für verschiedene Gegenstands- bzw. Diskursbereiche Thesen aus demselben Teilcluster sind oder aus verschiedenen (evtl. aus mehreren), ob für verschiedene Bereiche die Parameter 'unabhängig von menschlicher Erkenntnis' etc. unterschiedlich erläutert werden oder nicht etc.

Jemand, der der Ansicht ist, daß die für Realismus konstitutiven Thesen bereichsneutral sind, also sozusagen für alle Gegenstands- bzw. Diskursbereiche zum selben Teilcluster gehören und dieselbe Erläuterung der Parameter beinhalten, kann versuchen, den Streit um diese Thesen mit bereichsneutralen Argumenten zu entscheiden, also mit Argumenten, in denen der Bereich, von dem die jeweilige These handelt, keine Rolle spielt. Er kann versuchen, eine wissenschaftstheoretische Position "einfach" als Spezialfall einer allgemeineren erkenntnistheoretischen, sprachphilosophischen oder ontologischen Position zu gewinnen und zu begründen. ${ }^{93}$ Er muß aber diese Strategie natürlich nicht wählen, denn

\footnotetext{
${ }^{93}$ Ein Beispiel für eine Position dieser Art ist die von Dummett.
} 
auch für oder gegen eine Vielzahl gleichartiger Thesen sind verschiedenartige Argumente denkbar.

Wenn man dagegen der Ansicht ist, daß die Thesen, die eine realistische Position konstituieren, bereichsspezifisch sind, ist die für die wissenschaftstheoretische Realismusdebatte wichtige Anschlußfrage, ob die konstitutiven Thesen für den Bereich der Alltagsgegenstände einerseits und für die Gegenstandsbereiche der Wissenschaften (insbesondere für deren "unbeobachtbaren Teil") andererseits Thesen sind, die zum selben Teilcluster gehören und dieselben Erläuterungen der Parameter enthalten. Jemand, der meint, daß dies nicht so ist, wird für die beiden Bereiche nach verschiedenen Argumenten suchen müssen. ${ }^{94}$ Jemand, der meint, das es so ist, kann versuchen, Argumente zu finden, die zwar "nicht völlig" bereichsneutral sind, aber doch zumindest für den Bereich der Alltagsgegenstände und die Gegenstandsbereiche der Wissenschaften, also auf beiden Seiten der Grenze beobachtbar/unbeobachtbar, unterschiedslos anwendbar; er kann aber auch versuchen, für (oder gegen) realistische Thesen im Bereich des Unbeobachtbaren eigenständige Argumente ins Feld zu führen, die von denen für (oder gegen) realistische Thesen über Beobachtbares verschieden sind. ${ }^{95}$ Außerdem ist denkbar, daß er versucht, eine Art Mittelweg zu gehen, indem er für (oder gegen) die realistischen Thesen auf beiden Seiten der Grenze beobachtbar/unbeobachtbar eine Vielzahl von "lokalen" Argumenten ins Feld führt, die nur einen (mehr oder weniger kleinen) Ausschnitt aus dem Gegenstandsbereich der Alltagswelt und/oder den Gegenstandsbereichen der Wissenschaften abdecken (der diesseits, jenseits oder auf beiden Seiten der Grenze liegen kann), und zwar Argumente, die sich einerseits im Detail etwas unterscheiden, die andererseits aber dieselbe Struktur aufweisen. ${ }^{96}$

Von den an der wissenschaftstheoretischen Realismusdebatte beteiligten Autoren teilt die große Überzahl (trotz des fehlenden Konsenses darüber, was wissenschaftlichen Realismus ausmacht) die Überzeugung, daß die für wissenschaftlichen Realismus konstitutiven Thesen diesseits und jenseits der Grenze beobachtbar/unbeobachtbar gleichartig sind. In der Debatte findet man alle vier genannten, unter dieser Voraussetzung möglichen Argumentationsstrategien.

\subsubsection{Realistische Positionen im Mainstream der wissenschaftstheoreti- schen Debatte}

Obwohl sich in der wissenschaftstheoretischen Realismusdebatte ein ganzes Spektrum von realistischen Positionen und Argumentationen für diese findet, die sich deutlich unterscheiden können hinsichtlich der Fragen, welche konstitutiven Thesen sie einschließen, wie explizit und wie präzise diese Thesen von ihren Anhängern formuliert und erläutert werden und wie sie argumentativ begründet werden, läßt sich doch so etwas wie ein Mainstream der Debatte identifizieren, in dem die Positionen auf realistischer Seite zumindest ein gewisses Maß von Übereinstimmung aufweisen: Sie gleichen sich darin, wie und wie weit die realistischen Thesen in einer groben, vorläufigen Weise formuliert und erläutert werden und welche Voraussetzungen bei deren Begründung in bezug auf realistische Thesen über

\footnotetext{
${ }^{94}$ Ein Beispiel für eine Position dieser Art ist die von Crispin Wright; vgl. [Wrig93].

${ }^{95}$ Was nicht ausschließt, daß solche Argumente für realistische Thesen über Unbeobachtbares realistische Thesen bezüglich anderer Bereiche als Prämissen einsetzen. Das in Kap.9 diskutierte Wunderargument ist von dieser Art.

${ }^{96}$ Die in Kap. 8 diskutierten Kontinuitätsargumente legen eine solche Strategie nahe. Sie wird in Kap.14 verfolgt.
} 
den Bereich der (beobachtbaren) Alltagsgegenstände gemacht oder jedenfalls zugelassen werden.

\section{Nur grob umrissene realistische Thesen, relativer Realismus}

Mit der bereits erwähnten verbreiteten Überzeugung, daß die für wissenschaftlichen Realismus konstitutiven Thesen diesseits und jenseits der Grenze beobachtbar/unbeobachtbar gleichartig sind, hängt es zusammen, daß im Mainstream der wissenschaftstheoretischen Realismusdebatte die Anhänger realistischer Positionen die für die eigene Position konstitutiven Thesen meistens nur grob formulieren und erläutern. Man verläßt sich häufig darauf, daß es für den Bereich der Alltagsgegenstände intuitiv einigermaßen klar und verständlich ist, was eine realistische Einstellung ausmacht, auch ohne daß man dieses Verständnis explizit macht, und nimmt deswegen an, daß eine genaue Formulierung und Erläuterung der Thesen, die eine realistische Position konstituieren, (wenigstens vorläufig) offen bleiben kann. Zusammen mit der Überzeugung, daß die Grenze beobachtbar/unbeobachtbar für die Formulierung realistischer Thesen keinen Unterschied macht, führt dies offenbar häufig zu der Annahme, daß auch in der wissenschaftstheoretischen Debatte eine genaue Formulierung und Erläuterung der Thesen, die eine realistische Position konstituieren, (zumindest vorläufig) eingeklammert werden kann. Aus einer solchen Perspektive umreißt Ian Hacking die Pole, die das Diskussionsfeld der wissenschaftstheoretischen Realismusdebatte aufspannen, in einer auf den ersten Blick etwas lässig daherkommenden Passage folgendermaßen:

"Scientific realism says that the entities, states, and processes described by correct theories really do exist. Protons, photons, fields of force, and black holes are as real as toe-nails, turbines, eddies in a stream, and volcanoes. The weak interactions of small particle physics are as real as falling in love. Theories about the structure of molecules that carry genetic codes are either true or false, and a genuinely correct theory would be a true one [...].

Anti-realism says the opposite: there are no such things as electrons. Certainly there are phenomena of electricity and of inheritance but we construct theories about tiny states, processes and entities only in order to predict and produce events that interest us. The electrons are fictions. Theories about them are tools for thinking. Theories are adequate or useful or warranted or applicable, but no matter how much we admire the speculative and technological triumphs of natural science, we should not regard even its most telling theories as true. [...] Likewise antirealists [...] will not include theoretical entities among the kinds of things that really exist in the world: turbines yes, but photons no." 97

Wissenschaftlichen Realismus zu vertreten heißt aus dieser Perspektive, Thesen wie die zu verteidigen, daß, wie Hacking sich ausdrückt, Protonen, Photonen, Kraftfelder und schwarze Löcher genauso "real sind" oder im gleichen Sinn existieren wie Zehennägel, Turbinen, Strudel und Vulkane und daß die Sätze wissenschaftlicher Theorien im selben Sinn wahr oder falsch (und im günstigen Fall wahr) sind wie Sätze über Alltagsgegenstände. Wie genau zu erläutern ist, daß Zehennägel, Turbinen usw. und genauso Protonen, Photonen usw. "real sind" und existieren und in welchem Sinn genau entsprechende Sätze als wahr oder falsch (und im günstigen Fall als wahr) aufzufassen sind, kann gemäß diesem Zugang

\footnotetext{
${ }^{97}[$ Hack83a], S.21.
} 
zur wissenschaftstheoretischen Realismusdebatte (zumindest teilweise oder vorläufig) eingeklammert werden. Es geht demnach in der wissenschaftstheoretischen Diskussion "nur" um relativen Realismus ${ }^{98}$, d.h. um die Frage, ob für die Gegenstands- bzw. Diskursbereiche der Wissenschaften gleichartige realistische Thesen gelten wie für den Bereich der Alltagswelt, wie auch immer diese Thesen in beiden Bereichen im Detail zu erläutern sind.

Wie die in beiden Bereichen gleichartigen realismuskonstitutiven Thesen in expliziter und präziser Formulierung aussehen sollten, wird im Mainstream der wissenschaftstheoretischen Debatte kaum erörtert. Die meisten beteiligten Autoren setzen grob umrissene ontologische, semantische und/oder erkenntnistheoretische realistische Thesen in bezug auf den Bereich der materiellen Alltagsgegenstände voraus ${ }^{99}$, was gelegentlich als Commonsense-Realismus bezeichnet wird. ${ }^{100}$ Im Hinblick auf das oben angegebene Spektrum von realistischen Thesen läßt dieser Common-sense-Realismus Präzisierungen verschiedener Art zu, er ist aber andererseits sicher nicht inhaltsleer. ${ }^{101}$ Man geht offenbar davon aus, daß gleichartige, in derselben Weise umrissene realistische Thesen über Unbeobachtbares ausreichen, um eine "hinreichend gehaltvolle" Position in der wissenschaftstheoretischen Debatte zu konstituieren, und daß die in der wissenschaftstheoretischen Debatte zu diskutierenden Argumente für oder gegen realistische Positionen unabhängig davon sind, wie die realismuskonstitutiven Thesen (eventuell später) genauer erläutert und ausdifferenziert werden.

\section{Common-sense-Realismus als Voraussetzung in der wissenschaftstheoretischen Realismusdebatte, die Entkoppelung von wissenschaftstheoretischer und allgemein- philosophischer Realismusdebatte}

Im Mainstream der wissenschaftstheoretischen Realismusdebatte wird, wie schon erwähnt, üblicherweise etwas von der Art eines Common-sense-Realismus vorausgesetzt, ohne daß die Frage nach dessen Begründung oder Rechtfertigung diskutiert wird. Die wissenschaftstheoretische Debatte konzentriert sich auf die Konstruktion und Bewertung von Argumenten für oder gegen wissenschaftlichen Realismus, also realistische Thesen in bezug auf (unbeobachtbare) Entitäten, Eigenschaften etc. aus dem Bereich der Wissenschaften. Hacking bietet für diese Strukturierung der Realismusdebatte(n) ein instruktives Bild an:

"Scientific realism, opposed to anti-realism about science, is a colonial war. The scientific realist says that mesons and muons are just as much 'ours' as monkeys and meatballs. All of those things exist. We know it. We know some truths about each kind of thing and can find out more. The antirealist disagrees. In the positivist tradition [...] the phenomenal behaviour of meatballs and monkeys may be known, but talk about muons is at most an intellectual construct for prediction and control. Anti-realists about muons are realists about meatballs. I call this a colonial war because one side is trying to colonize new realms and call them reality, while the other side opposes such fanciful imperialism.

Then there is civil war, between say Locke and Berkeley. The realist (Locke) says that many familiar entities have an existence independent of any mental goings on: there would be monkeys even if there were no human thoughts. The

\footnotetext{
${ }^{98}[$ Krug81], S.227.

${ }^{99}$ Vgl. [Carr91], S.23, [Feye60a], [Krug83], S.572, [McMu84], S.8.

${ }^{100}$ Z.B. [Carr91], S.23.

${ }^{101}$ Eine idealistische Position wie die von Berkeley etwa ist damit sicherlich unverträglich.
} 
idealist (Berkeley) says everything is mental. I call this a civil war because it is fought on the familiar ground of everyday experience.

Civil wars need not be fought only on home territory. Berkeley fought a colonial war too. He detested the corpuscular and mechanical philosophy of Robert Boyle. [...] Berkeley fought a colonial war partly because he thought if he won, the imperialist home government of realism/materialism would collapse $[\ldots]$.

Finally there is total war, chiefly a product of more recent times. Maybe Kant began it. He rejects the assumptions of civil war. Material events occur with as much certainty as mental ones. [...] I can know that the meatball on my plate is mushy exactly as well as I know that my emotions are confusing." 102

Im Mainstream der Debatte hat der Streit um den wissenschaftlichen Realismus den Charakter eines Kolonialkrieges, setzt also Common-sense-Realismus voraus. Wenn diese Voraussetzungen in einem Bürgerkrieg oder in einem totalen Krieg (in dem auch für den Bereich mentaler Entitäten wie Ideen, Wahrnehmungen usw. eine realistische Einstellung nicht mehr unkontrovers ist, wie noch im Bürgerkrieg zwischen Locke und Berkeley) nicht verteidigt werden können, dann sind diejenigen Argumente der wissenschaftstheoretischen Debatte, die von diesen Voraussetzungen abhängen ${ }^{103}$ (auch wenn sie formal noch funktionieren), für Realisten nicht mehr viel wert. Wenn die Verteidigung jedoch in der einen oder anderen Form gelingt (und in diesem Punkt sind wissenschaftliche Realisten optimistisch), können die Argumente der wissenschaftstheoretischen Debatte daran anknüpfen. Indem man in der wissenschaftstheoretischen Debatte Common-sense-Realismus nicht begründet, sondern voraussetzt, kann man also, um in Hackings recht militaristischem Bild zu bleiben, den Kolonialkrieg um den wissenschaftlichen Realismus auch vor dem Hintergrund eines Bürgerkrieges oder eines totalen Krieges, und d.h. insbesondere von diesen weitgehend entkoppelt führen, auch wenn dann der Wert der von realistischer Seite erzielten Geländegewinne letztendlich davon abhängt, daß im Bürgerkrieg oder totalen Krieg wenigstens der wesentliche Kern der realistischen Stellungen verteidigt werden kann.

\subsubsection{Fazit}

Das Verhältnis der wissenschaftstheoretischen Realismusdebatte zu den allgemein-philosophischen Debatten läßt sich wie folgt charakterisieren. Die Thesen, die in der wissenschaftstheoretischen Debatte als konstitutiv für realistische Positionen genannt werden, lassen sich (bis auf die axiologischen) als Instantiierungen von Schemata auffassen (oder zumindest rekonstruieren), die drei Teilcluster von Thesen charakterisieren; die Instantiierungen dieser Schemata bezüglich anderer Gegenstandsbereiche die ergeben die Thesen (oder zumindest rekonstruierte Versionen der Thesen), die realistische Positionen in den allgemein-philosophischen Debatten konstituieren. Im Hinblick auf die Gesamtheit der diskutierten realistischen Thesen stellt sich das Verhältnis beider Debattenfelder also recht einfach dar: Die Thesen der wissenschaftstheoretischen Debatte betreffen (mit Ausnahme der axiologischen Thesen) ein "Spezialgebiet" unter anderen, mit denen sich die allgemeinphilosophischen Debatten beschäftigen.

Systematisch betrachtet lassen sich einzelne realistische Thesen in vielfältiger Weise zu realistischen Positionen kombinieren, deren konstitutive Thesen dann sehr unterschiedliche

\footnotetext{
${ }^{102}$ [Hack83a], S.95/96.

${ }^{103}$ Dies sind (s.o.) nur einige der in der Debatte diskutierten Argumente, nicht alle.
} 
und unterschiedlich weite Gegenstands- bzw. Diskursbereiche abdecken können und auch von mehr oder weniger "einheitlicher" Art sein können. Insbesondere kann eine realistische Position neben in der wissenschaftstheoretischen Debatte verhandelten Thesen in sehr unterschiedlichem Ausmaß außerdem auch Thesen verschiedener Art umfassen, die sich auf den Bereich der materiellen Alltagswelt beziehen. Im Hinblick auf wissenschaftlichen Realismus bedeutet dies, daß es von der jeweiligen Position im einzelnen abhängt, inwieweit mit realistischen Thesen bezüglich wissenschaftlicher Gegenstands- bzw. Diskursbereiche (mehr oder weniger) gleichartige Thesen über den Bereich der Alltagswelt kombiniert werden, die bei der Argumentation für wissenschaftlichen Realismus ins Spiel kommen können, z.B. indem sie vorausgesetzt werden, indem Argumente für sie übertragen oder erweitert werden können o.ä. Im Hinblick auf realistische Positionen und Argumentationen für sie ist auf die Frage nach dem Verhältnis der wissenschaftstheoretischen Realismusdebatte zu allgemein-philosophischen Debatten also offenbar keine einfache, einheitliche Antwort zu erwarten.

Im Mainstream der wissenschaftlichen Realismusdebatte legt man sich das Verhältnis zu den allgemein-philosophischen Debatten in einer Weise zurecht, die einem das Einklammern bestimmter Fragen ermöglicht: Man geht von der Gleichartigkeit realismuskonstitutiver Thesen auf beiden Seiten der Grenze beobachtbar/unbeobachtbar zumindest im Bereich materieller Entitäten, Eigenschaften etc. aus sowie davon, daß "auf der beobachtbaren Seite" der Grenze intuitiv klar und verständlich ist, was Realismus ausmacht, auch ohne daß man dieses Verständnis explizit macht. Dies erlaubt einem, (auch) die für wissenschaftlichen Realismus konstitutiven Thesen nur grob zu umreißen und die Frage nach ihrer präzisen Gestalt einzuklammern. Außerdem nimmt man an, daß für die Zwecke der wissenschaftstheoretischen Debatte solche grob umrissenen realismuskonstutiven Thesen, die die "beobachtbare Seite" der Grenze betreffen (Common-sense-Realismus), vorausgesetzt werden dürfen, ohne in derselben Weise wie "auf der unbeobachtbaren Seite" der Grenze nach Argumenten für diese Thesen zu fragen. 


\section{Teil I \\ Bedeutungs-, Referenz- und Wahrheitstheorien für die Sprache der Wissenschaften}



Nachdem in der Einleitung eine Übersicht über die wissenschaftstheoretische Realismusdebatte und ihr philosophisches Umfeld gewonnen wurde, sollen in diesem Teil Bedeutungs-, Referenz- und Wahrheitstheorien für die Sprache der Wissenschaften untersucht werden.

Bedeutungs-, Referenz- und Wahrheitstheorien sind aus mindestens zwei Gründen wichtig für die Debatte um den wissenschaftlichen Realismus. Zum einen können sie zum Inhalt einer realistischen oder antirealistischen Position zählen, und zwar dann, wenn semantische realistische Thesen oder entsprechende Gegenthesen für diese Position konstitutiv sind. Wie oben ${ }^{104}$ bereits erwähnt, können Bedeutungs-, Referenz- und insbesondere Wahrheitstheorien zur Erläuterung semantischer realistischer Thesen der Form (SR1) herangezogen oder verlangt werden, genauer: um zu erläutern, worin die Wahrheit (oder Falschheit) eines Satzes besteht und in welchem Sinn und warum Wahrheitswerte von Sätzen, Theorien etc. "unabhängig von menschlichen epistemischen Mitteln" sind (oder nicht). Um ein genaues Bild von realistischen Positionen zu bekommen, die semantische realistische Thesen einschließen, insbesondere davon, ob ggf. wie diese Thesen in zufriedenstellender Weise erläutert werden können, ist es daher erforderlich, die dazu in Frage kommenden Bedeutungs-, Referenz- und Wahrheitstheorien zu kennen.

Zum anderen können Bedeutungs-, Referenz- und Wahrheitstheorien eine wichtige Rolle bei der Argumentation für und gegen realistische oder antirealistische Positionen spielen, und das nicht nur, wenn sie zum Inhalt dieser Positionen zählen, sondern auch dann, wenn das nicht der Fall ist, also etwa beim Streit um eine realistische Position, deren Kern aus ontologischen realistischen Thesen besteht. Z.B. kommt eine solche Rolle in Frage, wenn es darum geht zu beurteilen, welche Konsequenzen der im Laufe der Geschichte der Wissenschaften zu verzeichnende Wandel in ihrem Theoriebestand für die Plausibilität realistischer Positionen hat. Auf antirealistischer Seite können Bedeutungs- und Wahrheitstheorien z.B. bei der Argumentation für instrumentalistische Positionen eine wichtige Rolle spielen, nämlich wenn zu deren Begründung eine Verifikationstheorie fungiert.

Im folgenden sollen daher die Bedeutungs-, Referenz- und Wahrheitstheorien untersucht werden, die für die Sprache der Wissenschaften vorgeschlagen wurden, insbesondere im Hinblick auf ihre Vorzüge und Nachteile aus realistischer Perspektive, bevor dann in den nächsten Kapiteln die Argumente für realistische Positionen genau in den Blick genommen werden. Diskutiert werden sollen, in etwa der Reihenfolge ihrer Entwicklung, zunächst verifikationistische Theorien und die "Standarddarstellung" des logischen Positivismus, dann Kontexttheorien, die kausale Bedeutungs- und Referenztheorie und schließlich Hybridtheorien.

\footnotetext{
${ }^{104}$ S.7, 12 .
} 


\section{Kapitel 2}

\section{Verifikationistische Theorien und die "Standarddarstellung" des logischen Positivismus}

\subsection{Die Verifikationstheorie}

Den wahrscheinlich wichtigsten Ausgangspunkt für alle späteren Debatten über die Bedeutung speziell wissenschaftlicher Ausdrücke und Sätze bildet eine Theorie, oder genauer: eine Reihe von Theorieansätzen, die im Wiener Kreis und dessen Umfeld von Moritz Schlick, Rudolf Carnap, Otto Neurath und anderen diskutiert wurden und unter dem Titel verifikationistisch zusammengefaßt werden können.

Das Hauptinteresse der Untersuchungen, die dort die Bedeutung von (sowohl alltagssprachlichen als auch wissenschaftlichen) Sätzen und Ausdrücken thematisierten, galt der Frage der Anbindung dieser Sätze und Ausdrücke an Wahrnehmungen und empirische Beobachtungen. Die Untersuchung dieser Anbindung zielte in erster Linie darauf ab, eine Grenze zu markieren zwischen "sinnvollen" Sätzen und Ausdrücken, die "eine Bedeutung haben" einerseits, und "sinnlosen" oder "bedeutungslosen" Sätzen und Ausdrücken andererseits. ${ }^{1}$ Für die Frage, was genau die Bedeutung eines Satzes oder eines Ausdrucks ist, interessierte man sich eher mittelbar, insofern dies etwas nützt bei der Abgrenzung von "bedeutungslosen" Sätzen von solchen, die "eine Bedeutung haben". In diesem Kapitel sollen die bedeutungstheoretischen Überlegungen weitgehend losgelöst von der "Abgrenzungsproblematik" diskutiert werden, durch die sie historisch motiviert wurden.

Den Grundgedanken der verifikationistischen Theorieansätze in bezug auf die Bedeutung von Sätzen formuliert ein vielzitierter Satz von Schlick:

"The meaning of a proposition is the method of its verification"

oder, wie er an anderer Stelle sagt,

"the rule of its verification in experience" 2 .

\footnotetext{
${ }^{1}$ Siehe z.B. [Reic53, Schl38c]. Carnap spricht in [Carn31] auch von "Scheinsätzen". Paradigmatische Beispiele für das, was in diesem Sinn als "sinnvoll" bzw. "sinnlos" ausgezeichnet werden sollte, sind einerseits Beobachtungssätze aus der Alltagswelt und die Sätze der empirischen Naturwissenschaften, andererseits Heideggers Metaphysik und die Psychoanalyse.

${ }^{2}$ [Schl38c], S.340 bzw. 341; s.a. [Carn31], S.236, [Wais30], S.229, [Witt67], S.79, 97.
} 
Als angemessene Erläuterung der "Methode der Verifikation" eines Satzes verlangen die verifikationistischen Bedeutungstheorien in der Regel eine Definition der in ihm auftretenden (nicht-logischen) Ausdrücke allein auf der Basis von Ausdrücken, über deren Erfülltsein oder Nichterfülltsein im konkreten Fall durch direkte Beobachtung definitiv entschieden werden kann. ${ }^{3}$ Sätze, die aus so "legitimierten" Ausdrücken (plus logischen Ausdrücken) aufgebaut sind, sind nach dieser Konzeption verifizierbar, d.h., ob sie wahr oder falsch sind, kann durch direkte Beobachtung (plus Anwendung der Regeln der Logik) entschieden werden.

Im Hinblick auf die Frage, wie genau die Basis der geforderten Definitionen auszusehen hat, von welcher Art also die im Definiens auftretenden (nicht-logischen) Ausdrücke sein müssen, über deren Erfülltsein oder Nichterfülltsein durch Beobachtung entschieden werden kann, lassen sich zwei Versionen der Verifikationstheorie unterscheiden ${ }^{4}$ : Physikalistische Versionen verlangen, daß Definitionen auf der Basis von Ausdrücken gegeben werden, die für beobachtbare Gegenstände, Ereignisse, Eigenschaften, Sachverhalte etc. "in der Außenwelt" stehen (z.B. Drähte, Zeigerausschläge, flüssig etc.). Phänomenalistische Versionen fordern dagegen Definitionen auf der Basis von Ausdrücken, die für Sinnesdaten und Wahrnehmungen stehen (z.B. Rotwahrnehmung, Kältegefühl etc.). In den Diskussionen innerhalb des logischen Positivismus hat sich eine physikalistische Version durchgesetzt, da diese weniger Probleme hinsichtlich der intersubjektiven Verifizierbarkeit bzw. Gültigkeit von Beobachtungssätzen aufweist. Wichtig ist in jedem Fall, daß die als Basis einer Definition dienenden Ausdrücke vorher verstanden werden, d.h., daß ihre Bedeutung als bekannt und unproblematisch vorausgesetzt werden kann und insbesondere unabhängig von den definierten Ausdrücken ist, die nicht für Beobachtbares stehen.

Genauere Formulierungen der Idee der Verifizierbarkeit auf dieser Linie erläutern die Redeweise von einer Methode der Verifikation in einigermaßen liberaler Weise und müssen dies auch, wenn sie die anvisierte Grenzziehung in zufriedenstellender Weise liefern sollen: Damit ein Satz intuitiv als verifizierbar gilt, muß nicht unbedingt in der Praxis entschieden werden können, ob er wahr oder falsch ist. Auch Sätze über epistemisch (noch oder kontingenterweise wahrscheinlich für immer) unzugängliche Gegenstandsbereiche (z.B. die Oberfläche des Planeten Pluto oder das Verhalten von Dinosauriern) sollten als verifizierbar zählen, wenn wenigstens im Prinzip (d.h. abgesehen von kontingenten epistemischen Hindernissen) durch direkte Beobachtung entschieden werden kann, ob sie wahr oder falsch sind. Dasselbe gilt für allquantifizierte Sätze, wenn sie Instantiierungen haben, über deren Wahrheit oder Falschheit durch Beobachtung entschieden werden kann (auch wenn man nicht für alle Instantiierungen tatsächlich Beobachtungen durchführen kann). ${ }^{5}$

Angewandt auf die Sprache der Wissenschaften besagt die Verifikationstheorie also: Die Bedeutung eines Ausdrucks, der nicht für Beobachtbares steht, ist also durch eine

\footnotetext{
${ }^{3}$ Siehe z.B. [Schl38c], S.340f.; laut [Ca36/37], S.464 ist Carnaps Frühwerk [Carn28] im selben Sinn zu lesen. Andere Ansätze, die Verifizierbarkeit eines Satzes zu erläutern, diskutieren [Hack75], Kap.9 und [Hemp65b], S.102ff.

${ }^{4}$ Siehe z.B. [Ca36/37], S.9ff., [Hemp52], S.21f.

${ }^{5}$ Wie genau die Modalität ( “. . entschieden werden kann") zu erläutern ist, ist strittig. Logische Möglichkeit muß man, praktische oder technische Möglichkeit kann man dagegen, wie gesagt, plausiblerweise nicht fordern. Physikalische Möglichkeit wäre eine "mittlere" Forderung, die aber präziser Formulierung bedarf, wenn sie nicht zu eng werden soll, etwa weil bestehende Naturgesetze den Transport menschlicher Beobachter oder ihren Aufenthalt in bestimmten Raum-Zeit-Gebieten verbieten; siehe z.B. [Hemp65b], S.103, [Reic53], S.97, [Schl38c]. Jedenfalls ist die Verifikationstheorie verträglich damit, daß man praktisch oft mit epistemischen Evidenzen für oder gegen die Wahrheit eines (im Prinzip verifizierbaren) Satzes arbeitet, die sozusagen unterhalb von Verifikation oder Falsifikation liegen, also schwächer sind als tatsächlich verifizierende oder falsifizierende Beobachtungen.
} 
Definition des Ausdrucks gegeben, da diese angibt, wie im konkreten Fall (im Prinzip) entschieden werden kann, ob der Ausdruck erfüllt ist oder nicht. Die Bedeutung eines Satzes ist gegeben durch die Bedeutung seiner Terme (und die Regeln der Logik). Dabei ist die Bedeutung der Terme, die nicht für Beobachtbares stehen, durch Definition gegeben, die der anderen wird als unproblematisch vorausgesetzt. Die Bedeutung der Terme (und die Regeln der Logik) ${ }^{6}$ liefern in diesem Sinne also die "Methode der Verifikation" des Satzes.

Als formalsprachliche Formulierung für die Definition eines Ausdrucks $P_{T}$, der nicht für Beobachtbares steht, hat Carnap in einem einfachen Fall den Satz

$$
\forall x\left(P_{T}(x) \leftrightarrow\left(P_{B_{1}}(x) \rightarrow P_{B_{2}}(x)\right)\right)
$$

angegeben, wobei $P_{B_{1}}$ und $P_{B_{2}}$ Terme sind, die für Beobachtbares stehen. ${ }^{7}$ Diese einfache Form einer Definition ist für Ausdrücke gedacht, die sich als Dispositionsterme auffassen lassen, ('magnetisch', 'Katalysator', 'spaltbar' u.ä., wobei $P_{B_{1}}$ die Manifestationsbedingungen für die Disposition beschreibt und $P_{B_{2}}$ die manifeste Eigenschaft) und für Ausdrücke für Größen und Eigenschaften, für die man Meß- oder Nachweisverfahren hat (wobei dann $P_{B_{1}}$ das Meß- bzw. Nachweisverfahren beschreibt und $P_{B_{2}}$ die dabei beobachtbare "Indikatoreigenschaft"; $P_{T}(x)$ könnte etwa stehen für 'x hat die Temperatur T', $P_{B_{1}}(x)$ für 'x wird in Kontakt mit dem Quecksilberthermometer QT gebracht' und $P_{B_{2}}(x)$ für 'Das Thermometer QT zeigt für x E Einheiten an'). ${ }^{8}$

Zwischen der in diesem Sinn erläuterten Bedeutung von Ausdrücken und Sätzen und der sprachlichen Kompetenz von Sprechern, die diese Ausdrücke und Sätze verwenden, besteht nach der Verifikationstheorie ein enger Zusammenhang: Um einen Ausdruck oder einen Satz zu verstehen oder damit eine Aussage zu machen, muß man seine Bedeutung, d.h. seine Anwendungs- bzw. Verifikationsbedingungen kennen. Ein kompetenter Sprecher muß also wissen, wie der Ausdruck anzuwenden bzw. der Satz zu verifizieren ist, d.h. die entsprechenden Definitionen (und die Regeln der Logik) kennen. Die Bedeutung der Ausdrücke und Sätze, die ein Sprecher verwendet, ist auf diese Weise durch die Kenntnisse des Sprechers bestimmt, die konstitutiv für seine sprachliche Kompetenz sind. ${ }^{9}$

\subsection{Die Erosion der Verifikationstheorie: Reduktionssätze versus Definitionen}

Die Forderung, daß "legitime" Ausdrücke definierbar sein müssen, erweist sich bei näherem Hinsehen schnell als ungeeignet, um den anvisierten Bereich der in der Praxis der Naturwissenschaften verwendeten Ausdrücke und Sätze, die intuitiv als "legitim" gelten sollen, wenigstens ungefähr zu charakterisieren. Die zentrale Schwierigkeit läßt bereits ein

\footnotetext{
${ }^{6} \mathrm{Im}$ folgenden bleibt dieser Zusatz meistens implizit.

${ }^{7}$ Diese Schreibweise einer Definition als analytischer Satz, also als Satz, der kraft Verwendungsregeln der Sprache wahr ist, findet sich in [Ca36/37], S.439. Die Auszeichnung als analytischer Satz, die in der formalen Gestalt des Satzes nicht zum Ausdruck kommt, ist wesentlich für eine Definition, denn formal unterscheidet sich der Satz nicht von empirischen bzw. kontingenten Sätzen. Eine andere Schreibweise für eine Definition, die deren Status auch formal zum Ausdruck bringt, wäre (für das obige Beispiel) $P_{T}(x):=P_{B_{1}}(x) \rightarrow P_{B_{2}}(x)$ (vgl. [Hemp52], S.2ff.).

${ }^{8}$ Siehe [Ca36/37], S.439ff., s.a. [Hemp52]. I.a. können auf der rechten Seite komplexere Ausdrücke aus Beobachtungstermen stehen. Ein "lebensnäheres" Beispiel für solche Definitionen findet sich (meines Wissens) in der Literatur nicht.

${ }^{9}$ Siehe z.B. [Schl38c], S.347.
} 
Blick auf die oben angeführte einfache Form einer Definition erkennen. Eine Definition eines Prädikates sollte für alle Gegenstände in allen Situationen festlegen, ob das Prädikat auf sie anzuwenden ist oder nicht. Die oben angeführte Form einer Definition leistet dies, aber sie führt für viele Situationen zu unakzeptablen Resultaten.

Ein Problem ist zunächst dies: Wenn die durch den Vordersatz der Subjunktion auf der rechten Seite beschriebenen Manifestationsbedingungen nicht vorliegen bzw. das Meßoder Nachweisverfahren nicht angewendet wird, ist die Subjunktion wahr, so daß gemäß dieser Form der Definition die Anwendungsbedingungen des definierten Prädikates erfüllt sind. (Im oben angegebenen Beispiel ist demnach jedem Körper, der nicht mit dem Quecksilberthermometer in Kontakt steht, die Temperatur T zuzuschreiben.)

Während dieser Aspekt der Schwierigkeiten eventuell ${ }^{10}$ durch Rückgriff auf modale (kontrafaktische) Sätze gelöst werden könnte, ${ }^{11}$ besteht dennoch wenig Aussicht, daß sich die gesamte Problematik dadurch oder durch eine andere, evtl. komplexere Form der rechten Seite der Definition lösen läßt. Der Grund ist der, daß es bei den in den Naturwissenschaften verwendeten Prädikaten, die nicht für beobachtbare Eigenschaften stehen, i.a. auf eine verzerrende Rekonstruktion der Sprachpraxis hinausliefe, wenn man behaupten wollte, daß die Anwendungsbedingungen eines solchen Prädikates für alle Gegenstände und in allen Situationen durch ein einziges oder einen festen, bei der Einführung des Prädikates festgelegten Satz von Meß- oder Nachweisverfahren definiert werden. Im allgemeinen werden Meß- oder Nachweisverfahren für eine Größe dieser Art erst nach und nach für verschiedene Anwendungsbereiche entwickelt, ohne daß dabei ein im Prinzip "global" anwendbares, bei der Einführung des Prädikates bekanntes und dessen Definition lieferndes Verfahren einen Standard der Korrektheit für die neuen Verfahren bilden würde. (Z.B. sind für sehr niedrige Temperaturen in der Nähe des absoluten Nullpunktes erst in den letzten Jahrzehnten Meßverfahren entwickelt worden, und diese werden nicht etwa an einer vorher festgelegten Temperaturdefinition mittels Quecksilberthermometer o.ä. ausgerichtet.) ${ }^{12}$ Carl G. Hempel bezeichnet diesen Sachverhalt, daß es i.a. nicht die Intention der Sprachgemeinschaft ist, die Bedeutung ihrer Ausdrücke durch die bei der Einführung oder zu einem bestimmten späteren Zeitpunkt etablierten Meß- oder Nachweisverfahren einfür allemal festzulegen, sondern sie für Ergänzungen durch neue Verfahren offenzuhalten, als openness of meaning. ${ }^{13}$

Angesichts dieser Sachlage erscheint der Schluß unvermeidbar, daß sich zumindest einem großen Teil der real-existierenden Naturwissenschaften gebräuchlichen Ausdrücken und Sätzen keine Bedeutung im Sinne der Verifikationstheorie zuordnen läßt. Man steht also vor der Alternative, entweder an der Verifikationstheorie als allgemeingültiger Bedeutungstheorie festzuhalten und zu akzeptieren, daß die Ausdrücke und Sätze, für die die Verifikationstheorie nicht funktioniert, tatsächlich keine Bedeutung haben, oder die Verifikationstheorie (zumindest für die Sprache der Wissenschaften) aufzugeben.

Diejenigen, die die erstere Möglichkeit gewählt haben, sind meistens zu einer instrumentalistischen Position ${ }^{14}$ übergegangen. Diesen Positionen zufolge sind die Ausdrücke, Sätze und Theorien, die nach den Standards der Verifikationstheorie keine Bedeutung haben, nicht als "semantisch vollwertige" sprachliche Gebilde aufzufassen, sondern nur als

\footnotetext{
${ }^{10}$ Wenn auch in für Empiristen möglicherweise problematischer Weise.

${ }^{11}$ Also durch Sätze, die beschreiben, wie ein Objekt sich verhalten würde, wenn es den fraglichen Manifestationsbedingungen bzw. Meß- oder Nachweisverfahren ausgesetzt wäre.

${ }^{12}$ [Ca36/37], S.448ff.

13 [Hemp52], S.29.

${ }^{14}$ In der ersten der beiden vorne (S.18 Einleitung) unterschiedenen Verwendungsweisen von 'instrumentalistisch'.
} 
praktisch für Prognosezwecke u.ä. einsetzbare "kognitive Instrumente", "inference tickets" o.ä., und Äußerungen solcher Sätze oder Theorien sind nicht als ernsthafte Behauptungen anzusehen.

Von denjenigen, die die zweite Möglichkeit gewählt haben, wurde die Forderung nach Definierbarkeit von Ausdrücken, über deren Erfülltsein nicht durch Beobachtung definitiv entschieden werden kann, ersetzt durch die ermäßigte Forderung nach Erläuterung durch sogenannte Reduktionssätze. ${ }^{15}$ Die zuvor geforderte Definition eines Ausdrucks sollte für diesen "vollständige" Anwendungsbedingungen spezifizieren: Gegeben eine Definition, sollte in jeder Situation bestimmt sein, wie (tatsächlich oder im Prinzip) definitiv festzustellen ist, ob der definierte Ausdruck dort erfüllt ist oder nicht. Die Idee bei den Reduktionssätzen ist dagegen, durch einen Reduktionssatz für einen Ausdruck "nur noch" in bestimmten Situationen Anwendungsbedingungen zu spezifizieren und für andersartige Situationen die Frage nach dessen Anwendungsbedingungen entweder grundsätzlich offen zu lassen oder jedenfalls durch andere, erst später zu gewinnende Reduktionssätze zu regeln. In den oben angeführten Beispielen würde man in diesem Sinn die Anwendungsbedingungen "nur" in den Situationen festlegen, in denen die Manifestationsbedingungen vorliegen bzw. die Meßoder Nachweisverfahren tatsächlich angewendet werden.

In formalsprachlicher Ausdrucksweise hat ein Reduktionssatz nach Carnap im einfachsten Fall die Gestalt

$$
\forall x\left(P_{B_{1}}(x) \rightarrow\left(P_{B_{2}}(x) \leftrightarrow P_{T}(x)\right)\right) .
$$

(Für das obige Beispiel des Temperaturbegriffs erhält man so Anwendungsbedingungen für Situationen bestimmter Art, etwa: Wenn x in Kontakt mit dem Quecksilberthermometer QT gebracht wird, dann gilt: Das Thermometer zeigt genau dann für x E Einheiten an, wenn x die Temperatur T hat.) ${ }^{16}$

Sätze, in denen Ausdrücke vorkommen, für die Reduktionssätze existieren, sind also (anders als Sätze aus definierten Ausdrücken) i.a. nicht in jedem Fall verifizierbar, ohne daß sie deswegen automatisch als "sinnlos" gelten. Sie können immerhin empirisch getestet oder bestätigt werden, indem man diejenigen ihrer logischen Konsequenzen verifiziert (oder falsifiziert), für die "passende" Reduktionssätze zur Verfügung stehen, sind also in dieser weniger engen Weise an Beobachtungen angebunden. ${ }^{17}$

Mit dem Schritt, für "legitime" wissenschaftliche Ausdrücke, über deren Erfülltsein nicht durch Beobachtung definitiv entschieden werden kann, nicht mehr Definierbarkeit zu

\footnotetext{
${ }^{15}$ [Ca36/37], S.463f., [Carn49], S.413ff., [Hemp52], S.31.

${ }^{16}$ [Ca36/37], S.441ff, s.a. [Carn49], S.414f. Im nächsteinfachen Fall zerfällt ein Reduktionssatz dieser einfachsten Art sozusagen in zwei Sätze

$$
\forall x\left(P_{B_{1}}(x) \rightarrow\left(P_{B_{2 A}}(x) \rightarrow P_{T}(x)\right)\right)
$$
}

und

$$
\forall x\left(P_{B_{1}}(x) \rightarrow\left(P_{B_{2 B}}(x) \rightarrow \neg P_{T}(x)\right)\right),
$$

die eine hinreichende und eine notwendige Bedingung für die Anwendung von $P_{T}$ formulieren. Konkrete Beispiele für einigermaßen "lebensnahe" Reduktionssätze finden sich in der Literatur nur selten; Carnap nennt sinngemäß als Reduktionssatz für 'Stromstärke': 'Wenn neben einen Leitungsdraht eine Magnetnadel plaziert wird, dann gilt: Wenn die Magnetnadel um einen Winkel $x$ von ihrer Normallage abweicht, dann fließt in dem Draht ein Strom der Stärke y' ([Ca36/37], S.445) und als Reduktionssatz "for the term 'electric charge' (taken here for the sake of simplicity as a nonquantitative term), i.e., for the statement form 'the body $x$ has an electric charge at the time $t$ ': 'If a light body $y$ is placed near $x$ at $t$, then: $x$ has an electric charge at $t \equiv y$ is attracted by $x$ at $t$.' ([Carn49], S.414).

${ }^{17}$ Die von den logischen Positivisten diskutierten Konzeptionen von Bestätigung etc. müssen hier beiseite bleiben. 
fordern, sondern nur noch die Anknüpfung an Beobachtungen durch Reduktionssätze, wird die Verifikationstheorie der Bedeutung effektiv aufgegeben oder jedenfalls in einer zentralen Hinsicht verändert: Wenn man sich die Möglichkeit der Einführung neuer, zusätzlicher Reduktionssätze für einen Ausdruck offen halten will und gleichzeitig (weiterhin) sagen wollte, daß die Bedeutung eines Ausdrucks durch die zu einem Zeitpunkt etablierte "Methode seiner Verifikation" gegeben ist, dann müßte dies ein Sinn von 'Bedeutung' sein, nach dem die Bedeutung eines Ausdrucks nicht festlegt, durch welche Gegenstände, Ereignisse etc. der Ausdruck erfüllt wird oder, in anachronistischer Terminologie ausgedrückt ${ }^{18}$, ein Sinn von 'Bedeutung', nach dem die Bedeutung eines Ausdrucks nicht seine Extension bestimmt. Während die Extension eines Ausdrucks durch eine Definition vollständig festgelegt wird, da eine Definition "im Prinzip" für jeden Gegenstand etc. definitiv zu entscheiden erlaubt, ob er den Ausdruck erfüllt oder nicht, spezifizieren Reduktionssätze die Extension offenbar nur zum Teil. Die logischen Positivisten sprechen in dieser Situation von partieller Definition oder partieller Interpretation eines Ausdrucks oder von partieller Spezifikation seiner Bedeutung durch Reduktionssätze, von partieller Unbestimmtheit der Bedeutung des Ausdrucks u.ä. ${ }^{19}$

Auch die Ermäßigung der ursprünglichen Forderung, daß jeder legitime wissenschaftliche Ausdruck explizit definierbar sein muß, zu der schwächeren Forderung, daß er im beschriebenen Sinn (wenigstens für einige Situationstypen) reduzierbar sein muß, erlaubt jedoch nicht, die gewünschte Grenzlinie zwischen "sinnvollen" und "sinnlosen" Ausdrücken und Sätzen an der anvisierten Stelle zu ziehen. Bei den in der Praxis der Wissenschaften gängigen Ausdrücken kennt man i.a. keineswegs für jeden einzelnen einen beobachtbaren "Indikator", sprich: lassen sich keineswegs für jeden einzelnen Ausdruck ein oder mehrere Reduktionssätze angeben. Für viele, insbesondere "hochtheoretische" Ausdrücke läßt sich eine Anknüpfung an direkte Beobachtung nur dadurch herstellen, daß man bekannte Beziehungen zu anderen Ausdrücken derselben Art ausnutzt, die ihrerseits (evtl. über weitere solche Zwischenschritte) reduzierbar sind. (Beispiele wären die Hamiltonfunktion eines physikalischen Systems und die elektromagnetischen Potentiale.) An direkte Beobachtung angebunden werden können die Ausdrücke der real-existierenden Wissenschaften also i.a. nicht einzeln, sondern nur in Clustern bzw. im Kontext eines "Netzes" weiterer Ausdrücke. ${ }^{20}$

Ein erneuter Blick auf die oben angeführten Beispiele für Reduktionssätze legt nahe, daß dieser zuletzt genannte Sachverhalt, daß wissenschaftliche Ausdrücke nicht einzeln an direkte Beobachtung angeknüpft werden können, nicht nur einige wenige dieser Ausdrücke betrifft, sondern möglicherweise alle, die nicht für Beobachtbares stehen: Daß etwa der von einem Quecksilberthermometer angezeigte Wert von E Einheiten ein notwendiges und hinreichendes Kriterium für das Vorliegen der Temperatur T ist, wird man in der Praxis selbst in den durch den entsprechenden Reduktionssatz spezifizierten Situationen (x wird in Kontakt mit dem Thermometer gebracht) nicht in aller Strenge akzeptieren wollen, da immer die denkbare Möglichkeit besteht, daß der Zusammenhang von tatsächlicher Temperatur und angezeigtem Wert durch einen "normalerweise" konstanten, bisher unbemerkten (und daher nicht in die Spezifikation der Situation aufgenommenen) Faktor gestört wird. ${ }^{21}$

Von den Vertretern des logischen Positivismus wurde aufgrund dieser Einsichten auch

\footnotetext{
${ }^{18}$ In diesem Entwicklungsstadium des logischen Positivismus sprechen seine Anhänger nicht von Extension, Referenz o.ä.

${ }^{19}$ Siehe z.B. [Ca36/37], S.449f., [Hemp52], S.26ff.

${ }^{20}$ [Carn56a], S.48, [Hemp52], S.31ff., [Hemp65b], S.112f., [Supp74], S.22ff.

${ }^{21}$ [Carn56a], S.68f.
} 
die Forderung, daß jeder einzelne "legitime" wissenschaftliche Ausdruck, über dessen Erfülltsein nicht durch Beobachtung definitiv entschieden werden kann, reduzierbar sein muß, aufgegeben zugunsten der schwächeren Forderung, daß die Gesamtheit derartiger Ausdrücke einer Theorie in bestimmer Weise ${ }^{22}$ an Beobachtungen angeschlossen werden muß.

\subsection{Die "Standarddarstellung" wissenschaftlicher Theorien}

In den fortlaufenden Diskussionen und damit einhergehenden Modifikationen der verifikationistischen Ansätze des Wiener Kreises kristallisierte sich im Laufe der 50er und 60er Jahre die im Diskussionszusammenhang des logischen Positivismus gelegentlich so genannte Standarddarstellung (standard conception ${ }^{23}$ oder auch received view ${ }^{24}$ oder orthodox view ${ }^{25}$ ) wissenschaftlicher Theorien heraus. ${ }^{26}$ Dieser zufolge läßt sich jede wissenschaftliche Theorie in präziser, formal sauberer Weise in einer prädikatenlogischen Sprache erster Ordnung formulieren. Die Ausdrücke, die dabei verwendet werden, gehören zu drei Klassen: logische Terme, nicht-logische Ausdrücke, die für beobachtbare Gegenstände, Eigenschaften, Ereignisse usw. stehen, (Beobachtungsterme) und nicht-logische Ausdrücke, die nicht für Beobachtbares stehen, (theoretische Terme). Die aus diesen Ausdrücken gebildeten Sätze unterteilen sich entsprechend in die Gruppe der theoretischen Postulate der Theorie, die nur theoretische (und evtl. logische) Terme enthalten, die Gruppe der Beobachtungsaussagen, die nur Beobachtungsterme (und evtl. logische Ausdrücke) enthalten, und die Gruppe der Sätze, die Beobachtungsterme und theoretische Terme (und evtl. logische Ausdrücke) enthalten und als Korrespondenz- oder Zuordnungsregeln (correspondence rules) oder Brückengesetze (bridge laws) bezeichnet werden ${ }^{27}$. Die Bedeutung der Beobachtungsterme und Beobachtungssätze wird als verstanden und unproblematisch und unabhängig von den theoretischen Termen vorausgesetzt. Die theoretischen Terme der Theorie werden durch Korrespondenzregeln und durch theoretische Postulate ${ }^{28}$ an empirische Beobachtungen angebunden, und zwar, anders als in der Verifikationstheorie, nicht mehr Term für Term einzeln, sondern i.a. "nur" in ihrer Gesamtheit. Zu den Korrespondenzregeln können Sätze von der Form von Definitionen oder Reduktionssätzen gehören, dies ist aber nicht erforderlich und wird i.a. selten so sein. ${ }^{29}$ Es muß nicht jeder theoretische Term in einer Korrespondenzregel vorkommen.

Im Hinblick auf die Frage nach einer Bedeutungstheorie wird die Sachlage durch den Übergang von den verifikationistischen Definitionen theoretischer Ausdrücke zu den Korrespondenzregeln der Standarddarstellung komplizierter. ${ }^{30}$ Eine Definition im Sinne der Verifikationstheorie ist ein Satz, der die Bedeutung des definierten Ausdrucks angibt und

\footnotetext{
${ }^{22}$ S.u.

${ }^{23}[$ Hemp70].

24 [Putn75d].

25 [Feig70].

${ }^{26}$ Siehe [Carn56a, Hemp63, Hemp65c]; s.a. [Supp74], bes. S.50f., [Hemp70, Steg70].

${ }^{27}$ Sowie natürlich rein logische und mathematische Aussagen.

${ }^{28}$ Letztere sorgen insbesondere für die "mittelbare" Anbindung von theoretischen Termen, für die es keine Korrespondenzregeln gibt.

${ }^{29}$ Stichwort: unbemerkte störende Faktoren.

${ }^{30}$ Die Frage, ob die Standarddarstellung in der Lage ist, das Problem der Grenzziehung zwischen legitimen, "sinnvollen" Ausdrücken und Sätzen einerseits und "sinnlosen" andererseits, zu lösen (das Problem also, zu dessen Lösung die Verifikationstheorie der Bedeutung konzipiert worden war), muß hier beiseite bleiben; siehe dazu [Carn56a, Hemp65b, Steg70].
} 
seine Extension festlegt. Reduktionssätze dagegen liefern für einen theoretischen Term allenfalls eine "partielle Spezifikation" seiner Bedeutung, da man sich die Einführung neuer, zusätzlicher Reduktionssätze offen hält; Reduktionssätze legen daher die Extension eines theoretischen Terms nur teilweise fest. Für die Korrespondenzregeln, die zu einem theoretischen Term gehören, gilt zunächst analog dasselbe wie für Reduktionssätze. "Problemverschärfend" kommt jedoch hinzu, daß es, wie erwähnt, nicht zu jedem theoretischen Term eine Korrespondenzregel oder mehrere gibt, so daß nicht einmal für jeden theoretischen Term eine "partielle Spezifikation" seiner Bedeutung sichergestellt ist. Außerdem läßt sich selbst bei den theoretischen Termen, für die es eine (nicht-leere) Menge von Korrespondenzregeln gibt, nicht ohne weiteres diese gesamte Menge als Menge von analytischen Sätzen auffassen, die die Bedeutung des Terms wenigstens partiell spezifiziert, da diese Menge i.a. empirische Konsequenzen hat. ${ }^{31}$ Es stellt sich daher die Frage, wie in der Standarddarstellung die Bedeutung eines theoretischen Termes charakterisiert werden kann.

Der elaborierteste Vorschlag dazu stammt von Carnap. ${ }^{32}$ Er formuliert das Problem als das der Auszeichnung der analytischen Sätze einer Theorie, die die Bedeutung ihrer theoretischen Ausdrücke spezifizieren, vor den synthetischen, die ihren "Beobachtungsgehalt" enthalten. Da die Korrespondenzregeln $K$ zur Charakterisierung der Bedeutung der theoretischen Ausdrücke nicht ausreichen, schlägt Carnap vor, zusätzlich die theoretischen Postulate $T$ der Theorie heranzuziehen, die gemäß der Standarddarstellung mit zur Anbindung der theoretischen Terme an empirische Beobachtungen beitragen. Die Gesamtheit der Korrespondenzregeln und theoretischen Postulate kann man nicht einfach als analytische Sätze auffassen, die die Bedeutung der in ihnen auftretenden Terme festlegen, da, wie erwähnt, i.a. bereits die Menge der Korrespondenzregeln empirische Konsequenzen hat und es im übrigen natürlich auch nicht plausibel ist, eine ganze Theorie als analytisch anzusehen. ${ }^{33}$

Carnaps Vorschlag ist der, innerhalb der Menge $T K$ der theoretischen Postulate und Korrespondenzregeln mit Hilfe des sogenannten Ramsey-Satzes

$$
R(T K):=\exists x_{1} \exists x_{2} \ldots T K\left[x_{1}, x_{2}, \ldots\right]^{34}
$$

\footnotetext{
${ }^{31}$ Dasselbe gilt schon für Reduktionssätze. Sehen kann man das am einfachsten bei einer Menge von Reduktionssätzen der vorne angegebenen einfachen Form: Die Spezifikation der Situation, für die ein Reduktionssatz "zuständig" ist, muß mit der von allen anderen Reduktionssätzen für dieselbe Größe in dem Sinne verträglich sein, daß nicht mehrere Reduktionssätze gleichzeitig Anwendung finden und widersprüchliche Aussagen über das Vorliegen oder Nichtvorliegen der reduzierten Größe treffen. Zum Beispiel kann der oben angeführte Reduktionssatz für ' $x$ hat die Temperatur $T$ ' nicht zusammen mit dem weiteren Reduktionssatz 'Wenn x mit dem Alkoholthermometer AT in Kontakt gebracht wird, dann gilt: Das Thermometer AT zeigt für x F Einheiten gdw. x die Temperatur $T^{*}$ hat' als analytisch betrachtet werden, weil aus beiden zusammen der klarerweise empirische Satz folgt: Wenn x mit dem Quecksilberthermometer QT und mit dem Alkoholthermometer AT in Kontakt gebracht wird, dann zeigt nicht QT E Einheiten für $\mathrm{x}$ und AT F Einheiten'; siehe z.B. [Ca36/37], S.444, [Hemp63], S.687.

${ }^{32}$ [Ca36/37], S.451ff., [Carn58], S.244ff., [Carn63b], S.963ff., [Carn66], Kap.28, [Lewi72, Lewi83b].

${ }^{33}$ Denn darauf liefe es hinaus, da nur noch die Beobachtungssätze als Kandidaten für synthetische Sätze übrigblieben und, sofern sie aus der Theorie folgen, nicht einmal diese.

${ }^{34}$ Sei eine Theorie, in der die theoretischen Terme $t_{1}, t_{2}, \ldots$ vorkommen, dargestellt durch einen Satz $T\left[t_{1}, t_{2}, \ldots\right]$ (den man für eine aus mehreren Sätzen bestehende Theorie als Konjunktion dieser Sätze erhält). Dann erhält man den Ramsey-Satz von $T$, indem man jeden theoretischen Term durch eine Variable ersetzt und über den entstandenen Ausdruck existenzquantifiziert:
}

$$
R\left(T\left[t_{1}, t_{2}, \ldots\right]\right):=\exists x_{1} \exists x_{2} \ldots T\left[x_{1}, x_{2}, \ldots\right]
$$

Da unter den theoretischen Termen i.a. Prädikate sein werden, formuliert man den Ramsey-Satz natürlicherweise in einer Prädikatenlogik zweiter Stufe. (Abweichend faßt David Lewis [Lewi72, Lewi83b] die 
dieser Menge die Grenze zwischen analytischen, also bedeutungsbestimmenden, und synthetischen Sätzen zu markieren. Folgendes läßt sich zeigen: Die Konjunktion aus dem Ramsey-Satz $R(T K)$ und dem sogenannten Carnap-Satz $R(T K) \rightarrow T K$ ist logisch äquivalent zu $T K$. Aus $R(T K)$ folgen dieselben Beobachtungssätze wie aus $T K$, aus $R(T K) \rightarrow$ $T K$ folgen keinerlei Beobachtungssätze, außerdem enthält $R(T K)$ per definitionem keine theoretischen Terme, $R(T K) \rightarrow T K$ dagegen alle theoretischen Terme der Theorie. Carnap schlägt daher vor, den Ramsey-Satz $R(T K)$ als Formulierung des Beobachtungsgehaltes der Theorie aufzufassen, den Carnap-Satz $R(T K) \rightarrow T K$ als Festlegung der Bedeutung der theoretischen Terme der Theorie. Alle Sätze, die aus dem Carnap-Satz folgen, sind demnach analytisch, der Rest synthetisch.

Die Bedeutung eines einzelnen theoretischen Ausdrucks, z.B. $t_{1}$, läßt sich dann mittels definiter Kennzeichnung charakterisieren: ${ }^{35}$

$$
t_{1}=\iota x_{1} \exists ! x_{2} \exists ! x_{3} \ldots T K\left[x_{1}, x_{2}, x_{3}, \ldots\right] .
$$

Nach dieser Konzeption der Bedeutung eines theoretischen Terms gibt die Spezifikation einer solchen Bedeutung offenbar nicht (wie es eine verifikationistische Definition tut) an, wie durch Beobachtung (und Anwendung der Regeln der Logik) definitiv über das Erfülltsein oder Nichterfülltsein des theoretischen Terms entschieden werden kann und Sätze, in denen theoretische Ausdrücke vorkommen, sind i.a. nicht verifizierbar. Direkt Beobachtbares liefert einen Beitrag zur Bedeutung theoretischer Ausdrücke, nämlich über die Beobachtungsausdrücke, die in den Carnap-Satz eingehen, aber eine "Methode der Verifikation" für einzelne theoretische Sätze oder Ausdrücke oder für deren Gesamtheit liefert diese Konzeption nicht mehr: Der Ramsey-Satz einer Theorie ist kein Beobachtungssatz, daher liefert der zugehörige Carnap-Satz keine Anwendungsbedingungen, auch keine "holistischen" für die Gesamtheit der theoretischen Ausdrücke. Anders als bei der Verifikationstheorie liefern auch die theoretischen Postulate einer Theorie einen Beitrag zur Bedeutung ihrer theoretischen Ausdrücke, wie sich am Carnap-Satz ablesen läßt.

Sätze bzw. Theorien, in denen theoretische Ausdrücke vorkommen, sind nach dieser Konzeption von Bedeutung nicht mehr verifizierbar. Carnap selbst ist der Ansicht, daß solche Sätze bzw. Theorien immerhin empirisch bestätigt oder getestet werden können. Er schlägt ein (formal einigermaßen komplexes) "Signifikanzkriterium" für theoretische Sätze vor, das, grob gesprochen, besagt, daß ein theoretischer Satz dann signifikant ist, wenn im Kontext der Theorie, in der er auftritt, mit seiner Hilfe ein Beobachtungssatz

Prädikate als Namen für Eigenschaften auf und kommt daher mit einer Logik erster Stufe aus.) Wenn die Theorie $T$ besagt, daß die theoretischen Entitäten und Eigenschaften $t_{1}, t_{2}, \ldots$ bestimmte Eigenschaften haben, in bestimmten Relationen zu beobachtbaren Entitäten stehen usw., dann sagt der Ramsey-Satz von $T$, anschaulich gesprochen, etwas Schwächeres, nämlich, daß es theoretische Entitäten bzw. Eigenschaften gibt, die die von $T$ genannten Eigenschaften haben, in den von $T$ angegebenen Relationen stehen usw. Ein Beispiel für eine übersimplifizierte "Spielzeugtheorie", die einem aber vielleicht ein Gefühl für den Gehalt eines Ramsey-Satzes gibt, wäre folgendes: Die Theorie besteht aus den drei Sätzen: 1) Elektronen sind Teilchen mit der Ladung q. 2) Der Detektor D knackt gdw. er von einem Teilchen mit der Ladung q getroffen wird. 3) D wird von einem Elektron getroffen. Der Ramsey-Satz dieser Theorie lautet: Es gibt theoretische Eigenschaften $\Phi_{1}$ und $\Phi_{2}$, für die gilt: Alle $\Phi_{1}$ sind $\Phi_{2}$ und Detektor D knackt gdw. es ein $\Phi_{2}$ gibt, und es gibt ein $\Phi_{1}$, von dem er getroffen wird. (Der Relationsterm 'getroffen werden' muß als beobachtbar gelten; siehe [Lewi83b], S.80, 84.)

${ }^{35}$ Genaugenommen gilt dies ohne weiteres nur, wenn es genau ein Tupel von Entitäten und Eigenschaften gibt, das den Ramsey-Satz erfüllt (siehe [Lewi72, Lewi83b]). Bei der Frage, wie Fälle zu behandeln sind, in denen es kein oder mehrere Tupel gibt, die den Ramsey-Satz erfüllen, bestehen Differenzen zwischen Carnap und Lewis; Lewis fordert, daß eine Theorie so formuliert werden muß, daß sie nur durch ein Tupel erfüllt wird (s.a. [Beda93]). 
abgeleitet werden kann, aber nicht ohne ihn. ${ }^{36}$ Nach Carnap erfüllen die meisten naturwissenschaftlichen Theorien, für die seine Bedeutungstheorie konzipiert ist, dieses Kriterium. Zumindest wenn man eine "geeignete" Konzeption von empirischer Bestätigung, Rechtfertigung o.ä. akzeptiert, für die die empirischen Konsequenzen eines Satzes zentral sind, ist daher sichergestellt, daß die Sätze bzw. Theorien, die den Anwendungsbereich von Carnaps Bedeutungstheorie bilden, "bestätigbar" sind, wenn auch nicht verifizierbar. Das Signifikanzkriterium ist allerdings nicht Teil der Bedeutungstheorie, auch wenn Carnap beide in unmittelbarem Zusammenhang diskutiert, daher folgt die empirische Zugänglichkeit von theoretischen Sätzen und Theorien bei Carnap nicht mehr aus der Bedeutungstheorie (wie es noch im Fall der Verifikationstheorie war), denn daß sich den theoretischen Termen einer Theorie durch den formalen Apparat der Ramsey- und Carnap-Sätze Bedeutungen zuordnen lassen, impliziert offenbar nicht, daß die Theorie genügend viele empirische Konsequenzen hat, um sie bestätigen, (oder überhaupt welche).

Lewis geht noch einen Schritt weiter und löst den Zusammenhang zwischen der Bedeutungstheorie und Fragen des epistemischen Zugangs ganz auf. Er vertritt dieselbe Bedeutungstheorie wie Carnap, jedoch ohne die Bestätigbarkeit, "Signifikanz" o.ä. von theoretischen Sätzen und Theorien in irgendeiner Form zu thematisieren.

Der Zusammenhang zwischen der so konzipierten Bedeutung theoretischer Ausdrücke und Sätze einerseits, und der sprachlichen Kompetenz von Sprechern, die die Ausdrücke und Sätze verwenden, andererseits läßt sich in verschiedener Weise bestimmen. Zum einen sozusagen genauso wie bei der Verifikationstheorie, nur daß der "holistische" Carnap-Satz an die Stelle der Verifikationsbedingungen für einzelne Ausdrücke tritt: Um einen theoretischen Ausdruck zu verstehen, muß man danach seine Bedeutung bzw. deren partielle Spezifikation kennen, d.h. den Carnap-Satz, also effektiv eine ganze Theorie. ${ }^{37}$ In dieser an die Verifikationstheorie angelehnten Lesart ist der "zugehörige" Carnap-Satz, der die Bedeutung eines Ausdrucks bestimmt, der Carnap-Satz der Theorie, die der jeweilige Sprecher (bzw. seine Sprachgemeinschaft) zu diesem Zeitpunkt akzeptiert.

Da wissenschaftliche Ausdrücke häufig in verschiedenen konkurrierenden, sich gegenseitig ablösenden Theorien vorkommen, bietet sich jedoch auch eine deutlich "unverifikationistische" Konzeption des Zusammenhangs zwischen der Bedeutung eines theoretischen Ausdrucks (bzw. deren partieller Spezifikation) und der sprachlichen Kompetenz eines Sprechers an: Als "zugehörigen" Carnap-Satz, der die Bedeutung eines Ausdrucks bestimmt, kann man etwa den Carnap-Satz der Theorie ansehen, in deren Kontext der Ausdruck historisch zum ersten Mal eingeführt wurde, oder auch den einer anderen, historisch vorausliegenden Theorie. Man wird dann nicht fordern, daß ein Sprecher, um einen theoretischen Ausdruck zu verstehen, den zugehörigen Carnap-Satz kennen muß und daß die Bedeutung des Ausdrucks durch seine Kenntnisse bestimmt ist. Diese Lesart der Bedeutungstheorie nennt Lewis. ${ }^{38}$

Eine andere, von der von Carnap abweichende Haltung zur Frage nach der Bedeutung

\footnotetext{
${ }^{36}$ Siehe [Carn56a]. Mit dem Signifikanzkriterium unternimmt Carnap einen weiteren Versuch, "sinnvollen" und "sinnlosen" Ausdrücke voneinander abzugrenzen, wie es die logischen Positivisten zuvor mit Hilfe der Verifikationstheorie versucht haben.

${ }^{37}$ Dies versetzt den Sprecher natürlich "nur" in die Lage, entsprechende Sätze zu testen oder zu bestätigen, nicht sie zu verifizieren.

${ }^{38}$ [Lewi83b], S.94/95. Carnaps Ansichten zu diesem Punkt sind wenig deutlich. Mit welcher Bedeutung ein Sprecher einen Ausdruck verwendet, ist nach Carnaps Ansicht eine empirische Frage, die die Dispositionen des Sprechers zur Verwendung des Ausdrucks betrifft und im Prinzip durch die Untersuchung seines Sprachverhaltens zu entscheiden ist [Carn56c], aber wie dies im Fall theoretischer Ausdrücke vor sich gehen soll, bleibt unklar (trotz der Andeutungen [Carn56c], S.241f., [Carn66], S.263f.).
} 
theoretischer Ausdrücke im Rahmen der Standarddarstellung nimmt Hempel ${ }^{39}$ ein. Er argumentiert ${ }^{40}$, daß eine Aufteilung der Sätze einer Theorie in einerseits bedeutungsbestimmende und andererseits solche mit empirischem Gehalt keine einleuchtende, systematische Begründung oder Pointe hat, da (auch nach Carnaps Auffassung) keine der beiden Sorten von Sätzen als unrevidierbar gelten soll, sondern vielmehr grundsätzlich beide Sorten infolge zukünftiger Erfahrungen, die mit bisherigen Überzeugungen in Konflikt stehen, zur Disposition gestellt und ggf. aufgegeben werden können. ${ }^{41}$ Hempel plädiert dafür, aus diesem Grund die Forderung nach Angabe der Bedeutung von theoretischen Ausdrücken durch Definitionen, Reduktionssätze oder analytische Sätze, sprich: das Projekt einer Bedeutungstheorie für theoretische Ausdrücke, fallen zu lassen. ${ }^{42}$ Entsprechend besteht nach Hempel die sprachliche Kompetenz eines Sprechers, der theoretische Ausdrücke und Sätze verwendet und versteht, nicht darin, daß er deren Bedeutung kennt, sondern in seiner Kenntnis von Inferenzregeln, mit Hilfe derer deduktive und induktive Verbindungen zu anderen (theoretischen und Beobachtungs-) Ausdrücken und Sätzen hergestellt werden können. ${ }^{43}$

Die Diskussion um die Bedeutung theoretischer Ausdrücke im Rahmen der Standarddarstellung wissenschaftlicher Theorien läßt also die verifikationistische Bedeutungstheorie in ihrer ursprünglichen Form hinter sich, aber sie führt nicht zu einem einheitlichen Ergebnis, sondern resultiert in zwei einander gegenüberstehenden Positionen. Die Position von Hempel ist es, die Unterscheidung zwischen Sätzen, die die Bedeutung theoretischer Ausdrücke bestimmen, einerseits, und Sätzen mit empirischem Gehalt, die mit Hilfe theoretischer Ausdrücke eine Aussage treffen, andererseits, aufzugeben, und damit auch das Problem der Bedeutung theoretischer Ausdrücke in der Form, in der es sich die logischen Positivisten ursprünglich gestellt hatten, fallenzulassen. Dadurch verliert die Unterscheidung beobachtbar/theoretisch an systematischem Gewicht: Sie bleibt als epistemische Unterscheidung bestehen, aber nicht mehr als Unterscheidung zwischen in puncto Bedeutung "problematischen" rsp. "unproblematischen" Ausdrücken, von denen ersteren nur durch die Anbindung an letztere eine Bedeutung zukommt. Die konservativere Position von Carnap und Lewis versucht, die Unterscheidung analytisch/synthetisch beizubehalten und präzise zu explizieren, und gelangt auf diese Weise zu einer holistischen Konzeption der Bedeutung (bzw. der "partiellen Spezifikation" der Bedeutung) eines theoretischen Ausdrucks. Diese Konzeption von Bedeutung ist noch immer an verifikationistischen Intuitionen orientiert, insofern die Anbindung an direkte Beobachtung einen Beitrag zur Festlegung der Bedeutung eines theoretischen Ausdrucks liefert, sie entfernt sich jedoch von verifikationistischen Motiven, insofern dazu auch die theoretischen Postulate der Theorie, in der der Ausdruck auftritt, einen Beitrag liefern und insofern (zögerlich bei Carnap, konsequent bei Lewis) die Bedeutung theoretischer Ausdrücke von Fragen der epistemischen Zugänglichkeit getrennt wird.

\footnotetext{
${ }^{39}$ In seinen späteren Aufsätzen.

${ }^{40}$ Im Anschluß an Quines bekannte Argumentation [Quin53c, Quin76b].

${ }^{41}$ [Hemp63], S.705ff., [Hemp73].

${ }^{42}$ Siehe [Hemp73], bes. S.376f.

${ }^{43}$ Vgl. [Hemp63], S.695, [Hemp70], S.162f.
} 


\subsection{Logischer Positivismus und Wahrheits- und Referenz- theorien}

Verglichen mit dem Problem der Bedeutung der Sätze und Ausdrücke der Sprache der Wissenschaften werden die Themen Wahrheit und Referenz in den wissenschaftstheoretischen Untersuchungen des logischen Positivismus nur wenig diskutiert. Zumindest in seiner Spätphase finden sich aber auch dazu Beiträge.

Für die Frühphase des logischen Positivismus liegt vielleicht die Vermutung nahe, daß mit einer Verifikationstheorie der Bedeutung, also einer epistemisch orientierten Bedeutungstheorie, auch eine epistemische Wahrheitstheorie einhergehen dürfte. Dies könnte eine Theorie sein, nach der die Wahrheit eines Satzes darin besteht, daß er (verifizierbar ist und) verifiziert wurde oder bei einer entsprechenden Untersuchung verifiziert würde (falls noch keine Untersuchung vorgenommen wurde), darin, daß er (unter idealen epistemischen Bedingungen) berechtigterweise behauptbar ist ${ }^{44}$ o.ä. Tatsächlich gibt es frühe Arbeiten von Neurath und Carnap, die dahingehend interpretiert worden sind, daß sie für wissenschaftliche Sätze eine Kohärenztheorie der Wahrheit skizzieren, der zufolge die Wahrheit solcher Sätze darin besteht, daß sie mit den akzeptierten Beobachtungs- und sonstigen Sätzen zusammen eine hinreichend "kohärente" Gesamtmenge ergeben. ${ }^{45}$ Bei genauerem Hinsehen wird jedoch klar, daß es in diesen Arbeiten im Hinblick auf wissenschaftliche Sätze nicht darum geht, worin die Wahrheit solcher Sätze besteht oder wie der Wahrheitsbegriff $\mathrm{zu}$ analysieren ist, sondern um das Thema Bestätigung, also die epistemische Frage, nach welchen Kriterien wissenschaftliche Sätze als wahr akzeptiert werden. ${ }^{46}$

Andere für wissenschaftliche Sätze und Theorien in Frage kommende Wahrheitstheorien, insbesondere die aus realistischer Perspektive interessanten korrespondenztheoretischen Konzeptionen, werden in der Frühphase des logischen Positivismus nicht diskutiert. ${ }^{47}$ Man ist allgemein der Ansicht, daß man über sprachliche Ausdrücke und Sätze, insbesondere über solche, die nicht von direkt Beobachtbarem handeln, nur in syntaktischer Hinsicht sinnvoll sprechen kann, wenn man nicht in einen Sumpf von "Scheinproblemen" geraten will. Aus realistischer Perspektive interessante Konzeptionen von Wahrheit, die prima facie mit der Semantik der Ausdrücke und Sätze zu tun haben, sind daher kein Thema. Für Referenztheorien gilt Entsprechendes.

Die allgemeine "Angst" vor semantischen Begriffen und Thesen verschwindet bei einigen, wenn auch nicht bei allen logischen Positivisten etwa zur selben Zeit, als die Erosion der Verifikationstheorie der Bedeutung einsetzt, und zwar nachdem Alfred Tarski seine semantische Wahrheitstheorie bekannt gemacht hat. ${ }^{48}$ Tarski geht aus von einer Unterscheidung von Objektsprache und Metasprache: Um Aussagen über die Wahrheit von bestimmten Sätzen und Ausdrücken zu treffen, muß man die Objektsprache, der diese Sätze und Ausdrücke angehören, abgrenzen von der Metasprache, in der man Aussagen über diese Sätze und Ausdrücke und ihre Wahrheit formuliert. Wenn die Metasprache "reichhaltig" genug ist, um sowohl über die Ausdrücke und Sätze der Objektsprache als auch über deren Gegenstandsbereich zu sprechen, kann man nach Tarski in dieser Me-

\footnotetext{
${ }^{44}$ Vgl. z.B. [Putn83d], S.84f.

${ }^{45}$ Siehe dazu [Hemp35] und Referenzen dort.

${ }^{46}$ Diese beiden Themen werden in der Frühphase des logischen Positivismus häufig nicht sauber voneinander abgegrenzt, Carnap markiert diese Unterscheidung jedoch klar in [Carn36].

${ }^{47}$ Für Sätze über direkt Beobachtbares gilt dies nicht in derselben Weise; siehe [Hemp35] und Referenzen dort.

${ }^{48}$ Siehe dazu [Carn63a], S.60ff.
} 
tasprache eine adäquate und mit keinerlei "Scheinproblemen" belastete "Definition" des Prädikates 'wahr' in bezug auf die Objektsprache angeben.

Die formal präzise "Implementierung" von Tarskis Idee ist vergleichsweise kompliziert, ${ }^{49}$ die Idee selbst ist jedoch einfach: Worin die Wahrheit eines bestimmten Satzes der Objektsprache besteht, sagt nach Tarski ${ }^{50}$ eine Aussage der Form:

(T) $\mathrm{X}$ ist wahr genau dann, wenn $\mathrm{p}$.

In diesem Schema ist für $\mathrm{X}$ ein Satz der Objektsprache einzusetzen und für $\mathrm{p}$ dessen Übersetzung in die Metasprache; ein Beispiel (mit Englisch als Objekt- und Deutsch als Metasprache) ist

'The grass is green' ist wahr genau dann wenn das Gras grün ist.

Nach Tarski gilt: Die Wahrheit einer Aussage besteht in ihrer Übereinstimmung oder Korrespondenz mit der Wirklichkeit. ${ }^{51}$ Die Instantiierungen des Schemas (T) explizieren, was dies für einen konkreten Satz besagt, worin also die "Übereinstimmung mit der Wirklichkeit" besteht. Tarski betrachtet seine Wahrheitstheorie daher als Korrespondenztheorie, die die hinter verschiedenen älteren korrespondenztheoretischen Ansätzen stehende Idee in präziser Weise artikuliert.

Tarskis eigentliche Wahrheitstheorie ${ }^{52}$ besteht aus einer komplexen "Definition" des Prädikates 'wahr', die die Wahrheit komplexer Sätze auf die Wahrheit einfacher Sätze zurückführt und diese wiederum auf die Referenz- und Erfüllungsrelationen der Individuenausdrücke und Prädikate, aus denen die einfachen Sätze aufgebaut sind. Zu den Elementen der Definition von 'wahr' zählen Sätze wie

(R) 'Grass' referiert auf Gras

und

(R) Ein Gegenstand erfüllt '. . is green' wenn er grün ist ,

die die Referenz bzw. Extension der Ausdrücke der Objektsprache zum Inhalt haben. Auf diese aufbauend wird die Wahrheit einfacher objektsprachlicher Sätze erklärt durch Schemata wie

' $\mathrm{F}(\mathrm{a})$ ' ist wahr genau dann wenn es einen Gegenstand gibt, auf den 'a' referiert, und dieser ' $\mathrm{F}$ ' erfüllt,

wobei für a eine Individuenkonstante und für F ein Prädikat der Objektsprache einzusetzen ist. Die Wahrheit komplexer Sätze wird dann rekursiv definiert durch Schemata der Art

'p and q' ist wahr genau dann, wenn 'p' wahr ist und 'q' wahr ist

'Not p' (bzw. 'It is not the case that p') ist wahr genau dann, wenn 'p' nicht wahr ist

\footnotetext{
${ }^{49}$ Siehe [Tars35].

${ }^{50}[\mathrm{Ta} 43 / 44]$, S.344.

51 [Ta43/44], S.343.

${ }^{52}$ Das Folgende ist an Fields Rekonstruktion und Terminologie in [Fiel72] angelehnt, die von Tarskis eigener Darstellung etwas abweicht.
} 
etc. Die gesamte aus solchen Elementen aufgebaute "Wahrheitsdefinition" impliziert für jeden Satz der Objektsprache eine Aussage der Form (T).

Entscheidend für die Akzeptanz von Tarskis Theorie bei den logischen Positivisten ist die Tatsache, daß sie sich ohne substanzielle Änderungen auch ohne die semantischen Begriffe der Referenz bzw. der Erfüllung formulieren läßt, wenn man für alle Ausdrücke der Objektsprache Übersetzungen in die Metasprache hat, daß Tarskis Wahrheitstheorie also in diesem Sinn ohne Rückgriff auf semantische Begriffe oder Aussagen auskommt. ${ }^{53}$ Die Tatsache, daß der Begriff der Referenz eliminierbar ist, impliziert jedoch nicht, daß man, in Analogie zu Tarskis Definition von 'wahr', in interessanter Weise eine Definition für 'referiert auf' gewinnen könnte: Alles, was bei der Elimination involviert ist, ergibt sozusagen bestenfalls eine "listenartige Definition" der Art

$\mathrm{X}$ referiert auf $\mathrm{Y}$ genau dann wenn $\mathrm{X}$ gleich 'grass' ist und $\mathrm{Y}$ gleich Gras oder $\mathrm{X}$ gleich 'snow' und Y gleich Schnee oder ...

Involviert ist also, außer einer Aufzählung, welcher objektsprachliche Ausdruck auf welchen Gegenstand referiert, keine Aussage darüber, worin Referenz besteht, keine Aussage über "Gemeinsamkeiten" der Elemente der Liste o.ä. Für 'erfüllt' gilt Entsprechendes. ${ }^{54}$

Tarskis semantische Wahrheitstheorie ist von einigen logischen Positivisten, insbesondere von Carnap, begrüßt worden, wenn auch nicht von allen. Auch diejenigen, die sie akzeptiert haben, haben sie jedoch nicht umstandslos und ohne weiteres auf wissenschaftliche Ausdrücke, Sätze und Theorien angewandt, obwohl sie einerseits keine Unterscheidung von beobachtbaren und nicht beobachtbaren Gegenständen, Eigenschaften etc. bzw. entsprechenden Ausdrücken involviert, und obwohl sie sich andererseits für die Sprache der Wissenschaften ${ }^{55}$ geradezu anzubieten scheint, da sie eine formal präzise definierte Sprache voraussetzt und daher auf eine Umgangssprache nicht ohne "Anpassungs- und Begradigungsaufwand" anwendbar ist. Carnap wendet Tarskis semantischen "Apparat" (also die Unterscheidung Objektsprache/Metasprache, die Zuordnung von Referenzentitäten zu objektsprachlichen Ausdrücken etc.) auf wissenschaftliche, insbesondere physikalische Theorien an und er akzeptiert auch, daß Tarskis semantische Explikation der Idee der Übereinstimmung von Sätzen mit der Wirklichkeit in adäquater Weise beschreibt, worin die Wahrheit einer Theorie besteht. ${ }^{56}$ In dieser Hinsicht akzeptiert Carnap also Tarskis Theorie als Wahrheitstheorie für die Sprache der Wissenschaften (neben seiner im Zusammenhang mit der Standarddarstellung entwickelten Bedeutungstheorie). Carnap nutzt aber gleichzeitig in verschiedenen seiner Arbeiten den semantischen Apparat und übersetzt dabei die objektsprachlichen Terme einer Theorie, die nicht etwas Beobachtbares bezeichnen, nicht in der "natürlichen" Weise, sondern ordnet ihnen als Referenzentitäten, Extensionen etc. einen "Ersatz" zu, der ihm in epistemischer Hinsicht weniger problematisch erscheint als die Entitäten, Extensionen etc., die bei "natürlicher" Übersetzung zugeordnet würden: Danach kann den Ausdrücken 'Massendichte' und 'Ladungsdichte' (im Raum) als Referenz jeweils eine reellwertige Funktion des Raumes, also eine Funktion mit

\footnotetext{
${ }^{53}$ Siehe [Fiel72], S.354ff. Der Punkt ist, daß man, wenn man für alle Ausdrücke Übersetzungen hat, die Referenz bzw. Extension beliebiger (auch komplexer) objektsprachlicher Ausdrücke und daher auch Wahrheitsbedingungen von objektsprachlichen Sätzen explizit angeben kann. Ob mit dem Begriff der Übersetzung nicht doch ein semantisches Element in die Theorie eingeht, ist erst später kontrovers diskutiert worden.

${ }^{54}$ [Fiel72], S.364f., [Tars35], Fn.42.

${ }^{55}$ Jedenfalls in der formalsprachlichen Rekonstruktion, die der logische Positivismus propagiert.

${ }^{56}$ Siehe z.B. [Carn39], S.56ff., bes.S.61.
} 
einer Menge mathematischer Entitäten (Zahlen) als Wertebereich zugeordnet werden, anstatt jeweils einer Funktion mit physikalischen Entitäten (Feldstärken) als Wertebereich, den Ausdrücken 'Temperatur' und 'Energie' (eines Systems) kann jeweils eine Zahl als Referenz zugeordnet werden, anstelle einer physikalischen Eigenschaft u.ä. ${ }^{57}$ Als Begründung für diese Zuordnungen von "Ersatzentitäten" gibt Carnap an, daß die "natürliche" Übersetzung nicht hilft, die jeweilige Theorie zu verstehen, wenn sie einem neu ist, und daß eine "natürliche" Übersetzung wohl möglich ist, aber "nicht nötig". ${ }^{58}$

Anders als Carnap es tut (und mit ihm die meisten logischen Positivisten), kann man Tarskis Theorie offenbar auch als Wahrheitstheorie für die Sprache der Wissenschaften akzeptieren und dabei die Terme der jeweils betrachteten Theorie in "natürlicher" Weise in eine Metasprache übersetzen und ihnen "natürliche" Referenzentitäten, Extensionen etc. zuordnen. Diese Position wird von Herbert Feigl vertreten. ${ }^{59}$ In dieser Weise angewendet trägt Tarskis semantischer Apparat klarerweise nicht dazu bei, eine konkrete Theorie zu verstehen, wenn sie neue Terme enthält, wie es Carnap für wünschenswert hält. Dies ist jedoch nach Feigls Ansicht auch nicht die Aufgabe der Semantik und insbesondere nicht die Aufgabe einer Wahrheitstheorie. Angewandt auf bestimmte Sätze und Ausdrücke einer Theorie liefert Tarskis Theorie Sätze wie

'Elektrische Stromstärke' (oder ‘j’) referiert auf die elektrische Stromstärke,

'Elektronen haben Spin $\frac{1}{2}$ ' (oder ' $s_{e l}=\frac{1}{2}$ ') ist wahr genau dann wenn Elektronen Spin $\frac{1}{2}$ haben

etc., die jemandem, für den die Größen elektrische Stromstärke und Spin neu sind, klarerweise nicht weiterhelfen; für ihn laufen diese Sätze über die Theorie, wie Feigl bemerkt, auf die Auskunft "it means precisely what it says" hinaus. ${ }^{60}$ Dies trägt jedoch nichts aus gegen die Ansicht, daß Tarskis Theorie korrekt erläutert, worin die Wahrheit (oder Falschheit) einer Theorie oder eines theoretischen Satzes besteht.

\subsection{Bedeutungs-, Referenz- und Wahrheitstheorien des lo- gischen Positivismus und semantischer Realismus}

Eine Möglichkeit, die von Nagel und Wright genannte realistische Intuition zu konkretisieren, genauer: deren eine Komponente, den bescheidenen Gedanken, daß die Welt unabhängig vom menschlichen Geist und menschlicher Erkenntnis ist, bieten semantische realistische Thesen der Form (SR1). Für den Bereich der Wissenschaften sind das Thesen, die sagen, daß eine bestimmte wissenschaftliche Theorie oder eine bestimmte Menge von Sätzen oder Theorien wahr oder falsch ist, unabhängig von menschlichen epistemischen Mitteln zum Erkennen ihres Wahrheitswertes. Die Idee wäre, daß die Wahrheit (oder Falschheit) eines Satzes oder einer Theorie sozusagen etwas mit einer Beziehung Sprache-(Rest der) Welt zu tun hat, die mit menschlichen epistemischen Zugangsweisen, Relationen etc. zu dem fraglichen Teil der Welt prinzipiell nichts zu tun hat, und daß darin die Unabhängigkeit der Welt vom menschlichen Geist und menschlicher Erkenntnis besteht, von der Nagel und Wright sprechen. Bedeutungs-, Referenz- und Wahrheitstheorien können Erläuterungen liefern, worin die semantischen Eigenschaften oder Relationen

\footnotetext{
${ }^{57}$ Siehe [Carn58], S.242f. [Carn56a], S.43ff., [Carn63b], S.963

${ }^{58}$ Siehe [Carn39], S.62, 68f., [Carn58], S.243.

${ }^{59}$ [Feig50a, Feig50b]; s.a. [Hemp63], S.695.

${ }^{60}$ [Feig50b], S.191.
} 
der fraglichen Sätze oder Theorien bestehen, durch die oder aufgrund derer diese Sätze oder Theorie wahr oder falsch sind, und damit auch Erläuterungen, in welchem Sinn genau und warum diese semantischen Eigenschaften oder Relationen "unabhängig von menschlichen epistemischen Mitteln zum Erkennen des Wahrheitswertes" sind, d.h. sie können präzise erläuterte Thesen der Form (SR1) liefern. Sofern man solche präzise erläuterten semantischen Thesen für konstitutiv für eine realistische Position hält, gehören die zur Erläuterung herangezogenen Bedeutungs-, Referenz- und Wahrheitstheorien zum Inhalt der realistischen Position.

Die Frage nach solchen Erläuterungen führt offenbar unmittelbar auf die Frage nach einer Wahrheitstheorie, also einer Theorie darüber, worin die Wahrheit (oder Falschheit) eines Satzes oder einer Theorie besteht. Eine Wahrheitstheorie sollte etwas über die zur Diskussion stehende Unabhängigkeit der von ihr beschriebenen semantischen Eigenschaften oder Relationen sagen oder implizieren.

Bei solchen Erläuterungen kann auch eine Referenztheorie involviert sein, nämlich insofern die Wahrheit (oder Falschheit) eines Satzes oder einer Theorie von der Referenz der ihn bzw. sie konstituierenden Ausdrücke abhängt. Letzteres ist etwa in Tarskis semantischer Wahrheitstheorie der Fall, nach der ein Satz der Form F(a) wahr ist genau dann, wenn der Gegenstand, auf den a referiert, Element der Extension von F ist. Denkbar ist aber auch, daß die Wahrheitstheorie, die für die genannten Erläuterungen herangezogen wird, ohne den Begriff der Referenz auskommt.

Eine Bedeutungstheorie kann ebenfalls (muß aber nicht) bei der Erläuterung semantischer realistischer Thesen involviert sein. Insbesondere kann man eine Bedeutungstheorie dann dazu heranziehen, wenn es sich um eine Beschreibungstheorie (description theory) handelt, d.h. um eine Theorie, der zufolge die Bedeutung eines Ausdrucks in seinen Erfüllungsbedingungen und die Bedeutung eines Satzes in seinen Wahrheitsbedingungen besteht. ${ }^{61}$ Die Erfüllungsbedingungen eines Individuenausdrucks oder Prädikates nennen einen Satz von Eigenschaften, die ein Gegenstand haben muß, damit der Individuenausdruck auf ihn referiert bzw. damit er zur Extension des Prädikates gehört, und die dafür auch hinreichend sind; die Wahrheitsbedingungen eines Satzes beschreiben entsprechend einen Sachverhalt, der vorliegen muß, damit der Satz als wahr zählt. Außerdem ist gemäß einer Beschreibungstheorie die Bedeutung eines Ausdrucks oder Satzes (normalerweise ${ }^{62}$ ) auch das, was ein kompetenter Sprecher kennen muß, um diesen Ausdruck oder Satz zu verstehen und damit Aussagen zu treffen, die bedeutungskonstituierenden Beschreibungen müssen aber i.a. nicht direkter Beobachtung zugänglich sein und daher auch nicht als Anwendungsbedingungen des Ausdrucks bzw. als Verifikationsbedingungen des Satzes einsetzbar sein. Gemäß einer Beschreibungstheorie bestimmt also die Bedeutung eines Ausdrucks seine Referenz ${ }^{63}$ bzw. seine Extension und die Bedeutung eines Satzes bestimmt seinen Wahrheitswert. Daher kann eine Bedeutungstheorie dieses Typs involviert sein bei der Erläuterung, worin die semantischen Eigenschaften oder Relationen eines Satzes bestehen, aufgrund derer er wahr (oder falsch) ist, und in welchem Sinn und warum diese unabhängig von menschlichen epistemischen Mitteln zu Bestimmung des Wahrheitswertes sind.

Bei den folgenden Überlegungen zur Erläuterung semantischer realistischer Thesen bleibt ein Typ von Sätzen beiseite, für den semantische realistische Thesen auf den ersten Blick problematisch aussehen: Analytische Sätze, also Sätze, die kraft der Verwendungsre-

\footnotetext{
${ }^{61}$ Die klassischen Formulierungen einer Beschreibungstheorie sind [Freg62b] und [Russ18d].

${ }^{62} \mathrm{Wg}$. dieser Qualifikation vgl. Kap.2.6.6.

${ }^{63}$ Deswegen wird gelegentlich auch die Bezeichnung "Beschreibungstheorie der Referenz" verwendet.
} 
geln der Sprache wahr sind, haben offenbar ihren Wahrheitswert, sobald sie Verwendungsregeln haben, und diesen Wahrheitswert kennt jeder, der die Sätze versteht und damit die Verwendungsregeln kennt, ohne daß er sozusagen zur Erlangung dieser Kenntnisse irgendetwas tun müßte, also so etwas wie Beobachtungs-, Meß-, oder sonstige epistemische Verfahren oder Mittel einsetzen müßte. Was als "epistemische Mittel" zur Bestimmung des Wahrheitswertes eines analytischen Satzes zählt, ist zumindest prima facie unklar. Daher scheinen semantische realistische Thesen der Form (SR1) einschließlich der gängigen Erläuterungen dafür, daß ein Satz wahr oder falsch ist, unabhängig von menschlichen epistemischen Mitteln ${ }^{64}$ für analytische Sätze nicht recht zu "passen". Ob und ggf. wie dennoch semantische realistische Thesen für analytische Sätze formuliert und erläutert werden können, kann hier offen bleiben, da solche Thesen jedenfalls nicht von Interesse sind, wenn es um semantische realistische Thesen geht, die eine realistische Position in der Wissenschaftstheorie konstituieren sollen.

Nach diesen Vorbemerkungen ist jetzt zu untersuchen, was die Bedeutungs-, Referenzund Wahrheitstheorien des logischen Positivismus im Hinblick auf die Frage nach der Unabhängigkeit der semantischen Eigenschaften von Sätzen und Theorien von menschlichen epistemischen Mitteln ergeben und damit als Erläuterung für semantische realistische Thesen der Form (SR1). Außerdem soll die Verträglichkeit dieser Theorien mit semantischen realistischen Thesen der Form (SR2) geprüft werden, durch die Thesen der Form (SR1) häufig ergänzt werden.

\subsubsection{Die Verifikationstheorie}

Die Verifikationstheorie des frühen logischen Positivismus besagt als Bedeutungstheorie per se nichts über semantische Eigenschaften und Relationen, die Sätze und Theorien wahr oder falsch machen, und da sie nicht durch eine Wahrheitstheorie ergänzt wurde, ergibt sich zunächst nichts, was für oder gegen die Unabhängigkeit dieser semantischen Eigenschaften und Relationen von menschlichen epistemischen Mitteln und damit für oder gegen eine These der Form (SR1) spräche.

Wenn man diese Bedeutungstheorie allerdings, wie oben erwähnt, durch eine epistemische Wahrheitstheorie ergänzt, was man vielleicht für verträglich mit dem "Geist" der Verifikationstheorie halten kann, dann gelten für Sätze und Theorien im Anwendungsbereich dieser beiden Theorien keine Thesen der Form (SR1), jedenfalls nicht mit den naheliegenden Erläuterungen (UvmeM1) oder (UvmeM2) für "unabhängig ..." 65: Wenn die Wahrheit eines Satzes darin besteht, daß er (unter idealen epistemischen Bedingungen) berechtigterweise behauptbar o.ä. ist, dann gilt offenbar nicht, daß dieser Satz seinen Wahrheitswert auch dann hätte, wenn niemand über epistemische Mittel verfügen würde, die es (wenigstens im Prinzip) ermöglichen, diesen Wahrheitswert zu ermitteln. Ebenso gilt dann offenbar nicht, daß die Eigenschaft des Satzes, wahr zu sein, nicht menschliche epistemische Mittel zum Erkennen des Wahrheitswertes involviert, denn diese Eigenschaft ist dann identisch mit der Eigenschaft, (unter idealen epistemischen Bedingungen) berechtigterweise behauptbar zu sein, d.h. mit der (relationalen) Eigenschaft des Satzes, daß es für diesen Satz geeignete epistemische Mittel (also Untersuchungsmethoden o. ̈.) gibt, derart daß jemand, der sie (unter idealen epistemischen Bedingungen) einsetzt, die Disposition hat, den Satz zu akzeptieren, ihm auf Befragen zuzustimmen o.ä. Andere geeignete Erläuterungen von "unabhängig ..." sind nicht in Sicht. Für einen Satz, für den

\footnotetext{
${ }^{64}$ Siehe S.7.

${ }^{65}$ Siehe S.7.
} 
eine epistemische Wahrheitstheorie gilt, gilt also in keinem erkennbaren Sinn, daß er wahr oder falsch ist, unabhängig von menschlichen epistemischen Mitteln zum Erkennen seines Wahrheitswertes.

Auch ohne eine Ergänzung durch eine epistemische Wahrheitstheorie konfligiert die Verifikationstheorie der Bedeutung mit einer These der Form (SR2). Eine verifikationistische Definition eines Ausdrucks ermöglicht es und ist sogar dazu da, den definierten Ausdruck (zugunsten phänomenalistischer oder physikalistischer "Ersetzungen") zu eliminieren. Der Verifikationstheorie zufolge ist ein definierter Ausdruck also nicht in der Weise wörtlich $\mathrm{zu}$ nehmen wie es in Thesen der Form (SR2) als Bedingung für semantischen Realismus formuliert wird.

Anstatt die Verifikationstheorie durch eine epistemische Wahrheitstheorie zu ergänzen könnte man alternativ versuchen, sie im Sinne einer Beschreibungstheorie aufzufassen, also verifikationistische Definitionen von Ausdrücken als referenzbestimmende Beschreibungen zu lesen, die auch die Wahrheitsbedingungen von Sätzen festlegen, die die Ausdrücke enthalten. ${ }^{66}$ In dieser Lesart der Verifikationstheorie würden (für den Bereich von Ausdrücken und Sätzen, für den sie gilt ${ }^{67}$ ) Anwendungsbedingungen und Erfüllungsbedingungen eines Ausdrucks bzw. Verifikations bedingungen und Wahrheits bedingungen eines Satzes zusammenfallen. Die semantischen Relationen, aufgrund derer ein Satz wahr (oder falsch) ist, wären dann unter einer bestimmten Voraussetzung unabhängig von menschlichen epistemischen Mitteln zur Ermittelung des Wahrheitswertes im Sinne der Erläuterungen (UvmeM1) und auch (UvmeM2), nämlich unter der Voraussetzung, daß man das Zusammenfallen der zwei Sorten von Bedingungen als kontingentes Faktum auffaßt, das für das Bestehen der semantischen Relationen nicht wesentlich ist: Gemäß dieser Lesart der Verifikationstheorie wäre dann ein Satz auch dann wahr (oder falsch), wenn niemand (wenigstens im Prinzip) in der Lage wäre, herauszufinden, ob er wahr ist (oder falsch), denn die verifikationistischen Definitionen von Ausdrücken wären nach dieser Lesart auch in diesem Fall dieselben (und referenzbestimmend). Z.B. wären nach dieser Lesart die Definitionen von Ausdrücken und damit die Wahrheitswerte von Sätzen auch dann dieselben, wenn der menschliche Wahrnehmungsapparat anders beschaffen wäre als er es kontingenterweise ist, beispielsweise wenn Menschen wesentlich schlechter sehen könnten als sie es (normalerweise) können, und wenn daher die Definitionen daher "nur noch" Erfüllungs- bzw. Wahrheitsbedingungen darstellen würden, nicht mehr gleichzeitig (wie sie es kontingenterweise tatsächlich tun) Anwendungs- bzw. Verifikationsbedingungen. Ebenso involviert gemäß dieser Lesart der Verifikationstheorie die Eigenschaft eines Satzes, wahr zu sein, nicht menschliche epistemische Mittel zum Erkennen des Wahrheitswertes, denn diese Eigenschaft ist dann für den einfachsten Fall eines Satzes der Form $F(a)$ identisch mit der Eigenschaft, aus einem Individuenausdruck und einem Prädikatausdruck zu bestehen, die beide referieren, und für die gilt, daß der Gegenstand, der die Erfüllungsbedingungen von $a$ erfüllt, Element der Menge von Gegenständen ist, die die Erfüllungsbedingungen von $F$ erfüllen, und für komplexere Sätze identisch mit entsprechenden komplexeren Eigenschaften; menschliche epistemische Mittel o.ä. sind dabei offenbar in keiner Weise involviert.

Wenn man dagegen die Verifikationstheorie als Beschreibungstheorie auffaßt und das

\footnotetext{
${ }^{66}$ Dies sieht prima facie vielleicht nach einer gewaltsamen Lesart aus. Sie erscheint aber weniger unplausibel im Lichte der Tatsache, daß, wie vorne notiert, in der Frühphase des logischen Positivismus meistens nicht sauber zwischen epistemischen Fragen und Fragen der Bedeutung sprachlicher Ausdrücke unterschieden wurde.

${ }^{67}$ Für die Plausibilität der Verifikationstheorie ist sicherlich relevant, daß man ihr evtl. einen beschränkten Anwendungsbereich zuschreiben kann.
} 
Zusammenfallen von Anwendung- und Erfüllungsbedingungen nicht für ein kontingentes Faktum hält, sondern für wesentlich für das Bestehen von Referenzrelationen, wenn also z.B. mit einem anderen menschlichen Wahrnehmungsapparat zwangsläufig veränderte Bedeutungen und Referenzrelationen einhergehen, dann sind die Sätze im Anwendungsbereich der Verifikationstheorie nicht im Sinne der beiden beschriebenen Erläuterungen wahr oder falsch, unabhängig von menschlichen epistemischen Mitteln zum Erkennen ihres Wahrheitswertes.

Die Antwort auf die Frage, ob für die Sätze im Anwendungsbereich der Verifikationstheorie semantische realistische Thesen der Form (SR1) gelten, wenn man die Verifikationstheorie als Beschreibungstheorie auffaßt, hängt also davon ab, ob man das Zusammenfallen von Anwendungs- und Erfüllungsbedingungen eines Ausdrucks bzw. von Verifikations- und Wahrheitsbedingungen eines Satzes für ein kontingentes Faktum hält oder nicht. ${ }^{68}$ Im ersteren Fall gelten Thesen der Form (SR1) mit der Erläuterung (UvmeM1) und auch mit der Erläuterung (UvmeM2) für "unabhängig ...", im letzteren Fall nicht.

Mit Thesen der Form (SR2) ist die Verifikationstheorie auch in der Lesart als Beschreibungstheorie nicht verträglich und von daher nicht als Teil einer realistischen Position geeignet, die Thesen der Form (SR2) beinhaltet, selbst dann nicht, wenn das vorne dargestellte Problem nicht bestünde, daß sich praktisch keine Definitionen für die Ausdrücke der real-existierenden Wissenschaften finden lassen (bzw. wenn es möglicherweise in bestimmten Bereichen nicht besteht).

Der Ansatz, die Bedeutung wissenschaftlicher Ausdrücke durch Reduktionssätze zu erläutern, war, wie oben dargestellt, im logischen Positivismus nur eine Zwischenstation auf dem Weg zur Standarddarstellung und da mit ihm im Hinblick auf semantischen Realismus die gleichen Optionen und Probleme verbunden sind, braucht er hier nicht gesondert diskutiert zu werden.

\subsubsection{Die Standarddarstellung}

Die Standarddarstellung und die mit ihr in der Spätphase des logischen Positivismus verbundenen bedeutungs-, referenz- und wahrheitstheoretischen Ansätze legen verschiedene Antworten auf die Frage nahe oder lassen sie zumindest zu, was sie im Hinblick auf die Abhängigkeit oder Unabhängigkeit der semantischen Eigenschaften und Relationen von Sätzen und Theorien von menschlichen epistemischen Mitteln besagen oder implizieren und damit auch im Hinblick auf die Erläuterung semantischer realistischer Thesen.

\section{Die Bedeutungstheorie von Carnap und Lewis, nicht als Beschreibungstheorie aufgefaßt}

Zunächst ist es denkbar, die an die Standarddarstellung geknüpfte Bedeutungstheorie von Carnap und Lewis nicht als Beschreibungstheorie aufzufassen, also so, daß sie nichts über semantische Eigenschaften und Relationen besagt, die Sätze und Theorien wahr oder falsch machen. Diese Lesart wird durch Carnaps Hinweise auf den oben erwähnten, durch die Stichworte openness of meaning, partielle Unbestimmtheit der Bedeutung etc. charakterisierten Sachverhalt nahegelegt. Man kann die Bedeutungstheorie von Carnap und Lewis

\footnotetext{
${ }^{68}$ Letzteres entspricht eher dem "Geist" des frühen logischen Positivismus. Welche Ansicht jemand, der eine Verifikationstheorie attraktiv findet, in diesem Punkt vertritt, wird i.a. von den anderen von ihm akzeptierten sprachphilosophischen Thesen und Theorien abhängen (vgl. dazu z.B. die Position von Dummett).
} 
dann durch eine Wahrheits- und Referenztheorie ergänzen, wozu sich mindestens zwei Möglichkeiten anbieten.

Die Tatsache, daß Carnap durch seine Überlegungen über ein Signifikanzkriterium, wie oben erwähnt, sicherstellen möchte, daß die Sätze und Theorien im Anwendungsbereich seiner Bedeutungstheorie bestätigbar sind (wenn auch nicht verifizierbar), legt es nahe, diese Bedeutungstheorie durch eine epistemische Wahrheitstheorie zu ergänzen. Dies könnte eine Wahrheitstheorie sein, nach der die Wahrheit eines Satzes oder einer Theorie darin besteht, daß er bzw. sie (bestätigbar ist und) den Bestätigungsgrad 1 hat oder bei einer entsprechenden Untersuchung (unter idealen epistemischen Bedingungen) den Bestätigungsgrad 1 bekommen würde (falls noch keine Untersuchung vorgenommen wurde) ${ }^{69}$ Damit würden für Sätze und Theorien im Anwendungsbereich dieser Bedeutungsund Wahrheitstheorie (genau wie im vorigen Abschnitt für die Verfikationstheorie diskutiert) keine semantischen realistischen Thesen der Form (SR1) gelten: Solche Sätze und Theorien wären dann offenbar nicht auch dann wahr (oder falsch), wenn niemand über epistemische Mittel verfügte, die (wenigstens im Prinzip) die Ermittelung des Wahrheitswertes ermöglichen. Es würde dann offenbar auch nicht gelten, daß die Eigenschaft dieser Sätze und Theorien, wahr zu sein, keine menschlichen epistemischen Mittel etc. zur Ermittelung des Wahrheitswertes involviert. Außer solchen Erläuterungen vom Typ (UvmeM1) und (UvmeM2) für die "Unabhängigkeitsklausel" von (SR1) sind andere geeignete Erläuterungen wiederum nicht in Sicht. Für Sätze und Theorien, für die die Bedeutungstheorie von Carnap und Lewis zusammen mit einer epistemischen Wahrheitstheorie gilt, gilt also in keinem erkennbaren Sinn, daß sie wahr oder falsch sind, unabhängig von menschlichen epistemischen Mitteln zum Erkennen ihres Wahrheitswertes, daher sind Thesen der Form (SR1) für sie ausgeschlossen.

Eine andere Möglichkeit ist, die Bedeutungstheorie von Carnap und Lewis durch Tarskis semantische Wahrheitstheorie zu ergänzen, der zufolge die Wahrheit eines Satzes oder einer Theorie in seiner bzw. ihrer Übereinstimmung mit der Wirklichkeit besteht, was wiederum durch Aussagen der Form (T) erläutert wird. Für den Fall einer konkreten Theorie läßt das, wie oben beschrieben, die Möglichkeiten offen, auf der rechten Seite von (T) entweder "natürliche" Übersetzungen der Ausdrücke und Sätze der Theorie einzusetzen, wie Feigl es propagiert, oder "unnatürliche" Übersetzungen, wie Carnap es tut, also den Ausdrücken der Theorie "Ersatzentitäten" als Referenz zuzuweisen. In beiden Fällen erfüllen die Sätze der Theorie semantische realistische Thesen der Form (SR1), wobei sich "unabhängig von ..." durch (UvmeM1) und durch (UvmeM2) erläutern läßt: Wenn die Wahrheit eines Satzes darin besteht, daß er wahr ist genau dann, wenn p, wobei p entweder einen physikalischen, chemischen o.ä. Sachverhalt oder einen mathematischen "Ersatz" bezeichnet, dann wäre der Satz offenbar auch dann wahr (oder falsch), wenn niemand (wenigstens im Prinzip) in der Lage wäre, herauszufinden, ob er wahr ist (oder falsch). Außerdem involviert die Eigenschaft eines Satzes, wahr (oder falsch) zu sein, auch nicht menschliche epistemische Mittel zum Erkennen des Wahrheitswertes. ${ }^{70}$

\footnotetext{
${ }^{69}$ Bzw. eine entsprechend modifizierte Wahrheitstheorie, wenn man eine andere, etwa eine nichtquantitative Konzeption von Bestätigung vertritt.

${ }^{70}$ Es ist denkbar, daß man den formalen Apparat von Tarskis Wahrheitstheorie in einer Weise mit weiteren semantischen Theorien bzw. Thesen kombiniert (z.B. mit einer verifikationistischen Referenztheorie, die Tarskis "listenartige Definition" von Referenz sozusagen als Output liefert), daß diese erweiterte Theorie bzw. die Kombination dieser Theorien ausschließt, daß ein Satz wahr ist (oder falsch) und gleichzeitig niemand (wenigstens im Prinzip) in der Lage ist, herauszufinden, was von beiden (vgl. dazu Dummetts Position, z.B. in [Dumm93c]). Es ist wichtig zu sehen, daß das, was dieses Resultat liefert, nicht Tarskis Wahrheitstheorie ist, sondern eine andere semantische Theorie, die Tarskis semantischen Apparat als eine
} 
Mit Thesen der Form (SR2) ist die Bedeutungstheorie von Carnap und Lewis in jeder Lesart verträglich, da sie für theoretische Terme i.a. keine Definitionen, Reduktionssätze o.ä. involviert, diese also in dem in (SR2) formulierten Sinn wörtlich genommen werden. Von den beiden erwähnten Wahrheitstheorien ist im Hinblick auf (SR2) nur die von Tarski relevant, insofern sie den Begriff der Übersetzung involviert. Die von Carnap im Kontext von Tarskis Wahrheitstheorie verwendeten "unnatürlichen" Übersetzungen nehmen (physikalische) theoretische Terme offenbar nicht wörtlich, anders als Feigls "natürliche" Übersetzungen. Tarskis Wahrheitstheorie ist mit Thesen der Form (SR2) also nur dann verträglich, wenn die Aussagen der Form (T) "natürliche" Übersetzungen enthalten.

\section{Die Bedeutungstheorie von Carnap und Lewis, als Beschreibungstheorie auf- gefaßt}

Wenn man die an die Standarddarstellung geknüpfte Bedeutungstheorie als Beschreibungstheorie auffaßt, also die von ihr zugeschriebenen Bedeutungen von Ausdrücken als referenzbestimmende Beschreibungen liest, die auch die Wahrheitsbedingungen von Sätzen festlegen, kommen im Hinblick auf die Frage nach der Unabhängigkeit der so festgelegten semantischen Relationen und Wahrheitswerte von menschlichen epistemischen Mitteln prima facie mehrere Antwortmöglichkeiten in Betracht, je nachdem, wie man das Verhältnis zwischen Bedeutungen und Fragen des epistemischen Zugangs genau sieht.

Wenn man die Bedeutungstheorie von Carnap und Lewis als Beschreibungstheorie liest und, wie Lewis es tut, konsequent zwischen den für die Wahrheit (oder Falschheit) verantwortlichen semantischen Relationen von Sätzen einerseits, und Fragen des epistemischen Zugangs zu ihrem Wahrheitswert andererseits unterscheidet, dann erfüllen Sätze und Theorien aus dem Geltungsbereich dieser Beschreibungstheorie semantische realistische Thesen der Form (SR1), deren "Unabhängigkeitsklauseln" durch (UvmeM1) oder (UvmeM2) erläutert werden: Gemäß dieser Lesart der Bedeutungstheorie von Carnap und Lewis besteht die Eigenschaft eines Satzes, wahr zu sein, für den einfachsten Fall eines Satzes der Form $F(a)$ darin, daß er aus einem Individuenausdruck und einem Prädikat besteht, die beide referieren, und daß der Gegenstand, der die Beschreibung erfüllt, die die Bedeutung von $a$ darstellt, auch die Beschreibung erfüllt, die die Bedeutung von $F$ darstellt, und für komplexere Sätze in entsprechenden komplexeren Eigenschaften. Daher wäre ein Satz, der wahr ist, offenbar auch dann war, wenn niemand (wenigstens im Prinzip) in der Lage wäre, herauszufinden, ob er wahr ist (oder falsch), und die Eigenschaft des Satzes, wahr (oder falsch) zu sein, involviert in keiner Weise epistemische Mittel oder Möglichkeiten, seinen Wahrheitswert zu bestimmen.

Wenn man die Bedeutungstheorie von Carnap und Lewis als Beschreibungstheorie liest, dabei aber gleichzeitig, wie Carnap, von einer außerhalb dieser Bedeutungstheorie liegenden These überzeugt ist, die sicherstellt, daß die Sätze und Theorien im Anwendungsbereich der Bedeutungstheorie durch direktes Beobachten bestätigbar sind, ${ }^{71}$ dann ist vielleicht auf den ersten Blick nicht klar, ob diese Sätze und Theorien semantische realistische Thesen der Form (SR1) erfüllen, ob sie also wahr oder falsch sind, unabhängig von menschlichen epistemischen Mitteln zum Erkennen ihres Wahrheitswertes, da diese

Komponente enthält. Mit 'Tarskis Wahrheitstheorie' ist also nicht nur Tarskis formaler Apparat gemeint, sondern eine Wahrheitstheorie, die sozusagen den Anspruch erhebt, die für die Wahrheit (bzw. Falschheit) von Sätzen verantwortlichen semantischen Relationen vollständig zu beschreiben, also alles zu sagen, was für die Wahrheit (bzw. Falschheit) von Sätzen wesentlich ist.

${ }^{71}$ Eine "geeignete" Konzeption von epistemischer Bestätigung vorausgesetzt; diese Qualifikation bleibt im folgenden implizit. 
Wahrheitswerte eben (wenn die fragliche These stimmt) alle zumindest im Prinzip epistemisch zugänglich sind. Auf den zweiten Blick spricht jedoch einiges dafür, daß trotz einer solchen These semantische realistische Thesen der Form (SR1) in der im vorigen Absatz erläuterten Weise und aus den dort genannten Gründen erfüllt sind, denn die von Carnap ins Auge gefaßte These liegt sozusagen außerhalb der Bedeutungstheorie, so daß die geforderte "Bestätigbarkeit" nicht wesentlich für das Vorliegen (oder Nicht-Vorliegen) der semantischen Eigenschaften und Relationen ist, die den Wahrheitswert festlegen: Wenn niemand (wenigstens im Prinzip) in der Lage wäre, herauszufinden, ob die fraglichen Sätze wahr sind (oder falsch), oder sie auch nur zu bestätigen, zu testen o.ä., wären diese Sätze nicht mehr "signifikant" in Carnaps Sinn. Dies ändert aber nichts daran, daß sie dennoch den Wahrheitswert hätten, den sie haben. Ebenso ist eine These über die "Signifikanz" von Sätzen, die außerhalb der Bedeutungstheorie liegt, nicht relevant für die Frage, worin die Eigenschaft eines Satzes, wahr (oder falsch) zu sein, besteht, und damit auch nicht für die Frage, ob diese Eigenschaft menschliche epistemische Mittel o.ä. involviert. Eine These über die "Signifikanz" bzw. "Bestätigbarkeit" wie die von Carnap ändert also nichts daran, daß Sätze und Theorien aus dem Geltungsbereich der (als Beschreibungstheorie aufgefaßten) Bedeutungstheorie von Carnap und Lewis semantische realistische Thesen der Form (SR1) erfüllen, deren "Unabhängigkeitsklauseln" durch (UvmeM1) oder (UvmeM2) erläutert werden.

Mit Thesen der Form (SR2) ist die Bedeutungstheorie von Carnap und Lewis offenbar problemlos verträglich, wenn man sie als Beschreibungstheorie auffaßt.

\section{Hempels Position}

Wenn man, wie es Hempel tut, die Frage nach einer Bedeutungstheorie fallenläßt, kommen noch Referenz- und Wahrheitstheorien in Frage, um Aussagen über semantische Eigenschaften und Relationen und deren Unabhängigkeit (oder Abhängigkeit) von menschlichen epistemischen Mitteln und damit Erläuterungen für semantische realistische Thesen der Form (SR1) zu gewinnen. Von den im logischen Positivismus diskutierten Theorien kommen als "Ergänzung" einer Position wie der Hempels offenbar eine epistemische Wahrheitstheorie und Tarskis Korrespondenztheorie in Betracht.

Eine epistemische Wahrheitstheorie liefert, wie oben diskutiert, in keinem erkennbaren Sinn Thesen der Form (SR1). Für Tarskis Wahrheitstheorie gilt ebenfalls das oben Gesagte: Sie läßt für den Fall einer konkreten Theorie die Möglichkeiten offen, auf der rechten Seite von des Schemas (T) entweder "natürliche" Übersetzungen der Ausdrücke und Sätze der Theorie einzusetzen, oder "unnatürliche" Übersetzungen einzusetzen, wie Carnap es tut, also den Ausdrücken der Theorie "Ersatzentitäten" als Referenz zuzuweisen. Letzteres widerspricht (SR2), ersteres nicht. In beiden Fällen erfüllen die Sätze der Theorie Thesen der Form (SR1), wobei sich "unabhängig ..." durch (UvmeM1) oder (UvmeM2) erläutern läßt.

\subsection{Probleme und Einwände}

An dieser Stelle sollen kurz die wichtigsten Probleme und Einwände diskutiert werden, mit denen man sich konfrontiert sieht, wenn man die im logischen Positivismus im Zusammenhang mit der Standarddarstellung diskutierten Bedeutungs-, Referenz- und Wahrheitstheorien für eine realistische Position heranziehen will, sei es zur Erläuterung semantischer realistischer Thesen, sei es "nur" im Rahmen der Argumentation für realistische Thesen. 


\subsubsection{Die Adäquatheit der Formalisierung}

Vor allem von Seiten von Vertretern der neueren Wissenschaftstheorie und Wissenschaftsgeschichte, die sich eng an der Praxis der real-existierenden Wissenschaften orientieren, wird gegen die Standarddarstellung des logischen Positivismus häufig der Vorwurf vorgetragen, daß deren Ansatz von einem in einigermaßen hoffnungsloser Weise überformalisierten Modell der "kognitiven Produkte" der Wissenschaften ausgeht, so daß die Relevanz von Diskussionen, die anhand dieses Modells geführt werden, für das Verständnis der real-existierenden Wissenschaften zweifelhaft sei. ${ }^{72}$ Dies betrifft u.a. auch die Realismusdebatte.

Prima facie hat dieser Einwand einiges für sich: Die Theorien, Modelle, Gesetze usw. aus der Praxis der Naturwissenschaften sind selten oder nie in einem prädikatenlogischen Kalkül erster Stufe ${ }^{73}$ formuliert, und ob sie in dieser Weise formulierbar wären, scheint zumindest für einen großen Teil der Naturwissenschaften außerhalb der theoretischen Physik fraglich oder jedenfalls ein Projekt für die sehr ferne Zukunft zu sein. Dennoch ergibt dies gegen die Standarddarstellung nur einen Einwand, der zu pauschal und undifferenziert ist, um ihren Wert generell in Frage zu stellen. Die Standarddarstellung ist in erster Linie an der Physik orientiert, und zumindest für die Teile der theoretischen Physik, die etwas hinter der Forschungsfront liegen, sieht die formale Modellierung, die die Standarddarstellung für Theorien vorschlägt, nicht grotesk inadäquat aus. Speziellere Punkte der Kritik sind damit natürlich noch nicht berührt, etwa die Frage, ob eine extensionale Sprache erster Stufe (versus z.B. modale Sprachen oder Sprachen höherer Stufe) geeignet ist zur Formulierung von Theorien, die Frage, ob und ggf. inwieweit allein mit den Ressourcen eines logischen Kalküls philosophisch interessante Fragen in fruchtbarer Weise diskutiert und beantwortet werden können (wie dies die logischen Positivisten vielfach annahmen ${ }^{74}$ ) oder die Frage, ob und ggf. wie weit man mit diesem Ansatz jenseits der (theoretischen) Physik kommt. Festgehalten werden soll hier lediglich der Punkt, daß überzeugende Einwände gegen die Standarddarstellung sich auf "konkrete" Probleme richten sollten, nicht auf deren allgemeinen Ansatz, mit formalen Sprachen zu arbeiten. Auch wenn man nicht, wie Carnap, am Projekt einer rationalen Rekonstruktion wissenschaftlichen Wissens in Form einer formalsprachlichen, sozusagen von den Spuren des kontingenten Forschungsprozesses gereinigten Darstellung von Theorien interessiert ist, spricht grundsätzlich nichts dagegen, die formale Modellierung der Standarddarstellung als erste, idealisierte, wenn auch grobe und ergänzungsbedürftige Beschreibung physikalischer Theorien, Modelle etc. zu betrachten, gleichsam wie die idealisierten, vereinfachten Modelle, die in der Physik selbst für komplexe reale Systeme verwendet werden.

\subsubsection{Die Unterscheidung Beobachtungsterme/theoretische Terme}

Ein zentrales konstitutives Element der Standarddarstellung und der an sie geknüpften Bedeutungstheorie ist die innerhalb der Wissenschaftssprache gezogene Unterscheidung zwischen theoretischen und Beobachtungstermen ${ }^{75}$ sowie, darauf basierend, die Unterscheidung von theoretischen Sätzen, Beobachtungssätzen und Korrespondenzregeln. Diese Unterscheidungen in Frage zu stellen ist Teil eines der wichtigsten Argumentationsstränge

\footnotetext{
${ }^{72}$ Siehe z.B. [Kuhn77b], S.10ff.

${ }^{73}$ Und gar noch in axiomatisierter Form, wie Hempel es fordert (vgl. [Hemp65c], S.183).

${ }^{74}$ Etwa wenn die Frage, worin die epistemische Bestätigung von Theorien durch Beobachtungssätze besteht, mit Hilfe der logischen Folgerungsbeziehung beantwortet werden soll o.ä.

${ }^{75}$ Sowie logischen Termen, die aber hier nicht relevant sind.
} 
für wissenschaftlichen Realismus; sie werden in diesem Kontext weiter unten diskutiert. ${ }^{76}$

An dieser Stelle soll noch eine mögliche Rückzugsposition erwähnt werden, die Anhängern der Standarddarstellung offensteht, falls sie zu der Ansicht kommen, daß die Unterscheidung Beobachtungssprache/theoretische Sprache nicht in zufriedenstellender Weise getroffen werden kann. Beobachtungsausdrücke bzw. -sätze sind oben, wie üblich, dadurch charakterisiert worden, daß über ihr Erfülltsein oder Nichterfülltsein bzw. ihren Wahrheitswert durch direkte Beobachtung (d.h. durch Wahrnehmung ohne Zuhilfenahme von Instrumenten u.ä. und unabhängig von Theorien) definitiv entschieden werden kann und sie daher vor theoretischen Ausdrücken bzw. Sätzen als unproblematisch in epistemischer und in semantischer Hinsicht ausgezeichnet sind. Die Rückzugsposition ist die, auf den Begriff der Beobachtungssprache zu verzichten, aber dennoch zu versuchen, zwei Klassen von Ausdrücken (und, darauf aufbauend, verschiedene Klassen von Sätzen) zu unterscheiden, von denen keine in epistemischer Hinsicht grundsätzlich unproblematischer als die andere ist, die sich aber dennoch unterscheiden hinsichtlich der Frage, ob ihre Bedeutung theoretische Ausdrücke oder Sätze involviert. Hempel hat in diesem Sinn die Unterscheidung des zur Formulierung einer Theorie verwendeten theoretischen Vokabulars von dem in bezug auf diese Theorie vortheoretischen, vor Einführung der Theorie und von ihr unabhängig verstandenen Vokabulars eingeführt. ${ }^{77}$ Die Klassifikation einer Gruppe von Ausdrücken als vortheoretisch oder theoretisch ist relativ zu einer bestimmten Theorie, nicht mehr absolut, wie bei der Unterscheidung Beobachtungsterme/theoretische Terme, bei der die Bedeutung von Beobachtungsausdrücken von allen Theorien unabhängig sein soll. Die Bedeutungstheorie von Carnap und Lewis läßt sich auch auf der Basis der Unterscheidung vortheoretisch/theoretisch anstelle der Unterscheidung Beobachtungssprache/theoretische Sprache aufbauen. ${ }^{78}$

\subsubsection{Die Unterscheidung analytisch/synthetisch}

Die Bedeutungstheorie von Carnap und Lewis ist, wie viele Bedeutungs- und Referenztheorien, mit den Einwänden konfrontiert, die vor allem von Quine ${ }^{79}$ gegen die Unterscheidung analytisch/synthetisch vorgebracht worden sind. Nach Carnap und Lewis involviert die Bedeutung eines theoretischen Ausdrucks eine Theorie, in der der Ausdruck auftritt, und es wird innerhalb dieser Theorie eine Grenze gezogen zwischen den Sätzen, die die Bedeutung eines theoretischen Ausdrucks (mit)konstituieren und (sofern man die Bedeutungstheorie als Beschreibungstheorie auffaßt) seine Referenz bestimmen, und dem Rest, sprich: zwischen analytischen und synthetischen Sätzen. Diese Grenzziehung wird von Quine in Frage gestellt.

Quines Argumentation hat bis heute andauernde Diskussionen nach sich gezogen, die an dieser Stelle nicht aufgearbeitet werden können. Es läßt sich jedoch festhalten, daß es keinesfalls unkontrovers ist, daß die Unterscheidung analytisch/synthetisch nicht in legitimer und sinnvoller Weise in einer Bedeutungs- oder Referenztheorie eingesetzt werden kann, und zwar unabhängig davon, ob dies eine allgemeine Theorie ist oder ob sie speziell die Sprache der Wissenschaften zum Thema hat, wie die Theorie von Carnap und Lewis. Quines Argumentation wird von vielen als überzeugend angesehen, insofern sie sich gegen bestimmte epistemische Verwendungsweisen dieser Unterscheidung richtet, insbe-

\footnotetext{
${ }^{76}$ Siehe Kap. 3 und 8 .

${ }^{77}$ [Hemp66], S.74f., [Hemp70], S.143, [Hemp73], S.371ff., s.a. [Lewi83b], S.79.

${ }^{78}$ Lewis selbst tut dies.

${ }^{79}$ [Quin53c, Quin76b].
} 
sondere wenn analytische Sätze als unrevidierbar dargestellt werden oder als Wissen $a$ priori, das einer von empirischer Erfahrung verschiedener und unabhängiger "Erkenntnisquelle" entstammt. Wenn dies zugegeben wird, dann bleibt als Kern von Quines Kritik die Herausforderung an die Anhänger der Unterscheidung analytisch/synthetisch, den Punkt einer solchen Unterscheidung plausibel zu machen, d.h. darzulegen, wozu und auf welcher Basis man unter lauter prinzipiell revidierbaren Sätzen eine solche Unterscheidung markieren will. In dem Moment, in dem man anerkennt, daß alle Sätze epistemisch in dem Sinne denselben Status haben, daß bei "hinreichend merkwürdigen" empirischen Erfahrungen prinzipiell jeder Satz aufgegeben werden kann, hat nach Quine eine Unterscheidung von analytischen und synthetischen Sätzen keine Pointe mehr. ${ }^{80}$ Dieser Schluß Quines hat jedoch keineswegs allgemeine Zustimmung gefunden: Zwischen bedeutungs- und referenzbestimmenden Sätzen einerseits und sonstigen Sätzen andererseits unterscheiden zu können, ist nach Ansicht verschiedener Autoren sozusagen Pointe genug für eine Unterscheidung analytisch/synthetisch. ${ }^{81} \mathrm{Ob}$ oder inwieweit man diese Ansicht teilt, hängt von sehr grundlegenden und weitreichenden Annahmen über Status, Aufgabe und epistemische Grundlagen von Bedeutungs- und Referenztheorien im allgemeinen, also nicht nur in bezug auf die Sprache der Wissenschaften, ab, die hier nicht diskutiert werden können; die entsprechenden Aspekte von Quines Position sind jedenfalls sehr strittig. ${ }^{82}$

Indem die Bedeutungstheorie von Carnap und Lewis die Unterscheidung analytisch/synthetisch einsetzt, bietet sie also den Einwänden von Quine eine Angriffsfläche, wieviel Überzeugungskraft diese haben, hängt aber von kontroversen sprachphilosophischen Thesen und Voraussetzungen ab, die weit über den Bereich der Wissenschaftstheorie hinausreichen und hier nicht in angemessener Weise diskutiert und beurteilt werden können.

\subsubsection{Veränderungen der Bedeutung theoretischer Ausdrücke und die "pessimistische Induktion"}

Der Übergang von der Verifikationstheorie zu der Bedeutungstheorie von Carnap und Lewis bringt es mit sich, daß die Bedeutung eines theoretischen Ausdrucks nicht mehr von der Bedeutung anderer theoretischer Ausdrücke unabhängig ist, sondern, wie sich am jeweiligen Carnap-Satz ablesen läßt, i.a. von der gesamten bedeutungsbestimmenden Theorie abhängt, in der der Ausdruck auftritt. Angewandt auf zwei Theorien, von denen man intuitiv sagen würde, daß die eine eine ergänzte oder modifizierte Version der anderen ist oder deren Nachfolgetheorie, die sie aufgrund neuer Erkenntnisse ersetzt, liefert diese Bedeutungstheorie für die Ausdrücke der beiden Theorien i.a. verschiedene Bedeutungen, und zwar auch dann, wenn beide Theorien viele oder alle Ausdrücke teilen und wenn die eine Theorie eine durch nur geringfügige Veränderungen aus der anderen entstanden ist. Da in der Praxis der Wissenschaften regelmäßig Veränderungen im Bestand der akzeptierten Theorien vorkommen, stellt sich die Frage, wie sich diese aus der Perspektive der Bedeutungstheorie von Carnap und Lewis genau darstellen und welche Konsequenzen damit möglicherweise für realistische Positionen verbunden sind.

Ob und inwieweit die in der Praxis der Wissenschaften auftretenden Veränderungen in der Menge akzeptierter Theorien tatsächlich zu Veränderungen der Bedeutung der involvierten theoretischen Ausdrücke führen, wenn man die Bedeutungstheorie von Carnap und

\footnotetext{
${ }^{80}$ Dies ist, wie inzwischen auch Quine selbst anerkennt (vgl. [Quin91], S.271), der Kern seiner Argumentation, nicht so sehr die in [Quin53c] auch diskutierte Frage nach einer präzisen formalen Explikation der Unterscheidung.

${ }^{81}$ Eine Verteidigung dieser Verwendungsweise der Unterscheidung findet sich z.B. in [Devi96], Kap.1.

${ }^{82}$ Siehe dazu u.a. [Anto87].
} 
Lewis akzeptiert, hängt davon ab, welche Version dieser Theorie man vertritt, genauer: durch welche Theorien, sprich: durch welche Carnap-Sätze die Bedeutung der Ausdrücke festgelegt wird, die ein Sprecher oder eine Sprachgemeinschaft verwenden. ${ }^{83}$ Wenn man die These vertritt, daß die Bedeutung eines Ausdrucks durch die Theorien festgelegt wird, die der Sprecher bzw. die Sprachgemeinschaft zum Zeitpunkt der Verwendung des Ausdrucks akzeptieren, dann zieht jede Veränderung in der Menge der akzeptierten Theorien Bedeutungsveränderungen nach sich: Ein theoretischer Ausdruck, der in verschiedenen, einander ablösenden Theorien auftritt, verändert seine Bedeutung mit jedem noch so geringfügigen Wandel der gerade akzeptierten Theorie. Diese Bedeutungstheorie verletzt dadurch in ziemlich massiver Weise vortheoretische Intuitionen, die viele hinsichtlich der Bedeutung von Ausdrücken und Sätzen haben: Es ist intuitiv wenig plausibel, daß z.B. die Bedeutung des Satzes 'Die Ladung des Elektrons beträgt $1,602 * 10^{-19} C^{\prime}$ nicht invariant ist gegenüber neuen Erkenntnissen über die Bandlücke von Galliumarsenid, und ähnliche Fälle lassen sich beliebig viele finden. ${ }^{84}$

Wenn man dagegen die These vertritt, daß die Bedeutung eines Ausdrucks bei seiner Einführung, also durch die zu diesem Zeitpunkt von den damaligen Sprechern akzeptierte Theorie, in der der Ausdruck erstmals auftritt, festgelegt wird, und zwar ein- für allemal, dann führen alle folgenden Veränderungen in der Menge der akzeptierten Theorien nicht zu Bedeutungsänderungen. (Sofern die Theorien jeweils geglaubt werden, handelt es sich um die Änderung von Überzeugungen.) Die Bedeutung theoretischer Ausdrücke bleibt dann stabil, und auch einmal eingeführte Ausdrücke, die in neueren Theorien nicht mehr verwendet werden (z.B. 'Äther'), verlieren dann nicht ihre Bedeutung.

Wenn man die Bedeutungstheorie von Carnap und Lewis als Beschreibungstheorie auffaßt, also die Bedeutung eines Ausdrucks als referenzbestimmend betrachtet, kann der theoretische Wandel in den Wissenschaften auch zu Veränderungen der Referenz der theoretischen Ausdrücke führen, je nachdem, welche der beiden genannten Versionen man vertritt. Für realistische Positionen können beide Versionen zusammen mit dem Befund des Theorienwandels in den Wissenschaften ein Problem mit der Referenz der theoretischen Ausdrücke mit sich bringen, egal, an welcher Stelle der "Mechanismus" der Bedeutungsfestlegung mittels Carnap-Satz zum Einsatz kommt. Dies betrifft insbesondere Fälle, in denen man intuitiv sagen würde - oder in denen jedenfalls viele Realisten intuitiv sagen würden - daß verschiedene aufeinanderfolgende (mehr oder weniger voneinander abweichende) Theorien zunehmend bessere Theorien über dieselben Gegenstände, Phänomene etc. sind (z.B. über Elektronen, die starke Wechselwirkung oder das Phänomen der Supraleitung), daß also stabile Referenz der entsprechenden zentralen Ausdrücke über den Wechsel der Theorien hinaus vorliegt. ${ }^{85}$

Wenn die Bedeutung der Ausdrücke eines Sprechers durch die von ihm bzw. von seiner Sprachgemeinschaft zum jeweiligen Zeitpunkt akzeptierten Theorien festgelegt wird, dann sind bei solchen Theorieentwicklungsprozessen Instabilitäten der Referenz nicht nur nicht ausgeschlossen, sondern in den meisten interessanten Fällen positiv garantiert: Wenn eine Theorie (mindestens) einen falschen Satz enthält, führt das dazu, daß die "intendierten" Entitäten den Ramsey-Satz nicht erfüllen und daher nicht mit Hilfe des Carnap-Satzes gekennzeichnet werden. Die theoretischen Ausdrücke einer Theorie haben nur bzw. erst

\footnotetext{
${ }^{83}$ Siehe S.40.

${ }^{84}$ Siehe z.B. [Engl78], S.71, [Putn87b], S.257ff., [Putn90c], S.284ff. Die Qualifikation 'geringfügig' ist wichtig. Daß große Veränderungen der akzeptierten Theorien Bedeutungsänderungen nach sich ziehen, klingt intuitiv plausibler.

${ }^{85}$ Siehe z.B. [Lewi83b], S.94.
} 
dann Referenz, wenn die gesamte Theorie wahr ist. Bei Ergänzungen einer wahren Theorie durch weitere wahre Sätze wird die Referenz der Ausdrücke konstant bleiben. Solange aber eine Theorie irgendeinen falschen Satz enthält, haben ihre Ausdrücke keine Referenz (oder jedenfalls nicht die intendierte ${ }^{86}$ ). Von einer Folge von immer besseren Theorien über dieselben Gegenstände oder Phänomene kann also nur dann die Rede sein, wenn eine vollständig wahre Theorie um weitere wahre Sätze erweitert wird, und damit dürften praktisch alle interessanten historischen Fälle ausgeschlossen sein.

Wenn die Bedeutung der Ausdrücke durch die bei der erstmaligen Einführung der Ausdrücke akzeptierten Theorien festgelegt wird und danach stabil bleibt, sieht die Lage im Hinblick auf Referenzstabilität nicht günstiger aus: Die Referenz der Ausdrücke ändert sich dann nicht mit dem Wandel der Theorien, das hieße aber, sofern die fraglichen bei der Einführung der Ausdrücke involvierten Theorien auch nur einen falschen Satz enthalten, daß die Ausdrücke sozusagen in stabiler Weise keine Referenz hätten (oder jedenfalls nicht die intendierte).

Wie bedrohlich die skizzierten Stabilitätsprobleme für realistische Positionen sind, hängt davon ab, welches Bild von den zeitlichen Veränderungen des Gesamtbestandes der akzeptierten wissenschaftlichen Theorien, Gesetze usw. der Blick auf die Wissenschaftsgeschichte ergibt. Im Anschluß an Thomas $\mathrm{Kuhn}^{87}$ wurde von dieser zeitlichen Entwicklung häufig das Bild von Folgen von Theorien gezeichnet, die einander im Laufe von "Revolutionen" ablösen und die voneinander in der Regel fundamental verschieden sind: Was vor einer Revolution als anerkanntes Wissen galt, wird hinterher meistens verworfen und selbst in den Fällen, in denen Vorgänger- und Nachfolgetheorie prima facie denselben Gegenstandsbereich haben, unterscheiden sie sich bei näherem Hinsehen grundlegend, also nicht nur in Details ihrer Aussagen und den Nachkommastellen der von ihnen zugeschriebenen Größenwerte. Wenn man Darstellungen dieser Art ${ }^{88}$ folgt, drängt sich ein weitreichender Pessimismus im Hinblick auf die epistemische Bewertung wissenschaftlicher Theorien auf: Wenn es für jeden beliebigen Zeitpunkt in der gesamten bisherigen Geschichte so war, daß die gerade akzeptierten Theorien spätestens einige Jahrzehnte danach als falsch aufgegeben werden mußten, was soll dann Anlaß zu der Hoffnung geben, daß es unseren heutigen Theorien anders ergehen wird ${ }^{89}$ Dieser - aus realistischer Perspektive düstere - Gedanke wird häufig als pessimistische Induktion (pessimistic induction oder dismal induction) bezeichnet.

Die pessimistische Induktion formuliert ein epistemisches Problem, mit dem jede in epistemischer Hinsicht "optimistische" realistische Position konfrontiert ist, also jede Position, die ontologische oder epistemische realistische Thesen einschließt. Dieses Problem wird sozusagen verschärft, wenn man die Bedeutungstheorie von Carnap und Lewis akzeptiert: Diese impliziert dann Bedeutungsinstabilitäten, wenn man die Bedeutung an die zum jeweiligen Zeitpunkt akzeptierten Theorien knüpft, und sie impliziert vor allem Referenzinstabilitäten, wenn man sie als Beschreibungstheorie auffaßt. Bedeutungsinstabilitäten theoretischer Ausdrücke müssen aus realistischer Perspektive nicht bedrohlich sein, denn sie stehen zu ontologischen, semantischen und auch zu epistemischen realistischen Thesen direkt nicht im Widerspruch und haben per se auch keine Konsequenzen für die epi-

\footnotetext{
${ }^{86}$ Sofern es Fälle geben sollte, in denen, intuitiv gesprochen, eine falsche Theorie z.B. über ein physikalisches System (etwa über die Entstehung eines bestimmten Sterns) gleichsam aus Versehen eine wahre Beschreibung eines anderen Systems (etwa eines anderen Sterns) darstellt, an den die Wissenschaftler überhaupt nicht gedacht hatten und von dem sie vielleicht gar nichts wissen.

${ }^{87}[$ Kuhn70].

${ }^{88}$ Hier zugegebenermaßen vergröbert wiedergegeben.

${ }^{89}$ Siehe z.B. [Putn78], S.24/25.
} 
stemische Bewertung von historischen Theorien. ${ }^{90}$ Referenzinstabilitäten dagegen haben Folgen für die epistemische Bewertung historischer Theorien, auch wenn sie ontologischen, semantischen oder epistemischen realistischen Thesen nicht widersprechen. Wenn man Referenzinstabilitäten als gängiges Phänomen anerkennt, hat das die Konsequenz, daß man von der Geschichte der Wissenschaften ein Bild bekommt, das lange Sequenzen von Theorien, Modellen usw. zeigt, deren theoretische Ausdrücke fast alle keine Referenz haben und die daher allesamt falsch sein müssen, und zwar vollständig falsch, denn wenn ein Teil einer Theorie wahr (oder wahrheitsähnlich o.ä.) wäre, müßten zumindest die in diesem Teil auftretenden Ausdrücke referieren. Die Bedeutungstheorie von Carnap und Lewis führt also, wenn man sie als Beschreibungstheorie auffaßt, sozusagen dazu, daß sich das Bild der Wissenschaftsgeschichte aus realistischer Perspektive vollständig verdüstert, da in epistemischer Hinsicht nichts als völlige Fehlschläge mehr zu erkennen sind.

Diese Verdüsterung kann massive Auswirkungen für die epistemische Beurteilung aktueller wissenschaftlicher Theorien, Modelle etc. haben, also auch für die Beurteilung ontologischer und epistemischer realistischer Thesen. Ob sie diese hat oder nicht und, wenn ja, in welchem Ausmaß, hängt davon ab, was für eine erkenntnistheoretische Position man vertritt. Massive Auswirkungen derart, daß man nur wenige oder gar keine ontologischen oder epistemischen realistischen Thesen für hinreichend begründbar hält, sind insbesondere dann möglich, wenn man eine Konzeption der epistemischen Bestätigung, Rechtfertigung o.ä. wissenschaftlicher Theorien und Gesetze akzeptiert, deren Anwendung auf die Wissenschaftsgeschichte ergibt, daß die historischen Theorien, Gesetze etc. zu dem Zeitpunkt, als sie akzeptiert waren, tatsächlich als gut bestätigt, gerechtfertigt o.ä. zu bewerten waren. ${ }^{91}$ Wenn die von realistischer Seite akzeptierte Konzeption von Bestätigung, Rechtfertigung o.ä. in diesem Sinn im Einklang mit der epistemischen Praxis der historischen Akteure steht, dann kann das skizzierte Bild der Wissenschaftsgeschichte die Überzeugung nach sich ziehen, daß die Kriterien der Theoriewahl, die Standards der Rechtfertigung o.ä., die zum Akzeptieren all der inzwischen verworfenen und auch der derzeit akzeptierten Theorien, Gesetze etc. geführt haben, sich im Laufe der Wissenschaftsgeschichte als völlig unzuverlässig erwiesen haben und daher in epistemischer Hinsicht wertlos sind. In diesem Fall wird man auch die aktuell akzeptierten Theorien und Gesetze nicht für epistemisch hinreichend begründet halten und ebensowenig die realistischen Thesen, die diese Theorien und Gesetze (z.T.) zum Inhalt haben. Weniger massive Auswirkungen sind zu erwarten, wenn man eine Konzeption epistemischer Bestätigung, Rechtfertigung o.ä. vertritt, die nicht im beschriebenen Sinn im Einklang mit der historischen epistemischen Praxis steht. Wie massiv die Auswirkungen sind, hängt außerdem natürlich davon ab, ob oder inwieweit sich zeigen läßt, daß die aktuell akzeptierten Theorien besser bestätigt,

\footnotetext{
${ }^{90}$ Wenn man etwa von realistischer Seite zeigen könnte, daß historisch aufeinanderfolgende Theorien meistens Aussagen über dieselben Gegenstände und Phänomene treffen, also übereinstimmende Referenz haben, und dabei immer mehr korrekte Aussagen machen, der Wahrheit immer näher kommen o.ä., obwohl die Theorien stets einige falsche Aussagen einschließen, könnte dies ausreichen, um die pessimistische Induktion zu entkräften, ohne daß man bestreiten müßte, daß durchgehend Bedeutungsinstabilitäten vorliegen.

${ }^{91}$ In der Literatur zur pessimistischen Induktion wird häufig implizit und ohne Diskussion eine Konzeption von epistemischer Bestätigung vorausgesetzt, für die dies gilt, nämlich etwa von der Art: Eine Theorie ist gerechtfertigt genau dann, wenn sie unter den zum jeweiligen Zeitpunkt vorliegenden "Kandidaten" die größte Zahl von "Theorietugenden" von einer (mehr oder weniger langen) Liste aufweist, die "Eigenschaften" enthält wie z.B. Einfachheit, prognostische Erfolge, Erklärungskraft, keine ad-hoc-Elemente, u.ä. In dieser Richtung finden sich sicherlich denkbare und diskussionswürdige Konzeptionen von epistemischer Bestätigung, es ist jedoch für die Beurteilung der pessimistischen Induktion wichtig zu sehen, daß diese nicht alternativenlos sind.
} 
gerechtfertigt o.ä. sind als die inzwischen verworfenen. Fazit: Ob die Verdüsterung des Bildes der Wissenschaftsgeschichte, die die Bedeutungstheorie von Carnap und Lewis aufgrund von Referenzinstabilitäten nach sich zieht, Folgen für die Bewertung ontologischer oder epistemischer realistischer Thesen hat, hängt im einzelnen von der jeweiligen epistemischen Position ab; zumindest für bestimmte epistemische Positionen sind dramatische Folgen möglich, für alle epistemischen Positionen zwingend sind diese nicht.

Wenn man, wie Hempel, keine Bedeutungstheorie an die Standarddarstellung knüpft, wird das Problem der pessimistischen Induktion nicht in der beschriebenen Weise verschärft. ${ }^{92}$ Wenn man Tarskis semantische Wahrheitstheorie akzeptiert, gilt Entsprechendes: Ob und wenn ja, inwieweit sich bei der Anwendung von Tarskis Theorie auf die Wissenschaftsgeschichte Referenzinstabilitäten ergeben, hängt davon ab, welche Aussagen der Form (R) sich ergeben, wenn man die historischen Theorien übersetzt, welchen Ausdrücken der historischen Theorien also Referenzgegenstände zugeordnet werden und welche; ${ }^{93}$ davon wiederum, und von der jeweils vertretenen erkenntnistheoretischen Position, hängt ab, wie bedrohlich das Problem der pessimistischen Induktion in epistemischer Hinsicht für Realisten aussieht.

\subsubsection{Unterbestimmtheit}

Wenn man als Realist eine in epistemischer Hinsicht optimistische Position vertreten möchte, also eine, die ontologische oder epistemische realistische Thesen einschließt, hat die Bedeutungstheorie von Carnap und Lewis zumindest prima facie einen wesentlichen Vorzug, sofern man sie als Beschreibungstheorie auffaßt und die Bedeutung theoretischer Ausdrücke an die zum jeweiligen Zeitpunkt akzeptierten Theorien knüpft: Sie impliziert dann, daß zwei Theorien, die sich in ihren empirischen Konsequenzen, also in allen aus ihnen ableitbaren Beobachtungssätzen nicht widersprechen, auch in ihren theoretischen Aussagen verträglich sind. English hat gezeigt, daß zwei Theorien, aus denen miteinander verträgliche Mengen von Beobachtungssätzen ableitbar sind, auch miteinander verträgliche Ramsey-Sätze haben und daß daher ihre Carnap-Sätze nur in dem oberflächlichen Sinn in Konflikt miteinander stehen können, daß sie verschiedene Ausdrücke zur Bezeichnung der theoretischen Entitäten einführen, für die der im jeweilige Ramsey-Satz eine Existenzaussage trifft. ${ }^{94}$ Da durch den Carnap-Satz einer Theorie die Bedeutung, und damit die Referenz, ihrer theoretischen Ausdrücke festgelegt wird, sind solche oberflächlichen Konflikte von Carnap-Sätzen dahingehend zu analysieren, daß von den beiden Theorien verschiedene Ausdrücke eingeführt werden, die auf dieselbe theoretische Entität referieren. Fälle von Theorien, die in ihren Beobachtungsaussagen übereinstimmen, aber in ihren theoreti-

\footnotetext{
${ }^{92}$ Ohne Bedeutungsbegriff stellt sich die Frage nach Bedeutungsinstabilitäten naturgemäß nicht und es können auf diesem Wege auch keine Referenzinstabilitäten resultieren.

${ }^{93}$ An dieser Stelle liegt es vielleicht nahe, zu dem Schluß zu kommen, daß eine realistische Position, die Tarskis semantische Theorie einschließt, auf eine Bedeutungstheorie angewiesen ist, weil das Übersetzen von objektsprachlichen Ausdrücken die Zuordnung metasprachlicher Ausdrücke derselben Bedeutung ist und man ohne Übersetzungen kein Bild der Wissenschaftsgeschichte gewinnen kann, etwa um die pessimistische Induktion zu entkräften. Dieser Schluß ist jedoch nicht zwingend, denn obwohl es sicherlich ein prima facie plausibler Ansatz ist, die Übersetzungen, die Tarskis Theorie involviert, mit Bedeutungsgleichheit in Verbindung zu bringen, ist dies keineswegs zwingend oder alternativenlos. Es lassen sich Konzeptionen von Übersetzung gewinnen, die ohne den Begriff der Bedeutung oder gar eine Bedeutungstheorie auskommen, und vor allem läßt sich argumentieren, daß man über die korrekte Übersetzung eines Ausdrucks, insbesondere im Bereich der Wissenschaftsgeschichte, in vielen konkreten Fällen weit sicherere vortheoretische Intuitionen hat als über die Bedeutung von Ausdrücken.

${ }^{94}$ Siehe [Engl73], S.459f., [Engl78], S.68ff.
} 
schen Aussagen "wirklich" konkurrieren, d.h. nicht bloß um terminologische Festlegungen, können nicht vorkommen.

Ohne eine Bedeutungs- bzw. Referenztheorie, die garantiert, daß sich Theorien, die in ihren Beobachtungssätzen übereinstimmen, auch in ihren theoretischen Aussagen nicht widersprechen, ist gibt es sozusagen Raum für das Problem der Unterbestimmtheit.

Allgemein spricht man von Unterbestimmtheit in Situationen, in denen es zu einer Menge von Beobachtungssätzen, Daten, Phänomenen o.ä. mehrere in epistemischer Hinsicht gleichwertige, aber inhaltlich inkompatible Theorien gibt, also unterschiedliche Theorien, die durch die Beobachtungen, Daten o.ä. gleich gut bestätigt oder gestützt werden. Eine häufig von Anhängern antirealistischer Positionen vertretene These in diesem Zusammenhang ist die, daß es zu jeder wissenschaftlichen Theorie, aus der sich eine bestimmte Menge von Beobachtungen, Daten o.ä. ableiten läßt, empirisch äquivalente, aber inkompatible Alternativen gibt. Der Gedanke ist der, daß sich, ausgehend von einer Unterscheidung zwischen theoretischen Aussagen der Theorie und ihren Beobachtungs- oder vortheoretischen Aussagen, stets andere Theorien finden lassen, die in ihrem "theoretischen Teil" abweichen, aus denen aber dennoch dieselben Beobachtungen, Daten o.ä. folgen bzw., allgemeiner, von denen keine nach relevanten epistemischen Kriterien ausgezeichnet ist, d.h. nach Kriterien, die nur die Beobachtungen, Daten o.ä. und deren logische Relationen zu den theoretischen Aussagen involvieren dürfen. Insofern bei empirisch äquivalenten Theorien alle ihre epistemisch relevanten Eigenschaften und Relationen identisch sind, ist demnach die Auswahl einer der konkurrierenden Theorien aufgrund empirischer Evidenzen unterbestimmt. ${ }^{95}$

Unterbestimmtheit ist also ein epistemisches Problem. Es kann offenbar im Prinzip für jede Position auftreten, die von einer Unterscheidung zwischen theoretischen Sätzen und (theorieunabhängigen) Beobachtungssätzen, Daten o.ä. (oder auch vortheoretischen Sätzen) ausgeht, von denen letztere in epistemischer Hinsicht unproblematisch sind, erstere nicht. Die Bedeutungstheorie von Carnap und Lewis ist (als Beschreibungstheorie aufgefaßt) eine Referenztheorie, die ausschließt, daß dieses epistemische Problem auftreten kann, die also die Möglichkeit ausschließt, daß empirisch äquivalente, prima facie unverträgliche Theorien tatsächlich Verschiedenes besagen, verschiedenen Gehalt haben. Die andere im Zusammenhang mit der Standarddarstellung diskutierte referenztheorretische Konzeption, die von Tarski, tut dies nicht: Ihr zufolge können verschiedene Ausdrücke dieselbe Referenz haben, dies muß jedoch nicht so sein, und ob es im Fall empirisch äquivalenter Theorien so ist, hängt von den Aussagen der Form (R) über die theoretischen

\footnotetext{
${ }^{95}$ Eine genaue Formulierung dieser Unterbestimmtheitsthese erfordert in verschiedener Hinsicht Präzisierungen: Unstrittig ist, daß mit der Idee der empirischen Äquivalenz, wenn sie philosophisch von prinzipiellem Interesse sein soll, nicht eine Äquivalenz bezüglich der zu einem Zeitpunkt tatsächlich vorliegenden Beobachtungen gemeint sein kann, die durch zukünftig zu gewinnende Beobachtungen noch beseitigt werden kann, sondern Äquivalenz bezüglich aller möglichen Beobachtungen. Ein kontroverser Punkt für die Formulierung der Unterbestimmtheitsthese ist die Spezifikation der "Größenordnung" der Theorien, für die die These diskutiert werden soll (siehe z.B. [HoRo94, LaLe91]). Da mehrere Theorien mit nichtidentischen Gegenstandsbereichen zusammen möglicherweise andere und mehr beobachtbare Konsequenzen haben können als jede Theorie einzeln genommen, kann eine "lokale" empirische Äquivalenz zwischen einer Theorie und ihren Konkurrenten unter Umständen durch die Kooperation mehrerer Theorien (vielleicht erst zukünftiger) "gebrochen" werden. Äquivalenzen zwischen Theorien mit "globalem" Gegenstandsbereich, also "Theories of Everything", sind davon natürlich nicht betroffen. Für die Frage, wieviel Gewicht die Unterbestimmtheitsthese als Argument im Streit um ontologische oder epistemische realistische Thesen hat, ist die Unterscheidung lokal/global deswegen wichtig, weil die These tendenziell vielleicht umso weniger bedrohlich ist, je "globaler" sie formuliert ist, da "Theories of Everything" eher Projekte für die ferne Zukunft mit sehr unklaren Erfolgsaussichten sind.
} 
Ausdrücke der Theorien ab.

Wenn man eine realistische Position vertreten möchte, die ontologische oder epistemische realistische Thesen einschließt, hat die Bedeutungstheorie von Carnap und Lewis (in der genannten Lesart) also prima facie den Vorzug, daß man sozusagen ein epistemisches Problem weniger hat, nämlich das der Unterbestimmtheit, und sich in epistemischer Hinsicht lediglich mit Beobachtungssätzen, Daten o.ä. beschäftigen muß. Wieviel Gewicht diesem Vorzug zukommt, hängt jedoch entscheidend davon ab, ob man die mit der Standarddarstellung meistens verbundene Annahme akzeptiert, daß Beobachtungssätze, Daten o.ä. in epistemischer Hinsicht "unproblematisch", theoretische Sätze jedoch "problematisch" sind: Aus realistischer Perspektive wird man ihn jedenfalls dann nicht für einen entscheidenden Vorzug halten, wenn man der Ansicht ist, daß theoretische Sätze nicht nur durch die aus ihnen ableitbaren Beobachtungssätze, Daten o.ä. und ihre logischen Beziehungen epistemisch "zugänglich" sind und es daher (jedenfalls grundsätzlich) auch im Fall empirisch äquivalenter Theorien, die nicht dasselbe besagen, epistemische Evidenzen geben kann, die diese Theorien in unterschiedlicher Weise bestätigen.

\subsubsection{Bedeutungskonstituierende Beschreibungen, sprachliche Kompe- tenz und Referenzbestimmung}

Die meisten Beschreibungstheorien ${ }^{96}$, und so auch die Bedeutungstheorie von Carnap und Lewis in der einen der oben genannten Lesarten, schreiben den die Bedeutung eines Ausdrucks konstitutierenden Beschreibungen eine doppelte Funktion zu: Einerseits legen sie fest, was die Referenz des Ausdrucks ist, andererseits sind sie das, was jeder kompetente Sprecher kennen muß, damit er den Ausdruck verstehen und selbst referierend verwenden kann. ${ }^{97}$

Beide Funktionen sind von Kripke und Putnam grundsätzlich in Zweifel gezogen worden, und zwar für Ausdrücke der Alltagssprache genauso wie für theoretische Ausdrücke der Wissenschaften. ${ }^{98}$ Kripke und Putnam haben eine ganze Reihe von Beispielen und Gedankenexperimenten angegeben, die ihrer Ansicht nach deutlich machen, daß es nicht plausibel ist, anzunehmen, daß die Beschreibungen, die ein Sprecher mit einem Ausdruck assoziiert, seine sprachliche Kompetenz in bezug auf diesen Ausdruck konstituieren, und ebenso wenig, daß diese Beschreibungen die Referenz des Ausdrucks festlegen. Putnam selbst kann nach eigener Aussage Ulmen und Buchen nicht auseinanderhalten, kennt also keine Beschreibungen, die ihm das Identifizieren dieser beiden Arten ermöglichen, und meint, daß er klarerweise die Ausdrücke 'Ulme' und 'Buche' dennoch versteht und diese, wenn er sie verwendet, auf Ulmen bzw. Buchen referieren. ${ }^{99}$ Genauso läßt sich für wissenschaftliche Ausdrücke wie 'Molybdän', 'HIV' u.ä. argumentieren. Putnam meint, daß außer Sprechern, die sozusagen zu wenig über die Referenzobjekte ihrer Sprache wissen, um diese zu identifizieren, wie er selbst im Fall von Ulmen und Buchen, auch Sprecher, die falsche Beschreibungen mit einem Ausdruck assoziieren, klarerweise dennoch auf die "richtigen" Objekte referieren können.

Beispiele dieser Art belegen überzeugend, daß Beschreibungstheorien zumindest dann unplausibel sind, wenn sie fordern, daß jeder Sprecher der Sprachgemeinschaft die referenzbestimmenden Beschreibungen kennen muß, um als kompetenter Sprecher zu gelten,

\footnotetext{
${ }^{96}$ Auch solche, die sich nicht speziell mit der Sprache der Wissenschaft beschäftigen.

${ }^{97}$ Diese Doppelfunktion geht auf Freges Konzeption des "Sinns" zurück.

${ }^{98}$ [Krip80, Putn75i].

${ }^{99}$ [Putn75i], S.226.
} 
der die Sprache versteht und dessen Worte referieren. Eine plausible Antwort darauf hat Putnam selbst unter dem Titel linguistische Arbeitsteilung (division of linguistic labour) gegeben: ${ }^{100}$ Man sollte die bedeutungskonstitutiven Beschreibungen von der zweiten ihrer beiden Funktionen entlasten, d.h., man sollte die These fallen lassen, daß jeder Sprecher die referenzbestimmenden Beschreibungen kennen muß. Es reicht, wenn es in der Sprachgemeinschaft Experten gibt, die diese kennen und auf die sich der Rest der Sprachgemeinschaft sozusagen (implizit oder explizit) bei der Referenzbestimmung berufen kann. Man sollte also die sprachliche Kompetenz eines "Durchschnittssprechers", die für Verstehen und referierende Verwendung eines Ausdrucks notwendig ist, trennen von der Kenntnis der referenzbestimmenden Beschreibungen. Über die Anforderungen, die man an die Experten stellt, ist damit noch nichts gesagt, jedenfalls nicht, daß eine Beschreibungstheorie dort nicht adäquat ist.

Putnam selbst plädiert für weitreichendere Konsequenzen für die Bedeutungs- und Referenztheorie. Seiner Ansicht nach sprechen die genannten und ähnliche ${ }^{101}$ Beispiele und Gedankenexperimente dafür, daß man die Grundannahme der Beschreibungstheorien aufgeben sollte, daß die Referenz eines Ausdrucks durch Beschreibungen festgelegt wird, egal ob diese von Durchschnittssprechern oder nur von Experten mit dem Ausdruck assoziiert werden. Nach Putnam sollten also in einer adäquaten Bedeutungs- und Referenztheorie, die mit den durch die Beispiele erläuterten vortheoretischen Intuitionen verträglich ist, bedeutungskonstituierende Beschreibungen keine der beiden Funktionen erfüllen, die ihnen von Beschreibungstheorien zugeschrieben werden.

Diesem radikalen Schritt, den Ansatz der Beschreibungstheorien ganz aufzugeben, verleihen Putnams Beispiele vielleicht eine gewisse Prima-facie-Plausibilität, es scheint aber intuitiv wesentlich weniger klar zu sein, daß ein Sprecher auch dann auf Ulmen, Molybdän oder HIV referieren kann, wenn nicht einmal Experten über so etwas wie korrekte referenzbestimmende Beschreibungen verfügen, als es intuitiv klar ist, daß ein Laie dies kann, der einer Sprachgemeinschaft angehört, deren Experten Ulmen, Molybdän und HIV korrekt identifizieren können. In jedem Fall ist der Schritt nicht zwingend, denn Putnams Beispiele erläutern vortheoretische Intuitionen, die natürlich nicht unumstößlich sind und bei der Beurteilung einer Beschreibungstheorie gegen andere Intuitionen und Argumente abgewogen werden müssen. Aus realistischer Perspektive erscheint der Schritt, alle Beschreibungstheorien aufzugeben, insofern attraktiv, als damit natürlich auch deren Probleme irrelevant werden, insbesondere das Problem der Referenzinstabilität, das gerade durch die von Putnam kritisierte Eigenschaft der Beschreibungstheorien verursacht wird, daß eine Sprachgemeinschaft, die auch nur eine falsche Beschreibung mit einem Ausdruck assoziiert, nicht auf den "intendierten" Gegenstand referiert.

\section{$2.7 \quad$ Fazit}

Im Verlauf der Entwicklung des logischen Positivismus sind mehrere bedeutungs-, referenzund wahrheitstheoretische Konzeptionen vorgeschlagen und diskutiert worden. Die gemeinsame Idee hinter den Bedeutungstheorien, von der frühen Verifikationstheorie bis hin zur Theorie von Carnap und Lewis, ist es, ausgehend von der Unterscheidung zwischen in epistemischer Hinsicht "unproblematischer" Beobachtungssprache und "problematischer" theoretischer Sprache den theoretischen Ausdrücken und Sätzen durch eine Anbindung an

\footnotetext{
${ }^{100}[$ Putn75i], S.227.

${ }^{101}$ U.a. die "twin-earth"-Geschichte in [Putn75i].
} 
die Beobachtungssprache eine Bedeutung zuzuweisen. Bei der Verifikationstheorie ist die Bedeutung von Ausdrücken und Sätzen sehr eng mit ihrer epistemischen Zugänglichkeit verknüpft, diese Verknüpfung wird jedoch auf dem Weg zur Standarddarstellung nach und nach gelöst und ist schließlich bei der Bedeutungstheorie von Carnap und Lewis (zumindest in der Lesart von Lewis) ganz verschwunden. Den Themen Wahrheit und Referenz weicht man im logischen Positivismus zunächst (aus Angst vor "Scheinproblemen") aus, später steht mit Tarskis semantischer Wahrheitstheorie eine akzeptable Konzeption zur Verfügung, die keinerlei Bezug auf epistemische Fragen nimmt.

Die verschiedenen Theorien des logischen Positivismus unterscheiden sich deutlich im Hinblick auf ihre Verwendbarkeit zur Erläuterung semantischer realistischer Thesen und damit als Teil des Inhalts einer realistischen Position.

Die Verifikationstheorie "paßt" nicht zur Sprache der Wissenschaften, weil sich für die meisten theoretischen Ausdrücke keine verifikationistischen Definitionen finden lassen, und ist dort schon deshalb nicht mit semantischem Realismus verträglich. An ihr festzuhalten führt zum Instrumentalismus.

Die im Zusammenhang mit der Standarddarstellung diskutierten Bedeutungs-, Referenz- und Wahrheitstheorien bieten drei verschiedene Möglichkeiten, semantische realistische Thesen zu erläutern. Eine Möglichkeit ist, dazu die Bedeutungstheorie von Carnap und Lewis heranzuziehen und diese als Beschreibungstheorie aufzufassen. Zwei weitere Möglichkeiten bekommt man, wenn man Tarskis Wahrheitstheorie heranzieht und sie entweder mit der Bedeutungstheorie von Carnap und Lewis kombiniert, diese jetzt aber nicht als Beschreibungstheorie auffaßt, oder, wie Hempel es vorschlägt, auf eine Bedeutungstheorie verzichtet. Beide Möglichkeiten führen zu einer Charakterisierung der semantischen Relationen von Sätzen und Theorien, nach der diese semantische realistische Thesen der Form (SR1) erfüllen, sowie auch Thesen der Form (SR2), sofern man in Tarskis semantischen Apparat "natürliche" Übersetzungen der Sätze und Theorien einsetzt. Alle drei Möglichkeiten ergeben Erläuterungen bzw. Ergänzungen einer semantischen realistischen Position, denen zufolge (bestimmte) wissenschaftliche Sätze, Theorien etc. wahr (oder falsch) sind, unabhängig von menschlichen epistemischen Mitteln im Sinne von (UvmeM1) und (UvmeM2), und außerdem wörtlich zu nehmen.

Im Hinblick auf die Argumentation für eine realistische Position sind mit den verschiedenen Theorien verschiedene Vor- und Nachteile verbunden. Wenn man die Bedeutungstheorie von Carnap und Lewis als Beschreibungstheorie auffaßt, hat sie den Prima-facieVorzug, daß das Problem der Unterbestimmtheit nicht auftreten kann, gleichzeitig aber den Prima-facie-Nachteil, daß in ihrem Licht betrachtet der Theorienwandel im Laufe der Wissenschaftsgeschichte zu Referenzinstabilitäten in großem Umfang führt. Tarskis Wahrheitstheorie hat keinen von beiden, ebenso die Bedeutungstheorie von Carnap und Lewis, sofern sie nicht als Beschreibungstheorie aufgefaßt wird. Ob dies ein tatsächlicher Vorzug bzw. ein tatsächlicher Nachteil ist und, falls ja, ein wie gewichtiger, wenn es um die Begründung ontologischer oder epistemischer realistischer Thesen geht, hängt von der jeweils vertretenen Konzeption epistemischer Bestätigung, Rechtfertigung o.ä. ab; zumindest in Kombination mit bestimmten erkenntnistheoretischen Positionen kann es aus realistischer Perspektive ein massiver Vorzug bzw. Nachteil sein.

Gegen die Bedeutungstheorie von Carnap und Lewis lassen sich, neben den genannten, speziell mit der Debatte um realistische Thesen zusammenhängenden Problemen, weitere allgemeinere Kritikpunkte anführen: Sie setzt (in allen Lesarten) voraus, daß man eine Unterscheidung Beobachtungssprache/theoretische Sprache in zufriedenstellender Weise ziehen kann (oder, wenn man die "Rückzugsposition" von Hempel bezieht, 
eine theoriespezifische Unterscheidung vortheoretische/theoretische Sprache). Sie steht (in einer Lesart) im Widerspruch zu der Intuition, daß nicht jeder Theorienwandel mit Bedeutungsänderungen verbunden ist. Und schließlich steht sie (als Beschreibungstheorie aufgefaßt) im Widerspruch zu (allerdings nicht unkontroversen) Intuitionen, denen zufolge ein Sprecher, der einen Ausdruck gebraucht, damit auch dann auf einen Gegenstand referieren kann, wenn er mit diesem Ausdruck falsche Beschreibungen des Gegenstandes assoziiert oder wenn er damit richtige, aber zu wenige Beschreibungen assoziiert. 


\section{Kapitel 3}

\section{Kontexttheorien}

\subsection{Die Idee einer Kontexttheorie und ihre Varianten}

Eine in den 60er Jahren aufgekommene Alternative zu den bedeutungstheoretischen Konzeptionen des logischen Positivismus stellen die häufig unter dem Etikett Kontexttheorie (contextual theory $)^{1}$ zusammengefaßten Ansätze dar. Dabei handelt es sich vielfach weniger um eine systematisch ausgearbeitete Bedeutungstheorie als eher um so etwas wie eine Skizze oder Andeutungen einer Theorie, die sich als Nebenprodukt bei der Diskussion anderer Themen wie Theoriendynamik und wissenschaftlicher Fortschritt ergeben.

Die entscheidende Differenz zu den Bedeutungstheorien des logischen Positivismus liegt darin, daß die dort vorausgesetzte These abgelehnt wird, daß es eine Beobachtungssprache gibt, deren Ausdrücke unabhängig von Theorien und deren theoretischer Sprache verstanden werden können, und daß die Bedeutung der Beobachtungsausdrücke und -sätze keine Theorien, d.h. keine theoretischen Ausdrücke und Sätze, involviert. ${ }^{2}$ Damit wird der für die positivistischen Bedeutungstheorien grundlegende Ansatz angegriffen, daß die Bedeutung theoretischer Ausdrücke durch eine ausgezeichnete Klasse von Ausdrücken, die Beobachtungsausdrücke, (mit)bestimmt wird, ${ }^{3}$ die "theorieneutral" und in epistemischer Hinsicht "unproblematisch" sind.

Die Anhänger der Kontexttheorie sprechen stattdessen von einer sogenannten Theoriebeladenheit der Beobachtung (theory-loadedness of observation). ${ }^{4}$ Sie bezeichnen damit eine Gruppe von verschiedenen, aber verwandten Thesen. Von diesen ist hier die sprachphilosophische These relevant, daß in die Bedeutung "beobachtungsnaher" Ausdrücke und Sätze, die der logische Positivismus als Beobachtungsausdrücke bzw. -sätze klassifiziert, "beobachtungsferne" Ausdrücke und Sätze eingehen, die die Positivisten als theoretisch einstufen. Die Bedeutung beobachtungsnaher Ausdrücke bzw. Sätze und ebenso auch die von beobachtungsfernen Ausdrücken bzw. Sätzen wird demnach durch den "theoretischen Kontext" (mit-)bestimmt, in den sie eingebettet sind, d.h. durch einen Teil der für die Bedeutungsfestlegung relevanten Theorie $(n)^{5}$, nämlich durch die Menge der Sätze, in denen

\footnotetext{
${ }^{1}$ Z.B. [Feye81b], S.74, [Shap89].

${ }^{2}$ Bzw. daß sich wenigstens theorierelative Unterscheidungen von vortheoretischer und theoretischer Sprache in Hempels Sinn ziehen lassen, für die sinngemäß dasselbe gilt. Siehe z.B. [Feye65], S.213ff.

${ }^{3}$ D.h. allein durch Beobachtungsausdrücke, wie bei der Verifikationstheorie, oder durch Beobachtungsausdrücke als wesentliches, aber nicht einziges Element, wie bei der Bedeutungstheorie von Carnap und Lewis.

${ }^{4}$ Der Terminus stammt von Hanson ([Hans58], S.19, 54ff.).

${ }^{5}$ S.u.
} 
der Ausdruck bzw. die den Satz bildenden Ausdrücke auftreten. ${ }^{6}$ Eine Bedeutungstheorie, die diese These implementiert, wird daher als Kontexttheorie der Bedeutung bezeichnet. ${ }^{7}$ Allgemein kann gemäß einer Kontexttheorie natürlich nicht nur der theoretische Kontext eines Ausdrucks in seine Bedeutung eingehen, sondern sein gesamter Kontext, d.h. auch beobachtungsnahe Sätze, in denen er auftritt.

Im Zusammenhang mit der Kontexttheorie werden die Referenz und die Wahrheit von Ausdrücken und Sätzen fast nie explizit thematisiert ${ }^{8}$, die Art und Weise, wie die Anhänger der Kontexttheorie vom Begriff der Bedeutung Gebrauch machen, legt aber in vielen Fällen die Annahme nahe, daß sie die Kontexttheorie implizit als Beschreibungstheorie auffassen. Danach bestimmt also die Bedeutung eines Ausdrucks, in die sein theoretischer Kontext eingeht, seine Referenz ${ }^{9}$ und die Referenz der Ausdrücke, die in einem Satz vorkommen, seinen Wahrheitswert. Denkbar ist aber auch, die Kontexttheorie nicht als Beschreibungstheorie aufzufassen und die Frage nach einer Referenz- bzw. Wahrheitstheorie offen zu lassen.

Unter den Ansätzen zur Formulierung einer Kontexttheorie lassen sich, ziemlich grob, drei Varianten unterscheiden. Sie unterscheiden sich zum einen darin, wie viel vom Kontext eines Ausdrucks als konstitutiv für seine Bedeutung angesehen wird, zum andern dadurch, welcher Status der Bedeutung genau zugeschrieben wird:

- Die erste Variante zeichnet innerhalb des Kontextes eines Ausdrucks einen Teil als bedeutungskonstituierend aus. Faßt man die Kontexttheorie als Beschreibungstheorie auf, dann stellt dieser Teil einen Satz von einzeln notwendigen und zusammen hinreichenden Erfüllungsbedingungen dar, die die Referenz des Ausdrucks bestimmen. ${ }^{10}$ Diese Variante soll hier enge Kontexttheorie heißen.

- In der zweiten, von Putnam vorgeschlagenen Variante konstituiert der gesamte Kontext eines Ausdrucks seine Bedeutung, aber nicht in der Weise, daß, wie Putnam sich ausdrückt, für die "Identität des Begriffes" jedes einzelne Element des Kontextes unverzichtbar wäre. ${ }^{11}$ Auch wenn sich Teile des Kontextes verändern, bleibt nach Putnam die "Identität des Begriffes" gewahrt, solange der überwiegende oder wenigstens ein nennenswerter Teil des Kontextes derselbe bleibt. Faßt man die Kontexttheorie als Referenztheorie auf, dann heißt das, daß die bedeutungskonstituierenden Sätze nicht als Sätze betrachtet werden, die einzeln notwendige und zusammen hinreichende Erfüllungsbedingungen formulieren, sondern als ein Cluster von Bedingungen, der die Referenz des Ausdrucks in der Weise bestimmt, daß für eine Referenzbeziehung im Regelfall ${ }^{12}$ "nur" die Erfüllung einer überwiegenden oder wenigstens einer nennenswerten Zahl der Bedingungen (d.h. nicht aller Bedingungen)

\footnotetext{
${ }^{6}$ Darin, daß dies auch für die beobachtungsnahen Ausdrücke gilt, liegt eine grundlegende Differenz zu den positivistischen Bedeutungstheorien. Dort wurde der theoretische Kontext eines Ausdrucks, zwar nicht in der Verifikationstheorie, aber dann in Carnaps und Lewis' Bedeutungstheorie, als in bestimmter Hinsicht (Stichwort: Carnap-Satz) teilweise bedeutungskonstituierend für theoretische Ausdrücke anerkannt.

${ }^{7}$ Neben der genannten bedeutungstheoretischen These bezeichnet das Stichwort Theoriebeladenheit die erkenntnistheoretische These, daß die epistemische Rechtfertigung von Beobachtungssätzen bzw. vortheoretischen Sätzen Theorien und theoretische Überzeugungen erfordert, sowie weiter kognitionspsychologische u.ä. Thesen über "Erzeugungsbedingungen" von Beobachtungssätzen (vgl. [Hans58]).

${ }^{8}$ Eine Ausnahme stellen Feyerabends Andeutungen in [Feye60a], S.70ff. dar.

${ }^{9}$ Man kann daher auch von einer Kontexttheorie der Referenz sprechen.

${ }^{10}$ Siehe z.B. [Achi68], S.1ff., 101ff.

${ }^{11}$ [Putn75e], S.52.

${ }^{12} \mathrm{Zu}$ dieser Qualifikation s.u.
} 
gefordert wird. Diese von Putnam vor allem für "hochtheoretische" Ausdrücke der Physik vorgeschlagene Version heißt Gesetzesclustertheorie (law cluster theory). ${ }^{13}$

- In der dritten Variante schließlich wird der gesamte Kontext eines Ausdrucks sozusagen ohne Qualifikation oder Einschränkung als bedeutungskonstituierend aufgefaßt. ${ }^{14}$ Faßt man diese Version der Kontexttheorie als Beschreibungstheorie auf, dann stellt der gesamte Kontext eines Ausdrucks einzeln notwendige und zusammen hinreichende Erfüllungsbedingungen dar. Diese Version soll hier weite Kontexttheorie heißen. ${ }^{15}$

Eine zusätzliche Ausdifferenzierung von Varianten der Kontexttheorie bekommt man, wenn man zuläßt, daß bei verschiedenen Typen von Ausdrücken unterschiedlich viel von ihrem Kontext zur Bedeutung zählt. ${ }^{16}$ Weiterhin kann man den Zusammenhang von Bedeutungen und sprachlicher Kompetenz von Sprechern in verschiedener Weise konzipieren: Man kann einerseits die These vertreten, daß ein kompetenter Sprecher die Bedeutung eines Ausdrucks kennen muß, oder andererseits Putnams Idee der linguistischen Arbeitsteilung im Rahmen einer Kontexttheorie implementieren.

Die Anhänger einer Kontexttheorie sind in der Regel der Ansicht, daß für die Festlegung der Bedeutung der Ausdrücke und Sätze eines Sprechers die zu dieser Zeit akzeptierten Theorien relevant sind, daß also die jeweils zeitgenössischen Theorien den bedeutungsbestimmenden Kontext bereitstellen. Denkbar ist aber auch, daß man die Theorien, innerhalb derer ein Ausdruck erstmals eingeführt wurde, als die für die Bedeutungsfestlegung relevanten Theorien betrachtet.

\subsection{Kontexttheorie und semantischer Realismus}

Eine mögliche Rolle, die Bedeutungs-, Referenz- und Wahrheitstheorien für eine realistische Position spielen können, besteht darin, semantische realistische Thesen, die zu dieser Position gehören, zu erläutern oder zu ergänzen, genauer: zu erläutern, inwieweit und in welchem Sinn die Sätze oder Theorien, von denen diese Thesen handeln, wahr (oder falsch) sind, unabhängig von menschlichen epistemischen Mitteln, dies herauszufinden. Die Kontexttheorie verhält sich in diesem Punkt im wesentlichen wie die im vorigen Abschnitt diskutierte Bedeutungstheorie von Carnap und Lewis. ${ }^{17}$

Als Bedeutungstheorie besagt die Kontexttheorie per se nichts über die Wahrheitswerte von Sätzen oder Theorien, wenn man sie nicht als Beschreibungstheorie auffaßt; sie läßt sich dann jedoch durch eine Wahrheitstheorie ergänzen. Dazu kommt Tarskis Korrespondenztheorie in Frage, die die semantischen Relationen von Sätzen und Theorien so

\footnotetext{
${ }^{13}$ Da bei diesen "hochtheoretischen" Ausdrücken im wesentlichen physikalische Gesetze den Kontext bilden; siehe [Putn75e], S.50ff.

${ }^{14}$ Feyerabend redet manchmal sogar so, als ob für die Bedeutung eines Ausdruck aus der gesamten Menge der Sätze der für die Bedeutungsfestlegung relevanten Theorie(n) (s.u.) nicht nur die Sätze, in denen der Ausdruck auftritt, konstitutiv sind, sondern alle Sätze. Die Überlegung dahinter scheint die zu sein, daß, wenn man die "eingeschränkte" Menge als Bedeutung ansehen würde, sich diese Bedeutung eines Ausdrucks sozusagen mittelbar ändert, wenn sich bei einem der weiteren Ausdrücke aus den bedeutungskonstituierenden Sätzen seinerseits die Bedeutung ändert, usw.

${ }^{15}$ Vgl. z.B. [Feye65], S.180, 184, [Feye81b], S.74, [Kuhn70], S.102ff.

${ }^{16}$ Putnam etwa hat seine Gesetzesclustertheorie für hochtheoretische Ausdrücke wie 'Energie' oder 'Elektron' konzipiert, läßt aber gleichzeitig zu, daß andere Ausdrücke (wie 'Junggeselle') evtl. notwendige und zusammen hinreichende Erfüllungsbedingungen haben können; vgl. [Putn75e], s.a. [Achi68].

${ }^{17}$ Sofern bei den Kontexttheorien analytische Sätze auftreten, bleiben diese hier beiseite; vgl. S.46.
} 
charakterisiert, daß diese semantische realistische Thesen der Form (SR1), erläutert durch (UvmeM1) oder (UvmeM2), und auch (SR2) erfüllen, sofern man mit "natürlichen" Übersetzungen der Sätze und Theorien arbeitet. Andererseits scheint es durchaus auch mit dem "Geist" der Kontexttheorien verträglich zu sein und zu den Diskussionszusammenhängen, in denen sie entstanden sind, zu passen, sie durch eine epistemische Wahrheitstheorie zu ergänzen. In diesem Fall bekäme man dann in keinem erkennbaren Sinn Thesen der Form (SR1).

Wenn man die Versionen der Kontexttheorie als Beschreibungstheorien auffaßt, also die von ihr zugeschriebenen Bedeutungen von Ausdrücken als referenzbestimmende Beschreibungen liest, die auch die Wahrheitsbedingungen von Sätzen festlegen, erfüllen Sätze und Theorien in ihrem Anwendungsbereich semantische realistische Thesen der Form (SR1), deren Unabhängigkeitsklauseln durch Aussagen der Form (UvmeM1) und (UvmeM2) erläutert werden können. Dies gilt, ähnlich wie im Fall der Bedeutungstheorie von Carnap und Lewis, auch dann, wenn man eine außerhalb der Kontexttheorie liegende These akzeptiert, die sicherstellt, ${ }^{18}$ daß die Sätze und Theorien im Anwendungsbereich der Kontexttheorie bestätigbar sind. ${ }^{19}$

Bei einer Kontexttheorie gibt es also zwei Lesarten, nach denen die von ihr charakterisierten semantischen Relationen in der Weise unabhängig von menschlichen epistemischen Mitteln sind, wie es durch semantische realistische Thesen formuliert werden soll; es ist aber auch eine Lesart möglich, die in keinem erkennbaren Sinn semantischen Realismus liefert. Den in der Literatur skizzierten Ansätzen zu einer Kontexttheorie läßt sich zu diesem für die Realismusdebatte relevanten Punkt keine klare Auskunft über die Ansichten ihrer Autoren entnehmen. In systematischer Hinsicht ist das Fazit der obigen Überlegungen, daß eine Kontexttheorie zur Erläuterung oder Ergänzung semantischer realistischer Thesen der Form (SR1) dienen kann, wenn man sie als Beschreibungstheorie auffaßt oder in geeigneter Weise mit Tarskis Wahrheitstheorie kombiniert. Sie ist dann auch mit Thesen der Form (SR2) verträglich.

Im Hinblick auf die Argumentation für semantische realistische Thesen, die in dieser Weise erläutert werden, gibt es (mindestens) einen wesentlichen Unterschied zwischen den meisten Versionen der Kontexttheorie und den Bedeutungstheorien des logischen Positivismus: Während die logischen Positivisten sich "nur" mit wissenschaftlichen Ausdrücken und Sätzen beschäftigen, die nicht von Beobachtbarem handeln, also die Frage nach der Bedeutung der Beobachtungsausdrücke und -sätze ausklammern oder dafür jedenfalls nicht dieselbe Bedeutungstheorie vorsehen, sind die (meisten) Versionen der Kontexttheorie gleichermaßen für sämtliche Ausdrücke und Sätze konzipiert, die im Bereich der Wissenschaften und auch des Alltags verwendet werden. Dadurch wird für die Suche nach Argumenten für realistische Thesen eine andere Strategie nahegelegt: Wenn die semantischen realistischen Thesen, die eine realistische Position konstituieren, in derselben Weise und mit Hilfe

\footnotetext{
${ }^{18}$ Eine geeignete Konzeption von epistemischer Bestätigung o.ä. vorausgesetzt; diese Qualifikation bleibt hier wiederum implizit.

${ }^{19}$ Da die Anhänger der Kontexttheorie die positivistische Konzeption einer Beobachtungssprache ablehnen, kann zwar Carnaps Signifikanzkriterium nicht ohne weiteres auf eine Kontexttheorie anwenden. Es ist aber gleichwohl denkbar, daß man analoge Überlegungen für eine Kontexttheorie anstellt und diese Theorie durch die These ergänzt, daß alle wissenschaftlichen Sätze in eine Theorie oder in ein Theoriegebäude eingebettet sind, das ihre Bestätigbarkeit sicherstellt, in der bzw. in dem es also zwar keine Beobachtungssätze im Sinne des logischen Positivismus gibt, aber doch (theoriebeladene) beobachtungsnahe Sätze, die in puncto Bestätigung eine äquivalente Funktion haben. Dies müßten Sätze sein, über deren Wahrheit oder Falschheit empirisch durch (theoriebeladene) Beobachtung, Messung o.ä. entschieden werden kann und die dadurch beobachtungsferne Sätze bestätigen.
} 
derselben Bedeutungs- bzw. Referenztheorie formuliert und erläutert werden, egal ob es um Sätze oder Theorien über Beobachtbares bzw. "Beobachtungsnahes" wie Drähte, Kristalle und Kaninchen oder um Sätze oder Theorien über Unbeobachtbares bzw. "Hochtheoretisches" wie DNA-Stränge, elektrische Felder oder Neutronen geht, dann liegt es nahe zu versuchen, in beiden Bereichen dieselben oder jedenfalls gleichartige Argumente für die semantischen realistischen Thesen ins Feld zu führen. ${ }^{20}$ Wie solche Argumente aussehen sollen, ist damit natürlich noch nicht gesagt, aber man hat so immerhin eine aussichtsreiche "Suchstrategie", denn sofern, wie im Mainstream der wissenschaftstheoretischen Realismusdebatte üblich, ${ }^{21}$ realistische Thesen über den Bereich der beobachtbaren Alltagsgegenstände vorausgesetzt werden, kann man nach deren argumentativer Begründung fragen und versuchen, diese Begründungen auf realistische Thesen über den Bereich des "Hochtheoretischen" zu übertragen. ${ }^{22}$

\subsection{Probleme und Einwände}

Die verschiedenen Versionen der Kontexttheorie unterscheiden sich in grundlegenden Zügen von den Bedeutungstheorien des logischen Positivismus, es gibt aber auch wesentliche Gemeinsamkeiten, und dies spiegelt sich u.a. in den Problemen und Einwänden wieder, mit denen man konfrontiert ist, wenn man eine Kontexttheorie für eine realistische Position verwenden will, also zur Erläuterung semantischer realistischer Thesen oder im Rahmen der Argumentation für realistische Thesen. Die vorne ${ }^{23}$ diskutierten Einwände von Putnam gegen Beschreibungstheorien etwa betreffen auch die in diesem Sinn aufgefaßten Versionen der Kontexttheorie. Die wichtigsten für die Kontexttheorien besonderen Probleme und Einwände sollen im folgenden diskutiert werden.

\subsubsection{Die Abgrenzung des bedeutungskonstituierenden Kontextes eines Ausdrucks}

Auf die Frage, wie zu bestimmen ist, welcher Teil der für die Bedeutungsfestlegung relevanten Theorien genau die Bedeutung eines Ausdrucks konstituiert, finden sich in den Arbeiten der Anhänger einer Kontexttheorie meistens nur mehr oder weniger ungenaue und ausweichende Antworten. Feyerabends Äußerungen zu diesem Punkt etwa laufen meistens darauf hinaus, daß zum bedeutungskonstituierenden Kontext eines Ausdrucks nicht nur eine (bzw. die) Theorie, in der dieser Ausdruck vorkommt, sondern sogar die Gesamtheit aller zum Zeitpunkt der Verwendung des Ausdrucks akzeptierten Theorien und Sätze. ${ }^{24}$ Die einzige Grenze, die Feyerabend anscheinend ziehen will, ist die, daß Überzeugungen von einzelnen Personen, die von allgemein in der Sprachgemeinschaft akzeptierten Meinungen zu weit abweichen, nicht als bedeutungsbestimmend zählen. ${ }^{25}$

Von den Anhängern einer Kontexttheorie äußert sich Achinstein am deutlichsten zu dieser Frage. Er faßt die Kontexttheorie als Beschreibungstheorie auf und meint, daß sich

\footnotetext{
${ }^{20}$ Vgl. Kap.1.4.2. S.a. [Feye60a].

${ }^{21}$ Siehe Kap.1.4.3.

${ }^{22}$ Die in Fn.7 erwähnte erkenntnistheoretische These, die mit dem Stichwort Theoriebeladenheit der Beobachtung verbunden wird, legt eine analoge Strategie auch für die Suche nach epistemischen Argumenten für ontologische oder epistemische realistische Thesen nahe.

${ }^{23}$ Abschnitt 2.6.6.

${ }^{24}$ Siehe [Feye81b], S.74.

${ }^{25}$ Siehe z.B. [Feye60b], S.249f.
} 
bei jedem Ausdruck, auch bei jedem wissenschaftlichen, im Prinzip durch empirische Untersuchungen bedeutungsbestimmende Erfüllungsbedingungen feststellen lassen. Man muß dazu das Sprachverhalten von Sprechern bzw. Sprachgemeinschaften daraufhin ansehen, welche Merkmale einer Entität sie zur Anwendung bzw. Nichtanwendung eines Ausdrucks veranlassen, und weiterhin durch Fragen herausbekommen, wie sie den Ausdruck in kontrafaktischen Situationen verwenden würden. Es geht dabei nicht darum, eine exakte Beschreibung des Sprachverhaltens zu gewinnen, sondern die von dem Sprecher bzw. der Sprachgemeinschaft akzeptierten Erfüllungsbedingungen des Ausdrucks empirisch festzustellen. ${ }^{26}$ Dabei ist nach Achinstein als Ergebnis zu erwarten, daß die "Weite" des bedeutungskonstituierenden Kontextes eines Ausdrucks von Fall zu Fall oder bei verschiedenen Gruppen von Ausdrücken deutlich variiert. Im Hinblick auf die These der Theoriebeladenheit der Beobachtungssprache bedeutet das, daß man sie weder generell zurückweist, noch in der pauschalen Form akzeptiert, wie sie die Anhänger der weiten Kontexttheorie formulieren, sondern ihre Gültigkeit und Reichweite Ausdruck für Ausdruck durch die Untersuchung des Sprachverhaltens von Sprechern prüft; es lassen sich aber vielleicht einigermaßen plausible Vermutungen anstellen, wie das Resultat solcher Untersuchungen in etwa ausfallen dürfte: Unter den beobachtungsnahen Ausdrücken dürfte man einige finden, die in keiner nennenswerten Weise theoriebeladen sind ('rot', 'dreieckig' u.ä.), dagegen auch viele, die stark theoriebeladen sind ('Halogenlampe', 'Röntgenbild' u.ä.). Weiterhin ist zu erwarten, daß sich unter den theoriebeladenen Ausdrücken solche finden, deren Theorieabhängigkeit sich auf eine oder wenige Theorien oder mehr oder weniger große Teile von Theorien beschränkt ('Lupe', 'Komet' u.ä.), so daß sie relativ zu anderen Theorien als vortheoretisch in Hempels Sinn gelten können, während bei anderen die Bedeutung kaum oder gar nicht in dieser Weise "beschränkt" ist ('Energie', 'Typ-II-Supraleiter' u.ä.).

Darin, daß sie einerseits die positivistische Konzeption einer Beobachtungssprache fallenlassen, aber gleichzeitig die Möglichkeit offen halten, daß es, wie die meisten intuitiv annehmen, Ausdrücke (wie 'rot') gibt, deren Bedeutung in keiner nennenswerten Weise theoriebeladen ist, liegt prima facie ein Vorzug enger Kontexttheorien wie der von Achinstein. $^{27}$

Ein mögliches Problem, das mit Achinsteins Vorschlag zur Abgrenzung des bedeutungskonstituierenden Kontextes eines Ausdrucks und allgemein mit jeder als Beschreibungstheorie aufgefaßten engen Kontexttheorie verbunden ist, teilen diese mit der Bedeutungstheorie von Carnap und Lewis: Eine innerhalb der für die Bedeutung eines Ausdrucks relevanten Theorie(n) gezogene Grenze zwischen dem bedeutungskonstituierenden Teil und dem Rest läuft auf eine Unterscheidung von analytischen und synthetischen Sätzen hinaus und ist damit den Einwänden ausgesetzt, die gegen diese Unterscheidung gerichtet sind. ${ }^{28}$ Für eine weite Kontexttheorie kann dieses Problem nicht auftreten.

Inwieweit dieses Problem für die Gesetzesclustertheorie auftritt, hängt davon ab, ob man sie als Referenztheorie auffaßt oder nicht: Wenn die Erfüllung eines überwiegenden oder wenigstens eines nennenswerten Teiles des mit einem Ausdruck assoziierten Gesetzes-

\footnotetext{
${ }^{26}$ Siehe [Achi68], S.10ff. Achinsteins Vorstellungen scheinen im wesentlichen mit den von Carnap in [Carn56c] skizzierten (s.a. Fn.38) übereinzustimmen.

${ }^{27}$ Die gegen diese Intuition gerichteten Einwände, die sich bei Feyerabend und Hanson finden, setzen bereits voraus, daß sich keinerlei Unterscheidung treffen läßt zwischen der Bedeutung eines Ausdrucks und (nicht bedeutungskonstitutiven) Überzeugung jedweder Art, insbesondere Überzeugungen, von denen die Anwendung oder Rechtfertigung der Anwendung eines Ausdrucks in einer konkreten Situation abhängt (etwa Überzeugungen über meine Verläßlichkeit als Beobachter unter bestimmten Bedingungen und das Vorliegen dieser Bedingungen).

${ }^{28}$ Siehe Abschnitt 2.6.3.
} 
clusters eine hinreichende und notwendige Bedingung dafür darstellt, daß eine Entität zur Extension des Ausdrucks zählt, dann bekommt man durch diese Mindestbedingungen ${ }^{29}$ analytische Sätze. Wenn man die Gesetzesclustertheorie nicht als Referenztheorie auffaßt, dann ist sie frei von der Unterscheidung analytisch/synthetisch und etwaigen damit verbundenen Problemen. Putnam selbst faßt die Gesetzesclustertheorie im letzteren Sinn auf und läßt (in seiner diesbezüglichen Arbeit) die Frage der Referenzbestimmung offen. ${ }^{30}$

\subsubsection{Veränderungen von Bedeutung und Referenz}

Bei der Bedeutungstheorie von Carnaps und Lewis war aufgrund ihres holistischen Charakters das Problem aufgetreten, daß sie, wenn man sie auf zwei sehr ähnliche Theorien anwendet (z.B. auf zwei, von denen die eine durch geringfügige Modifikationen aus der anderen hervorgegangen ist), verschiedene Bedeutungen für deren theoretische Ausdrücke liefert. Wenn man die These vertritt, daß die Bedeutung eines Ausdrucks durch die Theorie(n) bestimmt wird, die der jeweilige Sprecher zum jeweiligen Zeitpunkt akzeptiert, dann hat das zur Folge, daß praktisch jede Modifikation einer Theorie aus dem Gesamtbestand der zu einem Zeitpunkt akzeptierten Theorien dazu führt, daß sich die Bedeutung aller theoretischen Ausdrücke dieser Theorie ändert. Wenn man die Theorie von Carnap und Lewis als Beschreibungstheorie auffaßt, zog ihr holistische Charakter weiterhin die Konsequenz nach sich, daß in Fällen von Theorienwandel praktisch nie von stabiler Referenz der theoretischen Ausdrücke über die Veränderung der Theorie hinweg die Rede sein kann. Dadurch werden vortheoretische Intuitionen, die viele über die Bedeutung und Referenz von Ausdrücken haben, verletzt. Soweit die verschiedenen Versionen der Kontexttheorie ebenfalls holistischen Charakter haben, treten bei ihnen dieselben Probleme auf, und sie können dies sogar in bestimmter Hinsicht noch verstärkt tun, insofern bei einer Kontexttheorie die bei Theorienwandel invariante "Basis" der Beobachtungsausdrücke und -sätze fehlt.

In welchem Ausmaß theoretischer Wandel im Lichte einer Kontexttheorie betrachtet zu Bedeutungsveränderungen und zu Referenzinstabilitäten führt, hängt von der "Weite" der bedeutungskonstituierenden Kontexte ab. Bei einer engen Kontexttheorie brauchen kleinere Theoriemodifikationen nicht viele oder überhaupt neue Bedeutungen mit sich zu bringen, bei einer weiten Kontexttheorie hat jeder noch so geringfügige theoretische Wandel einige neue Bedeutungen zur Folge und Veränderungen an den zentralen Aussagen einer Theorie wirken sich i.a. in der gesamten Theorie bzw. im ganzen Theoriegebäude auf die Bedeutungen aus. Letzteres gilt auch für Putnams Gesetzesclustertheorie, nach Putnam ist dies jedoch kein Problem, da die "Identität der Begriffe" gewahrt bleibt. Entsprechend brauchen mit einer kleineren Theoriemodifikation bei einer engen Kontexttheorie und auch bei einer Gesetzesclustertheorie, wenn man sie als Referenztheorie auffaßt, nicht viele oder überhaupt irgendwelche Referenzinstabilitäten einherzugehen, bei einer weiten Kontexttheorie dagegen führt praktisch jeder theoretische Wandel zu mehr oder weniger weitreichenden Referenzinstabilitäten. All dies betrifft bei einer Kontexttheorie, anders als bei der Bedeutungstheorie von Carnap und Lewis, i.a. auch beobachtungsnahe Ausdrücke und Sätze.

\footnotetext{
${ }^{29}$ Auch wenn sie noch so schwach sind, etwa: Wenigstens die Hälfte der Gesetze, 10\% der Gesetze, ein Gesetz aus dem Cluster o.ä. muß erfüllt sein.

${ }^{30}$ Obwohl der Text in [Putn75e] nicht spannungsfrei zu sein scheint; vgl. auch [Putn90b], S.59, [Putn90c], S.290. Diese Theorie stellt in Putnams Euvre jedenfalls nur eine Zwischenstation auf dem Weg zur kausalen Referenztheorie dar.
} 
Im Hinblick auf die Einsetzbarkeit einer Kontexttheorie zur Erläuterung oder argumentativen Begründung einer realistischen Position gilt für Bedeutungsveränderungen und Referenzinstabilitäten im wesentlichen dasselbe wie im Fall der Bedeutungstheorie von Carnap und Lewis: Per se steht keins der beiden Phänomene im Widerspruch zu ontologischen, semantischen oder epistemischen realistischen Thesen. Wenn man Referenzinstabilitäten als gängiges Phänomen anerkennt, hat das aber die Konsequenz, daß man in epistemischer Hinsicht von der bisherigen Wissenschaftsgeschichte im wesentlichen das Bild von Serien völliger Fehlschläge bekommt, und dies kann (muß aber nicht), je nach erkenntnistheoretischer Position, massive Auswirkungen für die epistemische Beurteilung aktueller wissenschaftlicher Theorien, Modelle etc. haben, also auch für die Beurteilung ontologischer und epistemischer realistischer Thesen.

\subsubsection{Inkommensurabilitätsprobleme}

Im Zusammenhang mit der Kontexttheorie wird in der Literatur ein Bündel von Thesen diskutiert, die eine Reihe "familienähnlicher" Sachverhalte zum Inhalt haben, für die die Bezeichnung Inkommensurabilität gebräuchlich ist. Grundlage dieser Thesen ist das im vorigen Abschnitt diskutierte Problem der Bedeutungsveränderungen zusammen mit der Ablehnung der Konzeption einer theorieneutralen Beobachtungssprache.

Zwei Theorien werden dann als inkommensurabel bezeichnet, wenn sie bzw. die Ausdrücke der Sprache, in der sie formuliert sind, (mindestens teilweise) nicht in die Sprache der jeweils anderen Theorie übersetzbar sind oder wenn die beiden Theorien (mindestens teilweise) hinsichtlich ihres Gehaltes nicht vergleichbar sind. ${ }^{31}$

Wenn man eine Kontexttheorie vertritt und außerdem die (zumindest prima facie) plausible These akzeptiert, daß ein Ausdruck bzw. ein Satz dann nicht in eine andere Sprache übersetzbar ist, wenn es dort keinen bedeutungsgleichen Ausdruck bzw. Satz gibt, gelangt man für viele Paare von Theorien, die man intuitiv als (mehr oder weniger) verschiedene Theorien über denselben Gegenstands- oder Phänomenbereich bezeichnen würde, zu dem Schluß, daß diese Theorien inkommensurabel sind: Wie im vorigen Abschnitt diskutiert, führt eine Kontexttheorie, zusammen mit der These, daß für die Bedeutung eines Ausdrucks die zum jeweiligen Zeitpunkt akzeptierten Theorien relevant sind, dazu, daß Veränderungen im Bestand der akzeptierten Theorien i.a. Bedeutungsveränderungen mit sich bringen, und zwar je nach Variante der Kontexttheorie und je nach Umfang des Theorienwandels mehr oder weniger viele. Wenn Bedeutungsunterschiede Unübersetzbarkeit implizieren, heißt das also, daß aufeinanderfolgende Theorien, die intuitiv gesprochen denselben Gegenstandsbereich haben, i.a. inkommensurabel sind. Hinsichtlich ihres Gehaltes können sie zumindest insofern nicht verglichen werden, als zwei Theorien, die nicht beide in einer Sprache formuliert werden können, nicht in logischen Relationen zueinander stehen, d.h. sich nicht widersprechen können, auseinander ableitbar sein können usw., und insofern es bei zwei unübersetzbaren Theorien auch nicht möglich ist, die Sprache der einen als Metasprache zu benutzen, um der (ganzen) anderen Theorie mittels Tarskis semantischem Apparat Referenzentitäten und Wahrheitsbedingungen zuzuordnen.

Dadurch, daß die Versionen der Kontexttheorie i.a. zulassen, daß in die Bedeutung beobachtungsnaher Ausdrücke und Sätze hochtheoretische Sätze bzw. Theorien eingehen, ist auch eine noch stärkere und spektakulärere Form von Inkommensurabilität zweier Theorien möglich: Es ist denkbar (und insbesondere wenn man eine weite Kontexttheo-

\footnotetext{
${ }^{31}$ Für diese und andere Verwendungsweisen siehe z.B. [Hack83a], Kap.5. Eine luzide Analyse der verschiedenen Verwendungsweisen des Inkommensurabilitätsbegriffs bei Kuhn findet sich in [Hoyn93], Kap.6.3.
} 
rie voraussetzt, nicht unplausibel), daß gar nichts von der Sprache der einen Theorie in die Sprache der anderen übersetzbar ist, nicht einmal beobachtungsnahe Ausdrücke und Sätze. Solche Theorien können dann hinsichtlich ihres Gehaltes noch nicht einmal in dem schwachen Sinn verglichen werden, daß aus ihnen ableitbare beobachtungsnahe Sätze übereinstimmen oder sich widersprechen können o.ä. oder daß wenigstens einem beobachtungsnahen Teil der einen Sprache mittels Tarskis semantischem Apparat und der anderen Sprache als Metasprache Referenzentitäten und Wahrheitsbedingungen zugeordnet werden können. Da die Kontexttheorien keine theorieneutrale Beobachtungssprache kennen, scheint es also möglich zu sein, daß zwei Theorien, die intuitiv gesprochen vom selben Gegenstandsbereich handeln, hinsichtlich der Bedeutung und Referenz ihrer Sprachen sozusagen völlig beziehungslos nebeneinanderstehen und keinerlei Basis für einen Vergleich der Theorien existiert.

Die These, daß wissenschaftliche Theorien, insbesondere zeitlich aufeinanderfolgende Theorien, inkommensurabel sein können und es in vielen Fällen tatsächlich sind, ist vielfach als mit realistischen Positionen unverträglich oder zumindest für sie bedrohlich wahrgenommen worden. ${ }^{32}$ Bei genauerem Hinsehen ist jedoch schwer zu erkennen, wodurch diese Wahrnehmung gerechtfertigt sein sollte, denn wenn man sich konkrete ontologische, semantische oder epistemische realistische Thesen ansieht, ist offensichtlich, daß diese in keinerlei Widerspruch oder Spannungsverhältnis zu einer These stehen, daß zwei (oder mehr) Theorien inkommensurabel sind.

Bei ontologischen realistischen Thesen ist das schon deshalb klar, weil sie von Elektronen, Genen, Magnetfeldern o.ä. und deren Eigenschaften handeln, eine Inkommensurabilitätsthese dagegen von Theorien und deren Eigenschaften, also von völlig verschiedenen Dingen. ${ }^{33}$

\footnotetext{
${ }^{32}$ Vgl. z.B. [Hack83a], Kap.5.

${ }^{33}$ Man könnte an dieser Stelle vielleicht einwenden, daß sich ein Spannungsverhältnis darin zeigt, daß eine realistische Position natürlich mehrere ontologische realistische Thesen der Form (OR) einschließen kann und damit auch mehrere solche Thesen, die inkommensurablen Theorien entstammen und sich schon deshalb nicht widersprechen können. (Die ontologischen realistischen Thesen würden dann in verschiedenen Sprachen formuliert, die der Anhänger dieser realistischen Position beide beherrschen müßte, ohne sie ineinander übersetzen zu können, aber dagegen ist prinzipiell nichts einzuwenden.) Es ist also auch nicht ausgeschlossen, daß eine realistische Position zwei ontologische realistische Thesen einschließt, die zwei inkommensurablen Theorien entstammen, die, intuitiv gesprochen, denselben Gegenstandsbereich haben und von denen eine historisch die andere abgelöst hat (z.B. die Quantenmechanik und Lorentz' Theorie des Elektrons), wobei die der ersten entstammende These verworfen wurde. Eine solche Position sieht aber klarerweise unplausibel aus; ein Spannungsverhältnis scheint zwar nicht zwischen der These, daß zwei Theorien inkommensurabel sind, und einzelnen ontologischen realistischen Thesen zu bestehen, aber doch zwischen ersterer und einer Gesamtheit von ontologischen realistischen Thesen, die beiden Theorien entstammen.

Auf den zweiten Blick jedoch steht auch die Gesamtheit von ontologischen realistischen Thesen nicht zu der Inkommensurabilitätsaussage in einem Spannungsverhältnis, sondern zu der Intuition, daß die beiden Theorien denselben Gegenstandsbereich haben. Das Kombinieren ontologischer realistischer Thesen, die inkommensurablen Theorien entstammen (und sich schon von daher nicht widersprechen können), ist per se kein Problem, wie man sich an Beispielen klarmachen kann, in denen die Theorien, intuitiv gesprochen, verschiedene Gegenstandsbereiche haben (z.B. Evolutionstheorie und Quantenelektrodynamik). Ein Problem wie in dem oben skizzierten Beispiel entsteht nur, wenn eine Intuition im Spiel ist, daß es um denselben Gegenstandsbereich geht, und zwar in einer Weise, daß nicht beide Theorien wahr sein können, also offenbar eine spezielle, an den jeweiligen konkreten Fall geknüpfte Intuition über die Referenz der beiden Theorien und speziell der beiden fraglichen ontologischen realistischen Thesen, und damit eine Intuition über die Übersetzbarkeit zumindest von Teilen der Theorien in eine weitere Sprache (siehe Fn.35): Diese Intuition impliziert dann, daß zumindest spezielle Konsequenzen der fraglichen Thesen in eine dritte Sprache übersetzbar sind und sich dort widersprechen. Ein Problem entsteht also nicht durch die Kombination inkommensurabler Thesen, sondern durch die Kombination von Thesen, die nicht völlig inkommensura-
} 
Bei semantischen realistischen Thesen der Form (SR1) könnte man vielleicht ein Problem sehen, wenn man mit Hilfe von Tarskis Wahrheitstheorie erläutern will, in welchem Sinne die semantischen Relationen einer Theorie unabhängig von menschlichen epistemischen Mitteln sind, denn um einer Theorie Referenzentitäten und Wahrheitsbedingungen zuzuschreiben, muß man ihre Ausdrücke und Sätze nach Tarski in eine Metasprache übersetzen können. Auf den zweiten Blick liegt hier jedoch ebenfalls kein Problem vor, denn nach Tarski ist keine Übersetzung in die Sprache einer anderen Theorie oder in eine theorieneutrale Sprache o.ä. gefordert, sondern eine Sprache kann (im wesentlichen) als ihre eigene Metasprache fungieren. Ein Realist, der die Sprache einer Theorie beherrscht, kann also für sie eine semantische realistische These formulieren und erläutern, ohne die Theorie in eine andere Sprache zu übersetzen, und ein Realist der die Sprachen zweier inkommensurabler Theorien beherrscht (ohne sie ineinander übersetzen zu können), kann auch für beide Theorien semantische realistische Thesen formulieren und mit Hilfe von Tarskis Wahrheitstheorie erläutern. ${ }^{34}$ Für epistemische realistische Thesen gilt Entsprechendes.

Eine Bedrohung für realistische Positionen stellt eine Inkommensurabilitätsaussage am ehesten im Hinblick auf die epistemische Rechtfertigung ontologischer oder epistemischer realistischer Thesen dar: Es scheint grundsätzlich plausibel (wenn auch im einzelnen abhängig davon, welche Theorie der Bestätigung, der epistemischen Rechtfertigung o.ä. man vertritt), daß die Inkommensurabilität zweier Theorien möglicherweise dazu führen könnte, daß keine von ihnen (bzw. daraus entnommene Aussagen) als epistemisch hinreichend gerechtfertigt gelten kann, um eine entsprechende ontologische oder epistemische realistische These zu akzeptieren. Dies gilt jedoch nur für Fälle, in denen die beiden Theorien oder wenigstens Teile von ihnen in irgendeiner Form einen gemeinsamen Gegenstand haben: Für (inkommensurable) Theorien, bei denen das nicht so ist (z.B. Evolutionstheorie und Quantenelektrodynamik) ist nicht zu sehen, wieso der epistemische Status der einen in irgendeiner Weise von dem der anderen abhängen sollte. Wenn dagegen wenigstens Teile der beiden Theorien (etwa beobachtungsnahe) dieselbe Referenz haben, ${ }^{35}$ ist grundsätzlich plausibel, daß der epistemische Status der beiden Theorien voneinander abhängen kann, obwohl sie (teilweise) inkommensurabel sind. ${ }^{36}$ Wie häufig Fälle inkommensurabler

bel sind und sich daher widersprechen können (und tatsächlich widersprechen). Probleme dieser Art, daß ontologische realistische Thesen oder ihre Konsequenzen (und andere Überzeugungen) sich widersprechen können, können tatsächlich bei der Kombination von ontologischen realistischen Thesen auftreten, aber das ist natürlich immer so, egal ob diese Thesen (teilweise) inkommensurablen Theorien entstammen oder nicht.

${ }^{34}$ Wenn es um zwei Theorien geht, von denen im Verlauf der Wissenschaftsgeschichte die eine die andere abgelöst hat, wird man als Realist höchstens von einer davon überzeugt sein. Man muß also, wenn jemand die Sprachen zweier inkommensurabler Theorien beherrscht, die These aufgeben, daß für die Festlegung der Bedeutung der Ausdrücke und Sätze eines Sprechers die zu dieser Zeit akzeptierten Theorien relevant sind, und statt dessen zumindest die eine der beiden Theorien als relevant für die Bedeutungsfestlegung der zugehörigen Sprache betrachten, obwohl sie nicht (mehr) zu den akzeptierten Theorien zählt.

Die Idee, daß ein Sprecher zwei zu inkommensurablen Theorien gehörende Sprachen beherrschen kann, findet sich in [Leed97].

${ }^{35}$ Gemeinsame Referenz ist im Prinzip verträglich mit wechselseitiger Unübersetzbarkeit, auch wenn man eine Kontexttheorie als Beschreibungstheorie auffaßt, (wenn nicht, ohnehin); sie impliziert jedoch, daß beide Theorien (teilweise) in eine dritte Sprache übersetzbar sind, eben in die, in der man die gemeinsame Referenz feststellt. (Dies muß natürlich keine gegenüber allen Theorien neutrale Beobachtungssprache im Sinne des logischen Positivismus sein, und es muß auch keine "Term-für-Term-Übersetzung" sein, d.h. keine, bei der einem objektsprachlichen Ausdruck stets (unabhängig vom Zusammenhang, in dem er auftritt, etc.) ein Ausdruck als Übersetzung zugeordnet wird.) Die Ansicht zu vertreten, daß zwei inkommensurable Theorien nicht einmal teilweise in eine dritte Sprache übersetzbar sind, und gleichzeitig an der Intuition festzuhalten, daß die beiden Theorien einen gemeinsamen Gegenstand haben, wäre offenbar inkohärent.

${ }^{36}$ Dies ist sozusagen ein Nachfolgeproblem zur Unterbestimmtheitsproblematik, wenn es keine Grenze 
Theorien mit (teilweise) gemeinsamer Referenz vorkommen, hängt von der Variante der Kontexttheorie ab: Bei einer als Beschreibungstheorie aufgefaßten Kontexttheorie dürften sie, wie die Diskussion von Referenzinstabilitäten im vorigen Abschnitt gezeigt hat, selten sein, wenn es eine weite, weniger selten, wenn es eine enge Kontexttheorie ist; bei einer nicht als Beschreibungstheorie aufgefaßten Kontexttheorie hängt alles von der damit kombinierten Referenztheorie ab. Von dieser Art von Fällen von Inkommensurabilität scheint jedenfalls, soweit sie vorkommen, am ehesten eine Bedrohung für realistische Positionen auszugehen.

Ob und, wenn ja, inwieweit das mit einer Kontexttheorie verbundene Problem der Inkommensurabilität auf diese Weise tatsächlich in epistemischer Hinsicht einen gewichtigen Einwand gegen eine realistische Position darstellt, hängt zum einen von der damit verbundenen Konzeption von Bestätigung, Rechtfertigung o.ä. ab, zum anderen davon, wie weit in den konkreten Fällen die Übereinstimmungen der Referenz reichen und ob diese nicht in epistemischer Hinsicht zu einer hinreichend begründeten Entscheidung zwischen den jeweiligen (inkommensurablen) Theorien ausreichen. Eine Antwort auf diese Frage läßt sich also nicht ohne Detailuntersuchungen in Einzelfällen geben, es scheint aber jedenfalls nicht offensichtlich, daß sich in der Wissenschaftsgeschichte nennenswert viele Fälle inkommensurabler Theorien finden lassen, die teilweise gemeinsame Referenz haben, aber dennoch so wenig, daß sich deswegen ontologische oder epistemische realistische Thesen nicht hinreichend begründen lassen.

Daß die Inkommensurabilitäten wissenschaftlicher Theorien, die sich aus der Perspektive einer Kontexttheorie ergeben, für eine realistische Position Probleme epistemischer Art mit sich bringen, ist also nicht generell ausgeschlossen; dies muß, je nach Version der Kontexttheorie und je nach erkenntnistheoretischem Standpunkt, in Einzelfällen geprüft werden; ansonsten stellen Inkommensurabilitäten, anders als gelegentlich angenommen, kein grundsätzliches Hindernis für realistische Positionen dar.

\subsection{Fazit}

Kontexttheorien gibt es in verschiedenen Versionen, u.a. lassen sich enge Kontexttheorien, weite Kontexttheorien und Gesetzesclustertheorien unterscheiden.

Kontexttheorien bieten, genau wie die Bedeutungstheorie von Carnap und Lewis, zwei Möglichkeiten zur Erläuterung oder Ergänzung semantischer realistischer Thesen und damit des Inhalts einer realistischen Position: Wenn man eine Kontexttheorie nicht als Beschreibungstheorie auffaßt, kann man sie durch Tarskis Korrespondenztheorie ergänzen und so eine Charakterisierung semantischer Eigenschaften und Relationen gewinnen, der zufolge die Sätze und Theorien aus dem Anwendungsbereich der Kontexttheorie Thesen der Form (SR1) erfüllen. Wenn man eine Kontexttheorie als Beschreibungstheorie auffaßt, liefert sie ebenfalls eine geeignete Erläuterung oder Ergänzung für Thesen der Form (SR1). Ein Satz, für den eine in einer dieser beiden Weisen aufgefaßte bzw. ergänzte Kontexttheorie gilt, ist dann wahr oder falsch, unabhängig von menschlichen epistemischen Mitteln zum Erkennen dieses Wahrheitswertes, wie es (SR1), erläutert durch (UvmeM1) und (UvmeM2), vorsieht. Mit Thesen der Form (SR2) sind die Kontexttheorien ebenfalls verträglich.

Im Hinblick auf die Argumentation für eine realistische Position haben die Kontexttheo-

zwischen Beobachtungssprache und theoretischer Sprache mehr gibt, wie noch bei den logischen Positivisten. 
rien, wenn man sie als Beschreibungstheorie auffaßt, wie die Bedeutungstheorie von Carnap und Lewis, den Prima-facie-Nachteil, daß der Theorienwandel im Laufe der Geschichte der Wissenschaften in ihrem Lichte betrachtet Referenzinstabilitäten mit sich bringt. Solche Referenzinstabilitäten sind bei den drei Arten von Kontexttheorien in unterschiedlichem Ausmaß zu erwarten, nämlich umso mehr, je weiter die bedeutungskonstitutiven Kontexte konzipiert werden. Wenn man die Kontexttheorien nicht als Beschreibungstheorien auffaßt, haben sie diesen Nachteil nicht. Die Kontexttheorien haben ferner, anders als die positivistischen Bedeutungstheorien, den Prima-facie-Nachteil, daß sie in vielen Fällen die Inkommensurabilität von Theorien mit sich bringen, was zu Problemen bei der epistemischen Begründung realistischer Thesen führen kann. Ob dies tatsächliche Nachteile sind und, falls ja, wie schwer sie wiegen, wenn es um die Begründung einer realistischen Position geht, hängt von der jeweils vertretenen Konzeption von epistemischer Bestätigung, Rechtfertigung o.ä. ab; zumindest in Kombination mit bestimmten erkenntnistheoretischen Positionen können dies aus realistischer Perspektive massive Nachteile sein, insbesondere für weite Kontexttheorien.

Außer diesen beiden speziell die Argumentation für realistische Positionen betreffenden Punkten sprechen einige allgemeine Einwände gegen die Kontexttheorien: Das Problem der Abgrenzung der bedeutungskonstituierenden Kontexte ist (zumindest noch) nicht in zufriedenstellender Weise gelöst. Zumindest die weite Kontexttheorie steht (in einer Lesart) im Widerspruch zu der Intuition, daß nicht jeder Theorienwandel mit Bedeutungsänderungen verbunden ist. Als Beschreibungstheorie aufgefaßt stehen die Kontexttheorien im Widerspruch zu den von Putnam genannten Intuitionen, daß ein Sprecher, der einen Ausdruck gebraucht, damit auch dann auf einen Gegenstand referieren kann, wenn er mit diesem Ausdruck falsche Beschreibungen des Gegenstandes assoziiert oder wenn er damit richtige, aber zu wenige Beschreibungen assoziiert. 


\section{Kapitel 4}

\section{Kausale Referenz- und Bedeutungstheorien}

Die kausale Theorie der Referenz, die von Saul Kripke entworfen wurde,${ }^{1}$ ist die wichtigste Alternative zu den Beschreibungstheorien der Referenz, die bisher vorgestellt wurden. Hilary Putnam hat eine daran anschließende Bedeutungstheorie entwickelt. ${ }^{2}$

\subsection{Kripkes kausale Theorie der Referenz}

\subsubsection{Eigennamen}

Da die kausale Theorie der Referenz in erster Linie als Theorie der Eigennamen konzipiert wurde und erst danach (in etwas modifizierter Form) auf Ausdrücke übertragen wurde, die für natürliche Arten und für physikalische Größen stehen, soll hier zunächst diese Theorie der Namen kurz skizziert werden.

Kripke geht aus von einer Kritik an allen Beschreibungstheorien, also den Theorien, nach denen die Referenz eines Namens durch Beschreibungen des Namensträgers ${ }^{3}$ festgelegt wird, ${ }^{4}$ und entwickelt aus seiner Kritik heraus folgendes Modell für den Zusammenhang von Eigennamen und ihrer Referenz: ${ }^{5}$

1. Die Referenz eines Namens wird festgelegt, indem der Name bei einer ursprünglichen Taufe eingeführt wird. ${ }^{6}$ Diese Taufe kann ostensiv, also durch Hinweis, erfolgen, wie es tatsächlich bei der Taufe von Kindern getan wird, sie kann aber auch mittels einer definiten Beschreibung vorgenommen werden. Als Beispiel für die letztere Möglichkeit nennt Kripke die Taufe des (zu dem Zeitpunkt noch nicht beobachteten) Planeten Neptun durch die Beschreibung 'der Planet, der die und die Störungen in den Umlaufbahnen der anderen Planeten verursacht'. ${ }^{7}$ Falls die Taufe mittels einer

\footnotetext{
${ }^{1}[$ Krip71, Krip80].

${ }^{2}$ [Putn75h, Putn75i]; s.a. [Putn75f, Putn75g, Putn75j, Putn88, Putn90b].

${ }^{3}$ Eine, mehrere oder einen ganzen Cluster von beschreibenden Eigenschaften.

${ }^{4}$ Diese Kritik kann hier nicht diskutiert werden; vgl. dazu [Evan82, Krip80, McCu89].

${ }^{5}$ Der Ausdruck 'Modell' steht hier, um anzudeuten, daß weniger als eine Theorie gemeint ist. Kripke selbst beansprucht ausdrücklich nicht, eine einigermaßen vollständige, zufriedenstellende Theorie der Referenz vorgelegt zu haben. Er spricht von einem "Bild", das vielleicht zu einer Theorie ausgebaut werden kann; vgl. [Krip80], S.93f.

${ }^{6}$ [Krip80], S.91ff., 96f.

${ }^{7}$ [Krip80], S.79.
} 
Beschreibung erfolgt, werden die in dieser Beschreibung erwähnten Eigenschaften dadurch nicht Teil einer Bedeutung des Namens, die die Referenz bestimmt, d.h. die Zuschreibung dieser Eigenschaften an das getaufte Objekt liefert keine analytischen Sätze. ${ }^{8}$ Eine Bedeutung im Sinne einer Beschreibungstheorie haben Namen nicht.

2. Der Name wird dann von den an der Taufe beteiligten Personen in der Kommunikation mit den anderen Mitgliedern der Sprachgemeinschaft weitergegeben. Ein Sprecher in dieser Sprachgemeinschaft, der den Namen irgendwann verwendet, referiert damit auf das getaufte Objekt, wenn eine kausale Kette der Weitergabe des Namens besteht, die in der Taufsituation beginnt und bei ihm, dem Sprecher, endet. Außerdem muß nach Kripke jeder "Empfänger" des Namens in der kausalen Kette den Namen mit der Absicht weiterverwenden, sich auf denselben Referenzgegenstand zu beziehen wie derjenige, von dem er ihn übernommen hat. ${ }^{9}$

Nach Kripke haben Namen keine Bedeutung im Sinne einer Beschreibungstheorie und sie brauchen auch keine, um ihre Funktion zu erfüllen: Ihre Referenz ist nicht durch eine Beschreibung, durch Erfüllungsbedingungen für den jeweiligen Namen bestimmt, sondern durch den Taufakt und die kausale Kette der Weitergabe. Die Beschreibungen, die ein Sprecher mit dem Namen assoziiert, sprich: die Eigenschaften, die er dem Namensträger zuschreibt, sind irrelevant für die Bestimmung der Referenz. Der Sprecher kann sich also über alle Eigenschaften des Referenzgegenstandes irren, ohne daß die Referenzbeziehung zwischen dem Namen und dem bezeichneten Gegenstand beeinträchtigt wird und ohne daß der Sprecher den Namen deswegen nicht mehr kompetent verwenden oder verstehen könnte. ${ }^{10}$

\subsubsection{Bezeichnungen für natürliche Arten}

Kripke sieht eine enge Verwandtschaft zwischen Eigennamen einerseits und Ausdrücken, die für natürliche Arten stehen, (natural kind terms) andererseits. Zu diesen Artbezeichnungen zählt er neben Ausdrücken wie 'Tiger', 'Kuh' u.ä. Massenterme wie 'Gold' und 'Wasser' und auch Ausdrücke wie 'Licht', 'Wärme' und 'Elektrizität'. ${ }^{11}$ Kripke konzipiert daher für die Referenz von Artbezeichnungen ein Modell, auf das er die für Eigennamen entwickelten Ideen weitgehend überträgt:

1. Die Referenz einer Artbezeichnung wird durch Einführung des Ausdruckes in einem ursprünglichen Taufakt festgelegt. ${ }^{12}$ Bei Arten wie Gold, Wasser oder Tiger kann die Taufe ostensiv erfolgen oder durch definite Beschreibung einiger Exemplare oder einer Probe bzw. eines Musters der Art. Arten wie Wärme und Licht, die Kripke aber eher am Rande erwähnt, werden als 'das, was Wärmeempfindungen verursacht' und 'das, was visuelle Eindrücke hervorruft' identifiziert, d.h. ihre Benennung erfolgt über ihre kausale Rolle in bestimmten Situationen. ${ }^{13}$

\footnotetext{
${ }^{8}$ Die zur Namenseinführung verwendeten Eigenschaften können nach Kripke nicht nur akzidentell sein, sondern sich darüber hinaus im Einzelfall sogar als falsch erweisen; vgl. [Krip80], S.80, Fn.34.

${ }^{9}$ Vgl. [Krip80], S.96, 163; Kripke betont aber, wie schon erwähnt, daß seine Konzeption der kausalen Kette der Weitergabe weiterer Ausarbeitung bedarf, um zu einer Theorie zu werden, und jedenfalls ohne weitere Qualifikationen keine notwendige und hinreichende Bedingung für Referenz darstellt.

${ }^{10}$ Siehe [Krip80], S.86.

${ }^{11}[$ Krip80], S.134

12 [Krip80], S.135.

${ }^{13}$ [Krip80], S.129ff. Auch für Arten, die keine Sinneswahrnehmungen als direkte Wirkungen haben (wie Wärme), sondern nur andere "konkrete experimentelle Wirkungen" (Kripkes Beispiel ist Elektrizität;
} 
2. Eine Artbezeichnung wird, ausgehend vom Taufakt, von Sprecher zu Sprecher in der Sprachgemeinschaft weitergegeben. Jemand, der den Terminus verwendet, referiert damit, sofern eine kausale Kette der Weitergabe von der ursprünglichen Taufe aus bis zu ihm vorliegt, auf die Art, von der beim Taufakt einige Exemplare bzw. ein Muster getauft wurden. ${ }^{14}$

Artbezeichnungen funktionieren also nach Kripke weitgehend wie Eigennamen, was sich terminologisch dadurch wiedergeben läßt, daß man von Artnamen spricht.

In einem Punkt besteht allerdings ein Unterschied zwischen Artnamen und Eigennamen: Ein Eigenname wird beim Taufakt an einen Einzelgegenstand vergeben, ein Artname dagegen nicht nur an die in der Taufsituation präsenten bzw. durch definite Beschreibung herausgegriffenen Einzeldinge oder Proben der Art, sondern an alle Individuen der Art. Die Einführung eines Artnamens durch die Taufe einiger Exemplare bzw. einer Probe erfolgt unter der Annahme, daß dieses Muster tatsächlich eine einheitliche Art exemplifiziert. Diese Annahme kann sich als falsch erweisen (wie es historisch z.B. bei Jade der Fall war, wo es sich tatsächlich um zwei sehr ähnliche Mineralienarten handelt), ist aber in den meisten Fällen, so Kripke, offenbar erfolgreich. ${ }^{15}$

Was eine natürliche Art ausmacht, sind nach Kripke "grundlegende Strukturmerkmale". Die Aufdeckung dieses "Wesens", der "essentiellen Eigenschaften" oder der "Natur" der Art ist seiner Ansicht nach im allgemeinen Aufgabe wissenschaftlicher Untersuchungen. ${ }^{16}$ Konkret nennt Kripke in seinen Beispielen stets mikroskopische Strukturmerkmale: bei chemischen Arten die atomare Struktur oder die Ordnungszahl ${ }^{17}$, bei biologischen Arten die DNA-Struktur. Putnam nennt ergänzend (mit bestimmten Strukturmerkmalen einhergehende) Gesetze, denen eine Art unterliegt, als wesentliche Eigenschaften. ${ }^{18} \mathrm{Zu}$ der Art, die bei einer Taufe benannt wird, gehören also neben den getauften Exemplaren alle anderen Objekte, die in diesem Sinn dieselben mikroskopischen Strukturmerkmale haben oder, in einer Formulierung von Putnam, die bezüglich ihrer wesentlichen Eigenschaften in einer Äquivalenzrelation (sameness relation) ${ }^{19} \mathrm{zu}$ den getauften Exemplaren stehen.

Artnamen haben nach Kripke, genau wie Eigennamen, keine Bedeutung im Sinne einer Beschreibungstheorie. Die Beschreibungen, die ein Sprecher mit einem Artnamen verbindet, sind irrelevant für die Festlegung der Referenz des von ihm gebrauchten Ausdrucks. Sofern eine kausale Kette der Namensweitergabe zwischen Taufakt und Sprecher besteht und außerdem die getauften Exemplare tatsächlich eine natürliche Art bilden, kann sich der Sprecher bezüglich aller Eigenschaften der Art (inklusive der wesentlichen Struktureigenschaften, die die Art ausmachen) irren, ohne daß das die Referenzbeziehung zwischen dem von ihm verwendeten Artnamen und der Art berührt und ohne daß er den Artnamen deswegen nicht kompetent verwenden und verstehen könnte. ${ }^{20}$

[Krip80], S.137), ermöglicht ihre kausale Rolle die Taufe.

Physikalische Terme wie 'Wärme' und 'Licht' scheint Kripke (ohne daß er dies explizit diskutiert) über eine definite Beschreibung an einen Typ von Situation knüpfen zu wollen, nicht an ein token; vgl. [Krip80], S.151ff.

${ }^{14}[$ Krip80], S.139.

${ }^{15}$ [Krip80], S.120ff.; denkbar sind natürlich weitere problematische, aber nach Kripke offenbar nur selten auftretende Fälle, etwa, daß einige wenige der Musterexemplare zu einer anderen Art gehören, daß das gesamte Muster zu einer bereits bekannten Art gehört u.ä., vgl. dazu [Krip80], S.135.

${ }^{16}$ [Krip80], S.138; s.a. S.140 Fn.71: "If we take the 'fixes a reference' view, then it is up to the physical scientist to identify the property so marked out in any more fundamental physical terms."

${ }^{17}$ Bei Wasser die Formel $\mathrm{H}_{2} \mathrm{O}$, bei Gold die Ordnungszahl 79.

${ }^{18}$ [Putn90b], S.60f., 69.

${ }^{19}$ [Putn75i], S.225.

${ }^{20}$ [Krip80], S.121. 


\subsection{Putnams Bedeutungstheorie}

\subsubsection{Die Theorie für natürliche Arten und physikalische Größen}

Hilary Putnam hat eine gewissermaßen um Kripkes kausale Theorie der Referenz herum konstruierte Bedeutungstheorie vorgeschlagen.

Bei Putnams Bedeutungstheorie geht es, wie bei Kripke, um Artnamen, sowie außerdem um Ausdrücke für physikalische Größen (elektrische Ladung, Temperatur u.ä.). ${ }^{21}$ Nach dieser Theorie läßt sich die Bedeutung solcher Ausdrücke durch einen Vektor mit vier Komponenten beschreiben. ${ }^{22}$ Die vier Komponenten sind:

1. syntaktische Marker

2. semantische Marker

3. das Stereotyp

4. die Extension.

Syntaktische Marker kennzeichnen die syntaktischen Eigenschaften eines Wortes (wie Pluralbildung, Komposition mit anderen Wortarten u.ä.); z.B. nennt Putnam für das Beispiel 'Wasser' als syntaktische Marker Substantiv und Massenterm.

Semantische Marker geben so etwas wie kategorielle, mehr oder weniger allgemeine Klassifikationen an, unter die (normalerweise ${ }^{23}$ ) alle Referenzobjekte des Ausdrucks fallen, Putnam spricht auch von Kategorialindikatoren oder broad spectrum terms. ${ }^{24}$ Für das Beispiel 'Wasser' gibt Putnam natürliche Art und Flüssigkeit an, andere Beispiele für semantische Marker sind Tier, Lebewesen, Artefakt, Wochentag.

Die dritte Komponente des Bedeutungsvektors, das Stereotyp, faßt die minimalen Kenntnisse, die "core facts" ${ }^{25}$, zusammen, die die Sprachgemeinschaft von einem Sprecher verlangt, um ihn als jemanden anzuerkennen, der den Ausdruck versteht. Das Stereotyp enthält Eigenschaften, die ein typischer, paradigmatischer Gegenstand, der unter den Begriff fällt, nach landläufiger Ansicht aufweist und die häufig verwendet werden, um zu entscheiden, ob ein Gegenstand unter diesen Begriff fällt. Als Beispiel nennt Putnam das Stereotyp für 'Tiger', das u.a. Merkmale wie gestreift, gelb, lebt im Dschungel umfaßt; das Stereotyp für 'Gold' wäre etwa gelb, wertvoll, schmiedbar usw.

Wichtig ist, daß das Stereotyp eines Ausdrucks, zusammen mit den syntaktischen und semantischen Markern, Mindestbedingungen dafür beschreibt, daß ein Sprecher den Aus-

\footnotetext{
${ }^{21}$ Diese behandelt Putnam, anders als Kripke, getrennt von den Artnamen.

${ }^{22}$ [Putn75i], S.269.

${ }^{23}$ Genaugenommen verlangt Putnam nicht, daß die Extension eines Ausdrucks in ausnahmslos allen Fällen unter den jeweiligen semantischen Marker fällt, sondern läßt unter besonderen Umständen einige "weit hergeholte Fälle" ([Putn75i], S.267) von Ausnahmen zu. Dies hängt damit zusammen, daß er die Unterscheidung analytisch/synthetisch zwar nicht mit der Radikalität Quines einebnen, aber doch verschwimmen lassen will hin zu einer graduellen "Zentralität" von Sätzen: Ein Satz hat nach seiner Konzeption einen niedrigen oder hohen Grad von Zentralität, je nachdem ob er leicht oder nur schwer revidierbar ist. Kein Satz ist wirklich unter gar keinen Umständen revidierbar, auch nicht einer, der einen Ausdruck mit seinem semantischen Marker im Verbindung bringt wie 'Alle Tiger sind Tiere'; dennoch haben solche Sätze nach Putnam einen weit höheren Grad an Zentralität als andere Eigenschaftszuschreibungen und werden tatsächlich "praktisch nie" ([Putn75i], S.267) revidiert.

${ }^{24}$ [Putn75d], S.222.

${ }^{25}$ [Putn75g], S.148.
} 
druck versteht. ${ }^{26}$ Das Stereotyp nennt nicht etwa Eigenschaften, die wie bei einer Beschreibungstheorie die Referenz bestimmen, sondern Bedingungen der Zuschreibung von Sprachkompetenz an einen Sprecher. Die im Stereotyp zusammengefaßten Beschreibungen brauchen nicht korrekt zu sein, d.h., ein unter den fraglichen Begriff fallender Gegenstand braucht die entsprechenden Eigenschaften nicht zu haben, und die Beschreibungen brauchen nicht einmal ausreichend zu sein, um für einen gegebenen Gegenstand eine Entscheidung zu treffen, ob er zur Extension gehört oder nicht. Vielmehr reicht es nach Putnams Ansicht bei Ausdrücken wie z.B. 'Gold' oder 'Molybdän', wenn es in der Sprachgemeinschaft Experten gibt, die über Identifikationskriterien verfügen und auf die sich ein Durchschnittssprecher berufen kann, bei den genannten Beispielen etwa Chemiker oder Metallurgen. ${ }^{27}$

Da Putnam an dem Prinzip festhalten will, daß die Bedeutung eines Ausdrucks die Referenz bestimmt, und die ersten drei Komponenten des Bedeutungsvektors dies i.a. nicht tun, fügt er als vierte Komponente schließlich die Extension hinzu, die Menge der Gegenstände, die unter den Ausdruck fallen. ${ }^{28}$ Zur Beantwortung der Frage, wodurch die Referenz eines Ausdrucks effektiv festgelegt wird, greift Putnam auf Kripkes kausale Referenztheorie für Artnamen zurück. ${ }^{29}$ Die Referenz wird nach Putnam durch ein Einführungsereignis ${ }^{30}$ festgelegt, bei dem jemand (ostensiv oder durch eine definite Beschreibung) dem Ausdruck die Referenz zuordnet, auf die sich ein Sprecher der Sprachgemeinschaft bezieht, wenn er den Ausdruck später verwendet. Dieses Einführungsereignis kann nach Putnam mit der erstmaligen Einführung des Ausdrucks in die Sprache (also mit Kripkes ursprünglicher Taufe) identisch sein, muß es aber nicht unbedingt; prinzipiell kann die Verwendung eines Ausdruckes durch weitere Einführungsereignisse neu geregelt werden. ${ }^{31}$ Bei einem Einführungsereignis muß das, worauf der Ausdruck referieren soll, wenigstens so gut es nach dem zeitgenössischen Stand des Wissens geht, identifiziert werden. Damit ein Sprecher, der den so eingeführten Artnamen verwendet, auf die Art referieren kann, muß eine kausale Kette der Weitergabe des Ausdrucks zwischen ihm und dem Einführungsereignis bestehen. Es ist dazu nicht erforderlich, daß er (oder ein Experte seiner Sprachgemeinschaft) von dem Einführungsereignis weiß oder dabei evtl. verwendete Beschreibungen kennt. Das Einführungsereignis und dabei evtl. involvierte einführende Beschreibungen gehen i.a. auch nicht in das Stereotyp oder in die Identifikationskriterien der Experten ein.

In zwei Punkten weicht Putnam von Kripke ab: Für Kripke ist die kausale Kette der Namensweitergabe zwischen Taufsituation und Sprecher hinreichend dafür, daß der Sprecher auf die getaufte Art referiert. ${ }^{32}$ Putnam verlangt dafür mehr, nämlich ein Mindestmaß

\footnotetext{
${ }^{26}$ Mittlerweile schwächt Putnam diese Forderung ab, er verlangt nur noch, daß ein Sprecher das Stereotyp im wesentlichen kennt; vgl. [Putn87b], S.270/271, [Putn90c], S.293.

${ }^{27}$ Putnam nennt diesen Sachverhalt division of linguistic labour (vgl. [Putn75i], S.227). Das "Wissen" der Experten bekommt keinen eigenen Eintrag in Putnams Bedeutungsvektor, weil Putnam nicht herausbekommen möchte, daß die Bedeutung eines Ausdrucks sich jedesmal ändert, wenn die Identifikationskriterien der Experten sich ändern ([Putn78], S.114). Deren Identifikationskriterien brauchen nicht korrekt zu sein (vgl. nächster Abschnitt; s.a. [Krip86]).

${ }^{28}$ Putnams Bedeutungen "bestimmen" die Referenz der Ausdrücke also in einem völlig trivialen Sinn, nicht wie eine Bedeutung im Sinne einer Beschreibungstheorie.

${ }^{29}$ [Putn75i], S.246/247, [Putn75h], S.203f.

${ }^{30}$ [Putn75h], S.200.

${ }^{31}$ Anders als [Fine75] annimmt ([Putn75j], S.274f.).

${ }^{32}$ Hier bleibt Kripkes Bedingung beiseite, daß jeder Namensempfänger in der Kette den Namen selbst mit der Intention verwenden muß, auf dasselbe zu referieren wie sein Vorgänger in der Kette, die von Putnam nicht explizit thematisiert wird, ebenso die empirische Annahme, daß tatsächlich eine Art getauft
} 
an sprachlicher Kompetenz auf Seiten des Sprechers. Dieser soll neben den syntaktischen Markern wenigstens die semantischen Marker und das Stereotyp kennen, d.h. er soll wenigstens wissen, von was für einer Kategorie von Dingen er redet und was die in der Sprachgemeinschaft allgemein verbreiteten Meinungen über diese Dinge sind. So kann nach Putnam jemand - trotz vorhandener kausaler Kette - nicht auf Tiger referieren, wenn er nicht mindestens weiß, daß dies Tiere sind, die normalerweise gestreift und gelb sind, usw., oder auf Gold, ohne zu wissen, daß es sich dabei um ein gewöhnlich gelbes Metall handelt. ${ }^{33}$

Der zweite Punkt ist der, daß Putnam neben den natürlichen Arten auch Ausdrücke, die für physikalische Größen stehen (physical magnitude terms), ${ }^{34}$ ausführlich diskutiert, d.h. Ausdrücke mit dem semantischen Marker 'physikalische Größe'. Solche Ausdrücke für physikalische Größen lassen sich typischerweise nicht in demselben Sinn ostensiv einführen wie 'Tiger' oder 'Wasser', man kann auf elektrische Ladung oder Wärme nicht im selben Sinn hinweisen wie auf Goldklumpen oder Kühe. Deshalb werden Ausdrücke für physikalische Größen nach Putnam i.a. durch kausale Beschreibungen eingeführt, z.B. 'Elektrizität' durch eine Beschreibung "which singles out electricity as the physical magnitude responsible for certain effects in a certain way". ${ }^{35}$ Die "Wirkungen" müssen epistemisch gut zugänglich sein, wenn auch nicht unbedingt mit bloßem Auge beobachtbar, ${ }^{36}$ also bereits etablierte Phänomene, Größen(änderungen) o.ä., die zumindest mit Hilfe von Instrumenten nachweisbar, meßbar o.ä. sind. Die Qualifikation "kausal" versteht Putnam in einem weiten Sinn: Als kausal soll eine Beschreibung bereits dann gelten, wenn ein Größenname durch Angabe eines Gesetzes eingeführt wird, das die neue Größe mit bereits etablierten verknüpft. ${ }^{37}$ In diesem Sinn wird eine physikalische Größe also gekennzeichnet als etwas, was kausal zusammenhängt mit einem bestimmten (Typ ${ }^{38}$ von) Phänomen, einer anderen Größe o.ä.

Im Fall der Größennamen kommt das Stichwort Kausalität also an zwei Stellen der Theorie ins Spiel: Einmal bei der kausalen Kette der Weitergabe des Ausdrucks, zum anderen bei der kausalen Beschreibung, mit der die Größe gekennzeichnet wird als mit dem beim Einführungsereignis herangezogenen Phänomen, der dabei involvierten Größe, o.ä. verknüpft.

\subsubsection{Der Zusammenhang zwischen der Referenz eines Art- oder Größen- namens und den Eigenschaften, die den Referenzobjekten zuge- schrieben werden}

Anders als Beschreibungstheorien es vorsehen, gibt es Putnams Theorie zufolge nur einen sehr losen Zusammenhang zwischen der Referenz eines Ausdrucks und den Eigenschaften,

\footnotetext{
wurde.

${ }^{33}$ Siehe [Putn75h], S.201ff.; vgl. aber Fn.23.

${ }^{34}$ Die bei Kripke nur am Rande vorkommen; [Putn75h], S.198.

35 [Putn75h], S.200.

${ }^{36}$ Putnam lehnt die positivistische Unterscheidung beobachtbar/theoretisch ab.

${ }^{37}$ [Putn75h], S.202; damit scheinen Koexistenzgesetze (im Unterschied zu in einem engeren Sinn kausalen Gesetzen) nicht ausgeschlossen zu sein.

${ }^{38}$ In der genannten einführenden Beschreibung für 'Elektrizität' dürfte diese Größenbezeichnung mit “... responsible for certain effects" über einen Typ von Wirkung bzw. Effekt an ihre Referenz angeknüpft werden, nicht über einzelne Vorkommnisse (token), wie bei den Arten. Putnam äußert sich dazu nicht explizit, für die weiter unten diskutierten Generalisierungsprobleme hängt von diesem Punkt jedenfalls nichts ab, da über einen Typ von Phänomen jedenfalls i.a. nicht die gesamte Extension des eingeführten Ausdrucks erfaßt wird, weil die Größe auch in anderen Kontexten und Phänomenen instantiiert sein wird.
} 
die den Referenzobjekten zugeschrieben werden: Die Referenz, genauer: die Extension eines Art- oder Größennamens wird in der oben skizzierten Weise durch die für die Art oder Größe wesentlichen Eigenschaften bestimmt. Nach Putnam sind diese wesentlichen Eigenschaften grundsätzlich zu underscheiden von sämtlichen Eigenschaften, die den Referenzobjekten von irgendwelchen Sprechern oder Sprachgemeinschaften zugeschrieben werden. $\mathrm{Zu}$ diesen letzteren Eigenschaften zählen nicht nur die, die das Stereotyp umfaßt, sondern außerdem die Eigenschaften, die die Referenzobjekte gemäß sonstiger Überzeugungen eines Durchschnittssprechers, eines Experten oder einer ganzen Sprachgemeinschaft haben, und auch die Eigenschaften, die in der bei der Einführung des Ausdrucks verwendeten Beschreibung genannt werden. Zwischen der Gruppe der für eine Art oder Größe wesentlichen Eigenschaften und den Eigenschaften, die den Referenzobjekten von irgendwelchen Sprechern oder Sprachgemeinschaften zugeschrieben werden, kann es Überschneidungen geben, dies ist jedoch in keiner Weise erforderlich. Dieser charakteristische Zug von Putnams Bedeutungstheorie hat zur Folge, daß für sie das Problem der Referenzinstabilitäten bei Theorienwandel nicht (oder fast nicht ${ }^{39}$ ) auftritt, das alle Beschreibungstheorien (in unterschiedlichem Ausmaß) belastet, und stellt damit zumindest einen Prima-facie-Vorteil von Putnams Theorie dar, wenn es um die Erläuterung oder Ergänzung realistischer Thesen geht.

\section{Der Zusammenhang zwischen der Referenz eines Art- oder Größennamens und der einführenden Beschreibung}

Putnam verlangt für die Einführung eines Art- oder Größennamens ein Mindestmaß an Beschreibungen der Größe bzw. Entität auf Seiten des oder der am (für die Sprachgemeinschaft relevanten) Einführungsereignis beteiligten Sprecher, nämlich genug für eine sozusagen nach deren bestem Wissen und Gewissen definite Beschreibung der Referenzgröße bzw. -entität. Normalerweise ${ }^{40}$ wird dieses Mindestmaß nach Putnam in einer kausalen Beschreibung bestehen: Eine physikalische Größe wird i.a. beschrieben als "responsible for certain effects in a certain way" 41 , wobei diese Art und Weise durch Angabe eines Gesetzes oder mehrerer Gesetze spezifiziert wird. Außerdem muß nach Putnam durch semantische Marker vorgegeben werden, was für eine Kategorie von Ding benannt werden soll. ${ }^{42}$ Putnam verlangt jedoch für referierende Verwendbarkeit eines Ausdrucks nicht, daß die zu seiner Einführung verwendeten Beschreibungen dessen Referenz korrekt charakterisieren. Am Beispiel 'Elektrizität' erläutert er:

"[...] if anyone knows that 'electricity' is the name of a physical quantity, and his use of the word is connected by the sort of causal chain I described before to an introducing event in which the causal description given was, in fact, a causal description of electricity, then we have a clear basis for saying that he uses the word to refer to electricity. Even if the causal description failed to describe electricity, if there is good reason to treat it as a mis-description of electricity (rather than as a description of nothing at all) - for example, if electricity was described as the physical magnitude with such-and-such properties which is responsible for such-and-such effects, where in fact electricity is responsible for the effects in question, and the speaker intended to refer to the magnitude 
responsible for those effects, but mistakenly added the incorrect information 'electricity has such-and-such properties' because he mistakenly thought that the magnitude responsible for those effects had those further properties - we still have a basis for saying that both the original speaker and the persons to whom he teaches the word use the word to refer to electricity." ${ }^{43}$

"Thus, suppose I were standing next to Ben Franklin as he performed his famous experiment. Supposed he told me that 'electricity' is a physical quantity which behaves in certain respects like a liquid (if he were a mathematician he might say 'obeys an equation of continuity'); that it collects in clouds, and then, when a critical point of some kind is reached, a large quantity flows from the cloud to the earth in the form of a lightning bolt; that it runs along (or perhaps 'through') his metal kite string; etc. He would have given me an approximately correct definite description of a physical magnitude." 44

Putnam lehnt die analytisch/synthetisch-Dichotomie ab und will daher keine im strengen Sinn notwendigen oder hinreichenden Bedingungen angeben, was und wieviel von der einführenden Beschreibung mindestens korrekt sein muß, damit diese noch eine Referenzbeziehung liefert: Solange man von einer "annähernd korrekten Beschreibung" sprechen kann oder diese jedenfalls noch als eine "Fehlbeschreibung von Elektrizität (im Gegensatz zu einer leeren Beschreibung)" erkennen kann, soll Referenz vorliegen, aber letzten Endes kann jeder einzelne der Sätze der einführenden Beschreibung falsch sein. Die verschiedenen Elemente einer einführenden Beschreibung sind nach Putnam keineswegs alle gleichwertig im Hinblick auf eine Bewertung der Beschreibung als (annähernd) korrekt oder leer; vielmehr müssen sie nach ihrer Wichtigkeit deutlich differenziert werden. Besonderes Gewicht kommt dabei nach Putnams Ansicht meistens dem semantischen Marker zu. Auch eine zur Referenzfixierung angegebene Kausalrelation ist nach Putnam bei physikalischen Größen etc. in praktisch allen Fällen so zentral, daß keine Referenzbeziehung zustandekommt, falls tatsächlich keine Kausalrelation vorliegt, ${ }^{45}$ aber prinzipiell ist eine Referenzbeziehung auch ohne bzw. bei falscher Angabe einer Kausalrelation möglich. ${ }^{46}$ Putnam ist der Ansicht, daß sich unter den Ausdrücken der real-existierenden Wissenschaften allenfalls selten Grenz- und Zweifelsfälle finden lassen, bei denen nicht klar ist, ob die einführende Beschreibung eine Fehlbeschreibung der Referenz liefert oder eine leere Beschreibung. Er glaubt jedenfalls nicht, daß sich so etwas wie eine allgemeine Theorie oder generelle, präzise Regeln darüber finden lassen, unter welchen Bedingungen ein Ausdruck, der durch eine Beschreibung eingeführt wurde, auf eine bestimmte Art oder Größe referiert.

Alles in allem ist es also nicht so, daß gemäß Putnams Bedeutungstheorie gar kein Zusammenhang zwischen der einführenden Beschreibung und der Referenz eines Art- oder Größennamens bestünde, Putnam konzipiert aber zwischen beiden einen sehr lockeren Zusammenhang, über den sich offenbar nichts wirklich Präzises, Kontextunabhängiges sagen läßt. ${ }^{47}$

\footnotetext{
${ }^{43}$ [Putn75h], S.201.

${ }^{44}$ [Putn75h], S.200. Putnam beschreibt diese Episode als Einführungsereignis des Ausdrucks 'Elektrizität', obwohl sie historisch zweifellos nicht die Erstverwendung dieses Ausdrucks darstellt. Er faßt sie vermutlich als die für uns relevante Termeinführung auf, in jedem Fall hängt daran aber nichts systematisch Wichtiges.

${ }^{45}$ Siehe [Putn75j], S.277; in Putnams oben zitierter Diskussion von 'Elektrizität' liegt bei der "Fehlbeschreibung" ebenfalls wenigstens die Kausalrelation vor.

${ }^{46}$ Vgl. [Putn75h], S.204.

${ }^{47}$ Siehe [Putn88], S.12ff.
} 


\section{Der Zusammenhang zwischen der Referenz eines Art- oder Größennamens und Überzeugungen über die Referenzobjekte}

Ein Sprecher, der mit einem Art- oder Größennamen auf eine Art bzw. Größe referiert, muß nach Putnam nicht die für diese wesentlichen Struktureigenschaften kennen, und allgemeiner müssen seine Überzeugungen (und die seiner Sprachgemeinschaft und deren Experten) keinerlei Bedingungen erfüllen: Weder ist gefordert, daß unter diesen Überzeugungen bestimmte korrekte Beschreibungen der Referenzobjekte sind, noch sind falsche Beschreibungen ausgeschlossen. Letzteres gilt für das Stereotyp (dessen Kenntnis von dem Sprecher verlangt wird) und auch für seine sonstigen Überzeugungen über die Referenzobjekte.

Diese gleichsam offizielle Linie, nach der die wesentlichen Eigenschaften, die die Referenz eines Art- oder Größennamens bestimmen, und die von einem Sprecher bzw. einer Sprachgemeinschaft damit assoziierten Beschreibungen systematisch auseinanderfallen können, versucht Putnam jedoch in zweierlei Weise wieder etwas abzumildern.

Zum einen hält Putnam zwar daran fest, daß das Stereotyp eines Ausdrucks, dessen Kenntnis er mindestens von einem kompetenten Sprecher verlangt, keinerlei wirklich notwendige Erfüllungsbedingungen enthält und daß für Referenz auch nicht erforderlich ist, daß die Mehrzahl der darin genannten Beschreibungen der Referenzobjekte korrekt ist, ${ }^{48}$ aber in Fällen, in denen ein Sprecher nicht wenigstens einige korrekte Beschreibungen kennt, sieht Putnam dann doch "keine große Pointe" 49 darin, den Worten eines derart fehlinformierten Sprechers Referenz zuzuschreiben. Ebenso schreibt Putnam zwar, daß sogar ein falscher semantischer Marker nicht zwangsläufig zu dem Schluß führen muß, daß keine Referenz vorliegt, er will dies jedoch nur in äußerst seltenen Einzelfällen ausnahmsweise zulassen. ${ }^{50}$

Zum anderen vertritt Putnam die These, daß wissenschaftliche Art- und Größennamen von den Wissenschaftlern selbst in dem Bewußtsein und mit der Absicht gebraucht werden, daß die wesentlichen Eigenschaften der Art bzw. Größe und damit die Extension erst durch zukünftige Forschung aufgedeckt werden und daß durch entsprechende Forschungsergebnisse die bisherigen Überzeugungen über die Referenzobjekte (inklusive der von Experten verwendeten Identifikationskriterien) korrigiert werden, sofern sie falsch sind:

"It is beyond question that scientists use terms as if the associated criteria were not necessary and sufficient conditions, but rather approximately correct characterizations of some world of theory-independent entities, and that they talk as if later theories in a mature science were, in general, better descriptions of the same entities that earlier theories referred to." 51

Für Gold sind die extensionsbestimmenden Strukturmerkmale nach Putnam mittlerweile bekannt (Ordnungszahl 79); bereits Archimedes aber hat den Ausdruck 'Gold' im Vertrauen auf diese irgendwann in der Zukunft bevorstehende Entdeckung verwendet.

"It is possible (and let us suppose it to be the case) that [...] there were or are pieces of metal which could not have been determined not to be gold in Archimedes' day, but which we can distinguish from gold quite easily with modern techniques. Let $X$ be such a piece of metal [...]

\footnotetext{
${ }^{48}$ Siehe [Putn75i], S.256, 270f.

${ }^{49}[$ Putn75h], S.203.

${ }^{50} \mathrm{Vgl}$. Fn.23, S.80.

${ }^{51}$ [Putn75i], S.237.
} 
In the view I am advocating, when Archimedes asserted that something was gold $(\chi \rho v \sigma o ̀ \varsigma)$ he was not just saying that it had the superficial characteristics of gold (in exceptional cases, something may belong to a natural kind and not have the superficial characteristics of a member of that natural kind, in fact); he was saying that it had the same general hidden structure (the same 'essence', so to speak) as any normal piece of gold. Archimedes would have said that our hypothetical piece of metal $X$ was gold, but he would have been wrong [...]

If, now, we had gone on to inform Archimedes that gold had such and such a molecular structure (except for $X$ ), and that $X$ behaved differently because it had a different molecular structure, is there any doubt that he would have agreed with us that $X$ isn't gold?" 52

Nach Putnam war also Archimedes selbst der Meinung, und sind es Wissenschaftler im allgemeinen wohl ebenso, daß die Referenz der von ihnen verwendeten Art- oder Größennamen durch die wesentlichen Eigenschaften der Art oder Größe bestimmt wird, auch wenn ihnen diese wesentlichen Eigenschaften nicht bekannt sind und daher in ihren Überzeugungen über die Referenzobjekte keine Rolle spielen. Dieser Befund trägt nach Putnams Ansicht zur Plausibilität seiner Bedeutungs- und Referenztheorie bei, insbesondere des ihr zufolge sehr losen Zusammenhangs von Referenz bzw. Extension einerseits und Überzeugungen über die Referenzobjekte andererseits.

\section{Urteile über die Referenz von Art- oder Größennamen}

Um zu entscheiden, ob ein Sprecher, der einen Art- oder Größennamen verwendet (und der dessen Marker und Stereotyp kennt), damit referiert und wenn ja, was die Extension des Ausdrucks ist, muß man, wie von Putnam am Beispiel 'Elektrizität' vorgeführt, erstens die historische Einführung des Ausdrucks und die einführende Beschreibung (sofern verwendet) kennen und zweitens die wesentlichen Eigenschaften der Art bzw. Größe, d.h. die (mikroskopischen) Strukturmerkmale und Gesetze, die die Extension des Art- bzw. Größennamens bestimmen. Man muß dazu also die Geschichte des Ausdrucks kennen und man muß einen hinreichend fortgeschrittenen Wissensstand über die "Natur" der Art bzw. Größe haben.

Diese Voraussetzungen erfüllen der Sprecher selbst und auch seine Sprachgemeinschaft und deren Experten i.a. nicht. ${ }^{53}$ Wenn das so ist, wie z.B. bei Putnams Archimedes, können sie keine gut begründeten Urteile darüber fällen, ob der von ihnen verwendete Ausdruck Referenz hat und was zu seiner Extension zählt, z.B. darüber, ob 'Gold' Referenz hat und welche Metallstücke oder sonstigen Objekte zur Extension von 'Gold' gehören. Wenn sie die Voraussetzungen erfüllen, sich aber über die Geschichte des Ausdrucks oder über die "Natur" der Art bzw. Größe täuschen, kommen sie auch zu falschen Überzeugungen über die Extension des Ausdrucks. Beide Sorten von Fällen können auch dann leicht eintreten, wenn der Sprecher tatsächlich mit dem Art- oder Größennamen referiert. Daß das so ist, ist eine (von manchen als kontraintuitiv wahrgenommene) Konsequenz des in der Theorie von Kripke und Putnam sehr lose angelegten Zusammenhangs zwischen der Referenz eines Ausdrucks und den Überzeugungen der Sprecher über die Referenzobjekte: Wenn die Überzeugungen, aufgrund derer der Sprecher z.B. bestimmte Objekte als Gold klassifiziert, enger mit der Referenz von 'Gold' verknüpft wären, wie es Beschreibungstheorien

\footnotetext{
${ }^{52}$ [Putn75i], S.235-238, s.a. [Putn88], S.31.

${ }^{53}$ [Putn78], S.97ff.
} 
vorsehen, könnten beide Sorten von Fällen zumindest weniger leicht eintreten. ${ }^{54}$

Dadurch, daß der Zusammenhang zwischen der Referenz eines Art- oder Größennamens und den Überzeugungen der Sprecher nur sehr lose ist, macht es die Theorie von Kripke und Putnam also für einen Sprecher bzw. eine Sprachgemeinschaft i.a. schwierig, zu gut begründeten und verläßlichen Urteilen über das Referieren und die Extension ihrer eigenen Ausdrücke zu gelangen; von einer historisch späteren, mit einem besseren Kenntnisstand versehenen Position aus sind solche Urteile dagegen eher möglich.

Wenn man solche Urteile im historischen Rückblick fällt, wie von Putnam an den Beispielen Franklin und Archimedes vorgeführt, dann wird das Resultat häufig sein, daß den Ausdrücken eines Sprechers Referenzobjekte bzw. eine Extension zugeschrieben werden, für die sie selbst (und auch derjenige, der den Ausdruck eingeführt hat) keine definite Beschreibung besaßen und/oder über die sie falsche Überzeugungen hatten. Putnam hat eine Maxime formuliert, nach der genau dies korrekt sein kann, und dafür den Terminus "Principle of the Benefit of Doubt" geprägt. ${ }^{55}$

\section{Bedeutung und Referenz von Art- oder Größennamen und Theorienwandel}

Für das Interesse, das die Theorie von Kripke und Putnam in der wissenschaftstheoretischen Realismusdebatte findet, ist wesentlich das Bild verantwortlich, das sie vom Verhalten der Bedeutung und insbesondere der Referenz wissenschaftlicher Ausdrücke bei Theorienwandel liefert. Die Ausdrücke, die in der Realismusdebatte im Zentrum des Interesses stehen, lassen sich, zumindest soweit es um die Naturwissenschaften geht, zum überwiegenden Teil Putnams Artnamen (Elektron, Quark ${ }^{56}$ ) oder Größennamen (Wärme, elektrische Ladung ${ }^{57}$ ) zuordnen. Das Bild, das die Theorie von Kripke und Putnam vom Verhalten dieser Ausdrücke bei Theorienwandel zeichnet, wird entscheidend geprägt durch den nur losen Zusammenhang zwischen der Referenz eines Art- oder Größennamens einerseits und der einführenden Beschreibung und den Überzeugungen der Sprecher, die ihn verwenden, andererseits.

Ein Prima-facie-Nachteil der Bedeutungstheorie von Carnap und Lewis und der Kontexttheorien (in einer Lesart) ist, daß Veränderungen im Bestand der akzeptierten Theorien i.a. zu veränderten Bedeutungen der theoretischen Ausdrücke führen, und zwar (je nachdem, wie holistisch die Theorie ist) u.U. schon sehr kleine Veränderungen. Wenn man diese Theorien als Beschreibungstheorien auffaßt, haben sie außerdem (in allen Lesarten) den Prima-facie-Nachteil, daß Veränderungen im Bestand der akzeptierten Theorien Referenzinstabilitäten mit sich bringen. ${ }^{58}$ Diese Referenzinstabilitäten können, je nach erkenntnistheoretischer Position, ein gewichtiges Problem darstellen, wenn eine Beschreibungstheorie zur Erläuterung oder Ergänzung einer realistischen Position herangezogen werden soll. Für Putnams Bedeutungs- und Referenztheorie treten beide Probleme nicht auf oder zumindest nicht in dem Ausmaß wie bei den meisten Beschreibungstheorien.

Nach Putnams Bedeutungstheorie kann der Bestand der zu einem Zeitpunkt akzeptierten wissenschaftlichen Theorien in die bei der Einführung eines Art- oder Größennamens verwendeten referenzbestimmenden Beschreibungen eingehen, die Überzeugungen

\footnotetext{
${ }^{54}$ Für diese Intuitionen machen nicht unbedingt referenzbestimmende Beschreibungen im allgemeinen einen Unterschied, aber sicherlich solche, die epistemisch einigermaßen gut zugängliche Eigenschaften zum Inhalt haben, etwa gelb für 'Gold'.

${ }^{55}$ [Putn75j], S.274/275, [Putn78], S.22, [Putn88], S.11ff.

${ }^{56}[$ Putn75j], S.274/275.

${ }^{57}$ [Putn75h], S.198.

${ }^{58} \mathrm{Vgl}$. die Abschnitte 2.6.4, 3.3.2.
} 
von Durchschnittssprechern und Experten über die Art bzw. Größe werden i.a. aus einem Ausschnitt dieser Theorien bestehen, und diese Theorien werden möglicherweise auch zu geringen Teilen in das Stereotyp des Ausdrucks eingehen. Da von diesen aber nur das Stereotyp zur Bedeutung des Ausdrucks zählt, führen Veränderungen im Bestand der akzeptierten Theorien nur dann zu Bedeutungsveränderungen, wenn sich der (i.a. geringe) Teil der Theorien verändert, der in das Stereotyp eines Art- oder Größennamens eingeht, ansonsten bleiben die Bedeutungen auch bei Theorienwandel stabil. Veränderungen, die sozusagen bis zu den Stereotypen durchschlagen, dürften allenfalls einen Bruchteil des im Laufe der Wissenschaftsgeschichte zu verzeichnenden Theorienwandels ausmachen.

Weiterhin bleibt auch die Referenz von Art- oder Größennamen bei Veränderungen im Bestand der akzeptierten Theorien weitgehend stabil, da weder Überzeugungen von Sprechern, noch Stereotypen die Referenz (mit)bestimmen, und auch die einführenden Beschreibungen sowie die semantischen Marker, in die Theorien eingehen können, nur in dem sehr begrenzten Maß Einfluß auf die Referenz haben, das Putnams "Principle of the Benefit of Doubt" zuläßt. Nach der kausalen Referenztheorie kann ein Art- oder Größenname, der in mehreren verschiedenen Theorien auftritt bzw. verwendet wird, in allen Fällen dieselbe Referenz haben, und dies insbesondere auch dann, wenn (mindestens) eine der Theorien falsche Sätze über die Referenzentitäten enthält. Dies gilt für zeitlich gleichzeitig diskutierte, konkurrierende Theorien, vor allem aber gilt es auch für zeitlich aufeinander folgende Theorien, sofern die Veränderungen nicht gerade so weitreichende sind, daß man selbst bei Anwendung des "Principle of the Benefit of Doubt" den Sprechern, die eine inzwischen verworfene Theorie akzeptiert haben, keine Referenz mehr zubilligen kann.

\subsection{Kausale Referenztheorie und Wahrheit}

Thema der Theorie von Kripke und Putnam ist die Bedeutung und die Referenz von Ausdrücken; Sätze und deren Wahrheit oder Falschheit kommen unmittelbar nicht vor. Dennoch läßt sich ihre Theorie in gewissermaßen natürlicher Weise zu einer Wahrheitstheorie ausbauen, und zwar mit Hilfe des formalen Apparates von Tarskis semantischer Wahrheitstheorie.

Wenn man Tarskis Theorie auf eine bestimmte Objektsprache anwendet, wird die Referenz bzw. die Erfüllung der objektsprachlichen Individuen- und Prädikatausdrücken durch Sätze der Form (R) angegeben. ${ }^{59}$ Auf diese aufbauend wird die Wahrheit objektsprachlicher Sätze erklärt durch Schemata wie

' $F(a)$ ' ist wahr genau dann wenn es einen Gegenstand gibt, auf den 'a' referiert, und dieser ' $F$ ' erfüllt.

Da die Referenztheorie von Kripke und Putnam gerade die Referenz von Namen und Prädikaten zum Thema hat, ${ }^{60}$ muß sie, angewandt auf eine Objektsprache offenbar Sätze der Form (R) liefern, auf die sich in der von Tarski angegebenen Weise eine Wahrheitstheorie aufbauen läßt.

Die Referenztheorie von Kripke und Putnam läßt sich also in natürlicher Weise zu einer Korrespondenztheorie der Wahrheit ausbauen. ${ }^{61}$

\footnotetext{
${ }^{59}$ Siehe Kap.2.4.

${ }^{60}$ Bei Prädikaten war im Kontext von Tarskis Theorie von "Erfüllung" gesprochen worden, bei Kripke und Putnam dagegen von "Referenz", dies ist aber nur ein terminologischer, kein inhaltlicher Unterschied.

${ }^{61}$ Siehe u.a. [Fiel72], S.366f., [Frie79], S.377f., [Devi81], [Devi84], S.27/28.
} 


\subsection{Die kausale Referenztheorie und semantischer Realis- mus}

Eine Rolle, die Bedeutungs-, Referenz- und Wahrheitstheorien für eine realistische Position spielen können, ist, semantische realistische Thesen, zu erläutern oder zu ergänzen, d.h. zu erläutern, inwieweit und in welchem Sinn die Sätze oder Theorien, von denen diese Thesen handeln, wahr (oder falsch) sind, unabhängig von menschlichen epistemischen Mitteln, dies herauszufinden. Für diese Rolle ist die kausale Referenztheorie gut geeignet, wenn man sie in der skizzierten Weise mit dem Apparat von Tarskis semantischer Wahrheitstheorie kombiniert und so zu einer Korrespondenztheorie gelangt.

Das, was nach der kausalen Referenztheorie die "Natur" einer Referenzrelation ausmacht, nämlich die erfolgreiche Benennung einer Art oder Größe und das Bestehen einer kausalen Kette der Weitergabe des Art- oder Größennamens, und damit auch das Bestehen oder Nichtbestehen der Referenzrelation sind offenbar völlig unabhängig davon, ob irgendjemand etwas über die Referenzobjekte weiß oder auch nur prinzipiell über irgendwelche epistemischen Mittel verfügt, etwas in Erfahrung zu bringen, insbesondere das, was bestimmte Theorien oder Sätze zum Inhalt haben, auf die sich semantische realistische Thesen beziehen. Wenn man die Wahrheit (oder Falschheit) dieser Theorien oder Sätze in der beschriebenen Weise mit Hilfe von Tarskis semantischem Apparat erläutert, haben diese Theorien oder Sätze daher offenbar Wahrheitswerte, die ebenfalls völlig unabhängig davon sind, ob irgendjemand weiß oder über die epistemischen Mittel verfügt herauszufinden, welche: Theorien oder Sätze, die wahr (oder falsch) sind, wären offenbar auch dann wahr (oder falsch), wenn niemand (wenigstens im Prinzip) in der Lage wäre, herauszufinden, was von beiden, die Theorien oder Sätze zu bestätigen o.ä. Ebenso involviert die Eigenschaft eines Satzes oder einer Theorie, wahr (oder falsch) zu sein, offenbar in keiner Weise epistemische Mittel o.ä. zur Ermittelung ihres Wahrheitswertes.

Eine auf die kausale Referenztheorie aufgebaute Korrespondenztheorie eignet sich also gut zur Erläuterung von semantischen realistischen Thesen der Form (SR1). Deren Unabhängigkeitsklausel kann durch Aussagen der Form (UvmeM1) und (UvmeM2) erläutert werden. Da keinerlei Definitionen, Reduktionen o.ä. im Spiel sind, ist diese Kombination aus kausaler Referenztheorie und Korrespondenztheorie auch mit Thesen der Form (SR2) verträglich.

\subsection{Probleme und Einwände}

Wenn man die kausale Bedeutungs- und Referenztheorie zur Erläuterung oder Ergänzung einer realistischen Position heranziehen will oder auch im Rahmen der Argumentation für realistische Thesen, stößt man auf andere Probleme als bei den in den vorigen Kapiteln vorgestellten Bedeutungs- und Referenztheorien. Die wichtigsten dieser Probleme und Einwände, insbesondere die, die ihre Anwendung auf Art- und Größennamen betreffen, sollen an dieser Stelle diskutiert werden. ${ }^{62}$

\footnotetext{
${ }^{62}$ Für eine Diskussion der Adäquatheit der kausalen Theorie als Theorie der Eigennamen siehe z.B. [Evan82, McCu89].
} 


\subsubsection{Probleme der deskriptiven Adäquatheit des Modells von Kripke und Putnam}

Mehrere naheliegende Fragen stellen sich, wenn man das Modell und seine Annahmen etwas ausführlicher und genauer mit der Verwendung von "realen" Art- und Größennamen und den in den real-existierenden Wissenschaften gängigen Annahmen über Arten und Größen konfrontiert, als es durch die wenigen Beispiele bei Putnam und Kripke selbst geschieht.

So läßt sich fragen, was eigentlich für die Annahme spricht, daß es stets mikroskopische Struktureigenschaften bzw. Gesetze sind, die eine natürliche Art ausmachen.

Diese Annahme sieht für Arten wie z.B. Polystyrol und Positron vielleicht intuitiv plausibel aus, für andere erscheint sie eher unplausibel, insbesondere ${ }^{63}$ für Arten, für die außerhalb wissenschaftlicher Kontexte oder sogar vor der Entstehung der modernen Naturwissenschaften (im engeren Sinn) Namen eingeführt wurden. Bei dieser Gruppe scheint die oben genannte Annahme im wesentlichen durch eine szientistische Haltung gestützt zu werden, die grundsätzlich die Wissenschaften zur Entscheidungsinstanz in ontologischen Fragen erklärt. Dieser Punkt betrifft Arten wie Wasser und Gold, läßt sich vielleicht aber für Wärme u.ä. analog machen. ${ }^{64}$

Auch wenn man die szientistische Prämisse zugibt oder den Anwendungsbereich der Theorie von Putnam und Kripke auf spezifisch wissenschaftliche Ausdrücke eingrenzt, ist noch fraglich, ob bzw. wie weit sie die in den Wissenschaften etablierten Überzeugungen bezüglich dessen, was eine natürliche Art ausmacht, adäquat beschreiben. Für den Fall biologischer Spezies etwa scheint dies (nach heutigem Verständnis) nicht der Fall zu sein, denn dort wird eine Art üblicherweise definiert durch die Fähigkeit der ihr angehörenden Individuen, miteinander fruchtbare Nachkommen hervorzubringen, nicht, wie Kripke meint, durch eine gemeinsame DNA-Struktur. Diese Fähigkeit ist bei einigen Spezies nicht einmal eine Äquivalenzrelation, ${ }^{65}$ jedenfalls ist sie aber keine Relation, die auf der Ebene mikroskopischer Strukturmerkmale liegt, und daß sie irgendwann in der Zukunft auf mikroskopische Struktureigenschaften reduziert bzw. durch solche ersetzt wird, erscheint wenig plausibel. ${ }^{66}$ Kripke und Putnam könnten auf diesen Einwand reagieren, indem sie behaupten, daß die heute gängigen Überzeugungen über die "Natur" biologischer Spezies fehlerhaft sind, oder sie könnten sagen, daß biologische Spezies keine "richtigen" natürlichen Arten sind. Eine plausiblere Reaktion wäre es vielleicht, einzuräumen, daß sie selbst sich im Falle der biologischen Spezies über die wesentlichen Eigenschaften, die eine Art ausmachen, geirrt haben. Für chemische und physikalische Arten funktioniert das Modell von Kripke und Putnam in dieser Hinsicht besser, jedenfalls wenn man sich auf möglichst gegenwartsnahe Stadien dieser Naturwissenschaften konzentriert. Dort scheinen mikroskopische Strukturmerkmale zentraler zu sein. Insgesamt würde es der kausalen Referenztheorie sicherlich keinen Abbruch tun, wenn man die Annahmen über das Wesen natürlicher Arten (evtl. bereichsspezifisch) modifiziert.

Eine weitere Frage betrifft die deskriptive Adäquatheit der Konzeption der Referenzfestlegung durch Einführung des Ausdrucks per ostensive Taufe oder definite Beschrei-

\footnotetext{
${ }^{63}$ Pace Putnams Archimedes.

${ }^{64}$ Vgl. [Zema76], S.119f.; Putnam akzeptiert diesen Einwand inzwischen — vgl. [Putn90b], S.69.

${ }^{65}$ Solche Spezies stellen allerdings Ausnahmefälle dar. Dort fehlt zu einer Äquivalenzrelation die Transitivität, weil die Fähigkeit eines Individuums, gemeinsam mit einem anderen Individuum fruchtbaren Nachwuchs zu produzieren, sich nur auf andere Individuen aus örtlich benachbarten Populationen bezieht, dagegen nicht auf Individuen, die weit entfernt leben. Dieses Beispiel findet sich u.a. bei [Mell77], S.309/310.

${ }^{66}$ Vgl. z.B. [Dupr81], S.84ff., [Wilk93], S.7ff.
} 
bung plus kausale Kette der Weitergabe. Man sollte dieses Modell fairerweise vielleicht nicht zu genau an der "Feinstruktur" der realen Sprachpraxis messen, weil es Putnam und Kripke erklärtermaßen zunächst nur darum geht, eine grobe Skizze zu entwerfen und mit dem Stichwort kausale Kette auf ein systematisch wichtiges Element für eine noch zu entwickelnde Theorie hinzuweisen. Auch hat Putnam bereits zwei der bei Kripke offensichtlich viel zu stilisierten bzw. deskriptiv nicht adäquaten Punkte korrigiert oder etwas abgemildert, indem er zum einen den Kenntnissen von Beschreibungen der Referenzobjekte auf Seiten der Sprecher und relevanten Experten wenigstens einen gewissen Stellenwert einräumt (wenn auch zögerlich), zum anderen die Termeinführung durch Taufakt in Gegenwart eines Musters zugunsten der Einführung mittels Beschreibungen in den Hintergrund rückt. Dieser letztgenannte Punkt ist wichtig, um das Modell nicht in Konflikt mit der Geschichte der Wissenschaften zu bringen, in der sich sicherlich nur wenige Ausdrücke aufweisen lassen (insbesondere unter den "beobachtungsfernen" Ausdrücken), deren Referenz wirklich durch eine einmalige Prozedur der Taufe eines Musters festgelegt wurde. Wie ein bestimmter Ausdruck eingeführt wurde, muß im Einzelfall durch historische Untersuchungen bzw. Rekonstruktionen geklärt werden. Für die kausale Referenztheorie ist Kripkes ursprüngliche Konzeption der Taufe jedenfalls kein unverzichtbares Element, sie funktioniert ebensogut für Ausdrücke, die durch eine Beschreibung eingeführt werden.

Auch wenn man all dies einräumt, kann man Kripke und Putnam schließlich dennoch entgegenhalten, daß sich in der Geschichte der Wissenschaften zumindest einige Artund Größennamen aufweisen lassen, die historisch durch eine Beschreibung eingeführt wurden, jedoch durch eine Beschreibung, die sich auch bei großzügiger Lesart nicht als kausale Beschreibung auffassen läßt, die einen (in einem weiten Sinn) kausalen Zusammenhang zwischen der benannten Art oder Größe und einem bereits etablierten, epistemisch zugänglichen Phänomen o.ä. zum Inhalt hat. Beispiele dieser Art finden sich u.a. in der Teilchenphysik, wo manchmal Namen für neue Arten von Teilchen mit bestimmten hochtheoretischen Eigenschaften aufgrund gruppentheoretischer o.ä. Symmetrieüberlegungen vergeben wurden, lange bevor an einen experimentellen Nachweis o.ä. auch nur zu denken war. ${ }^{67}$ Kripke und Putnam können auf diesen Einwand reagieren, indem sie bestreiten, daß in den genannten Fällen den Art- oder Größennamen tatsächlich eine Referenz zugeordnet wurde. Ihr Modell könnte eventuell dahingehend ergänzt bzw. modifiziert werden, daß man eine Verwendung von Art- und Größennamen auch ohne eine referenzfixierende Termeinführung zuläßt, allerdings eine nicht-referierende Verwendung, oder, terminologisch vielleicht angemessener, dahingehend, daß man die (historische) Einführung eines Art- oder Größennamens von der Referenzfixierung unterscheidet. Eine andere denkbare Reaktion ist, einzuräumen, daß das Modell von Kripke und Putnam tatsächlich nicht für alle wissenschaftlichen Art- und Größennamen angemessen ist, sondern "nur" für einen Teil. Das hieße, daß man mehrere Möglichkeiten zuläßt, einem Art- oder Größennamen bei seiner Einführung eine Referenz zuzuordnen. Damit würde man die kausale Referenztheorie und (einige) Beschreibungstheorien effektiv nicht mehr als sich ausschließende Theorien mit "universellem" Geltungsbereich betrachten, sondern als Alternativen mit sich ergänzenden Anwendungsbereichen.

\footnotetext{
${ }^{67}$ Ein solches Beispiel ist das von Gell-Mann 1962 benannte $\Omega^{-}$; siehe dazu [Pais86], S.557, [ClMS87], Kap.7.
} 


\subsubsection{Konflikte mit vortheoretischen Intuitionen über die Referenz wis- senschaftlicher Art- und Größennamen: "Zu stabile" Referenzre- lationen}

Auch wenn man das Modell von Kripke und Putnam als erste, grobe Skizze liest, scheint es dennoch einen intuitiv unplausiblen Zug aufzuweisen, der grundlegend, d.h. von den Details der weiteren Ausformulierung unabhängig aussieht. Während es einerseits im Hinblick auf die Realismusdebatte gerade ein Prima-facie-Vorzug des Modells ist, daß eine einmal etablierte Referenzbeziehung zwischen Ausdruck und Referenzobjekt(en) so "stabil" angelegt ist, so unabhängig von den Überzeugungen der Sprecher über das (die) Referenzobjekt(e), daß sie auch durch falsche Überzeugungen und Überzeugungsänderungen bis hin zum Wechsel ganzer Theorien nicht beeinträchtigt wird, ist andererseits schwer zu sehen, wie und wieso es nach diesem Modell überhaupt noch zu einer "Wechselwirkung" zwischen den semantischen Tatsachen, sprich: den bestehenden (oder nicht bestehenden) Referenzrelationenen, und der Erkenntnispraxis der Sprachgemeinschaft kommen kann und sollte. Das heißt vor allem, daß schwer zu sehen ist, wie und wieso sich die Referenz eines Ausdrucks jemals verändern kann und sollte. Intuitiv unplausibel erscheint dies vor allem in Fällen, in denen es die Intention der Sprachgemeinschaft zu sein scheint, nach der Einsicht in frühere Irrtümer die Referenz eines Ausdrucks neu zu bestimmen. ${ }^{68}$

In der Sprache der heutigen Wissenschaften und deren historischen Stadien lassen sich Ausdrücke finden, von denen viele intuitiv sagen würden, daß sich ihre Referenz bzw. Extension (nicht bloß Meinungen darüber, was zur Extension gehört) infolge bestimmter Veränderungen des Bestandes akzeptierter Theorien verändert hat. Dazu gehören Ausdrücke, deren Extension sich erweitert hat, solche, deren Extension geschrumpft ist, und auch solche, bei denen sie sich in komplizierterer Weise verschoben hat. Diese vortheoretischen Intuitionen bestehen in diesen Fällen, obwohl bzw. auch dann, wenn die nach Kripke und Putnam relevanten Kausalketten, wenn man sie rekonstruieren könnte, möglicherweise auf eine Taufe bzw. Einführungsereignisse führen würden, die den Ausdrücken eine stabile Referenz zuordnen: So bezeichnete man etwa mit dem Ausdruck 'Wasser' vor der chemischen Revolution Ende des 18.Jahrhunderts nur die Flüssigkeit, danach auch Eis und Wasserdampf, ${ }^{69}$ intuitiv wird man von einer Extensionserweiterung sprechen wollen. Als Beispiel für den gegenteiligen Fall nennt Kuhn 'kräftefreie Bewegung', worunter vor Newton u.a. die Fallbewegung eines Steines und präzedierende Kreisel fielen, nach Newton nicht mehr. ${ }^{70}$ Kandidaten für Extensionsverschiebungen komplizierterer Art sind Ausdrücke wie 'Masse' (im Hinblick auf den Übergang von der klassischen Mechanik zu speziellen Relativitätstheorie ${ }^{71}$ ), 'Säure'72 und 'Meson' (womit historisch zunächst Myonen benannt wurden). ${ }^{73}$ Gemäß der kausalen Referenztheorie sind solche Fälle dahingehend zu rekonstruieren, daß alle Veränderungen auf der Ebene der Überzeugungen der Sprachgemeinschaft über die Arten (bzw. Größen) und ihre wesentlichen Eigenschaften stattfinden: Auf der Sachebene existiert eine Art (oder Größe), oder sie existiert nicht, die Einführung eines Ausdrucks stellt eine Referenzbeziehung zu ihr her oder nicht, und falls ja, liegt die Extension des Ausdrucks damit fest, falls nein, ist sie leer. Allerdings kann sich die Sprachgemeinschaft darüber täuschen (sogar jahrhundertelang), ob sie erfolgreich eine Art

\footnotetext{
${ }^{68}[$ Fine75], S.22ff.

${ }^{69}$ [Kuhn90], S.311/312, [Kuhn89], S.28; vgl. auch [Shap82a], S.10ff.

${ }^{70}$ [Kuhn90], S.303, [Kuhn89], S.17.

${ }^{71}$ Siehe z.B. [Fiel73, EaFi77].

${ }^{72}$ [Hack83a], S.84ff.

${ }^{73} \mathrm{Vgl}$. [Hack83a], S.87ff.
} 
(bzw. Größe) benannt hat, welches deren wesentliche und sonstige Eigenschaften sind und was deren Extension ist. Die genannten historischen Fälle sind dann dementsprechend alle im Sinne der Korrektur solcher Irrtümer zu interpretieren, gegenläufige vortheoretische Intuitionen über Referenzbeziehungen sind zurückzuweisen. ${ }^{74}$

Probleme verwandter Art treten auf bei Ausdrücken, über die viele intuitiv sagen würden, daß sie nicht referieren, obwohl man das früher einmal dachte. Wenn man z.B. die Einführung des Ausdrucks 'Phlogiston' rekonstruiert als Referenzfixierung mittels der Beschreibung 'das, was die Umwandlung von Metall in Metalloxid bei Erhitzung verursacht', dann ist schwer zu sehen, was dagegen spricht, daß 'Phlogiston' auf Sauerstoff referiert. Dies ist ein Fall, in dem nach dem Modell von Kripke und Putnam herauskommt, daß ein Ausdruck eine nicht-leere Extension hat, die er intuitiv nicht haben sollte. ${ }^{75}$

Solche Intuitionen über die Extension wissenschaftlicher Ausdrücke sprechen zumindest prima facie gegen Kripkes Modell, aber auch gegen Putnams (demgegenüber etwas modifizierte) Konzeption von Referenz, obwohl sich bei ihm Andeutungen finden, mit welchen Mitteln das Problem ausgeräumt werden könnte: Putnams "Principle of the Benefit of Doubt" läßt zwar zu, daß ein Teil der zur Termeinführung benutzten referenzbestimmenden Beschreibungen und der Überzeugungen der Sprecher falsch ist, aber es soll andererseits Referenz in solchen Fällen ausschließen, in denen von den referenzbestimmenden Beschreibungen und den Überzeugungen zu wenig wahr ist, und Putnam räumt außerden die Möglichkeit mehrerer Einführungsereignisse mittels verschiedener Beschreibungen für denselben Ausdruck ein. Damit läßt sich nach Putnam der Fall 'Phlogiston' behandeln ${ }^{76}$ und vielleicht auch einige weitere der genannten Problemfälle. Es scheint also, als ob Putnam in gewisser Weise Elemente einer Beschreibungstheorie in sein Modell integrieren wollte, tatsächlich tut er diesen Schritt jedoch nicht, da er erklärtermaßen nichts Präzises und Allgemeines darüber sagen kann und will, was oder wieviel von den einführenden Beschreibungen und den Überzeugungen eines Sprechers korrekt sein muß, um gemäß dem

\footnotetext{
${ }^{74}$ Alternativ könnte man versuchen, diese Fälle mit Hilfe von erneuten Taufen bzw. Termeinführungen (zu den Zeitpunkten, an denen man intuitiv von einer Extensionsverschiebung sprechen würde) zu rekonstruieren. (Man müßte dann versuchen, für den jeweiligen Ausdruck zwei historische Einführungsereignisse zu finden bzw. zu rekonstruieren, die dem Ausdruck die beiden für die Zeiten vor und nach der Extensionsveränderung intuitiv angemessenen Extensionen zuordnen.) Diese Lösung erscheint (abgesehen von historischen Fragen) grundsätzlich nicht unplausibel, es tritt jedoch sofort das Problem auf, daß bei Annahme einer kausalen Referenztheorie nicht klar ist, wieso eine Sprachgemeinschaft zum Mittel einer erneuten Termeinführung greifen sollte, wenn sich ihre Überzeugungen bzw. die akzeptierten Theorien über die jeweilige Art oder Größe (massiv) verändert haben. Wenn die Referenzrelation eines Ausdrucks tatsächlich eine Sache ist, und die Überzeugungen der Sprecher bzw. die akzeptierten Theorien über die Extension des Ausdrucks eine andere, scheint es nach der kausalen Referenztheorie keinen guten Grund für eine erneute Taufe oder Termeinführung zu geben. Wenn eine Sprachgemeinschaft tatsächlich regelmäßig Neutaufen bzw. erneute Termeinführungen vornimmt, wenn sie zu der Ansicht kommt, daß ihre bisherigen Überzeugungen oder Theorien über das, worauf ein Ausdruck referiert, zu fehlerhaft waren, stellt sich sofort die Frage, welche (Art von) Überzeugungen bzw. welche Teile der akzeptierten Theorien sich nicht als fehlerhaft erweisen dürfen, wenn es nicht zu einer Neueinführung des entsprechenden Ausdrucks kommen soll. Diese Überzeugungen bzw. Theorieteile scheinen dann in ihrer Funktion kaum noch von den referenzbestimmenden Beschreibungen einer Beschreibungstheorie zu unterscheiden zu sein: Die Referenz des fraglichen Ausdrucks wird aufgrund der Aufgabe dieser Überzeugungen bzw. Theorieteile neu bestimmt; die wesentliche verbliebene Differenz scheint zu sein, daß diese Neubestimmung der Referenz unterschiedlich beschrieben wird. Mit anderen Worten: Es sieht so aus, als ob eine Beschreibungstheorie gleichsam durch die Hintertür wieder eingeführt würde, wenn man erneute Termeinführungen aufgrund von Änderungen in den Überzeugungen oder den akzeptierten Theorien zuläßt. Dies mag ein plausibler Schritt sein, ob ihn Putnam und Kripke gehen wollen, ist jedoch zweifelhaft (s.u.).

${ }^{75}$ Vgl. z.B. [Nola80], S.520.

${ }^{76}$ Vgl. [Putn88], S.13/14.
} 
"Principle of the Benefit of Doubt" noch eine Referenzbeziehung zu ergeben. Dadurch bleibt seine Referenztheorie an dieser im Hinblick auf die oben genannten Problemfälle entscheidenden Stelle unscharf, und er setzt sich dem Verdacht aus, daß er Konflikte zwischen den genannten Intuitionen und seiner Referenztheorie nur deswegen vermeiden kann, weil die Anwendung seines Modell (und des "Principle of the Benefit of Doubt") auf einen konkreten Fall nicht in systematischer und sozusagen autonomer Weise ein Urteil über das Vorliegen oder Nicht-Vorliegen einer Referenzrelation liefert, sondern solche Urteile von Fall zu Fall ad hoc durch Intuitionen über den Einzelfall beeinflußt werden.

Auf die genannten Intuitionen zu reagieren, indem man insistiert, daß in den genannten Problemfällen keine Extensionsveränderungen vorliegen, sondern lediglich Veränderungen der Überzeugungen der Sprachgemeinschaft über die Extension ihrer Ausdrücke, ist eine Position, die sich ohne Inkohärenz durchhalten läßt, sie würde jedoch für viele, diesen Intuitionen einiges an Gewicht beimessen, die Plausibilität der kausalen Referenztheorie massiv beeinträchtigen.

\subsubsection{Generalisierungsprobleme bei der Einführung von Art- und Größen- namen}

Der "Herstellungsmechanismus" für Referenzbeziehungen, der gemäß der Theorie von Kripke und Putnam bei der Einführung eines Art- oder Größennamens wirksam ist, erscheint in mehreren Hinsichten erläuterungsbedürftig. Den problematischen Punkt stellen die Erweiterungen dar, die Kripke und Putnam zu den Ideen der kausalen Theorie für Eigennamen hinzufügen, um sie auf Art- und Größennamen zu übertragen.

Bei der Vergabe eines Eigennamens an ein Individuum in einem Taufakt muß "lediglich" ein Einzelding (auf irgendeine Weise ${ }^{77}$ ) identifiziert werden. Dagegen wird bei der Vergabe eines Art- bzw. Größennamens eine ganze Art bzw. eine Größe benannt, d.h. der Art- bzw. Größenname wird an eine ganze Menge von Individuen bzw. Instantiierungen (die Extension) vergeben, die nach Kripke und Putnam mit den bei der Namensvergabe herausgegriffenen bzw. gekennzeichneten Exemplaren ${ }^{78}$ gewissermaßen verbunden sind durch eine (im Fall einer physikalischen Größe) oder mehrere (i.a. im Fall einer Art) gemeinsame Eigenschaften. Der Punkt, der erläuterungsbedürftig ist, ist die Generalisierung von den bei der Namensvergabe herausgegriffenen Individuen bzw. Instantiierungen auf die gesamte Extension des Art- bzw. Größennamens: Wodurch wird bestimmt, an welche Individuen bzw. Instantiierungen (neben den referenzfixierenden) der Name vergeben wird?

Die Reaktion von Kripke und Putnam an dieser Stelle ist die, darauf zu bestehen, daß die referenzfixierenden Exemplare entweder genau einer Art angehören bzw. eine Größe exemplifizieren oder nicht, ${ }^{79}$ und falls ja, legt diese die Generalisierung fest, falls nein, wurde der Name zu Unrecht vergeben und muß wieder aus dem Verkehr gezogen werden.

Diese Antwort ist in mehreren Hinsichten erläuterungsbedürftig. Eine davon wird sichtbar, wenn man sich "echte", in der Praxis verwendete Artnamen ansieht, z.B. gerade die

\footnotetext{
${ }^{77}$ Die damit verbundenen Probleme (Identitätskriterien für Einzeldinge verschiedener Kategorien u.ä.) können hier nicht erörtert werden.

${ }^{78}$ Bei der Einführung eines Artnamens (wie 'Gold') per Taufe in Gegenwart eines Musters sind dies einige wenige Exemplare, bei der Einführung eines Größentermes oder eines Artnamens (wie 'Elektron') per kausaler Beschreibung als Ursache eines Phänomentyps ist es eine unbegrenzte Menge von Exemplaren, aber dennoch nur ein Teil der Extension, da dieselbe Größe bzw. Entität sich i.a. auch in anderen Phänomenen zeigt.

${ }^{79}$ Die Möglichkeit, daß einzelne "falsche" Exemplare benannt werden, bleibt hier beiseite.
} 
paradigmatischen Beispiele von Kripke und Putnam: Bei Gold ist es die Ordnungszahl 79, die die Art ausmacht ${ }^{80}$ — nicht beispielsweise das Atomgewicht (womit jedes Isotop zu einer Art würde), die quantenmechanische Wellenfunktion der Atome (eine sicherlich noch fundamentalere Eigenschaft als die Ordnungszahl, die in jeder chemischen Verbindung etwas anders aussieht) oder die Struktur des Kristallgitters. ${ }^{81}$ Bei Wasser ist es die chemische Zusammensetzung $\mathrm{H}_{2} \mathrm{O}$ - und nicht etwa (zusätzlich) der Aggregatzustand (so daß flüssiges Wasser, Eis und Wasserdampf verschiedene Arten wären) oder das Molekulargewicht (womit schweres Wasser eine eigene Art darstellen würde). ${ }^{82}$ Der durch diese Beispiele illustrierte Punkt ist der, daß (nach heutigem Kenntnisstand jedenfalls) die referenzfixierenden Exemplare einer Art (welche das auch immer bei der jeweiligen historischen Termeinführung gewesen sind) i.a. mehrere gemeinsame Struktureigenschaften aufweisen bzw. entsprechenden Gesetzen unterliegen (die zum Teil auf verschiedenen mikroskopischen Ebenen liegen). Nach dem Modell von Kripke und Putnam wird durch die Termeinführung (im Erfolgsfall) eine einzelne bzw. eine bestimmte Gruppe dieser Eigenschaften bzw. Gesetze als artkonstituierend ausgezeichnet, und an dieser Auszeichnung hängt die Extrapolation von den referenzfixierenden Exemplaren zu den anderen, die zur selben Art gehören, sprich: zur Extension der Art. Der erläuterungsbedürftige Punkt ist, wie und mit Hilfe welcher Ressourcen diese Auszeichnung vorgenommen wird. ${ }^{83}$

Dieser Punkt hat sozusagen zwei Dimensionen, eine ontologische und eine sprachphilosophische. Von einem nominalistisch orientierten Standpunkt aus kann man die (ontologische) Frage stellen, wieso die Ordnungszahl 79 artkonstituierend für Gold ist, bzw. allgemein formuliert, was eine Eigenschaft zur essentiellen oder wesentlichen Eigenschaft einer Art macht, also den Essentialismus hinterfragen, der zu den Modellannahmen von Kripke und Putnam zu zählen scheint. ${ }^{84}$ Wenn man die Prämisse zugibt, daß es auf der Sachebene Arten gibt, die durch bestimmte essentielle Eigenschaften konstituiert werden (was immer das heißt), kann man weiter die (sprachphilosophische) Frage stellen, in genau welcher Weise sich von einem solchen Sachverhalt zur Referenzfixierung Gebrauch machen läßt, anders formuliert: auf genau welche Weise unter den Eigenschaften und Gesetzen, die den benannten Exemplaren gemeinsam sind, die essentiellen Eigenschaften ausgezeichnet werden. Die Antwort, die man im Sinne von Kripke und Putnam darauf geben könnte, ist zunächst die, daß eine essentielle Eigenschaft (und damit die benannte Art) mittels der (als definit und nicht-leer unterstellten) Kennzeichnung 'diejenige gemeinsame Eigenschaft der benannten Exemplare, die essentiell ist' identifiziert werden kann. Man kennzeichnet also eine Eigenschaft erster Ordnung (z.B. Ordnungszahl 79) durch eine Eigenschaft zweiter Ordnung (essentiell). ${ }^{85} \mathrm{Ob}$ mit dieser Antwort viel gewonnen ist, solange man nicht erläutert, was eine Eigenschaft zu einer essentiellen macht, oder wenigstens, woran sich erkennen läßt oder was epistemisch dafür (oder dagegen) spricht, daß eine Eigenschaft

\footnotetext{
${ }^{80}$ Vorausgesetzt die heutigen diesbezüglichen Überzeugungen bzw. Kripkes und Putnams Lesart davon sind korrekt.

${ }^{81}$ Die Eigenschaften und Größen, von denen in der Quantenmechanik die Rede ist (wie insbesondere die Wellenfunktion, aber auch Gitterstruktureigenschaften), kommen hier nur unter der — natürlich kontroversen - Annahme in Betracht, daß es sich dabei um reale Eigenschaften und Größen handelt.

${ }^{82}$ [Zema76], S.120.

${ }^{83}$ Kritik an der kausalen Referenztheorie, die an diesem Punkt ansetzt, meldet z.B. Kuhn an; vgl. [Kuhn89], S.28ff., [Kuhn90], S.312ff.

${ }^{84}$ Diese Frage richtet sich vielleicht mehr an Kripkes Verständnis von artkonstituierenden Eigenschaften als an das von Putnam. Putnam ist in ontologischer Hinsicht gleichsam weniger anspruchsvoll, von essentiellen Eigenschaften ist bei ihm nur beiläufig die Rede ([Putn75i], S.235, [Putn75g], S.140/141; vgl. dazu auch [Putn90b]).

${ }^{85}$ Hier ist vorausgesetzt, das klar ist, was als Eigenschaft erster Ordnung zählt — s.u.
} 
essentiell ist, läßt sich jedoch bezweifeln.

Bei Kripke und Putnam findet sich wenig Erhellendes zu diesem Punkt; es liegt aber immerhin eine (und vielleicht die einzige) Richtung nahe, in der mit Aussicht auf Erfolg nach einer Erläuterung zu suchen wäre: Daß eine Eigenschaft essentiell ist, sollte sich erläutern lassen unter Bezugnahme darauf, wie fundamental, explanatorisch zentral o.ä. sie in Relation zu anderen Eigenschaften ist. Wenn sich eine Erläuterung dieser Art finden läßt, spricht nichts mehr gegen die obige Antwort auf die anschließende sprachphilosophische Frage. Eine solche Erläuterung dürfte mit einiger Wahrscheinlichkeit zur Folge haben, daß man ein begründetes Urteil darüber, ob eine Eigenschaft wesentlich ist, erst dann fällen kann, wenn man über umfangreiche, mehr oder weniger vollständige Kenntnisse über die fragliche Art oder sogar den ganzen "umliegenden" Gegenstandsbereich verfügt (vielleicht sogar über die "finale Theorie" des jeweiligen Gegenstandsbereichs $\left.{ }^{86}\right) .{ }^{87}$ Darin läge aber kein besonderes Problem für die kausale Referenztheorie, da sie grundsätzlich zwischen semantischen Tatsachen und dem epistemischen Zugang zu diesen trennt.

Zwei weitere erklärungsbedürftige, in gewisser Weise grundsätzlichere Aspekte der "Herstellung" einer Referenzbeziehung bei der Einführung eines generellen Ausdrucks sieht man klarer bei den Größennamen, wo die Unterscheidung essentielle/nicht-essentielle Eigenschaften nicht relevant ist. ${ }^{88}$ Zum einen: Wenn ein Größenname mittels der (kausalen) Verknüpfung mit einem in der referenzfixierenden Kennzeichnung genannten Phänomen, einer Größe o.ä. vergeben werden soll, muß zunächst auf irgendeine Weise festgelegt werden, was für eine Kategorie von Entität benannt werden soll, nämlich bei Größennamen eine Größe (nicht ein Typ von Ereignissen, eine Menge von Gegenständen o.ä.). Elektrische Ladung etwa ist eine physikalische Größe, die in Blitzen bzw. den vorausgehenden Prozessen instantiiert ist, ${ }^{89}$ nicht z.B. eine Menge von Ereignissen, die die Ursache von Blitzen einschließt. Zum anderen: Wenn die Kausalrelation, wie meistens üblich, als Relation zwischen Ereignissen aufgefaßt wird und daher eine referenzfixierende kausale Verknüpfung per se zunächst auf Ereignisse als Exemplare führt, muß zur Benennung einer Größe ferner bestimmt werden, welche Größe von den in diesen Ereignissen gemeinsam instantiierten benannt werden soll, und damit, welche Individuen, Ereignisse o.ä. neben denen, die (kausal) mit den in der referenzfixierenden Kennzeichnung genannten verknüpft sind, noch zur Extension gehören. Grundsätzlich kann jede begrenzte Menge von Individuen, Ereignissen o.ä. auf verschiedene Weisen "extrapoliert" werden, es soll aber z.B. 'elektrische Ladung' elektrische Ladung bezeichnen, nicht elektrische Leitfähigkeit, Ionendichte o.ä. ${ }^{90}$

Hinsichtlich des ersten der beiden genannten Probleme besteht eine Differenz zwischen den Positionen von Kripke und Putnam: Putnam will z.B. die Referenz des Ausdruckes

\footnotetext{
${ }^{86}$ Sofern es so etwas gibt.

${ }^{87}$ Ironischerweise illustrieren Kripke und Putnam diesen Punkt selbst, wenn sie, offenbar aufgrund (nach heutigem Kenntnisstand) mangelhafter biologischer Kenntnisse, die DNA-Struktur für die essentielle Eigenschaft einer biologischen Spezies halten; vgl. S.90.

${ }^{88}$ Die im folgenden diskutierten Probleme betreffen aber natürlich auch die Artnamen.

${ }^{89}$ Vielleicht auch Stromstärke, Feldstärke o.ä. Putnams Beispiel wird hier modifiziert, da Elektrizität, jedenfalls nach heutigem Sprachgebrauch, eher eine summarische, wenig scharfe Bezeichnung für einen Phänomenbereich ist, keine physikalische Größe in dem engeren Sinn, daß sie eine Maßeinheit hat, Zahlenwerte annimmt usw.

${ }^{90}$ An dieser Stelle ließe sich auch das von Goodman konstruierte Problem "bizarrer" Eigenschaften wie grue und bleen [Good55] und Größen wie elektrische-Ladung-in-Blitzen-und-Masse-außerhalb-von-Blitzen aufwerfen, sowie die Frage, wie sicherzustellen ist, daß ein Ausdruck auf "anständige" Eigenschaften und Größen referiert und nicht auf ähnliche der von Goodman konstruierten Art. Dieses Problem bleibt hier beiseite, weil es sich für jede Referenztheorie stellt, für Beschreibungstheorien ebenso wie für die kausale Referenztheorie.
} 
'Elektrizität' festlegen durch "die Größe, die Ursache von Blitzen ist", Kripke dagegen schlägt eine Kennzeichnung von der Art "was immer die Ursache von Blitzen ... ist" vor. ${ }^{91}$ Kripkes Kennzeichnung der Referenz ist also rein kausal, während Putnam dem durch den semantischen Marker 'physikalische Größe' eine Art minimale Beschreibung hinzufügt. Inwieweit das für die Referenztheorie einen Unterschied macht, hängt allerdings davon ab, wie man Putnams These bewertet, daß die Spezifikation der Ursache eines Phänomens durch den semantischen Marker, wenn es sozusagen hart auf hart kommt, revidierbar ist, ohne daß dadurch notwendigerweise die Referenzbeziehung berührt wird. ${ }^{92}$ Die Angabe einer Kategorie als Teil der referenzfixierenden Beschreibung würde jedenfalls das erste der beiden Probleme lösen.

Das zweite der beiden genannten Probleme ist aus der Sicht von Kripke und Putnam kein grundsätzliches, sondern löst sich von selbst, wenn ontologische Fragen und "praktische" Fragen der Referenzfixierung auseinandergehalten werden: Ihrer Ansicht nach liegen Eigenschaften und Größen (und ihre Extension) und ebenso ihre kausalen Beziehungen zu anderen Eigenschaften/Dingen/Ereignissen sozusagen auf der Sachebene fest $;{ }^{93}$ alle Probleme, die mit der Extrapolation einer endlichen Menge zu tun haben, sind "praktische" Probleme, die prinzipiell bei jeder als definit intendierten Kennzeichnung auftreten können, die aber in der Praxis in der Regel durch "genügend reichhaltige" Beschreibungen lösbar sind, auch wenn Irrtümer natürlich immer möglich sind.

Wenn man die ontologischen Annahmen von Kripke und Putnam, daß es auf der Sachebene Größen gibt, zugesteht und wenn man weiterhin mit Putnam (jedoch anders als Kripke) fordert, daß bei der Einführung eines Größennamens die Kategorie der zu benennenden Entität per Beschreibung festgelegt werden muß, dann bleibt von den beiden genannten Problemen lediglich der Befund, daß bei der Einführung eines Art- oder Größennamens die referenzfixierende Beschreibung so gewählt werden muß, daß die Beschreibung eine Art bzw. Größe wirklich eindeutig kennzeichnet (innerhalb des Spielraums, den das "Principle of the Benefit of Doubt" läßt). Daß dies, wie Putnam vorschlägt, durch die Angabe hinreichend vieler Eigenschaften oder Gesetze erreicht werden kann, erscheint grundsätzlich plausibel.

Dieser letztgenannte Befund, daß die Einführung eines Art- oder Größennamens eine Kennzeichnung durch hinreichend viele Eigenschaften oder Gesetze erfordert, legt vielleicht den Verdacht nahe, daß solche Namen (anders als vorne ${ }^{94}$ dargestellt) gemäß der kausalen Referenztheorie doch mit Problemen der Referenzinstabilität bei Theorienwandel belastet sind. Bei der Einführung eines Art- oder Größennamens durch Beschreibungen der intendierten Referenzobjekte besteht (anders als im Fall einer ostensiven Taufe) naturgemäß die Gefahr, fehlerhafte Beschreibungen zu verwenden. Dies bedeutet gemäß Putnams "Principle of the Benefit of Doubt" zwar nicht automatisch, daß keine Referenzrelation zustande kommt, aber auch nach Putnam darf eine einführende Beschreibung nicht "zu fehlerhaft" sein, und die Gefahr, daß sie das ist, dürfte tendenziell bei hochtheoretischen Arten und Größen größer sein als bei beobachtungsnahen und sie dürfte tendentiell umso größer sein, je mehr hochtheoretische Eigenschaften und Gesetze zur eindeutigen Kennzeichnung einer Art oder Größe (also zu ihrer Abgrenzung von anderen, ebenso hochtheoretischen) erforderlich sind. Die kennzeichnenden Eigenschaften und Gesetze dürften insbesondere im Fall

\footnotetext{
${ }^{91}$ Wenn man seine wenigen Bemerkungen zu diesem Punkt — vgl. [Krip80], S.129/130 — so weit pressen darf; Hervorhebungen von mir.

${ }^{92} \mathrm{Vgl}$. S.80.

${ }^{93}$ Siehe z.B. [Putn75j], S.288.

${ }^{94}$ S.87f.
} 
hochtheoretischer Arten und Größen zu dem zum Zeitpunkt der Termeinführung akzeptierten Theorienbestand gehören und damit grundsätzlich auch dem historischen Wandel unterworfen sein, dem dieser Bestand unterliegt. Welche Konsequenzen dies hat, ob also zur Einführung eines Art- oder Größennamens verwendete Beschreibungen, die "reichhaltig" genug sind, um die diskutierten Generalisierungsprobleme zu lösen, dann doch, wie bei vielen Beschreibungstheorien, zu (zumindest prima facie) problematischen Referenzinstabilitäten bei Theorienwandel führen, hängt davon ab, wie Putnams "Principle of the Benefit of Doubt" genau aufzufassen und anzuwenden ist, und läßt sich erst dann entscheiden, wenn man von dessen Inhalt eine genaues Bild hat. Putnams Texte deuten jedoch, wie oben erörtert, darauf hin, daß die Anforderungen, die er in puncto Korrektheit an einführende Beschreibungen stellt, so schwach sind, daß auch bei hochtheoretischen Beschreibungen, die "hinreichend reichhaltig" sind, um Generalisierungsprobleme zu lösen, keine nennenswerten Referenzinstabilitäten zu erwarten sind.

Fazit: Bei der Einführung von Art- und Größennamen treten verschiedenen Generalisierungsprobleme auf, die aber alle lösbar aussehen, wenn man die (ontologische) Annahme von Kripke und Putnam akzeptiert, daß es Eigenschaften und Größen gibt. Was eine Eigenschaft bzw. Größe zu einer essentiellen macht, bleibt erläuterungsbedürftig, und es scheint erforderlich, die kausale Referenztheorie, wie von Putnam angedeutet, in der Weise zu ergänzen, daß für eine referenzfixierende Beschreibung die Angabe von so etwas wie einer Kategorie gefordert wird. Ansonsten betreffen die genannten Generalisierungsprobleme lediglich "praktische" Fragen bei der "ordnungsgemäßen" und erfolgreichen Einführung von Art- und Größennamen.

\subsubsection{Die Rolle der Kausalität in der kausalen Referenztheorie}

Eine weitere Frage, die man an Kripke und Putnam richten kann, ist schließlich die nach näheren Erläuterungen zu dem von ihnen an zwei Stellen ins Spiel gebrachten, philosophisch kontroversen Stichwort Kausalität. ${ }^{95}$ Bei Putnam findet sich eine knappe Bemerkung, daß Humes Regularitätsanalyse der Kausalität für seine Zwecke nicht geeignet ist, ${ }^{96}$ ansonsten äußern sich Kripke und Putnam dazu nicht. Dies sieht vielleicht auf den ersten Blick enttäuschend aus, es lassen sich aber Gründe für dieses Vorgehen finden.

Zum einen bereitet die Erläuterung dessen, was Kausalität ist, notorisch hartnäckige Probleme, und dies generell, also in sämtlichen Bereichen, in denen davon die Rede ist; gleichzeitig ist der Begriff der Kausalität in vielen Bereichen von derart zentraler Bedeutung, daß es ${ }^{97}$ keine plausible Option ist, auf ihn $\mathrm{zu}$ verzichten. Es ist es daher in einer sprachphilosophischen Untersuchung eine plausible Strategie, den Kausalbegriff ohne Erläuterung, Analyse o.ä. zu verwenden, solange intuitiv einigermaßen klar ist, wovon die Rede ist, und letzteres ist bei der kausalen Referenztheorie zweifellos der Fall. Damit hält man die Möglichkeit offen, später eventuell geeignete Erläuterungen hinzuzufügen, möglicherweise verschiedene für die beiden Rollen der Kausalität.

Zum anderen ist bei genauerem Hinsehen ohnehin fraglich, ob Kripkes und Putnams Rede von Kausalität mehr ist als eine grobe, vorläufige Charakterisierung dessen, was sie im Sinn haben: Bei der als "kausal" charakterisierten Beziehung zwischen physikalischer Größe und referenzfixierendem Phänomen kommt es offenbar nur darauf an, die Größe definit zu kennzeichnen durch eine "gesetzesartige" Relation zu einem epistemisch zugäng-

\footnotetext{
${ }^{95} \mathrm{Vgl} .[\mathrm{Kim} 77]$.

${ }^{96}$ [Putn75h], S.206.

${ }^{97}$ Pace Russell [Russ18c].
} 
lichen Phänomen. Putnam selbst räumt ein, daß dazu auch nicht-kausale Gesetze dienen können. ${ }^{98}$ Bei der Kette der Namensweitergabe kommt es offenbar im wesentlichen darauf an, daß die Referenz durch eine Relation festgelegt wird, die auf der Sachebene liegt und von Überzeugungen, sprachlicher Kompetenz u.ä. der Sprecher unabhängig ist. ${ }^{99}$ Kripke und Putnam sprechen von einer kausalen Kette, es steht jedoch auch für sie außer Frage, daß das Merkmal 'kausal' alleine nicht ausreicht, um einigermaßen zufriedenstellend zu charakterisieren, was eine solche Kette ausmacht, um also in der langen Vorgeschichte der Äußerungen eines Sprechers eine Kette von Ereignissen auszuzeichnen u.ä. Die Bezeichnung der Kette der Namensweitergabe als kausal ist daher plausiblerweise als vorläufig aufzufassen und es ist durchaus denkbar, daß man sie fallenläßt, wenn man über eine genauere Charakterisierung verfügt (obwohl damit die Grundlage der Bezeichnung kausale Referenztheorie verloren ginge). Damit würde man Keith Donnellan folgen, dessen Namenstheorie der von Kripke nahesteht und der nicht von kausalen Ketten spricht, sondern von historical connections. ${ }^{100}$

Daß Kripke und Putnam keine systematischen Erläuterungen der von ihnen in Anspruch genommenen Konzeption von Kausalität liefern, stellt also, gegeben den Entwicklungsstand ihres Modells und der philosophischen Untersuchungen zum Thema Kausalität generell, kaum einen ernsthaften Mangel dar. Davon unabhängig ist allerdings der Punkt, daß das Problem einer genaueren Charakterisierung der referenzkonstituierenden Ketten der Namensweitergabe, die über den Stand des erklärtermaßen vorläufigen Modells von Kripke und Putnam hinausgeht, auch über zwei Jahrzehnte nach Aufkommen der kausalen Referenztheorie weiter offen ist. ${ }^{101}$

\subsection{Fazit}

Auf der Grundlage der kausalen Referenztheorie läßt sich mit Hilfe von Tarskis semantischem Apparat eine Korrespondenztheorie der Wahrheit aufbauen. Referenz- und Wahrheitstheorie zusammen ergeben ein Bild von den semantischen Relationen von Sätzen und Theorien, nach dem ihr Wahrheitswert ohne Einschränkungen unabhängig von epistemischen Mitteln zu seiner Ermittelung ist. Referenz- und Wahrheitstheorie zusammen eignen sich daher gut zur Erläuterung oder Ergänzung semantischer realistischer Thesen und damit des Inhalts realistischer Positionen, die solche Thesen einschließen.

Im Hinblick auf die Argumentation für eine realistische Position, genauer: für eine Position, die ontologische oder epistemische realistische Thesen einschließt, hat die kausale Referenztheorie einen Prima-facie-Vorzug, der sie für viele Anhänger realistischer Positionen attraktiver erscheinen läßt als Beschreibungstheorien: Gemäß der kausalen Referenztheorie kann ein Sprecher auch dann auf Gegenstände, Arten und Größen referieren, wenn er (oder seine Sprachgemeinschaft) nicht über eine definite Beschreibung verfügt und/oder eine, mehrere oder viele falsche Beschreibungen damit verbindet. Dies hat zur Folge, daß Veränderungen im Bestand der akzeptierten wissenschaftlichen Theorien i.a. nicht zu Referenzinstabilitäten führen, und damit erhält man im Lichte der kausalen Referenztheorie von Teilen der Wissenschaftsgeschichte, die durch wiederholten Theorienwandel gekennzeichnet sind, nicht automatisch ein derart düsteres Bild wie es viele Beschreibungstheorien

\footnotetext{
${ }^{98}$ Vgl. S.82.

${ }^{99}$ Die Intentionen der Sprecher werden hier vernachlässigt.

${ }^{100}$ [Donn74]. Vgl. auch [Putn83d], S.213.

${ }^{101}$ Der bisher ausführlichste Versuch, den Ansatz von Kripke und Putnam weiter auszuarbeiten, ist wahrscheinlich noch immer [Devi81].
} 
liefern: ${ }^{102}$ Auch die in falschen Theorien auftretenden Ausdrücke können nach der kausalen Referenztheorie Referenz haben, daher können Theorien nicht nur ganz wahr oder ganz falsch sein, sondern sie können auch zu (mehr oder weniger großen) Teilen wahr bzw. falsch sein. Die Frage, welche Auswirkungen der Theorienwandel im Laufe der Wissenschaftsgeschichte bzw. der daran geknüpfte Gedanke einer pessimistischen Induktion auf die epistemische Bewertung realistischer Thesen hat, ist damit natürlich noch offen, aber es ist dann wenigstens sichergestellt, daß das Bild der Wissenschaftsgeschichte nicht durch die referenztheoretische Perspektive gleichsam automatisch verfinstert wird.

Trotz dieses Vorzugs läßt sich die kausale Referenztheorie nicht problemlos für eine realistische Position in Anspruch nehmen. Zunächst machen die oben erörterten Probleme der deskriptiven Adäquatheit des von Kripke und Putnam entworfenen Modells einige Modifikationen und/oder Einschränkungen des Anwendungsbereiches erforderlich, die den Ansatz jedoch nicht entwerten. Weniger ein grundsätzliches Problem, als eines der Anwendung ist, daß der Entwurf von Kripke und Putnam noch immer nicht sehr weit über das Stadium einer Skizze hinausgekommen ist. Diese Skizze genügt um den systematisch wichtigen Punkt zu machen, daß (in einem weiten Sinn) kausale Beziehungen zwischen Sprecher und Einführungsereignis bzw. Referenzentität zentral für Referenz und Bedeutung eines Ausdrucks sind, sie reicht jedoch in vielen Fällen nicht für eine Anwendung des Modells, insbesondere wenn es darum geht, in (mehr oder weniger) problematischen Fällen aus der Wissenschaftsgeschichte zu entscheiden, ob und wenn ja, worauf ein Ausdruck referiert.

Zwei weitere Punkte, die dagegen sprechen, die kausale Referenztheorie ohne weiteres als die für Realisten ideale semantische Theorie zu akzeptieren, lassen sich bereits beim derzeitigen Entwicklungsstand der Theorie erkennen. Zum einen legt das eine der oben diskutierten Generalisierungsprobleme den Schluß nahe, daß die kausale Referenztheorie dahingehend modifiziert werden sollte, daß sie als notwendige Bedingung für das Referieren eines Art- oder Größennamens fordert, daß die zur Termeinführung verwendete referenzfixierende Beschreibung die Angabe einer Kategorie einschließt. Zum anderen, und dies ist vielleicht der gewichtigste Einwand gegen die kausale Referenztheorie, ordnet sie vielen irgendwann in der Geschichte der Wissenschaften gebräuchlichen Art- und Größennamen, auf die sie sich bereits in ihrer derzeitigen Form in einigermaßen unkontroverser Weise anwenden läßt, eine Referenz bzw. Extension zu, die mit klaren, von vielen geteilten vortheoretischen Intuitionen über die Referenz bzw. Extension dieser Ausdrücke im Konflikt steht. Dieser Punkt deutet darauf hin, daß die kausale Referenztheorie sozusagen zu wenig "Wechselwirkung" zwischen den semantischen Relationen von Sätzen und Theorien einerseits und der Erkenntnispraxis der Sprecher andererseits zuläßt. Er legt ebenfalls den Schluß nahe, daß die kausale Referenztheorie modifiziert werden sollte, und zwar dahingehend, daß sie als notwendige Bedingung für das Referieren eines Art- oder Größennamens fordert, daß die zur Termeinführung verwendete referenzfixierende Beschreibung und auch die Kenntnisse eines Sprechers (oder seiner Sprachgemeinschaft) bestimmte korrekte minimale Beschreibungen einschließen.

Putnam versucht diese zuletzt genannten Probleme mit Hilfe seines "Principle of the Benefit of Doubt" auszuräumen. Inwieweit dies in überzeugender Weise gelingt, ist aufgrund des (erklärtermaßen) unscharfen Charakters dieses Prinzips schwer einzuschätzen, es liegt jedoch der Eindruck nahe, daß es so unscharf und flexibel ist, daß es in konkreten Anwendungsfällen alleine und ohne weitere "Zutaten" i.a. gar kein Urteil daüber liefert, ob ein Ausdruck Referenz hat und ggf. worauf er referiert, sondern daß Putnams konkrete

\footnotetext{
${ }^{102} \mathrm{Vgl.} \mathrm{Kap.2.6.4.}$
} 
Fälle betreffende (und vom Ergebnis durchaus plausible) Urteile, bei denen er sich auf sein Prinzip beruft, tatsächlich in wenig transparenter Weise aufgrund von Intuitionen über den jeweiligen Einzelfall zustandekommen. Wenn dieser Eindruck richtig ist, muß man offenbar zu dem Schluß kommen, daß es wünschenswert wäre, zusätzliche Mindestbedingungen für Referenz in systematischerer und unzweideutigerer Weise in eine (modifizierte) kausale Referenztheorie "einzubauen" als es Putnam tut, um zu einer Referenztheorie zu gelangen, die aus realistischer Perspektive sozusagen allen Ansprüchen genügt. 


\section{Kapitel 5}

\section{Hybridtheorien}

\subsection{Die Idee einer Hybridtheorie und ihre Varianten}

\subsubsection{Die Idee}

Ausgangspunkt für die Entwicklung der kausalen Referenztheorie war für Kripke und Putnam eine Kritik an den Beschreibungstheorien, also an den Referenztheorien, nach denen die Referenz eines Ausdrucks durch die seine Referenzobjekte beschreibenden (einzeln notwendigen und zusammen hinreichenden) Erfüllungsbedingungen bestimmt wird, die ein kompetenter Sprecher (oder die Sprachgemeinschaft ${ }^{1}$ ) mit dem Ausdruck verbindet. In ihrer eigenen Referenztheorie für Art- und Größennamen rücken Kripke und Putnam anstelle solcher Beschreibungen "kausale" Relationen ${ }^{2}$ zwischen dem Sprecher, der einen Ausdruck verwendet, und der Einführung des Ausdrucks bzw. zwischen den Referenzobjekten und dem zur Referenzfixierung herangezogenen Phänomen ins Zentrum und koppeln Referenzrelationen weitgehend von irgendwelchen Beschreibungen, die ein Sprecher (oder die Sprachgemeinschaft) mit dem Ausdruck verbindet bzw. den Referenzobjekten zuschreibt, und von Fragen der sprachlichen Kompetenz ab. Beschreibungen der Referenzobjekte spielen in der "reinen" Form der kausalen Theorie, wie Kripke sie skizziert, für die Bestimmung der Referenz (fast ${ }^{3}$ ) keine Rolle. Nach Putnam kommt solchen Beschreibungen eine gewisse, begrenzte Rolle dabei zu, jedoch nicht die von (einzeln notwendigen und zusammen hinreichenden) Erfüllungsbedingungen; Putnams positive Charakterisierung dieser Rolle bleibt unscharf und letzlich nicht zufriedenstellend.

Als Reaktion auf die im vorigen Kapitel diskutierten Einwände gegen die kausale Referenztheorie liegt es nahe, nach einer Art Hybridtheorie ${ }^{4}$ zu suchen, die sozusagen das Beste aus den beiden Welten der Beschreibungstheorie und der kausalen Theorie vereinigt, also nach einer Konzeption von der Referenz eines Ausdrucks, in die sowohl Beschreibungen im Sinne einer Beschreibungstheorie, als auch kausale Relationen im Sinne der kausalen Referenztheorie eingehen. Drei der Ansätze, in dieser Richtung eine Theorie für Art- und Größennamen zu entwickeln (insbesondere für "beobachtungsferne" aus den Wissenschaften), sollen hier erwähnt werden. ${ }^{5}$

\footnotetext{
${ }^{1}$ Diese Variante der Beschreibungstheorien geht allerdings bereits auf Putnams Kritik und seine Idee der linguistischen Arbeitsteilung zurück; vgl. Abschnitt 2.6.6.

${ }^{2}$ Siehe Abschnitt 4.5.4.

${ }^{3} \mathrm{Vgl}$. S.79.

${ }^{4}$ Diesen Terminus verwenden z.B. [Cumm92, Kim77].

${ }^{5}$ Eine Theorie dieser Art für Eigennamen findet sich in [Evan73].
} 
Die den verschiedenen Hybridtheorien gemeinsame Idee ist, der zentralen Aussage der kausalen Referenztheorie darüber, unter welchen Bedingungen ein von einem Sprecher verwendeter Art- oder Größenname auf eine bestimmte Art oder Größe referiert, eine weitere Bedingung hinzuzufügen. Diese Ergänzung betrifft beide nach Kripke und Putnam für eine Referenzrelation erforderlichen Voraussetzungen, die Einführung des Art- oder Größennamens und auch die Kette der Namensweitergabe:

1. Den Hybridtheorien zufolge ist für eine Referenzrelation zwischen einem von einem Sprecher verwendeten Art- oder Größennamen und einer Art bzw. Größe nicht nur eine kausale Charakterisierung seiner Referenz als Ursache bestimmter Phänomene bei der Einführung des Namens erforderlich, sondern die Referenzentitäten müssen bei der Namenseinführung zusätzlich durch eine bestimmte minimale Beschreibung (korrekt) gekennzeichnet werden. ${ }^{6}$

2. Den Hybridtheorien zufolge ist für eine referierende Verwendung eines Art- oder Größennamens nicht nur erforderlich, daß der Sprecher durch eine kausale Kette der Weitergabe mit dem Einführungsereignis dieses Namens verbunden ist. Vielmehr ist dazu außerdem die Kenntnis der zur Einführung erforderlichen Charakterisierung der Referenzobjekte erforderlich, also der kausalen und der zusätzlichen minimalen Beschreibung. Je nach Version der Hybridtheorie wird diese Kenntnis von jedem Sprecher selbst gefordert, damit er den Art- oder Größennamen referierend verwenden kann, oder, wenn man Putnams Idee der linguistischen Arbeitsteilung in die Hybridtheorie "einbaut", nur von den Experten der jeweiligen Sprachgemeinschaft. ${ }^{7}$

Eine Hybridtheorie fügt also gewissermaßen einer kausalen Referenztheorie Elemente einer Beschreibungstheorie hinzu, nicht umgekehrt: Die gemäß der Hybridtheorien für eine Referenzrelation erforderlichen Beschreibungen haben nicht den Status von Erfüllungsbedingungen, wie sie eine Beschreibungstheorie vorsieht: Die kausale Beschreibung und die zusätzliche minimale Beschreibung der Referenzobjekte müssen zwar zu den Überzeugungen desjenigen, der den Art- oder Größennamen einführt, und des jeweiligen Sprechers (bzw. Experten) zählen; sie müssen unter deren Überzeugungen jedoch keinerlei ausgezeichneten Status aufweisen, etwa zur Bedeutung, Intension o.ä. des Namens gehören (sofern dieser so etwas hat $\left.{ }^{8}\right)$. Gemäß der Hybridtheorien ist die Referenz eines Art- oder Größennamens also nicht völlig unabhängig von den Überzeugungen bzw. den Beschreibungen, die ein Sprecher (bzw. Experte) damit assoziiert, aber doch weitgehend, nämlich unabhängig von allen bis auf die einführende kausale Beschreibung und die zusätzliche minimale Beschreibung der Referenzobjekte.

Der entscheidende Punkt bei der Entwicklung einer Hybridtheorie ist klarerweise, was genau als minimale Beschreibung der Referenzobjekte gefordert wird. Die geforderte Beschreibung sollte "reichhaltig genug" sein, um die oben diskutierten Probleme der rein kausalen Referenztheorie zu vermeiden, andererseits muß sie offenbar einigermaßen sparsam ausfallen, wenn die Hybridtheorie nicht mit denselben Problemen der Referenzinstabilitäten belastet sein soll wie viele Beschreibungstheorien. Die drei im folgenden erläuterten Ansätze fordern als minimale Beschreibung die Angabe der Kategorie der benannten Entität(en), des kausalen Mechanismus, der die Referenzobjekte mit dem zur Einführung herangezogenen Phänomen o.ä. verbindet, oder einer explanatorischen Metapher.

\footnotetext{
${ }^{6}$ Für Näheres zur geforderten Art der korrekten Kennzeichnung s.u.

${ }^{7}$ Diese beiden Versionen der Hybridtheorien werden im folgenden meistens nicht explizit unterschieden.

${ }^{8}$ Die Hybridtheorien sind Referenztheorien und können grundsätzlich mit verschiedenen Bedeutungstheorien kombiniert werden; s.u.
} 


\subsubsection{Die Angabe einer Kategorie als minimale Beschreibung}

Eins der oben ${ }^{9}$ diskutierten Generalisierungsprobleme der kausalen Referenztheorie war, daß bei der Einführung eines Art- oder Größennamens festgelegt werden muß, was für eine Kategorie von Entität benannt soll, was jedoch in Kripkes "rein" kausaler Referenztheorie nicht gefordert wird. Eine Möglichkeit, eine Hybridtheorie zu konzipieren, ist, genau dies zur Bedingung für Referenz zu erklären, also als minimale Beschreibung, die bei der Einführung eines Art- oder Größennamens zur kausalen Beschreibung hinzutreten muß und die ein späterer Sprecher kennen muß, damit der von ihm verwendete Name referiert, die richtige Kategorie der benannten Entität zu verlangen.

Putnam scheint mit seiner Forderung, daß die Einführung eines Art- oder Größennamens und auch seine referierende Verwendung die Angabe bzw. Kenntnis eines semantischen Markers erfordert, offenbar einen Schritt in diese Richtung gehen zu wollen, er verlangt aber, wie oben diskutiert, letzten Endes als Bedingung für Referenz weder bei der Termeinführung, noch auf Seiten eines späteren Sprechers (in wirklich allen Fällen) einen korrekten Marker. ${ }^{10}$ Explizit wird der Vorschlag, daß die bei der Referenzfixierung bzw. auf Seiten eines Sprechers erforderliche, korrekte minimale Beschreibung etwas von der Art einer Kategorie sein soll, von Cummiskey am Beispiel Phlogiston diskutiert: ${ }^{11}$ Für Phlogiston sollte danach die geforderte minimale Beschreibung sein, daß es sich um eine materielle Substanz handelt.

\subsubsection{Die Angabe eines kausalen Mechanismus als minimale Beschrei- bung}

Eine zweite Möglichkeit, eine Hybridtheorie für Art- oder Größennamen zu konzipieren, ist, als minimale Beschreibung die Angabe des kausalen Mechanismus zu fordern, durch den die Art oder Größe das zur Namenseinführung herangezogene Phänomen o.ä. verursacht. Robert Nola vertritt diese Position. ${ }^{12}$ Er verlangt für die erfolgreiche, also spätere referierende Verwendung ermöglichende Einführung eines Art- oder Größennamens, daß

"[...] the person introducing the term [...] must have some causal beliefs about how the object picked out brings about the effect it does, i.e., the person has an explanatory account of how the object causes its effects." 13

Zur näheren Erläuterung dieser Idee bringt er den Ausdruck 'causal powers' ins Spiel:

"The general account of reference-fixing [...] can be expressed as follows: A scientist in observing phenomena $O$ may hypothesize that one kind of nonobservable entity is causally responsible in a particular way for $O$ and he may begin to call the kind of entity by the name ' $\mathrm{T}$ '. The scientist might make an explicit term introduction, or an historian of science with an interest in semantics might construct a hypothetical term introduction from the scientist's theoretical pronouncements and his experimental behavior. In introducing the name ' $\mathrm{T}$ ' to talk about $T$ the scientist will also attribute causal powers to $T$ such that it brings about phenomena $O$ in a particular way. That is, the

\footnotetext{
${ }^{9}$ Siehe Abschnitt 4.5.3.

${ }^{10}$ Vgl. Kap.4, Fn.23.

${ }^{11}$ Allerdings nur kurz; siehe [Cumm92], S.29/30.

${ }^{12}$ [Nola80]. Im Umriß findet sie sich auch bei [Kroo85], vgl. S.154, 162.

${ }^{13}$ [Nola80], S.516/517.
} 
scientist will form beliefs about $T$ of the form: all $T$ have power $P$ which in circumstances $C$ cause $O$ (for example, all phlogiston has the power to leave metal when the metal is heated thereby causing it to collapse into a powdery calx). Such causal beliefs enter crucially into fixing the reference of ' $T$ '. There is no separation, as there is in the bare causal account, between claiming the mere existence of a causal connection between $T$ and $O$ and a causal belief about how $T$ brings about $O$. The scientist may then attribute more causal powers $P^{\prime}, P^{\prime \prime}$, etc. to explain how $T$ gives rise to other phenomena $O^{\prime}, O^{\prime \prime}$, etc. in different conditions $C^{\prime}, C^{\prime \prime}$ etc. (for example, the extension of phlogiston theory to account for respiration, etc.) Such hypotheses about the causal powers of $T$ would have to be subject to test. However the original causal beliefs involved in fixing the reference of ' $\mathrm{T}$ ', being a priori true of $T$, would not be subject to test. This would not preclude the development and test at a later time of "higher" level theories concerning the precise way in which $T$ brings about $O$. For example, the claim that phlogiston's leaving metals causes calcination would not be subject to test but theories about how phlogiston is bonded or joined inside metals and how its leaving causes the collapse of the metal could be subject to test $[. .$.

The properties attributed to $T$ tell us more about the kind of thing $T$ is. In the case of phlogiston it is clear that it cannot be the same kind of thing as oxygen since, even though both are alleged to cause the same effects in the same conditions, they do so by exercising different causal powers." 14

Die Beschreibung des kausalen Mechanismus, die bei der Einführung des Art- oder Größennamens involviert ist, muß ein späterer Sprecher kennen, um den Namen referierend verwenden zu können. ${ }^{15}$

Nola erläutert nicht präzise, was er unter kausalen Vermögen (causal powers) oder unter einer Darstellung (account), "wie der Gegenstand seine Wirkungen verursacht", versteht, aber er macht immerhin an zwei Beispielen deutlich, daß er an so etwas wie die Grundzüge oder die qualitative Struktur einer detaillierten Kausalerklärung denkt:

"[...] theoretical beliefs about phlogiston must enter into any definition which fixes a reference for 'phlogiston'. The bare causal definition says nothing about how phlogiston is alleged to bring about its effect, or what restriction there should be on the range of causal mechanisms alleged to lead to the effect. Subsequent developments of a science will no doubt give an account of precisely how the cause brings about its effect. But the reference-fixing definition should specify how the cause is thought, in outline, to bring about its effect in the absence of more detailed knowledge of the causal powers of the entity named. What account can be given of this in the case of phlogiston?

All phlogiston theorists believed that when a metal is heated (a metal was believed to be a compound which always contained phlogiston) the phlogiston leaves the metal. Moreover it is the leaving of the phlogiston that causes the

\footnotetext{
${ }^{14}$ [Nola80], S.524/525.

${ }^{15}$ [Nola80], S.526. Nola spricht davon, daß das zur Namenseinführung verwendete Phänomen $O$ beobachtet wird, damit ist jedoch nicht notwendigerweise Beobachtung mit dem bloßen Auge gemeint, sondern in einem weiten Sinn, der den Einsatz von Meß-, Nachweis- und sonstigen Geräten zuläßt. An diesem Punkt liegt also keine oder keine nennenswerte Differenz zur Putnams kausaler Referenztheorie vor, nach der bei der Namenseinführung bereits etablierte, epistemisch gut zugängliche Phänomene, Gesetze o.ä. involviert sind.
} 
metal to collapse into a powdery calx. The solid metal could be restored by heating the calx with charcoal which was believed to be replete with phlogiston available for re-absorption into the calx. Even though no further information is supplied about how the leaving phlogiston causes the metal to collapse into a powder, the range of causal mechanisms whereby phlogiston brings about its effect is restricted. In particular it rules out cases where the same effects in the same conditions of heating are produced by something joining, rather than leaving, the metal, as is the case with oxygen." 16

"William Gilbert [...] spoke of fluid-like electric effluvia which were breath-like emanations from electrics [i.e. materials, such as amber and jet, which had the power to attract objects when rubbed ...] The electric effluvia were thought by Gilbert to penetrate the surrounding space of the electric uniting any external body to it thereby causing the attraction of the body to the electric [...]

Gilbert attributes particular causal powers to electric effluvia that we do not attribute to electricity. Through these powers it is believed to bring about the observed effects. Anything lacking these powers would not be electric effluvia. Hence a difference in the causal powers of electric effluvia and electricity whereby they are thought to bring about the same attraction effects in the same conditions is sufficient grounds for claiming that electric effluvia and electricity are different entities." 17

Mit der Angabe des Mechanismus, wie die Art oder Größe das zur Namenseinführung herangezogene Phänomen o.ä. verursacht, als minimale Beschreibung ist nach Nola implizit auch die Angabe der Kategorie der Art oder Größe gefordert. ${ }^{18}$

\subsubsection{Die Angabe einer explanatorischen Metapher als minimale Be- schreibung}

Cummiskey hat ${ }^{19}$ eine Hybridtheorie vorgeschlagen, der zufolge für die erfolgreiche Einführung eines Art- oder Größennamens als minimale Beschreibung zweierlei erforderlich ist: Erstens die Charakterisierung der Art oder Größe als die Ursache eines bestimmten, zur Referenzfixierung herangezogenen Phänomens und, zweitens, die Charakterisierung der Art oder Größe durch eine explanatorische oder theoriekonstitutive Metapher. Er nennt dies metaphor plus causal interaction analysis. ${ }^{20}$ Cummiskey erläutert diesen Vorschlag folgendermaßen:

"A metaphor involves a primary subject which is well understood and a secondary subject which is thought to have interesting similarities to the primary subject [...] The specific nature of these similarities, however, displays what Boyd calls 'inductive open-endedness' [... ] Boyd writes:

The reader is invited to explore the similarities and analogies between features of the primary and secondary subject, including features not yet discovered or not yet fully understood ... Theory constitutive metaphors are introduced when there is (or seems to be) good

\footnotetext{
${ }^{16}$ [Nola80], S.522/523.

${ }^{17}$ [Nola80], S.517-519.

${ }^{18}$ Vgl. [Nola80], S.517, 525.

${ }^{19}$ An eine Idee von Richard Boyd anknüpfend.

${ }^{20}$ [Cumm92], S.32.
} 
reason to believe that there are theoretically important respects of similarity or analogy between the literal subjects of the metaphors and their secondary subjects. The function of such metaphors is to put us on the track of those respects of similarity or analogy. ${ }^{21}$

In short, theory constitutive metaphors are 'invitations to future research': they serve to introduce terms without specifying the defining characteristics of the referent of the term, but instead leave it open for the routine business of scientists to discover the yet unspecified essential properties of the referent in question." 22

Cummiskey gibt einige Beispiele für explanatorische Metaphern:

"The idea is not just to introduce a term which will refer to whatever is responsible for certain empirical phenomena. The term 'optical aether' is introduced and used by Fresnel, MacCullagh, and Maxwell with more specific intentions. Optical aethers were supposed to provide a medium of transmission of transversal optical waves. The manner in which this medium transmitted optical waves was supposed to be similar to waves in a liquid. If optical aethers were similar to a liquid, then light could be explained by analogy to waves in a liquid. This would provide a purely mechanical account of light on a par with the mechanical rising and falling that constitutes the crest and trough of a wave propagated through a medium. The term is essentially linked to this metaphor $[\ldots]$ " 23

"In order to explain the phenomenon of heat, scientists introduced 'caloric' as a term they understood to refer to some kind of subtle, conserved, fluid-like stuff. The basic idea was that caloric, this conserved stuff, was held in other stuffs in a manner similar to water in a sponge. The term was grounded to the world via the scientists' ability to measure heat, and otherwise experience heat, and the term allegedly referred to something they took to be analogous to a subtle fluid." 24

Die Einführung eines Art- oder Größennamens erfolgt nach Cummiskey unter der Annahme, daß es genau eine Art bzw. Größe gibt, die kausal für das zur Referenzfixierung verwendete Phänomen verantwortlich ist und auf die die Metapher "paßt". Herauszufinden, ob diese Annahme erfüllt ist, und, wenn ja, in genau welcher Weise die Metapher "paßt", wird zukünftiger Forschung überlassen. Cummiskey spricht davon, daß in einem Forschungsprogramm die Metapher "artikuliert" werden muß im Hinblick auf die Natur bzw. die essentiellen Eigenschaften der Referenzentitäten. ${ }^{25}$ Damit ein späterer Sprecher den Art- oder Größennamen referierend verwenden kann, muß er (bzw. ein Experte) die bei der Namenseinführung involvierte kausale Charakterisierung und die Metapher kennen.

Charakteristisch für Cummiskeys Ansatz ist, daß er (wie Putnam es effektiv durch sein "Principle of the Benefit of Doubt" tut) keine "harten" Bedingungen spezifiziert, die eine Entität erfüllen muß, um zur Referenz eines Art- oder Größennamens zu zählen. Was er

\footnotetext{
${ }^{21}[$ Boyd79], S.363.

${ }^{22}$ [Cumm92], S.28.

${ }^{23}$ [Cumm92], S.29.

${ }^{24}$ [Cumm92], S.34.

${ }^{25}$ [Cumm92], S.30, 35.
} 
den von der "reinen" kausalen Referenztheorie genannten Bedingungen für das Vorliegen einer Referenzrelation als minimale Beschreibung hinzufügt, soll keine Angabe einer bestimmten Eigenschaft oder Relation sein (nicht einmal einer sehr allgemeinen, sprich: einer Kategorie ${ }^{26}$ ), die eine Entität entweder hat oder nicht hat, sondern etwas Flexibleres, eben eine Metapher, bei der die Hinsicht, in der eine Ähnlichkeit zum jeweiligen "primary subject" vorliegen muß, zunächst nicht exakt spezifiziert werden kann und soll. Dennoch leistet eine Metapher nach Cummiskey etwas für die Bestimmung der Referenz eines Art- oder Größennamens: Wie er an den Beispielen Wärmestoff und Äther zu illustrieren versucht, kann man seiner Ansicht nach unterscheiden zwischen Fällen, in denen das "primary subject" einem (pontentiellen) Referenzobjekt in relevanter Weise ähnlich ${ }^{27}$ ist, und Fällen, in denen dies nicht so ist, oder anders formuliert, zwischen Entitäten, für die eine bestimmte Metapher noch "angemessen" 28 ist, und solchen, für die das nicht gilt. Nach Cummiskey lassen sich explanatorische Metaphern sozusagen nicht beliebig weit dehnen. ${ }^{29}$

\subsubsection{Der Zusammenhang zwischen der Referenz eines Art- oder Größen- namens und den Eigenschaften, die den Referenzobjekten zuge- schrieben werden}

Den Hybridtheorien zufolge ist der Zusammenhang zwischen der Referenz eines Art- oder Größennamens und den Eigenschaften, die den Referenzobjekten zugeschrieben werden, wesentlich loser als gemäß der Beschreibungstheorien, aber andererseits deutlich enger als nach der kausalen Referenztbeorie. Die Extension eines Art- oder Größennamens wird nach den Hybridtheorien durch die für die Art oder Größe wesentlichen Eigenschaften bestimmt, genau wie bei Kripke und Putnam, und die wesentlichen Eigenschaften sind grundsätzlich zu underscheiden von sämtlichen Eigenschaften, die den Referenzobjekten von irgendwelchen Sprechern oder Sprachgemeinschaften zugeschrieben werden. Zu den letzteren Eigenschaften zählen die, die die Referenzobjekte gemäß irgendwelcher Überzeugungen eines Durchschnittssprechers, eines Experten oder einer ganzen Sprachgemeinschaft haben, und auch die Eigenschaften, die in der bei der Einführung des Art- bzw. Größennamens verwendeten Beschreibung genannt werden. Dennoch dürfen gemäß der Hybridtheorien (anders als gemäß der kausalen Referenztheorie) bestimmte bei einer Namenseinführung verwendete Beschreibungen und bestimmte Überzeugungen eines Sprechers (oder Experten) nicht falsch sein, nämlich die kausale Charakterisierung der Referenz und die zusätzliche minimale Beschreibung. Die kausale Charakterisierung und die zusätzliche minimale Beschreibung der Referenz müssen keine wesentlichen Eigenschaften bzw. Relationen zum Inhalt haben, aber die Eigenschaften bzw. Relationen, die sie zum Inhalt haben, müssen die Referenzobjekte des jeweiligen Art- oder Größennamens tatsächlich aufweisen, sonst besteht keine Referenzrelation.

In diesem zuletzt genannten Punkt ähneln die Hybridtheorien den Beschreibungstheorien der Referenz, ansonsten stehen sie der kausalen Referenztheorie näher und teilen deren charakteristische Züge: Nach den Hybridtheorien kann ein Sprecher einen Art- oder

\footnotetext{
${ }^{26}$ Siehe [Cumm92], S.30.

27 "Relevantly similar" ([Cumm92], S.30).

28 "Appropriate" ([Cumm92], S.27, 33).

29 “Äther' hat nach Cummiskey keine Referenz, weil das "primary subject" der Metapher eines "flüssigkeitsartigen" materiellen Trägers der Lichtwellen keine relevante Ähnlichkeit ([Cumm92], S.30) zu (nach heutigem Kenntnisstand) realen Entitäten hat. 'Wärmestoff' referiert nach Cummiskey nicht auf Wärme, weil diese nicht hinreichend "analog" ([Cumm92], S.34) zum "primary subject" der Metapher einer flüssigkeitsartigen materiellen Substanz ist, für die ein Erhaltungssatz gilt.
} 
Größennamen referierend verwenden, obwohl er falsche Überzeugungen über die Art bzw. Größe hat und obwohl bei der Einführung des Namens falsche Beschreibungen im Spiel waren. ${ }^{30}$ Die Hybridtheorien sind verträglich mit Putnams These, daß wissenschaftliche Art- und Größennamen häufig bewußt mit der Intention verwendet werden, die Bestimmung ihrer Extension zukünftiger Forschung zu überlassen. Die Hybridtheorien haben zur Folge, daß die Sprecher (bzw. Experten), die einen Art- oder Größennamen verwenden, selbst i.a. keine gut begründeten Urteile darüber fällen können, ob ihre Ausdrücke referieren und, wenn ja, worauf; solche Urteile sind jedoch eventuell von einem historisch späteren Standpunkt aus möglich.

Durch diesen Art, den Zusammenhang zwischen der Referenz eines Art- oder Größennamens und den Eigenschaften, die den Referenzobjekten zugeschrieben werden, nicht ganz eng, aber auch nicht ganz lose zu konzipieren, versuchen die Anhänger einer Hybridtheorie einerseits die Nachteile zu vermeiden, die bei vielen Beschreibungstheorien durch einen zu engen Zusammenhang entstehen, andererseits aber auch die Probleme, die bei der kausalen Referenztheorie durch einen zu losen Zusammenhang verursacht werden. Ersteres sind vor allem die mit dem Stichwort Referenzinstabilität bezeichneten Probleme, zur letzteren Gruppe gehören zum einen die oben ${ }^{31}$ diskutierten Konflikte der kausalen Referenztheorie mit vortheoretischen Intuitionen über die Referenz vieler Art- und Größennamen aus der Wissenschaftsgeschichte, zum anderen das eine der diskutierten Generalisierungsprobleme bei der Einführung von Art- oder Größennamen. Das Ziel und zugleich die Schwierigkeit beim Entwurf einer Hybridtheorie ist, als Bedingung für Referenz eines Art- oder Größennamens eine minimale Beschreibung zu fordern, die genau von der richtigen Art ist und den richtigen Grad an "Reichhaltigkeit" hat, um beide gleichsam von zwei Seiten drohenden Gruppen von Problemen zugleich zu vermeiden.

\subsection{Hybridtheorien, Bedeutung, Wahrheit, semantischer Rea- lismus}

Die skizzierten Hybridtheorien sind für sich genommen "nur" Theorien der Referenz von Art- und Größennamen, sie lassen sich aber in der gleichen Weise wie die kausale Referenztheorie kombinieren mit einer Bedeutungstheorie wie sie Putnam vorgeschlagen hat und mit einer (mit Hilfe von Tarskis semantischem Apparat gewonnenen) Korrespondenztheorie der Wahrheit.

Wenn man eine Hybridtheorie so mit einer Korrespondenztheorie kombiniert, dann eignet sie sich, in derselben Weise wie die kausale Referenztheorie, gut zur Erläuterung semantischer realistischer Thesen. ${ }^{32}$

\footnotetext{
${ }^{30}$ Hinsichtlich falscher Überzeugungen bzw. Beschreibungen scheint allerdings ein Unterschied zwischen der kausalen Referenztheorie und den Hybridtheorien zu bestehen: Bei den oben dargestellten Vorschlägen für eine Hybridtheorie geht man offenbar, ohne daß das explizit diskutiert wird, davon aus, daß der Teil der zur Namenseinführung verwendeten Charakterisierung der Referenzobjekte, der nicht falsch sein darf, ausreicht, um die Referenz eindeutig zu bestimmen. Falsche Überzeugungen, die die Referenz nicht beeinträchtigen, müßten demnach bei einer Hybridtheorie sozusagen redundant sein, so daß die Frage, wieviel von den Überzeugungen bzw. Charakterisierungen der Referenzobjekte falsch sein kann, ohne daß das das Referieren verhindert, bei einer Hybridtheorie ohne weiteres mit "alles bis auf die kausale Charakterisierung plus die minimale Beschreibung" beantwortet werden kann. Für die kausale Referenztheorie ist eine plausible Antwort schwieriger (vgl. Abschnitt 4.2.2).

${ }^{31}$ Abschnitt 4.5.2.

${ }^{32}$ Sofern bei einer Kontexttheorie analytische Sätze auftreten (z.B. in der Version von Nola Sätze, die den Referenzobjekten den Kausalmechanismus bzw. die "causal power" zuschreiben, die Inhalt der minimalen
} 


\subsection{Probleme und Einwände}

Im Hinblick auf ihre Eignung zur Erläuterung oder Ergänzung einer realistischen Position und zur Argumentation für realistische Thesen stehen die Hybridtheorien der kausalen Theorie von Kripke und Putnam nahe, aus der sie durch Hinzufügung von Elementen einer Beschreibungstheorie hervorgehen. Es soll daher hier vor allem untersucht werden, ob bzw. inwieweit man mit dem Schritt zu einer Hybridtheorie die wichtigsten Nachteile der kausalen Theorie los wird und ob bzw. inwieweit dies gelingt, ohne sich wiederum die Nachteile der Beschreibungstheorien oder andere neue Nachteile einzuhandeln. ${ }^{33}$

\subsubsection{Wie klar und wohldefiniert sind die verschiedenen Vorschläge für minimale Beschreibungen?}

Von den genannten Vorschlägen, von welcher Art die für eine Referenzbeziehung erforderliche minimale Beschreibung sein soll, ist der erste, der die Angabe bzw. die Kenntnis einer Kategorie der Referenzentität(en) verlangt, einigermaßen klar, auch wenn so etwas wie eine Definition, was eine Kategorie (oder, in Putnams Terminologie, ein semantischer Marker, Kategorialindikator oder broad spectrum term) ist, oder eine Liste aller Kategorien vielleicht nicht $\mathrm{zu}$ haben sind.

Putnam gibt für die Art- und Größennamen der Physik als Kategorien, neben 'natural kind', nur 'physical magnitude', 'physical object', 'space-time point' und 'particle' an. ${ }^{34}$ Dies sind sehr hochstufige generelle Ausdrücke, die eine Art abstrakte Klassifikation von Entitäten des "physikalischen Universums" liefern. Nach Putnam sind es weder Beobachtungsausdrücke, noch sind es typische (mehr oder weniger) "beobachtungsferne" theoretische Ausdrücke, wie sie zur Formulierung physikalischer Theorien verwendet werden. ${ }^{35} \mathrm{Ihr}$ wesentliches Charakteristikum ist, daß sie erfahrungsgemäß sehr stabile Klassifikationen von Entitäten liefern, die auch bei Veränderungen im Bestand der akzeptierten Theorien allenfalls sehr selten revidiert werden müssen; ${ }^{36}$ es macht daher nichts aus, daß die Gruppe der von Putnam genannten Kategorialindikatoren im Hinblick auf ihren Allgemeinheitsoder Abstraktionsgrad etwas heterogen aussieht ${ }^{37}$ und daß es generell einen fließenden Übergang von hochstufigen Kategorien zu spezielleren zu geben scheint bzw., um Putnams Terminologie etwas zu dehnen, von broad-spectrum terms über medium-spectrum terms zu narrow-spectrum terms.

Nolas Vorschlag für minimale Beschreibungen ist ebenfalls einigermaßen klar, auch wenn eine weitere Präzisierung sicherlich möglich und wünschenswert wäre. Nola macht klar, daß er als minimale Beschreibung so etwas wie die Skizze des kausalen Mechanismus verlangt, durch den die jeweilige Art oder Größe das zur Referenzfixierung dienen-

\footnotetext{
Beschreibung sind), bleiben diese hier beiseite; vgl. S.46.

${ }^{33}$ Ein möglicherweise problematischer Zug der Hybridtheorien, den sie mit mehreren Beschreibungstheorien teilen, bleibt hier beiseite, nämlich der, daß sie durch die minimale Beschreibung eine Unterscheidung analytisch/synthetisch involvieren. Die Antwort auf diesen Einwand ist in beiden Fällen dieselbe; siehe dazu Abschnitt 2.6.3. Ebenso bleiben die Modifikationen und Einschränkungen des Geltungsbereichs beiseite, die bei den Hybridtheorien in derselben Weise wie bei der kausalen Referenztheorie erforderlich sind; siehe dazu Abschnitt 4.5.1.

${ }^{34}$ [Putn75d], S.222 bzw. [Putn75j], S.274.

${ }^{35}$ Siehe [Putn75d], S.222/223.

${ }^{36}$ Vgl. [Putn75i], S.266f.

${ }^{37}$ Außerhalb des Bereiches der wissenschaftlichen Ausdrücke gibt Putnam als semantische Marker ebenfalls unterschiedlich abstrakte Klassifikationen an, etwa 'Flüssigkeit' und 'Tier', aber auch 'materielle Substanz' und 'Lebewesen'.
} 
de Phänomen verursacht, keine detaillierte Darstellung des Kausalmechanismus, die auf der fundamentalsten physikalischen Ebene liegt, quantitativ formuliert und exakt ist u.ä. Man kann sicherlich nach genaueren Erläuterungen fragen, wie grob bzw. detailliert eine adäquate minimale Beschreibung einen kausalen Mechanismus beschreiben darf bzw. muß und, wie bei der kausalen Referenztheorie, was als kausaler Mechanismus zählt; dennoch dürfte in vielen konkreten Fällen, etwa in Nolas Beispielen, klar sein, ob eine minimale Beschreibung in Nolas Sinn vorliegt oder nicht, auch wenn es eine "Grauzone" von unklaren Fällen geben mag. Klar scheint außerdem, daß Nola eine engere Konzeption von Kausalität im Auge hat als Putnam, daß es also bei ihm um die Benennung von Arten bzw. Größen geht, die das zur Benennung verwendete Phänomen in einem engen Sinn verursachen, nicht "nur" in irgendeinem gesetzmäßigen Zusammenhang damit stehen.

Cummiskeys Vorschlag, daß die für eine Referenzbeziehung erforderliche minimale Beschreibung die Form einer explanatorischen Metapher haben soll, sieht dagegen nicht hinreichend klar und wohldefiniert aus, zumindest in der vorliegenden Form, um ihn im Hinblick auf Vorzüge und Nachteile mit anderen Referenztheorien zu vergleichen. Die für die Anwendung von Cummiskeys Hybridtheorie zentrale Unterscheidung zwischen relevanten und irrelevanten Ähnlichkeiten zwischen dem "primary subject" einer Metapher und den (potentiellen) Referenzentitäten und entsprechend Cummiskeys Rede von einer Metapher angemessenen Entitäten sind nicht hinreichend klar. Solange keine genaueren Erläuterungen dazu und allgemeiner zum Gebrauch und besonders der Referenz von Metaphern vorliegen, ist nicht erkennbar, ob und, falls ja, in welcher Weise genau Cummiskeys Theorie in der Anwendung auf konkrete Fälle ein Resultat liefert (und dies nicht nur in einer "Grauzone" unklarer Fälle, sondern sogar bei seinen eigenen Beispielen). Cummiskeys Referenztheorie bleibt, genau wie die von Putnam, an der entscheidenden Stelle unscharf, und er setzt sich daher, wie Putnam, dem Verdacht aus, daß die Anwendung seiner Theorie auf einen konkreten Fall nicht in systematischer und sozusagen autonomer Weise ein Urteil über das Vorliegen oder Nicht-Vorliegen einer Referenzrelation liefert, sondern daß solche Urteile von Fall zu Fall ad hoc durch Intuitionen über den Einzelfall beeinflußt werden. ${ }^{38}$

Von den drei genannten Hybridtheorien sind also nur zwei hinreichend klar und wohldefiniert, um sie mit anderen Referenztheorien im Hinblick auf Vorzüge und Nachteile zu vergleichen. Nolas Version einer Hybridtheorie wird im folgenden als KausalmechanismusVersion bezeichnet, im Unterschied zur zuvor diskutierten Kategorien-Version.

\footnotetext{
${ }^{38}$ Cummiskeys eigene Anwendungsbeispiele für seine Theorie legen den Verdacht nahe, daß er über das Referieren einer explanatorischen Metapher implizit nach den Kriterien entscheidet, die Nolas Hybridtheorie nennt. Cummiskeys Beispiele für explanatorische Metaphern zielen offenbar alle auf Eigenschaften, die für kausale Mechanismen im Sinne Nolas zentral sind (obwohl die Konzeption einer explanatorischen Metapher an sich viel allgemeiner aussieht und nicht unbedingt etwas mit Kausalmechanismen zu tun haben müßte), und es spricht einiges dafür, daß historische Fälle, in denen Cummiskey sagt, daß eine Metapher nicht referiert, gerade solche sind, in denen sich nach Nola Annahmen bezüglich eines kausalen Mechanismus als falsch erwiesen haben. Besonders deutlich wird dies bei Cummiskey an einer Stelle, an der er diskutiert, warum 'Phlogiston' nicht auf Sauerstoff referiert: "The reason scientists came to believe in oxygen and not phlogiston is that the explanatory mechanism, the metaphor of a substance emitted from burning objects, was rejected and the new explanatory mechanism associated with oxygen was accepted" ([Cumm92], S.30). Umgekehrt findet sich bei Cummiskey kein Beispiel dafür, daß eine Metapher nicht referiert, weil eine explanatorische Metapher aufgegeben wurde, ohne daß so etwas wie ein kausaler Mechanismus im Sinne Nolas verworfen wurde.

Wenn dieser Verdacht zutrifft, hieße das, daß sich Cummiskeys Hybridtheorie zwar präzisieren läßt, jedoch dann mit der von Nola zusammenfällt.
} 


\subsubsection{Sind die Hybridtheorien frei von den Problemen der kausalen Re- ferenztheorie?}

Die beiden wichtigsten Probleme der kausalen Referenztheorie, die man durch den Schritt zu einer Hybridtheorie loswerden möchte, waren zum einen das eine der oben genannten Generalisierungsprobleme, ${ }^{39}$ zum anderen die Konflikte der kausalen Referenztheorie mit vortheoretischen Intuitionen über die Referenz von Art- und Größennamen aus der Wissenschaftsgeschichte, die dadurch zustande zu kommen schienen, daß die kausale Referenztheorie die Referenzrelationen solcher Ausdrücke zu unabhängig von der Erkenntnispraxis der jeweiligen Sprachgemeinschaft konzipiert. ${ }^{40}$

Das Generalisierungsproblem wird offenbar sowohl durch die Kategorien-Version, als auch durch die Kausalmechanismus-Version der Hybridtheorie gelöst, denn beide verlangen als notwendige Bedingung für eine referierende Verwendung eines Art- oder Größennamens, daß bei dessen Einführung die Kategorie der benannten Entität festgelegt wird.

Hinsichtlich des zweiten der beiden Probleme bieten die Hybridtheorien dagegen ein gemischtes Bild. Die Kategorien-Version der Hybridtheorie ist nicht in der Lage, dieses Problem generell zu lösen; dies läßt sich am Beispiel 'Phlogiston' zeigen: ${ }^{41}$ Nach der kausalen Referenztheorie hätte man die referenzfixierende Beschreibung für 'Phlogiston' etwa zu rekonstruieren als 'das, was die Umwandlung von Metall zu Metalloxid bei Erhitzung verursacht', so daß man aus heutiger Perspektive sagen müßte, daß 'Phlogiston' auf Sauerstoff referiert. Die Ergänzung der Beschreibung durch eine Kategorie zu 'die (materielle) Substanz, die die Umwandlung ... verursacht' macht für diesen Befund offenbar keinen Unterschied. Dagegen bekommt man das intuitiv korrekte Urteil über die Referenz von 'Phlogiston' (nämlich daß 'Phlogiston' nicht referiert), wenn man die referenzfixierende Beschreibung rekonstruiert als 'die (materielle) Substanz, die die Umwandlung von Metall in Metalloxid bei Erhitzung verursacht, indem sie aus dem Metall entweicht'. Nach heutigem Verständnis reagiert bei den fraglichen Vorgängen das Metall mit Sauerstoff, es handelt sich also um eine Aufnahme einer Substanz, nicht um ein Entweichen. Sofern man diese Charakterisierung des ablaufenden Prozesses als Entweichen bzw. Aufnahme einer materiellen Substanz als die grobe Beschreibung eines kausalen Mechanismus akzeptiert, löst die Kausalmechanismus-Version der Hybridtheorie also in diesem Fall das Problem.

Es lassen sich unter den für die kausale Referenztheorie problematischen Art- und Größennamen aus der Wissenschaftsgeschichte aber auch Fälle finden, in denen weder die Kategorien-Version, noch die Kausalmechanismus-Version der Hybridtheorie ein intuitiv korrektes Bild von der Referenz des jeweiligen Ausdrucks ergeben. Ein solcher Fall ist der Ausdruck 'Meson'. ${ }^{42}$ Das Anfangsstadium der Geschichte dieses Ausdrucks läßt sich im Lichte beider Versionen der Hybridtheorie in einigermaßen plausibler Weise rekonstruieren: Bei der Untersuchung von kosmischer Strahlung wurde in den 30er Jahren eine neue Teilchenart entdeckt. Die Etablierung der Bezeichnung 'Meson' für diese Teilchenart läßt sich aus der Perspektive der Kategorien-Version der Hybridtheorie (ziemlich grob) als Einführung eines Artnamens mittels der referenzfixierenden Beschreibung 'das Teilchen, das in einer mit N cm dicken Bleiplatten abgeschirmten Nebelkammer Spuren vom Typ X verursacht' rekonstruieren. Aus der Perspektive der Kausalmechanismus-Version müßte die referenzfixierende Beschreibung in etwa rekonstruiert werden als 'das Teilchen,

\footnotetext{
${ }^{39}$ Siehe Kap.4.5.3.

${ }^{40}$ Siehe Kap.4.5.2.

${ }^{41}$ Vgl. [Cumm92], S.30, [Nola80].

${ }^{42}$ Vgl. [Gali87], Kap.3, [Hack83a], S.87ff., [Pais86], S.429ff., 452ff.; eine etwas populärere Darstellung findet sich in [ClMS87], Kap.4.
} 
das ... Spuren vom Typ X verursacht, indem seine elektrische Ladung e in seiner unmittelbaren Nähe die Kondensation kleiner Tröpfchen aus dem übersättigten Dampf in der Nebelkammer auslöst'. ${ }^{43}$ Dem neuen Teilchen wurden verschiedene weitere Eigenschaften zugeschrieben, u.a. eine bestimmte Masse und die Eigenschaft, der starken Wechselwirkung zu unterliegen, die durch ein Modell von Yukawa beschrieben wurde.

Die weitere Geschichte des Ausdrucks 'Meson' ist, so wie sie in wissenschaftshistorischen Darstellungen wiedergegeben wird, mit beiden Versionen der Hybridtheorie nicht verträglich: Nach einigen Jahren wurde in der kosmischen Strahlung eine weitere neue Teilchenart gefunden und $\pi$-Meson genannt, gleichzeitig wurde der bisherige Name 'Meson' in ' $\mu$-Meson' abgeändert. Später stellte sich heraus, daß die als $\pi$-Mesonen bezeichneten Teilchen der starken Wechselwirkung unterliegen, die als $\mu$-Mesonen bezeichneten dagegen (entgegen der bisherigen Überzeugung) nicht, sondern der schwachen Wechselwirkung. Die anfangs dem zuerst entdeckten Teilchen zugeschriebene Eigenschaft, der durch das Modell von Yukawa beschriebenen starken Wechselwirkung zu unterliegen, wurde also jetzt dem später entdeckten Teilchen zugeschrieben. Der Terminus 'Meson' wurde daraufhin nur noch für die als zweite entdeckten $\pi$-Mesonen verwendet, für die zuerst entdeckte Teilchenart wurde der neue Name 'Myonen' etabliert. Dieser zweite Teil der Geschichte des Ausdrucks 'Meson' und die darin enthaltenen intuitiven Urteile über seine Referenz sind offenbar weder mit der Kategorien-Version, noch mit der Kausalmechanismus-Version der Hybridtheorie verträglich, denn nach beiden Versionen gibt es keinen Grund, die zuerst entdeckten Teilchen nicht mehr zur Extension von 'Meson' zu zählen, und ebenso wenig dafür, für diese Teilchen den neuen Artnamen 'Myonen' einzuführen: An der ersten Namenseinführung ist sozusagen nichts auszusetzen; die in der Folge gewonnenen neuen Überzeugungen enthalten keinerlei Hinweis, daß sie nach den Standards der Hybridtheorien nicht erfolgreich war. ${ }^{44}$ Gemäß der Hybridtheorien müßte der Artname 'Mesonen' nach wie vor auf die zuerst entdeckten Teilchen referieren; daß man inzwischen gelernt hat, daß diese nicht der starken Wechselwirkung unterliegen, ändert danach nichts an der Referenz. Daher konfligieren die Hybridtheorien mit der vortheoretischen Intuition, daß der Ausdruck 'Meson' in den ersten Jahren nach seiner (ersten) Einführung eine andere Referenz hatte als heute.

Um ein fundiertes Urteil zu gewinnen, ob und, wenn ja, wieweit die beiden Versionen der Hybridtheorie von den Konflikten mit vortheoretischen Intuitionen über die Referenz von Art- und Größennamen aus der Wissenschaftsgeschichte frei sind, die die kausale Referenztheorie belasten, sind weit umfangreichere begriffsgeschichtliche Untersuchungen erforderlich als an dieser Stelle möglich sind. Bereits die zwei diskutierten Fälle belegen jedoch, daß keine der beiden Versionen alle Problemfälle ausräumen kann; außerdem deuten sie darauf hin, daß die Kausalmechanismus-Version dabei besser abschneiden dürfte als die Kategorien-Version.

Zusammenfassend läßt sich festhalten, daß die Hybridtheorien grundsätzlich geeignet zu sein scheinen, einen Teil der Probleme los zu werden, mit denen die kausale Referenztheorie belastet ist, weil sie Referenzrelationen zu unabhängig von der Erkenntnispraxis der jeweiligen Sprachgemeinschaft konzipiert, kaum jedoch um alle Probleme los zu werden. In welchem Umfang die Versionen der Hybridtheorie in diesem Punkt erfolgreich sind, müßte (möglichst nachdem sie in präziserer Weise formuliert sind) durch umfangreiche wissenschaftshistorische Untersuchungen ermittelt werden.

\footnotetext{
${ }^{43}$ Tatsächlich wurden zum Nachweis auch andere Detektoren verwendet, die hier beiseite bleiben; siehe die in der vorigen Fn. genannten Referenzen.

${ }^{44} \mathrm{Vgl}$. dazu auch Fn.74.
} 


\subsubsection{Sind die Hybridtheorien frei vom Problem der Referenzinstabi- litäten, das Beschreibungstheorien häufig belastet?}

Die Hybridtheorien fügen der kausalen Referenztheorie gewissermaßen Elemente einer Beschreibungstheorie hinzu; daher kann der Schritt von der kausalen Referenztheorie zu einer Hybridtheorie nur dann zu einer zufriedenstellenden Referenztheorie führen, wenn nicht dadurch die Hybridtheorie auch mit den Nachteilen der Beschreibungstheorien belastet wird, von denen der wichtigste das Problem der Referenzinstabilitäten bei Veränderungen im Bestand der akzeptierten wissenschaftlichen Theorien war.

Da bei den beiden diskutierten Versionen der Hybridtheorie offenbar nur ein i.a. geringer Teil der zum Zeitpunkt der Einführung des Art- oder Größennamens bzw. seiner Verwendung akzeptierten Gesetze, Theorien etc. in die referenzbestimmende minimale Beschreibung eingehen, liefert die Anwendung der Hybridtheorien auf Ausschnitte der Wissenschaftsgeschichte sicherlich weit weniger Referenzinstabilitäten als holistische Beschreibungstheorien. ${ }^{45} \mathrm{Ob}$ dies dennoch zu viele sind, ob also die Hybridtheorien die Referenz eines Ausdrucks bereits wieder zu eng an die Überzeugungen und die Erkenntnispraxis der jeweiligen Sprachgemeinschaft knüpfen, um intuitiv "hinreichend stabile" Referenzrelationen zu ergeben, müßte durch wissenschaftshistorische Untersuchungen geklärt werden. Es wäre zu prüfen, wie häufig in der Geschichte der Wissenschaften Gesetze, theoretische Sätze o.̈̈. aufgegeben wurden, die die gemäß der Hybridtheorien für eine Referenzrelation erforderlichen minimalen Beschreibungen zum Inhalt haben, und insbesondere, ob und, wenn ja, wie häufig sich darunter Fälle finden lassen, in denen man intuitiv von konstanter Referenz sprechen würde.

Für die Kategorien-Version der Hybridtheorie dürfte eine solche Prüfung kaum etwas Problematisches zutage fördern. Es dürfte schwer sein, überhaupt Art- oder Größennamen zu finden, bei denen im Verlauf der Wissenschaftsgeschichte die zugehörige Kategorie verworfen wurde. Einige prima facie problematische Fälle finden sich vielleicht im $\mathrm{Zu}-$ sammenhang mit dem Übergang von der klassischen Physik zur Quantenmechanik und Quantenfeldtheorie: Dort ließe sich vielleicht die Frage stellen, ob die Klassifikation von Elektronen, Gravitationsfeldern etc. als Teilchen, Feld, physikalisches Objekt u.ä. über diesen Übergang hinweg als stabil aufzufassen ist. Abgesehen von diesem (wahrscheinlich singulären) Fall eines Überganges zwischen Theorien mit fundamental verschiedener begrifflicher Struktur, der im einzelnen zu untersuchen wäre, dürfte die Forderung der Hybridtheorien nach einer Kategorie als für eine Referenzrelation erforderliche minimale Beschreibung kaum zu irgendwelchen Referenzinstabilitäten führen.

Für die Kausalmechanismus-Version der Hybridtheorie ist schwieriger abzuschätzen, was eine entsprechende Prüfung ergeben wird. Zumindest einzelne Fälle, in denen die zur Referenzfixierung verwendete Beschreibung eines Kausalmechanismus verworfen wurde, lassen sich finden, ein Beispiel ist der im vorigen Abschnitt diskutierte Artname 'Phlogiston'. Daß darunter Fälle sind, in denen außerdem intuitiv stabile Referenz vorliegt, ist zumindest nicht offensichtlich, 'Phlogiston' ist jedenfalls keiner.

Um ein fundiertes Urteil zu gewinnen, ob und, wenn ja, in welchem Ausmaß die beiden Versionen der Hybridtheorie zu Referenzinstabilitäten führen und damit zumindest zu einem gewissen Grad mit demselben Problem belastet sind wie manche Beschreibungstheorien, sind wiederum umfangreichere begriffsgeschichtliche Untersuchungen erforderlich als an dieser Stelle möglich sind. Unter den hier diskutierten Beispielen fanden sich jedenfalls

\footnotetext{
${ }^{45}$ Also etwa die Theorie von Carnap und Lewis und die weite Kontexttheorie, wenn man sie als Beschreibungstheorien auffaßt.
} 
keine klaren "Problemfälle".

\section{$5.4 \quad$ Fazit}

Hybridtheorien gibt es in mehreren Versionen, die alle als Reaktion auf die Probleme der kausalen Referenztheorie entworfen wurden. Davon sind bis jetzt zwei, die KategorienVersion und die Kausalmechanismus-Version, zumindest so genau skizziert, daß sich ihre Vor- und Nachteile grob abschätzen lassen.

Im Hinblick auf ihre Eignung zur Erläuterung oder Ergänzung des Inhalts realistischer Positionen gleichen die Hybridtheorien der kausalen Referenztheorie: Mit Hilfe von Tarskis semantischem Apparat läßt sich auf ihrer Grundlage eine Korrespondenztheorie der Wahrheit aufbauen; Referenz- und Wahrheitstheorie zusammen eignen sich dann gut zur Erläuterung oder Ergänzung semantischer realistischer Thesen.

Auch im Hinblick auf die Argumentation für eine realistische Position, genauer: für eine Position, die ontologische oder epistemische realistische Thesen einschließt, teilen die Hybridtheorien die wesentlichen aus realistischer Perspektive attraktiven Züge der kausalen Referenztheorie, insbesondere den, daß ein Sprecher auch dann auf eine Art oder Größe bzw. deren Extension referieren kann, wenn er (oder seine Sprachgemeinschaft) eine oder mehrere falsche Beschreibungen damit verbindet. Ob die Hybridtheorien darüber hinaus der kausalen Referenztheorie vorzuziehen sind, weil sie, wie von ihren "Erfindern" angestrebt, nicht deren Nachteile aufweisen, die durch einen zu lose konzipierten Zusammenhang zwischen den Referenzrelationen von Art- und Größennamen einerseits und der Erkenntnispraxis der jeweiligen Sprachgemeinschaft andererseits zustande kommen, kann nur aufgrund umfangreicher wissenschaftshistorischer Studien in fundierter Weise beurteilt werden. Die wenigen Beispiele, die hier diskutiert werden konnten, deuten darauf hin, daß die Hybridtheorien zum einen das genannte Generalisierungsproblem lösen können, zum anderen im Hinblick auf Konflikte mit vortheoretischen Intuitionen über die Referenz wissenschaftlicher Art- und Größennamen deutlich besser abschneiden als die kausale Referenztheorie, jedoch wahrscheinlich nicht frei sind von Problemen dieser Art. Gleichzeitig scheinen die Hybridtheorien nicht oder zumindest nicht in wesentlichem Umfang mit Problemen der Referenzinstabilität belastet zu sein.

Der Schritt von der kausalen Referenztheorie zu den Hybridtheorien scheint also einen Fortschritt darzustellen, aber zumindest bisher noch nicht zu einer in allen wesentlichen Hinsichten zufriedenstellenden Referenztheorie zu führen. Um zu beurteilen, wie groß der Fortschritt ist und wieviel sozusagen noch zu tun bleibt, sind umfangreiche wissenschaftshistorische Studien erforderlich sowie außerdem genauere, über die bisherigen Skizzen hinausgehende Formulierungen verschiedener Versionen einer Hybridtheorie. 


\section{Kapitel 6}

\section{Fazit: Bedeutungs-, Referenz- und Wahrheitstheorien für die Sprache der Wissenschaften und ihre Eignung für eine Rolle in der Realismusdebatte}

In der vorigen Kapiteln sind die wichtigsten bisher vorgeschlagenen Bedeutungs-, Referenzund Wahrheitstheorien für die Sprache der Wissenschaften vorgestellt und untersucht worden, und zwar hauptsächlich im Hinblick auf ihre Eignung für eine Rolle in der wissenschaftstheoretischen Realismusdebatte (nicht in allen sprachphilosophisch relevanten Aspekten, denn dazu müßten die weitläufigen Grundlagenprobleme und -debatten der Sprachphilosophie aufgearbeitet werden).

Eine solche Rolle für Bedeutungs-, Referenz- und Wahrheitstheorien in der wissenschaftstheoretischen Realismusdebatte ist, die für eine realistische Position konstitutiven semantischen realistischen Thesen zu erläutern oder zu ergänzen, indem sie angeben, worin die Wahrheit (oder Falschheit) eines Satzes, einer Theorie etc. besteht und in welchem Sinn Wahrheitswerte von Sätzen, Theorien etc. "unabhängig von menschlichen epistemischen Mitteln" sind (oder nicht). Eine Bedeutungs-, Referenz- oder Wahrheitstheorie, die diese Rolle erfüllt, zählt damit zum Inhalt der jeweiligen realistischen Position.

Für diese Rolle eignen sich mehrere der vorgestellten Theorien, und zwar zum einen Tarskis Korrespondenztheorie der Wahrheit (allein oder kombiniert mit einer nicht als Beschreibungstheorie aufgefaßten Bedeutungstheorie), zum anderen die vorgestellten Beschreibungstheorien (die von Carnap und Lewis und die Kontexttheorien) und schließlich auch die kausale Referenztheorie und die Hybridtheorien zusammen mit einer darauf (mit Hilfe von Tarskis semantischem Apparat) aufgebauten Wahrheitstheorie. Sie alle haben die Eigenschaft, daß Sätze und Theorien in ihrem Anwendungsbereich semantische realistische Thesen der Form (SR1) erfüllen, wobei sich durch Aussagen der Form (UvmeM1) und (UvmeM2) erläutern läßt, in welchem Sinn genau die Wahrheitswerte der Sätze und Theorien "unabhängig ..." sind.

Andere der vorgestellten Theorien eignen sich dagegen nicht zur Erläuterung oder Ergänzung semantischer realistischer Thesen. Stattdessen können sie antirealistische Positionen motivieren oder (mit)konstituieren. Dies gilt zum einen für epistemische Wahr- 
heitstheorien, zum anderen für verifikationistische Bedeutungstheorien, die zu einer instrumentalistischen Einstellung bezüglich der Sprache der Wissenschaften führen.

Außer zur Erläuterung oder Ergänzung der Thesen, die eine realistische oder antirealistische Position konstituieren, können Bedeutungs-, Referenz- und Wahrheitstheorien eine Rolle in der wissenschaftstheoretischen Realismusdebatte spielen, indem sie in die Argumentation für oder gegen diese Thesen eingehen. Die vorgestellten Theorien haben unterschiedliche Charakteristika, aufgrund derer sie in verschiedener Weise für die Argumentation für oder gegen realistische Thesen relevant sein können.

Aus realistischer Perspektive weist Tarskis Korrespondenztheorie allein in dieser Hinsicht keine besonderen Vor- oder Nachteile auf; dasselbe gilt, wenn man sie mit der (nicht als Beschreibungstheorie aufgefaßten) Bedeutungstheorie von Carnap und Lewis kombiniert. Wenn man Tarskis Wahrheitstheorie mit einer (nicht als Beschreibungstheorie aufgefaßten) Kontexttheorie kombiniert, können Inkommensurabilitätsprobleme auftreten, die, je nachdem, was für eine Konzeption epistemischer Rechtfertigung, Bestätigung o.ä. man akzeptiert, Schwierigkeiten für die epistemische Begründung ontologischer und epistemischer realistischer Thesen mit sich bringen können, und zwar tendentiell umso massivere Schwierigkeiten, je mehr vom theoretischen Kontext eines Ausdrucks als bedeutungskonstitutiv zählt.

Die vorgestellten Beschreibungstheorien (also die so aufgefaßten Theorien von Carnap und Lewis und die Kontexttheorien) sind alle mit dem Problem der Referenzinstabilitäten bei Theorienwandel belastet, das, ebenfalls je nach akzeptierter Konzeption von epistemischer Rechtfertigung, Bestätigung o.ä., zu Schwierigkeiten bei der epistemischen Begründung ontologischer und epistemischer realistischer Thesen führen kann. Referenzinstabilitäten sind tendenziell umso mehr zu erwarten, je mehr vom Gesamtbestand der zu einem Zeitpunkt akzeptierten wissenschaftlichen Theorien in die bedeutungskonstituierenden Beschreibungen eingeht, d.h. bei der Theorie von Carnap und Lewis und bei weiten Kontexttheorien wird man mit massiven Referenzinstabilitäten rechnen müssen, bei engen Kontexttheorien nicht im selben Ausmaß. Als Beschreibungstheorie aufgefaßt hat die Theorie von Carnap und Lewis, aus realistischer Perspektive betrachtet, weiterhin den Prima-facie-Vorteil, daß das Problem der Unterbestimmtheit nicht auftreten kann, die Kontexttheorien haben dagegen den schon genannten Nachteil, daß Inkommensurabilitätsprobleme auftreten können.

Die kausale Referenztheorie, kombiniert mit einer darauf aufgebauten Wahrheitstheorie, hat aus realistischer Perspektive den Vorzug, daß ihr zufolge ein Sprecher bzw. eine Sprachgemeinschaft einen Ausdruck auch dann referierend verwenden können, wenn sie damit falsche Beschreibungen der Referenzobjekte verbinden, und daß diese Theorie daher nicht mit dem Problem der Referenzinstabilitäten bei Theorienwandel belastet ist. Dasselbe gilt entsprechend für die Hybridtheorien. Die kausale Referenztheorie hat den Nachteil, daß sie im Konflikt mit vortheoretischen Intuitionen über die Referenz einer Reihe von Ausdrücken aus der Wissenschaftsgeschichte steht; dieser Konflikt kann, soweit derzeit absehbar, durch eine der vorgestellten Hybridtheorien teilweise, nicht aber völlig ausgeräumt werden.

Angesichts dieser Probleme der vorgestellten Bedeutungs-, Referenz- und Wahrheitstheorien muß man zu dem Schluß kommen, daß einerseits mit Tarskis Korrespondenztheorie eine für realistische Zwecke geeignete Wahrheitstheorie zur Verfügung steht, daß es aber andererseits derzeit keine Bedeutungstheorie und keine Referenztheorie für die Sprache der Wissenschaften gibt, die aus realistischer Perspektive betrachtet sozusagen nichts zu wünschen übrig lassen. Tarskis Wahrheitstheorie für sich genommen läßt die 
Frage nach einer systematischen Bedeutungs- und Referenztheorie offen, ebenso trägt sie naturgemäß nichts zur Lösung epistemischer Probleme bei. Sofern sich herausstellen sollte, daß zur Begründung oder Verteidigung einer realistischen Position eine Bedeutungsund/oder Referenztheorie erforderlich ist, müßte Tarskis Theorie entsprechend ergänzt werden, die obigen Überlegungen haben jedoch nichts ergeben, was dies zwingend notwendig oder auch nur wahrscheinlich erscheinen ließe. Die vorgestellten Bedeutungs- und Referenztheorien sind mit den genannten Problemen belastet, die mit einiger Wahrscheinlichkeit, je nachdem, wie "der Rest" der realistischen Position aussieht, zumindest teilweise schwerwiegende sind.

Aus antirealistischer Perspektive betrachtet müssen die genannten "Probleme" der Bedeutungs- und Referenztheorien keine sein oder jedenfalls nicht alle, sondern man kann sie zumindest zum Teil als korrekte Einsichten auffassen, aus denen man die - mit realistischen Intuitionen und Thesen möglicherweise unverträglichen - philosophischen Konsequenzen zu ziehen hat. Auch wenn man die vorgestellten Bedeutungs- und Referenztheorien nicht von einem realistischen Standpunkt aus betrachtet, wird man aber zu dem Ergebnis gelangen, daß zur Zeit keine insgesamt zufriedenstellende Bedeutungs- und Referenztheorie für die Sprache der Wissenschaften zur Verfügung steht, wenn man die vorne diskutierten Probleme der vorgestellten Theorien mit in den Blick nimmt, die nicht speziell mit der Realismusdebatte zu tun haben, sowie außerdem den Befund, daß die meisten dieser Theorien bisher nur in mehr oder weniger grob skizzierter Form vorliegen.

Unter den diskutierten Bedeutungs- und Referenztheorien sind die (als Beschreibungstheorie aufgefaßte) enge Kontexttheorie und die Hybridtheorien mit den wenigsten Problemen behaftet. Sie dürften daher die aussichtsreichen Ansätze darstellen, die sich vielleicht in Richtung auf eine - für Realisten, aber auch unabhängig von der Realismusdebatte — in jeder Hinsicht zufriedenstellende Bedeutungs- und/oder Referenztheorie entwickeln lassen könnten. Für solche weiterführenden Untersuchungen bieten sich verschiedene Richtungen an, in denen diese beiden Ansätze weiterentwickelt werden könnten und müßten. Bei der engen Kontexttheorie müßten sicherlich die Probleme gelöst werden, die mit der Abgrenzung des bedeutungskonstituierenden Teils des Kontextes eines Ausdrucks verbunden sind. Bei den Hybridtheorien liegt die Idee nahe, die minimale Beschreibung noch etwas über das, was die Kausalmechanismus-Version der Hybridtheorie fordert, hinaus anzureichern oder auch verschiedene (möglicherweise bereichsspezifische) Arten minimaler Beschreibungen zuzulassen, um das Problem der Konflikte mit vortheoretischen Intuitionen über die Referenz von Ausdrücken aus der Wissenschaftsgeschichte zu beseitigen. Sowohl bei der engen Kontexttheorie als auch bei der Hybridtheorie könnte man versuchen, die von verschiedenen Autoren angedeutete Idee zu implementieren, referenzbestimmende Beschreibungen nicht als exakte, sondern als angenäherte Beschreibungen zu verstehen: Bedingung dafür, daß ein Ausdruck auf ein bestimmtes Objekt referiert, wäre danach, daß dieser die Beschreibung näherungsweise erfüllt, wobei man den dabei involvierten Begriff der Näherung erläutern müßte. ${ }^{1}$

Soweit beim gegenwärtigen Diskussionsstand abzusehen, dürfte sich eine zufriedenstellende semantische Theorie für die Sprache der Wissenschaften, die eine systematische Bedeutungs-, Referenz- und Wahrheitstheorie einschließt, am ehesten in einer dieser Richtungen aus einer engen Kontexttheorie oder einer Hybridtheorie gewinnen lassen (oder auch aus beiden, sofern beide Ansätze im Verlauf der Fortentwicklung konvergieren). Derzeit steht eine solche Theorie nicht zur Verfügung, sondern "nur" eine für realistische

\footnotetext{
${ }^{1}$ Die Grundidee der annähernden Referenz findet sich z.B. in [Fiel73, Lewi83b], eine quantitative Version in [Niin97a, Niin97b].
} 
Zwecke geeignete Wahrheitstheorie, die von Tarski. 


\section{Teil II}

\section{Argumente für wissenschaftlichen Realismus}



Nachdem in der Einleitung eine systematisierende Übersicht über die Realismusdebatte gewonnen wurde und im vorigen Teil Bedeutungs-, Referenz- und Wahrheitstheorien für die Sprache der Wissenschaften vorgestellt und im Hinblick auf ihre Funktion in der Realismusdebatte untersucht worden sind, sollen nach diesen Vorbereitungen jetzt die $A r$ gumente in den Blick genommen werden, die in dieser Debatte zugunsten realistischer Thesen und Positionen angeführt werden.

Für eine realistische Auffassung wissenschaftlicher Theorien haben zu verschiedenen Zeiten eine Vielzahl von Philosophen plädiert, der klassische Vertreter oder die klassische Vertreterin des wissenschaftlichen Realismus läßt sich nicht herausheben. Die Argumente für realistische Thesen und Positionen, die sich in der philosophischen Literatur finden, sind dementsprechend vielgestaltig, sie lassen aber eine grobe Klassifikation zu. Es gibt dort im wesentlichen drei Typen von Argumenten: Zum einen eine Art, die hier als Präsuppositionsargumente bezeichnet werden sollen, dann eine Gruppe von Argumenten, die hier Kontinuitätsargumente heißen sollen, und schließlich die verschiedenen Versionen eines Argumentationstyps, der meistens Wunderargument, ultimatives Argument oder Erfolgsargument genannt wird.

Der Streit um Argumente dieser drei Arten durchzieht und prägt den überwiegenden Teil der wissenschaftstheoretischen Realismusdebatte. Die meisten Vertreter(innen) realistischer Positionen stützen sich auf ein Argument (mindestens) eines dieser drei Typen. Was es mit diesen Argumenten, ihrer Struktur, ihren Voraussetzungen und Argumentationszielen auf sich hat, soll in diesem Teil ausführlich untersucht werden. 


\section{Kapitel 7}

\section{Präsuppositionsargumente}

Unter den Argumenten, die für den wissenschaftlichen Realismus vorgebracht werden, findet sich eine Gruppe, die hier als Präsuppositionsargumente bezeichnet werden sollen. ${ }^{1}$ Die Idee ist, für realistische Thesen zu argumentieren, indem man auf bestimmte Elemente der Praxis der Wissenschaften oder bestimmte dieser Praxis zugrundeliegende Methoden hinweist und anschließend Voraussetzungen oder Präsuppositionen herausarbeitet, unter denen diese Praxis eine (in zu erläuterndem Sinn) rationale ist. Von den Argumenten dieser Art sollen hier eines von Hilary Putnam und ein anderes von Nancy Cartwright diskutiert werden. ${ }^{2}$

\subsection{Putnams Konjunktionsargument}

Hilary Putnam äußert in einer seiner frühen Arbeiten die Überzeugung, daß ein großer Teil von dem, was Wissenschaftler in ihrer Arbeit tun, nur dann sinnvoll ist, wenn sie wissenschaftliche Realisten sind. Er nennt es "intellectual dishonesty" 3 oder sogar inkohärent, die Forschungsprojekte zu verfolgen, die das "Tagesgeschäft" z.B. der Physik ausmachen, und dabei eine antirealistische Einstellung zu den Theorien und deren Gegenständen einzunehmen, die dazu "unentbehrlich" ${ }^{4}$ sind. Eine antirealistische Haltung führt nach Putnam

\footnotetext{
${ }^{1}$ Zur Erläuterung des Ausdrucks 'Präsupposition' s.u. Er bezeichnet hier keine semantischen Präsuppositionen im Sinne Strawsons (vgl. [Stra71b]); eine gewisse Verwandtschaft besteht eher zu Stalnakers Konzeption pragmatischer Präsuppositionen ([Stal74]), obwohl sich diese auf Präsuppositionen bezieht, die einer Person im Zusammenhang mit bestimmten Sprechakten zuzuschreiben sind, während es hier um Handlungen oder Praktiken in einem umfassenderen Sinn geht.

${ }^{2}$ Ein anderes Argument, das die Struktur eines Präsuppositionsargumentes hat, gibt Popper an ([Popp63a], S.111ff.); es geht dort darum, zu "erklären" (account for), daß und wie wissenschaftliche Theorien getestet werden. Ein weiteres Argument dieser Art findet sich bei Hellman ([Hell83], S.231/232); seine These ist, daß die auf "esoterische" Gegenstände und Ziele gerichteten Untersuchungen in den Naturwissenschaften ohne eine realistische Einstellung wenig oder gar keinen "Sinn machen". Ebenfalls im Sinne eines Präsuppositionsargumentes läßt sich die Argumentation auffassen, die Sellars für eine realistische Deutung theoretischer Entitäten anbietet (u.a. [Sell63], Kap.3, 4): Sellars argumentiert, daß Theorien für die Erklärungspraxis der Wissenschaften "unentbehrlich" ([Sell63], S.122, s.a. S.118) sind und deshalb realistisch aufzufassen sind.

${ }^{3}[$ Putn71], S.57.

${ }^{4}$ [Putn71], S.57ff. Putnam spricht dort von "indispensability arguments" und nennt Quine als Vertreter dieser Argumentationslinie. Diese Anknüpfung an Quine ist aber ungenau: Quine ist der Ansicht, daß beobachtbare, unbeobachtbare und auch mathematische Entitäten und Sachverhalte in epistemischer Hinsicht im wesentlichen denselben (d.h. allenfalls graduell verschiedenen) Status haben; alle sind gleichermaßen Gegenstand der Elemente eines "Netzes von Überzeugungen" ("web of belief"), das nur an den Rändern Beobachtungs- oder beobachtungsnahe Sätze enthält und so in holistischer Weise mit Erfahrungen kon-
} 
dazu, daß die Praxis der Naturwissenschaften nicht in einem kohärenten Zusammenhang mit den Überzeugungen derjenigen steht, deren Handlungen diese Praxis ausmachen.

In eine konkretere Form gebracht hat Putnam diesen Gedanken in einer Argumentation, die gewöhnlich als Konjunktionsargument (conjunction argument) ${ }^{5}$ oder Konjunktionseinwand (conjunction objection) ${ }^{6}$ bezeichnet wird.

"When a realistically minded scientist — that is to say, a scientist whose practice is realistic, not one whose official 'philosophy of science' is realistic accepts a theory $T_{1}$ as true and he accepts a theory $T_{2}$ as true, then he knows that $T_{1} \& T_{2}$ - the conjunction of $T_{1}$ and $T_{2}$ - is also true, by logic, and so he accepts $T_{1} \& T_{2}[\ldots]$ I want to suggest that the move [...] to the acceptance of the conjunction is one to which one is not entitled on positivist philosophy of science. One of the simplest moves that scientists daily make [...] is totally arbitrary if positivist philosophy of science is right.

The difficulty is very simple. Acceptance of $T_{1}$, for a positivist, means acceptance of a calculus $T_{1}$ as leading to successful predictions (i.e. all observation sentences which are theorems of $T_{1}$ are 'true'; not all sentences which are theorems of $T_{1}$ are 'true' in any fixed trans-theoretic sense). Similarly, the acceptance of $T_{2}$ means the acceptance of $T_{2}$ as leading to successful predictions. But from the fact that $T_{1}$ leads to successful predictions and the fact that $T_{2}$ leads to successful predictions it does not follow at all that the conjunction $T_{1} \& T_{2}$ leads to successful predictions. The difficulty, in a nutshell, is that the predicate which plays the role of truth - the predicate 'leads to successful predictions' - does not have the properties of truth." 7

Ein plausibles konkretes Beispiel für die in Putnams Argument beschriebene Praxis ist vielleicht die "Kooperation" von Evolutionstheorie, Festkörperphysik und Kernphysik bei der Auswertung von Fossilienfunden. ${ }^{8}$ Fossilien können in vielen Fällen durch physikalische Methoden datiert werden, nämlich über ihren Gehalt an bestimmten, mit der Zeit zerfallenden radioaktiven Elementen oder über die räumliche Orientierung magnetischer Bestandteile des einbettenden Gesteins, die auf die (auf langen Zeitskalen veränderliche) Stellung des Erdmagnetfeldes zur Entstehungszeit zurückgeht. Beobachtbare Phänomene, die aus der Konjunktion von Kern- bzw. Festkörperphysik und einer bestimmten evolutionstheoretischen Annahme folgen, sind z.B. bestimmte Zusammenhänge zwischen aufgefundenen Fossilienspezies und deren Gehalt an bestimmten radioaktiven Elementen. ${ }^{9}$

frontiert werden kann, und aus dem keine der genannten Arten von Entitäten und Sachverhalten bzw. auf sie bezogenen Überzeugungen eliminiert werden kann, ohne die Leistungen und Vorzüge des Netzes massiv zu beeinträchtigen (siehe z.B. [Quin81b], S.13ff., [Quin81d], S.149f.). In diesem Sinn spricht Quine tatsächlich von Unentbehrlichkeit (wörtlich z.B. in [Quin91], S.269). Für die davon verschiedene These, daß man zu allem, was Teil des Netzes der Überzeugungen ist, eine gleichermaßen realistische Einstellung einnehmen sollte, argumentiert Quine jedoch nicht, wie Putnam, mit Hilfe eines Präsuppositionsargumentes. Das sozusagen einem Argument für diese These am nächsten kommende Theoriestück bei Quine ist sein Kriterium der ontologischen Verpflichtung (ontological commitment), das alle Elemente des Netzes gleichartig behandelt (siehe z.B. [Quin53b, Quin81b]). Inwiefern Quine für dieses Kriterium überhaupt argumentiert, ist eine komplizierte Frage, er tut dies jedenfalls nicht, indem er auf eine genau spezifizierte Praxis hinweist und auf deren Rationalität o.ä. Bezug nimmt. Am ehesten dürften seine Äußerungen dazu vielleicht im Sinne eines Kontinuitätsargumentes zu verstehen sein; vgl. dazu Kap.8.

${ }^{5}[$ Kukl94].

${ }^{6}$ [vFra80], S.83.

${ }^{7}$ [Putn75h], S.210/211.

${ }^{8}$ Das Beispiel stammt aus [Trou92].

${ }^{9}$ Genaugenommen muß natürlich der Gehalt an radioaktiven Elementen noch an ein im strengen Sinn 
Putnam schildert es als in den Wissenschaften gängige Praxis, daß mit dem Akzeptieren mehrerer einzelner Theorien auch deren Konjunktion akzeptiert wird (wie auch immer "akzeptieren" zu erläutern ist) und daß damit nicht nur die empirischen Konsequenzen, die aus jeweils einer dieser Theorien allein ableitbar sind, als wahr anerkannt werden, sondern auch die empirischen Konsequenzen, die nur aus mehreren der Theorien zusammen ableitbar sind. Putnam will Präsuppositionen dieser Praxis explizit machen, unter denen sie eine rationale Praxis ist; ${ }^{10}$ er spricht von Voraussetzungen, die einen Rechtfertigungsgrund für die Annahme liefern, daß diese Praxis zu wahren Überzeugungen führt ${ }^{11}$, von Voraussetzungen, unter denen man zu dieser Praxis "berechtigt" (entitled) ist, unter denen sie nicht "vollkommen willkürlich" (totally arbitrary) ist" ${ }^{12}$ oder die es gestatten, eine Erklärung (account) dieser Praxis zu geben, durch die sie gerechtfertigt wird ${ }^{13}$.

Daß die Konjunktion mehrerer Theorien, also mehrere einzelne Theorien zusammen, von Wissenschaftlern zur Ableitung von Beobachtungssätzen herangezogen werden und diese empirischen Konsequenzen dann von ihnen genauso als wahr anerkannt werden wie aus einzelnen Theorien abgeleitete Beobachtungssätze, ist eine in einem bestimmten Sinn ${ }^{14}$ rationale Vorgehensweise, wenn die Wissenschaftler zum einen den Wunsch haben, wahre Überzeugungen (über Beobachtbares) zu haben, zum anderen eine realistische Einstellung zu den Theorien einnehmen, genauer: es ist eine rationale Vorgehensweise unter den Voraussetzungen, daß die Wissenschaftler

1. den Wunsch haben, wahre Überzeugungen (über Beobachtbares) zu haben,

2. der Überzeugung sind, daß für die Theorien die auf Putnams kausaler Bedeutungsund Referenztheorie aufgebaute Korrespondenztheorie der Wahrheit gilt und

3. der Überzeugung sind, daß die Theorien wahr sind. ${ }^{15}$

Unter den beiden letzten Voraussetzungen können sie schließen, ${ }^{16}$ daß jeder aus der Konjunktion mehrerer dieser akzeptierten Theorien (und ebenso natürlich jeder aus einer einzelnen Theorie) abgeleitete Beobachtungssatz wahr ist, und damit, daß ihre Praxis, so abgeleitete Beobachtungssätze zu akzeptieren, zu wahren Überzeugungen führt; bei einer antirealistischen Einstellung zu den akzeptierten Theorien ist dagegen nicht klar, wieso das so sein sollte. Bei einem Wissenschaftler, der die Praxis ausübt, und die drei Voraussetzungen erfüllt, besteht ein kohärenter Zusammenhang zwischen seinen Wünschen und Überzeugungen und seinen Handlungen, die die Praxis ausmachen: Er handelt so, daß seinen Überzeugungen zufolge seine Handlungen dazu führen, daß das eintritt, was er wünscht. In diesem Sinn sind seine Handlungen bzw. ist die Praxis rational. Ein Wissenschaftler, der die Praxis ausübt, die empirischen Konsequenzen der Konjunktion mehrerer

beobachtbares Phänomen gekoppelt werden, etwa: Wenn man eine Probe in den Detektor des Typs X steckt, dann bekommt man ein Signal vom Typ Y.

${ }^{10}$ Der Ausdruck 'rational' fällt allerdings bei Putnam selbst nicht.

11 "[...] reason to think [...] that scientific practice tends to discover truth" ([Putn75h], S.209).

${ }^{12}$ Siehe das obige Zitat, s.a. [Putn75h], S.207, 209.

${ }^{13}$ [Putn75h], S.207.

${ }^{14}$ Vgl. S.14.

${ }^{15}$ An der oben zitierten Stelle erwähnt Putnam die kausale Bedeutungs- und Referenztheorie nicht explizit; daß sie gemeint ist, ergibt sich jedoch aus dem Zusammenhang seines Aufsatzes [Putn75h], in dessen erstem Teil diese Theorie skizziert wird. Als dritte Voraussetzung schlägt Putnam genaugenommen eine epistemisch "abgeschwächte" Überzeugung vor, die besagt, daß die Theorien annähernd wahr sind o.ä.; diese Komplikation spielt jedoch für die Argumentation keine Rolle und bleibt hier beiseite.

${ }^{16}$ Wie in jedem Logik-Lehrbuch nachzulesen. 
akzeptierter Theorien als wahr anzuerkennen, und die drei Voraussetzungen erfüllt, kann, um Putnams Formulierungen aufzugreifen, Rechtfertigungsgründe für die Annahme angeben, daß seine Praxis zu wahren Überzeugungen führt, er ist in diesem Sinn zu der Praxis "berechtigt", und die Praxis ist nicht "vollkommen willkürlich", sondern er kann eine "Erklärung" für sie geben, die sie rechtfertigt.

Die beiden Überzeugungen, die in der zweiten und der dritten der drei Voraussetzungen genannt sind, betreffen inhaltlich Verschiedenes: Die eine handelt von der Semantik der Theorien, die bei der Praxis involviert sind, die zweite betrifft die epistemische Bewertung der Theorien. Der Inhalt dieser beiden Überzeugungen, die von Putnam selbst nicht präzise formuliert oder erläutert werden, läßt sich mit Hilfe der oben ${ }^{17}$ formulierten semantischen und epistemischen realistischen Thesen rekonstruieren: Die genannte Praxis ist im erläuterten Sinn eine rationale, wenn die beteiligten Wissenschaftler

1. den Wunsch haben, wahre Überzeugungen (über Beobachtbares) zu haben,

2. der Überzeugung sind, daß für die fraglichen Theorien semantische realistische Thesen der Form (SR1) und (SR2) gelten, deren "Unabhängigkeitsklausel" mit Hilfe der kausalen Referenztheorie und einer darauf aufbauenden Korrespondenztheorie erläutert wird, und

3. der Überzeugung sind, daß für die fraglichen Theorien epistemische realistische Thesen der Form (ER) gelten.

Die Praxis ist also rational, wenn die Wissenschaftler wahre Überzeugungen haben wollen und wenn sie glauben, daß die fraglichen Theorien Wahrheitswerte haben, unabhängig von menschlichen epistemischen Mitteln zum Erkennen dieser Wahrheitswerte, und daß sie wörtlich zu nehmen und wahr sind, wobei "unabhängig ..." mit Hilfe der kausalen Referenztheorie plus Korrespondenztheorie erläutert wird. Diese Erläuterung kann durch Aussagen der Form (UvmeM1) und/oder (UvmeM2) formuliert werden, die für jede Theorie im Geltungsbereich der kausalen Referenztheorie plus darauf aufgebauten Korrespondenztheorie erfüllt sind, d.h., die "Unabhängigkeit ..." besteht darin, daß die fraglichen Theorien auch dann wahr (oder falsch) wären, wenn niemand über epistemische Mittel verfügen würde, um herauszufinden, ob sie wahr sind (oder falsch), und/oder darin, daß die Eigenschaft der fraglichen Theorien, wahr (oder falsch) zu sein, nicht menschliche epistemische Mittel zum Erkennen ihrer Wahrheitswerte involviert. ${ }^{18}$

\footnotetext{
${ }^{17}$ Siehe die Abschnitte 1.2.1 und 1.3.1.

${ }^{18}$ Das Stichwort 'unabhängig' fällt zwar in [Putn75h] nicht (möglicherweise weil man die Art der "Unabhängigkeit ..." nicht explizit zu machen braucht, um mit Hilfe der kausalen Referenztheorie bzw. Korrespondenztheorie zu zeigen, daß die zur Debatte stehende Praxis rational ist), in späteren Arbeiten spricht Putnam jedoch von "Unabhängigkeit" in einer Weise, die er zwar nicht völlig klar und unzweideutig erläutert, die sich aber durch die oben angegebenen Möglichkeiten rekonstruieren läßt (vgl. [Putn78], S.125, [Putn81], S.56), und er läßt in diesem Zusammenhang auch erkennen, daß er Thesen über "Unabhängigkeit" für zentral für (von ihm zur Entstehungszeit dieser späteren Arbeiten abgelehnte) realistische Positionen hält.

Putnams Argumentation richtet sich seiner eigenen Aussage zufolge gegen positivistische Positionen, also Positionen, die eine der semantischen Theorien des logischen Positivismus einschließen (vgl. [Putn75h], S.197f., 208f.). Das ist insofern nicht korrekt, als sich, wie in Teil I diskutiert, zumindest für einige dieser Theorien Lesarten finden lassen, nach denen sie semantische realistische Thesen liefern, und zumindest einige davon sollten auch im oben genannten Sinn als Voraussetzung taugen, um die von Putnam genannte Praxis zu einer rationalen zu machen; dieser Punkt kann jedoch hier beiseite bleiben, da Putnams Argumentation hier als "positives" Argument für wissenschaftlichen Realismus betrachtet werden soll.
} 
Die von Putnam beschriebene Praxis läßt sich andererseits auch in einem zweiten Sinn ${ }^{19}$ als rational auffassen: Man kann ihr aus der Perspektive eines Außenstehenden das Ziel zuschreiben, wahre Überzeugungen über Beobachtbares zu gewinnen, also eine axiologische realistische These $^{20}$ vertreten, die lautet:

Das Ziel der Praxis, die empirischen Konsequenzen der Konjunktion mehrerer akzeptierter Theorien als wahr zu akzeptieren, ist es, wahre Beobachtungssätze zu gewinnen, genauer: diese Praxis führt stets zur Gewinnung wahrer Beobachtungssätze.

Die Praxis kann durch dieses Ziel in gewisser Weise erklärt werden, und sie ist in dem Sinn rational, daß man ihr "von außen" ein solches Ziel zuschreiben kann.

Dafür daß die Praxis in diesem Sinn rational ist, ist es nicht Voraussetzung, daß die an ihr beteiligten Wissenschaftler bestimmte (oder irgendwelche) Wünsche oder Überzeugungen haben. Es lassen sich Bedingungen angeben, die in einem anderen Sinn Präsuppositionen für die Rationalität der Praxis darstellen, nämlich Bedingungen, deren Vorliegen garantiert, daß die Praxis das genannte Ziel hat: Voraussetzungen in diesem Sinn für die Rationalität der Praxis sind offenbar gegeben durch

1. semantische realistische Thesen der Form (SR1) und (SR2) in bezug auf die Theorien, die zur Ableitung von empirischen Konsequenzen herangezogen werden, und zwar Thesen, deren "Unabhängigkeitsklausel" mit Hilfe der kausalen Referenztheorie und einer darauf aufbauenden Korrespondenztheorie erläutert wird,

2. epistemische realistische Thesen der Form (ER) in bezug auf die Theorien,

denn aus diesen Voraussetzungen läßt sich offenbar schließen, daß die obige axiologische realistische These gilt und damit die Praxis eine rationale ist. Wenn die an der Praxis beteiligten Wissenschaftler überzeugt sind, daß diese Voraussetzungen erfüllt sind, sind sie selbst in der Lage, die Praxis als rational (im zweiten Sinn) zu rechtfertigen. Wenn ein Außenstehender, der den Blick auf das Unternehmen Wissenschaft richtet, ohne selbst daran beteiligt zu sein, überzeugt ist, daß die Voraussetzungen erfüllt sind, kann er die Praxis als rational rechtfertigen und, um Putnams Formulierungen aufzugreifen, er kann dann Gründe für die Annahme angeben, daß die Praxis zu wahren Überzeugungen führt, oder eine Erklärung, die die Praxis rechtfertigt bzw. sie als nicht völlig willkürlich erscheinen läßt, selbst wenn die beteiligten Wissenschaftler dies nicht können oder sie sich um diese Frage nicht kümmern.

In Putnams Texten findet sich keine unmißverständliche Antwort auf die Frage, ob seine Argumentation die Rationalität der von ihm beschriebenen Praxis und deren Präsuppositionen in einer der beiden vorgeschlagenen Lesarten in Anspruch nehmen soll und, wenn ja, in welcher; da es sich um ein Argument für wissenschaftlichen Realismus handeln soll, bietet sich aber offenbar eine Rekonstruktion im Sinne der zweiten Lesart an: Wie Putnams Formulierungen zu entnehmen, soll für wissenschaftlichen Realismus argumentiert werden, indem Voraussetzungen aufgewiesen werden, unter denen die beschriebene Praxis eine rationale ist, und ein solches Argument ergibt sich in der zweiten Lesart, nicht aber

\footnotetext{
${ }^{19}$ Vgl. S.14.

${ }^{20}$ Allerdings eine in zweierlei Hinsicht etwas ungewöhnliche (vgl. Abschnitt 1.3.1): Zum einen handelt sie von dem Ziel wahre Beobachtungssätze, nicht wahre Theorien, zum anderen wird "Ziel" hier in einem sehr starken Sinn erläutert, nämlich dahingehend, daß die Praxis stets zur Gewinnung wahrer Beobachtungssätze führt, nicht nur wahrscheinlich dazu führt, eine dazu notwendige Bedingung erfüllt o.ä.
} 
in der ersten, denn nur in der zweiten Lesart handelt es sich bei den herausgearbeiteten Voraussetzungen um realistische Thesen (nämlich um semantische und epistemische), während in der ersten Lesart "nur" Aussagen über die Überzeugungen und Wünsche der an der Praxis beteiligten Wissenschaftler als Voraussetzungen fungieren, die per se für die Realismusdebatte nicht von Interesse sind (selbst wenn die Überzeugungen realistische Thesen zum Inhalt haben). ${ }^{21}$

\subsection{Cartwrights Generalisierungsargument}

Nancy Cartwright deutet an verschiedenen Stellen ihrer Arbeiten ${ }^{22}$ Argumente eines Typs an, in dem auf bestimmte Ausschnitte der Wissenschaftspraxis hingewiesen wird und anschließend bestimmte Präsuppositionen der Rationalität dieser Praxis herausarbeitet werden, um realistische Thesen zu begründen. Cartwrights expliziteste Überlegungen dieser Art beschäftigen sich mit der Praxis der Auswahl und Präparation experimentalphysikalisch zu untersuchender Systeme sowie der Generalisierung der an diesen Systemen experimentell gewonnenen Resultate und ihrer "Übertragung" auf andere Systeme.

\footnotetext{
${ }^{21}$ Von der hier gewählten Lesart abweichend präsentiert Boyd das Konjunktionsargument Putnams als eine Variante des (in Kap.9 zu diskutierenden) Wunderargumentes ([Boyd81], S.644ff., [Boyd85b], S.16f.). Nach seiner Lesart gibt es ein methodologisches Prinzip ("unity of science principle"), das besagt, daß Evidenzen für zwei Theorien $T_{1}$ und $T_{2}$ auch Evidenzen für die Konjunktion $T_{1} \& T_{2}$ darstellen. Der Erfolg dieses Prinzips ist nach Boyd erklärungsbedürftig und kann nur realistisch erklärt werden (dazu s. Kap.9). Bei Putnam selbst tritt das Wunderargument jedoch zeitlich erst nach dem davon verschiedenen, 1973 publizierten Konjunktionsargument auf, nämlich 1975 in [Putn75c].

Michael Friedman bietet ein weiteres Argument für eine realistische Einstellung zu wissenschaftlichen Theorien an, das die Struktur eines Präsuppositionsargumentes zu haben scheint und auf die "Vereinheitlichungsleistungen" von Theorien Bezug nimmt. Bei Friedman heißt es ([Frie83], S.259):
}

"A theoretical structure should be taken literally when, and only when, it has sufficient unifying power."

Friedman begründet diese These folgendermaßen (siehe [Frie83], S.236ff., s.a. [Frie81]): Eine Theorie, die verschiedene Phänomenbereiche, sprich: phänomenologische Gesetze, vereinheitlicht, also auf eine gemeinsame Tiefenstruktur (z.B. Prozesse auf molekularer Ebene) zurückführt, führt, verglichen mit der nicht vereinheitlichten Kollektion derselben phänomenologischen Gesetze, zu höheren Bestätigungsgraden für die Gesetze: Während bei den "unverbundenen" phänomenologischen Gesetzen jedes einzelne durch "seine eigenen" Meß- oder Beobachtungsdaten gestützt wird, tragen im Fall des vereinheitlichten Theoriegebäudes die Daten jedes Gesetzes auch zur Stützung der anderen phänomenologischen Gesetze bei, indem sie über "ihr eigenes" Gesetz die Theorie und durch diese indirekt auch die anderen Gesetze bestätigen. Dieser Mechanismus der Übertragung von empirischer Bestätigung von einem Gesetz auf ein anderes funktioniert laut Friedman nur, wenn garantiert ist, daß die Gesetze in eine theoretische Struktur eingebettet werden können, sprich: wenn man eine vereinheitlichte Theorie hat, nicht aber, wenn man z.B. nur einen Cluster von "ähnlichen" Modellen hat (obwohl diese in puncto empirischer Konsequenzen gleichwertig sein können, wenn jedes Gesetz von einem anderen Modell abgeleitet wird).

Friedman begründet seine These, daß man zu einer Theorie mit vereinheitlichender Kraft eine realistische Einstellung einnehmen sollte, dadurch, daß solche Theorien im ganzen besser bestätigte Theoriegebäude ergeben, somit also für die Bestätigungspraxis der Physik unentbehrlich sind ([Frie83], S.246, Fn.16):

"The point of the present discussion is that this practice [of conjoining two independently supported theories] plays a central role in the confirmation of theories; if we give up this practice, we give up an important source of confirmation".

Friedmans Punkt scheint zu sein, daß die in der Physik etablierte Bestätigungspraxis für phänomenologische Gesetze eine rationale Praxis im obigen Sinn nur unter der Bedingung ist, daß realistische Thesen bezüglich der dabei involvierten "vereinheitlichend wirkenden" hochstufigen Theorien gelten. Für die Bewertung von Friedmans Argumentation gilt analog dasselbe wie für Putnams Präsuppositionsargument; s. dazu Kap. 7.3.

${ }^{22}$ Parallel zu ihrer Hauptargumentation für wissenschaftlichen Realismus; siehe Kap.11.4. 
Cartwrights Argument geht von der Beobachtung aus, daß in der Physik von den zahllosen in Frage kommenden physikalischen Systemen tatsächlich nur eine kleine Anzahl in der Regel sehr "künstlicher", erst in komplizierter Weise zu präparierender "idealer" Fälle in Experimenten untersucht wird (z.B. die Gravitationskraft zwischen zwei Körpern möglichst ohne gleichzeitig wirkende elektromagnetische und andere Kräfte). Diese Auswahlpraxis und die Praxis, die an diesen Fällen gewonnenen Ergebnisse auf andere Systeme zu übertragen bzw. zu verallgemeinern, sind nach Cartwright nur unter bestimmten Voraussetzungen rational ${ }^{23}$; Cartwright spricht von Annahmen, ohne die die Praktiken nicht "verständlich sind" (make sense ${ }^{24}$ ) und die die Praktiken "erklären" (account for ${ }^{25}$ ), und von Annahmen, die "sicherstellen" (ensure ${ }^{26}$ ), daß die an speziellen "idealen" Systemen gewonnenen Resultate verallgemeinert werden können, oder die einen zu diesen Verallgemeinerungen "berechtigen" (entitle ${ }^{27}$ ).

Die Auswahlpraxis ist nach Cartwright rational unter der Voraussetzung, daß die experimentalphysikalischen Untersuchungen auf die Untersuchung von bestimmten Dispositionseigenschaften physikalischer Systeme zielen, in Cartwrights Terminologie: auf die Untersuchung von Naturen (natures) oder Tendenzen (tendencies) oder, wenn es sich um kausale Dispositionen handelt, Wirkungsvermögen (capacities). Die Praxis, aus Resultaten, die an sehr speziellen Systemen gewonnen worden sind, allgemeinere Resultate zu gewinnen, ist nach Cartwright rational unter der Voraussetzung, daß im jeweiligen Fall Eigenschaften einer bestimmten ontologischen Kategorie, nämlich von (kausalen oder nicht-kausalen) Dispositionseigenschaften, existieren bzw. vorliegen, und daß sowohl die an den speziellen Systemen gewonnenen Resultate als auch die Verallgemeinerungen "im Grunde" Naturen, Tendenzen oder Wirkungsvermögen der Systeme zum Inhalt haben. ${ }^{28}$

"My argument [...] hinges on a [...] connection between methodology and ontology. If you want to find out how a scientific discipline pictures the world, you can study its laws, its theories, its models, and its claims - you can listen to what it says about the world. But you can also consider not just what is said but what is done. How we choose to look at the world is just as sure a clue to what we think the world is like as what we say about it. Modern experimental physics looks at the world under precisely controlled or highly contrived circumstances; and in the best of cases, one look is enough. That, I claim, is just how one looks for natures, and not how one looks for information about what things do." 29

"Situations that lend themselves to generalization are very special, and it is these special kinds of situations that we aim to create, both in our experiments and in our technology. My central thesis here is that what makes these situations special is that they are situations that permit a stable display of the nature of the process under study, or the stable display of the interaction of several different natures." 30

\footnotetext{
${ }^{23}$ Der Ausdruck 'rational' fällt bei Cartwright selbst nicht.

${ }^{24}$ [Cart92], S.47.

${ }^{25}$ [Cart92], S.52.

${ }^{26}$ [Cart92], S.56.

${ }^{27}$ [Cart92], S.55.

${ }^{28}$ Cartwrights Formulierung ist "are basically about natures" ([Cart92], S.47).

${ }^{29}$ [Cart92], S.69.

${ }^{30}$ [Cart92], S.52; vgl. auch [Cart89a], S.191.
} 
"[...] one cannot make sense of modern experimental method unless one assumes that laws are basically about natures." 31

Nach Cartwright hängen die Auswahlpraxis und die Praxis, die an "idealen" Systemen experimentell gewonnenen Resultate zu verallgemeinern, unmittelbar zusammen: Die Auswahl und Präparation von physikalischen Systemen, die experimentell untersucht werden, wird gerade so vorgenommen, daß mit den bei einem Experiment durchgeführten, vergleichsweise wenigen Messungen dennoch generelle Aussagen etabliert werden können. Cartwright hat dabei zwei verschiedene "Stufen" der Generalisierung im Auge, wie sie am Beispiel des (geplanten) Gravity Probe B-Experimentes ${ }^{32}$ erläutert:

"I claim that the Gravity Probe aims to establish a general law about the nature of the coupling of a spinning gyroscope to curved space-time [...] But along the way [...] the experiment will reveal, or instantiate, another considerably less abstract law [... to the effect that any fused-quartz gyroscope of just this kind $[. .$.$] will precess at the rate predicted." 33$

Beide Sorten von Generalisierungen hängen nach Cartwright von Präsuppositionen ab, die Dispositionseigenschaften involvieren. Die niederstufige Generalisierung von den (endlich vielen) Meßläufen eines konkreten Experiments auf alle anderen Instantiierungen desselben speziellen Experimentaufbaus hängt davon ab, daß bei den Versuchsläufen alle (kausal) relevanten Faktoren kontrolliert werden, und dies bedeutet nach Cartwright, daß bei den Versuchsläufen eine Situation vorliegt, in der eine Disposition ${ }^{34}$ ungestört wirksam werden kann:

"[...] we need the notion of natures to [...] infer from the results of the experiment some general law that describes what happens, just in this experimental situation, whenever the experiment is run again [...] Not every feature is necessary to ensure its repeatability [...] the features that are necessary are exactly those which, in this very specific concrete situation, allow the nature of the process under study to express itself in some readable way. No weaker account will do." 35

Cartwrights "abstraktere" Generalisierung ist eine auf ein Gesetz, das auch für andere experimentelle Situationen Gültigkeit hat, und zwar nicht unbedingt in der Weise, daß dieses Gesetz für sich allein das Verhalten anderer Systeme beschreibt, sondern unter Umständen dadurch, daß es einen "Beitrag liefert" zu Gesetzen, die andere Systeme korrekt beschreiben. Beispielsweise gilt das Coulomb-Gesetz auch für Mehrteilchensysteme, bei denen neben den elektrostatischen Anziehungs- bzw. Abstoßungskräften noch weitere Kräfte wirken; das Coulomb-Gesetz liefert dann einen Beitrag zur Gesamtwechselwirkung, die sich additiv aus allen beitragenden Kraftkomponenten zusammensetzt. Die so beschriebene "Verallgemeinerungspraxis" hängt nach Cartwright von Voraussetzungen ab, die das Vorliegen von Dispositionen involvieren, genauer: das Vorliegen derselben Dispositionen

\footnotetext{
${ }^{31}$ [Cart92], S.47. Auf einer ähnlichen Linie argumentiert Cartwright auch in [Cart83], S.21ff. und [Cart94], S.279f.

${ }^{32}$ Dieses Experiment soll ein Gesetz der allgemeinen Relativitätstheorie testen und besteht im wesentlichen aus mehreren in einem Satelliten untergebrachten, frei rotierenden Quarzkugeln.

${ }^{33}$ [Cart92], S.54.

${ }^{34}$ Oder eine stabile Konfiguration von Dispositionen.

${ }^{35}$ [Cart92], S.56.
} 
in allen Situationen, die durch die Verallgemeinerung abgedeckt werden, d.h. für das Beispiel des Coulomb-Gesetzes: in allen Situationen, in denen es einen identischen Beitrag zur Gesamtwechselwirkung liefert:

"[...] the logic that uses what happens in ideal circumstances to explain what happens in real ones is the logic of tendencies or capacities. What is an ideal situation for studying a particular factor? It is a situation in which all other 'disturbing' factors are missing. And what is special about that? When all other disturbances are absent, the factor manifests its power explicitly in its behaviour [...] This tells you something about what will happen in very different, mixed circumstances - but only if you assume that the factor has a fixed capacity that it carries with it from situation to situation.

[...] The fundamental idea of the Galilean method is to use what happens in special or ideal cases to explain very different kinds of thing that happen in very non-ideal cases $[\ldots]$ to reason in that way is to presuppose that there are stable tendencies, or capacities, at work in nature". ${ }^{36}$

Cartwright schildert es also als eine in der Physik gängige Praxis, aus experimentellen Resultaten, die an sehr speziellen "idealen" Systemen gewonnen worden sind, in den zwei beschriebenen "Stufen" allgemeinere Aussagen bzw. Gesetze zu gewinnen. Sie will Präsuppositionen aufweisen, unter denen diese Praxis rational ist oder, wie sie sich ausdrückt, Voraussetzungen, unter denen die Praxis verständlich ist, die sie erklären oder die einen zu dieser Praxis berechtigen, und auch Voraussetzungen, unter denen Entsprechendes für die damit zusammenhängende Auswahlpraxis gilt.

In Cartwrights Ausführungen zu der Frage, unter welchen Bedingungen es eine rationale Praxis ist, in der beschriebenen Weise aus an "idealen" Systemen gewonnenen Resultaten allgemeine Gesetze, Sätze o.ä. zu gewinnen, werden offenbar zwei unterscheidbare Voraussetzungen genannt: Zum einen, daß im jeweiligen konkreten Fall, in dem verallgemeinert wird, eine oder mehrere (kausale oder nicht-kausale) Dispositionseigenschaften existieren bzw. vorliegen (also Naturen, Tendenzen oder Wirkungsvermögen), ${ }^{37}$ zum anderen, daß sowohl die an den "idealen" Systemen gewonnenen Resultate, als auch die daraus gewonnenen allgemeineren Gesetze, Sätze o.̈̈. "im Grunde" Dispositionseigenschaften zum Inhalt haben ${ }^{38}$. Die Auswahlpraxis für Experimente ist nach Cartwright offenbar insofern rational, als sie zu Experimenten führt, deren Resultate sich sozusagen als Input für die Verallgemeinerungspraxis eignen.

Cartwright erläutert ihr Argument nicht mit der wünschenswerten Klarheit, insbesondere werden drei Punkte nicht mit der erstrebenswerten Genauigkeit spezifiziert, nämlich

1. worin genau die Praxis der Verallgemeinerung besteht, um die es ihr geht,

2. was genau die beiden Voraussetzungen sind, unter denen diese Praxis rational ist, und

3. in welchem Sinn genau sie rational ist bzw. verständlich ist, gerechtfertigt werden kann o.ä.

\footnotetext{
${ }^{36}$ [Cart89a], S.190/191; s.a. [Cart92], S.47ff.

37 "[... there are stable tendencies, or capacities, at work in nature" ([Cart89a], S.190/191).

38 "[... ] laws are basically about natures" ([Cart92], S.47).
} 
Klar ist aber, daß Cartwright dadurch, daß sie Voraussetzungen aufweist, unter denen die beschriebene Praxis rational ist, für eine realistische Einstellung zu Dispositionseigenschaften oder zu entsprechenden Sätzen und Prädikaten argumentieren will, und sich nicht nur, wie man vielleicht auch vermuten könnte, mit der quer zur Realismusdebatte liegenden Frage beschäftigt, ob bei der Formulierung physikalischer Theorien, Gesetze u.ä. auch Ausdrücke zulässig ${ }^{39}$ sind, die für Dispositionen, Wirkungsvermögen etc. stehen, oder nur Ausdrücke, die für manifeste Eigenschaften, Dinge und Sachverhalte stehen ${ }^{40}$. Dies wird u.a. in den programmatischen Sätzen deutlich, mit denen ihr Buch "Nature's Capacities and their Measurement" beginnt:

"Science is measurement; capacities can be measured; and science cannot be understood without them: These are the three major theses of this book.

The third thesis could be more simply put: capacities are real." 41

Obwohl Cartwright die Struktur ihres Argumentes nicht in unmißverständlicher Weise darlegt, legen es die angeführten Argumentationsstücke, zusammen mit einigen weiteren Äußerungen, nahe, das Argument in ähnlicher Weise wie Putnams Konjunktionsargument zu rekonstruieren. Zunächst finden sich bei genauerem Hinsehen bei Cartwright zumindest einige Hinweise, welche Gestalt die (beiden) genannten Voraussetzungen der Rationalität der Praxis haben. Am Beispiel des Coulomb-Gesetzes gibt Cartwright explizit an, wie eine allgemeine Aussage über eine Dispositionseigenschaft aussieht:

(V2) "Charged bodies [...] have the capacity to [...] exert a force of $k q_{1} q_{2} / r^{2}$." ${ }^{42}$

Dies legt nahe, daß eine Aussage, die das Vorliegen einer Dispositionseigenschaft an einem bestimmten "idealen" System zum Inhalt hat, in etwa lautet:

(V0) Im Versuchsaufbau $X$ hatten die beiden im Abstand $r$ angeordneten und geladenen Körper $K_{1}$ und $K_{2}$ zum Zeitpunkt $t$ das Wirkungsvermögen, eine Kraft $k q_{1} q_{2} / r^{2}$ aufeinander auszuüben,

und eine entsprechende, etwas allgemeinere Aussage:

(V1) Zwei unter Bedingungen vom Typ $X$ im Abstand $r$ angeordnete Körper vom Typ $K_{1}$ und $K_{2}$ mit Ladungen $q_{1}$ und $q_{2}$ haben das Wirkungsvermögen, eine Kraft $k q_{1} q_{2} / r^{2}$ aufeinander auszuüben.

Durch Aussagen dieser Art läßt sich in konkreten Fällen die eine der beiden unterschiedenen Voraussetzungen für die Rationalität der Verallgemeinerungspraxis formulieren, daß eine oder mehrere Dispositionseigenschaften existieren bzw. vorliegen. Aussagen dieser Art eignen sich aber auch zur Explikation der anderen der beiden Voraussetzungen: Cartwrights Formulierung, daß Gesetze etc. "im Grunde" Dispositionseigenschaften zum Inhalt haben, läßt sich auffassen als die Aussage, daß die in der Physik durch die Verallgemeinerungspraxis etablierten Gesetze und Aussagen nicht wörtlich zu nehmen sind, sondern zu paraphrasieren sind durch Aussagen über Dispositionseigenschaften, also Aussagen wie

\footnotetext{
${ }^{39}$ In ggf. zu erläuterndem Sinn.

${ }^{40}$ So daß die Frage, ob eine Theorie mit dem Basisvokabular des vorzuziehenden ontologischen Typs dann realistisch oder antirealistisch zu lesen ist, noch offen bliebe.

${ }^{41}$ [Cart89a], S.1, s.a. S.162f.; vgl. auch [Cart94], besonders den ersten, "For Realism" überschriebenen Abschnitt.

${ }^{42}[$ Cart95a], S.180.
} 
(V0), (V1) und (V2), daß also der eigentliche Gehalt dieser Gesetze und Aussagen nicht der ist, den ihre Oberflächengestalt nahelegt, sondern erst durch Paraphrasierung gleichsam ans Licht gebracht wird, und daß die korrekten Paraphrasen Aussagen über Dispositionen wie (V0), (V1) und (V2) sind. ${ }^{43}$ Cartwrights Aussage, daß die Verallgemeinerungspraxis rational ist, verständlich ist o.ä. unter der Voraussetzung, daß die involvierten Gesetze und Aussagen "im Grunde" Dispositionseigenschaften zum Inhalt haben, wäre demnach zu explizieren als die These, daß die Praxis rational, verständlich o.ä. ist unter der Voraussetzung, daß die involvierten Gesetze und Aussagen nicht wörtlich zu nehmen sind, sondern zu paraphrasieren sind durch Aussagen wie (V0), (V1) und (V2) über Dispositionseigenschaften.

Einen Hinweis darauf, worin genau die Verallgemeinerungspraxis besteht, die Cartwright im Auge hat, kann man ihren Formulierungen "infer from the results of the experiment some general law ..." und "logic" 44 entnehmen: Es geht offenbar um eine Inferenzpraxis, d.h. um eine Praxis, die so etwas wie (ein oder mehrere) Inferenzverfahren oder Inferenzregeln involviert, bei denen die an "idealen" Systemen gewonnenen Resultate als Prämissen fungieren können (evtl. zusammen mit anderen Prämissen), und die dann die allgemeinen Gesetze und Aussagen als Output liefern. Wie genau die Inferenzverfahren oder -regeln lauten, läßt Cartwright offen, sie schreibt ihnen aber offenbar eine für ihre Argumentation zentrale Eigenschaft zu: Cartwright ist augenscheinlich der Ansicht, daß es keinen Grund für die Annahme gibt, daß diese Inferenzverfahren oder -regeln in irgendeinem Sinn verläßlich sind, d.h. bei wahren Prämissen stets, meistens, wahrscheinlich o.ä. wahren Output liefern, wenn als Prämissen die wörtlich genommenen, unparaphrasierten Aussagen über manifeste Eigenschaften fungieren, die als Resultate experimenteller Untersuchungen "idealer" Systeme gewonnen werden. Dagegen scheint Cartwright der Ansicht zu sein, daß aus "in korrekter Weise" (d.h. als Aussagen über Dispositionen) paraphrasierten Resultaten der Untersuchungen "idealer" Systeme in verläßlicher Weise auf entsprechend paraphrasierte allgemeine Gesetze und Aussagen geschlossen werden kann. Es bleibt allerdings offen, ob sich dies auf dieselben Inferenzverfahren oder -regeln bezieht, die in der Praxis der Wissenschaft tatsächlich verwendet werden, oder auf andere, die die Inferenzpraxis sozusagen rekonstruieren, und es bleibt auch offen, in welchem Sinn genau die Inferenzen "verläßlich" sind.

Wenn diese beiden Explikationen dessen, was Cartwright über die Verallgemeinerungspraxis und Präsuppositionen ihrer Rationalität sagt, richtig sind, dann liegt folgende Erläuterung nahe, in welchem Sinn genau die Praxis rational ist, wenn die von ihr genannten Voraussetzungen erfüllt sind: Die Praxis ist rational im Sinne der zweiten der im Abschnitt über Putnams Konjunktionsargument diskutierten Erläuterungen ${ }^{45}$ sie ist also rational in dem Sinn, daß man ihr gleichsam von außen ein Ziel zuschreiben kann, das durch die axiologische realistische These formuliert wird:

Die Verallgemeinerungspraxis hat das Ziel, Gesetze und Aussagen zu gewinnen, deren eigentlicher Gehalt durch Paraphrasen über Dispositionseigenschaften wie (V1) und (V2) gegeben ist, die wahr sind, d.h. die Praxis führt stets, meistens, wahrscheinlich o.ä. zu Gesetzen und Aussagen, deren eigentlicher Gehalt durch solche Paraphrasen gegeben ist.

\footnotetext{
${ }^{43}$ Zur Unterscheidung wörtlich/nicht-wörtlich vgl. auch Abschnitt 13.2.2.

${ }^{44}$ Siehe die Zitate oben; Hervorhebung von mir.

${ }^{45}$ Die erste der Erläuterungen ist aus demselben Grund wie bei Putnams Argument für die Realismusdebatte nicht von Interesse.
} 
Sie ist in diesem Sinn rational, wenn die Voraussetzungen erfüllt sind, daß

1. der eigentliche Gehalt der involvierten Gesetze und Aussagen durch Paraphrasen über Dispositionseigenschaften wie (V0), (V1) und (V2) gegeben ist und

2. die Paraphrasen der als Prämissen der Inferenzen fungierenden Aussagen wahr sind,

denn dann, so müßte man in dieser Rekonstruktion von Cartwrights Überlegungen argumentieren, kann man schließen, daß die Verallgemeinerungspraxis stets, meistens, wahrscheinlich o.ä. zur Gewinnung von Aussagen führt, deren Paraphrasen wahr sind. Für diesen Schluß ist offenbar eine Prämisse über die Verläßlichkeit der Inferenzverfahren oder -regeln erforderlich, die die Inferenzpraxis sozusagen rekonstruieren, ${ }^{46}$ d.h. eine Prämisse, die besagt, daß diese Verfahren oder Regeln bei wahren Prämissen stets, meistens, wahrscheinlich o.ä. wahren Output liefern. Ob eine solche Prämisse gilt, läßt sich nur beurteilen, wenn die Inferenzverfahren oder -regeln genauer spezifiziert werden, als es Cartwright tut. ${ }^{47}$

Die zweite der Voraussetzungen ist in der hier angegebenen Form 2. nicht mit der weiter oben angegebenen Rekonstruktion identisch, nach der sie sozusagen direkt durch die Paraphrasen der als Prämissen fungierenden Aussagen gegeben ist, nicht durch die Aussage, daß diese Paraphrasen wahr sind. Letztere folgt aber offenbar aus den Paraphrasen selbst, zusammen mit der Prämisse, daß für Sätze ' $\mathrm{P}$ ' der fraglichen Art gilt, daß sie wahr sind genau dann, wenn $P$ (Tarskis Schema $(\mathrm{T})^{48}$ ), die unkontroverses Element jeder nichtepistemischen Wahrheitstheorie ist. Gegeben das Schema $(\mathrm{T})$ ist also eine hinreichende Bedingung dafür, daß 2. erfüllt ist, durch die Paraphrasen selbst, d.h. durch Aussagen wie (V0) und (V1) gegeben, die sagen, daß in bestimmten Situationen bestimmte Dispositionseigenschaften vorliegen, so daß 2. ersetzt werden kann durch

$$
\text { 2'. (V0), (V1) .. }
$$

Cartwrights oben zitierte Formulierungen legen nahe, daß sich das, was sie als Präsuppositionen dafür nennt, daß die von ihr beschriebene experimentalphysikalische Verallgemeinerungspraxis rational ist, durch 1. und 2'. rekonstruieren läßt. 1. ist eine pragmatische These über die im Diskurs der Physik getroffenen Aussagen. 2. hat prima facie die Gestalt einer epistemischen realistischen These, würde dann aber eine semantische realistische These voraussetzen bzw. eine Erläuterung von 'wahr' erfordern; da Cartwright das Thema Semantik wissenschaftlicher Sätze und Theorien (also Wahrheits-, Referenz- und Bedeutungstheorien) generell nicht thematisiert, dürfte dies der Grund sein, weswegen Cartwrights Formulierungen 2'. näher kommen. ${ }^{49}$ Im Hinblick auf die Realismusdebatte läßt sich 2'. als Teil einer bzw. mehrerer ontologischer realistischer Thesen des oben ${ }^{50}$ formulierten Typs (OR) auffassen. Von den genannten Präsuppositionen ist also im Hinblick auf die Realismusdebatte vor allem 2'. relevant. Cartwrights Argumentationsziel sollte sich daher rekonstruieren lassen als eine realistische Position, die ontologische realistische Thesen des

\footnotetext{
${ }^{46}$ D.h. der Inferenzverfahren oder -regeln, die aus den in der zweiten Voraussetzung genannten Paraphrasen der Prämissen die Paraphrasen der in der Verallgemeinerungspraxis gewonnenen allgemeinen Gesetze und Ausssagen als Output liefern.

${ }^{47} \mathrm{Im}$ Unterschied zu Putnam, bei dessen Konjunktionsargument es an der entsprechenden Stelle um Deduktion geht.

${ }^{48} \mathrm{Vgl}$. Abschnitt 2.4 .

${ }^{49}$ In dieser Rekonstruktion muß sie das Schema (T) akzeptieren, aber darüber hinaus keine bestimmte semantische Theorie.

${ }^{50}$ Siehe die Abschnitte 1.2.1 und 1.3.1.
} 
Typs (OR) in bezug auf Dispositionseigenschaften einschließt, die aus den in 2' genannten Aussagen (V0), (V1) etc. hervorgehen, indem man diese um eine Unabhängigkeitsaussage ergänzt, die bei Cartwrights Argumentation keine Rolle spielt. ${ }^{51}$

Durch solche ontologischen realistischen Thesen über bestimmte, spezifizierte Dispositionseigenschaften sowie durch die weiteren genannten Thesen, die für die Realismusdebatte nicht unmittelbar relevant sind, sind nach dieser Rekonstruktion Voraussetzungen gegeben, unter denen die von Cartwright beschriebene experimentalphysikalische Praxis rational ist. Wenn die an der Praxis beteiligten Wissenschaftler überzeugt wären, daß diese Voraussetzungen erfüllt sind, wären sie selbst in der Lage, die Praxis als rational zu rechtfertigen. Wenn eine Außenstehende wie Cartwright, die den Blick auf diese Praxis richtet, ohne selbst daran beteiligt zu sein, überzeugt ist, daß die Voraussetzungen erfüllt sind, kann sie die Praxis als rational rechtfertigen und, um Cartwrights Formulierungen aufzugreifen, sie kann dann Gründe angeben, die die Praxis erklären, die zu ihr berechtigen und aufgrund derer sie verständlich ist, selbst wenn die beteiligten Wissenschaftler dies nicht können oder sich um diese Frage nicht kümmern.

In dieser Rekonstruktion ist Cartwrights Präsuppositionsargument genaugenommen eher das Schema eines Argumentes für realistische Thesen als ein Argument, da sie im wesentlichen offen läßt, welche Inferenzverfahren oder -regeln die Verallgemeinerungspraxis ausmachen bzw. zu rekonstruieren erlauben und in welchem Sinn genau sie verläßlich (o.ä.) sind. Für die Bewertung des Argumentes spielt dies jedoch, wie sich zeigen wird, keine entscheidende Rolle.

\subsection{Probleme und Kritik}

Eine erste Frage, die an Argumentationen zu richten ist, die von der Praxis der Wissenschaften ausgehen, ist, ob sich die in Anspruch genommenen Methoden und Praktiken tatsächlich in der real-existierenden Wissenschaft aufweisen lassen. Sie ist für das Argument von Putnam zumindest für Teile der Naturwissenschaften ohne weiteres positiv zu beantworten ${ }^{52}$ und, soweit bei der nicht ganz genauen Charakterisierung der von Cartwright in Anspruch genommenen Praxis erkennbar, auch für ihr Argument.

Wichtigere Einwände setzen an drei anderen Punkten an: Erstens ist der epistemische Status der Prämisse über die Rationalität einer Praxis ungeklärt, von der die beiden Argumente (in den vorgeschlagenen Rekonstruktionen) ausgehen, zweitens ist ungeklärt, inwiefern jeweils alternativenlose Voraussetzungen der Rationalität der in Anspruch genommenen Praxis identifiziert werden können, und drittens ist unklar, ob bzw. wieso sich selbst dann, wenn das der Fall ist, ein für die Realismusdebatte relevantes Argument daraus ergibt.

Der erste Punkt betrifft die (in den vorgeschlagenen Rekonstruktionen) jeweils als Ausgangspunkt der Argumente fungierende Annahme, daß die in Anspruch genommene Praxis rational ist in dem Sinn, daß sie stets, wahrscheinlich o.ä. auf wahre Sätze eines bestimmten Typs führt (bei Putnam Beobachtungssätze, bei Cartwright (paraphrasierte) Gesetze oder Sätze über bestimmte Dispositionen). Diese Annahme wird jeweils für das Argument vorausgesetzt, ohne daß etwas über ihren epistemischen Status gesagt wird, sie

\footnotetext{
${ }^{51}$ Das Stichwort 'unabhängig' fällt bei Cartwright nicht, möglicherweise gerade aus diesem Grund, also weil die für die meisten Realisten wichtigen Unabhängigkeitsintuitionen (siehe Einleitung) in ihrer Argumentation keine besondere Rolle spielen und sie sie daher, wie im Mainstream der wissenschaftstheoretischen Realismusdebatte üblich, nicht näher erläutert.

${ }^{52}$ Pace van Fraassen ([vFra80], S.83ff.).
} 
ist aber in beiden Fällen keinesfalls offensichtlich wahr: Es ist klarerweise möglich, daß aus der Konjunktion mehrerer akzeptierter Theorien abgeleitete Beobachtungssätze falsch sind, und ebenso, daß durch Verallgemeinerung aus an "idealen" Systemen gewonnenen Resultaten gewonnene Gesetze falsch sind, egal ob die entsprechende Praxis etabliert ist oder nicht. ${ }^{53}$ Für die Annahme, daß die jeweilige (etablierte) Praxis tatsächlich stets, meistens, wahrscheinlich o.ä. zu wahren Sätzen führt, können Gründe vorliegen (etwa induktive ${ }^{54}$ ), ob das so ist, bleibt jedoch bei Putnam und Cartwright offen; der epistemische Status der Annahmen, von denen ihre Argumente ausgehen, bleibt ungeklärt.

Der zweite Punkt ist im Fall von Putnams Konjunktionsargument der Einwand, daß unklar ist, ob und wenn ja, warum durch semantische und epistemische realistische Thesen in bezug auf die involvierten Theorien die einzigen denkbaren Voraussetzungen gegeben sind, unter denen die Praxis rational ist, die "gemeinsamen" empirischen Konsequenzen mehrerer akzeptierter wissenschaftlicher Theorien als wahr zu akzeptieren. Daß die Praxis rational ist, wenn die semantischen und epistemischen realistischen Thesen gelten, ist plausibel, zumindest prima facie scheint jedoch nicht klar, daß es keine anderen Voraussetzungen geben kann, unter denen die Praxis ebenfalls rational ist. Für Cartwrights Argumentation gilt Entsprechendes. Weder Putnam noch Cartwright argumentieren für die These, daß die von ihnen angegebenen Voraussetzungen die einzigen sind, unter denen die jeweilige Praxis rational ist, d.h. die garantieren, daß die Praxis stets, meistens o.ä. zu wahren Überzeugungen führt. Ob sie diese These selbst akzeptieren, läßt sich anhand ihrer Texte nicht entscheiden; ${ }^{55}$ begründet wird eine solche These von ihnen jedenfalls nicht.

Selbst wenn man zugesteht, daß sich andere als die von Putnam und Cartwright angegebenen Voraussetzungen für die Rationalität der beschriebenen Praktiken nicht identifizieren lassen, oder sogar, daß es keine anderen Sachverhalte gibt, die so wie die von Putnam und Cartwright vorgeschlagenen realistischen Thesen garantieren würden, daß die jeweilige Praxis stets, meistens o.ä. zu wahren Überzeugungen führt, bleibt dennoch ein weiterer und grundsätzlicherer Einwand. Die Argumente von Putnam und Cartwright haben im wesentlichen die Struktur: Wenn bestimmte Voraussetzungen (die durch bestimmte realistische Thesen (und weitere Thesen) beschrieben werden) erfüllt sind, dann ist eine bestimmte in den Wissenschaften gängige Praxis rational, d.h. dann ist garantiert, daß die Praxis stets, meistens o.ä. zu wahren Gesetzen, Aussagen o.ä. führt. Warum und in welcher Weise dies ein Argument für die realistischen Thesen darstellen soll, wieso es begründen soll, daß diese realistischen Thesen wahr sind, also jemanden, der glaubt, daß die Praxis rational ist, von diesen realistischen Thesen überzeugen soll, wird von Putnam und Cartwright mit keinem Wort diskutiert und bleibt völlig offen. Eine prägnante Formulierung, die die Struktur der Präsuppositionsargumente mit Hilfe einer theologischen Analogie verdeutlicht, findet sich bei Boyd; er nennt

\footnotetext{
${ }^{53}$ Intuitiv sieht man das vielleicht deutlicher, wenn man etablierte Praktiken der Überzeugungsgewinnung außerhalb der Wissenschaften in den Blick nimmt, etwa die an weltanschauliche Überzeugungssysteme religiöser Art, new age o.ä. geknüpften.

${ }^{54}$ Im Fall von Putnams Argument könnte die (durch Beobachtung gewonnene) Erfahrung, daß das Ableiten von Beobachtungssätzen aus der Konjunktion mehrerer akzeptierter Theorien bisher stets, meistens, wahrscheinlich o.ä. zu wahren Beobachtungssätzen geführt hat (in ggf. zu spezifizierender Weise) einen induktiven Grund für die Annahme liefern, daß dies immer so ist. Für Cartwrights Argument ist schwieriger zu sehen, wie ein solcher Grund aussehen könnte, da die ihm zugrunde liegende Annahme bereits Dispositionseigenschaften involviert.

${ }^{55}$ Putnam erwähnt diesen Punkt mit keinem Wort, bei Cartwright finden sich einige Formulierungen, die darauf hindeuten, daß sie die von ihr genannten Voraussetzungen für alternativenlos hält (vgl. das Zitat auf S.133: “... only if you assume ..." (Hervorhebung von mir), s.a. [Cart94], S.279).
} 
"[...] the dictum attributed to Pope St. Celestine I [...]: "Lex orandi est lex credendi," "the rule for praying is the rule for believing," or (in a freer translation) "believe what is necessary to 'rationally reconstruct' liturgical practice." For "liturgical practice" put "scientific practice" and you get the strategy for the defense of realism employed here." 56

Der Schritt vom Ausgangspunkt der Präsuppositionsargumente von Putnam und Cartwright (der Annahme, daß die Praxis rational ist) zum Argumentationsziel (den realistischen Thesen) ist keiner, der einer logischen Schlußregel folgt, und was diesen Schritt ansonsten begründen sollte, bleibt offen. Daran ändert sich auch dann nichts, wenn man zugesteht, daß sich keine anderen Voraussetzungen identifizieren lassen, die (anstelle der realistischen Thesen) garantieren würden, daß die Praxis rational ist; dies sieht man, wenn man sich vor Augen führt, daß es schlicht eine Tatsache, ein "brute fact" sein kann, daß die Praxis rational ist, also stets, meistens o.ä. zu wahren Überzeugungen führt. ${ }^{57}$

\subsection{Fazit}

In der wissenschaftstheoretischen Realismusdebatte sind eine Reihe von Präsuppositionsargumenten vorgebracht worden, die in der einen oder anderen Form auf bestimmte Elemente oder Methoden der Praxis der Wissenschaften hinweisen und für realistische Thesen argumentieren, indem Präsuppositionen genannt werden, unter denen die jeweilige Praxis eine rationale ist. Von diesen Argumenten sind hier die beiden von Putnam und von Cartwright untersucht worden. Die dabei konstatierten Probleme sind bei beiden im wesentlichen dieselben und auch für die anderen Argumente dieser Art typisch.

Für die Begründung einer realistischen Position leisten die beiden diskutierten Präsuppositionsargumente in der vorliegenden Form kaum etwas. Beide Argumente haben selbst für jemanden, der ihren Ausgangspunkt (die Annahme, daß die jeweilige Praxis rational ist) akzeptiert und der außerdem akzeptiert, daß sich keine anderen Voraussetzungen identifizieren lassen, die (anstelle der realistischen Thesen) garantieren würden, daß die Praxis rational ist, keine Überzeugungskraft, solange nicht klar ist, wie der Schritt zum Argumentationsziel (den realistischen Thesen) begründet sein soll. Genau dieser Schritt müßte plausibel gemacht werden, wenn die Überlegungen zur Rationalität einer bestimmten wissenschaftlichen Praxis als Argument für realistische Thesen taugen sollen, er wird es jedoch bei Putnam und Cartwright nicht.

Cartwright deutet an einer Stelle ${ }^{58}$ an, daß sie so etwas wie ein transzendentales Argument für wissenschaftlichen Realismus im Auge hat. Wenn es gelingen sollte, diese Form der Argumentation in überzeugender Weise zu erläutern oder zu explizieren, könnten sich die Präsuppositionsargumente möglicherweise vor diesem Hintergrund rekonstruieren lassen und Überzeugungskraft gewinnen. Die damit verbundenen Schwierigkeiten sind aber notorisch hartnäckig und bis heute ungelöst. ${ }^{59}$

\footnotetext{
${ }^{56}$ [Boyd85b], S.32. Boyd selbst deutet ein Präsuppositionsargument an, das sich auf die Gesamtheit der "principles of scientific methodology" ([Boyd85b], S.33) oder jedenfalls ein völlig allgemeines Inferenzschema für das Schließen auf die beste Erklärung bezieht, nicht, wie bei Putnam und Cartwright, auf eine "lokale", genau spezifizierte Praxis; dazu siehe Kap.9.10.4.

${ }^{57}$ Hier liegt vielleicht die Replik nahe, daß ein "brute fact" dieser Art nicht unerklärt stehenbleiben kann, daß also die Rationalität einer Praxis einer Erklärung bedarf und dadurch der Schritt zum Argumentationsziel, also zu den realistischen Thesen begründet werden kann. Diese Replik führt auf Argumente einer anderen Art, nämlich auf die verschiedenen Varianten des Wunderargumentes; siehe Kap.9.

${ }^{58}$ [Cart94], S.279.

${ }^{59}$ Für eine klare Darstellung der Probleme dieser Form von Argumenten siehe [Stro68].
} 


\section{Kapitel 8}

\section{Kontinuitätsargumente}

Eine zweite Gruppe von Argumenten für wissenschaftlichen Realismus soll hier unter dem Titel Kontinuitätsargumente ${ }^{1}$ zusammengefaßt werden. Die Idee, die hinter diesen Argumenten steht, ist, daß Anhänger antirealistischer Positionen regelmäßig von einer verzerrenden oder zumindest übermäßig dramatisierten Darstellung der Ausgangssituation in der Realismusdebatte ausgehen: Antirealisten sehen sozusagen einen tiefen Graben, eine fundamentale Differenz zwischen dem Bereich des Beobachtbaren und dem Bereich der unbeobachtbaren oder theoretischen Entitäten und Sachverhalte, wo sich nach realistischer Sichtweise höchstens abgestufte, mehr oder weniger kontinuierliche Übergänge finden, denen philosophisch keine besondere Relevanz zukommt.

Unter den Argumenten, die diese Idee entwickeln, lassen sich zwei Gruppen unterscheiden: Einerseits "destruktive" Argumente, die darauf zielen, antirealistische Positionen zu unterminieren, indem man bestreitet, daß die Unterscheidung beobachtbar/theoretisch eine für philosophische Zwecke hinreichend wohldefinierte und von kontingenten und kontextspezifischen Sachverhalten unabhängige Grenzziehung ergibt. Andererseits "positive" Argumente, die plausibel zu machen versuchen, daß es aufweisbare Gemeinsamkeiten zwischen dem Bereich des Beobachtbaren und dem Bereich der unbeobachtbaren Entitäten gibt oder jedenfalls graduelle oder kontinuierliche Übergänge, und daß diese für einen gleichartigen semantischen Status von Beobachtungsausdrücken und theoretischen Ausdrücken sprechen und auch dafür, daß im Prinzip, d.h. von speziellen Problemen und Besonderheiten im Einzelfall abgesehen, beide Bereiche (oder Teile von beiden Bereichen) in gleicher Weise epistemisch zugänglich sind.

\section{1 "Destruktive" Kontinuitätsargumente}

\subsubsection{Zweifel, daß die Unterscheidung beobachtbar/theoretisch eine für philosophische Zwecke brauchbare Grenzziehung ergibt}

Die Unterscheidung beobachtbar/theoretisch kann auf zwei verschiedenen Ebenen getroffen werden: Zum einen auf sprachlicher Ebene als eine Unterscheidung von Ausdrücken und, darauf aufbauend, von Sätzen (wie im logischen Positivismus üblich), zum anderen auf der Sachebene als eine Unterscheidung von Gegenständen, Ereignissen und Sachverhalten.

Gegen alle antirealistischen Positionen, die sich auf eine Form dieser Unterscheidung

\footnotetext{
${ }^{1}$ Diese Bezeichnung findet sich in [Krug83], S.578.
} 
stützen, ist eingewendet worden, daß diese Unterscheidung sich nicht so explizieren läßt, wie es erforderlich ist, um das auf ihr lastende argumentative Gewicht zu tragen. Wenn diese Unterscheidung einen philosophisch relevanten Unterschied zwischen zwei Klassen von Ausdrücken bzw. zwischen zwei Klassen von Entitäten markieren soll, dann sollte jeder Ausdruck bzw. jede Entität eindeutig und unabhängig von kontingenten, den epistemischen Zugang in speziellen Situationen betreffenden Sachverhalten einer der beiden unterschiedenen Klassen zugeordnet werden.

Hilary Putnam hat in diesem Zusammenhang bemerkt, daß die Unterscheidung beobachtbar/theoretisch auf der sprachlichen Ebene und die auf der Gegenstandsebene nicht ohne weiteres aufeinander abbildbar sind: Viele der Ausdrücke, die prima facie gute Kandidaten für Beobachtungsausdrücke sind, lassen sich, so wie sie üblicherweise verwendet werden, ohne weiteres auch auf unbeobachtbare Gegenstände und Sachverhalte anwenden (etwa 'blau' oder 'dreieckig' auf Gegenstände, die zu klein sind, um sie mit bloßem Auge zu erkennen), und es läßt sich sogar bezweifeln, ob bei genauem Hinsehen überhaupt eine nennenswerte Anzahl von Ausdrücken übrigbleibt, die eine Beobachtungssprache im Sinne des logischen Positivismus ergeben. ${ }^{2}$

Grover Maxwell hat darauf hingewiesen, daß in der Praxis der Wissenschaften keine den genannten Anforderungen genügende Unterscheidung beobachtbar/theoretisch getroffen wird. Vielmehr hängt es dort in der Regel vom speziellen Kontext der Untersuchung ab, ob der Zugang zu einer Entität, Größe o.ä. als direktes Beobachten oder als theoretisches Erschließen gilt. Es kommt durchaus vor, daß ein und dieselbe Entität (bzw. ein und derselbe Typ von Entitäten) in bestimmten Experimenten als direkt beobachtbar betrachtet wird, in anderen dagegen nur in die theoretische Deutung eingeht bzw. über diese erschlossen wird. Außerdem kann es nach Maxwell vom Entwicklungsstand des Instrumentenbaus abhängen, ob eine Entität in den Naturwissenschaften als beobachtbar zählt oder nicht. So hat die Entwicklung des Mikroskops z.B. das Beobachten von Zellstrukturen ermöglicht, die vorher keiner Beobachtung zugänglich waren, und damit sozusagen die Grenze des Beobachtbaren ein Stück weiter in Richtung kleiner Längenskalen verschoben. Einer in dieser Weise von kontingenten historischen und kontextspezifischen Sachverhalten abhängigen Unterscheidung beobachtbar/theoretisch kann nach Maxwell plausiblerweise keine philosophische Relevanz zukommen. ${ }^{3}$

\subsubsection{Van Fraassens Replik: Eine Präzisierung des Begriffes der Beob- achtbarkeit}

Eine antirealistische Antwort auf diese Einwände hat Bas van Fraassen formuliert. ${ }^{4} \mathrm{Zu}-$ nächst ist klar, daß die Ausdrücke 'Beobachtung' und 'beobachtbar' in den Wissenschaften einerseits und in der Wissenschaftsphilosophie andererseits in verschiedener Weise verwendet werden. ${ }^{5}$ Für die Realismusdebatte ist die philosophische Verwendungsweise relevant, und die läßt sich nach van Fraassen mit für diesen Zweck ausreichender Genauigkeit formulieren, auch wenn eine präzise Definition oder Erläuterung vielleicht nicht (oder zumindest noch nicht) zu haben ist. Van Fraassen gibt als grobe Charakterisierung an:

" $\mathrm{X}$ is observable if there are circumstances which are such that, if $\mathrm{X}$ is present

\footnotetext{
${ }^{2}[$ Putn75d], S.217/218.

3 [Maxw62].

${ }^{4}$ [vFra80], S.13ff.

${ }^{5}$ Siehe auch [Carn66], Kap.23, und [Shap82b].
} 
to us under those circumstances, then we observe it." 6

Van Fraassen orientiert sich mit dieser Charakterisierung von Beobachtbarkeit an den in der Physik gängigen Charakterisierungen von Meßbarkeit mittels eines Meßinstrumentes. Er betrachtet menschliche Beobachter in Analogie zu Meßinstrumenten, wobei die kausale Beeinflussung des Instrumentes durch die gemessene Größe offenbar der Stimulation der Photorezeptoren des menschlichen Auges entsprechen soll und die Anzeige oder Zeigerstellung des Meßgerätes einer gewonnenen Überzeugung bzw. einem Beobachtungssatz entsprechenden Inhalts. Die Eigenschaft, beobachtbar zu sein, faßt van Fraassen sozusagen auf als die Eigenschaft, durch das Meßgerät menschlicher Wahrnehmungsapparat meßbar zu sein.

"If we follow the principles of the general theory of measurement used in discussions of the foundations of quantum mechanics, we call system $Y$ a measurement apparatus for quantity $A$ exactly if $Y$ has a certain possible state (the ground-state) such that if $Y$ is in that state and coupled with another system $X$ in any of its possible states, the evolution of the combined system $(X$ plus $Y$ ) is subject to a law of interaction which has the effect of correlating the values of $A$ in $X$ with distinct values of a certain quantity $B$ (often called the 'pointer reading observable') in system $Y$. Since observation is a special subspecies of measurement, this is a good picture to keep in mind as a partial guide." 7

Beobachtbarkeit in van Fraassens Sinn ist eine Eigenschaft, die eine Entität oder ein Ereignis oder ein Sachverhalt ${ }^{8}$ hat oder nicht hat, je nachdem, ob jemand mit normalem menschlichen Wahrnehmungsapparat sie bzw. es bzw. ihn unter geeigneten Bedingungen mit dem unbewaffneten Auge beobachten kann. Diese Erläuterung müßte noch präzisiert werden, um in klarer und nachvollziehbarer Weise Entitäten, Ereignisse und Sachverhalte auszuschließen, die man intuitiv als beobachtbar einstufen könnte, wenigstens im Sinne "indirekter" Beobachtbarkeit, die aber nicht unter van Fraassens Begriff fallen sollen: Man könnte der Ansicht sein, daß jemand, der eine Nebelkammerspur mit bloßem Auge betrachtet, nicht nur diese Spur beobachtet, sondern auch das Positron, das diese Spur hervorruft — so wie jemand, der die Tankanzeige seines Autos betrachtet, nicht nur den Zeigerstand beobachtet, sondern "indirekt" auch beobachtet, daß der Tank leer ist. Wenn eine solche Präzisierung von van Fraassens Erläuterung von 'beobachtbar' gelingt (was keineswegs selbstverständlich ist ${ }^{9}$, wogegen aber auch nichts Prinzipielles spricht ${ }^{10}$ ), dann dürfte der so erläuterte Begriff die von Maxwell bemängelte Abhängigkeit von speziellen Umständen des epistemischen Zugangs und vom historischen Entwicklungsstand der Beobachtungsinstrumente nicht aufweisen. Van Fraassen formuliert die Unterscheidung beobachtbar/unbeobachtbar damit auf der Sachebene. Er betont, daß dies die relevante Ebene der Unterscheidung ist, wohingegen die auf der Sprachebene liegende Unterscheidung zwischen theoretischen Ausdrücken und Beobachtungsausdrücken seiner Meinung

\footnotetext{
${ }^{6}[\mathrm{vFra} 80], \mathrm{S} .16$.

${ }^{7}$ [vFra80], S.58/59; s.a. [vFra92], S.14.

${ }^{8}$ Van Fraassens Konzeption von Beobachtbarkeit erfaßt diese Kategorien sinngemäß in gleicher Weise; vgl. [vFra80], S.58f.

${ }^{9}$ Jedenfalls dann nicht, wenn man, wie van Fraassen, nicht die Ansicht vertreten will, daß nur Sinnesdaten, Empfindungen o.ä. beobachtbar sind, also direkten Realismus (siehe Fn.29) zumindest für makroskopische Alltagsgegenstände akzeptiert.

${ }^{10}$ [Fodo84] läßt sich als ein Schritt in diese Richtung lesen.
} 
nach nebensächlich ist. ${ }^{11}$

Um auch auf der sprachlichen Ebene eine entsprechende Unterscheidung markieren zu können, die Putnams Einwand berücksichtigt, müßte man die gängige Sprache der Wissenschaften und auch die des Alltags einigermaßen weitgehend reformieren, und zwar dahingehend, daß man die von Putnam angeführten "problematischen" Ausdrücke abschafft zugunsten jeweils eines Beobachtungsausdrucks, der nur für beobachtbare Entitäten, Eigenschaften usw. steht, und eines theoretischen Ausdrucks, der gewissermaßen dasselbe Prädikat in den unbeobachtbaren Bereich fortsetzt (Z.B. wäre 'dreieckig' zu ersetzen durch

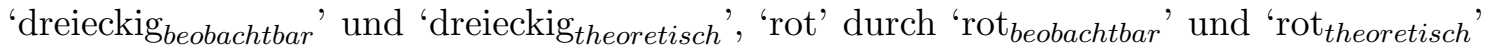
usw.). ${ }^{12}$ Nach einer solchen Sprachreform hätte man eine einwandfreie Unterscheidung von Beobachtungsausdrücken und theoretischen Ausdrücken, sowie auch eine einwandfreie Unterscheidung von Beobachtungssätzen, die aus Beobachtungsausdrücken aufgebaut sind, und theoretischen Sätzen, die theoretische Ausdrücke enthalten. Diese Unterscheidungen auf der sprachlichen Ebene entsprächen dann den Unterscheidungen auf der Sachebene, d.h. Beobachtungsausdrücke stünden nur für beobachtbare Entitäten, Eigenschaften usw. und Beobachtungssätze stünden nur für beobachtbare Sachverhalte.

Es bleibt damit durchaus noch Raum für Zweifel, ob van Fraassens Erläuterung ausreicht, eine scharfe und willkürfreie Grenzlinie zwischen beobachtbaren und unbeobachtbaren Entitäten zu ziehen. Ein Ansatzpunkt für Kritik wäre der, daß van Fraassen eine etwas idiosynkratische Präferenz für visuelle Wahrnehmung (im Unterschied zu Wahrnehmung mittels der anderen Sinne) als Kriterium der Beobachtbarkeit zeigt ${ }^{13}$. Eine andere Frage wäre, wo Entitäten einzuordnen sind, die einige beobachtbare Eigenschaften aufweisen, aber auch einige unbeobachtbare (z.B. eine Tasse Kaffee, die man sicherlich beobachten kann, deren Temperatur oder Gewicht aber nach van Fraassen als unbeobachtbar zählen müßten), und wie Ereignisse und Prozesse (bzw. die daran beteiligten Entitäten) einzustufen sind, die phasenweise zu schnell sind, um sie mit dem unbewaffneten Auge zu verfolgen (das Platzen eines Luftballons, der Flügelschlag einer Libelle, die Muster, die ein Wassertropfen beim Auftreffen auf eine Wasseroberfläche erzeugt, die Bahn einer Gewehrkugel u.ä.). Eine dritte, wichtigere Frage ließe $\operatorname{sich}^{14} \mathrm{zu}$ der subjunktiven Formulierung des Beobachtbarkeitsbegriffs stellen: Wann genau soll die Bedingung als erfüllt gelten, daß "wir" X bei Vorliegen bestimmter Umstände beobachten, falls X dort präsent ist? Problematisch sind hier Fälle von Entitäten, bei denen aus kontingenten Gründen oder sogar aufgrund von Naturgesetzen klar ist, daß in sämtlichen Situationen, in denen die fraglichen Umstände vorliegen, niemals Beobachter anwesend sind bzw. etwas beobachten können. Wie stellt man sich z.B. zu Gegenständen in der Vergangenheit (Dinosaurier, Objekte in der Frühzeit des Universums)? Wie zu schwarzen Löchern und Oberflächenstrukturen der Sonne oder von Neutronensternen, die man intuitiv als beobachtbar einstufen wird, bei denen aber klar ist, daß kein menschlicher Beobachter die fraglichen Dinge jemals mit unbewaffnetem Auge sehen wird, weil er physisch die an den potentiellen Beobachtungsorten

\footnotetext{
${ }^{11}$ [vFra80], S.13ff., [vFra92], S.18ff. Daher ist bei ihm der Gegenbegriff zu 'beobachtbar' nicht 'theoretisch', sondern 'unbeobachtbar'.

${ }^{12}$ Vgl. [Supp72], S.7ff. An dieser Stelle ist noch keine Annahme darüber gemacht, ob die so aufgefaßten Beobachtungssätze bzw. die Beobachtungsausdrücke einer so reformierten Sprache (alle oder zum Teil) theoriebeladen sind oder nicht. Van Fraassen selbst glaubt nicht, daß die theorieneutrale Beschreibung von Beobachtungen i.a. möglich ist; zu den damit verbundenen Problemen einer denkbaren reformierten Sprache vgl. Kap.10.3.1.

${ }^{13}$ Anders als etwa die logischen Positivisten, die (teilweise) auch Beobachtungssätze aufgrund von Tast-, Geruchs- usw. Wahrnehmungen zulassen.

${ }^{14}$ Wie schon bei der Verifikationstheorie, vgl. S.32, Fn.5.
} 
herrschenden Bedingungen (Temperatur, Gravitationsfelder usw.) nicht überstehen kann?

Die verbleibende Unschärfe von van Fraassens Erläuterung des Begriffs beobachtbar dürfte aber für den Kontext der Realismusdebatte nicht entscheidend sein. Die Unterscheidung beobachtbar/unbeobachtbar ist sicherlich zu einem gewissen Grad vage (zumindest beim gegenwärtigen Stand der Erläuterung), aber sie wird dadurch nicht völlig untauglich, weil die Vagheit sich sozusagen nur auf eine Übergangszone bezieht, die zwischen "unproblematischen" Bereichen mit klaren Fällen von beobachtbaren Entitäten und klaren Fällen von unbeobachtbaren Entitäten liegt. Der Hinweis auf diese Art von Vagheit allein reicht nicht aus, um eine antirealistische Position zu Fall zu bringen, die einen Statusunterschied zwischen beobachtbaren und unbeobachtbaren Entitäten bzw. Beobachtungsätzen und theoretischen Sätzen behauptet. Diese "destruktive" Argumentationslinie gegen antirealistische Positionen ist daher nicht durchschlagend.

\section{2 "Positive" Kontinuitätsargumente: vortheoretische In- tuitionen über Kontinuitäten auf der Sachebene}

\subsubsection{Die "Merkwürdigkeit" eines anthropozentrischen Weltbildes}

Eine zweite Weise, die hinter den Kontinuitätsargumenten stehende Intuition zu konkretisieren, daß zwischen dem Bereich des Beobachtbaren und dem Bereich des Theoretischen bzw. Unbeobachtbaren keineswegs ein tiefer Graben oder eine fundamentale Differenz liegt, betrifft nicht Probleme der Vagheit oder Wohldefiniertheit der Unterscheidung beobachtbar/unbeobachtbar, sondern inhaltliche Überzeugungen allgemeiner Art, und zwar die Umrisse eines Bildes von der Stellung des Menschen in der Natur. Wenn das Bild, das die Wissenschaften davon zeichnen, auch nur in den allergröbsten Grundzügen korrekt ist, dann ist schon menschliches Leben auf einen räumlich und zeitlich sehr kleinen Sektor des Universums beschränkt. Darüber hinaus ist der menschliche Wahrnehmungsapparat so beschaffen, daß selbst von den Vorgängen und Sachverhalten in unmittelbarer raumzeitlicher Umgebung nur ein Bruchteil direkter Wahrnehmung zugänglich ist, so wie es auch bei anderen biologischen Spezies ist. Daß es Dinge gibt, die Maulwürfe nicht sehen können, ist sicherlich unkontrovers; genauso unproblematisch erscheint es von diesem Standpunkt, daß manche Tiere Dinge wahrnehmen können, die dem menschlichen Wahrnehmungsapparat nicht direkt zugänglich sind (z.B. manche Vögel polarisiertes Licht, Schlangen Infrarotstrahlung und einige Fische elektrische Felder).

Geht man von einer solchen Perspektive aus, dann muß eine Aufteilung des Universums in einen beobachtbaren und einen unbeobachtbaren Bereich, der philosophische Relevanz zukommen soll, als Ausdruck einer, flapsig ausgedrückt, merkwürdigen, ziemlich provinziellen Sichtweise erscheinen, etwas vornehmer formuliert, als in unplausibler und unangemessener Weise anthropozentrisch. Im Hinblick auf die Realismusdebatte erscheint es aus einer solchen Perspektive wenig plausibel, daß eine derart anthropozentrische Unterscheidung auf der Sachebene eine Grenze des Bereiches der in der Natur vorkommenden Entitäten, Ereignisse und Sachverhalte markieren sollte, und ebenso wenig plausibel erscheint es, daß eine solche Unterscheidung in semantischer Hinsicht relevant sein sollte, also eine Grenze markieren sollte, jenseits derer sprachliche Repräsentationen nur noch instrumentalistisch, operationalistisch o.ä. aufzufassen sein sollten. ${ }^{15}$

Dieser Eindruck einer unangemessen anthropozentrischen Einstellung wird womöglich

\footnotetext{
${ }^{15}$ Dieses Motiv findet sich z.B. in [Feig50b], S.190f.
} 
noch verstärkt, wenn man sich vor Augen führt, daß die von antirealistischer Seite gezogene Grenze zwischen kontingenterweise (d.h. aus technischen, praktischen oder physiologischen Gründen) unbeobachtbaren und prinzipiell unbeobachtbaren Entitäten, Ereignissen und Sachverhalten bzw. entsprechenden Sätzen und Ausdrücken verlaufen müßte. Beispielsweise müßte also die Rede von Gegenständen in der Vergangenheit (Dinosauriern etc.) als grundsätzlich "unproblematisch" gelten, die von mikroskopischen Gegenständen (Einzellern, die Zeitgenossen der Dinosaurier waren, etc.) jedoch nicht. ${ }^{16}$

Die "Merkwürdigkeit" der von antirealistischer Seite vorgenommenen Grenzziehung läßt sich illustrieren, indem man sich an konkreten Beispielen die Auswirkungen dieser Grenzziehung auf das gängige wissenschaftliche Bild der Welt vor Augen führt. Besonders eignen sich dazu Folgen von Entitäten, die sich in den ihnen zugeschriebenen Eigenschaften von Folgeglied zu Folgeglied nur graduell unterscheiden, bei denen aber an einem Punkt der Folge die Grenze (prinzipiell) beobachtbar/(prinzipiell) unbeobachtbar überschritten wird. Ein Beispiel dafür findet sich bei Maxwell:

"[...] contemporary valency theory tells us that there is a virtually continuous transition from very small molecules (such as those of hydrogen) through "medium-sized" ones (such as those of the fatty acids, polypeptides, proteins, and viruses) to extremely large ones (such as crystals of the salts, diamonds, and lumps of polymeric plastic). The molecules in the last-mentioned group are macro, "directly observable" physical objects but are, nevertheless, genuine, single molecules; on the other hand, those in the first mentioned group have the same perplexing properties as subatomic particles (de Broglie waves, Heisenberg indeterminacy, etc.)." 17

$\mathrm{Zu}$ beachten ist bei diesem Beispiel, daß es dieselben Größen (Masse, Volumen, Anzahl der Atome in einem Molekül ... ) sind, die sich "beim Überqueren" der Grenzlinie beobachtbar/unbeobachtbar nur graduell ändern, darunter sowohl beobachtbare Größen (Volumen) als auch unbeobachtbare (Anzahl der Atome in einem Molekül). ${ }^{18}$ Ein ähnlicher Fall ist die Folge von (monochrom) rotem Licht, gelbem Licht usw., das sichtbare Spektrum entlang, über blaues Licht, violettes Licht, ultraviolettes Licht, bis hin zu Röntgenlicht, Gammastrahlung usw.

An Fällen wie diesen wird besonders deutlich, wie unplausibel die von antirealistischer Seite gezogene Grenze aussieht, wenn das Bild, das die Wissenschaften von der Natur und der Stellung des Menschen darin zeichnen, auch nur in wesentlichen Zügen korrekt ist, und wie unplausibel, um nicht zu sagen bizarr es dann aussieht, daß diese an die kontingente Beschaffenheit des menschlichen Wahrnehmungsapparates geknüpfte Grenze den Bereich der in der Natur existierenden Entitäten und Phänomene begrenzen soll, und daß auch der semantische Status von Ausdrücken und Sätzen von dieser Grenze abhängen soll: Es klingt in unplausibler Weise anthropozentrisch, daß sich die Rede von Molekülen im

\footnotetext{
${ }^{16}$ Darauf weist z.B. Herbert Feigl hin; siehe [Feig50a].

${ }^{17}$ [Maxw62], S.9. Der Gedanke findet sich schon früher, z.B. in [Reic30], S.205f. und (angedeutet) in [Plan49b], S.48.

${ }^{18}$ Dieses Beispiel läßt sich nicht einfach mit dem Hinweis beiseite schieben, daß 'Masse', 'Volumen' usw. für die beiden Enden der Folge, sprich: im Kontext der klassischen Physik und im Kontext der Quantenphysik, nur in einem uneigentlichen oder jedenfalls nicht unproblematischen Sinn dieselbe Größe bezeichnen, so daß keine Rede von einer "kontinuierlichen" Folge sein kann. In der Beispielfolge fällt die Grenze zwischen den "Zuständigkeitsbereichen" von klassischer Mechanik und Quantenmechanik nicht mit der Grenze beobachtbar/unbeobachtbar zusammen, nicht einmal ungefähr; der Zuständigkeitsbereich der klassischen Mechanik reicht sozusagen weit in den Bereich des Unbeobachtbaren hinein.
} 
Millimeterbereich und darüber auf reale Moleküle bezieht (oder wenigstens beziehen kann), die Rede von Molekülen geringerer Größe aber instrumentalistisch, operationalistisch o.ä. aufzufassen sein soll, oder daß sich die Rede von sichtbarem Licht auf ein reales Phänomen beziehen, die Rede von UV-Licht dagegen instrumentalistisch o.ä. aufzufassen sein soll.

Indem man auf diese Weise auf allgemeine Überzeugungen und konkrete Beispiele hinweist, die belegen, wie "merkwürdig" anthropozentrisch das Weltbild ist, das sich aus antirealistischer Perspektive ergibt, weil der Grenze beobachtbar/unbeobachtbar grundlegende Bedeutung beigemessen wird, appelliert man an vortheoretische Intuitionen, die von vielen geteilt werden dürften, die zumindest wesentliche Züge des von den modernen Wissenschaften gezeichneten Weltbildes akzeptieren, die aber natürlich nicht jeder teilt. Der Hinweis auf solche vortheoretischen Intuitionen stellt per se kein Argument in dem Sinn dar, daß aus Prämissen auf eine das Argumentationsziel darstellende These geschlossen wird, weder ein Argument (in diesem Sinn) für eine realistische These, noch eins gegen eine antirealistische These; z.B. werden dadurch verifikationistische oder operationalistische Bedeutungstheorien oder daran geknüpfte antirealistische Thesen nicht widerlegt. Es werden aber eben vortheoretische Überzeugungen identifiziert, die zwar keine präzise formulierten ontologischen, semantischen und/oder epistemischen realistischen Thesen zum Inhalt haben, die sich aber durch Thesen dieser Art präzisieren lassen sollten und jedenfalls mit solchen Thesen verträglich sind, und die vor allem mit antirealistischen Thesen konfligieren. Wer vortheoretische Intuitionen, möglicherweise starke Intuitionen dieser Art teilt, der wird gute Gründe für antirealistische Thesen verlangen, die mit seinen vortheoretischen Intuitionen im Widerspruch stehen, z.B. wird er verifikationistische oder operationalistische Bedeutungstheorien prima facie für unplausibel halten und gute Gründe für die Adäquatheit dieser semantischen Theorien fordern, die ihre kontraintuitiven Konsequenzen aufwiegen. "Nur" in diesem Sinn stellt ein Appell an vortheoretische Intuitionen ein Argument dar.

\subsubsection{Zwei antirealistische Repliken}

Eine mögliche antirealistische Antwort auf diese Argumentationslinie ist, den realistischen Intuitionen frontal antirealistische entgegenzusetzen und die Relevanz der realistischen Intuitionen zu bestreiten, weil diese eine von Anfang an zu große "Wissenschaftsgläubigkeit" zum Ausdruck bringen. Dies betrifft sowohl die Grundzüge des von den modernen Wissenschaften gezeichneten Bildes der Welt und der Stellung des Menschen darin, als auch sämtliche "Details" wie die von Maxwell ins Spiel gebrachten kontinuierlichen Folgen, soweit dabei von Unbeobachtbarem die Rede ist. Bei den kontinuierlichen Folgen äußert sich die zu große "Wissenschaftsgläubigkeit" insbesondere darin, daß den Folgengliedern, also Diamanten, sichtbarem Licht u.ä., bereits "auf der beobachtbaren Seite" der Folgen unbeobachtbare Eigenschaften (Molekül, elektromagnetische Strahlung) zugeschrieben werden. ${ }^{19}$ Auf antirealistischer Seite wird man i.a. keine dieser vortheoretischen Intuitionen teilen; man wird dem Appell an solche Intuitionen die These entgegensetzen, daß der Unterscheidung beobachtbar/unbeobachtbar trotz (oder gerade wegen) ihres anthropozentrischen Charakters grundlegende philosophische Relevanz zukommt. Instrumentalisten etwa können in diesem Sinn den von realistischer Seite in Anspruch genommenen Intuitionen

\footnotetext{
${ }^{19}$ Dies scheint der Punkt von van Fraassens Replik in [vFra80], S.214 zu sein. Ob die Zuschreibung der fraglichen theoretischen Eigenschaften geschieht, indem die entsprechenden theoretischen Prädikate in die Bedeutungen von 'Diamant, 'Licht' etc. eingehen, diese Ausdrücke also in diesem Sinn theoriebeladen sind, oder ob die Identifikation von Diamanten mit Kohlenstoffmolekülen usw. in Form von Hintergrundüberzeugungen ins Spiel gebracht wird, ist unerheblich.
} 
frontal die These entgegensetzen, daß die Unterscheidung beobachtbar/unbeobachtbar für semantische Fragen grundlegend ist und daß nur solche Sätze als semantisch vollwertig akzeptiert werden sollten, die in theorieneutralen ${ }^{20}$ Beobachtungsausdrücken formuliert sind. ${ }^{21}$

Eine solche konsequente Erwiderung von instrumentalistischer Seite stellt klar, daß dort die vortheoretischen Intuitionen i.a. nicht geteilt werden, an die u.a. Maxwell appelliert, so daß man sich nach anderen Argumente umsehen muß, um die instrumentalistische Seite von realistischen Thesen zu überzeugen. Diese Intuitionen können allerdings von realistischer Seiten unter Umständen dennoch zu Argumentationszwecken eingesetzt werden, nämlich in der Diskussion mit einem "nicht ganz konsequenten" Instrumentalisten und vor allem in der Diskussion mit jemandem, der noch keinen elaborierten und reflektierten Standpunkt in der Realismusdebatte bezogen hat. Dort kann die Plausibilität einer realistischen Position schon durch einige geteilte Intuitionen beeinflußt werden, daher ist es wichtig, daß es sich bei den "Kontinuitätsintuitionen", die von realistischer Seite angeführt werden, um die "Merkwürdigkeit" der von antirealistischer Seite gezogenen Grenze zu belegen, nicht um eine einzelne "anti-anthropozentrische" These handelt, sondern um eine Vielzahl von allgemeineren und spezielleren Überzeugungen und Beispielen. Z.B. ist es denkbar, daß jemand die von Maxwell genannte kontinuierliche Folge insofern nicht überzeugend findet, als dort gänzlich unbeobachtbare Größen bzw. entsprechende Ausdrücke (Anzahl der Atome) ins Spiel gebracht werden, daß er jedoch gleichzeitig die durch sie illustrierte Intuition teilt, daß die involvierten beobachtbaren, in graduellen Abstufungen vorkommenden Größen (Volumen etc.) auch Werte bzw. Ausprägungen annehmen können, die sozusagen jenseits der Grenze beobachtbar/unbeobachtbar liegen, bzw. daß für die Semantik der entsprechenden Ausdrücke die Grenze irrelevant ist.

Eine andere, in der neueren Realismusdebatte gängigere Replik von antirealistischer Seite ist, anzuerkennen, daß durch den Appell an vortheoretische Intuitionen wie die genannten plausibel gemacht wird, daß der Unterscheidung beobachtbar/unbeobachtbar im Hinblick auf den semantischen Status von Ausdrücken und Sätzen keine prinzipielle Relevanz zukommt, ${ }^{22}$ gleichzeitig jedoch an der These festzuhalten, daß die Unterscheidung beobachtbar/unbeobachtbar in epistemischer Hinsicht von entscheidender Bedeutung ist. ${ }^{23}$ Dem Hinweis auf intuitiv plausible Überzeugungen und Beispiele von realistischer Seite wird also von antirealistischer Seite der Vorwurf zu großer "Wissenschaftsgläubigkeit" in epistemischer Hinsicht entgegengehalten. Die antirealistische Seite besteht darauf, daß der Hinweis auf vortheoretische Intuitionen keine Überzeugungskraft haben kann, solange die Frage nach der epistemischen Rechtfertigung dieser Intuitionen nicht geklärt ist, und dazu leistet der blanke Hinweis auf solche Intuitionen per se nichts. Wenn sich von antirealistischer Seite plausibel machen läßt, daß der menschlicher Erkenntnis zugängliche Bereich nicht weiter reicht als der Bereich des Beobachtbaren oder daß jedenfalls der Bereich jenseits der Grenze beobachtbar/unbeobachtbar nur noch in sehr eingeschränktem Umfang epistemisch zugänglich ist, dann müssen vortheoretische Intuitionen, die Unbeobachtbares zum Inhalt haben, als epistemisch nicht hinreichend begründet aufgegeben werden. Eine antirealistische Antwort dieser zweiten Art auf "Kontinuitätsintuitionen" wie die von Maxwell ins Spiel gebrachten ist also, die Rede von unbeobachtbaren Entitäten und

\footnotetext{
${ }^{20}$ Und ggf. im oben genannten Sinn reformierten.

${ }^{21}$ Auf etwa dieser Linie argumentiert z.B. Nagel in [Nage50], bes. S.180.

${ }^{22}$ Dies erfordert nicht unbedingt, daß man eine bestimmte semantische Theorie oder semantische realistische Thesen akzeptiert.

${ }^{23}$ Dies ist van Fraassens Reaktion; siehe u.a. [vFra85].
} 
Phänomenen als semantisch vollwertig anzuerkennen, also instrumentalistische, operationalistische u.ä. Thesen fallen zu lassen, ohne damit aber (ontologische oder epistemische) realistische Thesen über Unbeobachtbares zu akzeptieren.

\section{3 "Positive" Kontinuitätsargumente: epistemische Konti- nuitätsargumente}

Wenn man akzeptiert, daß sich die Unterscheidung beobachtbar/unbeobachtbar in einer von Unschärfen zwar nicht ganz freien, aber doch für antirealistische Zwecke ausreichenden Weise präzisieren läßt, und wenn man weiter annimmt, daß die aus antirealistischer Perspektive aussichtsreichste "Verwendungsweise" dieser Unterscheidung ist, sie auf epistemischer Ebene ins Spiel zu bringen, um realistischen Thesen und Positionen entgegenzutreten, dann besteht eine denkbare Strategie, dagegen für wissenschaftlichen Realismus zu argumentieren, darin, in epistemischer Hinsicht wichtige Kontinuitäten zu identifizieren, die die Unterscheidung beobachtbar/unbeobachtbar als für die Bewertung realistischer Thesen nicht besonders oder gar in grundlegender Weise relevant erscheinen lassen.

Um diese Argumentationsstrategie in der wissenschaftstheoretischen Realismusdebatte zu implementieren, müßte man idealerweise alle erkenntnistheoretischen Probleme und Fragestellungen geklärt haben, die bzw. soweit sie nicht den Bereich des Unbeobachtbaren betreffen. Man müßte also außerhalb des in der wissenschaftstheoretischen Debatte strittigen Bereichs des Unbeobachtbaren, d.h. u.a. für den Bereich der beobachtbaren Gegenstände und Sachverhalte der Alltagswelt, über eine zufriedenstellende erkenntnistheoretische Position verfügen, insbesondere über eine adäquate Konzeption davon, was Wissen ist und was gerechtfertigte Überzeugungen sind, um dann zu untersuchen, inwieweit sich diese Position für den Bereich des Unbeobachtbaren "kontinuierlich fortsetzen" läßt. Ausgehend von einer solchen Konzeption von Wissen und Rechtfertigung, die das Resultat der erkenntnistheoretischen Debatten sein müßte, die sich in erster Linie am "Anwendungsbereich" beobachtbare Gegenstände und Sachverhalte der Alltagswelt orientieren, würde man dann untersuchen, ob und wie weit sich in deren Licht realistische Thesen zunächst für den Bereich des Beobachtbaren begründen lassen, vor allem aber dann, ob sich in epistemischer Hinsicht relevante Kontinuitäten identifizieren lassen, die in der gleichen Weise und "genauso gut" auch realistische Thesen für den Bereich jenseits der Grenze beobachtbar/unbeobachtbar zu begründen erlauben. ${ }^{24}$ Von einem solchen "idealen" Kenntnisstand ist man in der allgemeinen Erkenntnistheorie bekanntlich weit entfernt, schon über grundsätzliche Fragen ist dort kein Konsens in Sicht. Die diesbezüglichen generellen Debatten sind jedoch zu umfangreich und weitverzweigt, um hier im einzelnen

\footnotetext{
${ }^{24}$ Falls die allgemeinen erkenntnistheoretischen Debatten auf Konzeptionen von Wissen, Rechtfertigung etc. führen, in deren Licht sich keine realistischen Thesen über Beobachtbares begründen lassen, führt diese Strategie nicht zum Ziel. Dies spricht jedoch kaum gegen sie: Es ist kaum zu erwarten, daß sich realistische Thesen bezüglich des Gegenstandsbereiches "jenseits" der Grenze beobachtbar/unbeobachtbar generell oder gar grundsätzlich besser begründen oder verteidigen lassen als realistische Thesen bezüglich des Bereiches des Beobachtbaren.

Die Argumentationsstrategie, die durch die epistemischen Kontinuitätsargumente implementiert wird, hängt offenbar von der Annahme ab, daß eine einheitliche Konzeption von Wissen und Rechtfertigung für den Common-Sense-Bereich und für den Bereich der Wissenschaften angemessen ist. Diese Annahme ist prinzipiell angreifbar, für oder gegen sie zu argumentieren dürfte aber kaum anders möglich sein, als alternative erkenntnistheoretische Konzeptionen zu entwickeln und als ganze gegeneinander abzuwägen, was hier nicht möglich ist.
} 
darauf eingehen zu können. ${ }^{25}$ Falls epistemische Kontinuitätsargumente auf die Details einer allgemeinen erkenntnistheoretischen Position angewiesen sein sollten, um Überzeugungskraft zu entwickeln, müßte man das Ende der allgemeinen erkenntnistheoretischen Debatten abwarten, um solche Argumente zu formulieren und zu untersuchen.

In der wissenschaftstheoretischen Literatur finden sich nun verschiedene Ansätze zu epistemischen Kontinuitätsargumenten, die, wenn überhaupt, dann nur lose und implizit an eine bestimmte erkenntnistheoretische Position angeknüpft werden. Inwieweit diese Ansätze bzw. daraus weiterentwickelte Argumente an verschiedene "vollständige" erkenntnistheoretische Positionen angeschlossen werden können oder müssen, läßt sich beim gegenwärtigen Stand der Dinge nicht entscheiden; andererseits können die in der Literatur vorliegenden Skizzen für Kontinuitätsargumente nur insoweit Überzeugungskraft entwickeln, als wenigstens im Umriß identifiziert werden kann, was die "epistemische Kontinuität" zwischen dem Bereich des Beobachtbaren und dem Bereich des Unbeobachtbaren ausmacht und in welcher Weise ihr erkenntnistheoretische Relevanz zukommt.

Was sich bei diesem Stand der Dinge tun läßt, ist, unter den beim derzeitigen Stand der allgemeinen erkenntnistheoretischen Debatte aussichtsreichen erkenntnistheoretischen Positionen bzw. Ansätzen den (oder einen der) aussichtsreichsten ohne eingehende Diskussion seiner Vorzüge und Nachteile auszuwählen und zu untersuchen, ob bzw. inwieweit bereits vor dem Hintergrund dieses erkenntnistheoretischen Ansatzes die in der Literatur vorliegenden Skizzen für epistemische Kontinuitätsargumente Konturen und Überzeugungskraft gewinnen. Damit läßt sich zum einen die Hoffnung verbinden, daß die so formulierten oder rekonstruierten Argumente unempfindlich sind gegen zukünftige Präzisierungen und Weiterentwicklungen des erkenntnistheoretischen Ansatzes und auch durch eventuell erforderliche Modifikationen nicht beeinträchtigt werden oder gar ihre Überzeugungskraft verlieren. Zum anderen könnte die frühzeitige Entwicklung von Kontinuitätsargumenten zur allgemeinen erkenntnistheoretischen Debatte beitragen bzw. Rückwirkungen auf diese haben, insofern die Plausibilität einer erkenntnistheoretischen Position auch davon abhängen kann, welches Bild sie von den kognitiven Produkten der Wissenschaften ergibt. ${ }^{26}$ Schließlich ist auch denkbar, daß sich die vor dem Hintergrund eines bestimmten erkenntnistheoretischen Ansatzes formulierten Kontinuitätsargumente für andere Ansätze gleichsam transponieren lassen.

In diesem Sinn soll hier ein naturalistischer Ansatz in der Erkenntnistheorie aufgenommen werden und genauer ein reliabilistischer, um als Hintergrund für die Untersuchung und Rekonstruktion der in der Literatur vorliegenden Skizzen für epistemische Kontinuitätsargumente zu dienen. Dieser reliabilistische Ansatz soll im folgenden Abschnitt grob skizziert werden. ${ }^{27}$

\footnotetext{
${ }^{25}$ Einen Einblick geben z.B. [Audi98, Bier87].

${ }^{26}$ Dies gilt dann, wenn man diese kognitiven Produkte oder wenigstens einen Teil davon als paradigmatische Beispiele für menschliches Wissen, gerechtfertigte Überzeugungen o.ä. betrachtet.

${ }^{27}$ Angesichts der weitläufigen Debatten, die in der Erkenntnistheorie zu den Themen Naturalismus und Reliabilismus geführt werden, ist die folgende Skizze zweifellos sehr grob. Zur Rechtfertigung läßt sich zum einen vorbringen, daß an dieser Stelle aus Platzgründen nicht mehr möglich ist, zum anderen, daß damit immerhin wenigstens in grober Form eine Antwort auf eine Frage skizziert wird, die in der Wissenschaftstheorie üblicherweise völlig ausgeblendet wird, obwohl sie in der Erkenntnistheorie extensiv diskutiert wird, eben die Frage, worin Wissen über Beobachtbares und dessen Rechtfertigung bestehen. Solange diese Frage ausgeblendet wird, bleibt sozusagen der Ansatzpunkt für epistemische Kontinuitätsargumente verdeckt, und um ihn sichtbar zu machen, muß die wissenschaftstheoretische Realismusdebatte wenigstens in dieser groben, skizzenhaften Weise mit systematischen erkenntnistheoretischen Thesen und Positionen in Verbindung gebracht werden.
} 


\subsubsection{Naturalistische und reliabilistische Ansätze in der Erkenntnistheo- rie}

Eine naturalistische Position in der Erkenntnistheorie ist eine, nach der erkenntnistheoretische Aussagen nicht von grundsätzlich anderer Natur sind als Aussagen der empirischen Wissenschaften "über die Welt" und nicht durch spezifisch philosophische Begründungen zu rechtfertigen sind, die Begründungen für "inhaltliche" empirische Überzeugungen prinzipiell vor- oder übergeordnet wären. ${ }^{28}$ Als Reliabilismus wird üblicherweise eine Gruppe von Ansätzen bezeichnet, die verwandte Antworten geben auf die zentralen erkenntnistheoretischen Fragen, was Wissen ist und worin die Eigenschaft einer Überzeugung besteht, gerechtfertigt zu sein. ${ }^{29}$ Eine reliabilistische Antwort auf die erste Frage lautet in erster, grober Näherung

Wi1 Eine Person $A$ weiß, daß $P$, genau dann, wenn sie die wahre Überzeugung hat, daß $P$, und wenn diese Überzeugung durch einen verläßlichen ${ }^{30}$ Kausalprozeß oder, allgemeiner, ein verläßliches epistemisches Verfahren erzeugt oder stabilisiert wurde.

Eine entsprechende Antwort auf die zweite Frage ist

Re1 Eine Person $A$ hat die gerechtfertigte Überzeugung, daß $P$, genau dann, wenn diese Überzeugung durch einen verläßlichen Kausalprozeß oder, allgemeiner, ein verläßliches epistemisches Verfahren erzeugt oder stabilisiert wurde.

Der Kausalprozeß bzw. das epistemische Verfahren, der bzw. das zu der Überzeugung führt, und dessen Charakteristika müssen der Person $A$ nicht notwendigerweise bekannt, bewußt oder sonstwie zugänglich sein; in diesem Sinn geben reliabilistische Ansätze externalistische Antworten auf die Fragen, was Wissen bzw. was eine gerechtfertigte Überzeugung ist. Das paradigmatische Beispiel für die Typen von Kausalprozessen, an die hier gedacht ist, sind Beobachtungen mit dem bloßen Auge; dort führt ein Kausalprozeß vom beobachteten Sachverhalt zu der darüber gewonnenen Überzeugung. Epistemische Verfahren im weiteren Sinne sollen aber auch Vorgänge wie die Anwendung eines deduktiven oder induktiven Inferenzschemas u.ä. umfassen, bei denen eine solche kausale Verbindung nicht besteht. ${ }^{31}$ Die Unterscheidung von "erzeugen" und "stabilisieren" einer Überzeugung bezieht sich darauf, daß für den epistemischen Status einer Überzeugung nicht nur ihre Entstehung relevant ist, sondern außerdem auch etwaige spätere "Anwendungen" epistemischer Verfahren, die als Output diese Überzeugung geliefert hätten bzw. diese erzeugt hätten, wenn sie nicht bereits vorhanden gewesen wäre, und in diesem Sinn die (bereits existierende) Überzeugung stabilisiert haben. ${ }^{32}$

Wie die beiden genannten reliabilistischen Antworten auf die Fragen, was Wissen und was eine gerechtfertigte Überzeugung ist, zu präzisieren und im einzelnen zu erläutern und eventuell zu modifizieren sind, wird in der Literatur kontrovers diskutiert. Dabei stehen vor allem zwei Problemkomplexe im Mittelpunkt:

\footnotetext{
${ }^{28}$ Vgl. z.B. [Mitt95], Bd.2, S.964 und [KeSc00].

${ }^{29}$ Einige wichtige Arbeiten, die naturalistische und reliabilistische Positionen entwickeln und diskutieren, sind [Blac93b, Boyd81, Crai90, Gold79, Gold86, Gold94, Kitc92, Laud87, Papi93, Sosa91a].

${ }^{30}$ Engl. 'reliable', daher die Bezeichnung 'reliabilism'.

${ }^{31}$ S.u.

${ }^{32} \mathrm{Vgl}$. etwa [Alst86], S.11. Stabilisieren lassen sich also sowohl Überzeugungen, die in verläßlicher Weise erzeugt wurden, als auch andere, in unzuverlässiger Weise zustande gekommene. Im folgenden ist, wenn von erzeugen von Überzeugungen die Rede ist, stets erzeugen oder stabilisieren gemeint, obwohl letzteres meistens implizit bleibt.
} 
1. die Frage, wie allgemein zu erläutern ist, was genau ein Kausalprozeß oder ein epistemisches Verfahren ist und unter welchen Bedingungen diese als verläßlich zählen,

2. die Frage, ob der Status einer gerechtfertigten Überzeugung, aber auch der von Wissen tatsächlich nur an bestimmte Charakteristika der Erzeugung oder Stabilisierung der fraglichen Überzeugung geknüpft ist, wie es die reliabilistischen Ansätze vorsehen, oder ob deren Status nicht auch an Rechtfertigungsgründe geknüpft ist, die der Person $A$ selbst zugänglich sein müssen und die sie für ihre Überzeugung anführen kann.

Auf die umfangreichen Diskussionen zu diesen beiden Problemkomplexen kann hier nicht im einzelnen eingegangen werden. Es soll aber wenigstens die Idee skizziert und festgehalten werden, die hinter den reliabilistischen Ansätzen steht und an der sich eine Präzisierung und Verteidigung einer solchen Position orientieren wird.

Aus naturalistischer Perspektive sind Menschen Teil der Natur und menschliche Erkenntnis ist etwas, was sich nicht kategoriell von anderen Vorgängen und Zuständen in der Natur unterscheidet. Das Erwerben von Überzeugungen erfolgt durch "natürliche" (physikalischen, biologischen, psychologischen usw. Gesetzen folgende) Kausalprozesse bzw. epistemische Verfahren; das paradigmatische Beispiel dafür sind Beobachtungen mit dem unbewaffneten Auge, andere Verfahren sind ${ }^{33}$ etwa akustisches Wahrnehmen von Sprache und deduktives und induktives Schließen. Zur genaueren Erläuterung des reliabilistischen Ansatzes muß man bei epistemischen Verfahren unterscheiden zwischen Erzeugungsverfahren und Übertragungsverfahren. ${ }^{34}$ Übertragungsverfahren sind epistemische Verfahren wie z.B. deduktives oder induktives Schließen ${ }^{35}$, die auf einen Input von bereits vorliegenden Überzeugungen (sprich: Prämissen) angewiesen sind. Erzeugungsverfahren sind epistemische Verfahren wie das Beobachten mit dem bloßen Auge, die ohne einen Input von Überzeugungen neue Überzeugungen liefern. ${ }^{36}$

Eine etwas genauere Erläuterung, was ein Erzeugungsverfahren ist, ist folgende ${ }^{37}$ :

Ev Daß eine Person $A$ eine Überzeugung mittels eines bestimmten Erzeugungsverfahrens gewinnt, heißt — im Fall "basaler" Verfahren —, daß diese Überzeugung durch einen bestimmten Teil des kognitiven Apparates von $A$ erzeugt wird, der die Disposition hat, unter bestimmten Bedingungen $B$ Überzeugungen bezüglich einer oder mehrerer Propositionen $P$ aus einem bestimmten Feld $F$ von Propositionen zu erzeugen. Im Fall anderer, "nicht-basaler" Erzeugungsverfahren heißt es Entsprechendes, mit dem Unterschied, daß die Überzeugung durch einen Teil des durch Hilfsmittel, Meßgeräte etc. (z.B. durch eine Brille, ein Metermaß, ein Thermometer) ergänzten kognitiven Apparates von $A$ erzeugt wird, der in Kombination mit diesen Hilfsmitteln eine Disposition der beschriebenen Art hat.

Im Falle des Beobachtens mit dem bloßen Auge schließt der relevante Teil des kognitiven Apparates offenbar die Augen, Sehnerven, das Gehirn etc. von $A$ ein, ein relevantes Feld $F$ von Propositionen wäre etwa eine Menge von Propositionen, die makroskopischen

\footnotetext{
${ }^{33}$ Grob charakterisiert - s.u.

${ }^{34}$ Diese Terminologie ist angelehnt an Ernest Sosas Unterscheidung von "generative faculties" und "transmission faculties" (z.B. [Sosa91a], S.225f.).

${ }^{35}$ Genauer: Schließen nach bestimmten Inferenzregeln, -schemata o.ä.; s.u.

${ }^{36}$ Aber natürlich i.a. nicht ohne kausalen "Input".

${ }^{37}$ Diese Erläuterung ist angelehnt an Sosas Erläuterungen von "faculty" bzw. "intellectual virtue" in [Sosa91a], bes. S.284ff.
} 
Gegenständen eine Farbe (oder auch mehrere) aus einer bestimmten Menge von Farben zuschreibt, und die Bedingungen $B$ könnten etwa sein, daß sich $A$ auf der Erdoberfläche aufhält und die Gegenstände, deren Farbe er beobachtet, unter "Normalbedingungen", d.h. bei Tageslicht, aus einer Entfernung von wenigen Metern, ohne verzerrende Linsen, Spiegel in der Sichtlinie usw. sieht. Die Bedingungen $B$ schließen sowohl allgemeine Umstände $(A$ hält sich auf der Erdoberfläche auf) ein, als auch Bedingungen in bezug auf die Propositionen $P$, bezüglich derer $A$ durch das Verfahren eine Überzeugung (oder mehrere) gewinnt (die beobachteten Gegenstände werden durch Tageslicht beleuchtet). Dieses Erzeugungsverfahren ist von der Art, daß ein (Typ von) Kausalprozeß vom jeweiligen Sachverhalt zu einer diesbezüglichen Überzeugung führt, dies muß jedoch nicht notwendigerweise so sein. Denkbar sind auch Erzeugungsverfahren, bei denen ebenfalls neue Überzeugungen erzeugt bzw. verursacht werden, bei denen aber kein Kausalprozeß involviert ist, der vom jeweiligen Sachverhalt $P$ ausgehend zur diesbezüglichen Überzeugung führt; es ist also nicht so, daß reliabilistische Ansätze nur Erzeugungsverfahren anerkennen könnten, die zu Überzeugungen über kausal wirksame Entitäten, Sachverhalte usw. führen. ${ }^{38}$

Eine etwas genauere Erläuterung, was ein Übertragungsverfahren ist, ist folgende:

Üv Daß eine Person $A$ eine Überzeugung mittels eines bestimmten Übertragungsverfahrens gewinnt, heißt — im Fall "basaler" Verfahren —, daß diese Überzeugung durch einen bestimmten Teil des kognitiven Apparates von $A$ erzeugt wird, der die Disposition hat, unter bestimmten Bedingungen $B$ zu gegebenen Überzeugungen (sprich: Prämissen) bestimmter Art eine neue Überzeugung (sprich: eine Konklusion) zu erzeugen. Im Fall "nicht-basaler" Übertragungsverfahren heißt es Entsprechendes, mit dem Unterschied, daß die Überzeugung durch einen durch Hilfsmittel (z.B. durch einen Rechenschieber, Taschenrechner, Zettel und Stift) ergänzten Teil des kognitiven Apparates von $A$ erzeugt wird, der in Kombination mit diesen Hilfsmitteln eine Disposition der beschriebenen Art hat.

Die Idee der reliabilistischen Ansätze ist nun, daß man von einer gerechtfertigten Überzeugung bzw. von Wissen nur dann sprechen kann, wenn die Überzeugung durch ein verläßliches epistemisches Verfahren (wie Beobachten mit dem unbewaffneten Auge unter Normalbedingungen) erzeugt wurde und nicht durch ein unzuverlässiges (wie Beobachten mit dem unbewaffneten Auge bei Dämmerlicht). Intuitiv gesprochen zählt ein Erzeugungsverfahren als verläßlich, wenn es mit hoher Wahrscheinlichkeit wahre Überzeugungen liefert, also gleichsam sensitiv für das Vorliegen oder Nichtvorliegen des Sachverhaltes ist, den die erzeugte Überzeugung zum Inhalt hat. ${ }^{39}$ Entsprechend zählt ein Übertragungsverfahren intuitiv gesprochen als verläßlich, wenn es, bei wahren Überzeugungen als Input mit hoher Wahrscheinlichkeit wahre Überzeugungen liefert. ${ }^{40}$ Eine etwas genauere, aber noch immer grobe Erläuterung, was ein verläßliches Erzeugungsverfahren ist, ist folgende:

VeEv Ein Erzeugungsverfahren $E V$, das eine Person $A$ verwendet, ist unter den Bedingungen $B$ für das Feld $F$ von Propositionen verläßlich genau dann, wenn gilt:

\footnotetext{
${ }^{38}$ Erzeugungsverfahren sind etwa auch für Felder von Propositionen aus dem Bereich der Mathematik denkbar; man könnte in diesem Sinne versuchen, einer Person eine Art mathematische Wahrnehmung zuzuschreiben, also so etwas wie ein Vermögen mathematischer Intuition (vgl. [Kitc83, Rey98]).

${ }^{39}$ Bei den Wahrscheinlichkeiten, von denen hier die Rede ist, handelt es sich um objektive Wahrscheinlichkeiten; sofern dazu von Anhängern reliabilistischer Positionen weitere Erläuterungen gegeben werden, sprechen sie i.a. von Propensitäten (etwa [Sosa91a]).

${ }^{40}$ Komplexe Verfahren wie die Gewinnung demographischer Daten durch Sampling von Stichproben u.ä. lassen sich eventuell als zusammengesetzt aus Teilverfahren (wie Beobachten, induktives Schließen etc.) auffassen, deren Verläßlichkeit die Verläßlichkeit des zusammengesetzten Verfahrens sicherstellt.
} 
Wenn 1) $A$ das Verfahren $E V$ einsetzt,

2) die Proposition, daß $P$, zu $F$ gehört und

3) die Bedingungen $B$ vorliegen ${ }^{41}$,

dann gewinnt $A$ eine sehr wahrscheinlich wahre Überzeugung darüber, ob $P$ oder $\neg P .{ }^{42}$

Eine entsprechende Erläuterung, was ein verläßliches Übertragungsverfahren ist, ist:

VeÜv Ein Übertragungsverfahren $\ddot{U} V$, das eine Person $A$ verwendet, ist unter den Bedingungen $B$ für das Feld $F$ von Propositionen verläßlich genau dann, wenn gilt:

Wenn 1) $A$ das Verfahren $\ddot{U} V$ einsetzt,

2) die Propositionen, daß $P_{1}$, daß $P_{2}$ etc., die Inhalt der als Prämissen verwendeten Überzeugungen sind, zu $F$ gehören,

3) die als Prämissen verwendeten Überzeugungen wahr sind und

4) die Bedingungen $B$ vorliegen ${ }^{43}$,

dann gewinnt $A$ eine neue, sehr wahrscheinlich wahre Überzeugung.

Wie darüber hinausgehend noch genauer zu erläutern ist, was ein epistemisches Verfahren und seine Verläßlichkeit sind, ist, wie erwähnt, eine der zentralen, nicht abschließend geklärten Fragen des Reliabilismus. Klar und unkontrovers ist jedenfalls, daß ein epistemisches Verfahren nicht zu speziell und nicht zu allgemein "zugeschnitten" sein darf, sprich: daß die Bedingungen $B$ und das Feld $F$ nicht zu eng und nicht zu weit spezifiziert sein dürfen, um einerseits in der epistemischen Praxis relevant und nützlich, andererseits tatsächlich verläßlich zu sein. ${ }^{44}$ Wenigstens für paradigmatische Fälle wie das Beobachten mit bloßem Auge unter "Normalbedingungen" dürfte klar sein, daß sie im relevanten Sinn als epistemisches Verfahren zählen und verläßlich sind, da sie einen "hinreichend, aber nicht zu allgemeinen" Typ von Kausalprozessen involvieren, die unter "hinreichend, aber nicht zu allgemeinen" Bedingungen in einem "hinreichend, aber nicht zu großen" Feld jeweils von einem Sachverhalt $P$ (bzw. $\neg P$ ) zur Überzeugung, daß $P$ (bzw. $\neg P$ ), führen, und daher das darauf basierende (kausale) epistemische Verfahren in erkennbarem Sinn "sensitiv" für die fraglichen Sachverhalte ist und mit hoher Wahrscheinlichkeit wahre Überzeugungen liefert. Dagegen ist das Beobachten mit dem bloßen Auge unter beliebigen Bedingungen sicherlich kein verläßliches Verfahren, das Beobachten einer Blaumeise mit dem bloßen Auge aus genau 7,38 Meter Entfernung in südwestlicher Richtung bei Sonnenlicht, das genau von oben kommt, vielleicht ein verläßliches, aber sicherlich kein für die epistemische Praxis relevantes, weil zu speziell zugeschnittenes Verfahren.

Reliabilistische Erläuterungen, was Wissen und was eine gerechtfertigte Überzeugung ist, lauten demnach in zweiter Näherung:

Wi2 Eine Person $A$ weiß, daß $P$, genau dann, wenn sie die wahre Überzeugung hat, daß $P$, und wenn diese Überzeugung durch ein verläßliches epistemisches Verfahren erzeugt

\footnotetext{
${ }^{41}$ Darunter i.a. Bedingungen in bezug auf $P$, etwa: der Gegenstand, von dem $P$ handelt, wird durch Tageslicht beleuchtet.

${ }^{42}$ Dies ist eine modifizierte Version der von Sosa in [Sosa91a], S.286 für seine Konzeption eines "intellectual virtue" angegebenen Erläuterung.

${ }^{43}$ Darunter i.a. Bedingungen in bezug auf $P_{1}, P_{2}$ etc.

${ }^{44}$ Es soll sozusagen weder zu jeder wahren Überzeugung ein eigenes (verläßliches) Verfahren gehören, denn dann helfen einem diese Verfahren nicht bei der Bewertung von Überzeugungen (dazu s.u.), noch dürfen epistemische Verfahren "zu allgemein zugeschnitten" sein, denn erfahrungsgemäß sind epistemische Verfahren nur in einem begrenzten Bereich verläßlich. Dieses Problem wird in der Literatur unter dem Stichwort generality problem diskutiert. Lösungsvorschläge skizzieren u.a. [Crai90], [Sosa91a], S.281ff., [Alst95].
} 
oder stabilisiert wurde und wenn, falls dieses ein Übertragungsverfahren war, die verwendeten Prämissen wahr sind.

Re2 Eine Person $A$ hat die gerechtfertigte Überzeugung, daß $P$, genau dann, wenn diese Überzeugung durch ein verläßliches epistemisches Verfahren erzeugt oder stabilisiert wurde und wenn, falls dieses ein Übertragungsverfahren war, die verwendeten Prämissen wahr sind.

Darin sind ‘epistemisches Verfahren' und 'verläßlich' wie in (Ev), (Üv), (VeEv) und (VeÜv) erläutert zu verstehen.

Zur zweiten der oben ${ }^{45}$ genannten Fragen, ob eine nur die Gewinnung bzw. Stabilisierung einer Überzeugung involvierende Charakterisierung dessen, was eine gerechtfertigte Überzeugung bzw. was Wissen ist, adäquat sein kann, läßt sich festhalten, daß eine reliabilistische Perspektive hier Manövrierraum läßt, um Erläuterungen wie die beiden oben angegebenen eventuell durch eine oder mehrere Zusatzbedingungen zu ergänzen. In Frage kommt etwa die Zusatzbedingung, daß eine gerechtfertigte Überzeugung, daß $P$, bzw. Wissen, daß $P$, auf Seiten der Person eine (implizite oder explizite) Überzeugung über die Verläßlichkeit des Verfahrens der Gewinnung der Überzeugung voraussetzt oder die Zusatzbedingung, daß eine gerechtfertigte Überzeugung bzw. Wissen, daß $P$, mit dem übrigen Überzeugungssystem der Person (nach deren bestem Wissen) konsistent sein muß, o.ä. ${ }^{46}$ Außerdem, und wichtiger für die Realismusdebatte, schließen reliabilistische Positionen, indem sie das, was Wissen bzw. was eine gerechtfertigte Überzeugung ist, in externalistischer Weise erläutern, also zulassen, daß eine Person wissen bzw. die gerechtfertigte Meinung haben kann, daß $\mathrm{P}$, ohne über Rechtfertigungsgründe für $\mathrm{P}$ zu verfügen, natürlich auch nicht aus, daß eine Person Rechtfertigungsgründe für ihre Überzeugung bzw. ihr Wissen haben kann. Auf die Beantwortung der Frage, ob jemand, der eine durch ein verläßliches Verfahren erzeugte Überzeugung hat, damit schon Wissen bzw. eine gerechtfertigte Überzeugung hat, auch wenn er nicht über Rechtfertigungsgründe für diese Überzeugung verfügt, kommt es in der wissenschaftstheoretischen Realismusdebatte offenbar nicht (oder jedenfalls nicht in erster Linie) an, denn dort streitet man um den epistemischen Status inhaltlicher Aussagen, d.h. es geht (von realistischer Seite) darum, Argumente und damit Rechtfertigungsgründe für die eigenen Überzeugungen (sprich: für realistische Thesen) vorzubringen. Die "externalistische" Tatsache, daß eine meiner Überzeugungen auf verläßliche Weise erzeugt wurde, liefert mir jedoch per se kein Argument für diese Überzeugung, denn für argumentative Zwecke nützt mir diese Tatsache nichts, wenn sie mir in keiner Weise zugänglich ist. Einen Rechtfertigungsgrund für meine Überzeugung, der auch argumentativ einsetzbar ist, kann dagegen eine zusätzliche (mir zugängliche) Überzeugung zweiter Ordnung darstellen, daß erstere durch ein bestimmtes epistemisches Verfahren erzeugt wurde und daß dieses Verfahren verläßlich ist. Wenn ich eine solche (mir zugängliche) Überzeugung über die verläßliche Gewinnung der erstgenannten Überzeugung als Argument dafür anführe, daß diese gerechtfertigt ist, ist also die erste der oben genannten denkbaren Zusatzbedingungen für das Vorliegen einer gerechtfertigten Überzeugung bzw. von Wissen sozusagen automatisch erfüllt. Weitere denkbare Zusatzbedingungen wie die der Konsistenz der fraglichen Überzeugung mit dem restlichen Überzeugungssystem müßten, wenn

\footnotetext{
${ }^{45} \mathrm{~S} .152$.

${ }^{46}$ Es besteht also Manövrierraum, um evtl. kontraintuitive Konsequenzen des externalistischen Ansatzes des Reliabilismus durch Hinzufügen einer internalistischen Komponente (der Person zugängliche Überzeugungen) abzumildern; vgl. [Dret92], S.335f., [Sosa91a].
} 
sie im Rahmen der Fortentwicklung des reliabilistischen Ansatzes etabliert werden sollten, bei der Argumentation für konkrete realistische Thesen im Rahmen der Realismusdebatte berücksichtigt werden; daraus dürften sich jedoch für diese Argumentation i.a. nur wenige Veränderungen ergeben, denn plausible Zusatzbedingungen dürften nur solche der jeweiligen Person zugängliche Bedingungen, Kriterien o.ä. sein, die aus ihrer Perspektive für ihre zur Debatte stehende Überzeugung sprechen und die sie daher natürlicherweise ohnehin als Argument für ihre realistischen Thesen ins Spiel bringt.

Eine reliabilistische Position der skizzierten Art weist zwei "Merkmale" auf, die im Hinblick auf die Realismusdebatte relevant sind: Zum einen geht in die Erläuterungen, was Wissen, gerechtfertigte Überzeugungen, verläßliche Verfahren etc. sind, in keiner Weise die Unterscheidung beobachtbar/unbeobachtbar ein. Diese Erläuterungen sagen oder implizieren nicht, daß Wissen oder gerechtfertigte Überzeugungen nur über beobachtbare Dinge, Sachverhalte etc. möglich oder zu haben ist, denn durch ein verläßliches epistemisches Verfahren erzeugt worden sein kann eine Überzeugung über Beobachtbares offenbar so gut wie eine Überzeugung über Unbeobachtbares. Zum anderen sind diese Erläuterungen in dem Sinn offen, daß sie keine Liste von epistemischen Verfahren enthalten. Damit sind Wissen oder gerechtfertigte Überzeugungen über Beobachtbares auch nicht, wie ansonsten denkbar, kontingenterweise dadurch ausgeschlossen, daß die "zulässigen" epistemischen Verfahren alle nur Überzeugungen über Beobachtbares liefern. Vielmehr läßt die reliabilistische Konzeption von Wissen und gerechtfertigter Überzeugung offen, durch welche epistemischen Verfahren Menschen Wissen und gerechtfertigte Überzeugungen erwerben können, und selbst wenn es so sein sollte, daß die tatsächlich (zu einem bestimmten Zeitpunkt) zur Gewinnung von Überzeugungen verwendeten epistemischen Verfahren allesamt nur Überzeugungen über Beobachtbares liefern, schließt die reliabilistische Konzeption also nicht aus, daß auch epistemische Verfahren existieren und (eventuell zu einem späteren Zeitpunkt) zum Einsatz kommen können, die Überzeugungen über Unbeobachtbares liefern.

Die skizzierte reliabilistische Konzeption von Wissen und gerechtfertigter Überzeugung ist also, obwohl sie im Kontext allgemeiner erkenntnistheoretischer Debatten entwickelt wurde, in natürlicher Weise auch auf für die Wissenschaftstheorie relevante Gegenstandsbereiche und Fragestellungen anwendbar, und sie ist in diesem Sinn insbesondere über die Grenze beobachtbar/unbeobachtbar hinaus, also für den Bereich des Unbeobachtbaren "kontinuierlich fortsetzbar". Sie ermöglicht es, erkenntnistheoretische Fragestellungen bezüglich der Alltagswelt und solche bezüglich der Gegenstandsbereiche der Wissenschaften in prinzipiell einheitlicher Weise zu behandeln und zu beantworten. Epistemische Probleme bezüglich des Bereichs der Wissenschaften können so, anders als in der Wissenschaftstheorie sonst üblich, in einen Zusammenhang mit einer systematischen allgemeinen erkenntnistheoretischen Position gebracht und vor diesem Hintergrund diskutiert werden.

Gegeben eine solche reliabilistische Position ist unschwer zu sehen, wie sich die epistemischen Kontinuitätsargumenten zugrundeliegende Idee implementieren läßt, für wissenschaftlichen Realismus zu argumentieren, indem man in epistemischer Hinsicht wichtige Kontinuitäten identifiziert, die die Unterscheidung beobachtbar/unbeobachtbar als nicht besonders oder gar grundlegend relevant für die Bewertung realistischer Thesen aussehen lassen: Überzeugungen "auf beiden Seiten der Grenze", also Überzeugungen über Beobachtbares und Überzeugungen über Unbeobachtbares, können nicht nur in exakt demselben Sinn gerechtfertigt sein und den Status von Wissen haben, sondern sie können offenbar darüberhinaus durch weitgehend übereinstimmende epistemische Verfahren erzeugt werden oder sogar durch ein und dasselbe epistemische Verfahren. Um für wissenschaftli- 
chen Realismus zu argumentieren, kann man auf Fälle von weitgehend übereinstimmenden verläßlichen epistemischen Verfahren auf beiden Seiten der Grenze hinweisen, und vor allem auf einzelne epistemische Verfahren, die auf beiden Seiten der Grenze anwendbar und verläßlich sind, also auf epistemische Verfahren, für deren Anwendbarkeit und Verläßlichkeit die Unterscheidung beobachtbar/unbeobachtbar keine Rolle spielt. Wenn es solche epistemischen Verfahren gibt, dann ist der Output dieser Verfahren, sind also die dadurch erzeugten Überzeugungen auf beiden Seiten der Grenze nicht nur im selben Sinn gerechtfertigt, sondern darüber hinaus besteht die Eigenschaft dieser Überzeugungen, gerechtfertigt zu sein, darin, durch auf beiden Seiten der Grenze weitgehend übereinstimmende oder sogar ein und dasselbe Verfahren erzeugt worden zu sein. Hinweise auf solche epistemischen Verfahren finden sich bei mehreren Autoren. ${ }^{47}$

\subsubsection{Kontinuität durch eine "grenzüberschreitende" Folge von Beob- achtungsverfahren mit überlappendem Anwendungsbereich (Max- well)}

Einige Bemerkungen von Maxwell deuten eine Überlegung an, die gegen die epistemische Relevanz der Unterscheidung beobachtbar/unbeobachtbar spricht, indem darauf hingewiesen wird, daß optische Beobachtungsverfahren im allgemeinen in einem spezifizierbaren, häufig mehrere Größenordnungen umfassenden Bereich anwendbar sind. Mit dem bloßen Auge kann man (bei normaler Sehkraft) Dinge und Strukturen auf der Größenskala von Kilometern wahrnehmen, aber auch noch solche, die weniger als einen Millimeter groß sind. Mit Hilfe einer Lupe lassen sich auch etwas kleinere Strukturen noch auflösen, durch ein Mikroskop kann man Dinge im Bereich zwischen Millimetern und Mikrometern erkennen usw. Im Hinblick auf die Unterscheidung beobachtbar/unbeobachtbar ist daran offenbar zweierlei relevant: Zum einen gibt es "grenzüberschreitende" Verfahren wie das Beobachten mit einer Lupe, also Verfahren, deren Anwendungsbereich teilweise diesseits, teilweise jen-

\footnotetext{
${ }^{47}$ In vom Grundsatz ähnlicher Weise, aber ohne die Bezugnahme auf epistemische Verfahren, argumentiert Quine für einen in epistemischer Hinsicht gleichen (oder nur graduell verschiedenen) Status für beobachtbare und unbeobachtbare Entitäten und Sachverhalte: " [...] common-sense bodies are epistemologically much on a par with the molecules" ([Quin76c], S.251), "If we have evidence for the existence of the bodies of common sense, we have it only in the way in which we may be said to have evidence for the existence of molecules. The positing of either sort of body is good science insofar merely as it helps us formulate our laws - laws whose ultimate evidence lies in the sense data of the past, and whose ultimate vindication lies in anticipation of sense data of the future. The positing of molecules differs from the positing of common sense mainly in degree of sophistication. In whatever sense the molecules in my desk are unreal and a figment of the imagination of the scientist, in that sense the desk itself is unreal and a figment of the imagination of the race" ([Quin76c], S.250, s.a. [Quin60], S.22f., [Quin81b]). Das Thema epistemische Rechtfertigung, Bestätigung o.ä. ("the way in which we have evidence") diskutiert Quine nur auf einer sehr allgemeinen Ebene: Sätze werden nach Quine nicht einzeln empirisch gestützt, sondern holistisch in einem ganzen "Netz von Überzeugungen", das nur an den Rändern durch Beobachtungssätze "mit der Welt verknüpft" ist und in Konfliktfällen modifiziert und angepaßt wird. Darüber hinaus äußert sich Quine kaum zu der Frage, wie genau Erweiterungen und Änderungen des Netzes vorgenommen werden. Er nennt lediglich eine Reihe von (wiederum nur sehr allgemein umschriebenen) Tugenden (virtues) oder Vorzügen (benefits), die ein modifiziertes Netz aufweisen sollte, wie Einfachheit, Erhaltung bisheriger Überzeugungen u.ä. (siehe [QuU170], S.66ff., [Quin76c], S.247). In einem losen Sinn kann man die epistemischen Kontinuitätsargumente also vielleicht auf Quinesche Ansätze zurückführen und Quines zitierte Bemerkungen sozusagen als den holistischen Grenzfall einer Kontinuitätsüberlegung (da es in Quines Bild gewissermaßen nur ein einziges epistemisches Verfahren gibt) auffassen. Quine thematisiert die Verläßlichkeit dieses holistischen Verfahrens jedoch nicht, und es läßt sich über die Verläßlichkeit eines derart allgemein "zugeschnittenen" epistemischen Verfahrens offenbar auch wenig Erhellendes sagen, außer daß sich das Gesamtsystem der Überzeugungen einer Person regelmäßig verändert.
} 
seits der Grenze beobachtbar/unbeobachtbar liegt. Zum anderen lassen sich Folgen von Beobachtungsverfahren aufweisen, deren Anwendungsbereiche teilweise überlappen: Die größeren der Strukturen, die man mit der Lupe sieht, sind auch mit bloßem Auge sichtbar, bei mäßiger Vergrößerung zeigt einem ein Mikroskop dieselben Dinge wie die Lupe usw. Dadurch sollte eine Art schrittweise Kalibrierung derjenigen Beobachtungsverfahren, deren Anwendungsbereich ganz jenseits der Grenze beobachtbar/unbeobachtbar liegt, an grenzüberschreitenden Verfahren möglich sein, also etwa eines Mikroskopes an einer Lupe, eines Elektronenmikroskops an einem Mikroskop u.ä. Maxwell führt eine in diesem Sinn grenzüberschreitende Folge von Beobachtungsverfahren mit überlappendem Anwendungsbereich an, für deren Verläßlichkeit es seiner Meinung nach nicht von Relevanz ist, ob sie diesseits oder jenseits der Grenze beobachtbar/unbeobachtbar eingesetzt werden, und deren Output daher in beiden Fällen derselbe epistemische Status zukommen sollte.

"[...] there is, in principle, a continuous series beginning with looking through a vacuum and containing these as members: looking through a window-pane, looking through glasses, looking through binoculars, looking through a lowpower microscope, looking through a high-power microscope, etc., in the order given." 48

\subsubsection{Kontinuität durch ein grenzüberschreitendes kausales Beobach- tungsverfahren (Salmon)}

Wesley Salmon weist ebenfalls auf grenzüberschreitende optische Beobachtungsverfahren wie das Beobachten mit einer Lupe oder einem Mikroskop mäßiger Vergrößerungsstufe hin, um plausibel zu machen, daß der Unterscheidung beobachtbar/unbeobachtbar in epistemischer Hinsicht keine prinzipielle Relevanz zukommt. Wie Maxwell ist er überzeugt, daß diese Verfahren auch jenseits der Grenze verläßlich sind, er beschäftigt sich aber eingehender mit der Frage, wie eine entsprechende Verläßlichkeitsannahme begründet werden kann. Salmon argumentiert wie folgt:

"Consider a telescope. One can observe, with the naked eye, a distant object that appears small and lacking in detailed features. When it is observed with the aid of a telescope, it appears larger and more fully endowed with features. Relinquishing the telescope, we can approach the distant object and verify the fact that the telescope does indeed furnish us with observational information about the object not available by means of the unaided senses from that vantage point. Such generalizations about the properties of telescopes are completely empirical; they compare the observable properties of objects seen from different vantage points $[\ldots]$

A similar approach can be taken toward magnifying glasses. One can open the compact edition of the Oxford English Dictionary and observe some words printed in type large enough to be read easily with the naked eye. One can see words in smaller type that can be read, but only with considerable difficulty, without the aid of a magnifying glass. When the magnifying glass is used, these words also are easy to read. Other words, printed in still smaller type, appear to the naked eye to consist of letters, but the letters cannot be discerned clearly. With the aid of the magnifying glass, even these words can be read, though

\footnotetext{
${ }^{48}[\operatorname{Maxw62}]$, S.7.
} 
not necessarily with ease. Similar experiments, using low-power microscopes to view small visible objects, can be conducted. Such experiments with telescopes, magnifying glasses, and microscopes provide a satisfactory basis for empirical generalizations about the optical properties of lenses [...]

The next step in the argument is, of course, to make an inductive extrapolation from the foregoing generalizations about the optical properties of lenses used to observe visible objects to a full-blown theory of geometrical optics, from which we may infer that the objects that are too small to be seen by the naked eye alone can be observed with the aid of microscopes.

How is this crucial step, which takes us from the realm of observables to that of unobservables, to be characterized? It is, I think, both a causal argument and an argument by analogy. The causal aspects of the situation are revealed by such considerations as the fact that light transmission is a causal process [...] and the fact that intersections of light rays with lenses and other kinds of material objects are causal interactions [...] Rather crudely speaking, the analogy takes the following form:

It is observed that:

An effect of type $E_{1}$ is produced by a cause of type $C_{1}$, An effect of type $E_{2}$ is produced by a cause of type $C_{2}$,

An effect of type $E_{k}$ occurred.

We conclude that:

A cause of type $C_{k}$ produced $E_{k}$.

An analogical argument of this sort can take us from premises about observables to a conclusion about unobservables, for $C_{k}$ may be an unobservable cause that is similar to $C_{1}, C_{2}, \ldots$ in most respects other than size [..]

[...] Suppose that we observe a number of objects of different sizes under a particular low-powered microscope. An object that is $0.5 \mathrm{~mm}$ in diameter (as measured without using any optical instruments) appears under this microscope to have the same diameter as an object $2 \mathrm{~mm}$ in diameter viewed from the same distance without the aid of the microscope. An object that is $0.1 \mathrm{~mm}$ in diameter appears under the microscope to have the same diameter as an object that is $0.4 \mathrm{~mm}$ in diameter viewed from the same distance without the aid of a microscope. And so on. Suppose that no particle that I can see without the aid of a microscope has a diameter as small as $0.01 \mathrm{~mm}$, but that I can see one whose diameter is 0.04 . Then, if under the microscope I see a particle that appears to have the same diameter as one whose diameter is $0.04 \mathrm{~mm}$ as seen without the microscope, I infer by analogy that there is a particle in the field of the microscope that is too small to be seen with the naked eye. This analogy may not be a very strong inductive argument, but it does at least lend plausibility to its conclusion." 49

Salmon begründet seine Überzeugung, daß das Mikroskop auch jenseits der Grenze beobachtbar/unbeobachtbar verläßlich ist, in zwei Teilschritten: Im ersten Schritt werden

${ }^{49}[$ Salm84], S.232-235. 
die Abbildungseigenschaften des Mikroskops und damit seine Verläßlichkeit im Bereich des Beobachtbaren untersucht, und zwar mit dem bloßen Auge, indem man beobachtbare Gegenstände bzw. Sachverhalte mit ihrem Mikroskopbild vergleicht. Wenn dabei Verläßlichkeit in einem "hinreichend wohldefinierten" Bereich von untereinander ähnlichen Gegenständen oder Sachverhalten festgestellt wird, läßt sich nach Salmon in einem zweiten Schritt "induktiv extrapolierend" schließen, daß das Mikroskop auch Gegenstände oder Sachverhalte verläßlich abbildet, die denen in dem im ersten Schritt ermittelten Verläßlichkeitsbereich in allen oder fast allen Eigenschaften mit Ausnahme ihrer Größe gleichen oder zumindest ähnlich sind. ${ }^{50}$ Diesen entscheidenden zweiten Schritt, der gleichsam etwas über den Rand des vorher ermittelten Verläßlichkeitsbereiches hinausführt, bezeichnet Salmon als Analogieargument.

Salmons Argumentskizze ist in beiden Schritten nicht so genau wie es vielleicht wünschenswert wäre, dennoch werden zwei Punkte deutlich. Zum einen: Bereits im ersten Schritt sind induktive Schlüsse ("empirical generalizations") im Spiel, die - auf welche Weise genau auch immer ${ }^{51}$ - Aussagen darüber liefern, daß bestimmte Typen von (beobachtbaren) Gegenständen oder Sachverhalten bestimmte Mikroskopbilder verursachen, also eine kausale (Teil-)Beschreibung der Input-Output-Relation des Mikroskops geben. Diese Aussagen, auf die der zweite Argumentationsschritt aufzubauen scheint, sind in dem Sinne grobe oder abstrakte kausale Beschreibungen der Eigenschaften des Mikroskops, daß sie den Mechanismus, der für den Input-Output-Zusammenhang verantwortlich ist, weitgehend unspezifiziert lassen. ${ }^{52}$

Zweitens handelt es sich bei Salmons "induktiv extrapolierendem" zweiten Argumentationsschritt nicht um einen "gewöhnlichen" Induktionsschluß, sondern um eine Art von induktivem Schluß, bei der Größen (in Salmons Beispiel: Durchmesser) eine wesentliche Rolle spielen, also Eigenschaften, die in verschiedenen, kontinuierlich oder zumindest graduell abgestuften Ausprägungen vorkommen bzw. entsprechende Werte annehmen können $(1 \mathrm{~mm}, 2 \mathrm{~mm}$...): Ein in der Literatur gängiges Beispiel für einen Induktionsschluß ist, daß jemand nach der Beobachtung von 47 Raben, die allesamt schwarzes Gefieder haben, schließt, daß alle Raben schwarzes Gefieder haben. Bei einem Schluß dieser Art wird aus der Beobachtung, daß alle bisher beobachteten Gegenstände, die eine oder mehrere Eigenschaften(en) $A_{i}$ teilen (ein Rabe zu sein bzw. alles, was dazu erforderlich ist), auch eine weitere Eigenschaft $B$ teilen (schwarz zu sein), geschlossen, daß alle Gegenstände, die die Eigenschaft(en) $A_{i}$ haben, auch die Eigenschaft $B$ haben. Für solche Schlüsse ist die Bezeichnung enumerative Induktion üblich; ein Schema dafür ist

$$
A\left(a_{1}\right) \wedge B\left(a_{1}\right)
$$

\footnotetext{
${ }^{50}$ Hier bleibt die "technische" Komplikation beiseite, daß Salmon das Prinzip der gemeinsamen Ursache "nur" einsetzt, um Anfangswahrscheinlichkeiten (ungleich null) für einen Bayesschen Bestätigungsalgorithmus zu begründen, vgl. [Salm84], S.234f.

${ }^{51}$ Salmons Ausführungen lassen nicht wirklich deutlich werden, welche Rolle er einer "full-blown theory of geometrical optics" zuschreiben will, wie weit er also für die Argumentation eine systematische Theorie der optischen Eigenschaften von Linsen im Beobachtbaren für erforderlich hält (im Unterschied zu bloßen Aussagen über kausale Input-Output-Zusammenhänge wie "An effect of type $E_{1}$ is produced by a cause of type $C_{1} "$ ).

${ }^{52}$ Salmon erwähnt zwar "considerations as the fact that light transmission is a causal process" und sogar eine "full-blown theory of geometrical optics, from which we may infer that the objects too small to be seen by the naked eye can be observed with the aid of microscopes", will also das Mikroskop offenbar nicht als vollkommen undurchsichtige black box behandeln, aber seine folgende Skizze einer Formalisierung des Argumentes und das erläuternde Zahlenbeispiel am Ende der zitierten Passage lassen erkennen, daß der zweite Argumentationsschritt wohl doch keine systematische, vollständige Theorie des Mikroskops involvieren oder voraussetzen soll.
} 


$$
\begin{aligned}
& A\left(a_{2}\right) \wedge B\left(a_{2}\right) \\
& \vdots \\
& A\left(a_{n}\right) \wedge B\left(a_{n}\right)
\end{aligned}
$$

Also:

$$
\forall x(A(x) \rightarrow B(x)) .53
$$

Der Bereich, auf den von den bisher beobachteten Fällen verallgemeinert wird, wird hier durch eine (oder, in einem analogen, etwas komplizierteren Schema, durch mehrere) "qualitative" Eigenschaft(en) $A$ (bzw. $A_{i}$ ), die ein Gegenstand hat oder nicht hat, spezifiziert. Bei Salmons induktivem Extrapolationsschluß dagegen wird dieser Bereich durch eine Größe $D$ (Durchmesser), also durch eine "quantitative" Eigenschaft spezifiziert (oder mitspezifiziert), die ein Gegenstand $a$ nicht nur haben oder nicht haben kann, sondern von der ihm verschiedene Ausprägungen bzw. Werte $D(a)$ zukommen können, und diese Tatsache scheint für die intuitive Plausibilität des Schlusses wesentlich zu sein: Alle beobachteten Gegenstände haben einen (i.a.) verschiedenen Wert dieser Größe und die Werte liegen alle in einem Intervall $I$, dessen Grenzen der kleinste und der größte bisher beobachtete Wert $\left(d_{\min }\right.$ bzw. $\left.d_{\max }\right)$ bilden. Daraus, daß alle beobachteten Gegenstände, die einen Wert dieser Größe $D$ im Intervall $I$ (und eine weitere Eigenschaft $A$ ) haben, außerdem eine weitere Eigenschaft $B$ haben, wird geschlossen, daß diese Eigenschaft $B$ allen Gegenständen zukommt, die einen Wert der Größe $D$, der in dem etwas erweiterten Intervall $I_{\delta}=\left[d_{\min }-\delta, d_{\max }\right]$ liegt, (und die weitere Eigenschaft $A$ ) haben. ${ }^{54}$ Ein Schema, das nach dem obigen Schema der enumerativen Induktion modelliert ist und das hilft, die Struktur von Salmons induktivem Extrapolationsschluß zu verdeutlichen, ist

$$
\begin{aligned}
& A\left(a_{1}\right) \wedge D\left(a_{1}\right)=d_{1} \wedge B\left(a_{1}\right) \\
& A\left(a_{2}\right) \wedge D\left(a_{2}\right)=d_{2} \wedge B\left(a_{2}\right) \\
& \quad \vdots \\
& A\left(a_{n}\right) \wedge D\left(a_{n}\right)=d_{n} \wedge B\left(a_{n}\right)
\end{aligned}
$$

Also:

$$
\forall x\left(\left(A(x) \wedge D(x) \in I_{\delta}\right) \rightarrow B(x)\right) .
$$

Mit Hilfe dieses Schemas läßt sich Salmons konkreter Schluß als aus mehreren Teilschritten zusammengesetzt auffassen. Den ersten Teilschritt erhält man, indem man für $A(x)$ so etwas wie ' $x$ ist ein Mikroskopbild' und für $B(x)$ 'es gibt ein Objekt, das $x$ verursacht' einsetzt. Den zweiten Teilschritt seines Schlusses bekommt man, indem man ein analoges Schema formuliert, dessen Prämissen einem Quadrupel aus zwei (beliebigen) Mikroskopbildern und den zugehörigen verursachenden Objekten die Relation zuschreibt, daß das kleinere Objekt das kleinere Bild hervorruft, und daraus schließt, daß für alle solchen Quadrupel der Durchmesser der Bilder (streng) monoton mit dem Durchmesser der Objekte variiert. Gegeben die Konklusionen dieser beiden Zwischenschritte läßt sich schließen, daß zu einem Mikroskopbild, das kleiner ist als alle bisherigen (und dessen Durchmesser in $I_{\delta}$ liegt), ein verursachendes Objekt existiert, und weiter, daß dieses Objekt kleiner ist als alle bisher beobachteten. ${ }^{55}$

\footnotetext{
${ }^{53}$ Zum Problem der Spezifikation induktiver Inferenzschemata siehe S.452.

${ }^{54}$ Analog ließe sich das Intervall auch nach oben oder nach beiden Seiten erweitern.

${ }^{55}$ Die Zahlen in Salmons Beispiel legen vielleicht nahe, daß das Mikroskop einen konstanten Vergrößerungsfaktor 4 hat, den man linear extrapolieren kann. Dies tut Salmon in seinem Text jedoch nicht, zumindest nicht explizit, denn er sagt tatsächlich nicht, daß das 0,04 mm große Mikroskopbild von einem Objekt von 0,01 mm Durchmesser verursacht wird. Er beläßt es bei der vorsichtigeren Aussage, daß ein Teilchen "too small to be seen with the naked eye" die Ursache ist.
} 
Anschaulich gesprochen schließt man also bei einem enumerativen Induktionsschluß auf das Vorliegen einer Eigenschaft bei allen Gegenständen in einem Bereich, der durch eine andere, bei allen bekannten Gegenständen gemeinsam mit ihr auftretende qualitative Eigenschaft spezifiziert wird. Bei einem extrapolierenden Induktionsschluß dagegen schließt man auf das Vorliegen einer Eigenschaft bei allen Gegenständen in einem Bereich, der spezifiziert wird als Intervall einer (bei allen bekannten Gegenständen gemeinsam mit ihr auftretenden) Größe, das nicht nur die Werte dieser Größe bei allen bekannten Gegenständen einschließt, sondern "etwas" darüber hinausreicht. ${ }^{56}$

\subsubsection{Kontinuität durch ein grenzüberschreitendes kausales Inferenz- prinzip (Salmon)}

Bei Salmon findet sich eine weitere Überlegung, die für denselben epistemischen Status für beobachtbare und unbeobachtbare Gegenstände und Sachverhalte spricht. Er weist auf ein kausales Inferenzschema hin, das keinen Unterschied zwischen beiden Bereichen macht: Nach ein und demselben, nach Salmon in Alltag und Wissenschaften etablierten Inferenzschema ausgeführte Schlüsse auf die Ursachen bestimmter Phänomene können sowohl auf Überzeugungen über beobachtbare, als auch auf Überzeugungen über unbeobachtbare Gegenstände und Sachverhalte führen. ${ }^{57}$

\section{Das Prinzip der gemeinsamen Ursache}

Salmons Argument stützt sich auf seine Theorie kausaler Erklärungen. Diese geht von Hans Reichenbachs Idee eines Prinzips der gemeinsamen Ursache (principle of the common cause) aus. Dieses Prinzip besagt, grob gesprochen, daß zwei gleichzeitige Ereignisse, die korreliert auftreten, nach einer kausalen Erklärung verlangen, und zwar, sofern bestimmte Bedingungen erfüllt sind, nach einer Erklärung durch eine gemeinsame Ursache. Nach dem Prinzip der gemeinsamen Ursache existiert zu zwei solchen korrelierten Ereignissen $A$ und $B$ ein drittes, zeitlich früheres Ereignis $C$, das $A$ und $B$ verursacht. ${ }^{58}$ Bei den besagten Bedingungen handelt es sich im wesentlichen darum, daß ausgeschlossen sein muß, daß eins der beiden Ereignisse das andere direkt verursacht..$^{59}$

\footnotetext{
${ }^{56}$ Ein weiteres "grenzüberschreitendes" Verfahren (neben Lupe, Mikroskop und ähnlichen Vergrößerungsgeräten), für das man ähnlich argumentieren könnte, ist das Abbilden von Bewegungsvorgängen per Kamera, womit sowohl langsame, als auch extrem schnelle (und deswegen unbeobachtbare) Vorgänge erfaßt werden können, die nur per Zeitlupe sichtbar werden.

${ }^{57}$ In derselben Richtung argumentiert u.a. auch [Sobe84], S.237ff.

${ }^{58}$ 'Ereignis' ist hier in dem in der Wahrscheinlichkeitstheorie gängigen Sinn gebraucht.

${ }^{59}$ [Reic56], S.157ff. Die formale Fassung bei Reichenbach lautet: In einer Situation, in der einer Menge von Ereignissen Wahrscheinlichkeiten zugewiesen werden können, nennt man zwei Ereignisse $A$ und $B$ korreliert, wenn gilt:

$$
P(A \wedge B)>P(A) \cdot P(B) .
$$

Eine gemeinsame Ursache von $A$ und $B$ ist ein Ereignis $C$, für das gilt:

$$
\begin{aligned}
& P(A \wedge B \mid C)=P(A \mid C) \cdot P(B \mid C) \quad \text { oder, äquivalent, } \\
& P(A \mid C)=P(A \mid C \wedge B) \quad \text { und } P(B \mid C)=P(B \mid C \wedge A) \\
& P(A \wedge B \mid \neg C)=P(A \mid \neg C) \cdot P(B \mid \neg C) \\
& P(A \mid C)>P(A \mid \neg C) \\
& P(B \mid C)>P(B \mid \neg C) .
\end{aligned}
$$
}

(8.2) wird gewöhnlich Abschirmbedingung (screening-off condition) genannt. Aus (8.2) bis (8.5) folgt (8.1). 
Wie Salmon diese Idee einsetzt, läßt sich, ohne hier auf ihre präzise formale Fassung einzugehen ${ }^{60}$, am besten an den von ihm angegebenen Beispielen zeigen; zunächst ein etwas konstruiertes, dann zwei "lebensnähere":

"Suppose we have a pair of dice that are rolled together. If the first die comes to rest with side 6 on the top, that is an event of the type $A$; if the second die comes to rest with the side 6 uppermost, that is an event of type $B$. These dice are like standard dice except for the fact that each one has a tiny magnet embedded in it. In addition, the table on which they are thrown has a powerful electromagnet beneath its surface. This magnet can be turned on or off with a concealed switch. If the dice are rolled when the electromagnet is on, it is considered an instance of the common cause $C$; if the magnet is off when the dice are tossed, the event is designated as $\bar{C}$. Let us further assume that when the electromagnet is turned off, these dice behave exactly as standard dice. The probability of getting 6 with either die is $1 / 6$, and the probability of getting double 6 is $1 / 36$. If the electromagnet is turned on, let us assume, the chance of getting 6 with either die is $1 / 2$, and the probability of double 6 is $1 / 4$." 61

In diesem Fall ist $C$, das Vorliegen des Magnetfeldes, die gemeinsame Ursache für $A$ und $B$, das Fallen der Augenzahl 6 bei den beiden Würfeln.

"If [...] two students in a class turn in identical term papers, and if we can rule out the possibility that either copied directly from the other, then we search for a common cause - for example, a paper in a fraternity file from which both of them copied independently of each other." 62

"The twin quasars $0975+561 \mathrm{~A}$ and B are separated by an angular width of 5.7 seconds of arc. Two quasars in such apparent proximity would be a rather improbable occurrence given simply the observed distribution of quasars. Examination of their spectra indicates equal red shifts, and hence, equal distances. Thus these objects are close together in space, as well as appearing close together as seen from earth. Moreover, close examination of their spectra reveals a striking similarity [...] This situation is in sharp contrast to the relations between the spectra of any two quasars picked at random. Astronomers immediately recognized the need to explain this astonishing coincidence in terms of some common cause. One hypothesis that was entertained quite early was that twin quasars had somehow [...] developed from some common ancestor. Another hypothesis was the gravitational lens effect - that is, there are not in fact two distinct quasars, but the two images were produced from a single body by the gravitational bending of the light by an intervening massive object [...] Further observation [...] has subsequently revealed the presence of a galaxy that would be adequate to produce the gravitational splitting of the image. This explanation is now [...] accepted by virtually all of the experts." ${ }^{2}$

Nach Salmons Theorie verlangen solche Fälle korrelierter Ereignisse eine Erklärung einer bestimmten Art, nämlich eine Erklärung durch die Angabe von kausalen Prozessen, die

\footnotetext{
${ }^{60}$ Siehe [Salm84], Kap.6.

${ }^{61}$ [Salm84], S.161/162.

${ }^{62}$ [Salm84], S.159.

${ }^{63}$ [Salm84], S.159.
} 
die gemeinsame Ursache mit den Ereignissen verbinden. Die Idee, daß die Kausalrelation mit Hilfe von (physikalischen) Prozessen zu erläutern ist, bildet den Kern von Salmons Konzeption von Kausalität. Was ein kausaler Prozeß ist, läßt sich wiederum am einfachsten an den schon angeführten Beispielen erläutern. Im Fall der Würfel sind deren Trajektorien die kausalen Prozesse. Das zweite Beispiel:

"Two students, Adams and Baker, submit essentially identical term papers in a particular course. There is, of course, the logical possibility that the two papers were produced entirely independently, and that the resemblance is a matter of pure chance. Given the overwhelming improbability of this sort of coincidence, no one takes this suggestion seriously. Three reasonable explanatory hypotheses are available: (1) Baker copied from Adams, (2) Adams copied from Baker, or (3) both copied from a common source. We can understand these possibilities in terms of [causal] processes [...] There is either (1) a causal process running from Adam's production of the paper to Baker's, (2) a causal process running from Baker's production of the paper to Adam's, or (3) a common cause - for example, a paper in a fraternity file to which both Adams and Baker had access. In the case of the third alternative, there are two distinct causal processes running from the paper in the file to each of the two papers submitted by Adams and Baker, respectively." 64

Im Fall der zwei Quasare 0975+561 A und B bestehen die beiden kausalen Prozesse in der Ausbreitung der elektromagnetischen Wellen entlang verschiedener Wege, jeweils unter Einfluß der Gravitationslinse. Die gemeinsame Ursache, die räumliche Konstellation des Quasars und der Gravitationslinse, wird durch die Prozesse der Lichtausbreitung verbunden mit den korrelierten Ereignissen auf der Erde (zwei ähnliche Signale in den Detektoren, auf einer Photoplatte o.ä.). ${ }^{65}$

Allgemeiner versteht Salmon unter einem Kausalprozeß einen physikalischen, raumzeitlich kontinuierlich verlaufenden Prozeß, der markierbar ist, d.h., grob gesprochen, der geeignet ist, Markierungen oder Signale dadurch zu übertragen, daß sich eine an einer Stelle des Prozesses vorgenommene (in der Regel "kleine") Modifikation mit dem Prozeß weiter fortpflanzt. Der physikalische Vorgang der Lichtausbreitung etwa (der im Beispiel der Quasare die Kausalprozesse bildet) erweist seinen Charakter eines kausalen Prozesses dadurch, daß man den Strahlengang durch das Einbringen eines Farbfilters markieren kann, die Trajektorie eines Würfels dadurch, daß man den Würfel etwa farblich markieren kann. ${ }^{66}$

Das Prinzip der gemeinsamen Ursache in der Version von Salmon verlangt für korrelierte Ereignisse eine kausale Erklärung der beschriebenen Art. Präziser gesprochen besteht das Prinzip der gemeinsamen Ursache in Salmons Version aus zwei Teilaussagen: Zum einen aus einem "Inferenzprinzip", das Existenzaussagen liefert: Zu zwei korrelierten Ereignissen existiert entweder ein Kausalprozeß, der eines der Ereignisse als Ursache mit dem zweiten als Wirkung verbindet, oder es existiert eine (von den beiden korrelierten Ereignissen verschiedene) gemeinsame Ursache und zwei Kausalprozesse, die jeweils die gemeinsame Ursache mit einem der beiden Ereignisse als Wirkung verbinden. ${ }^{67}$ Zum

\footnotetext{
${ }^{64}$ [Salm84], S.207.

${ }^{65}$ Vgl. [Salm84], S.180, 210.

${ }^{66}$ Für Details siehe [Salm84], Kap.5. Salmon hat seine Theorie der Kausalprozesse mittlerweile stark modifiziert; siehe [Salm94].

${ }^{67}$ [Salm84], S.207ff., 228. Für eine gemeinsame Ursache gelten die in Fn.59 genannten Bedingungen bzw.
} 
anderen aus dem "Erklärungsprinzip"68, daß die Korrelation der Ereignisse durch den sie verbindenden Kausalprozeß bzw. die gemeinsame Ursache plus Kausalprozesse erklärt wird. ${ }^{69}$

Salmon beansprucht ausdrücklich nicht, daß sein Prinzip der gemeinsamen Ursache ein in allen Kontexten und ausnahmslos gültiges Inferenz- bzw. Erklärungsprinzip darstellt. ${ }^{70}$ Man hat damit aber seiner Ansicht nach immerhin ein in weiten Bereichen der Alltagswelt und der Wissenschaften verläßliches Inferenzschema in der Hand. Wichtig für die Bewertung des Prinzips der gemeinsamen Ursache ist es, genau zu sehen, was es in diesen Bereichen leistet: Wenn man zwei korrelierte Ereignisse hat, dann erlaubt Salmons Prinzip (sofern direkte Verursachung ausgeschlossen ist) den Schluß auf die Existenz einer gemeinsamen Ursache und zweier Kausalprozesse, die bestimmten Bedingungen statistischer Art genügen. Um welchen Sachverhalt und um welche Kausalprozesse es sich dabei handelt, muß man mit anderen Mitteln in Erfahrung bringen, die genannten statistischen Bedingungen sind im allgemeinen nur notwendige, keine hinreichenden, und sie reichen nicht aus, um die gemeinsame Ursache bzw. die Kausalprozesse zu identifizieren. ${ }^{71}$

\section{Grenzüberschreitendes Schließen auf eine gemeinsame Ursache}

Zur Begründung seiner Überzeugung, daß man mit dem Prinzip der gemeinsamen Ursache ein verläßliches grenzüberschreitendes kausales Inferenzprinzip in der Hand hat, weist Salmon, ähnlich wie im Fall der optischen Beobachtungsverfahren, darauf hin, daß sich die Verläßlichkeit des Inferenzprinzips induktiv bewerten läßt:

"The basic form of inductive reasoning can be applied — at a higher level, so to speak - to evaluate other methods of nondemonstrative inference. If a given principle of inference has proved to be quite reliable in past applications, then we may reasonably have some confidence in further uses of it. "72

Angewandt auf das Prinzip der gemeinsamen Ursache scheint Salmons Idee folgende zu sein: Wenn in einem bestimmten Bereich zu vielen Fällen von korrelierten Ereignissen

eine Variante davon: Salmon unterscheidet zwei Typen von gemeinsamen Ursachen, die entsprechenden Situationen bezeichnet er als conjunctive forks und als interactive forks: $\mathrm{Zu}$ den conjunctive forks zählen die angeführten Beispiele; allgemeiner gesprochen handelt es sich um Situationen, in denen die beiden Kausalprozesse physikalisch voneinander unabhängig sind, also nicht wechselwirken, und bei denen die gemeinsame Ursache den von Reichenbach angegebenen Bedingungen genügt. Die gemeinsame Ursache kann hier ein genereller, sozusagen an verschiedenen Raumzeitpunkten instantiierter Sachverhalt, eine allgemeine Hintergrundbedingung o.ä. sein, der am Ausgangspunkt beider Kausalprozesse involviert ist. Eine interactive fork liegt dagegen in einer Situation vor, in der die beiden Kausalprozesse physikalisch wechselwirken, sich also raumzeitlich schneiden müssen, z.B. beim Stoß zweier Billardkugeln; dort schirmt die gemeinsame Ursache die korrelierten Ereignisse nicht ab, stattdessen gilt: $P(A \wedge B \mid C)>P(A \mid$ $C) \cdot P(B \mid C)$; vgl. [Salm84], Kap.6.

Neben diesen "Komplikationen" und der Rolle von Kausalprozessen ist ein dritter Unterschied zwischen Reichenbachs und Salmons Version des Prinzips der gemeinsamen Ursache, daß Salmon die Einschränkung fallenläßt, daß nur gleichzeitige korrelierte Ereignisse zu erklären sind.

${ }^{68}$ [Salm84], S.211.

${ }^{69}$ Salmons Verwendung der Ausdruckes 'common cause principle' ist insofern eine spezielle, als er dabei auf Kausalprozesse Bezug nimmt. Ansonsten bezeichnet der Ausdruck in der Literatur Reichenbachs oder ein ähnliches Prinzip, das "nur" Ereignisse und ihre Wahrscheinlichkeiten involviert.

${ }^{70}$ [Salm84], S.237, 242ff.; siehe auch schon [Reic56], S.157/158. Im Bereich der Quantenmechanik Stichwort: EPR-Korrelationen — versagt es offenbar in der Form, die Salmon im Auge hat; vgl. aber [Heal94].

${ }^{71}$ [Salm84], S.167f.

72 [Salm84], S.237. 
aufgrund des Prinzips der gemeinsamen Ursache erfolgreich die Existenz von gemeinsamen Ursachen und verbindenden Kausalprozessen erschlossen und diese anschließend identifiziert worden sind, dann wird man dies als Evidenz für die Verläßlichkeit des Inferenzprinzips in dem gesamten Bereich ansehen. Man wird induktiv von der Verläßlichkeit des Prinzips in bereits überprüften Anwendungsfällen auf Verläßlichkeit in einem Bereich "hinreichend ähnlicher" Fälle korrelierter Ereignisse schließen. Ein Verfahren, das mehr als "nur" Existenzaussagen liefert, hat man dann, wenn man außerdem in diesem Bereich in verläßlicher Weise die gemeinsamen Ursachen und die verbindenden Kausalprozesse identifizieren kann. Wenn sowohl dies, als auch die Verläßlichkeit des Prinzips der gemeinsamen Ursache für einen Bereich plausibel gemacht werden kann, der über die Grenze beobachtbar/unbeobachtbar hinausreicht, d.h., in dem die ermittelten gemeinsamen Ursachen und Kausalprozesse teilweise beobachtbar und teilweise unbeobachtbar sind, dann ist damit plausibel gemacht, daß in diesem Bereich mit Hilfe des Prinzips der gemeinsamen Ursache unbeobachtbare Gegenstände und Sachverhalte epistemisch (im Prinzip) genauso gut zugänglich sind wie beobachtbare.

Als grenzüberschreitenden Anwendungsfall des Prinzips der gemeinsamen Ursache präsentiert Salmon die (historisch einflußreiche) Argumentation des französischen Physikers Jean Perrin für die Existenz von Atomen und Molekülen. Perrins Argument stützt sich auf eine ganze Reihe von (eigenen oder von anderen Physikern durchgeführten) Experimenten zur Bestimmung der Avogadro-Konstante ${ }^{73}$, u.a. die Beobachtung der Brownschen Bewegung von Harzkügelchen in einer Flüssigkeit, die Bestimmung der Anzahl von Molekülen in einem Kristall durch Röntgenbeugung und die Bestimmung der zur elektrolytischen Abscheidung von Silber benötigten Ladungsmenge. Jedes dieser Experimente ermöglicht auf einem anderen Weg indirekt (mit Hilfe bestimmter Annahmen) die Ermittelung der Avogadro-Konstante.

"In 1913, Perrin published Les Atomes, in which he [...] summarized the evidence for the reality of molecules. Instead of focusing upon one or two beautiful experimental determinations of precise values of Avogadro's number, he lays great stress upon the fact that $N$ has been ascertained in a considerable number of independent ways - in fact he lists thirteen distinct methods [...] It seems clear that Perrin would not have been satisfied with the determination of Avogadro's number by any single method, no matter how carefully applied and no matter how precise the results. It is the "remarkable agreement" among the results of many diverse methods that supports his conclusion about the reality of molecules.

If there were no such micro-entities as atoms, molecules, and ions, then these different experiments designed to ascertain Avogadro's number would be genuinely independent experiments, and the striking numerical agreement in their results would constitute an utterly astonishing coincidence. To those who were in doubt about the existence of such micro-entities, the "remarkable agreement" constitutes strong evidence that these experiments are not fully independent - that they reveal the existence of such entities [...]

The claim I should like to make about the argument [...] stated [...] by Perrin, is that it relies upon the principle of the common cause [...] The situation is, I think, quite analogous to the testimony of independent witnesses.

\footnotetext{
${ }^{73}$ Also der Anzahl von Molekülen in einem Mol einer Substanz.
} 
Suppose that a murder has been committed, and that one crucial factor in the investigation concerns whether a particular suspect, John Doe, was in the vicinity of the crime at about the time it was committed. Suppose that several different witnesses testify, not only to his whereabouts, but also to a variety of details - such as how he was dressed, what he was carrying, and the fact that he arrived in a taxi. If collusion can be ruled out, and if we can be confident that they were not coached, then the agreement of the witnesses on details of the foregoing sorts would constitute strong evidence that they were reporting facts that they had observed. Moreover, even if none of the witnesses could be considered particularly reliable, the agreement among their reports would greatly enhance our confidence in the veracity of their account [...]

The situation pertaining to Avogadro's number can be viewed in much the same way $[\ldots]$

[...] There is little difficulty, I think, in seeing that the required causal processes do connect the existence and behavior of the micro-particles with the experimental results that furnish the basis for the calculation of Avogadro's number. In the case of X-ray diffraction, for example, electromagnetic radiation of known wavelength is emitted from an X-ray source, it travels a spatiotemporally continuous path from the source to the crystall to a photographic plate, where another causal interaction occurs, yielding an inference pattern when the plate is developed [...] The causal processes that lead from the microstructure of matter to the observed phenomena that yield values of $N$ are quite complex, but our physical theories provide a straightforward account of them."74

\subsubsection{Kontinuität durch ein grenzüberschreitendes Inferenzprinzip des Schließens auf die beste Erklärung (Glymour)}

Im Mittelpunkt einer weiteren Überlegung, die für einen identischen epistemischen Status für Gegenstände und Sachverhalte auf beiden Seiten der Grenze beobachtbar/unbeobachtbar spricht, steht ein anderes Inferenzprinzip, nämlich das Prinzip des Schließens auf die beste Erklärung (inference to the best explanation). Eine Möglichkeit, mit Hilfe dieses Inferenzprinzips für eine realistische Position zu argumentieren, ${ }^{75}$ ist, das Schließen auf die beste Erklärung als universell anwendbares Inferenzschema zu präsentieren, d.h. als eines, dem in Alltagskontexten wie in wissenschaftlichen Kontexten jedweder Art dieselbe Legitimität zukommt, oder, wenn nicht als universell anwendbares Inferenzschema, dann zumindest als eines, für dessen Anwendbarkeit und Verläßlichkeit die Unterscheidung zwischen beobachtbaren und unbeobachtbaren Gegenständen und Sachverhalten keine Rolle spielt.

\section{Schließen auf die beste Erklärung}

Den Terminus 'Schluß auf die beste Erklärung' ('inference to the best explanation') hat Gilbert Harman geprägt, ${ }^{76}$ die zugrundeliegende Idee findet sich (unter dem Titel Abduktion) schon bei Charles Sanders Peirce. ${ }^{77}$ Harman erläutert das Schließen auf die beste

\footnotetext{
${ }^{74}$ [Salm84], S.216-224.

${ }^{75}$ Eine andere Art ist das Wunderargument; siehe Kap.9.

${ }^{76}$ [Harm65].

${ }^{77}$ Siehe z.B. [Peir34b], S.117f. (5.189).
} 
Erklärung wie folgt:

"In making this inference one infers, from the fact that a certain hypothesis would explain the evidence, to the truth of that hypothesis. In general, there will be several hypotheses which might explain the evidence, so one must be able to reject all such alternative hypotheses before one is warranted in making the inference. Thus one infers, from the premise that a given hypothesis would provide a "better" explanation for the evidence than would any other hypothesis, to the conclusion that the given hypothesis is true."78

Alan Musgrave faßt den Gedanken etwas formaler, aber der Sache nach im wesentlichen identisch; er fügt Harmans Erläuterung lediglich die Bedingung hinzu, daß ein Schluß auf die beste Erklärung plausiblerweise nur dann vorgenommen werden sollte, wenn die beste verfügbare Erklärung bestimmten Mindestanforderungen an die Qualität der Erklärung genügt und, wie Musgrave sich ausdrückt, zumindest "zufriedenstellend" ist, also nicht, wenn auch die beste zur Verfügung stehende Erklärung lausig schlecht ist. Mit Musgrave läßt sich die Idee des Schließens auf die beste Erklärung dann als ein Inferenzschema formulieren: ${ }^{79}$

(IBE)

$F$ is a fact.

Hypothesis $H$ explains $F$.

Hypothesis $H$ satisfactorily explains $F$.

No available competing hypothesis explains $F$ as well as $H$ does.

Therefore, $H$ is true.

Schlüsse, die sich durch dieses Inferenzschema beschreiben lassen, spielen nach Ansicht einiger Autoren eine zentrale Rolle in der epistemischen Praxis in Alltag und Wissenschaften. ${ }^{80}$ Einige Beispiele:

"Uses of the inference to the best explanation are manifold. When a detective puts the evidence together and decides that it must have been the butler, he is reasoning that no other explanation which accounts for all the facts is plausible enough or simple enough to be accepted. When a scientist infers the existence of atoms and subatomic particles, he is inferring the truth of an explanation for various data which he wishes to account for." 81

Um zu einem noch präziser formulierten, zweifelsfrei anwendbaren Inferenzschema des Schließens auf die beste Erklärung zu gelangen, müßte (mindestens) der dafür zentrale Begriff der Erklärung erläutert werden, insbesondere müßte erläutert werden, was eine Erklärung zu einer guten und befriedigenden macht und ggf. zu einer besseren im Vergleich zu anderen, konkurrierenden Erklärungen. Angesichts der notorischen Schwierigkeiten,

\footnotetext{
${ }^{78}[$ Harm65], S.89.

${ }^{79}$ Siehe [Musg88], S.239. Musgrave selbst gibt nicht genau dieses Schema an, sondern bringt es durch eine zusätzliche Prämisse auf die Form eines gültigen deduktiven Inferenzschemas. Diese Prämisse lautet: "It is reasonable to accept a satisfactory explanation of any fact, which is also the best available explanation of that fact, as true" (und entsprechend wird die Konklusion abgeschwächt zu: "Therefore, it is reasonable to accept $H$ as true"). Sachlich bringt dies keinen Vorteil, denn die Begründungs- oder Rechtfertigungsprobleme sind in beiden Fällen die gleichen: Im einen Fall ist der "kritische Punkt" die Begründung bzw. Rechtfertigung des nicht-deduktiven Inferenzschemas als ganzes, im anderen Fall die Begründung bzw. Rechtfertigung der zusätzlichen Prämisse.

${ }^{80}$ Siehe z.B. [BonJ85, Gold88, Harm73].

${ }^{81}$ [Harm65]; S.89.
} 
zufriedenstellende Erläuterungen dieser Art zu finden, werden diese Fragen im Kontext philosophischer Diskussionen, in denen auf das Schließen auf die beste Erklärung Bezug genommen wird, meistens eingeklammert und es wird vorausgesetzt, daß die Anwendung eines Schemas wie (IBE) in den meisten Fällen auch ohne solche expliziten Erläuterungen unkontrovers ist.

\section{Grenzüberschreitendes Schließen auf die beste Erklärung}

Clark Glymour beruft sich auf ein Inferenzschema dieser $\mathrm{Art}^{82}$, um für wissenschaftlichen Realismus zu argumentieren. Glymour schlägt (Teil-) Kriterien für den Vergleich der Qualität der Erklärungsleistungen konkurrierender wissenschaftlicher Theorien vor ${ }^{83}$, die seiner Ansicht nach zumindest Teile der epistemischen Praxis der Theoriewahl in den realexistierenden Wissenschaften angemessen beschreiben, und liefert damit effektiv ein (zum Teil) erläutertes Inferenzschema der Form (IBE) für den Anwendungsbereich wissenschaftliche Theorien. Die Kriterien, und damit das Schließen auf die beste Erklärung, involvieren keine Unterscheidung zwischen beobachtbaren und unbeobachtbaren Explanantia.

Dieser letztere Befund hat nach Glymour Konsequenzen für die epistemische Bewertung des Schließens auf die beste Erklärung und der aufgrund eines entsprechenden Inferenzschemas der Form (IBE) akzeptierten Theorien: Man steht vor der Alternative, entweder generell alle Resultate des Schließens auf die beste Erklärung als Überzeugungen zu akzeptieren oder keins davon (zumindest nicht qua beste Erklärung). Die letztere Option scheidet offenbar für jeden aus, der die Rechtfertigungspraxis der Wissenschaften nicht in radikaler Weise reformieren will, nämlich auch soweit sie Theorien über beobachtbare Dinge und Sachverhalte betrifft. Auf dieser Linie argumentiert Glymour, wenn er über seinen Vorschlag für Kriterien für die Bewertung von Erklärungsleistungen konkurrierender Theorien schreibt:

"[...] the $[\ldots]$ criteria for comparing scientific explanations [...] make no use of the notion of observability [...] the same features of inference which lead to general conclusions about the observable also lead in other contexts to determinate conclusions about the unobservable. In consequence, I believe there are only two ways to maintain the antirealist position: either by impoverishing (perhaps I should say emasculating) the methods of science, and disallowing altogether explanatory criteria such as those I will describe, or by arbitrarily (and vaguely) restricting the scope of application of such principles to the realm of the observable." 84

Die zuletzt genannte Option hält Glymour für unplausibel. Entweder muß man seiner Ansicht nach ein grenzüberschreitendes Inferenzschema der Form (IBE) und damit auch die erschlossenen Theorien akzeptieren, egal ob sie von Beobachtbarem oder von Unbeobachtbarem handeln, oder man muß das in den Wissenschaften praktizierte Schließen auf die beste Erklärung insgesamt zurückweisen, und damit alle so erschlossenen Theorien:

"The argument for atoms is as good as the argument for [planetary] orbits." 85

\footnotetext{
${ }^{82}$ Das er allerdings nicht explizit macht.

${ }^{83} \mathrm{Im}$ wesentlichen, daß möglichst viele empirische Regelmäßigkeiten mit Hilfe der Theorie auf andere Phänomene zurückgeführt werden können (s. [Glym84]); der genaue Inhalt dieser (etwas komplizierten) Kriterien kann an dieser Stelle beiseite bleiben.

${ }^{84}$ [Glym84], S.174/175.

${ }^{85}$ [Glym84], S.187. Eine ähnliche Überlegung für ein Inferenzschema, das kausale Erklärungen involviert, skizziert Lipton ([Lipt91], S.174ff.).
} 
Alle hier angeführten, von den verschiedenen Autoren mehr oder weniger genau skizzierten epistemischen Kontinuitätsargumente haben also, so wie sie hier rekonstruiert wurden, eine ähnliche Gestalt: Es wird auf epistemische Verfahren hingewiesen, deren Output sozusagen über die Grenze beobachtbar/unbeobachtbar hinausreicht oder sogar (im Fall von Maxwells Folge von Beobachtungsverfahren) ganz jenseits dieser Grenze liegt, d.h. auf Verfahren, die (auch) Überzeugungen über Unbeobachtbares liefern. Die Annahme, daß das jeweilige Verfahren (auch) jenseits der Grenze beobachtbar/unbeobachtbar verläßlich ist, wird entweder als intuitiv plausibel präsentiert, oder es wird eine Begründung dafür zumindest skizziert, und zwar eine, die sich auf einen induktiven Schluß oder auf einen induktiv extrapolierenden Schluß stützt.

Damit ist zwar explizit noch kein Argument oder Rechtfertigungsgrund für eine konkrete realistische These oder mehrere formuliert, aber es ist sozusagen der Weg beschrieben, auf dem sich mit Hilfe der genannten epistemischen Verfahren konkrete realistische Thesen über Unbeobachtbares gewinnen und rechtfertigen lassen, wenn man eine reliabilistische Konzeption von Wissen und Rechtfertigung akzeptiert: Der Output dieser Verfahren, also die damit erzeugten Überzeugungen, haben bestimmte (unbeobachtbare) Gegenstände und ihre Eigenschaften, die Gesetzmäßigkeiten ihres Verhaltens etc. zum Inhalt. Es handelt sich also jeweils um einen Teil einer ontologischen realistischen These der Form $(O R)^{86}$, genauer: um den Teil, der den, wie Wright sich ausdrückt, anmaßenden Gedanken der allgemeinen realistischen Intuition konkretisiert ${ }^{87}$. Wenn semantische realistische Thesen in bezug auf die Sätze oder Theorien, die den Output der grenzüberschreitenden Verfahren bilden, vorausgesetzt werden können, impliziert dieser Output offenbar entsprechende epistemische realistische Thesen der Form (ER). Nach der reliabilistischen Konzeption von gerechtfertigten Überzeugungen sind Überzeugungen, die durch ein epistemisches Verfahren gewonnen wurden, gerechtfertigt, wenn das Verfahren verläßlich ist. Die ontologischen bzw. epistemischen realistischen (Teil-)Thesen über Unbeobachtbares, die man als Output der in den epistemischen Kontinuitätsargumenten genannten Verfahren erhält, sind also gerechtfertigt, wenn die epistemischen Verfahren (auch) jenseits der Grenze beobachtbar/unbeobachtbar verläßlich sind. Eine entsprechende Verläßlichkeitsaussage kann man als Rechtfertigungsgrund anführen, um für die realistischen Thesen zu argumentieren.

Um eine solche Verläßlichkeitsaussage ihrerseits zu begründen, werden in den epistemischen Kontinuitätsargumenten induktive Schlüsse oder induktiv extrapolierende Schlüsse vorgeschlagen oder angedeutet, die allesamt davon ausgehen, daß sich die Verläßlichkeit eines epistemischen Verfahrens im Beobachtbaren durch Beobachtung etablieren, und dann für grenzüberschreitende Verfahren induktiv bzw. induktiv extrapolierend auf Verläßlichkeit (auch) jenseits der Grenze beobachtbar/unbeobachtbar schließen läßt. (Maxwells Idee einer Folge von epistemischen Verfahren, die aneinander kalibriert werden können, setzt diese Anwendung induktiver Extrapolationsschlüsse sukzessiv im Unbeobachtbaren fort.) An dieser Stelle kommen also die "Kontinuitäten" ins Spiel, auf die die Autoren der epistemischen Kontinuitätsargumente hinweisen: Diese "Kontinuitäten" bestehen darin, daß in vielen Fällen der Anwendungsbereich eines epistemischen Verfahrens oder sogar die Vereinigungsmenge der Anwendungsbereiche mehrerer epistemischer Verfahren aus einer Gesamtheit von Gegenständen, Sachverhalten o.ä. besteht, deren Eigenschaften sich "nur" graduell oder kontinuierlich unterscheiden, und daß außerdem in in diesem Sinn ähnlichen, "benachbarten" Anwendungsbereichen, insbesondere auf beiden Seiten der Grenze beob-

\footnotetext{
${ }^{86} \mathrm{Vgl}$. Kap.1.2.1, 1.3.1.

${ }^{87}$ Und der evtl. durch eine Unabhängigkeitsaussage ergänzt werden kann, die den entsprechenden bescheidenen Gedanken zum Ausdruck bringt.
} 
achtbar/unbeobachtbar, weitgehend übereinstimmende, in ihren Eigenschaften nur graduell verschiedene epistemische Verfahren zur Gewinnung von Überzeugungen eingesetzt werden oder sogar ein und dasselbe Verfahren. Diese "Kontinuitäten" liegen offenbar den induktiven oder induktiv extrapolierenden Schlüssen auf Verläßlichkeitsaussagen zugrunde.

Bei den epistemischen Kontinuitätsargumenten handelt es sich also in folgendem Sinn um Argumente für wissenschaftlichen Realismus: Es wird auf bestimmte epistemische Verfahren hingewiesen, für die entweder vortheoretische Intuitionen in Anspruch genommen werden, denen zufolge sie verläßlich sind, oder für deren Verläßlichkeit ein induktiver oder induktiv extrapolierender Schluß skizziert wird. Durch solche Verläßlichkeitsaussagen lassen sich die ontologischen bzw. epistemischen realistischen (Teil-)Thesen über Unbeobachtbares rechtfertigen, die man als Output der epistemischen Verfahren gewinnt. Diese realistischen Thesen werden in den Kontinuitätsargumenten nicht explizit genannt und entsprechend auch keine expliziten Rechtfertigungsgründe für sie; es wird aber skizziert, wie für solche konkreten realistischen Thesen Rechtfertigungsgründe bzw. Argumente zu formulieren sind. Um eine realistische Position mit Hilfe von Kontinuitätsargumenten zu etablieren, reicht es nicht, ein einziges, abstrakt formuliertes Argument vorzubringen, sondern man wird eine Vielzahl von Argumenten ins Spiel bringen müssen, die sich auf verschiedene (einzeln oder kombiniert eingesetzte) epistemische Verfahren mit begrenzten, vielfach stückweise "überlappenden" Anwendungsbereichen beziehen und die jeweils nur eine begrenzte Menge realistischer Thesen zu rechtfertigen gestatten.

\subsubsection{Probleme und Einwände}

Zunächst läßt sich an alle diskutierten epistemischen Kontinuitätsargumente die Frage richten, ob und inwieweit sie bzw. die involvierten Begriffe, Thesen etc. wirklich in zufriedenstellender Weise erläutert sind oder werden können. So kann man fragen, ob die dort genannten epistemischen Verfahren "hinreichend wohldefiniert" sind (insbesondere, wenn man Erläuterungen der Form (EV), (ÜV), (VeEV) und (VeÜV) im Auge hat ${ }^{88}$ ), was genau als verläßlich zählt, was als Erklärung, als Kausalzusammenhang usw. Die damit angedeuteten Probleme sollen an dieser Stelle aber nicht diskutiert werden, da der aus antirealistischer Sicht zentrale Einwand unabhängig von solchen Details ist. In konkreten Fällen wie den genannten ist es häufig intuitiv klar, wie die entscheidenden Begriffe und Thesen zu verstehen sind, und ihre Anwendung ist damit auch ohne genauere Erläuterungen unkontrovers.

Es bleiben sicherlich in vielen Fällen Erläuterungsaufgaben für die Zukunft, dies gilt aber, wie oben erwähnt, generell für reliabilistische Ansätze in der Erkenntnistheorie und betrifft nicht nur und nicht in besonderer Weise den in der wissenschaftstheoretischen Realismusdebatte im Blickpunkt stehenden Bereich des Unbeobachtbaren. Die oben angegebenen bzw. zitierten groben, vorläufigen Beschreibungen der in den Kontinuitätsargumenten involvierten epistemischen Verfahren deuten darauf hin, daß auch zukünftig zu gewinnende präzisere Beschreibungen und Erläuterungen mit einiger Wahrscheinlichkeit nicht auf "einfache" Beschreibungen führen werden, die die epistemischen Verfahren und ihre Anwendungsbedingungen, Verläßlichkeitsbereiche etc. durch einige wenige einzeln notwendige und zusammen hinreichende, von speziellen Kontexten unabhängige etc. Bedingungen charakterisieren, wie man sie im Fall deduktiver Inferenzschemata zur Verfügung hat, deren "ordentliche", formal "saubere" Gestalt in der Wissenschaftstheorie häufig als

\footnotetext{
${ }^{88}$ Dort wird die Spezifikation eines Feldes $F$ von Propositionen, von Bedingungen $B$ usw. gefordert.
} 
eine Art Ideal fungiert. Dies ist jedoch kein grundsätzliche Mangel der epistemischen Verfahren, wie man sich leicht daran deutlich machen kann, daß das Beobachten mit dem bloßen Auge und seine Anwendungs- und Verläßlichkeitsbedingungen offenbar ebenfalls nicht in einer solchen "einfachen", "ordentlichen" Weise charakterisierbar sind. Für das, was als Ergebnis zukünftiger präziserer Beschreibungen und Erläuterungen epistemischer Verfahren zu erwarten ist, dürfte das Beobachten mit dem bloßen Auge einen plausibleren Orientierungspunkt darstellen als deduktive Inferenzschemata.

\section{Lassen sich epistemische Verfahren, die einen begrenzten Anwendungsbereich haben und nicht unfehlbar sind, in der Argumentation für wissenschaftlichen Realismus einsetzen?}

Ein Einwand gegen die Kontinuitätsargumente betrifft die Frage, wie groß der Anwendungsbereich eines epistemischen Verfahrens sein muß oder sein darf und wie verläßlich es in diesem Bereich sein muß, wenn es dazu taugen soll, ein Argument für wissenschaftlichen Realismus zu gewinnen. Van Fraassen wendet gegen Salmons Kontinuitätsargument, das sich auf das Prinzip der gemeinsamen Ursache stützt, ein, daß dies genaugenommen kein Argument für eine realistische Position darstelle:

"As long as there is no universal demand for a common cause for every pervasive regularity or correlation, there is no argument for realism here. There is only an explanation of why it is satisfying to the mind to postulate explanatory, if unobservable, mechanisms when we can. There is no argument in that the premisses do not compel the realist conclusion." 89

"[...] weakening the principle [...] is an agreement to leave some sorts of "cosmic coincidence" unexplained. But that is to admit the tenability of the nominalist/empiricist point of view, for the demand for explanation ceases then to be a scientific 'categorial imperative'." 90

Welches genau der Punkt ist, auf den van Fraassen zielt, wird nicht wirklich deutlich, aber sein Einwand läuft in allen naheliegenden Lesarten darauf hinaus, etwas vorauszusetzen, was unplausibel aussieht und jedenfalls zu begründen wäre.

Klar ist zunächst, daß die Anwendung des Prinzips der gemeinsamen Ursache kein deduktives Inferenzverfahren ist, also in diesem Sinn keine "zwingenden" Argumente liefert. Ebenso klar ist jedoch auch, daß ein epistemisches Verfahren bzw. ein Argument nicht schon deswegen untauglich oder illegitim ist, weil es in diesem Sinn nicht "zwingend" ist. Da auch van Fraassen dies anerkennt, ist anzunehmen, daß sein Einwand auf einen anderen Punkt zielt.

Zwei Lesarten liegen nahe für van Fraassens Befund, daß das Prinzip der gemeinsamen Ursache für Argumentationszwecke unbrauchbar wird durch die Tatsache, daß es "keine universelle Nachfrage nach einer gemeinsamen Ursache für jede weitverbreitete Regelmäßigkeit oder Korrelation" gibt: Zum einen könnte das daran liegen, daß das Prinzip "nur" in einem begrenzten Anwendungsbereich verläßlich ist, nicht universell. Zum anderen könnte der Grund sein, daß das Prinzip in dem Bereich, in dem es verläßlich ist (egal ob dieser beschränkt ist oder nicht), nicht unfehlbar ist, sondern eben nur verläßlich,

\footnotetext{
${ }^{89}[$ vFra80], S.217 Fn.14.

90 [vFra80], S.30/31
} 
d.h. nicht ausnahmslos wahre Konklusionen liefert, sondern "nur" mit hoher Wahrscheinlichkeit. In beiden Lesarten überzeugt der Einwand nicht, denn er scheint im einen Fall vorauszusetzen, daß epistemische Verfahren mit begrenztem, "lokalem" Verläßlichkeitsbereich für Begründungs- und Argumentationszwecke wertlos sind, im anderen Fall, daß dies für fehlbare Verfahren gilt. Beide Annahmen sind offenbar völlig unplausibel, wie man schon daran erkennt, daß das sicherlich wichtigste epistemische Verfahren, das Beobachten mit bloßem Auge, nicht unter allen Umständen verläßlich ist, sondern nur unter "Normalbedingungen" (geeignete Beleuchtung, keine Konstellationen, die optische Täuschungen produzieren, usw.), und auch dort eben "nur" verläßlich, nicht unfehlbar.

Im Zusammenhang mit der Abgrenzung des Verläßlichkeitsbereichs eines epistemischen Verfahrens liegt sozusagen eher in der entgegengesetzten Richtung ein Problem: Wenn man etwa ein Inferenzprinzip wie Salmons Prinzip der gemeinsamen Ursache zu global und kontextunabhängig formuliert, sieht man sich schnell mit Gegenbeispielen konfrontiert. ${ }^{91}$ Wie solche Gegenbeispiele zu bewerten sind (als einzelne Ausnahmen oder als Indikatoren für systematisches Versagen), ist bei einer globalen Formulierung kaum abzuschätzen. Der problematische Punkt der epistemischen Kontinuitätsargumente ist demnach eher, für die involvierten epistemischen Verfahren präzise einen begrenzten und für die Zwecke realistischer Argumentation interessanten Anwendungsbereich zu spezifizieren, in dem sie als verläßlich etabliert werden können. Daß sich universell gültige und unfehlbare Verfahren aufweisen lassen, ist offenbar nicht zu erwarten, aber das entwertet die Idee der Kontinuitätsargumente keineswegs.

\section{Der fundamentale antirealistische Einwand gegen induktive, induktiv extrapo- lierende und andere Begründungen für Verläßlichkeitsaussagen für epistemi- sche Verfahren jenseits der Grenze beobachtbar/unbeobachtbar}

Die diskutierten epistemischen Kontinuitätsargumente weisen alle auf epistemische Verfahren hin, die (auch) Überzeugungen über Unbeobachtbares liefern. Die Annahme, daß das jeweilige Verfahren (auch) jenseits der Grenze beobachtbar/unbeobachtbar verläßlich ist, wird entweder als intuitiv plausibel präsentiert, oder es wird eine induktive oder induktiv extrapolierende Begründung dafür zumindest skizziert. In beiden Fällen wird ein Antirealist widersprechen: Daß es intuitiv plausibel sei, daß ein epistemisches Verfahren (etwa das Beobachten mit der Lupe) (auch) jenseits der Grenze beobachtbar/unbeobachtbar verläßlich ist, wird er bestreiten, eine entsprechende vortheoretische Intuition wird er nicht teilen. Die angegebenen Begründungen und Begründungsskizzen für entsprechende Verläßlichkeitsaussagen wird er allesamt als nicht überzeugend zurückweisen, und zwar alle aus im wesentlichen demselben Grund.

Der fundamentale antirealistische Einwand gegen jede Begründung, die für eine Verläßlichkeitsaussage bezüglich eines epistemischen Verfahrens "im Unbeobachtbaren" angeboten wird, ist unabhängig von sämtlichen Unterschieden zwischen den diversen epistemi-

\footnotetext{
${ }^{91}$ Für Salmons Prinzip finden sich keineswegs nur im Bereich der Quantenmechanik Fälle, die zumindest prima facie problematisch sind. In der makroskopischen Welt finden sich reichlich Beispiele für Korrelationen, die nicht auf eine gemeinsame Ursache plus Kausalprozesse (in irgendeinem interessanten Sinn, d.h. solche Ursachen wie den Urknall ausgeschlossen) zurückgeführt werden, etwa die Korrelation zwischen dem jahrzehntelangen Anstieg des Meeresspiegels in Venedig und dem Anstieg der Brotpreise in England ([Sobe88], S.214f.) oder die Korrelation zwischen Größe und Form eines Baseballs und dem SpaltmaterialKern von Atombomben ([DeLi97], S.172). Die Frage, ob diese Prima-facie-Gegenbeispiele gegen das Prinzip der gemeinsamen Ursache tatsächlich Gegenbeispiele sind, führt jedoch auf technische Probleme, die mit der angemessenen Spezifikation von statistischen Gesamtheiten und relevanten Variablen zusammenhängen und zu komplex sind, um hier diskutiert zu werden; siehe dazu u.a. [SpGS93], Kap.3, bes. S.57ff.
} 
schen Verfahren und auch von den Einzelheiten der Begründungen, die für entsprechende Verläßlichkeitsaussagen angeboten werden. Dieser Einwand richtet sich gegen alle derartigen Begründungen für Verläßlichkeitsaussagen, gegen die oben skizzierten induktiven und induktiv extrapolierenden Begründungen, aber auch gegen andere denkbare Begründungen, die sich von diesen mehr oder weniger unterscheiden können, etwa deduktive. Z.B. kann eine Verläßlichkeitsaussage für das Beobachten mit der Lupe deduktiv aus einer Theorie der Optik bzw. einem theoretischen Modell der Lupe erschlossen werden (die Begründung der Verläßlichkeitsaussage hängt damit von Voraussetzungen ab, die evtl. ihrerseits begründet werden müssen), eine solche Verläßlichkeitsaussage für die Lupe kann aber auch, wie von Salmon skizziert, ohne Rekurs auf Theorien oder Modelle durch einen Induktionsschluß bzw. induktive Extrapolation begründet werden. Der fundamentale antirealistische Einwand gegen jede Begründung einer Verläßlichkeitsaussage für ein konkretes Verfahren für einen Bereich jenseits der Grenze beobachtbar/unbeobachtbar ist, daß jede derartige Begründung, wenn man sie im entscheidenden Punkt explizit und präzise formuliert, etwas voraussetzt, was nach Ansicht der antirealistischen Seite nicht vorausgesetzt werden darf, sondern selbst zu begründen wäre, aber nicht überzeugend begründet werden kann.

Das, was vorausgesetzt wird, aber nach antirealistischer Ansicht nicht vorausgesetzt werden darf, kann eine inhaltliche Prämisse sein oder ein Inferenzschema; was es ist, muß im konkreten Einzelfall aufgewiesen werden. Z.B. ist eine deduktive Begründung einer Verläßlichkeitsaussage für die Lupe durch die Gesetze der Optik nach antirealistischer Ansicht allenfalls für den Bereich des Beobachtbaren akzeptabel, denn von diesen Gesetzen selbst darf höchstens der Teil als Prämisse eingesetzt werden, der von beobachtbaren Dingen und Sachverhalten handelt. Diese Gesetze als ganze, d.h. als auch im Bereich des Unbeobachtbaren gültig vorauszusetzen hieße, eine nach antirealistischen Standards unzulässige inhaltliche Prämisse in Anspruch zu nehmen. Eine induktive oder induktiv extrapolierende Begründung einer Verläßlichkeitsaussage für die Lupe ist nach antirealistischer Ansicht ebenfalls höchstens für den Bereich des Beobachtbaren akzeptabel, denn jede Begründung, die von da aus (in irgendeiner Weise) induktiv oder induktiv extrapolierend auf die Verläßlichkeit der Lupe auch über die Grenzen des Beobachtbaren hinaus schließt, folgt einem grenzüberschreitenden induktiven oder induktiv extrapolierenden Inferenzschema, das nach antirealistischer Ansicht nicht vorausgesetzt werden darf (egal welche Gestalt es im einzelnen hat). Ein solches Inferenzschema darf nach antirealistischer Ansicht nicht vorausgesetzt werden, weil man dazu annehmen müßte, daß es jenseits der Grenze beobachtbar/unbeobachtbar verläßlich ist; eine solche Verläßlichkeitsannahme ist aber aus antirealistischer Sicht unzulässig. Aus diesem Grund läßt sich auch für kausale oder andere Inferenzschemata wie die oben genannten nach antirealistischer Ansicht eine Verläßlichkeitsannahme allenfalls im Bereich des Beobachtbaren begründen, nicht auch für einen Bereich jenseits der Grenze beobachtbar/unbeobachtbar, denn jeder induktive oder induktiv extrapolierende Schluß von der Verläßlichkeit eines Inferenzschemas im Beobachtbaren auf seine Verläßlichkeit auch über die Grenzen des Beobachtbaren hinaus folgt selbst einem induktiven Inferenzschema und muß dessen Verläßlichkeit voraussetzen, was nach antirealistischer Ansicht nicht akzeptabel ist. ${ }^{92}$

Mit einer Begründung auf dieser Linie kann ein Antirealist jedes epistemische Kontinuitätsargument zurückweisen. Daß Beobachten mit Hilfe einer Lupe ein verläßliches epistemisches Verfahren ist, läßt sich nach antirealistischen Standards nur für den Be-

\footnotetext{
${ }^{92}$ Auf dieser Linie argumentiert van Fraassen in [vFra85], S.256ff.
} 
reich der Dinge und Eigenschaften zeigen, die auch ohne Lupe erkennbar sind. Entsprechend läßt sich eine Verläßlichkeitsannahme für ein kausales oder sonstiges Inferenzschema nach antirealistischen Standards allenfalls für den Bereich des Beobachtbaren begründen. Aussagen über die Verläßlichkeit (oder Unzuverlässigkeit) eines epistemischen Verfahrens jenseits der Grenze beobachtbar/unbeobachtbar lassen sich nach antirealistischer Ansicht nicht rechtfertigen. Es mag danach grenzüberschreitende epistemische Verfahren geben, aber der Status ihres Outputs hinsichtlich seiner Rechtfertigung ist auf beiden Seiten der Grenze beobachtbar/unbeobachtbar verschieden. Daher wird von antirealistischer Seite auch die Strategie der epistemischen Kontinuitätsargumente zurückgewiesen, durch eine Verläßlichkeitsannahme in bezug auf grenzüberschreitende epistemische Verfahren die Aussagen über Unbeobachtbares (sprich: die realistischen Thesen) zu begründen, die als Output der Verfahren gewonnen werden.

Diese antirealistische Argumentationslinie orientiert sich an der empiristischen Grundüberzeugung, daß Beobachtbarkeit das alleinige und ausschlaggebende Kriterium dafür ist, ob etwas im Zugriffsbereich menschlicher Erkenntnis liegt, ob man also gerechtfertigte Überzeugungen darüber haben kann. Eine explizite Formulierung dieser Grundüberzeugung gibt van Fraassen:

"[...] the core doctrine of empiricism is that experience is the sole source of information about the world and that its limits are very strict [...] I explicate the general limits as follows: experience can give us information only about what is both observable and actual." 93

Der antirealistische Einwand gegen die epistemischen Kontinuitätsargumente läuft also darauf hinaus, konsequent an dieser Grundüberzeugung festzuhalten. Ein konsequenter Antirealist wird nur Überzeugungen haben und Inferenzschemata akzeptieren, die mit dieser Grundüberzeugung verträglich sind, also Überzeugungen über Beobachtbares und Inferenzschemata, die daraus neue Überzeugungen nur über Beobachtbares erschließen, oder er wird jedenfalls, falls er auf Überzeugungen oder Inferenzschemata aufmerksam werden sollte, die mit der Grundüberzeugung konfligieren, diese Überzeugungen oder Inferenzschemata verwerfen (selbst wenn er damit mehr oder weniger große Teile einer etablierten epistemischen Praxis revidieren müßte). Einen "hinreichend konsequenten" Antirealisten dieser Art können epistemische Kontinuitätsargumente nicht umstimmen, da er die vortheoretischen Überzeugungen und induktiven bzw. induktiv extrapolierenden Inferenzschemata nicht akzeptiert, die die Kontinuitätsargumente voraussetzen. ${ }^{94}$

\footnotetext{
93 [vFra85], S.253, Sperrung im Original; s.a. S.257.

${ }^{94}$ Ein denkbarer Einwand an dieser Stelle ist, daß ein Antirealist nicht unbedingt die ihm hier zugeschriebene empiristische Grundüberzeugung haben muß, genauer: daß er nicht unbedingt deren "negativen Teil" teilen muß, der sagt, daß die "Erfahrung" nur über Beobachtbares Informationen liefert, also keine Informationen über (mit dem bloßen Auge) Unbeobachtbares. Stattdessen könnte er nur den "positiven Teil” dieser Grundüberzeugung haben oder auch gar keine Überzeugungen über menschliche Erkenntnismöglichkeiten und deren Grenzen, sondern einfach nur Überzeugungen erster Ordnung über Beobachtbares (vgl. dazu Abschnitt 10.2.4). Den induktiven Begründungen, die die Kontinuitätsargumente für die Verläßlichkeitsannahmen für epistemische Verfahren jenseits der Grenze beobachtbar/unbeobachtbar nennen, würde der Antirealist dann keine empiristische Grundüberzeugung entgegenhalten, sondern "nur" bemerken, daß ihn die Begründungen nicht überzeugen, weil er die für die Begründung in Anspruch genommenen Inferenzverfahren nicht für verläßlich hält, soweit sie etwas über Unbeobachtbares ergeben. Für die Plausibilität und Überzeugungskraft der antirealistischen Position macht dies keinen wesentlichen Unterschied; dazu s.u.
} 


\section{Epistemische Kontinuitätsargumente, der fundamentale antirealistische Ein- wand und die argumentative Konstellation in der Realismusdebatte}

An diesem Punkt der Diskussion wird man von realistischer Seite die Gegenfrage stellen, ob die antirealistische Seite mit ihrem fundamentalen Einwand Gründe vorbringt, die ihrerseits einen Realisten davon überzeugen können, seine diversen, den epistemischen Kontinuitätsargumenten zugrundeliegenden Überzeugungen über die Verläßlichkeit grenzüberschreitender epistemischer Verfahren ${ }^{95}$ aufzugeben. Man wird also von realistischer Seite die Frage stellen, ob der fundamentale antirealistische Einwand gegen die Kontinuitätsargumente ein überzeugungskräftiges Argument gegen realistische Thesen darstellt, die mit Hilfe der entsprechenden Verfahren gewonnen bzw. gerechtfertigt werden. Die Antwort scheint zu sein, daß das einzige, was den realistischen Überzeugungen damit von antirealistischer Seite entgegengehalten wird, die genannte empiristische Grundüberzeugung ist, genauer: deren "negativer Teil", der sagt daß die Erfahrung keine Informationen über Unbeobachtbares liefern kann. ${ }^{96}$ Da diese Grundüberzeugung natürlich von realistischer Seite nicht geteilt wird, wird ein Realist weiter nach einer Begründung dieser Grundüberzeugung, d.h. ihres negativen Teils, fragen. Eine solche Begründung findet sich bei den Anhängern des Antirealismus nicht.

Ohne eine solche Begründung hat die empiristische Grundüberzeugung und damit der antirealistische Einwand gegen die epistemischen Kontinuitätsargumente keine Plausibilität oder Überzeugungskraft für "konsequente Realisten", aber i.a. auch nicht für jemanden, der in der Realismusdebatte (noch) keine systematische Position bezogen hat, jedoch einige der den Kontinuitätsargumenten zugrundeliegenden Intuitionen teilt. Daß dies so ist, wird besonders deutlich, wenn man sich vor Augen führt, daß Antirealisten in ihrer epistemischen Praxis im allgemeinen ebenso auf epistemische Verfahren und diesbezügliche Verläßlichkeitsannahmen angewiesen sein dürften wie Realisten, und zwar auf epistemische Verfahren und Verläßlichkeitsannahmen "derselben Art" wie sie von realistischer Seite in den Kontinuitätsargumenten ins Spiel gebracht werden. Mit einem klaren Bild dieser Sachlage vor Augen wird deutlich, daß der fundamentale antirealistische Einwand gegen die epistemischen Kontinuitätsargumente niemanden dazu bringen dürfte, realistische Thesen oder vortheoretische Intuitionen der Art aufzugeben, auf die sich die Begründungen solcher Thesen und entsprechend die Kontinuitätsargumente stützen.

Dafür, daß auch Antirealisten in ihrer epistemischen Praxis nicht ohne Annahmen über die Verläßlichkeit epistemischer Verfahren und Rechtfertigungsgründe dafür auskommen, spricht Verschiedenes. So kann man fragen, wie tatsächlich gemachte Beobachtungen in der Praxis hinsichtlich ihres epistemischen Status beurteilt werden. Sofern man Beobachtungen nicht den Status eines sicheren, unhintergehbaren Fundamentes allen Wissens zuschreiben will (und das will etwa van Fraassen $n i c h t^{97}$ ), wird man dazu Annahmen über die Verläßlichkeit ihrer Gewinnung (in bestimmten Bereichen, unter bestimmten Be-

\footnotetext{
${ }^{95}$ Verläßlichkeitsüberzeugungen, die direkt die in den Kontinuitätsargumenten genannten Verfahren (Beobachten mit der Lupe, Schließen auf die beste Erklärung etc.) betreffen, oder Verläßlichkeitsüberzeugungen bezüglich der induktiven bzw. induktiv extrapolierenden Verfahren, die Begründungen für die ersteren Verläßlichkeitsaussagen liefern.

96 "[...] experience can give us information only about what is [...] observable"; Hervorhebung von mir. Der "positive Teil" ist, daß die Erfahrung Informationen über Beobachtbares liefern kann.

Die antirealistische Seite kann natürlich außerdem auf spezielle Probleme mit der Verläßlichkeit bestimmter epistemischer Verfahren hinweisen, die hier beiseite bleiben. Auf diese Weise lassen sich evtl. einzelne Verläßlichkeitsüberzeugungen (und damit Begründungen realistischer Thesen über Unbeobachtbares) widerlegen, aber kaum alle.

${ }^{97}$ [vFra80], S.72, [vFra92].
} 
obachtungsbedingungen usw.) benötigen, die zumindest für Grenzbereiche der Wahrnehmungsfähigkeit ${ }^{98}$ nicht "selbstverständlich" oder unkontrovers sind und in irgendeiner Weise begründet werden müssen (sei es durch einen induktiven oder induktiv extrapolierenden Schluß auf der Grundlage von vergangenen Beobachtungen, sei es deduktiv durch Theorien des menschlichen kognitiven Apparates ${ }^{99}$, die dann ihrerseits begründet werden müssen, z.B. per Schluß auf die beste Erklärung). Zumindest in solchen Grenzbereichen dürften in der Praxis auch für Antirealisten Annahmen über die Verläßlichkeit des Beobachtens mit dem bloßen Auge und die Frage nach der Rechtfertigung von Verläßlichkeitsüberzeugungen nicht zu umgehen sein.

Wichtiger als solche Fälle, die Grenzbereiche der Wahrnehmung betreffen, ist für die epistemische Praxis die Frage nach der Rechtfertigung von Überzeugungen über Beobachbares, für die tatsächlich keine Beobachtung mit dem unbewaffneten Auge vorliegt. Ein Antirealist wird in der Praxis im Bereich des Beobachtbaren nicht ohne epistemische Verfahren von der Art der in den Kontinuitätsargumenten genannten auskommen und dazu auch deren Verläßlichkeit bewerten und dann gegebenenfalls bei der nächsten Anwendung voraussetzen müssen; jedenfalls wird er dies tun müssen, insofern er Überzeugungen hat und haben will, die sich auf Beobachtbares, aber tatsächlich nicht mit dem bloßen Auge Beobachtetes beziehen. An dem von Salmon genannten Beispiel des Fernrohres läßt sich dies klar erkennen: Das epistemische Verfahren des Beobachtens mit einem Teleskop sollte auch nach antirealistischen Standards als verläßliches Verfahren gelten, denn man kann seine Verläßlichkeit etwa im Fall von Kirchtürmen, Kühen, Schiffen u.ä. durch Augenschein überprüfen. Ein Antirealist wird sich auf die Verläßlichkeit des Teleskops verlassen müssen, wenn er sich, auf Beobachtung mit dem Teleskop gestützt, beobachtbare Objekte betreffende Überzeugungen bildet und das Teleskopbild in diesen Einzelfällen nicht per Augenschein überprüft. ${ }^{100}$ Ebenso wird ein Antirealist i.a. auch Überzeugungen bezüglich beobachtbarer Sachverhalte haben, die er tatsächlich nicht selbst beobachtet, sondern aufgrund von Inferenzverfahren wie den genannten erschlossen hat (z.B. Salmons Professor über seine Studenten Adams und Baker), und zur Begründung dieser Überzeugungen wird er sich auf die Verläßlichkeit dieser Verfahren berufen müssen. Um solche Verläßlichkeitsüberzeugungen ihrerseits zu rechtfertigen, wird er sich in irgendeiner Form auf Induktionsschlüsse, induktive Extrapolationen o.ä. stützen müssen. Auf Verläßlichkeitsannahmen hinsichtlich bestimmter epistemischer Verfahren und deren Begründung dürften in der Praxis also nicht nur Realisten und speziell Reliabilisten angewiesen sein, sondern ebenso Antirealisten, sofern sie nicht bereit sind, den radikalen Schritt zu gehen, nicht nur auf Überzeugungen über Unbeobachtbares zu verzichten, sondern auch auf Überzeugungen über Beobachtbares, aber tatsächlich nicht mit dem bloßen Auge Beobachtetes, oder zumindest auf Rechtfertigungsgründe für solche Überzeugungen. ${ }^{101}$ Wie ein Antirealist seine Überzeugungen rechtfertigt, hängt im einzelnen davon ab, welche erkenntnistheoretische

\footnotetext{
${ }^{98}$ Etwa wenn es um Beobachtung bei hohen Geschwindigkeiten, unter den Bedingungen der Schwerelosigkeit im Weltraum oder nach langen Phasen des Mangels an visuellen Reizen (in Isolationssituationen, eingeschlossen in einer dunklen Höhle, in der Wüste o.ä.) geht.

${ }^{99}$ Oder evtl. durch die (für Antirealisten eher akzeptable) Aussage, daß diese Theorien empirisch adäquat sind.

${ }^{100}$ Und letzteres wird er i.a. nicht tun, wenn die Benutzung eines Teleskops eine Pointe haben soll.

${ }^{101}$ Van Fraassen scheint dies an einer Stelle anzuerkennen; vgl. [vFra80], S.72. Die von van Fraassen an anderer Stelle (z.B. [vFra85], S.294f.) betonten Ansichten, daß es keine zufriedenstellende induktive Logik gibt und daß das Schließen auf die beste Erklärung kein akzeptables Inferenzschema ist, widersprechen dem obigen Punkt nicht, vielmehr verdeutlicht dieser Punkt, welchen hohen Preis es für die epistemische Praxis hat, wenn man van Fraassens Ansichten folgt und daraus die Konsequenz zieht, auf die Anwendung aller nur grob und vorläufig charakterisierbaren und nicht völlig verläßlichen Inferenzverfahren zu verzichten.
} 
Position er vertritt, welche Konzeption von Wissen, Rechtfertigung etc. er also akzeptiert. In der Praxis dürften die Rechtfertigungsgründe, die er für Überzeugungen über Beobachtbares, jedoch nicht Beobachtetes angeben kann, aber stets von der skizzierten Art sein, wie auch immer diese im Rahmen einer systematischen erkenntnistheoretischen Position genau implementiert werden, denn es ist nicht zu sehen, welche davon verschiedene Art von Gründen ansonsten in Betracht kommt. ${ }^{102}$

Wenn man die skizzierten Rechtfertigungsgründe, die von antirealistischer Seite für Verläßlichkeitsannahmen "im Beobachtbaren" angegeben werden können, und die Begründungen, die in den Kontinuitätsargumenten für Verläßlichkeitsüberzeugungen in bezug auf grenzüberschreitende epistemische Verfahren skizziert werden, nebeneinander stellt, sieht man, daß im Fall eines grenzüberschreitenden Verfahrens (Beobachtung mit der Lupe, Schließen auf die beste Erklärung etc.) für die Annahme, daß dieses verläßlich ist, von realistischer und von antirealistischer Seite sozusagen bis zur Grenze beobachtbar/unbeobachtbar dieselben Begründungen gegeben werden. Beide Seiten können ihre jeweiligen Verläßlichkeitsüberzeugungen induktiv begründen, also indem sie von der Verläßlichkeit des Verfahrens in einer bestimmten Menge von (per Augenschein untersuchten) Fällen auf Verläßlichkeit in einem Bereich schließen, der diese Fälle einschließt. Beide können ihre Verläßlichkeitsüberzeugungen vielleicht auch deduktiv begründen, also durch eine Theorie des menschlichen Wahrnehmungsapparates ${ }^{103}$ etc., die dann ihrerseits induktiv o.ä. begründet werden muß. Beidesmal ist jedoch die Grenze des so begründeten Verläßlichkeitsbereichs zwischen beiden Seiten strittig: Die antirealistische Seite akzeptiert zwar einen induktiven Schritt von einigen per Augenschein untersuchten Fällen zu einer Verläßlichkeitsannahme für nicht per Augenschein untersuchte Fälle, nicht jedoch einen induktiven Schritt, der über die Grenze beobachtbar/unbeobachtbar hinausführt, wie ihn die realistische Seite im Falle der Kontinuitätsargumente geht. Entsprechend akzeptiert die antirealistische Seite eine deduktive Begründung für eine Verläßlichkeitsannahme nur bis zur Grenze beobachtbar/unbeobachtbar, denn sie akzeptiert von jedweder Theorie des menschlichen Wahrnehmungsapparates nur den Teil, der von Beobachtbarem handelt, und dies wiederum, weil sie jeden induktiven o.ä. Schritt, der eine solche Theorie begründen könnte, nur akzeptiert, sofern er nicht über die Grenze beobachtbar/unbeobachtbar hinausführt.

Der fundamentale Einwand der antirealistischen Seite gegen die Kontinuitätsargumente sieht vor dem Hintergrund dieser weitreichenden "Parallelen" zwischen den Rechtfertigungsgründen beider Seiten aus wie ein Insistieren darauf, daß die jeweils entscheidende Induktion an der Grenze beobachtbar/unbeobachtbar gleichsam abrupt abbricht, obwohl nicht $\mathrm{zu}$ sehen ist, daß diese Grenze in epistemischer Hinsicht durch irgendetwas ausgezeichnet wäre ${ }^{104}$. Die Auffassung der antirealistischen Seite, daß die Grenze beobachtbar/unbeobachtbar eine prinzipielle Grenze für gerechtfertigte Überzeugungen ist, erscheint aus realistischer Perspektive willkürlich, denn es liegen sozusagen auf beiden Seiten dieser Grenzlinie zwischen Beobachtbarem und Unbeobachtbarem Überzeugungen, deren Wahrheit nicht durch tatsächliche Beobachtung mit dem bloßen Auge gesichert ist, die aber in derselben Weise durch die Verläßlichkeit des Verfahrens ihrer Gewinnung gerechtfertigt werden können. Insbesondere bei grenzüberschreitenden epistemischen Verfahren wie dem

\footnotetext{
${ }^{102}$ Der antirealistischen Seite wird also nicht etwa eine reliabilistische Konzeption von Wissen und Rechtfertigung untergeschoben. Rechtfertigungsgründe der skizzierten Art lassen sich sozusagen in natürlicher Weise in eine reliabilistische Position integrieren, sie lassen sich aber auch mit anderen erkenntnistheoretischen Positionen kombinieren (wenn auch nicht mit allen).

${ }^{103}$ Bzw. durch die (für Antirealisten eher akzeptable) Aussage, daß eine solche Theorie empirisch adäquat ist.

${ }^{104}$ Von der ihrerseits nicht begründeten empiristischen Grundüberzeugung abgesehen.
} 
Beobachten per Lupe sieht es aus realistischer Perspektive so aus, als ob der Antirealist mit dem Schritt zur Überzeugung, daß das Verfahren für tatsächlich nicht mit dem bloßen Auge beobachtete (aber beobachtbare) Fälle verläßlich ist, gleichsam eine schiefe Ebene betreten hat, auf der er nicht mehr an der Grenze des Beobachtbaren zum Stehen kommt. 105

Der Eindruck einer willkürlichen Grenzziehung könnte beseitigt werden durch eine Begründung der empiristischen Grundüberzeugung, daß Beobachtbarkeit das alleinige Kriterium dafür ist, ob etwas in der Reichweite menschlicher Erkenntnis liegt. Dies könnte geschehen, indem eine Begründung des "negativen Teils" dieser Grundüberzeugung, der allein für das abrupte Abbrechen aller induktiven Schlüsse an der Grenze beobachtbar/unbeobachtbar verantwortlich ist, zeigt und verständlich macht, daß und warum epistemische Verfahren im Bereich des Unbeobachtbaren weniger verläßlich sind oder sein müssen als im Bereich des Beobachtbaren, aber tatsächlich nicht mit dem bloßen Auge Beobachteten. Etwas polemisch zugespitzt: Es müßte von antirealistischer Seite nicht nur behauptet, sondern begründet und damit verständlich gemacht werden, daß es für die Verläßlichkeit sowohl eines induktiven Inferenzschemas, das zur Bewertung anderer epistemischer Verfahren eingesetzt wird, als auch eines dadurch bewerteten Beobachtungsverfahrens, Inferenzprinzips o.ä. einen Unterschied macht, ob die beobachteten bzw. erschlossenen Sachverhalte aus "prinzipiellen" Gründen (Beispiele: Verläßlichkeit der Lupe "im Unbeobachtbaren", Zellstrukturen) oder aus "kontingenten" Gründen (Beispiele: Verläßlichkeit des Teleskops bei der Beobachtung ferner Galaxien, Planeten von anderen Sternen) niemals mit unbewaffnetem Auge beobachtet wurden und werden. Aus realistischer Perspektive ist nicht ersichtlich, welche epistemische Relevanz die Qualifikationen "prinzipiell" und "kontingent" hier haben sollten. Für Salmons Beispiel der Lupe hieße das: Es müßte von antirealistischer Seite begründet und damit verständlich gemacht werden, warum man sich auf die Lupe verlassen darf, wenn man damit einen auch mit bloßem Auge lesbaren Text liest, ohne das mit der Lupe gelesene per Augenschein zu prüfen, nicht aber, wenn man damit etwas beobachtet, was man ohne Lupe nicht erkennen kann, und ebenso, warum man sich auf einen induktiven Schluß verlassen darf, der von einigen per Augenschein überprüften Fällen, in denen die Lupe beobachtbare Gegenstände korrekt abgebildet hat, zur Überzeugung führt, daß die Lupe exakt bis zur Grenze beobachtbar/unbeobachtbar verläßlich abbildet, nicht aber auf einen entsprechenden induktiven Schluß, der zu einer weiterreichenden Verläßlichkeitsannahme führt. Eine Begründung der empiristischen Grundüberzeugung, die dies leistet, findet sich bei den Anhängern des Antirealismus nicht, und damit auch nichts, was jemanden, der die Überzeugungen bzw. vortheoretischen Intuitionen teilt, an die die epistemischen Kontinuitätsargumente appellieren, davon überzeugen könnte, diese eigenen Überzeugungen bzw. Intuitionen aufzugeben. Das gilt für Realisten ebenso wie für jeden, der solche Überzeugungen bzw. Intuitionen teilt, ohne eine systematische Position in der Realismusdebatte zu haben. ${ }^{106}$

\footnotetext{
${ }^{105}$ Für Argumente auf dieser Linie vgl. z.B. [Chur85], S.38ff., [Frie82], S.279f., [Krug83], S.578ff., [Lipt91], S.176, [Musg85], S.199f., 206, [Worr84], S.69.

${ }^{106}$ An dieser Stelle könnte man daran denken, eine Begründung der empiristischen Grundüberzeugung auf das von antirealistischer Seite häufig genannte Problem der Unterbestimmtheit zu stützen. Diese Idee führt jedoch nicht weiter. Unter Unterbestimmtheit wird allgemein die These verstanden, daß auch sämtliche möglichen Beobachtungen nicht erlauben, auf eine eindeutig ausgezeichnete Theorie zu schließen. Diese These ist, wenn überhaupt, dann für die induktiven usw. Inferenzen im Beobachtbaren, die die antirealistische Seite akzeptiert, ebenso bedrohlich wie für die "gleichartigen" Inferenzen, die über die Grenze beobachtbar/unbeobachtbar hinausführen. Um die empiristische Grundüberzeugung plausibel zu machen, müßte begründet und damit verständlich gemacht werden, daß es für die "Bedrohlichkeit" der Unterbe-
} 
Der zentrale antirealistische Einwand gegen die epistemischen Kontinuitätsargumente erlaubt es also der antirealistischen Seite, die Kontinuitätsargumente zurückzuweisen, d.h. er zeigt, daß und warum diese Argumente "hinreichend konsequente" Antirealisten nicht von realistischen Thesen überzeugen können; gleichzeitig enthält dieser Einwand aber auch nichts, was irgendjemanden, der nicht bereits die empiristische Grundüberzeugung teilt, davon überzeugen könnte, daß die Überzeugungen und vortheoretischen Intuitionen falsch sind, auf die sich die Kontinuitätsargumente stützen.

Dieser Befund scheint prima facie darauf hinauszulaufen, daß die diskutierten epistemischen Kontinuitätsargumente wertlos sind. Sie entwickeln gegen konsequente Antirealisten keine Überzeugungskraft, und genau darum scheint es der realistischen Seite in der Realismusdebatte zu gehen; das darüber hinausgehende Resultat der obigen Überlegungen, daß die Einwände der antirealistischen Seite die realistischen Überzeugungen und Intuitionen unangetastet lassen, sieht auf den ersten Blick irrelevant aus. Bei genauerem Hinsehen erscheint die Sachlage jedoch in einem etwas anderen Licht, wenn man erstens auf die Rolle achtet, die der Grenze beobachtbar/unbeobachtbar bei der Argumentation der beiden Seiten zukommt, und wenn man zweitens die Argumentationsstrategie, die die antirealistische Seite mit dem fundamentalen Einwand verfolgt, mit etwas Abstand betrachtet.

Wenn man auf die Rolle achtet, die die Grenze beobachtbar/unbeobachtbar spielt, sieht man, daß sich in der Position der antirealistischen Seite die Grenze beobachtbar/unbeobachtbar sozusagen durch eine Vielzahl, wenn nicht beliebig viele andere Grenzen ersetzen läßt, ohne daß sich an der argumentativen Konstellation etwas Wesentliches ändert: An die Stelle der empiristischen Grundüberzeugung, die Beobachtbarkeit mit dem bloßen Auge zum entscheidenden Kriterium dafür macht, ob etwas epistemisch zugänglich ist, könnte man analoge Grundüberzeugungen setzen, die "bizarre" Kriterien für epistemische Zugänglichkeit enthalten, also die Grenze beobachtbar/unbeobachtbar durch eine "bizarre" Grenze ersetzen, etwa die Grenze zwischen Gegenständen, Sachverhalten usw., die aus mindestens 10 Meter Entfernung (mit dem bloßen Auge) beobachtbar sind, und solchen, die das nicht sind, oder der Grenze zwischen Dingen, die bei Beleuchtung mit monochrom blauem Licht (mit dem bloßen Auge) beobachtbar sind, und solchen, die es nicht sind, oder Dingen, die (mit dem bloßen Auge) beobachtbar und leichter als 500kg sind, und solchen, die dies nicht sind. ${ }^{107}$ Solche bizarren antirealistischen Positionen könnte man in derselben Weise "konsequent" entwickeln wie die oben diskutierte "normale" antirealistische Position, d.h., ein "hinreichend konsequenter" bizarrer Antirealist könnte nur Überzeugungen über Gegenstände, Sachverhalte usw. haben, die aus mindestens 10 Meter Entfernung beobachtbar sind, die beobachtbar und leichter als $500 \mathrm{~kg}$ sind etc., und alle über die jeweilige bizarre Grenze hinausgehenden Überzeugungen zurückweisen, und für alle induktiven, induktiv extrapolierenden o.ä. Inferenzschemata und sonstigen epistemischen Verfahren, die Überzeugungen über Gegenstände, Sachverhalte etc. jenseits der jeweiligen bizarren Grenze liefern, ihre Verläßlichkeit jenseits der Grenze als epistemisch unzugänglich einstufen und daher jede Anwendung der Verfahren in diesem Bereich als illegitim zurückweisen. Ein Realist könnte versuchen, den Antirealisten mit auf die jeweilige bizarre Grenze zugeschnittenen epistemischen Kontinuitätsargumenten zu überzeugen, also etwa für die Verläßlichkeit des Beobachtens mit dem bloßen Auge auch für Gegenstände von $500 \mathrm{~kg}$ Gewicht und darüber zu argumentieren, indem er einen induktiv extrapolierenden Schluß vorschlägt, der davon ausgeht, daß man Gegenstände von $10 \mathrm{~kg}$,

stimmtheitsproblematik einen Unterschied macht, ob Sachverhalte, über die man Überzeugungen hat, aus prinzipiellen oder aus kontingenten Gründen nicht mit bloßem Auge beobachtet werden.

${ }^{107}$ Das letzte Beispiel stammt aus [Chur85], S.41. 
$20 \mathrm{~kg}, 30 \mathrm{~kg} \ldots 490 \mathrm{~kg}, 500 \mathrm{~kg}$ verläßlich beobachten kann, also auch Gegenstände von $510 \mathrm{~kg}$ o.̈̈., und er könnte allgemein darauf hinweisen, daß der jeweiligen bizarren Grenze keinerlei erkennbare epistemische Relevanz zukommt und daß die bizarre antirealistische Grundüberzeugung willkürlich aussieht. Damit würde er jedoch nichts ausrichten gegen einen "hinreichend konsequenten" bizarren Antirealisten, der seine Position auf derselben Linie verteidigt wie oben im Fall der "normalen" Antirealisten erörtert. Die oben konstatierte Tatsache, daß epistemische Kontinuitätsargumente keine Überzeugungskraft gegen "hinreichend konsequente" Antirealisten haben, ist also offenbar unabhängig davon, wo von antirealistischer Seite die Grenze gezogen wird, die sie verteidigt.

Dieser Befund sieht nun prima facie wie ein verheerendes Resultat über den Wert der epistemischen Kontinuitätsargumente aus: Sie scheinen nicht nur keine Überzeugungskraft für "normale" Antirealisten zu besitzen, sondern noch nicht einmal für bizarre Antirealisten. Die Lage stellt sich aber anders dar, wenn man die beschriebene Argumentationsstrategie der antirealistischen Seite mit etwas Abstand betrachtet. Die oben beschriebene Strategie eines "hinreichend konsequenten" Antirealisten geht aus von einer Gesamtheit von Überzeugungen und akzeptierten epistemischen Verfahren, die Überzeugungen nur über Beobachtbares enthält, und als epistemische Verfahren nur Erzeugungsverfahren, die Überzeugungen über Beobachtbares liefern, und Übertragungsverfahren, die aus Prämissen über Beobachtbares nur Konklusionen über Beobachtbares liefern. Die Verteidigungsstrategie gegen die epistemischen Kontinuitätsargumente besteht, abstrakt beschrieben, darin, darauf hinzuweisen, daß jedes dieser Argumente mindestens eine Prämisse oder ein Inferenzverfahren in Anspruch nimmt, die bzw. das die antirealistische Seite nicht akzeptiert und die daher nicht für die Argumentation vorausgesetzt werden darf. Diese Verteidigungsstrategie ist also, in dieser Weise mit etwas Abstand betrachtet, offenbar nicht speziell auf epistemische Kontinuitätsargumente zugeschnitten, sondern viel allgemeiner anwendbar: Jedes Argument, das von realistischer Seite vorgebracht wird, muß Prämissen und mindestens ein Inferenzverfahren in Anspruch nehmen, nicht nur epistemische Kontinuitätsargumente. Wenn die antirealistische Seite erstens nur Überzeugungen über Beobachtbares hat, die als Prämissen in Anspruch genommen werden können, und zweitens nur Inferenzverfahren akzeptiert, die aus Prämissen über Beobachtbares nur Konklusionen über Beobachtbares liefern, dann ist die beschriebene Verteidigungsstrategie offenbar nicht nur gegen epistemische Kontinuitätsargumente erfolgreich, sondern gegen jedes Argument, das von realistischer Seite vorgebracht werden kann. Wenn dies tatsächlich so ist und wenn weiterhin, wie oben erläutert, gilt, daß die argumentative Konstellation zwischen Realisten und Antirealisten unabhängig davon ist, an welcher Stelle von antirealistischer Seite die strittige Grenze gezogen wird, dann erscheint der obige Befund, daß die epistemischen Kontinuitätsargumente für hinreichend konsequente Antirealisten keine Überzeugungskraft haben, in einem anderen Licht: Er scheint dann sozusagen nicht mehr oder jedenfalls nicht notwendigerweise auf eine spezielle Untauglichkeit oder spezielle Mängel epistemischer Kontinuitätsargumente hinzudeuten, sondern eher auf so etwas wie prinzipielle Grenzen dessen, was mit Argumenten gegen hinreichend konsequente Antirealisten auszurichten ist, und zwar auf Grenzen, die solchen antirealistischen Positionen kaum oder keinerlei Attraktivität oder Plausibilität zu verleihen scheinen, da für bizarre Positionen dieselben Grenzen bestehen.

Um zu einem Urteil zu gelangen, ob die argumentative Konstellation in der Debatte zwischen Realisten und Antirealisten tatsächlich so oder so ähnlich aussieht und die bei den epistemischen Kontinuitätsargumenten vorliegende Situation einen Spezialfall dieser allgemeinen argumentativen Konstellation darstellt, muß die antirealistische Position ge- 
nauer untersucht werden. Insbesondere muß untersucht werden, ob eine antirealistische Position tatsächlich in konsistenter Weise nur Überzeugungen über Beobachtbares und Inferenzverfahren, die aus Prämissen über Beobachtbares nur Konklusionen über Beobachtbares liefern, akzeptieren kann, denn es ist zumindest prima facie nicht klar, ob nicht schon deduktive Inferenzschemata zu unlösbaren Problemen führen. ${ }^{108}$ Vom Ergebnis dieser Untersuchungen wird letztlich auch die Bewertung der epistemischen Kontinuitätsargumente abhängen, denn wenn sich die antirealistische Position und damit die Verteidigungsstrategie als konsistent herausstellt, besteht die Möglichkeit, daß sich die bisher für die Realismusdebatte irrelevant oder jedenfalls nebensächlich aussehende "Eigenschaft" der Kontinuitätsargumente, sich zur Überzeugung von "nicht-konsequenten" Antirealisten und Personen, die noch keine Position bezogen haben, zu eignen, sozusagen als das beste erweist, was von einem Argument für wissenschaftlichen Realismus zu erwarten ist.

\subsection{Fazit}

In der wissenschaftstheoretischen Realismusdebatte sind von realistischer Seite eine Reihe von Argumenten und Argumentskizzen vorgebracht worden, die in verschiedener Weise die Idee entwickeln, daß zwischen dem Bereich des Beobachtbaren und dem Bereich des Theoretischen oder Unbeobachtbaren nicht etwa, wie von antirealistischer Seite angenommen, eine prinzipielle, philosophisch grundlegende Differenz besteht, sondern daß beide Bereiche in mehr oder weniger kontinuierlicher Weise ineinander übergehen. $\mathrm{Zu}$ diesen Kontinuitätsargumenten zählen einerseits "destruktive" Versuche, antirealistische Positionen zu untergraben, indem bestritten wird, daß die Unterscheidung beobachtbar/theoretisch eine für philosophische Zwecke brauchbare Grenzziehung ergibt, andererseits "positive" Argumente, die Gemeinsamkeiten oder graduelle oder kontinuierliche Übergänge zwischen dem Bereich des Beobachtbaren und dem Bereich des Unbeobachtbaren aufzuweisen versuchen, mit deren Hilfe sich realistische Thesen über Unbeobachtbares begründen lassen. $\mathrm{Zu}$ den "positiven" Kontinuitätsargumenten gehören zum einen die Argumente, die an vortheoretische Intuitionen auf der Sachebene appellieren und auf die "Merkwürdigkeit" des anthropozentrischen Weltbildes hinweisen, das sich aus antirealistischer Perspektive ergibt, zum anderen die epistemischen Kontinuitätsargumente. Die epistemischen Kontinuitätsargumente wurden hier vor dem Hintergrund einer reliabilistischen Position in der Erkenntnistheorie rekonstruiert, die eine im Beobachtbaren und im Unbeobachtbaren einheitliche Konzeption von Wissen und gerechtfertigter Überzeugung bereitstellt. Sie bestehen in dem Hinweis auf ein grenzüberschreitendes oder ganz im Unbeobachtbaren operierendes epistemisches Verfahren, für das eine Verläßlichkeitsaussage entweder als intuitiv plausibel präsentiert oder (skizzenhaft) induktiv o.ä. begründet wird, die ihrerseits zur Rechtfertigung der ontologischen oder epistemischen realistischen (Teil-)Thesen über Unbeobachtbares herangezogen werden kann, die man als Output des epistemischen Verfahrens gewinnt.

Die Bilanz dessen, was die Kontinuitätsargumente in der Realismusdebatte leisten, fällt im Hinblick auf das, was üblicherweise von Argumenten für wissenschaftlichen Realismus erwartet wird, im wesentlichen negativ aus. Es haben sich allerdings im Laufe der Diskussion einige Hinweise ergeben, die möglicherweise zu einem neuen Bild der gesamten argumentativen Konstellation in der Realismusdebatte und damit auch zu einer neuen Bewertung der Kontinuitätsargumente führen könnten. Zusammenfassend läßt sich das

\footnotetext{
${ }^{108}$ Diese Probleme werden in Kap.10.3.1 diskutiert.
} 
Folgende festhalten.

Die "destruktive" Argumentation gegen die Unterscheidung beobachtbar/unbeobachtbar ist nicht durchschlagend. Die Erläuterung der Unterscheidung ist, zumindest beim gegenwärtigen Stand der Debatte, sicherlich zu einem gewissen Grad unscharf und auch sonst nicht in jeder Hinsicht zufriedenstellend, aber die Unterscheidung ist deswegen nicht unbrauchbar und jedenfalls für antirealistische Zwecke ausreichend genau.

Die "positiven" Kontinuitätsargumente, die an vortheoretische Intuitionen auf der Sachebene appellieren, die den "merkwürdigen" anthropozentrischen Charakter antirealistischer Positionen illustrieren, haben keine Überzeugungskraft für Antirealisten, die die Intuitionen nicht teilen. Sie können jedoch möglicherweise dazu beitragen, jemanden von realistischen Thesen zu überzeugen, der noch keine systematisch entwickelte Position in der Realismusdebatte bezogen hat.

Die epistemischen Kontinuitätsargumente haben keine Überzeugungskraft für konsequente Antirealisten, die ihre Position auf der Linie des diskutierten fundamentalen antirealistischen Einwandes verteidigen, die also die Prämissen und/oder Inferenzschemata nicht akzeptieren, die die Kontinuitätsargumente voraussetzen müssen, oder jedenfalls strikt an der empiristischen Grundüberzeugung festhalten, daß Beobachtbarkeit mit dem bloßen Auge das alleinige Kriterium für epistemische Zugänglichkeit ist, und alle damit konfligierenden Überzeugungen zurückweisen. Auch die epistemischen Kontinuitätsargumente können aber immerhin dazu dienen, jemanden, der noch keine systematische realistische oder antirealistische Position einnimmt, von realistischen Thesen zu überzeugen.

Fazit ist also, daß sämtliche Kontinuitätsargumente sich nicht eignen, um hinreichend konsequente Antirealisten zu überzeugen, und damit in dieser, von vielen als zentral angesehenen Hinsicht in der Realismusdebatte nichts leisten, auch wenn die positiven, insbesondere die epistemischen Kontinuitätsargumente eventuell dazu beitragen können, "nichtkonsequente" Antirealisten und Personen ohne systematische Position von realistischen Thesen zu überzeugen.

Um zu beurteilen, ob diese Bilanz tatsächlich so negativ ist, wie sie aus realistischer Perspektive prima facie aussieht, sind weitergehende Untersuchungen der argumentativen Konstellation, in der sich Realisten und Antirealisten in der Realismusdebatte gegenüberstehen, erforderlich. Bei der Diskussion der antirealistischen Verteidigungsstrategie gegen die epistemischen Kontinuitätsargumente haben sich einige Beobachtungen ergeben, die diese Argumente in einem anderen Licht erscheinen lassen könnten: Die Befunde, daß die antirealistische Argumentation nichts enthält, was Realisten oder "noch unentschiedene" Personen davon überzeugen könnte, realistische Thesen und Intuitionen aufzugeben, daß weiterhin die antirealistische Verteidigungsstrategie gegen die epistemischen Kontinuitätsargumente auch dann erfolgreich wäre, wenn statt der Grenze beobachtbar/unbeobachtbar eine bizarre Grenze verteidigt würde, und schließlich, daß die Struktur der antirealistischen Verteidigungsstrategie auf die Möglichkeit hinzudeuten scheint, daß sie (auch zur Verteidigung einer bizarren Grenze) gegen jedes von realistischer Seite vorgebrachte Argument erfolgreich sein sollte, könnten einen Hinweis darauf darstellen, daß die "Erfolglosigkeit" der epistemischen Kontinuitätsargumente nichts mit speziellen Mängeln dieser Argumente zu tun hat, sondern eher mit so etwas wie prinzipiellen Grenzen für das, was sich mit Argumenten ausrichten läßt, um einen Diskussionsgegner mit einer "hinreichend verschiedenen" Position zu überzeugen. Wenn sich dieser Hinweis als richtig erweisen sollte, könnte dies eine veränderte Bewertung der epistemischen Kontinuitätsargumente und insbesondere ihrer Eignung zur Überzeugung von "nicht-konsequenten" Antirealisten und Personen ohne systematische Position nach sich ziehen. 
Die epistemischen Kontinuitätsargumente sind hier vor dem Hintergrund einer reliabilistischen Perspektive rekonstruiert worden, die derzeit den aussichtsreichsten Ansatz in der Erkenntnistheorie darzustellen scheint. Dieser Ansatz hat den Vorzug, eine einheitliche Konzeption von Wissen und Rechtfertigung für den Common-Sense-Bereich und für den Bereich der Wissenschaften zu liefern, und er hat im Hinblick auf die epistemischen Kontinuitätsargumente außerdem den Vorzug, daß er sozusagen einen Rahmen für die Rekonstruktion der zum Teil sehr skizzenhaften Argumente aus der Literatur darstellt, der durch die Erläuterungen zu den zentralen Begriffen des epistemischen Verfahrens, der Verläßlichkeit etc. vorgibt, in welchen Hinsichten die Argumentskizzen zu präzisieren und genauer zu erläutern sind und welche Gestalt zufriedenstellende Präzisierungen und Erläuterungen in etwa haben müßten. Diese Rekonstruktionen der Kontinuitätsargumente hängen damit von der Annahme ab, daß sich der reliabilistische Ansatz als tragfähig erweist; die epistemischen Kontinuitätsargumente und die obige Diskussion ihrer "Eigenschaften" sollten sich aber (wenigstens teilweise) auch in andere erkenntnistheoretische Perspektiven "transponieren" lassen.

Wieviel Überzeugungskraft die epistemischen Kontinuitätsargumente in der Realismusdebatte entwickeln können, wird auch dann, wenn man von all den diskutierten Problemen grundsätzlicher Art absieht, noch davon abhängen, wie präzise und überzeugend die involvierten epistemischen Verfahren und deren Verläßlichkeit identifiziert und erläutert werden können. Die diskutierten epistemischen Kontinuitätsargumente aus der Literatur stellen grundsätzlich plausible, wenn auch in der Ausführung nur teilweise zufriedenstellende Ansätze dar. 


\section{Kapitel 9}

\section{Das Wunderargument und seine Varianten}

Einen dritten, von den Präsuppositionsargumenten und den Kontinuitätsargumenten verschiedenen Typ von Argument für wissenschaftlichen Realismus stellt das sogenannte Wunderargument (miracle argument) dar, in der Literatur auch als Erfolgsargument (success of science argument) bezeichnet oder, mit Bas van Fraassens etwas despektierlichem Etikett ${ }^{1}$, als ultimatives Argument (ultimate argument). ${ }^{2}$ Die Idee, die hinter dem Wunderargument und seinen Varianten steht, ist, eine realistische Position mit Hilfe von Erklärungen für bestimmte Erfolge oder Leistungen zu begründen, die wissenschaftliche Theorien erzielen oder ermöglichen. Das Wunderargument ist in der wissenschaftstheoretischen Realismusdebatte das am meisten diskutierte und umstrittene Argument und die Mehrzahl der Anhänger einer realistischen Position stützt diese entscheidend auf eine der diversen Varianten dieses Arguments. Diese Argumentationslinie soll daher hier ausführlich untersucht werden.

\subsection{Formulierungen des Wunderarguments}

\subsubsection{Die Idee, grob formuliert (Putnam, Smart)}

Die sloganartigsten und meistzitierten Formulierungen des Wunderarguments stammen von Putnam:

"[...] the positive argument for realism is that it is the only philosophy that doesn't make the success of science a miracle. That terms in mature theories typically refer $[. .$.$] that the theories accepted in a mature science are typically$ approximately true, that the same term can refer to the same thing even when it occurs in different theories - these statements are viewed by the scientific realist not as necessary truths but as part of the only scientific explanation of the success of science". ${ }^{3}$

\footnotetext{
${ }^{1}$ [vFra80], S.39.

${ }^{2}$ Weitere Bezeichnungen, die sich in der Literatur finden: no miracle argument [Psil96], no miracles argument [Worr89], truth argument ([Lipt91], S.159). Soweit erkennbar hat sich bis jetzt keine präzisere, evtl. verschiedene Argumentvarianten voneinander unterscheidende Verwendungsweise dieser Bezeichnungen allgemein durchgesetzt.

${ }^{3}[$ Putn75c], S.73.
} 
Als grundlegende Idee seines Arguments nennt Putnam also, daß der "Erfolg der Wissenschaften" nach einer Erklärung verlangt und ohne eine solche Erklärung ein Wunder darstellen würde. Was er mit diesem "Erfolg" meint, wird an einer anderen Stelle deutlicher, an der er seinen Gedanken erläutert:

"[...] the modern positivist has to leave it without explanation (the realist charges) that 'electron calculi' and 'space-time calculi' and 'DNA calculi' correctly predict observable phenomena if, in reality, there are no electrons, no curved space-time, and no DNA molecules. If there are such things, then a natural explanation of the success of these theories is that they are partially true accounts of how they behave. And a natural account of the way in which scientific theories succeed each other - say, the way in which Einstein's Relativity succeeded Newton's Universal Gravitation - is that a partially correct/partially incorrect account of a theoretical object - say, the gravitational field, or the metric structure of space-time, or both - is replaced by a better account of the same object or objects. But if these objects don't really exist at all, then it is a miracle that a theory which speaks of gravitational action at a distance successfully predicts phenomena; it is a miracle that a theory which speaks of curved space-time successfully predicts phenomena". ${ }^{4}$

Als Explanandum nennt Putnam also die Leistungen wissenschaftlicher Theorien in puncto Prognose beobachtbarer Phänomene; der "Erfolg der Wissenschaften" besteht in solchen Prognoseerfolgen. Putnam ist der Ansicht, daß, erstens, dieses Explanandum plausiblerweise nicht unerklärt stehenbleiben kann (denn das käme der kommentarlosen Zurkenntnisnahme eines Wunders gleich) und daß, zweitens, der Realist eine plausible Erklärung dafür anzubieten hat (nämlich die, daß die theoretischen Ausdrücke der Theorien referieren, und zwar in "theorieunabhängiger" Weise ${ }^{5}$, daß die Theorien Beschreibungen des Verhaltens der Referenzentitäten darstellen ${ }^{6}$ und daß sie annähernd wahr sind).

Ein plausibles Beispiel für Prognoseerfolge einer wissenschaftlichen Theorie ist vielleicht der Fall von Einsteins allgemeiner Relativitätstheorie (ein "space-time calculus" in Putnams Sinn), die die Periheldrehung des Merkur und eine Ablenkung von Sternenlicht am Sonnenrand prognostiziert hat. Der Nachweis dieser beiden Effekte hat wesentlich zur Etablierung der Theorie beigetragen. ${ }^{7}$

An anderer Stelle gibt Putnam eine weitere, mit der ersten zusammenhängende, aber doch davon unterscheidbare Erläuterung von "Erfolg der Wissenschaften":

"[...] science succeeds in [...] devising better ways of controlling nature [...]. $[\ldots]$ realism is an explanation of this fact". 8

"Let me try to unpack this notion [of 'success']. What 'succeeds' or 'fails' is not, in general, linguistic behavior by itself but total behavior. E.g. we say certain things, conduct certain reasonings with each other, manipulate materials in a certain way, and finally we have a bridge that enables us to cross a river that we couldn't cross before.

\footnotetext{
${ }^{4}[$ Putn78], S.18/19.

5 "[...] the same term can refer to the same thing even when it occurs in different theories"; Putnam scheint sich hier auf seine kausale Referenztheorie zu beziehen; vgl. Kap.4.2.

6 "[...] theories [...] are [...] accounts of how they behave".

${ }^{7}$ Siehe z.B. [Pais82], S.303-305. Pais spricht sogar, wie Putnam, von "miracles".

${ }^{8}$ Putn78], S.19.
} 
[... The explanation is that certain kinds of beliefs we hold tend to be true". ${ }^{9}$

Als Explanandum des Realisten nennt Putnam hier Handlungserfolge, die mit Hilfe wissenschaftlicher Theorien zustandegekommen sind.

Ähnliche Formulierungen wie die von Putnam finden sich bei John Smart:

The realist's most general argument against instrumentalism is that he can explain the success of microphysics in predicting facts on the macro-level. The instrumentalist just has to accept this success as brute fact. Why should things happen on the macro-level just as if there were electrons, neutrinos, and so on, if there really is no micro-level and if discourse that appears to be about unobservable micro-entities is not to be taken at face value? The scientific realist holds that his or her opponent is left with something like a cosmic miracle. That theories work, or that certain generalizations on the observational level hold true, is something for which his instrumentalist opponent can give no explanation.

[...] by postulating unobservable particles, and so on, and by stating a relatively small number of laws pertaining to these, a scientist can explain the untidy and multifarious facts about the macro-level in a relatively simple and unified manner." 10

"If the phenomenalist about theoretical entities is correct we must believe in a cosmic coincidence. That is, if this is so, statements about electrons, etc., are of only instrumental value: they simply enable us to predict phenomena on the level of galvanometers and cloud chambers. They do nothing to remove the surprising character of these phenomena. Admittedly the physicist will not be surprised in the sense that he will find these phenomena arising in unexpected ways; his theory will have instrumental value in preventing this sort of surprise. But $[\ldots]$ he ought still to find it surprising that the world should be such as to contain these odd and ontologically disconnected phenomena [...] Is it not odd that the phenomena of the world should be such as to make a purely instrumental theory true? On the other hand, if we interpret a theory in a realist way, then we have no need for such a cosmic coincidence: it is not surprising that galvanometers and cloud chambers behave in the sort of way they do, for if there really are electrons, etc., this is just what we should expect. A lot of surprising facts no longer seem surprising." 11

Putnam und Smart formulieren hier - in mehreren Anläufen mit etwas voneinander abweichenden Resultaten und weniger klar als wünschenswert - den Grundgedanken des Wunderarguments, daß bestimmte Eigenschaften oder Leistungen wissenschaftlicher Theorien erklärungsbedürftig sind, daß (nur) vom Standpunkt einer realistischen Position aus eine Erklärung dafür gegeben werden kann und daß die Eigenschaften oder Leistungen der Theorien ohne eine solche Erklärung ein Wunder darstellen würden. Während dieser Grundgedanke von verschiedenen Autoren geteilt wird, gehen die Ansichten darüber

\footnotetext{
${ }^{9}[$ Putn78], S.100/101.

${ }^{10}$ [Smar87b], S.133/134.

${ }^{11}$ [Smar63], S.39; vgl. auch [Smar68], S.151. Eine noch frühere Formulierung ähnlicher Gedanken findet sich in [Maxw62], S.18-22.
} 
auseinander, worin genau die erklärungsbedürftigen Eigenschaften oder Leistungen wissenschaftlicher Theorien bestehen und worin genau die Explanantia und die explanatorischen Relationen einer Erklärung für diese Eigenschaften oder Leistungen bestehen. In der Literatur finden sich verschiedene Varianten des Wunderarguments, die den genannten Grundgedanken entwickeln und sich dazu auf verschiedene Eigenschaften oder Leistungen von Theorien beziehen und verschiedene Explanantia und verschiedene Arten, etwas zu erklären, ins Spiel bringen.

\subsubsection{Ein präzisierter Vorschlag für das Explanandum: erfolgreiche neue Prognosen und unbeabsichtigte Vereinheitlichungsleistungen}

Putnams und Smarts früher Vorschlag, daß Erfolge bei der Prognose beobachtbarer Phänomene das Explanandum des Wunderarguments darstellen, ist als in einer bestimmten Hinsicht zu unspezifisch kritisiert worden. ${ }^{12}$ Putnam scheint unter Prognoseerfolgen das deduktive Ableiten von wahren Gesetzen oder Sätzen über beobachtbare Phänomene zu verstehen, Smart das Ableiten von wahren Gesetzen oder Sätzen über eine "unordentliche und vielfältige" Menge von beobachtbaren Phänomenen, ohne daß sie dies näher spezifizieren oder einschränken würden. Damit zählen als Prognoseerfolge insbesondere auch Fälle, in denen aus einer Theorie wahre Sätze über Phänomene abgeleitet wurden, zu deren Erklärung sie gerade konstruiert worden war oder deren Kenntnis jedenfalls in die Konstruktion der Theorie eingegangen ist. In solchen Fällen, so die Kritik, scheint nun aber eine andere Erklärung des Erfolgs auf der Hand zu liegen: Bei der Konstruktion der Theorie wurden diese Prognoseerfolge sozusagen eingebaut, die Theorie wurde gerade so entworfen, daß die fraglichen Phänomene "erfolgreich" aus ihr abzuleiten sind, für eine darüber hinausgehende Erklärung des Erfolges scheint kein Bedarf zu bestehen. ${ }^{13}$

Ein Verbesserungsvorschlag bietet sich an: Erklärungsbedürftig bzw. als ein Wunder erscheinen danach Fälle, in denen eine Theorie Erfolge bei der Ableitung neuer, zum Zeitpunkt der Konstruktion der Theorie noch unbeobachteter Phänomene bzw. Gesetze vorweisen kann. Schon Pierre Duhem hat auf die Bedeutung derartiger Fälle hingewiesen:

"Nehmen wir nun an, es gelte im Moment, wenn die Voraussagungen der Theorie mit der Wirklichkeit konfrontiert werden, eine Wette für oder gegen die Theorie zu schließen. Zugunsten welcher Seite würden wir unseren Einsatz wagen?

Wenn die Theorie ein rein künstliches System ist, wenn wir in den Hypothesen, auf denen sie ruht, Ausdrücke sehen, die mit Geschick so aufgestellt werden, daß sie die bereits bekannten experimentellen Gesetze darstellen, wenn wir in ihnen aber keinen Reflex der wirklichen Beziehungen zwischen den Realitäten, die sich vor unseren Augen verbergen, vermuten, so werden wir denken, daß eine derartige Theorie von einer neu gefundenen Tatsache eher widerlegt als bestätigt werden wird. Es wäre ein wunderbarer Zufall, wenn die bisher unbekannte Gesetzmäßigkeit gerade einen ganz geeigneten Platz in dem Raume finden würde, der von den anderen Gesetzmäßigkeiten freigelassen wurde, und wir wären toll, wollten wir auf diese Hoffnung hin unseren Einsatz wagen.

\footnotetext{
${ }^{12}$ Z.B. [Carr91], S.25f., [Musg85], S.210/211, [Musg88], S.230ff., [Wrig91], S.11.

${ }^{13} \mathrm{Vgl}$. etwa [Carr91], S.25/26: "If a theory is constructed such that it fits certain known phenomena, we aren't struck by the fact that it actually fits these phenomena. There is no miracle involved here. And if there is no explanandum, realism can hardly be credited with providing the explanans."
} 
Wenn wir im Gegenteil in der Theorie eine naturgemäße Klassifikation erblicken, wenn wir wissen, daß ihre Prinzipien tiefe und wirkliche Beziehungen zwischen den Dingen ausdrücken, werden wir nicht erstaunt sein zu sehen, daß ihre Folgerungen der Erfahrung vorauseilen und die Entdeckung neuer Gesetze befördern. Wir werden kühn auf sie wetten.

Wenn wir von einer Klassifikation fordern, daß sie von vornherein Tatsachen, die erst in Zukunft entdeckt werden, ihren Platz anweist, zeigt das am deutlichsten, daß wir diese Klassifikation für naturgemäß halten. Und wenn die Erfahrung die Voraussagungen unserer Theorie bestätigt, dann fühlen wir, wie sich in uns die Überzeugung festigt, daß die Beziehungen, die unser Verstand zwischen den abstrakten Begriffen hergestellt hat, tatsächlich den Beziehungen zwischen den Dingen entsprechen." 14

Ein anderer präzisierter Vorschlag für ein Explanandum ist, Fälle ins Auge zu fassen, in denen eine Theorie, die zur Erklärung bestimmter Gesetze oder Phänomene konstruiert wurde, zusätzlich und sozusagen unbeabsichtigt die Ableitung eines anderen Gesetzes oder Phänomens gestattet, das zwar zum Zeitpunkt der Theoriekonstruktion bekannt war, bis dahin aber in keinem Zusammenhang mit den Gesetzen stand, zu deren Erklärung die Theorie konstruiert wurde und in die Konstruktion nicht eingegangen ist. William Whewell hat solche Fälle unter dem Titel consilience of inductions beschrieben:

"No example can be pointed out, in the whole history of science, so far as I am aware, in which this Consilience of Inductions has given testimony in favour of an hypothesis afterwards discovered to be false. If we take one class of facts only, knowing the law which they follow, we may construct an hypothesis, or perhaps several, which may represent them: and as new circumstances are discovered, we may often adjust the hypothesis so as to correspond to these also. But when the hypothesis, of itself and without adjustment for the purpose, gives us the rule and reason of a class not contemplated in its construction, we have a criterion of its reality, which has never yet been produced in favour of falsehood." 15

In Fällen dieser Art kann man ein zweites präzisiertes Explanandum erblicken: ${ }^{16}$ Wenn aus einer Theorie nicht nur die Phänomene ableitbar sind, für die dies per Konstruktion gilt, sondern zusätzlich und unerwarteterweise auch andere Phänomene, so daß die Theorie eine Vereinheitlichung dieses Phänomenbereiches mit anderen Bereichen liefert, dann scheint diese unbeabsichtigte Vereinheitlichungsleistung einen Ansatzpunkt für eine Erklärung zu bieten.

\subsubsection{Ein präzisierter Vorschlag für das Explanandum: die Verläßlichkeit wissenschaftlicher Methodologie (Boyd)}

Richard Boyd stellt ein anderes Explanandum als die bisher genannten ins Zentrum seiner Argumentation für wissenschaftlichen Realismus:

\footnotetext{
${ }^{14}$ [Duhe78], S.32/33. In der neueren Diskussion wird dieser Punkt z.B. in [Carr91], S.26ff., [Musg85], S.210/211, [Musg88], S.232ff., [Worr84], S.68 und [Worr89], S.101ff. im Anschluß an Duhem gemacht.

${ }^{15}$ [Whew47], vol.II, S.67/68, zitiert nach [Carr91], S.26.

${ }^{16}$ [Carr91], S.26ff. Musgrave liest Whewell anders, nämlich als, wie Duhem, auf den Punkt Prognose neuer Phänomene zielend, nicht auf Vereinheitlichungsleistungen; vgl. [Musg88], S.232.
} 
"[...] a realistic account of scientific theories is a component in the only scientifically plausible explanation for the instrumental reliability of scientific methodology." 17

Unter wissenschaftlicher Methodologie versteht Boyd alle Prinzipien, Standards, Verfahren u.ä., die zur Gewinnung und Etablierung neuer Theorien beitragen. Er nennt eine ganze Reihe von Beispielen, u.a. die Prinzipien, nach denen der Bestätigungsgrad von Theorien und die Projizierbarkeit ${ }^{18}$ theoretischer Begriffe beurteilt werden, ${ }^{19}$ die Regeln, nach denen Experimente entworfen bzw. unter den denkbaren Experimenten die tatsächlich zu realisierenden ausgewählt werden ${ }^{20}$, Prinzipien, die bei der Auswahl von Forschungsproblemen zum Tragen kommen, und Standards der Bewertung experimenteller Resultate. ${ }^{21}$

Prinzipien, Verfahren etc. dieser Art nennt Boyd instrumentell verläßlich, wenn man durch ihre Anwendung neue Theorien gewinnt oder etabliert, die selbst instrumentell verläßlich sind, und das wiederum heißt, daß die Theorien "annähernd korrekte Prognosen über das Verhalten beobachtbarer Phänomene" liefern. ${ }^{22}$

Die fraglichen Prinzipien, Verfahren etc. sind nun, wie Boyd an einigen davon erläutert, allesamt theorieabhängig, d.h., ihre Anwendung in einem konkreten Fall involviert bereits etablierte Theorien des jeweiligen Gegenstandsbereiches selbst oder anderer Gegenstandsbereiche. Drei Beispiele:

"We [...] take seriously only those theories which relatively closely resemble our existing theories in respect of their ontological commitments and the laws they contain. We prefer theories which quantify over familiar "theoretical entities" - - or at least entities very much like familiar ones [...]; we prefer theories which predicate of theoretical entities familiar properties - - or at least properties like familiar ones; we prefer new theories whose laws are - - if not consistent with those we have previously adopted - - at least compatible with the maintenance of most of our previously accepted laws as approximations [...]

[...] our preference for "simpler" theories is, in the first instance, a preference for theories which represent relatively "simple" modifications of our existing theories [...] simplicity judgements are profoundly dependent on the existing theoretical tradition [...]"23

"[...] consider the question of experimental design: Suppose that $\mathrm{T}$ is a suitably plausible theory. Which experimental tests are sufficient to warrant our accepting it [...] ? [...] I propose the following:

The Fundamental Rule of Experimental Design:

1. Subject $\mathrm{T}$ to theoretical criticism. [Ask, in the light of the best available theories, what alternatives there are to the mechanisms/processes posited or

${ }^{17}$ [Boyd91], S.207, vgl. auch [Boyd81], S.617ff.

${ }^{18} \mathrm{Im}$ Sinn von Goodman [Good55].

${ }^{19}$ [Boyd91], S.207, 214ff.

${ }^{20}$ [Boyd81], S.620f.

21 [Boyd88], S.189/190; s.a. [Boyd81], S.617f.

22 "approximately accurate predictions about the behavior of observable phenomena" ([Boyd81], S.616, s.a. [Boyd90a], S.360). Boyd thematisiert die im vorigen Abschnitt erwähnte Differenz zwischen der Ableitung bekannter und der Ableitung neuer beobachtbarer Phänomene nicht ausdrücklich, er scheint aber eher letztere im Auge zu haben, wenn er von Prognosen spricht.

${ }^{23}[$ Boyd81], S.617/618. 
required by $\mathrm{T}$. What mechanisms, known on the basis of other theories, might interfere with the operation of the mechanisms which $\mathrm{T}$ posits or requires? [...]]

2. After you have subjected $\mathrm{T}$ to theoretical criticism [...], then test $\mathrm{T}$ under circumstances representative of those which theoretical criticism indicate as places where it might plausibly go wrong.

That is how we do it. And that's as theory-dependent as you can get." 24

"Experimental Artifact. Suppose that $T$ is theoretically plausible and thus represents a projectable pattern in observable data, and suppose that the experimental results in $E$ appear to support (or refute) $T$. If these results are really to be evidentially relevant, then there must be reason to think that the results favorable (or unfavorable) to $T$ were not the results of features of the experimental situation which are irrelevant to the assessment of $T$. Of course, it is impossible to control for all epistemically possible experimental artifacts [...] Instead, we rely upon established theory to indicate the conditions under which the presence of experimental artifacts is to be suspected and the sorts of experimental controls which permit us to avoid or discount for their effects. [...] our theory-dependent judgements in this area cut down the number of epistemically possible artifactual effects we actually control for from infinitely many to rather few". ${ }^{25}$

In der instrumentellen Verläßlichkeit der in dieser Weise theorieabhängigen Prinzipien, Verfahren etc., oder, wie Boyd sich ausdrückt, der in dieser Weise theorieabhängigen Methodologie der Wissenschaften, besteht Boyds Explanandum. In Boyds Augen ist es erklärungsbedürftig, daß bei der Erforschung eines Gegenstandsbereichs der Einsatz von Prinzipien, Verfahren etc., die sich wesentlich auf zu diesem Zeitpunkt akzeptierte Theorien stützen, zur Gewinnung und Etablierung von neuen, bei der Prognose von beobachtbaren Phänomenen erfolgreichen Theorien führt. Die einzig plausible Erklärung dafür ist nach Boyd, daß bereits die bei der Anwendung der Prinzipien und Verfahren involvierten Theorien annähernd wahr sind.

"the reliability [...] of scientific methods at a given time will typically be explicable only on the assumption that the existing theoretical beliefs which form the background for its operation are (in relevant respects) approximately true. The basic idea which I have defended is that theoretical considerations are so heavily and so crucially involved in the operation of actual scientific method that the only way to explain even the instrumental reliability of that method is to portray it as reliable with respect to theoretical knowledge as well.". 26

Auch Boyds Argument für wissenschaftlichen Realismus hat also die Struktur, daß auf bestimmte, als erklärungsbedürftig dargestellte Leistungen wissenschaftlicher Theorien hingewiesen wird, für die (nur) vom Standpunkt einer realistischen Position aus eine

\footnotetext{
${ }^{24}[$ Boyd81], S.620/621.

25 [Boyd85b], S.7/8.

${ }^{26}$ [Boyd81], S.617/618, s.a. [Boyd90a], S.362. Zum Begriff 'annähernd wahr' liefert Boyd in [Boyd90a] einige Erläuterungen. Im Kern schreibt er dort, daß er einen "general context- and episode-neutral account of degrees of approximation" (S.378) nicht liefern kann, daß dies aber auch nicht erforderlich sei, da sich aus den Methodendiskussionen in den Wissenschaften selbst entnehmen lasse, welches die "relevanten Hinsichten" sind, in denen eine konkrete Theorie annähernd wahr sein muß, um ihre Rolle bei der Anwendung bestimmter Prinzipien und Verfahren erfolgreich spielen zu können.
} 
Erklärung gegeben werden kann, eben die, daß die dabei involvierten Theorien annähernd wahr sind. Die erklärungsbedürftigen Leistungen der Theorien sind für Boyd nicht Prognoseerfolge per se, sondern eher der Beitrag der Theorien zur Gewinnung und Etablierung neuer Theorien, die ihrerseits Prognoseerfolge aufweisen. Boyds unmittelbares Explanandum ist also die Verläßlichkeit von Prinzipien, Verfahren etc. und erst durch deren Theorieabhängigkeit kommen mittelbar die wissenschaftlichen Theorien bzw. ihre Leistungen ins Spiel.

\subsubsection{Ein Vorschlag für ein "abgeschwächtes" Explanans: Realismus der Phänomenarten (Carrier)}

Gegen das Wunderargument ist der Einwand erhoben worden, daß die historische Erfahrung zeigt, daß sich Theorien, die einmal aufgrund ihrer Prognoseerfolge akzeptiert worden waren, später oft als falsch erwiesen haben. ${ }^{27}$ Dieser Einwand hat die Entwicklung von Varianten des Wunderarguments angeregt, die mit einem "bescheideneren", schwächeren Explanans arbeiten als der von Putnam vorgeschlagenen (annähernden) Wahrheit von Theorien.

Martin Carrier konzipiert auf dieser Linie einen Realismus der Phänomenarten (realism of kinds):

"My claim is that the Miracle Argument is basically all right; it was only applied to the wrong subject matter. What the argument in fact supports is a realism of kinds. The Miracle Argument is right in supposing that there has to be an explanation of strong success [i.e. successful prediction of novel regularities or novel relations between known regularities]. It is wrong in attributing the reason to the truth of theories and to the existence of entities. What explains strong success is that the corresponding theories induced the right relations of similarity among the phenomena in question." 28

Nach Carrier ist das korrekte, weil (anders als das Explanans Wahrheit bzw. annähernde Wahrheit) nicht mit "falsifizierenden" historischen Gegenbeispielen belastete Explanans des Wunderarguments, daß die von den im Explanandum genannten prognostisch erfolgreichen Theorien gelieferte Klassifikation von "Phänomenen" (d.h. beobachtbaren Prozessen, Gegenständen u. $\ddot{a}^{29}$ ) nach Arten richtig ist.

Genauer ist das Explanans des Wunderarguments nach Carrier nicht, daß die gesamte Klassifikationsstruktur, die die jeweiligen prognostisch erfolgreichen Theorien liefern, richtig ist, sondern nur, daß der Teil der Klassifikationsstruktur richtig ist, der für die Erfolge der Theorien (also z.B. für neue Prognosen) verantwortlich ist: ${ }^{30}$ Erklärungsbedürftige Prognoseerfolge von Theorien beruhen nach Carrier darauf, daß die Theorien bestimmte beobachtbare Phänomene als zur selben Art gehörig behandeln; diese Äquivalenzbeziehung ist jedoch im allgemeinen nur eine von mehreren, die die Theorien liefern. Nur auf in diesem Sinn erfolgreiche Äquivalenzbeziehungen bezieht sich Carriers Explanans, nicht auf andere, die dieselben Theorien möglicherweise liefern.

\footnotetext{
${ }^{27}$ Siehe Abschnitt 2.6.4.

${ }^{28}$ [Carr93], S.405.

${ }^{29}$ Carrier definiert den Terminus "Phänomene" nicht explizit, hat aber, wie sich an den angegebenen Beispielen ablesen läßt, offenbar beobachtbare (vgl. [Carr91], S.34) Prozesse, Gegenstände u.ä. im Auge. ${ }^{30}$ [Carr93], S.406.
} 
Carrier nennt als Beispiele für so durch eine Äquivalenzbeziehung verbundene Phänomene Oxidationsprozesse von Metallen wie Blei und Oxidationsprozesse von Nichtmetallen wie Kohle und Schwefel (als zu einer Klasse von chemischen Reaktionen gehörig), Venus und Erde (als zur Klasse der Planeten gehörig), sowie die Prozesse thermischer Ausdehnung bei verschiedenen Substanzen im gasförmigen Aggregatzustand, die alle mit demselben thermischen Ausdehnungskoeffizienten ablaufen. ${ }^{31}$

\subsubsection{Ein Vorschlag für ein "abgeschwächtes" Explanans: Realismus der mathematischen Strukturen (Worrall)}

Einen anderen Vorschlag für ein abgeschwächtes Explanans für das Wunderargument propagiert John Worrall. ${ }^{32}$ Er knüpft an Ideen von Henri Poincaré an und sucht nach den Elementen oder Teilen theoretischer Beschreibungen, die durch den Wandel der Theorien hindurch erhalten bleiben, der im Verlauf der Wissenschaftsgeschichte zu verzeichnen ist. Ausgehend von einer historischen Fallstudie über den Übergang von Fresnels Äthertheorie des Lichtes zu Maxwells Theorie des Elektromagnetismus identifiziert Worrall mathematische Strukturen als dieses stabile Element.

"There was an important element of continuity in the shift from Fresnel to Maxwell - and this was much more than a simple question of carrying over the successful empirical content into the new theory. At the same time it was rather less than a carrying over of the full theoretical content or full theoretical mechanisms (even in "approximate" form) [...] There was continuity or accumulation in the shift, but the continuity is one of form or structure, not of content." 33

Worrall arbeitet mit einer Unterscheidung zwischen der mathematischen "Form" oder "Struktur" einer Theorie und ihrem "theoretischen Inhalt" oder den "theoretischen Mechanismen", die die Theorie beschreibt, und seine Idee ist, daß aufeinanderfolgende Theorien dieselbe (oder annähernd dieselbe ${ }^{34}$ ) mathematische Struktur oder Form haben können, dabei aber gleichzeitig ein (möglicherweise völlig) unterschiedliches Bild von der Art der Entitäten oder Prozesse (oder, wie Worrall sich ausdrückt, von ihrer Natur ${ }^{35}$ ) zeichnen, deren Verhalten die mathematischen Gleichungen beschreiben.

"Poincaré is claiming that, although from the point of view of Maxwell's theory, Fresnel entirely misidentified the nature of light, his theory accurately described not just light's observable effects but its structure. There is no elastic solid ether. There is, however, from the later point of view, a (disembodied) electromagnetic field. The field in no clear sense approximates the ether, but disturbances in it do obey formally similar laws to those obeyed by elastic disturbances in a mechanical medium. Although Fresnel was quite wrong about what oscillates, he was, from this later point of view, right, not just about the optical phenomena, but right also that these phenomena depend on the oscillations of something or other at right angles to the light.

\footnotetext{
${ }^{31}$ Vgl. [Carr93], S.405-408.

${ }^{32}$ [Worr89]; Andeutungen in derselben Richtung finden sich auch bei Howard Stein ([Stei87], S.393, [Stei89], S.57/58). Dagegen geht es McMullin mit seinem Begriff der strukturellen Erklärung ([McMu78], [McMu84], S.26ff.) um eine anders gelagerte Idee.

${ }^{33}$ [Worr89], S.117.

${ }^{34}$ Vgl. [Worr89], S.120.

${ }^{35}$ [Worr89], S.118.
} 
Thus if we restrict ourselves to the level of mathematical equations - not notice the phenomenal level - there is in fact complete continuity between Fresnel's and Maxwell's theories. Fresnel developed a famous set of equations for the relative intensities of the reflected and the refracted light beams in various circumstances $[\ldots]$

Fresnel developed these equations on the basis of the following picture of light. Light consists of vibrations transmitted through a mechanical medium. These vibrations occur at right angles to the direction of the transmission of light through the medium [...] The bigger the vibrations, that is, the larger the maximum distance the particles are forced from their equilibrium positions by the vibration, the more intense the light $[\ldots]$

From the vantage point of Maxwell's theory ... this account, to repeat, is entirely wrong. How could it be anything else when there is no elastic ether to do any vibrating? Nonetheless from this vantage point, Fresnel's theory has exactly the right structure - it's "just" that what vibrates according to Maxwell's theory, are electric and magnetic field strengths." 36

Nach Worralls Ansicht ist das korrekte (nicht mit "falsifizierenden" historischen Gegenbeispielen belastete) Explanans des Wunderarguments, daß die mathematische Struktur der im Explanandum genannten prognostisch erfolgreichen Theorien richtig ist.

"Roughly speaking, it seems right to say that Fresnel completely misidentified the nature of light, but nonetheless it is no miracle that his theory enjoyed the empirical predictive success that it did; it is no miracle because Fresnel's theory, as science later saw it, attributed to light the right structure." 37

Der Erfolg einer Theorie in puncto neue Prognosen wird erklärt durch die Tatsache, daß die Theorie die Struktur ihres Gegenstandsbereiches (d.h. des Bereiches der unbeobachtbaren Entitäten und Gesetze, nicht nur der beobachtbaren oder "beobachtungsnahen" Phänomene) korrekt repräsentiert. ${ }^{38}$ Worrall nennt seine Position strukturellen oder syntaktischen Realismus (structural or syntactic realism). ${ }^{39}$

\subsection{Die Versionen des Wunderarguments als Schlüsse auf die beste Erklärung: Die Version von Putnam und Smart und deren Varianten mit präzisiertem Explanandum (er- folgreiche neue Prognosen und unbeabsichtigte Verein- heitlichungsleistungen)}

Die im vorigen Abschnitt vorgestellten Formulierungen des Wunderarguments gehen allesamt davon aus, daß wissenschaftliche Theorien bestimmte Erfolge erzielen oder ermöglichen; teilweise werden diese Erfolge als erklärungsbedürftig oder gar als ein Wunder

\footnotetext{
${ }^{36}$ [Worr89], S.118/119.

${ }^{37}$ [Worr89], S.117.

${ }^{38}$ Psillos gibt eine explizite Formulierung des Wunderarguments für den strukturellen Realismus an und bemerkt dazu, daß sich das Wunderargument in Worralls Text nicht findet ([Psil95], S.27f.). Dies trifft offensichtlich nicht zu; neben dem obigen Zitat vgl. S.119 unten sowie S.121 Mitte.

${ }^{39}$ [Worr89], S.112.
} 
präsentiert. Daran anschließend vertreten die genannten Autoren die These, daß (nur) vom Standpunkt einer realistischen Position aus eine Erklärung für diese (z.T. als erklärungsbedürftig oder sogar als Wunder bezeichneten) Erfolge gegeben werden kann, und zwar durch die Annahme, daß die jeweiligen Theorien wahr sind, annähernd wahr sind, die richtige Klassifikationsstruktur von Phänomenen liefern etc. Auf diese Weise soll ein Argument für wissenschaftlichen Realismus gegeben sein.

Da aus Annahmen oder Thesen der beiden genannten Sorten offenbar keinerlei realistische Thesen deduktiv folgen, haben die Anhänger des Wunderarguments offensichtlich ein Argument für wissenschaftlichen Realismus in einem anderen, nicht-deduktiven Sinn von 'Argument' im Auge. Eine naheliegende und von einigen Autoren auch explizit genannte oder wenigstens angedeutete Lesart ist, daß sie ein Argument von der Form des Schließens auf die beste Erklärung ${ }^{40}$ meinen. Es stellt sich also die Frage, ob oder inwieweit sich die verschiedenen Formulierungen des Wunderarguments als Argumente von der Form des Schließens auf die beste Erklärung auffassen lassen. Schlüsse auf die beste Erklärung lassen sich, Musgrave folgend ${ }^{41}$, durch folgendes Inferenzschema beschreiben:

(IBE)

$F$ is a fact.

Hypothesis $H$ explains $F$.

Hypothesis $H$ satisfactorily explains $F$.

No available competing hypothesis explains $F$ as well as $H$ does.

Therefore, $H$ is true.

Zwecks Präzisierung und genaueren Verständnisses des Wunderarguments ist also für die verschiedenen Formulierungen zu prüfen, ob man durch Ersetzen der Variablen dieses Schemas eine transparente und adäquate Rekonstruktion der intendierten Argumentation erhält und was ggf. für die Variablen dieses Schemas (das Explanandum $F$, das Explanans $H$, und das Spektrum der mit $H$ konkurrierenden Hypothesen) einzusetzen wäre.

Zuerst sollen in diesem Sinn das Wunderargument in der Formulierung von Putnam und Smart und die Varianten mit den präzisierten Explananda erfolgreiche neue Prognosen und unbeabsichtigte Vereinheitlichungsleistungen in den Blick genommen werden.

\subsubsection{Erfolge einzelner Theorien oder Erfolge der Gesamtheit wissen- schaftlicher Theorien als Explanandum}

Bei diesen Versionen des Wunderarguments bringt der Versuch, sie explizit in der Form des Inferenzschemas (IBE) zu reformulieren, eine Unschärfe in den Angaben für Explanans und Explanandum heraus. Für das Explanandum $F$ kommt ein Sachverhalt, der eine einzelne Theorie betrifft, in Frage, also etwa: ${ }^{42}$

Die Theorie $T$ liefert erfolgreiche (neue) Prognosen/erbringt unbeabsichtigte Vereinheitlichungsleistungen.

Alternativ kommt ein Sachverhalt in Frage, der die Gesamtheit aller (zu einem Zeitpunkt, z.B. heute, oder in einem bestimmten Zeitraum akzeptierten) wissenschaftlichen Theorien betrifft oder jedenfalls nicht eine Theorie, sondern eine (zu spezifizierende) Menge von Theorien, etwa:

\footnotetext{
${ }^{40}$ Siehe Abschnitt 8.3.5.

${ }^{41}$ Vgl. S.168.

${ }^{42}$ Die Formulierungen für die Explananda und Explanantia an dieser Stelle sind vorläufige, die noch weiterer Präzisierungen bedürfen (s.u.); hier kommt es zunächst nur auf die eine genannte Unschärfe an.
} 
Die (zu einem bestimmten Zeitpunkt akzeptierten o.ä.) Theorien der Naturwissenschaften liefern erfolgreiche (neue) Prognosen/erbringen unbeabsichtigte Vereinheitlichungsleistungen.

Entsprechend müßte die erklärende Hypothese $H$ entweder lauten

Die theoretischen Ausdrücke der Theorie $T$ referieren (in theorieunabhängiger Weise)/die Theorie $T$ stellt eine Beschreibung des Verhaltens der Referenzentitäten dar/die Theorie $T$ ist (annähernd) wahr,

oder

Die theoretischen Ausdrücke der (zu einem bestimmten Zeitpunkt akzeptierten o.ä.) Theorien der Naturwissenschaften referieren (in theorieunabhängiger Weise)/die (zu einem bestimmten Zeitpunkt akzeptierten o.ä.) Theorien der Naturwissenschaften stellen Beschreibungen des Verhaltens der Referenzentitäten dar/die (zu einem bestimmten Zeitpunkt akzeptierten o.ä.) Theorien der Naturwissenschaften sind (annähernd) wahr.

Putnams und Smarts Ausführungen zum Wunderargument lassen beide Lesarten zu und diese sind natürlich auch nicht miteinander unverträglich: Wenn man die Erfolge jeder einzelnen Theorie aus einer spezifizierten Gesamtheit durch das zugehörige Explanans erklärt, impliziert das eine Erklärung für die Erfolge der Gesamtheit der Theorien. Umgekehrt muß eine Erklärung für die Erfolge einer Gesamtheit von Theorien vielleicht nicht in einzelne Erklärungen für die Erfolge der einzelnen Theorien zerfallen — man müßte jedenfalls die Möglichkeit bedenken, daß Erfolge von der Kooperation mehrerer Theorien abhängen können ${ }^{43}$ - , aber der Erfolg einer Gesamtheit von Theorien und dessen Erklärung können jedenfalls durch eine Menge voneinander unabhängiger Erfolge der einzelnen Theorien und entsprechende Erklärungen realisiert sein.

Welche von beiden Lesarten man für eine Rekonstruktion des Wunderarguments wählt, kann Konsequenzen für dessen Plausibilität und Überzeugungskraft haben. Daher haben andere Autoren als Putnam und Smart ihre Version des Wunderarguments in diesem Punkt präziser formuliert.

Einige Autoren präsentieren das Explanans des Wunderarguments, das Theorieerfolge erklären soll, gewissermaßen als These einer "Wissenschaftswissenschaft" und schreiben ihm den Status einer falsifizierbaren These über die im Laufe der Geschichte der Wissenschaften auftretenden Theorien zu; diese Autoren rekonstruieren das Wunderargument i.a. als Argument, das alle oder jedenfalls eine Gesamtheit von Theorien und ihre Erfolge betrifft. ${ }^{44}$ Die entsprechende, als Explanans fungierende generelle Aussage wird bereits durch einzelne Fälle erfolgreicher, aber anerkanntermaßen nicht referierender, falscher etc. Theorien falsifiziert, die Überzeugungskraft dieser Versionen des Wunderarguments bereits durch solche einzelnen Fälle untergraben.

Andere Autoren dagegen rekonstruieren das Wunderargument als Argument, das einzelne Theorien und ihre Erfolge betrifft. ${ }^{45}$ Auch sie sind i.a. an generellen Aussagen über die Wissenschaften und ihre Theorien interessiert, aber sie betrachten dennoch die Erklärungen der Erfolge einzelner Theorien als den Kern dessen, worum es beim Wunderargument geht; aus dieser Perspektive sind generelle Aussagen über die Theorien der Wissenschaften o.ä. möglicherweise in einem zweiten (induktiven) Schritt zu gewinnen, nicht

\footnotetext{
${ }^{43}$ Vgl. Putnams in Kap.7 diskutierten Konjunktionseinwand.

${ }^{44}$ Vgl. [Carr91], S.24, [Laud81] und auch [Putn78], S.19 (bes. Fn.1).

${ }^{45}$ Z.B. [Musg88], S.239/240.
} 
direkt durch das Wunderargument. Es ist dann auch kein entscheidendes Problem für die Überzeugungskraft des Wunderarguments, wenn es sich als fehlbar erweist, wenn also das erschlossene Explanans nicht in jedem Fall korrekt ist, solange das Inferenzschema, dem das Wunderargument folgt, ein verläßliches Inferenzverfahren darstellt. Wenn das Wunderargument nicht seine Überzeugungskraft einbüßen soll, sollte das Explanans wenigstens mit hoher Wahrscheinlichkeit korrekt sein, aber es muß nicht in ausnahmslos jedem Fall korrekt sein. Die einzelnen Explanantia, die das Wunderargument liefert, sollten zusammen eine Aussage ergeben wie etwa

Die theoretischen Ausdrücke der (zu einem bestimmten Zeitpunkt akzeptierten o.ä.) Theorien der Naturwissenschaften referieren in der überwiegenden Zahl der Fälle (in theorieunabhängiger Weise)/die (zu einem bestimmten Zeitpunkt akzeptierten o.̈̈.) Theorien der Naturwissenschaften stellen in der überwiegenden Zahl der Fälle Beschreibungen des Verhaltens der Referenzentitäten dar/die (zu einem bestimmten Zeitpunkt akzeptierten o.ä.) Theorien der Naturwissenschaften sind in der überwiegenden Zahl der Fälle (annähernd) wahr.

\subsubsection{Semantische oder epistemische Antirealisten als Diskussionsgeg- ner}

Bei der sorgfältigen Formulierung des Wunderarguments als Schluß auf die beste Erklärung spielt es an mehreren Stellen eine Rolle, welches die Diskussionsgegner sind, die mit Hilfe des Wunderarguments für den wissenschaftlichen Realismus gewonnen werden sollen: Zum einen können Antirealisten für die Eigenschaften oder Leistungen von Theorien, die das Explanandum des Wunderarguments bilden, eigene Erklärungen anbieten, die mit der Erklärung konkurrieren, die das Wunderargument vorsieht. Wenn das so ist, muß sichergestellt sein, daß die Erklärung des Wunderarguments die bessere ist, damit auf sie geschlossen werden kann. Zum anderen sollten bei einem Argument, das erfolgreich in einer Diskussion eingesetzt werden soll, die Prämissen zwischen den Diskussionsgegnern unkontrovers sein, beim Wunderargument also insbesondere die Beschreibung des Explanandums (im Schema (IBE) also $F$ ).

Die Anzahl der antirealistischen Positionen und der von ihnen angebotenen alternativen Erklärungen, auf die sich die Anhänger des Wunderarguments explizit beziehen, ist unterschiedlich groß. Putnam nennt als Diskussionsgegner summarisch den "modernen Positivismus" oder "Operationalismus"; er meint, daß diese gar keine Erklärung für das Explanandum des Wunderarguments anzubieten haben, daß also das Explanans des Wunderarguments schon deswegen eine bessere Erklärung liefert als seine Diskussionsgegner anbieten können. ${ }^{46}$ Smart charakterisiert die antirealistischen Alternativen zu seinem Realismus etwas sorgfältiger; er hat die physikalistische Version des logischen Positivismus sowie den (bedeutungstheoretisch motivierten) Instrumentalismus im Auge. ${ }^{47}$ Auch Smart meint, daß seine Diskussionsgegner keine Erklärung für das Explanandum des Wunderarguments vorweisen können. Putnam und Smart wollen das Wunderargument also in der Diskussion mit Gegnern einsetzen, die in semantischer Hinsicht antirealistische Positionen vertreten. Dagegen zielen Autoren wie Musgrave, die neuere, präzisierte Versionen des Wunderarguments propagieren, in der Regel auf das gesamte Spektrum antirealistischer Positionen, also sowohl auf Diskussionsgegner, die in semantischer Hinsicht antirealisti-

\footnotetext{
${ }^{46}[$ Putn78], S.18f.

${ }^{47}$ [Smar63], S.27ff., [Smar87b], S.132; vgl. Abschnitt 1.3.2.
} 
sche Positionen vertreten, als auch auf solche, die "nur" in epistemischer Hinsicht antirealistische Positionen verteidigen. Von diesen Diskussionsgegnern bieten einige alternative Erklärungen für die im Wunderargument thematisierten Theorieerfolge oder -leistungen an. ${ }^{48}$

Da die Prämissen des Wunderarguments zwischen der realistischen Seite und deren Diskussionsgegnern unstrittig sein müssen, muß bei einer präzisen Formulierung des Arguments das Explanandum, das besagt, daß eine Theorie $T^{49}$ erfolgreiche (neue) Prognosen liefert, Vereinheitlichungsleistungen erbringt o.ä., in bestimmter Weise aufgefaßt werden: Wenn zu den Diskussionsgegnern semantische Antirealisten zählen, darf das Explanandum, wie immer es genau zu formulieren ist, nur in syntaktischer Hinsicht auf die Theorie $T$ Bezug nehmen, d.h., das Explanandum handelt von einem formalen Kalkül, von graphischen o.ä. Gebilden, mit denen kalkülartige Operationen vorgenommen werden können. Es darf nicht vorausgesetzt werden, daß es sich bei der Theorie $T$ um interpretierte Zeichen, also um semantisch vollwertige sprachliche Ausdrücke handelt, denen Bedeutung, Referenz und Wahrheitswerte zukommen, und es darf nicht vorausgesetzt werden, daß es sich bei den kalkülartigen Operationen, durch die aus der Theorie $T$ die im Explanandum erwähnten (unstrittig semantisch vollwertigen) Beobachtungssätze ${ }^{50}$ abgeleitet werden, um deduktive Schlüsse handelt, die aus wahren Prämissen stets wahre Konklusionen erzeugen. Es darf also keine semantische realistische These über die Theorie $T$ vorausgesetzt werden und damit auch nicht in die Formulierung des Explanandums des Wunderarguments eingehen, wenn es als Argument gegen semantische Antirealisten eingesetzt werden soll. Dagegen können Annahmen über die Bedeutung, Referenz und Wahr- oder Falschheit der Theorie $T$ bzw. semantische realistische Thesen über $T$ unstrittig sein und daher auch bei der Formulierung des Wunderarguments vorausgesetzt werden, wenn es "nur" gegen Positionen eingesetzt werden soll, die lediglich in epistemischer Hinsicht antirealistisch sind.

Je nachdem, ob solche Aussagen über die Bedeutung, Referenz und Wahr- oder Falschheit der Theorie $T$ bzw. semantische realistische Thesen über $T$ unstrittig sind, können sie auch bei der genauen Formulierung des Explanans des Wunderarguments (im Schema (IBE) also $H$ ) eine etwas unterschiedliche Rolle spielen: Zumindest bei einigen Anhängern des Wunderarguments, z.B. bei Putnam, ${ }^{51}$ sollen neben der Aussage, daß T wahr oder annähernd wahr ist, offenbar auch Aussagen über die Semantik der Theorie $T$ Teil des Explanans des Wunderarguments sein ("Die theoretischen Ausdrücke der Theorie $T$ referieren (in theorieunabhängiger Weise)/die Theorie $T$ stellt eine Beschreibung des Verhaltens der Referenzentitäten dar"). Wenn sie zwischen den Diskussionsgegnern unstrittig sind, stellen sie einen unproblematischen Teil des Explanans dar; nur wenn sie strittig sind, müssen sie durch das Wunderargument begründet werden, stellt das Wunderargument also ein Argument dar, das die antirealistische Seite zu einem Schluß auf (u.a.) diese semantischen Aussagen bewegen soll. Im letzteren Fall muß das Wunderargument sozusagen mehr leisten, da die Differenz zwischen den unkontroversen, von den Diskussionsgegnern geteilten Voraussetzungen und den von der realistischen Seite anvisierten Thesen größer ist.

\footnotetext{
${ }^{48}$ Siehe dazu Abschnitt 9.10.3.

${ }^{49}$ Oder mehrere Theorien; diese Alternative bleibt im folgenden meistens implizit.

${ }^{50}$ Also die Beobachtungssätze, die die erfolgreichen Prognosen zum Inhalt haben, die Phänomene, die vereinheitlich werden, o.ä.

${ }^{51}$ Siehe die Zitate vorne.
} 


\subsubsection{Prognoseerfolge als Explanandum}

Nach den vorbereitenden Überlegungen der letzten beiden Abschnitte lassen sich jetzt präzise Formulierungen für Explanandum und Explanans für eine Rekonstruktion des Wunderarguments gewinnen. Explizit formuliert werden hier im Sinne der Unterscheidung des vorletzten Abschnittes lediglich Argumentversionen, die von Erfolgen einzelner Theorien ausgehen; analoge Argumente, die von den Erfolgen von Gesamtheiten von Theorien ausgehen, erhält man leicht durch sinngemäße Ersetzung der entsprechenden Aussagen.

Als erstes sollen präzise Formulierungen für Explanandum und Explanans für diejenigen Versionen des Wunderarguments gewonnen werden, deren Ausgangspunkt die Erklärung von Prognoseerfolgen bildet. Es empfiehlt sich dazu, die schon oben ${ }^{52}$ genannte Unterscheidung zwischen einfachen Prognoseerfolgen (von hier ab: ePEen) und neuen Prognoseerfolgen (von hier ab: nPEen) zu berücksichtigen. ${ }^{53}$

Viele Anhänger des Wunderarguments, u.a. Putnam, scheinen unter Prognoseerfolgen einer Theorie das Ableiten von wahren Beobachtungssätzen aus der Theorie zu verstehen. ${ }^{54}$ Sie scheinen als prognostisch erfolgreich nur Theorien zu zählen, die mit allen oder jedenfalls allen bekannten Beobachtungen verträglich sind, die also keine "Prognosemißerfolge" aufweisen, sondern nur Prognoseerfolge, ansonsten aber keine weiteren Qualifikationen oder Einschränkungen zu fordern, und damit als Prognoseerfolge insbesondere auch Fälle zu zählen, in denen eine Theorie Beobachtungssätze über Phänomene abzuleiten gestattet, zu deren Erklärung die Theorie gerade konstruiert wurde oder die jedenfalls in die Konstruktion der Theorie eingegangen sind. Ein Beispiel für Prognoseerfolge der letzteren Art wäre eine durch die Ptolemäische Theorie des Sonnensystems erfolgreich prognostizierte Konstellation der Planeten am Himmel (denn in die Konstruktion der Ptolemäischen Theorie ist das "Phänomen" der periodischen Planetenbahnen am Firmament eingegangen). ${ }^{55}$ Prognoseerfolge in dem weiten Sinn, wie u.a. Putnam den Ausdruck verwendet, sollen hier einfache Prognoseerfolge heißen.

Andere Anhänger des Wunderarguments, u.a. Musgrave, spezifizieren einen engeren Bereich von Prognoseerfolgen einer Theorie, der den Ausgangspunkt ihrer Versionen des Wunderarguments bildet, nämlich neue Prognoseerfolge. Unter neuen Prognoseerfolgen einer Theorie verstehen sie das Ableiten von wahren Beobachtungssätzen über zum Zeitpunkt der Konstruktion der Theorie noch nicht bekannte Phänomene aus der Theorie. Als $\mathrm{nPE}$ in diesem Sinn zählt nicht das Ableiten wahrer Beobachtungssätze über singuläre, zeitlich datierbare (etwa zukünftige) Ereignisse oder Sachverhalte, die zum Zeitpunkt der Konstruktion der Theorie noch nicht bekannt waren, die aber ein zu diesem Zeitpunkt bereits bekanntes Phänomen instantiieren, wie im Fall der oben genannten Prognoseerfolge der Ptolemäischen Theorie des Sonnensystems. Vielmehr liegt ein nPE einer Theorie nur dann vor, wenn sie ein neues Phänomen bzw. wahre Beobachtungssätze über Ereignisse oder Sachverhalte, die dieses neue Phänomen instantiieren, abzuleiten gestattet. Nur auf Theorien die neue Prognoseerfolge (und natürlich keine "Prognosemißerfolge") aufweisen, beziehen sich die von Musgrave u.a. vorgeschlagenen Versionen des Wunderarguments.

Wenn man nach einer Rekonstruktion der Versionen des Wunderarguments, die sich auf

\footnotetext{
${ }^{52}$ Siehe Abschnitt 9.1.2.

${ }^{53}$ Carrier ([Carr91], S.28) trifft eine ähnliche Unterscheidung von "schwachen" und "starken" Prognoseerfolgen. Seine schwachen Prognoseerfolge entsprechen den obigen einfachen, er zählt jedoch zu den starken Prognoseerfolgen nicht nur neue Prognoseerfolge, sondern auch unbeabsichtigte Vereinheitlichungsleistungen, die hier gesondert behandelt werden.

${ }^{54}$ Für eine noch genauere Erläuterung s.u.

${ }^{55}$ Vgl. [Musg88], S.229ff.
} 
Prognoseerfolge beziehen, in Form des Schließens auf die beste Erklärung sucht, ergeben sich zwischen den Versionen des Arguments, die sich auf ePEe beziehen, und den Versionen, die sich auf nPEe beziehen, Unterschiede bei der präzisen Formulierung des Explanandums, nicht aber bei der Formulierung des Explanans.

Für Versionen des Wunderarguments wie die von Putnam, die sich auf ePEe als Explanandum beziehen, liegen zwei etwas unterschiedliche Explikationen dieses Explanandums und damit zwei etwas unterschiedliche präzise Formulierungen für F im Inferenzschema (IBE) nahe, ${ }^{56}$ nämlich zum einen

$$
T \vdash P
$$

und

$$
P \text { ist wahr, }
$$

zum anderen

$$
P \text { wurde aus } T \text { abgeleitet }
$$

und (9.2). Dabei wird jeweils, wie im vorigen Abschnitt diskutiert, auf die Theorie $T$ nur im Sinne eines graphischen o.ä. Gebildes Bezug genommen und entsprechend das Ableiten von $P$ aus $T$ als rein syntaktische Operation betrachtet. $P$ dagegen kann als semantisch vollwertig betrachtet werden (wie es auch von (9.2) vorausgesetzt wird).

Die erste dieser beiden Explikationen erläutert ePEe mit Hilfe einer (zeitlosen) Relation zwischen $P$ und $T$, nämlich der Ableitbarkeitsrelation, die zweite mit Hilfe eines (zeitlich und auch räumlich lokalisierbaren) Ableitungsvorganges, der tatsächlich stattgefunden hat. ${ }^{57}$ Wie sich zeigen wird, spielt die Differenz zwischen beiden Explikationen für Putnams Version des Wunderarguments keine nennenswerte Rolle, sie ist aber für andere Versionen von Bedeutung.

Gegen beide Explikationen des Explanandums ePEe ließe sich vielleicht einwenden, daß sie insofern nicht angemessen sind, als sie nicht berücksichtigen, daß der wahre Satz, um den es geht, also $P$, etwas zum Zeitpunkt der Gewinnung von $P$ Zukünftiges oder wenigstens noch nicht Bekanntes zum Inhalt hat, da es sich sonst nicht um eine Prognose handeln würde, d.h. um eine Vorhersage - im Unterschied zu einer "Nachhersage". ${ }^{58}$ Tatsächlich ist jedoch der gängige Sprachgebrauch in diesem Punkt nicht eindeutig: Der Ausdruck 'Prognose' ('prediction') kann so verwendet werden, daß impliziert wird, daß sich die fragliche Aussage auf zukünftige Ereignisse oder Sachverhalte bezieht; er kann ferner so verwendet werden, daß impliziert ist, daß er sich auf bisher nicht bekannte Ereignisse oder Sachverhalte bezieht. Ersteres ist offenbar nur für Aussagen über singuläre, zeitlich datierbare Ereignisse oder Sachverhalte sinnvoll, letzteres auch für Aussagen über "zeitlose" generelle Sachverhalte und Gesetze. In beiden Verwendungsweisen wird (mindestens implizit) auf ein zeitlich datierbares Ereignis (das Treffen einer entsprechenden Aussage, das Gewinnen oder Bekanntwerden von Informationen über den von $P$ beschriebenen Sachverhalt) Bezug genommen, was auch in eine angemessene Explikation eingehen

\footnotetext{
${ }^{56}$ Hier und im folgenden bleiben mögliche Unterscheidungen der verschiedenen Elemente einer "Theorie", die bei einer realen wissenschaftlichen Theorie i.a. erforderlich sind, um Beobachtungssätze abzuleiten (dynamische Grundgleichungen, Randbedingungen, Materialkonstanten u.ä.), implizit; für die Argumentation hängt davon nichts wesentliches ab.

${ }^{57}$ Die zweite dieser Explikationen nimmt auf einen bestimmten der i.a. mehreren verschiedenen möglichen Wege, $P$ aus $T$ abzuleiten, Bezug, die erste nicht.

${ }^{58}$ Diese Überlegung führt nicht (oder zumindest nicht notwendigerweise) zum Explanandum nPEe, denn es gibt offenbar Sätze, die sich auf zukünftige oder noch nicht bekannte Instantiierungen eines bekannten Phänomens beziehen.
} 
sollte. Beide Verwendungsweisen finden sich häufig in philosophischen Texten. ${ }^{59}$ Es gibt jedoch, insbesondere in den Naturwissenschaften, noch eine weitere Verwendungsweise, bei der keine Bezugnahme auf Zukünftiges oder Unbekanntes impliziert wird, sondern nur auf eine Deduktionsbeziehung zwischen $T$ und $P .{ }^{60}$ Putnam diskutiert diesen Punkt an den vorne zitierten Stellen nicht explizit, folgt aber in deren Umkreis meistens der dritten, naturwissenschaftlichen Verwendungsweise ${ }^{61}$ da er außerdem nirgends eine Beschränkung seines Explanandums auf Prognosen in dem engeren Sinn, daß sie sich auf Zukünftiges oder noch nicht Bekanntes beziehen, erwähnt, liegen für seine Version des Wunderarguments die beiden obigen, weiten Explikationen seines Explanandums nahe. Für andere Anhänger des Wunderarguments, die sich auf ePEe beziehen, gilt i.a. dasselbe.

Für die Versionen des Wunderarguments, die sich auf ePEe beziehen, eine Explikation dessen, was von den Anhängern dieser Versionen des Wunderarguments als Explanans genannt wird, anzugeben und damit eine präzise Formulierung für $H$ im Inferenzschema (IBE), ist teils unproblematisch, teils erweist es sich als schwierig. Der unproblematische Teil einer Explikation des Explanans lautet

$$
T \text { ist wahr }
$$

bzw.

$$
T \text { ist annähernd wahr. }
$$

Weniger offensichtlich ist, wie die von einigen Autoren außerdem als Teil des Explanans genannten Aussagen über die Semantik der Theorie $T$ genau aufzufassen sind, etwa die von Putnam, daß die theoretischen Ausdrücke der Theorie $T$ in theorieunabhängiger Weise referieren und daß $T$ eine Beschreibung des Verhaltens der Referenzentitäten darstellt. Putnam dürfte mit dem Stichwort theorieunabhängige Referenz auf seine kausale Referenztheorie ${ }^{62}$ Bezug nehmen; eine plausible Explikation für das von ihm ins Auge gefaßte Explanans des Wunderarguments sollte daher durch (9.4) oder (9.5) zusammen mit

Die Theorie $T$ bzw. ihre Sätze haben Wahrheitswerte, d.h. sind wahr oder falsch

gegeben sein, wobei durch die kausale Referenztheorie und eine darauf aufgebaute Korrespondenztheorie der Wahrheit erläutert wird, worin die semantische Eigenschaft der Theorie $T$ bzw. ihrer Sätze, Wahrheitswerte zu haben, besteht. Für andere Anhänger des Wunderarguments, die ähnliche Aussagen wie Putnam über die Semantik von $T$ als Teil des Explanans nennen, jedoch ohne sich auf die kausale Referenztheorie zu beziehen, sollte eine plausible Explikation für das Explanans ebenfalls durch (9.4) oder (9.5) zusammen mit (9.6) gegeben sein, wobei aber (9.6) nicht mit Hilfe der kausalen Referenztheorie erläutert wird, sondern etwa durch Tarskis Korrespondenztheorie. ${ }^{63}$ Wie im vorigen Abschnitt diskutiert, wird (9.6) samt Erläuterungen durch das Wunderargument begründet, wenn semantische Antirealisten die Diskussionsgegner sind; wenn das Wunderargument dagegen lediglich gegen epistemische Antirealisten eingesetzt wird, kann (9.6) unkontrovers sein und daher ein unproblematischer Teil des Explanans.

\footnotetext{
${ }^{59}$ Erstere z.B. in [Hemp65d], S.367f., letztere z.B. in [Musg74], S.2.

${ }^{60}$ Ein Beispiel: "For the orbit of the planet Mercury, general relativity predicts a precession rate of 43 seconds of arc per century. Precisely this residual precession rate had been observed [...] prior to the formulation of general relativity" ([Wald84], S.143).

${ }^{61}$ Vgl. z.B. [Putn78], S.20f.

${ }^{62}$ Siehe Kap.4.2.

${ }^{63}$ Siehe Abschnitt 2.4 .
} 
Für Versionen des Wunderarguments wie die von Musgrave, die sich auf nPEe als Explanandum beziehen, lassen sich in naheliegender Weise durch Ergänzung der beiden obigen Explikationen für ePEe zwei Explikationen für das Explanandum (und damit zwei präzise Formulierungen für $F$ im Schema (IBE)) gewinnen: Die beiden, etwas unterschiedlichen Explikationen für das Explanandum nPEe bestehen aus (9.1) und (9.2) bzw. aus (9.3) und (9.2), jeweils ergänzt um die Bedingung:

$P$ hat ein zum Zeitpunkt der Konstruktion von $T$ noch nicht bekanntes Phänomen zum Inhalt.

Die naheliegende Explikation für das Explanans (und damit eine präzise Formulierung für $H$ im Schema (IBE)) ist für diese Versionen des Wunderarguments dieselbe wie im Fall der ePEe, nämlich (9.4) bzw. (9.5), sowie, wenn Aussagen über die Semantik der erfolgreichen Theorie $T$ Teil des Explanans sind, (9.6), erläutert wiederum durch die kausale Referenztheorie, die Korrespondenztheorie von Tarski o.ä.

\subsubsection{Vereinheitlichungsleistungen als Explanandum}

Einige Anhänger des Wunderarguments, u.a. Smart und Carrier, nennen als Explanandum (entweder anstelle von, oder neben Prognoseerfolgen) Vereinheitlichungsleistungen einer Theorie. ${ }^{64}$ Genauer werden zwei verschiedene mögliche Leistungen einer Theorie genannt: Zum einen die Tatsache, daß eine "einfache" Theorie mehrere oder sogar eine Vielzahl verschiedenartiger beobachtbarer Phänomene abzuleiten gestattet, ${ }^{65}$ zum anderen die Tatsache, daß eine Theorie Phänomene abzuleiten gestattet, die nicht in die Konstruktion der Theorie eingegangen sind und von den darin eingegangenen verschiedenartig sind. ${ }^{6}$

Das erste dieser beiden leicht verschiedenen Explananda, also nicht weiter qualifizierte Verheitlichungsleistungen einer Theorie, stellt offenbar einen Spezialfall des Explanandums ePEe dar: Erklärungsbedürftig ist es nach dieser Version des Wunderarguments, wenn eine Theorie $T$ mehrere wahre Beobachtungssätze $P_{1}, P_{2}, \ldots$ abzuleiten gestattet, die — dies macht solche Fälle zu Spezialfällen von ePEen — verschiedenartige Phänomene zum Inhalt haben. Was dabei als verschiedenartig zählt, wird von den Anhängern dieser Argumentversion nicht genauer erläutert, es dürfte aber in vielen konkreten Fällen intuitiv verständlich und einigermaßen unkontrovers sein, was gemeint ist. Eine Explikation für dieses Explanandum (und damit eine präzise Formulierung für $F$ im Schema (IBE)) für die Rekonstruktion dieser Version des Wunderarguments ist daher durch (9.1) und (9.2) gegeben, ergänzt durch die Bedingung

$$
\begin{aligned}
& P=P_{1} \wedge P_{2} \wedge \ldots \wedge P_{n} \text { und die } P_{i} \text { haben verschiedenartige Phänomene } \\
& \text { zum Inhalt. }
\end{aligned}
$$

Eine zweite, davon etwas verschiedene Explikation bekommt man wiederum, indem man (9.1) durch (9.3) ersetzt.

Das zweite der beiden Explananda qualifiziert Vereinheitlichungsleistungen zu unbeabsichtigten Vereinheitlichungsleistungen, schränkt also den Bereich der Fälle, die zum

\footnotetext{
${ }^{64}$ Explizit berücksichtigt werden hier wiederum nur Argumentversionen, die von Erfolgen einzelner Theorien ausgehen.

${ }^{65}$ Vgl. das Zitat S.187: "[...] by stating a relatively small number of laws [...] a scientist can explain the untidy and multifarious facts about the macro-level in a relatively simple and unified manner".

${ }^{66}$ Siehe S.189.
} 
Explanandum zählen sollen, im Vergleich zum ersten der beiden Explananda ein, eben auf Fälle, in denen die ableitbaren Phänomene tatsächlich nicht in die Konstruktion der Theorie eingegangen sind und von den darin eingegangenen Phänomenen verschiedenartig sind. Eine Explikation für dieses Explanandum und damit eine präzise Formulierung für $F$ im Schema (IBE) ist daher gegeben durch (9.1), (9.2) und (9.8), ergänzt durch die weitere Bedingung

Einige der $P_{i}$ sind nicht in die Konstruktion von $T$ eingegangen.

Eine zweite, davon etwas verschiedene Explikation bekommt man wiederum, indem man (9.1) durch (9.3) ersetzt.

\subsubsection{Handlungserfolge als Explanandum}

Putnam nennt als Explanandum des Wunderarguments neben Prognoseerfolgen einer Theorie gelegentlich Handlungserfolge, die jemand erzielt, der über die Theorie verfügt. ${ }^{67}$ Diese beiden Explananda scheinen zumindest prima facie verschieden zu sein, andererseits aber auch systematisch zusammenzuhängen. Wie das Explanandum Handlungserfolge für das Wunderargument präzise zu formulieren oder zu explizieren ist und wie es genau mit Prognoseerfolgen zusammenhängt, scheint jedoch nicht offensichtlich.

\section{Präzise Formulierungen für Explanandum und Explanans}

Daß jemand, der über eine Theorie $T$ verfügt, mit deren Hilfe Handlungserfolge erzielt, heißt, zumindest in einfachen Fällen, ${ }^{68}$ etwa folgendes:

Eine Person $A$, die über die Theorie $T$ verfügt, die wünscht, daß der durch $Q$ beschriebene Sachverhalt eintritt, und die überzeugt ist, daß $P \rightarrow Q$ aus $T$ ableitbar ist, ${ }^{69}$ handelt daher so, daß der durch $P$ beschriebene Sachverhalt eintritt, und führt dadurch den gewünschten, durch $Q$ beschriebenen Sachverhalt herbei. ${ }^{70}$

Das so zunächst grob charakterisierte Explanandum Handlungserfolge ist offenbar komplexer als die bisher diskutierten Explananda für das Wunderargument, insbesondere besteht es nicht nur aus einer Reihe nebeneinanderstehender Aussagen, sondern einige dieser Aussagen stehen (wie durch den Ausdruck 'daher' angedeutet) bereits untereinander in einem

\footnotetext{
${ }^{67} \mathrm{Vgl}$. S.186.

${ }^{68}$ Neben den hier berücksichtigten Überzeugungen können z.B. auch Wahrnehmungen, weitere komplexere Überzeugungen, Inferenzen u.ä. in das Explanandum eingehen; solche Komplikationen bleiben hier beiseite.

${ }^{69}$ Hier bleiben mögliche Unterscheidungen von verschiedenen Elementen innerhalb von $T$ wiederum beiseite (s. Fn.56). Ebenso bleiben die Probleme beiseite, die damit zusammenhängen, daß es für realexistierende physikalische Theorien eher selten so sein dürfte, daß eine "Handlungsstrategie" wie $P \rightarrow Q$ wirklich im strengen Sinn ableitbar ist. Beiseite bleibt schließlich auch die Frage, ob eine "Handlungsstrategie" nicht einen kausalen, gesetzmäßigen o.ä. Zusammenhang zwischen $P$ und $Q$ voraussetzt und, falls ja, ob dies durch $P \rightarrow Q$ adäquat repräsentiert werden kann.

${ }^{70}$ Wenn das Wunderargument "nur" gegen epistemische Antirealisten als Diskussionsgegner eingesetzt werden soll und die semantische Vollwertigkeit von $T$ unkontrovers ist (siehe Abschnitt 9.2.2), kann man diese bei der Formulierung des Explanandum voraussetzen, d.h. man kann Handlungserfolge erläutern als

Eine Person $A$, die glaubt, daß T, die wünscht, daß ..."
}

Für das Folgende macht dies keinen wesentlichen Unterschied. 
explanatorischen Zusammenhang. Eine ausführlichere Formulierung für dieses Explanandum Handlungserfolge, die diesen "internen" explanatorischen Zusammenhang explizit macht, lautet:

(1) $A$ wünscht, daß der durch $Q$ beschriebene Sachverhalt eintritt

(2) $A$ verfügt über die Theorie $T^{71}$

(3) $A$ glaubt, daß $T \vdash P \rightarrow Q$

(4) Wenn $A$ glaubt, daß $T \vdash X$, dann glaubt $A$, daß $X$

(5) $A$ glaubt, daß $P \rightarrow Q$

(aus (2), (3) und (4))

(6) Wenn $A$ wünscht, daß der durch $Y$ beschriebene Sachverhalt eintritt, und glaubt, daß $X \rightarrow Y,{ }^{72}$ dann handelt $A$ so, daß der durch $X$ beschriebene Sachverhalt eintritt

(7) $A$ handelt so, daß der durch $P$ beschriebene Sachverhalt eintritt

$$
\text { (aus (1), (5) und (6)) }
$$

(8) Der durch $Q$ beschriebene Sachverhalt tritt ein.

Das so explizierte Explanandum Handlungserfolge enthält also eine Art psychologische Erklärung für das Zustandekommen der Handlungen, die die Handlungserfolge ausmachen bzw. nach sich ziehen. Diese psychologische Erklärung besteht aus den Aussagen (1) bis (6), aus denen (7) folgt; sie erklärt, warum die Person $A$ so handelt, daß der durch $P$ beschriebene Sachverhalt eintritt, und zwar durch $A$ 's Wunsch, daß der durch $Q$ beschriebene Sachverhalt eintritt, $A$ 's Verwendung der Theorie $T$ zur Gewinnung von Überzeugungen und die durch (6) beschriebenen allgemeinen psychologischen "Mechanismen", die in Abhängigkeit von Wünschen und Überzeugungen Handlungen "auslösen". Zu erklären ist an dem so explizierten Explanandum Handlungserfolge, warum $A$ mit einer so charakterisierten Handlung Erfolg hat, also ihren Wunsch realisieren kann. Anders ausgedrückt: Zu erklären ist die Übereinstimmung von $A$ 's Wunsch mit dem tatsächlich durch ihre Handlung herbeigeführten Sachverhalt oder, wenn $A$ mit Hilfe der Theorie $T$ nicht nur einen, sondern eine Vielzahl von Handlungserfolgen erzielt, die Korrelation von $A$ 's Wünschen mit den tatsächlichen Folgen ihrer Handlungen.

Wie das Explanans zum Explanandum Handlungserfolge lautet, wird von Putnam nur angedeutet, ${ }^{73}$ eine plausible Explikation dafür lautet offenbar (der Übersichtlichkeit halber als Liste von einzelnen Aussagen geschrieben):

(9) Die Theorie $T$ bzw. ihre Sätze haben Wahrheitswerte, d.h. sind wahr oder falsch $^{74}$

(10) $T$ ist wahr ${ }^{75}$

(11) $A$ 's Überzeugung, daß $T \vdash P \rightarrow Q$, ist wahr

(12) $A$ 's Überzeugung, daß $P \rightarrow Q$, ist wahr.

\footnotetext{
${ }^{71}$ Wenn das Wunderargument "nur" gegen epistemische Antirealisten eingesetzt werden soll, kann hier stehen "A glaubt, daß T"; siehe Fn.70.

${ }^{72} \mathrm{Zu}$ ergänzen sind hier evtl. noch Bedingungen darüber, daß $A$ den durch $X$ beschriebenen Sachverhalt herbeiführen kann, und das auch glaubt.

${ }^{73} \mathrm{Vgl}$. das Zitat S.187: "The explanation is that certain kinds of beliefs we hold tend to be true".

${ }^{74}$ S. Fn.70.

${ }^{75}$ Die mögliche Abschwächung zu annähernd wahr bleibt hier beiseite.
} 
(9) ist für Putnams Version des Wunderarguments wiederum mit Hilfe der kausalen Referenztheorie und einer darauf aufgebauten Korrespondenztheorie der Wahrheit zu erläutern, grundsätzlich ist aber auch einer Erläuterung mit Hilfe von Tarskis Korrespondenztheorie o.ä. denkbar.

Das so explizierte Explanans erklärt das Explanandum Handlungserfolge offenbar insofern, als (8) aus (7) und (12) folgt. Daß $A$ mit ihrer in (7) genannten Handlung (deren Zustandekommen bereits im Explanandum psychologisch erklärt ist) Erfolg hat, also die Übereinstimmung von $A$ 's Wunsch, der durch (1) beschrieben wird, mit der tatsächlichen Handlungsfolge (8), wird erklärt durch die Wahrheit von $A$ 's in (5) genannter Überzeugung über die Folgen ihrer Handlung, d.h. durch (12). (12) wiederum folgt aus (9) bis (11), d.h. aus der semantischen Vollwertigkeit und Wahrheit von $T$ und der Wahrheit von $A$ 's Überzeugung, daß $P \rightarrow Q$ aus $T$ ableitbar ist. Dieses zuletzt genannte Implikationsverhältnis von (9) bis (11) und (12) zeigt, daß die zum Explanans zählenden Aussagen offenbar bereits untereinander in einem explanatorischen Zusammenhang stehen (genau wie die Aussagen des obigen Explanandums).

Mit diesen beiden Explikationen für Explanandum und Explanans hat man präzise Formulierungen für $F$ und $H$ im Schema (IBE), um die von Putnam angedeutete Version des Wunderarguments, die sich auf Handlungserfolge bezieht, die jemand mit Hilfe einer Theorie $T$ erzielt, in der Form des Schließens auf die beste Erklärung zu rekonstruieren.

Wie diese Version des Wunderarguments und ihr Explanandum Handlungserfolge mit der Version des Wunderarguments zusammenhängt, die sich auf Prognoseerfolge bezieht, läßt sich jetzt erkennen, wenn man die Rolle ins Auge faßt, die die Theorie $T$ im Explanandum Handlungserfolge und im zugehörigen Explanans spielt. Dabei sieht man zweierlei. Erstens sieht man, daß sowohl die im Explanandum Handlungserfolge enthaltene psychologische Erklärung, als auch die Erklärung eines Handlungserfolges durch das angegebene Explanans aus zwei Teilerklärungen bestehen und daß die Theorie $T$ jeweils nur in der zweiten Teilerklärung eine Rolle spielt. Wenn man diese zweite Teilerklärung genauer in den Blick nimmt, sieht man, zweitens, daß eine solche Erklärung sozusagen aus zwei parallelen Strängen besteht und daß nur in einem davon die semantische Vollwertigkeit und Wahrheit von $T$ eine Rolle spielen. Beide Befunde zusammen haben zur Folge, daß das Explanandum ePEe in einem bestimmten Sinn den im Hinblick auf das Wunderargument wesentlichen Kern des Explanandums Handlungserfolge darstellt. Die Überlegung ist im einzelnen die Folgende.

\section{Die Erklärung von Handlungserfolgen besteht aus zwei Teilerklärungen}

Wenn man die Rolle, die die Theorie $T$ im Explanandum Handlungserfolge und im zugehörigen Explanans spielt, genauer ins Auge faßt, sieht man, daß sowohl die im Explanandum Handlungserfolge enthaltene psychologische Erklärung, als auch die Erklärung eines Handlungserfolges durch das angegebene Explanans aus zwei Teilerklärungen bestehen. Die psychologische Erklärung besteht aus einem Teil, der erklärt, wie A's Handlung (7) zustandekommt, nämlich aufgrund ihrer Überzeugung über die Folgen dieser Handlung (d.h. (5)), aufgrund des Wunsches (1) sowie aufgrund des psychologischen "Mechanismus" (6), und aus einem weiteren Teil, der erklärt, wie $A$ 's bei der Entscheidung für ihre Handlung vorausgesetzte Überzeugung (5) zustandekommt, nämlich durch Ableiten aus der Theorie $T((2)$ bis (4)). Die Theorie $T$ ist nur im zweiten dieser beiden Teile involviert; bei der Erklärung, wie A's Handlung zustandekommt, spielt $T$ keine direkte Rolle, sondern erst dann, wenn auch das Zustandekommen der in (5) genannten Überzeugung erklärt 
werden soll. Die Erklärung eines Handlungserfolges durch das angegebene Explanans besteht aus einem Teil, der die Übereinstimmung von $A$ 's Wunsch (1) und der Folge von $A$ 's Handlung (8) erklärt, nämlich dadurch, daß $A$ 's Wunsch (wie durch die psychologische Erklärung dargelegt) $A$ 's Handlung (7) zur Folge hat, sowie durch (12), die Wahrheit von $A$ 's Überzeugung, daß $P \rightarrow Q$, also die Wahrheit von $A$ 's Überzeugung über die Folgen ihrer Handlung, und aus einem weiteren Teil, in dem die Wahrheit von $A$ 's letzterer Überzeugung (d.h. (12)) erklärt wird durch die semantische Vollwertigkeit und Wahrheit von $T$ und die Wahrheit von $A$ 's Überzeugung, daß $P \rightarrow Q$ aus $T$ ableitbar ist, ((9) bis (11)). Die Theorie $T$ ist wiederum nur im zweiten der beiden Teile involviert; bei der Erklärung der Übereinstimmung von $A$ 's Wunsch und den Folgen ihrer Handlung spielt $T$ keine direkte Rolle, sondern erst dann, wenn auch (12), also die Wahrheit von $A$ 's Überzeugung über die Folgen ihrer Handlung erklärt werden soll.

Die mit dem Explanandum Handlungserfolge gestellte Erklärungsaufgabe läßt sich also offenbar in zwei Teile zerlegen: Erstens soll erklärt werden, warum die Folgen einer Handlung, die aufgrund eines bestimmten Wunsches und einer bestimmten Überzeugung über die Folgen dieser Handlung zustandegekommen ist, mit dem Inhalt des Wunsches "übereinstimmen"; dies wird durch die Wahrheit der genannten Überzeugung erklärt. Zweitens soll die Wahrheit dieser (durch Ableiten aus einer Theorie gewonnenen) Überzeugung erklärt werden; diese wird durch die semantische Vollwertigkeit und Wahrheit der Theorie erklärt. Dieser zweite Teil der Erklärungsaufgabe, die durch das Explanandum Handlungserfolge gegeben ist, stellt offenbar einen Spezialfall eines wesentlich allgemeineren Typs von Explanandum samt zugehöriger Erklärung dar: Dieses allgemeinere Explanandum lautet, daß die Überzeugung einer Person $A$, daß P, die diese durch Ableiten aus einer Theorie $T$ gewonnen hat, wahr ist (oder entsprechendes für mehrere Überzeugungen). Die zugehörige allgemeinere Erklärung lautet, daß die Theorie $T$ semantisch vollwertig und wahr ist und daß $A$ 's Überzeugung, daß $P$ aus $T$ ableitbar ist, wahr ist. Der zweite Teil des Explanandums Handlungserfolge stellt davon den Spezialfall dar, in dem die Überzeugung, daß $P$, einen speziellen Inhalt hat, nämlich die Folgen einer von $A$ ausführbaren Handlung, genauer: die Folgen einer von $A$ ausführbaren Handlung, die einem Wunsch von $A$ entsprechen. Eine ausführliche Formulierung für das allgemeinere Explanandum lautet:

( $\left.2^{*}\right) A$ verfügt über die Theorie $T^{76}$

$\left(3^{*}\right) A$ glaubt, daß $T \vdash P$

(4*) Wenn $A$ glaubt, daß $T \vdash X$, dann glaubt $A$, daß $X$

(5*) $A$ glaubt, daß $P$ $\left(\right.$ aus $\left(2^{*}\right),\left(3^{*}\right)$ und $\left.\left(4^{*}\right)\right)$

$\left(8^{*}\right)$ 's Überzeugung, daß $P$, ist wahr

Das Explanans ist entsprechend

( $\left.9^{*}\right)$ Die Theorie $T$ bzw. ihre Sätze haben Wahrheitswerte, d.h. sind wahr oder falsch

$\left(10^{*}\right) T$ ist wahr

$\left(11^{*}\right) A$ 's Überzeugung, daß $T \vdash P$, ist wahr.

Das Explanandum wird durch das Explanans erklärt, insofern $\left(8^{*}\right)$ aus $\left(9^{*}\right)$ bis $\left(11^{*}\right)$ folgt.

Die Rolle, die die semantische Vollwertigkeit und Wahrheit der Theorie $T$ bei der Erklärung von Handlungserfolgen spielen, läßt sich in diesem Sinn als Spezialfall einer

\footnotetext{
${ }^{76}$ S. Fn.70.
} 
allgemeiner beschreibbaren Rolle auffassen, für die Handlungen nicht wesentlich sind: Die semantische Vollwertigkeit und Wahrheit einer Theorie $T$ können allgemein die Wahrheit von Überzeugungen erklären, die durch Ableiten aus $T$ gewonnen wurden. Dies gilt u.a. auch, aber nicht nur für Fälle, in denen die fraglichen Überzeugungen die Folgen einer Handlung zum Inhalt haben und damit ihrerseits den Erfolg dieser Handlung erklären können.

\section{Die Erklärung der Wahrheit einer aus einer Theorie abgeleiteten Überzeugung besteht aus zwei parallelen Erklärungssträngen}

Wenn man die Rolle, die die Theorie $T$ im Explanandum Handlungserfolge und dem zugehörigen Explanans spielt, ins Auge faßt, sieht man also, daß $T$ bei der Erklärung von Handlungserfolgen "nur" in einer Teilerklärung vorkommt, die einen Spezialfall eines allgemeinere Typs von Erklärung darstellt. Wenn man diesen allgemeineren Typ, die Erklärung der Wahrheit einer durch Ableiten aus einer Theorie gewonnenen Überzeugung, genauer in den Blick nimmt, sieht man außerdem, daß eine solche Erklärung sozusagen aus zwei parallelen Strängen besteht und daß nur in einem davon die semantische Vollwertigkeit und Wahrheit der Theorie eine Rolle spielen.

Die Überlegung ist folgende: Die Sätze $\left(8^{*}\right)$ und $\left(11^{*}\right)$ lassen sich in Konjunktionen umformulieren, nämlich in 77

(8*) $A$ glaubt, daß $P$, und $P$ ist wahr

$\left(11^{* *}\right) A$ glaubt, daß $T \vdash P$, und $T \vdash P$ ist wahr.

Nach dieser Umformung sieht man, daß ein Teil des Gehaltes von $\left(11^{*}\right)$, nämlich der, der in der neuen Formulierung durch das erste Konjunktionsglied ausgedrückt wird, bereits im Explanandum enthalten ist, nämlich als $\left(3^{*}\right)$. $\left(8^{*}\right)$ gehörte ohnehin zum Explanandum, man sieht aber jetzt, daß ein Teil seines Gehaltes sozusagen redundant ist, denn das erste Konjunktionsglied der neuen Formulierung entspricht $\left(5^{*}\right)$. Was dem Explanandum durch das Explanans hinzugefügt wird, ist also "nur" das zweite Konjunktionsglied von $\left(11^{* *}\right)$

$\left(11^{* *} b\right) T \vdash P$ ist wahr

sowie $\left(9^{*}\right)$ und $\left(10^{*}\right)$.

Damit wird die Struktur der genannten Erklärung für das Explanandum Wahrheit einer durch Ableiten aus der Theorie $T$ gewonnenen Überzeugung durchsichtiger: Bisher sah es so aus, als ob die Erklärungsleistung darin besteht, daß $\left(8^{*}\right)$ aus $\left(9^{*}\right)$ bis $\left(11^{*}\right)$ folgt; dafür scheinbar irrelevant stand die im Explanandum enthaltene psychologische Erklärung von (5) durch (2) bis (4) sozusagen beziehungslos daneben. Jetzt, nach der Umformung, sieht man, daß die Erklärung von $\left(8^{* *}\right)$ sozusagen durch zwei parallele und in bestimmter Hinsicht unabhängige Schlüsse erfolgt. Die Erklärung der Wahrheit einer aus einer Theorie $T$ abgeleiteten Überzeugung, daß $P$, besteht gleichsam aus zwei parallelen Strängen: der psychologischen Erklärung dafür, wie die Person $A$ zu der Überzeugung, daß $P$, kommt (also der bereits im Explanandum enthaltenen Erklärung von $\left(5^{*}\right)$ durch $\left(2^{*}\right)$ bis $\left(4^{*}\right)$ ), und der Erklärung dafür, daß $P$ wahr ist, also der Ableitung von

\footnotetext{
${ }^{77}$ Bei dieser Umformulierung ist vorausgesetzt, daß Überzeugungen bzw. ihre Wahrheit über Sätze zu erläutern sind (wie etwa in [Fiel78] skizziert). Die folgende Argumentation funktioniert aber genauso, wenn man Überzeugungen unter Bezugnahme auf Propositionen erläutert. Anstelle von ( $\left.8^{* *}\right)$ müßte dann etwa stehen:

$A$ glaubt, daß $P$, und die Proposition, daß $P$, ist wahr

usw.
} 
$\left(8^{* *} b\right) P$ ist wahr

aus $\left(9^{*}\right),\left(10^{*}\right)$ und $\left(11^{* *} b\right)$. Der psychologische Erklärungsstrang erklärt, wie die Überzeugung, daß $P$, zustandekommt, der zweite Erklärungsstrang erklärt die Wahrheit des Satzes $P$ dadurch, daß er sich aus einer semantisch vollwertigen und wahren Theorie ableiten läßt. Die beiden Erklärungsstränge sind in dem Sinn parallel, daß der Satz $P$ und die Ableitbarkeitsrelation, von denen im zweiten Erklärungsstrang die Rede ist, gerade den Inhalt der Überzeugungen darstellen, die im psychologischen Erklärungsstrang vorkommen, und daß auch die Theorie $T$ in beiden Strängen dieselbe ist. Die beiden Erklärungsstränge sind dennoch unabhängig in dem Sinn, daß man die psychologische (kausale) Rolle von Überzeugungen von ihren Wahrheitswerten getrennt betrachten kann und die "psychologische" Verwendung einer Theorie durch eine Person von der semantischen Vollwertigkeit und Wahrheit dieser Theorie.

Von diesen beiden Erklärungssträngen involvieren zwar beide die Theorie $T$, aber nur der zweite, nicht-psychologische dieser Stränge involviert die semantische Vollwertigkeit und die Wahrheit der Theorie $T$ und damit das, was für das Argumentationsziel des Wunderarguments relevant ist, nur dort erbringen die semantische Vollwertigkeit und die Wahrheit von $T$ sozusagen eine Erklärungsleistung. Außerdem kommen nur im zweiten dieser Erklärungsstränge im Explanans Annahmen zum Einsatz, die nicht bereits im Explanandum enthalten waren. Im Hinblick auf das Wunderargument stellt dieser zweite nicht-psychologische Erklärungsstrang daher gewissermaßen den Kern der Erklärung des Explanandums Wahrheit einer durch Ableiten aus einer Theorie gewonnenen Überzeugung dar, denn nur in diesem Erklärungsstrang treten überhaupt Annahmen auf, die nicht bereits Teil des Explanandums waren, d.h. deren Erklärungsleistungen evtl. als Argument für diese Annahmen benötigt werden bzw. eingesetzt werden brauchen, insbesondere eben die Annahmen, die das Argumentationsziel des Wunderarguments darstellen, nämlich, daß die Theorie $T$ semantisch vollwertig und wahr ist. Im Hinblick auf das Wunderargument kann man daher diesen zweiten, nicht-psychologischen Erklärungsstrang isoliert betrachten. Wenn in einem konkreten Fall als Explanandum die Wahrheit einer durch Ableiten aus einer Theorie gewonnenen Überzeugung, daß $P$, gegeben ist, kann man für die Wahrheit von $P$ eine Erklärung von der Art des zweiten, nicht-psychologischen Strangs konstruieren; wenn man aufgrund der Erklärungsleistungen der dabei als Explanans fungierenden Annahmen auf diese Annahmen schließen kann und wenn die so konstruierten Erklärung "parallel" zu dem im Explanandum enthaltenen psychologischen Erklärungsstrang verläuft, ${ }^{78}$ dann hat man damit ohne einen weiteren Schluß die "volle" Erklärung der Wahrheit der Überzeugung, daß $P$.

Der zweite, nicht-psychologische Strang einer Erklärung für die Wahrheit einer aus einer Theorie $T$ abgeleiteten Überzeugung, weist, getrennt betrachtet, offenbar weitgehende Ähnlichkeit mit der vorne diskutierten Erklärung für ePEe auf. Ein Unterschied besteht allerdings: Das Explanandum ePEe war vorne expliziert worden durch (9.1) und (9.2), das zugehörige Explanans durch (9.4) und (9.6); vergleicht man dies mit der Erklärung von $\left(8^{* *} b\right)$ durch $\left(9^{*}\right),\left(10^{*}\right)$ und $\left(11^{* *} b\right)$, dann sieht man, daß alle "Elemente" der beiden Erklärungen identisch sind bis auf den einen Unterschied, daß erstere die Aussage (9.1), daß $T \vdash P$, enthält, und zwar als Teil des Explanandums, die letztere dagegen die Aussage $\left(11^{* *} b\right)$, daß $T \vdash P$ wahr ist, und zwar als Teil des Explanans. Dieser Unterschied ist jedoch kein substantieller: Die (metasprachliche) Aussage, daß $T \vdash P$ wahr ist, im-

\footnotetext{
${ }^{78}$ D.h. wenn in beiden Erklärungssträngen dieselbe Theorie $T$ involviert ist.
} 
pliziert $^{79}$ die (objektsprachliche) Aussage, daß $T \vdash P$, und ihre Rolle für die Erklärung besteht gerade in dieser "Implikationsleistung", danach tritt in der Erklärung nur noch die Aussage, daß $T \vdash P$, auf. Daß der durch $T \vdash P$ beschriebene Sachverhalt einmal zum Explanans gezählt wird und einmal zum Explanandum, hat "nur" den Grund, daß beim Explanandum Wahrheit der aus einer Theorie abgeleiteten Überzeugungen, so wie es oben expliziert wurde, zunächst eine etwas größere Menge von Fällen als Kandidaten für eine Erklärung zugelassen werden als beim Explanandum ePEe: Es fallen offenbar auch Fälle darunter, in denen offen ist, ob $P$ tatsächlich, wie $A$ es glaubt, aus $T$ ableitbar ist; dagegen werden beim Explanandum ePEe von vorneherein nur Fälle betrachtet, in denen $P$ tatsächlich aus $T$ ableitbar ist. Praktisch spielt diese Differenz im Zusammenhang mit dem Wunderargument jedoch keine Rolle, da es dort nie ein epistemisches Problem ist, festzustellen, ob $P$ aus $T$ ableitbar ist, und man auf das Bestehen dieser Ableitbarkeitsbeziehung jedenfalls nicht aufgrund der Erklärungsleistung einer entsprechenden Annahme schließt, sondern es durch "Nachrechnen" feststellt. Die Rolle dieser unabhängig vom Wunderargument gewonnenen bzw. begründeten Annahme über die Ableitbarkeit von $P$ aus $T$ bei den beiden oben genannten "ähnlichen" Erklärungen ist dieselbe, egal ob man diese Annahme "offiziell" zum Explanandum oder zum Explanans zählt: In beiden Fällen impliziert der Satz, daß $P$ aus $T$ ableitbar ist, zusammen mit der Wahrheit von $T$ die Wahrheit von $P .{ }^{80}$ Von dem genannten unwesentlichen Unterschied in der genauen Formulierung von Explanans und Explanandum abgesehen ist also der nicht-psychologische Strang der Erklärung des Explanandums Wahrheit einer aus einer Theorie T abgeleiteten Überzeugung identisch mit der Erklärung eines ePEes, wie sie in den entsprechenden vorne diskutierten Versionen des Wunderarguments in Anspruch genommen werden.

\section{Der Zusammenhang des Explanandums Handlungserfolge und des Explanan- dums ePEe}

Damit ist klar, wie die Version des Wunderarguments, die sich auf das Explanandum Handlungserfolge bezieht, mit der Version des Wunderarguments zusammenhängt, die sich auf das Explanandum ePEe bezieht: Wenn man die erstere Version des Wunderarguments als Argument für die semantische Vollwertigkeit und Wahrheit einer Theorie einsetzen will, kann man den Schritt vom Explanandum zum Explanans in zwei Schlüsse zerlegen, die den oben genannten beiden Teilerklärungen entsprechen. Der erste dieser Schlüsse müßte, ausgehend vom Explanandum, die Wahrheit der Überzeugung der handelnden Person über die Folgen ihrer Handlung (12) als Konklusion ergeben, der zweite dieser Schlüsse müßte von da aus weiter auf die semantische Vollwertigkeit und Wahrheit der Theorie $\left(\left(9^{*}\right)\right.$ und $\left(10^{*}\right)$ ) führen. Wenn man die Version des Wunderarguments, die sich auf ePEe bezieht, als Argument für die semantische Vollwertigkeit und Wahrheit einer Theorie einsetzen will, ist "nur" ein Schluß erforderlich, der von einem ePE "direkt" auf die semantische Vollwertigkeit und Wahrheit der Theorie $\left(\left(9^{*}\right)\right.$ und $\left.\left(10^{*}\right)\right)$ führt. Wie oben erläutert, stellt ein Schluß dieser zuletzt genannten Art den wesentlichen Kern des zweiten der beiden Schlüsse dar, die in der Version des Wunderarguments, die sich auf Handlungserfolge bezieht, vom Explanandum zum Argumentationsziel führen. Anders ausgedrückt: Der erste

\footnotetext{
${ }^{79}$ Zusammen mit der Übersetzung zwischen Meta- und Objektsprache und dem Schema (T); vgl. Abschnitt 2.4 .

${ }^{80}$ Bei der Erklärung des Explanandums ePEe ist es (anders als bei dem nicht-psychologischen Strang der Erklärung des Explanandums Wahrheit einer aus einer Theorie abgeleiteten Überzeugung) nicht so, daß alle das Explanandum darstellenden Sätze aus dem Explanans deduktiv folgen. Vielmehr wird mit Hilfe des Explanans ein deduktiver Zusammenhang zwischen den beiden Teilen des Explanandums hergestellt.
} 
der beiden Schlüsse, die in der Version des Wunderarguments, die sich auf Handlungserfolge bezieht, vom Explanandum zum Argumentationsziel führen, ergibt eine Konklusion, die "im wesentlichen" einen Spezialfall des Explanandums ePEe darstellt.

Gegeben diese Sachlage ist klar, daß die Version des Wunderarguments, die sich auf Handlungserfolge bezieht, als erweiterter Spezialfall der Version, die sich auf ePEe bezieht, betrachtet werden kann. Wenn die Version des Wunderarguments mit dem Explanandum ePEe als korrektes, überzeugungskräftiges Argument etabliert bzw. verteidigt werden kann, dann ist damit auch der wesentliche Schritt zur Etablierung bzw. Verteidigung der Version des Wunderarguments mit dem Explanandum Handlungserfolge getan: Sofern man Fälle des Explanandums Handlungserfolge der oben explizierten Form aufweisen kann und sofern man in diesen Fällen den ersten Schluß (auf (12)) etablieren bzw. verteidigen kann (was i.a. in irgendeiner Weise induktiv möglich sein sollte), ${ }^{81}$ hat man damit einen Fall des Explanandums ePEe, d.h. man kann sozusagen die Version des Wunderarguments mit dem Explanandum ePEe anwenden, und erhält durch den entsprechenden Schluß, zusammengenommen mit Teilen des Explanandums Handlungserfolge, das Explanans für Handlungserfolge in der oben explizierten Form.

Die Versionen des Wunderarguments, die sich auf Handlungserfolge beziehen, lassen sich in diesem Sinn als etwas erweiterter Anwendungsfall der Versionen auffassen, die sich auf ePEe beziehen. Diese Lesart ist aber natürlich nicht zwingend, d.h. der Übergang vom Explanandum Handlungserfolge zum oben genannten Explanans kann auch als ein (nicht weiter "unterteilter") Schluß, also unabhängig von einem Zusammenhang mit ePEen, aufgefaßt werden.

\subsection{Die Versionen des Wunderarguments als Schlüsse auf die beste Erklärung: Die Version von Boyd}

Boyds Version des Wunderarguments läßt sich ohne Probleme als ein Schluß auf die beste Erklärung rekonstruieren. Boyd argumentiert sozusagen en bloc für eine realistische Einstellung in bezug auf die Gesamtheit der Theorien der reifen Naturwissenschaften, sein Argument zielt auf einen "unfragmentierten Realismus": 82

"What we have in the scientific method is a theoretical-presupposition-dependent total-science modification procedure, a procedure or strategy for deciding which modifications or additions to make to our existing body of accepted theories. If the total science with which we begin is relevantly sufficiently true and comprehensive, then the operation of this method will tend to ensure that later total sciences are successively more accurate and more comprehensive." 83

Boyds unmittelbarer Ansatzpunkt ist zunächst die instrumentelle Verläßlichkeit einzelner Prinzipien, Verfahren etc., also ihre Verläßlichkeit bei der Gewinnung oder Etablierung von Theorien, die annähernd wahre Prognosen liefern. ${ }^{84}$ Daß Explanans und Explanandum seiner Version des Wunderarguments dennoch die Gesamtheit der Theorien der Naturwissenschaften involvieren, kann man sich folgendermaßen zurechtlegen: Die Gewinnung und

\footnotetext{
${ }^{81}$ Und sofern man außerdem (s.o.) in verläßlicher Weise feststellen kann, daß $T \vdash P \rightarrow Q$.

${ }^{82}$ [Boyd90b], S.176.

83 [Boyd81], S.623, Hervorhebung von mir; s.a. Boyds Plädoyer für "the integrity of scientific realism" in [Boyd90b].

${ }^{84}$ Vgl. [Boyd81], S.621, [Boyd73], S.3.
} 
Etablierung einer Theorie erfordert im allgemeinen den Einsatz mehrerer Prinzipien oder Verfahren. Außerdem setzt eine Beurteilung der Verläßlichkeit jedes einzelnen Prinzips oder Verfahrens seine Anwendung in einer Vielzahl von Fällen voraus. Da weiterhin schon bei der Anwendung eines Prinzips oder Verfahrens bei der Gewinnung oder Etablierung einer Theorie mehrere Hintergrundtheorien eingehen können, ergibt sich insgesamt eine Art Vernetzung der Theorien und Prinzipien, Verfahren etc., die dazu führt, daß nur die Gesamtheit der Prinzipien und Verfahren im Hinblick auf ihre Verläßlichkeit bewertet und dann zum Ausgangspunkt von Boyds Argument werden kann und daß sein Explanans entsprechend den gesamten Bestand an Theorien betrifft, die zu einem Zeitpunkt etabliert sind.

Boyds Argumentation richtet sich gegen das ganze Spektrum antirealistischer Positionen, also sowohl gegen epistemische, als auch gegen semantische Antirealisten. ${ }^{85}$

Eine präzise Formulierung für das Explanandum von Boyds Version des Wunderarguments (und damit für $F$ im Schema (IBE)) ist

Die Gesamtheit der Prinzipien, Verfahren etc. der Wissenschaften, die sich auf die zum jeweiligen Zeitpunkt akzeptierten Theorien $\left\{T_{i}^{a l t}\right\}$ stützen,

liefert in verläßlicher Weise neue Theorien $\left\{T_{i}^{\text {neu }}\right\}$, die ihrerseits annähernd wahre Prognosen liefern,

wobei mit "annähernd wahre Prognosen" ePEe, wie in (9.1) und (9.2) oder in (9.3) und (9.2) erläutert, gemeint sind, ${ }^{86}$ allerdings mit der Modifikation, daß die prognostizierten Sätze "nur" annähernd wahr sein müssen.

Eine präzise Formulierung für Boyds Explanans (und damit für $H$ im Schema (IBE)) lautet:

Die Theorien $\left\{T_{i}^{a l t}\right\}$ sind annähernd wahr

und

Die Theorien $\left\{T_{i}^{a l t}\right\}$ bzw. ihre Sätze haben Wahrheitswerte, d.h. sie sind wahr oder falsch.

Boyd meint, daß seine Diskussionsgegner keine alternativen Erklärungen für das Explanandum seiner Version des Wunderarguments anzubieten haben. ${ }^{87}$

\subsection{Die Versionen des Wunderarguments als Schlüsse auf die beste Erklärung: Die Version von Carrier}

Die von Carrier favorisierte Version des Wunderarguments bezieht sich, wie die von Boyd, nicht auf einzelne Theorien, sondern auf die Gesamtheit der Theorien der reifen Naturwissenschaften. Carriers Argument setzt semantischen Realismus voraus und soll "nur" gegen epistemische Antirealisten als Diskussionsgegner eingesetzt werden. ${ }^{88}$

\footnotetext{
${ }^{85} \mathrm{Vgl}$. [Boyd81, Boyd91].

${ }^{86}$ Die Differenz zwischen beiden Lesarten scheint auch hier nicht relevant zu sein.

${ }^{87}$ Boyds Version des Wunderarguments wird an einigen Stellen auch von Putnam genannt (vgl. das Zitat S.186 und [Putn78], S.20ff.). Putnam scheint sie zusätzlich zu seiner Version des Wunderarguments in Anspruch nehmen zu wollen, er trennt allerdings die verschiedenen Explananda bzw. Argumentversionen nicht sauber.

${ }^{88}$ Es kann aber natürlich zu einem Argument gegen semantische Antirealisten ergänzt werden.
} 
Carriers Argument zeichnet sich dadurch aus, daß neue Prognoseerfolge und unbeabsichtigte Vereinheitlichungsleistungen das Explanandum darstellen. ${ }^{89}$ Eine plausible präzise Formulierung für dieses Explanandum und damit für $F$ im Schema (IBE) ist:

Unter den Theorien der Naturwissenschaften gibt es einige, die erfolgreiche neue Prognosen liefern und/oder unbeabsichtigte Vereinheitlichungsleistungen erbringen,

wobei mit "erfolgreiche neue Prognosen" nPEe, wie in (9.1), (9.2) und (9.7) oder in (9.3), (9.2) und (9.7) erläutert, gemeint sind und mit "unbeabsichtigte Vereinheitlichungsleistungen" qualifizierte ePEe, wie in (9.1), (9.2), (9.8) und (9.9) oder in (9.3), (9.2), (9.8) und (9.9) erläutert. Eine präzise Formulierung für das Explanans und damit für $H$ im Schema (IBE) ist:

Die in den in puncto neue Prognosen und unbeabsichtigte Vereinheitlichungsleistungen erfolgreichen Theorien der Naturwissenschaften enthaltenen Aussagen über die Klassifikation von Phänomenen nach Arten, die für die Erfolge der Theorien verantwortlich sind, sind wahr. ${ }^{90}$

Nach Carrier spricht die historische Erfahrung dafür, daß dies das korrekte Explanans ist, nicht die ebenfalls in Frage kommende, weniger "vorsichtige" Aussage, daß die Gesamtheit der erfolgreichen Theorien (annähernd) wahr ist, denn es sind zumindest bisher keine Beispiele für Theorien bekannt, die im genannten Sinn erfolgreich waren, bei denen aber die in ihnen enthaltenen Aussagen über die Klassifikation von Phänomenen falsch sind, die für die Erfolge verantwortlich sind, wohingegen sich Beispiele für erfolgreiche, aber falsche Theorien finden lassen. ${ }^{91}$ Einen davon verschiedenen Grund, etwa den, daß das "vorsichtige" Explanans eine bessere Erklärung liefert als das "unvorsichtige", nennt Carrier nicht.

Antirealisten haben nach Carrier keine alternativen Erklärungen von Theorieerfolgen der spezifizierten Art anzubieten. ${ }^{92}$

\subsection{Die Versionen des Wunderarguments als Schlüsse auf die beste Erklärung: Die Version von Worrall}

Worralls Version des Wunderarguments bezieht sich auf Erfolge einzelner Theorien und richtet sich gegen das gesamte Spektrum antirealistischer Positionen, also semantische wie epistemische Antirealisten. ${ }^{93}$

Das Explanandum von Worralls Argument bilden nPEe, ${ }^{94}$ die sich präzise durch (9.1), (9.2) und (9.7) oder durch (9.3), (9.2) und (9.7) beschreiben lassen. ${ }^{95}$

\footnotetext{
${ }^{89}$ Siehe Abschnitt 9.1.2.

${ }^{90}$ Vgl. [Carr93], S.405, 408.

${ }^{91}$ Siehe Abschnitt 9.10.1.

${ }^{92}$ Siehe [Carr93], S.404/405.

${ }^{93}$ S. [Worr89], S.100/101.

${ }^{94}$ Vgl.[Worr89], S.101f.

${ }^{95}$ Hier bleiben einige Details der Erläuterung von nPEen beiseite: Worrall meint, grob gesprochen, daß es nicht darauf ankommt, daß ein Prognoseerfolg ein Phänomen zum Inhalt hat, das zum Zeitpunkt der Konstruktion der prognostizierenden Theorie nicht bekannt war, sondern darauf, daß die Konstruktion der Theorie nicht durch Wissen über dieses Phänomen beeinflußt wurde; siehe dazu [Worr89], S.101/102, [Worr85].
} 
Eine präzise Formulierung für das Explanans von Worralls Argument ist nicht leicht zu finden; Worralls eigene Formulierungen legen so etwas wie

Die mathematische Struktur der Theorie $T$ ist (annähernd) korrekt

nahe, sowie eine Aussage wie (9.6) über die semantische Vollwertigkeit von $T$, darin ist jedoch nicht von (annähernder) Wahrheit die Rede. Eine Formulierung, in der der Begriff wahr vorkommt, wäre

Die in der Theorie $T$ enthaltenen Aussagen, die ihre mathematische Struktur ausmachen, haben Wahrheitswerte, d.h. sind wahr oder falsch, und sie sind (annähernd) wahr.

Nach Worrall sind Explanantia dieser Art höchstens in seltenen Fällen falsch, d.h. es findet sich allenfalls sehr selten, wenn überhaupt, ${ }^{96}$ eine Theorie, die nPEe aufweist, die aber anerkanntermaßen eine nicht korrekte mathematische Struktur aufweist. Dagegen zeigt die historische Erfahrung, daß ein weniger "vorsichtiges" Explanans wie ' $T$ ist wahr' manchmal falsch ist. Wie Carrier nennt auch Worrall ansonsten keinen Grund, der für das "vorsichtigere" Explanans spräche, etwa daß es die bessere Erklärung liefert.

Die Frage, welche alternativen Erklärungen von antirealistischer Seite für das Explanandum seiner Version des Wunderarguments angeboten werden können, diskutiert Worrall nicht.

\subsection{Die Versionen des Wunderarguments als Schlüsse auf die beste Erklärung: Explanantia des Wunderarguments und realistische Thesen}

Wie die obigen Überlegungen gezeigt haben, haben die Thesen, die in den diversen Versionen des Wunderarguments als Explanans fungieren und auf die geschlossen werden soll, allesamt (explizit oder jedenfalls wenn man sie in präziser Form rekonstruiert und — beim Explanandum Handlungserfolge - ihren wesentlichen Kern isoliert) zweierlei zum Inhalt. Sie handeln zum einen von der Semantik der (in einer der verschiedenen erläuterten Weisen) erfolgreichen Theorien, zum anderen betreffen sie die epistemische Bewertung dieser Theorien. Wenn das Wunderargument in der Debatte mit epistemischen Antirealisten eingesetzt werden soll, bleiben Aussagen über die Semantik der Theorien meistens implizit, weil sie unkontrovers sind und vorausgesetzt werden können; wenn das Wunderargument gegen semantische Antirealisten eingesetzt werden soll, sind die Aussagen über die Semantik der Theorien wesentlicher Teil des Argumentationsziels und werden daher meist explizit gemacht.

Die Thesen über die Semantik erfolgreicher Theorien, die in den diversen Versionen des Wunderarguments Teil des Explanans sind, lassen sich alle in plausibler Weise als semantische realistische Thesen der Form (SR1) rekonstruieren. ${ }^{97}$ Putnam erläutert für seine Versionen des Wunderarguments das Explanans durch die kausale Referenztheorie und eine darauf aufgebaute Korrespondenztheorie der Wahrheit; damit läßt sich die in Thesen der Form (SR1) enthaltene Unabhängigkeitsaussage durch (UvmeM1) und/oder

\footnotetext{
${ }^{96}$ Worrall läßt diese Differenz offen; eine genauere Aussage müßte durch weitere historische Untersuchungen gewonnen werden.

${ }^{97} \mathrm{~S}$. Abschnitt 1.2.1 und 1.3.1.
} 
(UvmeM2) erläutern und man kann die realistische Position, für die argumentiert wird, auch durch Thesen der Form (SR2) ergänzen. ${ }^{98}$ Die anderen Anhänger des Wunderarguments geben für ihr Explanans keine erläuternde Wahrheits- und Referenztheorie an oder verweisen allenfalls am Rande auf die kausale Referenztheorie oder auf Tarskis Korrespondenztheorie der Wahrheit, in jedem Fall lassen sich ihre Positionen in natürlicher Weise durch eine dieser beiden Möglichkeiten ergänzen. Beide Möglichkeiten erlauben, die in Thesen der Form (SR1) enthaltene Unabhängigkeitsaussage durch (UvmeM1) und/oder (UvmeM2) zu erläutern und Thesen der Form (SR2) zu ergänzen. ${ }^{99}$

Die Thesen über die epistemische Bewertung erfolgreicher Theorien, die in den diversen Versionen des Wunderarguments Teil des Explanans sind, stellen offenbar allesamt epistemische realistische Thesen dar, entweder Thesen der Form (ER), die sich auf eine ganze Theorie oder mehrere beziehen, oder abgeschwächte Versionen davon, die "nur" einen Teil der Theorie betreffen und/oder der Theorie oder den Theorien nicht "unqualifizierte" Wahrheit zuschreiben, sondern "nur" annähernde Wahrheit.

Eine realistische Position, die mit Hilfe des Wunderarguments begründet wird, konkretisiert also die von Nagel und Wright genannte allgemeine realistische Intuition ${ }^{100}$ durch semantische und durch epistemische realistische Thesen.

\subsection{Die Versionen des Wunderarguments als Schlüsse auf die beste Erklärung: Probabilistische Modelle für ko- gnitive Zustände}

Die bisher diskutierten Versionen des Wunderarguments ließen sich alle als Argumente von der Form des Schließens auf die beste Erklärung auffassen, die, ausgehend von bestimmten, von der realistischen und der antirealistischen Seite geteilten Überzeugungen über bestimmte Theorieerfolge oder -leistungen, die antirealistische Seite zu einem Schluß auf bestimmte realistische Thesen veranlassen sollen, also dazu, diese realistischen Thesen als Überzeugungen zu akzeptieren. Der kognitive Zustand einer Person wurde also, wie in der Erkenntnistheorie üblich, dahingehend charakterisiert, daß sie bestimmte Überzeugungen hat (oder nicht hat).

Zur Modellierung des kognitiven Zustand einer Person werden in der philosophischen Literatur, neben solchen Konzeptionen, gelegentlich auch probabilistische Modelle verwendet, die einer Person statt Überzeugungen Überzeugungsgrade (degrees of belief) in bezug auf Sätze bzw. Mengen von Sätzen zuschreiben. Überzeugungsgrade haben die Eigenschaften von (epistemischen) Wahrscheinlichkeiten. Der Überzeugungsgrad einer Person bezüglich eines bestimmten Satzes ist also eine Zahl zwischen null und eins, zeitliche Veränderungen des kognitiven Zustandes einer Person bestehen nicht im Akzeptieren oder Aufgeben von Überzeugungen, sondern in der Veränderung der Überzeugungsgrade dieser Person. ${ }^{101}$

\footnotetext{
${ }^{98} \mathrm{~S}$. Abschnitt 4.4.

${ }^{99} \mathrm{~S}$. Abschnitt 2.5.2.

${ }^{100} \mathrm{~S}$. Abschnitt 1.2 .

${ }^{101}$ Man kann versuchen, in probabilistische Modelle Überzeugungen "einzubauen", indem man eine Überzeugung rekonstruiert als einen Satz mit der epistemischen Wahrscheinlichkeit 1 (siehe z.B. [Gard88], S.38) oder als einen Satz mit einer hohen Wahrscheinlichkeit, etwa $p \geq 1-\epsilon$. Beide Optionen haben jedoch intuitiv problematische Eigenschaften: Daß man einem Satz die epistemische Wahrscheinlichkeit 1 zuweist, ist im wissenschaftstheoretischen Diskussionszusammenhang insbesondere für theoretische Sätze problematisch, insofern dieser Wert dann zukünftig nicht mehr durch weitere Beobachtungsdaten per Bayesscher
} 
Einige Autoren haben vorgeschlagen, die Idee des Schließens auf die beste Erklärung nicht durch ein Inferenzschema wie (IBE) zu explizieren, und damit unter der Voraussetzung, daß es um Überzeugungen geht, sondern diese Idee vor dem Hintergrund eines probabilistischen Modells zu "implementieren". Im Hinblick auf die Suche nach Möglichkeiten für eine präzise Rekonstruktion des Wunderarguments empfiehlt es sich, auch solche probabilistischen Rekonstruktionen für die Idee des Schließens auf die beste Erklärung zur Kenntnis zu nehmen.

Die probabilistischen Modelle für kognitive Zustände einer Person werden üblicherweise unter dem Titel Bayesianismus zusammengefaßt. Es handelt sich dabei um eine Vielzahl verwandter, aber in Details unterschiedlicher Ansätze, die darin übereinstimmen, daß sie einer Person Überzeugungsgrade in bezug auf Sätze zuschreiben, die den Axiomen für Wahrscheinlichkeiten genügen müssen. ${ }^{102}$ Die meisten ("orthodoxen") Anhänger Bayesianischer Modelle stimmen außerdem darin überein, daß Veränderungen der Überzeugungsgrade dann und nur dann vorgenommen werden, wenn eine neue Beobachtung gemacht wird, also ein neuer Beobachtungssatz $E$ bekannt wird; zu einem solchen Zeitpunkt $t_{E}$ ändern sich die Überzeugungsgrade für alle Sätze $H$ gemäß der Bayesschen Regel (Bayes's rule)

$$
p_{t \leq t_{E}}(H) \longrightarrow p_{t>t_{E}}(H)=p_{t \leq t_{E}}(H \mid E) .
$$

Die Aktualisierung der epistemischen Wahrscheinlichkeiten gemäß dieser Regel wird als Konditionalisierung (conditionalization) bezeichnet. ${ }^{103}$ Einige "unorthodoxe" Bayesianer lassen, zusätzlich zur Bayesschen Regel, auch andere Regeln zur Aktualisierung der Überzeugungsgrade zu; man spricht dann von non-Bayesian shifts. ${ }^{104}$

Bayessche Modelle lassen auch für Sätze über Unbeobachtbares und insbesondere für wissenschaftliche Theorien Überzeugungsgrade größer null zu; die Konditionalisierungsregel kann i.a. ${ }^{105}$ dazu führen, daß sich diese Überzeugungsgrade aufgrund "geeigneter" Beobachtungen erhöhen und sich sogar dem Wert eins nähern. Aus diesem Grund lehnen einige Antirealisten, z.B. van Fraassen, Bayessche Modelle in der skizzierten Form ab. Modifizierte, für Antirealisten akzeptable Varianten diese Modelle bekommt man, indem man Sätzen und Theorien über Unbeobachtbares keine epistemischen Wahrscheinlichkeitswerte zuweist, sondern Wahrscheinlichkeitsintervalle mit der unteren Grenze null. Die Bayessche Regel wird auf ein Wahrscheinlichkeitsintervall "punktweise" angewendet, insbesondere auf die beiden Grenzen. Diese Modelle sind aus antirealistischer Perspektive akzeptabel, weil eine Wahrscheinlichkeit bzw. Intervallgrenze null nicht per Konditionalisierung veränderbar ist. ${ }^{106}$

Konditionalisierung (s.u.) veränderbar ist, was in unangemessener Weise dogmatisch aussieht. Die Überzeugungen einer Person zu rekonstruieren als die Menge der Sätze mit einer epistemischen Wahrscheinlichkeit von "fast" 1 bringt die Probleme mit sich, daß die Gesamtheit der Überzeugungen dann i.a. nicht mehr deduktiv abgeschlossen ist und auch inkonsistent sein kann (vgl. [Harm86], Kap.3). Für einen komplexeren Ansatz, den Begriff der Überzeugung in eine Bayessche Position einzubauen, siehe [Mahe93], Kap.6.

${ }^{102}$ Die Standardtexte zum Bayesianismus sind [HoUr93] und [Earm92b].

${ }^{103}$ Die bedingte Wahrscheinlichkeit kann mit Hilfe des Bayesschen Theorems errechnet werden, das im einfachsten Fall

$$
p(H \mid E)=\frac{p(H) \cdot p(E \mid H)}{p(E)}
$$

lautet.

${ }^{104}$ [Earm92b], S.196.

${ }^{105}$ Wenn die Anfangswahrscheinlichkeit $p(H)$ nicht null ist.

${ }^{106}$ Dies läßt sich leicht an (9.14) und (9.13) ablesen. Zur Idee, kognitive Zustände mit Hilfe von Wahrscheinlichkeitsintervallen zu modellieren, siehe [vFra85], S.249ff., [vFra89a], S.193f., [vFra90, vFra98]. Van Fraassen selbst ist allerdings der Ansicht, daß man gar keine Regeln für die Veränderung epistemischer 
Wenn mit Hilfe probabilistischer Modelle die Idee des Schließens auf die beste Erklärung und insbesondere das Wunderargument rekonstruiert werden sollen, sind mehrere Punkte zu klären. Einer davon betrifft die Anwendbarkeit der probabilistischen Modelle auf die Aussagen, um die es beim Wunderargument geht: Es handelt sich bei diesen Aussagen (u.a.) um metasprachliche Aussagen über Sätze und Theorien und deren syntaktische und semantische Eigenschaften und Relationen, die auf den ersten Blick vielleicht "ungewöhnlich" aussehen neben den wissenschaftlichen und alltagsweltlichen Sätzen und Theorien, auf die Bayessche Modelle üblicherweise angewendet werden, und es ist prima facie vielleicht nicht klar, ob und wie sich solchen metasprachlichen Aussagen Wahrscheinlichkeiten zuordnen lassen. Darin sollte aber kein grundsätzliches Problem liegen, sondern höchstens ein praktisches; grundsätzlich lassen sich in konsistenter Weise Wahrscheinlichkeiten für Sprachen definieren, die (u.a.) als Metasprache für eine Objektsprache fungieren können. ${ }^{107}$

Ein zweiter klärungsbedürftiger Punkt betrifft die Frage, in welcher Weise genau die Idee des Schließens auf die beste Erklärung in einem probabilistischen Modell implementiert werden soll. Eine Möglichkeit, die dafür vorgeschlagen worden ist, ${ }^{108}$ ist, die explanatorischen Leistungen eines Satzes oder einer Theorie $H$ bei der Bestimmung der Anfangswahrscheinlichkeiten $p(H)$ und der Likelihoods $p(E \mid H)$ zu berücksichtigen und ansonsten an einem orthodoxen Bayesschen Modell festzuhalten. So könnte man $p(E \mid H)$ umso höher ansetzen, je besser $H E$ erklärt, man könnte $p(H)$ umso höher wählen, je mehr intrinsische "explanatorische Tugenden" wie Einfachheit, innere Kohärenz u.ä. $H$ aufweist, o.ä. Man bekommt dann sozusagen automatisch heraus, daß durch die Konditionalisierung, die eine neue Beobachtung $E$ nach sich zieht, von mehreren Sätzen bzw. Theorien $H_{i}$ demjenigen bzw. derjenigen der höchste Überzeugungsgrad zugewiesen wird, der bzw. die die beste Erklärung für $E$ liefert. ${ }^{109}$ Diese Möglichkeit ist grundsätzlich nicht unplausibel, sie hat jedoch den Nachteil, daß sämtliche Sätze bzw. Theorien und ihre Erklärungsleistungen bekannt sein müssen, wenn man das Bayessche Modell sozusagen in Betrieb nimmt, und die aufgrund ihrer explanatorischen Leistungen zugewiesenen Wahrscheinlichkeiten danach nicht mehr verändert werden können, etwa wenn neue Theorien entworfen werden oder über die Erklärungsleistungen einer bekannten Theorie oder eines bekannten Satzes Neues herausgefunden wird; beides kommt in der real-existierenden Wissenschaft und im Alltag vor, kann aber durch ein orthodoxes Bayessches Modell offenbar nicht angemessen beschrieben werden. ${ }^{110}$

Eine andere Möglichkeit, die Idee des Schließens auf die beste Erklärung in einem probabilistischen Modell zu implementieren, ist, über den Rahmen des orthodoxen Bayesianismus hinauszugehen, indem man die Bayessche Konditionalisierungsregel durch eine zweite Regel zur Aktualisierung der Überzeugungsgrade ergänzt, und zwar durch eine Regel zur Aktualisierung der Wahrscheinlichkeiten $p(H)$, die eine Art probabilistisches Analogon zum Schema (IBE) darstellt. ${ }^{111}$ Eine solche Regel ist:

(IBEpr) Wenn eine neue Beobachtung $E$ bekannt wird, wird im Anschluß an die Anwendung der Bayesschen Konditionalisierungsregel wie folgt verfahren: Wenn $H_{1}, H_{2} \ldots$ $H_{n}$ Sätze sind, die sich gegenseitig ausschließen, von denen aber einer wahr sein

Wahrscheinlichkeiten akzeptieren sollte, auch nicht die Bayessche Regel.

${ }^{107}$ Siehe dazu z.B. [Garb83, Earm92b].

${ }^{108}$ Siehe z.B. [DaKi94], S.285/286.

${ }^{109}$ Man sieht dies leicht an (9.14) und (9.13).

${ }^{110}$ S. dazu [Earm92b], Kap.8.

${ }^{111}$ Siehe [vFra89a], S.166, [Douv99], S.S426. 
muß ${ }^{112}$, und von denen mindestens einer eine zufriedenstellende Erklärung für $E$ liefert, dann wird zum Wahrscheinlichkeitswert des Satzes $H_{k}$, der die beste Erklärung für $E$ liefert, ein Erklärungsbonus $b(b>0)$ addiert, und anschließend werden die Wahrscheinlichkeiten für alle $H_{i}$ wieder auf eins normiert. ${ }^{113}$

Diese zweite Möglichkeit hat nicht den Nachteil, daß sämtliche für Erklärungen in Frage kommenden Sätze und Theorien und ihre explanatorischen Leistungen bereits bei der "Inbetriebnahme" des Bayesschen Modells bekannt sein müssen.

Ein Argument, das die Form eines Schlusses auf die beste Erklärung hat und sich mit Hilfe des Schemas (IBE) rekonstruieren läßt, wenn man kognitive Zustände durch Überzeugungen charakterisiert, sollte sich analog auch mit Hilfe der probabilistischen Regel (IBEpr) rekonstruieren lassen, wenn man kognitive Zustände mit Hilfe von Überzeugungsgraden modelliert. Dies gilt insbesondere für sämtliche oben diskutierten Versionen des Wunderarguments. Argumentationsziel ist es in einer solchen Rekonstruktion des Wunderarguments dann nicht, den Diskussionsgegner dazu zu bringen, die Thesen als Überzeugungen zu akzeptieren, die das Explanans darstellen, sondern ihn dazu zu veranlassen, diesen Thesen einen hohen Überzeugungsgrad zuzuweisen.

\subsection{Die Versionen des Wunderarguments als Schlüsse auf die beste Erklärung: Fazit}

Fazit dieser Überlegungen ist, daß sich sämtliche Varianten des Wunderarguments in natürlicher Weise als Argumente auffassen lassen, die in der Weise für das jeweils für bestimmte Erfolge angebotene Explanans argumentieren, daß sie dem Diskussionsgegner einen Schluß auf das Explanans gemäß dem Schema (IBE) vorschlagen.

Dadurch, daß die diversen Varianten des Wunderarguments auf die Form dieses Inferenzschemas gebracht werden, werden zum einen einige Ungenauigkeiten in der Formulierung des Arguments bei verschiedenen Autoren sichtbar, die der Präzisierung bedürfen, vor allem aber treten die inhaltlichen Unterschiede zwischen den verschiedenen Varianten deutlich zutage, die für ihre Beurteilung relevant sein können, d.h. für die Frage, wieviel Angriffsfläche sie für bestimmte Einwände bieten.

Wenn man den kognitiven Zustand einer Person nicht durch Überzeugungen charakterisiert, sondern durch Überzeugungsgrade, lassen sich die diskutierten Versionen des Wunderarguments alternativ auch als Argumente auffassen, die dem Diskussionsgegner vorschlagen, dem jeweiligen für bestimmte Erfolge angebotenen Explanans gemäß der probabilistischen Regel (IBEpr) einen hohen Überzeugungsgrad zuzuweisen.

\footnotetext{
${ }^{112}$ Also $\vdash\left(H_{1} \vee H_{2} \vee \ldots \vee H_{n}\right)$ und für alle $i, j \vdash \neg\left(H_{i} \wedge H_{j}\right)$.

${ }^{113}$ Siehe [vFra89a], S.166, [Douv99], S.S426. Für $b$ kann man einen festen Wert wählen, z.B. $b=0,1$, oder einen, der den Abstand zu 1 berücksichtigt, z.B. $b=\frac{1-p\left(H_{k}\right)}{2}$, o.ä. Auf Wahrscheinlichkeitsintervalle kann diese Regel, wie die Bayessche Regel, "punktweise" angewendet werden.

Gegen alle Regeln zur Aktualisierung von Überzeugungsgraden, die, wie die oben angegebene, nonBayesian shifts vorsehen, sind sogenannte diachrone Dutch-Book-Argumente vorgebracht worden (siehe z.B. [vFra89a], Kap.7). Auf die komplexe Debatte um diese Argumente kann und braucht hier nicht eingegangen werden; verteidigt werden non-Bayesian shifts etwa in [Hell97], S.214ff., [Hows97, Douv99].
} 


\subsection{In welchem Sinn von 'erklären' wird das Explanandum des Wunderarguments durch dessen Explanans erklärt (und in welchem Sinn nicht)?}

Ergebnis der obigen Erörterungen ist, daß sämtliche Versionen des Wunderarguments hinsichtlich ihrer Struktur insofern übereinzustimmen scheinen, als sie als Instantiierungen des Schemas (IBE) oder des probabilistischen Analogons (IBEpr) aufgefaßt werden können. Wie weit darüber hinaus die inhaltlichen Übereinstimmungen oder Parallelen reichen, ist nicht klar, da zumindest auf den ersten Blick nicht offensichtlich ist, in genau welchem Sinn von 'erklären' das Explanans in den verschiedenen Versionen des Wunderarguments das Explanandum erklärt, worin also die explanatorische Relation zwischen Explanans und Explanandum besteht, und ob die verschiedenen Versionen den im Schema (IBE) bzw. der probabilistischen Regel (IBEpr) enthaltenen Begriff der Erklärung in derselben Weise in Anspruch nehmen, sich also auf Erklärungen derselben Art beziehen. ${ }^{114}$

Das Schema (IBE) und die analoge probabilistische Regel (IBEpr) stellen hinsichtlich der Art der Erklärungen und der explanatorischen Relation zwischen Explanans und Explanandum, auf die sie sich beziehen, keine Bedingungen; sie scheinen auf Erklärungen jeder Art anwendbar zu sein. Sie setzen aber, wie man leicht sieht, wenn man versucht, sie anzuwenden, zumindest implizit voraus, daß man verschiedene Arten von Erklärungen unterscheiden kann, denn indem sie sagen, daß auf das beste aus einem Spektrum konkurrierender Explanantia geschlossen werden darf, ${ }^{115}$ beziehen sie sich auf ein Spektrum potentieller Explanantia, die erstens nicht zugleich wahr sein können und zweitens das Explanandum in einer gemeinsamen Hinsicht erklären können, also einer gemeinsamen Art von Erklärung zugerechnet werden können, für die man über Kriterien für den Vergleich der Erklärungsleistungen aller potentiellen Explanantia, die diese Art von Erklärung liefern, verfügt. ${ }^{116}$ Explanantia, die zugleich wahr sein können, konkurrieren nicht und Explanantia, die dasselbe Explanandum nicht in einer gemeinsamen Hinsicht erklären, können nicht hinsichtlich ihrer Erklärungsleistungen verglichen werden, um dasjenige auszuwählen, das die beste Erklärung liefert. ${ }^{117}$

\footnotetext{
${ }^{114} \mathrm{McMullin}$ spricht treffend von "the rather muddy notion of "explaining the success of a theory'" ([McMu94], S.99).

${ }^{115}$ Im Schema (IBE) ist explizit von konkurrierenden ("competing") potentiellen Explanantia die Rede, in der probabilistischen Regel (IBEpr) von erklärenden Sätzen, die sich wechselseitig ausschließen.

${ }^{116}$ Damit ist nicht ausgeschlossen, daß man "Arten" von Erklärungen so weit oder lose definieren oder charakterisieren kann, daß mehrere Erklärungen einer solchen Art für dasselbe Explanandum zugleich wahr sein können und/oder daß man für die (potentiellen) Erklärungen einer solchen Art keine plausiblen Vergleichskriterien hat. Letzteres, also daß man keine plausiblen Vergleichskriterien für die Güte der Erklärungsleistungen hat, gilt insbesondere, wenn man alle (potentiellen) Erklärungen für ein Explanandum zusammen ins Auge faßt.

${ }^{117}$ Ein Beispiel aus einem nicht-wissenschafstheoretischen Bereich, das diesen Punkt verdeutlicht: Dafür, daß eine Person $A$ infolge einer Pilzmahlzeit gestorben ist, kann man verschiedene Erklärungen angeben. Ein potentielles Explanans wäre etwa, daß A's Butler sich einen Giftpilz beschafft und in $A$ 's Abendessen gemischt hat, ein anderes Explanans wäre die Angabe des tödlichen Giftstoffes und seines biochemischen Wirkungsmechanismus, ein drittes wäre die Angabe des Giftstoffes plus das, was zu einer evolutionstheoretischen Erklärung nötig ist, warum diese Substanz für alle Menschen giftig ist, usw. Alle diese Explanantia können zugleich wahr sein, d.h. sie konkurrieren nicht. Zu jedem dieser Explanantia lassen sich außerdem aber auch konkurrierende Alternativen angeben (Daß $A$ selbst die Pilze für ihr Abendessen gesammelt hat und dabei versehentlich einen Giftpilz gesammelt hat, die Angabe einer anderen tödlichen Substanz im Abendessen und deren Wirkungsmechanismus usw.), die das Explanandum in einer gemeinsamen Hinsicht erklären können, also einer gemeinsamen Art von Erklärung zugerechnet werden können, für die sich vielleicht plausiblerweise Vergleichskriterien für ihre Erklärungsleistungen angeben lassen (Kausalerklärungen,
} 
Die Anhänger des Wunderarguments äußern sich in der Regel nicht oder allenfalls andeutungsweise zu der Frage, in welchem Sinn von 'erklären' das Explanandum in ihrer Version des Wunderarguments durch das Explanans erklärt wird. ${ }^{118}$ Sie setzen üblicherweise als intuitiv plausibel und unkontrovers voraus, daß eine Erklärung vorliegt und, sofern alternative, von antirealistischer Seite angebotene Explanantia diskutiert werden, daß diese mit ihrem Explanans konkurrieren und daß die Erklärungsleistungen der Explanantia verglichen werden können und müssen. Bei etwas genauerer Betrachtung liegt der Verdacht nahe, daß die gemeinsame, nicht näher erläuterte Verwendung des Ausdrucks 'Erklärung' und des diesen Begriff involvierenden Schemas (IBE) bzw. der probabilistischen Regel (IBEpr) Unterschiede zwischen den verschiedenen Versionen des Wunderarguments und teilweise auch inhaltliche Ungenauigkeiten verdeckt, die für ein genaues Verständnis des Wunderarguments und eine Bewertung seiner Plausibilität und Überzeugungskraft relevant sind. Um in diesen Punkten für Klarheit zu sorgen, soll im folgenden untersucht werden, in welchem Sinn von 'erklären' das Explanandum der verschiedenen Versionen des Wunderarguments durch das zugehörige Explanans erklärt wird. Außerdem sollen auch, da sich dies später als relevant für die Bewertung des Wunderarguments erweisen wird, zumindest einige Hinsichten genannt werden, in denen man das Explanandum auch erklären könnte bzw. für erklärungsbedürftig halten könnte, in denen es aber tatsächlich durch das Explanans des Wunderarguments nicht erklärt wird.

Wenn man in diesem Punkt für mehr Klarheit sorgen möchte, ist man mit der Schwierigkeit konfrontiert, daß es bekanntlich (zumindest derzeit) keine einigermaßen zufriedenstellende, (mehr oder weniger) allgemein akzeptierte Theorie darüber gibt, was eine Erklärung ist, worin explanatorische Beziehungen bestehen, welche Arten von Erklärungen es gibt etc., die man in unkontroverser Weise heranziehen könnte, um den im Fall des Wunderarguments relevanten Sinn von 'erklären' explizit zu machen und evtl. verschiedene Hinsichten zu identifizieren, in denen das Explanandum des Wunderarguments erklärt wird oder erklärt werden könnte. Auch ohne eine solche allgemeine Theorie der Erklärung läßt sich aber Einiges, was für eine Bewertung des Wunderarguments und seiner Varianten

die ein Ereignis nennen, das das durch das Explanandum beschriebene Ereignis, oder genauer: den Tod einer Person, verursacht hat, Kausalerklärungen, die den kausalen Prozeß beschreiben, der zum Tod der Person geführt hat, usw.).

Dieses Beispiel illustriert auch, daß es für mehrere Explanantia, die nicht zugleich wahr sein können, nicht in jedem Fall plausible Kriterien für den Vergleich ihrer Erklärungsleistungen geben dürfte (daß also die oben genannte "Zusatzbedingung", daß vergleichbare Explanantia das Explanandum in einer gemeinsamen Hinsicht erklären, tatsächlich erforderlich ist): Denkbar ist z.B., daß es nicht zugleich wahr sein kann, daß einerseits ein bestimmter Giftstoff im Essen den Tod verursacht hat, und daß andererseits $A$ selbst die Pilze gesammelt hat und darunter versehentlich einen Giftpilz. Dies könnte etwa so sein, weil der fragliche Giftstoff nur in Pilzen vorkommt, die in dem Gebiet, in dem $A$ gesammelt hat, gar nicht wachsen, sondern nur ganz woanders. Dennoch dürfte es kaum plausible Kriterien geben, die einen Vergleich der beiden Explanantia hinsichtlich ihrer Erklärungsleistungen erlauben.

${ }^{118}$ Von den Anhängern des Wunderarguments gibt Musgrave dazu die ausführlichste (mir bekannte) Erläuterung ([Musg88], S.234):

"Perhaps what we have (in the simplest case) are explanations of the following kind:

Theory $T$ is true.

Theory $T$ yielded several novel predictions.

Therefore, T's novel predictions were also true.

Is this an explanation? Well, its (alleged) explanandum certainly follows from its (alleged) explanans, as we require [...] And as in all non-circular explanations, its (alleged) explanans transcends its (alleged) explanandum."

Vgl. auch [BenM90], S.333, 337. 
wichtig ist, zur Charakterisierung der explanatorischen Relation zwischen Explanans und Explanandum im Fall des Wunderarguments sagen, zu den Hinsichten, in denen dort das Explanandum erklärt wird oder erklärt werden könnte, und zu den Arten von Erklärung, um die es dort geht.

\subsubsection{Die Erklärung einfacher Prognoseerfolge}

Die Versionen des Wunderarguments, die sich auf ePEe beziehen, sind im Hinblick auf die Frage, worin die explanatorische Relation zwischen Explanans und Explanandum besteht, vergleichsweise die unproblematischsten, aber schon hier zeigt sich bei genauerem Hinsehen, daß die Beantwortung dieser Frage keineswegs trivial ist. Intuitiv scheint eine Art Implikationsverhältnis zwischen Explanans und Explanandum vorzuliegen, das Explanandum ePEe also in irgendeiner Weise deduktiv aus dem Explanans zu folgen. Was genau die Prämissen eines solchen deduktiven Schlusses sind und was die Konklusion, ist jedoch nicht offensichtlich und wird von den Anhängern dieser Version des Wunderarguments jedenfalls nicht explizit gemacht.

Klar ist zunächst, daß das Explanandum ePEe, wenn man es durch die Aussagen (9.1), daß $P$ aus $T$ ableitbar ist, und (9.2), daß $P$ wahr ist, rekonstruiert, nicht ohne weiteres aus dem Explanans (9.4), daß $T$ wahr ist, folgt. ${ }^{119}$ Eine naheliegende Möglichkeit, einen deduktiven Zusammenhang zwischen Explanans und Explanandum zu bekommen, ist aber, das Explanans um eine Prämisse zu ergänzen, und zwar um eine Prämisse über die Korrektheit des Kalküls, zu dem die (syntaktisch betrachtete) Theorie $T$ und die Regeln gehören, nach denen $P$ aus $T$ ableitbar ist:

Für alle Mengen von Sätzen $\left\{P_{j}\right\}$ und für alle Sätze $Q$ gilt:

Wenn $\left\{P_{j}\right\}$ wahr ist und $\left\{P_{j}\right\} \vdash Q$, dann ist $Q$ wahr.

Aus (9.15), (9.4) und (9.1) folgt dann (9.2). Es ist also genaugenommen nicht so, daß das Explanandum ePEe durch das Explanans impliziert wird, auch nicht durch das durch (9.15) ergänzte Explanans, sondern ein Teil des Explanandums, nämlich (9.2), folgt aus dem (ergänzten) Explanans und dem anderen Teil des Explanandums, nämlich (9.4), d.h. das Explanans stellt sozusagen einen deduktiven Zusammenhang zwischen den beiden Teilen des Explanandums her.

Wenn man das Explanandum ePEe alternativ durch die Aussagen (9.3), daß $P$ aus $T$ abgeleitet wurde, und (9.2) rekonstruiert, gilt im wesentlichen dasselbe, denn aus der Prämisse (9.3), daß $P$ aus $T$ abgeleitet wurde, folgt offenbar, daß $P$ aus $T$ ableitbar ist, also (9.1). Man bekommt also auch in dieser Lesart des Explanandums ePEe bei Ergänzung von (9.15) den beschriebenen deduktiven Zusammenhang.

Welchen Status hat (9.15)? Diese Annahme wird von den Anhängern des Wunderarguments nicht explizit als Teil des Explanans genannt, so daß es auf den ersten Blick vielleicht problematisch aussieht, sie in Anspruch zu nehmen, tatsächlich sollte dies aber unkontrovers sein: (9.15) folgt aus einer Annahme (9.6), daß die Theorie T Wahrheitswerte hat, zusammen mit deren Erläuterung durch eine Korrespondenztheorie, kausale Referenztheorie o.ä., genauer: (9.15) folgt aus einer entsprechenden Annahme plus Erläuterung in bezug auf die Sprache bzw. den Kalkül, deren bzw. dessen Teil $T$ ist. Eine Annahme (9.6) plus Erläuterung durch eine Wahrheitstheorie (und evtl. eine Referenztheorie) enthält oder

\footnotetext{
${ }^{119}$ Die Komplikationen, die damit zusammenhängen, daß das Explanans zu (9.5), also zu annähernder Wahrheit, abgeschwächt wird, können hier beiseite bleiben.
} 
impliziert eine Interpretation der Sprache bzw. des Kalküls und eine Wahrheitsdefinition im Sinne der formalen Logik; damit enthält oder impliziert sie alles, was für den Beweis der Korrektheit des Kalküls erforderlich ist, der in jedem Logik-Lehrbuch zu finden ist, ${ }^{120}$ also alles, was für einen deduktiven Schluß auf (9.15), erforderlich ist.

Eine Aussage der Form (9.6) wird, wie vorne diskutiert, von epistemischen Antirealisten akzeptiert und sollte daher in der Diskussion zwischen Realisten und epistemischen Antirealisten unkontrovers sein. ${ }^{121}$ In der Diskussion zwischen Realisten und semantischen Antirealisten ist eine Aussage der Form (9.6) nicht unkontrovers, dort ist sie jedoch, wie oben diskutiert, Teil des von realistischer Seite vorgeschlagenen Explanans des Wunderarguments, auf das geschlossen werden soll.

Bei der Erklärung des Explanandums ePEe stellt also (9.15) lediglich einen Zwischenschritt dar; die Prämisse, durch die das Explanans ergänzt wird, ist nicht (9.15), sondern (9.6) samt Erläuterung. Das Explanandum ePEe und das dafür von realistischer Seite angegebene Explanans stehen demnach in einem deduktiven Zusammenhang: Aus (9.6) samt Erläuterung, die entweder — in der Diskussion mit semantischen Antirealisten zum zu erschließenden Teil des Explanans gehören, oder — in der Diskussion mit epistemischen Antirealisten - als unkontroverse, von beiden Seiten geteilte Annahmen in Anspruch genommen werden dürfen, folgt (9.15), und daraus und aus (9.4) und (9.1) folgt dann (9.2).

Worin besteht also nach dem, was gesagt wurde, bei den Versionen des Wunderarguments, die sich auf ePEe beziehen, die explanatorische Relation zwischen Explanans und Explanandum? Welcher Art (oder welchen Arten) von Erklärung läßt sich eine Erklärung für das Explanandum ePEe zurechnen?

Wenn (9.15) nicht nur einen Zwischenschritt in der Erklärung darstellen würde, sondern die "Erklärung" von ePEen sich darin erschöpfen würde, daß (9.2) aus (9.15), (9.4) und (9.1) (rsp. (9.3)) folgt, dann würden ePEe offenbar nur in einem relativ schwachen Sinn erklärt: Daß ein Satz $P$, der aus einer wahren Theorie $T$ ableitbar ist (rsp. abgeleitet wurde), wahr ist, würde effektiv dadurch "erklärt", daß alle Sätze, die aus einer wahren Theorie ableitbar sind, wahr sind. Die explanatorische Relation würde dann offenbar durch den genannten deduktiven Zusammenhang hergestellt, durch den ein Einzelfall unter einen generellen Sachverhalt subsumiert wird. Diese Erklärung könnte sich dann als deduktiv-nomologische Erklärung in dem von Hempel beschriebenen Sinn ${ }^{123}$ auffassen lassen, also als Erklärung, die darin besteht, daß ein bestimmtes Phänomen oder ein bestimmter Sachverhalt dadurch erklärt wird, daß er aus einem allgemeinen Gesetz (oder mehreren) und den im konkreten Fall vorliegenden Neben- und Randbedingungen folgt. Ob dies eine plausible Charakterisierung dieser Erklärung von ePEen wäre, hängt davon ab, ob es sich bei (9.15) um ein Gesetz handelt oder um einem kontingenten allgemeinen Satz, was zumindest nicht klar ist. ${ }^{124}$ Unabhängig von der Antwort auf diese Frage, die hier offen bleiben kann, würden ePEe dadurch jedenfalls nur in der Hinsicht erklärt, daß sie unter einen generellen Sachverhalt subsumiert würden, und dies ist offenbar ein relativ

\footnotetext{
${ }^{120}$ Siehe z.B. [Mate78, vDal83].

${ }^{121}$ Möglich ist, daß sich beide Seiten im einzelnen nicht über die Wahrheits- und/oder Referenztheorie und damit auch nicht über die Erläuterung von (9.6) einig sind; beide Seiten akzeptieren aber sicherlich eine Version von (9.6) plus Erläuterung, aus der die Korrektheit des Kalküls, also (9.15), folgt.

${ }^{122}$ Das aus (9.3) folgt, wenn die zweite Rekonstruktion für ePEe gewählt wird.

${ }^{123}$ Siehe [Hemp65a], Kap.10, 12.

${ }^{124}$ Die Unterscheidung zwischen Gesetzen und anderen Sätzen konnte bekanntlich bis heute nicht in allgemein akzeptierter Weise erläutert werden, und (9.15) ist offenbar kein klarer, paradigmatischer Fall eines Gesetzes wie etwa das Newtonsche Gravitationsgesetz, die Maxwell-Gleichungen u.ä.
} 
schwacher Sinn von 'erklären'. ${ }^{125}$ Etwas allgemeiner könnte man diese Erklärung als Erklärung epistemischer Art charakterisieren, also als Erklärung, bei der das Explanandum aufgrund des Explanans zu erwarten ist bzw. bei der ein Teil des Explanandums aufgrund des Explanans und des anderen Teils des Explanandums zu erwarten ist. ${ }^{126}$

Da tatsächlich, wie oben diskutiert, die Erklärung, die von den Anhängern des Wunderarguments für ePEe angeboten wird, darin besteht, daß (9.2) aus (9.6) samt Erläuterung und aus (9.4) und (9.1) (rsp. (9.3)) folgt, wobei (9.15) (sprich: das Subsumieren eines ePEes unter den durch (9.15) beschriebenen generellen Sachverhalt) lediglich einen Zwischenschritt darstellt, handelt es sich offenbar nicht nur in dem genannten schwachen Sinn um eine Erklärung. Explanans und Explanandum stehen auch in dieser Rekonstruktion der Erklärung von ePEen in einem deduktiven Zusammenhang, so daß man sie als deduktiv-nomologische Erklärung in Hempels Sinn auffassen kann. Ob dies eine angemessene Charakterisierung der Erklärung ist, hängt auch hier davon ab, ob (9.6) und die zugehörige Erläuterung durch eine Wahrheitstheorie (plus evtl. eine Referenztheorie) ein Gesetz (oder mehrere) involviert, und ob dies so ist, ist wiederum zumindest nicht klar. ${ }^{127}$ Es handelt sich jedenfalls nicht nur im genannten schwachen Sinn um eine Erklärung, denn das, was das Explanans beschreibt, ist ein vergleichsweise kompliziert strukturierter Komplex von Sachverhalten (die Referenzrelationen von Ausdrücken, die Wahrheitsbedingungen von Sätzen etc.), aus dem die Wahrheit des prognostizierten Satzes in der oben skizzierten, vergleichsweise komplizierten Weise folgt, nicht bloß ein allgemeiner Sachverhalt, unter den sie subsumiert wird. Etwas allgemeiner kann man die Erklärung wiederum als Erklärung epistemischer Art charakterisieren kann, bei der ein Teil des Explanandums aufgrund des Explanans und des anderen Teils des Explanandums zu erwarten ist.

Das, was über die Erklärung von ePEen gesagt wurde, impliziert einige "negative" Charakterisierungen, die relevant sind für die Frage, welche (potentiellen) Explanantia mit dem von den Anhängern des Wunderarguments vorgeschlagenen Explanans konkurrieren und welche nicht, und es impliziert auch Einiges darüber, welchen Arten von Erklärung diese Erklärungen von ePEen nicht zuzurechnen sind (obwohl grundsätzlich auch Erklärungen dieser Arten für ePEe denkbar sind); z.B. handelt es sich danach bei den Erklärungen von ePEen, die das Wunderargument involviert, nicht um kausale Erklärungen, die die Entstehung der jeweiligen wahren Aussage bzw. Repräsentation, daß $P$, durch Angabe ihrer "kausalen Vorgeschichte" erklären, also etwa ein verursachendes Ereignis und einen verbindenden Kausalprozeß nennen, ${ }^{128}$ und ePEe werden dabei auch nicht dadurch erklärt, daß die Prozesse, Verfahren, Kriterien und/oder Ziele genannt oder beschrieben werden, die bei der Gewinnung und/oder Auswahl der (später prognostisch erfolgreichen) Theorie $T$ involviert waren (obwohl auch Erklärungen dieser Arten für ePEe denkbar sind).

Der Kürze halber sollen von hier ab die Art von Erklärungen von ePEen, bei denen

\footnotetext{
${ }^{125}$ Musgrave kommt (in [Musg88], S.245) dieser Lesart der Erklärung von Prognoseerfolgen (allerdings von nPEen) zumindest nahe.

${ }^{126}$ Vgl. z.B. [Hemp65d], S.337, [Salm84], S.15f., 84ff. Salmon spricht explizit von einer "epistemic conception [of explanation]".

${ }^{127}$ Vgl. Fn.124. (9.6) selbst sieht klarerweise nicht nach einem Gesetz aus, aber unter den Aussagen, die eine Wahrheits- und Referenztheorie ausmachen, finden sich welche, die zumindest prima facie vielleicht nicht völlig unplausible Kandidaten für Gesetze darstellen, etwa die Aussage der kausalen Referenztheorie, daß jede Referenzrelation in einer kausalen Kette der Weitergabe eines Ausdrucks vom Einführungsereignis zum jeweiligen Sprecher besteht.

${ }^{128}$ In der Lesart von ePEen, die (9.3) involviert, wird die Erzeugung der wahren Repräsentation durch Ableiten aus $T$ genannt, also sozusagen das erste Stück der kausalen Vorgeschichte; das Wunderargument gibt aber nicht die davor liegende kausale Vorgeschichte als Erklärung an, wie man es prinzipiell auch tun könnte.
} 
in der skizzierten Weise aus, erstens, den semantischen Eigenschaften einer Sprache und der Wahrheit einer in dieser Sprache formulierten Theorie und, zweitens, der Tatsache, daß ein Satz aus der Theorie ableitbar ist (rsp. abgeleitet wurde), dessen Wahrheit folgt, deduktive semantische Erklärungen heißen.

\subsubsection{Die Erklärung neuer Prognoseerfolge}

Für die Versionen des Wunderarguments, die sich auf nPEe beziehen und diese durch die Wahrheit einer Theorie ${ }^{129}$ erklären, ist die Frage, worin die explanatorische Relation zwischen Explanans und Explanandum besteht, im wesentlichen genauso zu beantworten wie im Fall ePEe.

Wie oben diskutiert, sind Explanandum und Explanans beidesmal in derselben Weise zu rekonstruieren, mit dem einen Unterschied allerdings, daß im Fall nPEe das Explanandum die zusätzliche Bedingung (9.7) enthält, daß es also nicht um "beliebige" Fälle geht, in denen aus einer Theorie $T$ ein wahrer Satz $P$ ableitbar ist bzw. abgeleitet wurde, sondern nur um solche Fälle, in denen der Satz $P$ ein noch nicht bekanntes Phänomen zum Inhalt hat. Intuitiv besteht auch hier ein Implikationsverhältnis zwischen Explanans und Explanandum und diese Intuition läßt sich auch hier in plausibler Weise dahingehend konkretisieren, daß nPEe in genau der oben für ePEe beschriebenen Weise erklärt werden. Auch diese Erklärungen lassen sich als deduktive semantische Erklärungen charakterisieren.

Die Bedingung (9.7) spielt bei diesen Erklärungen von nPEen offenbar nur eine bestimmte Nebenrolle: (9.7) formuliert eine Bedingung, die Fälle von Prognoseerfolgen erfüllen müssen, um zum Explanandum nPEe zu zählen; die Menge der nPEe ist also eine Teilmenge der Menge der ePEe und (9.7) ist sozusagen für die Differenz verantwortlich. Für den deduktiven Zusammenhang zwischen Explanans und Explanandum spielt (9.7) dagegen keine Rolle: (9.7) fungiert darin weder als Prämisse, noch als (Teil der) Konklusion. Prämissen, Konklusion und Inferenzregel des Schlusses, der den deduktiven Zusammenhangs zwischen Explanans und Explanandum herstellt, sind bei einer solchen Erklärung eines nPEes die gleichen wie bei einer Erklärung eines ePEes.

Eine allgemeinere Art von Erklärungen, denen sich diese Erklärungen für nPEe zurechnen lassen, sind wiederum die Erklärungen epistemischer Art, bei denen ein Teil des Explanandums aufgrund des Explanans und des anderen Teil des Explanandums zu erwarten ist.

Wenn man die explanatorische Relation zwischen Explanans und Explanandum für die Versionen des Wunderarguments, die sich auf nPEe beziehen, in dieser Weise expliziert und damit klar wird, daß die Bedingung (9.7) für den explanatorischen Zusammenhang keine Rolle spielt, lenkt das den Blick auf die Begründung oder das Motiv für die Einschränkung des Explanandums durch (9.7), also für den Schritt vom Explanandum ePEe zum Explanandum nPEe. Für ePEe kann man offenbar Erklärungen mit "gleichartigen" Explanantia geben wie für nPEe, bei denen auch dieselbe explanatorische Relation zwischen Explanans und Explanandum besteht, so daß sich die Frage stellt, warum man nur bei letzteren, also dann, wenn die Zusatzbedingung (9.7) erfüllt ist, auf das Explanans einer solchen Erklärung schließen soll, nicht auch bei ersteren.

Auf diese Frage finden sich bei den Anhängern des Wunderarguments verschiedene Antworten. Eine davon lautet, daß im Fall von ePEen, die keine nPEe sind, kein Er-

\footnotetext{
${ }^{129}$ Oder auch durch deren annähernde Wahrheit; die Komplikationen, die durch diese Abschwächung entstehen können, können hier wiederum beiseite bleiben.
} 
klärungsbedarf vorliegt, weil man hier (häufig) bereits eine andere Erklärung für die Prognoseerfolge hat, nämlich eine, die diese Prognoseerfolge darauf zurückführt, daß sie bei der Konstruktion der Theorie sozusagen eingebaut wurden, d.h., daß die Theorie gerade so konstruiert oder ausgewählt wurde, daß die fraglichen Sätze "erfolgreich" aus ihr abgeleitet werden können. ${ }^{130}$ Was genau unter "Erklärungsbedarf" zu verstehen ist, wird weiter unten diskutiert werden; dort wird sich zeigen, daß diesem jedenfalls im Kontext des Wunderarguments plausiblerweise keine argumentative Rolle zukommen kann. ${ }^{131}$ Unabhängig davon kann der Grund, im Fall eingebauter Prognoseerfolge nicht auf die gemäß dem Wunderargument vorgesehene deduktive semantische Erklärung zu schließen, jedenfalls nicht darin liegen, daß in diesen Fällen eine Erklärung, die die Erfolge auf das Einbauen zurückführt, die bessere Erklärung wäre: Ein Schluß auf die beste Erklärung ist, wie am Schema (IBE) explizit ablesbar, ein Schluß auf die beste von i.a. mehreren konkurrierenden Erklärungen. Wie auch immer die Erklärung genau aussieht, die das Einbauen von Prognoseerfolgen bei der Konstruktion einer Theorie für die Prognoseerfolge liefert, klar scheint, daß diese Erklärung jedenfalls mit einer Erklärung für Prognoseerfolge, wie sie oben beschrieben wurde, nicht konkurriert. Beide Erklärungen für einen Prognoseerfolg können offenbar zugleich wahr sein und damit konkurrieren sie nicht, so daß ein Vergleich zwischen Erklärungen der beiden Arten, um die beste von ihnen zu bestimmen und anschließend nach dem Schema (IBE) auf diese beste Erklärung zu schließen, nicht sinnvoll ist. $^{132}$

Eine andere, überzeugendere Antwort auf die Frage, warum man nur bei nPEen auf das im Wunderargument genannte Explanans schließen soll, nicht jedoch bei ePEen, und damit ein anderes Motiv für die Einschränkung des Explanandums durch die Bedingung (9.7) lautet, daß man Gründe für die Annahme zu haben glaubt, daß nur bei nPEen in verläßlicher Weise auf das genannte Explanans geschlossen werden kann, während ein entsprechender Schluß bei ePEen oft zu einer falschen Konklusion führt. ${ }^{133}$ Diese zweite Antwort ist plausi-

\footnotetext{
${ }^{130}$ Siehe S.188.

${ }^{131}$ Siehe S.282ff.

${ }^{132}$ Eine Analogie, die diesen Punkt anhand des in Fn.117 genannten Beispiels verdeutlicht: Wenn es um den Tod der Person $A$ infolge einer Pilzmahlzeit geht und zur Erklärung des Todes zum einen die Erklärung angeboten wird, daß ein Giftpilz in der Mahlzeit war, zum anderen die Erklärung, daß der Butler $A$ aus Haß ermordet hat, dann ist es nicht sinnvoll, nach der besten der beiden Erklärungen zu fragen und auf diese zu schließen, weil beide Erklärungen zugleich wahr sein können.

${ }^{133}$ Dieses Motiv nennen u.a. Carrier und Worrall (vgl. die Abschnitte 9.4, 9.5). Solche Gründe können induktiver Art sein, d.h. sie können in der historischen Erfahrung bestehen, daß sich Theorien, die neue Prognoseerfolge aufweisen, im Verlauf der bisherigen Geschichte der Wissenschaften selten oder nie als falsch erwiesen haben, so daß nPEe ein verläßliches Kriterium für historisch stabile Theorien darstellen (s.a. Abschnitt 9.10.1). Weiter stützen lassen sich solche Gründe durch eine Überlegung, die plausibel macht, warum nPEe ein verläßliches Kriterium darstellen: Diese Überlegung setzt voraus, daß wahre oder annähernd wahre Theorien nicht nur empirisch adäquat sind, sondern sich (zumindest meistens, häufig o.ä.) außerdem durch Theorietugenden wie Einfachheit, Kohärenz usw. auszeichnen. Da dies (im Vergleich zur empirischen Adäquatheit) eher "weiche" Kriterien für eine gute Theorie ergibt, die nicht ausnahmslos gelten und deren Anwendung in vielen Fällen schwierig und kontrovers ist, erscheint es verständlich, daß Wissenschaftler bei der Konstruktion von Theorien auf der Basis bekannter, insbesondere verschiedenartiger Phänomene möglicherweise dazu neigen können (bewußt oder unbewußt), eine Theorie vorzuschlagen, die "gewaltsam", d.h. auf Kosten dieser Theorietugenden, in Einklang mit den bekannten Phänomenen und Beobachtungen gebracht wurde. Diese Gefahr besteht jedoch nicht für Phänomene bzw. Beobachtungssätze, die unbeabsichtigterweise aus der Theorie folgen. Daher erscheint es plausibel, daß die Fähigkeit, neue Phänomene zu prognostizieren, ein Kriterium darstellen könnte für gute und damit historisch stabile Theorien oder Theorieteile, allerdings nur ein grobes, da natürlich nicht ausgeschlossen ist, daß auch auf der Basis bekannter Phänomene eine "natürliche" Theorie mit allen Theorietugenden konstruiert wird. Diese letztere Überlegung skizziert Peter Lipton unter dem Stichwort fudging explanation (s. [Lipt91],
} 
bler, aber sie setzt eine für die Rekonstruktion des Wunderarguments systematisch wichtige Annahme voraus: Sie setzt voraus, daß man das Wunderargument sozusagen entkoppeln kann von einer positiven Antwort auf die Frage, ob das Inferenzschema (IBE) universell verläßlich ist, denn die Version des Wunderarguments, die sich auf nPEe bezieht, wird dann offenbar nicht als Instantiierung oder Anwendungsfall des (als universell anwendbar unterstellten) Schemas (IBE) aufgefaßt, ${ }^{134}$ sondern als Instantiierung oder Anwendungsfall eines "verwandten" Schemas mit beschränktem Anwendungs- bzw. Verläßlichkeitsbereich.

\subsubsection{Die Erklärung von Vereinheitlichungsleistungen}

Auch für die Versionen des Wunderarguments, die sich auf Vereinheitlichungsleistungen beziehen und diese durch die Wahrheit einer Theorie erklären, ist die Frage, worin die explanatorische Relation zwischen Explanans und Explanandum besteht, im wesentlichen genauso zu beantworten wie im Fall ePEe.

Wie oben diskutiert, sind zwei Arten von Vereinheitlichungsleistungen zu unterscheiden, beide Explananda und das zugehörige Explanans sind aber wiederum genauso zu rekonstruieren wie im Fall ePEe, es treten jedoch bei den Explananda Vereinheitlichungsleistungen zu den Aussagen (9.1) und (9.4) rsp. (9.3) und (9.4) eine bzw. zwei zusätzliche Bedingungen hinzu, nämlich für unqualifizierte Vereinheitlichungsleistungen (9.8), daß der abgeleitete Satz nicht "irgendein" wahrer Satz ist, sondern aus mehreren Sätzen über verschiedenartige Phänomene besteht, und, bei unbeabsichtigten Vereinheitlichungsleistungen zusätzlich (9.9), daß von diesen Sätzen über verschiedenartige Phänomene zumindest einige nicht in die Konstruktion der Theorie eingegangen sind. In beiden Fällen läßt sich der explanatorische Zusammenhang von Explanans und Explanandum wiederum am plausibelsten in derselben Weise rekonstruieren wie oben für ePEe beschrieben. Die Bedingungen (9.8) und (9.9) spielen, genau wie die Bedingung (9.7) beim Explanandum nPEe, nur eine Nebenrolle bei der Erklärung: Beides sind Bedingungen, die Fälle von ePEen erfüllen müssen, um als unqualifizierte oder sogar als unbeabsichtigte Vereinheitlichungserfolge zu zählen; die Menge der Fälle von unbeabsichtigten Vereinheitlichungsleistungen ist also eine Teilmenge der Menge der Fälle von unqualifizierten Vereinheitlichungsleistungen, und diese wiederum eine Teilmenge der Menge der ePEe. Für den deduktiven Zusammenhang zwischen Explanans und Explanandum spielen (9.8) und (9.9) beide keine Rolle.

Auch die Erklärungen für Vereinheitlichungsleistungen lassen sich als deduktive semantische Erklärung und als Erklärung epistemischer Art charakterisieren.

Für die Frage nach der Begründung für die Einschränkung des Explanandums durch (9.8) und (9.9) gilt mutatis mutandis das, was oben für das Explanandum nPEe diskutiert wurde. Auch hier verweist die plausibelste Antwort auf Verläßlichkeitsüberlegungen und führt dazu, diese Version des Wunderarguments nicht als Instantiierung oder Anwendungsfall des (als universell verläßlich angenommenen) Inferenzschemas (IBE) zu rekonstruieren, sondern als Instantiierung oder Anwendungsfall eines "verwandten" Inferenzschemas mit beschränktem Anwendungs- bzw. Verläßlichkeitsbereich.

\subsubsection{Die Erklärung von Handlungserfolgen}

Die Version des Wunderarguments, die sich auf Handlungserfolge bezieht, involviert für diese Handlungserfolge Erklärungen, die, wie oben rekonstruiert, eine vergleichsweise kom- 
plexe Struktur aufweisen. Auf die Frage, worin die explanatorische Relation zwischen Explanans und Explanandum besteht, scheint es in diesem Fall keine so "einfache" Antwort zu geben wie bei den anderen bisher diskutierten Versionen des Wunderarguments. Der Grund dafür hängt offenbar damit zusammen, daß bereits das Explanandum nicht "nur" aus ein oder zwei Sachverhalten und/oder Ereignissen besteht, sondern aus einer ganzen Reihe davon, die, wie oben diskutiert, bereits untereinander eine Art kausale, psychologische Erklärung für das Zustandekommen einer Handlung bilden, plus einer Aussage über die Folgen dieser Handlung. Was sich dennoch (über die obige Rekonstruktion hinaus) über die Art der Erklärung, die in diesem Fall vorliegt, und über den explanatorischen Zusammenhang zwischen Explanans und Explanandum sagen läßt, scheint etwa Folgendes zu sein.

Die Erklärungsleistung, die das Explanans liefert, besteht offenbar aus zwei "Teilerklärungsleistungen": Zum einen fügt das Explanans dem Explanandum effektiv (s.u.) eine Aussage über die Folgen der Handlung hinzu, die zusammen mit dem Explanandum eine Erklärung des Erfolges der Handlung ergeben, zum anderen enthält das Explanans Aussagen, die, zusammen mit dem Explanandum, die Wahrheit der (aus einer Theorie abgeleiteten) Überzeugung der handelnden Person erklären, die genau diesen Zusammenhang von Handlung und Folgen zum Inhalt hat. Die erste dieser beiden Teilerklärungsleistungen scheint zu sein, daß das Explanans sozusagen das fehlende Glied eines ansonsten durch das Explanandum beschriebenen kausalen Prozesses oder einer solchen kausalen Kette liefert, der bzw. die von dem Wunsch der Person $A$, daß ein bestimmter Sachverhalt eintritt, zum tatsächlichen Eintreten dieses Sachverhaltes führt, und so die Übereinstimmung von A's Wunsch mit dem tatsächlich durch ihre Handlung herbeigeführten Sachverhalt erklärt (oder, wenn $A$ in derselben Weise nicht nur einen, sondern eine Vielzahl gleichartiger Handlungserfolge erzielt, die Korrelation von $A$ 's Wünschen mit dem tatsächlichen Eintreten der entsprechenden Sachverhalte). Das Explanans schließt genaugenommen nicht die Aussage über den Zusammenhang von Handlung und Folgen selbst ein, sondern die Prämisse (12), die die metasprachliche Aussage enthält, daß eine Überzeugung bzw. Aussage, die den Zusammenhang zum Inhalt hat; die erstere Aussage wird aber natürlich durch die letztere impliziert.

Die zweite der beiden Teilerklärungsleistungen scheint zu sein, daß die "Übereinstimmung" oder Korrelation zwischen dem Bestehen der Überzeugung von A, die den genannten Zusammenhang von Handlung und Folgen zum Inhalt hat, einerseits, und der Wahrheit dieser Überzeugung andererseits erklärt wird durch eine "Übereinstimmung" oder Korrelation zwischen den Überzeugungen von A, die bei der Gewinnung fraglichen Überzeugung involviert waren, (also den Überzeugungen, die $T$ und $T \vdash P \rightarrow Q$ zum Inhalt haben) und der Wahrheit dieser Überzeugungen: Daß, was das Explanans dem Explanandum tatsächlich hinzufügt, stellt für sich eine "vollständige" deduktive semantische Erklärung dafür dar, daß eine Repräsentation, die den genannten Zusammenhang von Handlung und Folgen zum Inhalt hat, wahr ist; diese Erklärung stellt, wie oben diskutiert, einen von zwei parallelen Strängen dar, die zusammen die Erklärung der Wahrheit der (aus einer Theorie abgeleiteten) Überzeugung der handelnden Person über diesen Zusammenhang bilden. Der zweite Strang ist die bereits im Explanandum enthaltene kausale, psychologische Erklärung für die Entstehung der Überzeugung. Die Erklärungsleistung scheint darin zu bestehen, daß die "Übereinstimmung" zwischen den Enden der beiden Stränge auf "Übereinstimmungen" der vorausliegenden Elemente der beiden Stränge zurückgeführt wird, anders ausgedrückt: auf die Parallelität des Gewinnungsprozesses der fraglichen Überzeugung und der genannten deduktiven semantischen Erklärung. Die explanatorische Relation 
zwischen Explanans und Explanandum im Hinblick auf die zweite Teilerklärungsleistung scheint also zu sein, daß Explanans und eine Teil des Explanandums jeweils einen der beiden parallelen Stränge einer Erklärung der beschriebenen Art bilden.

Wie im Fall der Version des Wunderarguments, die sich auf Handlungserfolge bezieht, die Art der Erklärung, um die es geht und die explanatorische Relation zwischen Explanans und Explanandum in einer "einfacheren", weniger komplexen, aber dennoch angemessenen Weise charakterisiert werden könnten, ist schwer zu sehen.

\subsubsection{Die Erklärung der instrumentellen Verläßlichkeit der Methodolo- gie der Wissenschaften (Boyd)}

Für Boyds Version des Wunderarguments ist nicht ganz leicht zu erkennen, wie die Frage zu beantworten ist, worin die explanatorische Relation zwischen Explanans und Explanandum besteht, klar ist aber, daß eine Antwort anders, vor allem komplizierter, ausfallen muß als für die Versionen, die sich auf ePEe oder nPEe beziehen.

Klar scheint zunächst, daß sich die von Boyd vorgesehenen Erklärungen in zwei Teile zerlegen lassen. Boyds Explanandum war, daß die Gesamtheit der Prinzipien, Verfahren etc. der Wissenschaften, die zur Gewinnung und Etablierung von Theorien eingesetzt werden und sich dabei auf die zum jeweiligen Zeitpunkt akzeptierten Theorien stützen, in verläßlicher Weise neue Theorien liefert, die prognostisch erfolgreich sind. Es liegt nahe, in einem ersten Schritt zu erklären, warum die neuen Theorien Prognoseerfolge liefern, und dann in einem zweiten Schritt zu erklären, warum die Prinzipien, Verfahren etc. der Wissenschaften in verläßlicher Weise neue Theorien mit den Eigenschaften liefern, die zu Prognoseerfolgen führen.

Was im ersten Schritt zu erklären ist, sind offenbar ePEe, wobei allerdings bei Boyd erstens die prognostizierten Sätze "nur" annähernd wahr sein müssen und zweitens die Erfolge für alle Theorien zusammen betrachtet und erklärt werden sollen. Es liegt also nahe, im ersten Schritt die Prognoseerfolge der neuen Theorien $\left\{T_{i}^{n e u}\right\}$ in der oben für ePEe erläuterten Weise (unter Berücksichtigung der beiden genannten Punkte) durch die semantische Vollwertigkeit und die annähernde Wahrheit der Theorien zu erklären, also durch

Die Theorien $\left\{T_{i}^{\text {neu }}\right\}$ bzw. ihre Sätze haben Wahrheitswerte, d.h. sie sind wahr oder falsch.

und

$$
\text { Die Theorien }\left\{T_{i}^{\text {neu }}\right\} \text { sind annähernd wahr. }
$$

(9.16) samt zugehöriger Erläuterung läßt sich dann nicht weiter erklären, wohl aber (9.17): Im zweiten Erklärungsschritt ist zu erklären, warum die Gesamtheit der Prinzipien, Verfahren etc. der Wissenschaften, die zur Gewinnung und Etablierung neuer Theorien eingesetzt werden und die sich dabei auf die zum jeweiligen Zeitpunkt akzeptierten Theorien $\left\{T_{i}^{a l t}\right\}$ stützen, in verläßlicher Weise Theorien $\left\{T_{i}^{n e u}\right\}$ liefern, die (annähernd) wahr sind, für die also (9.17) gilt. Bei diesem Erklärungsschritt muß dann offenbar das in Boyds Version des Wunderarguments vorgesehene Explanans, daß die Theorien $\left\{T_{i}^{a l t}\right\}$ semantisch vollwertig und annähernd wahr sind, also (9.11) und (9.12), zum Einsatz kommen.

Von welcher Art der zweite Erklärungsschritt ist, liegt nahe, wenn man die Erklärungsaufgabe aus einer bestimmten Perspektive in den Blick nimmt: Daß erklärt werden soll, warum auf bestimmtem Wege in verläßlicher Weise wahre Theorien gewonnen und etabliert werden, läßt sich von einem reliabilistischen Standpunkt auffassen als die Aufgabe, 
zu erklären, warum ein bestimmtes epistemisches Verfahren verläßlich in reliabilistischem Sinn ist. ${ }^{135}$ Man kann versuchen, die Gesamtheit der Prinzipien, Verfahren etc., die in den Wissenschaften zur Gewinnung und Etablierung neuer Theorien eingesetzt werden, Boyds "total-science modification procedure", als ein "großes" epistemisches Verfahren aufzufassen, dessen Output die Theorien $\left\{T_{i}^{\text {neu }}\right\}$ sind. Daß die Theorien $\left\{T_{i}^{\text {neu }}\right\}$ alle annähernd wahr sind, also (9.17), kann dann zunächst in einem schwachen Sinn durch die Annahme erklärt werden, daß dieses Verfahren verläßlich im reliabilistischen Sinn ist, also (unter bestimmten Bedingungen) immer oder sehr wahrscheinlich wahren Output liefert. ${ }^{136}$ Eine substantiellere Erklärung dafür muß jedoch darüber hinaus erklären, warum das Verfahren verläßlich ist.

Wie eine Erklärung für die Verläßlichkeit eines epistemischen Verfahrens aussieht, ist für einige der paradigmatischen epistemischen Verfahren, an denen sich reliabilistische Positionen orientieren, zumindest im Umriß leicht zu erkennen: Für Erzeugungsverfahren wie das Beobachten mit dem bloßen Auge (unter Normalbedingungen) oder das Beobachten mit einem Mikroskop läßt sich zumindest im Umriß, wenn auch nicht exakt, aus den Gesetzen der Optik zusammen mit den relevanten physiologischen etc. Gesetzmäßigkeiten, denen der menschliche Wahrnehmungsapparat unterliegt, ableiten, daß eine Person, die eines dieser Verfahren (unter geeigneten, zu spezifizierenden Bedingungen hinsichtlich der Beleuchtung etc.) einsetzt, sehr wahrscheinlich wahre Überzeugungen über die Gegenstände (bestimmter Größenordnung etc.) in ihrem Blickfeld und (bestimmte von) deren Eigenschaften gewinnt. Für das paradigmatische Übertragungsverfahren, das deduktive Schließen, wird Verläßlichkeit im reliabilistischen Sinn durch eine Korrektheitsaussage der Form (9.15) formuliert, die, wie bereits erwähnt, aus einer Prämisse (9.6) über die semantische Vollwertigkeit der zugrundeliegenden Sprache samt der Erläuterung von (9.6) durch eine Wahrheits- bzw. Referenztheorie folgt. Für diese epistemischen Verfahren ist also wenigstens im Umriß klar, wie eine Erklärung ihrer Verläßlichkeit aussieht, und bei diesen Erklärungen kommen im Explanans auch Prämissen über die semantische Vollwertigkeit und die Wahrheit von Theorien vor, erstere im Fall deduktives Schließen, letztere sowohl im Fall deduktives Schließen (als Bedingung, die die Prämissen eines Schlusses erfüllen müssen), als auch in den Fällen Beobachten mit dem Mikroskop und mit dem bloßen Auge (als Prämissen, die die Funktionsweise des Mikroskops etc. beschreiben ${ }^{137}$ ).

Naturalistische Erklärungen dieser Art für die Verläßlichkeit epistemischer Verfahren hat Boyd im Auge, wenn er bei seiner Version des Wunderarguments von einer Erklärung der Verläßlichkeit der "total-science modification procedure", also der Gesamtheit der Prinzipien, Verfahren etc. spricht, die in den Wissenschaften zur Gewinnung und Etablierung von Theorien eingesetzt werden. ${ }^{138}$ Die Anwendung bzw. Übertragung dieser Idee von paradigmatischen epistemischen Verfahren wie den beiden genannten auf Boyds "großes" Verfahren, das in der Anwendung der Gesamtheit von Prinzipien, Verfahren etc. der Wissenschaften besteht, ist jedoch nicht trivial und ergibt, soweit erkennbar, "nur" eine Erklärungsskizze, die weit unvollständiger ist und in weit größerem Ausmaß von kontingenten, derzeit nicht weiter begründbaren und teilweise nicht einmal einigermaßen genau formulierbaren Voraussetzungen abzuhängen scheint als es die oben beschriebenen Er-

\footnotetext{
${ }^{135}$ S. Kap.8.3.1.

${ }^{136}$ Siehe S.153.

${ }^{137}$ Genaugenommen fungieren dabei als Prämissen eine Theorie oder Gesetze der Optik etc., nicht die (metasprachliche) Aussage, daß diese Theorie oder diese Gesetze wahr sind. Letztere implizieren aber natürlich erstere.

${ }^{138}$ Siehe z.B. [Boyd81], S.622ff., [Boyd89], S.11ff.
} 
klärungen für die genannten paradigmatischen epistemischen Verfahren bereits sind bzw. tun.

Um eine naturalistische Erklärung für die Verläßlichkeit von Boyds "total-science modification procedure" zu gewinnen, empfiehlt es sich offenbar, diese als aus einzelnen verläßlichen Teilverfahren "zusammengesetztes" epistemisches Verfahren zu betrachten: Die Teilverfahren bestehen in der Anwendung der von Boyd genannten Beispiele von Prinzipien, Verfahren etc., die man in verschiedenen Kombinationen nacheinander anwenden kann, so wie man etwa auch das Beobachten mit dem Mikroskop und (anschließendes) deduktives Schließen (aus den Beobachtungsresultaten zusammen mit anderen Prämissen) zu einem "zusammengesetzten" Verfahren kombinieren kann. Wenn man eine Erklärung für die Verläßlichkeit der Teilverfahren hat, hat man damit auch eine Erklärung für die Verläßlichkeit eines daraus zusammengesetzten Verfahrens. ${ }^{139}$

Wenn man nach diesen Vorüberlegungen die von Boyd genannten Prinzipien, Verfahren, Regeln etc. in den Blick nimmt, sieht man, daß für ihre Verläßlichkeit eine naturalistische Erklärung von etwa der Art, wie sie oben für die paradigmatischen Verfahren Beobachten mit bloßem Auge oder mit dem Mikroskop und deduktives Schließen skizziert wurden, sicherlich prinzipiell denkbar und nicht ausgeschlossen ist, daß aber die Erklärungsskizzen, die man sich derzeit für ihre Verläßlichkeit zurechtlegen kann, wesentlich gröber und unvollständiger sind als die Erklärungsskizzen im Fall der genannten paradigmatischen Verfahren. Die drei vorne ${ }^{140}$ zitierten Beispiele für die von Boyd genannten Prinzipien, Verfahren etc. sind in dieser Hinsicht durchaus typisch.

Das Prinzip, daß "wir nur diejenigen Theorien ernstnehmen, die im Hinblick auf ihre ontologischen Verpflichtungen und die Gesetze, die sie enthalten, relativ stark unseren schon existierenden Theorien ähneln", ${ }^{141}$ soll zum Einsatz kommen, wenn es darum geht, eine Theorie für einen bestimmten Gegenstands- oder Phänomenbereich zu gewinnen und zu etablieren, und dabei dazu dienen, die Menge der Theorien zu begrenzen, die als "ernsthafte" Kandidaten in Frage kommen (und daher experimentellen Tests unterworfen werden u.ä.). Um dieses Prinzip in einem konkreten Fall einsetzen zu können, braucht man weitere Prämissen darüber, welche Theorien den bereits etablierten "relativ stark ähneln" und welche nicht. Solche Prämissen dürften sich in vielen Fällen durch das (mehr oder

\footnotetext{
${ }^{139}$ Wenn man Boyds "total-science modification procedure" nicht in dieser Weise in Teilverfahren zerlegt, ist nicht zu sehen, wie eine diesbezügliche reliabilistische Erklärung für Verläßlichkeit aussehen könnte, denn aus reliabilistischer Perspektive betrachtet kann man in den diversen Einzelfällen, in denen eine Theorie, ein Modell o.ä. mit Hilfe der von Boyd genannten Prinzipien, Verfahren etc. gewonnen oder etabliert wurde, nur in einem losen Sinn von der Anwendung ein- und desselben epistemischen Verfahrens, eben der "total-science modification procedure", sprechen: I.a. werden in jedem Einzelfall mehrere der Prinzipien, Verfahren etc. angewendet, aber in verschiedenen Einzelfällen i.a. verschiedene Kombinationen davon. Aus reliabilistischer Perspektive könnte man eine bestimmte Kombination als ein Verfahren auffassen und evtl. in der skizzierten Weise naturalistisch erklären; für eine Gesamtheit von Einzelfällen, die aus verschiedenen Kombinationen besteht, dürfte eine "einheitliche" Erklärung der skizzierten Art nicht zu haben sein.

Daß Boyd von einer "total-science modification procedure" und damit von so etwas wie einem "großen" epistemischen Verfahren spricht, dürfte dadurch zu erklären sein, daß er als Explanandum die Verläßlichkeit eines Verfahrens angeben möchte, und damit etwas, was auch für Antirealisten in unkontroverser Weise epistemisch zugänglich ist: Da zur Gewinnung oder Etablierung einer (prognostisch erfolgreichen) Theorie eines der von ihm genannten Prinzipien, Verfahren etc. nicht ausreicht und außerdem zweifelhaft oder zumindest nicht klar ist, ob i.a. in der Praxis häufig genug ein- und dieselbe Kombination dieser Prinzipien, Verfahren etc. eingesetzt wird, um festzustellen, ob diese Kombination verläßlich ist, ist die "total-science modification procedure" offenbar das einzige "epistemische Verfahren", dem sich tatsächlich eine Vielzahl prognostisch erfolgreicher Theorien als Output zuschreiben läßt.

${ }^{140}$ Siehe Abschnitt 9.1.3.

${ }^{141}$ Siehe das Zitat S.190.
} 
weniger unkontroverse) Urteil der Experten auf dem jeweiligen Gebiet gewinnen lassen; es ist allerdings nicht zu erkennen, daß sich darüber hinaus über die Gewinnung entsprechender Prämissen etwas Systematisches sagen ließe oder daß sie sich gar "algorithmisieren" lassen sollte o.ä. Man kann also die Auswahl der "ernsthaften Kandidaten" für eine Theorie eines bestimmten Gegenstands- oder Phänomenbereiches im Prinzip als verläßliches epistemisches Verfahren auffassen, genauer: als Übertragungsverfahren, das die bereits etablierten Theorien und eine Menge überhaupt denkbarer "Kandidatentheorien" als Input benötigt und die "ernstzunehmenden Kandidatentheorien" als Output liefert. Wie eine Erklärung für die Verläßlichkeit dieses Verfahrens aussehen könnte, ist jedoch allenfalls im allergröbsten Umriß erkennbar: Daß dieses Verfahren verläßlich ist, hieße, daß es als Output eine Menge von "ernstzunehmenden Kandidatentheorien" liefert, unter denen sich sehr wahrscheinlich die (annähernd) wahre Theorie für den fraglichen Gegenstandsoder Phänomenbereich befindet, wenn, erstens, die (als Input fungierenden) bereits etablierten Theorien (annähernd) wahr sind und wenn, zweitens, in der (ebenfalls als Input fungierenden) Menge der überhaupt denkbaren "Kandidatentheorien" eine (annähernd) wahre Theorie enthalten ist. Eine Erklärung für diese Verläßlichkeit müßte vermutlich eine Prämisse involvieren, die besagt, daß alle (annähernd) wahren Theorien (oder vielleicht nur alle wahren Theorien "benachbarter" Gegenstands- oder Phänomenbereiche o.ä.) sich tatsächlich im Hinblick auf ihre ontologischen Verpflichtungen und die Gesetze, die sie enthalten, relativ stark ähneln. Außerdem müßte sie vermutlich auf die Fähigkeit der Experten, in verläßlicher Weise Urteile über die Ähnlichkeit von Theorien zu fällen, Bezug nehmen; in welcher Weise dies geschehen soll, ist jedoch derzeit kaum zu erkennen: Eine solche Fähigkeit ohne weitere Analyse oder Erklärung als Prämisse in Anspruch zu nehmen, ergibt kaum eine zufriedenstellende Erklärung; eine kognitionspsychologische o.ä. Erklärung für diese Fähigkeit scheint aber derzeit nicht in Sicht.

Fazit: Eine Erklärung für die Verläßlichkeit des, wie Boyd sich ausdrückt, Prinzips, daß "wir nur diejenigen Theorien ernstnehmen, die im Hinblick auf ihre ontologischen Verpflichtungen und die Gesetze, die sie enthalten, relativ stark unseren schon existierenden Theorien ähneln", ist im Prinzip vielleicht denkbar, aber derzeit allenfalls im allergröbsten Umriß formulierbar, und hängt vermutlich von der starken Prämisse ab, daß alle (annähernd) wahren Theorien sich im Hinblick auf ihre ontologischen Verpflichtungen und die Gesetze, die sie enthalten, relativ stark ähneln. Eine Erklärung dafür, daß mit Hilfe dieses Prinzips tatsächlich prognostisch erfolgreiche Theorien gewonnen bzw. etabliert wurden, muß vermutlich zusätzlich die Prämisse enthalten, daß die bereits etablierten Theorien, die als Input bei der Anwendung des Verfahrens fungieren, (annähernd) wahr sind, und damit das, was Boyd als Explanans nennt, sie muß aber vermutlich außerdem noch eine weitere starke Prämisse in Anspruch nehmen, nämlich die, daß in jedem Anwendungsfall in der als Input des Verfahrens fungierenden Menge der denkbaren "Kandidatentheorien" eine (annähernd) wahre Theorie enthalten ist.

Für Boyds "Fundamental Rule of Experimental Design" gilt Ähnliches: Sie scheint eine Art Übertragungsverfahren zu beschreiben, dessen Anwendung in einem konkreten Fall als Input eine "Kandidatentheorie" für den jeweils zur Diskussion stehenden Gegenstandsoder Phänomenbereich und die Menge der zum jeweiligen Zeitpunkt bereits akzeptierten anderen Theorien erfordert und als Output so etwas wie einen Satz von Beschreibungen von Testsituationen liefert. Dieser Satz von Testsituationen ist von der Art, daß sie, wie Boyd sich ausdrückt, ${ }^{142}$ hinreichen um einen zum Akzeptieren der Theorie zu berechti-

\footnotetext{
${ }^{142}$ Siehe das Zitat S.190.
} 
gen, wenn die entsprechenden Tests experimentell realisiert werden und zugunsten der Theorie ausfallen. Das Verfahren hat offenbar mit dem (näherungsweisen) Ableiten von experimentell zugänglichen Konsequenzen aus der zur Debatte stehenden Theorie und deren Konkurrenten zu tun, eine systematische Beschreibung des Verfahrens oder gar eine Art Algorithmisierung ist aber auch in diesem Fall nicht in Sicht. Eine naturalistische Erklärung für die Verläßlichkeit dieses Verfahrens müßte vermutlich zum einen auf die semantische Vollwertigkeit der Theorien Bezug nehmen, zum anderen auf die Fähigkeit der relevanten Experten, im konkreten Fall aus den Theorien alle "richtigen" Konsequenzen zu ziehen, d.h. alle, die zusammen eine "geeignete" Menge von Testsituationen ergeben; eine solche Fähigkeit ohne weitergehende Erklärung als Prämisse in Anspruch zu nehmen, ergibt wiederum kaum eine zufriedenstellende Erklärung, eine kognitionspsychologische o.ä. Erklärung für diese Fähigkeit ist aber auch hier nicht in Sicht. Eine Erklärung dafür, daß mit Hilfe dieses Verfahrens tatsächlich prognostisch erfolgreiche Theorien gewonnen bzw. etabliert wurden, muß zusätzlich die Prämisse enthalten, daß die Menge der bereits etablierten Theorien, die als Input bei der Anwendung des Verfahrens fungieren, (annähernd) wahr sind, und damit das, was Boyd als Explanans nennt, sie muß aber vermutlich außerdem noch eine weitere starke Prämisse in Anspruch nehmen, nämlich die, daß diese Menge "hinreichend vollständig" ist, um tatsächlich alle relevanten Alternativen experimentell ausschließen zu können.

Mutatis mutandis dasselbe gilt für das von Boyd skizzierte Verfahren, bei der Realisierung eines bestimmten experimentellen Tests einer bestimmten Theorie experimentelle Artefakte auszuschließen. ${ }^{143}$

Ein etwas genauerer Blick auf die von Boyd genannten Prinzipien, Verfahren etc. zeigt also deutlich, daß für ihre Verläßlichkeit (im reliabilistischen Sinn) derzeit nur Erklärungsskizzen zu haben sind, die weit unvollständiger sind und in weit größerem Ausmaß von starken Prämissen abhängen, die gegenwärtig nicht weiter erklärbar und teilweise nicht einmal genau formulierbar sind, als es bei den oben skizzierten Erklärungen für die Verläßlichkeit epistemischer Verfahren wie dem Beobachten mit dem Mikroskop oder dem deduktiven Schließen der Fall ist. Erklärungen dafür, daß die von Boyd genannten Prinzipien tatsächlich zur Gewinnung bzw. Etablierung von prognostisch erfolgreichen Theorien geführt haben, hängen, wie sich gezeigt hat, i.a. von noch weiteren starken Prämissen ab, deren weitere Erklärung ebenfalls offen bleibt. ${ }^{144}$ Erklärungen dieser Art, die sich auf einzelne Prinzipien, Verfahren etc. beziehen, zusammenzusetzen zu der von Boyd ins Auge gefaßten Erklärung für die Verläßlichkeit bzw. die tatsächlichen Erfolge der "total-science modification procedure" führt offenbar zu einer Potenzierung dieser Abhängigkeiten und Ungenauigkeiten.

Das, was Boyd als Explanans seiner Version des Wunderarguments nennt, nämlich die semantische Vollwertigkeit und die (annähernde) Wahrheit der alten Theorien, ist also offenbar gedacht als Teil einer "vollständigen", derzeit aber nur im allergröbsten Umriß angebbaren Erklärung. Diese "Unvollständigkeit" des hier und heute von Boyd in seiner Version des Wunderarguments angegebenen Explanans stellt aber seiner Ansicht nach keineswegs einen Mangel dieses Explanans und der darauf basierenden Erklärung dar. Seine Begründung für diese Ansicht bezieht sich auf seine Charakterisierung der Art von Erklärung und der explanatorischen Relation zwischen Explanans und Explanandum, die im Fall des Wunderarguments vorliegen.

Die Erklärung, auf die Boyd in seiner Version des Wunderarguments Bezug nimmt,

\footnotetext{
${ }^{143}$ Siehe S.191.

${ }^{144}$ Boyd erkennt diesen Befund an; siehe z.B. [Boyd85a], S.90ff.
} 
ist eine naturalistische, die sich seiner Ansicht nach in keiner grundlegenden Weise von gewöhnlichen naturwissenschaftlichen Erklärungen unterscheidet: So wie es wissenschaftliche Erklärungen für Phänomene wie den Hall-Effekt, Malaria, die Entstehung von Vulkanen u.ä. gibt, so gibt es nach Boyd eine wissenschaftliche Erklärung gleicher Art für

"[...] a very complex natural phenomenon - - the reliable development of successively more accurate and comprehensive theories and beliefs, about both observable and unobservable features of the world." 145

Wissenschaftliche Erklärungen sind nach Boyd kausale Erklärungen: ${ }^{146}$

"At least for many central cases [...] an explanation of an event is an account of how it was caused [...] To explain a law or a regularity is to give an account $[\ldots]$ of the causal factors, mechanisms, processes, and the like that bring about the regularity or the phenomena described in the law." 147

Auch die Erklärung, auf die gemäß Boyds Version des Wunderarguments geschlossen werden soll, ist eine kausale Erklärung:

"[...] the realist's explanation has the form of an ordinary causal explanation in science subject to confirmation or disconfirmation by ordinary scientific standards." 148

"[...] the causal mechanisms relevant to knowledge will include mechanisms, social and technological as well as psychological, for the criticism, testing, acceptance, modification and transmission of scientific theories". ${ }^{149}$

Für kausale Erklärungen ist es nach Boyd typisch und keineswegs ein Mangel, daß sie nicht "vollständig" sind:

"In all but the most atypical cases [of a causal explanation] the account will be partial: Not all the causally determining factors will be indicated, nor will the relevant mechanisms be fully specified." 150

Das von Boyd in seiner Version des Wunderargument angegebene Explanans, daß die bereits etablierten Theorien semantisch vollwertig und wahr sind, nennt einen kausalen Faktor unter mehreren, die zusammen eine "vollständige" kausale Erklärung für das Explanandum ergeben sollen. Daß derzeit nur dieser eine kausale Faktor angegeben werden kann, macht die derzeit verfügbare Erklärung daher nach Boyd zu einer typischen Kausalerklärung und stellt nicht etwa einen Defekt dar.

Für die Frage nach der explanatorischen Relation zwischen Explanans und Explanandum, die im Fall von Boyds Version des Wunderarguments vorliegt, und die Frage, welcher Art von Erklärung sich die von Boyd für dessen Explanandum vorgesehene Erklärung zurechnen läßt, ergeben sich aus diesen Überlegungen Antworten, die deutlich anders ausfallen als etwa im Fall der oben diskutierten Versionen des Wunderarguments,

\footnotetext{
${ }^{145}$ [Boyd81], S.628.

${ }^{146}$ Boyd setzt einen unreduzierten, "nicht-Humeschen" Begriff von Kausalität voraus, für den er u.a. in [Boyd85a] plädiert.

${ }^{147}[$ Boyd85a], S.80/81.

148 [Boyd90a], S.376.

149 [Boyd89], S.12.

150 [Boyd85a], S.81.
} 
die sich auf ePEe und nPEe beziehen: Die explanatorische Relation ist die, daß das Explanans einen von mehreren kausalen Faktoren nennt, die das Explanandum verursachen bzw. verursacht haben. Dagegen besteht keine deduktive Beziehung zwischen Explanans und Explanandum. Die Erklärung läßt sich also als kausale Erklärung charakterisieren, und zwar als eine "unvollständige". Dagegen läßt sie sich etwa nicht den DN-Erklärungen oder den Erklärungen epistemischer Art zurechnen, denn das Explanandum folgt nicht deduktiv aus dem Explanans und es ist daher auch nicht aufgrund des Explanans zu erwarten.

\subsubsection{Die Erklärung neuer Prognoseerfolge durch abgeschwächte Expla- nantia (Carrier/Worrall)}

Für Versionen des Wunderarguments wie die von Carrier und Worrall, die sich auf nPEe beziehen, diese aber nicht durch die Wahrheit oder annähernde Wahrheit von Theorien erklären, sondern durch abgeschwächte Explanantia sollte die explanatorische Relation zwischen Explanans und Explanandum intuitiv und wohl auch nach Ansicht ihrer Anhänger im wesentlichen von derselben Art sein wie im Fall der Erklärung von nPEen durch die Wahrheit von Theorien. Bei genauerem Hinsehen zeigt sich jedoch, daß die abgeschwächten Explanantia nicht in einem deduktiven Zusammenhang mit dem Explanandum nPEe stehen und eine Erklärung von nPEen durch die abgeschwächten Explanantia nicht ohne weiteres als deduktive semantische Erklärung charakterisiert werden kann. Diese Explanantia erklären nPEe "nur" in einem verwandten, aber etwas modifizierten Sinn, der im Diskussionszusammenhang des Wunderarguments Probleme mit sich bringen kann.

Die Idee hinter den Versionen des Wunderarguments, denen zufolge nPEe durch die vorgeschlagenen abgeschwächten Explanantia zu erklären sind, scheint zu sein, daß nPEe einer Theorie $T^{151}$ einen Grund für die Annahme liefern, daß $T$ zwar nicht wahr ist, aber mit der wahren Theorie $T_{W}$ des fraglichen Gegenstandsbereiches die Aussagen teilt, die für die nPEe verantwortlich sind. Diese Aussagen (die die Klassifikation von Phänomenen nach Arten, die mathematische Struktur der Theorie o.ä. zum Inhalt haben) sollten einen Teil von $T$ ausmachen. Sei $\tilde{T}$ die Teilmenge der für die Erfolge von $T$ verantwortlichen Sätze von $T$. Das Explanans besagt dann, daß $\tilde{T}$ nur wahre Sätze enthält; $T \backslash \tilde{T}$ enthält i.a. auch falsche. Damit ist klar, daß (9.2), daß $P$ wahr ist, aus ' $\tilde{T}$ ist wahr', ' $\tilde{T} \vdash P$ ' (rsp. ' $P$ wurde aus $\tilde{T}$ abgeleitet') und der Prämisse (9.15) über die Korrektheit des "Theoriekalküls" folgt, aber nicht aus ' $\tilde{T}$ ist wahr' und (9.1), daß ' $T \vdash P$ ', (rsp. (9.3)) zusammen mit (9.15). Daß aus einer Menge von zum Teil falschen Sätzen ein Satz $P$ ableitbar ist, läßt nicht den Schluß zu, daß $P$ wahr ist.

Wenn eine deduktive Relation dieser Art wesentlicher Teil des explanatorischen Zusammenhangs zwischen Explanans und Explanandum sein soll, d.h., wenn eine deduktive Relation dieser Art zusammen mit der Ableitung der Korrektheitsaussage (9.15) aus einer Prämisse (9.6) über die semantische Vollwertigkeit der Theorie eine Erklärung für nPEe liefern soll, dann ergibt ' $\tilde{T}$ ist wahr' also offenbar für Erfolge von $\tilde{T}$ eine Erklärung dieser Art, nicht aber für Erfolge von T. Letztere, nicht erstere bilden jedoch das Explanandum des Wunderarguments.

In einem etwas modifizierten, weiteren Sinn kann man jedoch auch in dieser Situation von einer Erklärung der Erfolge von $T$ durch ' $\tilde{T}$ ist wahr' sprechen: ' $\tilde{T}$ ist wahr' liefert eine Erklärung der Erfolge von $\tilde{T}$, die sich als deduktive semantische Erklärung charakterisieren läßt, und $\tilde{T}$ ist Teil von $T$; wenn die Sätze $P$, die die Prognoseerfolge

\footnotetext{
${ }^{151}$ Oder, im Fall Carriers, nPEe einer Gesamtheit von Theorien; diese Differenz bleibt hier implizit.
} 
von $T$ ausmachen, auch aus $\tilde{T}$ ableitbar sind, kann man daher in gewissem Sinn auch von nPEen von $T$ sprechen und von ihrer Erklärung durch ' $\tilde{T}$ ist wahr'. Man könnte dies eine deduktive semantische Erklärung im weiten Sinn nennen. Ein analoger Fall, der diese Redeweise plausibel macht, wäre z.B. der, daß die guten Leistungen einiger Spieler einer Schach-Mannschaft nicht nur ihre eigenen Erfolge erklären, sondern auch den Erfolg der Mannschaft (obwohl die anderen Mannschaftsmitglieder schlecht gespielt haben).

Die explanatorische Relation zwischen Explanans und Explanandum ist also im Fall der Erklärung von nPEen durch die abgeschwächten Explanantia zwar nicht dieselbe wie im Fall der Erklärung durch die Wahrheit der erfolgreichen Theorie, aber sie ist doch von verwandter Art: Sie kommt nicht dadurch zustande, daß aus dem Explanans und einem Teil des Explanandums, nämlich (9.1) rsp. (9.3), der andere Teil des Explanandums deduktiv folgt. Stattdessen besteht sie aus einem gleichartigen deduktiven Schluß, bei dem (9.1) rsp. (9.3), also der eine Teil des Explanandums, durch die Prämisse ' $\tilde{T} \vdash P$ ' (rsp. ' $P$ wurde aus $\tilde{T}$ abgeleitet') ersetzt wird; diese Prämisse ist etwas stärker als (9.1) (rsp. (9.3)), so daß letztere deduktiv aus ersterer folgt. Um die explanatorische Relation herzustellen, muß also das Explanans um die zusätzliche Prämisse ' $\tilde{T} \vdash P$ ' (rsp. ' $P$ wurde aus $\tilde{T}$ abgeleitet') ergänzt werden. Wenn man die Implikationsrelation zwischen ihr und (9.1) (rsp. (9.3)) zur Erklärung zählt, besteht also bei der Erklärung von nPEen durch die abgeschwächten Explanantia die explanatorische Relation darin, daß das Explanandum (und zwar das gesamte, nicht nur ein Teil) deduktiv aus dem um die zusätzliche Prämisse ergänzten Explanans folgt. Die Art der Erklärung, die durch diese explanatorische Relation geliefert wird, kann außer, wie obne erläutert, als deduktive semantische Erklärung im weiten Sinn, auch als Erklärung epistemischer Art charakterisiert werden.

Ein für den Diskussionszusammenhang des Wunderarguments relevanter Punkt, der sich aus diesen Überlegungen ergibt, ist, daß man für bestimmte nPEe einer Theorie eine Erklärung, die als eine deduktive semantische Erklärung im weiten Sinn oder als Erklärung epistemischer Art charakterisiert werden kann, nur dann tatsächlich vorweisen kann, wenn man die Teile der erfolgreichen Theorie isolieren kann, die für die Erfolge verantwortlich sind, so daß man die zusätzliche Prämisse ' $\tilde{T} \vdash P^{\prime}$ ' (rsp. ' $P$ wurde aus $\tilde{T}$ abgeleitet') angeben kann. Solange man dies nicht kann, bleibt der Ansatz, nPEe durch abgeschwächte Explanantia zu erklären, programmatisch. Eine Version des Wunderarguments, die unter Bezugnahme auf eine Erklärung der beschriebenen Art durch abgeschwächte Explanantia realistische Thesen begründen kann, bekommt man nur, wenn die für die nPEe verantwortlichen Teile der erfolgreichen Theorie angegeben werden können. Da die abgeschwächten Explanantia (also bei Carrier Aussagen, die die Klassifikation von Phänomenen nach Arten, und bei Worrall Aussagen, die die mathematische Struktur der Theorie zum Inhalt haben) bisher nur skizzenhaft umrissen und nur durch einzelne konkrete Beispiele erläutert worden sind, ist derzeit schwer zu beurteilen, ob diese Explanantia in konkreten Fällen tatsächlich (zumindest in der Regel, in vielen Fällen o.ä.) allein für die nPEe verantwortlich sind, ob also aus den jeweiligen Mengen $\tilde{T}$ tatsächlich die nPEe $P$ ableitbar sind und die Explanantia damit "gehaltvoll genug" sind, um Erklärungen der beschriebenen Art für die nPEe zu liefern. Zur Beantwortung dieser Frage sind eingehendere Untersuchungen konkreter Fälle erforderlich als bisher verfügbar. ${ }^{152}$

\footnotetext{
${ }^{152}$ Wie die Antwort ausfällt, ist z.B. im Fall des von Worrall vorgeschlagenen strukturellen Realismus alles andere als klar.

Ein analoger Fall, der die Probleme veranschaulicht, die mit der Erklärung von Prognoseerfolgen durch die abgeschwächten Explanantia verbunden sind, ist vielleicht der Folgende: Ein Tourist, der sich auf einen Stadtplan aus dem Jahre 1900 stützt, findet im Berlin des Jahres 2000 erfolgreich die Stationen
} 
Wenn man für die Versionen des Wunderarguments, die sich auf nPEe und auf abgeschwächte Explanantia für diese beziehen, die explanatorische Relation zwischen Explanans und Explanandum in dieser Weise erläutert, sieht man, daß der Grund für den Schritt vom Explanans (annähernde) Wahrheit zu den abgeschwächten Explanantia gleichzeitig einen (weiteren ${ }^{153}$ ) Grund darstellt, das Wunderargument nicht als Instantiierung des Schemas (IBE) zu rekonstruieren, sondern als Instantiierung eines "verwandten" Inferenzschemas, dessen Anwendungsbereich nicht nur hinsichtlich der Explananda beschränkt ist, sondern außerdem auch hinsichtlich der Arten von Erklärung: Das Motiv, von nPEen nicht auf die (annähernde) Wahrheit der erfolgreichen Theorien zu schließen, ist, daß ein solcher Schluß erfahrungsgemäß manchmal zu einer falschen Konklusion führt, also nicht hinreichend verläßlich ist; stattdessen kann aber gemäß dieser Version des Wunderarguments auf ein abgeschwächtes Explanans geschlossen werden. Dieses Motiv trägt offenbar nichts gegen die (in den bisher diskutierten Versionen des Wunderarguments als plausibel vorausgesetzte, wenn auch selten erläuterte) Annahme aus, daß die (annähernde) Wahrheit einer erfolgreichen Theorie die beste Erklärung für die nPEe liefern würde, sondern besagt eben, daß das Explanans dieser Erklärung erfahrungsgemäß manchmal falsch ist; es enthält keinerlei Hinweis darauf, daß ein abgeschwächtes Explanans eine bessere Erklärung liefern könnte als die (annähernde) Wahrheit der erfolgreichen Theorie.

Wenn die Versionen des Wunderarguments, die sich auf nPEe und abgeschwächte Explanantia beziehen, als irgendeine Art von Schluß auf die beste Erklärung rekonstruiert werden sollen, ist daher eine naheliegende Möglichkeit, sie als Instantiierungen oder Anwendungsfälle eines Inferenzschemas aufzufassen, das aus dem Schema (IBE) hervorgeht, indem man einen eingeschränkten Anwendungsbereich spezifiziert, indem man zum einen als Explanandum nur nPEe zuläßt, und zum anderen die erklärenden Hypothesen $H$ auf solche einschränkt, die eine bestimmte Art von Erklärung für $F$ liefern, und zwar eine deduktive semantische Erklärung im weiten Sinn.

\subsubsection{Fazit}

Die verschiedenen Versionen des Wunderarguments involvieren allesamt an zentraler Stelle eine Erklärung für bestimmte Leistungen oder Erfolge, die wissenschaftliche Theorien erzielen oder ermöglichen, und schlagen einen Schluß auf diese Erklärung vor. Sie beziehen sich aber bei genauerem Hinsehen auf deutlich verschiedene Erklärungen für diese Leistungen oder Erfolge; die explanatorische Relation zwischen Explanans und Explanandum ist in den verschiedenen Versionen des Wunderarguments eine deutlich verschiedene. Die Erklärungen lassen sich i.a. nicht so systematisch klassifizieren und nicht so präzise charakterisierten Arten von Erklärungen zuordnen wie es vielleicht wünschenswert wäre, die oben gewonnenen Charakterisierungen reichen aber aus, um die bei verschiedenen Versionen des Wunderarguments involvierten Erklärungen deutlich unterscheidbaren Arten von Erklärungen zuzuordnen: Die Erklärungen für ePEe, nPEe und Vereinheitlichungsleistungen,

seines Stadtrundganges auf. Da der Stadtplan heute sicherlich nicht mehr in allen Einzelheiten "wahr" ist, könnte man versuchen, die Erfolge des Touristen durch ein abgeschwächtes Explanans zu erklären, etwa durch die Annahme, daß der Stadtplan "die Struktur der Stadt” richtig wiedergibt o.ä. Eine solche Erklärung ist grundsätzlich nicht unplausibel, aber sie hat ersichtlich nur wenig Überzeugungskraft, solange man nicht hinreichend genau spezifizieren kann, was die "Struktur der Stadt" o.ä. ist (die Lage der wichtigen historischen Gebäude, die Struktur des Netzes der großen Hauptstraßen o.ä.) und durch welche Elemente des Stadtplanes sie dargestellt wird, und außerdem plausibel machen kann, daß es tatsächlich allein diese Elemente waren, die für die Erfolge des Touristen verantwortlich sind und sie daher erklären können.

${ }^{153}$ Neben dem, der vorne beim Schritt vom Explanandum ePEe zum Explanandum nPEe diskutiert wurde. 
die sich als deduktive semantische Erklärungen einstufen lassen, sind deutlich verschieden von den skizzierten Erklärungen für Handlungserfolge und Boyds "unvollständigen" kausalen Erklärungen für die Verläßlichkeit wissenschaftlicher Methodologie.

Die gewonnenen Charakterisierungen der verschiedenen Erklärungen und der Differenzen zwischen ihnen werden sich als relevant für die Bewertung des Wunderarguments erweisen. Eine wichtige Einsicht, die sich bereits hier ergab, ist die, daß bei genauer Betrachtung zumindest einige Versionen des Wunderarguments - anders als es zunächst nach der ersten Untersuchung des Zusammenhangs von Wunderargument und der Idee des Schließens auf die beste Erklärung schien - nicht als Instantiierungen des Inferenzschemas (IBE) rekonstruiert werden sollten, sondern eher als Instantiierungen eines "verwandten" Inferenzschemas zu rekonstruieren sind, in dem genauer spezifiziert wird, was als Explanandum $F$ zugelassen wird und welche Art von Erklärung $H$ für $F$ liefern muß. Ein solches spezielles Inferenzschema mit beschränkterem Anwendungs- bzw. Verläßlichkeitsbereich könnte, in Anlehnung an Musgraves Schema (IBE) etwa folgendermaßen formuliert werden: ${ }^{154}$

(IBEsp) $\quad F$ is a fact of type $\mathrm{x}$.

Hypothesis $H$ explains $_{y} F$.

Hypothesis $H$ satisfactorily explains ${ }_{y} F$.

No available competing hypothesis explains $y$ as well as $H$ does.

Therefore, $H$ is true,

wobei der Typ von Faktum $F$ und die Art von Erklärung zu spezifizieren ist, z.B. $F$ als nPEe einer Theorie und die Art von Erklärung als deduktive semantische Erklärung.

\subsection{Probleme und Einwände}

Mit dieser Zusammenstellung und Rekonstruktion der unterschiedlichen Versionen des Wunderarguments und den zugehörigen Erläuterungen in der Hand können jetzt die Probleme und Einwände diskutiert werden, mit denen das Wunderargument konfrontiert worden ist bzw. konfrontiert werden kann.

\subsubsection{Das Wunderargument im Lichte der Geschichte der Wissenschaf- ten betrachtet}

Eine der wichtigsten von Kritikern des Wunderarguments verfolgte Argumentationslinie ist, dieses Argument mit der Geschichte der Wissenschaften zu konfrontieren und dadurch Hinweise zu gewinnen, wie die Schlüsse zu bewerten sind, die gemäß der verschiedenen Versionen des Wunderarguments vom Erfolg wissenschaftlicher Theorien auf ihre semantische Vollwertigkeit, Wahrheit, annähernde Wahrheit u.ä. vorgenommen werden können. Die Idee ist, anhand von historischen, also vor mehr oder weniger langer Zeit entstandenen Theorien zu prüfen, wie es um die Korrelation der Erfolge von Theorien, von denen das Explanandum des Wunderarguments handelt, mit der Wahrheit, der annähernden Wahrheit etc. der Theorien bestellt ist, die Inhalt des Explanans des Wunderarguments sind. Historische Theorien haben dabei den Vorteil, daß sie einerseits sozusagen lange Zeit hatten, erfolgreich zu sein, und daß sich andererseits häufig im Laufe der Zeit neue und mehr Evidenzen für und vor allem gegen die Wahrheit, annähernde Wahrheit etc. von Theorien

\footnotetext{
${ }^{154}$ Die probabilistische Regel (IBEpr) ist entsprechend zu modifizieren.
} 
ergeben. Man kann sich daher im Rückblick ansehen, zu welchen Zeiten in ihrer Geschichte die Voraussetzungen für den "Einsatz" des Wunderarguments gegeben waren (und zu welchen Zeiten nicht) und zu welchen Überzeugungen das Wunderargument daher zu den verschiedenen Zeiten geführt hat bzw. hätte, und die so konstruierten oder rekonstruierten Beurteilungen von Theorien mit dem heutigen Urteil über sie vergleichen.

In diesem Sinn kann man zunächst nach Theorien suchen, die den Anforderungen genügen, die das Explanans (einer Version) des Wunderarguments erfüllen muß, nicht aber denen an das Explanandum, die also wahr sind, annähernd wahr sind, die korrekte mathematische Struktur aufweisen o.ä., die aber dennoch nicht im relevanten Sinn erfolgreich waren. Larry Laudan hat einige Beispiele für Theorien angegeben, deren theoretische Ausdrücke (nach heutigem Kenntnisstand) referieren, die also wahre Existenzaussagen über theoretische Entitäten enthalten bzw. implizieren, die aber dennoch ohne Erfolge in einem für das Wunderargument relevanten Sinn geblieben sind. ${ }^{155}$ Er nennt u.a. die Atomtheorien des 18. Jahrhunderts und Wegeners Kontinentaldrift-Theorie.

Diese Beispiele tragen jedoch aus mehreren Gründen wenig gegen das Wunderargument aus: Zum einen dürfte es keinen Anhänger des Wunderarguments geben, der die Wahrheit "blanker" Existenzsätze bezüglich der theoretischen Entitäten einer Theorie (und nicht zusätzlich die Wahrheit irgendwelcher Aussagen über diese Entitäten) als Explanans vorschlägt. Beispiele für wahre oder annähernd wahre Theorien, die erfolglos geblieben sind, nennt aber weder Laudan, noch hat bisher sonst jemand solche Beispiele präsentiert. ${ }^{156}$ Zum anderen kann das Ausbleiben von Erfolgen bei einer Theorie natürlich immer darauf zurückzuführen sein, daß der zeitgenössische mathematische Kenntnisstand nicht ausreicht, um daraus ableitbare Prognosen, die zu Erfolgen führen würden, tatsächlich abzuleiten. Solche Theorien geben keinen Anlaß zur Anwendung (einer Version) des Wunderarguments, aber sie sprechen auch nicht gegen dessen Anwendung in anderen Fällen, also bei Theorien, die tatsächlich erfolgreich sind. Laudans genannte Beispiele können bestenfalls belegen, daß das Wunderargument nicht in jedem Fall, in dem man eine Theorie findet, die wahre Existenzsätze über theoretische Entitäten enthält, ermöglicht, dies zu erkennen; sie sprechen jedoch in keiner Weise dagegen, daß die Konklusionen des Wunderarguments in den Fällen richtig sind, in denen es anwendbar ist.

Für die Beurteilung des Wunderarguments relevanter sind Beispiele von erfolgreichen Theorien, die nach heutigem Kenntnisstand falsch sind und darüber hinaus noch nicht einmal annähernd wahr oder wenigstens in ihren Existenzaussagen über theoretische Entitäten wahr sind. Laudan führt eine ganze Liste einstmals erfolgreicher Theorien an, deren theoretische Entitäten (nach heutigem Kenntnisstand) nicht existieren, und meint, daß diese Liste "ad nauseam fortgesetzt" werden könnte. ${ }^{157}$ Er nennt u.a. die Phlogistontheorien der Chemie, die Wärmestofftheorie und die Theorien, die vom elektromagnetischen bzw. optischen Äther handeln. Sofern man die Existenz der unbeobachtbaren Entitäten, von denen in einer Theorie die Rede ist, auch als Minimalbedingung für die Wahrheit und die annähernde Wahrheit dieser Theorie akzeptiert, stellen die angeführten Beispiele gleichzeitig Fälle von erfolgreichen Theorien dar, die nicht wahr und auch nicht annähernd wahr sind. Diese Beispiele stellen für die meisten Versionen des Wunderarguments ein ernstes Problem dar. Wenn Fälle dieser Art tatsächlich, wie Laudan behauptet, systematisch und

\footnotetext{
${ }^{155}$ [Laud81], S.24. Laudan umreißt den von ihm vorausgesetzten Begriff von Erfolg nur grob; er sollte aber ePEe, Handlungserfolge und Vereinheitlichungsleistungen abdecken; s. [Laud81], S.23.

${ }^{156}$ Zumindest meines Wissens nicht.

${ }^{157}$ [Laud81], S.33.
} 
in großer Zahl auftreten, führt dies zu einer "pessimistischen Induktion" 158 bezüglich der Verläßlichkeit (der meisten Versionen) des Wunderarguments. ${ }^{159}$

Laudans zweite Gruppe von Beispielen ergibt einen Einwand gegen das Wunderargument, der zumindest teilweise, d.h. als Einwand gegen einige wichtige seiner Versionen, überzeugend aussieht. Die von ihm genannten Fälle erfolgreicher, aber falscher Theorien müßten im einzelnen auf ihre historische Plausibilität geprüft werden, aber selbst wenn nicht jedes seiner Beispiele genaueren historischen Nachforschungen standhalten sollte, ${ }^{160}$ erscheint es wenig wahrscheinlich, daß sich auf diesem Weg alle Problemfälle "wegargumentieren" lassen. Damit werden diejenigen Versionen des Wunderarguments entkräftet, die sich auf ePEe der Gesamtheit wissenschaftlicher Theorien (nicht einzelner Theorien) als Explanandum beziehen ${ }^{161}$ und als Explanans einer Erklärung für diese Erfolge die Wahrheit oder die annähernde Wahrheit dieser Gesamtheit von Theorien und/oder die Wahrheit der in ihnen enthaltenen Existenzsätze angeben. Gegen Versionen des Wunderarguments wie etwa die von Boyd, die als Explanans für ePEe eine generelle Aussage über die annähernde Wahrheit aller gegenwärtigen Theorien o.ä. anbieten, ist Laudans Liste auch dann durchschlagend, wenn sie aufgrund detaillierter Untersuchungen wesentlich schrumpfen sollte, aber nicht verschwindet.

Weniger klar ist, ob oder inwieweit Laudans Liste von Beispielen auch einen durchschlagenden Einwand gegen Versionen des Wunderarguments ergibt, die sich auf nPEe und/oder auf Erfolge einzelner Theorien als Explanandum beziehen und/oder diese durch ein abgeschwächtes Explanans erklären. Versionen des Wunderarguments, die sich auf Erfolge einzelner Theorien beziehen, werden durch einzelne Gegenbeispiele der von Laudan angeführten Art nicht entkräftet; für sie entsteht erst dann ein ernstes Problem, wenn solche Gegenbeispiele systematisch und in großer Anzahl auftreten: Einzelne Gegenbeispiele belegen nur, daß Schlüsse, die eine Version des Wunderarguments vorschlägt, nicht unfehlbar sind; erst Gegenbeispiele, die systematisch und in großer Zahl auftreten, zeigen, daß solche Schlüsse nicht einmal verläßlich sind, also nicht einmal mit großer Wahrscheinlichkeit zu wahren Konklusionen führen, und daß dies für die genannten Versionen des Wunderarguments der Fall ist, wird durch Laudans Liste nicht hinreichend belegt, wenn auch andererseits nicht offensichtlich ist, daß das Gegenteil richtig ist.

Für eine zufriedenstellende Beurteilung der Stichhaltigkeit von Laudans Einwand im Hinblick auf die verschiedenen Versionen des Wunderarguments sind demnach umfangreiche wissenschaftshistorische Untersuchungen erforderlich, die an dieser Stelle natürlich nicht möglich sind. Es müßte für jede der diversen unterschiedenen Versionen des Wunderarguments systematisch nach historischen Theorien gesucht werden, die im Verlauf ihrer Geschichte einmal die Voraussetzungen für die Anwendung der jeweiligen Version

\footnotetext{
${ }^{158} \mathrm{Vgl}$. Kap.2.6.4.

${ }^{159}$ Laudans auf den beiden genannten Sorten von Beispielen basierender Einwand gegen das Wunderargument ist, je nachdem, von wem er vorgetragen wird, eventuell teilweise im Sinne eines Arguments ad hominem aufzufassen: Ein Antirealist wird möglicherweise aufgrund seiner eigenen erkenntnistheoretischen Überzeugungen die Prämissen des Arguments selbst nicht alle akzeptieren, insbesondere nicht die, daß bestimmte (einstmals erfolglose) Theorien wahr, annähernd wahr o.ä. sind, vielleicht aber auch die nicht, daß bestimmte (erfolgreiche) Theorien falsch sind (nämlich wenn es sich um historische Theorien handelt, die nicht falsifiziert, sondern lediglich aufgrund besserer Erklärungsleistungen und ähnlicher "nichtempirischer" Theorietugenden einer anderen Theorie verdrängt wurden). Ein Realist wird diese Prämissen aber — je nach seiner erkenntnistheoretischen Position — i.a. akzeptieren, daher kann der Einwand für ihn Überzeugungskraft entwickeln.

${ }^{160}$ Etwa hinsichtlich der Frage, ob die Theorien wirklich in einem präziser als von Laudan selbst erläuterten Sinn erfolgreich waren.

${ }^{161} \mathrm{Vgl}$. Abschnitt 9.2.1.
} 
des Wunderarguments erfüllt haben, bei denen sich aber später gezeigt hat, daß die Aussagen falsch sind, die das zugehörige Explanans über sie trifft, d.h. es müßte auf diese Weise systematisch nach Evidenzen gesucht werden, die nicht nur gegen die Verläßlichkeit eines allgemeinen Schemas der Schließens auf die beste Erklärung sprechen, sondern auch gegen die Verläßlichkeit spezieller, genau auf die jeweilige Version des Wunderarguments zugeschnittener Inferenzschemata der Form (IBEsp). Aus realistischer Perspektive aussichtsreiche Kandidaten könnten dabei vielleicht Inferenzschemata der Form (IBEsp) sein, die als Explanandum nPEe einzelner Theorien verlangen und für diese eine deduktive semantische Erklärung oder zumindest eine deduktive semantische Erklärung im weiten Sinne vorsehen. Aussichtsreich könnten aber auch einige etwas andere Inferenzschemata dieser Form sein, die keiner der oben diskutierten Versionen des Wunderarguments genau entsprechen: Eine denkbare Möglichkeit ist, die verlangten Prognoseerfolge zu quantifizieren und eine bestimmte Mindestanzahl von Erfolgen zu fordern. Eine andere Möglichkeit, die in der Literatur gelegentlich genannt wird, ${ }^{162}$ ist, als Explanans die (annähernde) Wahrheit derjenigen Teile der jeweiligen erfolgreichen Theorie vorzusehen, die wirklich für das Ableiten der erfolgreichen Prognosen verantwortlich und dazu unentbehrlich sind ${ }^{163}$ (im Unterschied zur gesamten Theorie), bzw. eine entsprechende Art von Erklärung, die man vielleicht minimale deduktive semantische Erklärung nennen könnte. ${ }^{164}$ Denkbar ist schließlich auch, daß wissenschaftshistorische oder andere Untersuchungen noch auf andere Modifikationen der Inferenzschemata führen, insbesondere auf zusätzliche Bedingungen, die den Anwendungsbereich weiter einschränken, und ein so modifiziertes Inferenzschema sich im Lichte der Wissenschaftsgeschichte als immun gegen Laudans Einwand erweist. ${ }^{165}$ Daß Inferenzschemata dieser Art allesamt durch historische Erfahrungen, wie sie Laudan gegen das Wunderargument ins Feld führt, als nicht verläßlich erwiesen werden können, sieht prima facie wenig wahrscheinlich aus oder ist jedenfalls sicherlich nicht offensichtlich, so daß man die Situation aus realistischer Perspektive vielleicht vorsichtig optimistisch einschätzen kann. Letzten Endes muß die Frage nach der Stichhaltigkeit von Laudans Einwand aber bis zum Vorliegen umfangreicher wissenschaftshistorischer Studien offen bleiben. ${ }^{166}$

\subsubsection{Unterbestimmtheit}

Jede Argumentationsstrategie, die auf die epistemische Begründung realistischer Thesen zielt, ${ }^{167}$ ist mit der Problematik konfrontiert, die meistens durch das Stichwort Unterbestimmtheit bezeichnet wird. Angewandt auf den Fall des Wunderarguments nimmt sie die Gestalt des Einwandes an, daß das Explanandum, von dem man bei der Anwendung des

\footnotetext{
162Z.B. [Psil96].

${ }^{163}$ Ohne die Art dieser Teile allgemein zu spezifizieren, wie es bei den oben diskutierten Versionen des Wunderarguments mit abgeschwächten Explanantia getan wird.

${ }^{164}$ Für die probabilistische Regel (IBEpr) gilt mutatis mutandis dasselbe.

${ }^{165}$ Die im folgenden Abschnitt vorgeschlagenen, aufgrund der Unterbestimmtheitsproblematik modifizierten Inferenzschemata sind prima facie plausible Kandidaten, insofern zumindest in einigen der von Laudan genannten historischen Problemfällen vermutlich (und beim damaligen Stand der Wissenschaft vielleicht nicht verwunderlich) der Frage nach empirisch äquivalenten Theorien wenig Aufmerksamkeit geschenkt worden sein dürfte.

${ }^{166}$ [Kitc93], Kap.5 und [Psil96] versuchen plausibel zu machen, daß Laudans Einwand sich dabei gegen mindestens ein (aus realistischer Perspektive relevantes, gewichtiges) spezielles Inferenzschemata der Form (IBEsp) als nicht stichhaltig erweisen wird.

${ }^{167}$ Genau genommen: fast jede. Die Ausnahme sind Argumente für realistische Positionen, die eine semantische Theorie einschließen, die Unterbestimmtheitsprobleme ausschließt; siehe Abschnitt 2.6.5.
} 
Wunderarguments ausgeht, nicht eindeutig bestimmt ist: ${ }^{168}$ Aus empirisch äquivalenten Theorien lassen sich per definitionem dieselben Beobachtungssätze ableiten, sie liefern also dieselben Erfolge, genauer: dieselben ePEe und Vereinheitlichungsleitungen und, sofern sie gleichzeitig konstruiert werden bzw. bekannt sind, auch dieselben nPEe, unbeabsichtigten Vereinheitlichungsleistungen und Handlungserfolge ${ }^{169}$. Es scheint daher, daß dann, wenn es zu einer erfolgreichen Theorie andere empirisch äquivalente Theorien gibt, nicht nur ein Explanandum vorliegt, das sich sozusagen als Ansatzpunkt des Wunderarguments eignet, sondern mehrere, und daß für die Anwendung des Wunderarguments auf die Erfolge der einen Theorie genauso viel spricht wie für seine Anwendung auf die Erfolge einer empirisch äquivalenten Theorie. Der Schluß auf die beste Erklärung, den das Wunderargument gestattet, sieht bei den Erfolgen der einen Theorie ebenso legitim aus wie bei den Erfolgen einer empirisch äquivalenten Theorie, die verschiedenen Schlüsse führen aber auf unterschiedliche und i.a. unverträgliche Explanantia. ${ }^{170}$

Situationen, in denen verschiedene empirisch äquivalente Theorien erfolgreich sind, müssen nicht für jede der verschiedenen Versionen des Wunderarguments in jedem Fall ein Problem darstellen: Für Versionen, die die Wahrheit der erfolgreichen Theorien als Explanans vorschlagen, ist jede solche Situation problematisch, denn konkurrierende empirisch äquivalente Theorien können nicht zugleich wahr sein. Daß zwei oder mehrere konkurrierende empirisch äquivalente Theorien zugleich annähernd wahr sind, ist dagegen möglich, wenn es auch vielleicht unwahrscheinlich ist, daß das Spektrum der konkurrierenden empirisch äquivalenten Theorien in realen Fällen gerade so beschaffen sein sollte, daß alle gleichzeitig annähernd wahr sind. Daß konkurrierende empirisch äquivalente Theorien dieselben Existenzaussagen über unbeobachtbare Entitäten enthalten, dieselbe Klassifikation von Phänomenen nach Arten liefern oder dieselbe mathematische Struktur aufweisen, ist ebenso möglich und in realen Fällen vielleicht wahrscheinlicher. Versionen des Wunderarguments, die als Explanans "nur" die annähernde Wahrheit der erfolgreichen Theorien oder andere abgeschwächte Explanantia vorschlagen, können daher, wenn man sie auf die Erfolge verschiedener empirisch äquivalenter Theorien anwendet, durchaus verträgliche Konklusionen liefern, ob sie dies tun, hängt aber natürlich vom konkreten Fall ab, also davon, wie dort das Spektrum der empirisch äquivalenten Theorien aussieht. Tendenziell dürften Unterbestimmtheitsprobleme für eine Version des Wunderarguments umso weniger problematisch sein, je weiter abgeschwächt (im Vergleich zur Wahrheit der erfolgreichen Theorien) das von dieser Version vorgesehene Explanans ist; ob oder wie weit es auf diese Weise verschwindet, müßte durch die Untersuchung konkreter Fälle ermittelt werden.

Um Unterbestimmtheitsprobleme zu beseitigen, ohne zu einer Version des Wunderarguments mit abgeschwächtem Explanans zu greifen, könnte man versuchen, die bisher vorausgesetzte Annahme in Zweifel zu ziehen, daß die Anwendung des Wunderarguments stets einen Schluß von den Erfolgen bestimmter Theorien auf die Wahrheit dieser Theorien liefert: Sämtliche Versionen des Wunderarguments sehen einen Schluß von Erfolgen bestimmter Theorien auf die beste Erklärung (einer bestimmten Art) für diese Erfolge

\footnotetext{
${ }^{168}$ Die Konsequenzen, die die Unterbestimmtheitsproblematik für das Wunderargument hat, diskutiert (allerdings in nicht zufriedenstellender Weise, insbesondere im Hinblick auf die Unterscheidung verschiedener Versionen des Wunderarguments, und mit anderem als dem hier gewonnenen Resultat) Matheson in [Math98]; s.a. [BenM90], S.334ff.

${ }^{169}$ Oder jedenfalls würden sie dieselben nPEe etc. liefern, wenn sie gleichzeitig konstruiert würden bzw. bekannt wären.

${ }^{170}$ Eine Ausnahme stellt hier zunächst Boyds Version des Wunderarguments dar, denn dort ergeben mehrere empirisch äquivalente Theorien, die durch die "wissenschaftliche Methodologie" gewonnen wurden, nicht mehrere verschiedene Explananda; dazu s.u.
} 
vor; man könnte aber bestreiten, daß stets die Wahrheit der erfolgreichen Theorien diese beste Erklärung liefert. Man könnte etwa versuchen plausibel zu machen, daß die Erfolge einer bestimmten Theorie $T_{1}$ nicht nur durch die Wahrheit von $T_{1}$ erklärt werden können, sondern auch durch die Wahrheit einer empirisch äquivalenten Theorie $T_{2}$, und daß zumindest prima facie nicht offensichtlich ist, welche Erklärung die bessere von beiden ist. Mit Hilfe dieser Überlegung könnten Unterbestimmtheitsprobleme dann gelöst werden, wenn in Situationen, in denen mehrere empirisch äquivalente Theorien erfolgreich sind, das Wunderargument auf jeden dieser Erfolge angewendet wird und bei jeder solchen Anwendung als potentielle Erklärungen die Wahrheit jeder der empirisch äquivalenten Theorien betrachtet wird und alle diese potentiellen Erklärungen verglichen werden: Wenn das Resultat dieser Vergleiche bei jeder einzelnen Anwendung des Wunderarguments dasselbe ist, d.h., wenn die Wahrheit einer bestimmten Theorie die beste Erklärung für ihre eigenen Erfolge und auch für die Erfolge der empirisch äquivalenten Theorien darstellt, dann stellen die empirisch äquivalenten Theorien kein Problem für das Wunderargument dar.

Daß sich die Unterbestimmtheitsproblematik auf diese Weise ausräumen läßt, ist aber bei genauerer Betrachtung nicht plausibel. Zwar ist eine Erklärung der Erfolge einer Theorie $T_{1}$ etwa durch die Wahrheit einer empirisch äquivalenten Theorie $T_{2}$ vorstellbar: Das Explanans bestünde aus den Aussagen, daß $T_{2}$ wahr ist und daß $T_{1}$ und $T_{2}$ empirisch äquivalent sind, sowie aus einer Korrektheitsaussage über den "Theoriekalkül"; aus der Prämisse, daß $P$ aus $T_{1}$ ableitbar ist, (die Teil des Explanandums ist) und der empirischen Äquivalenz von $T_{1}$ und $T_{2}$ folgt, daß $P$ aus $T_{2}$ ableitbar ist, und daraus, zusammen mit der Korrektheitsaussage und der Aussage, daß $T_{2}$ wahr ist, folgt (in derselben Weise wie vorne unter dem Stichwort deduktive semantische Erklärung erläutert) die Wahrheit von $P$. Ein solcher deduktiver Zusammenhang ließe sich als Erklärung der Erfolge von $T_{1}$ durch die Wahrheit der empirisch äquivalenten Theorie $T_{2}$ auffassen, wenn auch vielleicht nicht als deduktive semantische Erklärung. Wenig plausibel ist jedenfalls, daß in einer Situation, in der zwei erfolgreiche empirisch äquivalente Theorien $T_{1}$ und $T_{2}$ vorliegen, ${ }^{171}$ die Wahrheit von $T_{2}$ die bessere Erklärung für die Erfolge der (empirisch äquivalenten) Theorie $T_{1}$ liefert als die Wahrheit von $T_{1}$ selbst und gleichzeitig auch die bessere Erklärung für die Erfolge von $T_{2}$ (also sozusagen die eigenen Erfolge) liefert als es die Wahrheit der (empirisch äquivalenten) Theorie $T_{1}$ tut. Auch ohne über eine zufriedenstellende Erläuterung zu verfügen, was eine Erklärung zu einer guten bzw. besseren im Vergleich zu einer anderen macht, scheint klar, daß kaum plausibel ist, daß für die Erfolge einer Theorie eine Erklärung durch die Wahrheit dieser Theorie besser ist als eine Erklärung der skizzierten Art durch die Wahrheit einer zweiten, empirisch äquivalenten Theorie, es sich aber gleichzeitig bei der zweiten Theorie genau umgekehrt verhält. ${ }^{172}$ Es ist also wenig plausibel, daß sich die Unterbestimmtheitsproblematik sozusagen dadurch ausräumen läßt, daß man die Entscheidung zwischen empirisch äquivalenten (erfolgreichen) Theorien in das Wunderargument einbaut.

Das Fazit dieser Überlegungen ist nicht, daß das Wunderargument oder zumindest einige seiner Versionen durch Unterbestimmtheitsprobleme völlig entwertet werden. Viel-

\footnotetext{
${ }^{171}$ Oder i.a. mehrere; hier genügt es, den einfachsten Fall zu betrachten.

${ }^{172}$ Man könnte versuchen, die gegenteilige Ansicht zu stützen, indem man auf intrinsische Eigenschaften der beiden Theorien verweist, etwa auf (in der Literatur zum Erklärungsbegriff häufig diskutierte) "Erklärungstugenden" ("explanatory virtues") wie Einfachheit, Kohärenz o.ä. Ein solcher Hinweis überzeugt jedoch nicht, da es bei den hier zur Diskussion stehenden Erklärungen nicht um Erklärungstugenden der beiden Theorien selbst gehen müßte, sondern um Erklärungstugenden der Aussagen, daß diese Theorien wahr sind. Daß und warum ' $T_{1}$ ist wahr' aber eine einfachere, kohärentere o.ä. und daher bessere Erklärung liefern sollte als ' $T_{2}$ ist wahr', ist nicht zu erkennen.
} 
mehr sprechen diese Überlegungen dafür, daß ein Schluß von der Art, wie ihn das Wunderargument (bzw. eine Version des Wunderarguments) vorsieht, nicht in jeder Situation vorgenommen werden sollte, die unter die bisherigen Formulierungen für das Explanandum fällt, nämlich dann nicht, wenn es außer der Theorie (bzw. den Theorien), deren Erfolge erklärt werden sollen, auch (eine oder mehrere) empirisch äquivalente Theorien gibt, die nicht aus anderen guten Gründen ausgeschlossen werden können bzw. gegen die nicht andere gute Gründe sprechen, d.h. gute Gründe, die unabhängig von den für das Wunderargument relevanten Erklärungsleistungen der Wahrheit, annähernden Wahrheit etc. dieser Theorien sind.

Dagegen scheint nichts gegen die Anwendung (einer Version) des Wunderarguments in Situationen zu sprechen, in denen Erfolge einer Theorie vorliegen, und es keine empirisch äquivalente Theorie gibt oder in denen, falls es empirische äquivalente Theorien gibt, jedenfalls (vom Wunderargument unabhängige) gute Gründe gegen diese empirisch äquivalenten Theorien sprechen. Solche Gründe können prinzipiell von verschiedener Art sein: Denkbar sind z.B. induktiv begründete Überzeugungen, daß alle (annähernd) wahren Theorien (in einem bestimmten Bereich) bestimmte "Theorietugenden" allgemeiner Art wie Einfachheit, Kohärenz etc. aufweisen, oder ebenfalls induktiv begründete Überzeugungen, daß alle (annähernd) wahren Theorien (in einem bestimmten Bereich) bestimmte inhaltliche Merkmale haben, etwa, daß sie keine Fernwirkungen involvieren, bestimmte raumzeitliche Symmetrien aufweisen o.ä. Wie solche Überzeugungen genau aussehen und ob und ggf. wie sie hinreichend gut induktiv begründet werden können, muß im Einzelfall untersucht werden; daß es Überzeugungen dieser Art geben kann, die unabhängig von den Erklärungsleistungen sind, um die es beim Wunderargument geht, und die im Zusammenhang mit dem Wunderargument die Funktion erfüllen können, in konkreten Fällen, in denen Erfolge einer Theorie vorliegen, alle empirisch äquivalenten Theorien auszuschließen, ist zumindest prima facie plausibel.

Für die Rekonstruktion des Wunderarguments bedeutet dies, daß es die durch das Stichwort Unterbestimmtheit bezeichnete Problematik nahelegt, das Inferenzschema (bzw. die -schemata), als dessen (bzw. deren) Instantiierung die Versionen des Wunderarguments aufgefaßt werden sollen, noch genauer zu spezifizieren als bisher geschehen: Wenn man das Schema (IBE) bzw. eines der Schemata (IBEsp) in einer Situation einsetzt, in der Theorieerfolge vorliegen und es empirisch äquivalente Theorien gibt, gegen die nichts spricht, liefert die Anwendung auf die verschiedenen Explananda widersprüchliche Konklusionen als Output. Die obigen Überlegungen lassen sich in eine Modifikation der Inferenzschemata umsetzen, indem man das Explanandum $F$ noch genauer spezifiziert als bisher angegeben: Die bisher angegebenen Beschränkungen des Anwendungsbereiches auf ePEe, nPEe, Handlungserfolge etc. von Theorien sind danach zu ergänzen, so daß die Anwendung des jeweiligen Schemas jetzt beschränkt ist auf Situationen, in denen ePEe, nPEe, Handlungserfolge etc. vorliegen und es gleichzeitig keine empirisch äquivalenten Theorien gibt, die nicht aus anderen guten Gründen ausgeschlossen werden können bzw. gegen die nicht andere gute Gründe sprechen. Eine solche Ergänzung stellt sozusagen wieder sicher, daß in den Situationen, in denen das Wunderargument anwendbar ist, das Explanandum eindeutig bestimmt ist, daher kann das Wunderargument nicht mehr auf widersprüchliche Explanantia führen. Ob es in konkreten Situationen tatsächlich anwendbar ist, muß im Einzelfall geprüft werden.

Diese bisherigen Überlegungen zum Problem empirisch äquivalenter Theorien im Zusammenhang mit dem Wunderargument betreffen alle Versionen des Wunderarguments mit einer Ausnahme, nämlich der Version von Boyd. Boyd nennt als Teil wissenschaftli- 
cher Methodologie einige Prinzipien und Verfahren, die eine Entscheidung zwischen empirisch äquivalenten Theorien ermöglichen sollen, es ist jedoch nicht klar, ob er damit die These verbindet, daß diese in jedem Fall eine Entscheidung zwischen empirisch äquivalenten Theorien ermöglichen. ${ }^{173}$ Wenn dies nicht so ist, wenn es also Fälle empirisch äquivalenter Theorien gibt, die durch die wissenschaftliche Methodologie nicht entschieden werden können, dann ergeben sich dadurch jedenfalls in Boyds Version des Wunderarguments - anders als in den anderen Versionen - nicht mehrere Explananda, die zu widersprüchlichen Explanantia führen. Wenn zwei oder mehrere empirisch äquivalente Theorien als "Produkt" der wissenschaftlichen Methodologie zählen, deren Verläßlichkeit den Ausgangspunkt von Boyds Version des Wunderarguments darstellt, führt dieses jedenfalls auf ein konsistentes Explanans (die annähernde Wahrheit der — als miteinander verträglich vorausgesetzten — bereits etablierten Theorien). Die empirische Äquivalenz mehrerer Theorien scheint also für Boyds Version des Wunderarguments zunächst kein Problem darzustellen. Wenn man jedoch die Zeitentwicklung des Bestandes wissenschaftlicher Theorien sozusagen einen Zeitschritt weiter verfolgt, sieht man, daß auch für Boyd ein Problem entsteht, wenn auch ein etwas anderes als für die anderen Versionen des Wunderarguments: Wenn zwei oder mehrere empirisch äquivalente Theorien, die zunächst kein Problem darstellten, sozusagen im nächsten Zeitschritt bei der Anwendung der wissenschaftlichen Methodologie herangezogen werden, um neue Theorien zu gewinnen, und beide bzw. alle zur instrumentellen Verläßlichkeit dieser Methodologie beitragen, sprich: zur Gewinnung neuer, erfolgreicher Theorien, dann führt die Anwendung von Boyds Version des Wunderarguments an dieser Stelle zu einem widersprüchlichen Explanans. Es liegt daher nahe, Boyds Version des Wunderarguments, wie die anderen Versionen, durch eine genauere Spezifikation des Explanandums zu ergänzen, um Probleme mit empirisch äquivalenten Theorien zu vermeiden: Das Explanandum sollte lauten: ${ }^{174}$ Die Gesamtheit der Prinzipien, Verfahren etc. der Wissenschaften, die sich auf die zum jeweiligen Zeitpunkt akzeptierten Theorien $\left\{T_{i}^{a l t}\right\}$ stützen, unter denen keine empirisch äquivalenten Theorien sind und zu denen es keine empirisch äquivalenten Theorien gibt, die nicht aus guten Gründen ausgeschlossen werden können, liefert in verläßlicher Weise neue Theorien $\left\{T_{i}^{n e u}\right\}$, die ihrerseits annähernd wahre Prognosen liefern.

Ob die wissenschaftliche Methodologie "unentschiedene" Fälle empirisch äquivalenter Theorien offenläßt bzw. ob die genannten stärkeren Bedingungen für das Explanandum von Boyds Version des Wunderarguments für die real-existierenden Wissenschaften erfüllt sind, muß, wie bei den anderen Versionen des Wunderarguments, in konkreten Fällen untersucht werden.

Gegen die hier skizzierte Replik auf Einwände gegen das Wunderargument, die auf die Unterbestimmtheitsproblematik hinweisen, läßt sich ein erneuter Einwand grundsätzlicher Art erheben: Die beschriebene "Verteidigungsstrategie" für das Wunderargument bestand darin, seine Anwendung auf Situationen zu beschränken, in denen es zu der (bzw. zu den) erfolgreichen Theorie(n), deren Erfolge das Explanandum des Wunderarguments bilden sollen, keine (konkurrierenden) empirisch äquivalenten und daher ebenso erfolgreichen Theorien gibt, die nicht auf anderem Wege ausgeschlossen werden können. Diese Strategie, so kann man argumentieren, sieht vielleicht plausibel und aus der Perspektive der Anhänger des Wunderarguments aussichtsreich aus, solange man das Blickfeld sozusagen beschränkt auf die Theorien, die in den real-existierenden Wissenschaften "ernsthaft"

\footnotetext{
${ }^{173}$ Etwa das Prinzip, nur Theorien zu akzeptieren, die den bereits etablierten Theorien im Hinblick auf ihre ontologischen Verpflichtungen ähneln; siehe Abschnitt 9.1.3, s.a. [Boyd91], S.208.

${ }^{174}$ Vgl. S.211.
} 
diskutiert werden: Unter diesen kommen Fälle von zumindest prima facie empirisch äquivalenten Theorien, von denen nicht alle bis auf eine ausgeschlossen werden können, durchaus vor (ein Beispiel stellen derzeit die nicht-relativistische Standard-Quantenmechanik und die Bohmsche Mechanik dar), aber sie sind wohl vergleichsweise selten. Ob es zu erfolgreichen Theorien empirisch äquivalente Theorien gibt, die in den real-existierenden Wissenschaften tatsächlich "ernsthaft" diskutiert werden, aber nicht ausgeschlossen werden können, ist aber, so der grundsätzliche Einwand, nicht die philosophisch relevante Frage; relevant ist vielmehr, ob es zu erfolgreichen Theorien empirisch äquivalente Theorien gibt, die nicht ausgeschlossen werden können, und zwar unabhängig davon, was in den real-existierenden Wissenschaften diskutiert wird, und diese Frage kann man völlig allgemein positiv beantworten. Man kann, so eine in der wissenschaftstheoretischen Literatur häufig vertretene These, zu jeder Theorie empirisch äquivalente Alternativen angeben, vor denen sich die Theorie selbst in epistemisch relevanter Hinsicht durch nichts auszeichnet. Diese These wird manchmal gestützt durch den Hinweis auf ein "Rezept" allgemeiner Art zur Erzeugung empirisch äquivalenter Theorien zu einer gegebenen Theorie: Ein solches von Quine genanntes Rezept ${ }^{175}$ ist, in einer Theorie zwei Ausdrücke, die in keinem Beobachtungssatz vorkommen, systematisch überall gegeneinander auszutauschen und so eine alternative, empirisch äquivalente Theorie zu gewinnen. Ein anderes Rezept besteht darin, einer gegebenen Theorie zusätzliche theoretische Sätze hinzuzufügen, die keine zusätzlichen empirischen Konsequenzen mit sich bringen. Selbst wenn man die grundsätzliche, zwischen Realisten und Antirealisten notorisch umstrittene Frage einklammert, ob induktiv begründete Überzeugungen der oben genannten Art (über Theorietugenden etc.) gute epistemische Gründe darstellen können, eine oder mehrere aus einer Menge von empirisch äquivalenten Theorien auszuschließen, lassen es Rezepte wie die genannten doch jedenfalls wenig plausibel erscheinen, daß durch solche Gründe stets alle Theorien bis auf eine aus der Menge empirisch äquivalenter Theorien, die durch diese Rezepte erzeugt werden kann, ausgeschlossen werden können. Entsprechend wenig aussichtsreich sieht dann vielleicht auch die oben beschriebene "Verteidigungsstrategie" für das Wunderargument aus, denn daß es nennenswert viele oder überhaupt Situationen gibt, in denen man tatsächlich über gute Gründe verfügt, um alle zu einer erfolgreichen Theorie empirisch äquivalenten Theorien auszuschließen, die es gibt, erscheint im Lichte der genannten Rezepte dann vielleicht wenig wahrscheinlich.

Eine angemessene Antwort auf diesen grundsätzlichen Einwand gegen die obige Verteidigungsstrategie für das Wunderargument muß differenziert und in bestimmter Hinsicht offen ausfallen. ${ }^{176}$ Sie besteht darin, zum einen die These zu bestreiten, daß zu jeder Theorie empirisch äquivalente Alternativen angegeben werden können, vor denen sich die Theorie selbst in epistemisch relevanter Hinsicht durch nichts auszeichnet, sprich: die nicht durch gute Gründe ausgeschlossen werden können, zum zweiten zuzugeben, daß dies, wie schon gesagt, in konkreten Fällen durchaus möglich ist und im Einzelfall zu prüfen wäre, und zum dritten darauf hinzuweisen, daß Rezepte allgemeiner Art wie die genannten vor allem dann erfolgreich sein können, wenn sie auf eine sehr "großformatige" Theorie angewendet werden oder auf eine umfangreiche Gesamtheit von Theorien und Überzeugungen oder sogar auf die Gesamtheit aller Theorien und Überzeugungen über Unbeobachtbares, kaum dagegen, wenn es um einzelne und/oder "kleinformatige" Theorien geht, wie bei den aussichtsreichsten Versionen des Wunderarguments bzw. deren Anwendung. Für die

\footnotetext{
${ }^{175}$ [Quin75], S.319, [Quin81c], S.28f.

${ }^{176}$ Diese Antwort entspricht der Argumentationslinie, die Laudan zur Unterbestimmtheitsproblematik verfolgt (vgl. [LaLe91]).
} 
Überzeugungskraft dieser Antwort ist es insbesondere wichtig, daß der dritte Punkt plausibel gemacht werden kann, daher soll er hier für die die beiden angegebenen Rezepte kurz erläutert werden.

Quines Rezept, in einer Theorie zwei Ausdrücke, die in keinem Beobachtungssatz vorkommen, systematisch überall gegeneinander auszutauschen und so eine alternative, empirisch äquivalente Theorie zu gewinnen, mag funktionieren, wenn die Theorie sämtliche akzeptierten Sätze bzw. Überzeugungen einschließt, in denen die ausgetauschten Ausdrücke vorkommen. ${ }^{177}$ Wenn es jedoch außer der Theorie, zu der nach Quines Rezept eine empirisch äquivalente Alternative konstruiert wird, noch eine oder mehrere andere akzeptierte Theorien bzw. Überzeugungen gibt, in denen mindestens einer der ausgetauschten Ausdrücke auftritt, dann werden diese i.a. mit der konstruierten Alternativtheorie nicht verträglich sein. Wenn man z.B. in einer Theorie des Helium-Neon-Lasers die Ausdrücke 'Elektron' und 'Molekül' systematisch austauscht, ${ }^{178}$ bekommt man zwar eine empirisch äquivalente Theorie, diese enthält jedoch Aussagen über Elektronen und Moleküle, die offenbar zu weiten Teilen der übrigen akzeptierten physikalischen Theorien im Widerspruch stehen. ${ }^{179}$

Das zweite genannte Rezept, einer gegebenen Theorie zusätzliche theoretische Sätze hinzuzufügen, die keine zusätzlichen empirischen Konsequenzen mit sich bringen, wird im allgemeinen ebenfalls nicht zu einer Bedrohung für die Anwendung des Wunderarguments führen, da die zu einer gegebenen Theorie hinzugefügten Sätze, obwohl sie zusammen mit dieser Theorie keine weiteren empirischen Konsequenzen haben, natürlich zum einen zusammen mit anderen akzeptierten Theorien bzw. Überzeugungen neue empirische Konsequenzen haben können, zum anderen auch unverträglich mit solchen anderen akzeptierten Theorien bzw. Überzeugungen sein können. Außerdem können gegen eine so "erweiterte" Theorie auch induktiv gut begründete Überzeugungen der oben genannten Art sprechen, nach denen alle (annähernd) wahren Theorien (in einem bestimmten Bereich) bestimmte Theorietugenden aufweisen oder bestimmte inhaltliche Merkmale allgemeiner Art haben o.ä. Aus diesen Gründen wird auch dieses Rezept bei der Anwendung auf einzelne und/oder "kleinformatige" Theorien i.a. nur zu empirisch äquivalenten Alternativen führen, gegen die andere gute Gründe sprechen. Daß es auch bei einzelnen und/oder "kleinformatigen" Theorien zu Alternativen führen kann, gegen die keine guten Gründe vorliegen, ist natürlich nicht ausgeschlossen, und bei der Anwendung auf "großformatige" Theorien oder auf eine umfangreiche Gesamtheit von Theorien und Überzeugungen oder sogar auf die Gesamtheit aller Theorien und Überzeugungen erscheint dies zunehmend wahrscheinlicher. ${ }^{180}$ Ob es so ist, muß, wie schon gesagt, im konkreten Fall untersucht werden, wichtig für die Bewertung des Wunderarguments ist, daß das genannte Rezept kein "sicheres" ist,

\footnotetext{
${ }^{177}$ Es ist auch von Quine explizit für die Anwendung auf "an exhaustive encyclopedic formulation of our total scientific theory of the world" ([Quin81c], S.28) vorgesehen.

${ }^{178}$ Wie Quine es vorschlägt ([Quin81c], S.28f.).

${ }^{179}$ Etwa Aussagen, daß es zwei Sorten von Elektronen mit unterschiedlicher Masse und unterschiedlichen Bestandteilen gibt, nämlich Helium-Elektronen und Neon-Elektronen, und ähnlich Bizarres.

${ }^{180}$ Ein unabhängig vom Diskussionszusammenhang des Wunderarguments häufig diskutierter Fall von Unterbestimmtheit (siehe u.a. [vFra80], Kap.3, [LaLe91], S.457ff.), aus dem sich zumindest ein fiktives (wenn auch nicht historisch korrektes) und einigermaßen plausibles Beispiel für eine "erfolgreiche" Anwendung dieses zweiten Rezeptes konstruieren ließe, ist die Newtonsche Mechanik inklusive Gravitationstheorie: Wenn man diese Theorie als Theorie der Bewegungen relativ zum Schwerpunktsystem des Universums formuliert (also ohne daß vom absoluten Raum die Rede ist), kann man anschließend eine Aussage (von beliebig vielen verschiedenen, je nach Geschwindigkeit und Bewegungsrichtung) über die Bewegung des Schwerpunktsystems relativ zum absoluten Raum hinzufügen und erhält so eine empirisch äquivalente Theorie (von beliebig vielen).
} 
das in jedem Fall funktioniert. Tendenziell ist als Resultat entsprechender Untersuchungen konkreter Fälle zu erwarten, daß sich zu einer erfolgreichen Theorie empirisch äquivalente Alternativen, gegen die keine guten Gründe sprechen, umso eher aufweisen lassen, je "großformatiger" die Theorie ist, und wenn es um Gesamtheiten von Theorien geht, umso eher, je größer die Gesamtheit ist. Zu erwarten ist dementsprechend, daß sich aus dieser Perspektive betrachtet Versionen des Wunderarguments, die sich auf die Erfolge einzelner, nicht zu "großformatiger" Theorien beziehen, als aussichtsreicher erweisen werden als Versionen, die sich auf Erfolge von sehr "großformatigen" Theorien oder sogar Gesamtheiten von solchen beziehen. ${ }^{181}$

Der genannte grundsätzliche Einwand gegen die oben skizzierte Verteidigungsstrategie für das Wunderargument ist also nicht stichhaltig. Damit ist nicht gesagt, daß die Unterbestimmtheitsproblematik keine Bedrohung für das Wunderargument darstellt, sondern es bleibt, wie oben notiert, die Aufgabe, im konkreten Fall zu prüfen, ob es anwendbar ist bzw. welche seiner Versionen es sind, oder ob dem eine Unterbestimmtheitskonstellation im Wege steht.

Eine andere Möglichkeit, diese Verteidigungsstrategie anzugreifen, besteht offenbar darin, die Gründe zu hinterfragen, die in konkreten Sitationen gegen empirisch äquivalente Alternativen zu einer erfolgreichen Theorie sprechen. Von antirealistischer Seite liegt dies insbesondere dann nahe, wenn es sich um induktiv begründete Überzeugungen der oben genannten Art (also Überzeugungen des Inhalts, daß eine wahre Theorie bestimmte "Tugenden" allgemeiner Art oder bestimmte inhaltliche Züge aufweisen muß) handelt, weil diese offenbar Unbeobachtbares zum Inhalt haben. Dies ist eine denkbare und legitime Argumentationsrichtung, sie führt aber von den speziellen Problemen, mit denen das Wunderargument konfrontiert ist, weg und hin zu Fragen allgemeinerer Art, nämlich darüber, ob und, wenn ja, wie oder inwieweit (unabhängig vom Wunderargument) Überzeugungen über Unbeobachtbares begründet oder gerechtfertigt werden können, und eventuell (nämlich dann, wenn, wie es von antirealistischer Seite nicht selten getan wird, die Frage nach Rechtfertigungsgründen immer wieder in erweiterter Form iteriert wird, solange als Gründe Überzeugungen über Unbeobachtbares angeführt werden) darüber, wie eine oder viele Überzeugungen über Unbeobachtbares ausschließlich auf der Basis von Überzeugungen über Beobachtbares begründet oder gerechtfertigt werden können. Dadurch daß diese Argumentationsrichtung offen steht, wird ein Charakteristikum der oben skizzierten Verteidigungsstrategie für das Wunderargument deutlich herausgestellt, das für die wissenschaftstheoretische Realismusdebatte von systematischer Bedeutung ist: Die verteidigten Versionen des Wunderarguments eignen sich i.a. nicht, um in Situationen, in denen ausschließlich Überzeugungen bzw. Prämissen über Beobachtbares vorliegen, auf Aussagen über Unbeobachtbares zu schließen. Wenn letzteres die von seinen Anhängern intendierte Funktion des Wunderarguments gewesen sein sollte, dann wird es durch die Unbestimmtheitsproblematik i.a. entwertet. Dagegen können die verteidigten Versionen des Wunderarguments grundsätzlich eine Rolle bei der Begründung oder Rechtfertigung realistischer Positionen spielen, wenn induktiv o.ä. begründete Überzeugungen bzw. Prämissen der genannten Art zur Verfügung stehen, wenn also zumindest prinzipiell Möglichkeiten der Begründung oder Rechtfertigung von Überzeugungen bzw. Prämissen über Unbeobachtbares zur Verfügung stehen, die vom Wunderargument unabhängig sind. Wie akzep-

\footnotetext{
${ }^{181}$ Sämtliche Problemfälle, die durch das zweite genannte Rezept erzeugt werden können, sollten sich ausräumen lassen, wenn die im vorigen Abschnitt genannte Idee einer Version des Wunderarguments in zufriedenstellender Weise entwickelt werden kann, die einen Schluß auf die beste minimale deduktive semantische Erklärung vorsieht.
} 
table Möglichkeiten induktiver o.ä. Begründung aussehen könnten, hängt von der allgemeinen erkenntnistheoretischen Position, genauer: von der Konzeption von epistemischer Begründung, Rechtfertigung o.ä., ab, die man akzeptiert, und kann daher an dieser Stelle nicht diskutiert werden.

Die moderatere, aber dennoch letztlich überzeugendere und für das Wunderargument vielleicht bedrohlichere Variante der genannten antirealistischen Argumentationsrichtung dürfte die sein, die nicht grundsätzlich und gleichzeitig jede Möglichkeit der epistemischen Begründung von Aussagen über Unbeobachtbares in Frage stellt, sondern grundsätzlich die Möglichkeit induktiver o.ä. Begründung von Überzeugungen wie den oben genannten akzeptiert (wie auch immer dies genau auszubuchstabieren ist) und sich auf die Frage konzentriert, ob in konkreten Fällen tatsächlich genügend viele Überzeugungen dieser Art in einigermaßen plausibler Weise begründet werden können, um wirklich alle Unterbestimmtheitsprobleme auszuräumen. Diese Frage läßt sich nur durch detaillierte Fallstudien beantworten, deren Resultate kaum abschätzbar sind. Es ist jedoch keineswegs klar, daß sich die Unterbestimmtheitsproblematik nicht an dieser Stelle als schwerwiegendes Hindernis für das Wunderargument erweist oder jedenfalls als weit schwerwiegenderes als häufig von den Anhängern realistischer Positionen intuitiv angenommen.

Ein weiterer, bisher noch nicht erwähnter Einwand gegen das Wunderargument, der ebenfalls mit der Unterbestimmtheitsproblematik zusammenhängt, ist Folgender: ${ }^{182}$ Der oben skizzierten Verteidigungsstrategie für das Wunderargument zufolge soll ein Schluß der von der jeweiligen Version vorgesehenen Art nur in Situationen vorgenommen werden, in denen es zu der (den) erfolgreichen Theorie(n) keine konkurrierenden empirisch äquivalenten Alternativen gibt, die nicht durch andere gute Gründe ausgeschlossen werden können. Eine bereits diskutierte Schwierigkeit damit besteht darin, daß man alle konkurrierenden empirisch äquivalenten Alternativen ausschließen muß, um einen solchen Schluß zu recht auszuführen; es darf also sozusagen keine konkurrierende Theorie übrig bleiben, gegen die keine guten Gründe sprechen. Eine in gewisser Weise noch grundlegendere Schwierigkeit scheint aber zu sein, daß man sozusagen erst einmal eine Menge von erfolgreichen und empirisch äquivalenten Theorien in der Hand haben muß, unter denen (mindestens) eine (annähernd) wahre Theorie ist. Wenn es "echte" Fälle von Unterbestimmtheit gibt, dann ist prinzipiell vorstellbar, daß man über eine Menge von erfolgreichen und empirisch äquivalenten Theorien verfügt, unter denen keine (annähernd) wahre Theorie ist, während einfach noch niemand auf die wahre (oder eine annähernd wahre) Theorie für den jeweiligen Gegenstandsbereich gekommen ist. Um das Wunderargument, so wie es oben rekonstruiert wurde, in einer konkreten Situation auf die Erfolge einer Theorie (oder einer Menge von Theorien) anwenden zu können, muß man also nicht nur gute Gründe gegen alle explizit verfügbaren konkurrierenden empirisch äquivalenten Alternativen haben, sondern man muß auch gute Gründe für die Annahme haben, daß es keine bisher übersehene konkurrierende Alternative gibt, gegen die nichts spricht, d.h. man muß sozusagen in irgendeiner Weise die Gesamtheit möglicher Alternativen unter Kontrolle haben. Die Tatsache allein, daß bisher niemandem etwas anderes eingefallen ist, stellt keinen guten Grund dar.

Daß man in konkreten Fällen solche guten Gründe haben kann, ist grundsätzlich denkbar. So ist zumindest vorstellbar, daß es gute induktive Gründe für die Annahme gibt, daß eine (annähernd) wahre physikalische Theorie für einen bestimmmten Phänomenbereich bestimmte Symmetrieeigenschaften hat, bestimmte allgemeine Prinzipien wie Energieer-

\footnotetext{
${ }^{182} \mathrm{Im}$ wesentlichen ist dies der von van Fraassen in [vFra89a], S.142f. präsentierte Gedanke, der üblicherweise unter dem Titel argument from a bad lot diskutiert wird.
} 
haltung o.ä. erfüllt u.ä. und man dadurch die Gesamtheit der möglichen Theorien für diesen Phänomenbereich in der erforderlichen Weise unter Kontrolle hat. Ob dies in konkreten Fällen so ist und, wenn ja, in wie vielen, läßt sich wiederum nur durch detaillierte Fallstudien beantworten. Das Resultat solcher Fallstudien ist im Vorhinein kaum abschätzbar, prima facie liegt aber die Vermutung nahe, daß es im Fall wissenschaftlicher Theorien tendenziell deutlich schwieriger sein dürfte, die Gesamtheit der möglichen Theorien für einen bestimmten Phänomenbereich zu übersehen und unter Kontrolle zu bekommen, als im Fall alltagsweltlicher "Theorien". ${ }^{183}$ Es scheint also nicht unwahrscheinlich, daß hier ein weiteres schwerwiegendes Hindernis für die Anwendung des Wunderarguments in konkreten Fällen zu lokalisieren ist, das nicht schon dadurch verschwindet, daß man grundsätzlich die Möglichkeit induktiver o.ä. epistemischer Begründung oder Rechtfertigung von Überzeugungen über Unbeobachtbares akzeptiert. ${ }^{184}$

Fazit: Die üblicherweise durch das Stichwort Unterbestimmtheit bezeichnete Problematik legt es nahe, die Inferenzschemata, als deren Instantiierung die Versionen des Wunderarguments nach der bisherigen Rekonstruktion aufgefaßt werden sollen, nochmals zu modifizieren: Die Spezifikation des Explanandums in den Schemata (IBE) bzw. (IBEsp) als ePEe, nPEe, Handlungserfolge etc. von Theorien sollte so ergänzt werden, daß die Anwendung des jeweiligen Schemas beschränkt wird auf Situationen, in denen ePEe, nPEe, Handlungserfolge etc. vorliegen und es gleichzeitig keine empirisch äquivalenten Theorien gibt, die nicht aus anderen guten Gründen ausgeschlossen werden können bzw. gegen die nicht andere gute Gründe sprechen. Dadurch wird sichergestellt, daß die Anwendung eines solchen Schemas und damit das Wunderargument nicht zu widersprüchlichen Konklusionen führen. $\mathrm{Ob}$ die so modifizierten Versionen in konkreten Situationen tatsächlich anwendbar sind, wie häufig und mit wie guten Gründen, hängt zum einen von der jeweils akzeptierten erkenntnistheoretischen Position ab, und kann zum anderen auch dann, wenn eine bestimmte solche Position vorausgesetzt wird, nur durch umfangreiche Fallstudien geklärt werden, die derzeit nicht vorliegen, für die aber keinesfalls klar ist, daß sie ein aus der Perspektive der Anhänger des Wunderarguments betrachtet positives Resultat liefern werden.

\subsubsection{Vorschläge für Alternativen zu den Erklärungen, auf die gemäß dem Wunderargument zu schließen ist; Kriterien für die beste Erklärung}

Ansatzpunkt eines anderen Einwandes gegen das Wunderargument ist, daß es (in allen Versionen) einen Schluß auf die beste Erklärung für bestimmte Erfolge vorsieht. Zu den

\footnotetext{
${ }^{183}$ Ein Beispiel aus dem alltagsweltlichen Bereich ist vielleicht ein Mordprozeß, in dem verschiedene "Theorien" darüber untersucht werden, wie eine Person zu Tode gekommen ist. In solchen Fällen läßt sich der Bereich möglicher "Theorien" manchmal auf eine handhabbare Zahl begrenzen, daß man die bei Menschen erfahrungsgemäß möglichen Todesursachen und deren Symptome sowie die als Täter (aufgrund ihres Aufenthaltsorts zur Tatzeit, ihrer physischen Fähigkeiten etc.) in Frage kommenden Personen auflistet. Bei wissenschaftlichen Theorien, insbesondere bei einigermaßen hochstufigen physikalischen Theorien, scheint es zumindest deutlich weniger klar zu sein, daß genügend viele und ebenso gut gestützte Prämissen zur Verfügung stehen, die die Rolle der Liste möglicher Todesursachen, der Überzeugung, daß Menschen nur bestimmte physische Fähigkeiten haben (sich nicht durch Wände hindurchbewegen können u.ä.) etc. spielen könnten. Zumindest im mikroskopischen Bereich wird man nach den Erfahrungen der bisherigen Physikgeschichte weit eher mit der Verletzung sehr allgemeiner Prinzipien rechnen, die für diese Rolle prima facie in Frage kämen, als im makroskopischen Bereich der Alltagswelt.

${ }^{184}$ Eine instruktive Diskussion eines konkreten Falles aus der Physik, und zwar der allgemeinen Relativitätstheorie, der die beiden zuletzt beschriebenen Probleme illustriert, findet sich in [Earm92b], Kap.7.4.
} 
Erklärungen, die von den Anhängern des Wunderarguments genannt werden, gibt es nach Ansicht einiger anderer Autoren Alternativen, die die fraglichen Erfolge mindestens genauso gut erklären. Wenn das so ist, so der Einwand, entfällt damit die Grundlage für den Schluß auf die beste Erklärung, den das Wunderargument vorsieht. Die wichtigsten Vorschläge für alternative Erklärungen stammen von van Fraassen und von Fine.

\section{Van Fraassens darwinistische Erklärungen}

Van Fraassen meint, daß man eine Art darwinistischer Erklärungen für die Erfolge wissenschaftlicher Theorien geben kann. Er will diese Erfolge durch die Tatsache erklären, daß wissenschaftliche Theorien durch einen Ausleseprozeß aus einem Feld von konkurrierenden Theorien ausgewählt werden, ähnlich wie seiner Ansicht nach bestimmte Verhaltens- bzw. Erkenntnisleistungen von Tieren durch natürliche Selektion erklärt werden können:

"I can best make the point by contrasting two accounts of the mouse who runs from its enemy, the cat. St.Augustine already [...] provided an intentional explanation: the mouse perceives that the cat is its enemy, hence the mouse runs. What is postulated here is the 'adequacy' of the mouse's thought to the order of nature: the relation of enmity ist correctly reflected in his mind. But the Darwinist says: Do not ask why the mouse runs from its enemy. Species which did not cope with their natural enemies no longer exist. That is why there are only ones who do.

In just the same way, I claim that the success of current scientific theories is no miracle. It is not even surprising to the scientific (Darwinist) mind. For any scientific theory is born into a life of fierce competition, a jungle red in tooth and claw. Only the successful theories survive - the ones which in fact latched on to actual regularities in nature." 185

Für die Beurteilung von van Fraassens Einwand ist es wichtig, genau zu sehen, was das Explanandum einer Darwinistischen Erklärung der von ihm skizzierten Art ist: Es ist die Tatsache, daß die Gesamtheit der zu einem Zeitpunkt akzeptierten wissenschaftlichen Theorien nur Theorien einschließt, die erfolgreich sind, die also zu diesem (zeitlich nach dem Akzeptieren der Theorien liegenden) Zeitpunkt und später Erfolge aufweisen. Dies ist nicht das Explanandum des Wunderarguments, und zwar in keiner seiner Varianten. Der Hinweis auf eine Art Theorieselektion erklärt weder ePEe, noch nPEe, Handlungserfolge usw., wie es die verschiedenen Versionen des Wunderarguments tun; van Fraassens Explanandum, also die Tatsache, daß die Gesamtheit der zu einem Zeitpunkt akzeptierten wissenschaftlichen Theorien nur Theorien einschließt, die erfolgreich sind, ist nicht identisch mit den Explananda der verschiedenen Versionen des Wunderarguments, also mit ePEen, nPEen, Handlungserfolgen usw., was sich schon daran erkennen läßt, daß letztere nichts darüber besagen oder voraussetzen, ob die erfolgreichen Theorien akzeptiert werden oder worden sind oder nicht. ${ }^{186}$

Daß es um zwei verschiedene Explananda und entsprechend um verschiedenartige Erklärungen geht, sieht man deutlich, wenn man van Fraassens Analogie zwischen Theorie und Maus etwas genauer auszieht und dazu beide Seiten genauer in den Blick nimmt: Der Hinweis auf den Selektionsdruck durch hungrige Katzen in der Vergangenheit erklärt, daß es heute nur Spezies gibt, die diesem Druck standhalten können, daß also Individuen

\footnotetext{
${ }^{185}$ [vFra80], S.39/40.

${ }^{186}$ Dies scheint auch van Fraassens eigene Meinung zu sein — vgl. [vFra80], S.219, Fn.34.
} 
solcher Spezies, z.B. Mäuse, heute im allgemeinen die Fähigkeit haben, Katzen wahrzunehmen und vor ihnen zu fliehen, und vielleicht auch in der Zukunft (falls sich die Umweltbedingungen (etwa Hunger und Nahrungsangebot der Katzen, physische Umwelt der Mäuse u.ä.) nicht allzusehr verändern). Für eine (davon verschiedene) Erklärung bestimmter "Handlungserfolge" einer Maus, die u.a. die Wahrheit ihrer Überzeugungen involviert, bleibt damit ohne weiteres noch Raum, ${ }^{187}$ die verschiedenen Explanantia sind offenbar miteinander verträglich, konkurrieren also nicht. Zu beiden Explananda und den entsprechenden Erklärungen lassen sich Analoga auf der Seite der wissenschaftlichen Theorien angeben; hier wie da handelt es sich um verschiedene Explananda und verschiedene Erklärungen. Es ist eine Sache, bestimmte "wundersame" Erfolge einer Maus oder einer wissenschaftlichen Theorie zu konstatieren und durch bestimmte ihrer Eigenschaften zu erklären, eine andere Sache ist es zu konstatieren, daß es zu einem bestimmten Zeitpunkt nur Mäuse bzw. Theorien gibt, die bestimmte Erfolge aufweisen, und dies dadurch zu erklären, daß Erfolge derselben Art in der Vergangenheit Voraussetzung für das Überleben der Mäuse bzw. Theorien waren. Beide Erklärungen konkurrieren in keiner Weise. Deutlicher sieht man dies vielleicht an einem anderen Beispiel, bei dem es nicht um Überzeugungen und Theorien o.ä. geht: Es ist eine Sache, die erstaunlichen Ausdauerleistungen eines Radprofis bei einem Radrennen zu konstatieren und zu erklären z.B. durch das Vorhandensein eines bestimmten Quantums eines bestimmten Produktes der pharmazeutischen Industrie in seinem Körper, eine andere Sache ist es, zu konstatieren, daß alle heutigen Radprofis solche Ausdauerleistungen erbringen, und dies durch Hinweis auf die Kriterien der "Jobvergabe" der Rennställe zu erklären, also dadurch, daß jemand, der nicht solche Leistungen erbringt, heute nicht Radprofi ist. Beide Erklärungen sind offenbar miteinander verträglich. ${ }^{188}$

Van Fraassens darwinistische Erklärung und die Erklärung des Wunderarguments haben also verschiedene Explananda und darüberhinaus sind die zugehörigen Erklärungen

\footnotetext{
${ }^{187}$ In der Fußnote auf S.219 in [vFra80] erkennt van Fraassen dies offenbar an — trotz der im Haupttext aufgemachten Kontrastierung zwischen Darwinistischer und "Adäquatheitserklärung".

${ }^{188}$ Unabhängig von der Frage, ob darwinistische Erklärungen und die Erklärungen des Wunderarguments tatsächlich konkurrieren, kann man die Erklärungsleistung der "darwinistischen Wissenschaftstheorie" für sich kritisch unter die Lupe nehmen, sprich: die Relevanz der Analogie hinterfragen. Das Analogon zu einem Selektionsfaktor wie den Katzen müßte für den Bereich wissenschaftlicher Theorien offenbar ein bestimmtes Kriterium (oder ein Satz von Kriterien) der Theoriewahl sein. Durch dieses Kriterium müßten Theorien mit Eigenschaften selektiert werden, die auch später noch unter "hinreichend ähnlichen" Bedingungen erfolgreich sind. Wenn im biologischen Fall die selektierte Fähigkeit der Mäuse, die weiteren Erfolg garantiert, etwa die ist, Katzen unter normalen Bedingungen (bzgl. Lichtverhältnissen usw.) in mitteleuropäischen Feld- und Wiesenlandschaften zu erkennen und ihnen zu entfliehen, dann müßte eine analoge "Fähigkeit" einer Theorie, die aufgrund bestimmter Erfolge akzeptiert wurde, identifizierbar sein, die unter "hinreichend ähnlichen" Bedingungen weiter gleichartige Erfolge garantiert. Was das genau heißen könnte, scheint nicht klar zu sein. Bei den Mäusen erklärt die Selektion durch "vergangene" Katzen heutige Erfolge, insofern bei ihnen ein (genetisch determinierter) Wahrnehmungs-, Fortbewegungs- usw. Apparat etabliert wurde, der bei hinreichend ähnlichem Input auch hinreichend ähnlichen Output liefert (wobei die physische Implementierung den Standard der Ähnlichkeit festlegt). Bei einer Theorie ist schwer zu sehen, was in Analogie dazu die Erklärung weiterer gleichartiger Erfolge (nach der Selektion) in hinreichend ähnlichen Fällen sein sollte und welche spezifischen Eigenschaften der Theorie dafür — in Analogie zur genetischen Ausstattung der Mäuse — verantwortlich sein sollte. (Angenommen etwa, die Quantenmechanik wäre akzeptiert worden, weil sie das Wasserstoffspektrum korrekt prognostiziert. Erklärt dies (darwinistisch,) daß sie auch das Heliumspektrum korrekt voraussagt? Es ist schwer zu sehen, was hier die Rolle der physischen Implementierung der selektierten Fähigkeit bei der Maus spielen sollte.) Fazit: Die Analogie zwischen natürlicher Selektion der Arten und der "Selektion" wissenschaftlicher Theorien scheint bei näherem Hinsehen nicht wirklich tragfähig zu sein oder jedenfalls bleibt sie bei van Fraassen undurchsichtig.
} 
miteinander verträglich. Es besteht daher kein Grund, die von van Fraassen vorgeschlagenen Erklärungen als in irgendeiner Weise konkurrierende Alternativen zu den Erklärungen zu betrachten, die die verschiedenen Versionen des Wunderarguments vorschlagen, vielmehr kann man in bezug auf eine oder mehrere wissenschaftliche Theorien ohne weiteres beide Erklärungen zugleich akzeptieren. ${ }^{189}$

\section{Fines Vorschlag für die Erklärung von Erfolgen durch die "instrumentelle Verläßlichkeit" wissenschaftlicher Theorien}

Arthur Fine bietet eine andere alternative Erklärung für die für das Wunderargument relevanten Erfolge an. Er meint, daß sie durch die Annahme erklärt werden können, daß die für die Erfolge verantwortlichen Theorien "instrumentell verläßlich" sind und erläutert dies durch ein instruktives Bild:

"Suppose we had a machine, running 'on-line', that provided the premisses for valid arguments whose conclusions checked out as instrumentally correct time and time again (the 'abundant' instrumental success of science). Puzzled and intrigued, it would certainly be appropriate to look for a rational account of what is going on here. Surely a good account (perhaps, one might slyly insinuate, the very best) would be to infer that the premisses turned out by the machine are true (or, at any rate, largely true), for only that could explain the repeated generation of correct conclusions. The explanationist defence of realism is much the same, for the realist contends that only the truth (or approximate truth) of science could explain its generation of instrumental successes over time, and feels entitled to infer from this explanation that science is true — or largely so. [...] the analogy, however, [...] does not necessarily pull in the direction of realism, for, if the machine generates premisses that lead only to instrumentally correct conclusions, we do not need to move to the full truth of the premisses to account for the outcomes. It would certainly be sufficient just to suppose that the premisses themselves are reliable merely with regard to their instrumental consequences. Similarly, if it is the instrumental success of science that we think wants explaining, then it seems that we require nothing more than the instrumental reliability of science in order to carry the explanation off." 190

Fine hält seine Erklärung nicht nur für gleichwertig zu denen des Wunderarguments, sondern für besser, weil letztere weiterreichende Annahmen machen, die seiner Meinung nach für die Erklärung nichts leisten und daher überflüssig sind.

Fine erläutert nicht genau, worin das Explanandum der von ihm vorgeschlagenen Erklärungen besteht, was also mit "instrumental success of science" gemeint ist, seine Argumentation scheint aber auf alle vorne unterschiedenen Explananda gleichermaßen zu zielen, also sowohl auf ePEe, als auch auf nPEe, Handlungserfolge etc. ${ }^{191}$ Anders als van

\footnotetext{
${ }^{189}$ In ähnlicher Richtung argumentiert z.B. [Musg88], S.242; vgl. auch [Brow85], [Lipt91], S.169ff. Laudans Vorschlag (in [Laud84]), die Erfolge einer Theorie dadurch zu erklären, daß sie harte Tests überstanden hat, liefert aus demselben Grund keine mit den Erklärungen des Wunderarguments konkurrierenden Alternativen.

${ }^{190}[$ Fine86b], S.153.

${ }^{191}$ Fine sagt zwar ([Fine86b], S.152), daß es ihm um "the instrumental success of science, i.e. [...] the sort of practical success one can observe in our everyday lives and culture", geht und damit wohl eher um Handlungserfolge, ePEe und vielleicht auch nPEe (letztere sind in "unserem täglichen Leben und
} 
Fraassens darwinistische Erklärungen haben also die von Fine vorgeschlagenen Erklärungen und die Erklärungen, die das Wunderargument vorsieht, dieselben Explananda.

Dennoch konkurrieren Fines Erklärungen und die Erklärungen der verschiedenen Versionen des Wunderarguments für diese Explananda nicht, denn die von beiden vorgesehenen Explanantia können zugleich wahr sein. Fine nennt als Explanans für die Erfolge einer Theorie $T$ die "instrumentelle Verläßlichkeit" der Theorie, womit er im wesentlichen das zu meinen scheint, was üblicherweise als empirische Adäquatheit bezeichnet wird. ${ }^{192}$ Er erläutert nicht, in welcher explanatorischen Relation dieses Explanans zu den Erfolgen einer Theorie stehen soll oder was für eine Art von Erklärung er im Auge hat, aber es kann offenbar nur in einem weiten, vergleichsweise schwachen Sinn eine Erklärung sein: Daß eine Theorie empirisch adäquat ist, ist eine generelle Aussage über alle empirischen Konsequenzen dieser Theorie; eine "verwandte" Aussage, die vielleicht stattdessen mit der Redeweise von der "instrumentellen Verläßlichkeit" einer Theorie intendiert sein könnte, wäre eine Aussage über eine Art Dispositionseigenschaft der Theorie, nämlich eine, die der Theorie die Disposition zuschreibt, durch deduktives Ableiten nur wahre empirische Konsequenzen zu liefern. Beide Lesarten von Fines Explanans ergeben nur in einem schwachen Sinn eine Erklärung: Daß eine Theorie empirisch adäquat ist, impliziert natürlich, daß ein bestimmter daraus abgeleiteter Beobachtungssatz wahr ist, aber die explanatorische Relation besteht dann offenbar nur darin, daß ein Einzelfall unter einen allgemeinen Sachverhalt subsumiert wird, das Explanandum epistemisch "erwartbar" gemacht wird o.ä. ${ }^{193}$ Ebenso impliziert die Annahme, daß eine Theorie die genannten Disposition hat, daß ein daraus abgeleiteter Beobachtungssatz wahr ist, aber die explanatorische Relation besteht dann nur darin, daß ein manifester Einzelfall als Resultat einer allgemeinen Disposition aufgefaßt wird, epistemisch "erwartbar" wird o.ä. ${ }^{194}$ In beiden Lesarten liegt offenbar für die Erfolge einer Theorie keine Erklärung, wie sie das Wunderargument vorsieht, vor, etwa keine Erklärung mit der Wahrheit der Theorie als Explanans (die als deduktive semantische Erklärung charakterisierbar ist), und eine solche ist mit der von Fine vorgeschlagenen "schwachen" Erklärung in beiden Lesarten verträglich, denn eine wahre Theorie ist offenbar empirisch adäquat und hat die genannte Disposition und umgekehrt kann eine empirisch adäquate Theorie bzw. eine mit der genannten Disposition zumindest wahr sein. Für deduktive semantische Erklärungen im weiten Sinn, Handlungserklärungen, Boyds kausale Erklärungen etc. gilt mutatis mutandis dasselbe. Fines Vorschlag für die Erklärung von Theorieerfolgen steht also, wie der von van Fraassen, bei genauerer Betrachtung nicht in Konkurrenz zu den Erklärungen des Wunderarguments.

unserer Alltagskultur" sicherlich seltener zu beobachten als erstere, aber auch sie kommen vor, etwa die ersten Atombombenexplosionen) als um Vereinheitlichungsleistungen, aber für seine Argumentation scheint davon nichts abzuhängen, und an einer anderen Stelle heißt es dann auch: "One could [...] enlarge the notion of instrumental success so as to include all the predictive and explanatory success of science in the observable realm" ([Fine86b], S.154).

${ }^{192}$ Ein Grund, warum Fine den üblichen Ausdruck nicht verwendet, scheint darin zu liegen, daß er die damit gewöhnlich, etwa von van Fraassen, verbundene Erläuterung des Wahrheitsbegriffs ablehnt (vgl. [Fine86b], bes. S.157, 158, 175ff.); auf diese Differenz kommt es aber an dieser Stelle nicht an.

Explizit wird die empirische Adäquatheit einer Theorie als Explanans für ihren Erfolg von Musgrave in [Musg88], S.242 genannt.

${ }^{193}$ Vgl. auch S.221.

${ }^{194}$ Eine Analogie, die verdeutlicht, daß beides nur in einem schwachen Sinn Erklärungen sind: Die Beobachtung, daß ein Magnet einen Eisennagel anzieht, wird erklärt durch die generelle Aussage, daß der Magnet alle Eisennägel anzieht, oder durch die Aussage, daß er die Disposition hat, Eisennägel anzuziehen. 


\section{Andere Alternativen zu den Erfolgserklärungen des Wunderarguments}

Angesichts dieser Replik auf van Fraassens und Fines Vorschläge für Alternativen zu den Erklärungen, auf die gemäß dem Wunderargument zu schließen ist, liegt vielleicht die Frage nahe, ob es überhaupt (potentielle) Erklärungen gibt, die mit den Erklärungen konkurrieren, die das Wunderargument vorsieht, also Erklärungen für dasselbe Explanandum, deren Explanans nicht zugleich mit dem Explanans des Wunderarguments wahr sein kann, und die daher eventuell als weniger gute Erklärungen als die des Wunderarguments erwiesen werden müssen, um auf das vom Wunderargument vorgesehene Explanans schließen zu können. Die Anhänger des Wunderarguments nennen und diskutieren keine Vorschläge für solche konkurrierenden Erklärungen, zumindest in einigen Fällen läßt sich aber eine alternative Erklärung angeben, die nicht zugleich mit dem Explanans des Wunderarguments wahr sein kann.

Für die Versionen des Wunderarguments, die sich auf Prognoseerfolge oder Vereinheitlichungsleistungen beziehen, kommen als konkurrierende Alternativen die im vorigen Abschnitt ${ }^{195}$ genannten Erklärungen in Frage, die die Erfolge einer Theorie $T_{1}$ durch die Wahrheit einer empirisch äquivalenten, aber mit ihr unverträglichen Theorie $T_{2}$ erklären: ${ }^{196}$ In einer solchen Erklärung für die Erfolge einer Theorie $T_{1}$ bestünde das Explanans aus den Aussagen, daß $T_{2}$ wahr ist und daß $T_{1}$ und $T_{2}$ empirisch äquivalent sind, sowie aus einer Korrektheitsaussage über den "Theoriekalkül". Der Zusammenhang zwischen Explanans und Explanandum wäre dann der, daß aus der Prämisse, daß $P$ aus $T_{1}$ ableitbar ist, (die Teil des Explanandums ist) und der empirischen Äquivalenz von $T_{1}$ und $T_{2}$ folgt, daß $P$ aus $T_{2}$ ableitbar ist, und daß daraus, zusammen mit der Korrektheitsaussage und der Aussage, daß $T_{2}$ wahr ist, die Wahrheit von $P$ folgt. Das Explanans einer solchen Erklärung kann offenbar nicht zugleich mit dem Explanans einer Erklärung der Erfolge von $T_{1}$ durch die Wahrheit von $T_{1}$, wie sie das Wunderargument vorsieht, wahr sein.

Ob die beiden Erklärungen auch in dem Sinne Alternativen darstellen, daß die letztere, also die Erklärung der Erfolge von $T_{1}$ durch die Wahrheit von $T_{1}$, als die bessere ausgezeichnet werden muß, um das Argumentationsziel des Wunderarguments zu erreichen, ist damit jedoch noch nicht ausgemacht. Vielmehr hängt dies davon ab, mit Hilfe welchen Inferenzschemas man das Wunderargument rekonstruiert. Ein Inferenzschema der Form (IBE) gestattet einen Schluß auf die beste der konkurrierenden (potentiellen) Erklärungen, ohne die Art der Erklärungen näher zu spezifizieren, daher kann man gemäß einem Schema der Form (IBE) offenbar nur dann auf die Wahrheit von $T_{1}$ schließen, wenn man über Kriterien für den Vergleich der Qualität der beiden genannten Erklärungen verfügt und mit deren Hilfe die entsprechende Erklärung für die Erfolge von $T_{1}$ als die bessere der beiden ausgezeichnet werden kann. Ein Inferenzschema der Form (IBEsp) dagegen gestattet einen Schluß auf die beste der konkurrierenden (potentiellen) Erklärungen derselben Art. Um gemäß einem Schema der Form (IBEsp) auf die Wahrheit von $T_{1}$ zu schließen, ist es daher nicht unbedingt erforderlich, die entsprechende Erklärung für die Erfolge von $T_{1}$ als die bessere der beiden genannten Erklärungen auszuzeichnen, genauer: Es ist nur dann erforderlich, wenn beide Erklärungen (nicht nur die durch die Wahrheit von $T_{1}$ ) Erklärungen der Art sind, auf die sich das in Anspruch genommene Inferenzschema der Form (IBEsp) bezieht.

Ob die beiden Erklärungen Alternativen im beschriebenen Sinn darstellen, hängt also

\footnotetext{
${ }^{195}$ Siehe S.241.

${ }^{196}$ Varianten mit dem Explanans annähernde Wahrheit etc. werden hier nicht gesondert erörtert.
} 
davon ab, ob die Version des Wunderarguments, die man vertritt, als Instantiierung eines Inferenzschemas der Form (IBE) zu rekonstruieren ist oder als Instantiierung eines spezielleren Schemas der Form (IBEsp) und falls letzteres, auf welche Art von Erklärungen sich dieses bezieht. Da die Erklärung der Erfolge einer Theorie $T_{1}$ durch deren Wahrheit und die Erklärung dieser Erfolge durch die Wahrheit einer empirisch äquivalenten, aber unverträglichen Theorie $T_{2}$ so, wie sie oben erläutert wurden, intuitiv gesprochen, verschiedenartige, aber nicht völlig verschiedenartige Erklärungen sind, ist es offenbar sowohl möglich, eine Art von Erklärung zu spezifizieren, zu dem die erstere, aber nicht die letztere zählt, als auch eine Art von Erklärung, zu der beide zählen, und auch entsprechende Inferenzschemata der Form (IBEsp). Die vorne ${ }^{197}$ angegebene Charakterisierung einer deduktiven semantischen Erklärung spezifiziert offenbar eine Art von Erklärung, für die ersteres gilt ${ }^{198}$, denn bei einer Erklärung dieser Art darf das Explanans nur die Wahrheit der erfolgreichen Theorie selbst involvieren. Eine Art von Erklärung, zu der beide genannten Erklärungen für die Erfolge von $T_{1}$ zählen, wäre etwa Erklärungen epistemischer Art, für die lediglich erforderlich ist, daß das Explanandum aus dem Explanans (oder evtl. Teile des Explanandums aus dem Explanans plus dem Rest des Explanandums) folgt und das Explanandum (oder evtl. Teile des Explanandums) dadurch "erwartbar" werden.

Für die Versionen des Wunderarguments, die sich auf Handlungserfolge beziehen, für Boyds Version etc. lassen sich, mutatis mutandis, dieselben Überlegungen anstellen.

\section{Alternativen zu den Erfolgserklärungen des Wunderarguments und Kriterien für die beste Erklärung}

Diese Überlegungen illustrieren offenbar einen allgemeinen Punkt: Ob es zu dem Explanans, auf das in einer Version des Wunderarguments geschlossen werden soll, Alternativen gibt (und, wenn ja, welche), gegenüber denen es zuvor dadurch ausgezeichnet werden muß, daß es die bessere Erklärung liefert, hängt u.a. davon ab, welches Inferenzschema diese Version des Wunderarguments genau in Anspruch nimmt. Auch (potentielle) Erklärungen für dasselbe Explanandum, deren Explanans nicht zugleich mit dem durch das Wunderargument vorgeschlagenen Explanans wahr sein kann, können ohne vergleichende Bewertung der Erklärungsleistungen beiseite gelassen werden, wenn ein Inferenzschema der Form (IBEsp) in Anspruch genommen werden kann, das sich auf eine Art von Erklärungen bezieht, zu der die "potentiellen Alternativen" nicht zählen. Je enger die Art von Erklärung spezifiziert ist, auf die sich das Inferenzschema bezieht, das man für das Wunderargument in Anspruch nimmt, desto weniger ist man tendenziell darauf angewiesen, die Erklärungsleistungen des vorgesehenen Explanans als die besten erweisen zu können, und am wenigsten ist man dies, wenn man ein Inferenzschema der Form (IBEsp) in Anspruch nimmt, das sich auf eine Art von Erklärung bezieht, die so eng spezifiziert ist, daß bei gegebenem Explanandum nur genau ein Explanans darunter fällt. Diese letztere Möglichkeit stellt sozusagen den "entarteten Grenzfall” eines Schemas der Form (IBEsp) dar.

Ein plausibler Kandidat für einen solchen entarteten Grenzfall ist gerade ein Inferenzschema, das für Prognoseerfolge etc. als Art von Erklärung eine deduktive semantische Erklärung vorsieht bzw. eine dahingehend präzisierte Art von Erklärung: Ein solches Inferenzschema würde bei gegebenem Explanandum direkt, d.h. ohne irgendwelche Vergleiche der Erklärungsleistungen von verschiedenen potentiellen Erklärungen, auf das eindeutig

\footnotetext{
${ }^{197} \mathrm{~S} .223$.

${ }^{198}$ Oder läßt sich jedenfalls dahingehend präzisieren.
} 
spezifizierte Explanans zu schließen gestatten, etwa auf die Wahrheit der prognostisch erfolgreichen Theorie.

Ob die Anhänger des Wunderarguments eine Rekonstruktion ihrer jeweiligen Version des Arguments mit Hilfe eines (mehr oder weniger) speziellen Inferenzschemas der Form (IBEsp) als adäquat akzeptieren würden, ist schwer zu beurteilen; die wenigen Hinweise, die sich in ihren Texten zu der Fragen finden, welches Inferenzschema ihr Argument instantiieren soll, deuten jedoch eher darauf hin, daß sie ein allgemeines Schema der Form (IBE) im Auge haben. ${ }^{199}$

Auch wenn dies so ist, könnte eine "verbessernde" Rekonstruktion des Wunderarguments (oder vielleicht einiger seiner Versionen) mit Hilfe spezieller Inferenzschemata der Form (IBEsp) dennoch in systematischer Hinsicht von Vorteil sein. Ein Grund dafür ist, daß die Anhänger des Wunderarguments in ihren Texten praktisch nichts über Kriterien des Vergleichs von Erklärungsleistungen sagen, die etwa in Fällen wie dem oben skizzierten, in denen es mehrere potentielle Erklärungen für bestimmte Erfolge gibt, die Ermittelung der besten Erklärung ermöglichen. ${ }^{200}$

Daß die Frage nach solchen Kriterien von den Anhängern des Wunderarguments weitgehend offen gelassen wird, ohne daß sie darin einen Mangel ihrer Argumentation sehen, wie man prima facie vermuten könnte, dürfte daran liegen, daß die meisten von ihnen der Ansicht sind, daß es überhaupt keine konkurrierenden Erklärungen für die Erfolge gibt, die das Explanandum des Wunderarguments darstellen. Wenn aber, wie oben argumentiert, solche konkurrierenden Erklärungen zumindest in einzelnen Fällen vorkommen können, kann die Überzeugungskraft des Wunderarguments von der Beantwortung dieser Frage abhängen. Man könnte in dieser Situation versuchen, die Hinweise heranzuziehen, die sich in der Literatur zum Themenbereich wissenschaftliche Erklärungen zum Vergleich der Erklärungsleistungen wissenschaftlicher Theorien finden: Dort werden als Kriterien für eine gute Erklärung verschiedene (allerdings i.a. nur wenig präzise erläuterte) "Erklärungstugenden" wie Einfachheit, Kohärenz, Vermeidung von ad-hoc-Erklärungen u.ä. genannt, ${ }^{201}$ die sich auch für einen Vergleich von Erklärungsleistungen eignen sollen. Daß sich diese Kriterien auch für einen Vergleich der Erklärungen des Wunderarguments mit deren Alternativen eignen, läßt sich jedoch bezweifeln: Wenn man sich eine hinreichend lange Reihe konkreter Beispiele ansieht, spricht vieles dafür, daß es allenfalls wenige völlig allgemeine, bereichsunabhängigen Kriterien für die Güte einer Erklärung jedweder Art geben dürfte, ${ }^{202}$ die für Vergleiche von Erklärungsleistungen i.a. nicht ausreichen, und daß plausible Vergleichskriterien, wenn sich solche identifizieren lassen, mehr oder weniger bereichsspezifische und nur auf eine Menge mehr oder weniger "ähnlicher" oder gleichartiger Erklärungen anwendbare sein dürften. ${ }^{203}$ Sofern sich etwa plausible Kriterien für den Vergleich der Erklärungsleistungen physikalischer Theorien identifizieren lassen, dürften sich diese nicht für Erklärungen beliebiger Art verwenden lassen (und damit nicht auf alle Erklärungen, die ein Inferenzschema der Form (IBE) zuläßt), und insbesondere auch nicht auf die Erklärungen, die das Wunderargument für Theorieerfolge vorsieht, und mögliche

\footnotetext{
${ }^{199}$ Explizit äußern Musgrave und Boyd diese Ansicht; s.a. den folgenden Abschnitt.

${ }^{200}$ Vgl. etwa [Musg88], S.239, 242ff.

${ }^{201}$ Siehe z.B. [McMu83], [McMu94], S.102f.

${ }^{202}$ Etwa innere Konsistenz und empirische Adäquatheit.

${ }^{203}$ Zur Veranschaulichung: Es ist wenig plausibel, daß sich Kriterien aufweisen lassen, die sowohl Sherlock Holmes die Wahl der besten Erklärung für den Tod des Grafen ermöglichen, als auch einem Hochenenergiephysiker die Wahl der besten Erklärung für bestimmte Blasenkammerspuren, als auch einem Paläontologen für das Aussterben einer Dinosaurierart etc. Diesen Punkt machen Timothy Day und Harold Kincaid in [DaKi94]; s.a. [BenM90].
} 
Alternativen dazu.

Gegeben diese Sachlage ist klar, warum eine "verbessernde" Rekonstruktion des Wunderarguments mit Hilfe spezieller Inferenzschemata der Form (IBEsp) von Vorteil sein kann: Eine Rekonstruktion (einer Version) des Wunderarguments, nach der dies als Instantiierung eines Schemas der Form (IBEsp) aufzufassen ist, ist eine Möglichkeit, Probleme zu vermeiden oder zu beseitigen, die entstehen können, wenn es zu den vom Wunderargument vorgesehenen Explanantia konkurrierende Erklärungen gibt und man keine Kriterien zum Vergleich der Erklärungsleistungen zur Verfügung hat, die die Erklärungen, die das Wunderargument vorsieht, als die besseren auszuzeichnen erlauben. Wenn man das Wunderargument als Instantiierung eines Schemas der Form (IBE) auffaßt, kann man ohne solche Kriterien in einem solchen Fall nicht auf das Explanans des Wunderarguments schließen, wenn man es dagegen als Instantiierung eines Schemas der Form (IBEsp) rekonstruiert, das sich auf eine Art von Erklärung bezieht, zu dem die alternativen Erklärungen nicht zählen, kann man ohne Vergleichskriterien auf das Explanans des Wunderarguments schließen. Bei einer Rekonstruktion (einer Version) des Wunderarguments mit Hilfe eines "entarteten Grenzfalls" eines Schemas der Form (IBEsp) sind derartige Probleme sogar prinzipiell ausgeschlossen.

Ob solche verbessernden Rekonstruktionen tatsächlich alles in allem überzeugend sind, müßte durch eingehendere Untersuchungen geprüft werden, denn es ist zumindest denkbar, daß damit andere Nachteile verbunden sind, etwa daß speziellere Inferenzschemata nicht in der Weise vom jeweiligen Diskussionsgegner als intuitiv plausibel akzeptiert werden oder schwieriger zu begründen sind als ein allgemeines Schema der Form (IBE).

\subsubsection{Der Petitio-Principii-Einwand}

Larry Laudan und Arthur Fine haben gegen das Wunderargument den Einwand erhoben, daß es auf eine Petitio Principii hinausläuft. Laudan erläutert seinen Einwand folgendermaßen:

"Fundamentally, the realist is utilizing [...] an abductive inference which proceeds from the success of science to the conclusion that science is approximately true, verisimilar, or referential (or any combination of these) [...]

It is little short of remarkable that realists would imagine that their critics would find the argument compelling. [...] ever since antiquity critics of epistemic realism have based their scepticism upon a deep-rooted conviction that the fallacy of affirming the consequent is indeed fallacious. [...] Indeed, many non-realists have been non-realists precisely because they believed that false theories, as well as true ones, could have true consequences.

Now enters a new breed of realists (e.g. Putnam, Boyd and Newton-Smith) who wants to argue that epistemic realism can reasonably be presumed to be true by virtue of the fact that it has true consequences. But this is a monumental case of begging the question. The non-realist refuses to admit that a scientific theory can be warrantedly judged to be true simply because it has some true consequences. Such non-realists are not likely to be impressed by the claim that a philosophical theory like realism can be warranted as true because it arguably has some true consequences. If non-realists are chary about first-order abductions to avowedly true conclusions, they are not likely to be impressed 
by second-order abductions". ${ }^{204}$

Fine formuliert denselben Einwand noch etwas klarer, indem er deutlicher als Laudan (der nur einmal etwas unauffällig von "abductive inference" spricht) die Rolle des Schließens auf die beste Erklärung herausarbeitet:

"Those suspicious of realism [...] have been worried about the significance of the explanatory apparatus in scientific investigations. While they appreciate the systematization and coherence brought about by scientific explanation, they question whether acceptable explanations need to be true and, hence, whether the entities mentioned in explanatory principles need to exist. Suppose they are right. Suppose, that is, that the usual explanation-inferring devices in scientific practice do not lead to principles that are reliably true (or nearly so), nor to entities whose existence (or near-existence) is reliable. In that case, the usual abductive methods that lead us to good explanations (even to "the best explanation') cannot be counted on to yield results even approximately true. But the strategy that leads to realism [...] is just such an ordinary sort of abductive inference. Hence, if the nonrealist were correct in his doubts, then such an inference to realism as the best explanation (or the like), while possible, would be of no significance [...] one must not beg the question as to the significance of explanatory hypotheses by assuming that they carry truth as well as explanatory efficiacy.

There is a second way of seeing the same result. Notice that the issue over realism is precisely the issue as to whether we should believe in the reality of those individuals, properties, relations, processes, and so forth, used in wellsupported explanatory hypotheses. Now what is the hypothesis of realism, as it arises as an explanation of scientific practice? It is just the hypothesis that our accepted scientific theories are approximately true, where "being approximately true" is taken to denote an extratheoretical relation between theories and the world. Thus, to address doubts over the reality of relations posited by explanatory hypotheses, the realist proceeds to introduce a further explanatory hypothesis (realism), itself positing such a relation (approximate truth). [...]

Thus [...] no support accrues to realism by showing that realism is a good hypothesis for explaining scientific practice. If we are open-minded about realism to begin with, then such a demonstration (even if successful) merely begs the question that we have left open ("need we take good explanatory hypotheses as true?")." 205

Laudan und Fine stellen eine Annahme in Frage, die sämtlichen Versionen des Wunderarguments zugrundeliegt, die aber bei seinen Anhängern häufig implizit und sozusagen außerhalb des Blickfeldes bleibt, insbesondere bei den frühen Formulierungen wie denen von Putnam und Smart, in denen das Wunderargument nicht explizit als Argument von der Form eines Schlusses auf die beste Erklärung präsentiert wird: Es ist die Annahme, daß die Tatsache, daß das Explanans der jeweiligen Version des Wunderarguments die beste Erklärung des jeweiligen Explanandums liefert, ipso facto einen guten Grund darstellt, einen Schluß auf die Erklärung zu ziehen, die das Wunderargument anbietet, also das jeweilige Explanans zu glauben.

\footnotetext{
${ }^{204}$ [Laud81], S.45.

${ }^{205}$ [Fine84a], S.85/86, vgl. auch [Fine86b], S.153/154, $160 f$.
} 
Laudan und Fine geben ihrerseits keine expliziten Rekonstruktionen für die verschiedenen Versionen des Wunderarguments an, offenbar fassen sie sie aber allesamt als Anwendungen eines allgemeinen und kontextunabhängigen Inferenzschemas von der Art des von Musgrave für das Schließen auf die beste Erklärung angegebenen Schemas (IBE) ${ }^{206}$ auf. Sie gehen davon aus, daß die Anhänger des Wunderarguments deswegen der Meinung sind, daß die Tatsache, daß das Explanans der jeweiligen Version des Wunderarguments die beste Erklärung des jeweiligen Explanandums liefert, einen guten Grund darstellt, einen Schluß auf diese Erklärung zu ziehen, weil sie ein allgemeines, kontextunabhängiges Inferenzschema wie (IBE) akzeptieren, das in diesem Fall angewendet werden kann. Diese Lesart von Laudan und Fine sieht zumindest prima facie plausibel aus, denn Musgrave gibt ein solches Inferenzschema explizit an, einige andere Autoren, etwa Boyd, sprechen am Rande und ohne genauere Erläuterung vom Schließen auf die beste Erklärung und bei anderen Anhängern des Wunderarguments, insbesondere bei frühen wie Putnam und Smart, findet sich zumindest nichts, was gegen diese Annahme spricht, insbesondere findet sich keine andere Begründung, warum im Fall des Wunderarguments das vorgeschlagene Explanans geglaubt werden sollte.

Wenn man diese Struktur des Wunderarguments, also die Tatsache, daß es von seinen Anhängern als Instantiierung eines allgemeinen Inferenzschemas wie (IBE) aufgefaßt wird, einmal explizit gemacht hat, dann liegt der Einwand von Laudan und Fine auf der Hand: Wenn ein allgemeines Inferenzschema wie (IBE) vorausgesetzt werden kann, dann kann man aufgrund dieser Voraussetzung das Argumentationsziel des Wunderarguments in vielen Fällen erreichen, ohne sich um die Explananda des Wunderarguments, sprich: um Prognoseerfolge etc., zu kümmern: Eine wissenschaftliche Theorie, die bestimmte Phänomene prognostiziert, vereinheitlicht o.ä., liefert in vielen Fällen gleichzeitig die beste wissenschaftliche Erklärung für diese Phänomene; dies dürfte auch zwischen den Kontrahenten der Realismusdebatte (in der das Wunderargument eingesetzt werden soll) in der Regel nicht kontrovers sein. In diesen Fällen kann man, wenn ein allgemeines Inferenzschema wie (IBE) vorausgesetzt werden kann, aufgrund der wissenschaftlichen Erklärungsleistung "direkt" auf die Wahrheit der erklärenden physikalischen, chemischen o.ä. Theorie schließen. Anders formuliert: Das allgemeine Inferenzschema kann auf die wissenschaftliche Erklärung bestimmter Phänomene angewendet werden und liefert dann einen Schluß auf die Wahrheit der erklärenden physikalischen, chemischen o.ä. Theorie. In diesen Fällen führt also ein allgemeines Inferenzschema wie (IBE), wenn man es akzeptiert und voraussetzen kann, zu der Konklusion, die die Anhänger des Wunderarguments erreichen wollen, ohne daß Prognoseerfolge, Handlungserfolge etc. und deduktive semantische etc. Erklärungen dafür überhaupt ins Spiel kommen. Da dies so ist, werden (einigermaßen reflektierte und konsequente) Antirealisten, so der Einwand von Laudan und Fine, im allgemeinen kein allgemeines Inferenzschema wie (IBE) akzeptieren, und man kann daher plausiblerweise in der Realismusdebatte von realistischer Seite kein solches Inferenzschema für ein Argument in Anspruch nehmen, das die antirealistische Seite überzeugen soll. Bei Antirealisten, die kein solches Inferenzschema akzeptieren, fehlt sozusagen die Grundlage für die Anwendung des Wunderarguments; wenn es Antirealisten geben sollte, die ein solches Schema akzeptieren, wäre das Wunderargument (in vielen Fällen) überflüssig.

Nach Laudan und Fine ist das Wunderargument also als Instantiierung eines allgemeinen Inferenzschemas wie (IBE) aufzufassen, und wenn man dies einmal explizit gemacht hat, ist klar, daß das Wunderargument zwar keine Petitio Principii im üblichen Sinn

\footnotetext{
${ }^{206}$ Siehe S.168.
} 
enthält, also die Konklusion nicht etwa bereits als Prämisse auftritt oder zu deren Rechtfertigung erforderlich ist, daß es aber ein für das Argument unverzichtbares Inferenzschema voraussetzt, das ein Antirealist (typischerweise) nicht akzeptiert, das im Streit zwischen Realisten und Antirealisten nicht als unkontrovers vorausgesetzt werden kann und das, wenn es vorausgesetzt werden könnte, das Argument (in vielen Fällen) überflüssig machen würde. In diesem Sinn spricht Laudan offenbar von einer Petitio Principii.

Dieser Einwand von Laudan und Fine begründet in überzeugender Weise, warum das Wunderargument in der von ihnen rekonstruierten Form nicht greifen kann, wenn es von realistischer Seite in der Diskussion mit antirealistischen Gegnern eingesetzt wird. Es kann vielleicht dem Realisten selbst dazu dienen, seine Position sozusagen auszubauen und abzurunden: Wer überzeugt ist, daß ein allgemeines Inferenzschema wie (IBE) verläßlich ist und daher die Konklusionen, die es liefert, als Überzeugungen akzeptiert, der kann dies nicht nur bei der Anwendung auf wissenschaftliche Erklärungen, sondern auch im Fall des Wunderarguments tun. Wer jedoch ein solches Inferenzschema nicht akzeptiert, wird die Inanspruchnahme dieses Schemas auch im Fall des Wunderarguments zurückweisen.

Auf Seiten der Anhänger des Wunderarguments findet sich in der Literatur (bisher) nur bei Boyd eine Antwort auf diesen Einwand. ${ }^{207}$ Boyd erkennt die Diagnose an, daß das Wunderargument ein allgemeines Inferenzschema wie (IBE) voraussetzt, das ebenso gut auch auf die Erklärungsleistungen wissenschaftlicher Theorien angewendet werden kann, um auf die beste wissenschaftliche Erklärung zu schließen, er bestreitet jedoch, daß das Wunderargument dadurch wertlos wird. Boyd ist der Ansicht, daß das Schließen auf die beste Erklärung eine allgemeine Inferenzregel ist, die für eine realistische Position so zentral und unverzichtbar ist, daß plausiblerweise nicht erwartet werden kann, daß man bei der Begründung und Verteidigung einer realistischen Position auf sie verzichtet, wenn der Diskussionsgegner sie nicht akzeptiert. Zur Begründung und Verteidigung einer realistischen Position trägt nach Boyds Meinung ein Schluß auf die beste Erklärung, wie ihn das Wunderargument vorsieht, ebenso bei wie Schlüsse auf die beste wissenschaftliche Erklärung bestimmter Phänomene, auch wenn diese Schlüsse dasselbe allgemeine Inferenzschema voraussetzen. Alle diese Anwendungen eines allgemeinen Schemas wie (IBE) tragen zu einer realistischen Position bei, die sowohl ein realistisches Bild von den Wissenschaften, ihren Methoden, ihren "kognitiven Produkte" und deren semantischem und epistemischem Status etc., als auch physikalische, geologische, biologische etc. Thesen bzw. Überzeugungen einschließt, und die nach Boyd so gut wie möglich artikuliert und ausgebaut werden und als Gesamtposition, d.h. als ganze antirealistischen Positionen gegenübergestellt und mit ihnen im Hinblick auf Plausibilität und Überzeugungskraft verglichen werden muß. Boyd spricht in diesem Zusammenhang von verschiedenen "philosophischen Paketen" ("philosophical packages"), u.a. einem realistischen und einem empiristischen ${ }^{208}$, von denen das realistische den anderen "überlegen" ist. ${ }^{209} \mathrm{Zu}$ dieser Überlegenheit trägt das Wunderargument nach Boyd bei, indem es beim Ausbau jeder realistischen Position hilft, die bereits ein Inferenzschema wie (IBE) einschließt, und diese um bestimmte Erklärungen ergänzt und dadurch sozusagen zu einer "explanatorisch kohärenteren" und daher zufriedenstellenderen Gesamtposition macht. Als Argument, das einen Diskussionsgegner, der kein allgemeines Inferenzschema wie (IBE) akzeptiert, von der Überlegenheit einer so ausgebauten realistischen Position überzeugen kann, nennt Boyd nicht (genauer: in seinen neueren Ar-

\footnotetext{
${ }^{207}$ Siehe [Boyd85b], S.32f., [Boyd90a], S.385ff., [Boyd91], S.212ff.

${ }^{208}$ Mit "empiristisch" meint Boyd eine in epistemischer Hinsicht antirealistische Position wie die von van Fraassen.

${ }^{209}$ [Boyd90a], S.385ff.; die Formulierung "überlegen" ("superior to") steht auf S.386. S.a. [Boyd91], S.217.
} 
beiten nicht mehr) das Wunderargument, sondern er weist statt dessen bei verschiedenen alternativen Positionen auf (jeweils verschiedene) interne Probleme hin. ${ }^{210}$

Boyds Antwort auf den Petitio-Principii-Einwand von Laudan und Fine ist eine vielleicht nicht unplausible Reaktion, die man als Anhänger des Wunderarguments sicherlich wählen kann, sie läuft aber offenbar darauf hinaus, den Punkt des Einwandes im wesentlichen zuzugeben. Indem man das Wunderargument in den Zusammenhang einer realistischen Gesamtposition einbettet, die ein allgemeines Inferenzschema wie (IBE) einschließt und "nur noch" als ganze mit antirealistischen Gegenpositionen konfrontiert werden soll, verliert das Wunderargument seinen herausgehobenen Status als das zentrale Argument für wissenschaftlichen Realismus, der ihm zumindest von vielen seiner Anhänger zugeschrieben wird. Die Erklärungen, die das Wunderargument liefert, werden dann in das weite Feld der Erklärungen eingegliedert, die eine realistische Position einschließt, und einem Schluß auf die Erklärungen, den das Wunderargument vorsieht, kommt in der Argumentation für dieses "philosophische Paket" keine besonders ausgezeichnete Rolle mehr zu. Die Funktion, die dem Wunderargument von vielen seiner Anhänger in der Realismusdebatte zugeschrieben wird, ist jedoch die eines Angriffsarguments gegen antirealistische Positionen: Der "Appeal" des Wunderarguments scheint klarerweise an den Eindruck geknüpft, daß man antirealistische Positionen sozusagen auf neutralem Boden attackieren kann, daß das Wunderargument also nichts voraussetzt, was zwischen Realisten und Antirealisten strittig ist, und der Antirealist sich daher gezwungen sieht, den Schritt zur Konklusion des Wunderarguments mitzugehen. Diese Funktion als Angriffsargument, das auf neutralem Boden operiert, wird mit Boyds Antwort auf den Petitio-Principii-Einwand aufgegeben; wenn man Boyd folgt, verliert das Wunderargument die zentrale argumentative Rolle in der Realismusdebatte, die ihm viele seiner Anhänger zuschreiben, denn es kann dann nicht mehr den wesentlichen und entscheidenden Teil der Argumentationslast tragen, wenn es darum geht, Antirealisten von realistischen Thesen zu überzeugen.

Wenn man als Anhänger des Wunderarguments dessen argumentative Rolle nicht so weitgehend beschränken möchte wie Boyd es tut, kann man auf den Petitio-PrincipiiEinwand von Laudan und Fine auch eine andere Antwort geben. Boyds Antwort ist naheliegend und vielleicht sogar unausweichlich, wenn man, wie er, anerkennt, daß das Wunderargument als Instantiierung eines allgemeinen, kontextunabhängigen Inferenzschemas wie (IBE) aufzufassen ist und ihm daher nur dann Überzeugungskraft zukommt, wenn man dieses allgemeine Inferenzschema akzeptiert. Diese Rekonstruktion des Wunderarguments ist jedoch keineswegs zwingend oder alternativenlos. Bereits oben bei der Untersuchung der verschiedenen Versionen des Wunderarguments ${ }^{211}$ hatte sich gezeigt, daß einige davon nicht als Instantiierungen eines generellen, kontextunabhängigen Inferenzschemas der Form (IBE) rekonstruiert werden sollten, sondern plausiblerweise eher als Instantiierungen eines spezielleren Inferenzschemas mit beschränktem Anwendungs- bzw. Verläßlichkeitsbereich, etwa als Instantiierung eines Inferenzschemas der Form (IBEsp), bei dem der Bereich der Sachverhalte, die als Explanandum zählen, und die Art der dafür

\footnotetext{
${ }^{210}$ Siehe [Boyd90a], S.387ff., [Boyd91], S.217ff. Um "Empiristen" wie van Fraassen von der Überlegenheit einer realistischen Position zu überzeugen, führt Boyd an dieser Stelle eine Art Präsuppositionsargument ins Feld: "[...] accepting the realist explanation provides [...] the only justification we have for accepting the instrumental findings of science" ([Boyd90a], S.387); "[...] the empiricist who rejects abductive inferences is probably unable to avoid [...] the conclusion that the inductive inferences which scientists make about observables are unjustified" ([Boyd91], S.217). Dieses Argument ist von ganz anderer Struktur als das Wunderargument; für die Bewertung von Präsuppositionsargumenten gilt das in Kap.7, bes. in Abschnitt 7.3 und 7.4 Gesagte.

${ }^{211}$ S. Abschnitte 9.9.2, 9.9.3 und 9.9.6.
} 
vorgesehenen Erklärung genau spezifiziert werden. ${ }^{212}$ Wenn man das Wunderargument bzw. eine Version des Wunderarguments als Instantiierung eines solchen speziellen, im Vergleich zu (IBE) eingeschränkteren Inferenzschemas auffaßt, trifft einen der PetitioPrincipii-Einwand aber (im allgemeinen) offenbar nicht: Wenn man z.B. eine Version des Wunderarguments vertritt, die sich auf nPEe bezieht und für diese einen Schluß auf die beste deduktive semantische Erklärung vorsieht, und diese Version als Instantiierung eines Inferenzschemas der Form (IBEsp) auffaßt, bei dem der Anwendungsbereich (d.h. das Explanandum $F$ ) als nPEe spezifiziert wird und die Art der Erklärung als deduktive semantische Erklärung, dann setzt diese Version des Wunderarguments eben dieses spezielle Inferenzschema der Form (IBEsp) voraus, nicht das allgemeine Schema (IBE), und dieses Schema der Form (IBEsp) ist eben nur auf nPEe anwendbar und nicht auf die Erklärungsleistungen wissenschaftlicher Theorien im allgemeinen und erlaubt daher keinen Schluß auf die beste wissenschaftliche Erklärung für bestimmte physikalische, chemische etc. Phänomene. Eine so rekonstruierte Version des Wunderarguments setzt (wie jedes Argument) auch ein Inferenzschema voraus, aber keines, das das Wunderargument (in vielen Fällen) überflüssig macht, daher trifft sie der Petitio-Principii-Einwand von Laudan und Fine nicht. Entsprechendes gilt für alle Versionen des Wunderarguments, die sich als Instantiierungen eines speziellen Inferenzschemas auffassen lassen, bei dem das Explanandum und/oder die dafür vorgesehene Art von Erklärung so spezifiziert sind, daß wissenschaftliche Erklärungen nicht darunter fallen, und das sind offenbar alle vorne untersuchten Versionen. ${ }^{213}$

Die Tatsache, daß in der beschriebenen Weise rekonstruierte Versionen des Wunderarguments nicht durch den Petitio-Principii-Einwand entkräftet werden, ändert natürlich nichts daran, daß auch diese Versionen einen Diskussionsgegner nur dann überzeugen können, wenn er das Inferenzschema akzeptiert, das das Argument in Anspruch nimmt. Daß ein Antirealist das hier jeweils vorausgesetzte Schema der Form (IBEsp) akzeptiert, ist zwar, anders als bei (IBE), nicht schon deswegen unplausibel, weil damit das Wunderargument überflüssig würde, aber es ist deswegen offenbar nicht selbstverständlich. Ob ein antirealistischer Diskussionsgegner dies tut, muß man grundsätzlich im Einzelfall sehen; zu erwarten ist im Fall eines speziellen Inferenzschemas der Form (IBEsp), daß es von reflektierten und "hinreichend konsequenten" Antirealisten nicht akzeptiert wird, bei weniger konsequenten Antirealisten und bei Personen, die (noch) keine systematisch entwickelte Position in der Realismusdebatte bezogen haben, ist denkbar, daß sie es akzeptieren. Wenn ein Diskussionsgegner das jeweils in Anspruch genommene Inferenzschema nicht akzeptiert, steht man vor der Aufgabe, dieses Schema seinerseits zu begründen, und diese Aufgabe ist natürlich noch offen, wenn man den Petitio-Principii-Einwand von Laudan und Fine in der beschriebenen Weise zurückgewiesen hat.

Dieses weiterreichende Begründungsproblem, mit dem sich ein Anhänger des Wunderarguments auch dann konfrontiert sehen kann, wenn er es mit Hilfe eines speziellen, beschränkten Inferenzschemas der Form (IBEsp) rekonstruiert, ${ }^{214}$ ist von sehr allgemeiner Art: Jedes Argument nimmt eine Inferenzregel in Anspruch, die evtl. vom Diskussionsgegner nicht akzeptiert wird und dann begründet werden muß, damit das Argument überzeu-

\footnotetext{
${ }^{212}$ Siehe S.236.

${ }^{213}$ Bei der Version von Boyd sieht dies vielleicht prima facie am problematischsten aus, da dort kausale Erklärungen involviert sind, die von der gleichen Art sind wie andere wissenschaftliche Erklärungen, aber auch für Boyds Version sollte sich ein "geeignetes" Inferenzschema finden lassen, das den Petition-PrincipiiEinwand entkräftet, indem man das Explanandum hinreichend genau spezifiziert.

${ }^{214}$ Dasselbe Problem kann natürlich prinzipiell auch bei (IBE) auftreten, denn auch ein generelles Inferenzschema kann man hinterfragen. Begründungen hierfür finden sich in der Literatur kaum; Musgrave etwa bemerkt dazu nur, (IBE) sei "not obviously mistaken" ([Musg88], S.238).
} 
gen kann. Zur Begründung eines Inferenzschemas der Form (IBEsp) kommt vielleicht am ehesten ein Kontinuitätsargument ${ }^{215}$ in Frage: Man könnte versuchen, ein solches Schema induktiv zu begründen, indem man sich Fälle zurechtlegt, die unter die Beschreibung des jeweiligen Explanandums fallen und in denen das zugehörige Explanans durch Beobachtung mit dem bloßen Auge zugänglich ist, und anhand dieser Fälle die Verläßlichkeit des Inferenzschemas testet, also das Schema induktiv "im Beobachtbaren" etabliert, und anschließend den Verläßlichkeitsbereich vorsichtig in den Bereich des Unbeobachtbaren "extrapoliert". 216

Fälle, die sich für eine Argumentationsstrategie dieser Art eignen, sollten sich im Bereich der Alltagswelt einige finden lassen. Vorstellbar sind z.B. für ein Inferenzschema, das sich auf nPEe als Explananda bezieht, Fälle wie der folgende (konstruierte): Nachdem die Person A infolge einer Pilzmahlzeit gestorben ist, und zwar, wie die chemische Untersuchung der Essensreste ergeben hat, an einem einzelnen Pilz einer sehr seltenen, schwer zu erkennenden Art, die zudem nur in einem bestimmten, kurzen Stadium der Reifung tödlich wirkt, entwickelt Sherlock Holmes aufgrund der vorliegenden Indizien die Hypothese, daß der seit zwanzig Jahren im Haus angestellte Butler A umgebracht hat, indem er den Giftpilz vorsätzlich in das Essen gemischt hat. Diese Hypothese impliziert allerdings, daß der Butler die sehr speziellen botanischen bzw. biochemischen Kenntnisse hatte, die dazu nötig sind, was wenig wahrscheinlich scheint, weil es sich dabei zwar um biochemisches Standard-Lehrbuchwissen handelt, das jedoch Laien gewöhnlich unzugänglich ist. Sherlock Holmes erfährt dann überraschend, daß der Butler vor seiner Butler-Karriere eine Forscherkarriere als Biochemiker begonnen hatte, die er dann jedoch aufgrund einer skandalösen persönlichen Verfehlung abbrechen mußte, und seitdem eine zurückgezogene Butler-Existenz geführt hat, und somit höchstwahrscheinlich das fragliche biochemische Wissen hat. Die beste (deduktive semantische) Erklärung für diesen überraschenden Prognoseerfolg von Holmes' "Theorie" ist, daß sie wahr ist; Holmes schließt daher, daß sie es ist. Seine Überzeugung wird durch das Geständnis des Butlers bestätigt.

Mit genügend Phantasie sollten sich eine Reihe von Fällen dieser oder ähnlicher Art aufweisen lassen, die für eine induktive Begründung der verschiedenen in den diversen Versionen des Wunderarguments in Anspruch genommenen Inferenzschemata der Form (IBEsp) herangezogen werden können, vielleicht auch nicht nur "alltagsweltliche" Beispiele wie das genannte, sondern auch welche, die Erfolge wissenschaftlicher Theorien (über Beobachtbares) involvieren. Denkbar wären z.B. Erfolge von Theorien über den Aufbau, die Geologie etc. anderer Planeten, die zwar derzeit noch nicht, aber vielleicht irgendwann in der Zukunft durch direkte Beobachtung bestätigt werden können, oder Erfolge analoger historischer Theorien über die Erde. Wenn eine solche Begründung "im Beobachtbaren" gelingt und es für die Schlüsse ersichtlich keine Rolle spielt, ob die erschlossenen Explanantia sich auf Beobachtbares oder auf Unbeobachtbares beziehen, kann man vielleicht auch einen induktiven "Extrapolationsschluß" plausibel machen, der sozusagen über die Grenze beobachtbar/unbeobachtbar hinausführt, also das fragliche Inferenzschema auch für diesen Bereich etabliert. Um diese Argumentationsstrategie zu realisieren, müßten offenbar umfangreiche Untersuchungen konkreter Inferenzschemata anhand von alltagsweltlichen Anwendungsfällen und auch anhand ihrer Anwendung auf Erfolge aktueller und vor allem historischer wissenschaftlicher Theorien durchgeführt werden. Solche Untersuchungen finden sich in der Literatur (derzeit) nicht und sie können auch an dieser Stelle nicht durchgeführt werden. Prima facie sieht eine solche Begründungsstrategie nicht aussichts-

\footnotetext{
${ }^{215}$ Vgl. Kap.8.

${ }^{216}$ Vgl. die in Kap.8 diskutierten Argumente dieser Struktur.
} 
los aus, andererseits ist aber auch nicht klar, daß sie erfolgreich realisiert werden kann; als Anhänger des Wunderarguments kann man aber beim derzeitigen Stand der Dinge jedenfalls plausiblerweise hoffen, daß zumindest das eine oder andere speziellen Inferenzschema der Form (IBEsp) und damit wenigstens die eine oder andere Version des Wunderarguments auf diesem Weg begründet werden kann.

Falls sich auf diese Weise ein induktives Argument für ein Inferenzschema gewinnen läßt, kann dies von einem Diskussionsgegner wiederum zurückgewiesen werden, weil dieses Argument seinerseits irgendein induktives Inferenzschema in Anspruch nimmt und dieses von antirealistischer Seite nicht akzeptiert wird oder jedenfalls nur, sofern die Konklusionen Beobachtbares zum Inhalt haben. Wenn die Debatte zwischen Anhängern des Wunderarguments und antirealistischen Gegnern an diesem Punkt angelangt ist, hat man offenbar die bereits oben bei der Diskussion der Kontinuitätsargumente vorgefundene argumentative Konstellation erreicht, in der die antirealistische Seite einen Einwand einsetzt, mit dessen Hilfe sie jedes Argument der realistischen Seite zurückweisen kann. Für die Bewertung dieses fundamentalen antirealistischen Einwandes gilt das oben Gesagte. ${ }^{217}$

Fazit: Wenn man das Wunderargument als Instantiierung eines generellen Inferenzschemas der Form (IBE) auffaßt, wird es durch den Petitio-Principii-Einwand von Laudan und Fine als für die Realismusdebatte weitgehend wirkungslos erwiesen, wie Boyd in seiner Reaktion effektiv einräumt. Man kann dem Petitio-Principii-Einwand jedoch ausweichen, wenn man das Wunderargument mit Hilfe eines spezielleres Inferenzschemas der Form (IBEsp) rekonstruiert. Es bleibt dann evtl. die Aufgabe, dieses speziellere Inferenzschema zu begründen; dies kann grundsätzlich induktiv durch ein Kontinuitätsargument der skizzierten Art geschehen. Zu entscheiden, ob und, wenn ja, inwieweit tatsächlich für die diversen Versionen des Wunderarguments eine solche Begründung für das entsprechende Inferenzschema gefunden werden kann, erfordert umfangreichere Untersuchungen als an dieser Stelle möglich sind und muß daher hier offen bleiben. Falls das Resultat solcher Untersuchungen positiv ist, kann von antirealistischer Seite noch der genannte fundamentale Einwand erhoben werden, dies ist jedoch kein "Spezialproblem" des Wunderarguments mehr, sondern die bereits oben bei der Diskussion der Kontinutitätsargumente vorgefundene allgemeine argumentative Konstellation zwischen Realisten und Antirealisten. Wie der Wert des Wunderargument angesichts dieses fundamentalen Einwandes zu beurteilen ist, ist, wie schon im Fall der Kontinuitätsargumente, nicht ohne eingehendere Untersuchungen grundsätzlicher erkenntnistheoretischer Art zu entscheiden.

\subsubsection{In welchem Sinn sind die Explananda, auf die sich das Wunderar- gument bezieht, erklärungsbedürftig oder "wundersam" und wel- che argumentative Rolle spielen die Inanspruchnahme von Er- klärungsbedarf und die Rede von "Wunder"?}

\section{Zweifel am Erklärungsbedarf bei den Explananda des Wunderarguments und an dessen argumentativer Relevanz}

Ein Einwand, der gelegentlich einigen Versionen des Wunderarguments entgegengehalten worden ist, besteht darin zu bestreiten, daß bei deren Explananda tatsächlich ein Erklärungsbedarf besteht, oder jedenfalls, daß ein solcher Erklärungsbedarf argumentativ irgendetwas austrägt. Van Fraassen etwa weist darauf hin ${ }^{218}$, daß man im Bereich der

\footnotetext{
${ }^{217}$ Siehe S.173ff.

${ }^{218}$ Siehe [vFra80], S.23ff.
} 
Wissenschaften nicht alle Korrelationen, Koinzidenzen u.ä. erklären kann und braucht; er verweist in diesem Zusammenhang auf die Quantenmechanik, die EPR-Korrelationen als brute facts unerklärt stehen läßt, auch wenn sie vielleicht von einigen intuitiv als erklärungsbedürftig empfunden werden. Nach van Fraassens Ansicht spricht nichts dagegen, die "kosmischen Koinzidenzen", auf die sich Smarts Version des Wunderarguments bezieht, ${ }^{219}$ sprich: die Vereinheitlichungsleistungen von Theorien, ebenso als unerklärte brute facts hinzunehmen. Van Fraassen bestreitet also, daß solche Koinzidenzen erklärungsbedürftig sind, oder jedenfalls, daß sich daraus für die Argumentation für wissenschaftlichen Realismus Kapital schlagen läßt.

Dieser Einwand sieht wenig überzeugend oder sogar unverständlich aus, wenn man die Versionen des Wunderarguments so rekonstruiert wie oben vorgeschlagen. Jede solche Version, z.B. die von Smart, ist in dieser Rekonstruktion ein Argument, das ein (mehr oder weniger genau) spezifiziertes und mehr oder weniger spezielles Inferenzschema der Form (IBEsp) in Anspruch nimmt, in dem von Erklärungsbedarf (oder auch von "Wundern") keine Rede ist. Wenn ein Sachverhalt die mit diesem Inferenzschema verbundene Beschreibung für das Explanandum erfüllt und außerdem eine Erklärung vorliegt, die die entsprechenden Bedingungen erfüllt, dann gestattet das Inferenzschema einen Schluß auf das Explanans dieser Erklärung; wenn man das Inferenzschema akzeptiert, kann man diesen Schluß in einer entsprechenden Situation ziehen. Aus dieser Perspektive betrachtet sieht der Einwand, daß in dieser Situation kein Erklärungsbedarf besteht, völlig irrelevant aus, genau wie jemand, der die beiden Überzeugungen hat, daß $P$ und daß $P \rightarrow Q$, und das Inferenzschema Modus ponens akzeptiert, den Einwand als völlig irrelevant ansehen wird, daß in dieser Situation kein "Deduktionsbedarf", kein "Bedarf" für die Konklusion $Q$ o.ä. vorliegt.

An dieser Reaktion auf den Einwand ist per se nichts Falsches, sie trifft aber vielleicht nicht seinen Punkt. Van Fraassen zumindest richtet diesen Einwand gegen Smart, der nicht explizit macht, warum einen die Tatsache, daß das in seiner Version des Wunderarguments vorgesehene Explanans eine bzw. die beste Erklärung für die Vereinheitlichungsleistungen von Theorien liefert, dazu veranlassen soll, dieses Explanans als Überzeugung zu akzeptieren, und der jedenfalls kein Inferenzschema wie (IBEsp) angibt, als dessen Instantiierung ein solcher Schluß angesehen werden soll. Plausiblerweise sollte man den Einwand von van Fraassen daher vielleicht dahingehend auffassen, daß er die Begründung oder Rechtfertigung dieses Schlusses betrifft, und wenn man die obige Rekonstruktion des Wunderarguments voraussetzt, heißt das, daß er die Begründung oder Rechtfertigung des jeweiligen Inferenzschemas der Form (IBEsp) betrifft: Die These, daß bei den Erfolgen oder Leistungen, die das Explanandum (einer Version) des Wunderarguments kein Erklärungsbedarf besteht, müßte danach in irgendeiner Weise mit einer Begründung oder Rechtfertigung eines Inferenzschemas der Form (IBEsp) im Konflikt stehen. Auch für einen solchen Konflikt scheint die obige Rekonstruktion des Wunderarguments keinen Ansatzpunkt zu bieten, denn zumindest prima facie ist nicht zu sehen, welche Rolle das Vorliegen (oder Nichtvorliegen) von Erklärungsbedarf für die Begründung der Inferenzschemata spielen sollte. Dieser Befund genügt jedoch vielleicht noch nicht, um den Einwand in überzeugender Weise als irrelevant zu erweisen, denn er berührt, indem er im Fall der Explananda des Wunderarguments Erklärungsbedarf leugnet, klarerweise einen Aspekt des Wunderarguments, der in der bisherigen Rekonstruktion noch nicht in angemessener Weise berücksichtigt ist.

\footnotetext{
${ }^{219}$ Siehe S.187.
} 


\section{Ein vernachlässigter Aspekt des Wunderarguments: Die Inanspruchnahme von Erklärungsbedarf und die Rede von "Wunder" und deren argumentative Funk- tion}

Die Erklärungen, um die es beim Wunderargument geht, haben zumindest in einigen Versionen des Arguments nach Ansicht von deren Anhängern die besondere Eigenschaft, daß sie einen als dringlich präsentierten Erklärungsbedarf decken oder sogar ein Wunder "zum Verschwinden bringen" können. Diese Funktion der für Theorieerfolge etc. vorgesehenen Erklärungen wird von vielen, wenn auch nicht von allen Anhängern des Wunderarguments herausgestrichen und scheint ihrer Ansicht nach wesentlich zu sein für den Appeal des Wunderarguments, für den, wie Fine sich ausdrückt, "strong, almost primitive pull" ${ }^{220}$, den das Wunderargument häufig auch (oder gerade) auf Nicht-Philosophen ausübt, denen man es präsentiert. Beim Wunderargument involvierte Erklärungen unterscheiden sich dadurch von Erklärungen im allgemeinen: Eine wissenschaftliche Erklärung etwa kann im Einzelfall einen als dringlich empfundenen Erklärungsbedarf decken oder gar ein Wunder "wegerklären", dies muß aber sicherlich nicht so sein, und es sind in der Praxis auch nicht nur wundersame oder sonstwie als stark erklärungsbedürftig wahrgenommene Sachverhalte, für die man wissenschaftliche Erklärungen konstruiert und akzeptiert. Beim Wunderargument dagegen, oder zumindest bei einigen seiner Versionen, scheint die intuitive Überzeugungskraft des Arguments, das einen dazu bringen soll, das Explanans als Überzeugung zu akzeptieren, entscheidend davon abzuhängen, daß erstens das Explanandum als stark erklärungsbedürftig oder sogar als wundersam betrachtet wird (nicht nur als erklärbar oder als etwas in irgendeinem schwachen Sinn "zu erklärendes") und daß zweitens die Erklärung den Erklärungsbedarf deckt bzw. das Wunder zum Verschwinden bringt — oder zumindest legen die Ausführungen einiger Anhänger des Wunderarguments einen Eindruck dieser Art nahe. Diese Besonderheit der Erklärungen, von denen das Wunderargument bzw. einige seiner Versionen handeln, ist in deren Rekonstruktion bisher nicht eingegangen.

Um den genannten, u.a. von van Fraassen vorgebrachten Einwand in begründeter Weise $\mathrm{zu}$ bewerten, aber auch um generell eine in jeder Hinsicht klare und angemessene Rekonstruktion des Wunderarguments zu gewinnen, ist es erforderlich, die beschriebene Besonderheit der involvierten Erklärungen genauer in den Blick zu nehmen, also die Frage zu untersuchen, welche argumentative Rolle die Inanspruchnahme von Erklärungsbedarf und die Rede von "Wundern" beim Wunderargument genau spielen. Dies wiederum erfordert, sich Klarheit darüber zu verschaffen, in welchem Sinn die Explananda, auf die sich das Wunderargument bezieht, erklärungsbedürftig oder "wundersam" sind.

Die Anhänger des Wunderarguments, die betonen und herausstreichen, daß dessen Explanandum erklärungsbedürftig oder sogar wundersam ist, erklären nicht explizit, worin der Erklärungsbedarf bzw. das Wunder bestehen. Sie beschränken sich meistens darauf, ihr Explanandum als erklärungsbedürftig bzw. wundersam zu präsentieren, d.h. an entsprechende Intuitionen zu appellieren; gelegentlich werden auch erläuternde Beispiele und Analogien angeführt, um dies plausibel zu machen. ${ }^{221}$ Entsprechend wird auch nicht explizit erklärt, wie und warum, sondern lediglich als intuitiv plausibel in Anspruch genommen, daß das von der jeweiligen Version des Wunderarguments vorgesehene Explanans den angemeldeten Erklärungsbedarf tatsächlich deckt bzw. das Wunder zum Verschwinden bringt. Man ist daher darauf angewiesen, sich selbst eine möglichst plausible Lesart der Inanspruchnahme von Erklärungsbedarf und der Redeweisen von Wundern zurechtzulegen.

\footnotetext{
${ }^{220}[$ Fine86b], S.153.

${ }^{221}$ Siehe z.B. [Musg88], S.231/232.
} 
Dazu empfiehlt es sich, sich zunächst anzusehen, unter welchen Umständen man im allgemeinen von Erklärungsbedarf oder von einem Wunder spricht und in welcher Weise solcher Erklärungsbedarf gedeckt werden und ein Wunder "wegerklärt" bzw. zum Verschwinden gebracht werden kann.

\section{Wann spricht man im allgemeinen von Erklärungsbedarf oder von einem Wun- der?}

Wenn jemand einen Sachverhalt ${ }^{222}$ als erklärungsbedürftig einstuft, sagt er damit, daß dafür in der Gesamtheit seiner Überzeugungen keine Erklärung (einer bestimmten Art) vorhanden ist, er dafür aber eine Erklärung (dieser Art) benötigt oder wünscht. Er setzt dabei voraus, daß es dafür eine Erklärung (dieser Art) gibt, daß der Sachverhalt also erklärbar ist, d.h. er hat eine Überzeugung (zweiter Ordnung), daß es einen anderen Sachverhalt gibt, der eine Erklärung für den erklärungsbedürftigen Sachverhalt liefert. Daß jemand eine Erklärung benötigt oder wünscht, kann verschiedene Gründe haben, praktische, aber auch von praktischen Erwägungen unabhängige, etwa ein Bedürfnis, die eigene Gesamtheit von Überzeugungen (in bestimmter Hinsicht, in bestimmten Bereichen o.ä.) "explanatorisch kohärent" zu halten, also in einen Zustand zu bringen oder darin zu halten, in dem es keine, möglichst wenige o.ä. Überzeugungen über Sachverhalte (bestimmter Art, in bestimmten Bereichen o.ä.) einschließt, die sozusagen nicht durch Erklärungen (einer bestimmten Art) an den Rest des Überzeugungssystems angeknüpft sind. ${ }^{223}$

Was jemand sagt, der einen Sachverhalt als Wunder einstuft, ist weniger einfach zu erläutern. Für den Ausdruck 'Wunder' gibt es historisch und auch heute verschiedene, zum Teil nicht scharf voneinander abgrenzbare Verwendungsweisen. Grob lassen sich zunächst religiöse von nicht-religiösen Verwendungsweisen des Ausdrucks 'Wunder' unterscheiden. In religiösen Kontexten wird als Wunder meistens ein Sachverhalt bezeichnet, der auf einen Eingriff (eines) Gottes zurückzuführen ist, der die natürliche Ordnung, die Naturgesetze o.ä. durchbricht, und der dazu dient, eine religiöse Lehre oder Botschaft, einen "besonderen" Status einer Person o.ä. zu etablieren. Seltener bezeichnet man als Wunder auch einen Sachverhalt, der zwar kein Naturgesetz o.ä. durchbricht, aber dennoch zur Etablierung einer religiösen Lehre, Botschaft o.ä. dient, z.B. "Koinzidenzen" besonderer, als bedeutsam empfundener Art. ${ }^{224}$ Solche religiösen Verwendungsweisen spielen für den hier interessierenden Kontext des Wunderarguments keine Rolle.

Neben den religiösen gibt es nicht-religiöse oder zumindest nicht auf religiöse Kontexte beschränkte Verwendungsweisen, die sich kaum in präziser Weise allgemein charakterisieren lassen. Die Encylopaedia Britannica gibt dafür eine treffende, weil den angemessenen Grad an Unschärfe aufweisende Charakterisierung an:

"A miracle is generally defined [...] as that which causes wonder and astonishment, being extraordinary in itself and amazing or inexplicable by normal standards." 225

\footnotetext{
${ }^{222}$ Hier und im folgenden werden der Kürze halber explizit nur Sachverhalte als erklärungsbedürftig genannt; implizit sollen damit auch Ereignisse, Prozesse etc. erfaßt sein.

${ }^{223}$ Ein Bedürfnis dieser Art scheint etwa McMullin zum Ausdruck zu bringen, indem er über van Fraassens Position schreibt: "[I]t does require the sort of tolerance for the unexplained that empiricists of the eliminationist variety must possess in abundance" ([McMu94], S.100).

${ }^{224} \mathrm{Zu}$ diesen Verwendungsweisen von 'Wunder' siehe z.B. [Hard54, Holl65].

${ }^{225}$ [EnBr86].
} 
Diese "Definition" deutet offenbar verschiedene Möglichkeiten an, wie ein Sachverhalt "wonder and astonishment" verursachen kann, spezifiziert diese Möglichkeiten jedoch nicht im einzelnen. Wenn im Diskussionszusammenhang des Wunderarguments der Einstufung eines Sachverhalts als Wunder bzw. wundersam eine argumentative Funktion zukommen soll, dürfte dies eine genauere Spezifikation erfordern, wodurch und in welchem Sinn der Sachverhalt "wonder and astonishment" verursacht, warum er also als Wunder bzw. wundersam zählt, denn eine Einstufung als Wunder bzw. wundersam, die nicht genauer erläutert wird als es die obige "Definition" tut, dürfte kaum argumentativ interessante Schlüsse ermöglichen.

Wodurch und in welchem Sinn kann ein Sachverhalt, der als Explanandum des Wunderarguments fungiert, "wonder and astonishment" verursachen und daher als Wunder erscheinen?

Für den Diskussionszusammenhang des Wunderarguments in Frage kommende Möglichkeiten, wodurch und in welchem Sinn ein Sachverhalt "wonder and astonishment" verursachen kann, sind die folgenden: ${ }^{226}$

Wundersam, weil einem Naturgesetz o.ä. widersprechend: Ein neu eingetretener oder bekannt gewordener Sachverhalt kann "wonder and astonishment" verursachen, weil $\mathrm{er}^{227}$ im Widerspruch steht zu bereits akzeptierten Überzeugungen, die ein Naturgesetz zum Inhalt haben, den Normalverlauf eines natürlichen Vorgangs oder Prozesses oder andere Regelmäßigkeiten allgemeiner Natur, indem er also in diesem epistemischen Sinn ein Naturgesetz verletzt, eine Regelmäßigkeit durchbricht o.ä.

Wundersam, weil epistemisch unwahrscheinlich: Ein Sachverhalt kann in einem anderen Sinn "wonder and astonishment" hervorrufen, wenn er unwahrscheinlich ist, bevor er eintritt oder bevor man Kenntnis von ihm erlangt. Diese Erläuterung setzt voraus, daß man dem fraglichen Sachverhalt bzw. einem entsprechenden Satz eine Wahrscheinlichkeit zuschreibt. In diesem Sinn kann man einen Sachverhalt als wundersam betrachten, wenn er vor seinem Eintreten bzw. Bekanntwerden einen Wahrscheinlichkeitswert von null oder fast null hat. Für die Zuschreibung solcher Wahrscheinlichkeiten kommt vor allem ein subjektiver oder epistemischer Wahrscheinlichkeitsbegriff in Frage, der den Überzeugunggrad der jeweiligen Person angibt. ${ }^{228}$ Die epistemische Wahrscheinlichkeit eines wundersamen Sachverhaltes springt dann mit dessen Eintreten bzw. Bekanntwerden von null oder fast null auf eins oder einen Wert nahe eins; nach diesem Sprung stellen sich "wonder and astonishment" ein. ${ }^{229}$

${ }^{226}$ Mit dieser Liste ist kein Anspruch auf Vollständigkeit im Hinblick auf die Verwendungsweisen des Ausdrucks 'Wunder' verbunden; es sollen jedoch die im Zusammenhang mit dem Wunderargument relevanten Möglichkeiten erfaßt sein, wodurch und in welchem Sinn ein Sachverhalt "wonder and astonishment" hervorrufen kann, bei denen die Rede von einem "Wunder" einen einigermaßen greifbaren Gehalt hat.

${ }^{227}$ Genaugenommen: eine Überzeugung, die ihn zum Inhalt hat.

${ }^{228}$ S. Kap.9.7.

${ }^{229}$ Die Erläuterung der "Wundersamkeit" eines Sachverhaltes durch einen solchen Sprung einer epistemischen Wahrscheinlichkeit entspricht der Idee hinter Peter Gärdenfors' Definition eines "surprise value" (siehe [Gard88], Kap.8; s.a. [Salm92], S.73). Die Fälle, die unter die erste Erläuterung, was ein Wunder ist, fallen, lassen sich als Grenzfälle der unter die zweite Erläuterung fallenden auffassen, falls man Sachverhalte mit der epistemischen Wahrscheinlichkeit null bzw. fast null und für falsch gehaltene Sachverhalte identifiziert (siehe aber Fn.101).

Ob man einen exakten Schwellwert dafür festlegen kann und sollte, was als epistemische Wahrscheinlichkeit "fast null" zählt, und, wenn ja, welchen, muß ggf. im einzelnen erörtert werden, kann aber hier 
Wundersam, weil objektiv unwahrscheinlich: Ein Sachverhalt kann in einem anderen Sinn "wonder and astonishment" hervorrufen, wenn er in einem objektiven Sinn unwahrscheinlich war, bevor er eintrat oder bevor man Kenntnis von ihm erlangt hat, d.h. wenn er einen Wahrscheinlichkeitswert null oder fast null hatte, der einer relativen Häufigkeit oder einer Propensität entspricht.

Wundersam, weil nicht erklärbar: In einer weiteren Weise kann ein Sachverhalt "wonder and astonishment" verursachen (auch ohne anderen Überzeugungen zu widersprechen oder einen geringen oder überhaupt einen Wahrscheinlichkeitswert zu haben), wenn man die Überzeugung (zweiter Ordnung) hat, daß es für ihn eine Erklärung einer bestimmten Art gibt (genauer: einen Sachverhalt, der für ihn eine Erklärung dieser Art liefert), aber feststellt, daß diese Überzeugung im Widerspruch zu anderen "relevanten" Überzeugungen (erster Ordnung) steht. ${ }^{230}$

offen bleiben. Klar ist aber, daß mit "fast null" nicht ein Wahrscheinlichkeitswert (exakt oder ungefähr) $1 / 2$ gemeint ist, denn eine epistemische Wahrscheinlichkeit 1/2 steht, intuitiv gesprochen, nicht für einen epistemisch unwahrscheinlichen Sachverhalt, sondern für einen Sachverhalt, für dessen Vorliegen genauso viel oder wenig spricht wie dagegen, also für einen Sachverhalt, bezüglich dessen man nicht über (relevante) Informationen, Evidenzen o.ä. verfügt. (Ein Beispiel ist etwa die Geradzahligkeit der Anzahl der Münzen in meinem Geldbeutel: Wenn ich (bevor ich sie nachzähle) keinerlei Hinweise habe, ob ihre Anzahl gerade ist oder ungerade, ordne ich beiden Sachverhalten epistemische Wahrscheinlichkeiten 1/2 zu.) Das Eintreten oder Bekanntwerden eines Sachverhaltes mit einer Wahrscheinlichkeit (ungefähr) 1/2 kann man vielleicht als unvorhergesehen, unerwartet o.ä. auffassen, aber es ist intuitiv nicht angemessen, es als Wunder zu bezeichnen (jedenfalls nicht im allgemeinen, nicht qua Sachverhalt mit der Wahrscheinlichkeit 1/2).

Eine hier nicht eigens angeführte Erläuterung von 'Wunder', die der obigen, die auf epistemische Wahrscheinlichkeiten Bezug nimmt, verwandt ist, ist eine, bei der statt Wahrscheinlichkeitswerten qualitative epistemische Bewertungen von Sachverhalten vorausgesetzt werden, die sozusagen eine Vergröberung von Wahrscheinlichkeitswerten darstellen, z.B. Bewertungen von Sachverhalten als wahrscheinlich zu erwarten (oder nicht), fast sicher (oder fast ausgeschlossen), möglich, aber weder sicher noch ausgeschlossen, u.ä. Ein Sachverhalt kann in diesem Sinn "wonder and astonishment" verursachen, wenn er eintritt oder wenn man Kenntnis von ihm erlangt, wenn er zuvor als nicht zu erwarten, fast ausgeschlossen o.ä. eingestuft wurde. Um eine auf dieser Erläuterung basierende Lesart des Wunderarguments zu konstruieren, müßte mindestens die "Dynamik" der qualitativen Bewertungen spezifiziert werden; für eine solche Lesart würde, mutatis mutandis, das gelten, was im folgenden zur Erläuterung "wundersam, weil epistemisch unwahrscheinlich" gesagt wird.

${ }^{230}$ Als nicht erklärbar und daher als wundersam in diesem Sinn kann ein Sachverhalt etwa dann erscheinen, wenn man für eine Gruppe gleichartiger oder ähnlicher Sachverhalte jeweils eine Erklärung einer bestimmten Art kennt und deswegen überzeugt ist, daß es für alle Sachverhalte dieser Art eine solche Erklärung gibt, und man dann aber feststellt, daß alle in Frage kommenden Explanantia zu anderen Überzeugungen (erster Ordnung) im Widerspruch stehen. Zwei Beispiele: 1) Sherlock Holmes ist sicher, daß einer der auf dem Schloß anwesenden Personen den Grafen in der Nacht umgebracht hat, daß es also für den Tod des Grafen eine entsprechende kausale Erklärung gibt. Andererseits zeigt sich, daß jede dieser Personen ein hieb- und stichfestes Alibi hat. 2) Ein Mediziner ist davon überzeugt, daß der Ausbruch einer neuen Tropenkrankheit, die durch Körperkontakt übertragen wird und auch sonst alle äußeren Merkmale einer Infektionskrankheit zeigt, durch ein Bakterium oder einen Virus zu erklären ist. Sorgfältige Untersuchungen des Blutes, Gewebes etc. von Kranken ergeben jedoch, daß dort keinerlei Erreger vorhanden ist.

Dafür, daß ein Sachverhalt wundersam in diesem Sinn ist (im Unterschied zu erklärungsbedürftig im oben erläuterten Sinn), ist wesentlich, daß man für ihn nicht nur keine Erklärung kennt, sondern darüberhinaus Überzeugungen (erster Ordnung) hat, die im Widerspruch zu der Annahme stehen, daß es eine Erklärung gibt, denn Fälle, in denen ich keine Erklärung kenne, weil ich mir nicht die Mühe gemacht habe, über in Frage kommende Erklärungen nachzudenken, weil ich kontingenterweise nicht in der Lage bin, die in Frage kommenden Möglichkeiten näher zu untersuchen o.ä., sind klarerweise nicht wundersam. Sie wären unerklärt und vielleicht auch erklärungsbedürftig, aber ich hätte keinen Grund, sie als nicht erklärbar und daher wundersam einzustufen. 
Von diesen vier auf den ersten Blick für den Diskussionszusammenhang des Wunderarguments in Frage kommenden Möglichkeiten, wodurch und in welchem Sinn ein Sachverhalt "wonder and astonishment" verursachen kann, kann die dritte bereits auf den zweiten Blick beiseite gelegt werden. Um dem Explanandum (einer Version) des Wunderarguments, also ePEen, nPEen, Handlungserfolgen, Vereinheitlichungsleistungen etc., eine objektive Wahrscheinlichkeit null oder fast null zuzuschreiben, muß man, wenn es sich bei den Wahrscheinlichkeiten um relative Häufigkeiten handeln soll, in einigermaßen genauer Weise Referenzklassen für die Häufigkeiten spezifizieren, wenn es sich um Propensitäten handeln soll, entsprechend Systeme, Zustände o.ä., denen diese Dispositionseigenschaften zukommen. Wie solche objektiven Wahrscheinlichkeiten in einer Weise zu spezifizieren oder zu explizieren sein sollten, die wenigstens ungefähr den Intuitionen entspricht, die der Rede von "Wunder" auf Seiten der Anhänger des Wunderarguments zugrundezuliegen scheinen, ist nicht zu sehen.

Ein Gedanke, der vielleicht naheliegt und aussichtsreich aussehen könnte, ist, geeignete objektive Wahrscheinlichkeiten über die Gesamtheit der empirischen Konsequenzen einer bzw. mehrerer Theorien zu erläutern. Z.B. könnte man versuchen, die Wahrscheinlichkeit für einen ePE einer bestimmten Theorie zu erläutern als die relative Häufigkeit wahrer Beobachtungssätze in der Gesamtheit der empirischen Konsequenzen dieser Theorie; da eine falsche Theorie wahre und falsche Konsequenzen hat, eine wahre Theorie dagegen nur wahre Konsequenzen (und damit weniger falsche als eine falsche Theorie), sollte die relative Häufigkeit wahrer Beobachtungssätze in der Gesamtheit der empirischen Konsequenzen einer wahren Theorie trivialerweise eins sein, bei einer falschen Theorie jedenfalls kleiner und vielleicht sehr klein. Entsprechend sollte es bei einer falschen Theorie seltener vorkommen, daß eine "zufällig herausgegriffene" ihrer empirischen Konsequenzen wahr ist als bei einer wahren Theorie. Für sich genommen ergibt diese Idee noch keine zur Erläuterung des Wunderarguments tauglichen Wahrscheinlichkeiten, da man in der Situation, in der man z.B. einen ePE für unwahrscheinlich hält, i.a. keine Überzeugung hat, ob die prognostizierende Theorie wahr oder falsch ist, aber man könnte vielleicht daran denken, sie auszubauen, indem man auf so etwas wie die Gesamtheit aller Theorien des fraglichen Gegenstandsbereichs Bezug nimmt, d.h. die Wahrscheinlichkeit für einen ePE zu erläutern als die relative Häufigkeit wahrer Beobachtungssätze in der Gesamtheit der empirischen Konsequenzen aller Theorien des fraglichen Gegenstandsbereichs: Diese relative Häufigkeit sollte sehr klein sein, sofern es mehr falsche als wahre Theorien geben sollte und, wie schon erwähnt, eine falsche Theorie mehr falsche als wahre empirische Konsequenzen haben sollte. In diesem Sinn könnten ePEe vielleicht objektiv unwahrscheinlich und daher wundersam sein.

Dieser Gedanke sieht prima facie vielleicht plausibel aus, aber wenn man versucht, ihm eine präzise und haltbare Gestalt zu geben, stößt man zum einen auf das Problem, daß jede einzelne Theorie unendlich viele empirische Konsequenzen hat und nicht ersichtlich ist, wie für diese in angemessener Weise relative Häufigkeiten zu spezifizieren wären, die die skizzierte Idee "implementieren", zum anderen ist natürlich völlig unklar, was mit einer Gesamtheit aller Theorien (eines Gegenstandsbereichs) gemeint sein könnte. Für die Explananda der anderen Versionen des Wunderarguments, auf die sich diese Idee übertragen lassen könnte, gilt mutatis mutandis dasselbe. Die skizzierte Idee, mittels objektiver Wahrscheinlichkeiten zu erläutern, was wundersam ist an den Explananda des Wunderarguments, scheint, obwohl sie auf den erste Blick vielleicht plausibel aussieht, auf den zweiten Blick nicht in einer haltbaren Weise formulierbar zu sein. 
Bei den anderen drei der vier genannten Möglichkeiten, wodurch und in welchem Sinn ein Sachverhalt "wonder and astonishment" verursachen kann, stößt ihre "Anwendung" auf das Wunderargument nicht auf Probleme dieser Art. Bevor diese drei Möglichkeiten näher in den Blick genommen werden, empfiehlt es sich jedoch, sich allgemein anzusehen, wie und wodurch ein Wunder "wegerklärt" werden, d.h. durch eine Erklärung zum Verschwinden gebracht werden kann, und außerdem auch, was es heißt, daß ein bestehender Erklärungsbedarf gedeckt wird.

\section{Wie und wodurch kann ein Wunder durch eine Erklärung zum Verschwinden gebracht oder ein Erklärungsbedarf gedeckt werden?}

Ein Wunder, das darin besteht, daß ein neu eingetretener oder neu zur Kenntnis genommener Sachverhalt im Widerspruch zu einer alten Überzeugung steht, insbesondere zu einer, die ein Naturgesetz o.ä. zum Inhalt hat, kann "beseitigt" werden, indem man diese Überzeugung als falsch aufgibt. Man kann sie anschließend durch eine andere Überzeugung ersetzen, man muß dies aber nicht. Eine Erklärung kann bei dieser Art, den Zustand von "wonder and astonishment" zum Verschwinden zu bringen, in zweierlei Weise im Spiel sein: Wenn man die aufgegebene Überzeugung durch eine neue ersetzt, kann letztere möglicherweise als Explanans in einer explanatorischen Relation (einer bestimmten Art) zu dem neuen Sachverhalt stehen. Es kann aber auch die Aufgabe der alten Überzeugung bereits per se bzw. die damit einhergehende Modifikation des gesamten Überzeugungssystems als Erklärung des neuen Sachverhalts aufgefaßt werden, insofern nach dem Übergang zu dem neuen Überzeugungssystem kein Widerspruch mehr zwischen dem neuen Sachverhalt und dem restlichen Überzeugungssystem besteht. ${ }^{231}$ "Wonder and astonishment", die der neue Sachverhalt verursacht hat, werden dadurch nicht ungeschehen gemacht, aber sie werden dennoch in zweierlei Sinn zum Verschwinden gebracht: Zum einen besteht in dem modifizierten Überzeugungssystem der Widerspruch nicht mehr und kann daher sozusagen nicht weiter "wonder and astonishment" verursachen. Zum anderen läßt sich das modifizierte Überzeugungssystem kontrafaktisch auf die Situation vor dem Eintreten bzw. der Zurkenntnisnahme des neuen Sachverhaltes beziehen: Wenn man die fraglichen Modifikationen bereits vor diesem Zeitpunkt vorgenommen hätte, dann hätte dieser Sachverhalt kein "wonder and astonishment" verursacht. Die im Nachhinein vorgenommene Veränderung des Überzeugungssystems ist also von der Art, daß sie "wonder and astonishment" sozusagen "kontrafaktisch verhindert".

Ein Wunder, das darin besteht, daß ein epistemisch unwahrscheinlicher Sachverhalt eintritt oder bekannt wird, kann zum Verschwinden gebracht werden, indem die Wahrscheinlichkeitsfunktion, die die Überzeugungsgrade der jeweiligen Person angibt, gemäß den dafür vorgesehenen Regeln aktualisiert wird ${ }^{232}$. Wie im Fall der wundersamen, weil im Widerspruch zu einem Naturgesetz o.ä. stehenden Sachverhalte kann auch hier bei der "Beseitigung" von "wonder and astonishment" in zweierlei Weise eine Erklärung im Spiel

\footnotetext{
${ }^{231}$ Hempel bezeichnet dies als 'how-possibly' explanation; vgl. [Hemp65d], S.428.

${ }^{232}$ Im Normalfall also gemäß der Bayesschen Regel und evtl. gemäß einer Regel der Form (IBEpr); siehe Kap.9.7. Der Wahrscheinlichkeitswert für den fraglichen Sachverhalt wird dabei in jedem Fall, also auch wenn "nur" die Bayessche Regel zum Einsatz kommt, eins (oder fast eins) und kann daher durch die Anwendung zusätzlicher Regeln etwa der Form (IBEpr) nicht mehr (wesentlich) steigen. Die "Diskrepanz" zwischen dem niedrigen Wahrscheinlichkeitswert für den Sachverhalt und seinem tatsächlichen Eintreten, die "wonder and astonishment" hervorruft, besteht also nur für den Moment zwischen dem Eintreten bzw. Bekanntwerden des Sachverhaltes und dem Abschluß des dadurch ausgelösten Aktualisierungsprozesses der Wahrscheinlichkeitsfunktion (oder zumindest des Teils des Aktualisierungsprozesses, der den Wahrscheinlichkeitswert für den Sachverhalt selbst betrifft).
} 
sein: Zum einen kann die Veränderung der Wahrscheinlichkeitsfunktion (u.a.) einen hohen Wahrscheinlichkeitswert für einen Satz ergeben, der den wundersamen Sachverhalt erklärt, d.h. der als Explanans in einer explanatorischen Relation (einer bestimmten Art) zu diesem Sachverhalt steht. Zum anderen kann man einen Übergang zu einer neuen Wahrscheinlichkeitsfunktion, die dem fraglichen Sachverhalt einen hohen Wahrscheinlichkeitswert zuschreibt, vielleicht schon per se als Erklärung für diesen Sachverhalt betrachten, insofern nach dem Übergang keine "Diskrepanz" mehr zwischen dem niedrigen Wahrscheinlichkeitswert für diesen Sachverhalt und seinem tatsächlichen Eintreten besteht. ${ }^{233}$ "Wonder and astonishment", die der neue Sachverhalt verursacht hat, können also wiederum nicht ungeschehen gemacht werden, denn an epistemischen Wahrscheinlichkeitswerten der Vergangenheit ist im Nachhinein nichts mehr zu ändern. Dennoch läßt sich auch hier vielleicht in zweierlei Sinn davon sprechen, daß "wonder and astonishment" zum Verschwinden gebracht werden: Zum einen besteht nach dem Übergang zu einer neuen Wahrscheinlichkeitsfunktion keine Diskrepanz mehr zwischen einem niedrigen Wahrscheinlichkeitswert für den fraglichen Sachverhalt und seinem tatsächlichen Eintreten. Zum anderen kann man die veränderte Wahrscheinlichkeitsfunktion vielleicht wiederum kontrafaktisch auf die Situation unmittelbar vor dem Eintreten bzw. Bekanntwerden des wundersamen Sachverhaltes beziehen: Wenn dessen Wahrscheinlichkeit zu diesem Zeitpunkt bereits den neuen Wert eins gehabt hätte, dann hätte das darauf folgende Eintreten bzw. Bekanntwerden kein "wonder and astonishment" mehr hervorgerufen. Die Idee ist also, daß einem ein als wundersam wahrgenommener Sachverhalt, von dem man zu einem bestimmten Zeitpunkt Kenntnis bekommen hat, nicht wundersam erschienen wäre, wenn man bereits zu diesem Zeitpunkt eine bestimmte andere Wahrscheinlichkeitsfunktion gehabt hätte. Die im Nachhinein vorgenommene Veränderung der Wahrscheinlichkeitsfunktion ist wiederum von der Art, daß sie "wonder and astonishment" sozusagen "kontrafaktisch verhindert".

Ein Wunder schließlich, das darin besteht, daß ein Sachverhalt im erläuterten Sinn nicht erklärbar aussieht, kann zum Verschwinden gebracht werden, indem man eine neue Überzeugung akzeptiert, die als Explanans für ihn fungiert, also etwa indem man einen Schluß auf die beste Erklärung (einer bestimmten Art) des fraglichen Sachverhalts vornimmt. Dies setzt offenbar voraus, daß von den Überzeugungen, die vorher im Widerspruch zur diesem Explanans standen, hinreichend viele aufgegeben werden. ${ }^{234}$

Daß der Erklärungsbedarf gedeckt wird, den jemand angesichts eines Sachverhaltes wahrnimmt, ist dagegen einfach zu erläutern: Es heißt schlicht, daß diese Person eine Erklärung (der "geforderten" Art) für den erklärungsbedürftigen Sachverhalt als Überzeugung akzeptiert, so daß dieser eben nicht mehr erklärungsbedürftig ist.

Mit diesen Erläuterungen in der Hand, unter welchen Umständen man von Erklärungsbedarf oder von einem Wunder spricht und in welcher Weise solcher Erklärungsbedarf gedeckt werden und ein Wunder "wegerklärt" bzw. zum Verschwinden gebracht werden kann, kann man jetzt die beiden Fragen in Angriff nehmen, erstens, ob und, wenn ja, in welchem Sinn die Explananda der verschiedenen Versionen des Wunderarguments erklärungsbedürftig sind oder ein Wunder darstellen, und, zweitens, ob ggf. die Explanantia

\footnotetext{
${ }^{233}$ Auch dies ließe sich als 'how-possibly' explanation im Sinne Hempels auffassen.

${ }^{234}$ Außerdem kann ein wundersamer, weil nicht erklärbarer Sachverhalt seinen Status als Wunder verlieren, indem man die Überzeugung (zweiter Ordnung) aufgibt, daß es für ihn eine Erklärung (einer bestimmten Art) gibt, oder indem man hinreichend viele der Überzeugungen aufgibt, die im Widerspruch zu potentiellen Explanantia stehen, ohne außerdem eines dieser Explanantia als Überzeugung zu akzeptieren. In diesen Fällen wäre der Sachverhalt noch immer unerklärt (und im letzteren Fall vielleicht auch erklärungsbedürftig), aber nicht mehr (im erläuterten Sinn) nicht erklärbar; beim Beseitigen des Wunders ist jedoch in diesen Fällen keine Erklärung involviert.
} 
der verschiedenen Versionen des Wunderarguments diesen Erklärungsbedarf decken oder das Wunder zum Verschwinden bringen.

\section{In welchem Sinn lassen sich die Explananda der verschiedenen Versionen des Wunderarguments als erklärungsbedürftig auffassen?}

Jemand, der das Explanandum (einer Version) des Wunderarguments als erklärungsbedürftig einstuft, sagt damit, daß er für dieses Explanandum eine Erklärung benötigt oder wünscht und daß er der Überzeugung (zweiter Ordnung) ist, daß es dafür eine Erklärung gibt. Grundsätzlich gibt es mehrere Möglichkeiten, worauf sich ein solches Bedürfnis und eine solche Überzeugung beziehen können: Der Erklärungsbedarf kann in dem Bedürfnis nach einer Erklärung einer einigermaßen genau spezifizierten Art bestehen, wie sie gerade durch das Explanans der jeweils zur Debatte stehenden Version des Wunderarguments geliefert wird, und eine Überzeugung (zweiter Ordnung) voraussetzen, daß es eine Erklärung dieser einigermaßen genau spezifizierten Art gibt, wie sie durch das Explanans dieser Version des Wunderarguments gerade geliefert wird. Im Fall der Version des Wunderarguments, die sich auf ePEe bezieht und diese durch die Wahrheit der prognostizierenden Theorie erklärt, könnte dies also das Bedürfnis bzw. der Wunsch nach einer deduktiven semantischen Erklärung für den ePE und die Überzeugung, daß es für diesen ePE eine deduktive semantische Erklärung gibt, sein, ebenso für die Versionen, die sich auf nPEe oder Vereinheitlichungsleistungen beziehen, im Fall von Boyds Version des Wunderarguments könnte es das Bedürfnis nach einer kausalen Erklärung und die Überzeugung, daß es eine kausale Erklärung gibt, sein etc. Erklärungsbedarf dieser Art wird offenbar durch das Explanans der jeweiligen Version des Wunderarguments gedeckt.

Eine andere denkbare Möglichkeit ist, daß jemand angesichts eines Sachverhalts, der das Explanandum einer Version des Wunderarguments darstellt, Erklärungsbedarf allgemeinerer Art anmeldet, der aber auch durch das Explanans gedeckt wird, das die jeweilige Version des Wunderarguments liefert: Solcher Erklärungsbedarf könnte in dem Bedürfnis bzw. dem Wunsch nach einer Erklärung epistemischer Art bestehen, deren Explanans das Explanandum impliziert, wahrscheinlich macht oder in irgendeiner anderen Weise "erwartbar" macht, ${ }^{235}$ oder, noch allgemeiner, in dem Bedürfnis bzw. dem Wunsch nach einer Erklärung irgendeiner Art sowie jeweils der entsprechenden Überzeugung, daß es eine solche Erklärung gibt.

Eine weitere denkbare Möglichkeit ist schließlich, daß jemand angesichts eines Sachverhalts, der das Explanandum einer Version des Wunderarguments darstellt, Erklärungsbedarf von einer Art anmeldet, der durch das Explanans dieser Version nicht gedeckt wird. So könnte z.B. jemand angesichts eines ePEes das Bedürfnis bzw. den Wunsch nach einer kausalen Erklärung haben und die Überzeugung, daß es für diesen ePE eine kausale Erklärung gibt, o.ä.

Ein Anhänger des Wunderarguments, der dessen Explanandum als erklärungsbedürftig präsentiert, wird dieses Explanandum i.a. selbst nicht als erklärungsbedürftig einstufen, denn er selbst akzeptiert i.a. bereits die Erklärung, die das Wunderargument dafür vorsieht. Er selbst würde es als erklärungsbedürftig betrachten, wenn er das gemäß dem Wunderargument vorgesehene Explanans nicht schon als Überzeugung akzeptieren würde, aber da er dies tatsächlich i.a. tut, benötigt oder wünscht er selbst keine Erklärung mehr. Ein Anhänger des Wunderarguments, der bei dessen Explanandum Erklärungsbedarf anmeldet und in Anspruch nimmt, kann damit aber auf eine Art Argument ad hominem zielen:

\footnotetext{
${ }^{235}$ Vgl. Fn.126.
} 
Er kann damit an Bedürfnisse und vortheoretische Intuitionen des Diskussionsgegners appellieren, d.h., er kann versuchen, diesen darauf hinzuweisen, daß er, der Diskussionsgegner, dieses Explanandum für erklärungsbedürftig hält, also eine Erklärung für dieses Explanandum benötigt oder wünscht und überzeugt ist, daß es eine solche Erklärung gibt, oder, wenn der Diskussionsgegner noch kein explizites Bedürfnis und/oder keine explizite Überzeugung dieser Art hat, ihm ein solches Bedürfnis und eine solche Überzeugung als plausibel erscheinen zu lassen und nahezulegen. Ob er damit Erfolg hat, hängt offenbar vom jeweiligen Diskussionsgegner ab, grundsätzlich kann aber auf diese Weise auch ein Anhänger des Wunderarguments, der dessen Explanandum selbst nicht als erklärungsbedürftig einstuft, für dieses Explanandum Erklärungsbedarf (einer der oben genannten Arten) anmelden und in Anspruch nehmen, und diesen für eine Argumentation ad hominem einsetzen.

Auf dieser Linie lassen sich die Versionen des Wunderarguments, die sich auf ePEe beziehen, etwa die von Putnam, in plausibler Weise dahingehend lesen bzw. rekonstruieren, daß dort Bedarf nach einer deduktiven semantischen Erklärung angemeldet und in Anspruch genommen wird, also Erklärungsbedarf im Sinne der ersten der drei genannten Möglichkeiten, der durch das Explanans (dieser Versionen) des Wunderarguments gerade gedeckt wird. Man könnte gegen diese Lesart möglicherweise einwenden, daß Putnams Redeweise von Wunder eine "stärkere" Lesart erfordert oder zumindest nahelegt, die entsprechenden Äußerungen von Putnam lassen sich aber vielleicht als rhetorisch überspitzte, genaugenommen unpassende Formulierungen beiseite legen. Dagegen wäre eine Lesart dieser Versionen des Wunderarguments, nach der dort allgemeinerer Bedarf nach einer Erklärung epistemischer Art oder überhaupt irgendeiner Art angemeldet wird, problematisch: Solcher Erklärungsbedarf würde auch durch andere Erklärungen gedeckt als durch die, die das Wunderargument vorsieht, etwa durch die oben diskutierten, die Fine vorgeschlagen hat. ${ }^{236}$ Solchen Erklärungsbedarf anzumelden kann also offenbar argumentativ nichts leisten, was spezifisch für das Explanans des Wunderarguments spricht, genausowenig wie jeder angesichts des Explanandums (dieser Versionen) des Wunderarguments angemeldete Erklärungsbedarf im Sinne der dritten der drei genannten Möglichkeiten argumentativ etwas für das Explanans des Wunderarguments leisten kann. Für die Versionen des Wunderarguments, die sich auf Handlungserfolge oder (unqualifizierte) Vereinheitlichungsleistungen beziehen, und für die Version von Boyd gilt, mutatis mutandis, dasselbe, d.h., sie lassen sich sich in plausibler Weise dahingehend lesen, daß dort Bedarf nach einer Handlungserklärung, nach einer deduktiven semantischen Erklärung bzw. nach einer kausalen Erklärung in Anspruch genommen wird. ${ }^{237}$

Für die Versionen des Wunderarguments, die sich auf nPEe oder auf unbeabsichtigte Vereinheitlichungsleistungen beziehen, lassen sich dieselben Überlegungen anstellen, obwohl eine Lesart dieser Versionen, die dahin geht, daß dort Bedarf nach einer deduktiven semantischen Erklärung oder nach einer deduktiven semantischen Erklärung im weiten Sinn in Anspruch genommen wird, zumindest auf den ersten Blick im Konflikt zu stehen scheint mit einigen Äußerungen der Anhänger dieser Versionen des Wunderarguments: Das Explanandum dieser Versionen bilden nPEe bzw. unbeabsichtigte Vereinheitlichungsleistungen;

\footnotetext{
${ }^{236}$ Siehe Abschnitt 9.10.3. Da diese Erklärungen mit denen des Wunderarguments nicht konkurrieren, läßt sich dieses Problem auch nicht ausräumen, indem man argumentiert, daß die Erklärungen, die das Wunderargument vorsieht, die besseren sind.

${ }^{237}$ Die von Fine vorgeschlagenen alternativen Erklärungen eignen sich nicht für alle Explananda, es lassen sich jedoch offenbar in jedem Fall Explanantia finden, die für dasselbe Explanandum eine andere Art von Erklärung liefern und daher einen weniger differenzierten Erklärungsbedarf decken würden.
} 
nur bei neuen Prognoseerfolgen bzw. unbeabsichtigten Vereinheitlichungsleistungen, nicht aber bei einfachen Prognoseerfolgen oder unqualifizierten Vereinheitlichungsleistungen ist gemäß dieser Versionen auf das jeweils vorgesehene Explanans zu schließen, obwohl man auch für letztere eine Erklärung exakt derselben Art angeben könnte, nämlich eine deduktive semantische Erklärung bzw. eine deduktive semantische Erklärung im weiten Sinn. Zur Begründung dieses Kontrastes, also der Einschränkung des Explanandums durch (9.7) bzw. (9.9), wird von einigen Anhängern des Wunderarguments angegeben, daß man bei einfachen Prognoseerfolgen und unqualifizierten Vereinheitlichungsleistungen häufig keine Erklärung benötigt, weil man bereits eine andere Erklärung für sie hat, nämlich eine, die diese Erfolge bzw. Leistungen darauf zurückführt, daß sie bei der Konstruktion der jeweiligen Theorie sozusagen eingebaut wurden, d.h., daß die Theorie gerade so konstruiert oder ausgewählt wurde, daß die fraglichen Sätze "erfolgreich" aus ihr abgeleitet werden können. ${ }^{238}$ So schreibt John Wright:

"An explanation of weak predictive success [i.e. of the successful prediction of regularities which are not novel] only needs to appeal to our intentions in constructing a theory. If someone were to ask 'Why is this theory weakly predictive successful?' a sufficient reply would be 'Because we explicitely designed the theory to account for certain known observations. There is no need to appeal to the truth (or anything akin to the truth) of the theory in order to explain weak predictive success. But appealing to our intentions in constructing a theory will obviously not explain its strong predictive success [...] Another explanation is required. One explanation which at least has prima facie plausibility is that the theory is true". ${ }^{239}$

Diese Linie der Begründung scheint darauf hinauszulaufen, daß bei ePEen und unqualifizierten Vereinheitlichungsleistungen grundsätzlich derselbe Erklärungsbedarf anzumelden wäre wie bei nPEen und unbeabsichtigten Vereinheitlichungsleistungen, tatsächlich jedoch i.a. nicht anzumelden ist, weil dieser Erklärungsbedarf bei ersteren häufig bereits gedeckt wird durch eine Erklärung, bei der das "Einbauen" von Erfolgen oder, wie Wright schreibt, "our intentions in constructing a theory" als Explanans fungieren. Wenn dies so ist, kann der von Wright und anderen Anhängern dieser Versionen des Wunderarguments in Anspruch genommene Erklärungsbedarf offenbar nicht der Bedarf nach einer deduktiven semantischen Erklärung oder einer deduktiven semantischen Erklärung im weiten Sinn sein, denn eine solche Erklärung liefern das "Einbauen" von Erfolgen oder, wie Wright schreibt, die Intentionen bei der Konstruktion der Theorie offenbar nicht (wie auch immer die Erklärungen genau aussehen, die dadurch geliefert werden). Der in Anspruch genommene Erklärungsbedarf müßte danach ein weniger spezifischer sein, etwa der Bedarf nach einer Erklärung epistemischer oder überhaupt irgendeiner Art sein, jedenfalls Bedarf nach einer Art von Erklärung, die so weit spezifiziert ist, daß sowohl deduktive semantische Erklärungen (im weiten Sinn) darunter fallen, als auch die Erklärungen für Theorieerfolge bzw. -leistungen, bei denen das "Einbauen" der Erfolge als Explanans fungiert. Wenn man bei nPEen und unbeabsichtigten Vereinheitlichungsleistungen derart weit spezifizierten Erklärungsbedarf in Anspruch nimmt, kann dieser aber wahrscheinlich wiederum durch Erklärungen anderer Art als deduktive semantische (im weiten Sinn) gedeckt werden, etwa die von Fine genannten, so daß die Inanspruchnahme von Erklärungsbedarf dieser Art

\footnotetext{
${ }^{238}$ Siehe S.188.

${ }^{239}$ [Wrig91], S.11.
} 
argumentativ nichts leisten kann, was spezifisch für das Explanans des Wunderarguments spricht.

Eine Lösung dieses Problems liegt aber auf der Hand: Wenn man die genannte Linie der Begründung der Einschränkung des Explanandums auf nPEe bzw. unbeabsichtigte Vereinheitlichungsleistungen fallenläßt, kann man die Versionen des Wunderarguments, die sich auf diese eingeschränkten Explananda beziehen, doch dahingehend rekonstruieren, daß dort Bedarf nach einer deduktiven semantischen Erklärung oder nach einer deduktiven semantischen Erklärung im weiten Sinn angemeldet und in Anspruch genommen wird. Zur Begründung des Schrittes vom Explanandum ePEe bzw. unqualifizierte Vereinheitlichungsleistungen zum eingeschränkteren Explanandum nPEe bzw. unbeabsichtigte Vereinheitlichungsleistungen steht dann noch immer ein zweiter Grund zur Verfügung, der sich ebenfalls bei den Anhängern dieser Versionen des Wunderarguments findet, nämlich der, daß man (etwa aufgrund historischer Erfahrungen ${ }^{240}$ ) glaubt, daß nur bei nPEen bzw. unbeabsichtigten Vereinheitlichungsleistungen in verläßlicher Weise auf das genannte Explanans geschlossen werden kann, während ein entsprechender Schluß bei ePEen bzw. unqualifizierten Vereinheitlichungsleistungen oft zu einer falschen Konklusion führt. ${ }^{241}$ Eine solche Überzeugung stellt einen hinreichenden Grund dar, das Explanandum des Wunderarguments auf nPEe bzw. unbeabsichtigte Vereinheitlichungsleistungen einzuschränken, unabhängig davon, ob das "Einbauen" von Erfolgen eine Erklärung für diese liefert und ggf. in welchem Sinn.

\section{In welchem Sinn lassen sich die Explananda der verschiedenen Versionen des Wunderarguments als Wunder auffassen?}

Sind die Explananda wundersam, weil nicht erklärbar? Mit der beschriebenen Lesart (der verschiedenen Versionen) des Wunderarguments, nach der seine Anhänger für das Explanandum Erklärungsbedarf in Anspruch nehmen, ist in gewisser Weise eine andere Lesart verwandt, nach der das Explanandum als Wunder im Sinne der dritten der oben genannten Erläuterungen präsentiert wird: In beiden Fällen muß jemand, der die jeweilige Charakterisierung des Explanandums für richtig hält, überzeugt sein, daß es für das Explanandum eine Erklärung (einer bestimmten Art) gibt; wer das Explanandum nicht nur für erklärungsbedürftig, sondern sogar für wundersam, weil nicht erklärbar hält, müßte darüber hinaus andere Überzeugungen haben, die mit der ersteren im Widerspruch stehen (etwa indem sie allen in Frage kommenden Explanantia widersprechen).

Ein Anhänger des Wunderarguments, der dessen Explanandum als wundersam, weil nicht erklärbar präsentiert, wird dieses Explanandum i.a. selbst nicht als Wunder in diesem Sinn einstufen, denn er selbst wird i.a. die Erklärung akzeptieren, die das Wunderargument dafür vorsieht, und außerdem keine anderen Überzeugungen haben, die dem widersprechen. Er selbst würde das Explanandum wohl als Wunder einstufen, wenn er das gemäß dem Wunderargument vorgesehene Explanans nicht schon als Überzeugung akzeptieren würde und andere Überzeugungen hätte, die im Widerspruch zu diesem Explanans stehen, aber da dies tatsächlich i.a. nicht der Fall ist, stellt das Explanandum für ihn selbst kein Wunder dar.

Dennoch gibt es wiederum eine Möglichkeit, die Redeweisen von Wunder, die sich bei Anhängern des Wunderarguments wie Putnam und Smart finden, in der dritten der oben

\footnotetext{
${ }^{240}$ Siehe Abschnitt 9.10.1.

${ }^{241}$ Dieses Motiv nennen u.a. Carrier und Worrall (vgl. die Abschnitte 9.4, 9.5, s.a. Abschnitt 9.10.1 und Fn.133).
} 
genannten Weisen zu erläutern: Wenn die Anhänger des Wunderarguments deren Explananda als Wunder präsentieren, könnten sie eine Art Argument ad hominem im Auge haben, das an vortheoretische Intuitionen des Diskussionsgegners appelliert. Gemeint sein könnte also, daß nicht sie selbst die Explananda für ein Wunder, weil unerklärbar, halten, sondern daß sie der Ansicht sind, daß ihre Diskussionsgegner dies tun müßten, weil diese einerseits überzeugt sind, daß es eine Erklärung (einer bestimmten Art) für die Explananda gibt, andererseits aber auch Überzeugungen haben, die dazu im Widerspruch stehen. $\mathrm{Ob}$ dies zutrifft, ob die vortheoretischen Intuitionen, auf die die Anhänger des Wunderarguments so hinweisen könnten, tatsächlich vorhanden sind oder plausibel gemacht werden können, hängt offenbar vom jeweiligen Diskussionsgegner ab, und für reflektierte, konsequente Antirealisten wird es sicherlich nicht zutreffen (denn dieses werden eben nicht glauben, daß es eine Erklärung der fraglichen Art gibt). Es könnte aber vielleicht für weniger reflektierte und konsequente Antirealisten zutreffen und vor allem für Personen, die noch keinen systematisch ausgearbeiteten Standpunkt in der Realismusdebatte eingenommen haben, aber antirealistische Thesen oder Positionen attraktiv finden: Putnam etwa richtet seine Version des Wunderarguments gegen den logischen Positivismus und den Operationalismus; ${ }^{242}$ deren zentrale Thesen über die Semantik wissenschaftlicher Ausdrücke und Sätze bzw. darüber, welchen Ausdrücken und Sätzen überhaupt Bedeutung und Referenz zukommt, sind sicherlich nicht mit den den Explanantia des Wunderarguments verträglich ${ }^{243}$ und könnten daher die Rolle der Überzeugungen spielen, die im Widerspruch zu einer Überzeugung stehen, daß es für die Explananda des Wunderarguments eine Erklärung (einer bestimmten Art) gibt. Putnams Redeweisen von Wunder könnten sich also an Diskussionsgegner richten, die eine solche Überzeugung akzeptieren, daß es für die Explananda eine Erklärung gibt, (oder denen man eine solche Überzeugung vielleicht plausibel machen kann) und die gleichzeitig positivistische oder operationalistische Thesen akzeptieren oder zumindest attraktiv finden; Putnams Rede von Wunder könnte darauf zielen, diese Diskussionsgegner darauf hinzuweisen, daß sie, gegeben die genannten Kombination von Überzeugungen (oder zumindest von "potentiellen Überzeugungen", also ihnen attraktiv erscheinenden Thesen), die Explananda, auf die sich das Wunderargument bezieht, als Wunder, weil nicht erklärbar betrachten müssen oder müßten (er selbst dagegen nicht). Wenn sie dagegen die positivistischen oder operationalistischen Thesen fallen lassen (und evtl. die Explanantia des Wunderarguments akzeptieren), verschwindet das Wunder. In analoger Weise lassen sich neben Putnams Rede von Wunder auch entsprechende Formulierungen von anderen Anhängern des Wunderarguments auffassen, die sich auf die Explananda anderer Argumentversionen beziehen, d.h. man kann analog auch Vereinheitlichungsleistungen, Handlungserfolge etc. als wundersam, weil unerklärbar bezeichnen.

Exkurs: Prognoseerfolge als wundersam, weil nicht erklärbar, in einer für das Wunderargument irrelevanten Hinsicht Die dritte der oben genannten Erläuterungen von 'Wunder' ergibt also für das Wunderargument zumindest eine Lesart als eine Art Argument ad hominem im erläuterten Sinn. Diese Erläuterung ist im Zusammenhang mit dem Wunderargument jedoch noch in einer weiteren Hinsicht von Interesse, obwohl diese nicht auf eine überzeugende Lesart des Arguments führt, weil sie die Artikulation oder Konkretisierung einer verbreiteten, aber ungenauen Intuition ermöglicht, die bei genauerer Betrachtung für die Argumentation des Wunderarguments irrelevant ist, aber

\footnotetext{
${ }^{242}$ S. Abschnitt 9.2.2.

${ }^{243}$ Genauer: mit den darin enthaltenen semantischen realistischen Thesen; vgl. Abschnitt 9.9.1.
} 
mit den dafür relevanten Intuitionen leicht vermengt oder verwechselt werden kann: In den Texten einiger Naturwissenschaftler finden sich gelegentlich Äußerungen, in denen sie Prognoseerfolge von Theorien als Wunder bezeichnen, ohne daß dies eingehend diskutiert würde; einige Bemerkungen im Zusammenhang damit legen jedoch nahe, daß damit ein Wunder im Sinne der dritten der oben genannten Erläuterungen gemeint sein könnte, daß also Prognoseerfolge als wundersam, weil nicht erklärbar erscheinen, weil man einerseits überzeugt ist (oder jedenfalls die Annahme plausibel oder naheliegend findet), daß es für Prognoseerfolge eine Erklärung einer bestimmten Art geben sollte, andererseits jedoch andere, damit konfligierende Überzeugungen hat.

Das vielleicht bekannteste Beispiel für solche Äußerungen sind Eugene Wigners Ausführungen zum Thema Prognoseerfolge wissenschaftlicher Theorien. ${ }^{244}$ Wigner nennt eine Reihe solcher Prognoseerfolge aus dem Bereich der klassischen Mechanik und Quantenmechanik, bei denen bekannt ist, auf welche Weise und mit welchem "Input" an Beobachtungen und Messungen die für die Prognosen verwendeten Gesetze gewonnen wurden. Nach Wigners Ansicht haben für die Gewinnung dieser Gesetze Beobachtungen und Messungen eine erstaunlich geringe Rolle gespielt, dafür aber mathematische Begriffe, die allein nach "innermathematischen" Kriterien wie einfacher Manipulierbarkeit, Schönheit, der Formulierbarkeit und Ableitbarkeit mathematisch interessanter Theoreme u.ä. gebildet wurden, eine erstaunlich große Rolle. Wigner betrachtet Prognoseerfolge eines Gesetzes bzw. einer Theorie als guten Grund für die Annahme, daß das Gesetz bzw. die Theorie annähernd wahr ist, ${ }^{245}$ gleichzeitig bezeichnet er es aber explizit als Wunder, daß ein Gesetz, das auf diese Weise, d.h. mit Hilfe der genannten Kriterien, gewonnen wurde, wahre Prognosen liefert. Für Wigner verschwindet dieses Wunder also offenbar nicht, wenn man anerkennt, daß das prognostisch erfolgreiche Gesetz bzw. die prognostisch erfolgreiche Theorie wahr ist, d.h., dieses Wunder wird nach Wigners Ansicht durch eine Erklärung, wie sie das Wunderargument für Prognoseerfolge vorsieht, nicht "wegerklärt".

Einen Hinweis darauf, in welchem Sinn Wigner die genannten Prognoseerfolge für wundersam hält, läßt sich vielleicht einer Textstelle entnehmen, an der er sie etwas informell charakterisiert:

"Surely in this case we "got something out" of the equations that we did not put in". 246

Wigner bezweifelt nicht, daß die fraglichen Gleichungen (annähernd) wahr sind und daß man daher für die Prognoseerfolge eine deduktive semantische Erklärung geben kann, er hält die Prognoseerfolge dennoch für ein Wunder und scheint der Ansicht zu sein, daß eine Erklärung einer anderen Art erforderlich wäre, um das Wunder zum Verschwinden zu bringen. Die zitierte Stelle scheint einen Hinweis zu geben, was für eine Art von Erklärung dies sein müßte, nämlich eine, die erklärt, auf welche Weise die Information, die den Inhalt des Prognoseerfolgs ausmacht, "in die Gleichungen hineingekommen ist" (da, wie Wigner sich ausdrückt, wir sie nicht hineingesteckt haben). ${ }^{247}$ Ein weiterer Hinweis, in welchem Sinn Prognoseerfolge, wie Wigner sie nennt, sich als wundersam auffassen lassen, läßt sich

\footnotetext{
${ }^{244}$ [Wign79b]. Äußerungen ähnlicher Art finden sich z.B. in [Feyn65], S.170/171.

245 [Wign79b], S.230.

${ }^{246}$ [Wign79b], S.232.

${ }^{247}$ Wigner selbst sieht keine Aussichten, eine solche Erklärung zu gewinnen. Er konstatiert am Ende seines Aufsatzes, die Prognoseerfolge von Gesetzen und Theorien, die wesentlich mit Hilfe mathematischer Begriffe gewonnen wurden, seien "a wonderful gift which we neither understand nor deserve" ([Wign79b], S.237).
} 
einem Aufsatz von Hamming entnehmen, der direkt an Wigner anschließt. ${ }^{248}$ Hamming kommentiert die erstaunlichen Prognoseerfolge von Gesetzen und Theorien, die mit Hilfe mathematischer Begriffe gewonnen wurden, informell in etwas anderer Weise als Wigner:

"During my thirty years of practicing mathematics [...], I often worried about the predictions I made. From the mathematics that I did in my office I confidently (at least to others) predicted some future events - if you do so and so, you will see such and such - and it usually turned out that I was right. How could the phenomena know what I had predicted (based on human-made mathematics) so that it could support my predictions?" 249

Zusammengenommen legen diese beiden Hinweise nahe, durch welche Art von Erklärung der Eindruck beseitigt würde, daß es sich bei den Prognoseerfolgen um ein Wunder handelt: Wigners Formulierung, daß aus einer Gleichung bzw. Theorie etwas "herausgeholt" oder etwas in sie "hineingesteckt" wird, und Hammings Frage, auf welchem Wege die Phänomene von der Prognose erfahren, deuten darauf hin, daß es für den Eindruck eines Wunders wesentlich ist, daß die physikalisch realisierte Repräsentation, die die Prognose liefert, (sprich: die konkreten Instantiierungen, die token der Gleichung oder Theorie und des prognostizierten Beobachtungssatzes), und der Sachverhalt, von dem die jeweilige Prognose handelt, i.a. räumlich und zeitlich (mehr oder weniger weit) voneinander entfernt sind, und daß der Eindruck eines Wunders nicht entstünde, wenn man einen Kausalprozeß kennen würde, der von dem repräsentierten Sachverhalt zur physikalisch realisierten Repräsentation führt (und durch den die Information über den Sachverhalt "in die Repräsentation hineingesteckt wird"), oder einen Kausalprozeß, der von der physikalisch realisierten Repräsentation zum repräsentierten Sachverhalt führt (und durch den "die Phänomene von der Prognose erfahren"). Der Eindruck eines Wunders würde demnach durch eine Kausalerklärung für die Übereinstimmung zwischen Repräsentation und repräsentiertem Sachverhalt beseitigt, und zwar durch eine Kausalerklärung der Art, wie sie Salmons Prinzip der gemeinsamen Ursache allgemein für korrelierte Ereignisse postuliert. ${ }^{250}$

Für einige Fälle von Übereinstimmung zwischen Repräsentation und repräsentiertem Sachverhalt kennt man durchaus solche Kausalprozesse, die die Übereinstimmung kausal erklären: Bei Überzeugungen über singuläre Sachverhalte, die man durch Beobachten mit dem bloßen Auge oder auch mit Hilfe von Instrumenten wie der Lupe, dem Teleskop oder dem Mikroskop gewinnnt, kennt man einen Kausalprozeß (nämlich ein elektromagnetisches Signal), der vom repräsentierten Sachverhalt zum Beobachter führt und "in ihm" die entsprechenden Überzeugungen auslöst und so erklärt, wie die Information über den repräsentierten Sachverhalt in die Repräsentation "hineinkommt", und damit die Übereinstimmung zwischen repräsentiertem Sachverhalt und Repräsentation erklärt. ${ }^{251}$ Fälle, in denen man einen Kausalprozeß in der anderen Richtung, also von der Repräsentation zum repräsentierten Sachverhalt, kennt, findet man, wenn man etwa - tatsächlich realisierte - Baupläne für Häuser etc. betrachtet; dort läßt sich durch einen Kausalprozeß erklären, auf welchem Weg die repräsentierten Phänomene, sprich: die Häuser, von den

\footnotetext{
${ }^{248}$ [Hamm80].

249 [Hamm80], S.83.

${ }^{250}$ Siehe Kap.8.3.3.

${ }^{251}$ Ähnliche kausale Erklärungen lassen sich auch für einige andere epistemische Verfahren finden, etwa für die Übereinstimmung von Landkarten mit der Gestalt des abgebildeten Geländes, für die Verläßlichkeit der ${ }^{14} \mathrm{C}$-Methode zur Altersbestimmung u.ä.
} 
Repräsentationen, sprich: den Bauplänen, erfahren, und damit wird auch die Übereinstimmung zwischen Repräsentation und repräsentiertem Sachverhalt erklärt. Angesichts solcher und ähnlicher Beispiele könnte man vielleicht (auf irgendeine Weise) induktiv zu der Überzeugung gelangen, daß es für Fälle von Übereinstimmung zwischen (hinreichend komplexen ${ }^{252}$ ) Repräsentationen und repräsentierten Sachverhalten generell eine Kausalerklärung der beschriebenen Art gibt, also für alle oder zumindest für fast alle Fälle solcher Übereinstimmungen, oder, etwas allgemeiner, daß für Fälle von Übereinstimmung zwischen (hinreichend komplexen) Repräsentationen und repräsentierten Sachverhalten so etwas wie eine lokale Version des Prinzips der gemeinsamen Ursache gilt. ${ }^{253}$ Eine solche Überzeugung würde auf die — zumindest auf den ersten Blick nicht unplausibel klingende - Ansicht hinauslaufen, daß physikalisch realisierte Repräsentationen, die korrekte Informationen enthalten, d.h. mit den repräsentierten Sachverhalten übereinstimmen, nicht irgendwie oder zufällig zustandekommen, sondern daß es im Normalfall so etwas wie einen ebenfalls physikalisch realisierten Informationsfluß (sprich: einen Kausalprozeß) gibt, der die Informationen von den Tatsachen hin zu den Repräsentationen oder umgekehrt transportiert ${ }^{254}$ und damit die Übereinstimmungen erklärt.

Wenn man überzeugt ist, daß es für Übereinstimmungen zwischen Repräsentationen und repräsentierten Sachverhalten eine Kausalerklärung der genannten Art gibt, sei es aus den angedeuteten induktiven Gründen, sei es weil man eine entsprechende vortheoretische Intuition hat, dann werden einem Prognoseerfolge wissenschaftlicher Theorien zumindest in vielen Fällen (insbesondere "nicht-eingebaute" Prognoseerfolge) als Wunder im Sinne der dritten der oben angegebenen Erläuterungen erscheinen, denn diese Überzeugung steht im Widerspruch allgemein akzeptierten und als gut gestützt geltenden Ansichten darüber, was für Kausalprozesse es tatsächlich "in der Natur" gibt (also elektromagnetischen Signale, "Materieströme" etc.): Danach gibt es keine Kausalprozesse, die von der Zukunft in die Vergangenheit laufen, gibt es auch in Fällen, in denen der repräsentierte Sachverhalt nicht in der Zukunft liegt, i.a. (sofern es nicht gerade um eingebaute Prognoseerfolge geht) keine Kausalprozesse, die von einem prognostizierten Sachverhalt zur Repräsentation laufen, und gibt es auch i.a. (sofern es nicht gerade um analoge Fälle zu den oben genannten Bauplänen für ein Haus geht) keine Kausalprozesse, die von einer Repräsentation zum repräsentierten Sachverhalt laufen, und damit keine Kausalprozesse, die eine Kausalerklärung der genannten Art ergeben. ${ }^{255}$ Prognoseerfolge wissenschaftlicher

\footnotetext{
${ }^{252}$ Eine solche (präzisierungsbedürftige) Qualifikation ist erforderlich, da in nicht "hinreichend komplexen" Fällen, in denen die Übereinstimmung "durch Zufall” zustandekommt, eine kausale Erklärung intuitiv nicht erforderlich ist, etwa, wenn jemand durch einen Münzwurf eine wahre Überzeugung darüber gewinnt, welche Mannschaft ein Fußballspiel gewinnen wird.

${ }^{253}$ Damit wären neben Kausalprozessen der beiden genannten Richtungen noch Common-cause-Erklärungen zugelassen, die selten sein dürften, aber vielleicht auch vorkommen. Einige — allerdings sehr vorsichtige und auch nicht sonderlich klare - Andeutungen, daß es für Prognoseerfolge wissenschaftlicher Theorien eine Erklärung durch eine gemeinsame Ursache für Repräsentation und repräsentierten Sachverhalt geben könnte, finden sich bei Peirce; ein Beispiel ([Peir98], S.68):
}

"How can the reason of man attain to prognosis?

How shall we answer? Must we not say that the fact that he can so attain proves that there is an energizing reasonableness that shapes phenomena in some sense, and that this same working reasonableness has moulded the reason of man into something like his own image?"

${ }^{254}$ Oder wenn nicht dies, dann jedenfalls einen (durch zwei Kausalprozesse realisierten) Informationsfluß von einer gemeinsamen Ursache zu Repräsentation und Sachverhalt hin.

${ }^{255}$ Hier liegt vielleicht der Einwand nahe, daß in Fällen, in denen eine Prognose durch ein eigens dafür durchgeführtes Experiment getestet wird, sehr wohl ein Kausalprozeß von der Repräsentation zum re- 
Theorien müssen dann also als wundersam, weil unerklärbar erscheinen.

Die zitierten Äußerungen von Wigner und Hamming legen nahe, daß ihnen die von ihnen genannten Prognoseerfolge als wundersam in diesem Sinn erscheinen, oder könnten zumindest in diesem Sinn zu verstehen sein. ${ }^{256}$ Unabhängig davon, ob diese Interpretation der Äußerungen von Wigner und Hamming adäquat ist, scheint die These, daß Prognoseerfolge wissenschaftlicher Theorien, insbesondere "nicht-eingebaute" Prognoseerfolge, in diesem Sinn wundersam sind, eine verbreitete Intuition zu formulieren oder zu artikulieren, die von vielen geteilt wird, auch oder gerade von Personen, die (noch) keinen systematischen Standpunkt in der Realismusdebatte bezogen haben. Die intuitive Plausibilität dieser These scheint kaum dadurch beeinträchtigt zu werden, daß explizite Gründe für sie (insbesondere für die Annahme, daß es eine Kausalerklärung der skizzierten Art geben muß) kaum angegeben werden können, und wenn, dann lediglich induktive Gründe der oben angedeuteten Art. Für viele scheinen Prognoseerfolge wissenschaftlicher Theorien in diesem Sinn ein Wunder darzustellen. ${ }^{257}$

Wenn jemand Prognoseerfolge in diesem Sinn als Wunder ansieht, ist eine mögliche Art, das Wunder zum Verschwinden zu bringen, die Überzeugung aufzugeben, daß es eine Kausalerklärung der genannten Art gibt, und vielleicht ist dies auch die plausibelste und überzeugendste Reaktion. Ob man diesen Schritt geht (oder welchen sonst), ist aber jedenfalls für den Diskussionszusammenhang des Wunderarguments irrelevant, denn ob Prognoseerfolge von Theorien in diesem Sinn wundersam sind oder nicht, trägt für das Wunderargument offenbar nichts aus: Auch unabhängig davon, wie die Frage generell zu beantworten ist, welche argumentative Rolle die Tatsache, daß ein bestimmter Erfolg einer Theorie ein Wunder darstellt, für das Wunderargument spielen kann, ${ }^{258}$ ist klar, daß dem Status als Wunder im hier zur Debatte stehenden Sinn keine argumentative Rolle für das Wunderargument zukommen kann, denn von Kausalerklärungen der skizzierten Art ist im Wunderargument (insbesondere in dessen Explanans) nicht die Rede und die Erklärungen, die das Wunderargument vorsieht, bringen dieses Wunder nicht zum Verschwinden. Wenn man Prognoseerfolge als Wunder in diesem Sinn ansieht, und dies scheint eine verbreitete Intuition zu sein oder zumindest eine naheliegende Art, eine weit verbreitete, aber ungenaue Intuition zu artikulieren und zu konkretisieren, dann führt dies sicherlich nicht auf eine plausible Lesart des Wunderarguments.

Sind die Explananda wundersam, weil einem Naturgesetz o.ä. widersprechend? Die erste der drei oben genannten Erläuterungen von Wunder, nach der ein Sachverhalt wundersam ist, weil er im Widerspruch zu bereits akzeptierten Überzeugungen steht, die ein Naturgesetz zum Inhalt haben, den Normalverlauf eines natürlichen Vorgangs o.ä., führt nicht auf eine plausible Lesart des Wunderarguments. Im Falle eines Prognoseerfolges ist es zwar klarerweise möglich, daß er ein Wunder in diesem Sinn darstellt, und dafür sind grundsätzlich auch verschiedene Gründe denkbar: Im Widerspruch zu akzeptierten Überzeugungen könnte entweder die Tatsache stehen, daß aus einer Theorie bestimmte

präsentierten Sachverhalt führt. Dieser Einwand ist jedoch unberechtigt: Es führt in solchen Fällen möglicherweise ein Kausalprozeß von der Repräsentation zum Experimentaufbau o.ä., aber nicht bis zum repräsentierten Sachverhalt, denn ein Kausalprozeß in Salmons Sinn muß markierbar sein (siehe S. 8.3.4), d.h. in diesem Fall, eine kleine Änderung der Prognose müßte auch eine kleine Änderung des repräsentierten Sachverhalts nach sich ziehen. Dies ist offenbar nicht der Fall.

${ }^{256}$ Dies ist eine Explikation der Ausführungen von Wigner und Hamming; sie selbst erläutern ihren Eindruck, daß Prognoseerfolge wundersam sind, nicht näher.

${ }^{257}$ Dies ist jedenfalls meine Erfahrung.

${ }^{258}$ Dazu s.u. 
Beobachtungssätze ableitbar sind oder abgeleitet wurden (also (9.1) bzw. (9.3)), oder die Tatsache, daß diese Beobachtungssätze wahr sind (also (9.2)), oder sogar beides. Keine dieser Möglichkeiten ist jedoch für Prognoseerfolge im allgemeinen oder in den meisten oder auch nur in vielen Fällen plausibel, und dies gilt für ePEe ebenso wie für nPEe: Es mag einzelne Fälle geben in denen jemand überzeugt ist, daß bestimmte Phänomene nicht aus einer bestimmten Theorie ableitbar sind, und dann überrascht das Gegenteil bemerkt, aber daß dies generell für alle oder auch nur für viele Prognoseerfolge gilt oder daß es gar ein allgemeines Gesetz o.ä. geben sollte, das solche Ableitungen "verbietet", ist völlig unplausibel, denn es ist nicht zu sehen, wie ein (wenigstens halbwegs plausibles) Gesetz o.ä. dieser Art lauten sollte. Ebenso gibt es sicherlich Fälle von Prognoseerfolgen, in denen jemand zunächst überzeugt war, daß der prognostizierte Satz falsch ist (etwa weil er einem etablierten Naturgesetz widerspricht), und dann überrascht das Gegenteil zur Kenntnis nehmen muß. Fälle dieser Art kommen beispielsweise in Situationen vor, in denen ein Experimentum crucis, das eine Entscheidung zwischen einer etablierten alten Theorie und einer neuen Theorie herbeiführen soll, zugunsten der neuen Theorie ausgeht. Daß alle oder viele oder auch nur die meisten Prognoseerfolge Fälle dieser Art sein sollten, ist jedoch wiederum nicht plausibel; es gibt sicherlich Prognoseerfolge, die es nicht sind. ${ }^{259}$

Daß Prognoseerfolge "wonder and astonishment" hervorrufen, also wundersam sind, weil sie im Widerspruch zu einem Naturgesetz oder zu anderen etablierten Überzeugungen stehen, mag also im Einzelfall sein, aber es gilt sicherlich nicht allgemein, für ePEe so wenig wie für nPEe; daher ergibt diese Erläuterung von Wunder keine plausible Lesart der Versionen des Wunderarguments, die sich auf Prognoseerfolge beziehen. Entsprechendes gilt auch für Versionen des Wunderarguments, die sich auf (unqualifizierte oder unbeabsichtigte) Vereinheitlichungsleistungen beziehen, für Versionen, die sich auf Handlungserfolge beziehen, und für Boyds Version.

Sind die Explananda wundersam, weil epistemisch unwahrscheinlich? Die zweite der drei oben genannten Erläuterungen von Wunder schließlich, nach der ein Sachverhalt wundersam ist, weil er vor seinem Eintreten bzw. Bekanntwerden eine epistemische Wahrscheinlichkeit null (oder fast null) hat, führt ebenfalls nicht auf eine plausible Lesart des Wunderarguments. Das Explanandum (einer Version) des Wunderarguments als wundersam, weil epistemisch unwahrscheinlich aufzufassen, setzt voraus, daß man kognitive Zustände durch Überzeugungsgrade charakterisiert, ${ }^{260}$ was Anhänger des Wunderarguments i.a. nicht tun, zumindest Putnam, Smart, Boyd, Musgrave, Carrier und Worrall nicht. ${ }^{261}$ Schon deswegen kommt die zweite der drei Erläuterungen von Wunder für eine adäquate Rekonstruktion von deren Versionen des Wunderarguments nicht in Frage.

Damit bleibt noch die Möglichkeit zu versuchen, (eine oder mehrere) Versionen des Wunderarguments zu konstruieren, die sich von den Versionen der bisher genannten Autoren in gewisser Weise lösen und mit Hilfe eines probabilistischen Modells für kognitive Zustände, sprich: mit Hilfe epistemischer Wahrscheinlichkeiten, deren Ideen in verbesserter und vielleicht überzeugenderer Form implementieren. Solche verbesserten Versionen

\footnotetext{
${ }^{259}$ Dazu zählen i.a. nPEe, die sich auf einen neuen, noch unerforschten Gegenstandsbereich beziehen, über den es gar keine etablierten Theorien und sonstigen Kenntnisse gibt, und damit auch keine, die einer Prognose widersprechen könnten. Ein Beispiel, das in [Carr91], S.30 beschrieben wird, ist Priestleys nPE, daß Wasserstoff (nach seiner Meinung: "inflammable air") und verschiedene Metalloxide ("calces") bei Erhitzen zu den jeweiligen Metallen reagieren.

${ }^{260}$ S. Kap.9.7.

${ }^{261}$ Jedenfalls nicht im Zusammenhang ihrer jeweiligen Version des Wunderarguments. Smart schließt eine solche Lesart seiner Version des Wunderarguments sogar explizit aus (siehe das Zitat S.187).
} 
des Wunderarguments sind grundsätzlich denkbar, gegen sie sprechen jedoch, mutatis mutandis, dieselben Überlegungen wie gegen jede Lesart des Wunderarguments, die sich auf die erste der drei Erläuterungen von Wunder stützt: Es ist denkbar, daß es jemand (vor Eintreten bzw. Bekanntwerden der jeweiligen Sachverhalte) als epistemisch sehr unwahrscheinlich einstuft, daß aus einer Theorie bestimmte Beobachtungssätze ableitbar sind oder abgeleitet werden oder daß diese Beobachtungssätze wahr sind oder sogar beides; wiederum ist jedoch keine dieser Möglichkeiten für Prognoseerfolge im allgemeinen oder in den meisten oder auch nur in vielen Fällen plausibel, und wiederum gilt dies für ePEe ebenso wie für nPEe und, mutatis mutandis, auch für die Explananda, auf die sich die anderen diskutierten Versionen des Wunderarguments beziehen. ${ }^{262}$ Auch die Idee, "verbesserte" Versionen des Wunderarguments zu konstruieren, die mit epistemischen Wahrscheinlichkeiten arbeiten, führt daher nicht zu einer plausiblen Erläuterung, in welchem Sinn das jeweilige Explanandum ein Wunder darstellt, und daher auch nicht zu plausiblen Versionen des Wunderarguments.

\section{Welche argumentative Rolle spielen die Inanspruchnahme von Erklärungsbe- darf und die Rede von "Wunder" beim Wunderargument?}

Fazit der obigen Überlegungen ist, daß sich sowohl für die Hinweise auf Erklärungsbedarf, als auch für die Rede von Wundern, die sich bei vielen Anhängern des Wunderarguments finden, eine plausible Lesart identifizieren läßt. In beiden Fällen ist die entsprechende Charakterisierung der Explananda des Wunderarguments im Sinne einer Argumentati-

\footnotetext{
${ }^{262}$ An dieser Stelle könnte der Einwand naheliegen, daß es für die Explananda neue Prognoseerfolge und unbeabsichtigte Vereinheitlichungsleistungen sehr wohl plausibel ist, daß sie, wenn nicht in allen, dann zumindest in vielen Fällen als epistemisch sehr unwahrscheinlich bewertet werden, und daß sich daher plausible Versionen des Wunderarguments konstruieren lassen sollten, die sich auf diese beiden Explananda beziehen und mit Hilfe epistemischer Wahrscheinlichkeiten erläutern, in welchem Sinn diese Explananda wundersam sind. Dieser Einwand könnte etwa deswegen naheliegen, weil ein Motiv hinter dem Schritt vom Explanandum ePEe zum Explanandum nPEe und entsprechend von Vereinheitlichungsleistungen zu unbeabsichtigten Vereinheitlichungsleistungen war, bei der Theoriekonstruktion "eingebaute" Erfolge auszuschließen, und "eingebaute" Erfolge i.a. gerade Phänomene etc. mit hoher epistemischer Wahrscheinlichkeit betreffen werden (ansonsten würde man sie nicht "einbauen"). Dieser Einwand überzeugt jedoch nicht, weil es bei genauerer Betrachtung eben nicht plausibel ist, daß viele oder gar alle nPEe und unbeabsichtigten Vereinheitlichungsleistungen sehr unwahrscheinlich sind: "Sehr unwahrscheinlich" im Sinne der vorne angegebenen Erläuterung von "Wunder" heißt, daß der Wahrscheinlichkeitswert null oder fast null ist, und nicht, daß er $1 / 2$ oder fast $1 / 2$ ist (vgl. Fn.229). Bei nPEen etwa, die einen bisher völlig unerforschten Gegenstandsbereich betreffen (etwa die Eigenschaften und das Verhalten einer bisher unbekannten oder unzugänglichen Substanz), ist es plausibel, daß man vielen erst noch zu untersuchenden Eigenschaften, Phänomenen etc. (bzw. entsprechenden Sätzen) Wahrscheinlichkeiten 1/2 oder fast 1/2 zuweist, eben weil man noch keinerlei Hinweise hat, ob bestimmte Eigenschaften vorliegen oder nicht; das heißt aber nicht, daß man sie für sehr unwahrscheinlich hält (ihnen also Wahrscheinlichkeiten null oder fast null gibt). Letzteres wäre i.a. intuitiv nicht plausibel: Wenn man das Vorliegen einer bestimmten Eigenschaft für sehr unwahrscheinlich hält, muß man das Gegenteil, also ihr Nicht-Vorliegen, für sehr wahrscheinlich halten, und dafür wird man in noch völlig unerforschten Gegenstandsbereichen i.a. keine Grundlage haben. Das Eintreten eines Sachverhalts etwa, der Inhalt einer (neuen) Prognose war, mag also häufig unvorhergesehen, unerwartet u.ä. sein, aber das Eintreten des Gegenteils wäre i.a. genauso unvorhergesehen, unerwartet u.ä. gewesen, und in solchen Fällen ist es intuitiv nicht angemessen, von einem Wunder zu sprechen (vgl. auch Fn.229). Gegen diese Überlegungen könnte man noch einwenden, daß man in unerforschten Gegenstandsbereichen den genannten Plausibilitätsüberlegungen folgen kann, nach denen unerforschte Sachverhalte und ihr Gegenteil jeweils die Wahrscheinlichkeit $1 / 2$ bekommen, aber nicht muß, weil epistemische Anfangswahrscheinlichkeiten gemäß orthodoxer Bayesianischer Positionen willkürlich festgelegt werden können. Auch wenn man dies tut, kann man aber nicht einem Sachverhalt und seinem Gegenteil zugleich Anfangswahrscheinlichkeiten von (fast) null zuordnen, so daß auch dann nicht alle oder auch nur die meisten nPEe vorher sehr unwahrscheinlich sein dürften.
} 
on ad hominem zu verstehen: Die Aussage eines Anhängers des Wunderarguments, daß Prognoseerfolge, Vereinheitlichungsleistungen etc. erklärungsbedürftig sind, läßt sich als Appell an vortheoretische Intuitionen und Bedürfnisse des Diskussionsgegners auffassen, und zwar als Hinweis darauf, daß er, der Diskussionsgegner, glaubt, daß es für die Prognoseerfolge, Vereinheitlichungsleistungen etc. eine Erklärung einer bestimmten Art gibt, und daß er außerdem eine solche Erklärung benötigt oder wünscht. Dabei ist die Art von Erklärung, auf die sich diese Überzeugung bzw. dieser Wunsch bezieht, eine Art, zu der die durch das Explanans der jeweiligen Version des Wunderarguments gelieferte gerade zählt, also eine deduktive semantische Erklärung für Prognoseerfolge etc., oder eventuell auch eine allgemeinere, weniger genau spezifizierte Art. ${ }^{263}$ Die vortheoretischen Intuitionen und Bedürfnisse, an die dabei appelliert wird, sind sozusagen im Idealfall explizite, denen sich der Diskussionsgegner bewußt ist, denkbar ist aber auch, daß erst der Appell dazu führt, daß bislang implizite Überzeugungen und Bedürfnisse artikuliert und explizit gemacht werden. Die Aussage eines Anhängers des Wunderarguments, daß Prognoseerfolge, Vereinheitlichungsleistungen etc. ein Wunder darstellen, läßt sich ebenfalls als Appell an vortheoretische Intuitionen des Diskussionsgegners auffassen, und zwar als Hinweis darauf, daß er, der Diskussionsgegner, überzeugt ist, daß es für die Prognoseerfolge etc. eine Erklärung einer bestimmten Art gibt, und andererseits aber auch Überzeugungen hat, die zu der ersten Überzeugung im Widerspruch stehen, daß er die Prognoseerfolge etc. also in diesem Sinn für wundersam, weil unerklärbar hält. Wenn der Diskussionsgegner infolge der Hinweise des Anhängers des Wunderarguments die Erklärungen akzeptiert, die das Wunderargument für die Prognoseerfolge etc. vorsieht, und dazu zuvor, wenn nötig (also im Fall eines wundersamen Explanandums), entgegenstehende Überzeugungen aufgibt, wird dadurch der Erklärungsbedarf gedeckt und das Wunder zum Verschwinden gebracht. Mit diesen Erläuterungen der Inanspruchnahme von Erklärungsbedarf und der Rede von "Wunder" in der Hand läßt sich jetzt die Frage angehen, welche argumentative Rolle beide beim Wunderargument spielen können und spielen.

Die Inanspruchnahme von Erklärungsbedarf und die Rede von Wundern, die sich bei den Anhängern des Wunderarguments finden, können offenbar, wie jede Argumentation, die an vortheoretische Intuitionen und Bedürfnisse appelliert, nur dann irgendwelche Überzeugungskraft entwickeln, wenn der jeweilige Diskussionsgegner diese Intuitionen und Bedürfnisse tatsächlich hat. Dies wird, wie schon erwähnt, bei reflektierten, konsequenten Antirealisten i.a. nicht der Fall sein, denn sie werden i.a. nicht die Überzeugung teilen, daß es für Prognoseerfolge etc. eine Erklärung der relevanten Art gibt, und keinen Wunsch nach einer solchen Erklärung haben. Dagegen ist es durchaus denkbar, daß weniger reflektierte und konsequente Antirealisten die fraglichen Intuitionen und Bedürfnisse haben, und vor allem auch, daß dies für Personen gilt, die noch keinen systematisch ausgearbeiteten Standpunkt in der Realismusdebatte eingenommen haben.

In welcher Weise können die Inanspruchnahme von Erklärungsbedarf und die Rede von einem Wunder bzw. die Tatsache, daß durch das Explanans des Wunderarguments der Erklärungsbedarf gedeckt und das Wunder zum Verschwinden gebracht werden kann, zur Überzeugungskraft des Wunderarguments beitragen, wenn das Wunderargument in einer Diskussion mit Personen eingesetzt wird, die die Einstufung des Explanandums als erklärungsbedürftig oder sogar als wundersam akzeptieren? Ein Diskussionsgegner, der Prognoseerfolge etc. für erklärungsbedürftig im erläuterten Sinn hält, hat den Wunsch nach einer Erklärung einer bestimmten Art dafür und glaubt, daß es eine solche Erklärung

\footnotetext{
${ }^{263}$ Gegen die letztere Möglichkeit spricht jedoch, daß sich dadurch kein Argument speziell für das Explanans des Wunderarguments ergeben dürfte.
} 
tatsächlich gibt. Dieser Wunsch wird ihn möglicherweise veranlassen, nach einer Erklärung zu suchen, und die Überzeugung, daß es eine solche Erklärung gibt, mag ihn dabei sozusagen zuversichtlich stimmen, daß das Ziel seiner Suche nicht illusorisch ist, es ist jedoch - einen Sonderfall ausgenommen (s.u.) - schwer zu sehen, was dieser Wunsch oder diese Überzeugung dazu beitragen könnten, ihn dazu zu veranlassen, den Schluß auf das Explanans zu ziehen, den das Wunderargument vorsieht. Entscheidend für die Frage, ob er diesen Schluß zieht oder nicht, ist offenbar, ob er das Inferenzschema akzeptiert, dem der vorgesehene Schluß folgt. Wenn er es akzeptiert (und die sonstigen Voraussetzungen für seine Anwendung gegeben sind), wird er diesen Schluß ziehen, wenn nicht, dann nicht; ob er selbst unabhängig von der Diskussion mit dem Anhänger des Wunderarguments den Wunsch nach einer Erklärung hatte, ist dafür nicht relevant, ${ }^{264}$ und die Überzeugung, daß es eine Erklärung gibt, ist mit diesem Schluß, insbesondere mit seiner Konklusion, verträglich, spielt für ihn aber ansonsten — einen Sonderfall wiederum ausgenommen keine erkennbare Rolle. ${ }^{265}$

Der Sonderfall ist der, das die Art der Erklärung, von der die Überzeugung handelt, so genau spezifiziert ist, daß dadurch das Explanans für ein konkretes Explanandum eindeutig ausgezeichnet ist. Jemand, der eine solche Überzeugung hat, wird gleichzeitig das entsprechende Explanans als Überzeugung akzeptieren, denn in einem solchen Sonderfall impliziert eine Aussage, daß es eine Erklärung der fraglichen Art gibt, offenbar das entsprechende Explanans; eine Überzeugung zu haben, daß es, in mehr oder weniger genau spezifizierten Fällen, eine so genau spezifizierte Erklärung gibt, ist offenbar äquivalent zum Akzeptieren eines "entarteten Grenzfalls" eines Inferenzschemas der Form (IBEsp), dessen Anwendungsbereich diese mehr oder weniger genau spezifizierten Fälle sind. ${ }^{266}$ In einem solchen Sonderfall wird also jemand, der Prognoseerfolge etc. für erklärungsbedürftig hält, auch das dadurch eindeutig ausgezeichnete Explanans akzeptieren. Ein solcher Sonderfall könnte etwa vorliegen, wenn jemand Erklärungsbedarf akzeptiert, der sich auf eine deduktive semantische Erklärung bezieht.

Ein Diskussionsgegner, der Prognoseerfolge etc. für ein Wunder, weil für nicht erklärbar hält, glaubt, daß es für sie eine Erklärung einer bestimmten Art gibt, hat aber außerdem andere, dazu im Widerspruch stehende Überzeugungen; damit ist die Gesamtheit seiner Überzeugungen inkohärent. Dies ist, wie erwähnt, bei weniger konsequenten und reflektierten Antirealisten zumindest denkbar, etwa bei Positivisten und Operationalisten, gegen die Putnam seine Version des Wunderarguments richtet, deren zentrale Thesen über die Semantik wissenschaftlicher Ausdrücke und Sätze mit den den Explanantia des Wunderarguments im Widerspruch stehen. Ein Diskussionsgegner, den man auf einen solchen Widerspruch in der Gesamtheit seiner Überzeugungen hinweist, wird diesen beseitigen, in dem er eine oder mehrere der unverträglichen Überzeugungen aufgibt; dies kann im

\footnotetext{
${ }^{264}$ Im Kontext einer Diskussion wäre es offenbar völlig unplausibel, einen Schluß nicht zu ziehen, für den man alle (vom jeweiligen Diskussionsgegner genannten) Prämissen und das Inferenzschema akzeptiert, bloß weil man keinen Bedarf für die Konklusion hat, sie einen nicht interessiert o.ä.

${ }^{265}$ Ein illustrierendes Beispiel: Wenn Sherlock Holmes den Tod des Grafen für erklärungsbedürftig hält, also glaubt, daß es dafür eine Erklärung einer bestimmten Art gibt (nämlich eine kausale Erklärung dadurch, daß eine der am Vortag im Schloß anwesenden Personen den Grafen vergiftet hat), und eine solche Erklärung wünscht, trägt dies per se nichts dazu bei, zu einer solchen Erklärung zu gelangen. Wenn er dagegen ein Inferenzschema der Form (IBE) akzeptiert und außerdem der Überzeugung ist, daß die beste Erklärung ist, daß der Butler einen Giftpilz in das Essen des Grafen gemischt hat, wird er schließen, daß es der Butler war.

${ }^{266}$ Wenn ein Diskussionsgegner in diesem Sinn effektiv ein solches Inferenzschema akzeptiert, muß das nicht dasselbe Schema sein wie das, was der Anhänger des Wunderargument selbst für den Schluß auf dessen Explanans vorgesehen hatte; dennoch führt es im konkreten Fall zur selben Konklusion.
} 
Fall wundersamer Prognoseerfolge etc. die Überzeugung sein, daß es dafür eine Erklärung (einer bestimmten Art) gibt, oder die dem widersprechenden Überzeugungen, und das wären in Putnams Fall die positivistischen oder operationalistischen Thesen. Welche von beiden Optionen er wählt, dürfte i.a. von den Einzelheiten seiner sonstigen Überzeugungen und seiner erkenntnistheoretischen Position abhängen; etablierte allgemeine Regeln zur Beseitigung von Inkohärenzen in einem Überzeugungssystem gibt es nicht, ${ }^{267}$ aber eine plausible grobe Annahme ist vielleicht, daß man eher an gut gestützten Überzeugungen festhält, deren Aufgabe große Modifikationen am restlichen Überzeugungssystem nach sich ziehen würde, und weniger gut gestützte Überzeugungen, die sich ohne größere Folgen aufgeben lassen, eher fallen läßt, und im Lichte einer solchen Annahme erscheint es wenig wahrscheinlich, daß jemand eine philosophische Grundüberzeugung zugunsten einer eher speziellen Überzeugung über die Existenz von Erklärungen für ziemlich spezielle Sachverhalte aufgibt. Wenn jemand nichtsdestotrotz zwecks Beseitigung der Inkohärenz, auf die ihn der Anhänger des Wunderarguments hingewiesen hat, seine positivistischen oder operationalistischen Thesen aufgibt, hätte der Anhänger des Wunderarguments damit den Diskussionserfolg erzielt, daß sein Diskussionsgegner sozusagen einen deutlichen Schritt weg von einer antirealistischen Position gegangen ist, um das Wunder zum Verschwinden zu bringen. Den Schluß, den das Wunderargument vorsieht, hätte dieser Diskussionsgegner damit aber noch nicht gezogen, das Explanans des Wunderarguments noch nicht akzeptiert und damit auch noch keine realistischen Thesen. Für die Frage, ob er diesen Schluß außerdem zieht oder nicht, ist offenbar wiederum entscheidend, ob er das Inferenzschema akzeptiert, dem der Schluß folgt; die Charakterisierung des Explanandums als Wunder, insbesondere also die Überzeugung, daß es für das Explanandum eine Erklärung gibt, spielt für diesen Schluß - einen Sonderfall der beschriebenen Art ausgenommen — wiederum keine erkennbare Rolle. Ein solcher Sonderfall könnte etwa vorliegen, wenn jemand die Überzeugung hat, daß es für Prognoseerfolge etc. eine deduktive semantische Erklärung gibt.

Eine an dieser Stelle naheliegende Vermutung könnte sein, daß jemand, der Prognoseerfolge etc. als erklärungsbedürftig oder als wundersam, weil nicht erklärbar akzeptiert, damit Überzeugungen hat, die (auch wenn kein Sonderfall der beschriebenen Art vorliegt) als Begründung für das Inferenzschema fungieren können, das die jeweilige Version des Wunderarguments in Anspruch nimmt. Wie eine solche Begründung aussehen sollte, ist jedoch nicht zu erkennen, denn als Begründung für ein Inferenzschema kommen vor allem induktive oder induktiv extrapolierende Schlüsse in Frage, ${ }^{268}$ und in solchen Argumenten spielt eine Überzeugung, daß es Erklärung einer bestimmten Art gibt, und ein Wunsch nach einer solchen Erklärung offenbar keine Rolle.

\section{Fazit}

Für die Redeweisen von Erklärungsbedarf und von Wundern, die sich bei vielen Anhängern des Wunderarguments finden, lassen sich plausible Lesarten angeben, in diesen Lesarten tragen jedoch das Vorliegen von Erklärungsbedarf oder eines Wunders allenfalls in zwei speziellen Sonderfällen etwas zur Überzeugungskraft des Wunderarguments bei.

Die Explananda des Wunderarguments als erklärungsbedürftig oder gar als Wunder zu präsentieren stellt einen Appell an vortheoretische Intuitionen des Diskussionsgegners dar und kann daher ohnehin nur dann irgendwelche Überzeugungskraft haben, wenn dieser

\footnotetext{
${ }^{267} \mathrm{Vgl}$. auch S.451.

${ }^{268}$ Siehe S.261. s.a. Kap.8, bes. S.169.
} 
diese Intuitionen tatsächlich hat, aber selbst dann tragen sie, wie oben diskutiert, allenfalls in zwei Sonderfällen etwas zur Überzeugungskraft des Wunderarguments bei: Ein Diskussionsgegner, der, indem er die Explananda als erklärungsbedürftig oder wundersam anerkennt, auch anerkennt, daß es für sie eine Erklärung einer so genau spezifizierten Art gibt, daß das Explanans in jedem konkreten Fall eindeutig bestimmt ist, akzeptiert damit effektiv einen "entarteten Grenzfall" eines Inferenzschemas der Form (IBEsp), der Schlüsse auf die gemäß dem Wunderargument vorgesehenen Explanantia gestattet, ${ }^{269}$ und damit noch nicht unbedingt die Version des Wunderarguments, die dessen Anhänger präsentiert, aber jedenfalls eine andere, "speziellere" Version, die den "entarteten Grenzfall" des Schemas (IBEsp) instantiiert und zur selben Konklusion führt. Ferner könnte ein Diskussionsgegner, der operationalistische, positivistische oder ähnliche antirealistische Grundüberzeugungen hat und die Explananda des Wunderarguments als wundersam, weil aufgrund dieser Grundüberzeugungen unerklärbar anerkennt, deswegen die antirealistischen Grundüberzeugungen aufgeben; daß er es tut, scheint jedoch aus den genannten Gründen i.a. eher unwahrscheinlich, und sogar wenn er es tut, ist damit nicht die Konklusion des Wunderarguments erreicht, sondern sozusagen nur ein (wenn auch signifikantes) Hindernis auf dem Weg dahin beseitigt. In allen anderen Fällen trägt das Vorliegen von Erklärungsbedarf oder gar eines Wunders auch dann nichts zur Überzeugungskraft des Wunderarguments bei, wenn der Diskussionsgegner dieses Vorliegen akzeptiert.

Damit ist natürlich nichts darüber gesagt, ob das Wunderargument bzw. seine diversen Versionen überzeugungskräftig, plausibel o.ä. ist, sondern lediglich, daß das Präsentieren des Explanandums als erklärungsbedürftig oder sogar als ein Wunder, wie es einige seiner Anhänger tun, im allgemeinen, d.h. abgesehen von Sonderfällen der beschriebenen Art, nichts zu seiner Überzeugungskraft beiträgt. Worauf es ankommt, ist, ob der jeweilige Diskussionsgegner das Inferenzschema akzeptiert, das das Wunderargument in Anspruch nimmt, und das hat mit Vorliegen von Erklärungsbedarf oder Wundern im allgemeinen, d.h. wiederum abgesehen von Sonderfällen der beschriebenen Art, nichts zu tun.

Wenn man zu diesem Befund noch hinzunimmt, daß reflektierte, konsequente Antirealisten die vortheoretischen Intuitionen nicht haben dürften, an die mit dem Hinweis auf Erklärungsbedarf und Wunder appelliert wird, sieht man also, daß die argumentative Rolle, die die Inanspruchnahme von Erklärungsbedarf und die Rede von Wundern beim Wunderargument spielen können, eine auf sehr spezielle Diskussionskonstellationen beschränkte ist: Nur bei Personen, die (noch) keine reflektierte, konsequente antirealistische Position einnehmen und die außerdem die genannten, einigermaßen speziellen Intuitionen haben, läßt sich möglicherweise dadurch eine argumentative Wirkung der beschriebenen Art erzielen, daß man das Explanandum als erklärungsbedürftig oder sogar als ein Wunder präsentiert.

Der von vielen Anhängern des Wunderarguments nahegelegte Eindruck, daß dessen Überzeugungskraft entscheidend davon abhängt, daß das Explanandum erklärungsbedürftig ist oder ein Wunder darstellt, erweist sich also bei genauerer Betrachtung als falsch. Durch diese Einsicht muß das Wunderargument keineswegs seine Überzeugungskraft einbüßen, denn sein Appeal, der, wie Fine sich ausdrückt, "primitive pull", den es auf viele ausübt, dürfte tatsächlich wenig mit Erklärungsbedarf oder Wundern zu tun haben, sondern eher damit, daß jemand, der diesen "pull" empfindet, ein Inferenzschema akzeptiert, das von den Prämissen des Wunderarguments zu seiner Konklusion führt.

Für den zu Beginn dieses Abschnittes genannten Einwand von van Fraassen, daß bei

\footnotetext{
${ }^{269}$ Auch wenn die Inferenzschemata nicht identisch sein müssen, sondern z.B. der "entartete Grenzfall" ein deutlich spezielleres Schema darstellen kann.
} 
den Explananda des Wunderarguments kein Erklärungsbedarf vorliegt oder daß sich daraus jedenfalls argumentativ kein Kapital schlagen läßt, ergibt sich somit der Befund, daß er berechtigt ist, aber ohnehin einen weitgehend irrelevanten Punkt des Wunderarguments betrifft: Van Fraassen kann von seiner Position aus zu Recht darauf hinweisen, daß er als reflektierter, konsequenter Antirealist die Intuition nicht hat, daß bei den Explananda des Wunderarguments Erklärungsbedarf vorliegt. Wie oben diskutiert, kann das Vorliegen von Erklärungsbedarf aber in einer plausiblen Rekonstruktion des Wunderarguments ohnehin nur in sehr speziellen Diskussionskontexten eine argumentative Rolle spielen.

\subsection{Fazit}

Unter der Bezeichnung Wunderargument (und ähnlichen Bezeichnungen ${ }^{270}$ ) ist in der Realismusdebatte ein ganzer Cluster von Argumenten präsentiert worden, deren gemeinsame Idee ist, mit Hilfe von Erklärungen für bestimmte Erfolge oder Leistungen, die wissenschaftliche Theorien erzielen oder ermöglichen, für realistische Thesen zu argumentieren. Die obigen Untersuchungen haben gezeigt, daß die verschiedenen Argumentvarianten sich bei genauerer Betrachtung untereinander teilweise deutlich unterscheiden hinsichtlich der Explananda, der Explanantia, der Art von Erklärung, die letztere für erstere liefern, und der in Anspruch genommenen Inferenzschemata. Die Bewertung des Wunderarguments fällt daher nicht so einheitlich aus wie man es angesichts der Bezeichnung "das Wunderargument" vielleicht erwartet. Darüber hinaus zeigte sich, daß für viele Varianten des Wunderarguments eine fundierte Beurteilung derzeit noch nicht möglich ist, weil dazu detaillierte wissenschaftshistorische und philosophische Detailuntersuchungen erforderlich sind, die zur Zeit noch nicht vorliegen.

Der von Laudan aus wissenschaftshistorischer Perspektive vorgetragene Einwand erscheint durchschlagend gegen Varianten des Wunderarguments wie die von Boyd, die als Explanans eine generelle Aussage über die (annähernde) Wahrheit aller wissenschaftlichen Theorien o.ä. vorsehen. Bei Varianten des Wunderarguments, die als Explanans Aussagen über einzelne Theorien und/oder Aussagen, die anstelle der (annähernden) Wahrheit dieser Theorien ein abgeschwächtes Explanans vorsehen, und/oder die sich als Explanandum auf einen eng spezifizierten Bereich beziehen (etwa auf nPEe), bleibt die Frage, wieviel Durchschlagskraft Laudans Einwand gegen sie hat, bis zum Vorliegen hinreichend detaillierter wissenschaftshistorischer Studien offen, man kann die Situation aus realistischer Perspektive vielleicht aber vorsichtig optimistisch einschätzen, da es eher unplausibel aussieht, daß aufgrund historischer Erfahrungen, wie sie Laudan gegen das Wunderargument ins Feld führt, für alle oben genannten oder skizzierten Versionen gezeigt werden kann, daß sie nicht nur in Einzelfällen fehlbar sind, sondern systematisch falsche Konklusionen liefern.

Die Diskussion der Unterbestimmtheitsproblematik ergab, daß das Wunderargument bzw. seine diversen Varianten dadurch nicht allgemein widerlegt oder als wertlos erwiesen werden, daß sie aber in überzeugender Weise nur in Situationen anwendbar sind, in denen es zu den Theorien, die für die jeweils als Explanandum fungierenden Erfolge verantwortlich sind, keine empirisch äquivalenten Theorien gibt, die nicht aus anderen Gründen (etwa induktiver Art) ausgeschlossen werden können. Ob es solche Situationen in der Praxis gibt, wie häufig sie sind etc., muß wiederum durch detaillierte Studien konkreter Fälle ermittelt werden und daher hier offen gelassen werden.

\footnotetext{
${ }^{270}$ Siehe S.185.
} 
Die Untersuchung von Alternativen zu den Erklärungen, die das Wunderargument für die als Explanandum fungierenden Erfolge vorsieht, hat gezeigt, daß die in der Literatur (von van Fraassen und Fine) angegebenen Erklärungen keine konkurrierenden Explanantia für dieselben Explananda liefern, daß aber Alternativen dieser Art denkbar sind, insbesondere in Situationen, in denen es zu den erfolgreichen Theorien empirisch äquivalente Theorien gibt. Um in solchen Situationen dennoch den Schluß auf das Explanans ziehen zu können, das das Wunderargument vorsieht, muß man entweder über Kriterien verfügen, die dieses Explanans als das beste auszuzeichnen erlauben, oder man muß auf eine (evtl. modifizierte) Variante des Wunderarguments zurückgreifen, die ein Inferenzschema in Anspruch nimmt, das die vorgesehene Art von Erklärung so eng spezifiziert, daß die konkurrierenden Alternativen nicht darunter fallen. Welche Varianten des Wunderarguments sich in dieser Weise in der Praxis als in der von realistischer Seite gewünschten Weise anwendbar erweisen, muß durch weitere Untersuchungen zur (in der Literatur notorisch vernachlässigten) Frage der Kriterien für die beste Erklärung sowie, wiederum, durch Untersuchung konkreter Fälle festgestellt werden und daher hier offenbleiben.

Der Petitio-Principii-Einwand entwertet Varianten des Wunderarguments, die ein allgemeines Inferenzschema der Form (IBE) in Anspruch nehmen, die also eine Instantiierung eines solchen allgemeinen Schemas darstellen, nicht indem er nachweist, daß diese Argumentvarianten zu falschen Konklusionen führen, sondern indem er zeigt, daß sie gegen einen Diskussionsgegner keine Überzeugungskraft entwickeln können. Es lassen sich aber, wie oben diskutiert, andere Varianten des Wunderarguments angeben, die der PetitioPrincipii-Einwand nicht trifft, nämlich solche, die ein Inferenzschema der Form (IBEsp) in Anspruch nehmen, dessen Anwendungsbereich "hinreichend eng" spezifiziert ist.

Die als letzter Punkt untersuchte Frage, in welchem Sinn die Explananda, auf die sich das Wunderargument in seinen verschiedenen Varianten bezieht, erklärungsbedürftig oder "wundersam" sind und welche argumentative Rolle die Inanspruchnahme von Erklärungsbedarf und die Rede von "Wunder" spielen, betrifft keinen Einwand gegen das Wunderargument, sondern "nur" Unklarheiten über die argumentativen Ressourcen, aus denen das Wunderargument seine Überzeugungskraft bezieht. Es ließen sich plausible Lesarten für 'erklärungsbedürftig' und für 'Wunder' angeben, die bestimmte vortheoretische Intuitionen möglicher Diskussionsgegner involvieren, diese können aber, wie gezeigt, allenfalls in speziellen Sonderfällen etwas zur Überzeugungskraft des Wunderarguments beitragen. Angesichts dieses Resultats, daß die Rede von Erklärungsbedarf und von Wunder keine wesentliche argumentative Funktion haben, erscheint die Bezeichnung "Wunderargument" als eher irreführend; angemessener wäre vielleicht eine Bezeichnung wie "Erfolgsargument".

Es zeigt sich also, daß jede Variante des Wunderarguments ein mehr oder weniger allgemeines Inferenzschema der Form (IBE) oder (IBEsp) in Anspruch nimmt und daß die Antwort auf die Frage, ob die diskutierten Einwände durchschlagend sind oder wieviel Angriffsfläche ihnen geboten wird, davon abhängt, wie dieses Inferenzschema genau zu spezifizieren ist. Eine fundierte Einschätzung, ob es Varianten des Wunderarguments gibt, die durch keinen der Einwände getroffen werden und, wenn ja, welche das sind, ist hier, mangels der dazu erforderlichen wissenschaftshistorischen und philosophischen Detailuntersuchungen, nicht möglich. Plausible Kandidaten dafür sind aber aus den diskutierten Gründen eher Varianten des Wunderarguments, die ein Inferenzschema der Form (IBEsp) mit einigermaßen eng spezifiziertem Anwendungsbereich instantiieren. Wieviel Überzeugungskraft die Varianten des Wunderarguments in der Realismusdebatte entwickeln können, wird aber letztlich vom Ergebnis solcher Detailuntersuchungen abhängen.

Da jede Variante des Wunderarguments ein solches Inferenzschema in Anspruch neh- 
men muß, kann es Überzeugungskraft offenbar jedenfalls nur in der Diskussion mit Gegnern entwickeln, die das jeweilige Inferenzschema akzeptieren. Wie ein solches Schema gegenüber Diskussionsgegnern, die dies nicht tun, begründet werden kann, wird von den Anhängern des Wunderarguments - und daher auch an dieser Stelle — nicht diskutiert. Dieses Problem führt offenbar auf die im Kapitel über Kontinuitätsargumente aufgekommene, allgemeine erkenntnistheoretische Grundüberzeugungen berührende Frage, wie ein Inferenzschema legitimiert werden kann. 


\section{Teil III}

\section{Drei neuere Positionen in der Realismusdebatte}



In diesem Abschnitt sollen drei neuere, für die wissenschaftstheoretische Realismusdebatte relevante Positionen vorgestellt und diskutiert werden, die realistischen Thesen und Standpunkten in verschiedenen Hinsichten und in unterschiedlichem Maß kritisch gegenüberstehen. Nach der Analyse der Argumente für wissenschaftlichen Realismus im vorigen Abschnitt sollen damit hier drei einflußreiche Positionen untersucht werden, die (in unterschiedlichem Maß) als Konkurrenten realistischer Positionen auftreten.

Als - für den Stand der neueren Realismusdebatte einigermaßen repräsentative Alternativen zu realistischen Positionen wird zum einen Bas van Fraassens konstruktiver Empirismus diskutiert, dann der experimentelle Realismus von Ian Hacking und Nancy Cartwright und schließlich Andrew Pickerings Sozialkonstruktivismus. 


\section{Kapitel 10}

\section{Bas van Fraassens konstruktiver Empirismus}

\section{$10.1 \quad$ Einleitung}

Bas van Fraassens konstruktiver Empirismus markiert unter den Positionen, die in Argumentationsstil und Themenzugriff an der traditionellen, formal ausgerichteten Wissenschaftstheorie orientiert sind, die wahrscheinlich elaborierteste antirealistische. Van Fraassen sieht sich selbst in der Traditionslinie des Empirismus. Sein erklärtes Ziel ist es, eine zeitgemäße empiristische Position zu entwickeln, die den Fehler seiner Vorgänger, der logischen Positivisten, vermeidet, sich zu sehr auf formale Sprachen als "philosophisches Werkzeug" zu stützen, was zu einer verzerrenden Perspektive auf die zentralen wissenschaftsphilosophischen Probleme führte. Von seinen umfangreichen Arbeiten zu diesem Projekt sollen hier nur seine Argumentation in der Realismusdebatte und die damit zusammenhängenden Aspekte diskutiert werden. ${ }^{1}$

\subsection{Konstruktiver Empirismus}

\subsubsection{Semantischer Realismus plus ontologischer, epistemischer und axiologischer Antirealismus}

Van Fraassens Position in der Realismusdebatte, die er konstruktiven Empirismus (constructive empiricism $)^{2}$ nennt, kombiniert semantischen Realismus mit ontologischem, epistemischem und axiologischem Antirealismus. Sie läßt sich im wesentlichen in drei Punkten zusammenfassen, die jeweils die Gesamtheit aller wissenschaftlichen Theorien betreffen:

Semantische realistische Thesen der Form (SR1) und (SR2): Wissenschaftliche Theorien bzw. Sätze "have truth conditions entirely independent of human activity

\footnotetext{
${ }^{1}$ Übergangen wird hier aus Platzgründen die von van Fraassen propagierte sogenannte semantische Theorienauffassung (semantic view of theories; [vFra80], Kap.3, [vFra87]), die ihm die Vermeidung der Fehler der Wissenschaftstheorie des logischen Positivismus erlauben soll. Diese Konzeption ist hinsichtlich der Realismusproblematik im wesentlichen neutral, was sich u.a. daran zeigt, daß auch Realisten wie Ronald Giere sie vertreten (vgl. [Gier88]). Ferner wird nicht eingegangen auf van Fraassens Überlegungen zur "Implementierung" seiner Position mit formalen Mitteln, sprich: durch eine unorthodoxe Version des Bayesianismus, die bereits in Kap.9.7 erwähnt wurde (S.215).

${ }^{2}$ [vFra80], S.6.
} 
or knowledge" 3 , "[they] can be true or false, [they ...] can describe reality correctly or incorrectly" 4 . Theorien sind in allen Teilen wörtlich zu nehmen ("to be literally construed" $)^{5}$, also auch in den Teilen, die sich auf Unbeobachtbares beziehen. ${ }^{6}$

Das Bestreiten ontologischer und epistemischer realistischer Thesen: Wissenschaftliche Theorien werden nicht ausschließlich nach dem Kriterium der empirischen Adäquatheit ausgewählt, d.h. danach, ob ihr beobachtbarer Teil wahr ist (soweit getestet). Vielmehr kommen dabei weitere, von van Fraassen als pragmatisch bezeichnete Kriterien wie Informationsgehalt, Erklärungspotential usw. zum Einsatz. Das ist nach van Fraassen faktisch in der Praxis der Wissenschaft so, aber auch legitimerweise: Nur die Wahrheit beobachtbarer Konsequenzen einer Theorie stellt zwingende empirische Evidenz dar, die diese Theorie vor anderen denkbaren Theorien für denselben Bereich von Gegenständen, Phänomenen o.ä. auszeichnen kann; da niemals in dieser Weise zwingend eine Theorie eindeutig ausgezeichnet wird, bleiben zwangsläufig Spielräume offen, in denen andere, pragmatische Kriterien wirksam werden können, wenn eine Theorie ausgewählt werden soll. Daher kann man für ontologische oder epistemische realistische Thesen nach van Fraassen prinzipiell keine guten Gründe haben, auch nicht in bezug auf Theorien, die in den real-existierenden Wissenschaften akzeptiert werden, bzw. in bezug auf die Sachverhalte und Entitäten, von denen diese handeln. Mit guten Gründen glauben kann man nach van Fraassen allenfalls, daß Theorien empirisch adäquat sind; bezüglich ihres unbeobachtbaren Teils muß man eine agnostische Haltung einnehmen, sich also mangels guter Gründe eines Urteils über Wahrheit oder Falschheit enthalten, und damit auch ontologischer und epistemischer realistischer Thesen. ${ }^{7}$

Das Bestreiten axiologischer realistischer Thesen: Ziel der Wissenschaft sind nach van Fraassen, im Einklang mit der beschriebenen epistemischen Sachlage, "nur" empirisch adäquate Theorien, nicht im ganzen wahre Theorien. ${ }^{8}$

\subsubsection{Die Unterscheidung beobachtbar/unbeobachtbar}

Von zentraler Bedeutung für van Fraassens Position ist also die Unterscheidung beobachtbar/unbeobachtbar. Seine Explikation dieser Unterscheidung ist bereits oben ${ }^{9}$ diskutiert worden; im Kern lautet sie:

\footnotetext{
${ }^{3}[\mathrm{vFra} 80], \mathrm{S} .38$.

4 [vFra89a], S.192.

${ }^{5}$ [vFra80], S.10.

${ }^{6}$ Van Fraassens Position als (u.a.) semantischen Realismus (im in der Einleitung erläuterten Sinn) zu klassifizieren, trifft genaugenommen seine Intentionen nicht exakt, was mit seiner "semantischen Theorienauffassung" (siehe Fn.1) zusammenhängt. (Deswegen findet sich z.B. bei ihm nichts zur Frage einer Wahrheits-, Bedeutungs- oder Referenztheorie.) Für die Fragestellung der Realismusdebatte hängt davon jedoch nichts ab.

${ }^{7}$ [vFra80], S.11ff., [vFra85], S.276ff., [vFra89a], S.192f. Van Fraassens Etikettierung seiner Position als konstruktiver Empirismus soll als Ausdruck dieses epistemischen Antirealismus verstanden werden (und hat also nichts mit konstruktivistischen Positionen zu tun): Da man niemals gute Gründe für die Annahme haben kann, daß eine Theorie wahr ist, sollte man nach van Fraassen nicht von der Entdeckung von Theorien oder Modellen sprechen (was nur bei wahren Theorien Sinn machen würde), sondern besser von der Konstruktion vom empirisch adäquaten Theorien und Modellen; vgl. [vFra80], S.5.

${ }^{8}$ [vFra80], S.12ff., [vFra89a], S.192f., [vFra91], S.4.

${ }^{9}$ Abschnitt 8.1.2.
} 
" $\mathrm{X}$ is observable if there are circumstances which are such that, if $\mathrm{X}$ is present to us under those circumstances, then we observe it." 10

Es handelt sich um eine Unterscheidung von Eigenschaften, Entitäten, Ereignissen oder Sachverhalten, nicht von Ausdrücken bzw. Sätzen, die in dem Sinne anthropozentrisch ist, daß sie von den Wahrnehmungsfähigkeiten der Mitglieder der "epistemischen Gemeinschaft", sprich: von der Beschaffenheit des normalen Wahrnehmungsapparates der Spezies Mensch abhängt.

Van Fraassen meint, daß die Ausdrücke und Sätze, mit denen Menschen beschreiben, was sie beobachten, häufig solche sind, die auch in wissenschaftlichen Theorien vorkommen. Dies gilt nicht nur für wissenschaftliche Beobachtungskontexte im Labor o.ä., sondern auch (und mit zunehmender Durchdringung der Alltagswelt durch Wissenschaft und Technik immer mehr) für alltagsweltliche Beobachtungssituationen. Van Fraassen bezeichnet die heute verwendeten Sprachen daher als "theorieinfiziert", er glaubt nicht, daß es eine theorieunabhängige Beobachtungssprache im Sinne des logischen Positivismus gibt. ${ }^{11}$

\subsubsection{Die Unterscheidung akzeptieren/glauben}

Eine terminologische Besonderheit bei van Fraassen ist seine Verwendung einer technischen Unterscheidung zwischen 'eine Theorie akzeptieren' (acceptance) und 'eine Theorie glauben' bzw. von ihr 'überzeugt sein' (belief): Die Begriffe 'Überzeugung' und 'glauben' verwendet van Fraassen in der gängigen Weise; von einer Theorie überzeugt sein oder sie glauben impliziert, sie für wahr zu halten. Eine Theorie zu akzeptieren, bedeutet dagegen in van Fraassens Sprechweise in einer Hinsicht weniger, nämlich "nur" zu glauben, daß die Theorie empirisch adäquat ist, in einer anderen Hinsicht aber mehr, nämlich sich sozusagen auf den Gebrauch der Theorie für wissenschaftliche Zwecke zu verpflichten, d.h. sie für wissenschaftliche Erklärungen heranzuziehen, Forschungsprogramme daran zu knüpfen u.ä. ${ }^{12}$ Ein Wissenschaftler, der eine Theorie akzeptiert (in van Fraassens Sinn des Wortes), verhält sich also zu ihrem unbeobachtbaren Teil agnostisch, arbeitet aber nichtsdestotrotz in seiner wissenschaftlichen Praxis uneingeschränkt damit.

\subsubsection{Van Fraassens Ideal epistemischer Rationalität}

Grundlegend für van Fraassens Position in der Realismusdebatte ist eine Art Ideal epistemischer Rationalität: Sich epistemisch rational zu verhalten, heißt nach van Fraassen, seine Überzeugungen im Rahmen der Grenzen zu halten, die durch die Erfahrung gezogen werden, und das heißt, daß durch Beobachtungen ein Bereich von Theorien, nämlich der Bereich der (nach dem zum jeweiligen Zeitpunkt vorliegenden Kenntnisstand) empirisch adäquaten, eingegrenzt wird, innerhalb dessen sich die Überzeugungen einer rationalen Person halten müssen. Ein Realist, der eine bestimmte Theorie glaubt, die innerhalb dieses Spielraumes liegt (etwa weil sie Theorietugenden wie Einfachheit oder Erklärungsleistungen aufweist), überschreitet damit also nicht die Grenzen des Bereiches epistemischer Rationalität. Dennoch hat van Fraassen für eine solche Haltung nur "Verachtung" 13 übrig, weil sie sozusagen nicht epistemisch enthaltsam genug ist, sondern sich dazu hinreißen läßt, ohne hinreichende Gründe eine Theorie nicht nur zu akzeptieren, sondern zu glauben. ${ }^{14}$

\footnotetext{
${ }^{10}$ [vFra80], S.16; s.a. S.143, [vFra80], S.13ff., 57ff., [vFra85], S.253f., [vFra92], S.18ff.

${ }^{11}$ Siehe z.B. [vFra80], S.14f., 56ff., 80ff., [vFra92], S.17f.

${ }^{12}$ Vgl. [vFra80], S.12f., 18, [vFra85], S.276ff.

13 "Disdain", [vFra85], S.252, 255.

${ }^{14}$ Siehe dazu [vFra85], S.247ff., 275ff., 286f., [vFra89a], S.171f.
} 
Van Fraassen versteht seinen konstruktiven Empirismus, wie schon gesagt, als zeitgemäße Form einer empiristischen Position im Bereich der Wissenschaftstheorie, und er interessiert sich innerhalb der Realismusdebatte im wesentlichen nur für die Auseinandersetzung mit realistischen Positionen. Vor diesem Hintergrund erscheint die Art und Weise natürlich, wie van Fraassen für seinen agnostischen epistemischen Antirealismus plädiert: So etwas wie "positive" Argumente für antirealistische Thesen finden sich bei ihm nicht, wohl aber "destruktive" Einwände gegen verschiedene von Anhängern realistischer Positionen vorgetragene Argumente für ontologische oder epistemische realistische Thesen. Van Fraassens Projekt ist in erster Linie, eine haltbare antirealistische Position zu formulieren und zu verteidigen, sowie zu diesem Zweck zu den wissenschaftsphilosophischen Themen, die mit der Realismusdebatte zusammenhängen (Erklärung, Gesetze etc.), konsistente Theorien als antirealistische Alternativen zu den entsprechenden realistischen Theorien zu erarbeiten. In der Diskussion mit Realisten, die weiterreichende Wissensansprüche erheben als er, beschränkt er sich darauf, deren Argumente zu unterminieren. ${ }^{15}$

Den Kern seiner empiristischen Position, die er dabei verteidigt, hat van Fraassen in seinen früheren Arbeiten beschrieben als die empiristische Grundüberzeugung, daß Erfahrung die einzige Quelle von Informationen über die Welt ist:

"[...] the core doctrine of empiricism is that experience is the sole source of information about the world and that its limits are very strict [...] I explicate the general limits as follows: experience can give us information only about what is both observable and actual." 16

Neuerdings verwirft er diese Charakterisierung seiner Position, weil sie auf eine inhaltliche Überzeugung über bestimmte Sachverhalte in der Welt hinausliefe, die seiner Ansicht nach nicht gerechtfertigt werden kann, nämlich auf eine Überzeugung über Personen und ihre Fähigkeiten, Gegenstände und Sachverhalte sinnlich wahrnehmen und dadurch Überzeugungen zu gewinnen. ${ }^{17}$ Statt durch eine Überzeugung charakterisiert van Fraassen den Kern seiner empiristischen Position jetzt als eine Art Haltung oder Einstellung gegenüber den Wissenschaften ("attitude toward science", "stance", "orientation"18), die zwar auch noch bestimmte Überzeugungen involviert, vor allem aber eine Art Ideal epistemischer Rationalität:

"[Some aspects of] science [...] are valued so highly as to set an ideal for practical and theoretical reason in general". ${ }^{19}$

Dieses Ideal sieht van Fraassen durch die epistemische Praxis der real-existierenden Wissenschaften wenigstens teilweise oder näherungsweise realisiert, es hätte seiner Ansicht nach aber auch unabhängig von seiner tatsächlichen Realisierung Bestand. ${ }^{20}$ Im Zentrum dieses Ideals steht die Art und Weise, wie man nach van Fraassen in den Wissenschaften mit Tatsachenfragen umgeht (oder jedenfalls umgehen sollte): ${ }^{21}$ Grundlage einer Antwort auf Tatsachenfragen sind Beobachtungen mit dem bloßen Auge (und falls die Verläßlichkeit

\footnotetext{
${ }^{15}$ Vgl. dazu Kap.9 und 8.

${ }^{16}$ [vFra85], S.253, Sperrung im Original; s.a. S.257.

17 [vFra94a, vFra95].

18 [vFra94a], u.a. S.318, [vFra95], u.a. S.83, 86.

19 [vFra94a], S.326.

${ }^{20}$ Siehe [vFra94a], bes. S.328ff.

21 "What is maintained here is a certain attitude, expressed by saying that I regard a certain approach to factual questions as paradigmatically rational"; [vFra94a], S.333.
} 
eines Beobachters in Frage steht, die Übereinstimmung mehrerer Beobachter ${ }^{22}$ ); darauf aufbauend werden Theorien als empirisch adäquat (oder nicht) beurteilt. Überzeugungen über Unbeobachtbares sind nicht in rationaler Weise zu begründen (auch dann nicht, wenn sie durch die jeweils vorliegenden rational begründeten Überzeugungen nicht ausgeschlossen werden, die Grenzen epistemischer Rationalität also nicht überschreiten) und werden nicht angestrebt:

"[...] an empiricist [...] stance would [...] involve a characterization of what science is (in my opinion it is a pursuit of empirical adequacy)". ${ }^{23}$

Sein "kognitives Leben" gemäß diesem Ideal zu führen, erfordert ein distanziertes Verhältnis zu den eigenen Überzeugungen und ein scharfes Bewußtsein von den eigenen Neigungen und Dispositionen, dogmatisch an Überzeugungen festzuhalten oder Überzeugungen zu erwerben, die die Grenzen menschlicher Erkenntnismöglichkeiten ignorieren:

"What empiricists have shared over the centuries [...] has not most obviously been a set of beliefs. More in evidence have been denials, in the sense of refusals to believe [...]. [It] is the celebration of a certain kind of freedom from oneself: One's own theoretical convictions, however much valued, must be always ready for suspension so as to allow a more neutral, less belief-ridden inquiry into the facts to which we have access. The spiritual tactic to be prized above all, when any factual question arises, is to find some method of inquiry neutral in its assumptions between oneself and one's actual or imagined opponents. This is not a belief, but an attitude toward the role of beliefs - a proper aesthetic distance to be preserved." 24

Van Fraassens Position in der wissenschaftstheoretischen Realismusdebatte formuliert also so etwas wie eine Rationalitätskonzeption oder ein Ideal epistemischer Rationalität, das das Kernstück dessen bildet, was er eine Einstellung oder Haltung zu den Wissenschaften nennt. Ein solches Rationalitätsideal kann nach van Fraassens Ansicht nicht gerechtfertigt werden durch Überzeugungen von der Art, daß es anderen, konkurrierenden Idealen überlegen ist o.ä., braucht es aber billigerweise auch nicht. ${ }^{25}$ Entsprechend charakterisiert er das, worum es beim Konflikt zwischen Realismus und konstruktivem Empirismus geht, als

"[to] choose an epistemic policy to govern under what condition, and how far, we will go beyond the evidence in our beliefs". ${ }^{26}$

Die "epistemische Politik" seiner Wahl ist die oben schon beschriebene: Etwas zu glauben will er sich bzw. jedem konstruktiven Empiristen nur in dem Maße gestatten, in dem wenigstens prinzipiell das Risiko besteht, mit aktuellen Beobachtungen mit unbewaffnetem Auge in Widerspruch zu geraten. Da es bei wissenschaftlichen Theorien, wenn man sie als ganze, inklusive ihrer unbeobachtbaren Teile, glauben würde, nicht mehr Möglichkeiten gäbe, in Widerspruch mit solchen Beobachtungen zu geraten, als wenn man nur ihren beobachtbaren Teil glaubt, darf ein konstruktiver Empirist gemäß dieser "Politik" höchstens den beobachtbaren Teil der Theorien glauben. Ontologische oder epistemische

\footnotetext{
${ }^{22}[\mathrm{vFra95}], \mathrm{S} .77 / 78$.

${ }^{23}$ [vFra95], S.86; vgl. auch [vFra94a], S.325ff.

${ }^{24}$ [vFra95], S.83, vgl. auch [vFra94a, vFra94b].

25 [vFra94a], S.326.

${ }^{26}$ [vFra85], S.254, Hervorhebung von mir.
} 
realistische Thesen über Unbeobachtbares zu glauben ist ihm daher nicht gestattet, wenn er van Fraassens Ideal epistemischer Rationalität folgen will.

\subsection{Probleme und Kritik}

Da die "destruktiven" Argumente, die van Fraassens zugunsten seines konstruktiven Empirismus ins Feld führt, sprich: seine Einwände gegen "positive" Argumente für realistische Thesen, bereits bei deren Diskussion zur Sprache gekommen sind,${ }^{27}$ und sich so etwas wie "positive" Argumente für antirealistische Thesen bei van Fraassen nicht finden, bleibt im Hinblick auf die Realismusdebatte nur die Frage nach der inneren Konsistenz und Haltbarkeit von van Fraassens Position zu untersuchen.

Zwei Einwände waren bereits diskutiert worden: ${ }^{28}$ Zum einen der Einwand, daß die Unterscheidung beobachtbar/unbeobachtbar für philosophische Zwecke nicht hinreichend wohldefiniert und explizierbar ist oder jedenfalls vage. Van Fraassens korrekte Replik war, ersteres zu leugnen sowie einen gewissen Grad von Vagheit zuzugeben, aber zu leugnen, daß dieser von Relevanz ist. Zum anderen der Einwand, daß van Fraassens Unterscheidung zu anthropozentrisch ist, um ihr philosophische Relevanz zuzuschreiben. Van Fraassens Antwort war, diese Intuition zurückzuweisen und darauf zu insistieren, daß der Unterscheidung in epistemischer Hinsicht Relevanz zukommt, so daß auch dieser Einwand argumentativ nichts ausrichten konnte.

\subsubsection{Die Frage nach der konsistenten Abgrenzung dessen, was ein kon- struktiver Empirist glauben darf}

\section{Musgraves Einwand}

Musgrave stellt die Frage, ob van Fraassen mit Hilfe seiner Unterscheidung beobachtbar/unbeobachtbar in konsistenter Weise den Bereich dessen abgrenzen kann, was ein konstruktiver Empirist glauben darf:

"He insists that what is observable by humans is a "function of facts about us qua organisms in the world," so that it is for science to tell us what is observable and what is not [...]. Now, suppose some theory $T$ does distinguish "the observable which it postulates from the whole it postulates" [...]. $T$ might even be van Fraassen's "final physics and biology," if such a theory is possible. $T$ will say, among other things, that $A$ is observable by humans, while $B$ is not. Of course, if we are to use $T$ to delineate the observable, we must accept it. But van Fraassen cannot have us accept it as true, since it concerns in part the unobservable $B$. The constructive empiricist can accept $T$ only as empirically adequate, that is, believe to be true only what $T$ says about the observable. But " $B$ is not observable by humans" cannot, on pain of contradiction, be a statement about something observable by humans. And, in general, the consistent constructive empiricist cannot believe it to be true that anything is unobservable by humans. And, if this is so, the consistent constructive empiricist cannot draw a workable observable/unobservable dichotomy at all." 29

\footnotetext{
${ }^{27}$ Siehe Kap. 8 und 9.

${ }^{28}$ Siehe Kap.8.1, 8.2.1 und 8.2.2.

${ }^{29}$ [Musg85], S.207/208.
} 
Van Fraassens korrekte Antwort ist, den von Musgrave angestellten Überlegungen im wesentlichen zuzustimmen, aber ihre Relevanz zu leugnen. Daß eine Entität oder ein Sachverhalt $B$ unbeobachtbar ist, ist selbst kein beobachtbarer Sachverhalt (denn wenn man $B$ nicht beobachten kann, dann kann man auch nicht beobachten, daß $B$ beobachtet werden kann). ${ }^{30}$ Was Menschen über die Unbeobachtbarkeit von $B$ sagen können, können sie allenfalls wissenschaftlichen Theorien entnehmen, und zwar deren unbeobachtbaren Teilen. Da man als konstruktiver Empirist nur Aussagen über Beobachtbares glauben darf, darf man konsequenterweise nicht glauben, daß $B$ unbeobachtbar ist; soweit hat Musgrave recht.

Was daraus folgt, ist jedoch nicht, daß das Operieren mit der Unterscheidung beobachtbar/unbeobachtbar inkonsistent wäre, sondern nur, daß man aus der Perspektive des konstruktiven Empirismus nicht in dem Sinne eine Grenze beobachtbar/unbeobachtbar ziehen kann, daß man eine Menge von Sachverhalten in zwei Teilmengen unterteilt, indem man bei jedem Sachverhalt prüft, in welche Teilmenge er nach den Anwendungskriterien der Unterscheidung gehört (wozu offenbar jeder Sachverhalt zu einem gewissen Grad epistemisch zugänglich sein müßte). Vielmehr ist es so, daß eine Menge in einer Richtung eine Grenze hat, über die man epistemisch nicht hinausgelangt, und daß man von dem Bereich dahinter gleichsam nur weiß, daß er jedenfalls epistemisch unzugänglich ist, falls da noch etwas sein sollte.

Über die Sachverhalte, auf die Musgrave hinweist, darf ein konstruktiver Empirist so viel glauben, wie durch Beobachtung zu entscheiden ist, und was das ist, kann man sich leicht zurechtlegen. Ausgehend von einer Situation, in der man nicht weiß, ob der Sachverhalt $B$ vorliegt oder nicht, und ebenfalls nicht weiß, ob Sachverhalte dieses Typs beobachtbar sind oder nicht, kann man durch Beobachtung zwei Resultate bekommen: Man beobachtet, daß $B$ vorliegt, oder man beobachtet dies nicht. Ersteres bedeutet, daß $B$ beobachtbar ist, letzteres kann daran liegen, daß $B$ nicht vorliegt, aber auch daran, daß Sachverhalte dieses Typs unbeobachtbar sind.

Was sich durch Beobachtung über den "Beobachtbarkeitsstatus" eines Sachverhaltes feststellen läßt, ist also, ob er vorliegt und beobachtbar ist oder ob dies nicht der Fall ist. Überzeugungen dieses Inhalts sind einem konstruktiven Empiristen gestattet (sowohl wenn sie durch Beobachtung gewonnen wurden, als auch wenn sie aus einer akzeptierten Theorie abgeleitet wurden). Die Überzeugung, daß ein Sachverhalt vorliegt und beobachtbar ist, impliziert nun trivialerweise, daß er beobachtbar ist; andererseits impliziert die Überzeugung, daß es nicht der Fall ist, daß der Sachverhalt vorliegt und beobachtbar ist, jedoch nicht, daß er unbeobachtbar ist. Was ein konstruktiver Empirist konsistenterweise über den Beobachtbarkeitsstatus eines Sachverhaltes glauben darf, ist also entweder, daß der Sachverhalt beobachtbar ist, oder, daß er unbeobachtbar ist, falls er vorliegt. Van Fraassen darf also von einem Sachverhalt nicht glauben, daß er unbeobachtbar ist — soweit hat Musgrave Recht - , aber er darf glauben, daß er unbeobachtbar ist, falls er existiert. ${ }^{31}$

\footnotetext{
${ }^{30}$ Dennoch wird man die Unbeobachtbarkeit von $B$ nicht als unbeobachtbaren Sachverhalt bezeichnen wollen. Das liegt daran, daß man von einem beobachtbaren (bzw. unbeobachtbaren) Sachverhalt dann spricht, wenn man durch Beobachtung entscheiden kann (bzw. nicht entscheiden kann), ob der Sachverhalt vorliegt oder nicht. Im Fall der Unbebachtbarkeit von $B$ ist es jedoch so, daß die Frage durch Beobachtung entschieden werden kann (nämlich negativ), falls $B$ beobachtbar ist, aber nicht entschieden werden kann, falls $B$ unbeobachtbar ist; s.u.

${ }^{31}$ [vFra85], S.256.
} 


\section{Friedmans Einwand}

Friedman diagnostiziert ein etwas anderes Konsistenzproblem als Musgrave. Während dieser bemängelt, daß ein konstruktiver Empirist nichts über den Beobachtbarkeitsstatus unbeobachtbarer Entitäten oder Sachverhalte glauben darf, weist Friedman darauf hin, daß von den für konstruktive Empiristen erlaubten Überzeugungen bezüglich beobachtbarer Entitäten und Sachverhalte zumindest einige logische Konsequenzen zu haben scheinen, die Unbeobachtbares betreffen und daher von einem konstruktiven Empiristen nicht geglaubt werden dürfen.

"Suppose that I, speaking the language of contemporary physical theory, assert the empirical adequacy of that theory: viz.

The observable objects are embeddable in the world picture of modern physics.

(i.e. the observable objects behave as if they were a subpart of the world of physics). But "the observable objects" are themselves characterized from within the world picture of modern physics: as those complicated systems of elementary particles of the right size and "configuration" for reflecting light in the visible spectrum, for example. Hence, if I assert that observable objects exist, I have also asserted that certain complicated systems of elementary particles exist as well! I have not, in accordance with van Fraassen's "constructive empiricism", remained agnostic about the unobservable part of the world." 32

Die beobachtbaren Konsequenzen einer Theorie, die ein konstruktiver Empirist glauben darf, müssen sprachlich formuliert werden, und da es nach van Fraassens Ansicht keine theorieneutrale Beobachtungssprache im Sinne des logischen Positivismus gibt, muß man sich dazu "theorieinfizierter" Sprache bedienen. Friedman weist nun darauf hin, daß Sätze über Beobachtbares, die in "theorieinfizierter" Sprache formuliert sind, andere Sätze über Unbeobachtbares implizieren können. Daher scheint die Haltung eines konstruktiven Empiristen, sich nur bezüglich beobachtbarer Entitäten und Sachverhalte Überzeugungen zu gestatten, unverträglich zu sein mit der in allen gängigen Konzeptionen von epistemischer Rationalität zentralen Annahme, daß man berechtigt ist, mit einer Menge von gerechtfertigten Überzeugungen auch deren logische Konsequenzen zu glauben. Es gibt "theorieinfizierte" Sätzen, wie sie Friedman im Auge hat, vielleicht nicht in beliebiger Menge, d.h., man findet sicherlich nicht für jeden beliebigen unbeobachtbaren Sachverhalt einen Satz über Beobachtbares, der ihn impliziert, ${ }^{33}$ aber einige Beispiele lassen sich zweifellos angeben, etwa folgendes: Wenn ich (als empirische Konsequenz einer chemischen Theorie) glaube, daß ein erhitztes Stück Natrium von $0,2 \mathrm{Mol}$ oder $1,2 * 10^{23}$ Atomen, das in ein Gefäß mit $0,1 \mathrm{Mol}$ oder $6 * 10^{22}$ Molekülen Chlorgas gebracht wird, dort vollständig verbrennt, dann sollte ich auch glauben dürfen, daß an diesem Prozeß (mindestens) ein Chlormolekül und ein Natriumatom beteiligt sind. Sowohl eine Menge von 0,1 Mol Chlor als auch ein Stück Natrium von 0,2 Mol sind beobachtbare Objekte, ${ }^{34}$ ein Molekül Chlor

\footnotetext{
${ }^{32}$ [Frie82], S.278.

${ }^{33}$ Viele Ausdrücke, die gelegentlich als paradigmatische Beispiele für "theorieinfizierte" Sprache genannt werden (z.B. 'Röntgenröhre', 'Mikrowellenherd', 'UKW-Radio', 'galvanisiert') liefern nicht ohne weiteres Implikationen über Unbeobachtbares, wenn man nicht vor dem Hintergrund einer sprachphilosophischen Position argumentiert, die analytische Sätze zuläßt ('Jede (intakte, in ein passendes Röntgengerät eingebaute) Röntgenröhre strahlt in eingeschaltetem Zustand Röntgenstrahlung aus' u.ä.).

${ }^{34}$ Dies und auch, daß die entsprechenden Ausdrücke bzw. Sätze zur Beschreibung von konkreter Beobachtungen benutzt werden dürfen, sollte unkontrovers sein; vgl. z.B. [vFra80], S.80f.
} 
und ein Natriumatom sind klarerweise nicht beobachtbar.

Friedmans Einwand stellt konstruktive Empiristen vor ein ernstes Problem. Wenn sie nicht zu der radikalen und kontraintuitiven Lösung greifen wollen, die Trennlinie zwischen als Überzeugungen "zulässigen" und agnostisch in der Schwebe zu haltenden Sätzen auch dort $\mathrm{zu}$ verteidigen, wo erstere letztere implizieren, werden sie nach einer Möglichkeit suchen müssen, Sätze über Beobachtbares und insbesondere die beobachtbaren Konsequenzen wissenschaftlicher Theorien generell so zu formulieren, daß eine Menge solcher Sätze deduktiv abgeschlossen ist. Ob und ggf. wie das möglich ist, ohne die positivistische Konzeption einer theorieneutralen Beobachtungssprache zu reaktivieren, kann hier nicht abschließend diskutiert werden, aber van Fraassens Position scheint hier zumindest ernsthafte Modifikation zu erfordern, ${ }^{35}$ wenn man nicht den radikalen Ausweg wählen will, konstruktiven Empiristen auch Überzeugungen, die "theorieinfizierte" Sätze über Beobachtbares zum Inhalt haben, nicht mehr zu gestatten und eventuell massive Sprachreformen vorzunehmen, um eine hinreichend reichhaltige Beobachtungssprache zu gewinnen. ${ }^{36}$ Dieser radikale Ausweg steht allerdings in jedem Fall offen. ${ }^{37}$

\subsubsection{Epistemische Kontinuitätsargumente}

Bereits oben diskutiert worden war die Strategie, in epistemischer Hinsicht antirealistische Positionen wie die von van Fraassen mit epistemischen Kontinuitätsargumenten anzugreifen. ${ }^{38}$ Die Idee dieser Kontinuitätsargumente ist, auf bestimmte epistemische Verfahren (Beispiel: Beobachten mit der Lupe) hinzuweisen, die sozusagen auf beiden Seiten der Grenze beobachtbar/unbeobachtbar einsetzbar sind, und bezüglich dieser Verfahren die vortheoretische Intuition in Anspruch zu nehmen, daß diese Verfahren auch im Unbeobachtbaren verläßlich sind, oder ein induktives oder induktiv extrapolierendes Argument für ihre Verläßlichkeit zu skizzieren und dann ontologische oder epistemische realistische Thesen zu rechtfertigen, indem man sie als "Produkte" dieser verläßlichen epistemischen Verfahren ausweist. Diese Argumentationsstrategie gegen van Fraassen zu wählen liegt insofern nahe - insbesondere wenn man sich auf "optische" epistemische Verfahren wie das Beobachten mit der Lupe konzentriert - , als van Fraassen selbst sich an einer Stelle auf zumindest prima facie ähnliche Verläßlichkeitsüberlegungen für das "gewöhlichste" epistemische Verfahren beruft, nämlich für das Beobachten mit bloßem Auge: Beobachtungssätze, die von Experimentatoren geäußert werden und die Grundlage der empirischen Prüfung von Theorien bilden, faßt er nicht als unumstößliches Fundament des Wissens auf, sondern als nur dann gerechtfertigt, wenn die Beobachter als verläßlich gelten können. ${ }^{39}$ Außerdem läßt seine Position grundsätzlich auch Überzeugungen über beobachtbare, aber tatsächlich nicht mit dem bloßen Auge, sondern mittels eines Teleskops o.ä. beobachtete Sachverhalte zu, und auch deren Rechtfertigung durch Verläßlichkeitsüberzeugungen bezüglich des Beobachtens mit einem Teleskop o.ä., so daß sich die Argumentationsstrategie der epistemischen Kontinuitätsargumente intuitiv anzubieten scheint.

\footnotetext{
${ }^{35}$ Eine pessimistische Einschätzung der Erfolgschancen dafür gibt [Leed94], eine optimistischere Sicht findet sich in [Kukl96], S.219ff. Van Fraassens semantische Theorienauffassung hilft bei diesem Problem nicht weiter, sondern verlagert es nur; siehe dazu z.B. [Kukl96], S.217f., [Leed94], S.198f.

${ }^{36} \mathrm{Vgl}$. S.144.

${ }^{37}$ Diese Option ist sicherlich wenig attraktiv, wenn man (wie van Fraassen) glaubt, daß Menschen heutzutage zur Beschreibung von Beobachtungen i.a. "theorieinfizierte" Sprache verwenden. Van Fraassen scheint allerdings in [vFra92] anzudeuten, daß er dennoch dazu neigt.

${ }^{38}$ Siehe Kap.8.

${ }^{39}$ Siehe [vFra92], S.16/17; vgl. auch [vFra80], S.72.
} 
Wie die Diskussion oben jedoch gezeigt hat, kann ein reflektierter und "hinreichend konsequenter" Antirealist wie van Fraassen jedes epistemische Kontinuitätsargument zurückweisen: Wenn er nur Überzeugungen über Beobachtbares hat und nur Inferenzschemata akzeptiert, die daraus nur andere Überzeugungen über Beobachtbares erschließen, fehlt den epistemischen Kontinuitätsargumenten sozusagen jeder Ansatzpunkt, um Überzeugungskraft entwickeln zu können, denn dann hat der Antirealist keine der vortheoretischen Intuitionen, an die die Kontinuitätsargumente appellieren. Da van Fraassen seine Position tatsächlich auf dieser Linie verteidigt, ${ }^{40}$ können Kontinuitätsargumente argumentativ gegen sie nichts ausrichten, obwohl diese Argumente für Realisten überzeugend aussehen mögen und in der Diskussion mit "weniger konsequenten" Antirealisten und Personen, die noch keine systematisch entwickelte Position in der Realismusdebatte bezogen haben, auch erfolgreich sein können.

\subsection{Fazit}

Van Fraassens konstruktiver Empirismus ist eine Position, die, wie er es seit neuerem in klärender Weise beschreibt, in möglichst konsequenter Weise eine Haltung artikuliert, deren Kern ein bestimmtes Ideal epistemischer Rationalität ist. Dieses Ideal bestimmt seine Position in der Realismusdebatte und durch dieses Ideal (insbesondere auch durch dessen Status als ein Ideal) sind die Möglichkeiten der Kritik an seiner Position vorgezeichnet: Man kann die innere Konsistenz der Position hinterfragen, man kann die Plausibilität des Ideals in Frage stellen, indem man es mit (mehr oder weniger konkreten) Beispielen und Situationen konfrontiert, in denen man klare vortheoretische Intuitionen hat bezüglich dessen, was epistemisch rational ist, oder auch mit eher allgemeinen Intuitionen über epistemische Rationalität, und schließlich kann man vielleicht auch zur Diskussion stellen, ob das (wie van Fraassen es nennt) Paradigma ${ }^{41}$, an dem er sich bei der Formulierung seines Ideals orientiert, eben die Wissenschaft, überhaupt korrekt gesehen wird.

Die diskutierten Probleme der Wohldefiniertheit und Vagheit der Unterscheidung beobachtbar/unbeobachtbar und der konsistenten Abgrenzung dessen, was ein konstruktiver Empirist glauben darf, gehören zur erstgenannten Gruppe kritischer Einwände. Hier liegt das von Friedman aufgeworfene, mit dem Thema "theorieinfizierte" Sprache zusammenhängende Konsistenzproblem, das substantiell aussieht, aber durch geeignete Modifikationen der Position behebbar sein könnte und jedenfalls um den Preis hinreichend radikaler Sprachreformen auszuräumen sein sollte.

Zur zweiten Gruppe von Einwänden gehören die epistemischen Kontinuitätsargumente und der Einwand, daß van Fraassens Unterscheidung beobachtbar/unbeobachtbar zu anthropozentrisch ist. Gegen einen entschlossenen, reflektierten Antirealisten wie van Fraassen läßt sich damit nichts ausrichten, weil er keine der Intuitionen teilt, an die diese Argumente appellieren.

Das Paradigma schließlich, an dem sich van Fraassen bei der Formulierung seines Ideals orientiert, ist die moderne Wissenschaft, so daß eine naheliegende Frage vielleicht die ist, ob seine These, das Ziel der Wissenschaft sei es, empirisch adäquate Theorien zu gewinnen, deren reale Praxis korrekt beschreibt. Diese Frage läßt sich mit Gründen negativ beantworten, ${ }^{42}$ zumindest wenn damit, wie bei van Fraassen, ein generelles, einheitliches Ziel

\footnotetext{
${ }^{40}$ Siehe [vFra85], S.256ff.

${ }^{41}$ [vFra94a], u.a. S.313, 328.

${ }^{42}$ Siehe z.B. [Hutt96]; vgl. auch Kap.7.
} 
gemeint ist. Einen überzeugungskräftigen Einwand gegen van Fraassens Position ergibt dieser Befund jedoch offenbar nicht, weil deren Kern eben ein Ideal epistemischer Rationalität ist: Der Befund, daß eine Diskrepanz zwischen Ideal und motivierendem Paradigma besteht, kann van Fraassen nicht zur Aufgabe des Ideals zwingen, sondern nur zu dem Zugeständnis, daß es in den real-existierenden Wissenschaften nur unvollkommen oder vielleicht sogar nur ansatzweise oder gar nicht verwirklicht ist und daß sein Paradigma epistemischer Rationalität genau besehen keins ist. ${ }^{43}$ Für viele mag dadurch die Attraktivität des Ideals verblassen, aber ein überzeugungskräftiges Argument gegen van Fraassen bekommt man dadurch klarerweise nicht.

Fazit der Untersuchung von van Fraassens antirealistischer Position in diesem Kapitel und seiner Einwände gegen Argumente für realistische Thesen in den vorhergehenden Kapiteln ist also, daß diese Position im Hinblick auf ihre innere Konsistenz zwar mit einem Problem belastet ist, für das aber zumindest ein radikaler Ausweg offensteht, und daß sie ansonsten gegen alle Einwände und von realistischer Seite vorgebrachten Argumente verteidigt werden kann. In diesem Sinn stellt van Fraassens konstruktiver Empirismus in der Realismusdebatte eine konsistente und haltbare Alternative zu realistischen Positionen dar. Für jemanden, der in der dieser Debatte noch keine so systematisch entwickelte Position wie van Fraassen eingenommen hat, dürfte der Übergang zu seiner Position i.a. nur um den Preis der Aufgabe einer großen Zahl vortheoretischer Intuitionen möglich sein, aber wenn er durch entschlossene, konsequente Preisgabe aller damit konfligierender Intuitionen einmal zu dieser Position gelangt ist, läßt sie sich gegen realistische Diskussionsgegner verteidigen, d.h., die oben diskutierten Argumente für ontologische und epistemische realistische Thesen können dann keine Überzeugungskraft mehr entwickeln. Umgekehrt enthält oder liefert van Fraassens Position allerdings auch keine Einwände, die die diskutierten Argumente für realistische Thesen nicht nur in Einzelfällen und/oder in speziellen Situationen als fehlerhaft erweisen könnten (wie es etwa der Hinweis auf das Problem der Unterbestimmtheit tut ${ }^{44}$ ) und die damit realistische Positionen in grundsätzlicher Weise bedrohen würden.

\footnotetext{
${ }^{43}$ Vgl. [vFra94a], S.332/333.
}

${ }^{44}$ Vgl. Abschnitt 9.10.2. 


\section{Kapitel 11}

\section{Der experimentelle Realismus von Ian Hacking und Nancy Cartwright}

\section{$11.1 \quad$ Einleitung}

Für die Wissenschaftstheorie der letzten zwei Jahrzehnte hat die von Ian Hacking und Nancy Cartwright formulierte Position, die häufig als experimenteller Realismus bezeichnet wird, eine Vielzahl von Anstößen und Neuerungen gebracht. Ihre parallel entstandenen und inhaltlich über weite Strecken komplementären Bücher "Representing and Intervening" 1 und "How the laws of physics lie" ${ }^{2}$ haben für eine ganze Reihe von Debatten neue Impulse geliefert.

Ein Motiv, das viele ihrer Arbeiten verbindet, ist die Überzeugung, daß eine angemessene Beantwortung philosophischer Fragen im Zusammenhang mit den Naturwissenschaften in einem weit größeren Maße Kenntnisse der konkreten Inhalte und Methoden der jeweiligen Sachgebiete und auch ihrer geschichtlichen Entwicklung erfordert, als die Wissenschaftstheorie im Gefolge des logischen Empirismus dies traditionellerweise annahm. Im Gegensatz zu dem in der Wissenschaftstheorie traditionell verbreiteten Ansatz, auf einer vergleichsweise abstrakten Ebene zu arbeiten, auf der von den Inhalten und Methoden realer Wissenschaften sozusagen nur noch das sichtbar ist, was sich durch Begriffe wie "Theorie", "Beobachtungssatz", "Gesetz" und "Modell" sowie logische oder mathematische Zusammenhänge und Relationen beschreiben läßt, verweisen Hacking und Cartwright immer wieder auf die Vielfalt und Heterogenität der Gegenstände, Praktiken und Argumentationsformen der real-existierenden Naturwissenschaften und betonen deren Relevanz für wissenschaftstheoretische Fragestellungen.

Ein weiteres Motiv, das vor allem von Hacking betont wird, ist die Überzeugung, daß der überwiegende Teil der etablierten Wissenschaftstheorie bei der Beschäftigung mit den Wissenschaften zu einseitig den Aspekt des "Repräsentierens", d.h. die von den Wissenschaften gewonnenen Theorien, in den Blickpunkt rückt. Hacking betont dagegen die systematische Bedeutung des "Intervenierens", d.h. experimenteller Eingriffsmöglichkeiten, für ein philosophisches Verständnis der Wissenschaften. ${ }^{3}$

\footnotetext{
${ }^{1}[$ Hack83a].

${ }^{2}$ [Cart83].

${ }^{3}$ Hackings Buch war eine der ersten einer inzwischen stark angewachsen Zahl von Arbeiten, die diese
} 
Beide Motive finden sich auch in den Beiträgen von Hacking und Cartwright zur Realismusdebatte. Sie rücken bestimmte Aspekte der experimentellen Praxis der realexistierenden Wissenschaften und die "experimentnahen" Teile der dort gewonnenen theoretischen Repräsentationen ins Zentrum ihrer Argumentation für wissenschaftlichen Realismus, denn, so Hacking:

"Experimental work provides the strongest evidence for scientific realism." 4

Hacking und Cartwright verwenden in ihrer Argumentation für wissenschaftlichen Realismus einige Begriffe und Unterscheidungen, die bis dahin in der Wissenschaftstheorie wenig oder gar nicht gebräuchlich waren. Diese sollen zunächst zusammengestellt werden, bevor die Argumentation von Hacking und Cartwright untersucht wird.

\subsection{Terminologisches}

Hacking und Cartwright erscheint die für die Wissenschaftstheorie traditionell zentrale, im wesentlichen dichotomische Unterscheidung von Theorien, theoretischen Ausdrücken und theoretischen Sätzen einerseits, Beobachtungen, Beobachtungsausdrücken und Beobachtungssätzen andererseits als zu grob für die Zwecke ihrer Untersuchungen. Sie führen daher einige neue, stärker an der Praxis der Naturwissenschaften orientierte Begriffe und Unterscheidungen ein.

Hacking ${ }^{5}$ bemängelt, daß der Ausdruck 'Theorie' für sprachliche oder mathematische Repräsentationen der unterschiedlichsten Allgemeinheits- und Abstraktionsgrade verwendet wird: für die Evolutionstheorie, die allgemeine Relativitätstheorie und die Quantenelektrodynamik, für "Theorien" über das Aussterben einer biologischen Spezies oder die hohe Sprungtemperatur einer bestimmten supraleitenden Substanz, aber auch für implizite Annahmen aller Art, die nach Ansicht einiger Autoren wissenschaftliche, aber auch gewöhnliche alltagsweltliche Aussagen ('Dieser Tennisball ist gelb') zu "theoriebeladenen" machen. ${ }^{6}$

Hacking schlägt vor, die unspezifischste der üblichen Verwendungsweisen von 'Theorie' fallenzulassen und dafür den Ausdruck 'Spekulation' ('speculation') zu verwenden; eine Spekulation in diesem Sinn ist also so etwas wie eine (mehr oder minder zusammenhängende) Menge von Aussagen, Gleichungen oder sonstigen Repräsentationen qualitativer oder "halbquantitativer" 7 Art, die einige Eigenschaften eines (mehr oder weniger großen) Gegenstandsbereiches oder Ausschnittes der Welt zum Inhalt haben. ${ }^{8}$ Unter den Spekulationen in diesem weiten Sinn lassen sich dann speziellere Arten unterscheiden. Das

Überzeugung programmatisch formulieren und zum Anlaß für detaillierte Untersuchungen zur Rolle von Experimenten in den Naturwissenschaften nehmen. Inzwischen wurde für diese Strömung in der neueren Wissenschaftstheorie der Terminus 'new experimentalism' geprägt [Acke89, Carr98, McLa93].

${ }^{4}$ [Hack83a], S.262.

${ }^{5}$ Hackings terminologische Erläuterungen finden sich vor allem in [Hack81] und [Hack83a], Kap.10, 12.

${ }^{6} \mathrm{Vgl}$. Kap.3.1.

${ }^{7}$ Mit Repräsentationen halbquantitativer Art sind Repräsentationen in Form mathematischer Strukturen oder Gleichungen gemeint, die Parameter, Material- und Naturkonstanten usw. enthalten, deren Wert in der Spekulation offen gelassen wird und ggf. bei der Anwendung auf konkrete Systeme spezifiziert werden muß; vgl. [Hack83a], S.213.

8 "By speculation I shall mean the intellectual representation of something of interest, a playing with and restructuring of ideas to give at least a qualitative understanding of some general feature of the world" ([Hack83a], S.212/213); "speculation intends a qualitative structure of some domain" ([Hack83a], S.215). Hacking unterscheidet terminologisch nicht scharf zwischen Spekulation als Tätigkeit und als Ergebnis der Tätigkeit; dies ist aber inhaltlich unerheblich. 
Wort 'Theorie' will Hacking für "some fairly specific body of speculation or propositions with a definitive subject matter" 9 reservieren. Offenbar hat er bei 'Spekulation' so etwas wie Repräsentationen über Teile der Welt im weitesten Sinn im Auge, bei 'Theorie' eher Spekulationen einer bestimmten "Größenordnung" mit einem präzise definierten Gegenstandsbereich. (Er nennt als Beispiel für eine Theorie in seinem Sinn Boscovichs Theorie der Materie von $1758^{10}$, andere Beispiele sind die klassische Elektrodynamik und die allgemeine Relativitätstheorie.)

Als zweite, von Theorien zu unterscheidende Art von Spekulationen nennt Hacking Modelle. Mit 'Modell' übernimmt er die in der heutigen Physik übliche Bezeichnung für theoretische Repräsentationen, die für speziellere, konkretere Situationstypen oder Systeme zugeschnitten sind als Theorien und die mathematisch handhabbarer sind und meistens Näherungen und Idealisierungen involvieren (z.B. das Ising-Modell des Ferromagnetismus, das Standardmodell der Sonne, Kelvins Modell für den magnetooptischen Effekt ${ }^{11}$ ).

Als phänomenologische Gesetze bezeichnet Hacking Gesetze, die sich — wie Modelle - auf spezielle, konkrete, vergleichsweise detailliert spezifizierte Typen von Systemen beziehen, i.a. in der Form von quantitativen, in der Regel mathematisch als Gleichungen zwischen meßbaren Größen formulierten Aussagen, die nur "beobachtungsnahe" oder (mehr oder weniger) direkter Messung zugängliche Größen involvieren (z.B. die Abhängigkeit der spontanen Magnetisierung von der Temperatur bei einem Ferromagneten, die Strom-Spannungs-Kennlinie einer Diode u.ä.). ${ }^{12}$

Zwei weitere von Hacking neu eingeführte, verwandte Ausdrücke, die er an systematisch wichtiger Stelle einsetzt, sind "home truths"13 und "low level generalizations" ${ }^{14}$. Er erklärt sie nirgends explizit, aber dem Kontext läßt sich entnehmen, daß in beiden Fällen phänomenologische Gesetze gemeint sind, die von "einfacher" Struktur und qualitativer oder halbquantitativer Art sind. Er nennt als Beispiele: Wenn ein GaAs-Kristall mit zirkular polarisiertem Licht einer bestimmten Frequenz bestrahlt wird, emittiert er Elektronen. ${ }^{15}$ Technisch herstellbare GaAs-Kristalle emittieren höchstens 37\% polarisierte Elektronen. ${ }^{16}$ Elektronen lassen sich mit Hilfe von Magneten lenken. ${ }^{17}$ Beugung von Elektronen mit Hilfe von Elektromagneten beeinflußt ihre Polarisationseigenschaften nicht. ${ }^{18}$

Für Hackings Position wichtig ist schließlich noch das, was er als theoretische Entitäten (theoretical entities) bezeichnet. Er bezieht sich damit nicht nur auf materielle "Gegenstände" wie Moleküle, Zellkerne u.ä., sondern auf, wie er sich ausdrückt, "all that

\footnotetext{
${ }^{9}$ [Hack83a], S.175, [Hack81], S.130.

${ }^{10}[$ Hack81], S.130.

${ }^{11}$ Die Drehung der Polarisationsebene von Licht durch ein optisches Medium im Magnetfeld.

${ }^{12}$ Damit weicht Hacking allerdings etwas vom Sprachgebrauch der Physik ab (entgegen seiner Absicht; siehe [Hack83a], S.221f.). Dort zählen als phänomenologisch auch "hochtheoretische" Gesetze in einer für spezielle Systeme spezifizierten Form, wie z.B. Lagrange-Dichten oder Hamilton-Funktionen; Hacking scheint diese nicht zu den phänomenologischen Gesetzen zu zählen. Auch in einer zweiten Hinsicht trifft Hacking (und ebenso Cartwright — s.u.) damit die in der Physik gängige Verwendungsweise des Ausdrucks 'phänomenologisches Gesetz' nicht genau: In der Physik bezeichnet dieser Ausdruck nicht nur Gesetze mit sehr spezifischem Anwendungsbereich, sondern trägt außerdem die Konnotation, daß es um Gesetze geht, die noch nicht durch eine fundamentale Theorie erklärt werden können, oder um Gesetze, die erklärt werden können, aber nicht exakt gelten, jedoch aus Gründen der Einfachheit weiter in Kontexten benutzt werden, in denen sie in ausreichender Näherung gültig sind.

${ }^{13}$ [Hack83a], S.265.

${ }^{14}$ [Hack83a], S.209.

15 [Hack83a], S.268.

${ }^{16}$ [Hack83a], S.270.

17 [Hack83a], S.269.

${ }^{18}$ [Hack83a], S.272.
} 
ragbag of stuff postulated by theories but which we cannot observe. That means, among other things, particles, fields, processes, structures, states and the like." 19

Bei Cartwright spielen die Ausdrücke 'phänomenologisches Gesetz' einerseits und 'fundamentales' oder 'theoretisches Gesetz' andererseits eine zentrale Rolle. ${ }^{20}$ Die Bezeichnung 'phänomenologisches Gesetz' verwendet sie im wesentlichen wie Hacking, als fundamentale oder theoretische Gesetze bezeichnet sie die dynamischen Grundgleichungen der "großen" Theorien der Physik in der allgemeinsten Form, in der sie sich noch nicht auf bestimmte Systeme beziehen (die Schrödinger-Gleichung, das zweite Newton-Axiom, die MaxwellGleichungen etc.), Gesetze über fundamentale Kräfte bzw. Wechselwirkungen (Newtons Gravitationsgesetz, das Coulomb-Gesetz etc.) sowie Gesetze von vergleichbarem Allgemeinheitsgrad (z.B. die Boltzmann-Gleichung).

\section{$11.3 \quad$ Hacking}

\subsubsection{Hackings "experimentelles Argument" für wissenschaftlichen Rea- lismus}

Hacking stellt seine Argumentation für wissenschaftlichen Realismus im wesentlichen im letzten Kapitel von 'Representing and Intervening' vor. Das dort so genannte "experimentelle Argument" für wissenschaftlichen Realismus hat nicht die Gestalt eines strukturierten Arguments, sprich: einer Reihe von als solche gekennzeichneten Prämissen und einer daraus resultierenden Konklusion, sondern eher die eines Resümees, das in etwas elliptischer Form eine Reihe von vorher präsentierten Überlegungen, Argumentationsfäden und an vortheoretische Intuitionen appellierenden Beispielen zusammenzieht. Eine typische Reaktion auf die Lektüre von Hackings Argumentation ist es, ${ }^{21}$ anzuerkennen, daß sie enormen intuitiven Appeal hat, daß es aber bei genauerem Hinsehen nicht ganz leicht ist, zu sagen, worauf dieser Appeal beruht und was genaugenommen überhaupt der wesentliche Gehalt der Argumentation ist. Dementsprechend ist es kaum möglich, Hackings Position in der Realismusdebatte und seine Argumentation dafür in neutraler Weise zusammenfassend wiederzugeben, ohne sie in gewissem Maße zu rekonstruieren. In diesem Sinn soll in diesem Abschnitt Hackings Argumentation für wissenschaftlichen Realismus dargestellt werden und dabei gleichzeitig versucht werden, herauszuarbeiten, worin sein "experimentelles Argument" im Kern besteht.

\section{"If you can spray them then they are real."}

Im ersten Kapitel von 'Representing and Intervening' erzählt Hacking von seinem persönlichen Schlüsselerlebnis, das ihn zum wissenschaftlichen Realismus "bekehrt" hat: Ein befreundeter Experimentalphysiker berichtet ihm im Gespräch von seiner Arbeit an einem Experiment, in dem nach freien Quarks gesucht wird. Die Grundidee dieses Experimentes ist die von Millikans klassischem Öltröpfchenversuch, die "Komponenten" sind verändert: Man läßt supraleitende Metallkügelchen aus Niob in einem Magnetfeld schweben (anstelle von Öltröpfchen in einem elektrischen Feld bei Millikan) und schließt von der Bewegung der Kügelchen auf die elektrische Ladung. Aus Gründen, die hier nicht von Interesse sind,

\footnotetext{
${ }^{19}[$ Hack83a], S.26.

${ }^{20}$ [Cart83], S.1ff.

${ }^{21}$ Jedenfalls meiner Erfahrung nach.
} 
ist es bei diesem Experiment nötig, die Ladung solcher schwebender Niobkügelchen zu verändern.

"Now how does one alter the charge on the niobium ball? 'Well, at that stage,' said my friend, 'we spray it with positrons to increase the charge or with electrons to decrease the charge.' From that day forth I've been a scientific realist. So far as I'm concerned, if you can spray them then they are real." 22

Dieser griffige Slogan ist für sich kein Argument und soll es auch nicht sein, ${ }^{23}$ aber er macht deutlich, aus welcher Quelle Hacking Intuitionen und Anregungen für die Argumentation für seine Position bezieht: aus der Praxis der Experimentalphysik.

\section{Das Benutzen und Manipulieren von Entitäten und deren dabei involvierte kausale Eigenschaften}

Hacking betont, daß es ihm wichtig ist, zwischen Experimenten an einem Objekt und Experimenten mit Hilfe eines Objektes zu unterscheiden. Das genannte Experiment zur Suche nach Quarks liefert nach Hackings Ansicht einen guten Grund für die Annahme, daß die Objekte, mit Hilfe derer experimentiert wird, wie er sich ausdrückt, "real sind", also nicht etwa für die Annahme, daß Quarks real sind, sondern für eine entsprechende Annahme in bezug auf Positronen und Elektronen. ${ }^{24}$ Zur Erläuterung dieses Punktes benutzt Hacking Formulierungen wie "eine Entität benutzen", "manipulieren" oder "als Werkzeug einsetzen":

"Experimenting on an entity does not commit you to believing that it exists. Only manipulating an entity, in order to experiment on something else, need do that." 25

"Experimental work provides the strongest evidence for scientific realism. This is $[\ldots]$ because entities that in principle cannot be 'observed' are regularly manipulated to produce new phenomena and to investigate other aspects of nature. They are tools, instruments not for thinking, but for doing." ${ }^{26}$

Hackings Redeweisen vom "Benutzen" und "Manipulieren" von Elektronen und anderen Entitäten als "Werkzeug" sind offensichtlich erläuterungsbedürftig, da die Analogie zu Laubsägen, Stricknadeln, Skalpellen, Schrotkugeln oder woran immer man bei "Werkzeug" und "benutzen" denken mag nicht ohne weiteres durchsichtig ist. Hacking bringt an dieser Stelle den Begriff der Kausalität ins Spiel. Er bezieht sich mit den Formulierungen vom Benutzen von Elektronen natürlich nicht etwa, wie man nach dem zitierten Slogan vielleicht denken könnte, auf simple heuristische oder populärwissenschaftliche Bilder, denen

\footnotetext{
${ }^{22}$ [Hack83a], S.23.

${ }^{23}$ Dieser vielzitierte Satz steht im Anfangskapitel des Buches und sollte, wenn man es im Hinblick auf die Realismusdebatte liest, als (vielleicht etwas hemdsärmeliger) rhetorischer Einwurf gelesen werden, mit dem Hacking eine gewisse Distanzierung zu den gängigen Argumentationsmustern herstellen und die Fixierung des Blickes auf Theorien, formale Rekonstruktionen usw. lösen will, die seiner Ansicht nach eine Sackgasse darstellt.

${ }^{24}$ Und es hätte nach Hacking auch dann, wenn die Suche nach Quarks nach den Standards der Experimentatoren erfolgreich gewesen wäre, keinen guten Grund für eine solche Annahme in bezug auf Quarks geliefert. Daß die Suche nach freien Quarks nicht erfolgreich war, ist für Hackings Punkt also nicht entscheidend.

${ }^{25}$ [Hack83a], S.263.

${ }^{26}$ [Hack83a], S.262.
} 
zufolge man mit Elektronen genauso schießen oder sprühen kann wie mit Schrotkugeln oder Wassertropfen. Er meint vielmehr mit dem "Benutzen" einer Entität das Ausnutzen (einiger) ihrer kausalen Eigenschaften zum routinemäßigen Bauen und Benutzen von Apparaten und Instrumenten.

"What convinced me of realism [...] was the fact that by now there are standard emitters with which we can spray positrons and electrons [...]. We understand the effects, we understand the causes, and we use these to find out something else." 27

Am Beispiel der Elektronenkanone erläutert er den Punkt genauer:

"Understanding some causal properties of electrons, you guess how to build a very ingenious complex device that enables you to line up the electrons the way you want, in order to see what will happen to something else. Once you have the right experimental idea you know in advance roughly how to try to build the device, because you know that this is the way to get the electrons to behave in such and such a way. Electrons are no longer ways of organizing our thoughts or saving the phenomena that have been observed. They are ways of creating phenomena in some domain of nature. Electrons are tools." ${ }^{28}$

\section{Wann hat man gute Gründe für die Annahme, daß eine Entität "real ist"? Zwei Antworten}

In Hackings Text lassen sich zwei Sorten von Formulierungen finden, wie er den Zusammenhang zwischen dem Benutzen einer Entität, dem Akzeptieren von Beschreibungen von kausalen Eigenschaften dieser Entität ${ }^{29}$ und der Annahme, daß diese Entität real ist, verstanden wissen will. Beide Sorten unterscheiden sich darin, woran genau die letztere Annahme geknüpft wird.

Nach den Formulierungen des ersten Typs soll das tatsächliche routinemäßige Benutzen einer Entität einen guten Grund für die Annahme liefern, daß diese Entität real ist, und Hackings Vorstellung scheint zu sein, daß es für das Benutzen notwendige Voraussetzung ist, einige kausale Beschreibungen der Entität zu akzeptieren. Diese kausalen Beschreibungen (d.h. Kausalgesetze, Aussagen über kausale Eigenschaften u.ä.) müssen demnach (oder können jedenfalls) vor dem Benutzen und unabhängig davon etabliert werden. Es würde dann nichts gegen die Annahme sprechen, daß von den in der Physik akzeptierten kausalen Beschreibungen möglicherweise nur ein Teil zum Benutzen verschiedener Entitäten herangezogen wird. Die Idee wäre dann, daß es wirklich erst der praktische Einsatz einer Entität, das routinemäßig von den entsprechenden kausalen Beschreibungen angeleitete Handeln ist, das einen guten Grund für die Annahme liefert, daß die Entität real ist, und daß konsequenterweise nur mit dem tatsächlich eingesetzten Teil der akzeptierten kausalen Beschreibungen die Annahme verbunden wird, daß die entsprechende Entität real ist. Auf dieser Linie erläutert Hacking den Zusammenhang zwischen dem Benutzen einer Entität, dem Akzeptieren von kausalen Beschreibungen dieser Entität und der Annahme, daß diese Entität real ist, in einigen Passagen, in denen er eher kurz zusammenfassend oder sloganartig formuliert:

\footnotetext{
${ }^{27}$ [Hack83a], S.24.

${ }^{28}$ [Hack83a], S.263.

${ }^{29}$ Gemeint ist hier van Fraassens Verwendungsweise von 'akzeptieren', die nicht impliziert, daß man von den fraglichen Beschreibungen überzeugt ist.
} 
"The 'direct' proof of electrons and the like is our ability to manipulate them using well-understood low-level causal properties." 30

"We believe in the reality of many entities postulated by theory because we can construct devices that use those entities in order to interfere in other aspects of nature [...] When we use entities as tools, as instruments of inquiry, we are entitled to regard them as real." 31

In den Formulierungen des zweiten Typs scheint für Hacking weniger das Benutzen einer Entität einen guten Grund für die Annahme zu liefern, daß diese Entität real ist, sondern einen solchen Grund scheinen dort eher die zum Benutzen der Entität herangezogenen kausalen Beschreibungen zu liefern. Auf dieser Linie argumentiert Hacking in den Passagen, in denen der Terminus 'experimentelles Argument' fällt:

"[...] the experimental argument for realism [...] is not that we infer the reality of electrons from our success. We do not make the instruments and then infer the reality of the electrons, as when we test an hypothesis, and then believe it because it passed the test. That gets the time-order wrong. By now we design apparatus relying on a modest number of home truths about electrons, in order to produce some other phenomenon that we wish to investigate.

This may sound as if we believe in the electrons because we predict how our apparatus will behave. That too is misleading. We have a number of general ideas about how to prepare polarized electrons, say. We spend a lot of time building prototypes that don't work. We get rid of innumerable bugs. Often we have to give up and try another approach. Debugging is not a matter of theoretically explaining or predicting what is going wrong. It is partly a matter of getting rid of 'noise' in the apparatus. Although it also has a precise meaning, 'noise' often means all the events that are not understood by any theory. The instrument must be able to isolate, physically, the properties of the entities that we wish to use, and damp down all the other effects that might get in our way. We are completely convinced of the reality of electrons when we regularly set out to build - and often enough succeed in building - new kinds of device that use various well-understood causal properties of electrons to interfere in other more hypothetical parts of nature."32

In dieser Passage ist der systematische Punkt, den Hacking machen will, sicherlich weniger deutlich herausgearbeitet, als es wünschenswert wäre, aber zweierlei läßt sich doch herauslesen. Zum einen: Die Aufgabe, die kausalen Beschreibungen beim Benutzen einer Entität zukommt, ist es nicht, eine Vorhersage im engeren Sinn zu gestatten, also quantitativ präzise und detailliert anzugeben, welche Randbedingungen, Materialkonfigurationen usw. herzustellen sind, um das gewünschte Resultat zu erreichen. Es geht eher darum, so etwas wie einen kausalen Mechanismus anzugeben, das wesentliche Funktionsprinzip für das Gerät zu entwerfen, das mit Hilfe von viel praktischer Arbeit, also Ausprobieren, "Basteln" an Details usw. erfolgreich umgesetzt werden kann. Nur auf dieses wesentliche Funktionsprinzip des Gerätes, also auf die im Gerät ausgenutzten kausalen Faktoren, bezieht sich die "Vorhersage", die aufgrund der vorher etablierten kausalen Beschreibungen möglich ist.

\footnotetext{
${ }^{30}$ [Hack83a], S.274.

${ }^{31}$ [Hack89], S.578, Hervorhebung von mir.

${ }^{32}$ [Hack83a], S.265.
} 
Von anderen, beim Bau störenden kausalen Faktoren muß man und wird man im allgemeinen nicht so viel wissen, daß man quantitative Voraussagen treffen kann, sondern nur so viel, daß man sie mit Hilfe von Probieren usw. beherrschen kann. Zum anderen (und wichtiger für das Verständnis des "experimentellen Arguments"): Die Annahme, daß Elektronen real sind, wird nicht durch ein hypothetisch-deduktives Testverfahren begründet, derart, daß das Konstruieren eines Instrumentes dem Test einer Hypothese gleichkommt, dessen erfolgreiches Bestehen ggf. einen Schluß auf die Realität der Elektronen rechtfertigt. Vielmehr liegt die Etablierung der Annahme, daß Elektronen real sind, zeitlich vor ihrem praktischen Einsatz. ("We do not make the instruments and then infer the reality of the electrons [...] That gets the time order wrong." ${ }^{33}$ )

Im Sinne der zweiten Lesart des experimentellen Arguments, daß also kausale Beschreibungen, nicht das Benutzen von Entitäten, einen guten Grund für die Annahme liefern, daß die Entitäten real sind, äußert sich Hacking auch an folgender Stelle:

"The best kinds of evidence for the reality of a postulated or inferred entity is that we can begin to measure it or otherwise understand its causal powers. The best evidence, in turn, that we have this kind of understanding is that we can set out, from scratch, to build machines that will work fairly reliably, taking advantage of this or that causal nexus [...] Perhaps there are some entities which in theory we can know about only through theory (black holes). Then our evidence is like that furnished by Lorentz [for the existence of electrons by his explanation of Faraday's effect]. Perhaps there are entities which we shall only measure and never use. The experimental argument for realism does not say that only experimenter's objects exist." 34

In dieser Passage scheint Hacking dem Benutzen einer Entität die Rolle eines Indikators dafür zuzuschreiben, daß gut begründete kausale Beschreibungen dieser Entität vorliegen, während es die kausalen Beschreibungen sind ("understand its causal powers"), die den Grund für die Annahme liefern, daß die Entität real ist. Das Benutzen der Entität stellt lediglich "Evidenz" dafür dar, daß solche gut begründeten kausalen Beschreibungen vorliegen ${ }^{35}$ und obwohl Hacking offenbar glaubt, daß gute "Evidenz" für das Vorliegen solcher gut begründeten kausalen Beschreibungen praktisch immer das Benutzen der Entität involvieren wird, macht er doch deutlich, daß dies nicht notwendigerweise so sein muß, daß also solche "Evidenz" prinzipiell auch eine andere Gestalt haben könnte.

Die zuletzt zitierte Passage ist nicht nur im Hinblick auf die Unterscheidung zweier Sorten von Formulierungen in Hackings Antwort auf die Frage von Interesse, wann man

\footnotetext{
${ }^{33} \mathrm{Vgl}$. auch [Hack83a], S.262: "The more we come to understand some of the causal powers of electrons, the more we can build devices that achieve well-understood effects in other parts of nature. By the time that we can use the electron to manipulate other parts of nature in a systematic way, the electron has ceased to be something hypothetical, something inferred."

${ }^{34}[$ Hack83a], S.274/75.

${ }^{35}$ Vgl. auch [Hack83a], S.36 (wo allerdings nicht völlig klar ist, ob Hacking "nur" Cartwrights Thesen referiert oder diese auch für sich übernimmt: "In [. . Nancy Cartwright's] opinion one makes a very strong claim in calling something a cause. We must understand why a certain type of event regularly produces an effect. Perhaps the clearest proof of such understanding is that we can actually use events of one kind to produce events of another kind. Positrons and electrons are thus to be called real, in her vocabulary, since we can for example spray them, separately, on the niobium droplet and thereby change its charge. It is well understood why this effect follows the spraying. One made the experimental device because one knew it would produce the effects. A vast number of very different causal claims are understood and employed. We are entitled to speak of the reality of electrons [...] because we know that they have quite specific causal powers."
} 
gute Gründe für die Annahme hat, daß eine Entität "real ist", denn die Schlußsätze dieser Passage enthalten eine Auskunft über einen anderen Aspekt dieser Antwort: Hacking will mit dieser Antwort offenbar hinreichende Bedingungen angeben, keine notwendigen. Wenn die von ihm genannten Bedingungen (also routinemäßiges Benutzen und/oder das Vorliegen kausaler Beschreibungen) erfüllt sind, hat man seiner Ansicht nach gute Gründe für die Annahme, daß die fraglichen Entitäten real sind, aber zumindest prinzipiell sind auch andere und andersartige Bedingungen bzw. andersartige gute Gründe möglich. Hacking selbst ist allerdings sehr skeptisch, daß sich solche anderen Bedingungen bzw. Gründe tatsächlich aufweisen und plausibel machen lassen:

"There are surely innumerable entities and processes that humans will never know about. Perhaps there are many that in principle we can never know about. Reality is bigger than us [...] The experimental argument for realism does not say that only experimenter's objects exist.

[...] The sceptic like myself has a slender induction. Long-lived theoretical entities, which don't end up being manipulated, commonly turn out to have been wonderful mistakes." 36

Diese Skepsis (und nicht etwa ein "prinzipiellerer" Grund) führt Hacking dazu, beispielsweise in bezug auf die Entitäten, von denen die Astrophysik handelt, gegen eine realistische Einstellung zu plädieren. ${ }^{37}$

In Hackings Text lassen sich also zwei Sorten von Formulierungen finden, durch die er zwei zumindest prima facie verschiedene Antworten auf die Frage zu geben scheint, wann man gute Gründe für die Annahme hat, daß eine Entität "real ist". Wie diese zwei beschriebenen Antworten sich zueinander verhalten, dazu gibt Hackings Text keine explizite, unzweideutige Auskunft, so daß man darauf angewiesen ist, sich selbst ein möglichst plausibles Gesamtbild seiner Argumentation zurechtzulegen. Dazu ist es erforderlich, zunächst einige weitere Argumentationsstücke zur Kenntnis zu nehmen sowie einige Probleme und Einwände zu untersuchen.

\section{Home truths, Entitätenrealismus}

In der vorletzten der zitierten Passagen formuliert Hacking, auf welche Art von Repräsentationen man sich nach seiner Ansicht beim Benutzen einer Entität stützt:

"[...] we design apparatus relying on a modest number of home truths". ${ }^{38}$

An anderer Stelle heißt es in ähnlichem Sinn:

"We are convinced [of the structures that we observe using a microscope ...] because of a large number of interlocking low level generalizations that enable us to controll and create phenomena in the microscope." 39

Hacking meint, daß von den von ihm unterschiedenen Arten von Repräsentationen ${ }^{40}$ im wesentlichen nur solche des niederstufigsten Typs, nämlich home truths und low-level generalizations, für die Benutzung einer Entität erforderlich sind. Er konstatiert das als

\footnotetext{
${ }^{36}[$ Hack83a], S.274/275.

${ }^{37} \mathrm{Vgl}$. [Hack83a], S.275, [Hack89].

${ }^{38}$ [Hack83a], S.265, Hervorhebung von mir.

${ }^{39}$ [Hack83a], S.209, Hervorhebung von mir.

${ }^{40}$ Siehe Abschnitt 11.2.
} 
deskriptiven Befund über die Praxis der Experimentalphysik, als Bericht darüber, auf welche Weise und in welchem Grade dort Repräsentationen beim Bauen und Benutzen von Geräten und Apparaten eingehen; er führt kein Argument an, daß dort prinzipiell nur solche niederstufigen Gesetze zum Einsatz kommen könnten oder daß es prinzipiell unmöglich ist, daß sich das Verhalten eines Gerätes exakt aus den Grundgleichungen einer Theorie ableiten läßt.

Hackings Beobachtung hat Folgen für seine Argumentation für wissenschaftlichen Realismus: Wenn das Benutzen einer Entität den Grund für die Annahme liefern soll, daß diese Entität real ist, oder jedenfalls einen Indikator für das Vorliegen gut begründeter kausaler Beschreibungen, die ihrerseits einen guten Grund für diese Annahme liefern, dann liegen sozusagen allenfalls diejenigen Repräsentationen, die für das Benutzen der Entität erforderlich sind, in der Reichweite von Hackings Argumentation. Das Benutzen von Entitäten liefert also nach Hacking gute Gründe für die Annahme, daß die benutzten Entitäten real sind, und darüber hinaus vielleicht auch das, was die entsprechenden home truths und phänomenologischen Gesetze beschreiben, ${ }^{41}$ aber es läßt sich auf diese Weise keine realistische Einstellung in bezug auf "hochstufigere" theoretische Gesetze, Modelle o.ä. oder gar in bezug auf fundamentale Theorien begründen. Die Position, die man auf diese Weise begründen kann, bezeichnet Hacking als Entitätenrealismus. ${ }^{42}$

\section{Eine das experimentelle Argument motivierende Parallele zwischen Alltags- praxis und Wissenschaft}

Hacking beantwortet also die Frage, wann man einen guten Grund für die Annahme hat, daß eine Entität real ist, indem er das Benutzen dieser Entität bzw. das Vorliegen kausaler Beschreibungen als Kriterium angibt; zur Begründung oder Rechtfertigung dieses Kriteriums findet sich in seinen Texten allerdings nur wenig, jedenfalls wenig Explizites. Er gibt aber immerhin an zwei Stellen einen Hinweis, wodurch sein Kriterium anscheinend motiviert ist, nämlich durch eine Parallele zwischen Alltagspraxis und Wissenschaft. An einer Stelle gibt er eine lose Formulierung für sein Kriterium an, die deutlich macht, daß sein Anwendungsbereich nicht auf die Wissenschaften beschränkt ist, daß also für dieses Kriterium eine Unterscheidung zwischen Entitäten, mit denen man nur in wissenschaftlichen Kontexten zu tun hat, und Entitäten der Alltagswelt oder zwischen beobachtbaren und unbeobachtbaren Entitäten keine Rolle spielt:

"Reality has to do with causation and our notions of reality are formed from our abilities to change the world [...]. We shall count as real what we can use to intervene in the world to affect something else, or what the world can use to affect us." 43

An einer zweiten Stelle schreibt Hacking mehr oder weniger explizit oder legt zumindest nahe, daß das Kriterium, das er im Zusammenhang der wissenschaftstheoretischen Realismusdebatte vorschlägt, durch die Anwendbarkeit und Plausibilität desselben Kriteriums im Bereich der Alltagswelt motiviert ist:

"The experimenter is convinced of the reality of entities, some of whose causal properties are sufficiently well understood that they can be used to interfere

\footnotetext{
${ }^{41}$ Hacking ist in diesem Punkt nicht besonders explizit.

${ }^{42}$ Vgl. S.17f., bes. Fn.71.

${ }^{43}$ [Hack83a], S.146.
} 
elsewhere in nature. One is impressed by entities that one can use to test conjectures about other, more hypothetical entities [...]. This should not be news, for why else are we (nonsceptics) sure of the reality of even macroscopic objects, but because of what we do with them, what we do to them, and what they do to us?

Interference and interaction are the stuff of reality." 44

\section{Die Thesen, die Hackings Entitätenrealismus konstituieren}

Eine systematisch wichtige, aber bisher zurückgestellte Frage ist, wie Hackings Formulierungen genau zu verstehen sind, daß eine Entität "real ist", daß man "an die Realität von Elektronen glaubt" etc., welche Thesen also genaugenommen Hackings entitätenrealistische Position konstituieren, insbesondere, ob es sich dabei um realistische Thesen der vorne $^{45}$ unterschiedenen Arten handelt, und wenn ja, um welche. Hacking gibt dazu folgende Erläuterung:

"Realism about entities says that a good many theoretical entities really do exist. Anti-realism denies that, and says that they are fictions, logical constructions, or parts of an intellectual instrument for reasoning about the world. Or, less dogmatically, it may say, that we have not and cannot have any reason to suppose they are not fictions $[\ldots]$.

I have just run together claims about reality and claims about what we know. My realism about entities implies both that a satisfactory theoretical entity would be one that existed (and was not merely a handy intellectual tool). That is a claim about entities and reality. It also implies that we actually know, or have good reasons to believe in, at least some such entities in present science. That is a claim about knowledge.

I run knowledge and reality together because the whole issue would be idle if we did not now have some entities that some of us think really do exist. If we were talking about some future scientific utopia I would withdraw from the discussion. The two strands that I run together can be readily unscrambled, as in the following scheme of W. Newton-Smith's. ${ }^{46}$ He notes three ingredients in scientific realism:

1 An ontological ingredient: scientific theories are either true or false, and that which a given theory is, is in virtue of how the world is.

2 A causal ingredient: if a theory is true, the theoretical terms of the theory denote theoretical entities which are causally responsible for the observable phenomena.

3 An epistemological ingredient: we can have warranted belief in theories or in entities (at least in principle).

Roughly speaking, Newton-Smith's causal and epistemological ingredients add up to my realism about entities [...].

[...My] realism about entities is not exactly (2) and (3). Newton-Smith's causal ingredient says that if a theory is true, then the theoretical terms denote entities

\footnotetext{
${ }^{44}[$ Hack82a], S.251.

${ }^{45}$ Siehe Kap.1.

${ }^{46}[\mathrm{MeSm} 78]$, S.72.
} 
that are causally responsible for what we can observe. He implies that belief in such entities depends on belief in a theory in which they are embedded. But one can believe in some entities without believing in any particular theory in which they are embedded." 47

Hacking macht in dieser Passage deutlich, daß er seinen Entitätenrealismus zwei verschiedenen Gegenpositionen entgegenstellt: Indem er etwa sagt, daß Elektronen real sind, weist er zum einen instrumentalistische Positionen (in bezug auf Elektronen) zurück, zum anderen in epistemischer Hinsicht antirealistische Positionen wie van Fraassens konstruktiven Empirismus.

Weniger deutlich wird hingegen, was die "positive" These des Entitätenrealismus etwa in bezug auf Elektronen ist. Hacking spricht von zwei (grundsätzlich voneinander trennbaren) Behauptungen oder auch "Strängen", die sein Entitätenrealismus zusammenbringt, aber bei beiden erklärt er nicht eindeutig, worin sie bestehen: Für die erste der beiden Behauptungen, die sich auf "die Realität" bezieht, gibt er einerseits Umschreibungen und Erläuterungen an, die darauf hindeuten, daß es sich um eine ontologische realistische These (im vorne erläuterten $\operatorname{Sinn}^{48}$ ) handelt, etwa wenn er sagt, daß Elektronen "existieren' und daß es dabei um eine Aussage über "Entitäten und die Realität" geht. Andererseits gibt er auch Umschreibungen und Erläuterungen an, die darauf hindeuten, daß es sich um eine semantische realistische These ${ }^{49}$ handelt, etwa wenn er sagt, daß "theoretische Ausdrücke theoretische Entitäten bezeichnen". Die Beschreibung der "kausalen Zutat" des Entitätenrealismus, die Hacking ohne weitere Erläuterung nennt, läßt sich mit beiden Möglichkeiten zusammenbringen: Daß bestimmte Entitäten "kausal für beobachtbare Phänomene verantwortlich" sind, läßt sich als Zuschreibung kausaler Eigenschaften im Sinne einer ontologischen realistischen These auffassen, es könnte jedoch auch ein Hinweis auf eine bestimmte semantische Theorie für die entsprechenden theoretischen "Entitätenausdrücke" sein, etwa auf eine kausale Referenztheorie oder eine Hybridtheorie. Diesen beiden Lesarten des ersten der beiden Stränge, die Hackings Entitätenrealismus zusammenbringt, als ontologischer oder als semantischer Realismus entsprechend läßt sich auch der zweite Strang, der sich auf "Wissen" bezieht, als Aussage über die epistemische Rechtfertigung der ontologischen realistischen Thesen lesen oder als epistemische realistische These bezüglich der Sätze bzw. Ausdrücke, auf die sich der semantische Realismus bezieht.

Sowohl ontologische als auch semantische realistische Thesen geben das, was Hacking als positive Aussagen seines Entitätenrealismus nennt, insofern nicht exakt wieder, als er die (realistischen Positionen vielfach zugrundeliegende) Idee der Unabhängigkeit der Welt vom menschlichen Geist und menschlicher Erkenntnis nicht explizit erörtert und sich in seinen Texten keine Entsprechungen zu den Teilen ontologischer bzw. semantischer realistischer Thesen finden, die diese Idee konkretisieren. ${ }^{50}$ Dies spricht jedoch nicht notwendigerweise dagegen, Hackings Entitätenrealismus mit Hilfe ontologischer oder semantischer realistischer Thesen zu explizieren, denn Hacking scheint diese Unabhängigkeitsidee nicht abzulehnen, sondern in diesem Punkt nur dem Mainstream der wissenschaftstheoretischen Realismusdebatte zu folgen und sich bei der Formulierung seiner Position auf einen relativen Realismus zu beschränken, der die genaue Konkretisierung der Unabhängigkeitsidee

\footnotetext{
${ }^{47}[$ Hack83a], S.27-29.

${ }^{48}$ Also nicht im Sinne von Hackings von Newton-Smith übernommener Verwendungsweise von 'ontologisch', denn diese entspricht am ehesten dem, was vorne als semantische realistische These der Form (SR1) bezeichnet wurde; vgl. Kap.1.

${ }^{49}$ In dem in Kap.1 erläuterten Sinn.

${ }^{50}$ Siehe Kap.1.
} 
offen läßt und lediglich sagt, daß eine solche Konkretisierung für den Bereich der theoretischen Entitäten der Wissenschaften von derselben Art sein muß wie die für den Bereich der beobachtbaren Alltagswelt: ${ }^{51}$

"Scientific realism says that the entities, states, and processes described by correct theories really do exist. Protons, photons, fields of force, and black holes are as real as toe-nails, turbines, eddies in a stream, and volcanoes." 52

Auf den ersten Blick könnte man denken, daß eine andere von Hacking vertretene These einer Explikation seines Entitätenrealismus mit Hilfe ontologischer realistischer Thesen gerade wegen der in ontologischen realistischen Thesen enthaltenen Konkretisierung der Unabhängigkeitsidee im Wege steht, nämlich Hackings These, daß die Entitäten und Phänomene, auf die sich sein Entitätenrealismus bezieht, in vielen oder vielleicht sogar in den meisten Fällen in der von menschlichen Eingriffen unberührten Natur nicht vorkommen, sondern eigens hergestellt und/oder präpariert werden müssen, um sie zu untersuchen und mit ihnen zu experimentieren. Hacking betont verschiedentlich, daß sich sein Entitätenrealismus hauptsächlich, wenn nicht ausschließlich auf Entitäten und Phänomene der "Laborwissenschaften" bezieht und daß sich der Anwendungs- bzw. Gültigkeitsbereich der dort im Labor gewonnenen Gesetze, home truths etc. selten oder nie über die im Labor hergestellten oder präparierten Systeme, Zustände etc. hinaus auf die unberührte Natur außerhalb des Labors erstreckt. ${ }^{53}$ Daher könnte die Vermutung naheliegen, daß ontologische realistische Thesen keine angemessene Explikation von Hackings Entitätenrealismus ergeben können, weil die in solchen Thesen enthaltene Unabhängigkeitsaussage ${ }^{54}$ nicht mit dem Befund verträglich ist, daß die Entitäten und Phänomene, auf die sich die ontologischen realistischen Thesen beziehen, von Menschen hergestellte und/oder präparierte sind. Bei genauerer Betrachtung besteht aber tatsächlich kein solcher Konflikt, jedenfalls dann nicht, wenn man die Unabhängigkeitsaussagen in geeigneter Weise formuliert: Entitäten und Phänomene, die in einem Labor hergestellt und/oder präpariert wurden, sind vielleicht nicht in dem Sinne unabhängig von menschlicher Erkenntnis, daß sie auch dann existieren würden, wenn es keine menschliche Erkenntnis gäbe, und auch nicht in dem Sinne, daß sie von menschlichen Erkenntnisverfahren, -zuständen etc. kausal nicht beeinflußt würden, aber sie würden auch dann existieren, wenn von ihrer Existenz niemand wüßte etc., und sie werden von den menschlichen Erkenntnisverfahren nicht kausal beeinflußt, die menschliches Wissen von ihnen konstituieren bzw. erzeugen. ${ }^{55}$ In dieser Weise, also durch (UvmE1a) oder (UvmE2a) erläuterte ontologische realistische Thesen sind mit dem Befund verträglich, daß die Entitäten und Phänomene, auf die sie sich beziehen, von Menschen hergestellt und/oder präpariert wurden und vielleicht in der unberührten Natur gar nicht vorkommen, so daß dieser Befund kein Hindernis für eine Explikation von Hackings Entitätenrealismus mit Hilfe von ontologischen realistischen Thesen darstellt.

Einen Hinweis darauf, daß es Existenzaussagen über unbeobachtbare Entitäten und Aussagen über deren Eigenschaften (in der Form von home truths und phänomenologischen Gesetzen) sind, die für Hacking den Kern seines Entitätenrealismus ausmachen, und daß daher eher ontologische als semantische realistische Thesen eine angemessene Explikation seiner Position ergeben dürften, läßt sich indirekt dem entnehmen, was Hacking zum

\footnotetext{
${ }^{51}$ Siehe Abschnitt 1.4.3.

${ }^{52}$ [Hack83a], S.21, zweite Hervorhebung von mir. S.a. S.23.

${ }^{53}$ Siehe z.B. [Hack83a], Kap.13.

${ }^{54}$ Siehe Kap.1.2.1, 1.3.1.

${ }^{55}$ Jedenfalls i.a.; besondere Probleme, die etwa bei quantenmechanischen Entitäten und Phänomenen auftreten können, bleiben hier beiseite.
} 
Thema Wahrheits-, Bedeutungs- und Referenztheorien schreibt: Das Thema Wahrheit diskutiert er im Zusammenhang mit seiner Konzeption des Entitätenrealismus gar nicht ${ }^{56}$, und das Thema Bedeutungs- und Referenztheorien diskutiert er ausführlich im Kontext der mit dem Stichwort "Inkommensurabilität" bezeichneten Problematik, ${ }^{57}$ nicht dagegen an den Stellen, an denen er formuliert und erläutert, was seine entitätenrealistische Position ausmacht. ${ }^{58}$ Dies scheint dagegen zu sprechen, daß semantische realistische Thesen zentral für seine Position sind.

Zusammenfassend läßt sich festhalten, daß sich bei Hacking keine unmißverständliche Antwort auf die Frage findet, welche Thesen seine entitätenrealistische Position konstituieren, daß dabei aber Existenzaussagen über unbeobachtbare Entitäten sowie home truths und phänomenologischen Gesetzen über deren Eigenschaften eine zentrale Rolle zukommt und daß einiges dafür spricht, daß entsprechende ontologische realistische Thesen eine angemessene Explikation dieser Position ergeben, während semantische Thesen und Theorien diese Position vielleicht ergänzen und eine Rolle bei ihrer Verteidigung gegen Einwände spielen können, aber nicht konstitutiv für den Entitätenrealismus sein dürften. Die These etwa, daß Elektronen "real sind", ist demnach zu verstehen als eine Existenzaussage über Elektronen plus einige Aussagen über deren kausale Eigenschaften, und wenn Hacking ein Kriterium dafür angibt, wann gute Gründe für die Annahme vorliegen, daß eine Entität "real ist", ist dies demnach aufzufassen als ein Kriterium dafür, wann gute Gründe für eine Existenzaussage bezüglich dieser Entität plus einige Aussagen über ihre kausalen Eigenschaften vorliegen. Im Hinblick auf die Debatte mit antirealistischen Gegnern gibt dieses Kriterium also an, wann sowohl eine instrumentalistische Einstellung bezüglich dieser Entität bzw. bezüglich der genannten Aussagen über sie zurückzuweisen ist als auch eine gute epistemische Begründung der Existenzaussage und der Aussagen über ihre kausalen Eigenschaften gegeben werden kann.

\subsubsection{Probleme und Kritik}

Hackings Entitätenrealismus und sein experimentelles Argument sind in den letzten Jahren vielfach diskutiert worden. ${ }^{59}$ Die im Hinblick auf die Realismusdebatte wichtigsten Einwände gegen Hackings Argumentation sollen an dieser Stelle erörtert werden.

\section{Stimmt Hackings Kriterium mit den in der Praxis der Wissenschaften eta- blierten Kriterien für Existenzannahmen überein?}

Ein Punkt, der insbesondere den mit Praxis und Geschichte der Physik Vertrauten unter Hackings Lesern sofort auffällt, ist, daß Hacking, bei allem Wert, den er auf detailgenaue Beschreibung real-existierender Wissenschaften legt, mit seinem Kriterium die Praxis der Physik jedenfalls insofern nicht korrekt abbildet, als zumindest in einer ganzen Reihe von

\footnotetext{
${ }^{56}$ Dagegen diskutiert er es im Zusammenhang mit anderen Positionen in der Realismusdebatte (vgl. [Hack83a], Kap.4, 8). Dieser Befund läßt sich nicht dadurch erklären, daß er sich als Entitätenrealist nicht mit der Wahrheit (oder Falschheit) von Theorien zu beschäftigen braucht, denn zumindest die Wahrheit (oder Falschheit) von Existenzsätzen, home truths und phänomenologischen Gesetzen müßte auch für seinen Entitätenrealismus ein relevantes Thema sein, wenn er durch semantische Thesen konstituiert würde.

${ }^{57}$ Genauer: um seinen Entitätenrealismus mit Hilfe einer kausalen Referenztheorie gegen entsprechende Einwände zu verteidigen ([Hack83a], Kap.6); dazu s. S.329.

${ }^{58}$ Die eine bereits erwähnte, möglicherweise in diese Richtung deutende Formulierung zur Charakterisierung der "kausalen Zutat" des Entitätenrealismus ausgenommen.

${ }^{59}$ Einige Arbeiten, die sich mit Hackings Position in der Realismusdebatte auseinandersetzen, sind [Carr98, Elsa94, Gros90, Morr90a, RePi95, Resn94, Seag95, Shap93].
} 
Fällen die große Mehrheit der Gemeinschaft der Physiker von der Existenz einer Entität nicht erst dann überzeugt war, als diese routinemäßig benutzt wurde bzw. dazu hinreichendes kausales Wissens etabliert war: ${ }^{60}$ Die Experimente beispielsweise, die üblicherweise als Nachweise des Positrons und des Z gelten, involvieren kein Benutzen dieser Teilchen in Hackings Sinn bzw. zum Benutzen hinreichendes kausales Wissen. ${ }^{61}$ Hackings Kriterium scheint also jedenfalls nach dem innerhalb der Physik vorherrschenden Verständnis kein notwendiges Kriterium für das Vorliegen guter Gründe für Existenzannahmen darzustellen.

Einige Autoren argumentieren ferner, daß das Benutzen einer Entität innerhalb der Physik auch nicht als hinreichendes Kriterium für Existenzannahmen giltt, ${ }^{62}$ die von ihnen angeführten Beispiele beziehen sich jedoch bestenfalls auf einzelne Fälle von Manipulation, nicht auf routinemäßiges Benutzen und entsprechend detailiertes kausales Wissen, wie Hacking es fordert.

Der Befund, daß eine Diskrepanz besteht zwischen Hackings Kriterium und den Existenzannahmen, die die Gemeinschaft der Physikerinnen und -Physiker selbst macht, ist zweifellos richtig (und Hacking dürfte diesen Punkt natürlich selbst gesehen haben), er stellt jedoch zumindest per se keinen Einwand gegen Hackings Position dar. Hackings Ziel ist es nicht, die physikinternen Standards für Existenzannahmen, d.h. die vorherrschende Meinung unter arbeitenden Physikern und Physikerinnen wiederzugeben, sondern eine Position in der Realismusdebatte zu formulieren. Bei der Formulierung einer solchen Position kann und sollte man die Praxis der Physik zur Kenntnis nehmen und berücksichtigen, aber man muß die dort vorherrschenden Standards und Überzeugungen nicht notwendigerweise eins zu eins übernehmen, sondern kann diese z.B. auch mit Argumenten konfrontieren und unter Gesichtspunkten bewerten, die ein Philosoph oder ein Wissenschaftshistoriker typischerweise vielleicht eher im Blick haben als ein arbeitender Physiker. Dabei kann durchaus herauskommen, daß nur ein Teil der Existenzannahmen, die in der Physik als etabliert gelten, auch nach strengeren, sich aus wissenschaftstheoretischen oder -historischen Überlegungen ergebenden Kriterien als gut begründet gelten kann, und wenn das so ist, spricht es nicht notwendigerweise gegen die philosophische Position, die diese Kriterien einschließt.

Eine weitere denkbare Reaktion auf den Einwand, daß Hackings Kriterium die physikinternen Standards für Existenzannahmen nicht korrekt wiedergibt, ist die, darauf hinzuweisen, daß dieses Kriterium, wie vorne erörtert, grundsätzlich als hinreichendes aufzufassen ist, so daß prinzipiell die Möglichkeit offensteht, es zu verbessern oder durch zusätzliche Kriterien zu ergänzen - auch wenn Hacking selbst die Erfolgschancen entsprechender Versuche gering einschätzt.

\section{Die Entkoppelung von Entitäten, home truths und phänomenologischen Ge- setzen einerseits und Theorien andererseits; Unklarheiten in bezug auf Status und Begründung von Hackings Kriterium}

Hackings Entitätenrealismus entkoppelt gewissermaßen theoretische Entitäten, home truths und phänomenologische Gesetze einerseits und Theorien andererseits. Hacking meint, daß einige home truths und/oder phänomenologische Gesetze ausreichen, um einer Entität kau-

\footnotetext{
${ }^{60}$ Vgl. [Gali86], S.119f., [Gali87], S.261f., [Gros90], S.426, [Morr90a], S.13f.

${ }^{61}$ Siehe z.B. [ClMS87], Kap.4, 9, [Gali87], Kap.3. Entsprechendes gilt für die Objekte der Astrophysik, die Hacking in [Hack83a], S.275 kurz erwähnt und dann in [Hack89]; vgl. dazu [Shap93].

${ }^{62}$ [Gros90], S.424f., [Morr90a], S.9, 13.
} 
sale Eigenschaften zuzuschreiben, die ihre routinemäßige Benutzung gestatten, und daß diesen home truths und phänomenologischen Gesetzen und den Existenzaussagen bzgl. der Entitäten daher im Hinblick auf die Realismusdebatte ein anderer Status zukommt als Theorien und theoretischen Modellen.

An dieser Entkoppelung ist zu Recht bemängelt worden, ${ }^{63}$ daß Hacking keine präzise Erläuterung dafür gibt, was als home truth oder als phänomenologisches Gesetz zählt und wie diese von den höherstufigen theoretischen Beschreibungen abzugrenzen sind. Da er es aber wenigstens im Umriß erläutert und jedenfalls bei Hackings konkreten Beispielen einigermaßen klar wird, was gemeint ist, kann man das Fehlen einer präziseren Erläuterung vielleicht als zu behebendes Defizit betrachten, nicht als irreparablen Mangel.

Ein zweiter gegen Hackings Entkoppelung vorgebrachter Einwand ist der, daß man einer unbeobachtbaren Entität zwar mittels home truths und phänomenologischen Gesetzen kausale Eigenschaften zuschreiben kann, daß man aber bei der epistemischen Rechtfertigung dieser Zuschreibungen i.a. nicht ohne hochstufigere theoretische Beschreibungen, sprich: Modelle und Theorien, auskommt. ${ }^{64}$ Ein Beispiel: Von einer home truth wie "Die Ladung des Elektrons beträgt $1,602 \cdot 10^{-19} C^{\prime \prime}$ kann man klarerweise überzeugt sein, ohne daß man (eine oder mehrere) Theorien über das Elektron und sein Verhalten glaubt oder auch nur kennt (Elektrodynamik, Mechanik, QED etc.), die epistemische Rechtfertigung dieser Überzeugung wird jedoch in der einen oder anderen Form auf einer experimentellen Messung beruhen, und, so der Einwand, das Resultat dieser Messung wird nur gerechtfertigt werden können, wenn man, je nach Meßverfahren, bestimmte Theorien und/oder Modelle der Meßgeräte etc. als wenigstens annähernd wahr voraussetzen kann. (Z.B. braucht man Newtons Bewegungsgleichungen mit dem Ausdruck für die LorentzKraft, wenn man $e / m$ über die Bewegung im Magnetfeld bestimmt, oder bei Millikans Öltröpfchenversuch analog einen Ausdruck für die Kraft auf eine Ladung im elektrischen Feld.) Indem man diesen Einwand erhebt, muß man nicht behaupten, daß zur Rechtfertigung von home truths etwa über Elektronen so etwas wie eine vollständige Theorie des Elektrons (wie das Standardmodell der elektroschwachen Wechselwirkung) erforderlich sei, und man muß auch nicht notwendigerweise behaupten, daß bei jeder home truth und jedem phänomenologischen Gesetz zur Rechtfertigung Theorien und Modelle erforderlich sind. Wie dieser Einwand genauer und expliziter zu formulieren wäre, hängt i.a. davon ab, was für eine Konzeption von epistemischer Rechtfertigung man akzeptiert. Was sich aber vielleicht auch ohne eine genauere und explizitere Formulierung durch Beispiele in zumindest prima facie plausibler Weise belegen läßt, ist, daß sich die Menge der von der modernen Physik gewonnenen home truths und phänomenologischen Gesetze im Hinblick auf ihre epistemische Rechtfertigung kaum vollständig vom restlichen, hochstufigeren Teil des Theoriegebäudes der Physik ablösen lassen dürfte.

Ein dritter Einwand, der gegen Hackings Entkoppelung vorgebracht worden ist, besteht in dem Hinweis darauf, daß home truths und phänomenologische Gesetze - entgegen dem, was Hacking schreibt - i.a. nicht ausreichen, um für das Benutzen einer Entität genug kausales Wissen bereitzustellen: Man kommt, so der Einwand, i.a. nicht mit home truths und phänomenologischen Gesetzen über eine Entität aus, wenn man diese Entität als Werkzeug benutzen will, also etwa ein Gerät bauen und verwenden will, das diese Entität einsetzt. ${ }^{65}$ Zwar ist es klarerweise möglich, daß jemand ein Gerät, etwa ein Elektronenmikroskop verwendet, das eine bestimmte Entität benutzt, nämlich Elektronen, ohne etwas

\footnotetext{
${ }^{63}$ Z.B. [Morr90a], S.14, [Resn94], S.409.

${ }^{64}$ Vgl. [Morr90a], Abschnitt 3.2, [Resn94], S.405ff., [Carr98].

${ }^{65}$ In dieser Richtung argumentiert Morrison in [Morr90a], Abschnitt 3.1; s.a. [Carr98].
} 
über diese zu wissen, was über home truths und phänomenologische Gesetze hinausgeht: Er könnte sich an eine detaillierte Bedienungsanleitung halten, die die Konstrukteure des Gerätes verfaßt haben, und genau die Handgriffe ausführen, die diese vorschreibt, o.ä. Zumindest die Experten, die ein Gerät dieser Komplexität bauen, bei Störungen zu Rat gezogen werden etc., dürften dazu aber i.a. nicht in der Lage sein, wenn sie nur über home truths und phänomenologische Gesetze über die benutzte Entität verfügen. Um die bei der Benutzung einer Entität ablaufenden Vorgänge hinreichend genau zu verstehen, sind, so der Einwand, i.a. hochstufigere theoretische Repräsentationen erforderlich, also Modelle und Theorien. Indem man diesen Einwand erhebt, muß man wiederum nicht behaupten, daß das Benutzen einer Entität so etwas wie eine vollständige Theorie über sie erfordert, und auch nicht, daß jeder Fall des Benutzens einer Entität in einem Gerät o.ä. Modelle und Theorien erfordert. Es läßt sich aber durch Beispiele in zumindest prima facie plausibler Weise belegen, daß ohne Modelle und Theorien jedenfalls nicht die gesamte Praxis des Benutzens von theoretischen Entitäten "funktionieren" würde.

Die beiden letztgenannten Einwände sehen überzeugend aus ${ }^{66}$, und zumindest den zweiten davon scheint Hacking in neueren Arbeiten auch implizit zuzugeben. ${ }^{67}$ Die Konsequenz ist offenbar, daß man zu detaillierten Einzelfalluntersuchungen greifen müßte, um festzustellen, ob und wie weit und wie genau für die epistemische Rechtfertigung einer home truth oder eines phänomenologischen Gesetzes Theorien und/oder Modelle erforderlich sind, und ebenso, um festzustellen, ob und in welchem Maße für die Benutzung einer Entität Theorien und/oder Modelle erforderlich sind. Was es für Auswirkungen auf die von Hacking anvisierte Position in der Realismusdebatte hat, wenn man die beiden Einwände akzeptiert, hängt dann von den Ergebnissen von Falluntersuchungen der genannten Art ab.

Im Fall des zweiten der beiden letztgenannten Einwände wären die Konsequenzen für Hackings Position allerdings auch dann unklar, wenn man genügend viele Fallstudien zur Verfügung hätte, und zwar deshalb, weil Hacking letzlich keine Klarheit schafft über den Status und die Begründung seines Kriteriums dafür, was "real ist". Wenn für das Benutzen einer Entität nicht nur home truths und phänomenologische Gesetze erforderlich sind, sondern auch Modelle und/oder Theorien, bzw. wenn die kausalen Beschreibungen, die eine Benutzung ermöglichen, nicht nur aus home truths und phänomenologischen Gesetzen bestehen, das Benutzen bzw. das Vorliegen der kausalen Beschreibungen aber das Kriterium dafür darstellen, was "real ist", bedeutet das, daß dieses Kriterium nicht die Trennlinie zwischen Entitäten- und Theorienrealismus ergibt, die Hacking im Auge hat, nämlich eine, die zwischen home truths und phänomenologischen Gesetzen einerseits und Theorien und Modellen andererseits verläuft, sondern eine, die irgendwo weiter inner-

\footnotetext{
${ }^{66}$ Sofern nicht behauptet wird, daß bei der Rechtfertigung einer home truth oder eines phänomenologischen Gesetzes in jedem Fall Theorien und/oder Modelle erforderlich sind und daß jedes Benutzen einer Entität Theorien und/oder Modelle erfordert, denn gegen solche allgemeinen Thesen finden sich bei Hacking Gegenbeispiele.

${ }^{67}$ In [Hack92b] beschäftigt sich Hacking (u.a.) mit Experimenten, ohne das Stichwort "home truths" zu erwähnen. Er nennt dort als einen Punkt auf einer Liste von Dingen, die für ein Experiment erforderlich sind,
}

"Modelling of the apparatus. There are theories, or at least background lore, about the instruments and equipment listed below [...]. I shall speak of the (theoretical) modelling of the apparatus, an account of how it works and what, in theory, it is like. We are concerned with phenomenological theory that enables us to design instruments and to calculate how they behave" ([Hack92b], S.45). 
halb des theoretischen Bereiches liegt. Gemäß diesem Kriterium müßte dann auch bei zumindest einigen Modellen und Theorien das, was sie beschreiben, als real gelten. Dies anzuerkennen und damit seine realistische Position sozusagen über den vorher skizzierten Entitätenrealismus hinaus auszudehnen, ist eine Möglichkeit für Hacking, auf den zuletzt genannten Einwand zu reagieren. Eine andere Option wäre, an der anvisierten Grenzlinie und damit dem Entitätenrealismus festzuhalten und das Kriterium dafür, was real ist, entsprechend zu modifizieren: Danach wäre das Benutzen "nur" ein Kriterium dafür, daß die benutzte Entität und das, was die involvierten home truths und phänomenologischen Gesetze beschreiben, real ist (auch wenn dabei Modelle und/oder Theorien involviert sind), oder das Kriterium wäre das Benutzen einer Entität, das nur aufgrund von home truths und phänomenologischen Gesetzen möglich ist, o.ä. Die Frage, welche von beiden Optionen aus Hackings Perspektive die angemessene Reaktion darstellt, ist schwer zu entscheiden und läßt einen unklaren oder zumindest offenen Punkt in Hackings Argumentation deutlich zutage treten: Hacking beantwortet durch die Angabe seines Kriteriums die Frage, wann gute Gründe für die Annahme vorliegen, daß eine Entität bzw. das, was bestimmte Repräsentationen beschreiben, real ist, aber er scheint weitgehend offen zu lassen, worin die guten Gründe bestehen. Sein Kriterium scheint sozusagen in der Gesamtheit der in den real-existierenden Wissenschaften etablierten Repräsentationen (also Gesetze, Modelle etc.) in extensionaler Weise einen Bereich zu markieren, für den seiner Ansicht nach gilt, daß gute Gründe für die Annahme vorliegen, daß alles real ist, worauf sich die Repräsentationen im Inneren dieses Bereiches beziehen — zumindest wird nicht klar, daß und warum das Kriterium sozusagen ein wesentliches, nicht bloß extensionales sein sollte. Es wird nicht klar, warum die Grenzen des markierten Bereiches so gezogen werden sollen, wie Hacking sie zieht; daher ist auch nicht klar, welche der beiden genannten Optionen aus Hackings Perspektive vorzuziehen ist.

Das, was sich bei Hacking nicht (oder jedenfalls nicht in zufriedenstellender, über Andeutungen hinausgehender Form - s.u.) findet und was eine begründete Wahl zwischen den beiden genannten Optionen ermöglichen würde, ist einerseits eine allgemeine Erläuterung, wie eine instrumentalistische Einstellung in bezug auf bestimmte Entitäten bzw. Repräsentationen zu begründen oder begründet zurückzuweisen ist, andererseits eine Konzeption epistemischer Rechtfertigung, die (u.a.) eine allgemeine Erläuterung einschließt, wie Existenz- und andere Aussagen über Entitäten und ihre Eigenschaften zu begründen sind. Ohne eine solche Erläuterung und eine Konzeption epistemischer Rechtfertigung bleiben Status und Begründung von Hackings Kriterium, was "real ist", unklar und damit auch die Konsequenzen des Einwandes, daß das Benutzen einer Entität tatsächlich i.a. "hochstufigere" Repräsentationen erfordert, als Hacking meint.

Wenn man eine Konzeption epistemischer Rechtfertigung zur Verfügung hat, lassen sich vor deren Hintergrund auch Einzelfallstudien darüber anstellen, ob zur Rechtfertigung der zur Benutzung einer Entität erforderlichen home truths und phänomenologischen Gesetze tatsächlich hochstufigere Repräsentationen erforderlich sind, wie es der zweite der drei genannten Einwände behauptet, und wenn ja, in welchem Umfang. Erst dann läßt sich zuverlässig bewerten, welche Konsequenzen dieser Einwand im einzelnen für Hackings Entitätenrealismus hat. 


\section{Ist Hackings experimentelles Argument eine Variante des Wunderarguments und/oder liegt ihm ein Schluß auf die beste Erklärung zugrunde?}

Die Tatsache, daß sich bei Hacking keine klare Auskunft zu der Konzeption von epistemischer Rechtfertigung findet, die seinem Kriterium dafür, was real ist, zugrundeliegt, bildet auch den Ansatzpunkt für einen weiteren Einwand.

Verschiedene Kritiker Hackings haben die Ansicht vertreten, daß sein experimentelles Argument eine Variante des Wunderarguments sei oder daß ihm jedenfalls ein Schluß auf die beste Erklärung zugrundeliegt. ${ }^{68}$ David Resnik etwa meint:

"Hacking's argument for experimental realism is, despite his strong denial, another version of the 'success of science' argument". ${ }^{69}$

Resnik ist der Ansicht, daß sich die Existenzannahmen, home truths und phänomenologischen Gesetze, auf die man sich verläßt, wenn man eine Entität benutzt, nur durch einen Schluß auf die beste Erklärung epistemisch rechtfertigen lassen, wie er auch beim Wunderargument gezogen wird, oder daß sie jedenfalls in Hackings Argument durch einen solchen Schluß gerechtfertigt werden, wenn man alle Schritte dieses Arguments explizit macht:

"In a nutshell, Hacking's argument for entity realism goes something like this:

(1) We are entitled to believe that a theoretical entity is real if and only if we can use that entity to do things in the world.

(2) We can use some theoretical entities, e.g. electrons, to do things to the world, e.g. change the charges of niobium balls.

(3) Hence, we are entitled to believe that some theoretical entities, e.g. electrons, are real.

$[\ldots]$

Hacking's argument is also a 'success of science argument' for realism. While Smart and Boyd focus on the success of theoretical science, viz., predictive and explanatory success, Hacking focuses on the success of experimental science. Success in experimentation is equated with the ability to reliably manipulate or control our instruments in order to produce desired effects [...]. Hacking's argument for premise (2) now takes shape:

(A) Our scientific instruments work fairly reliably in producing desired effects, e.g. changing the charge on niobium balls.

(B) The best explanation of this reliability is that these instruments take advantage of a (real) causal nexus in the world. That is, that we are using the instruments to do things in the world.

(C) According to our low-level generalizations (theories?) and other assumptions, our instruments take advantage of some theoretical entities in producing their effects.

(D) Hence, we can use some theoretical entities, e.g. electrons, to do things in the world, e.g. change the charge on niobium balls.

\footnotetext{
${ }^{68}$ Vgl. [Morr90a], S.16f., [RePi95], S.64ff., [Resn94].

${ }^{69}$ [Resn94], S.395.
} 
Hacking's argument, like other success of science arguments, also depends on our recognizing an incredible coincidence that cries out for explanation. The coincidence for the experimenter is that the instruments work reliably in producing desired effects. It would be an incredible coincidence if we managed to use an entity as a tool for inquiry that did not, in fact, exist." 70

Richard Reiner und Robert Pierson argumentieren in derselben Richtung:

"If we have access to certain unobservable entities through the laboratory skills by means of which we manipulate them, and if our confidence in these skills does not depend in any serious way on any scientific theory being true, or even possibly-true, then it looks as if we should have grounds for rational conviction that these entities are real.

Things are not, however, this simple. Laboratory skills do not give us access to otherwise unobservable entities, but only to certain observable interactions in the apparatus. Only by IBE [inference to the best explanation] can we come to believe that these observable signs indicate the presence of causal interactions, that these interactions are not artifacts, and that entities lie behind them. Moreover, only by an additional IBE can we take the evidence as warranting belief in the existence of exactly one kind of entity, rather than two kinds or a thousand kinds." 71

Sowohl Resnik als auch Reiner und Pierson nehmen zur Kenntnis, daß Hacking sich explizit dagegen ausspricht, eine realistische Position mit Hilfe des Wunderarguments oder ähnlicher Argumente zu begründen, die einen Schluß auf die beste Erklärung involvieren, ${ }^{72}$ und daß er seine Argumentation als davon verschieden aufgefaßt wissen will, aber sie meinen, daß Hacking für die von ihm behauptete Verschiedenheit jede Begründung schuldig bleibt. $^{73}$

Tatsächlich finden sich bei Hacking, wie schon erwähnt, keine expliziten Äußerungen zu der Frage, worin epistemische Rechtfertigung besteht, und insbesondere keine allgemeinen Erläuterungen, wie Existenzaussagen über Entitäten und home truths und phänomenologische Gesetze über ihre Eigenschaften zu begründen sind; gleichzeitig präsentiert er jedoch einige konkrete Fallbeispiele, in denen seiner Ansicht nach gute epistemische Rechtfertigungsgründe für derartige Aussagen vorliegen. ${ }^{74}$ Daher bietet es sich vielleicht an, zu versuchen, bei diesen konkreten Beispielen die von Hacking nur ungenau beschriebenen Begründungen explizit zu machen. Darüberhinaus legen Hackings Beispiele an einigen Stellen auch nahe, daß bei diesen Begründungen etwas von der Art eines Schlusses auf die beste Erklärung eine zentrale Rolle spielt (s.u.). Da Hacking diesen Gedanken aber diskutiert und eine Rekonstruktion der Begründungen mit Hilfe eines Inferenzschemas der Form (IBE) ${ }^{75}$ explizit ablehnt ${ }^{76}$ muß sein Widerspruch dagegen ernstgenommen werden und müssen die von Resnik und Reiner/Pierson vorgeschlagenen Rekonstruktionen von Hackings Argumentation zurückgewiesen werden. Hackings experimentelles Argument ist

\footnotetext{
${ }^{70}$ [Resn94], S.401ff.

${ }^{71}$ [RePi95], S.67.

${ }^{72}$ Siehe z.B. [Hack83a], S.52ff.

${ }^{73}$ Siehe [RePi95], S.64ff., [Resn94], S.405.

${ }^{74}$ Z.B. [Hack83a], S.200f., 202ff., 209.

${ }^{75}$ Siehe S.168.

${ }^{76}$ [Hack83a], S.201/202.
} 
seiner eigenen, wohlerwogenen Meinung nach keine Variante des Wunderarguments, und es liegt ihm kein Schluß auf die beste Erklärung zugrunde.

Damit ist natürlich über ein "positives" Verständnis von Hackings Argumentation nichts gesagt, insbesondere auch nicht über die epistemische Rechtfertigung der Existenzaussagen, home truths und phänomenologischen Gesetze, die im Mittelpunkt seines Entitätenrealismus stehen und die sich gemäß Hackings Kriterium auf etwas beziehen, was real ist. Hackings konkrete Beispiele enthalten dazu einige wenige Hinweise: Er deutet verschiedentlich an, daß epistemische Begründungen etwas "Lokales", Kontextspezifisches sind und daß es nicht ein Inferenzschema (wie (IBE)) geben dürfte, das für alle Begründungen, unabhängig von Gegenstandsbereich, der Art der Entität etc. in Anspruch genommen werden kann. Zumindest an einer Stelle scheint er so etwas wie ein lokales, sehr kontextspezifisches Inferenzschema im Auge zu haben, das zwar alleine noch keine hinreichende epistemische Rechtfertigung liefert, aber dies immerhin in Zusammenwirkung mit anderen Überzeugungen und Inferenzschemata leisten kann. Hackings (vielzitiertes) Beispiel bezieht sich auf Beobachtungen mit Mikroskopen verschiedener Art:

"There are many grounds for the conviction that a perceived bit of structure is real or true. One of the most natural is the most important. I shall illustrate it with my own first experience in the laboratory. Low powered electron microscopy reveals small dots in red blood platelets. These are called dense bodies [...]. [... Can] one see these selfsame bodies using quite different physical techniques? [...] The dense bodies do not show up under every technique, but are revealed by flourescent staining and subsequent observation by the flourescent microscope $[\ldots]$.

Two physical processes - electron transmission and fluorescent re-emission are used to detect the bodies. These processes have virtually nothing in common between them. They are essentially unrelated chunks of physics. It would be a preposterous coincidence if, time and again, two completely different physical processes produced identical visual configurations which were, however, artifacts of the physical processes rather than real structures in the cell [...].

[...] My argument from coincidence says simply that it would be a preposterous coincidence it two totally different kinds of physical systems were to produce exactly the same arrangements of dots on micrographs [...].

[...If] you can see the same fundamental features of structure using several different physical systems, you have excellent reason for saying, 'that's real' rather than, 'that's an artifact'. It is not a conclusive reason. But the situation is no different from ordinary vision $[\ldots]$.

[...] I do not advance the argument from coincidence as the sole basis of our conviction that we see through the microscope. It is one element, a compelling visual element, that combines with more intellectual modes of understanding, and with other kinds of experimental work." 77

Wie in diesem Fall ein kontextspezifisches Inferenzschema genau aussehen könnte, welche Prämissen seine Anwendung erfordert etc., erläutert Hacking nicht näher. Er macht jedoch

\footnotetext{
${ }^{77}$ [Hack83a], S.200-205. Eine ausführlichere Darstellung mehrerer Fälle, in denen Mikroskope und Elektronenmikroskope verschiedener Art eingesetzt wurden, um bestimmte Entitäten und Sachverhalte nachzuweisen, findet sich in [RaCh01].
} 
deutlich, daß Erklärungen jedenfalls keine Rolle spielen, daß es also nicht um eine spezielle Form des Schließens auf die beste Erklärung geht, also etwa um die Anwendung eines speziellen Inferenzschemas der Form (IBEsp), obwohl die Bezugnahme auf "Koinzidenzen" dies möglicherweise nahelegen könnte (insbesondere wenn man mit der Argumentationsweise bestimmter Versionen des Wunderarguments vertraut ist). ${ }^{78}$ Erklärungsleistungen liefern nach Hackings Ansicht generell allenfalls einen sehr schwachen epistemischen Grund für die erklärenden Aussagen, Theorien etc. ${ }^{79}$

Der Befund, daß Hackings experimentelles Argument — entgegen dem, was einige Kritiker einwenden — keine Variante des Wunderarguments ist und ihm auch nicht in anderer Form ein Schluß auf die beste Erklärung zugrundeliegt, verweist also wiederum auf Unklarheiten oder wenigstens offene Fragen in bezug auf Status und Begründung von Hackings Kriterium dafür, was real ist, insbesondere in bezug auf die Frage, wie die Existenzaussagen, home truths und phänomenologischen Gesetze, die für Hackings Entitätenrealismus zentral sind, epistemisch zu rechtfertigen sind.

\section{Entitätenrealismus und Theorienwandel}

Im Anschluß an Kuhn wird von der zeitlichen Entwicklung des Gesamtbestandes der wissenschaftlichen Theorien häufig das Bild von Folgen von Theorien gezeichnet, in denen jede Theorie die jeweils vorausgehende durch eine Revolution ablöst und vor- und nachrevolutionäre Theorien voneinander grundlegend und vollständig verschieden sind. ${ }^{80}$ Aus einer solchen wissenschaftshistorischen Perspektive wird man Hackings Entitätenrealismus mit dem Einwand konfrontieren, daß der Theorienwandel in den Wissenschaften sozusagen vollständig ist, also auch Entitäten, home truths und phänomenologische Gesetze erfaßt. Auch diese betrifft die pessimistische Induktion, die vielfach an eine solche wissenschaftshistorische Perspektive geknüpft wird.

Hackings Antwort auf diesen Einwand besteht aus zwei Teilen. Zum einen meint er, daß wissenschaftsgeschichtliche Untersuchungen das naive Bild eines kumulativ anwachsenden Wissensbestandes tatsächlich als falsch erweisen, daß ein differenzierteres Bild von der zeitlichen Entwicklung des Gesamtbestandes der akzeptierten Repräsentationen (also der Theorien, Gesetze, Modelle etc.) der Wissenschaften aber dennoch die Unterscheidung von Teilen, die regelmäßig revidiert werden, und Teilen, die weitgehend stabil bleiben und tatsächlich im Laufe der Geschichte kumulativ angesammelt werden, erlaubt. Zu den stabilen Elementen des Gesamtbestandes zählen nach Hacking gerade die Entitäten (wie Elektronen u.ä.) und Phänomene (wie der photoelektrische Effekt), die sein Kriterium dafür, was real ist, herausgreift, bzw. die Existenzaussagen, home truths und phänomenologischen Gesetze, die sich auf sie beziehen; diese überleben den Wandel von Theorien und Modellen seiner Ansicht nach nicht immer, aber doch in der Regel. ${ }^{81}$ Hackings Kriterium dafür, was real ist, greift also seiner Meinung nach aus dem Gesamtbestand der zu einem Zeitpunkt in den real-existierenden Wissenschaften akzeptierten Repräsentationen solche heraus, die, wie die Geschichte zeigt, in der Regel historisch stabil sind.

In einem neueren Aufsatz ${ }^{82}$ vertritt Hacking sogar die weiterreichende These, daß in den von ihm so genannten Laborwissenschaften (d.h. in den Teilen der Naturwissenschaften, die im wesentlichen mit im Labor hergestellten und/oder präparierten Systemen und

\footnotetext{
${ }^{78}$ [Hack83a], S.203; vgl. S.236.

79 "[A] feeble ground [for belief]"; [Hack83a], S.53.

${ }^{80}$ Vgl. Abschnitt 2.6.4.

${ }^{81}$ [Hack83a], S.56, 179.

${ }^{82}[$ Hack92b].
} 
Phänomenen arbeiten) auch die dort eingesetzten Modelle und Theorien, ${ }^{83}$ sofern sie einmal ein bestimmtes Stadium der Reife erreicht haben, häufig (wenn auch klarerweise nicht immer) in einem bestimmten Sinn stabil sind; von Modellen und Theorien in diesem Stadium spricht Hacking, etwas spöttisch, als von "toter und verdauter Wissenschaft": Theorien wie die geometrische Optik oder die klassische Mechanik werden in einem begrenzten Anwendungsbereich, d.h. für Systeme und Phänomene einer definierten Art und Größenordnung, die mit Hilfe bestimmter Instrumente präpariert und untersucht werden, nach wie vor als gültig akzeptiert. Hacking meint offenbar, daß diese Theorien trotz des Aufkommens von Wellenoptik, Quantenmechanik, Relativitätstheorie usw. nicht als falsch erwiesen wurden, sondern in ihrem begrenzten Bereich nach wie vor gültig sind ${ }^{84}$ Danach könnte sein Kriterium dafür, was real ist, auch dann noch historisch stabile Repräsentationen herausgreifen, wenn es dahingehend modifiziert werden müßte, daß neben Existenzaussagen, home truths und phänomenologischen Gesetzen auch Modelle und Theorien der Laborwissenschaften darunter fallen.

Der zweite Teil von Hackings Antwort besteht darin, daß er Putnams kausale Bedeutungs- und Referenztheorie heranzieht, um dem weiteren Einwand zu begegnen, daß sein Bild von einem (im wesentlichen) kumulativ anwachsenden Bestand von Entitäten und Phänomenen bzw. von Existenzaussagen, home truths und phänomenologischen Gesetzen bei wechselnden Theorien über diese Entitäten und Phänomene aus sprachphilosophischen Gründen unhaltbar sei. ${ }^{85}$ Hacking weist die Kontexttheorien, die diesem Einwand zugrundeliegen, zurück und hält diesen Putnams kausale Theorie sozusagen als Antidot entgegen, nicht weil er Putnams Theorie in allen Zügen überzeugend findet, sondern eher, weil sie plausibel macht, daß es möglich sein sollte, eine Bedeutungs- und Referenztheorie zu entwickeln, die mit seinem Bild von wechselnden Theorien über dieselben Entitäten und Phänomene verträglich ist. ${ }^{86}$

Hacking meint daher, daß der Blick auf die Wissenschaftsgeschichte, und insbesondere auf den Theorienwandel in deren Verlauf, keinen für seinen Entitätenrealismus bedrohlichen Einwand ergibt. Ob er damit recht hat, daß sein Kriterium dafür, was real ist, aus dem Gesamtbestand der zu einem Zeitpunkt in den real-existierenden Wissenschaften akzeptierten Repräsentationen tatsächlich nur oder fast nur solche herausgreift, die historisch stabil sind, müßte durch umfangreiche historische Untersuchungen geklärt werden. Zumindest bei einem nur kursorischen Blick auf die Geschichte der Physik sieht Hackings These aber plausibel aus, daß Existenzaussagen, home truths und phänomenologische Gesetze über routinemäßig benutzte Entitäten selten oder nie aufgegeben werden. Wenn Hackings Kriterium aufgrund der im vorletzten Abschnitt genannten Einwände so modifiziert wer-

\footnotetext{
${ }^{83}$ Also nicht nur home truths und phänomenologische Gesetze.

84 "[... Today's] students [of physics] have to master the dead and digested science [...,] because that is part of the stable knowledge with which many of the students will change bits of the world, and on which a few of the research oriented among them will build new knowledge" ([Hack92b], S.39/40).

Hacking äußert sich nicht explizit zum Thema Theorienreduktion, ist aber generell skeptisch hinsichtlich der diesbezüglichen Aussichten. Er meint, daß die genannten Vorgänger- und Nachfolgertheorien sich praktisch nie auf dieselben Laborphänomene und Daten beziehen lassen und hält sie deswegen für nicht konkurrierend und beide (jeweils in ihrem Bereich) für wahr; er spricht in diesem speziellen Sinn von Inkommensurabilität: "A collection of kinds of instruments evolves [...] hand in hand with theories that interpret the data that they produce. As a matter of brute contingent fact, instrumentaria and systematic theories mature, and data uninterpretable by theories are not generated. There is no drive for revision of the theory because it has acquired a stable data domain. What we later see as limitations of a theory are not data for the theory" ([Hack92b], S.55).

${ }^{85}$ Siehe Kap.4.2, bes. S.87ff.

${ }^{86}$ Vgl. [Hack82a], S.250, [Hack83a], Kap.6.
} 
den sollte, daß auch hochstufigere Repräsentationen wie Modelle und allgemeine Gesetze darunter fallen, dürfte der Einwand aus historischer Perspektive - pace Hackings kontroversen neueren Thesen über die Stabilität der "toten und verdauten" Theorien und Modelle der Laborwissenschaften — weniger leicht zu entkräften sein.

\section{Kausalität}

In Hackings Kriterium dafür, was real ist, spielt — zumindest in einer der beiden vorne unterschiedenen Sorten von Formulierungen - das philosophisch notorisch kontroverse Stichwort "Kausalität" eine wesentliche Rolle. Gleichzeitig finden sich bei Hacking keine nennenswerten Erläuterungen zu der Frage, was Kausalität ist und wie Aussagen über kausale Eigenschaften, Relationen etc. epistemisch gerechtfertigt werden können. ${ }^{87}$ Diese Sachlage werden Anhänger antirealistischer Positionen i.a. bemängeln, insbesondere werden Anhänger empiristisch orientierter Positionen daran Anstoß nehmen.

Tatsächlich würden Erläuterungen zum Thema Kausalität zur Klarheit von Hackings Kriterium beitragen, dennoch kann man das Fehlen solcher Erläuterungen vielleicht als zukünftig zu schließende Lücke seiner Position betrachten, nicht als irreparablen Mangel. Das Problem einer adäquaten Erläuterung dessen, was Kausalität ist, betrifft nicht nur die wissenschaftstheoretische Realismusdebatte, sondern eine Vielzahl philosophischer Themen, und ist notorisch hartnäckig; daher ist es eine plausible Strategie, den Kausalitätsbegriff auch ohne zufriedenstellende Erläuterungen einzusetzen, solange seine Verwendung intuitiv einigermaßen klar und unkontrovers ist, und dies kann Hacking sicherlich für die meisten der Fälle, die er im Auge hat, in Anspruch nehmen.

Wenn man sich in der philosophischen Literatur nach einer Konzeption von Kausalität umsieht, die die Lücke in Hackings Position schließen könnte, scheint sich eine geradezu anzubieten, nämlich die handlungstheoretische Analyse des Kausalbegriffs von von Wright, die er als "manipulative or experimentalist causation" bezeichnet. ${ }^{88}$ Danach gilt:

"[T]hat $p$ is the cause of q [...], means that I could bring about q, if I could do (so that) p". ${ }^{89}$

"What makes $p$ a cause-factor relative to the effect-factor $q$ is, I shall maintain, the fact that by manipulating $p$, i.e. by producing changes in it 'at will' as we say, we could bring about changes in $q . " 90$

Angesichts des Gewichts, das Hacking auf das Benutzen und Manipulieren von Entitäten und auf experimentelle Interventionen legt, liegt vielleicht der Gedanke nahe, daß Hacking von Wrights Konzeption von Kausalität in Anspruch nimmt oder jedenfalls nehmen könnte. Daß er es nicht tut, dürfte aber kein Versehen sein, denn auch Hacking dürfte den Standardeinwand gegen von Wrights Konzeption akzeptieren, daß sie zu eng ist, weil sie die Bereiche der Welt nicht in angemessener Weise abdeckt, die menschlichem Handeln nicht zugänglich sind, in denen aber Prozesse und Ereignisse ablaufen, die dennoch intuitiv klarerweise kausale sind. ${ }^{91}$ Obwohl Hacking das Benutzen und Manipulieren von Entitäten und ihren Eigenschaften und Kausalität bzw. kausale Eigenschaften zueinander

${ }^{87}$ Mit Ausnahme vielleicht einiger Hinweise auf Cartwrights Position.

${ }^{88}$ [vWri93], S.119.

${ }^{89}$ [vWri71], S.74.

${ }^{90}$ [vWri93], S.118.

${ }^{91}$ Beispiel: Ein Meteoriteneinschlag verursacht einen Krater oder hat das Aussterben der Dinosaurier zur Folge. Von Wright hat diese Fälle natürlich gesehen und meinte, daß sie durch die konjunktivische 
in Beziehung setzt, hat er dabei weder eine Analyse des Begriffs "Kausalität" im Auge, noch eine allgemeine Aussage darüber, was Kausalität ist.

Von den Konzeptionen von Kausalität, die sich in der Literatur finden, dürften sich als Ergänzung von Hackings Position vielleicht am ehesten solche eignen, die nicht auf eine Begriffsanalyse in der Form weniger, einfacher, einzeln notwendiger und zusammen hinreichender Bedingungen für das Vorliegen von Kausalität, einer kausalen Relation o.ä. zielen, sondern eher auf eine physikalistische Erläuterung, die Kausalität, die Kausalrelation etc. in "bereichsspezifischer" Weise mit physikalischen Eigenschaften, Relationen etc. identifiziert, ${ }^{92}$ oder auf eine Erläuterung (wie die von Cartwright ins Auge gefaßte ${ }^{93}$ ), die weder eine semantische noch eine ontologische Reduktion beinhaltet.

\subsubsection{Hackings experimentelles Argument - eine Zwischenbilanz}

Wie stellt sich nach diesen Überlegungen Hackings Argumentation für seinen Entitätenrealismus dar, worin genau besteht sein "experimentelles Argument"?

Hacking gibt ein Kriterium an, das im Gesamtbestand der in den real-existierenden Wissenschaften akzeptierten Repräsentationen (Gesetze, Modelle, Theorien etc.) eine Teilmenge auszeichnet, deren Elemente sich auf Entitäten, Sachverhalte etc. beziehen, die, wie er sich ausdrückt, real sind, gegenüber denen also seiner Meinung nach eine realistische Einstellung einzunehmen ist. Dieses Kriterium ist grundsätzlich ein hinreichendes, kein notwendiges, Hacking schätzt allerdings die Chancen gering ein, über die von seinem Kriterium gezogene Grenze hinaus etwas in plausibler Weise als real zu erweisen.

Bei den von Hackings Kriterium ausgezeichneten Elementen handelt es sich um Existenzaussagen bezüglich unbeobachtbarer Entitäten und um home truths und phänomenologische Gesetze über Eigenschaften und Verhalten dieser Entitäten. Hacking sagt nicht eindeutig, inwiefern damit "positive" Thesen gegeben sind, die eine realistische Position konstituieren, eine plausible Explikation ist aber, die durch sein Kriterium ausgezeichneten Existenzaussagen, home truths etc. durch eine Unabhängigkeitsaussage zu ontologischen realistischen Thesen zu ergänzen. Diese Thesen bilden den Kern von Hackings Entitätenrealismus, einer Position, die sozusagen zwischen antirealistischen Positionen (wie der von van Fraassen) und traditionelleren realistischen Positionen (wie etwa der von Boyd) liegt, da Hacking zu einem Teil der in den real-existierenden Wissenschaften etablierten unbeobachtbaren Entitäten, Phänomenen etc. eine realistische Einstellung einnimmt, aber nicht zu allen, von denen in den dort akzeptierten Theorien, Modellen, Gesetzen etc. die Rede ist.

Hacking motiviert das Kriterium, das den Inhalt seiner realistischen Position abgrenzt, indem er versucht, plausibel zu machen, daß dieses selbe Kriterium bereits im Bereich der Alltagswelt angemessen und akzeptabel ist, d.h., daß dieses Kriterium bereits dort anwendbar ist und daß das, was dort durch es ausgezeichnet wird, tatsächlich "real ist". Hacking greift damit einen Gedanken Poppers auf, den er an einer zentralen, aber im Zusammenhang mit seinem "experimentellen Argument" wenig beachteten Stelle von 'Representing and Intervening' zitiert:

"I suppose that the most central usage of the term 'real' is its use to charac-

Formulierung seiner Definition entschärft würden ( $\mathrm{p}$ ist die Ursache von q, wenn ich q herbeiführen könnte, wenn ich p tun könnte). Seine Argumentation in diesem Punkt wird aber allgemein als nicht überzeugend angesehen.

${ }_{92}$ Eine solche Konzeption stellt Dieks in [Diek86] vor.

${ }^{93}$ Siehe Abschnitt 11.4.2. 
terize material things of ordinary size - things which a baby can handle and (preferably) put into his mouth. From this, the usage of the term 'real' is extended, first, to bigger things - things which are too big for us to handle, like railway trains, houses, mountains, the earth and the stars, and also to smaller things - things like dust particles or mites. It is further extended, of course, to liquids and then also to air, to gases and to molecules and atoms.

What is the principles behind the extension? It is, I suggest, that the entities which we conjecture to be real should be able to exert a causal effect upon the prima facie real things; that is, upon material things of an ordinary size: that we can explain changes in the ordinary material world of things by the causal effects of entities conjectured to be real." 94

Eine anschauliche Formulierung desselben Gedankens gibt Popper auch an einer anderen Stelle:

"[...] by and large I regard as excellent Landé's suggestion to call physically real what is "kickable" (and able to kick back if kicked)". ${ }^{95}$

Hacking kommentiert die von ihm zitierte Stelle von Popper mit den Worten:

"That is Karl Popper's characterization of our usage of the word 'real'. Note the traditional Lockeian fantasy beginnings. 'Real' is a concept we get from what we, as infants, could put in our mouths. That is a charming picture, not free from nuance. Its absurdity equals that of my own preposterous story of reals and representations. Yet Popper points in the right direction. Reality has to do with causation and our notions of reality are formed from our abilities to change the world." 96

Der Punkt, den Hacking in dieser etwas flapsigen Passage plausibel machen will, ist offenbar der, daß wir sozusagen von Kindesbeinen an Dinge, Phänomene etc. aus dem Bereich der Alltagswelt, die wir benutzen oder manipulieren können und/oder denen wir kausale Eigenschaften zuschreiben, als real anerkennen, und daß im Bereich der unbeobachtbaren Entitäten der Wissenschaften dasselbe gelten sollte, daß also das Kriterium, das den Inhalt seines Entitätenrealismus abgrenzt, eines ist, das im Bereich der Alltagswelt unproblematisch oder sogar selbstverständlich ist und dessen Anwendungsbereich er lediglich auf den Bereich der Praxis und der Diskurse der Wissenschaften ausweitet. ${ }^{97}$

Für die Repräsentationen, die durch Hackings so motiviertes Kriterium ausgezeichnet werden, bzw. für die durch diese Repräsentationen bezeichneten Entitäten, Phänomene etc., die gemäß diesem Kriterium real sind, gilt nach Hacking zweierlei: Zum einen hat man gute Gründe, eine instrumentalistische Einstellung zu diesen Repräsentationen bzw. Entitäten, Phänomenen etc. zurückzuweisen, zum anderen hat man Grund zu der Annahme, daß für diese Repräsentationen gute epistemische Rechtfertigungsgründe vorliegen.

Das Kriterium selbst, also die Bedingungen, die eine Repräsentation erfüllen muß, um darunter zu fallen, formuliert Hacking nicht so genau wie es wünschenswert wäre,

\footnotetext{
${ }^{94}$ [Hack83a], S.145/146; das Popper-Zitat stammt aus [PoEc77], S.9.

${ }^{95}$ [Popp67], S.15.

${ }^{96}$ [Hack83a], S.146.

${ }^{97}$ Das Kriterium, daß eine Entität routinemäßig benutzt oder manipuliert wird, ist bereits im Bereich der Alltagswelt klarerweise ein hinreichendes, kein notwendiges, wie die Beispiele "mountains, the earth and the stars" deutlich machen.
} 
und dies gilt auch für das obige Zitat, in dem die Angemessenheit dieses Kriteriums im alltagsweltlichen Bereich plausibel gemacht werden soll. Vorne ${ }^{98}$ waren in Hackings Text zwei Sorten von Formulierungen unterschieden worden, mittels derer er angibt, worin sein Kriterium besteht, also zwei prima facie verschiedene Antworten auf die Frage, wann man gute Gründe für die Annahme hat, daß eine Entität, ein Phänomen o.ä. real ist: Gemäß der einen Sorte von Formulierungen schien das routinemäßige Benutzen oder Manipulieren einer Entität einen guten Grund für die Annahme liefern zu sollen, daß die Entität real ist, gemäß der zweiten Sorte schien das Vorliegen kausaler Beschreibungen der Entität, die bei deren Benutzung eingesetzt werden oder zumindest werden können, den Grund für die Annahme zu liefern, daß die Entität real ist. Entsprechend ist im obigen Zitat einerseits von "things which a baby can handle" und "our abilities to change the world" die Rede, andererseits von "entities which [are ...] able to exert a causal effect" und davon, daß "[r] eality has to do with causation". Die Formulierungen, die Hacking für sein Kriterium angibt, scheinen sich, den obigen Überlegungen folgend, in zwei prima facie verschiedene Richtungen hin präzisieren zu lassen. Eine Präzisierung in der einen Richtung wäre etwa:

Repräsentationen, die routinemäßig beim Benutzen oder Manipulieren von Instrumenten, Gegenständen oder sonstigen Entitäten ${ }^{99}$ eingesetzt werden und die dabei ablaufenden Vorgänge und Prozesse als das Benutzen oder Manipulieren von (beobachtbaren oder unbeobachtbaren) Entitäten und ihren Eigenschaften beschreiben, beziehen sich auf Entitäten und Eigenschaften, die real sind, d.h., für solche Repräsentationen ist eine instrumentalistische Einstellung zurückzuweisen und es liegen gute epistemische Rechtfertigungsgründe für sie vor.

Eine Präzisierung in der anderen Richtung wäre:

Repräsentationen, die Gegenständen oder sonstigen Entitäten kausale Eigenschaften zuschreiben, beziehen sich auf Gegenstände oder Entitäten und Eigenschaften, die real sind, d.h., für solche Repräsentationen ist eine instrumentalistische Einstellung zurückzuweisen und liegen gute epistemische Rechtfertigungsgründe vor.

Wenn man diese beiden Präzisierungen vor Augen hat, ist jedoch offensichtlich, daß keine der beiden von Hacking angegebenen Sorten von Formulierungen für sich genommen ein angemessenes Kriterium ergibt, und zwar weder im Bereich der Alltagswelt noch im Bereich der Wissenschaften: Es lassen sich sicherlich (mehr oder weniger allgemein akzeptierte) Aussagen aufweisen, in denen bestimmten Gegenständen oder Entitäten kausale Eigenschaften zugeschrieben werden, bei denen es aber zumindest nicht unkontrovers ist, daß wirklich gute epistemische Rechtfertigungsgründe für diese Aussagen vorliegen. Beispiele aus dem wissenschaftlichen Bereich sind die derzeit akzeptierten Aussagen, Modelle etc. über den Urknall und die Frühzeit des Universums, Beispiele aus dem alltagsweltlichen Bereich sind vielleicht seltener, aber es lassen sich doch einige finden, etwa alltagspsychologische Aussagen über psychische Zustände und Krankheiten oder Störungen, und vielleicht auch religiöse Aussagen über Handlungen Gottes (oder mehrerer Götter) "in der Welt". Ebenso lassen sich sicherlich Repräsentationen aufweisen, die routinemäßig beim Benutzen oder Manipulieren von Instrumenten, Gegenständen o.ä. eingesetzt werden und

\footnotetext{
${ }^{98}$ Siehe Abschnitt 11.3.1.

${ }^{99}$ In der Alltagswelt oder in der experimentellen und technologischen Praxis der Wissenschaften.
} 
die dabei ablaufenden Vorgänge und Prozesse als das Benutzen oder Manipulieren von Entitäten und ihren Eigenschaften beschreiben, für die es aber dennoch zumindest nicht unkontrovers ist, daß eine instrumentalistische Einstellung in bezug auf sie nicht angemessen ist. Beispiele sind hier Repräsentationen, die Zahlen (und andere mathematische Entitäten) involvieren, vielleicht auch solche, die von Dingen wie Spiegelbildern, Schatten und Schwerpunkten handeln. Der naheliegende Schluß ist der, daß keine der beiden obigen Präzisierungen Hackings Intentionen trifft, sondern daß er zwei (seinen beiden Sorten von Formulierungen entsprechende) Teilkriterien im Auge haben dürfte, die zusammen das anvisierte Kriterium darstellen, daß also nach Hacking dann ein guter Grund zu der Annahme besteht, daß sich bestimmte Repräsentationen auf Entitäten und Eigenschaften beziehen, die in seinem Sinn "real sind", wenn diese Repräsentationen beide Teilkriterien zugleich erfüllen: Dann ist nach Hacking sowohl eine instrumentalistische Einstellung zurückzuweisen und es sind auch gute epistemische Rechtfertigungsgründe vorhanden. Eine plausible Präzisierung von Hackings Kriterium, die die genannten kontroversen Beispiele ausschließt, müßte demnach etwa lauten:

Repräsentationen, die routinemäßig beim Benutzen oder Manipulieren von Instrumenten, Gegenständen oder sonstigen Entitäten eingesetzt werden und die dabei ablaufenden Vorgänge und Prozesse als das Benutzen oder Manipulieren von kausal wirksamen und beeinflußbaren Entitäten und ihren kausalen Eigenschaften beschreiben, beziehen sich auf Entitäten und Eigenschaften, die real sind, d.h., für solche Repräsentationen ist eine instrumentalistische Einstellung zurückzuweisen und es liegen gute epistemische Rechtfertigungsgründe für sie vor.

Gegeben diese Rekonstruktion von Hackings Kriterium stellt sich die Frage, was sich über Repräsentationen wie die in den genannten Beispielen sagen läßt, die nur eins der beiden Teilkriterien erfüllen. Die naheliegende Antwort ist, daß sich den beiden Teilkriterien je eine der beiden "Konsequenzen" zuordnen lassen sollte, die sich nach Hacking für Repräsentationen ziehen lassen, die das Gesamtkriterium erfüllen, und daß für eine Repräsentation, die nur eins der Teilkriterien erfüllt, eben nur eine der "Konsequenzen" gezogen werden kann: Es scheint plausibel, Hackings beide Teilkriterien und ihre Rolle dahingehend zu explizieren, daß das erste Teilkriterium besagt, daß für Repräsentationen, die Entitäten kausale Eigenschaften zuschreiben, eine instrumentalistische Einstellung zurückzuweisen ist (unabhängig davon, ob für diese Repräsentationen gute epistemische Gründe vorliegen), während das zweite Teilkriterium besagt, daß für Repräsentationen, die routinemäßig beim Benutzen oder Manipulieren von Instrumenten, Gegenständen oder sonstigen Entitäten eingesetzt werden und die dabei ablaufenden Vorgänge und Prozesse als das Benutzen oder Manipulieren von Entitäten und ihren Eigenschaften beschreiben, gute epistemische Rechtfertigungsgründe vorliegen (egal ob es sich um kausal wirksame und beeinflußbare Entitäten handelt oder nicht). Beispielsweise scheint es plausibel, eine instrumentalistische Einstellung in bezug auf die Aussagen und Modelle, die in der Kosmologie derzeit über den Urknall und die Frühzeit des Universums akzeptiert werden, zurückzuweisen, insofern dort von kausal wirksamen Entitäten, Prozessen etc. die Rede ist, auch wenn man der Meinung ist, daß die epistemischen Gründe, die für diese Aussagen und Modelle derzeit zur Verfügung stehen, nur schwache sind. Ebenso sieht die Annahme plausibel aus, daß für die Existenz der Zahlen, die routinemäßig beim Benutzen oder Manipulieren von Instrumenten, Geräten etc. verwendet werden, und ihre dabei involvierten Eigenschaften gute epistemische Rechtfertigungsgründe vorliegen, obwohl Zahlen und ihre Eigenschaften 
nach allgemeiner Ansicht nicht kausal wirksam oder beeinflußbar sind. ${ }^{100}$

Daß sich bei Hacking zwei von ihm nicht sauber getrennte Sorten von Formulierungen für sein Kriterium finden, sprich: zwei Teilkriterien, ist demnach dadurch zu erklären, daß sein Entitätenrealismus, wie er selbst sagt, zwei "Stränge" zusammenbringt und zwei verschiedenen Diskussionsgegnern entgegengestellt werden soll, nämlich Instrumentalisten und epistemischen Antirealisten, denen jeweils ein Teilkriterium zugeordnet werden kann.

Eine Begründung für sein Kriterium gibt Hacking — von den beschriebenen Ansätzen, es durch den Hinweis auf seine Anwendbarkeit und Angemessenheit im alltagsweltlichen Bereich plausibel zu machen, abgesehen — nicht. Er verteidigt es gegen Einwände aus wissenschaftshistorischer Perspektive durch die historische Beobachtung, daß die Repräsentationen, die sein Kriterium aus dem zu einem Zeitpunkt in den real-existierenden Wissenschaften akzeptierten Gesamtbestand herausgreift, in der Regel historisch stabil sind. Eine "positive" Begründung des Kriteriums, die verständlich macht, warum er im Gesamtbestand der in den real-existierenden Wissenschaften akzeptierten Repräsentationen genau die Trennlinie zieht, die sein Kriterium liefert, ${ }^{101}$ und gerade in bezug auf die durch diese Trennlinie begrenzte Menge von Repräsentationen eine realistische Einstellung einnimmt, findet sich bei Hacking anscheinend nicht: Es findet sich keine allgemeine Erläuterung, wie eine instrumentalistische Einstellung zu begründen oder begründet zurückzuweisen ist, und es findet sich auch keine Konzeption epistemischer Rechtfertigung, die eine allgemeine Erläuterung einschließt, worin gute epistemische Rechtfertigungsgründe für Existenzaussagen, home truths, phänomenologische Gesetze etc. bestehen. Mit Hilfe solcher Erläuterungen könnte sich Hackings Kriterium evtl. begründen lassen, ohne sie gibt es lediglich — in intuitiv durchaus plausibler Weise - an, wann man gute Gründe hat, anzunehmen, daß eine Entität und ihre Eigenschaften "real sind", es sagt jedoch nicht, worin diese Gründe bestehen.

Hackings "experimentelles Argument" für wissenschaftlichen Realismus besteht also offenbar in der Angabe des genannten groben, im einzelnen sicherlich weiter präzisierungsbedürftigen Kriteriums sowie den beschriebenen Überlegungen, die es motivieren, plausibel machen und verteidigen sollen. Um ein Argument im Sinne einer Reihe von Prämissen samt daraus folgender Konklusion handelt es sich dabei nicht.

\subsection{Cartwright}

\subsubsection{Cartwrights Argumentation für wissenschaftlichen Realismus}

In Cartwrights Argumentation für wissenschaftlichen Realismus spielen kausale Erklärungen konkreter Ereignisse oder Phänomene eine zentrale Rolle; ${ }^{102}$ den Hintergrund dieser Argumentation bilden daher Cartwrights Untersuchungen zum Thema "physikalische Erklärungen".

Cartwright unterscheidet zum einen, wie bereits ${ }^{103}$ erwähnt, fundamentale oder theoretische Gesetze von phänomenologischen Gesetzen, zum anderen unterscheidet sie kausale

\footnotetext{
${ }^{100}$ Sofern man für eine instrumentalistische Einstellung in bezug auf Aussagen über diese Zahlen und ihre Eigenschaften plädiert, dürfte der Grund dafür jedenfalls nicht darin liegen, daß an epistemischen Rechtfertigungsgründen sozusagen nicht alles vorliegt, was überhaupt zu haben ist.

${ }^{101} \mathrm{Im}$ Unterschied zu anderen denkbaren Trennlinien, etwa der entlang der Grenze beobachtbar/unbeobachtbar.

${ }^{102}$ Einen zweiten Strang ihrer Argumentation stellen Cartwrights in Kap.7 diskutierte Präsuppositionsargumente dar, die hier beiseite bleiben.

${ }^{103}$ Siehe Abschnitt 11.2.
} 
und nichtkausale Gesetze (causal laws versus laws of association). ${ }^{104}$ Außerdem unterscheidet sie zwischen theoretischen Erklärungen und kausalen Erklärungen. ${ }^{105}$ Dadurch werden Differenzen markiert, die für Cartwrights Position in der Realismusdebatte wesentlich sind.

\section{Cartwrights simulacrum account of explanation}

Cartwright entwickelt für theoretische Erklärungen (im Unterschied zu kausalen Erklärungen) ein eigenes Modell, das sie simulacrum account of explanation nennt. ${ }^{106}$ Dieses Modell gibt ihrer Ansicht nach die Erklärungspraxis in der real-existierenden Physik deskriptiv weit genauer und angemessener wieder als die in der wissenschaftstheoretischen Literatur gängigen Konzeptionen wissenschaftlicher Erklärung. Ihr Modell sieht in groben Zügen wie folgt aus. ${ }^{107}$

Gegenstand einer theoretischen Erklärung ist ein konkretes physikalisches System (z.B. das Heliumatom) und seine Eigenschaften bzw. sein Verhalten in bestimmten Situationen, die durch phänomenologische Gesetze beschrieben werden (z.B. das Energiespektrum des He-Atoms in einem Magnetfeld bekannter Stärke). Eine theoretische Erklärung für eine solche, durch ein phänomenologisches Gesetz beschriebene Eigenschaft zu geben heißt nach Cartwright, ein Modell für das System anzugeben, auf das sich, erstens, ein fundamentales Gesetz (z.B. die Schrödinger-Gleichung) anzuwenden läßt, so daß daraus, zweitens, eine akzeptable Näherung des phänomenologischen Gesetzes abgeleitet werden kann. (Ein Modell für das Heliumatom sind drei Punktteilchen mit bestimmten Ladungen, Massen und Spins — eins für den positiv geladenen Atomkern, zwei für die Elektronen — in einem konstanten, homogenen Magnetfeld.) Ein solches Modell bildet nach Cartwright teilweise "echte" Eigenschaften des Systems ab (Ladung, Masse, Spin), teilweise idealisierte Eigenschaften (konstantes, homogenes Magnetfeld, der He-Kern als ein Teilchen), teilweise enthält es völlig fiktive Elemente. (Cartwright nennt als ${ }^{108}$ Beispiel einer völlig fiktiven Eigenschaft die Wahrscheinlichkeitsverteilungen der statistischen Mechanik. ${ }^{109}$ ) Diese Tatsache, daß ein Modell typischerweise nicht nur Elemente und Eigenschaften enthält, die man dem modellierten System tatsächlich zuschreibt, sondern auch idealisierte und völlig fiktive, stellt den Grund dafür dar, daß Cartwright ein solches Modell als "work of fiction"110 oder als simulacrum bezeichnet:

"The [...] Oxford English Dictionary says that a simulacrum is 'something having merely the form or appearance of a certain thing, without possessing its substance or proper qualities'. [...] This is just what I have been urging that models in physics are like." 111

Auf ein Modell ein fundamentales Gesetz anwenden heißt, in dem allgemeinen, "systemneutralen" fundamentalen Gesetz die systemabhängigen Größen, Parameter und Randbedingungen für den Fall des Modells zu spezifizieren (im Beispiel: in der allgemeinen, systemunabhängigen Schrödinger-Gleichung einen für das Modell geeigneten HamiltonOperator einsetzen und Randbedingungen für die Wellenfunktion festlegen). Bei einer

\footnotetext{
${ }^{104}$ [Cart83], Einleitung, S.21.

105 [Cart83], S.74ff.

106 [Cart83], S.17, 151ff.

${ }^{107}$ [Cart83], Kap.7, 8.

${ }^{108}$ Allerdings kontroverses.

${ }^{109}$ [Cart83], S.153f.

${ }^{110}$ [Cart83], S.153.

111 [Cart83], S.152/153.
} 
gelungenen theoretischen Erklärung läßt sich aus dem so für das Modell (und damit nicht "direkt" für das modellierte physikalische System) spezialisierten fundamentalen Gesetz das zu erklärende phänomenologische Gesetz in akzeptabler Näherung ableiten. ${ }^{112}$

Cartwright betont, daß man in der "real-existierenden" Physik nur im Ausnahmefall ein phänomenologisches Gesetz, das durch Messungen an einem realen physikalischen System gewonnen wurde, wirklich exakt oder in numerisch guter Näherung auf diesem Wege ableiten kann; im allgemeinen arbeitet man dort mit nachträglich zu den tatsächlich abgeleiteten Gesetzen hinzugefügten, jedoch aus anderen Gründen plausiblen Ergänzungstermen, Fitparametern und ähnlichem, und in der Praxis gilt auch eine mit solchen Mitteln gewonnene theoretische Erklärung als akzeptabel. ${ }^{113}$

Ein anderer Zug der Erklärungspraxis der real-existierenden Physik, den Cartwright betont, ist der, daß ein fundamentales Gesetz wie die Schrödinger-Gleichung und das zweite Newton-Axiom nicht nur zur Gewinnung von Erklärungen für ein System oder gar nur für eine von dessen Eigenschaften herangezogen wird, sondern in der skizzierten Weise Erklärungen für eine Vielzahl verschiedener phänomenologischer Gesetze und Systeme liefert, indem man für die verschiedenen Modelle verschiedene Hamilton-Operatoren, Kraft-Terme etc. einsetzt, die normalerweise aus einem Satz weniger etablierter, gut bekannter "Komponenten" (Hamilton-Operator für den harmonischen Oszillator, Gravitationskraft gemäß Newtons Gravitationsgesetz, elektrostatische Kraft gemäß dem Coulomb-Gesetz etc.) zusammengesetzt werden. Effektiv werden also für eine theoretische Erklärung i.a. mehrere fundamentale Gesetze kombiniert eingesetzt (z.B. das zweite Newton-Axiom, das Newtonsche Gravitationsgesetz und das Coulomb-Gesetz zusammen), und dieselben fundamentalen Gesetze werden in anderen "Kombinationen" auch für andere theoretische Erklärungen herangezogen. Cartwright diskutiert diesen Sachverhalt vor allem mit Blick auf die verschiedenen Kraftgesetze, die in der klassischen Mechanik (in verschiedenen Kombinationen) in das zweite Newton-Axiom eingesetzt werden, und auf die Hamilton-Operatoren, die in der Quantenmechanik (in verschiedenen Kombinationen) in die Schrödinger-Gleichung eingesetzt werden; sie nennt diese Art, eine theoretische Erklärung zu gewinnen, explanation by composition of causes. ${ }^{114}$

Ein weiterer von Cartwright herausgestellter Befund über die Erklärungspraxis der real-existierenden Physik ist der, daß dort für ein phänomenologisches Gesetz bzw. für eine Eigenschaft eines Systems häufig mehrere verschiedene theoretische Erklärungen der skizzierten Art angegeben werden, die verschiedene Modelle und entsprechend mehrere verschiedene Kombinationen fundamentaler Gesetze einsetzen. ${ }^{115}$ Entgegen dem landläufigen Verständnis solcher Fälle, nach dem sich die verschiedenen Modelle und Kombinationen fundamentaler Gesetze auf verschiedene, jedoch miteinander verträgliche Aspekte des Systems beziehen oder sich in dem Sinne ergänzen, daß sie unterschiedliche Gruppen von (i.a. "echten") Eigenschaften des Systems (evtl. in unterschiedlich guter Näherung) berücksichtigen, vertritt Cartwright die These, daß es gängige Praxis in der Physik ist, ohne Klärung solcher Kompatibilitätsfragen mehrere verschiedene theoretische Erklärungen für eine Eigenschaft eines Systems gleichzeitig und nebeneinander zu akzeptieren. ${ }^{116}$ Sie spricht in

\footnotetext{
${ }^{112}$ Wobei als Ableitung nach Cartwright nicht nur strenges deduktives Schließen zählt, sondern auch die (teilweise mathematisch "unsauberen") Näherungsverfahren, die in der "real-existierenden" theoretischen Physik (u.a.) eingesetzt werden.

${ }^{113}$ Vgl. vor allem [Cart83], Kap.6.

${ }^{114}$ In Anlehnung an Mill; [Cart83], S.56ff.

${ }^{115}$ Vgl. Cartwrights Beispiel der Strahlungsdämpfung, [Cart83], S.78ff., in dem dasselbe phänomenologische Gesetz von drei verschiedenen (spezialisierten) Schrödinger-Gleichungen aus abgeleitet wird.

${ }^{116}$ Vgl. [Cart83], S.81.
} 
diesem Sinne von einer Redundanz theoretischer Erklärungen für dieselbe Systemeigenschaft. ${ }^{117}$ Cartwright behauptet nicht, daß es gängige Praxis in der Physik ist, für dasselbe phänomenologische Gesetz wirklich anerkanntermaßen und nachweisbar miteinander nicht konsistente Modelle bzw. darauf basierende theoretische Erklärungen gleichzeitig zu akzeptieren, sie vertritt aber die Ansicht, daß in der Praxis der Physik die Koexistenz verschiedener Modelle und theoretischer Erklärungen für ein und dieselbe Systemeigenschaft ohne eine genaue Untersuchung ihrer Verträglichkeit toleriert wird und daß dies dort auch nicht als in irgendeiner Weise problematisch betrachtet wird.

\section{Cartwrights These, daß die Praxis des Gewinnens und Akzeptierens theoreti- scher Erklärungen in der Physik gegen eine realistische Einstellung zu funda- mentalen Gesetzen spricht}

Cartwright ist der Ansicht, daß die von ihrem simulacrum account of explanation angemessen beschriebene Erklärungspraxis der Physik gegen eine realistischen Einstellung zu den Explanantia der dort gewonnenen theoretischen Erklärungen spricht und insbesondere auch gegen eine realistische Einstellung zu den einzelnen, in diese Explanantia eingehenden fundamentalen Gesetzen der Physik. Eine theoretische Erklärung stellt nach dem von Cartwright gezeichneten Bild zwar eine Art explanatorischen Zusammenhang zwischen bestimmten fundamentalen Gesetzen und einem phänomenologischen Gesetz her, es handelt sich dabei jedoch nicht, wie traditionelle Konzeptionen von Erklärung häufig annehmen, um einen deduktiven Zusammenhang (schon gar nicht um einen exakten und "sauberen") sondern um einen gleichsam durch ein Modell vermittelten Zusammenhang, und dieser Zusammenhang besteht außerdem i.a. zwischen einer Kombination von fundamentalen Gesetzen (nicht einem einzelnen) und einem phänomenologischen Gesetz. Diese Art von explanatorischem Zusammenhang, die sich in der Erklärungspraxis der real-existierenden Physik findet, bietet nach Cartwright keine Grundlage für die (für sie offenbar einzige in Frage kommende ${ }^{118}$ ) Argumentation, die eine realistische Einstellung zu den fundamentalen Gesetzen rechtfertigen könnte, nämlich das Schließen auf die beste Erklärung.

Cartwright erläutert nicht näher, was sie genau unter "Schließen auf die beste Erklärung" versteht, sie scheint aber Schlüsse gemäß einem Inferenzschema der Form (IBE) ${ }^{119}$ zu meinen. Sie nennt jedenfalls drei von den Details eines solchen Inferenzschemas unabhängige Argumente dagegen, ausgehend von den theoretischen Erklärungen, die in der real-existierenden Physik gegeben werden, einen Schluß auf die bei diesen Erklärungen involvierten theoretischen Gesetze zu ziehen. Diese drei Argumente knüpfen an die drei von Cartwright herausgestellten Charakteristika der Erklärungspraxis der Physik an, die oben genannt wurden:

- Cartwright meint, daß der Befund, daß bei den theoretischen Erklärungen der realexistierenden Physik das zu erklärende phänomenologische Gesetz in der Regel nicht exakt oder in numerisch guter Näherung deduktiv abgeleitet werden kann und man dann zu Ergänzungstermen, Fitfaktoren etc. greift, das Schließen auf die beste Erklärung zumindest in diesen Fällen unplausibel macht. ${ }^{120}$

- Cartwright zieht aus ihrem Befund, daß in der Praxis der Physik für dasselbe phänomenologische Gesetz häufig verschiedene (und, so ist wohl zu ergänzen, gleich gute)

\footnotetext{
${ }^{117}$ Cartwrights Ausdruck; vgl. [Cart83], S.17, 76.

${ }^{118}$ Vgl. z.B. [Cart83], S.82.

${ }^{119} \mathrm{~S} .168$.

${ }^{120}$ Siehe [Cart83], S.13ff., Kap.6, bes. S.126.
} 
theoretische Erklärungen ohne genaue Untersuchung ihrer Verträglichkeit akzeptiert werden, die Konsequenz, daß zumindest in den Fällen, in denen derartige Redundanz vorliegt, kein Schluß auf die beste Erklärung gezogen werden kann. ${ }^{121}$

- Cartwright meint, daß die von ihr als "explanation by composition of causes" bezeichnete Erklärungsstrategie und, allgemeiner, die Tatsache, daß für eine theoretische Erklärung i.a. mehrere fundamentale Gesetze (z.B. das zweite Newton-Axiom, das Newtonsche Gravitationsgesetz und das Coulomb-Gesetz) kombiniert eingesetzt werden, zur Folge hat, daß kein Schluß auf die einzelnen fundamentalen Gesetze (z.B. das Gravitationsgesetz) gezogen werden kann. Selbst bei konkreten theoretischen Erklärungen, für die die beiden vorigen Argumente keine Anwendung finden, führt ein Schluß auf die beste Erklärung nach Cartwright bestenfalls auf die "Kombination" der erklärenden fundamentalen Gesetze (also z.B. auf das zweite Newton-Axiom mit spezialisiertem, aus Gravitationsgesetz und Coulomb-Gesetz zusammengesetzten Kraftterm), und der Gültigkeitsbereich dieser Kombination ist nach Cartwright auf die Systeme beschränkt, deren Eigenschaften durch sie erklärt werden. Auf die einzelnen fundamentalen Gesetze, die in die Kombination eingegangen sind, kann man nach Cartwright nicht schließen, d.h. man kann ihr zufolge nicht schließen, daß ein einzelnes Gesetz (z.B. das Gravitationsgesetz) für alle Systeme gilt, bei denen es zur Erklärung ihrer Eigenschaften beiträgt (also beispielsweise nicht, daß das Gravitationsgesetz für alle massiven Körper gilt), denn für die Annahme, daß die "Komponenten", die bei der "composition of causes" zu einer "Gesamtursache" zusammengestellt wurden, tatsächlich "Teilursachen" bezeichnen, gibt es nach Cartwright keine guten epistemischen Gründe. (Beispielsweise gibt es nach Cartwrights Ansicht für die Zerlegung der in einem Modell angenommenen Gesamtkraft in eine Komponente für die Gravitation und eine elektrostatische Komponente - im Unterschied zu anderen denkbaren Zerlegungen — keine guten epistemischen Gründe.) ${ }^{122}$

Die angemessene Einstellung zu den Explanantia der theoretischen Erklärungen, die in der real-existierenden Physik gegeben werden, und damit zu den dort gewonnenen fundamentalen Gesetzen, ist daher nach Cartwright eine instrumentalistische:

"[...] the laws of physics do not provide true descriptions of reality [...].

[...] we can allow that all sorts of statements represent facts of nature, including the generalizations one learns in biology or engineering. It is just the fundamental explanatory laws that do not truly represent." 123

In diesem Punkt besteht nach Cartwrights Ansicht ein entscheidender Unterschied zwischen theoretischen Erklärungen und kausalen Erklärungen.

\section{Cartwrights Konzeption von kausalen Erklärungen}

Eine kausale Erklärung ist nach Cartwright (im einfachsten Fall) eine, die ein Ereignis oder Phänomen durch Angabe seiner Ursache, also eines anderen Ereignisses oder Phäno-

${ }^{122}$ [Cart83], Kap.3, bes. S.66/67. Dies scheint der Kern von Cartwrights komplexer und im einzelnen unübersichtlicher Argumentation zu sein; vgl. dazu etwa [Fors88], S.57ff.

${ }^{123}$ [Cart83], S.55/56. Cartwrights Instrumentalismus ist also epistemisch, nicht bedeutungstheoretisch motiviert; vgl. S.18.
} 
mens ${ }^{124}$ erklärt. Bei einer solchen Erklärung sind ein oder mehrere sehr "situationsspezifische", phänomenologische Kausalgesetze oder Kausalprinzipien (causal principles) involviert (s.u.). ${ }^{125}$ Was Cartwright genauer unter einer Kausalerklärung (im Unterschied zu einer theoretischen Erklärung) versteht, erläutert sie nicht in expliziter, systematischer Weise,${ }^{126}$ sondern im wesentlichen nur anhand von Beispielen wie dem folgenden:

"[...] consider the radiometer, invented by William Crookes in 1853. It is a little windmill whose vanes, black on one side, white on the other, are enclosed in an evacuated glass bowl. When light falls on the radiometer, the vanes rotate. At first it was assumed that light pressure causes the vanes to go round. Soon it was realized that the pressure of light would not be nearly great enough. It was then agreed that the rotation is due to the action of the gas molecules left inside the evacuated bowl [...].

There were two rival hypotheses about what the molecules did [...]. A first proposal was that the vanes are pushed around by pressure of the molecules bouncing more energetically from the black side than the white. But in 1879 James Clerk Maxwell, using the kinetic theory of gases, argued that the forces in the gas would be the same in all directions, and so could not push the vanes. Instead differential heating in the gas produces tangential stresses, which cause slippage of the gas over the surface. As the gas flows around the edge, it pulls the vanes with it $[\ldots]$.

[...] the propositions to which we commit ourselves when we accept a causal explanation are highly detailed causal principles and concrete phenomenological laws, specific to the situation at hand, not the abstract equations of a fundamental theory. Maxwell says that the vanes are dragged around by gas sliding over the edge. They are not pushed by light pressure or the normal force of the gas on the surface. The acceptability of his account depends on a host of general claims about what happens in radiometers.

Here is one phenomenological law — in this case a causal principle — which Maxwell uses:

[The] velocity (with which the gas slides over the surface) and the corresponding tangential stress are affected by inequalities of temperature at the surface

\footnotetext{
${ }^{124}$ Cartwright ist in ihrer Terminologie bzgl. dieser Kategorien nicht sehr präzise, was aber für ihre Zwecke kaum schadet. Zu beachten ist allerdings, daß Cartwright den Terminus 'causal law' sowohl für Kausalgesetze auf der phänomenologischen Ebene als auch für generische Kausalgesetze (s.u.) verwendet; vgl. [Cart83], S.21ff., [Cart89a], S.144.

${ }^{125}$ [Cart83], S.9ff. Cartwright formuliert in [Cart83] meistens nicht genau hinsichtlich der Frage, ob bei einer kausalen Erklärung token oder types von Ereignissen bzw. Phänomenen als Ursache und Wirkung in Beziehung gesetzt werden, an einer Stelle macht sie jedoch klar, daß es ihr um token geht:

"[...] falling under a causal law (plus the existence of suitable initial conditions) is neither necessary nor sufficient for explaining a phenomenon.

It is not sufficient because a single phenomenon may be in the domain of various causal laws, and in many cases it will be a legitimate question to ask, 'Which of these causal factors actually brought about the effect on this occasion?' [...] a phenomenon may be explained by a factor to which it is linked by a sequence of intervening steps, each step falling under a causal law, without there being any causal law that links the explanans itself with the phenomenon to be explained" ([Cart83], S.29/30).

${ }^{126}$ Vgl. [Cart83], S.29.
} 
of the solid, which give rise to a force tending to make the gas slide along the surface from colder to hotter places.

Here is another, this one critical to his argument that the vanes are not pushed by pressure normal to the surface:

When the flow of heat is steady, these forces (the total forces acting in all directions) are in equilibrium.

Maxwell's explanation of exactly how the motion in radiometers takes place will not be right unless these principles are true. But these are not fundamental laws. Maxwell sets his particular "causal story" into the framework of the developing kinetic theory of gases. It is useful to contrast the two specific laws quoted, about what happens in radiometers, with two fundamental equations from this basic theory which Maxwell uses [, viz. ...] Boltzmann's equation $[\ldots]$ and the general equation of continuity [...]. These are general, abstract equations; they are not about any particular happenings in any particular circumstances." 127

Cartwright verwendet die Ausdrücke 'Kausalgesetz' und 'Kausalprinzip' nicht scharf unterschieden, tendenziell bezeichnet sie als Gesetz eher eine quantitative Beziehung in Gestalt einer Gleichung, als Prinzip dagegen einen qualitativen Zusammenhang. Wenn sie explizit eine kausale Erklärung angibt, hat diese stets qualitativen Charakter; auch wenn ein quantitatives Gesetz in Form einer Gleichung vorliegt, das den Zusammenhang von Ursache und Wirkung beschreibt, gibt Cartwright, wie im oben zitierten Beispiel, als Erklärung eine Prosaformulierung an, die offenbar so etwas wie die qualitative Struktur der Gleichung oder eine ihr zugrundeliegende Kausalstruktur beschreibt. Das, was eine solche Prosaformulierung beschreibt, bezeichnet Cartwright als "causal story", und diese qualitative causal story (und nicht der quantitative, durch ein Kausalgesetz beschriebene Zusammenhang) scheint das zu sein, was nach Cartwright eine kausale Erklärung konstituiert, während ein phänomenologisches Kausalgesetz "nur" bei der Gewinnung der kausalen Erklärung wichtig ist:

"Physics is mathematical; yet its causal stories can be told in words." ${ }^{128}$

In komplexeren, mehr als nur ein Ursache-Wirkungs-Paar involvierenden Fällen wie dem des Radiometers hat die causal story, die ein Ereignis oder Phänomen erklärt, die Gestalt einer kausalen Kette, einer diskreten Sequenz von kausalen Faktoren (Ereignissen oder Phänomenen), die jeweils durch Ursache-Wirkungs-Beziehungen verbunden sind. Eine genauere Beschreibung des Zusammenhanges zweier Faktoren in einer solchen kausalen Kette kann durch ein (quantitatives, phänomenologisches) Kausalgesetz gegeben sein, das die beiden Faktoren enthält. ${ }^{129}$ Eine causal story nennt dagegen nur die kausalen Faktoren und die bestehenden kausalen Verknüpfungen.

Als Beispiel für eine causal story gibt Cartwright eine für den sogenannten Lamb dip an, ein Phänomen aus dem Bereich der Laserphysik: ${ }^{130}$

\footnotetext{
${ }^{127}$ [Cart83], S.5-9; vgl. auch das Beispiel der Strahlungsdämpfung in [Cart83], S.78/79.

${ }^{128}$ [Cart89a], S.40.

${ }^{129}$ Vgl. Fn.125.

${ }^{130}$ Als "Lamb dip" bezeichnet man den Sachverhalt, daß bei einem Gaslaser die Funktion, die die Intensität des Laserlichtes in Abhängigkeit von der Resonatorfrequenz angibt, eine bestimmte Form hat, nämlich einen peak um den Wert der Übergangsfrequenz der Gasatome herum, und zwar genauer einen peak, der sozusagen eine kleine "Delle" (den dip), also ein lokales Minimum hat (vgl. [Cart89a], S.42).
} 
"Existence of waves running in 2 directions $\Rightarrow$ saturation of the 2 velocities for which the 2 oscillating frequencies are appropriately up-and down-shifted [...] $\Rightarrow$ reduction in the population difference at those 2 velocities $[\ldots] \Rightarrow$ greater intensity in the cavity". ${ }^{131}$

Auf die Frage, wie eine causal story und die zugehörigen Kausalgesetze mit den Gesetzen und Modellen zusammenhängen, die in theoretischen Erklärungen der entsprechenden Systemeigenschaften involviert sind, hat Cartwright erklärtermaßen keine allgemeine oder auch nur einigermaßen systematische Antwort. ${ }^{132}$

\section{Cartwrights These, daß bei kausalen Erklärungen eine realistische Einstellung zu den Explanantia gerechtfertigt werden kann; Schließen auf die wahrschein- lichste Ursache}

Cartwright vertritt die These, daß bei kausalen Erklärungen - anders als bei theoretischen Erklärungen - eine realistische Einstellung zu den Explanantia gerechtfertigt werden kann, genauer: zu den Entitäten, Eigenschaften und Prozessen, die in den kausalen Erklärungen als Ursachen genannt werden, bzw. zu den phänomenologischen Kausalgesetzen und -prinzipien, die sich auf diese Entitäten, Eigenschaften und Prozesse beziehen.

Die Rechtfertigung besteht nach Cartwright darin, daß bei kausalen Erklärungen (unter bestimmten Umständen - s.u.) ein Schluß auf die wahrscheinlichste Ursache (inference to the most likely cause) $)^{133}$ gezogen werden kann:

"In the case of Maxwell's molecules and the tangential stresses in the radiometer $[. .$.$] we have good reason to believe in the entities, processes, and properties$ in question.

Causal reasoning provides good grounds for our beliefs in theoretical entities. Given our general knowledge about what kinds of conditions and happenings are possible in the circumstances, we reason backwards from the detailed structure of the effects to exactly what characteristics the causes must have in order to bring them about. I have sometimes summarized my view about explanation this way: no inference to best explanation; only inference to most likely cause. But that is right only if we are very careful about what makes a cause 'likely'. We must have reason to think that this cause, and no other, is the only practical possibility, and it should take a good deal of critical experience to convince us of this." 134

Cartwright deutet an verschiedenen Stellen an, daß sie einen Schluß auf die wahrscheinlichste Ursache als eine Art sehr spezifischen Spezialfall des Schließens auf die beste Erklärung betrachtet, ${ }^{135}$ und sie betont, daß ein solcher Schluß im konkreten Fall eine Menge detaillierter Kenntnisse über die verschiedenen in Frage kommenden Ursachen des kausal zu erklärenden Ereignisses oder Phänomens voraussetzt, ${ }^{136}$ sie gibt jedoch für das Schließen

${ }^{133}$ Der deutsche Ausdruck 'Wahrscheinlichkeit' differenziert nicht zwischen likelihood und probability; die Übersetzung 'Schluß auf die wahrscheinlichste Ursache' ist dennoch insofern gerechtfertigt, als Cartwright 'inference to the most likely cause' und '. . most probable cause' offensichtlich austauschbar verwendet.

${ }^{134}$ [Cart83], S.6.

135 [Cart83] S.83, 85.

${ }^{136}$ Vgl. das obige Zitat und [Cart83] S.83/84.
} 
auf die wahrscheinlichste Ursache kein Inferenzschema o.ä. an und spezifiziert die Art oder Form solcher Schlüsse nicht näher. ${ }^{137}$

Als das, worauf (unter geeigneten Umständen) geschlossen werden kann und wozu daher zu Recht eine realistische Einstellung eingenommen werden kann, nennt Cartwright die jeweilige Ursache im engeren Sinn, d.h. die Entitäten, Eigenschaften und Prozesse, die in den kausalen Erklärungen als Ursachen der erklärten Ereignisse oder Phänomene genannt werden, und die entsprechenden Kausalprinzipien, also die causal story, darüber hinaus nennt sie aber ausdrücklich auch die phänomenologischen Kausalgesetze, die den Zusammenhang von Ursache und Wirkung quantitativ beschreiben. ${ }^{138}$

Zur Begründung ihrer These, daß bei kausalen Erklärungen ein Schluß auf die wahrscheinlichste Ursache gezogen werden kann, führt Cartwright mehrere Überlegungen an:

- Sie weist darauf hin, daß in der Praxis der Physik eine Kausalerklärung nur dann akzeptiert wird, wenn sie eindeutig ist, d.h., es werden dort niemals mehrere konkurrierende Kausalerklärungen für dasselbe Ereignis oder Phänomen nebeneinander akzeptiert. Anders als im Fall theoretischer Erklärungen werden nach Cartwright in der Erklärungspraxis der real-existierenden Physik bei kausalen Erklärungen keine Redundanzen toleriert. ${ }^{139}$ Einem Schluß auf die wahrscheinlichste Ursache stehen daher keine Redundanzen im Wege, anders als es nach Cartwright i.a. bei einem Schluß auf die beste (theoretische) Erklärung wäre.

- Cartwright vertritt darüber hinaus die Ansicht, daß sogar die Verwendungsregeln für kausale Ausdrücke wie 'Kausalerklärung', 'verursachen', 'herbeiführen' etc. so sind, daß eine Aussage, daß ein Ereignis oder Phänomen $X$ durch ein anderes Ereignis oder Phänomen $Y$ kausal erklärt, verursacht, herbeigeführt etc. wird, impliziert, daß $Y$ existiert: ${ }^{140}$

"[...] causal explanations have truth built into them. When I infer from an effect to a cause, I am asking what made the effect occur, what brought it about. No explanation of that sort explains at all unless it does present a cause [...]. An explanation of an effect by a cause has an existential component, not just an optional extra ingredient." 141

"In explaining the [cloud chamber] track by the particle, I am saying that the particle causes the track, and that explanation, or inference to the most probable cause, has no sense unless one is asserting that the particle in motion brings about, causes, makes, produces, that very track [...]. What is special about explanation by theoretical entity is that it is causal explanation, and existence is an internal characteristic of causal claims. There is nothing similar for theoretical laws." ${ }^{142}$

"To the extent that we find the causal explanation acceptable, we must believe in the causes described." 143

\footnotetext{
${ }^{137}$ Vgl. [Cart83], S.89: "[...] inference from effect to cause is legitimate. I will have nothing new to say about the structure of these inferences."

${ }^{138}$ Vgl. das Zitat S.340 sowie [Cart83], S.4, 8, 10.

139 [Cart83], S.11/12, 76, 81, 85/86.

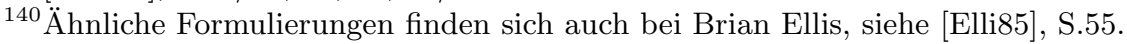

${ }^{141}$ [Cart83], S.91.

${ }^{142}$ [Cart83], S.92/93.

143 [Cart83], S.5.
} 
- Cartwright versucht, ihre These plausibel zu machen, daß bei kausalen Erklärungen ein Schluß auf die wahrscheinlichste Ursache gezogen werden kann, indem sie darauf hinweist, daß in diesem Punkt die Sachlage im Bereich der Alltagswelt einerseits und im Bereich der Wissenschaften andererseits weitreichende Parallelen aufweist:

"My newly planted lemon tree is sick, the leaves yellowing and dropping off. I finally explain this by saying that water has accumulated in the base of the planter: the water is the cause of the disease. I drill a hole in the base of the oak barrel where the lemon tree lives, and foul water flows out. That was the cause. Before I had drilled the hole, I could still give the explanation and to give that explanation was to present the supposed cause, the water. There must be such water for the explanation to be correct $[. .$.$] .$

Likewise when I explain the change in rate in fall of a light droplet in an electric field, by asserting that there are positrons or electrons on the ball, I am inferring from effect to cause, and the explanation has no sense at all without the direct implication that there are electrons or positrons on the ball. Here there is no drilling a hole to let the electrons gush out before our eyes. But there is the generation of other effects: if the ball is negatively charged, I spray it with a positron emitter and thereby change the rate of fall of the ball [...]. I infer to the most probable cause, and that cause is a specific item, what we call a theoretical entity." 144

Die Tatsache, daß für die Rechtfertigung einer realistischen Einstellung zu unbeobachtbaren Entitäten, Eigenschaften, Prozessen etc. nach Cartwright Schlüsse auf die wahrscheinlichste Ursache die entscheidende Rolle spielen, ist der Grund, warum für Cartwright — wie schon für Hacking, jedoch in etwas anderer Weise - der experimentellen Praxis der Wissenschaften und insbesondere experimentellen "Interventionen" und Manipulationen zentrale Bedeutung für die Begründung einer realistischen Position zukommt: Experimentellen Interventionen kommt diese Bedeutung nach Cartwright deshalb zu, weil sie es ermöglichen, Bedingungen zu schaffen, unter denen kausale Erklärungen gewonnen, getestet und bestätigt werden können, und sich solche Bedingungen allenfalls sehr selten in der "unberührten Natur" finden:

"[...] when do we have reasonable grounds for counting a causal account acceptable? [...] Here, as I have been stressing, the idea of direct experimental testing is crucial." 145

"We make our best causal inferences in very special situations - situations where our general view of the world makes us insist that a known phenomenon has a cause; where the cause we cite is the kind of thing that could bring about the effect and there is an appropriate process connecting the cause and the effect; and where the likelihood of other causes is ruled out. This is why controlled experiments are so important in finding out about entities and processes which we cannot observe. Seldom outside of the controlled conditions of an experiment are we in a situation where a cause can legitimately be inferred." 146

\footnotetext{
${ }^{144}$ [Cart83], S.91/92.

${ }^{145}$ [Cart83], S.98.

${ }^{146}$ [Cart83], S.6.
} 


\section{Cartwrights Entitätenrealismus}

Aus den genannten Thesen und Überlegungen ergibt sich für Cartwright eine Position in der Realismusdebatte, die der von Hacking offenbar verwandt ist und in ihren "positiven" Thesen auch mindestens ebenso grob und im einzelnen ungenau charakterisiert ist wie die von Hacking. Nach Cartwright ist "unter geeigneten Umständen" eine realistische Einstellung zu Entitäten, Eigenschaften und Prozessen gerechtfertigt, die in kausalen Erklärungen als Ursachen der erklärten Ereignisse oder Phänomene fungieren, sowie zu den entsprechenden Kausalprinzipien und phänomenologischen Kausalgesetzen. Damit scheint Cartwright Hackings Entitätenrealismus zumindest nahe zu kommen und ebenfalls eine Position einzunehmen, die sozusagen zwischen antirealistischen Positionen (wie der von van Fraassen) und traditionelleren realistischen Positionen (wie der von Boyd) liegt. Sie scheint, ähnlich wie Hacking, ein (hinreichendes) Kriterium anzugeben, das im Gesamtbestand der in den real-existierenden Wissenschaften akzeptierten Repräsentationen (Gesetze, Modelle, Theorien etc.) eine Teilmenge auszeichnet, deren Elemente sich auf Entitäten, Sachverhalte etc. beziehen, gegenüber denen eine realistische Einstellung einzunehmen ist, sie scheint jedoch dieses Kriterium, anders als Hacking, auch zu begründen, nämlich durch den Hinweis darauf, daß sich die durch das Kriterium ausgezeichneten Elemente durch einen Schluß auf die wahrscheinlichste Ursache rechtfertigen lassen. Bei genauerer Betrachtung erweist sich das, was Cartwright über das Schließen auf die beste Ursache sagt, jedoch als viel zu skizzenhaft und ungenau, um in konkreten Fällen zu beurteilen, ob auf eine Existenzaussage, ein phänomenologisches Gesetz o.ä. zu Recht geschlossen werden kann: Nach Cartwright kann keineswegs bei jeder Kausalerklärung zu Recht auf das Explanans geschlossen werden, sondern nur unter geeigneten Umständen, in, wie sie sich ausdrückt, "sehr speziellen Situationen", in denen man gute Gründe für die Annahme hat, daß ein bestimmtes Ereignis oder Phänomen eine Ursache hat, in denen man außerdem sozusagen die Gesamtheit der möglichen Ursachen unter Kontrolle hat und in denen man ferner gute Gründe hat, alle möglichen Ursachen bis auf eine auszuschließen. Wie die dazu erforderlichen guten Gründe aussehen, bleibt bei Cartwright offen, sie ist aber offenbar der Ansicht, daß bei den Kausalerklärungen, die in der Praxis der Physik akzeptiert werden, i.a. solche Gründe verfügbar sind.

Cartwrights Argumentation für eine realistische Position besteht also, wie die von Hacking, im wesentlichen in der Angabe eines Kriteriums dafür, welcher Teil des Gesamtbestands der in den real-existierenden Wissenschaften akzeptierten Repräsentationen sich auf Entitäten, Sachverhalte etc. bezieht, zu denen eine realistische Einstellung einzunehmen ist. Nach Cartwright ist dies der Teil, der in akzeptierten kausalen Erklärungen als Explanans der erklärten Ereignisse oder Phänomene fungiert. Dagegen ist nach Cartwright zu fundamentalen Gesetzen und Theorien eine instrumentalistische Einstellung angemessen.

Eine wichtige, bisher zurückgestellte Frage in bezug auf Cartwrights entitätenrealistische Position ist, welche "positiven" Thesen genaugenommen diese Position konstituieren, was also genaugenommen unter einer realistischen Einstellung zu den durch ihr Kriterium ausgezeichneten Entitäten, Sachverhalten etc. zu verstehen ist, und insbesondere, ob es dabei um realistische Thesen der vorne ${ }^{147}$ unterschiedenen Arten geht und wenn ja, um welche Arten von Thesen. Zu dieser Frage finden sich bei Cartwright - anders als bei Hacking — keine systematischen Erläuterungen. Um eine realistische Einstellung in konkreten Beispielen zum Ausdruck zu bringen, verwendet sie eine Vielzahl verschiedener

\footnotetext{
${ }^{147}$ Siehe Kap.1.
} 
Formulierungen. ${ }^{148}$ Die (realistischen Positionen vielfach zugrundeliegende) Idee der Unabhängigkeit der Welt vom menschlichen Geist und menschlicher Erkenntnis ${ }^{149}$ wird von Cartwright gar nicht thematisiert, dasselbe gilt für semantische Theorien in bezug auf die Sprache der Wissenschaften. Immerhin läßt sie erkennen, daß sie ihren Entitätenrealismus offenbar dem gesamten Spektrum antirealistischer Gegenpositionen entgegenstellen will, u.a. instrumentalistischen Positionen und van Fraassens konstruktivem Empirismus. ${ }^{150}$

Alles in allem läßt sich nur konstatieren, daß Cartwright keine klare Antwort auf die Frage gibt, welche (Art von) "positiven" Thesen ihre entitätenrealistische Position konstituieren. Eine denkbare und vielleicht naheliegende Möglichkeit, ihre Position zu explizieren, ist die schon im Fall Hackings genannte: Danach könnte man Existenzaussagen über unbeobachtbare Entitäten, Phänomene etc. und phänomenologische Gesetze über deren Eigenschaften, die Cartwrights Kriterium erfüllen, zu ontologischen realistischen Thesen ergänzen und diese als wesentlichen Kern der entitätenrealistischen Position auffassen. Eine realistische Einstellung etwa zu Elektronen wäre demnach zu verstehen als eine Existenzaussage über Elektronen plus evtl. einige Aussagen über deren Eigenschaften (plus eine Unabhängigkeitsaussage). Im Hinblick auf die Debatte mit antirealistischen Gegnern würde Cartwrights Kriterium dann Existenzaussagen, phänomenologische Gesetze etc. auszeichnen, bezüglich derer ihrer Ansicht nach eine instrumentalistische Einstellung zurückzuweisen ist und für die eine gute epistemische Begründung gegeben werden kann.

\subsubsection{Probleme und Kritik}

Die wichtigsten Probleme von Cartwrights Position in der Realismusdebatte sollen an dieser Stelle diskutiert werden. ${ }^{151}$ Beiseite bleiben dabei Probleme und Einwände, die auch Hackings Position betreffen und bereits oben diskutiert wurden und auf die Cartwright in derselben Weise antwortet bzw. antworten kann. Dies sind insbesondere der Einwand, daß Cartwrights Kriterium, zu welchen Repräsentationen eine realistische Einstellung einzunehmen ist, nicht mit den in der Praxis der Physik etablierten Kriterien für Existenzannahmen übereinstimmt, die Frage nach einer präzisen Erläuterung der Unterscheidung von phänomenologischen Gesetzen einerseits und hochstufigeren Repräsentationen andererseits und der Einwand, daß der Theorienwandel in den Wissenschaften auch Entitäten, phänomenologische Gesetze etc. betrifft und damit gegen Cartwrights Kriterium spricht. ${ }^{152}$

\section{Die Grenzziehung zwischen Repräsentationen, zu denen eine realistische Ein- stellung einzunehmen ist, und solchen, zu denen eine instrumentalistische Ein- stellung einzunehmen ist, und ihre Begründung}

Ein kritischer Punkt bei Cartwright ist, wie schon bei Hacking, die Art und Weise, wie durch die Angabe eines Kriteriums eine Grenze markiert werden soll zwischen den Re-

\footnotetext{
${ }^{148}$ Einige Beispiele: "I argue [...] for a kind of anti-realism [...] that accepts the phenomenological and rejects the theoretical" ([Cart83], S.2), "I believe in theoretical entities" ([Cart83], S.89), "we must be committed to the existence of the cause" ([Cart83], S.97), "[w]e can infer the truth of an explanation" ([Cart83], S.76), "phenomenological laws are meant to describe" ([Cart83], S.3); Hervorhebungen von mir. ${ }^{149}$ Siehe Kap.1.

${ }^{151}$ Einige Arbeiten, die sich mit Cartwrights Position auseinandersetzen, sind, ohne Anspruch auf Vollständigkeit, [Allp93, Fors88, Fran88, Gibb84, Hitc92, KlMa86, Laym89, Morr94, Need91].

${ }^{152}$ Zum letzteren Punkt siehe Cartwrights kurze Bemerkungen in [Cart83], S.98, zum vorletzen [Cart83], S.77/78.
} 
präsentationen, zu denen ihrer Ansicht nach eine realistische Einstellung einzunehmen ist, und dem Rest, zu dem sie eine instrumentalistische Einstellung empfiehlt. Cartwright begründet oder motiviert ihre Grenzziehung in zweierlei Weise, einmal durch "negative" Argumente, die dagegen sprechen, eine realistische Einstellung zu Repräsentationen einzunehmen, die gleichsam jenseits der Grenze liegen, andererseits durch "positive" Argumente und Überlegungen, die eine realistische Einstellung zu Repräsentationen begründen oder plausibel machen sollen, die innerhalb des eingegrenzten Bereichs liegen. Alle diese Argumente und Überlegungen sind jedoch mit Problemen behaftet.

Cartwrights negative Argumente weisen alle zu Recht auf Schwierigkeiten hin, auf die man stößt, wenn man realistische Thesen in bezug auf Theorien, fundamentale Gesetze etc. durch deren Erklärungsleistungen begründen will, und zwar insbesondere dann, wenn man die Erklärungen der real-existierenden Physik sozusagen mit hinreichend hoher Auflösung in den Blick nimmt. Diese Schwierigkeiten sind jedoch alle nicht von prinzipieller Natur (wie Cartwright gelegentlich selbst einräumt ${ }^{153}$ ), sondern eher von bereits (aus der Diskussion der Kontinuitätsargumente und des Wunderarguments) bekannter Art, nämlich Schwierigkeiten der präzisen und adäquaten Formulierung eines Inferenzschemas für die zur Diskussion stehenden Schlüsse auf die beste (theoretische, wissenschaftliche) Erklärung und des Anwendungs- und Verläßlichkeitsbereichs eines solchen Inferenzschemas. Im einzelnen stellt sich die Sachlage bei Cartwrights negativen Argumenten wie folgt dar.

Cartwrights Befund, daß in theoretischen Erklärungen in der real-existierenden Physik das zu erklärende phänomenologische Gesetz in der Regel nicht exakt oder in numerisch guter Näherung deduktiv abgeleitet wird und man dafür mit Ergänzungstermen, Fitfaktoren etc. arbeitet, spricht tatsächlich dagegen, daß bei diesen Erklärungen ein Inferenzschema der Form (IBE) ${ }^{154}$ oder verwandter Art eingesetzt werden kann, das eine Art von Erklärung voraussetzt, bei dem das Explanandum deduktiv aus dem Explanans folgt (etwa eine DN-Erklärung). Cartwrights Befund spricht jedoch nicht dagegen, ein ähnliches Inferenzschema zum Einsatz zu bringen, das eine Art von Erklärung voraussetzt, die Näherungen etc. zuläßt bzw. einschließt. ${ }^{155}$ Richtig ist allerdings, daß sich ein zufriedenstellend spezifiziertes Inferenzschema dieser Art in der Literatur (zumindest derzeit noch) nicht findet. ${ }^{156}$

Cartwrights Befund, daß in der Praxis der Physik für dasselbe phänomenologische Gesetz o.ä. häufig mehrere verschiedene theoretische Erklärungen ohne Untersuchung ihrer Verträglichkeit akzeptiert werden, mag korrekt sein oder nicht (oder vielleicht teilweise, aber nicht in dem von Cartwright behaupteten Maß), er hat jedenfalls nicht die von Cartwright gezogene Konsequenz, daß in den Fällen, in denen redundante Erklärungen vorliegen, kein Schluß auf diese Erklärungen gezogen werden kann. Bei den von ihr angeführten Beispielen für die Redundanz theoretischer Erklärungen deutet nichts darauf hin, daß eine echte Unverträglichkeit der verschiedenen Explanantia vorliegt, und es spricht nichts dagegen, die Explanantia als verschiedene genäherte Beschreibungen desselben Systemzustands bzw. derselben Systemeigenschaften aufzufassen oder als sich ergänzende Beschreibungen, die verschiedene Aspekte des Systems betreffen, und Cartwright erkennt dies auch an. Dann aber spricht offenbar grundsätzlich nichts dagegen, Schlüsse auf die Erklärun-

\footnotetext{
${ }^{153}$ Vgl. z.B. [Cart83], S.126.

${ }^{154}$ Siehe S.168.

${ }^{155}$ Darauf wird etwa in [KlMa86] hingewiesen.

${ }^{156}$ Erste Ansätze in dieser Richtung finden sich z.B. in [Laym89].
} 
gen $^{157}$ zu ziehen, und zwar bei den verschiedenen redundanten Erklärungen zugleich. ${ }^{158}$ In Fällen, in denen das exakte Verhältnis verschiedener Näherungen nicht wirklich sauber geklärt ist, geht man damit das Risko ein, daß später Inkonsistenzen entdeckt werden und dann mindestens eine der Konklusionen aufgegeben werden muß (oder allenfalls als nur für praktische Zwecke brauchbares Modell o.ä. beibehalten werden kann, zu dem dann eine instrumentalistische Einstellung einzunehmen ist). Es spricht aber wenig dafür, daß dieses Risiko groß ist, daß also für einen großen oder gar den überwiegenden Teil der Fälle, in denen in der Physik redundante theoretische Erklärungen akzeptiert werden, solche echten Unverträglichkeiten zu erwarten sind, jedenfalls liefert Cartwright keine Indizien für eine solche Annahme.

Cartwright scheint in ihren neueren Arbeiten ${ }^{159}$ die angeführten Einwände gegen ihre beiden genannten "negativen" Argumente zu akzeptieren. Sie legt auf die zugrundeliegenden Befunde immer weniger Gewicht und läßt die beiden Argumente schließlich effektiv fallen. ${ }^{160}$ Schlüsse auf die Explanantia theoretischer Erklärungen lehnt sie nun nicht mehr generell ab, sie insistiert aber darauf, daß solche Schlüsse auf für konkrete Systeme spezifizierte fundamentale Gesetze führen, nicht auf fundamentale Gesetze in ihrer systemunabhängigen Form und mit universellem (oder jedenfalls weitem, verschiedenartige konkrete Systeme abdeckendem) Geltungsbereich (also z.B. auf die Schrödinger-Gleichung für das Heliumatom im Magnetfeld, nicht auf die allgemeine Schrödinger-Gleichung). Cartwright vertritt die These, daß Schlüsse auf letztere epistemisch nicht gerechtfertigt sind, hält also damit am dritten ihrer drei genannten negativen Argumente fest. ${ }^{161}$ Cartwright scheint demnach in ihren neueren Arbeiten ihr Kriterium dafür, zu welchen Repräsentationen eine realistische Einstellung einzunehmen ist, zu modifizieren und die durch ihr Kriterium markierte Grenzlinie damit ein gutes Stück in Richtung "theoretischerer" Repräsentationen $\mathrm{zu}$ verschieben.

Für Cartwrights drittes negatives Argument, daß es nicht gerechtfertigt ist, aufgrund der Erklärungsleistungen fundamentaler Gesetze einen Schluß auf diese Gesetze vorzunehmen, weil die entsprechenden Erklärungen i.a. die Form von explanations by composition of causes haben, also mehrere fundamentale Gesetze kombiniert involvieren, gilt ebenfalls, daß es auf eine echte Schwierigkeit hinweist, jedoch nicht auf eine prinzipieller Art: Plausibel scheint, daß ein allgemeines Inferenzschema der Form (IBE) einen entsprechenden Schluß nicht zuläßt bzw. liefert, insbesondere nicht, wenn als Explanandum lediglich ein Phänomen oder eine Eigenschaft eines speziellen physikalischen Systems (oder Typs von Systemen) fungiert bzw. ein phänomenologisches Gesetz. Daraus folgt jedoch nicht, daß sich nicht ein anderes, spezielleres Inferenzschema formulieren läßt, das einen solchen Schluß gestattet und sich auch sonst plausibel machen läßt. In Betracht kommen hier insbesondere Schemata, die von "qualifizierten" Erklärungsleistungen ausgehen, die

\footnotetext{
${ }^{157}$ Die Konklusion eines solchen Schlusses sollte natürlich nicht "genau" das jeweilige Explanans sein, sondern eine durch eine Qualifikation wie 'näherungsweise', 'annähernd' o.ä. abgeschwächte Konklusion.

${ }^{158}$ Es ist offenbar keine plausible Forderung, daß ein Inferenzschema grundsätzlich nur dann angewendet werden darf, wenn so etwas wie ein "positiver Nachweis" geführt werden kann, daß die Konklusion mit dem Rest des jeweiligen Überzeugungssystems verträglich ist. Plausibel ist dagegen die Forderung, daß die Anwendung des Inferenzschemas nicht zu expliziten oder "offensichtlichen" Inkonsistenzen unter den Überzeugungen führen darf oder daß solche Inkonsistenzen jedenfalls anschließend durch andere Modifikationen beseitigt werden müssen; diese Forderung wird durch die oben genannten Schlüsse auf redundante Erklärungen nicht verletzt.

${ }^{159}$ [Cart89a, Cart92, Cart93b, Cart94].

${ }^{160}$ Explizit in [Cart94].

${ }^{161}$ Siehe z.B. [Cart93b], S.292ff., [Cart94], S.280/281. Die Gesamtheit von "spezialisierten" fundamentalen Gesetzen, die man so erhält, nennt sie ein patchwork of laws (vgl. [Cart94]).
} 
mehrere verschiedenartige Phänomene bzw. Systeme betreffen, etwa "vereinheitlichende" Erklärungen verschiedener Phänomene durch dieselben (und in unterschiedlicher Weise kombinierten) fundamentalen Gesetze. Cartwright weist zu Recht darauf hin, daß die präzise Formulierung eines solchen Inferenzschemas ein notorisch schwieriges Problem ist und sich ein zufriedenstellend spezifiziertes Inferenzschema dieser Art in der Literatur (zumindest derzeit noch) nicht findet; es finden sich aber immerhin Ansätze dazu, die plausibel machen, daß das Problem kein prinzipielles sein sollte. ${ }^{162}$

Cartwrights "positive" Argumente und Überlegungen, die eine realistische Einstellung zu den Repräsentationen, die ihr Kriterium auszeichnet, begründen oder plausibel machen sollen, leisten, genau besehen, wenig oder nichts, um dieses Ziel zu erreichen, und tragen daher ebenfalls wenig dazu bei, das Kriterium zu stützen. Offensichtlich gilt dies für Cartwrights Hinweise, daß bei kausalen Erklärungen in der Praxis der Physik keine Redundanz toleriert wird, denn damit sind, auch wenn dies so ist, ${ }^{163}$ offenbar keine epistemischen Rechtfertigungsgründe für die Explanantia gegeben; vielmehr wird damit lediglich das Fehlen von "Gegengründen" konstatiert. ${ }^{164}$

Cartwrights These, daß die Verwendungsregeln für kausale Ausdrücke wie 'Kausalerklärung', 'verursachen' etc. so sind, daß eine Aussage darüber, wodurch ein bestimmtes Ereignis oder Phänomen $X$ kausal erklärt wird, verursacht wird etc., eine Existenzaussage über das impliziert, was $X$ kausal erklärt, verursacht etc., liefert per se ebenfalls keine epistemischen Rechtfertigungsgründe für die fraglichen Existenzaussagen, sondern verschiebt das Begründungsproblem bestenfalls: Wenn man Cartwrights These akzeptiert, liefert sie dann begründete Existenzaussagen, wenn man gute epistemische Rechtfertigungsgründe für eine kausale Erklärung für $X$, für eine Aussage über die Ursache von $X$ etc. hat. Gute Gründe für solche komplexeren Aussagen zu finden, dürfte jedoch i.a. mindestens ebenso schwierig und nicht leichter sein als für die fraglichen Existenzaussagen, und antirealistische Diskussionsgegner, die Cartwrights These akzeptieren, von einer kausalen Erklärung für $X$, die, wie Cartwright sich ausdrückt, eine "Existenz-Komponente hat" bzw. "Wahrheit eingebaut hat" o.ä., zu überzeugen, dürfte mindestens ebenso schwierig sein, wie sie von den implizierten Existenzaussagen allein zu überzeugen. ${ }^{165}$

Cartwrights Hinweis auf Parallelen zwischen dem Schließen auf die wahrscheinlichste Ursache im Bereich der Alltagswelt einerseits und in den Wissenschaften andererseits schließlich scheint eine Begründung für ein Inferenzschema für das Schließen auf die wahrscheinlichste Ursache anzudeuten, wie sie bereits oben bei den epistemischen Kontinuitätsargumenten skizziert worden ist. ${ }^{166}$ Diese Begründungsstrategie sieht grundsätzlich plausibel aus, kann jedoch nicht viel Überzeugungskraft entwickeln, solange das Inferenzschema selbst nicht in einigermaßen zufriedenstellender Weise spezifiziert wird, und das wird es bei Cartwright nicht. Ihrem Hinweis auf Parallelen zwischen dem Bereich der Alltagswelt und den Wissenschaften läßt sich aber vielleicht, wie bei Hacking, die Aussage entnehmen, daß ihre Argumentation auf ein Kriterium zielt, das in beiden Bereichen anwendbar und plausibel ist.

Fazit ist also, daß weder die positiven noch die negativen Argumente und Überlegungen, die Cartwright zur Begründung und Motivation ihres Kriteriums anführt, dieses tatsächlich in einigermaßen überzeugender Weise begründen und motivieren.

\footnotetext{
${ }^{162}$ Siehe vor allem Forsters (an Whewell anknüpfender) Aufsatz [Fors88], bes. S.79ff.

${ }^{163}$ Zweifel daran werden in [Morr94] angemeldet.

${ }^{164}$ Deren Relevanz ohnehin zweifelhaft wäre (s.o.).

${ }^{165}$ Vgl. u.a. [Gibb84], S.397f., [Hitc92], S.162ff.

${ }^{166}$ Siehe Abschnitt 8.3.
} 
Über diesen Befund hinaus läßt sich gegen Cartwrights Kriterium — wie schon gegen das von Hacking ${ }^{167}$ — der Einwand erheben, daß die Entkoppelung von Entitäten und phänomenologischen Gesetzen einerseits und fundamentalen Gesetzen andererseits, auf die dieses Kriterium hinausläuft, deswegen nicht plausibel aussieht, weil für die epistemische Rechtfertigung von Existenzaussagen über Entitäten und von phänomenologischen Gesetzen i.a. (wenn auch wohl nicht in allen Fällen) fundamentale Gesetze, Modelle und Theorien erforderlich sind. Da Cartwright — trotz ihrer Andeutungen über das Schließen auf die wahrscheinlichste Ursache - letztlich keine klaren Erläuterungen zu ihrer Konzeption epistemischer Rechtfertigung gibt, bleibt unklar, ob und inwieweit dieser Einwand ihre Position trifft und welche Konsequenzen er ggf. hat; prima facie sieht dieser Einwand jedoch, wie oben erörtert, berechtigt aus.

Fazit dieser Überlegungen ist, daß für Cartwrights Position in der Realismusdebatte — wie schon für die von Hacking — die Angabe eines Kriteriums wesentlich zu sein scheint, durch das in der Gesamtheit der in den real-existierenden Wissenschaften etablierten Repräsentationen eine Teilmenge ausgezeichnet wird, die sich auf Entitäten, Eigenschaften etc. beziehen, zu denen nach Cartwright eine realistische Einstellung einzunehmen ist. Dieses Kriterium läuft in Cartwrights ursprünglicher Form, wie das von Hacking, auf eine Entkoppelung von Entitäten und phänomenologischen Gesetzen einerseits und fundamentalen Gesetzen und Theorien andererseits hinaus; in Cartwrights neueren Arbeiten scheint sie es dahingehend zu modifizieren, daß eine realistische Einstellung auch zu "systemspezifischen" fundamentalen Gesetzen als angemessen gilt. Cartwright führt einiges an Argumenten und Überlegungen an, um ihr Kriterium und die daraus resultierende Entkoppelung zu begründen und zu motivieren (jedenfalls mehr als Hacking), diese Argumente und Überlegungen haben jedoch bei genauerer Betrachtung wenig oder keine Überzeugungskraft. Wie schon bei Hacking finden sich auch bei Cartwright keine überzeugenden Gründe, warum sie die durch ihr Kriterium markierte Grenzlinie so zieht, wie sie es tut.

Dieser Befund läßt einen unklaren oder zumindest offenen Punkt von Cartwrights Position deutlich sichtbar werden, den sie mit der von Hacking teilt: Bei Cartwright findet sich - trotz ihrer Andeutungen über das Schließen auf die wahrscheinlichste Ursache - keine Konzeption epistemischer Rechtfertigung, die (u.a.) eine allgemeine Erläuterung einschließt, wie Existenzaussagen über Entitäten und phänomenologische Gesetze zu begründen sind. Außerdem findet sich auch keinerlei Erläuterung, wie eine instrumentalistische Einstellung in bezug auf bestimmte Entitäten bzw. Repräsentationen zu begründen oder begründet zurückzuweisen ist. Ohne solche Erläuterungen bleiben Status und Begründung von Cartwrights Kriterium und der daraus resultierenden Entkoppelung letztlich unklar.

\section{Kausalität}

Für Cartwrights Position in der Realismusdebatte spielt wegen des systematischen Gewichtes, das sie auf kausale Erklärungen legt, das Stichwort "Kausalität" eine wesentliche Rolle. Wie schon bei Hacking stellt sich damit auch hier die Frage nach einer Erläuterung dieses notorisch strittigen Begriffs.

Cartwright hat (anders als Hacking) eine Vielzahl von Arbeiten zum Thema Kausalität publiziert. ${ }^{168}$ Sie entwickelt dort nach und nach eine Konzeption von Kausalität,

\footnotetext{
${ }^{167}$ Siehe S.321ff.

${ }^{168}$ U.a. [Cart83], Kap.1, [Cart89a, Cart89b, CaJo91, Cart92, Cart93a, ChCa93, Cart95a, Cart95b,
} 
die sich von den meisten der in der philosophischen Literatur gängigen Kausaltheorien ${ }^{169}$ dadurch unterscheidet, daß sie weder auf eine semantische Reduktion des Kausalbegriffs zielt, noch auf eine ontologische Reduktion von Kausalität, daß ihr Ziel also weder eine Definition oder Analyse des Kausalbegriffes durch nicht-kausale Ausdrücke ist, noch eine Identifikation kausaler Eigenschaften, Relationen etc. mit nicht-kausalen Eigenschaften, Relationen etc. ${ }^{170}$ Stattdessen gibt Cartwright (Schemata für) Testverfahren für kausale Zusammenhänge an, d.h., sie beschreibt Bedingungen, unter denen die kausale Verknüpfung von Ereignissen, Sachverhalten o.ä. epistemisch zugänglich ist, und zwar Bedingungen, die (zum Teil) in kausalen Termen formuliert sind: Cartwright analysiert für verschiedene Situationstypen mit bestimmten vorliegenden kausalen Zusammenhängen, unter welchen Bedingungen und mit welchem vorausgesetzten Hintergrundwissen diese kausalen Zusammenhänge epistemisch erschlossen werden können; das Resultat sind unterschiedliche Testverfahren für verschiedene Kontexte und Gegenstandsbereiche. Es gibt also nach Cartwright keine Testverfahren, die ohne "kausalen Input" auskommen, und es gibt nicht ein einheitliches Testverfahren für sämtliche kausalen Zusammenhänge. ${ }^{171}$

Cartwrights nicht-reduktive Konzeption von Kausalität sieht für Anhänger empiristischer Positionen sicherlich suspekt aus und dürfte für sie nur schwer akzeptabel sein. Wenn man nicht auf eine empiristische Position festgelegt ist, erscheint Cartwrights Ansatz, das (den Zeiten und Diskussionszusammenhängen des logischen Positivismus entstammende) Projekt einer begrifflichen Analyse des Kausalbegriffs und ebenso die Suche nach einer ontologischen Reduktion von Kausalität fallenzulassen und sich auf die Frage des epistemischen Zugangs zu Kausalrelationen zu konzentrieren, angesichts der notorischen Probleme aller gängigen Vorschläge für eine Analyse zumindest prima facie attraktiv. Daß der Kausalbegriff keine einfachen hinreichenden und notwendigen Erfüllungsbedingungen hat, sondern eine komplexere Struktur, ${ }^{172}$ und daß Kausalität entsprechend nicht ontologisch reduzierbar ist, aber dennoch epistemisch zugänglich, ist eine weitreichende und kontroverse These, die aber intuitiv einiges für sich hat und weiterentwickelt werden sollte, die jedoch an dieser Stelle nicht diskutiert werden kann. ${ }^{173}$

Im Hinblick auf Cartwrights Position in der Realismusdebatte könnten allgemeine, systematische Erläuterungen zum Thema Kausalität insofern nützlich sein, als sie helfen könnten, kausale Erklärungen von nicht-kausalen zu unterscheiden und kausale Gesetze von nicht-kausalen und damit zu entscheiden, wo genau die Grenzlinie verläuft, die durch Cartwrights Kriterium gezogen werden soll (auch wenn Kausalität dafür in Cartwrights neueren Arbeiten eine geringere Rolle zu spielen scheint). Auch wenn der Kausalbegriff eine komplexe Struktur hat (also keine einfachen, einzeln notwendigen und zusammen hinreichenden Erfüllungsbedingungen), wäre es dazu hilfreich, diese Struktur zu kennen. $\mathrm{Zu}$ diesem Punkt läßt sich Cartwrights Arbeiten zum Thema Kausalität jedoch nichts Erhellendes entnehmen. Bei der Einstufung eines Gesetzes als Kausalgesetz oder einer

Cart97]

${ }^{169}$ Für eine Übersicht vgl. z.B. [Heid92].

${ }^{170}$ Siehe z.B. [Cart83], S.26.

${ }^{171}$ Vgl. z.B. [Cart83], S.98, [Cart95b], S.65.

${ }^{172}$ Möglicherweise von der Art eines Familienähnlichkeitsbegriffs oder eines prototype concept; vgl. [LaJo80], Kap.14, [Lako87], S.54ff.

${ }^{173}$ Insbesondere können Cartwrights komplexe und voraussetzungsreiche Testverfahren an dieser Stelle nicht erörtert werden. Zu diesem Thema hat sich in den letzten Jahren eine reichhaltige technische Literatur entwickelt; neben Cartwrights Arbeiten s. dazu u.a. [SpGS93] und daran anschließende Arbeiten.

Beiseite bleiben muß an dieser Stelle auch Cartwrights komplizierter Vorschlag zu der Frage, welche "Arten" kausaler Entitäten und Eigenschaften es gibt und wie diese zusammenhängen, insbesondere ihre in Abschnitt 7.2 bereits erwähnten Vorstellungen über Wirkungsvermögen und Kausalgesetze. 
Erklärung als Kausalerklärung ist man daher auf das intuitive, vortheoretische Verständnis von Kausalität angewiesen. Darin liegt im allgemeinen kein Problem, da eine solche Einstufung in den meisten Fällen tatsächlich intuitiv einigermaßen klar und unkontrovers sein dürfte. Da einen aber andererseits das vortheoretische Verständnis von Begriffen, die dem alltagsweltlichen Bereich entstammen, im Bereich der Wissenschaften erfahrungsgemäß auch gelegentlich im Stich läßt, würden systematische Erläuterungen zum Thema Kausalität sicherlich zur Klarheit von Cartwrights Position beitragen. Dennoch muß man das Fehlen solcher Erläuterungen (wie schon bei Hacking) vielleicht nicht als irreparablen Mangel ihrer Position, betrachten, sondern eher als zukünftig zu schließende Lücke.

\subsection{Der experimentelle Realismus von Hacking und Cart- wright - Fazit}

Hacking und Cartwright skizzieren mit ihren Beiträgen zur Realismusdebatte gewissermaßen den Grundriß einer geteilten Position und versuchen, diesen an verschiedenen Stellen in im einzelnen etwas unterschiedlicher Weise zu präzisieren und mit Argumenten zu rechtfertigen und plausibel zu machen. Die anvisierte Position, die häufig leicht mißverständlich als Entitätenrealismus, treffender jedoch als experimenteller Realismus bezeichnet wird, unterscheidet sich deutlich sowohl von einem "unfragmentierten" Realismus (wie ihn z.B. Boyd vertritt) als auch von einem "unfragmentierten" Antirealismus (wie dem von van Fraassen).

Zur Charakterisierung dieser Position schlagen Hacking und Cartwright ein (grobes) Kriterium vor, das im Gesamtbestand der in den Naturwissenschaften etablierten Repräsentationen eine Teilmenge auszeichnet, die sich auf Entitäten, Eigenschaften etc. bezieht, zu denen nach Hacking und Cartwright eine realistische Einstellung einzunehmen ist. Genauer schlagen beide leicht verschiedene Kriterien dieser Art vor, die sie außerdem in ihren neueren Arbeiten etwas zu modifizieren scheinen, die aber stets eine Trennlinie markieren sollen, die einerseits wesentliche Teile der in den real-existierenden Wissenschaften akzeptierten Theorien, Gesetze, Modelle etc. nicht einschließt, andererseits aber weit jenseits der Grenze beobachtbar/unbeobachtbar verläuft: Die ausgezeichnete Teilmenge enthält nach Hackings (ursprünglichem) Kriterium diejenigen Repräsentationen, die routinemäßig beim Benutzen oder Manipulieren von Instrumenten, Gegenständen u.ä. eingesetzt werden und die dabei ablaufenden Vorgänge und Prozesse als das Benutzen oder Manipulieren von kausal wirksamen und beeinflußbaren Entitäten beschreiben; nach Cartwrights (ursprünglichem) Kriterium enthält diese Teilmenge die Explanantia kausaler

Erklärungen und die zugehörigen phänomenologischen Gesetze; seit neuerem scheinen beide die Trennlinie etwas in Richtung "theoretischerer" Repräsentationen zu verschieben. Zu Repräsentationen, die nicht in der ausgezeichneten Teilmenge liegen, ist nach Hacking und Cartwright i.a. eine antirealistische oder instrumentalistische Einstellung angebracht, dies aber nicht aus prinzipiellen Gründen, sondern aufgrund des kontingenten Standes der Wissenschaft und der Rechtfertigungsmöglichkeiten; in diesem Sinn sind die vorgeschlagenen Kriterien hinreichende, nicht notwendige.

Hacking und Cartwright geben keine klare Antwort auf die Frage, worin eine realistische Einstellung zu den Repräsentationen besteht, die ihre Kriterien auszeichnen, welche positiven Thesen also ihren experimentellen Realismus ausmachen. Eine naheliegende Explikation ihrer Position ist es jedoch, die ausgezeichneten Existenzaussagen über Entitäten, phänomenologische Gesetze etc. (durch geeignete Unabhängigkeitsaussagen) zu 
ontologischen realistischen Thesen zu ergänzen und diese als den Kern des experimentellen Realismus zu betrachten.

Bei Hacking und Cartwright finden sich keine einigermaßen überzeugungskräftigen Argumente für ihren experimentellen Realismus oder gegen "ambitioniertere" realistische Positionen, die weiterreichende realistische Thesen vertreten.

Hacking und insbesondere Cartwright nennen zwar mehrere Einwände gegen eine realistische Einstellung zu fundamentalen Gesetzen und Theorien, die teilweise zu Recht auf Probleme bei deren epistemischer Rechtfertigung hinweisen. Die aufgewiesenen Probleme sind jedoch keine prinzipiellen, sondern formulieren eher eine Herausforderung für Realisten, die realistische Thesen begründen wollen, die über das hinausgehen, was Hackings und Cartwrights (erklärtermaßen hinreichende, nicht notwendige) Kriterien vorsehen.

Hacking und Cartwright verteidigen ihre Position in zumindest prima facie plausibler Weise gegen den Einwand, daß der Theorienwandel im Laufe der Wissenschaftsgeschichte auch die durch ihre Kriterien ausgezeichneten Repräsentationen erfaßt. Sie motivieren ihre Position und verleihen ihr vielleicht eine gewisse Plausibilität, indem sie auf Parallelen zwischen dem Bereich der Alltagswelt und dem der Wissenschaften hinweisen. Einigermaßen überzeugungskräftige Argumente für ihre Position, mit denen sich antirealistische Diskussionsgegner für diese Position gewinnen ließen, geben Hacking und Cartwright jedoch nicht an. Sowohl Hackings "experimentelles Argument" als auch Cartwrights Hinweise auf "Schließen auf die wahrscheinlichste Ursache" leisten dies nicht. Darüber hinaus findet sich weder bei Hacking noch bei Cartwright eine Konzeption epistemischer Rechtfertigung und/oder eine Erläuterung, wie eine instrumentalistische Einstellung zu begründen oder begründet zurückzuweisen ist, so daß auch nicht deutlich wird, wie ihrer Ansicht nach Argumente für ihre Position im Prinzip auszusehen hätten, und Status und Begründung ihrer Kriterien letztlich unklar bleiben.

Daß der experimentelle Realismus von Hacking und Cartwright dennoch für viele enormen intuitiven Appeal hat, dürfte zumindest teilweise daran liegen, daß sie einige konkrete Beispiele aus der Praxis der Physik nennen, in denen eine realistische Einstellung zu unbeobachtbaren Entitäten und Phänomenen intuitiv sehr plausibel und angemessen aussieht, etwa die oben zitierten der Beobachtungen mit mehreren Mikroskopen verschiedener Bauart und des Radiometers. ${ }^{174}$ Daß Hacking und Cartwright solche Beispiele aus der Praxis der Physik ins Zentrum der Realismusdebatte rücken und ihre Position daran orientieren und an ihren Intuitionen in bezug auf Beispiele dieser Art festhalten, obwohl ihre Position die genannten Probleme und Unklarheiten aufweist, dürfte das sein, was ihren experimentellen Realismus zu einem attraktiven Anknüpfungspunkt macht, wenn man vortheoretische Intuitionen hat, die nicht mit "unfragmentierten" Versionen von Realismus und Antirealismus verträglich sind, und daraus eine "moderate" realistische Position in der Wissenschaftstheorie entwickeln möchte. Für eine solche Position liefern Hacking und Cartwright immerhin einen Grundriß und vielleicht einige Bausteine, wenn auch nicht mehr.

\footnotetext{
${ }^{174}$ Siehe S.327f. bzw. 340f.
} 


\section{Kapitel 12}

\section{Andrew Pickerings Sozialkonstruktivismus}

\subsection{Einleitung}

Ein Teil der traditionellerweise in der Wissenschaftstheorie angesiedelten Fragen wird seit gut zwei Jahrzehnten zunehmend auch in Untersuchungen anderer Disziplinen wie der Wissenschaftsgeschichte, der Soziologie, der Anthropologie und insbesondere der Science Studies thematisiert oder wenigstens berührt, darunter auch einige der in der Realismusdebatte verhandelten Fragen. Mit unterschiedlichen methodischen Ansätzen werden dort detaillierte Studien von in der Regel kürzeren Zeitabschnitten oder Episoden aus der Praxis historischer oder aktueller Wissenschaft erarbeitet. Diese Studien zielen zwar in erster Linie meistens nicht auf im engeren Sinne wissenschaftstheoretische Fragestellungen, sondern auf ein Verständnis verschiedener anderer Aspekte wissenschaftlicher Forschung (insbesondere soziale, kulturelle, lokale historische u.ä. Hintergründe, Kontexte, Einflüsse, Implikationen etc.), die Ergebnisse der Untersuchungen werden jedoch mindestens am Rande solcher Studien häufig für wissenschaftsphilosophisch relevante Folgerungen ausgewertet. Insbesondere werden in einer Vielzahl solcher Arbeiten Thesen vertreten, die (zumindest dem Anspruch nach oder prima facie) für die im Zentrum der Realismusdebatte stehenden Fragen relevant sind, wahrscheinlich in der Überzahl der Fälle (aber keineswegs in allen Fällen) mit antirealistischer Stoßrichtung. Wie solche Studien aus dem Umkreis der Science Studies im Hinblick auf Konsequenzen für die Realismusdebatte zu bewerten sind, soll in diesem Abschnitt anhand der Arbeiten von Andrew Pickering, einem der herausragenden Autoren auf diesem Gebiet, untersucht werden.

Die Physik als eine der nach landläufiger Ansicht exaktesten, "härtesten" Naturwissenschaften, insbesondere die moderne Physik dieses Jahrhunderts, ist Gegenstand einer ganzen Reihe von Studien dieser Art. Von diesen sollen hier die Arbeiten von Pickering diskutiert werden, die auf dem einigermaßen heterogenen Feld der Science Studies eine wichtige Position markieren, die, trotz dieser Heterogenität, im Hinblick auf ihre philosophischen Motive für weite Teile der Science Studies typisch ist, wenn auch klarerweise nicht für das gesamte Feld. ${ }^{1}$

\footnotetext{
${ }^{1}$ Einige andere wichtige Studien, die sich mit der modernen Physik beschäftigen, sind — ohne Anspruch auf Vollständigkeit oder Repräsentativität: aus anthropologischer Perspektive [Traw88], aus soziologischer Perspektive [Coll85, Harv80, Harv81, Knor95, Lato88, Pinc86], aus eher traditioneller philosophischer Perspektive [Fran86, Fran90], aus einer philosophisch informierten historischen Perspektive [Gali87, Gali95a, Gali95b, Gali97]; wichtige Sammelbände sind [Buch95, GoPS89, Pick92].
} 
Pickering hat in zwei im Abstand von gut einem Jahrzehnt veröffentlichten Büchern zwei verschiedene, sich aber im wesentlichen ergänzende Ansätze für wissenschaftshistorische Untersuchungen vorgestellt, die hier kurz skizziert werden sollen.

\subsection{Constructing Quarks}

Pickering nimmt in seinem Buch "Constructing Quarks"2 gewissermaßen das Herz der "harten" Naturwissenschaft Physik in den Blick, ihren in der zweiten Hälfte des 20. Jahrhunderts grundlegendsten und wahrscheinlich prestigeträchtigsten Teil ${ }^{3}$, die Hochenergiebzw. Teilchenphysik.

Pickering studiert die Entwicklung der Hochenergiephysik im Zeitraum von 1964 bis 1980, die Epoche also, in die die sogenannte "Novemberrevolution" fällt: Der experimentelle Nachweis zweier neuer Teilchen (genannt $J / \Psi$ und $\Psi^{\prime}$ ) im November 1974 und die damit verbundenen theoretischen Arbeiten führten im Zeitraum bis ungefähr Ende 1976 zu großen Veränderungen in der Landschaft der theoretischen und experimentellen Hochenergiephysik. Seit der Identifikation der beiden neuen Teilchen als Mesonen ${ }^{4}$, die aus (bis dahin nicht nachgewiesenen) Charm-Quarks aufgebaut sind, wird in der Gemeinschaft der Physiker zum einen auf breiter Front akzeptiert, daß es Quarks gibt, zum anderen gelten seitdem das Standardmodell der elektroschwachen Wechselwirkung von Salam und Weinberg und die Quantenchromodynamik als etablierte Theorien. Entsprechend verschoben sich infolge der Novemberrevolution auf Seiten der experimentellen Hochenergiephysik die Schwerpunkte der Forschung im Hinblick auf die untersuchten Prozesse und die Technik der Beschleuniger entscheidend. Pickering unterstreicht die Bedeutung der Novemberrevolution durch die Periodisierung seines Untersuchungszeitraumes in eine Phase der "alten Physik" 1964-74, die Novemberrevolution selbst, und eine Phase der "neuen Physik" 1976-80.

Pickerings Buch läßt sich in zwei einigermaßen problemlos voneinander trennbare Komponenten zerlegen: in seine Erzählung der geschichtlichen Entwicklung, die den zentralen Hauptteil des Buches einnimmt, und in einen in Anfangs- und Abschlußkapitel angesiedelten Teil, in dem diese Entwicklung theoretisch analysiert wird. ${ }^{5}$

Für die theoretische Analyse setzt Pickering ein soziologisch orientiertes Modell für die Entwicklungsdynamik der theoretischen und experimentellen Praxis der Physik und des Bestandes der akzeptierten Theorien, Modelle etc. ein, das er durch die Bezeichnung Opportunismus im Kontext (opportunism in context) ${ }^{6}$ charakterisiert. Dieses Modell ist nicht speziell für die hier untersuchte Disziplin oder gar Episode zugeschnitten, sondern sollte auf weite Bereiche der Naturwissenschaften anwendbar sein.

Pickerings Szenario ist das von Wissenschaftlern, die sich im Umfeld verschiedener wis-

Ein herausragender Vertreter der Science Studies, dessen Position im Hinblick auf ihre philosophischen Motive der von Pickering entgegengesetzt ist, ist Peter Galison. Seine genannten Arbeiten haben eine vorsichtig realistische Stoßrichtung, können jedoch hier aus Platzgründen leider nicht diskutiert werden.

${ }^{2}$ [Pick84].

${ }^{3}$ Das gilt zumindest für die zeitgenössische Wahrnehmung bis etwa zum Ende des kalten Krieges und des Superconducting-Super-Collider-Projektes 1993.

${ }^{4}$ D.h. als aus zwei Quarks zusammengesetzte Teilchen.

${ }^{5}$ Es finden sich allerdings auch im Hauptteil, hauptsächlich in der zweiten Hälfte, einige Stellen, an denen Pickering sein soziologisches Modell ins Spiel bringt und an denen die Darstellung insbesondere des Verhältnisses von Theorien und Experimenten etwas durch seine "Modelloptik" verzerrt erscheint — vgl. [GiSc86], S.377ff.

${ }^{6}$ Pick84], S.10ff. 
senschaftlicher "Traditionen" theoretischer und experimenteller Art bzw. entsprechender, zum jeweiligen Zeitpunkt aktiver Wissenschaftlergemeinschaften bewegen und in einer Umgebung dieser Art Entscheidungen bezüglich ihrer Arbeit treffen müssen. Mit einer Tradition ist so etwas wie ein Forschungsfeld gemeint, in dem ein bestimmter Themenbereich mit bestimmten Methoden bearbeitet wird (z.B. Laserspektroskopie von Festkörpern, numerische Analyse von Gittereichtheorien o.ä.). Solche Traditionen theoretischer und experimenteller Art stellen nach Pickering durch ihren jeweiligen aktuellen Forschungsstand (d.h. die jeweils neuesten Theorien und Modelle, die neuesten experimentellen Resultate usw.) wechselseitig füreinander neue Problemstellungen bereit und liefern sich so gegenseitig Themen und Rechtfertigung für zukünftige Untersuchungen. In der zentralen Episode von Pickerings Studie etwa stellen so die von den Experimentatoren an zwei großen Beschleunigern gemessenen Daten verschiedenen Theoretikern neue Aufgaben und werden schließlich als überzeugende Evidenzen für "charmhaltige" Mesonen gedeutet, was über die damit akzeptierten Theorien Anlaß zu neuen Experimenten gibt.

Gemäß Pickerings Modell lenkt eine bestimmte Entscheidungsstrategie von Wissenschaftlern, die in einer Umgebung der skizzierten Art agieren, die Entwicklung der Praxis und des Bestandes der akzeptierten wissenschaftlichen Theorien, Modelle etc.: Jeder Wissenschaftler verfügt qua Ausbildung und instrumenteller Ausstattung über eine bestimmte Menge an Ressourcen, die er für seine Arbeit einsetzen kann (im Beispiel von Pickerings Studie: Zugang zu Beschleunigeranlagen einer bestimmten Bauweise und Ausstattung, Kenntnisse der Quantenelektrodynamik und der zugehörigen mathematischen Methoden und Techniken, die zur Entwicklung analoger Modelle und Theorien verwendbar sind). Er wird daher Entscheidungen bezüglich seiner wissenschaftlichen Arbeit so treffen, daß er seine Ressourcen in möglichst vorteilhafter und fruchtbarer Weise einsetzen kann. Ein Theoretiker wird nach Pickering vor allem mit solchen experimentellen Resultaten arbeiten, die ihm die Weiterentwicklung von Modellen und Theorien mittels der von ihm beherrschten Techniken ermöglichen, ohne diese experimentellen Resultate groß in Frage zu stellen, und er wird andere Resultate nach Möglichkeit ignorieren. Ein Experimentator wird nach Pickering vor allem solche Theorien zur Kenntnis nehmen, testen u.ä., die ihm zu neuen experimentellen Untersuchungen Anlaß geben, die er mit Hilfe der ihm zur Verfügung stehenden Ressourcen durchführen kann, andere dagegen unbeachtet lassen. ${ }^{7}$ Durch diese Entscheidungsstrategie erklärt sich Pickerings Bezeichnung "Opportunismus im Kontext".

In wissenschaftstheoretischer Hinsicht brisant wird Pickerings Modell durch die Details des Bildes, das er vom Zustandekommen und den Rechtfertigungsgrundlagen derjenigen Entscheidungsprozesse zeichnet, durch die bestimmt wird, welche Theorien und Modelle als Grundlage weiterer Arbeit und später teilweise als Überzeugungen akzeptiert werden. Pickering führt an dieser Stelle einige Gründe dafür an, daß Entscheidungen über das Weiterentwickeln, -untersuchen etc. und das Akzeptieren von Theorien nicht allein auf der Basis experimenteller Resultate fallen: Zum einen nennt er die gängigen Thesen der Unterbestimmtheit von Theorien durch endliche Datensätze ${ }^{8}$ und der Theoriebeladenheit von Beobachtungen und Experimenten, zum anderen verweist er darauf, daß in der realen

\footnotetext{
${ }^{7}$ [Pick84], S.13.

${ }^{8}$ Pickering hat offenbar nicht die sonst üblicherweise unter dem Titel Unterbestimmtheit verhandelte These im Auge, daß alle möglichen Beobachtungen nicht hinreichen, um unter verschiedenen empirisch äquivalenten Theorien eine auszusondern, sondern die schwächere These, daß für jeden beliebigen Zeitpunkt gilt, daß die jeweils aktuell vorliegenden, endlich vielen Beobachtungen keinen deduktiven Schluß auf eine Theorie zulassen, also in diesem Sinn keine eindeutige Auszeichnung einer Theorie liefern.
} 
Wissenschaftspraxis allenfalls für einen Teil der experimentellen Resultate wirklich eine Ableitung aus einer Theorie (im Unterschied zu einer qualitativen oder halbquantitativen Erklärungsskizze) angegeben werden kann, und diese darüber hinaus auch nur selten wirklich die exakten oder fast exakten Werte liefert. Aus diesen Gründen sind die Entscheidungen einer Wissenschaftlergemeinschaft darüber, welche Theorien, Modelle etc. zu einem Zeitpunkt weiteruntersucht, -entwickelt und evtl. akzeptiert werden, nach Pickering nicht allein durch "harte" experimentelle Fakten bestimmt; vielmehr gibt es dabei Spielraum für andersartige Kriterien, Erwägungen und Einflüsse. Pickerings Beschreibung für diese Sachlage ist, daß diese Entscheidungen, wie er sich ausdrückt, "Urteile" ( "judgements") darstellen, oder, in einer anderen, etwas idiosynkratischen Formulierung, daß zu diesen Entscheidungen keine unumstößlichen oder zwingenden Verpflichtungen (obligations) bestehen. ${ }^{9}$

An den Stellen, an denen "Urteile" gefällt werden, kommt Pickerings Modell des Opportunismus im Kontext zum Tragen: Sein Ansatz ist es, Entscheidungen von Wissenschaftlern, die nicht (in seinem Sinn) zwingend durch "harte" Fakten determiniert sind, grundsätzlich mit Hilfe ausschließlich soziologischer Sachverhalte und Kategorien zu beschreiben und zu erklären: Das Akzeptieren einer Theorie als Grundlage der weiteren Arbeit oder als Überzeugung trotz Unterbestimmtheit und ohne daß die relevanten experimentellen Resultate exakt ableitbar sind und auch die darauf aufbauende Entscheidung eines Experimentalphysikers, welche Experimente zu realisieren sind, sowie Entscheidungen, welche von verschiedenen durchgeführten experimentellen Messungen für die Wahl zwischen mehreren Theorien oder Modellen relevant sind trotz Theoriebeladenheit usw. sind nach Pickering zu erklären durch Erwägungen der Wissenschaftler, welche Entscheidungsoption ihnen als Individuum eine möglichst vorteilhafte und auch für die Wissenschaftlergemeinschaft möglichst fruchtbare Anwendung ihrer Ressourcen gestattet. ${ }^{10}$ Auf dieser Linie kommentiert Pickering in einigen kurzen, in seine historische Erzählung eingestreuten Bemerkungen die Ereignisse um die Novemberrevolution.

Die im Titel des Buches angekündigte konstruktivistische Wendung nimmt Pickerings Darstellung schließlich dadurch, daß er aus den Beschreibungen und Erklärungen, die sein soziologisches Modell liefert, bestimmte Konsequenzen zieht, die jedoch in keiner erkennbaren Weise durch die Beschreibungen und Erklärungen oder durch das Modell

\footnotetext{
${ }^{9}$ Vgl. [Pick84], S.6f., 404f. Im letzten Kapitel formuliert Pickering diesen Befund in zum Teil deutlich bis grotesk überspitzter Weise, z.B. "the decisions ... are free and unconstrained" (S.405/406).

${ }^{10}$ Vgl. [Pick84], S.13ff., 404ff.; der Tenor von Pickerings Darstellung dieses Sachverhaltes ist dabei nicht, wie man vielleicht ob der Kennzeichnung "Opportunismus" denken könnte, daß Wissenschaftler in der Praxis sozusagen in spitzfindiger Weise jedes noch so abseitige, logisch gerade noch erlaubte Hintertürchen nutzen, um ihre Interessen zu verfolgen, sondern geht eher dahin, daß diese bei ihren Entscheidungsprozessen natürlicherweise vorhandenen Spielräume in legitimer Weise nutzen. Pickering wehrt sich dagegen, seine Darstellung dieses Sachverhaltes dahingehend zusammenzufassen, daß Wissenschaftler nach ihren Interessen entscheiden (siehe [Pick95a], S.44); der Sache nach scheint diese Charakterisierung aber dennoch vollkommen korrekt zu sein, auch wenn Pickering selbst in [Pick84] nicht, wie noch in [Pick80], explizit von Interessen spricht.

In neueren Arbeiten (vgl. [Pick90], S.686f., 692ff.) betont Pickering die Bedeutung opportunistischer Erwägungen für Entscheidungen, welche Theorien und Modelle untersucht und weiterentwickelt und welche Experimente durchgeführt werden sollen, und spielt dafür tendenziell ihre Bedeutung für das Akzeptieren von Theorien und Modellen als Überzeugungen herunter. In [Pick84] soll jedoch klarerweise auch das Akzeptieren von Theorien und Modellen als Überzeugungen durch opportunistische Erwägungen erklärt werden; s. z.B. S.403: "The aim of this history of HEP has been to analyse the establishment of the newphysics world-view. I have sought to explain how particle physicists came to believe that the world was built from quarks and leptons and that the interactions of these fundamental entities were described by gauge theory."
} 
selbst begründet werden: Pickering geht ${ }^{11}$ ohne weitere Begründung oder Argumentation von einer "unspektakulären" Beschreibung der Resultate der geschilderten "opportunistischen" Entscheidungen von Wissenschaftlern (die hier bis zu diesem Punkt der Wiedergabe von Pickerings Ausführungen übernommen wurden) zu einer philosophisch brisanten Beschreibung dieser Resultate über: Er nennt als Resultate dieser Entscheidungen neben den künftigen Untersuchungen, Forschungsprojekten, Experimenten etc. und neben Überzeugungen (nämlich den Überzeugungen, daß bestimmte Theorien, Modelle o.ä. wahr, annähernd wahr, nach gegenwärtigem Wissensstand die besten verfügbaren o.ä. sind, bzw. den inhaltlichen Überzeugungen, die in den Theorien, Modellen o.ä. formuliert sind) auch die Gegenstände und Sachverhalte, auf die sich die inhaltlichen Überzeugungen bzw. die Untersuchungen etc. beziehen. In bezug auf den im Mittelpunkt des Buches stehenden Fall spricht er nicht mehr davon, daß eine Entscheidung zum Ergebnis hat, daß die Wissenschaftlergemeinschaft eine bestimmte Theorie über Quarks (oder, vorsichtiger, eine Existenzannahme bezüglich der Quarks) als Grundlage der weiteren Arbeit oder/und als Überzeugung akzeptiert, sondern vielmehr davon, daß diese Entscheidung die Quarks selbst und die sie betreffenden Sachverhalte hervorbringt oder "konstruiert":

"[...] the choices which were made produced the world of the new physics, its phenomena and its theoretical entities. As we saw [...] in the discussion of the neutral current discovery, the existence or nonexistence of pertinent neutral phenomena was a product of irreducible scientific judgements". ${ }^{12}$

Die gängige Charakterisierung von Pickerings Position als Sozialkonstruktivismus findet ihre Begründung darin, daß sein Modell eines ist, das für Wissenschaftlergemeinschaften zugeschnitten ist und nur dort funktioniert, da es verschiedene Traditionen sind, die sich wechselseitig Forschungsaufgaben und Rechtfertigungsgründe für den weiteren Einsatz ihrer Ressourcen liefern, also die "Kontexte" bereitstellen, in denen man sich "opportunistisch" verhalten kann. ${ }^{13}$

Das Fazit seiner Studie und die Bedeutung ihrer Ergebnisse für ein angemessenes Bild des Unternehmens Naturwissenschaft und seiner kognitiven Produkte bilanziert Pickering in dem, wie Arthur Fine sich ausdrückt, mit "romantic antiestablishment rhetoric" 14 vorgetragenen Finale des Buches:

"The quark-gauge theory picture of elementary particles should be seen as a culturally specific product. The theoretical entities of the new physics, and the natural phenomena which pointed to their existence, were the joint products of a historical process [...]. Many people do expect more of science than the production of a world congenial to social understanding and future practice. Consider the following quotation:

Twentieth-century science has a grand and impressive story to tell. Anyone framing a view of the world has to take account of what it has to say ... It is a non-trivial fact about the world that we can

\footnotetext{
${ }^{11}$ Hauptsächlich im Schlußkapitel des Buches.

${ }^{12}$ [Pick84], S.404; s.a. S.406: "[...] the facts themselves are the products of judgements structured within a theoretical context", S.409: "With the 1970s explosion of work on electroweak gauge theory, a new set of interpretative practices were adopted by neutrino experimenters. These practices brought the neutral current into being".

${ }^{13}$ Vgl. [Pick84], S.406.

${ }^{14}[$ Fine96], S.237.
} 
understand it and that mathematics provides the perfect language for physical science: that, in a word, science is possible at all. ${ }^{15}$

Such assertions about science are commonplace in our culture. In many circles they are taken to be incontestable. But the history of HEP [high-energy physics] suggests that they are mistaken. It is unproblematic that scientists produce accounts of the world that they find comprehensible: given their cultural resources, only singular incompetence could have prevented members of the HEP community producing an understandable version of reality at any point in their history. And, given their extensive training in sophisticated mathematical techniques, the preponderance of mathematics in particle physicist's accounts of reality is no more hard to explain than the fondness of ethnic groups for their native language. On the view advocated in this chapter, there is no obligation upon anyone framing a view of the world to take account of what twentieth-century science has to say. The particle physicists of the late 1970s were themselves quite happy to abandon most of the phenomenal world and much of the explanatory framework which they had constructed in the previous decade. There is no reason for outsiders to show the present HEP world-view any more respect. In certain contexts, such as the foundational studies in the philosophy of science, it may be profitable to pay close attention to contemporary scientific beliefs. In other contexts, to listen too closely to scientists may be simply to stifle the imagination. World-views are cultural products; there is no need to be intimidated by them." 16

\subsection{The Mangle of Practice}

In seinem zweiten Buch, "The Mangle of Practice"17, stellt Pickering ein verbessertes Modell für die Entwicklungsdynamik der theoretischen und experimentellen Praxis der Physik und des Bestandes der akzeptierten Theorien, Modelle etc. vor, ${ }^{18}$ nachdem er nach eigener Aussage erkannt hat, daß die eigentlichen Gegenstände der Physik ${ }^{19}$ für diese Dynamik gemäß seinem früheren, durch das Stichwort "Opportunismus im Kontext" charakterisierten Modell praktisch keine Rolle spielen. Sein neues Modell nennt er die Mangel der Praxis (mangle of practice), darin soll die Rolle der Gegenstände der Physik, also der materiellen Welt, aufgewertet werden, ohne daß dies aber zu einer realistischen Position in bezug auf physikalische Gegenstände, Sachverhalte etc. führen soll. ${ }^{20}$

Wie Pickerings neues Modell zu verstehen ist, sieht man am ehesten an den Fallbeispielen, die er im Lichte des Modells analysiert: Er wählt als typische Beispiele experimentalphysikalischer Praxis die Konstruktion der ersten Blasenkammern und die Experimente,

\footnotetext{
${ }^{15}$ Das Zitat ist von John Polkinghorne; Quest for a Natural God, Times Higher Educational Supplement, 10. Juni 1983, S.24.

${ }^{16}$ [Pick84], S.413/414.

17 Pick95b].

${ }^{18}$ Der Anwendungsbereich des Modells ist nach Pickering wiederum wesentlich größer. Im Anhang des Buches (S.246ff.) spielt er mit dem Gedanken, es als "Theory of Everything" aufzufassen — dieser Abschnitt mag allerdings satirisch gemeint sein.

${ }^{19}$ Die Formulierung, daß es die "Gegenstände der Physik" sind, die in Pickerings erstem Modell zu wenig Berücksichtigung finden, ist eine Rekonstruktion oder Interpretation von Pickerings eigenen Formulierungen; er selbst spricht an dieser Stelle ([Pick95b], S.IXf., 10f.) von "links" "between representations and the world" oder "material agency" (zu diesem Terminus siehe S.362, Fn.26).

${ }^{20}$ [Pick95b], S.Xff., 21ff., 39ff.
} 
in denen nach freien Quarks gesucht wurde, ${ }^{21}$ und zeichnet in diesen Fällen nach, wie ein Experiment durch meist langwierige Stadien der Planung, der Vorstudien, der ersten Teilexperimente, der Konstruktion von Komponenten, der Testläufe, der Modifikation von Plänen, Geräten und theoretischen Beschreibungen und Modellen, neuer Testläufe, der Datenauswertung, der erneuten Modifikation usw. geht. Pickering gibt eine eigentümliche Beschreibung solcher Folgen: Er schildert sie als Ergebnis des Zusammenwirkens verschiedener Instanzen, nämlich der Experimentatoren und ihrer Pläne, der (materiellen) Untersuchungsgegenstände und Geräte, der Theorien und Modelle und des sozialen Kontexts. Genauer beschreibt er diese Folgen als Sequenzen von Schritten, in denen Widerstände (resistances) auftreten, Anpassungen (accomodations) vorgenommen werden, die wiederum neue Widerstände nach sich ziehen, usw., bis eine interaktive Stabilisierung (interactive stabilization) zwischen den verschiedenen Instanzen erreicht ist. Beim Beispiel der Blasenkammer wurden zunächst Entwürfe und erste Realisierungen mit Flüssigkeiten ausprobiert, die keine Teilchenspuren lieferten (Widerstände), daraufhin abgeänderte Geräte entworfen sowie später eine neue Theorie der Blasenbildung geliefert (Anpassungen) usw., bis schließlich eine funktionierende Version vorlag. ${ }^{22}$ Das hier anhand konkreter Beispiele dargestellte, aber nach Pickering überall in den Naturwissenschaften aufweisbare Muster der wechselseitigen Anpassungen von Geräten, Untersuchungsgegenständen, Theorien und Modellen, Plänen usw., in deren Verlauf alle oder die meisten dieser Komponenten modifiziert werden, nennt Pickering die Mangel der Praxis. ${ }^{23}$

Das Bild, das Pickering mit Hilfe seines Modells der Mangel von der Entwicklungsdynamik der Physik zeichnet, schließt bestimmte Erklärungen, die man naheliegenderweise als Teil oder als Ergänzung dieses Bildes erwarten würde, ausdrücklich aus: Erklärungen des Prozesses der Gewinnung und Etablierung von Theorien und Modellen, des Zustandekommens von experimentellen Resultaten, des Scheiterns von Experimenten usw., die sich auf von diesen Theorien, Modellen und Experimenten behandelte bzw. untersuchte Gegenstände und Sachverhalte als Explanantia beziehen, weist Pickering zurück. ${ }^{24}$ So stellt etwa im Beispiel der Blasenkammerentwicklung die Erklärung für das NichtFunktionieren der ersten, mit Xenon gefüllten Modelle, die von den beteiligten Wissenschaftlern nachträglich aufgrund der neuen Theorie der Blasenbildung gegeben wurde, für Pickering keine bzw. keine relevante Erklärung des anfänglichen Fehlschlages dar. ${ }^{25}$

Die Rolle, die der "materiellen Welt" in Pickerings neuem Bild der Entwicklungsdynamik der Physik zukommt, ist daher eine sehr eigentümliche: Pickering spricht ihr kausale

\footnotetext{
${ }^{21}$ Daneben enthält [Pick95b] einen Abschnitt über eine Episode aus der Mathematikgeschichte und einen über einen Fall der industriellen Anwendung von Werkzeugmaschinen.

${ }^{22}$ Vgl. [Pick95b], S.38ff.

${ }^{23}$ Wie dieses Bild im einzelnen zu verstehen ist, sprich: ob bestimmte Elemente des skizzierten Bildes der Entwicklungsdynamik der Physik in Analogie zu bestimmten Bauelementen einer Mangel oder den gemangelten Wäschestücken gesetzt werden sollen, wird — mir jedenfalls — nicht deutlich. Pickerings eigene Beschreibungen seines Modells fallen z.T. sehr metaphorisch und wenig präzise aus; die Passage, in der Pickering seinen Terminus 'Mangel' einführt, lautet: "The practical, goal-oriented and goal-revising dialectic of resistance and accomodation is, as far as I can make out, a general feature of scientific practice. And it is [...] what I call the mangle of practice" ([Pick95b], S.22/23).

${ }^{24}$ Pickering diskutiert diesen Punkt unter dem Stichwort "real-time understanding of practice"; vgl. [Pick95b], S.3, 14f. In [Pick84] taucht ein ähnliches Motiv bereits unter dem Stichwort "retrospective legitimation" von Urteilen bzw. "retrospective realism" auf (vgl. S.7f.); dort ist dies aber sozusagen bloß ein Korollar des Ansatzes, alles außer opportunistischen Gründen für die Entscheidungen der Wissenschaftler auszublenden, während es in [Pick95b], wo die (mit kausaler Wirksamkeit ausgestattete — s.u.) "materielle Welt" erklärtermaßen ins Blickfeld gerückt werden soll, zu einer zentralen "unabhängigen" Modellannahme wird.

${ }^{25}$ [Pick95b], S.53.
} 
Wirksamkeit $^{26}$ beim Zustandekommen von experimentellen Resultaten zu, insbesondere auch, wenn diese Widerstände darstellen, lehnt aber gleichzeitig kausale naturwissenschaftliche Erklärungen des Zustandekommens solcher Resultate, die erst ex post als Produkt der "mangelförmigen" Entwicklungsdynamik zustandekommen, ab. ${ }^{27}$ So läßt sich nach Pickering von Widerständen wie dem Nicht-Funktionieren der Xenon-Blasenkammer nur sagen, daß sie im durch das Modell der Mangel beschriebenen Prozeß "einfach passieren". Die kausale Wirksamkeit der materiellen Welt findet sozusagen in der Form von brute facts, von Ereignissen ohne kausale Vorgeschichte statt; kausale naturwissenschaftliche Erklärungen für das Zustandekommen experimenteller Resultate weist Pickering zurück, seien es Erklärungen für "erfolgreiche" Messungen, Nachweisexperimente o.ä. (wie im Fall des $J / \Psi$ und des $\Psi^{\prime}$ ) oder seien es Erklärungen für "Widerstandsereignisse" (wie im Fall der Xenon-Blasenkammer), und insbesondere weist er eine realistische Einstellung zu den Explanantia solcher Erklärungen (und damit zu Teilchen wie dem $J / \Psi$ und dem $\Psi^{\prime}$, den Gesetzen der Blasenbildung etc.) zurück. Das Bild, das Pickering so von der zeitlichen Entwicklung der Physik erhält, charakterisiert er durch den Terminus 'temporal emergence'; er soll zum Ausdruck bringen, daß Pickering naturwissenschaftliche Erklärungen für diese Entwicklung mit Hilfe von (bestimmte Zeitspannen hindurch existierenden) Systemen (Atomen, Strömen, Feldern etc.) und deren zeitlicher Entwicklung zurückweist und sich mit der Anerkennung einer kausalen Wirksamkeit der materiellen Welt nicht zur Anerkennung solcher (über bestimmte Zeitintervalle existierender) kausal wirksamer Entitäten, Systeme o.ä. verpflichten will, auf die die für sein Modell wesentliche kausale Wirksamkeit der materiellen Welt (aus wissenschaftlicher oder jedenfalls aus realistischer Perspektive) zurückgeführt werden kann.

"[...] the particular pattern of resistances that Glaser encountered [... ] appeared as if by chance - they just happened. It just happened that, when Glaser configured his instrument this way (or this, or this), it did not produce tracks, but when he configured it that way, it did. This is the strong sense of temporal emergence implicit in the mangle." ${ }^{28}$

Pickering beschreibt das Verhältnis seines verbesserten Modells wissenschaftlicher Entwicklungsdynamik, die Mangel der Praxis, zu seinem älteren, durch das Stichwort "Opportunismus im Kontext" charakterisierten Modell folgendermaßen:

"[The new] model of practice [...] is one that refines and elaborates that of CQ [Constructing Quarks] [...].

In CQ, I tried to get to grips with a broad sweep of history, and my analysis was correspondingly coarse-grained. To get clearer on the nature of practice $[\ldots]$ one needs to examine practice in greater detail. [...] the opportunismin-context model of dynamics is not an exhaustive model of practice. It is

\footnotetext{
${ }^{26}$ Pickerings (zumindest aus philosophischer Perspektive) etwas idiosynkratischer Terminus dafür ist 'material agency'; vgl. [Pick95b], S.5ff.

27 "[...] Glaser's detectors did things — boiling explosively or along the lines of tracks or whatever [...]. $[\ldots]$ some $[\ldots]$ source of activity and agency was at work, and [...] that source was the material world (as configured this way or that in Glaser's prior activity). [...] particular material setups performed as they would, and he [Glaser] had to take it or leave it [...]. [...] Glaser did produce accounts of the functioning of the bubble chamber — knowledge — as he went along. He explained [...] the initial failure of the xenon chamber in terms of a revised understanding of the mechanism of bubble formation. But [...] such accounts [...] should themselves be seen as part and parcel of the mangling process, as products of the dialectic of resistance and accomodation [...]" ([Pick95b], S.51-53).

${ }^{28}$ [Pick95b], S.52/53.
} 
rather a model of one phase of practice, namely of goal-formation. The model illuminates why particular scientists embarked upon particular goal-oriented courses of research in particular circumstances. It does not illuminate what goal-oriented practice looks like. The gap between goals and their achievement is elided in CQ." 29

"[...] goal-oriented practice needs to be understood in terms of situated accomodations to resistances as they arise [...]. Here [...] we have an understanding of scientific practice that can [...] underpin the model of the dynamics of science put forward in CQ - it reduces to the latter if one seems to explain successful practice at a low level of temporal resolution". ${ }^{30}$

Das Modell der Mangel der Praxis kann also nach Pickering den Einfluß der materiellen Welt auf die Entwicklungsdynamik der Physik berücksichtigen, weil es Teile dieser Dynamik gewissermaßen mit größerer Auflösung in den Blick nimmt als das ältere, durch das Stichwort "Opportunismus im Kontext" charakterisierte Modell. Dadurch werden bei den Erklärungen, die das neue Modell für die Entschlüsse von Wissenschaftlern, bestimmte Theorien, Modelle etc. als Grundlage der weiteren Arbeit oder sogar als Überzeugungen zu akzeptieren, opportunistische Erwägungen der Wissenschaftler nicht mehr in dem Maße wie zuvor ins Zentrum des Blickfeldes gerückt, sondern als ein erklärender Faktor unter anderen behandelt, während als ein weiterer Faktor der Einfluß der materiellen Welt berücksichtigt wird. Gleichzeitig korrigiert Pickering mit dem Schritt zu einer größeren Auflösung die im Modell des Opportunismus im Kontext implizit vorausgesetzte Annahme, daß Wissenschaftler bei der Entscheidungsfindung (bezüglich des Akzeptierens von Theorien, des Ausführens von Experimenten etc.) die längerfristigen Auswirkungen der verschiedenen Optionen in bezug auf ihre opportunistischen Interessen überblicken könnten. Die in dem älteren Modell nicht berücksichtigten "Widerstände", die nach Pickering im durch die Mangel beschriebenen Prozeß in unvorhergesehener Weise auftreten können, führen dazu, daß die nach opportunistischen Kriterien gefällten Entscheidungen weniger Gewicht bei Erklärungen bekommen, weil die Folgen der Entscheidungen, wie Pickering jetzt meint, als zu berechenbar dargestellt wurden: Opportunistische Erwägungen sind in erster Linie für die Erklärung der Ziele wichtig, die sich Wissenschaftler für ihre Forschung setzen; bei der Erklärung dessen, was sie dabei erreichen, sprich: des Akzeptierens von Theorien, Modellen, experimentellen Resultaten etc., fungieren opportunistische Erwägungen gemäß Pickerings neuem Modell nur noch als ein Faktor unter mehreren.

Pickerings älteres Modell für wissenschaftliche Entwicklungsdynamik wird also durch sein neues Modell der Mangel der Praxis verfeinert und verbessert. Für die konstruktivistischen Thesen und Redeweisen, die Pickering in seinem ersten Buch formuliert bzw. verwendet, hat dies nur geringe Auswirkungen: Pickering spricht auch in 'The Mangle of Practice' vom "Produzieren von Tatsachen" etc. ${ }^{31}$ wenn auch weniger offensiv und akzentuiert; "produziert" werden die Tatsachen, Entitäten etc. hier allerdings nicht mehr durch die Wissenschaftler allein, sondern in einem sozusagen mehrdimensionalen Prozeß unter Mitwirkung der materiellen Welt.

Ein von Pickering betonter Aspekt seines Modells der Mangel der Praxis, der aus dem Blickwinkel der Realismusdebatte relevant ist, ist der sich daraus ergebende Ge-

\footnotetext{
${ }^{29}$ [Pick90], S.692/693.

${ }^{30}$ [Pick90], S.699/700; vgl. auch [Pick95b], S.59 Fn.21, 71ff. Fn.

${ }^{31}$ Z.B. [Pick95b], S.68, 86.
} 
danke der Historizität wissenschaftlichen Wissens (historicity of scientific knowledge). ${ }^{32}$ Nach Pickerings Modell wird die Entwicklungsdynamik der Wissenschaften von Faktoren entscheidend mitbestimmt, die viel mit kontingenten Gegebenheiten und Ereignissen zu tun haben, insbesondere mit den "lokalen", kontingenten Bedingungen, unter denen Wissenschaft stattfindet, und wenig mit deren Gegenständen. Dies gilt, ohne daß Pickering es explizit thematisiert hatte, bereits für sein erstes Modell: In Entscheidungen nach dem Schema des Opportunismus im Kontext gehen soziale, technologische, wirtschaftliche u.ä. Sachverhalte ein. In noch größerem Maße gilt es offenbar für das Modell der Mangel, denn das Muster der "Widerstände", die "einfach passieren", und darauf folgender "Anpassungen" involviert nach Pickering weitere kontingente Ereignisse, die den Verlauf der Physikgeschichte beeinflussen. Dadurch scheint sich der (aus realistischer Perspektive möglicherweise problematisch aussehende) Befund zu ergeben, daß die zeitliche Trajektorie des Bestandes der akzeptierten Theorien, Modelle etc. und damit auch der heute (oder zu einem beliebigen anderen "historisch späten" Zeitpunkt) erreichte Stand der akzeptierten Theorien, Modelle etc. in massiver Weise von den "außerwissenschaftlichen", kontingenten Einflüssen entlang der Trajektorie abhängt. Pickering spricht von einer Pfadabhängigkeit der Wissensproduktion (path-dependence of knowledge production). ${ }^{33}$

\subsection{Probleme und Kritik}

Von den Problemen und Einwänden, mit denen Pickerings Modelle und die darauf basierenden Analysen wissenschaftsgeschichtlicher Episoden konfrontiert worden sind oder konfrontiert werden können, sollen hier diejenigen diskutiert werden, die im Hinblick auf die Realismusdebatte von Interesse sind. ${ }^{34}$

\subsubsection{Constructing Quarks}

\section{Pickerings durch das Stichwort "Opportunismus im Kontext" charakterisiertes Modell und realistische Thesen}

Pickerings erstes Modell für die Entwicklungsdynamik der Wissenschaften und seine Darstellung eines Abschnitts der Geschichte der Hochenergiephysik im Lichte dieses Modells ${ }^{35}$ legen zumindest prima facie den Eindruck nahe, daß sie im Konflikt oder wenigstens in einem Spannungsverhältnis zu realistischen Thesen und Positionen stehen, da sie den epistemischen Status der kognitiven Produkte zweifelhaft erscheinen lassen, die als Resultate wissenschaftlicher Forschung gewonnen und etabliert werden, die gemäß diesem Modell abläuft. Genauer sind es sowohl epistemische realistische Thesen in bezug auf diese kognitiven Produkte als auch die epistemische Begründung oder Rechtfertigung entsprechender ontologischer realistischer Thesen, die durch Pickerings Modell gefährdet zu sein scheinen. Bei genauerer Betrachtung erweist sich dieser Eindruck jedoch als unbegründet, auch wenn Pickerings eigene Äußerungen gelegentlich etwas anderes zu suggerieren scheinen.

Bedrohlich für epistemische und ontologische realistische Thesen erscheint prima facie die Art und Weise, wie Pickering einige in der Wissenschaftstheorie viel diskutierte Thesen (Stichworte: Unterbestimmtheit, Theoriebeladenheit, keine exakte Ableitbarkeit

\footnotetext{
${ }^{32}$ Vgl. [Pick95b], S.33, 185, 208ff.

${ }^{33}$ [Pick95b], S.185, 208ff.

${ }^{34}$ Kritik an Pickerings historischen Darstellungen muß hier beiseite bleiben.

${ }^{35}$ Kritische Diskussionen von [Pick84] liefern u.a. [Buri90, GiSc86, RoBa90].
} 
experimenteller Resultate aus Theorien) heranzieht, um gleichsam Raum zu schaffen für soziologische Erklärungen (mit opportunistischen Erwägungen der Wissenschaftler als Explanantia) für die Entscheidungen, die gemäß seinem Modell die Entwicklungsdynamik der Physik bestimmen. Diese Vorgehensweise Pickerings sieht aus realistischer Perspektive deswegen bedrohlich aus, weil Pickerings Argumentationsweise und Duktus nahelegen, daß er hier die Annahme begründen will, daß durch die erfolgreiche Anwendung seines Modells in konkreten Fällen, also durch den Aufweis von opportunistischen Erwägungen von Wissenschaftlern als Erklärung für das Akzeptieren von Theorien, Modellen etc., sozusagen automatisch auch die Frage nach Begründungen oder Rechtfertigungsgründen für die Theorien, Modelle etc. beantwortet wird. Anders formuliert: Pickerings Modell und seine historischen Darstellungen im Lichte dieses Modells sind für realistische Positionen dann bedrohlich, wenn man voraussetzt, daß eine soziologische Erklärung für das Akzeptieren der fraglichen Theorien, Modelle etc. impliziert oder zumindest wahrscheinlich macht, daß es (neben den opportunistischen Gründen, aufgrund derer die beteiligten Wissenschaftler sie akzeptiert haben) keine epistemischen Begründungen oder Rechtfertigungsgründe für die Theorien, Modelle etc. gibt, und für genau diesen Implikations- oder Wahrscheinlichkeitszusammenhang scheint Pickering zu argumentieren, indem er die Stichworte "Unterbestimmtheit", "Theoriebeladenheit" etc. ins Spiel bringt.

Eine solche Annahme über die Implikationen von Pickerings Modell und dessen Anwendung würde diese tatsächlich nicht nur als bedrohlich für realistische Thesen erscheinen lassen, sondern wäre vor allem selbst offensichtlich unzureichend begründet: Pickering führt die - in der Wissenschaftsphilosophie umstrittenen und extensiv diskutierten Thesen der Unterbestimmtheit, Theoriebeladenheit etc. zunächst in ganz genereller, abstrakter Formulierung ${ }^{36}$ an, ohne dafür zu argumentieren. In konkreten Beispielen seiner Fallstudie werden die allgemeinen Thesen dann an einigen Stellen "angewendet" 37, aber nicht wirklich diskutiert oder gar begründet. Was Pickering mit Hilfe dieser Thesen in den konkreten Fällen zeigt, ist lediglich, daß von den dort vorliegenden experimentellen Resultaten kein deduktiver Schluß zu einer eindeutig bestimmten Theorie führt, daß es also keine zwingenden logischen Gründe gibt, die in einer bestimmten historischen Situation die Wahl einer anderen Theorie als der verboten hätten, die von der Gemeinschaft der Physiker tatsächlich für die weitere Arbeit oder als Überzeugung akzeptiert wurde. Mit diesen (offenbar einigermaßen trivialen) Befunden ist aber natürlich gar nichts darüber ausgesagt, ob oder inwieweit für das Akzeptieren einer Theorie, eines Modells o.ä. (mehr oder weniger gute) Gründe nicht-deduktiver Art vorliegen bzw. vorgelegen haben, ${ }^{38}$ und

\footnotetext{
${ }^{36}$ Wie etwa: Die Wahl einer Theorie ist durch jeden endlichen Datensatz unterbestimmt.

${ }^{37}$ Siehe z.B. [Pick84], S.294ff., bes. 301/302, wo er schildert, wie sich in der Gemeinschaft der Physiker das Standardmodell gegen konkurrierende Modelle durchsetzt, obwohl die vorliegenden Experimente nicht zwingend dafür sprechen.

${ }^{38}$ Dies ist eine Fragestellung, die grundsätzlich durch detaillierte wissenschaftshistorische Studien untersucht werden könnte, obwohl Pickering dies nicht tut: Man müßte zunächst unterscheiden zwischen Situationen, in denen es um die Wahl einer Theorie, eines Modells o.ä. für die weitere Arbeit, weitere Untersuchungen etc. geht, und Situationen, in denen es um das Akzeptieren einer Theorie, eines Modells usw. als Überzeugung geht. Aus erkenntnistheoretischer Perspektive interessieren vor allem Fälle des letzteren Typs. In solchen Fällen wäre es interessant, anhand detaillierter wissenschaftshistorischer Fallstudien zu untersuchen, wie in der "real-existierenden" Physik akzeptierte (mehr oder weniger gute) epistemische Gründe für das Akzeptieren einer Theorie (die natürlich i.a. keine zwingenden deduktiven Gründe sind) aussehen. Untersuchungen dieser Art können aufschlußreich sein, um die Plausibilität und Reichweite der diversen in der wissenschaftstheoretischen Literatur vorliegenden Erläuterungen und Explikationen der Begriffe der Bestätigung, Stützung etc. von Theorien, Modellen, Gesetzen etc. zu prüfen oder eventuell neue verbesserte Vorschläge zu entwickeln.
} 
damit leisten diese Befunde offenbar auch nichts, um zu begründen, daß der Aufweis von opportunistischen Gründen (in Situationen, in denen Unterbestimmtheit, Theoriebeladenheit etc. vorliegt,) per se irgendwelche Konsequenzen für die Frage nach der epistemischen Begründung oder Rechtfertigung der fraglichen Theorien, Modelle etc. haben soll. ${ }^{39}$

Eine plausiblere Lesart für Pickerings Modell und seine Darstellung eines Ausschnitts der Geschichte der Hochenergiephysik im Lichte seines Modells ist daher eine, die davon ausgeht, daß Pickering die Frage der epistemischen Begründung oder Rechtfertigung der Theorien und Modelle, die dort gewonnen und etabliert wurden, mit seinem Modellansatz systematisch ausblendet. Daß Pickering für die Entscheidungen der beteiligten Physiker soziologische Erklärungen, in denen opportunistische Erwägungen als Explanantia fungieren, angibt, ohne deren Verhältnis zu epistemischen Fragen in angemessener Weise zu untersuchen, ist demnach als methodologischer Ansatz aufzufassen, der für eine historische und/oder soziologische Untersuchung durchaus legitim ist, etwa um bestimmte, sonst vielleicht vernachlässigte Aspekte des Untersuchungsgegenstandes ins Blickfeld zu rücken oder generell die Reichweite seines Erklärungsansatzes zu erproben. Zu epistemischen Fragen und insbesondere in bezug auf epistemische und ontologische realistische Thesen sagen oder implizieren Pickerings Modell und die wissenschaftshistorischen Darstellungen aus der Perspektive seines Modells in dieser Lesart daher per se zunächst gar nichts. Insbesondere besagt oder impliziert Pickerings Befund, daß die Tatsache, daß bestimmte Theorien, Modelle etc. von den beteiligten Wissenschaftlern gewählt oder akzeptiert wurden, durch opportunistische Erwägungen auf Seiten der Wissenschaftler erklärt werden kann, per se nicht, daß diese Theorien, Modelle etc. nicht epistemisch gut begründet oder gerechtfertigt sind oder werden können. Pickerings Ausführungen in 'Constructing Quarks' scheinen dieser Lesart (zumindest in ihrem Duktus, wenn nicht wörtlich) in manchen Passagen zu widersprechen, ${ }^{40}$ sachlich scheint sie jedoch aus den genannten Gründen die plausibelste zu sein, und Pickering selbst akzeptiert sie in einer späteren Arbeit ausdrücklich. ${ }^{41}$ Pickerings Ausführungen zu den Stichworten "Unterbestimmtheit", "Theoriebeladenheit" etc. sollte man demzufolge am besten von seinem Modell für die Entwicklungsdynamik der Wissenschaften und seinen historischen Darstellungen abtrennen und beiseite lassen. ${ }^{42}$

Aus dem Befund, daß Pickering selbst keine überzeugenden Gründe dafür nennt, daß sein Modell und die darauf basierenden historischen Darstellungen nicht im Konflikt mit realistischen Thesen stehen, folgt andererseits nicht, daß es keinen solchen Konflikt gibt, und der Eindruck, daß soziologische Erklärungen von der Art, wie Pickering sie vorschlägt, zumindest in einem Spannungsverhältnis zu realistischen Thesen stehen, ist natürlich keineswegs absurd. Die Frage, ob ein solcher Konflikt tatsächlich besteht oder nicht, in angemessener Weise zu beantworten, ist aber weit komplizierter und schwieriger, als es auf den ersten Blick vielleicht scheint und als Pickerings Äußerungen es nahelegen, denn die Antwort hängt zum einen von der erkenntnistheoretischen Position ab, die man vertritt, zum anderen setzt sie umfangreichere historische Untersuchungen voraus, als Pickering sie liefert.

\footnotetext{
${ }^{39}$ S.a. [Buri90], S.167ff., [GiSc86], S.379.

${ }^{40}$ Ein deutliches Beispiel ist die in der in Fn.37 genannte Episode. Dort nennt Pickering zunächst einige von den beteiligten Physikern angeführte Gründe, die das Akzeptieren des Standardmodells und gleichzeitig das Anzweifeln bestimmter, ihm widersprechender experimenteller Resultate vernünftig erscheinen lassen (die Auswertung der Experimente hängt von unsicheren Näherungen ab; verschiedene Gruppen bekommen beim selben Experiment widersprüchliche Resultate), kommentiert dies dann aber dahingehend, daß diese Gründe nicht logisch zwingend waren, und zieht daraufhin ein soziologisches Explanans heran.

${ }^{41}$ [Pick90], bes. S.686f., 692f.

${ }^{42}$ Pickering selbst läßt sie in seinen späteren Arbeiten kommentarlos fallen.
} 
Der verbreitete intuitive Eindruck, daß Pickerings soziologische Erklärungen zumindest in einem Spannungsverhältnis zu realistischen Thesen stehen, dürfte auf der Annahme beruhen, daß jemand, der eine Theorie, ein Modell o.ä. aus den von Pickering beschriebenen opportunistischen Gründen akzeptiert, i.a. über keine anderen, insbesondere über keine guten epistemischen Gründe verfügt, diese Theorie, dieses Modell o.ä. zu akzeptieren. Diese Annahme legt den Schluß nahe, daß realistische Thesen, die sich auf Theorien, Modelle etc. beziehen, die von den beteiligten Wissenschaftlern aus opportunistischen Gründen akzeptiert wurden, in epistemischer Hinsicht i.a. nicht gut begründet oder gerechtfertigt sind bzw. werden können. Bei genauerer Betrachtung sind aber weder die Annahme noch der Schluß ohne weiteres plausibel oder selbstverständlich.

Die Annahme, daß ein Wissenschaftler, der eine Theorie, ein Modell etc. aus opportunistischen Gründen akzeptiert, i.a. nicht über gute epistemische Rechtfertigungsgründe verfügt, ist eine empirische Aussage, die empirisch untersucht werden müßte. Dabei müssen erkenntnistheoretische Annahmen, genauer: eine Konzeption epistemischer Begründung oder Rechtfertigung vorausgesetzt werden, da ansonsten nicht klar ist, was als Vorliegen von epistemischen Rechtfertigungsgründen (neben den opportunistischen Gründen) zählt. Als Ergebnis einer solchen Untersuchung ist kaum eine völlig einheitliche generelle Aussage zu erwarten: Opportunistische Erwägungen betreffen bestimmte praktische Folgen einer Entscheidung, sind also, um eine Analogie aus der Ethik zu benutzen, gleichsam utilitaristischer Natur. Epistemische Kriterien und Rechtfertigungsgründe sind (i.a.) von praktischen Folgen unabhängig, also gleichsam von deontologischer Art. Wie im Fall der Ethik können Erwägungen dieser beiden Sorten im konkreten Einzelfall durchaus zum selben Resultat führen, also verträglich sein, müssen es aber andererseits nicht; eine dritte Möglichkeit ist die, daß eine der Kriteriensorten keine Auskunft liefert. Man wird sich daher die konkreten Einzelfälle ansehen müssen, die sich als philosophisch wenig brisant erweisen können, nämlich dann, wenn es gute epistemische Rechtfertigungsgründe gibt, die zur selben Entscheidung führen wie die vorliegenden opportunistischen Gründe, ${ }^{43}$ aber auch als aus realistischer Perspektive problematisch, nämlich dann, wenn die Entscheidung über das Akzeptieren einer Theorie, eines Modells usw. aus opportunistischen Gründen getroffen wird und entweder konträre epistemische Gründe vorliegen oder die vorliegenden epistemischen Gründe einen echten Spielraum von Entscheidungsoptionen offen lassen. Untersuchungen dieser Art sind an dieser Stelle nicht möglich, und sie finden sich auch in Pickerings Fallstudie nicht, ${ }^{44}$ insbesondere finden sich dort auch keine Fälle von Theorie-, Modell- usw. Wahlentscheidungen, in denen epistemische Gründe von opportunistischen ausgestochen wurden, und keine überzeugende Fälle echter Spielräume, d.h. Fälle, in denen wirklich eine aufweisbare Menge von Alternativen (und zwar auf einer relevanten Zeitskala, nicht nur kurzfristig, innerhalb laufender Untersuchungen) offen geblieben ist.

Man könnte versuchen, die genannte Annahme auch ohne empirische Untersuchungen $\mathrm{zu}$ verteidigen, indem man darauf hinweist, daß bei zwei völlig unabhängigen Sorten von Entscheidungskriterien — opportunistischen einerseits und nicht-opportunistischen, epi-

\footnotetext{
${ }^{43}$ So wie in den Fällen, in denen sich ein Rechtsanwalt ein bestimmtes Plädoyer zurechtlegt, erstens, weil seine Darstellung nach den vorliegenden Aussagen und Indizien höchstwahrscheinlich der Wahrheit entspricht, und zweitens, weil er — außerdem und gleichzeitig — durch das Gewinnen des Prozesses seine berufliche Karriere voranbringen will.

${ }^{44}$ Man könnte versuchen, Pickerings Ausführungen zu den Stichworten Unterbestimmtheit, Theoriebeladenheit etc. als Untersuchung dieser Art aufzufassen. Damit würde man aber eine völlig unangemessene, weil viel zu enge Konzeption von epistemischer Rechtfertigung voraussetzen, nämlich eine, der zufolge eine Theorie, ein Modell etc. nur dann gerechtfertigt ist, wenn sie bzw. es deduktiv aus Beobachtungen, Meßdaten o. $\ddot{\text { a }}$ folgt.
} 
stemischen andererseits - eigentlich zu erwarten ist, daß beide in der überwiegenden Zahl der Anwendungsfälle divergierende Resultate liefern. Sofern eine große Zahl von Entscheidungen über die Wahl einer Theorie, eines Modells usw. durch opportunistische Gründe auf Seiten der Wissenschaftler erklärt werden kann, wäre es danach sehr unwahrscheinlich, daß dazu stets "parallele" epistemische Gründe existieren, auch wenn man das möglicherweise nicht eigens untersucht hat. Diese Überlegung ist aber nur dann schlüssig, wenn die beiden Sorten von Kriterien sozusagen statistisch unabhängig sind, was natürlich nicht ohne weiteres als plausibel vorausgesetzt werden kann, sondern vielmehr auf eine andere Frage führt, nämlich auf die, ob die Institution Wissenschaft so organisiert ist (in bezug auf die Verteilung von Stellen, Forschungsmitteln, Prestige usw.), daß opportunistische und epistemische Gründe im großen und ganzen parallel laufen oder nicht. Daß sie es (wenigstens in der Regel) tun, ist die gleichsam offizielle (und wenigstens prima facie nicht pauschal unplausible) Auskunft der für die Organisation der Wissenschaft Zuständigen, die sich nur aufgrund detaillierter soziologischer und epistemologischer Untersuchungen begründet beurteilen ließe. In Pickerings Untersuchungen findet sich jedenfalls nichts, was gegen die offizielle Auskunft spräche.

Selbst wenn sich die Annahme, daß ein Wissenschaftler, der eine Theorie, ein Modell etc. aus opportunistischen Gründen akzeptiert, i.a. nicht über gute epistemische Rechtfertigungsgründe verfügt, als wahr erweisen sollte, ist der dadurch nahegelegte Schluß, daß realistische Thesen, die sich auf Theorien, Modelle etc. beziehen, die von den beteiligten Wissenschaftlern aus opportunistischen Gründen akzeptiert wurden, in epistemischer Hinsicht i.a. nicht gut begründet oder gerechtfertigt sind bzw. werden können, ohne weitere Prämissen nicht zwingend: Daß ein Wissenschaftler eine Theorie sozusagen aus den falschen Gründen akzeptiert, impliziert nicht notwendigerweise, daß es keine guten Gründe gibt, die Theorie zu akzeptieren. ${ }^{45}$ Da es sich bei den Wissenschaftlern, um die es geht, i.a. um kompetente Experten für das fragliche Gebiet handelt, sind natürlich andere, insbesondere Laien, normalerweise nicht in einer Position, in der sie sozusagen aus eigener Kraft bessere epistemische Gründe als die Experten aufbringen können. Andere Experten auf demselben Gebiet jedoch können sehr wohl in einer solchen Position sein, insbesondere, wenn sie zu einer (historisch späteren) Zeit arbeiten, in der sie mehr und bessere Untersuchungsmittel, -methoden etc. zur Verfügung haben. Aus diesem Grund müssen soziologische Erklärungen von der Art, wie sie Pickering mit Hilfe seines Modells liefert, mit epistemischen und ontologischen realistischen Thesen selbst dann nicht notwendigerweise konfligieren, wenn sich in detaillierten historischen Untersuchungen nachweisen läßt, daß die beteiligten Wissenschaftler die entsprechenden Theorien aus opportunistischen Gründen akzeptiert haben und dabei nicht über gute "parallele" epistemische Rechtfertigungsgründe verfügten.

Fazit dieser Überlegungen ist, daß Pickerings durch das Stichwort "Opportunismus im Kontext" charakterisiertes Modell und auch seine Darstellung eines Abschnitts der Geschichte der Hochenergiephysik im Lichte dieses Modells, entgegen einem naheliegenden ersten Eindruck und offenbar auch entgegen Pickerings (ursprünglicher) eigener Einschätzung, für sich genommen nichts gegen epistemische oder ontologische realistische Thesen bezüglich der Theorien, Modelle etc. austrägt, deren Gewinnung und Etablierung sich durch Pickerings Modell beschreiben läßt. ${ }^{46}$ Das gilt insbesondere auch für den in seiner

\footnotetext{
${ }^{45}$ Unter Voraussetzung einer "geeigneten" Konzeption von epistemischer Rechtfertigung (nämlich einer externalistischen, etwa einer reliabilistischen; vgl. Abschnitt 8.3.1) folgt daraus noch nicht einmal zwingend, daß die Überzeugung des Wissenschaftlers selbst, die die Theorie zum Inhalt hat, nicht gerechtfertigt ist.

${ }^{46}$ Semantische und axiologische realistische Thesen werden ohnehin nicht berührt.
} 
historischen Darstellung behandelten konkreten Fall, d.h. für realistische Thesen bezüglich der Theorien und Modelle der Hochenergiephysik. Wenn die an der Gewinnung und Etablierung einer Theorie beteiligten Wissenschaftler diese Theorie aus opportunistischen Gründen akzeptieren, besagt dies nicht notwendigerweise, daß sie nicht gleichzeitig gute epistemische Rechtfertigungsgründe dafür haben, und selbst wenn sie selbst keine haben, besagt das nicht, daß keine existieren.

\section{Pickerings konstruktivistische Redeweisen}

Neben dem durch das Stichwort "Opportunismus im Kontext" gekennzeichneten Modell erwecken auch Pickerings konstruktivistische Redeweisen zumindest prima facie den Eindruck, daß seine Position im Konflikt oder wenigstens in einem Spannungsverhältnis zu realistischen Thesen und Positionen steht. Seine Aussagen, daß Quarks, schwache neutrale Ströme etc. "konstruiert" oder "produziert" wurden, scheinen, wie schon erwähnt, in keiner erkennbaren Weise durch sein Modell oder seine historischen Darstellungen impliziert oder nahegelegt zu werden, sondern davon unabhängig zu sein, ${ }^{47}$ aber auch sie scheinen auf den ersten Blick in irgendeiner Weise mit der realistischen Intuition zu konfligieren, daß die Welt unabhängig vom menschlichen Geist ist. Einigermaßen genau zu identifizieren, was der Gehalt von Pickerings konstruktivistischen Redeweisen ist und mit welchen realistischen Thesen sie im Konflikt stehen oder stehen sollen, erweist sich jedoch als schwierig; dasselbe gilt für eine Begründung für Pickerings konstruktivistische Aussagen. ${ }^{48}$

Klar identifizieren lassen sich einige Thesen, die Pickering mit seinen Redeweisen vom "Konstruieren", "Produzieren" etc. von Phänomenen, Entitäten und Tatsachen nicht meint oder jedenfalls nicht meinen sollte, wenn seine Redeweisen mit realistischen Thesen konfligieren sollen. Gemeint ist nicht, daß Begriffe, Theorien, Modelle u.ä., die bestimmte Phänomene, Entitäten oder Sachverhalte zum Inhalt haben, konstruiert oder produziert werden bzw. worden sind, also z.B. der Begriff "Quark" und das Standardmodell der elektroschwachen Wechselwirkung, denn das wäre eine These, die kaum jemand bestreitet ${ }^{49}$ und die daher nicht das Gewicht, das Pickering auf seine Formulierungen legt, und die Emphase, mit der er sie (u.a. im Titel seines Buches) präsentiert, rechtfertigen könnte. ${ }^{50}$

Gemeint sein kann auch nicht die (in der Literatur im Bereich der Science Studies und auch der Wissenschaftstheorie gelegentlich als konstruktivistisch bezeichnete) Aussage, daß die fraglichen Phänomene, Entitäten etc. in der von menschlichen Eingriffen unberührten

\footnotetext{
${ }^{47}$ S.a. [Buri90], S.168f., [GiSc86], S.377.

${ }^{48} \mathrm{Vgl}$. auch [RoBa90], S.590ff.

${ }^{49}$ Es mag "Begriffsplatonisten" geben, die das tun würden, aber die dürfte es erstens kaum unter Wissenschaftstheoretikern geben, und zweitens stellen sie klarerweise nicht Pickerings Diskussionsgegner dar.

${ }^{50}$ Irritierend ist allerdings in diesem Zusammenhang, mit welcher Selbstverständlichkeit und/oder Unachtsamkeit Pickering zwischen Formulierungen über die Konstruktion bzw. Produktion von Theorien, Modellen etc. und Formulierungen über die Konstruktion bzw. Produktion von Phänomenen, Entitäten etc. hin- und herwechselt. Neben den vorne zitierten Stellen aus dem Schlußkapitel seines Buches fällt dies besonders an einer Stelle auf, an der er auf Kritik antwortet, die genau diesen Punkt betrifft:
}

"The second main section of their essay [Roth and Barrett's [RoBa90]] is full of locutions like, 'To hold that theoretical entities are constructs made by scientists is, for Pickering, actually tantamount to holding that they are produced rather than discovered. So, by assuming this from the start, Pickering has presupposed the most striking and most central of his theses without having argued for it at all!' [... [RoBa90], S.596]. They are right, in a way. I did presuppose that knowledge is constructed by scientists - it is, isn't it? But the point of CQ [Constructing Quarks] was not to make this vacuous observation. It was to address the question of how knowledge is constructed" ([Pick90], S.688). 
Natur nicht vorkommen, sondern eigens hergestellt oder präpariert werden müssen, um sie zu untersuchen. Sie mag möglicherweise für einige Phänomene und Entitäten, von denen in Pickerings Buch die Rede ist, gelten, sie ist aber mit einer realistischen Position, insbesondere mit ontologischen und semantischen realistischen Thesen bezüglich dieser Phänomene und Entitäten bzw. bezüglich entsprechender Sätze und Ausdrücke verträglich, die die realistische Intuition von der Unabhängigkeit der Welt vom menschlichen Geist konkretisieren. Bei der Formulierung ontologischer realistischer Thesen bezüglich dieser Phänomene und Entitäten muß die Erläuterung der darin enthaltenen Unabhängigkeitsaussage ${ }^{51}$ sorgfältig gewählt werden: Phänomene und Entitäten, die in der von Menschen unberührten Natur nicht vorkommen, sind vielleicht nicht in dem Sinn unabhängig von menschlicher Erkenntnis, daß sie auch dann existieren würden, wenn es keine menschliche Erkenntnis gäbe, und auch nicht in dem Sinn, daß sie von menschlichen Erkenntnisverfahren, -zuständen etc. kausal nicht beeinflußt würden, aber sie würden auch dann existieren, wenn von ihrer Existenz niemand wüßte etc., und sie werden von den menschlichen Erkenntnisverfahren etc. nicht kausal beeinflußt, die menschliches Wissen von ihnen konstituieren bzw. erzeugen. In dieser Weise, also durch (UvmE1a) oder (UvmE2a) erläuterte ontologische realistische Thesen konfligieren nicht mit der Annahme, daß die fraglichen Phänomene und Entitäten in der unberührten Natur nicht vorkommen.

Nicht gemeint ist mit Pickerings Redeweisen vom "Konstruieren" oder "Produzieren" von Phänomenen, Entitäten etc. auch die These, daß die Gegenstände, Sachverhalte etc., von denen menschliche Überzeugungen, Repräsentationen etc. handeln, insofern "konstruierte" sind, als sie mittels Begriffen oder Begriffssystemen individuiert und identifiziert werden. Thesen dieser Art werden in der allgemein-philosophischen Realismusdebatte von verschiedenen Autoren angedeutet, um eine als Konstruktivismus bezeichnete Position zu markieren. ${ }^{52}$ Solche Thesen dürften, wie auch immer sie genau formuliert werden können, zum einen mit realistischen Thesen verträglich sein, vor allem aber ist das, worauf Pickerings konstruktivistische Redeweisen zielen, offenbar etwas anderes, denn Thesen der genannten Art sind völlig allgemein, betreffen also beobachtbare Gegenstände der Alltagswelt wie Tische und Teelöffel genauso wie die unbeobachtbaren Phänomene und Entitäten der Hochenergiephysik, die Pickering im Auge hat. ${ }^{53}$

Was ansonsten mit Pickerings Redeweisen vom "Konstruieren" oder "Produzieren" von Phänomenen, Entitäten, u.ä. gemeint sein könnte (was gleichzeitig nicht völlig unkontrovers oder trivial ist), ist nicht zu sehen, und da sich in seinen Texten auch keine Begründung für seine entsprechenden Aussagen findet, fällt es schwer, den Schluß zu vermeiden, daß es sich um spektakulär klingende, aber wenig gehaltvolle Schlagworte handelt; jedenfalls macht Pickering seine Position in diesem Punkt nicht hinreichend deutlich. Entgegen dem ersten Eindruck enthalten Pickerings konstruktivistische Aussagen also, soweit erkennbar, nichts, was im Konflikt mit oder auch nur in einem Spannungsverhältnis zu realistischen Thesen in bezug auf Quarks, schwache neutrale Ströme und ähnlichem steht.

\footnotetext{
${ }^{51}$ Siehe Kap.1.2.1, 1.3.1.

${ }^{52}$ Siehe S.10.

${ }^{53}$ Dafür spricht auch, daß Pickering sich nirgends auf die entsprechenden Thesen und Positionen von Autoren wie Goodman und Putnam bezieht, selbst da nicht, wo er diese erwähnt (etwa [Pick90], S.718, Fn.8).
} 


\section{Politische und weltanschauliche Implikationen von Pickerings Sozialkonstruk- tivismus}

Nachdem die Untersuchung von Pickerings entwicklungsdynamischem Modell und auch die seiner konstruktivistischen Redeweisen im Hinblick auf Argumente und Thesen, die für die Realismusdebatte relevant sind, einigermaßen enttäuschende Ergebnisse geliefert hat, liegt es angesichts der vielen Passagen und Formulierungen in Pickerings Texten, die eine antirealistische Einstellung anzudeuten und als wünschenswert zu präsentieren scheinen, nahe, nach den Motiven zu fragen, die dieser Position zugrundeliegen. Pickerings Rhetorik legt die Vermutung nahe, daß die Attraktivität seiner Position für ihn mindestens zum Teil daher rührt, daß sie seiner Ansicht nach, anders als realistische Positionen, ein Bild der Naturwissenschaften und besonders der Physik zu zeichnen erlaubt, das diese nicht als Hindernis für emanzipatorische politische Projekte und (in einem weiten Sinn) humane Weltbilder und Lebensformen erscheinen läßt. Damit ist er repräsentativ für eine ganze Reihe im Bereich der Science Studies arbeitender Autoren, die aus ihren wissenschaftshistorischen, -soziologischen oder -psychologischen Studien Konsequenzen mit antirealistischer Stoßrichtung ziehen. Pickering äußert sich zu diesem Punkt kaum explizit, so daß man auf Vermutungen angewiesen ist, inwiefern sich jemand von den Theorien der Teilchenphysik, wie er sich ausdrückt, "eingeschüchtert" fühlen könnte und wie und warum sich dies ändern soll, wenn man aus der Perspektive seiner sozialkonstruktivistischer Position erkennt, daß es sich bei dem "Weltbild" der Hochenergiephysik um ein "kulturelles Produkt" handelt. ${ }^{54}$

Denkbar sind verschiedene Bereiche, in denen man eine "Einschüchterung" befürchten könnte: Einmal wird zwischen dem "Weltbild der Physik" (was auch immer darunter genauer zu verstehen ist) und Überzeugungen religiöser oder in einem weiten Sinn weltanschaulicher Art häufig ein inhaltliches Konkurrenzverhältnis gesehen, zum anderen wird die "harte" Naturwissenschaft Physik gelegentlich für Sozial- und Geisteswissenschaften als Ideal im Hinblick auf Methodologie der Theorienbildung und Struktur der Theorien dargestellt. Beides sind Fragenkomplexe, die so wichtige praktische Auswirkungen haben, daß Pickerings (für wissenschaftstheoretische Diskussionen ungewöhnlich emotionale) Rede von Einschüchterung durchaus angemessen erscheinen kann. Um beide Fragen kann man mit guten Gründen streiten, zu diesen Debatten scheinen jedoch weder Pickerings Modell noch seine historische Darstellung noch seine konstruktivistischen Redeweisen etwas Überzeugendes beizutragen: Pickerings Modell sagt oder impliziert zu epistemischen Fragen, wie oben diskutiert, per se gar nichts, insbesondere sagt oder impliziert es natürlich nicht, daß Überzeugungen nach Belieben wählbar oder Konflikte zwischen verschiedenen Überzeugungen oder sogar "Weltbildern" gewissermaßen willkürlich zu entschärfen oder zu entscheiden sind. Was Pickerings unklare konstruktivistische Redeweisen zur Entschärfung oder Beseitigung solcher Konflikte beitragen könnten, ist ebenfalls nicht zu erkennen. ${ }^{55}$ Genausowenig ist zu sehen, daß ein Modell für die Entwicklungsdynamik der Physik oder konstruktivistische Redeweisen über deren Gegenstandsbereich irgend etwas darüber besagen oder implizieren sollten, wie im Bereich der Sozial- und Geisteswissenschaften eine angemessene Methodologie und akzeptable Theorien aussehen.

Ein dritter Bereich, in dem man möglicherweise "Einschüchterung" durch die Teil-

\footnotetext{
${ }^{54} \mathrm{Vgl}$. das Zitat auf S.360.

${ }^{55}$ Dagegen ist John Polkinghorne, den Pickering als Musterbeispiel für unkritische Wissenschaftsgläubigkeit zitiert, jemand, der einen der genannten Problembereiche, nämlich das Verhältnis zwischen dem von der modernen Physik gezeichneten "Weltbild" und religiösen Überzeugungen, in sorgfältig argumentierender Weise untersucht; s. [Polk86] und eine ganze Reihe neuerer Arbeiten.
} 
chenphysik befürchten könnte, ist die Verteilung von gesellschaftlichen Ressourcen, sprich: von Geld und Prestige. Hier könnten konstruktivistische Sprechweisen vielleicht dadurch Konsequenzen haben, daß sie sich für griffige, "medientaugliche" Formulierungen und Argumentationen heranziehen lassen: Für die Rechtfertigung der enormen finanziellen Mittel, die in die Teilchenphysik fließen, klingt es vielleicht nicht besonders überzeugend, wenn es sich bei den untersuchten Gegenständen "nur" um "Konstruktionen der Teilchenphysiker" handelt. Auch das stellt aber kein plausibles Motiv für die Attraktivität konstruktivistischer Sprechweisen dar, denn zum einen weist Pickering selbst (in einem neueren Aufsatz ${ }^{56}$ ) Paraphrasierungen seiner konstruktivistischen Redeweisen ausdrücklich zurück, die Formulierungen wie "nur konstruiert" oder "bloße Konstrukte" enthalten, und zum anderen hängt selbst bei einer oberflächlichen Argumentation der skizzierten Art die intuitive Überzeugungskraft klarerweise davon ab, ob ein Kontrast zwischen den Gegenständen der Physik und den Gegenständen der Alltagswelt plausibel gemacht werden kann, ob also Quarks, schwache neutrale Ströme usw. "Konstruktionen" im selben Sinn wie oder im Gegensatz zu Tischen, Katzen usw. sind. Dies aber tun weder Pickerings konstruktivistische Redeweisen noch sein Modell, er scheint es auch nicht zu beabsichtigen. Auch forschungspolitische Folgen der genannten Art geben also kein plausibles Motiv für die Attraktivität konstruktivistischer Redeweisen ab.

Denkbar wäre vielleicht noch, daß man sich von konstruktivistischen Sprechweisen auf eine etwas andere Weise forschungspolitische Konsequenzen verspricht, nämlich dadurch, daß sie es ermöglichen, verschiedene Disziplinen und ihre Gegenstandsbereiche rhetorisch sozusagen näher aneinanderzurücken: ${ }^{57}$ Wenn man die Ansicht vertritt, daß jede Wissenschaftsdisziplin (und ebenso alltagsweltliche Erkenntnisprozesse) ihre Gegenstände "konstruieren", daß also Elektronen und Quarks ebenso "konstruiert" sind wie soziale Rollen, die Romane von Jane Austen und das Mittelalter, dann führt einen das vielleicht zu der Meinung, daß die Verteilung von Ressourcen auf die verschiedenen Disziplinen an gesellschaftlichen Bedürfnissen und politischen Präferenzen orientiert werden kann, ohne daß man deswegen sozusagen auf in sich wertvollen Erkenntnisgewinn darüber, was "die Welt im Innersten zusammenhält", verzichtet, wenn die "harten" Naturwissenschaften dabei Einbußen hinnehmen müssen. Auch darin liegt aber bei genauerem Hinsehen kein plausibles Motiv für die Attraktivität konstruktivistischer Sprechweisen, denn selbst bei oberflächlicher Betrachtung ist klar, daß aus pauschalisierenden konstruktivistischen Sprechweisen praktisch nichts über den Status verschiedener Disziplinen und ihrer Gegenstände folgt, was plausiblerweise irgendwelche praktische Relevanz haben könnte. Gemeinsamkeiten und Differenzen zwischen den Disziplinen im Hinblick auf den ontologischen Status ihrer Gegenstände, den epistemischen Zugang dazu, methodologische Prinzipien, historische Stabilität der Erkenntnisse usw. sind komplexe, traditionell in der Wissenschaftsphilosophie behandelte Themen, denen man in keiner Weise mit vereinheitlichenden Redeweisen von "Konstruktion" gerecht wird, jedenfalls nicht, solange diese nicht weit genauer und ausführlicher erläutert werden als bei Pickering. Dies gilt insbesondere auch dann, wenn es um forschungspolitische Konsequenzen solcher "Statusfragen" geht, und tatsächlich dürften forschungspolitische Entscheidungen auch kaum durch Rhetorik der genannten Art beeinflußbar sein.

Sofern von der Hochenergiephysik tatsächlich "Einschüchterungen" der genannten Arten ausgehen sollten, ist also nicht zu erkennen, wieso und in welcher Weise eine sozialkonstruktivistische Position wie die von Pickering dagegen etwas ausrichten sollte. Wenn ent-

\footnotetext{
${ }^{56}$ [Pick90], S.684, 686, 705.

${ }^{57}$ Eine Passage in [Pick90] (S.684/685) deutet in diese Richtung.
} 
sprechende Erwartungen, allgemeiner gesprochen: (erhoffte) politische oder weltanschauliche Implikationen einer solchen Position für ihre Attraktivität verantwortlich sein sollten und man in den politischen oder weltanschaulichen Implikationen einer sozialkonstruktivistischen und damit antirealistischen Position insbesondere auch einen (oder sogar den entscheidenden) Vorzug einer solchen Position vor einer realistischen Position (genau welcher Art auch immer) sieht, wie es einige Anhänger sozialkonstruktivistischer Positionen zu tun scheinen, sollten diese Implikationen explizit gemacht werden, denn die obigen Überlegungen legen den Schluß nahe, daß es solche Implikationen tatsächlich nicht gibt, und damit würden diese Positionen offenbar deutlich an Attraktivität einbüßen.

Eine plausible Art von (in einem weiten Sinn) politischen oder weltanschaulichen Implikationen könnten dagegen wissenschaftshistorische, -soziologische und -psychologische Studien für sich genommen, d.h. unabhängig von einer daran geknüpften sozialkonstruktivistischen Position haben: Solche Studien könnten als Teil eines "Aufklärungsprojektes" aufgefaßt werden, das das Ziel hat, falsche, glorifizierende Vorstellungen von den "harten" Naturwissenschaften in der außerwissenschaftlichen Öffentlichkeit zu demontieren und stattdessen ein angemessenes Bild von den real-existierenden Naturwissenschaften zu vermitteln. Ein solches Projekt hätte in manchen Fällen und Bereichen sicherlich seine Berechtigung, und auch Pickerings Ansatz, die Rolle von opportunistischen Erwägungen für die Entwicklung der real-existierenden Wissenschaften herauszustellen, wäre in einem solchen Rahmen (zumindest als ein Ansatz unter anderen) plausibel. Zu einem solchen Projekt tragen jedoch konstruktivistische Redeweisen und Thesen offenbar nichts bei, jedenfalls nicht, solange sie nicht um einiges präziser formuliert und besser begründet werden, als dies bei Pickering geschieht.

\subsubsection{The Mangle of Practice}

Von den Veränderungen, die an Pickerings neuem Modell für die Entwicklungsdynamik der Wissenschaften im Vergleich mit dem Vorgängermodell zu verzeichnen sind, stellen die höhere "zeitliche Auflösung", die Berücksichtigung des Einflusses der materiellen Welt auf die Entwicklungsdynamik und, damit zusammenhängend, die Beschränkung des Einflusses opportunistischer Erwägungen der Wissenschaftler auf die Bestimmung von Zielen tendenziell sicherlich einen Schritt in Richtung auf eine angemessenere Darstellung wissenschaftlicher Entwicklungsdynamik dar. ${ }^{58}$ Im Hinblick auf die oben an Pickerings älterem Modell diskutierten und kritisierten Züge gibt es jedoch keine grundlegenden Änderungen, immerhin aber leichte Verbesserungen.

Das Verhältnis von Pickerings Erklärungen der Entwicklungsdynamik zu realistischen Thesen ist im Fall der Mangel der Praxis weniger mißverständlich: Pickering stellt klar, daß epistemische Fragen (und damit auch epistemische realistische Thesen und die epistemische Stützung ontologischer realistischer Thesen) nicht Thema seiner Untersuchungen sind. ${ }^{59}$ Sein neues Modell enthält sozusagen eine Schnittstelle, an der erkenntnistheoretische Diskussionen natürlicherweise angeknüpft werden könnten, nämlich seinen Begriff der "interaktiven Stabilisierung", der Stadien experimenteller Untersuchungen bezeichnet, in denen die involvierten Theorien bzw. Modelle und die untersuchten Gegenstände

\footnotetext{
${ }^{58}$ Eine kritische Diskussion von [Pick95b] liefert [Ging97].

${ }^{59}$ Siehe z.B. [Pick90], S.705: "Scientific realism (and its negation) represents a retrospective judgement that belief in the correspondence to reality of this or that theoretical entity is somehow warranted, whereas my analysis of practice aims at real-time explanation. The two enterprises are disjoint in their conception". S.a. [Pick90], S.708, [Pick95b], S.183/184.
} 
oder Systeme (sowie auch die Instrumente und Geräte und die Ziele der Wissenschaftler) sozusagen zusammenpassen; ${ }^{60}$ das Modell selbst sagt oder impliziert jedoch für sich genommen nichts zu epistemischen Fragen. ${ }^{61}$ Außerdem wird dadurch, daß opportunistischen Erwägungen jetzt ausdrücklich nur noch im Stadium der Formulierung von Untersuchungszielen eine Rolle zugewiesen wird, der Eindruck ausgeräumt, die Entscheidungen von Wissenschaftlern über das Akzeptieren von Theorien, Modellen etc. seien nach Pickering in einer Weise durch opportunistische Erwägungen bestimmt, die gute epistemische Rechtfertigungsgründe für die Theorien, Modelle etc. ausschließt oder wenigstens unwahrscheinlich macht und so zu einem Spannungsverhältnis zwischen Pickerings Darstellung und realistischen Thesen führt.

Konstruktivistische Redeweisen treten in Pickerings zweitem Buch noch immer auf und noch immer ohne eine einigermaßen zufriedenstellende Erläuterung ihres Gehaltes, sie werden aber weniger betont als zuvor. Für ihre Bewertung gilt das oben Gesagte.

Im Hinblick auf die Realismusdebatte sind an Pickerings Modell der Mangel der Praxis vor allem zwei Neuerungen relevant, nämlich zum einen die Zurückweisung kausaler Expost-Erklärungen, zum anderen der Gedanke der Historizität wissenschaftlichen Wissens. Diese sollen hier diskutiert werden.

\section{Pickerings Zurückweisung von Ex-post-Erklärungen}

Während das Bild, das Pickering mit Hilfe seines Modells der Mangel von der Entwicklungsdynamik der Physik zeichnet, aus realistischer Perspektive also im großen und ganzen zunächst plausibel aussieht (wenn auch im Hinblick auf die Realismusdebatte nicht sonderlich aufschlußreich), entsteht durch Pickerings Zurückweisung bestimmter Ex-postErklärungen, die man als Realist natürlicherweise als Teil oder als Ergänzung dieses Bildes erwartet, dann doch ein Konflikt mit realistischen Thesen und Positionen. Pickering weist Erklärungen des Prozesses der Gewinnung und Etablierung von Theorien und Modellen, des Zustandekommens von experimentellen Resultaten, des Scheiterns von Experimenten usw. ausdrücklich zurück, die sich auf von diesen Theorien, Modellen und Experimenten behandelte bzw. untersuchte Gegenstände und Sachverhalte als Explanantia beziehen. Damit scheint er epistemischen und ontologischen realistischen Thesen direkt zu widersprechen, die die Gegenstände und Sachverhalte bzw. entsprechende Theorien, Modelle etc. zum Inhalt haben, die im Explanans solcher Erklärungen auftreten. Zumindest aber scheint er den Geltungsbereich der fraglichen Theorien, Modelle etc. (und damit entsprechender realistischer Thesen) stark einschränken zu wollen, nämlich auf die Sachverhalte, die im "Endstadium" experimenteller Untersuchungen vorliegen, also in dem Stadium, das er als "interaktive Stabilisierung" bezeichnet.

Pickerings Ablehnung der genannten Erklärungen erscheint aus mehreren Gründen nicht überzeugend oder sogar bizarr. Zum einen scheint sie im Widerspruch zu dem von ihm anerkannten Befund zu stehen, daß sein Modell der Entwicklungsdynamik keine Aussagen über epistemische Fragen macht. Zum anderen wird sie nicht oder jedenfalls nur völlig unzureichend begründet: ${ }^{62}$ Pickering weist in diesem Zusammenhang auf den Sachverhalt hin, daß den an der Gewinnung einer Theorie, eines Modells o.ä. beteiligten Wissenschaftlern diese Theorie, dieses Modell o.ä. zum Zeitpunkt der Gewinnung eben noch

\footnotetext{
${ }^{60}$ Vgl. [Pick90], S.697/698.

${ }^{61}$ Pickering präsentiert allerdings im Zusammenhang mit seinem Modell ein neues Problem für realistische Positionen; siehe S.376.

${ }^{62} \mathrm{Vgl}$. auch [Ging97], S.322ff.
} 
nicht bekannt waren; eine andere Begründung findet sich in seinen Texten nicht. Dieser Sachverhalt scheint aber offensichtlich zur Begründung von Pickerings Ablehnung nichts beizutragen, zumindest ist nicht zu erkennen, wie er dies tun sollte. Dies läßt sich durch Analogbeispiele illustrieren, die nicht dem Bereich der Wissenschaften, sondern dem Alltagsbereich entstammen, auf die sich Pickerings "Begründungsstrategie" aber übertragen lassen sollte: Wenn ich bemerke, daß beim Betätigen des Lichtschalters das Licht nicht aufleuchtet, ich daraufhin die Glühbirne überprüfe, als defekt erkenne und durch eine neue ersetze, woraufhin die Lampe wieder funktioniert, darf ich nach Pickering das Nichtfunktionieren der Lampe beim Einschalten sowie meine diesbezüglichen Überzeugungen nicht dadurch ex post kausal erklären, daß der Glühfaden durchgebrannt war, denn diese Tatsache ist mir zu Beginn der "Untersuchung" noch nicht bekannt. Eine solche "Begründung" ist offenbar keine; wenn es eine wäre, fielen dieser Argumentationsstrategie große Teile der alltagsweltlichen Erklärungen zum Opfer, und es würde ein beträchtlicher Teil der die Alltagswelt betreffenden Überzeugungen untergraben, die eine Person typischerweise hat.

Eine an dieser Stelle vielleicht naheliegende Idee ist die, Pickerings Zurückweisung der genannten kausalen Ex-post-Erklärungen als Folge einer sehr vorsichtigen epistemischen Einstellung aufzufassen, der zufolge die Explanantia solcher Erklärungen nicht als Überzeugungen akzeptiert werden dürfen, weil kein verläßliches Inferenzschema verfügbar ist, das in verläßlicher Weise das Schließen auf diese Explanantia gestatten würde (Schließen auf die beste Erklärung o.ä.). Pickerings Ausführungen zum Stichwort "temporal emergence" und seine eigentümlichen Vorstellungen über die Art der kausalen Wirksamkeit der materiellen Welt sprechen jedoch deutlich gegen diese Interpretation. Er scheint nicht nur eine in epistemischer Hinsicht vorsichtige Haltung einzunehmen und deswegen die Geschichte der Physik bzw. bestimmter Ausschnitte daraus sozusagen als Abfolge kontingenter brute facts zur Kenntnis zu nehmen, sich aber jeder "dahinter zurückgreifenden" Erklärung zu enthalten, sondern mit dem Gedanken an so etwas wie den Entwurf eines neuen Weltbildes zu spielen, das mit dem Common sense und den gegenwärtig etablierten wissenschaftlichen Theorien inhaltlich in Konkurrenz steht. Er müßte letztere also für radikal falsch halten. Die Idee, die er im Auge hat, scheint zu sein, daß sein Modell der Mangel der Praxis eine Art "mangelförmigen", prozeßhaften Weltverlauf beschreiben könnte, der dem zugrundeliegt, was er "temporal emergence" nennt:63

"[...] almost everyone who recognizes temporal emergence in human practice seems to end up flirting with the idea that they are speaking not only about how the nonhuman world necessarily strikes us but about how it actually is". ${ }^{64}$

Pickering selbst stellt einige Spekulationen in dieser Richtung an, ohne sich auf irgendwelche Thesen festzulegen ${ }^{65}$ diese Spekulationen könnten aber das Motiv darstellen, das hinter seiner Zurückweisung kausaler Ex-post-Erklärungen des Prozesses der Gewinnung und Etablierung von Theorien und Modellen etc. und hinter seiner eigentümliche Konzeption der kausalen Wirksamkeit der "materiellen Welt" steht. Ein überzeugender Grund für die Zurückweisung der genannten kausalen Erklärungen und auch realistischer Thesen, die die als Explanans fungierenden Entitäten, Sachverhalte etc. betreffen, ist damit offenbar nicht gegeben.

Fazit dieser Überlegungen im Hinblick auf die Realismusdebatte ist, daß Pickering keine überzeugenden Gründe für seine Zurückweisung der genannten Erklärungen angibt

\footnotetext{
${ }^{63}$ Pickering erwähnt in diesem Zusammenhang ([Pick95b], S.246, 248) spekulative Ideen von Peirce.

${ }^{64}$ [Pick95b], S.248.

${ }^{65}$ [Pick95b], S.246ff.; vgl. aber Fn.18.
} 
und ein dadurch evtl. zustandekommender Konflikt mit realistischen Thesen daher für realistische Positionen keine Bedrohung darstellt.

\section{Der Gedanke der Historizität wissenschaftlichen Wissens}

Im Hinblick auf die Realismusdebatte ist mit dem Gedanken der Historizität wissenschaftlichen Wissens der vielleicht interessanteste Aspekt von Pickerings Modellen wissenschaftlicher Entwicklungsdynamik genannt. Die These, daß die zeitliche Trajektorie des Bestandes akzeptierter Theorien, Modelle etc., die zum Bestand der heute akzeptierten Theorien, Modelle etc. hinführt, zumindest an einigen Stellen von kontingenten Faktoren verschiedener Art beeinflußt wurde (wenn auch nicht ausschließlich durch die Interessen der beteiligten Wissenschaftler, wie es Pickerings älteres Modell suggeriert, und wohl auch nicht an so vielen Stellen, wie es das Modell der Mangel der Praxis nahelegt), ist grundsätzlich plausibel und läßt sich durch wissenschaftshistorische Studien gut belegen. ${ }^{66}$ Wenn sich weiterhin plausibel machen läßt, daß einmal wirksame Einflüsse in einer Weise als Weichenstellungen wirken, daß die weitere Trajektorie einen ganz anderen Verlauf nimmt, als sie es bei anderer Weichenstellung getan hätte, dann scheint damit prima facie ein Problem für realistische Positionen gegeben zu sein, oder zumindest vertritt Pickering diese Ansicht. ${ }^{67}$

Bei etwas genauerer Betrachtung, nämlich dann, wenn man präziser als Pickering formuliert, worin die "Pfadabhängigkeit der Wissensproduktion" besteht, zeigt sich jedoch, daß das Phänomen der Pfadabhängigkeit und damit der Gedanke der Historizität im allgemeinen keineswegs eine Bedrohung für realistische Positionen darstellen, oder jedenfalls nicht auf andere als die üblichen, in der Realismusdebatte verhandelten epistemischen Probleme führen, mit denen man konfrontiert ist, wenn man eine realistische Position vertreten will, die ontologische oder epistemische realistische Thesen einschließt.

Die These, daß es von kontingenten Faktoren abhängt, welche Theorien, Modelle etc. zu dem zu einem Zeitpunkt akzeptierten Gesamtbestand gehören, kann sich offenbar auf verschiedene Arten von Fällen beziehen. Eine Möglichkeit ist die, daß es von kontingenten Faktoren abhängt, welche wahren (annähernd wahren o.ä.) Theorien, Modelle usw. zu diesem Gesamtbestand gehören. Darin liegt für Realisten kein Problem, wie sich durch eine Analogie verdeutlichen läßt: Die Menge der Landschaftsphotos, die eine Gebirgsexpedition mitbringt, ist sicherlich in diesem Sinne "pfadabhängig", aber solange die verwendeten Photoapparate verläßlich funktionieren, ändert das offensichtlich nichts daran, daß es sich um eine Menge korrekter Abbildungen handelt. ${ }^{68}$ Ein Problem könnte sich dann ergeben,

\footnotetext{
${ }^{66}$ Eindrucksvollere Beispiele als die von Pickering finden sich hierfür in den Arbeiten von Peter Galison. Er schildert eine ganze Reihe von Episoden aus der Geschichte der Physik, in denen der "Gang der Wissenschaft" durch kontingente Faktoren und Umstände beeinflußt wurde, die man in traditioneller Sprechweise als eher physikextern bezeichnen würde: Für Einsteins Versuchsaufbau für das EinsteinDeHaas-Experiment lieferte ein Kreiselkompaß, mit dem er im Rahmen seiner Arbeit im Patentamt in Berührung gekommen war, Vorlage und Inspiration ([Gali87], S.34ff.), Schwingers Durchbruch bei der QED beruhte auf einer "black-boxing-Strategie", die er bei der Arbeit am Radar-Projekt im 2.Weltkrieg kennengelernt hatte ([Gali97], S.820ff.), Wilsons Entwicklung der Nebelkammer war motiviert durch das Interesse an meteorologischen Phänomenen ([Gali97], Kap.2). In allen diesen Fällen dürfte kaum ein Zweifel bestehen, daß ohne die genannten "externen" Einflüsse die Menge der zum fraglichen Zeitpunkt akzeptierten physikalischen Modelle, Gesetze, Theorien etc. anders ausgesehen hätte, und daß infolgedessen auch der heutige Bestand an Theorien, Modellen etc. ein anderer wäre, erscheint jedenfalls prima facie nicht unwahrscheinlich.

${ }^{67}$ [Pick95b], S.185.

${ }^{68} \mathrm{Im}$ Fall der von Galison präsentierten Beispiele etwa, die in der vorletzten Fn. erwähnt wurden, spricht wenig dagegen, sie auf dieser Linie zu kommentieren.
} 
wenn der Anspruch erhoben werden sollte, das durchwanderte Gebirge vollständig (in ggf. zu erläuterndem Sinn) abgebildet zu haben, ein analoger Anspruch, über eine vollständige Theorie oder einen vollständigen Satz von Theorien zu verfügen (was immer das genau heißt), ist aber im allgemeinen nicht Teil einer realistischen Position; an ontologische und epistemische realistische Thesen ist jedenfalls kein Anspruch dieser Art geknüpft. ${ }^{69}$

Eine zweite Art von Fällen, auf die sich die These der Pfadabhängigkeit beziehen kann, wären solche, in denen es von kontingenten Faktoren abhängt, ob falsche Sätze als wahr akzeptiert werden oder nicht. In dieser Lesart kann die These offenbar bedrohlich für realistische Positionen sein, ob oder in welchem Maße sie es tatsächlich ist, hängt davon ab, wie plausibel sie gemacht werden kann. Daß es im Laufe der Geschichte der Wissenschaften vorkommt, daß in Einzelfällen falsche Theorien, Modelle etc. akzeptiert werden, dürfte außer Frage stehen, stellt aber für sich genommen kein systematisches Problem dar. Zu einer systematischen Bedrohung für realistische Positionen, die durch die These der Pfadabhängigkeit in der genannten Lesart formuliert wird, werden solche Fälle dann, wenn sie hinreichend häufig auftreten und wenn es Mechanismen gibt, die das Fortbestehen einmal erfolgter falscher Entscheidungen sicherstellen oder wahrscheinlich machen, so daß sie als eine Art unkorrigierte falsche Weichenstellung fungieren. Daß diese Bedingungen für die Geschichte der Physik im allgemeinen, oder häufig erfüllt sind, ist zumindest nicht offensichtlich, insbesondere hinsichtlich des zweiten Punktes, und bei Pickering findet sich dafür keine plausible Begründung. ${ }^{70}$ Ein Blick auf die Geschichte und die Praxis der Physik legt eher das Gegenteil nahe: Bei der Entscheidung etwa, einzelne experimentelle Resultate zu akzeptieren, die von großem Gewicht für das Akzeptieren einer Theorie oder eines Modells sind, mögen kontingente Faktoren eine Rolle spielen, aber da es allgemeine Praxis ist, daß wirklich wichtige, weichenstellende Experimente von verschiedenen Gruppen unabhängig durchgeführt werden, scheint hier gerade ein Mechanismus aufweisbar zu sein, der sicherstellen soll, daß jedenfalls viele kontingente Faktoren nicht zu irreversiblen falschen Weichenstellungen führen können. ${ }^{71}$ Wie verbreitet solche Korrekturmechanismen in der real-existierenden Wissenschaft sind, müßte durch detaillierte Untersuchungen festgestellt werden, zumindest prima facie spricht wenig dagegen, daß sie es in ausreichendem Maße sind, um zu verhindern, daß falsche Weichenstellungen zu einem systematischen Problem

\footnotetext{
${ }^{69}$ Auch wenn ein "Vollständigkeitsanspruch" erhoben wird, muß dieser nicht mit der These der Pfadabhängigkeit kollidieren, solange sich diese These auf die "Zwischenstadien" eines (sich über möglicherweise sehr lange Zeiträume erstreckenden) Forschungsprozesses bezieht, der Vollständigkeitsanspruch aber auf das "Endstadium". Analog kann eine Gebirgsexpedition, deren Aufgabe die vollständige Kartierung des Geländes ist, dies offenbar i.a. auf verschiedenen "Pfaden" erreichen. Was unter "Vollständigkeit" zu verstehen ist, ist allerdings im Fall wissenschaftlicher Theorien (wenn überhaupt, dann) weit weniger klar als im Fall der Kartierung eines Geländes.

${ }^{70}$ Die allgemeinen Hinweise auf kontingente Einflüsse auf allen Ebenen im Verlauf des Prozesses des Mangelns reichen dazu offenbar nicht aus.

${ }^{71}$ Zumindest ein Beispiel dafür, daß kontingente "externe" Einflüsse zeitweilig dazu führen können, daß zweifelhaft begründete und (nach heutigem Kenntnisstand) falsche Ergebnisse akzeptiert werden, findet sich bei Galison: Millikan hat von ihm durchgeführte Höhenstrahlungsmessungen offenbar aufgrund religiös motivierter Überzeugungen als hinreichende Evidenz für die Erzeugung von "neuen" Atomen im Weltraum gedeutet ([Gali87], Kap.3.). In diesem Fall blieb die Akzeptanz seiner Überzeugung jedoch zeitlich und räumlich lokal begrenzt, zumindest in diesem Fall gab es also offenbar Korrekturmechanismen, die eine irreversible falsche Weichenstellung durch kontingente "externe" Faktoren verhindert haben.

Fälle dieser Art lassen sich auch Alan Nelsons Argumentation in [Nels94] entgegenhalten, der zufolge der Streit zwischen Konstruktivisten und Realisten um die Frage der Pfadabhängigkeit remis endet, weil kontrafaktische Sätze über Historisches nicht zu entscheiden sind. Für die Resultate bestimmter komplizierter Experimente an der aktuellen Forschungsfront mag seine Argumentation plausibel sein, nicht aber für gut untersuchte und mittels verschiedener Methoden zugängliche Gegenstandsbereiche.
} 
werden, das realistische Positionen ernsthaft bedrohen könnte.

Wenn es gelingen sollte, plausibel zu machen, daß es in den Wissenschaften vielfach oder zumindest in nennenswertem Maße von kontingenten Faktoren abhängt, ob falsche Theorien, Modelle etc. akzeptiert werden oder nicht, und daß einmal erfolgte falsche Weichenstellungen auch in der Regel, häufig o.ä. nicht mehr korrigiert werden, würde dies realistische Positionen bedrohen. Die Art der Bedrohung wäre sozusagen eine summarische, deren Auswirkungen auf bestimmte ontologische oder epistemische realistische Thesen im konkreten Fall zu prüfen wären: Es müßten die epistemischen Rechtfertigungsgründe, die sich für die Theorie oder die Theorien, das Modell o.ä. vorbringen lassen, auf die sich die jeweilige realistische These bezieht, mit der beschriebenen Pfadabhängigkeitsthese konfrontiert werden. Das Ergebnis könnte sein, daß sich die Rechtfertigungsgründe als zu schwach erweisen, möglich ist aber auch, daß aus der "pauschalen" Pfadabhängigkeitsthese für konkrete Einzelfälle (in bestimmten Bereichen o.ä.) wenig oder nichts folgt. Vom Standpunkt einer realistischen Position aus betrachtet gehen die Überlegungen, die für die Pfadabhängigkeitsthese sprechen, einfach in die üblichen Überlegungen zur epistemischen Rechtfertigung ontologischer oder epistemischer realistischer Thesen ein; darüberhinaus stellen sie sozusagen nichts Besonderes dar.

Eine andere denkbare Lesart der These von der "Pfadabhängigkeit der Wissensproduktion" wäre schließlich eine, die jede Bezugnahme auf die Wahrheit oder Falschheit von Theorien vermeidet und lediglich besagt, daß es von kontingenten Faktoren abhängt, welche von verschiedenen empirisch adäquaten oder, noch allgemeiner, welche von verschiedenen und in keinem erkennbaren Sinn äquivalenten Theorien über denselben Bereich beobachtbarer Gegenstände oder Phänomene akzeptiert wird. Auch dies ist eine These, die zu einer Bedrohung für realistische Positionen werden kann, nämlich dann, wenn sich zusätzlich plausibel machen läßt, daß für die Entscheidungen, eine der Theorien zu akzeptieren, gleichzeitig meistens, typischerweise o.ä. keine guten epistemischen Gründe vorliegen. Daß dies in den real-existierenden Wissenschaften meistens, häufig o.ä. so ist, ist prima facie wenig plausibel und müßte gezeigt werden; bei Pickering findet sich auch hierfür keine Begründung. Aus realistischer Perspektive betrachtet würden Überlegungen, die für eine Pfadabhängigkeitsthese in dieser Lesart sprechen, wiederum in die gängigen Überlegungen zur epistemischen Rechtfertigung ontologischer und epistemischer realistischer Thesen, genauer: zum Problem der Unterbestimmtheit eingehen; darüber hinaus stellen sie wiederum nichts Besonderes dar.

Fazit: Der Gedanke der Historizität wissenschaftlichen Wissens und die damit verbundene These von der "Pfadabhängigkeit der Wissensproduktion" stellen, anders als es prima facie scheinen mag, für realistische Positionen entweder keine Bedrohung dar oder verweisen jedenfalls nicht auf "besondere" Probleme für realistische Thesen, die über das hinausgingen, was gewöhnlich im Zusammenhang mit der epistemischen Rechtfertigung realistischer Thesen diskutiert wird. Bei Pickering finden sich auch für "gewöhnliche" epistemische Probleme im Zusammenhang mit konkreten Theorien, Modellen etc. keine überzeugenden Belege. Sofern man mit einer realistischen Position einen Anspruch auf so etwas wie Vollständigkeit des gewonnenen theoretischen Wissens verbinden möchte, geht von dem von Pickering und anderen Vertretern der Science Studies durch historische Studien gut belegten Punkt, daß die Trajektorie des Bestandes der akzeptierten Theorien, Modelle etc. der Physik durch kontingente Faktoren beeinflußt wird, eine Verunsicherung aus, deren Beseitigung gute Argumente erfordert. Die ontologischen und epistemischen realistischen Thesen, die üblicherweise Teil realistischer Positionen sind, erfordern aber keinen solchen Anspruch, und die meisten realistischen Positionen schließen auch keinen 
solchen Anspruch ein.

\subsection{Fazit}

In traditioneller philosophischer Terminologie ausgedrückt handeln Pickerings Studien, die in dieser Hinsicht repräsentativ für einen großen Teil der Science Studies sind, von der Gewinnung und Etablierung physikalischer Theorien, Modelle etc. Diese Studien zielen darauf, für die Gewinnung und Etablierung von Theorien, Modellen etc. in bestimmten Episoden oder Ausschnitten der Geschichte der Physik Erklärungen der beschriebenen (mehr oder weniger) soziologischen Art zu geben. Pickering hat zu diesem Zweck die zwei diskutierten Modelle für die Entwicklungsdynamik der Physik vorgeschlagen.

Pickering legt in seinen Studien, wie viele, aber keineswegs alle Autoren im Bereich der Science Studies, an diversen Stellen durch seine Formulierungen und den Duktus seiner Texte den Eindruck nahe, daß seine historischen Darstellungen und Analysen im Konflikt oder mindestens in einem Spannungsverhältnis zu realistischen Thesen und Positionen stehen. Bei genauerer Betrachtung finden sich bei ihm jedoch keine überzeugenden Gründe für einen solchen Konflikt oder ein Spannungsverhältnis. Das gilt sowohl für ontologische und epistemische realistische Thesen, für die Pickerings soziologische Erklärungen prima facie bedrohlich aussehen könnten, als auch für semantische und axiologische realistische Thesen, die offenbar gar nicht berührt werden.

Pickerings beiden Modelle besagen oder implizieren per se nichts über bzw. für epistemische Fragen. Fallstudien im Lichte dieser Modelle könnten Resultate haben, die mit ontologischen und epistemischen realistischen Thesen konfligieren, Pickerings eigene Studien, die verschiedene Theorien, Modelle und Experimente der Teilchenphysik behandeln, tun dies jedoch nicht, und es ist prima facie auch kein Grund für die Annahme zu erkennen, daß weitere Fallstudien in größerem Ausmaß solche Resultate liefern sollten. Pickerings konstruktivistische Formulierungen und Redeweisen vom "Konstruieren" und "Produzieren" von Quarks, neutralen Strömen usw. scheinen, soweit erkennbar, trotz des rhetorischen Gewichtes, das - u.a. durch den Titel 'Constructing Quarks' — auf sie gelegt wird, keinen einigermaßen greifbaren und präzisen Gehalt zu haben, jedenfalls keinen, der im Konflikt oder auch nur in einem Spannungsverhältnis zu realistischen Thesen steht. Für Pickerings Zurückweisung kausaler Ex-post-Erklärungen, die auf die Ablehnung bestimmter realistischer Thesen hinauszulaufen scheint, finden sich bei ihm keine überzeugenden Gründe. Schließlich stellt auch seine These über die "Pfadabhängigkeit der Wissensproduktion" genau besehen keine Bedrohung für realistische Thesen und Positionen dar, wenn auch möglicherweise für "Vollständigkeitsansprüche", die aber ohnehin nicht Teil einer realistischen Position sein sollten und es typischerweise auch nicht sind.

Resultat dieser Überlegungen ist also, daß Pickerings Studien und sein daran geknüpfter Sozialkonstruktivismus, entgegen einem naheliegenden ersten Eindruck und offenbar auch entgegen Pickerings (ursprünglicher) eigener Einschätzung, zur Realismusdebatte kaum etwas Nennenswertes beitragen. Ihr Wert als wissenschaftshistorische oder -soziologische Studien bleibt von diesem Befund natürlich völlig unberührt. 


\section{Teil IV}

\section{Das Programm eines selektiven wissenschaftlichen Realismus}





\section{Kapitel 13}

\section{Der Umriß einer selektiven realistischen Position in der wissenschaftstheoretischen Realismusdebatte}

\subsection{Eine Bilanz der bisherigen Debatte}

Mit den Untersuchungen der vorigen Kapitel in der Hand läßt sich jetzt eine Bilanz der bisherigen Debatte über wissenschaftlichen Realismus ziehen. Wie ist es danach um die Möglichkeiten und Aussichten bestellt, eine realistische Position in der wissenschaftstheoretischen Realismusdebatte zu formulieren, zu verteidigen und argumentativ zu begründen?

Zur Charakterisierung dessen, was eine realistische Position ausmacht, wird in der Realismusdebatte eine Vielzahl von Thesen genannt, die teilweise nur grob skizziert und angedeutet, teilweise (mehr oder weniger) präzise formuliert sind. Beim Inhalt dieser Thesen lassen sich, wie in der Einleitung diskutiert, vier Dimensionen unterscheiden und in Form von vier Arten von realistischen Thesen rekonstruieren, nämlich in Form von ontologischen, semantischen, epistemischen und axiologischen realistischen Thesen. Es gibt in der Debatte keinen Konsens zu der Frage, welche Arten von Thesen konstitutiv für eine realistische Position sind, insbesondere ob ontologische Thesen oder semantische plus epistemische Thesen eine angemessene Konkretisierung der allgemeinen, hinter vielen realistischen Positionen stehenden Intuition ergeben, daß die Welt unabhängig vom menschlichen Geist und menschlicher Erkenntnis ist, Menschen aber dennoch Wissen über sie haben können und haben. Beide Möglichkeiten erfordern eine Erläuterung, worin die Unabhängigkeit besteht, und eine solche Erläuterung läßt sich sowohl für ontologische realistische Thesen finden (wie in der Einleitung angegeben) als auch für semantische realistische Thesen (wie im Kapitel über Wahrheits-, Bedeutungs- und Referenztheorien diskutiert).

Die Argumente, die in der Realismusdebatte zur Begründung realistischer Positionen ins Feld geführt werden, lassen sich in drei Typen unterteilen, nämlich Präsuppositionsargumente, Kontinuitätsargumente und die Varianten des Wunderarguments. Die verschiedenen Argumente richten sich gegen verschiedene Diskussionsgegner und sollen verschiedene der genannten Arten realistischer Thesen begründen. Die Beurteilung der verschiedenen Argumente hinsichtlich ihrer Begründungsleistungen und Überzeugungskraft fällt unterschiedlich aus, aus realistischer Perspektive erweisen sich jedoch sämtliche Argumente als 
mehr oder weniger enttäuschend, denn zumindest in ihrer derzeitigen Form liefert keins davon eine in jeder (oder auch nur in fast jeder) Hinsicht zufriedenstellende Begründung realistischer Thesen.

Präsuppositionsargumente leisten, wie oben diskutiert, nichts Erkennbares für die Begründung realistischer Thesen, und dies scheint für alle Argumente dieses Typs zu gelten, nicht nur für die zwei oben untersuchten.

Von den Kontinuitätsargumenten lassen sich die "destruktiven", die bestreiten, daß die Unterscheidung beobachtbar/unbeobachtbar eine für philosophische Zwecke brauchbare Grenzziehung ergibt, durch eine Präzisierung der Unterscheidung entkräften. Die "positiven" Kontinuitätsargumente, die an vortheoretische Intuitionen über Kontinuitäten auf der Sachebene und den "merkwürdigen" anthropozentrischen Charakter des Weltbildes von Antirealisten appellieren, können möglicherweise dazu beitragen, jemanden von realistischen Thesen zu überzeugen, der diese Intuitionen hat; für konsequente, reflektierte Antirealisten haben sie jedoch keine Überzeugungskraft. Ähnliches gilt für die "positiven" epistemischen Kontinuitätsargumente, die auf Beobachtungsverfahren, Inferenzschemata etc. hinweisen, deren Output teilweise oder ausschließlich Unbeobachtbares zum Inhalt hat, und die (teilweise) die Verläßlichkeit der Beobachtungsverfahren, Inferenzschemata etc. (skizzenhaft) induktiv begründen: Diese Argumente setzen allesamt Inferenzschemata (und evtl. Prämissen) voraus, die ein konsequenter, reflektierter Antirealist nicht akzeptiert, und haben daher für diesen keine Überzeugungskraft, wenn auch vielleicht für jemanden, der die jeweiligen Voraussetzungen akzeptiert.

Von den diversen Varianten des Wunderargumentes werden einige durch die diskutierten Einwände entkräftet, insbesondere durch den von Laudan vorgetragenen, der das Wunderargument mit dem Theorienwandel im Verlauf der Wissenschaftsgeschichte konfrontiert. Dies gilt vor allem für Varianten des Wunderarguments, die sich auf ein sehr allgemeines Explanandum beziehen und ein sehr umfassendes, allgemeines Explanans vorsehen, etwa die (annähernde) Wahrheit aller derzeitigen wissenschaftlichen Theorien o.ä. Für Varianten des Wunderarguments, die sich auf ein enger spezifiziertes Explanandum beziehen und ein "eingeschränkteres" Explanans vorsehen, ist mangels hinreichender wissenschaftshistorischer Studien beim derzeitigen Stand der Debatte nicht fundiert zu beurteilen, inwieweit sie von den diskutierten Einwänden getroffen werden; von daher ist derzeit offen, wie ihre Leistungen bei der Begründung realistischer Thesen zu bewerten sind. In jedem Fall gilt aber für die diversen Varianten des Wunderarguments, daß sie ein (mehr oder weniger allgemein oder eng spezifiziertes) Inferenzschema für Schlüsse auf die beste Erklärung voraussetzen und damit, wie schon die epistemischen Kontinuitätsargumente, ein Inferenzschema, das ein konsequenter, reflektierter Antirealist nicht akzeptiert.

Die Untersuchung der Argumente, die in der Realismusdebatte zur Begründung realistischer Positionen ins Feld geführt werden, zeigt also, daß alle diese Argumente (auch wenn man von "Detailproblemen" der genauen Formulierung etc. absieht) für konsequente, reflektierte Antirealisten keine Überzeugungskraft haben. Die Kontinuitätsargumente und einige Varianten des Wunderarguments könnten, wenn ihre "Detailprobleme" gelöst werden können, dazu dienen, Personen von einer realistischen Position zu überzeugen, die noch keine systematische, reflektierte Position in der Realismusdebatte eingenommen haben (jedenfalls keine antirealistische) und die Intuitionen und/oder Inferenzschemata teilen bzw. akzeptieren, die diese Argumente in Anspruch nehmen. In der Diskussion zwischen Realisten und konsequenten, reflektierten Antirealisten jedoch läßt sich mit diesen Argumenten nichts ausrichten, und sofern man von realistischer Seite den Wert eines Argumentes nach seiner Überzeugungskraft in dieser Diskussionskonstellation bemißt, enttäuschen diese Ar- 
gumente damit vollständig.

Neben diesem negativen Befund hat die Untersuchung der zur Begründung realistischer Positionen vorgebrachten Argumente, insbesondere der Kontinuitätsargumente, einige Hinweise darauf ergeben, daß dieser Befund zu tun haben könnte mit prinzipiellen Grenzen der Möglichkeiten und Aussichten, eine realistische Position argumentativ zu begründen und einen Diskussionsgegner von ihr zu überzeugen: Einen solchen Hinweis liefert die Tatsache, daß es für die "Kraftlosigkeit" von Kontinuitätsargumenten in der Diskussion mit konsequenten Antirealisten nicht wesentlich ist, daß die Grenze beobachtbar/unbeobachtbar den strittigen Bereich begrenzt, sondern daß in einer analogen Diskussion, in der diese Grenze durch eine andere, intuitiv bizarre Grenze ersetzt würde, dieselbe argumentative Konstellation zustandekäme, analoge Kontinuitätsargumente also ebenfalls keine Überzeugungskraft entwickeln würden. Einen weiteren solchen Hinweis liefert die Einsicht, daß alle Argumente, die eine realistische These über Unbeobachtbares etablieren sollen, ein Inferenzschema in Anspruch nehmen müssen und daher nur für jemanden Überzeugungskraft haben, der dieses Inferenzschema akzeptiert, so daß ein konsequenter Antirealist nicht durch Argumente für eine realistische Position zu überzeugen ist, wenn er "hinreichend wenige" Inferenzschemata akzeptiert, insbesondere keine, die von Prämissen, die sich auf Beobachtbares beziehen, auf Konklusionen führen, die sich auf Unbeobachtbares beziehen.

Deutlich besser als die Aussichten, einen antirealistischen Diskussionsgegner von einer realistischen Position zu überzeugen, sehen aus realistischer Perspektive die Chancen aus, eine realistische Position zu verteidigen. Bei der Untersuchung neuerer Positionen, die in der Realismusdebatte als Konkurrenten realistischer Positionen auftreten, fanden sich jedenfalls keine überzeugenden Argumente prinzipieller Art gegen realistische Positionen und/oder für die vorgeschlagenen Alternativen. Es ergaben sich allerdings im Verlauf der Untersuchungen der bisherigen Kapitel verschiedene Befunde, die gewissermaßen Schranken oder Randbedingungen für eine tragfähige, haltbare realistische Position darstellen. Der vielleicht wichtigste davon ist, daß eine "unfragmentierte" realistische Position, die eine realistische Einstellung zu allen gegenwärtig akzeptierten Theorien, Gesetzen etc. einschließt, unplausibel und kaum zu verteidigen ist, wenn man ein einigermaßen adäquates Bild von der Geschichte und der Praxis der real-existierenden Wissenschaften hat. Ein anderer Punkt ist der, daß eine haltbare realistische Position keine "Vollständigkeitsansprüche" irgendwelcher Art erheben sollte. ${ }^{1}$

Den Grundriß einer moderaten, "fragmentierten" realistischen Position, die diese Befunde berücksichtigt, skizzieren Hacking und Cartwright. Obwohl ihre Idee eines experimentellen Realismus und ihre Orientierung an der Praxis der Physik und die von dort bezogenen Anregungen und konkreten Beispiele an Intuitionen appellieren, die von vielen geteilt werden dürften, die in irgendeiner Weise zu einer realistischen Position neigen, und daher intuitiv sehr plausibel und attraktiv aussehen, liefern Hacking und Cartwright aber für die genaue Formulierung einer solchen moderaten realistischen Position und ihre argumentative Begründung und Verteidigung doch nicht mehr als eben eine Skizze und vielleicht einige Bausteine.

Wenn man zu einer realistischen Position in der wissenschaftstheoretischen Realismusdebatte neigt, stellt sich an diesem Punkt offenbar die Frage, welches die angemessenen Konsequenzen sind, die aus dieser Bilanz der bisherigen Debatte zu ziehen sind. Was folgt, gegeben den bilanzierten Stand der Dinge, zwingend oder plausiblerweise, für realistische

\footnotetext{
${ }^{1}$ Vgl. S.376ff.
} 
Positionen, wenn man aus der bisherigen Debatte gelernt hat, was daraus zu lernen ist?

Zunächst einmal ist der Stand der Dinge natürlich nicht, daß realistische Positionen in der Wissenschaftstheorie als in jeder Form widerlegt oder grundsätzlich unhaltbar gelten müssen, wie einige an der Debatte beteiligte Autoren in ihren feuilletonistischeren Momenten gelegentlich verkünden ${ }^{2}$ — auch wenn sehr "ambitionierte" realistische Positionen, wie sie etwa Putnam, Smart und Boyd im Auge hatten, nicht mehr plausibel erscheinen. Was die Resultate der bisherigen Debatte nahelegen, ist vielmehr dreierlei.

Zum einen sollte genauer bestimmt werden, welche Thesen eine realistische Position konstituieren, und diese Thesen sollten präziser gefaßt werden, als dies in der Realismusdebatte meistens geschieht, da in diesem Punkt in der Literatur einige Unklarheit herrscht, außerdem aber offenbar tiefgreifende Meinungsunterschiede bestehen, und zwar nicht nur zwischen Realisten und Antirealisten, sondern auch unter den Anhängern realistischer Positionen. Dies betrifft sowohl die Reichweite realistischer Thesen, d.h. die Frage, auf welchen Teil der Theorien, Gesetze etc. der real-existierenden Wissenschaften sie sich beziehen, als auch die Art der Thesen. Insbesondere Differenzen über den letzteren Punkt werden nur selten und eher am Rande explizit gemacht, sind aber wichtig, weil sie die Bestimmung des Ziels betreffen, das die in der Realismusdebatte von realistischer Seite vorgebrachten Argumente erreichen sollen, um erfolgreich zu sein. Es sollte daher - abweichend von dem, was im Mainstream der wissenschaftstheoretischen Realismusdebatte üblich ist ${ }^{3}$ - herausgearbeitet werden, welche Arten von Thesen (ontologische, semantische, epistemische, axiologische) für eine angemessene realistische Position konstitutiv sind und wie diese Thesen genau zu spezifizieren sind, und damit u.a. auch, welche Reichweite sie haben sollen.

Wenn so einigermaßen genau und angemessen definiert ist, was eine realistische Position ausmacht, und somit klar ist, wofür genau man eigentlich argumentieren muß, wenn man andere für den wissenschaftlichen Realismus gewinnen möchte, dann sollte, zweitens, den genannten Hinweisen auf so etwas wie prinzipielle Grenzen der Möglichkeiten, eine realistische Position argumentativ zu begründen, nachgegangen werden und untersucht werden, was sich über solche Grenzen sagen läßt. Wenn es solche Grenzen gibt, ist es offenbar für die wissenschaftstheoretische Realismusdebatte wichtig, ein möglichst angemessenes Bild davon zu gewinnen, da dann durch diese Grenzen festgelegt ist, was sozusagen bestenfalls von einem Argument für eine realistische Position zu erwarten ist, was also von realistischer Seite durch die Suche nach möglichst guten, überzeugungskräftigen Argumenten und die Arbeit an deren Formulierung bestenfalls zu erreichen ist.

Drittens sollte schließlich geprüft werden, welche der oben untersuchten Argumente, die in der bisherigen Realismusdebatte zur Begründung realistischer Positionen ins Feld geführt werden, sich evtl. (ggf. im Rahmen dessen, was innerhalb der prinzipiellen Grenzen zu erreichen ist) grundsätzlich zur argumentativen Begründung und/oder Verteidigung der Thesen eignen, die als konstitutiv für wissenschaftlichen Realismus identifiziert wurden, ob diese Argumente möglicherweise durch Modifikationen und Verbesserungen zu überzeugungskräftigeren gemacht werden können und ob sich vielleicht sogar neue Argumente für die realistischen Thesen finden lassen.

Der erste Schritt in Richtung auf eine tragfähige realistische Position sollte also sein, die Frage zu beantworten, welche Art(en) realistischer Thesen Teil einer angemessenen realistischen Position sind, d.h. einer Position, die die von Nagel und Wright genannte

\footnotetext{
${ }^{2}$ Vgl. Fines ein wenig reißerische These "Realism is dead" ([Fine84a], S.83).

${ }^{3}$ Vgl. Abschnitt 1.4.3.
} 
allgemeine Intuition ${ }^{4}$ durch Thesen konkretisiert, die das und nur das beinhalten, was man sozusagen als wissenschaftlicher Realist sagen möchte, und so in intuitiv plausibler Weise zum Ausdruck bringen, was wissenschaftlicher Realismus ist.

\subsection{Welche Art(en) von Thesen ist (sind) konstitutiv für eine realistische Position?}

\subsubsection{Ontologische oder semantische plus epistemische Thesen als Herz- stück einer realistischen Position?}

Wie bereits vorne ${ }^{5}$ erwähnt, finden sich in der Literatur zur Realismusdebatte häufig zwei verschiedene Ansichten zu der Frage, von welcher Art die Thesen sind, die das Herzstück einer realistischen Position bilden: Diese Rolle wird, explizit oder implizit, entweder (einer oder mehreren) ontologischen realistischen Thesen oder (einer oder mehreren) semantischen (plus evtl. epistemischen) realistischen Thesen zugeschrieben. Durch diese Alternative sind zwei unterschiedliche Weisen gegeben, die von Nagel und Wright genannte allgemeine Intuition zu konkretisieren: Im einen Fall geschieht dies durch ontologische realistische Thesen, deren zwei Aspekte ${ }^{6}$ den beiden Komponenten der Intuition (der "anmaßenden" und der "bescheidenen") entsprechen, im anderen Fall durch semantische realistische Thesen zusammen mit epistemischen realistischen Thesen, die je einer der beiden Komponenten der von Nagel und Wright beschriebenen Intuition entsprechen. In den Untersuchungen der vorigen Kapitel war diese Alternative mehrmals berührt, aber nicht diskutiert worden. ${ }^{7}$

Um zu entscheiden, ob eine der durch diese Alternative gegebenen Möglichkeiten zu einer angemessenen realistischen Position führt, und wenn ja, welche, empfiehlt es sich offenbar, sich für konkrete Beispielfälle aus verschiedenen Gegenstandsbereichen bzw. Diskursen anzusehen, wodurch in diesen Fällen in intuitiv plausibler Weise eine realistische Einstellung zum Ausdruck gebracht wird. Außerdem sollte man sich zu diesem Zweck nach anderen Gründen und Motiven umsehen, die eventuell für oder gegen eine der beiden Möglichkeiten sprechen, und dann ggf. die Intuitionen in bezug auf Einzelfälle und andere Gründe und Motive gegeneinander abwägen. Wie meistens, wenn es um die Formulierung grundlegender philosophischer Einstellungen und Positionen und die Konkretisierung tiefliegender allgemeiner Intuitionen geht, sind hier "K.o.-Argumente" nicht zu erwarten, da die relevanten Intuitionen in der Regel nicht allgemein geteilt werden und natürlich auch nicht "sakrosankt" sind. Dies liegt jedoch in der Natur der Sache und ist nicht etwa ein Spezialproblem der Realismusdebatte oder gar nur des wissenschaftstheoretischen Teils dieser Debatte.

\footnotetext{
${ }^{4}$ Siehe S.2.

${ }^{5}$ Siehe Kap.1, bes. S.9, 15.

${ }^{6}$ Einerseits die These, daß bestimmte Entitäten existieren und bestimmte Eigenschaften haben, daß bestimmte Sachverhalte vorliegen etc., andererseits die Bestimmung, daß dies unabhängig von menschlicher Erkenntnis so ist.

${ }^{7}$ In dem Teil über Bedeutungs-, Referenz- und Wahrheitstheorien ging es darum, welche Art dieser Theorien sich zur Erläuterung semantischer realistischer Thesen eignet und welche argumentativen Vorzüge oder Nachteile eine realistische Position hat, wenn sie eine bestimmte (Art) dieser Theorien einschließt. Ob eine solche Theorie bzw. eine sich auf diese stützende semantische These im Zentrum einer realistischen Position stehen sollte, wurde dort nicht thematisiert.
} 


\section{Intuitionen, die für ontologische Thesen und gegen semantische Thesen als Herzstück einer realistischen Position sprechen}

Wenn man in diesem Sinn den Blick auf konkrete Beispielfälle richtet, die für die wissenschaftstheoretische Realismusdebatte relevant sind, wird deutlich, daß (zumindest) hier ontologische realistische Thesen eher geeignet zu sein scheinen als semantische realistische Thesen, um in intuitiv plausibler Weise eine realistische Einstellung zum Ausdruck zu bringen.

Um dies zu sehen, betrachtet man am besten zunächst einige semantische realistische Thesen der Form (SR1), bei denen mit Hilfe von Tarskis semantischer Wahrheitstheorie erläutert wird, worin die Wahrheit (oder Falschheit) der Sätze, Theorien o.ä. besteht, auf die sie sich beziehen. Solche Thesen sehen intuitiv zumindest nicht hinreichend aus als Formulierung einer realistischen Einstellung zu den Sätzen, Theorien o.ä.: Ohne ergänzende epistemische realistische Thesen über diese Sätze, Theorien o.ä. befriedigen sie schon deswegen nicht, weil die semantischen Thesen der Form (SR1) nur eine der beiden Komponenten der von Nagel und Wright genannten Intuition konkretisieren (nämlich die "bescheidene"). Auch zusammen mit epistemischen realistischen Thesen der Form (ER) stellen sie aber nicht zufrieden, denn daß für einen Satz, eine Theorie o.ä. eine mit Hilfe von Tarskis Wahrheitstheorie erläuterte These der Form (SR1) und eine These der Form (ER) gelten, schließt per se nicht aus, daß es sich bei den Entitäten, Eigenschaften etc., die den Satz, die Theorie o.ä. in der durch die Wahrheitstheorie erläuterten Weise wahr oder falsch machen, sozusagen nicht um die intendierten Entitäten, Eigenschaften etc. handelt, sondern um "Ersatzentitäten", "-eigenschaften" etc. Z.B. kann man für den Satz

'Für alle Festkörper aus Eisen gilt: Wenn ein Gegenstand zum Zeitpunkt $t_{1}$ die Temperatur $T_{1}$ und die Länge $l_{1}$ hat und zum Zeitpunkt $t_{2}$ die Temperatur $T_{2}$ und die Länge $l_{2}$, dann gilt $l_{2}=l_{1}\left(1+0.000012\left(T_{2}-T_{1}\right)\right)^{\prime}$

mit Hilfe von Tarskis semantischer Wahrheitstheorie erläutern, wodurch er wahr bzw. falsch gemacht wird, und dabei den theoretischen Ausdrücken 'Temperatur $T_{1}$ ' und 'Temperatur $T_{2}$ ' Zahlen als Referenzgegenstände zuzuordnen, also mathematische, nicht physikalische Entitäten. ${ }^{8}$ Ein anderes Beispiel wäre, daß man auf einen Satz wie

'Die Spannung des Drahtes $D$ zur Erde beträgt 17 Kilovolt'

Tarskis Wahrheitstheorie anwendet und dabei dem theoretischen Prädikat 'die Spannung von X zur Erde' als Referenzentität die Zeigerstellung eines (mit dem Referenzgegenstand von ' $\mathrm{X}$ ' verbundenen) Voltmeters zuordnet. In beiden Fällen sind die Wahrheitswerte der Sätze dann unabhängig von menschlichen epistemischen Mitteln zum Erkennen dieser Wahrheitswerte im Sinne der Erläuterungen (UvmeM1) und (UvmeM2). ${ }^{9}$ Jemand, der den theoretischen Ausdrücken in den beiden Beispielsätzen in der genannten Weise "Ersatzentitäten" zuweist, kann also Thesen der Form (SR1) in bezug auf diese Sätze akzeptieren und auch Thesen der Form (ER) und hat damit zwei Überzeugungen, die in gewisser Weise die beiden Komponenten der von Nagel und Wright beschriebenen Intuition konkretisieren. Intuitiv scheint er damit dennoch keine realistische Einstellung zu den beiden

\footnotetext{
${ }^{8}$ In dieser Weise verfährt Carnap verschiedentlich; vgl. Abschnitt 2.4. Das Beispiel stammt aus [Carn39], S.58f.

${ }^{9}$ Siehe Kap.1. Damit (UvmeM1) für den zweiten Beispielsatz erfüllt ist, muß man allerdings ein Voltmeter sozusagen als physikalisches System betrachten, für das nicht wesentlich ist, daß Menschen es zu Messungen benutzen können.
} 
Sätzen einzunehmen; entsprechend scheinen in diesen Fällen die beschriebenen Thesen der Form (SR1) und (ER) intuitiv nicht geeignet, um eine realistische Einstellung zum Ausdruck zu bringen.

Ein naheliegender Einwand gegen diese Bewertung der Beispielfälle ist, daß jemand, der eine realistische Einstellung durch semantische und epistemische realistische Thesen zum Ausdruck bringen will, die dazu verwendeten semantischen Thesen der Form (SR1) meistens durch Thesen der Form (SR2) ergänzt und daß dadurch die Zuschreibung von Ersatzentitäten gerade ausgeschlossen wird, die für die obigen Beispiele entscheidend ist. Dieser Einwand trägt jedoch gegen die oben genannten Intuitionen wenig aus: Eine intuitiv angemessene Weise, eine realistische Einstellung zum Ausdruck zu bringen, soll die beiden Komponenten der von Nagel und Wright beschriebenen Intuition konkretisieren, die bescheidene und die anmaßende. Ersteres leistet (in gewisser Weise) eine These der Form (SR1), indem sie die Unabhängigkeit der semantischen Relationen zwischen Sätzen bzw. Ausdrücken und Wahrheitsbedingungen bzw. Referenzentitäten von menschlichen epistemischen Mitteln konstatiert, letzteres leistet eine These der Form (ER). Eine These der Form (SR2) hat mit der Unabhängigkeit der semantischen Relationen nichts zu tun und scheint zur Konkretisierung der von Nagel und Wright genannten zentralen Intuition nichts beizutragen. Solche Thesen dennoch als konstitutiv für eine realistische Einstellung zu erklären und dadurch Problemfälle wie die oben genannten zu "beseitigen", sieht daher intuitiv nicht plausibel aus. Die obigen Beispielfälle deuten trotzdem darauf hin, daß das, wovon die bescheidene Komponente der von Nagel und Wright beschriebenen Intuition handelt, durch semantische realistische Thesen nicht angemessen formuliert wird, daß es nämlich dabei nicht (oder jedenfalls nicht nur) um die Unabhängigkeit semantischer Relationen von menschlicher Erkenntnis geht, sondern eher (oder zumindest auch) um die Existenz und die "Natur" der Entitäten, Eigenschaften etc., zu denen Sätze, Theorien etc. evtl. in semantischen Relationen stehen. Fazit: Semantische realistische Thesen der Form (SR1) plus epistemische Thesen der Form (ER) sehen intuitiv nicht hinreichend aus als Formulierung einer realistischen Einstellung und ergänzende Thesen der Form (SR2) erscheinen als konstitutiver Teil einer realistischen Einstellung nicht plausibel, weil ihr Inhalt intuitiv wenig mit dem zu tun hat, wovon die zentrale, von Nagel und Wright beschriebene Intuition handelt.

Wichtiger noch als der Befund, daß semantische realistische Thesen (auch zusammen mit epistemischen) nicht hinreichend sind für eine angemessene Formulierung einer realistischen Einstellung, ist vielleicht, daß auch nicht klar zu sein scheint, daß sie dazu notwendig sind. In konkreten Beispielfällen scheinen vielmehr ontologische realistische Thesen der Form (OR) hinreichend zu sein, um das auszudrücken, was intuitiv für eine realistische Einstellung konstitutiv ist. Angenommen etwa, es geht um eine realistische Einstellung in bezug auf eine Theorie der Planetenbewegungen im Sonnensystem. Eine entsprechende ontologische realistische These wäre, daß die Planeten, Monde etc., von denen die Theorie handelt, existieren und die angegebenen Massen haben, daß zwischen ihnen die von der Theorie angegebenen Kräfte wirken, daß sich die Himmelskörper aufgrund der Kräfte auf den von der Theorie angegebenen Bahnen bewegen usw. und daß all dies unabhängig von menschlicher Erkenntnis existiert, der Fall ist bzw. geschieht. Für die letztere Unabhängigkeitsaussage kann man z.B. eine Erläuterung der Form (UmeV) geben, daß das Sonnensystem auch dann existieren würde und (im wesentlichen) so sein würde, wie es ist, wenn es keine Menschen gäbe, oder eine Erläuterung der Form (UvmE2), daß die Existenz und das Verhalten der Planeten, Massen, Kräfte usw. durch menschliche Erkenntnis- und Wahrnehmungszustände, -verfahren etc. kausal (praktisch) nicht beeinflußt werden, oder 
eine Erläuterung der Form (UvmE3), daß die Planeten etc. nicht durch mentale Entitäten konstituiert werden. Eine in dieser oder ähnlicher Weise erläuterte ontologische realistische These der Form (OR) (oder evtl. eine "abgeschwächte" Variante davon ${ }^{10}$ ) scheint sozusagen alles zu enthalten, was man intuitiv als wissenschaftlicher Realist als konstitutiv für eine realistische Einstellung in bezug auf die Theorie des Planetensystems betrachtet, und für Beispiele wie die oben genannten Sätze über die thermische Ausdehnung von Eisen oder über elektrische Spannungen gilt Entsprechendes. Intuitiv scheint in solchen Fällen das Thema semantische Theorien wenig mit dem zu tun zu haben, was für eine realistische Einstellung in bezug auf physikalische Theorien, Sätze etc. konstitutiv ist, so daß es nicht erforderlich zu sein scheint, für diese physikalischen Theorien, Sätze etc. eine semantische Theorie, sprich: eine Wahrheitstheorie oder eine Bedeutungs- oder Referenztheorie, anzugeben, um eine realistische Einstellung zum Ausdruck zu bringen. ${ }^{11}$

\section{Gründe und Motive dafür, semantische Thesen als Herzstück einer realisti- schen Position anzusehen}

Den beschriebenen Intuitionen, die für ontologische Thesen und gegen semantische Thesen als Herzstück einer realistischen Position sprechen, lassen sich verschiedene Gründe und Motive entgegenhalten, die dafür sprechen, diese Rolle semantischen realistischen Thesen zuzuweisen. Diese Gründe und Motive werden in der Literatur teilweise explizit zugunsten der These angeführt, daß semantische realistische Thesen konstitutiv für eine realistische Position sind, teilweise scheinen sie einer entsprechenden Überzeugung implizit zugrunde zu liegen.

Zweifel, daß sich durch ontologische realistische Thesen zu allen Gegenstandsbereichen bzw. Diskursen in intuitiv plausibler Weise eine realistische Einstellung zum Ausdruck bringen läßt Einige Intuitionen, die gleichsam indirekt dafür sprechen, daß semantische realistische Thesen konstitutiv für wissenschaftlichen Realismus sind, werden sichtbar, wenn man das Blickfeld über die wissenschaftstheoretische Realismusdebatte hinaus erweitert und neben den Sätzen, Theorien etc., um die es dort geht, auch Sätze oder Theorien betrachtet, die ihrer Form nach ähnlich aussehen, deren Inhalt aber andere Gegenstandsbereiche bzw. Diskurse betrifft, wie etwa die folgenden:

1. Es existiert eine Primzahl zwischen 7 und 15 , die die Gleichung $x^{2}-9 x-22=0$ löst.

2. Es gibt Handlungen, die moralisch verwerflich sind und deren Verwerflichkeit nicht aus ihren Folgen resultiert.

3. In dem Textverarbeitungsprogramm auf meinem PC gibt es einen Zwischenspeicher, wo alle ausgeschnittenen oder gelöschten Textstücke abgelegt und bis zum Beenden des Programms aufbewahrt werden.

4. In der Basis der Partei gibt es eine starke Strömung, die die Sparpläne der Regierung ablehnt.

\footnotetext{
${ }^{10}$ Soll heißen: dahingehend modifizierte Aussagen, daß die Kräfte, Massen, Bahnen etc. annähernd die von der Theorie angegebenen Werte, Formen etc. haben u.ä.

${ }^{11}$ Damit ist noch nichts darüber gesagt, ob und inwieweit bestimmte Wahrheits-, Bedeutungs- und Referenztheorien kompatibel mit einer realistischen Position sind, sondern nur, daß sie für diese nicht konstitutiv sind oder jedenfalls nicht in deren Zentrum stehen; siehe dazu Abschnitt 13.3.
} 
5. Bei dem Flugzeugabsturz in der vorigen Woche gab es für den Piloten keine Chance, sich zu retten, nachdem das Höhenruder blockiert war.

6. Das Gutachten hat einen springenden Punkt, der bei oberflächlicher Lektüre kaum auffällt.

7. Der Babelfisch [...] ist klein, gelb und blutegelartig und wahrscheinlich das Eigentümlichste, was es im gesamten Universum gibt. Er lebt von Gehirnströmen, die er [...] seiner Umgebung entzieht [...] und scheidet ins Gehirn seines Wirtes eine telepathische Matrix aus [...] Der praktische Effekt der Sache ist, daß man mit einem Babelfisch im Ohr augenblicklich alles versteht, was einem in irgendeiner Sprache gesagt wird. ${ }^{12}$

Sätze wie diese scheinen die Existenz bestimmter Entitäten, Ereignisse etc. und deren Eigenschaften und Verhalten zum Inhalt zu haben (oder zu implizieren), genau wie die oben genannten Sätze einer Theorie der Planetenbewegungen im Sonnensystem und andere wissenschaftliche Sätze und Theorien. So wie aus letzteren durch Hinzufügen eines Satzes über die Unabhängigkeit der beschriebenen Planeten, Kräfte etc. von menschlicher Erkenntnis ontologische realistische Thesen der Form (OR) werden, lassen sich auch die aufgelisteten Sätze durch einen Satz über die Unabhängigkeit der beschriebenen Entitäten, Ereignisse etc. ergänzen. Eine plausible Erläuterung von 'unabhängig von menschlicher Erkenntnis' wird in einigen Fällen etwas anders aussehen als für die Theorie der Planetenbewegung: Für alle erwähnten Entitäten und Eigenschaften ist sicherlich eine Erläuterung der Form (UvmE3) plausibel, daß sie nicht durch mentale Entitäten konstituiert werden. Eine Erläuterung der Form (UvmE), daß die Entitäten, Eigenschaften etc. auch dann existieren, vorliegen etc. würden, wenn es keine Menschen gäbe, dagegen ist vielleicht im Fall der mathematischen Entitäten (1) und dem des Babelfischs (7) plausibel, für die anderen Beispielsätze jedoch nicht. Für die Sätze (2) und (3), die von Handlungen, Computern und Textverarbeitungsprogrammen und deren Eigenschaften handeln, ist dafür eine Erläuterung der Form (UvmE1a) plausibel, daß diese auch dann existieren bzw. vorliegen würden, wenn niemand von genau diesen Handlungen, Computern etc. wüßte. In dieser oder ähnlicher Weise sollte sich für alle Sätze der Liste eine in plausibler Weise erläuterte ontologische realistische These der Form (OR) formulieren lassen.

Dennoch ist es in diesen Fällen — oder zumindest in einigen von diesen Fällen — intuitiv vielleicht weniger offensichtlich, daß sich durch diese Thesen in angemessener Weise eine realistische Einstellung zu den Sätzen bzw. den Entitäten, Eigenschaften etc., von denen sie handeln, zum Ausdruck bringen läßt, als es im Fall der Sätze über das Planetensystem der Sonne aussah. Zumindest prima facie und ohne weitere Erläuterungen haben Zweifel vielleicht eine gewisse Plausibilität, ob im Fall der Diskurse, zu denen die aufgelisteten Sätze gehören, bzw. der zugehörigen Gegenstandsbereiche ontologische realistische Thesen tatsächlich konstitutiv für eine realistische Position sind. Wenn aus solchen Zweifeln eine Überzeugung wird, daß sich Thesen der Form (OR) im Fall dieser Diskurse bzw. Gegenstandsbereiche nicht eignen, um eine realistische Einstellung zum Ausdruck zu bringen, und wenn man außerdem der Ansicht ist, daß für alle Diskurs- bzw. Gegenstandsbereiche dieselbe Art von Thesen konstitutiv für eine realistische Position ist, ${ }^{13}$ dann folgt daraus die Überzeugung, daß auch für eine realistische Position in der Wissenschaftstheorie nicht ontologische realistische Thesen der Form (OR) konstitutiv sind.

\footnotetext{
${ }^{12}$ Dies ist ein Zitat aus dem Roman [Adam81] (S.60).

${ }^{13}$ Vgl. Kap.1.
} 
Wenn man nach einer genaueren Charakterisierung solcher Zweifel sucht, sieht man schon auf den ersten Blick, daß der letzte Satz der Liste aus der Reihe herausfällt. Er läßt einen Punkt erkennen, der im Zusammenhang mit ontologischen realistischen Thesen wichtig ist, aber für die Zweifel, die die anderen Beispielfälle der Liste betreffen, wenig Bedeutung haben dürfte: Das Beispiel (7) entstammt einem literarischen Werk, in diesem Fall einem Roman, und damit einem fiktionalen Kontext. Jemand, der einen Roman schreibt, daraus vorliest, in einer Theateraufführung spricht o.ä., trifft damit keine Aussagen, stellt also dadurch keine Behauptungen auf, sondern vollzieht einen Sprechakt anderer Art. Die dabei verwendeten Sätze können aber grundsätzlich in anderen Situationen auch als Behauptungen geäußert werden, d.h., man kann dieselben Sätze einerseits in fiktionalen Kontexten verwenden, andererseits um eine Aussage zu treffen. Dies gilt für (7) genau wie für die oben genannten Sätze inklusive derer über das Planetensystem und für daraus evtl. durch Ergänzung gewonnene ontologische realistische Thesen. Es spricht also nichts dagegen, daß sich (7) grundsätzlich eignet, um daraus (durch Ergänzung einer "Unabhängigkeitsklausel") eine ontologische realistische These zu gewinnen, die konstitutiv für eine realistische Position ist. ${ }^{14}$

Der allgemeine Punkt, der hier sichtbar wird, ist folgender: Wenn man einen bestimmten Diskurs aus der Perspektive der Realismusdebatte in den Blick nimmt, muß man die Frage, ob ein Satz, der in diesem Diskurs geäußert wird oder werden kann, die Form einer ontologischen realistischen These hat und evtl. in plausibler Weise zu einer solchen ergänzt werden kann, unterscheiden von der pragmatischen Frage, ob dieser Satz in diesem Diskurs assertorisch geäußert wird, also durch seine Äußerung eine entsprechende Aussage getroffen bzw. eine Behauptung aufgestellt wird. Eine ontologische realistische These zu vertreten heißt, einen Satz zu behaupten, und wenn man sich dafür interessiert, ob oder inwieweit in einem bestimmten Diskurs realistische Thesen vertreten oder impliziert werden, muß man darauf achten, ob in diesem Diskurs gemachte Äußerungen Aussagen, also "ernsthafte" Behauptungen darstellen bzw. für welche Äußerungen dies gilt. Angewandt auf die wissenschaftstheoretische Realismusdebatte heißt das, daß man, wenn man aus der Perspektive dieser Debatte die Diskurse der real-existierenden Wissenschaften in den Blick nimmt, d.h. die Gesamtheit der dort gewonnenen, akzeptierten und diskutierten Gesetze, Theorien, Modelle etc., unterscheiden muß zwischen der Frage, ob ein Gesetz o.ä. die Form einer ontologischen realistischen These hat oder evtl. in plausibler Weise zu einer solchen ergänzt werden kann, einerseits, und der Frage, ob die Verwendung dieses Gesetzes o.ä. als "ernsthafte" Behauptung aufzufassen ist oder nicht, andererseits. Die Verwendung eines Gesetzes o.ä. nicht als ernsthafte Behauptung aufzufassen hieße, zu ihm eine instrumentalistische Einstellung einzunehmen. ${ }^{15}$

Für die anderen Beispielfälle der Liste dürften sich die genannten Zweifel, daß sich durch eine durch Ergänzung der Sätze (um eine "Unabhängigkeitsklausel") gewonnene ontologische realistische These in intuitiv angemessener Weise eine realistische Einstellung zu den Sätzen bzw. den Entitäten, Eigenschaften etc., von denen sie handeln, zum Ausdruck bringen läßt, nicht durch den Hinweis beseitigen lassen, daß die ontologischen Thesen als "ernsthafte" Behauptungen aufzufassen sind. Zumindest prima facie ist es auch dann vielleicht nicht offensichtlich (oder wenigstens nicht in allen Fällen), daß diese ontologischen Thesen konstitutiv für eine realistische Position sind. Und wenn dies im Falle mathematischer, moralischer etc. Sätze bzw. Entitäten nicht offensichtlich ist, dann erscheint es dadurch vielleicht auch im Fall physikalischer, geologischer etc. Sätze bzw.

\footnotetext{
${ }^{14} \mathrm{Daß}(7)$ eine ziemlich unglaubhafte Aussage wäre, steht auf einem anderen Blatt.

${ }^{15}$ Vgl. S.18.
} 
Entitäten zweifelhaft.

Für jemanden, der solche Zweifel hegt, ob ontologische Thesen der Form (OR1) konstitutiv für eine realistische Position sind, oder sogar der Überzeugung ist, daß sie es nicht sind, erscheint möglicherweise die von verschiedenen Autoren propagierte Idee attraktiv, daß eine realistische Einstellung zu einem Diskurs bzw. zu dem Gegenstandsbereich, auf den dieser sich bezieht, nicht durch ontologische realistische Thesen zum Ausdruck gebracht wird, sondern durch Wahrheitstheorien und/oder Bedeutungstheorien bzw. durch semantische realistische Thesen, die mit Hilfe dieser Wahrheits- und Bedeutungstheorien erläutert werden. Damit kann entweder eine einheitliche semantische Theorie bzw. These für die verschiedenen Diskurse bzw. Gegenstandsbereiche gemeint sein oder eine Gruppe verschiedener Thesen für verschiedene Bereiche: Fine vertritt in diesem Sinn die Ansicht, daß für eine realistische Einstellung zu einem Diskurs bzw. Gegenstandsbereich die These konstitutiv ist, daß für die Sätze dieses Diskurses eine Korrespondenztheorie der Wahrheit gilt, oder, wie sich seine Ansicht rekonstruieren läßt, eine mit Hilfe dieser Korrespondenztheorie erläuterte semantische realistische These der Form (SR1). ${ }^{16}$ Nach Dummett wird eine realistische Einstellung zu einem Diskurs durch die These konstituiert, daß die Bedeutung der Sätze in diesem Diskurs in dem Sinn unabhängig von menschlicher Erkenntnis ist, daß die durch die Bedeutung festgelegten semantischen Relationen zwischen den Sätzen und dem, was sie wahr oder falsch macht, unabhängig davon bestehen, ob die Sprecher über irgendwelche Mittel verfügen, die Sätze zu verifizieren (oder zu falsifizieren). Die nach Dummett realismuskonstitutive These läßt sich ebenfalls als eine semantische realistische These der Form (SR1) rekonstruieren. ${ }^{17}$ Wright macht verschiedene Vorschläge für bereichsspezifische realismuskonstitutive Thesen, und zwar Thesen, die sich auf die Bedeutung des Wahrheitsbegriffs beziehen: Er schlägt u.a. vor, daß für eine realistische Einstellung zu einem Diskurs die These konstitutiv ist, daß die Wahrheitswerte der Sätze dort in dem Sinn unabhängig von menschlicher Erkenntnis sind, daß es (in diesem Diskurs) zur Bedeutung des Wahrheitsbegriffes gehört, daß Meinungsverschiedenheiten über den Wahrheitswert eines Satzes stets auf kognitive Fehlleistungen (mindestens) einer Seite zurückzuführen sind. ${ }^{18}$

Nach Ansicht von Autoren wie Fine, Dummett und Wright sind also für eine realistische Einstellung zu einem Diskurs semantische Theorien bzw. semantische realistische Thesen der angedeuteten Art konstitutiv, die metasprachlich (relativ zu dem fraglichen Diskurs) formuliert sind, nicht etwa objektsprachliche Existenz- und andere Aussagen (plus Unabhängigkeitsklauseln), also ontologische realistische Thesen. Wenn man es in Fällen und Bereichen, wie sie die obige Liste nennt, intuitiv nicht plausibel findet, daß es einen sozusagen zum Realisten (bezüglich des jeweiligen Diskurses oder Gegenstandsbereiches) machen soll, die Beispielsätze selbst (plus Unabhängigkeitsklauseln) zu akzeptieren, ${ }^{19}$ dann bietet die von Fine, Dummett und Wright propagierte Idee eine naheliegende andere Möglichkeit,

\footnotetext{
${ }^{16}$ Vgl. [Fine84a], S.96ff., [Fine84b], S.52, 53ff., [Fine86b], S.175f. Vgl. auch Fn.22.

${ }^{17}$ Vgl. etwa [Dumm78b], S.146, 155, [Dumm93b], S.465. Gelegentlich scheint Dummett dazu zusätzlich eine These der Form (SR2) für erforderlich zu halten (vgl. z.B. [Dumm93b], S.468). Dummetts Äußerungen sind häufig nicht klar hinsichtlich der Frage, ob eine realismuskonstitutive These dem Sachverhalt, der einen Satz wahr oder falsch macht, Unabhängigkeit zuschreiben soll oder der semantischen Relation zwischen dem Satz und dem Sachverhalt. In [Dumm93c], S.230 macht er deutlich, daß er beides im Sinn hat, auch wenn es ihm offenbar in erster Linie um die semantische Relation geht, d.h. die nach Dummett realismuskonstitutive These wäre danach durch eine These der Form (SR1) (plus evtl. eine der Form (SR2)) plus eine ontologische realistische These zu rekonstruieren.

${ }^{18}$ Nach Wright gibt es nicht einen einheitlichen Wahrheitsbegriff, sondern eine Menge bereichsspezifischer, untereinander familienähnlicher Wahrheitsbegriffe; für Genaueres siehe [Wrig92, Wrig93].

${ }^{19}$ Diese Ansicht vertritt explizit z.B. [Fine86b], S.176.
} 
die Frage zu beantworten, was einen zum Realisten macht (bzw. genaugenommen mehrere verwandte Möglichkeiten).

Die These, daß semantische realistische Thesen (zusätzlich zu "neutralen" ontologischen Thesen) für eine distinkte Position in der Realismusdebatte erforderlich sind Zweifel, daß ontologische realistische Thesen konstitutiv für eine realistische Position sind, speisen sich bei verschiedenen Autoren aus einer deskriptiv orientierten, "nicht-revisionistischen" allgemeinen Konzeption von Philosophie. Diese Autoren sind der Ansicht, daß es "geeignete" semantische Thesen ermöglichen, eine antirealistische Einstellung zu einem Diskurs einzunehmen, ohne die Existenz- und anderen Aussagen, die innerhalb dieses Diskurses getroffen werden, als falsch, revisionsbedürftig, "uneigentliche" Redeweisen o.ä. einstufen und damit gewissermaßen diskreditieren zu müssen. Ihrer Ansicht nach kann man eine antirealistische Einstellung etwa zu mathematischen Entitäten oder ethischen Werten einnehmen, ohne deswegen bestreiten zu müssen, daß es Zahlen, moralische Werte, verwerfliche Handlungen u.ä. gibt, eben indem man eine antirealistische These über die Semantik dieser Diskurse vertritt. Entsprechend kann man demnach eine antirealistische Einstellung zu Elektronen, Gravitationsfeldern, Genen etc. einnehmen, ohne zu bestreiten, daß es Elektronen, Gravitationsfelder, Gene etc. gibt. Diese Autoren möchten also Existenz- und andere Sätze eines Diskurses (einschließlich der Unabhängigkeitsklauseln entsprechender ontologischer realistischer Thesen) als wahr anerkennen und gleichzeitig hinzufügen können, daß die Bedeutung dieser Sätze und/oder die Tatsache, daß sie wahr (oder falsch) sind, in einer bestimmten antirealistischen Weise aufzufassen sind. ${ }^{20}$

In analoger Weise bieten diesen Autoren zufolge semantische realistische Thesen für Realisten die Möglichkeit, mehr zu sagen als "nur" das, was ontologische Thesen der Form (OR) beinhalten, und sich so von Antirealisten abzugrenzen, die diese ontologischen Thesen nicht bestreiten. Nur die semantischen Theorien bzw. Thesen, die den objektsprachlichen Diskursen hinzugefügt werden können, fallen nach dieser Konzeption von Philosophie in deren Kompetenzbereich, in dem auch die Realismusdebatte angesiedelt werden sollte, während über das Akzeptieren oder Zurückweisen von objektsprachlichen Existenzsätzen etc. und damit auch von Thesen der Form (OR) innerhalb der jeweils zuständigen Wissenschaften zu entscheiden ist.

Wichtiger noch als der Befund, daß semantische Thesen eine Möglichkeit bieten, eine realistische oder antirealistische Einstellung zu einem Diskurs zum Ausdruck zu bringen, die diesen Diskurs selbst gleichsam unangetastet läßt, ist es nach Ansicht einiger Anhänger einer nicht-revisionistischen Konzeption von Philosophie, daß diese Möglichkeit ihrer Meinung nach den einzigen sich anbietenden Weg darstellt, um überhaupt eine distinkte Position in der Realismusdebatte zu markieren. Fine etwa vertritt die These (allerdings ohne nähere Begründung), daß ontologische realistische Thesen der Form (OR) sowohl von Realisten als auch von Antirealisten geglaubt werden können, also neutral sind im Hinblick auf die Alternative Realismus/Antirealismus. ${ }^{21}$ Eine distinkte realistische Position zu markieren erfordert nach Fine andere, zusätzliche Thesen, und seiner Ansicht nach ist eine semantische Theorie, genauer: eine Korrespondenztheorie der Wahrheit, bzw. eine mit deren Hilfe erläuterte semantische realistische These das, was in der wissenschaftstheoretischen

\footnotetext{
${ }^{20}$ Dieses Motiv nennen etwa [Fine86b], S.166f. und [Wrig92], S.76ff.; eine sehr klare Formulierung findet sich in [Blac80], S.354f.

${ }^{21}$ [Fine84a], S.96ff., 101, [Fine84b], S.52ff., [Fine86b], S.156f., $175 f$.
} 
Realismusdebatte eine distinkte realistische Position markiert. ${ }^{22}$

Semantischer Realismus als Gegenposition zum Instrumentalismus Ein Motiv, semantische realistische Thesen als Herzstück einer realistischen Position zu betrachten, das in der wissenschaftstheoretischen Realismusdebatte häufig wirksam sein dürfte, obwohl es nur selten explizit genannt wird, ist, daß semantische Thesen sozusagen als das natürliche Mittel erscheinen, das Gegenteil einer instrumentalistischen Einstellung zu Theorien, Gesetzen etc. auszudrücken. Um zum Ausdruck zu bringen, daß sie den in den real-existierenden Wissenschaften gewonnenen und akzeptierten Theorien, Gesetzen etc. nicht den Status "ernsthafter" Behauptungen absprechen, wie es Instrumentalisten tun, ${ }^{23}$ vertreten einige Autoren semantische realistische Thesen. ${ }^{24}$ Dies wird dadurch nahegelegt, daß instrumentalistische Positionen häufig durch eine verifikationistische Bedeutungs- oder Wahrheitstheorie, d.h. durch eine semantische Theorie motiviert sind, der man dann von realistischer Seite "natürlicherweise" eine andere semantische Theorie bzw. semantische realistische Thesen entgegensetzen möchte. Da einer instrumentalistischen Einstellung zu Theorien, Gesetzen etc. der Wissenschaften häufig eine semantische Theorie zugrunde liegt, liegt es in gewisser Weise nahe, auch zu einer semantischen Theorie bzw. semantischen Thesen zu greifen, um zum Ausdruck zu bringen, daß man diese Theorien, Gesetze etc. als Realist nicht bloß als "intellektuelles Werkzeug", "inference ticket" u.ä. auffaßt.

\section{Semantischer Realismus als Ausdruck einer in epistemischer Hinsicht vor- sichtigen Einstellung Ein weiteres Motiv dafür, semantische realistische Thesen als Herzstück einer realistischen Position zu betrachten, das in der wissenschaftstheoretischen Realismusdebatte nur selten explizit genannt wird, aber häufig wirksam sein dürfte, ist in epistemischer Hinsicht nur begrenztes Vertrauen zu den bisher in den real-existierenden Wissenschaften vorliegenden Theorien, Gesetzen, Modellen etc. Wenn man grundsätzlich zu einer realistischen Position neigt, aber die Theorien, Gesetze etc. der derzeitigen Wis- senschaften nicht oder jedenfalls nur zum Teil für epistemisch hinreichend gut begründet hält, kann einen dies dazu führen, sozusagen von den epistemischen oder ontologischen realistischen Thesen, die man "eigentlich" gerne vertreten würde, auf eine semantische realistische These in bezug auf diese Theorien, Gesetze etc. auszuweichen, um eine reali- stische Position zu formulieren (plus evtl. auf epistemische oder ontologische realistische Thesen in bezug auf den begrenzten Teil der vorliegenden Theorien, Gesetze etc., den man für epistemisch hinreichend gut begründet hält). ${ }^{25}$}

\footnotetext{
${ }^{22}$ Siehe z.B. [Fine84b], S.54: "While there is no doubt a distinction to be drawn between those who do and those who do not believe in the existence, let us say, of magnetic monopoles, I think it would be a mistake to take that as distinguishing the realists from the others [...]. For it is not the form of a claim held true that marks off realism, it is rather the significance or content of the claim [...]. The fact that scientific practice involves serious monopole talk [...] does not even begin to address the issue of realism. For what realism is after is a very peculiar interpretation of that practice." Die Korrespondenztheorie der Wahrheit, die nach Fine wesentlich für eine realistische Position ist, muß eine "substantielle" sein, die die "Natur" der Korrespondenzrelation angibt o.ä.; Tarskis semantische Wahrheitstheorie reicht dazu nach Fine nicht aus, er gibt jedoch keine klare Auskunft, was eine "substantielle" Korrespondenztheorie auszeichnen würde (abgesehen von einigen, milde formuliert, sehr unplausiblen Charakterisierungen, die er — in argumentationsstrategisch wenig überzeugender Weise — erst seinen fiktiven realistischen Diskussionsgegnern zuschreibt und dann ins Lächerliche zieht; vgl. z.B. [Fine84a], S.99f., [Fine84b], S.54).

${ }^{23} \mathrm{Vgl}$. S.18.

${ }^{24}$ Z.B. [Feig50a].

${ }^{25}$ Dieses Motiv nennt z.B. [Earm93], S.19/20.
} 


\section{Einwände gegen die Gründe und Motive dafür, semantische Thesen als Herz- stück einer realistischen Position anzusehen}

Die genannten Gründe und Motive dafür, semantische Thesen als Herzstück einer realistischen Position anzusehen, mögen alle eine gewisse Prima-facie-Plausibilität haben, sie tragen jedoch bei genauer Betrachtung wenig gegen die oben genannte Intuition aus, daß ontologische realistische Thesen der Form (OR) hinreichend sind, um in konkreten, für die wissenschaftstheoretische Realismusdebatte typischen Fällen das auszudrücken, was für eine realistische Einstellung konstitutiv ist, und daß das, was eine realistische Position in der Wissenschaftstheorie ausmacht, einerseits, und Wahrheits- oder Bedeutungstheorien für wissenschaftliche Theorien, Modelle etc. andererseits zwei Themen sind, die unmittelbar nichts miteinander zu tun haben. Die genannten Gründe und Motive entkräften diese Intuition nicht und liefern, wie im folgenden gezeigt werden soll, bei genauerer Betrachtung auch keine überzeugende Begründung für die These, daß semantische realistische Thesen das Herzstück einer realistischen Position bilden.

Eine in epistemischer Hinsicht vorsichtige Einstellung läßt sich ohne semantische realistische Thesen zum Ausdruck bringen In epistemischer Hinsicht nur begrenztes Vertrauen zu den Theorien, Gesetzen etc., die bisher in den Wissenschaften gewonnen und akzeptiert wurden, ist ein nachvollziehbares Motiv dafür, zu semantischen realistischen Thesen zu greifen, wenn man grundsätzlich zu einer realistischen Position neigt, aber es ist kein zwingendes, denn um eine in epistemischer Hinsicht vorsichtige Einstellung zum Ausdruck zu bringen, sind keine semantischen realistischen Thesen erforderlich. Um in einer solchen Situation eine realistische Position zu formulieren, kann man ontologische realistische Thesen wählen, die dem Teil der Theorien, Gesetze etc. entsprechen, den man für epistemisch hinreichend gut begründet hält; um eine in epistemischer Hinsicht vorsichtige Einstellung zum anderen Teil der Theorien, Gesetze etc. zum Ausdruck zu bringen, kann man "disjunktive" objektsprachliche Aussagen wählen: Epistemische Vorsicht gegenüber der These beispielsweise, daß an der Oberfläche der Sonne ein stark schwankendes Magnetfeld herrscht, kann man ausdrücken durch einen Satz wie 'An der Oberfläche der Sonne herrscht ein stark schwankendes Magnetfeld oder es herrscht dort kein stark schwankendes Magnetfeld, aber es liegen (derzeit) keine hinreichenden Gründe vor, das eine oder das andere zu glauben'. ${ }^{26}$ Es ist dazu nicht erforderlich, zu einer semantischen realistischen These zu greifen, daß der Satz 'An der Oberfläche der Sonne herrscht ein stark schwankendes Magnetfeld' wahr oder falsch ist (und zwar unabhängig von menschlichen epistemischen Mitteln) o.ä. Disjunktive Aussagen dieser Art lassen sich auch für andere Gegenstandsbereiche formulieren.

Eine instrumentalistische Position zurückzuweisen erfordert keinen semantischen Realismus als Gegenposition Zum vorletzten der genannten Motive, semantische realistische Thesen als Herzstück einer realistischen Position aufzufassen, ist zu sagen, daß semantischer Realismus als Gegenposition zum Instrumentalismus unnötig stark ist: Instrumentalisten sprechen Aussagen im Diskurs der Wissenschaften, die sich auf Unbeobachtbares beziehen (sprich: Theorien, Gesetzen etc. über Unbeobachtbares) den Status von ernsthaften Behauptungen ab und betrachten die Äußerung entsprechender Sätze statt

\footnotetext{
${ }^{26}$ Einen solchen Satz kann man natürlich, wie eine These der Form (OR), durch eine Unabhängigkeitsklausel ergänzen.
} 
dessen als Verwendung "intellektueller Werkzeuge" o.ä. Um diese Einstellung zurückzuweisen, braucht man keine semantische Theorie für diese Sätze bzw. Äußerungen zu vertreten und keine semantischen realistischen Thesen. Mit einer instrumentalistischen Position ist es bereits unverträglich, die strittigen Sätze selbst ${ }^{27}$ "ernsthaft" zu behaupten und, wenn nötig, auf dem assertorischen Charakter der Aussagen zu bestehen, d.h. darauf zu insistieren, daß die eigenen Äußerungen nicht sprachlich irgendwie defekt, unverständlich oder paraphrasierungs- oder definitionsbedürftig sind. Damit weist man verifikationistische und operationalistische Bedeutungstheorien implizit zurück, man muß deswegen jedoch von realistischer Seite keine alternative semantische Theorie präsentieren, auch wenn dies argumentationsstrategisch vielleicht hilfreich wäre und man dies natürlich tun kann.

Wenn gegen diese "Zurückweisungsstrategie" von instrumentalistischer Seite eingewendet wird, daß die strittigen Sätze bzw. entsprechende ontologische realistische Thesen "bedeutungslos", ohne Paraphrasierung oder Definition unverständlich o.ä. seien, kann dem naturgemäß von realistischer Seite nicht durch die Angabe der Bedeutungen der verwendeten Ausdrücke und Sätze in einer nach verifikationistischen oder operationalistischen Standards zufriedenstellenden Weise begegnet werden. Dies zu fordern hieße jedoch auch, die Falschheit der realistischen Position einfach vorauszusetzen. ${ }^{28}$

Semantische realistische Thesen ergeben keine argumentationsstrategisch erfolgversprechendere Gegenposition zum Instrumentalismus als ontologische realistische Thesen, und sie ergeben auch keine plausible Abgrenzung von realistischen und anderen nicht-revisionistischen Positionen Die Autoren, die dafür plädieren, daß semantische Theorien und Thesen konstitutiv für realistische (und auch für antirealistische) Positionen in der Realismusdebatte sind, verfolgen damit den Ansatz, die Debatte auf der Ebene einer Metasprache bezüglich der Sprache bzw. der Diskurse der Wissenschaften zu führen. Es läßt sich jedoch generell mit Gründen bezweifeln, daß sich auf diese Weise haltbarere, in zufriedenstellenderer Weise formulierte realistische Positionen ergeben als auf objektsprachlicher Ebene, d.h. haltbarere und in zufriedenstellenderer Weise formulierte Positionen als ontologische realistische Thesen sie liefern. Insbesondere zeichnen sich metasprachlich formulierte semantische realistische Thesen in zwei Punkten nicht vor objektsprachlich formulierten ontologischen realistischen Thesen aus: Zum einen können semantische realistische Thesen für Instrumentalisten nicht "bedeutsamer" oder verständlicher sein als ontologische realistische Thesen, so daß für die Diskussion mit Instrumentalisten, die eine realistische Position, für die ontologische realistische Thesen konstitutiv sind, als "bedeutungslos" oder unverständlich zurückweisen, durch einen Übergang auf die metasprachliche Ebene nichts zu gewinnen ist. Zum anderen läßt sich bezweifeln, daß metasprachlich formulierte semantische Thesen eine plausible Abgrenzung von realistischen und anderen nicht-revisionistischen Positionen ergeben bzw. sogar, wie Fine meint, erforderlich sind, um überhaupt eine distinkte realistische Position zu markieren. Wenn objektsprachliche Aussagen im Diskurs der Wissenschaften, sprich: Gesetze, Theorien etc. über Unbeobachtbares, und damit ontologische realistische Thesen - aus instrumentalistischer Perspektive — "bedeutungslos" oder unverständlich sind, oder - nach Fines Ansicht - gar keine Abgrenzung von realistischen und anderen Positionen ergeben, wenn es einen also gleichsam noch nicht zum Realisten macht, diese objektsprachlichen Sätze zu akzeptieren, dann ist schwer zu sehen, wieso metasprachliche

\footnotetext{
${ }^{27}$ Eventuell durch eine geeignete Unabhängigkeitsklausel zu einer ontologischen realistischen These ergänzt.

${ }^{28}$ Siehe dazu auch den nächsten Punkt.
} 
semantische realistische Thesen "bedeutsam" oder verständlich sein können bzw. wieso durch metasprachliche semantische realistische Thesen eine Abgrenzung von realistischen und anderen nicht-revisionistischen Positionen zu gewinnen sein sollte, weshalb einen somit das zusätzliche Akzeptieren einer metasprachlichen semantischen These zum Realisten machen sollte. Der Punkt ist in beiden Fällen, daß die Gründe, die dagegen zu sprechen scheinen, objektsprachliche ontologische realistische Thesen als konstitutiv für eine realistische Position zu betrachten, in gleicher Weise dagegen sprechen, daß metasprachliche semantische Thesen diese Rolle ausfüllen können.

Daß durch den Ansatz, metasprachliche, nämlich semantische realistische Thesen als konstitutiv für eine realistische Position zu betrachten, für Realisten nichts zu gewinnen ist für die Diskussion mit Instrumentalisten, die ontologische realistische Thesen über Unbeobachtbares als "bedeutungslos" oder unverständlich zurückweisen, sieht man folgendermaßen. Eine realistische Einstellung zu bestimmten Sätzen, Theorien o.ä., die durch semantische Thesen zum Ausdruck gebracht wird, läßt sich durch (mindestens) semantische realistische Thesen der Form (SR1) rekonstruieren, die besagen, daß diese Sätze, Theorien o.ä. Wahrheitswerte haben, und zwar unabhängig von menschlichen epistemischen Mitteln zum Erkennen dieser Wahrheitswerte, wobei mit Hilfe einer semantischen Theorie erläutert wird, worin die Eigenschaft der Sätze, Theorien etc., Wahrheitswerte zu haben, besteht und in welchem Sinn sie "unabhängig ..." ist. Eine typische Erläuterung dieser Art ist eine, die Tarskis semantische Wahrheitstheorie heranzieht; für den Satz 'Elektronen haben Spin $\frac{1}{2}$ ' beispielsweise wäre die mit Hilfe von Tarskis Theorie erläuterte semantische realistische These:

Der Satz 'Elektronen haben Spin $\frac{1}{2}$ ' ist wahr genau dann, wenn Elektronen Spin $\frac{1}{2}$ haben, und er wäre auch dann wahr (oder falsch), wenn niemand in der Lage wäre, herauszufinden, ob er wahr ist (oder falsch). ${ }^{29}$

Diese semantische realistische These muß für Instrumentalisten, die den Satz 'Elektronen haben Spin $\frac{1}{2}$ ' bzw. eine entsprechende ontologische realistische These als "bedeutungslos" oder unverständlich zurückweisen, offenbar ebenso "bedeutungslos" oder unverständlich sein, da sie, grob gesprochen, dieselben "problematischen" Ausdrücke enthält bzw. genauer: deren (homophone) Übersetzungen in die Metasprache. ${ }^{30}$ Eine Definition oder Bedeutungserklärung, die verifikationistischen oder operationalistischen Ansprüchen genügt, ist natürlich für die metasprachliche Übersetzung etwa von 'Elektron' genausowenig zu haben wie für den objektsprachlichen Ausdruck 'Elektron' selbst (und aus realistischer Perspektive genausowenig erforderlich bzw. billigerweise zu verlangen). ${ }^{31}$ Wenn man zur Erläuterung semantischer realistischer Thesen anstelle von Tarskis Wahrheitstheorie (oder zusätzlich dazu) andere (für eine realistische Position "geeignete") semantische Theorien ${ }^{32}$ heranzieht, gilt Entsprechendes. ${ }^{33}$

\footnotetext{
${ }^{29}$ Gemäß dieser These liegt also "Unabhängigkeit ..." im Sinne von (UvmeM1) vor. Vgl. Abschnitt 2.4.

${ }^{30}$ Vgl. [Feig50a], S.209, [Hemp50], S.169/170, [Nage50], S.178/179.

${ }^{31}$ Die Sätze, in denen die "problematischen" Ausdrücke auftreten, sind auf objekt- und metasprachlicher Ebene nicht identisch bzw. homophone Übersetzungen und haben daher auch nicht dieselben Wahrheitsbedingungen. Dennoch sollte (auch ohne Diskussion der Wahrheitsbedingungen von Sätzen, die "eingebettete" Sätze enthalten, u.ä.) klar sein, daß durch den Schritt auf die metasprachliche Ebene für die Diskussion mit Verifikationisten, Operationalisten etc. nichts gewonnen ist, weil die fraglichen metasprachlichen Sätze die "problematischen" objektsprachlichen Sätze und Ausdrücke sozusagen als Teile enthalten.

${ }^{32} \mathrm{Vgl}$. Teil I.

${ }^{33}$ Es kommt dabei nicht darauf an, daß in jeder mit Hilfe einer semantischen Theorie erläuterten semantischen realistischen These für jeden objektsprachlichen Ausdruck, der sich auf Unbeobachtbares bezieht,
} 
Fines These, daß sich nur mit Hilfe von semantischen realistischen Thesen eine distinkte realistische Position in der wissenschaftstheoretischen Realismusdebatte markieren läßt, wird von ihm einerseits nicht begründet und steht andererseits im Widerspruch zu den vorne $^{34}$ genannten Intuitionen darüber, was eine realistische Einstellung ausmacht, und erscheint daher unplausibel, wenn man diese Intuitionen hat. Die dieser These zugrundeliegende andere These Fines, daß ontologische realistische Thesen "neutral" im Hinblick auf die Alternative Realismus/Antirealismus sind und daher "mehr" als ontologische realistische Thesen erforderlich ist zur Abgrenzung einer realistischen Position von anderen nicht-revisionistischen Positionen, erscheint bei genauerem Hinsehen ebenfalls als zweifelhaft. Ein nicht-revisionistischer Antirealist ${ }^{35}$ verfügt nach Fine, wie ein Realist, über die jeweils relevante Metasprache, und er teilt die Überzeugungen der realistischen Seite über Elektronen, Spins, magnetische Monopole etc. Diese Überzeugungen sollten sich sowohl objektsprachlich als auch metasprachlich formulieren lassen. Realisten und Antirealisten teilen sicherlich ebenso Überzeugungen (zweiter Ordnung), daß sie Überzeugungen (erster Ordnung) über Elektronen etc. haben und Sätze über diese äußern. Beide Seiten glauben also, daß es Elektronen etc. gibt, daß diese bestimmte Eigenschaften haben usw. und daß sie diesbezügliche Überzeugungen haben und Sätze äußern. Die einzige relevante Meinungsverschiedenheit zwischen Realisten und Antirealisten betrifft demnach die Frage, ob zwischen den Sätzen bzw. Überzeugungen einerseits und den Elektronen etc. andererseits semantische Relationen bestehen und von welcher "Natur" diese ggf. sind. Intuitiv sieht diese Meinungsverschiedenheit so speziell aus, einen so marginalen Teil der Eigenschaften von Elektronen etc. bzw. einen so geringen Teil ihrer Überzeugungen darüber betreffend, eben nur deren semantische Relationen, daß es nicht plausibel erscheint, daß diese Meinungsverschiedenheit den Unterschied zwischen einer realistischer und einer antirealistischen Position in bezug auf Elektronen etc. darstellen sollte. Intuitiv ergibt eine solche marginale Meinungsverschiedenheit also keine plausible Abgrenzung von realistischen und antirealistischen Einstellungen. Dieser Befund impliziert, wenn man (wie es in der Realismusdebatte weithin angenommen wird) voraussetzt, daß für eine realistische Einstellung entweder ontologische, oder semantische Thesen konstitutiv sind, daß ontologischen realistischen Thesen diese Rolle zukommt und sie also nicht "neutral" im Hinblick auf die Alternative Realismus/Antirealismus sind. Das wiederum heißt, daß die von Fine ins Spiel gebrachte Option einer nicht-revisionistischen antirealistischen Position tatsächlich keine kohärente Position ergibt: Jemand, der akzeptiert, daß es Elektronen etc. gibt (plus evtl. Unabhängigkeitsklauseln), akzeptiert alles, was für eine realistische Position konstitutiv ist; daran kann eine zusätzliche semantische These "antirealistischer Art" nichts mehr ändern. ${ }^{36}$

ein einzelner, diesen übersetzender Ausdruck vorkommt (und dies wird, je nach semantischer Theorie, i.a. auch nicht so sein), sondern darauf, daß sicherlich Ausdrücke vorkommen, die aus verifikationistischer, operationalistischer etc. Perspektive ebensowenig akzeptabel sind wie die objektsprachlichen.

${ }^{34} \mathrm{~S} .389 \mathrm{f}$.

${ }^{35}$ Und auch Fines NOA, der jedoch hier aus Gründen der Übersichtlichkeit aus dem Spiel bleiben soll.

${ }^{36}$ Eine kohärente antirealistische Position (allerdings eine "revisionistische") wäre dagegen eine, die bestreitet, daß Sätze über Elektronen in semantischen Relationen stehen, und die bestreitet, daß es Elektronen gibt. Eine dritte, möglicherweise denkbare Option, nämlich zwischen Objekt- und Metasprache zu trennen, und "objektsprachlich" zu akzeptieren, daß es Elektronen gibt, die metasprachliche Übersetzung jedoch zurückzuweisen, ist inkohärent (genau wie es inkohärent ist, einen deutschen Satz zu glauben, dessen als korrekt akzeptierte — englische Übersetzung jedoch zurückzuweisen).

Für eine Überlegung in ähnlicher Richtung vgl. [Devi84], S.40ff. 
Zweifel, daß sich durch ontologische realistische Thesen zu allen Gegenstandsbereichen bzw. Diskursen in intuitiv plausibler Weise eine realistische Einstellung zum Ausdruck bringen läßt, lassen sich ausräumen, ohne semantische realistische Thesen heranzuziehen Der vorne ${ }^{37}$ durch eine Liste von Beispielsätzen illustrierte Eindruck, daß ontologische realistische Thesen nicht in intuitiv zufriedenstellender Weise eine realistische Einstellung zum Ausdruck bringen, zumindest nicht für alle Gegenstandsbereiche bzw. Diskurse, hat zumindest prima facie eine gewisse Plausibilität und der dadurch motivierte Schritt zu semantischen realistischen Thesen daher vielleicht auch. Andererseits trägt dies gegen die ebenfalls vorne beschriebenen Intuitionen, die zumindest im Bereich der wissenschaftstheoretischen Debatte für ontologische Thesen und gegen semantische Thesen als Herzstück einer realistischen Position sprechen, direkt nichts aus, und da andere überzeugende Gründe und Motive dafür, semantische Thesen als konstitutiv für eine realistische Position anzusehen, wie diskutiert, nicht in Sicht sind, scheint es angemessen, an der Intuition festzuhalten, daß eine realistische Einstellung zu einem Diskurs oder Gegenstandsbereich (zumindest für den Bereich der wissenschaftstheoretischen Debatten) eine Sache ist und die Semantik des fraglichen Diskurses eine andere, und die genannten gegenläufigen Eindrücke bzw. Zweifel als Hinweise auf mögliche Unvollkommenheiten ontologischer realistischer Thesen der bisher angegebenen Form zu nehmen, die eventuell zu verbessern sind.

Die Reaktion auf die genannten Eindrücke bzw. Zweifel sollte also sein, diese genauer ins Auge zu fassen und eventuell nach Möglichkeiten zu suchen, ontologische realistische Thesen so zu erläutern, zu ergänzen und/oder zu verbessern, daß sich mit ihrer Hilfe in intuitiv plausibler Weise zu allen Diskursen bzw. Gegenstandsbereichen eine realistische Einstellung zum Ausdruck bringen läßt, ohne semantische realistische Thesen heranzuziehen. Wenn dies gelingt, bleiben semantische Theorien sicherlich dennoch ein wichtiges und, wie weiter unten noch diskutiert werden wird ${ }^{38}$, auch für realistische Positionen relevantes Thema, auch wenn man dann keinen Grund mehr für die Annahme hat, daß semantische (und nicht ontologische) realistische Thesen das Herzstück einer realistischen Position bilden sollten.

\subsubsection{Erläuterungen und Ergänzungen zu ontologischen realistischen Thesen}

In welcher Hinsicht (oder in welchen Hinsichten) sind ontologische realistische Thesen in Fällen wie denen auf der obigen Liste intuitiv nicht zufriedenstellend als Ausdruck einer realistischen Einstellung, und welche Möglichkeiten gibt es, sie zu erläutern, zu ergänzen und/oder zu verbessern?

Bei den Sätzen der Liste scheinen verschiedene Aspekte dafür verantwortlich zu sein, daß sie, auch nach Ergänzung durch eine geeignete Unabhängigkeitsklausel, prima facie vielleicht nicht konstitutiv für eine realistische Position aussehen. Von diesen Aspekten scheinen mehrere sozusagen durch Thesen der Form (SR2) erfaßt zu werden, wenn eine realistische Einstellung mit Hilfe semantischer Thesen zum Ausdruck gebracht wird, also durch Thesen, daß die fraglichen Sätze wörtlich zu nehmen sind, d.h. nicht als auf andere Sätze reduzierbar, als stehende Redewendungen, als Metaphern o.ä. aufzufassen sind, so daß ihr eigentlicher Gehalt erst durch eine Reduktion oder Paraphrasierung zum Ausdruck käme.

\footnotetext{
${ }^{37}$ S.390f.

${ }^{38}$ Siehe Abschnitt 13.3.
} 
Bei Satz (2) etwa dürfte der relevante Aspekt sein, daß man verschiedene Antworten auf die Frage geben kann, ob die Redeweise, daß eine Handlung verwerflich ist, wörtlich zu nehmen ist, oder ob sie zu paraphrasieren ist durch oder zu reduzieren auf den Satz, daß die Handlung bei den meisten Menschen Äußerungen von Abscheu hervorruft o.ä. Die letztere Antwort zu akzeptieren könnte man als hinreichend für eine antirealistische Einstellung zu Satz (2) bzw. zu der Eigenschaft, verwerflich zu sein, etc. betrachten, erstere Antwort zu akzeptieren als notwendig für eine realistische Einstellung, und zwar auch dann, wenn man (2) (evtl. durch eine Unabhängigkeitsklausel zu einer ontologischen realistischen These ergänzt) akzeptiert. Allgemein dürfte für moralische Eigenschaften, Werte etc. bzw. den Diskurs darüber sinngemäß dasselbe gelten.

In ähnlicher Weise könnte man es als notwendig für eine realistische Einstellung zu Satz (5) betrachten, die These zu akzeptieren, daß die Redeweise von einer Chance, sich $\mathrm{zu}$ retten, wörtlich zu nehmen ist ${ }^{39}$ dagegen als hinreichend für eine antirealistische Einstellung zu (5), die These zu vertreten, daß der Satz zu paraphrasieren ist etwa durch einen Satz über statistische Korrelationen zwischen verschiedenen Handlungen des Piloten und darauf folgenden Ereignissen in einem Ensemble ähnlicher Fälle o.ä. Bei Satz (6) dürfte der relevante Aspekt sein, daß die Formulierung, daß ein Gutachten einen springenden Punkt hat, eine stehende Redewendung ist, die durch so etwas wie "trifft eine wichtige und interessante Aussage" paraphrasiert werden kann. Genau dies zu akzeptieren könnte man als hinreichend für eine antirealistische Einstellung zu (6) betrachten, und zwar auch dann, wenn (6) geglaubt wird. Bei den Sätzen (3) und (4) dürfte der relevante Aspekt ebenfalls sein, daß man verschiedene Antworten auf die Frage geben kann, ob sie wörtlich zu nehmen oder auf andere, "unproblematische" Sätze bzw. Ausdrücke zu reduzieren sind: Beschreibungen der Handlungen der Parteibasis (bzw. einer Strömung darin) lassen sich möglicherweise reduzieren auf Beschreibungen der Handlungen einer Gruppe von Menschen, Beschreibungen der Programmabläufe und Funktionselemente eines Computerprogramms möglicherweise auf Beschreibungen der physikalischen Zustände und Zustandsänderungen der Hardware des Computers, auf dem das Programm installiert ist. Eine entsprechende "Reduzierbarkeitsthese" zu akzeptieren könnte man als hinreichend für eine antirealistische Einstellung zu (3) bzw. (4) bzw. zu Parteibasen, Zwischenspeichern etc. betrachten, eine solche Reduzierbarkeitsthese abzulehnen dagegen als notwendig für eine realistische Einstellung, und zwar wiederum auch dann, wenn man die Sätze selbst (evtl. durch eine Unabhängigkeitsklausel ergänzt) akzeptiert.

Es lassen sich also verschiedene Aspekte identifizieren, die für den Eindruck verantwortlich zu sein scheinen, daß einen in Fällen, wie die obige Liste sie nennt, das Akzeptieren ontologischer realistischer Thesen per se noch nicht zum Realisten macht, und die in diesen Fällen genannten, naheliegenden notwendigen "Zusatzbedingungen" für eine realistische Einstellung erscheinen prima facie vielleicht nicht unplausibel. Es zeigt sich jedoch, daß bei genauerer Betrachtung wenig dafür spricht, daß die genannten "Zusatzbedingungen" tatsächlich konstitutiv für eine realistische Einstellung sind, aber einiges dafür, daß der Eindruck falsch ist, daß ontologische realistische Thesen in der bisher angegebenen Form gleichsam zu wenig sagen, um in angemessener Weise eine realistische Einstellung zum Ausdruck zu bringen. Unabhängig davon zeigt sich jedenfalls, daß die für diesen Eindruck verantwortlichen Aspekte im Kern keine semantischen sind, also jedenfalls nicht auf semantische realistische Thesen als "Zusatzbedingungen" führen.

Sich die verschiedenen Aspekte anhand der obigen Liste genauer anzusehen und dort

\footnotetext{
${ }^{39}$ Und zwar auch dann notwendig, wenn (5) selbst (inklusive einer geeigneten Unabhängigkeitsklausel) akzeptiert wird.
} 
nach Möglichkeiten zu suchen, ontologische realistische Thesen zu erläutern, zu ergänzen oder zu verbessern, ist "im Erfolgsfall" aus zwei Gründen nützlich im Hinblick auf die Frage, was wissenschaftlichen Realismus ausmacht: Zum einen ist zumindest ein Teil dieser Aspekte auch für Fälle aus dem Bereich der wissenschaftstheoretischen Realismusdebatte relevant, und daher wären es auch entsprechende Erläuterungs-, Ergänzungs- und/oder Verbesserungsmöglichkeiten. Zum anderen hätte ein Befund, daß sich im Fall der Diskurse, zu denen die aufgelisteten Sätze gehören, bzw. der zugehörigen Gegenstandsbereiche ontologische realistische Thesen tatsächlich nicht eignen, um eine realistische Einstellung zum Ausdruck zu bringen, Konsequenzen für realistische Positionen in der Wissenschaftstheorie, sofern man außerdem die Hintergrundannahme macht, daß für alle Diskurs- bzw. Gegenstandsbereiche dieselbe Art von Thesen konstitutiv für eine realistische Position ist.

\section{Die pragmatische Unterscheidung von wörtlichem und nicht-wörtlichem be- hauptenden Gebrauch von Sätzen}

Bei den Sätzen (5) und (6) und ähnlichen Fällen ist der Eindruck, daß das Akzeptieren einer ontologischen realistischen These nicht ausreicht für eine realistische Einstellung, darauf zurückzuführen, daß pragmatische Fragen und semantische Fragen nicht hinreichend auseinandergehalten werden. Ob ein Satz als stehende Redewendung oder Metapher gebraucht wird, ist eine Frage darüber, wie und wozu er verwendet wird, nämlich, grob gesprochen, ob er verwendet wird, um die Behauptung aufzustellen, die durch die Oberflächengestalt des Satzes nahegelegt wird, oder ob er verwendet wird, um eine davon verschiedene Behauptung aufzustellen, die ein Hörer mit Hilfe des Kontextes der Äußerung des Satzes, der Voraussetzungen und besonderen Umstände von Sprecher und Hörer etc. verstehen kann, sowie evtl. außerdem noch anderes zu bewirken oder zu kommunizieren. ${ }^{40}$ Diese Unterscheidung ist eine pragmatische. Es sollte sich mit Hilfe von pragmatischen Kriterien zwischen wörtlich gemeinten Behauptungen und (in verschiedener Weise) nichtwörtlich gemeintem behauptenden Gebrauch von Sätzen unterscheiden lassen, und es sollte sich mit Hilfe pragmatischer Überlegungen beurteilen lassen, wie nicht-wörtlich gemeinte Äußerungen ggf. zu paraphrasieren oder zu ersetzen sind durch wörtlich gemeinte, die das, was sie aussagen sollen, explizit sagen.

Der Eindruck, daß Sätze, die die Form einer ontologischen realistischen These haben und außerdem stehende Redewendungen, Metaphern etc. enthalten, nicht ausreichen, um eine realistische Einstellung zum Ausdruck zu bringen, ist demnach falsch. Grundsätzlich eignen sich dazu auch Sätze wie (5) und $(6)^{41}$ (ergänzt durch eine Unabhängigkeitsklausel) — und zwar ohne irgendwelche Zusatzthesen, insbesondere ohne semantische -, man muß die Sätze dazu aber als wörtlich gemeinte Behauptungen äußern, und dies wird für einen Satz wie (6) natürlich niemand tun und für einen Satz wie (5) i.a. auch selten in Betracht gezogen werden. Der Eindruck dagegen, daß es auf eine antirealistische Einstellung zu solchen Sätzen hinausläuft, wenn man die These vertritt, daß ihr Gehalt durch eine bestimmte Paraphrase gewissermaßen erst ans Licht gebracht werden muß, ist demnach korrekt, dabei ist jedoch ein wichtiger Punkt zu beachten: Zusammen mit einer solchen antirealistischen These und den Paraphrasen kann man dann nicht die unparaphrasierten "Originalsätze" akzeptieren, sondern eine Äußerung dieser Sätze allenfalls als uneigentli-

\footnotetext{
${ }^{40}$ Eine Einstellung oder eine emotionale Stimmung des Sprechers oder Hörers, die Anerkennung der mit einem Diskurs verbundenen gesellschaftlichen oder gruppenspezifischen Gepflogenheiten o.ä.

${ }^{41}$ Vorausgesetzt natürlich, daß sich die Sätze überhaupt wörtlich verstehen lassen, was beispielsweise für die Redeweise von einem springenden Punkt durchaus geht, aber nicht für alle stehenden Redewendungen.
} 
che, strenggenommen falsche und nur aus pragmatischen Gründen gewählte Sprechweisen durchgehen lassen, nicht als ernsthafte Behauptungen. ${ }^{42}$

\section{Ontologische versus semantische Reduzierbarkeit, Supervenienz}

Der Bereich von Fällen, in denen Fragen der Reduzierbarkeit dem Eindruck zugrunde zu liegen scheinen, daß ontologische realistische Thesen nicht ausreichen, um eine realistische Einstellung zum Ausdruck zu bringen (wie dies etwa für (3) und (4) gilt), ist schwer systematisch zu überschauen, weil mit dem Begriff der Reduktion eine uneinheitliche Vielzahl von verschiedenen und teilweise kontroversen Intuitionen, Vorstellungen und Thesen verbunden wird. Anhand von Beispielen läßt sich jedoch plausibel machen, daß die für den genannten Eindruck verantwortlichen Aspekte tatsächlich keine zu ontologischen realistischen Thesen hinzutretenden Zusatzbedingungen für eine realistische Einstellung erforderlich machen (etwa die Zurückweisung von "Reduktionsthesen"), insbesondere keine Zusatzbedingungen, die die Semantik ontologischer Thesen betreffen.

In den Fällen, in denen es prima facie vielleicht plausibel klingt, daß das Akzeptieren der These, daß bestimmte Sätze (bzw. Ausdrücke, die in diesen Sätzen enthalten sind) reduzierbar sind, hinreichend ist für eine antirealistische Einstellung zu diesen Sätzen bzw. zu den Gegenständen, auf die sie sich beziehen, ${ }^{43}$ scheinen (mindestens) zwei verschiedene Intuitionen im Spiel zu sein, die für diese Prima-facie-Plausibilität verantwortlich sind.

Eine dieser Intutionen scheint die zu sein, daß die Tatsache, daß ein Ausdruck oder ein Satz auf andere Ausdrücke bzw. Sätze reduzierbar ist, es einem ermöglicht, den reduzierbaren Ausdruck bzw. Satz (zugunsten des oder der reduzierenden) ganz aus dem Diskurs, in dem er verwendet wird, zu eliminieren, bzw., wenn man dies nicht tun will, ihn jedenfalls "nur noch" aus pragmatischen Gründen weiter zu verwenden. So könnte man evtl. den Satz (3) eliminieren zugunsten eines Satzes, in dem nicht mehr von einem Computerprogramm, einem Zwischenspeicher etc. die Rede ist, sondern von den Spannungen, Strömen, Magnetisierungen etc. in den diversen Teilen der Hardware des Computers, und den Satz (4) zugunsten eines Satzes, der nicht mehr von einer Parteibasis und deren Strömungen handelt, sondern von Personen und ihren Handlungen und Überzeugungen. Für die wissenschaftstheoretische Debatte relevante Fälle derselben Art sind Sätze über Unbeobachtbares, die phänomenalistischen, physikalistischen oder operationalistischen Bedeutungstheorien zufolge allesamt reduzierbar sind auf Sätze über Beobachtungen, über (makroskopische) Meßgeräte und ihre Zeigerstellungen etc. und die man daher zu deren Gunsten eliminieren könnte, so etwa einen Satz über die Temperatur einer Flüssigkeit zugunsten eines Satzes über den Zeigerausschlag eines Thermometers bei Kontakt mit der Flüssigkeit u.ä. ${ }^{44}$ Die Intuition, daß das Akzeptieren einer These über die Eliminierbarkeit eines Ausdrucks oder Satzes hinreichend für eine antirealistische Einstellung ist, scheint damit zusammenzuhängen, daß bei einer Elimination die reduzierbaren Sätze bzw. die Existenz- und andere assertorischen Sätze, die die reduzierbaren Ausdrücke enthalten, aus dem Diskurs verschwinden, und damit auch entsprechende ontologische realistische Thesen "beseitigt" werden.

Wenn die letztere Bemerkung richtig ist, dann liegt damit dem Eindruck, daß einen das Akzeptieren einer Reduktionsthese automatisch zum Antirealisten macht, eine Intuition

\footnotetext{
${ }^{42}$ Auf diese Weise kann man Abstand halten zu Fines (inkohärenter) Konzeption eines nichtrevisionistischen Antirealismus (vgl. S.399).

${ }^{43}$ Und zwar auch dann, wenn man die Sätze selbst akzeptiert.

${ }^{44} \mathrm{Vgl}$. Kap.1.3.2 und 2.
} 
zugrunde, die sozusagen nur akzidentiell die Semantik von Sätzen und Ausdrücken involviert, denn eine Reduktion ist dann nur ein Mittel, das die "Beseitigung" ontologischer Thesen ermöglicht. Sofern man der Ansicht ist, daß eine intuitiv angemessene realistische Position Thesen einschließen sollte, die diese Form von Antirealismus ausschließen, brauchen das von daher jedenfalls keine semantischen Thesen (etwa der Form (SR2)) oder Theorien zu sein. Es sollte genügen, (in irgendeiner Weise) an den ontologischen realistischen Thesen festzuhalten.

Der wichtigere Einwand gegen die These, daß einen das Akzeptieren einer Reduktionsthese wegen der dadurch möglichen Elimination von Sätzen und Ausdrücken automatisch zum Antirealisten macht, besteht aber in dem Hinweis, daß die Möglichkeit, bestimmte Sätze oder Ausdrücke aus einem Diskurs zu eliminieren und durch andere zu ersetzen, per se sicherlich keinen Grund darstellt, dies tatsächlich zu tun, und daß denkbare Gründe, die dafür oder dagegen sprechen, bestimmte Sätze und insbesondere ontologische realistische Thesen zu akzeptieren oder fallen zu lassen, durch den Befund, daß man diese Sätze zugunsten anderer eliminieren kann, noch nicht einmal berührt werden. Dies sieht man vielleicht deutlicher an anderen als den oben genannten Beispielfällen: Die Möglichkeit, den Ausdruck 'Großmutter' zu eliminieren, weil er gleichbedeutend ist mit 'Mutter der/einer Mutter', also reduzierbar auf den Ausdruck 'Mutter', ist per se intuitiv irrelevant für eine realistische oder antirealistische Einstellung in bezug auf Großmütter, sofern die Existenz und die Eigenschaften von Großmüttern unkontrovers sind. Man kann den Ausdruck 'Großmutter' (und alle Sätze, in denen er vorkommt) eliminieren, aber man kann es auch lassen, und was von beiden man tut, tangiert die Existenz und die Eigenschaften von Großmüttern offenbar nicht, und für Ausdrücke wie 'Computerprogramm' und 'Parteibasis' gilt Entsprechendes. Die These, daß einen das Akzeptieren einer Reduktionsthese wegen der dadurch möglichen Elimination von Sätzen und Ausdrücken automatisch zum Antirealisten macht, scheint also falsch zu sein, und verleiht daher auch der These keine Plausibilität, daß eine realistische Position, für die ontologische realistische Thesen konstitutiv sind, keine Reduktionsthesen (bezüglich dieser ontologischen Thesen bzw. darin enthaltener Ausdrücke) einschließen darf bzw. solche sogar explizit ausschließen müßte.

Die zweite Intuition, die für die Prima-facie-Plausibilität der These verantwortlich zu sein scheint, daß einen das Akzeptieren einer Reduktionsthese automatisch zum Antirealisten macht, ist von der Frage der Eliminierbarkeit von Sätzen und Ausdrücken im Prinzip unabhängig. Diese Intuition scheint zu sein, daß mit semantischer Reduzierbarkeit stets ontologische Reduzierbarkeit einhergeht und daß einen das Akzeptieren der These, daß bestimmte Entitäten, Eigenschaften etc. ontologisch reduzierbar sind auf andere Entitäten, Eigenschaften etc., d.h., daß erstere aus letzteren bestehen, aufgebaut sind, zusammengesetzt sind, mit Gesamtheiten von letzteren identisch sind o.̈̈., zum Antirealisten in bezug auf die reduziblen Entitäten, Eigenschaften etc. macht. Anders ausgedrückt scheint die Intuition im Kern die zu sein, daß eine realistische Position, für die ontologische realistische Thesen konstitutiv sind, keine ontologischen Reduktionsthesen (bezüglich der Entitäten, Eigenschaften etc., auf die sich die ontologischen Thesen beziehen) einschließen darf bzw. solche sogar explizit ausschließen muß. Ontologische Reduktionsthesen, die in dieser Weise relevant für die Sätze (3) und (4) sind, könnten etwa die sein, daß der Zwischenspeicher des Programms identisch ist mit einem bestimmten Teil des Prozessors, daß die Parteibasis identisch ist mit einer bestimmten Menge von Personen u.ä., und ähnliche Fälle, die für die wissenschaftstheoretische Debatte relevant sind, lassen sich offenbar leicht finden. Diese zweite Intuition wird häufig durch Formulierungen zum Ausdruck gebracht wie die, daß ontologisch reduzierbare Entitäten, Eigenschaften etc. "nichts als" oder "nichts anderes 
als" Aggregate, Gesamtheiten, Mengen o.ä. von Entitäten, Eigenschaften etc. des reduzierenden Typs sind, nichts von den letzteren "Verschiedenes", nichts "darüber hinaus".

Neben Fällen, in denen ontologische Reduktionsthesen zu dem intuitiven Eindruck zu führen scheinen, daß ontologische realistische Thesen nicht ausreichen, um eine realistische Einstellung zum Ausdruck zu bringen, lassen sich auch weitgehend analoge Fälle finden, in denen dies eine Supervenienzthese tut. Die Intuition scheint hier zu sein, daß einen das Akzeptieren der These, daß bestimmte Entitäten, Eigenschaften etc. auf anderen Entitäten, Eigenschaften etc. supervenieren, ${ }^{45}$ zum Antirealisten in bezug auf die supervenienten Entitäten, Eigenschaften etc. macht. Bei Satz (3) etwa könnte es in Betracht kommen, von Supervenienz des Computerprogramms und seiner Elemente auf den physikalischen Zuständen der Hardware des Computers zu sprechen, und den Eindruck, daß das Akzeptieren von Satz (3) noch keine realistische Einstellung konstituiert, durch die Formulierungen zum Ausdruck zu bringen, daß es sich bei dem Programm und seinen Teilen um "nur" oder "nichts als" superveniente Entitäten und Eigenschaften handelt.

Wie ist die These zu bewerten, daß eine realistische Position, für die ontologische realistische Thesen konstitutiv sind, keine ontologischen Reduktions- oder Supervenienzthesen (bezüglich der Entitäten, Eigenschaften etc., auf die sich die ontologischen Thesen beziehen) einschließen darf bzw. solche sogar explizit ausschließen muß und daß einen entsprechend das Akzeptieren ontologischer Reduktions- oder Supervenienzthesen automatisch zum Antirealisten macht? Zunächst läßt sich auch hier festhalten, daß das, was für eine realistische Einstellung möglicherweise zusätzlich zu ontologischen realistischen Thesen erforderlich sein könnte, keine semantischen Thesen oder Theorien sind. Was möglicherweise als Zusatzbedingung zu den ontologischen realistischen Thesen in Frage kommen könnte, ist eine Ergänzung dieser Thesen durch die "Klausel", daß die Entitäten, Eigenschaften etc., um die es jeweils geht, nicht (ontologisch) reduzierbar sind und/oder nicht auf anderen Entitäten, Eigenschaften etc. supervenieren. Daß man ontologische realistische Thesen durch eine solche Klausel ergänzen kann, ohne daß daraus Probleme für eine realistische Position entstehen, ist klar, denn Reduzierbarkeit und Supervenienz sind sozusagen (relationale) Eigenschaften wie viele andere, die Inhalt ontologischer realistischer Thesen sind. Dagegen ist es nicht plausibel, daß die Ergänzung ontologischer realistischer Thesen durch eine solche Klausel notwendig ist, um eine angemessene realistische Position zu gewinnen, daß man also eine realistische Einstellung nur zu nicht-reduziblen (und nicht-supervenienten) Entitäten und Eigenschaften einnehmen kann. Dafür spricht verschiedenes: Zum einen scheinen weder Reduktions- und Supervenienzthesen, noch deren Negation etwas zur Konkretisierung der von Nagel und Wright genannten zentralen Intuition beizutragen. Zum anderen mag in Fällen wie den Sätzen (3) und (4) der Eindruck, daß eine realistische Einstellung mit dem Akzeptieren von Reduktions- oder Supervenienzannahmen unverträglich ist, eine gewisse Prima-facie-Plausibilität haben, aber dieser Eindruck kollidiert mit verbreiteten Intuitionen in anderen Fällen und dürfte daher täuschen: Es ist intuitiv nicht plausibel, daß eine realistische Einstellung etwa zu Sandhaufen, Skatblättern, Galaxien und Wäldern ausgeschlossen sein sollte, wenn man akzeptiert, daß diese aus Sandkörnern bzw. Karten bzw. Sternen bzw. Bäumen, Sträuchern etc. bestehen und in diesem Sinn reduzierbar sind. Ebenso erscheint es intuitiv nicht plausibel, daß eine realistische Position in bezug auf alle materiellen Gegenstände der Alltagswelt wie Tische und Bratpfannen ausgeschlossen sein sollte, wenn man akzeptiert, daß sie aus Atomen aufgebaut sind. ${ }^{46}$

\footnotetext{
${ }^{45}$ Zum Begriff der Supervenienz siehe z.B. [Kim84, Tell83].

${ }^{46}$ Pace [Eddi29], S.IXff.
} 
In dieselbe Richtung wie die zuletzt genannte Intuition deutet auch eine etwas allgemeinere Überlegung, die nicht nur eine realistische Einstellung zu Alltagsgegenständen betrifft, sondern auch eine zu einem Teil der unbeobachtbaren Entitäten der Physik, Chemie etc.: Die (prinzipielle) ontologische Reduzierbarkeit eines Tisches o.ä. auf die Atome, aus denen er aufgebaut ist, führt (nach dem derzeitigen Kenntnisstand der Physik) nicht auf eine fundamentale, letzte Ebene, sondern auf Elemente, die ihrerseits reduzierbar sind, nämlich auf Protonen, Neutronen, Elektronen etc., und die ersteren von diesen sind wiederum auf Quarks, Gluonen etc. reduzierbar. Zumindest bis heute gibt es in der Physik keine Theorie, die (im derzeitigen Entwicklungsstand) ein ernsthafter Kandidat für eine "Theory of Everything" wäre, die eine fundamentale, letzte Ebene beschreiben würde, auf die alle anderen physikalischen Entitäten reduzierbar sind. Der für die Argumentation an dieser Stelle wichtige Punkt ist der, daß es darüber hinaus auch völlig offen ist, ob eine solche fundamentale Ebene überhaupt existiert. Das heißt, daß derzeit nicht nur offen ist, ob die entsprechende "Theory of Everything" jemals gefunden werden wird, also epistemisch zugänglich ist, sondern daß vor allem offen ist, ob es so etwas wie fundamentalste Entitäten gibt oder stattdessen eine unendliche, sozusagen nach unten offene Hierarchie von Ebenen bzw. Entitäten auf immer kleineren Skalen, derart daß jede Entität (prinzipiell) auf die Entitäten der nächsttieferen Ebene reduzierbar ist. Falls sich dieses letztere Szenario als korrekt erweisen sollte und man außerdem annimmt, daß eine realistische Einstellung zu reduzierbaren Entitäten ausgeschlossen ist, dann hätte dies offenbar zur Folge, daß eine realistische Einstellung zu allen physikalischen Entitäten, Eigenschaften etc., also zu makroskopischen Alltagsgegenständen genau wie zu den mikroskopischen Entitäten der Physik, ausgeschlossen ist. Diese Konsequenz scheint intuitiv nicht plausibel, um nicht zu sagen absurd. Von derartigen mikroskopischen Details des Aufbaus der Materie sollte die Möglichkeit nicht berührt werden, eine realistische Einstellung zu Alltagsgegenständen, unbeobachtbare Entitäten "auf höheren Hierarchieebenen" usw. einzunehmen.

Fazit dieser Überlegungen scheint also zu sein, daß die These falsch ist, daß eine realistische Einstellung zu bestimmten Entitäten, Ereignissen o.ä. und deren Eigenschaften es ausschließt, diese Entitäten für (ontologisch) reduzierbar oder supervenient zu halten, oder umgekehrt, und daß daher auch die These falsch ist, daß das Akzeptieren einer (ontologischen) Reduktions- oder Supervenienzthese einen automatisch zum Antirealisten in bezug auf die reduziblen oder supervenienten Entitäten, Ereignisse o.ä. macht. Man sollte zwei Fragen auseinanderhalten: Einerseits die Frage nach der Existenz von Entitäten, Ereignissen u.ä. und deren Eigenschaften unabhängig von menschlicher Erkenntnis, andererseits die Frage, ob es sich dabei um (ontologisch) reduzierbare oder superveniente Entitäten etc. handelt oder um fundamentale. Dies gilt für Tische, Skatspiele, Moleküle und Galaxien genauso wie für die in den obigen Beispielsätzen genannten Computerprogramme und Parteibasen. Konstitutiv für eine realistische Position sind Antworten auf die erste Frage, nicht Antworten auf die zweite. Die zweite Frage ist weitaus speziellerer Natur, denn Antworten darauf haben spezielle Relationseigenschaften einer Entität o.ä. zum Thema. ${ }^{47}$ Daß für die Naturwissenschaften, insbesondere die Physik, fundamentale Entitäten, Eigenschaften etc. von besonderem und vielleicht sogar von zentralem Interesse sind, steht auf einem anderen Blatt.

\footnotetext{
${ }^{47} \mathrm{Zu}$ den Aussagen über ontologische Reduzierbarkeit oder Supervenienz gehören die Unabhängigkeitsaussagen der Form (UvmE3): Unabhängigkeit von menschlicher Erkenntnis schließt danach Reduzierbarkeit und Supervenienz auf mentale(n) Entitäten aus.
} 


\section{Mathematische Entitäten}

Bei Sätzen wie (1) bzw. daraus durch Ergänzung einer Unabhängigkeitsklausel gewonnenen ontologischen realistischen Thesen werden gelegentlich auch dann Zweifel daran geäußert, daß sie ausreichen, um eine realistische Einstellung zu mathematischen Entitäten und deren Eigenschaften zum Ausdruck zu bringen, wenn außer Frage steht, daß diese Sätze weder mittels semantischer Reduktionen eliminiert werden können, noch ontologisch reduzierbare oder superveniente Entitäten und Eigenschaften zum Inhalt haben.

Als Motiv für solche Zweifel dürfte am ehesten eine Intuition in Frage kommen, daß eine realistische Einstellung zu Entitäten, die nicht raumzeitlich lokalisierbar sind und/oder kausal wechselwirken, "keinen Sinn macht" o.ä. und daß eine These, die eine realistische Einstellung zu mathematischen Entitäten zum Ausdruck bringt, daher die - offenbar falsche - Annahme enthalten müßte, daß diese Entitäten raumzeitlich lokalisierbar sind und/oder kausal wechselwirken. Intuitionen dieser Art sind i.a. gut "verankerte" und grundlegende und hängen mit ähnlichen Intuitionen in bezug auf andere (nichtmathematische) abstrakte Entitäten zusammen. Wenn man Intuitionen dieser Art nicht teilt, erscheinen sie einem i.a. völlig unplausibel und man wird ihnen die eigene Überzeugung entgegensetzen, daß nichts Falsches oder besonders Problematisches an ontologischen realistischen Thesen der Form (OR) über mathematische Entitäten ist, und diese Thesen eventuell zur Vermeidung von Mißverständnissen um eine Erläuterung ergänzen, die den fraglichen mathematischen Entitäten Lokalisierbarkeit und kausale Wirksamkeit abspricht. ${ }^{48}$ Außerdem wird man darauf hinweisen, daß Intuitionen dieser Art in keinem ersichtlichen Zusammenhang zu der von Nagel und Wright genannten zentralen Intuition stehen. Darüber hinaus ist Intuitionen dieser Art argumentativ schwer etwas entgegenzusetzen, dies scheint jedoch in der Natur der Sache, sprich: gut verankerter Intuitionen, zu liegen und umgekehrt keinen Grund darzustellen, die eigene Überzeugung aufzugeben, daß ontologische realistische Thesen der Form (OR) auch im Fall mathematischer Entitäten ausreichen, um in angemessener Weise eine realistische Einstellung zum Ausdruck zu bringen.

Denkbar und zumindest prima facie plausibel ist es natürlich, daß jemand Zweifel daran hat, daß nicht-lokalisierbare und nicht kausal wechselwirkende Entitäten tatsächlich epistemisch zugänglich sind oder überhaupt sein können. ${ }^{49}$ Solche Zweifel betreffen jedoch "nur" die Frage, ob man hinreichend gute epistemische Gründe für ontologische realistische Thesen über derartige Entitäten hat, ob sich also eine realistische Einstellung zu mathematischen Entitäten und ihren Eigenschaften tatsächlich rechtfertigen läßt, und - daran anschließend — vielleicht auch die (pragmatische) Frage, ob es sich bei den Aussagen der Diskurse der real-existierenden Mathematik um Behauptungen handelt oder ob sie instrumentalistisch aufzufassen sind, nicht jedoch die Frage, ob ontologische realistische Thesen sich eignen, um eine realistische Einstellung zu mathematischen Entitäten zum Ausdruck zu bringen.

\section{"Anthropozentrische" Eigenschaften und die Unabhängigkeitsklauseln ontolo- gischer realistischer Thesen}

Der Satz (2) der obigen Liste gehört zu einem Bereich von Fällen, in denen der Eindruck, daß ontologische realistische Thesen nicht hinreichen, um eine realistische Einstellung zum

\footnotetext{
${ }^{48}$ Dies sind zwei sehr generelle Eigenschaften, die dann zu den anderen Eigenschaften hinzutreten, die eine ontologische realistische These den Entitäten zuschreibt.

${ }^{49}$ Siehe z.B. [Bena73].
} 
Ausdruck zu bringen, zumindest zum Teil auf einen anderen als die bisher genannten Gründe zurückzugehen scheint, insofern dieser Eindruck auch dann noch besteht, wenn klar ist, daß (2) wörtlich gemeint, also nicht zu paraphrasieren ist und daß Reduzierbarkeit oder Supervenienz mit einer realistischen Einstellung nicht konfligieren. Die Intuition, die diesen Eindruck motiviert, scheint zu sein, daß eine realistische Einstellung zu der Eigenschaft einer Handlung, moralisch verwerflich zu sein, ausgeschlossen ist, weil diese Eigenschaft gleichsam $z u$ anthropozentrisch ist. Gestützt wird diese Intuition vielleicht durch die Überzeugung, daß diese Eigenschaft eine Dispositionseigenschaft von Personen (einer bestimmten Sprachgemeinschaft, mit bestimmter Sozialisation o.ä.) ist, auf eine Handlung mit Äußerungen von Abscheu o.ä. zu reagieren. Für andere "anthropozentrische" Eigenschaften und Entitäten gilt, mutatis mutandis, Entsprechendes, etwa für die Eigenschaft rot zu sein, wenn man sie für identisch hält mit der Eigenschaft, bei menschlichen Beobachtern (mit normalem Wahrnehmungsvermögen) unter "Normalbedingungen" eine Rotempfindung hervorzurufen.

Intuitionen dieser Art führen auf die allgemeine Frage, welche Art von Unabhängigkeitsklauseln ontologische realistische Thesen enthalten müssen, um in intuitiv plausibler Weise eine realistische Einstellung zum Ausdruck zu bringen, ob also von den vier vorne genannten Erläuterungen (UvmE1) - (UvmE4) von 'unabhängig von menschlicher Erkenntnis ${ }^{50}$ eine oder mehrere erforderlich und unverzichtbar sind für eine realistische Einstellung zu einer Entität, Eigenschaft etc., und, falls ja, welche. Eine "zu anthropozentrische" Entität oder Eigenschaft ist eine, die nicht unabhängig von menschlicher Erkenntnis im Sinne von (UvmE4) ist. Wenn man eine Überzeugung, daß eine Entität, Eigenschaft o.̈̈. diese Art von Unabhängigkeit aufweist, für unverzichtbar für eine realistische Einstellung zu dieser Entität, Eigenschaft o.ä. hält, ist demnach eine realistische Einstellung zu der (wie beschrieben als Disposition aufgefaßten) Eigenschaft, moralisch verwerflich zu sein, ausgeschlossen und durch eine entsprechende ontologische realistische These, die keine Unabhängigkeitsklausel der Form (UvmE4) einschließt, kann dann keine realistische Einstellung zu moralisch verwerflichen Handlungen etc. zum Ausdruck gebracht werden. Entsprechendes gilt für andere anthropozentrische Entitäten, Eigenschaften etc.

Hinsichtlich der allgemeinen Frage nach Unabhängigkeitsklauseln in ontologischen realistischen Thesen, die in allen Gegenstandsbereichen unverzichtbar für eine realistische Einstellung sind, herrscht selbst unter den Anhängern realistischer Positionen kein Konsens. Wenig kontrovers ist noch, daß jemand, der eine ontologische realistische These über eine Entität oder Eigenschaft akzeptiert, die Unabhängigkeitsklauseln aller vier Formen (UvmE1) - (UvmE4) einschließt (was etwa für Kieselsteine, deren Eigenschaft, rund zu sein, u.ä. plausibel ist), damit eine realistische Einstellung zu der fraglichen Entität oder Eigenschaft einnimmt. Ob Unabhängigkeitsklauseln einer oder mehrerer dieser vier Formen generell, d.h. für jeden Gegenstandsbereich, hinreichend und notwendig oder auch nur notwendig sind, um durch ontologische realistische Thesen in intuitiv plausibler Weise eine realistische Einstellung zum Ausdruck zu bringen, dürfte dagegen i.a. strittig sein: Im Sinne von (UvmE1) und auch von (UvmE1a) sind mentale Entitäten nicht unabhängig von menschlicher Erkenntnis, wenn man bestimmte (sehr grob gesprochen: kartesische) Positionen in der Philosophie des Geistes akzeptiert ${ }^{51}$ gleichzeitig sollte eine realistische Einstellung zu mentalen Entitäten (auch unter kartesischen Prämissen) zumindest möglich sein, was dagegen spricht, eine Unabhängigkeitsklausel der Form (UvmE1) oder (UvmE1a)

\footnotetext{
${ }^{50}$ Siehe Kap.1.3.1.

${ }^{51}$ Positionen, denen zufolge man eine Wahrnehmung, Empfindung, Überzeugung o.ä. nicht haben kann, ohne zu glauben, zu wissen o.ä., daß man sie hat.
} 
als unverzichtbar für eine intuitiv angemessene ontologische realistische These aufzufassen. Andererseits wird Unabhängigkeit im Sinne von (UvmE1) oder (UvmE1a) intuitiv vielfach als konstitutiv für eine realistische Einstellung zu materiellen Gegenständen wie Kieselsteinen u.ä. und deren Eigenschaften betrachtet. Letzteres gilt auch für Unabhängigkeit im Sinne von (UvmE2); materielle Gegenstände, die von Menschen hergestellt, bearbeitet etc. wurden (Tische, Stricknadeln etc.) sind jedoch ${ }^{52}$ nicht unabhängig in diesem Sinn. Speziellere Unabhängigkeitsklauseln der Form (UvmE2a) dagegen scheinen vielleicht am ehesten plausible Kandidaten für eine für alle Gegenstandsbereiche (einschließlich Artefakte und mentale Entitäten) gültige Erläuterung von 'unabhängig von menschlicher Erkenntnis' zu sein. Im Sinne von (UvmE3) sind wiederum mentale Entitäten nicht 'unabhängig von menschlicher Erkenntnis', immerhin aber im Sinne speziellerer Unabhängigkeitsklauseln der Form (UvmE3a), so daß auch diese als Kandidaten für eine für alle Gegenstandsbereiche gültige Erläuterung von 'unabhängig ...' in Frage kommen. Die Frage, ob mit Unabhängigkeitsklauseln der Form (UvmE2a) und/oder (UvmE3a) versehene ontologische realistische Thesen für alle Gegenstandsbereiche notwendig sind und darüber hinaus vielleicht sogar hinreichen, um in intuitiv plausibler Weise eine realistische Einstellung zum Ausdruck zu bringen, wird jedoch in der Literatur üblicherweise nicht diskutiert, sondern allenfalls am Rande oder implizit berührt, und ein Konsens in diesem Punkt ist nicht erkennbar.

Ein Konsens ist ebensowenig (oder womöglich noch weniger) erkennbar in bezug auf die Frage, ob eine Überzeugung, daß für eine Entität, Eigenschaft o.ä. Unabhängigkeit im Sinne von (UvmE4) vorliegt, notwendig (oder vielleicht sogar hinreichend) ist für eine intuitiv angemessene realistische Einstellung zu dieser Entität, Eigenschaft o.ä., und daher auch nicht in bezug auf die Frage, ob Sätze wie (2) bzw. entsprechende ontologische realistische Thesen, die von "anthropozentrischen" Entitäten oder Eigenschaften handeln und keine Unabhängigkeitsklausel der Form (UvmE4) zulassen, eine realistische Einstellung zum Ausdruck bringen. Anhänger realistischer Positionen, die der Überzeugung sind, daß Unabhängigkeit im Sinne von (UvmE4) nicht notwendig ist für eine realistische Einstellung und daß sich Sätze wie (2) bzw. entsprechende ontologische realistische Thesen eignen, um eine solche realistische Einstelllung zu "anthropozentrischen" Entitäten, Eigenschaften etc. zum Ausdruck zu bringen, nehmen häufig eine Intuition sehr allgemeiner Art in Anspruch, die sich grob charakterisieren läßt als die Überzeugung, daß die Art von Unabhängigkeit, die durch (UvmE4) beschrieben wird, die Objektivität von Entitäten, Eigenschaften etc. betrifft und daß diese Objektivität eine Sache ist, eine realistische Einstellung zu (mehr oder weniger objektiven oder nicht-objektiven) Entitäten, Eigenschaften etc. jedoch eine andere Sache. ${ }^{53}$ Der damit angeschnittene Fragenkomplex ist jedoch zu groß und komplex, um ihn hier zu behandeln; glücklicherweise kann er, und sollte er daher, für die Zwecke der wissenschaftstheoretischen Realismusdebatte, oder zumindest weiter Teile davon, eingeklammert werden: Wenn man die Psychologie und ihre Gegenstände beiseite läßt, dürfte für die meisten der in der wissenschaftstheoretischen Debatte im Blickpunkt stehenden Entitäten, Eigenschaften etc., nämlich u.a. für die meisten physikalischen, chemischen, geologischen, biologischen, Unabhängigkeit im Sinne der Erläuterungen (UvmE1a), (UvmE2a), (UvmE3) und (UvmE4) im wesentlichen unkontrovers sein, und es dürften keine Zweifel bestehen, daß diese Entitäten, Eigenschaften etc. "zu anthropozentrisch" sein könnten. ${ }^{54}$

\footnotetext{
${ }^{52}$ Wie vorne diskutiert; vgl. S.319, 370 .

${ }^{53}$ Siehe dazu z.B. [Nage86, Pett91].

${ }^{54}$ Ein verwandter, für die wissenschaftstheoretische Debatte relevanter Fragenkomplex, der prima facie vielleicht Zweifel an dieser Aussage auslösen könnte, betrifft die (vor allem in der Relativitätstheorie
} 
Fazit dieser Überlegungen ist also, daß auch unter Anhängern realistischer Positionen kein Konsens besteht hinsichtlich der Frage, welche Art von Unabhängigkeitsklauseln ontologische realistische Thesen einschließen müssen, um in intuitiv plausibler Weise eine realistische Einstellung zum Ausdruck zu bringen, und ob dies für alle Gegenstandsbereiche dieselbe Art ist. Für die meisten der unbeobachtbaren Entitäten, Eigenschaften etc., die in der wissenschaftstheoretischen Realismusdebatte thematisiert werden, ist jedoch, genau wie für makroskopische, materielle Gegenstände der Alltagswelt, unkontrovers, daß Unabhängigkeit im Sinne von (UvmE1a), (UvmE2a), (UvmE3) und (UvmE4) vorliegt und daß ontologische realistische Thesen, die diese Unabhängigkeitsklauseln einschließen, hinreichend sind für eine realistische Einstellung. Ob Unabhängigkeit im Sinne von (UvmE4) notwendig für eine realistische Einstellung ist, oder ob eine realistische Einstellung zu "zu anthropozentrischen" Entitäten, Eigenschaften etc., also zu welchen, für die (UvmE4) nicht gilt, ausgeschlossen ist, kann für die Zwecke der wissenschaftstheoretischen Realismusdebatte offen bleiben, und damit auch, ob Sätze wie (2) hinreichen, um eine realistische Einstellung zum Ausdruck zu bringen.

\section{Fazit: Ontologische realistische Thesen genügen, um eine realistische Einstel- lung zum Ausdruck zu bringen}

Ergebnis der obigen Überlegungen ist, daß ontologische realistische Thesen der vorne angegebenen Form (OR), also bestehend zum einen aus Existenz- und anderen Aussagen über Entitäten, Ereignisse etc. und deren Eigenschaften, zum anderen aus einer Unabhängigkeitsaussage, ausreichen, um in intuitiv angemessener Weise eine realistische Einstellung zum Ausdruck zu bringen; irgendwelche Ergänzungen oder Verbesserungen dieser Thesen sind dazu nicht erforderlich. Dies gilt nicht nur für eine realistische Einstellung zu materiellen Gegenständen der Alltagswelt bzw. zu den entsprechenden Diskursen, sondern auch in bezug auf die (oder zumindest die meisten der ${ }^{55}$ ) Gegenstands- bzw. Diskursbereiche, von denen die Sätze der vorne angegebenen Liste handeln bzw. zu denen sie gehören.

Wenn die Sätze der Liste durch geeignete Unabhängigkeitsklauseln ergänzt werden, stellen sie - entgegen dem Eindruck, der prima facie vielleicht entstehen mag — ontologische realistische Thesen dar, die eine realistische Position konstituieren können, ohne daß sie dazu irgendwelcher weiterer Ergänzungen oder Verbesserungen bedürfen. Gegenteilige Intuitionen und Eindrücke erweisen sich bei genauerer Betrachtung als falsch, lassen sich "wegerklären" oder erscheinen angesichts anderer, konfligierender und besser begründeter Überzeugungen als unplausibel. Was man tun muß, um eine realistische Einstellung einzunehmen oder zu vertreten, ist, bestimmte ontologische realistische Thesen der Form (OR) als Überzeugungen zu akzeptieren bzw. zu behaupten (und ggf. epistemische Rechtfertigungsgründe dafür zu nennen), nicht mehr (insbesondere braucht man keine semantischen Thesen oder Theorien oder sonstige Ergänzungen zu den Thesen der Form (OR) zu akzeptieren oder zu vertreten), aber auch nicht weniger.

Im Hinblick auf die wissenschaftstheoretische Realismusdebatte sprechen die obigen

thematisierte) Unterscheidung zwischen bezugssystemabhängigen und -unabhängigen Größen und Gesetzen, insbesondere, da sich in der Literatur gelegentlich die These findet, daß nur bezugssystemunabhängige Größen "real” seien. Auf den zweiten Blick zeigt sich jedoch, daß Bezugssysteme allenfalls kontingenterweise auf den menschlichen kognitiven Apparat, menschliche Erkenntnisfähigkeiten u.ä. Bezug nehmen, so daß auch für bezugssystemabhängige Größen, Gesetze etc. (UvmE4) erfüllt ist. Daß die genannte Unterscheidung sinnvoll ist und bezugssystemunabhängige Größen in einem präzise angebbaren Sinn "objektiver" sind als bezugssystemabhängige, ist davon natürlich unberührt.

${ }^{55}$ Für "anthropozentrische" Eigenschaften war die Frage oben offen geblieben. 
Überlegungen dafür, daß auch dort ontologische realistische Thesen der Form (OR) ausreichen, um eine realistische Einstellung zu den (meisten der ${ }^{56}$ ) dort im Blickpunkt stehenden Gegenstandsbereichen bzw. Diskursen zum Ausdruck zu bringen. Für die meisten der dort relevanten Entitäten, Eigenschaften etc. scheint, genau wie für die (meisten der) Beispielfälle der obigen Liste, Unabhängigkeit von menschlicher Erkenntnis im Sinne von (UvmE1a), (UvmE2a), (UvmE3) und (UvmE4) vorzuliegen, und ontologische realistische Thesen, die entsprechende Unabhängigkeitsklauseln einschließen, sind in beiden Debattenfeldern hinreichend für eine realistische Einstellung (wenn auch vielleicht nicht alle Klauseln dazu notwendig sind). Für diesen letzteren Befund sprechen die obigen Überlegungen einerseits, insofern die angeführten Gründe für die Überzeugungen, daß eine realistische Einstellung mit dem Akzeptieren von Reduktionsthesen und Supervenienzthesen verträglich ist etc., auch auf Fälle in der wissenschaftstheoretischen Debatte anwendbar sind, andererseits, indem sie dem (möglichen) Argument die Grundlage entziehen, daß in Gegenstands- bzw. Diskursbereichen, die außerhalb der wissenschaftstheoretischen Debatten liegen, ontologische realistische Thesen nicht ausreichen, um eine intuitiv angemessene realistische Position zum Ausdruck zu bringen und daher ${ }^{57}$ auch nicht in der wissenschaftstheoretischen Debatte.

\subsubsection{Ontologische realistische Thesen und konstruktivistische Motive}

Wird die von Nagel und Wright beschriebene allgemeine Intuition durch eine realistische Position, für die ontologische realistische Thesen der Form (OR) konstitutiv sind, in allen ihren relevanten Aspekten und Facetten in zufriedenstellender Weise konkretisiert? Für eine positive Antwort auf diese Frage ist oben ausführlich argumentiert worden, die angegebenen Argumente und Überlegungen involvieren allerdings häufig einen Appell an vortheoretische Intuitionen und sind daher zweifellos nicht für jeden Diskussionsgegner überzeugungskräftig oder gar zwingend. Wie in allen Fällen, in denen philosophisch grundlegende Intuitionen im Spiel sind, sind aber auch hier "K.o.-Argumente" wohl nicht zu haben und zu erwarten. Eine in der Literatur von verschiedenen Autoren ins Spiel gebrachte "Quelle" von Einwänden gegen die vorgeschlagene Art der Konkretisierung der Intuition von Nagel und Wright ist jedoch bisher noch unberücksichtigt geblieben, nämlich konstruktivistische Motive und Intuitionen, die zu dem Einwand führen, daß die in ontologischen realistischen Thesen der oben vorgeschlagenen Art enthaltenen Unabhängigkeitsklauseln nicht den philosophisch interessanten und relevanten Gehalt dessen erfassen, worauf Nagel und Wright mit ihrer Rede von "Unabhängigkeit" hindeuten. Hinter diesem Einwand steht in der Regel die Überzeugung, daß realistische Thesen, die diesen philosophisch interessanten und relevanten Gehalt "einfangen", offenbar falsch wären.

Zwei in der wissenschaftstheoretischen Realismusdebatte als konstruktivistisch bezeichnete Thesen sind bereits oben ${ }^{58}$ bei der Diskussion der Positionen von Hacking und Pickering erwähnt worden: Einer dieser Thesen zufolge sind physikalische Theorien und Entitäten i.a. "konstruiert" und damit in einer Hinsicht nicht "unabhängig von menschlicher Erkenntnis", weil wissenschaftliche Instrumente und Geräte unerläßliche Voraussetzung der Theoriebildung sind. Einer anderen These zufolge sind sie es deshalb nicht, weil experimentell untersuchte Entitäten und Systeme meistens in einer Form präpariert oder

\footnotetext{
${ }^{56}$ Die Frage nach angemessenen Unabhängigkeitsklauseln für Thesen der Form (OR) über die Gegenstände der Psychologie war oben beiseite geblieben.

${ }^{57}$ Die Hintergrundannahme vorausgesetzt, daß "realismuskonstitutive" Thesen in allen Gegenstandsbzw. Diskursbereichen von derselben Art sind.

${ }^{58}$ S.319f., 369f.
} 
sogar eigens hergestellt werden, in der sie in der "unberührten Natur" außerhalb eines Labors nicht vorkommen. Beide Thesen sind plausibel und, wie oben diskutiert, mit Unabhängigkeitsklauseln der Form (UvmE1) und (UvmE2) nicht verträglich, wohl aber mit solchen der Form (UvmE1a), (UvmE2a), (UvmE3) und (UvmE4). Beide Thesen verweisen auf Probleme der epistemischen Rechtfertigung ontologischer realistischer Thesen, nämlich zum einen auf die Frage, ob die Gewinnung einer Theorie, eines Gesetzes o.ä., wenn sie von Instrumenten und Geräten "abhängig ist", eine Theorie, ein Gesetz o.ä. liefert, die bzw. das sich hinreichend gut epistemisch rechtfertigen läßt, zum anderen auf die Frage, ob oder inwieweit sich durch Untersuchungen an im Labor hergestellten oder präparierten Systemen epistemisch gerechtfertigte Theorien, Gesetze o.ä. über Systeme "in der unberührten Natur" gewinnen lassen. Beide Thesen berühren jedoch nicht die "Unabhängigkeit", auf die sich die Intuition von Nagel und Wright bezieht, und daß ontologische realistische Thesen, die "nur" Unabhängigkeitsklauseln der Form (UvmE1a), (UvmE2a), (UvmE3) und (UvmE4) einschließen, nicht aber welche der Form (UvmE1) und (UvmE2), ${ }^{59}$ keine zufriedenstellende Konkretisierung dieser Intuition ergeben, ist offenbar unplausibel: Damit wäre eine realistische Einstellung nicht nur zu unbeobachtbaren Entitäten wie K-Mesonen und Chromosomen ausgeschlossen, sondern auch zu beobachtbaren Entitäten wie im Labor gezüchteten Siliziumkristallen und genmanipulierten Maispflanzen (im Unterschied aber zu Kieselsteinen und "naturbelassenen" Pflanzen) und zu sämtlichen Artefakten wie Bratpfannen, Tischen und Fahrrädern.

Außer den beiden genannten Thesen finden sich in der Realismusdebatte auch allgemeinere, ebenfalls als konstruktivistisch bezeichnete Thesen, die sich nicht nur auf die Gegenstandsbereiche der wissenschaftstheoretischen Debatte beziehen. ${ }^{60}$ Diesen Thesen zufolge sind alle Entitäten, Eigenschaften, Sachverhalte etc., die für Menschen kognitiv zugänglich sind bzw. von denen sie Überzeugungen und/oder Wissen haben, in einem philosophisch relevanten Sinn nicht "unabhängig von menschlicher Erkenntnis", weil sie "nur" mit Hilfe menschlicher Begriffe und Begriffssysteme individuiert und identifiziert werden können und deshalb, d.h. dadurch, daß dabei menschliche Begriffe und Begriffssysteme involviert sind, eine Abhängigkeit der Entitäten, Eigenschaften etc. zustandekommt. Diesen konstruktivistischen Thesen zufolge müßten ontologische realistische Thesen, die eine angemessene Konkretisierung der Intuition von Nagel und Wright darstellen, diese Art von Abhängigkeit ausschließen und damit zwangsläufig falsch sein. Thesen, die in angemessener Weise zum Ausdruck bringen, was eine realistische Einstellung zu bestimmten Entitäten, Eigenschaften etc. intuitiv ausmacht, wären demnach allesamt falsch, egal auf welche Entitäten, Eigenschaften etc. sie sich beziehen.

Wenn man versucht, die Plausibilität dieser zuletzt genannten konstruktivistischen Thesen zu beurteilen, mit denen der Anspruch verbunden wird, eine von Unabhängigkeitsklauseln der Form (UvmE1a), (UvmE2a), (UvmE3) und (UvmE4) nicht berührte Art der Abhängigkeit von Entitäten, Eigenschaften etc. von menschlichen Begriffen, Begriffssystemen o.ä. zu identifizieren, stößt man auf große Schwierigkeiten: Die Anhänger dieser Thesen bieten für die Abhängigkeit nur Beschreibungen an, die entweder trivial aussehen und intuitiv klarerweise nichts gegen realistische Thesen auszutragen scheinen, oder so metaphorisch und ungenau sind, daß sie keine klare und wirklich verständliche Erläuterung der behaupteten Abhängigkeit ergeben und die konstruktivistischen Thesen daher keine Überzeugungskraft entwickeln können. Zur ersten Gruppe gehören Beschreibungen, die lediglich auf die triviale Beobachtung hinauszulaufen scheinen, daß man zur Formulie-

\footnotetext{
${ }^{59}$ Weil letztere mit den beiden genannten konstruktivistischen Thesen nicht verträglich wären.

${ }^{60} \mathrm{Vgl}$. S.11.
} 
rung von Sätzen und Aussagen über irgendwelche Entitäten, Sachverhalte etc. sprachliche Ausdrücke braucht, deren Verwendungsweise, Bedeutung etc. von Menschen konventionell festgelegt wurden. So heißt es z.B. bei Putnam:

"[...] signs do not intrinsically correspond to objects, independently of how those signs are employed and by whom. But a sign that is actually employed in a particular way by a particular community of users can correspond to particular objects within the conceptual scheme of those users. 'Objects' do not exist independently of conceptual schemes." 61

Zur zweiten Gruppe gehören Beschreibungen der Abhängigkeit der Entitäten, Eigenschaften etc. von Begriffen und Begriffssystemen wie die folgenden von Putnam:

"We cut up the world into objects when we introduce one or another scheme of descriptions" 62

"the mind and the world jointly make up the mind and the world" 63

"If, as I maintain, 'objects' themselves are as much made as discovered, as much products of our conceptual invention as of the 'objective' factor in experience, [...] then of course objects intrinsically belong under certain labels; because those labels are the tools we used to construct a version of the world with such objects in the first place. But this kind of 'Self-Identifying Object' is not mind-independent" 64

oder die folgende Beschreibung von Goodman:

"[We have made the stars] by making a space and time that contains those stars. By means of science, that world (indeed many another) was made with great difficulty and is [...] a more or less right or real world. We can make the sun stand still, not in the manner of Joshua but in the manner of Bruno. We make a star as we make a constellation, by putting its parts together and marking off its boundaries.

In short, we do not make stars as we make bricks; not all making is a moulding of mud. The worldmaking mainly in question here is making not with hands but with minds, or rather with languages or other symbol systems. Yet when I say that worlds are made, I mean it literally [... ]. Surely we make versions, right versions make worlds. And however distinct worlds may be from right versions, making right versions is making worlds." 65

Daß sich eine klare und wirklich verständliche Erläuterung der Abhängigkeit geben läßt, die von den konstruktivistischen Thesen identifiziert oder auf die jedenfalls durch Formulierungen wie die zitierten von Putnam und Goodman hingedeutet werden soll, und daß diese Abhängigkeit dann außerdem eine intuitiv für eine antirealistische Einstellung

\footnotetext{
${ }^{61}$ [Putn81], S.52.

${ }^{62}$ [Putn81], S.52; Putnam spricht in diesem Zusammenhang von "conceptual relativity" (u.a. [Putn87a], [Putn92], Kap.6).

${ }^{63}$ [Putn81], S.XI.

${ }^{64}$ [Putn81], S.54.

${ }^{65}$ [Good80], S.213; vgl. auch [Good78].
} 
hinreichende ist, d.h. eine, die durch realistische Thesen, die eine intuitiv plausible Konkretisierung der Intuition von Nagel und Wright darstellen, ausgeschlossen werden muß, kann man - angesichts der vielen unbefriedigenden Erläuterungsversuche in der Literatur vielleicht mit Gründen bezweifeln. Durch den Hinweis, daß man sprachliche Ausdrücke verwenden muß, um Sätze und Aussagen über Entitäten, Eigenschaften etc. zu formulieren, und daß von einer Sprachgemeinschaft konventionell festgelegt wird und im Prinzip auch anders festgelegt werden könnte, welcher sprachliche Ausdruck zur Bezeichnung welchen "Ausschnitts der Welt", also welcher Entität, Eigenschaft etc., verwendet wird, ${ }^{66}$ wird jedenfalls keine solche Abhängigkeit identifiziert.

Dieser Punkt kann an dieser Stelle wegen der Breite und Unübersichtlichkeit der Literatur zu diesem Fragenkomplex nicht in erschöpfender und zufriedenstellender Weise diskutiert werden, es sollte sich aber anhand von Beispielen plausibel machen lassen, daß realistische Thesen, die eine intuitiv angemessene Konkretisierung der Intuition von Nagel und Wright darstellen, keineswegs die angedeutete "Konventionalität" bei der Festlegung der Bedeutung, Referenz etc. sprachlicher Ausdrücke ausschließen müssen: Als Europa bezeichnet man die Landmassen bis zum Ural und einschließlich der britischen Inseln, Islands etc., der Name 'Europa' (oder ein anderer, zusätzlicher) hätte aber ebensogut als Bezeichnung eingeführt werden können, die die genannten Inseln nicht einschließt oder Grönland zusätzlich einschließt oder die Grenze zu Asien nicht am Ural zieht, sondern davor oder dahinter, o.ä. Einen Satz von 32 Karten, mit denen man Skat spielen kann, nennt man ein Skatblatt, es gibt aber keine eigenen Bezeichnungen für die Teilmengen der roten bzw. schwarzen Karten eines Skatblatts, obwohl man auch dafür eine Bezeichnung einführen könnte (etwa 'Halbblatt'), usw. Zur Beschreibung der Wetterverhältnisse an verschiedenen Orten und zu verschiedenen Zeiten verwendet man Bezeichnungen wie 'Regenwetter', 'heiß', 'windig' u.ä., man könnte aber (stattdessen oder zusätzlich) Bezeichnungen wie 'Arizona-Wetter' (für 'heiß und windig oder nicht heiß und nicht windig') ${ }^{67}$ u.ä. einführen. Diese Beispiele sollten genügen, um plausibel zu machen, daß die Möglichkeiten offenbar unbegrenzt sind, sprachliche Ausdrücke als Bezeichnung für etwas anderes zu verwenden als es derzeit getan wird und/oder zu diesem Zweck andere Ausdrücke einzuführen, und wenn es dieser Befund ist, den Putnam und Goodman mit Formulierungen wie "cut up the world" und "marking off [...] boundaries" bezeichnen wollen, dann ist ihre konstruktivistische These hinreichend klar. Im Zusammenhang mit diesem Befund von einer Abhängigkeit der bezeichneten Gegenstände von Begriffen, von einem Begriffschema o.ä. zu sprechen, wirkt dann allerdings eher mißverständlich, und intuitiv völlig unplausibel scheint jedenfalls in den genannten Beispielfällen die These, daß realistische Thesen die "Konventionalität" bei der Festlegung der Bedeutung, Referenz etc. der Ausdrücke ausschließen müssen, wenn sie in angemessener Weise eine realistische Einstellung zu den mit Hilfe dieser Ausdrücke individuierten oder identifizierten Entitäten, Eigenschaften etc. zum Ausdruck bringen sollen, also eine intuitiv angemessene Konkretisierung der Intuition von Nagel und Wright darstellen sollen. Eine realistische Einstellung zu Europa, Skatblättern und Regenwetter läßt sich in intuitiv angemessener Weise durch ontologische realistische Thesen der Form (OR) zum Ausdruck bringen, die die Existenz und die Eigenschaften von Europa, Skatblättern und Regenwetter zum Inhalt haben. Man kann offenbar zusammen mit diesen Thesen auch Thesen der Form (OR) akzeptieren, die die Existenz und die Eigenschaften von "Europa-ohne-die-Inseln-plus-Rußland", Halbblättern und Arizona-Wetter zum Inhalt haben, man muß dies aber natürlich nicht. Es ist nicht

\footnotetext{
${ }^{66}$ Goodmans "marking off its boundaries" bzw. Putnams "cut up the world" und "conceptual relativity". ${ }^{67}[$ Mill74].
} 
ersichtlich, warum Thesen der Form (OR) nur dann eine intuitiv angemessene realistische Einstellung zu Europa, Skatblättern und Regenwetter ergeben sollten, wenn man zugleich bestreitet, daß man zur Formulierung dieser Thesen Ausdrücke braucht, deren Verwendungsweise, Bedeutung etc. konventionell festgelegt wurden und im Prinzip auch anders hätten festgelegt werden können oder an deren Stelle (oder zusätzlich zu ihnen) andere Ausdrücke wie 'Europa-ohne-die-Inseln-plus-Rußland', 'Halbblatt' und 'Arizona-Wetter' hätten etabliert werden können oder auch gar keine. ${ }^{68}$

Für den Fall, daß sich — trotz der bis hierher formulierten Zweifel — dennoch eine klare und plausible konstruktivistische These identifizieren läßt bzw. eine nicht-triviale (und von Unabhängigkeitsklauseln der Form (UvmE1a), (UvmE2a), (UvmE3) und (UvmE4) nicht berührte) Art von Unabhängigkeit, die durch realistische Thesen erfaßt werden sollte, die die Intuition von Nagel und Wright in intuitiv plausibler Weise konkretisieren, die aber tatsächlich für die Entitäten, Eigenschaften etc. nicht vorliegt, um die es in der Realismusdebatte geht, soll hier noch die Richtung angedeutet werden, in der man dann nach einer Replik suchen kann, wenn man generell zu einer realistischen Positionen in der Wissenschaftstheorie neigt. Sofern die fragliche Art von Abhängigkeit die materiellen Entitäten, Eigenschaften etc. der Alltagswelt genauso betrifft wie die unbeobachtbaren Entitäten, Eigenschaften etc., die in der wissenschaftstheoretischen Realismusdebatte im Zentrum des Interesses stehen, kann man die vorne ${ }^{69}$ genannte Idee eines relativen Realismus ins Spiel bringen und argumentieren, daß es einem wissenschaftlichen Realisten in erster Linie "nur" darum geht, daß unbeobachtbare Entitäten, Eigenschaften etc. in keiner grundsätzlich anderen Weise und keinem höheren Grade "von menschlicher Erkenntnis abhängig" oder "konstruiert" sind als (gleichartige bzw. vergleichbare) alltagsweltliche Entitäten, Eigenschaften etc. und daher keinen anderen ontologischen Status haben als letztere. Da eine konstruktivistische These, wie sie hier angenommen wird, mit Thesen der Form (OR) (inklusive der angegebenen Unabhängigkeitsklauseln) grundsätzlich verträglich wäre, sollte sich dann unter Voraussetzung dieser konstruktivistischen These noch immer eine philosophisch interessante und relevante - Diskussion um Thesen der Form (OR) über unbeobachtbare Entitäten, Eigenschaften etc. führen lassen. Die wissenschaftstheoretische Realismusdebatte ließe sich also dann sozusagen vor dem Hintergrund dieser allgemeinen konstruktivistischen Thesen rekonstruieren - auch wenn eine in dieser Debatte verteidigte "realistische" Position dann nicht mehr alle Aspekte der Intuition von Nagel und Wright erfassen würde.

\subsubsection{Eine axiologische These als konstitutiv für eine realistische Posi- tion?}

In der Literatur zur wissenschaftstheoretischen Realismusdebatte wird gelegentlich sowohl von Anhängern realistischer als auch von Anhängern antirealistischer Positionen eine axiologische realistische These der Form (AR) als konstitutiv für eine realistische Position genannt. ${ }^{70}$ Als Grundlage für eine Entscheidung, ob einer axiologischen These tatsächlich diese Rolle zukommen sollte, steht offenbar kaum mehr zur Verfügung als vortheoretische Intuitionen darüber, was eine angemessene realistische Position beinhalten sollte, die allerdings bei vielen grundlegende und gut "verankerte" zu sein scheinen.

Wenn man die von Nagel und Wright beschriebene allgemeine Intuition teilt und der

\footnotetext{
${ }^{68}$ Erhellende Diskussionen zu diesem Punkt liefern u.a. [Sosa99] und [Wolt87].

${ }^{69} \mathrm{~S} .24$.

${ }^{70}$ S. S.13f.
} 
Ansicht ist, daß eine intuitiv angemessene realistische Position diese allgemeine Intuition konkretisieren sollte, spricht dies offenbar dagegen, eine axiologische realistische These als konstitutiv für wissenschaftlichen Realismus zu betrachten, denn eine solche These ergibt für keine der beiden "Komponenten" dieser Intuition eine plausible Konkretisierung, weder für den "bescheidenen", noch für den "anmaßenden Gedanken".

Das Motiv, eine axiologische These als konstitutiv für wissenschaftlichen Realismus zu betrachten, dürfte für Anhänger realistischer Positionen häufig sein, daß sie sozusagen "eigentlich lieber" ontologische oder epistemische Thesen zum Herzstück ihrer Position erklären würden, dies jedoch wegen des nicht tun möchten, weil sie in epistemischer Hinsicht nur sehr begrenztes oder gar kein Vertrauen zu den derzeit vorliegenden wissenschaftlichen Theorien, Gesetzen, Modellen usw. haben und sich daher nicht auf entsprechende ontologische oder epistemische realistische Thesen festlegen wollen, sondern auf eine axiologische These ausweichen. ${ }^{71}$

Eine These der Form (AR) über das Ziel der Wissenschaften dürfte in diesem Sinn häufig Ausdruck einer in epistemischer Hinsicht vorsichtigen Einstellung sein.

Einen überzeugenden Grund, eine axiologische These als konstitutiv für eine realistische Position zu betrachten, stellt dies jedoch kaum dar. Wenn man nicht wenigstens einen Teil der in den derzeitigen real-existierenden Wissenschaften akzeptierten Theorien, Gesetze etc. für epistemisch hinreichend gut begründet hält und entsprechende ontologische oder epistemische realistische Thesen akzeptiert, dann resultiert daraus zum einen eine Position, die allenfalls eine der beiden Komponenten der Intuition von Nagel und Wright konkretisiert, den "anmaßenden Gedanken" jedoch nicht, zum anderen ist dann auch nicht klar, woher Gründe für eine axiologische These der Form (AR) zu beziehen wären, also Gründe für die Annahme daß wahre Theorien etc. tatsächlich das Ziel des Unternehmens Wissenschaft sind. Wenn man sich aus "epistemischer Vorsicht" auf keinerlei ontologische oder epistemische realistische Thesen festlegen möchte, ist also nicht zu sehen, auf welcher Grundlage man sich auf eine axiologische realistische These festlegen sollte - selbst wenn man axiologische Thesen als konstitutiv für eine realistische Position betrachten sollte.

Das Gesagte spricht offenbar in keiner Weise dagegen, eine realistische Position durch eine These der Form (AR) zu ergänzen, etwa eine "in epistemischer Hinsicht vorsichtige" Position, die im Kern aus einigen epistemischen (plus semantischen) oder ontologischen realistischen Thesen besteht, die einem Teil der Theorien, Gesetze etc. der gegenwärtigen Wissenschaften entsprechen. Eine axiologische These wäre dann nicht konstitutiv für eine realistische Position, sondern würde lediglich eine These über das "Unternehmen" formulieren, das sozusagen bisher die Quelle der ontologischen oder epistemischen realistischen Thesen war und, so hofft man, weiterhin eine solche Quelle sein wird.

Fazit: Axiologische Thesen der Form (AR) sollten nicht als konstitutiv für eine Position aufgefaßt werden, die in intuitiv plausibler Weise eine realistische Einstellung zum Ausdruck bringt.

\footnotetext{
${ }^{71}$ Auf den ersten Blick könnte hier der Eindruck entstehen, daß eine These der Form (AR) — entgegen dem, was oben gesagt wurde — doch den "bescheidenen Gedanken" der Nagel/Wright-Intuition konkretisiert, genau besehen ist das aber nicht der Fall, denn über eine "Unabhängigkeit der Welt von menschlicher Erkenntnis" besagt (AR) ja tatsächlich nichts.
} 


\subsubsection{Fazit: Ontologische realistische Thesen bilden das Herzstück ei- ner intuitiv angemessenen realistischen Position}

Die Ausgangsfrage dieses Abschnittes war, welche der in der Einleitung zusammengestellten Arten von realistischen Thesen für eine realistische Position in der wissenschaftstheoretischen Realismusdebatte konstitutiv sind, ob also ontologische oder semantische (plus epistemische) oder axiologische Thesen das Herzstück einer realistischen Position bilden sollten. Die obigen Überlegungen sprechen deutlich dafür, diese Rolle ontologischen realistischen Thesen zuzuweisen; die diskutierten Gründe, Motive und Intuitionen, die dagegen sprechen bzw. dafür, diese Rolle semantischen oder axiologischen realistischen Thesen zuzuweisen, erwiesen sich als nicht überzeugend. Ontologische realistische Thesen der Form (OR) sind demnach konstitutiv für eine intuitiv angemessene realistische Position und sie reichen auch aus, um in intuitiv angemessener Weise eine realistische Einstellung zum Ausdruck zu bringen.

Im Verlauf der Diskussion, die diese Antwort auf die Ausgangsfrage des Abschnitts ergab, wurden außerdem verschiedene Punkte sichtbar, deren Beachtung von Nutzen ist, wenn es darum geht, eine realistische Position der genannten Art explizit zu formulieren, und man zu diesem Zweck bestimmte Diskurse, Thesen, Theorien u.ä. in den Blick nimmt, die ontologische realistische Thesen der Form (OR) ergeben könnten, im Fall einer realistischen Position in der Wissenschaftstheorie also die Diskurse, Theorien, Modelle etc. der real-existierenden Wissenschaften.

Einer dieser Punkte ist, daß es einer These der Form (OR) und ihrer Eignung als Ausdruck einer realistischen Einstellung zu bestimmten Entitäten, Eigenschaften etc. keinen Abbruch tut, wenn man die fraglichen Entitäten, Eigenschaften etc. für reduzierbare oder superveniente hält.

Ein anderer Punkt ist der, daß mehrere pragmatische Unterscheidungen zu beachten sind, wenn man im Hinblick auf die Formulierung einer realistischen Position bestimmte Diskurse, Thesen, Theorien etc. in den Blick nimmt: Zu unterscheiden ist erstens zwischen verschiedenen Arten von Sprechakten, nämlich zwischen "ernsthaften" assertorischen Sprechakten, die eine Behauptung involvieren, und sonstigen Verwendungsweisen sprachlicher Ausdrücke, die das nicht tun. Diese Unterscheidung wurde oben am Beispiel von Sätzen aus einem Roman eingeführt und sieht auf den ersten Blick für die wissenschaftstheoretische Realismusdebatte vielleicht wenig relevant aus, sie ist aber (wie sich zeigen wird) hilfreich, wenn beurteilt werden soll, zu welchen aus der Vielzahl von Theorien, Gesetzen, Modellen etc., die etwa in der Praxis der Physik zu verschiedenen Zwecken konstruiert und diskutiert werden, eine entsprechende ontologische realistische These begründet werden kann. Sie entspricht der Unterscheidung zwischen Theorien, Gesetzen, Modellen etc., zu denen die arbeitenden Wissenschaftler selbst eine instrumentalistische Einstellung einnehmen, ${ }^{72}$ und Theorien, Gesetzen, Modellen etc., für die dies nicht gilt. Zweitens ist innerhalb der Menge der "ernsthaften" assertorischen Sprechakte zu unterscheiden zwischen wörtlich gemeinten Äußerungen von Sätzen und anderen, nicht-wörtlich gemeinten Äußerungen, die zwar eine Behauptung involvieren, die aber erst durch eine Paraphrase "zum Vorschein kommt". Diese Unterscheidung wurde oben am Beispiel von Metaphern und Redewendungen eingeführt und scheint prima facie vielleicht ebenfalls wenig relevant für die wissenschaftstheoretische Realismusdebatte zu sein, dieser Eindruck wird sich jedoch bei genauerem Hinsehen wiederum als falsch erweisen, wie sich etwa im Zusammenhang mit den Diskussionen zeigt, die auch innerhalb der Physik unter dem

\footnotetext{
${ }^{72} \mathrm{Vgl}$. S.18.
} 
Stichwort "Interpretation physikalischer Theorien" geführt werden.

\subsection{Welche Rolle spielen Wahrheits-, Bedeutungs- und Re- ferenztheorien für eine realistische Position?}

Da semantische Theorien und mit deren Hilfe erläuterte semantische realistische Thesen, wie oben argumentiert, nicht das Herzstück einer intuitiv angemessenen realistischen Position bilden, stellt sich die Frage, ob semantische Theorien dennoch eine Rolle bei der Begründung oder Verteidigung der Position spielen können und sollten. Genauer stellen sich zwei Teilfragen. Erstens: Können semantische Theorien eine realistische Position ergänzen und falls ja, welche können das? Sind also die für eine realistische Position konstitutiven ontologischen realistischen Thesen mit verschiedenen semantischen Theorien verträglich oder nur mit einer bestimmten Wahrheits-, Bedeutungs- oder Referenztheorie? ${ }^{73}$ Zweitens: Ist es zur Begründung oder Verteidigung einer realistischen Position von Vorteil, eine semantische Theorie zu akzeptieren und einsetzen zu können und wenn ja, welche?

\subsubsection{Die Verträglichkeit von ontologischen realistischen Thesen und semantischen Theorien}

Auf die erste Frage nach der Verträglichkeit ontologischer realistischer Thesen mit semantischen Theorien liegt vielleicht die Antwort nahe, daß eine Korrespondenztheorie der Wahrheit, etwa die von Tarski, entweder zusammen mit der kausalen Referenztheorie (evtl. plus Bedeutungstheorie ${ }^{74}$ ), einer Hybridtheorie oder "allein", also ohne ergänzende Referenz- oder Bedeutungstheorie, sozusagen den natürlichen sprachphilosophischen Unterbau einer realistischen Position darstellt und mit deren konstitutiven Thesen verträglich sein müßte, und daß auch Beschreibungstheorien damit verträglich sein sollten, daß hingegen epistemische Wahrheitstheorien mit den Unabhängigkeitsklauseln konfligieren müßten, die ontologische realistische Thesen enthalten, ${ }^{75}$ und ebenso epistemische Bedeutungs- und Referenztheorien, sofern sie zu einer epistemischen Wahrheitstheorie führen. ${ }^{76}$

Eine solche Vermutung läßt sich am einfachsten für eine epistemische Wahrheitstheorie illustrieren, z.B. für die, nach der ein wahrer Satz einer ist, der berechtigterweise behauptbar ist. ${ }^{77}$ Wenn etwa die Aussage, daß der Satz 'Es gibt Elektronen und sie haben Spin $\frac{1}{2}$ ' wahr ist, besagt, daß er berechtigterweise behauptbar ist, scheint daraus zu folgen, daß er

\footnotetext{
${ }^{73}$ Um den Punkt dieser Frage klar in den Blick zu bekommen ist es vielleicht nützlich, sie der anderen Frage gegenüberzustellen, die in Teil I diskutiert wurde: Dort wurde untersucht, ob sich die diversen semantischen Theorien, die für die Sprache der Wissenschaften vorgeschlagen wurden, zur Erläuterung semantischer realistischer Thesen eignen und damit zur Ergänzung einer realistischen Position, für die semantische realistische Thesen konstitutiv sind. Die Frage war dort, ob semantische Relationen von Sätzen, Theorien etc., für die die diversen semantischen Theorien gelten, die Art von "Unabhängigkeit von menschlichen epistemischen Mitteln" aufweisen, die semantische realistische Thesen verlangen. Dagegen ist die Frage hier, welche der diversen semantischen Theorien sich zur Ergänzung einer realistischen Position eignen, für die ontologische realistische Thesen konstitutiv sind, und d.h., ob die "Unabhängigkeit von menschlicher Erkenntnis", die eine ontologische realistische These den Entitäten, Eigenschaften etc. zuschreibt, von denen sie handelt, mit dem verträglich ist, was die diversen semantischen Thesen über semantische Relationen von Sätzen, Theorien etc. sagen.

${ }^{74} \mathrm{Vgl}$. Kap.4.2.

${ }^{75}$ So etwa [Devi84], S.39ff.

${ }^{76} \mathrm{Vgl}$. die Abschnitte 2.5, 2.5.1.

${ }^{77}$ Engl.: "warranted assertible". Vgl. S.42.
} 
berechtigterweise behauptbar ist genau dann, wenn es Elektronen gibt und sie Spin $\frac{1}{2}$ haben. Dies scheint jedoch wenigstens prima facie nicht gut zu der Überzeugung zu passen, daß die Elektronen und ihre Eigenschaften "unabhängig von menschlicher Erkenntnis" im Sinne der Unabhängigkeitsklauseln ontologischer realistischer Thesen sind, also etwa zu einer Unabhängigkeitsklausel der Form (UvmE1a), nach der die Elektronen auch dann existieren und Spin $\frac{1}{2}$ haben würden, wenn niemand davon wüßte etc. Bei genauerer Betrachtung erweist sich die Sachlage jedoch als komplizierter.

Zunächst ist der Eindruck sicher richtig, daß eine Korrespondenztheorie der Wahrheit und die anderen genannten Theorien mit ontologischen realistischen Thesen verträglich sind. Ob es epistemische Wahrheits-, Bedeutungs- und Referenztheorien tatsächlich nicht sind, hängt jedoch, genau besehen, von zusätzlichen Annahmen ab, nicht nur von den Theorien selbst. ${ }^{78}$ Die epistemische Wahrheitstheorie im obigen Beispiel ergibt, daß der Satz 'Es gibt Elektronen und sie haben Spin $\frac{1}{2}$ ' wahr ist genau dann, wenn er berechtigterweise behauptbar ist, und zwar ergibt sie dies unabhängig davon, ob jemand, der die epistemische Wahrheitstheorie akzeptiert und sie auf den Satz über Elektronen anwendet, diesen Satz über Elektronen glaubt, gute Gründe für ihn hat o.ä., oder nicht. Die problematische These, daß es Elektronen gibt usw. genau dann, wenn der Satz 'Es gibt Elektronen ...' berechtigterweise behauptbar ist, folgt daraus, wenn als zusätzliche Prämisse das Disquotationsschema ' 'p' ist wahr genau dann, wenn p' zur Verfügung steht.

Die problematische These, daß es Elektronen gibt usw. genau dann, wenn der Satz 'Es gibt Elektronen ...' berechtigterweise behauptbar ist, widerspricht einer Unabhängigkeitsklausel der Form (UvmE1a) einer ontologischen realistischen These über Elektronen nicht unmittelbar, und auch anderen Klauseln der Form (UvmE2), (UvmE2a) etc. nicht. Es ist offenbar möglich, daß die problematische These und die Unabhängigkeitsklauseln zugleich wahr sind: Elektronen und ihre Eigenschaften können "unabhängig von menschlicher Erkenntnis" sein in dem Sinn, daß sie auch dann existieren würden, wenn niemand etwas von ihnen wüßte, daß sie durch menschliche Erkenntniszustände, -verfahren etc. kausal nicht beeinflußt werden, daß sie nicht durch mentale Entitäten konstituiert werden etc., und zugleich kann es sein, daß der Satz 'Es gibt Elektronen ...' berechtigterweise behauptbar ist genau dann, wenn es Elektronen gibt. Dies ist etwa dann der Fall, wenn es erstens Elektronen gibt und sie Spin $\frac{1}{2}$ haben, wenn zweitens die Elektronen und ihre Eigenschaften unabhängig im obigen Sinn sind, und wenn drittens die "epistemische Situation" so günstig ist, daß der Satz 'Es gibt Elektronen ...' berechtigterweise behauptbar ist. Da es plausibel ist, anzunehmen, daß man eine ontologische realistische These über die Existenz und den Spin von Elektronen nur dann akzeptiert, wenn man glaubt, daß der Satz 'Es gibt Elektronen ...' berechtigterweise behauptbar ist, kann man also tatsächlich ontologische realistische Thesen und eine epistemische Wahrheitstheorie zugleich akzeptieren bzw. vertreten, ohne daß es zu einem direkten Konflikt zwischen beiden käme.

Deutliche Unverträglichkeitsprobleme werden jedoch sichtbar, wenn die "epistemische Situation" nicht so günstig ist wie oben angenommen oder, allgemeiner, wenn man berücksichtigt, daß menschliche epistemische Mittel und Möglichkeiten i.a. unvollkommen und fehlbar sind: Ob ein Satz berechtigterweise behauptbar ist etwa kann sich i.a. mit der Zeit ändern, zumal im Bereich der Wissenschaften. Sätze von der Form der oben genannten problematischen These folgen jedoch allein aus der epistemischen Wahrheitstheorie und dem Disquotationsschema, und zwar für jedwede Entität, Eigenschaft etc., d.h. es folgt auch, daß es den Äther gibt genau dann, wenn der Satz 'Es gibt den Äther' berechtigterweise

\footnotetext{
${ }^{78}$ Die folgenden Überlegungen schließen an [Horw96], S.192f. an.
} 
behauptbar ist, daß es Strings gibt genau dann, wenn der Satz 'Es gibt Strings' berechtigterweise behauptbar ist, usw. Dies impliziert offenbar, daß jedesmal, wenn zu einem bestimmten Zeitpunkt (aufgrund neuer Untersuchungen) ein Satz dieser Art berechtigterweise behauptbar wird, der es zuvor nicht war (oder umgekehrt), die Elektronen, der Äther, die Strings usw., von denen der Satz handelt, beginnen (oder aufhören) zu existieren. Dies scheint absurd und darüber hinaus unverträglich mit den Unabhängigkeitsklauseln ontologischer realistischer Thesen.

Problemen dieser Art können etwas elaboriertere epistemische Wahrheitstheorien eventuell ausweichen. Sie treten möglicherweise in dieser Form nicht auf bei einer Theorie, nach der ein wahrer Satz einer ist, der vom Standpunkt einer reifen Wissenschaft o. ̈̈. berechtigterweise behauptbar ist. Auch solche epistemischen Wahrheitstheorien können jedoch einen Konflikt mit Unabhängigkeitsklauseln der genannten Art letztlich nicht vermeiden, weil sie (zusammen mit dem Disquotationsschema) Thesen über die Reichweite und Verläßlichkeit menschlicher Erkenntnisverfahren implizieren, die im Lichte dieser Unabhängigkeitsklauseln extrem unplausibel aussehen: Auch aus solchen Wahrheitstheorien und dem Disquotationsschema folgen für jedwede Entität, Eigenschaft etc. Sätze von der Form der oben genannten problematischen These, d.h. es folgt, daß es Elektronen gibt und sie Spin $\frac{1}{2}$ haben genau dann, wenn der Satz 'Es gibt Elektronen und sie haben Spin $\frac{1}{2}$ ' vom Standpunkt einer reifen Wissenschaft berechtigterweise behauptbar ist, usw. Es folgt also, daß es genau die Entitäten, Ereignisse etc. gibt und sie die Eigenschaften haben, von denen die reife Wissenschaft sagt, daß es sie gibt bzw. daß sie sie haben. Das bedeutet, daß die epistemischen Mittel und Methoden der reifen Wissenschaft, genauer: die dortigen Standards für berechtigte Behauptbarkeit, vollkommen verläßlich und unfehlbar sind. Dies ist nun nicht unmöglich und auch mit ontologischen realistischen Thesen über Elektronen und ihren Spin u.ä. und den zugehörigen Unabhängigkeitsklauseln nicht unverträglich. Es erscheint aber extrem unplausibel angesichts dessen, was allgemein als gut gesicherte Überzeugungen über menschliche epistemische Mittel und Methoden gilt. Es lassen sich ohne Schwierigkeiten ganze Bereiche von Sätzen finden, bei denen (auch wenn man generell großes Vertrauen in den wissenschaftlichen Fortschritt setzt) keinerlei Hoffnung besteht, daß es jemals verläßliche oder gar unfehlbare epistemische Mittel geben wird, um festzustellen, ob sie zutreffen oder ihr Gegenteil, bei denen man aber (aufgrund induktiver Schlüsse o.ä.) sicher ist, daß entweder das eine oder das andere der Fall ist, und bei denen man (ebenfalls aufgrund induktiver Schlüsse o.ä.) auch sicher ist, daß für das, was der Fall ist, Unabhängigkeitsklauseln erfüllt sind. Beispiele sind etwa Sätze über lokale Wetterverhältnisse oder das Verhalten bestimmter Lebewesen in der Frühzeit der Erde. Hinter der Überzeugung, daß es niemals verläßliche oder unfehlbare epistemische Mittel geben wird, um über diese Sätze zu entscheiden, stehen zum einen Kenntnisse über die Funktionsweise, die Mechanismen etc. menschlicher Erkenntnisgewinnung, zum anderen aber (induktiv o.ä. gewonnene) Unabhängigkeitsannahmen: Überzeugungen wie die, daß die Überzeugungsgewinnung durch Beobachtung, Messungen u.ä. bestimmte kausale Zusammenhänge zwischen Beobachtungsobjekten und Beobachter erfordert, die zu Gegenständen in der Frühzeit der Erde nicht vorliegen, daß z.B. bestimmte lokale Wetterphänomene keine lange Zeiten überdauernden "Spuren" hinterlassen etc., und auch "Unabhängigkeitsannahmen" wie die, daß Wetterphänomene in der Frühzeit der Erde nicht durch heutige Erkenntnisgewinnung kausal beeinflußt werden, daß sie auch dann vorgelegen haben oder hätten (oder nicht), wenn niemand jemals davon weiß oder wüßte etc. Daß Unabhängigkeitsannahmen tatsächlich eine Rolle spielen für die Überzeugung, daß menschliche epistemische Mittel niemals universell verläßlich und 
unfehlbar sein werden, sieht man, wenn man sich für einen Moment vorstellt (soweit das möglich ist), daß etwa Wetterphänomene in der Frühzeit der Erde kausal durch heutige Überzeugungsbildungsprozesse kausal beeinflußbar sind oder nicht existieren würden, wenn niemand jemals davon wüßte o.ä. Unter solchen Umständen ist jedenfalls nicht mehr klar, daß keine strenge Korrelation besteht zwischen dem Wetter in der Frühzeit der Erde und dem, was vom Standpunkt einer reifen Wissenschaft berechtigterweise behauptbar ist. Die Unverträglichkeit besteht also genaugenommen nicht zwischen der epistemischen Wahrheitstheorie und einer ontologischen realistischen These, die aus einem Satz wie 'Es gibt Elektronen und sie haben Spin $\frac{1}{2}$ ' plus Unabhängigkeitsklausel besteht, sondern eher zwischen der epistemischen Wahrheitstheorie und ontologischen realistischen Thesen, die sozusagen Wissenslücken beinhalten, etwa von der Art wie 'Der Archaeopteryx hatte entweder eine blaue oder eine rote Zunge, und die Farbe, die sie hatte, ist unabhängig davon, ob jemals jemand weiß, was von beiden'.

Eine epistemische Wahrheitstheorie kann also tatsächlich unverträglich mit ontologischen realistischen Thesen der genannten Art, insbesondere mit den darin enthaltenen Unabhängigkeitsklauseln, (plus plausiblen Annahmen über menschliche Erkenntnisverfahren etc.) sein, weil sie die Unfehlbarkeit menschlicher epistemischer Verfahren impliziert. Dieser Konsequenz kann man jedoch entgehen, wenn man das Disquotationsschema (zumindest in seiner allgemeinen Form) zurückweist, was, eine epistemische Wahrheitstheorie vorausgesetzt, nicht unplausibel aussieht. ${ }^{79}$ Dagegen spricht jedoch, daß viele das Disquotationsschema intuitiv für einen unverzichtbaren Teil einer adäquaten Wahrheitstheorie halten. Ob eine epistemische Wahrheitstheorie mit ontologischen realistischen Thesen verträglich ist, hängt also u.a. von Annahmen über menschliche Erkenntnisverfahren und deren Verläßlichkeit bzw. Fehlbarkeit ab und davon, ob man das Disquotationsschema für ein unverzichtbares Element einer adäquaten Wahrheitstheorie hält oder nicht.

Für epistemische Bedeutungs- und Referenztheorien gilt Entsprechendes, sofern sie an eine epistemische Wahrheitstheorie geknüpft sind.

Ontologische realistische Thesen sind also prinzipiell mit allen diskutierten semantischen Theorien verträglich, im Falle epistemischer Wahrheitstheorien allerdings wohl nur um den Preis der Aufgabe von Intuitionen über eine adäquate Wahrheitstheorie, an denen viele festhalten werden. Dieser Befund bestätigt und illustriert nochmals den im vorigen Kapitel verschiedentlich zutage getretenen grundsätzlichen Punkt, daß eine realistische Einstellung zu einem Diskurs oder Gegenstandsbereich eine Sache ist, semantische Theorien für die Sätze des Diskurses eine andere.

\subsubsection{Die Rolle semantischer Theorien bei der Begründung oder Ver- teidigung einer realistischen Position}

Die Frage, ob es für die Begründung oder Verteidigung einer realistischen Position von Vorteil ist, eine semantische Theorie zu akzeptieren und einsetzen zu können, und wenn ja, welche, war zum Teil bereits vorne im Teil über die semantischen Theorien für die Sprache der Wissenschaften diskutiert worden. ${ }^{80}$ Ergebnis war, daß die verschiedenen semantischen Theorien, wenn man sie zusammen mit einer realistischen Position akzeptiert,

\footnotetext{
${ }^{79}$ Daß generell gilt, daß 'p' wahr ist genau dann, wenn p, muß natürlich unplausibel aussehen, wenn man Wahrheit und berechtigte Behauptbarkeit identifiziert und sich nicht für unfehlbar hält. Einzelne Instantiierungen des Disquotationsschemas kann man dennoch akzeptieren, nämlich die für Sätze, für die man ein verläßliches Verifikationsverfahren zu haben glaubt.

${ }^{80}$ Siehe Teil I, bes. S.118f.
} 
verschiedene Vor- und Nachteile für die Argumentation für diese realistische Position, genauer: für die epistemische Begründung ontologischer realistischer Thesen mit sich bringen können. An Tarskis semantische Wahrheitstheorie scheinen keinerlei Vor- oder Nachteile dieser Art geknüpft zu sein, an epistemische Wahrheitstheorien auch nicht, an die anderen diskutierten Theorien dagegen durchaus. Welche Vor- oder Nachteile dies sind, hängt im einzelnen auch davon ab, was für eine Konzeption epistemischer Rechtfertigung man akzeptiert, relevant sind grundsätzlich die mit den Stichworten "Inkommensurabilität" und "Unterbestimmtheit" genannten Probleme, am gewichtigsten ist aber das Problem, das durch das Stichwort "Referenzinstabilitäten und pessimistische Induktion" bezeichnet wird. ${ }^{81}$

Eine für Anhänger realistischer Positionen naheliegende (oben schon mehrfach erwähn$\left.t^{82}\right)$ Reaktion auf die pessimistische Induktion ist, zuzugeben, daß angesichts des Theorienwandels im Verlaufe der Wissenschaftsgeschichte ein "unfragmentierter" wissenschaftlicher Realismus eine hoffnungslose Position ist, also ein wissenschaftlicher Realismus, der die Gesamtheit der Theorien, Gesetze, Modelle der jeweils zeitgenössischen Wissenschaft als ganze in Form von ontologischen realistischen Thesen als konstitutive Thesen "übernimmt" bzw. einschließt. Zugleich wird man darauf hinweisen, daß sich bei vielen inzwischen verworfenen Theorien Teile oder Elemente aufweisen lassen, die noch heute für (annähernd, in bestimmten Grenzen o.ä.) wahr gehalten werden, und versuchen, diese historischen Erfahrungen bei der epistemischen Bewertung der Theorien, Gesetze, Modelle etc. der heutigen Wissenschaft zu berücksichtigen, d.h. versuchen, aufgrund dieser historischen Erfahrungen im Gesamtbestand der zu einem Zeitpunkt akzeptierten Theorien, Gesetze etc. der Wissenschaften eine Unterscheidung zu treffen zwischen "historisch meistens stabilen" und "historisch meistens instabilen" Teilen und für die eigene realistische Position nur historisch voraussichtlich stabile Theorieteile, Gesetze etc. in Form von ontologischen realistischen Thesen zu übernehmen. Wenn sich diese Strategie als umsetzbar erweist, sollte die pessimistische Induktion für eine 'moderate' (im Gegensatz zu einer "unfragmentierten") realistische Position nicht mehr bedrohlich sein. Diese Strategie, auf die pessimistische Induktion zu reagieren, wird aber, wie oben diskutiert, nicht funktionieren, wenn man zusätzlich zu den ontologischen realistischen Thesen, die die realistische Position konstituieren, eine semantische Theorie akzeptiert, die sozusagen zu viele Referenzinstabilitäten ergibt, wenn man die Geschichte der Wissenschaft in ihrem Licht betrachtet. Eine realistische Position sollte daher keine weite Kontexttheorie enthalten und auch keine holistische Beschreibungstheorie wie die von Carnap und Lewis.

Daraus folgt nicht, daß man als Realist eine andere semantische Theorie akzeptieren muß, die weniger Referenzinstabilitäten liefert (etwa eine enge Kontexttheorie oder Hybridtheorie), um die eigene Position in der skizzierten Weise gegen die pessimistische Induktion zu verteidigen. Es scheint nichts zwingendes dagegen zu sprechen, auf der skizzierten Linie zu argumentieren und dabei nötigenfalls die problembeladenen semantischen Theorien zurückzuweisen, ohne gleichzeitig eine andere semantische Theorie zu akzeptieren oder gar selbst zu liefern. ${ }^{83}$ Zumindest für weite Teile der Geschichte der Wissenschaften braucht man keine elaborierten semantischen Theorien, um die Äußerungen der zeitgenössischen Akteure bzw. die Theorien, Modelle, Gesetze etc. zu verstehen und zu beurteilen, ob sie nach heutigem Kenntnisstand als richtig oder als falsch einzustufen sind. Dies zeigt die Praxis der wissenschaftshistorischer Untersuchungen, bei denen in dieser Hinsicht im all-

\footnotetext{
${ }^{81} \mathrm{Vgl}$. Kap.2.6.4.

${ }^{82}$ Z.B. Abschnitt 9.10.1, S.328f.

${ }^{83}$ Diese Option wählt Hacking; vgl. S.328f.
} 
gemeinen keine Probleme auftreten, wenigstens keine prinzipieller Art, obwohl es derzeit keine allgemein akzeptierte semantische Theorie für die Sprache der Wissenschaften gibt. ${ }^{84}$ Probleme dürften am ehesten auftreten, wenn es um die Beurteilung von wissenschaftsgeschichtlichen Epochen und den zu der Zeit akzeptierten Theorien, Gesetzen etc. geht, die in sprachlicher, kultureller usw. Hinsicht so weit "entfernt" sind, daß die Äußerungen der Akteure bzw. ihre Theorien, Gesetze etc. nicht ohne weiteres in unkontroverser Weise zu verstehen sind. Unter solchen Umständen könnte die Frage akut und kontrovers werden, wie wissenschaftliche Theorien, Gesetze etc. in heutiger (evtl. um geeignete Termini erweiterter) Sprache zu formulieren bzw. in diese zu übersetzen sind. Ob diese Frage zu beantworten ist, ohne auf bestimmte semantische Theorien zurückzugreifen, ist eine komplexe Frage, die an dieser Stelle nicht adäquat erörtert werden kann, ${ }^{85}$ sie betrifft aber sicherlich nur Teil- oder Randbereiche der Wissenschaftsgeschichte. Falls sich herausstellen sollte, daß dort eine semantische Theorie erforderlich ist, stünden jedenfalls als Ansätze Hybridtheorien und enge Kontexttheorien zur Verfügung.

Die anderen beiden oben genannten Vorzüge bzw. Nachteile, die sich für die Begründung oder Verteidigung einer realistischen Position ergeben können, wenn man bestimmte semantische Theorien akzeptiert, nämlich die mit den Stichworten Unterbestimmtheit und Inkommensurabilität bezeichneten, sind, wie vorne ${ }^{86}$ diskutiert, tatsächlich Primafacie-Vorzüge bzw. -Nachteile, nämlich von der Art, daß bestimmte Probleme bei der epistemischen Begründung ontologischer realistischer Thesen vermieden werden bzw. auftreten können, wenn man eine bestimmte semantische Theorie akzeptiert. Wieviel Gewicht sie haben, hängt aber von der jeweils akzeptierten Konzeption von epistemischer Rechtfertigung ab und müßte außerdem in Detailuntersuchungen in Einzelfällen geprüft werden; grundsätzlich ist denkbar und nicht unplausibel, daß etwaige Prima-facie-Nachteile wenig Gewicht haben, weil die jeweiligen Probleme faktisch mit epistemischen Mitteln gelöst werden können.

Zusammenfassend läßt sich festhalten, daß es in bestimmten Situationen hilfreich sein kann, zur Verteidigung einer realistischen Position gegen die pessimistische Induktion eine geeignete Bedeutungs- und Referenztheorie (also eine - weiterentwickelte Version der Hybridtheorie oder eine enge Kontexttheorie) zur Verfügung zu haben. Unverzichtbar ist dies jedoch für eine realistische Position klarerweise nicht, denn die relevanten Fälle ernsthafter "Übersetzungsprobleme" dürften sehr selten sein, so daß es nicht wesentlich ins Gewicht fällt, daß diese Theorien bisher nur im Umriß entwickelt sind. Auch im Hinblick auf die beiden anderen genannten Probleme kann es hilfreich sein, eine "geeignete" semantische Theorie zur Verfügung zu haben, diese Probleme sollten sich aber wohl auch ausräumen lassen, ohne eine semantische Theorie heranzuziehen. Alles in allem scheinen, soweit sich das beim gegenwärtigen Stand der Debatte sagen läßt, die Nachteile, die sich für die Begründung oder Verteidigung einer realistischen Position daraus ergeben, daß man bestimmte semantische Theorien akzeptiert, die Vorteile eher zu überwiegen.

\footnotetext{
${ }^{84} \mathrm{Zu}$ erwarten ist angesichts des Entwicklungsstandes sprachphilosophischer Theorien vielleicht eher, daß, umgekehrt, zumindest die unkontroversen Fälle solcher vortheoretischer Intuitionen darüber, wie die Aussagen historischer Wissenschaftler zu verstehen sind, in die Bewertung einer semantischen Theorie als plausibel und angemessen (oder nicht) eingehen. So wurde jedenfalls zum Teil oben bei der Diskussion der kausalen Referenztheorie und der Hybridtheorien argumentiert.

${ }^{85}$ An dieser Stelle müßte das allgemeine sprachphilosophische Problem der Übersetzung diskutiert werden.

${ }^{86}$ Siehe Abschnitte 2.6.5 und 3.3.3.
} 


\subsection{Eine selektive realistische Position in der wissenschafts- theoretischen Realismusdebatte, deren Herzstück on- tologische realistische Thesen bilden: einige Details}

Die ontologischen realistischen Thesen, die das Herzstück einer realistischen Position in der wissenschaftstheoretischen Realismusdebatte bilden, sollen jetzt in mehrfacher Hinsicht genauer in den Blick genommen werden.

\subsubsection{Natur, Herkunft und Inhalt ontologischer realistischer Thesen}

Ontologische realistische Thesen sind Aussagen "derselben Art" wie sie (u.a.) innerhalb der Diskurse der Naturwissenschaften getroffen werden. Die ontologischen Thesen, die eine realistische Position in der wissenschaftstheoretischen Realismusdebatte konstituieren, formulieren Erkenntnisse bzw. Überzeugungen, die (in der Regel) in den Wissenschaften gewonnen wurden, sie stellen nicht etwa in irgendeiner Weise genuin philosophische Einsichten dar, die auf einer den Wissenschaften vor- oder übergeordneten Ebene liegen oder sonstwie prinzipiell andersartig sind. Dies gilt sowohl für die Teilaussagen über die Existenz von Entitäten, Ereignissen etc., deren Eigenschaften, das Vorliegen von Sachverhalten etc., als auch für die Unabhängigkeitsklauseln ontologischer realistischer Thesen.

Um eine realistische Position der hier vorgeschlagenen Form explizit $\mathrm{zu}$ formulieren, d.h. um sich die für eine solche Position konstitutiven ontologischen realistischen Thesen konkret zurechtzulegen, wird man sich offenbar den real-existierenden Wissenschaften zuwenden, um deren Diskursen, sprich: der Gesamtheit der dort etablierten oder diskutierten Theorien, Gesetze, Modelle etc., epistemisch hinreichend gut begründete Aussagen zu entnehmen, die die Form ontologischer realistischer Thesen haben oder evtl. durch Paraphrasierung oder durch Ergänzung einer Unabhängigkeitsklausel in diese Form gebracht werden können. ${ }^{87}$ Ein wie großer Teil dieser Gesamtheit auf diese Weise hinreichend gut begründete ontologische realistische Thesen ergibt, wird u.a. davon abhängen, was für eine Konzeption epistemischer Rechtfertigung man akzeptiert, und diese muß nicht (oder jedenfalls nicht genau) mit den Standards übereinstimmen, nach denen innerhalb der Wissenschaften Theorien, Gesetze etc. akzeptiert werden. ${ }^{88} \mathrm{Zu}$ erwarten ist, daß eine realistische Position der anvisierten Art nicht die Gesamtheit der zu einem bestimmten Zeitpunkt vorliegenden Theorien, Gesetze etc. einer real-existierenden Wissenschaft wie der Physik oder gar der Wissenschaften insgesamt in der Form ontologischer realistischer Thesen übernimmt, sondern nur einen Teil. In Frage kommen dafür normalerweise nur solche Theorien, Gesetze, Modelle etc., die innerhalb der Wissenschaften als etabliert gelten, nicht dagegen Theorien, Gesetze etc. gleichsam direkt von der Forschungsfront, also welche, deren Untersuchung noch im Gange ist, so daß es noch zu früh ist für eine verläßliche epistemische Bewertung. In Frage kommen ferner normalerweise nur Theorien, Gesetze, Modelle etc. bzw. Teile davon, die innerhalb der Wissenschaften selbst als ernsthafte Behauptungen über bestimmte "Ausschnitte der Welt" aufgefaßt werden, nicht dagegen

\footnotetext{
${ }^{87}$ Eine angemessene Unabhängigkeitsklausel kann grundsätzlich für verschiedene Gegenstandsbereiche unterschiedlich aussehen, für die meisten der in der wissenschaftstheoretischen Realismusdebatte thematisierten Gegenstandsbereiche (wenn auch nicht für alle) ist jedoch (wie auf S.407ff. diskutiert) unkontrovers, daß Klauseln der Form (UvmE1a), (UvmE2a), (UvmE3) und (UvmE4) gelten. Die epistemische Begründung der Unabhängigkeitsklauseln ist meistens (wenn auch nicht immer) unproblematisch oder sogar trivial, wenn "der Rest" der jeweiligen ontologischen realistischen Thesen hinreichend gut begründet ist.

${ }^{88} \mathrm{Vgl}$. S.320f.
} 
Theorien und Modelle, die nur als "Spielzeugmodelle", zur Exploration bestimmter allgemeiner Annahmen o.ä. untersucht und diskutiert werden, ${ }^{89}$ oder Teile von Theorien und Modellen, die (aus Gründen der mathematischen Handhabbarkeit o.ä. eingeführte) klarerweise falsche Modellannahmen darstellen. ${ }^{90}$ In Frage kommen also normalerweise nur Theorien bzw. Theorieteile, Gesetze etc., zu denen die arbeitenden Wissenschaftler nicht selbst eine instrumentalistische Einstellung einnehmen.

$\mathrm{Zu}$ erwarten ist also, daß man auf diese Weise zu einer selektiven realistischen Position in der wissenschaftstheoretischen Realismusdebatte gelangt, die nicht die Gesamtheit der in den Wissenschaften etablierten Theorien, Gesetze, Modelle etc. in der Form ontologischer realistischer Thesen übernimmt, und auch die Aussagen einer physikalischen, biologischen etc. Theorie (etwa der klassischen Elektrodynamik, der allgemeinen Relativitätstheorie, der statistischen Mechanik) i.a. nicht oder nur selten en bloc übernimmt, ${ }^{91}$ sondern versucht, daraus einen epistemisch hinreichend gut gestützten Teil auszuwählen. Eine solche selektive realistische Position, wie sie Hacking und Cartwright anvisiert haben, ${ }^{92}$ besteht aus einer Vielzahl ontologischer realistischer Thesen speziellerer und allgemeinerer Art, die sich auf mehr oder weniger spezifische Entitäten, Ereignisse etc. und ihre Eigenschaften, Gesetze etc. beziehen. Eine solche Position wird sich also i.a. — anders als traditionelle realistische (oder antirealistische) Positionen häufig — nicht in Form einiger weniger Thesen zusammenfassen lassen.

$\mathrm{Zu}$ den ontologischen realistischen Thesen, die eine solche selektive realistische Position konstituieren, können Thesen sehr verschiedenen Allgemeinheitsgrades gehören: Sie können die Existenz und die Eigenschaften singulärer, raumzeitlich lokalisierter Entitäten, Phänomene, Ereignisse etc. betreffen (den Asteroideneinschlag, der zum Aussterben der Dinosaurier gegen Ende der Kreidezeit führte, die Entstehung des Sonnensystems, das Teilchen, das ein bestimmtes außergewöhnliches Detektorsignal hervorgerufen hat) oder die Existenz und Eigenschaften bestimmter Typen von Entitäten, Phänomenen etc. (den Hall-Effekt, Typ-II-Supernovae, ferromagnetische Substanzen, Elektronen) bis hin zu universellen Sachverhalten und Phänomenen (die Gravitation und ihre Gesetze, Energieerhaltung). In vielen Bereichen der Naturwissenschaften, insbesondere in der Physik, liegt sicherlich das Hauptinteresse bei universellen Entitäten, Phänomenen und Sachverhalten bzw. entsprechenden Theorien und Gesetzen, während spezifischere (oder sogar konkrete, raumzeitlich lokalisierte) Entitäten, Phänomene und Sachverhalte nur interessieren insofern sie erstere instantiieren. Für andere Bereiche der Naturwissenschaften, etwa die Biologie, gilt dies jedoch nicht oder nicht im selben Ausmaß, und es gilt auch für die Physik keinesfalls ausnahmslos (wie Beispiele aus der Halbleiterphysik und der Kosmologie zeigen). Ontologische realistische Thesen lassen sich für alle Allgemeinheitsgrade formulieren.

Eine weitere Dimension, in der sich die ontologischen realistischen Thesen unterschei-

\footnotetext{
${ }^{89}$ Etwa Quantenfeldtheorien in zwei Dimensionen.

${ }^{90}$ Beispiele dafür liefert etwa das Ising-Modell für den Ferromagnetismus (in einer gängigen Version), das mit den Modellannahmen arbeitet, daß man ein unendlich großes System vor sich hat, daß darin jedes Atom, genauer: sein Spin, mit jedem anderen in gleicher Stärke wechselwirkt, daß die Zeitentwicklung des Systems diskret verläuft u.ä.

${ }^{91}$ Also Aussagen wie "Das Universum unterliegt den Gesetzen des Standardmodells der QFT", "Das Sonnensystem verhält sich gemäß den Gesetzen der klassischen Mechanik" u.ä. (wobei Formulierungen wie "... verhalten sich gemäß den Gesetzen der klassischen Mechanik" bequeme Abkürzungen für eine Liste der Gesetze der klassischen Mechanik, angewandt auf das Sonnensystem, sein sollen).

${ }^{92}$ Für selektiven wissenschaftlichen Realismus in diesem Sinn plädiert außerdem auch McMullin; siehe [McMu91].
} 
den können, die für eine selektive realistische Position in Frage kommen, ist, daß sie sich auf Entitäten, Sachverhalte etc. verschiedener Kategorien beziehen können: Ontologische realistische Thesen können aktuelle Entitäten, Sachverhalte etc. betreffen, kontrafaktische und mögliche (allgemeiner: modale) Entitäten und Sachverhalte, manifeste Eigenschaften und Dispositionen, materielle Entitäten und Sachverhalte und mathematische, primäre und sekundäre Qualitäten und vieles mehr. Dies entspricht der Tatsache, daß eine einzelne wissenschaftliche Theorie im allgemeinen Entitäten, Sachverhalte etc. verschiedener Kategorien involviert; physikalische Theorien etwa involvieren häufig materielle, aber auch mathematische Entitäten, aktuelle, aber auch modale Sachverhalte. ${ }^{93}$ Als zentral für eine realistische Position in der Wissenschaftstheorie werden aber im allgemeinen aktuelle, manifeste und nicht-mathematische Entitäten und ihre Eigenschaften angesehen, deshalb werden sie auch im folgenden bei der Argumentation für eine selektive realistische Position im Mittelpunkt stehen.

\subsection{2 "Epistemisch vorsichtige" ontologische realistische Thesen}

Von Anhängern realistischer Positionen wird in der wissenschaftstheoretischen Realismusdebatte häufig der Begriff der annähernden Wahrheit, Wahrheitsnähe oder Wahrheitsähnlichkeit ins Spiel gebracht, um den epistemischen Status der Theorien, Gesetze etc., die in den real-existierenden Wissenschaften derzeit etabliert sind, in angemessener Weise charakterisieren zu können. ${ }^{94}$ Man möchte einerseits anerkennen, daß diese Theorien, Gesetze etc. wohl strenggenommen in der Regel falsch sind und daß die in den real-existierenden Wissenschaften zur Verfügung stehenden epistemischen Mittel und Möglichkeiten zumindest derzeit, vielleicht aber aus prinzipiellen Gründen unvollkommen sind und in der Regel keine exakt und im strengen Sinne wahren Theorien, Gesetze etc. liefern. Andererseits möchte man sozusagen nicht alle falschen Theorien, Gesetze etc. über einen Kamm scheren, da zwischen verschiedenen strenggenommen falschen Theorien, Gesetzen etc. hinsichtlich ihres epistemischen "Wertes" offensichtlich große Unterschiede bestehen können, etwa, um ein einfaches Beispiel zu nennen, zwischen zwei Aussagen über die Lichtgeschwindigkeit, von denen eine um 0,1\%, die andere um einen Faktor 100 vom korrekten Wert abweicht. Wenn man einen allgemein anwendbaren Begriff von annähernder Wahrheit zur Verfügung hat, kann man beides zugleich erreichen; man kann dann etwa sagen, daß ein Satz, der die Lichtgeschwindigkeit $0,1 \%$ abweichend vom korrekten Wert angibt, annähernd (wenn auch nicht exakt) wahr ist und der Wahrheit näher kommt als ein anderer, falscher Satz, der die Lichtgeschwindigkeit um einen Faktor 100 falsch angibt, und man kann so auch "epistemisch vorsichtige" (epistemische) realistische Thesen formulieren.

Da man einerseits auf große Schwierigkeiten stößt, wenn man nach einer zufriedenstellenden Erläuterung des Begriffs der annähernden Wahrheit sucht bzw. nach einer Theorie darüber, was annähernde Wahrheit ist, ${ }^{95}$ und da andererseits eine Position, die durch ontologische realistische Thesen konstituiert wird, ohne Verwendung des Begriffs "Wahrheit" auskommt (von dem der Begriff der annähernden Wahrheit intuitiv abhängt), ist es offenbar dann, wenn man im Prinzip ontologische realistische Thesen für konstitutiv für eine realistische Position hält, keine plausible oder attraktive Option, den Begriff der annähern-

\footnotetext{
${ }^{93}$ Beispielsweise bezieht sich die Rede von Zustandsräumen in physikalischen Theorien (gemäß einer gängigen Lesart) auf modale Eigenschaften bzw. Sachverhalte, ebenso tun dies Naturgesetze.

${ }^{94}$ Vgl. S.17. Ein Beispiel ist Boyd; s. S.191, Fn.26.

${ }^{95}$ Und zwar auf Schwierigkeiten, die wesentlich über die Probleme hinausgehen, die mit einer Erläuterung des Begriffes "Wahrheit" bzw. mit einer Wahrheitstheorie verbunden sind; vgl. dazu [Tsch93].
} 
den Wahrheit ins Spiel zu bringen, wenn man "epistemisch vorsichtige" realistische Thesen formulieren will.

Tatsächlich ist dies jedoch auch nicht erforderlich. Um die oben skizzierte Einschätzung des epistemischen Status' der in den Wissenschaften derzeit etablierten Theorien, Gesetze etc. zum Ausdruck zu bringen, benötigt man den Begriff der annähernden Wahrheit bzw. verwandte Begriffe nicht. Man kann dies auch tun, indem man "epistemisch vorsichtige" ontologische realistische Thesen formuliert, die sozusagen die "exakten", aber mit einiger Wahrscheinlichkeit (strenggenommen) falschen Theorien, Gesetze etc. in geeigneter Weise modifizieren oder abschwächen. Eine Möglichkeit, zu solchen epistemisch vorsichtigen ontologischen Thesen zu gelangen, ist, die jeweils verwendeten Prädikate durch Ausdrücke wie 'annähernd', 'ungefähr' u.ä. zu modifizieren: Einfache Beispiele sind 'Die Lichtgeschwindigkeit beträgt ungefähr $299.792 \mathrm{~km} / \mathrm{s}$ ' und 'Die Bahn des Jupiter ist annähernd elliptisch' ${ }^{96}$ Eine andere Möglichkeit, die den Vorteil hat, zu weniger vagen Thesen zu führen, ${ }^{97}$ ist, die Zuschreibungen einer Eigenschaft, eines Größenwertes u.ä. jeweils zur Angabe eines Intervalles oder Bereiches von "benachbarten" Eigenschaften, Größenwerten u.ä. "aufzuweichen", die man so wählt, daß man sehr sicher ist, daß innerhalb des Intervalls oder Bereichs der korrekte Wert, die korrekte Eigenschaft o.ä. liegt, wenn auch weniger sicher, daß der derzeit akzeptierte Wert, die derzeit akzeptierte Eigenschaft o.ä. die richtigen sind. Beispiele für in dieser Weise modifizierte ontologische Thesen sind 'Der Wert der Lichtgeschwindigkeit liegt zwischen $290.000 \mathrm{~km} / \mathrm{s}$ und $310.000 \mathrm{~km} / \mathrm{s}$ ' und 'Die Bahn des Jupiter weicht an keinem Punkt mehr als $1000 \mathrm{~km}$ von einer geeignet angepaßten Ellipse ab'. Wie ontologische realistische Thesen in dieser Weise zu epistemisch vorsichtigen zu modifizieren sind, ist im Prinzip offenbar klar, wenn es um die Zuschreibung eines Wertes einer reellwertigen Größe geht (wie im Beispiel der Lichtgeschwindigkeit); bei Thesen mit komplexerem Inhalt dürfte dies manchmal schwieriger sein, aber auch hier sollte es zumindest bei einzelnen Gesetzen in vielen Fällen möglich sein, etwa indem man ein geeignetes Abstandsmaß, sprich: eine Metrik definiert. ${ }^{98}$ Inwieweit es auch für ganze Theorien (insbesondere für solche von der Größenordnung der allgemeinen Relativitätstheorie, der Elektrodynamik etc.) möglich ist, inwieweit es also möglich ist, die Intervalle oder Bereiche, die man einzelnen Größenwerten und Gesetzen zuordnet, gleichsam zu aggregieren, ${ }^{99}$ müßte im Einzelfall geprüft werden; dies ist aber auch nicht notwendig. Wie im konkreten Einzelfall aus einem exakten Gesetz o.ä. eine angemessene epistemisch vorsichtige ontologische realistische These zu gewinnen ist, wie also ein geeignetes Intervall, ein Bereich o.ä. zu wählen ist, muß, je nach der epistemischen Sachlage, im jeweiligen Einzelfall entschieden werden.

Gegeben all dies liegt vielleicht die Frage nahe, ob eine realistische Position, für die epistemisch vorsichtige ontologische realistische Thesen konstitutiv sind, tatsächlich hinreichend epistemisch vorsichtig ist, um haltbar und plausibel zu sein, und zwar insbesondere im Hinblick auf wissenschaftliche Revolutionen und die pessimistische Induktion. Von antirealistischer Seite könnte man einwenden, daß nach einer wissenschaftlichen Revoluti-

\footnotetext{
${ }^{96}$ Die Unabhängigkeitsklauseln ontologischer realistischer Thesen werden von der "epistemischen Vorsicht" nicht berührt und bleiben daher in diesem Abschnitt beiseite.

${ }^{97}$ Thesen wie die genannten sind in gewissem Maße vage (und ihr Wahrheitswert mag daher in Grenzbereichen unbestimmt sein), sie sind jedoch keineswegs ohne Gehalt: Die beiden genannten Beispielthesen sind zweifellos wahr, wenn die Lichtgeschwindigkeit exakt $299.792,579 \mathrm{~km} / \mathrm{s}$ beträgt und die Jupiterbahn an keinem Punkt mehr als $10 \mathrm{~cm}$ von einer geeignet angepaßten Ellipse abweicht, und sie sind zweifellos falsch, wenn die Lichtgeschwindigkeit $300.000 .000 \mathrm{~km} / \mathrm{s}$ beträgt und die Jupiterbahn quadratisch ist. ${ }^{98} \mathrm{Vgl}$. dazu [Smit98, West92].

${ }^{99}$ Also ein Analogon zu der Aussage zu gewinnen, daß eine solche Theorie annähernd wahr ist.
} 
on typischerweise auch epistemisch vorsichtige ontologische realistische Thesen verworfen werden müssen, da in den "nachrevolutionären" Theorien von den Entitäten, Eigenschaften etc. der Vorgängertheorien in vielen Fällen nicht mehr die Rede ist; die Modifikation exakter ontologischer Thesen zu epistemisch vorsichtigen mit Hilfe von Intervallen, Bereichen o.ä. scheint dagegen nichts auszutragen. Wenn man etwa die Quantenmechanik als Nachfolgetheorie der klassischen Mechanik betrachtet, ${ }^{100}$ muß danach auch die oben genannte These über die Bahn des Jupiter aufgegeben werden, weil von Bahnen von Körpern in der Quantenmechanik nicht mehr die Rede ist. Wenn man die allgemeine Relativitätstheorie als Nachfolgetheorie der Newtonschen Gravitationstheorie betrachtet, muß danach jede These über Gravitationskräfte aufgegeben werden usw. Überlegungen auf dieser Linie legen den Einwand nahe, daß eine Position, für die ontologische realistische Thesen konstitutiv sind, und seien es auch epistemisch vorsichtige der beschriebenen Art, zum einen keine ontologischen realistischen Thesen über vorrevolutionäre Entitäten, Eigenschaften etc. einschließen darf, von denen in den nachrevolutionären Theorien nicht mehr die Rede ist, und daß eine solche Position darüber hinaus im Verlauf der (weiteren) Geschichte der Wissenschaften in weiten Teilen nicht "stabil" sein dürfte. Der Einwand ist also, daß auch epistemisch vorsichtige ontologische realistischen Thesen der beschriebenen Art nicht hinreichend epistemisch vorsichtig sein dürften.

Dieser Einwand wirft einen Fragenkomplex auf, der an dieser Stelle nicht in angemessener Weise beantwortet werden kann; es läßt sich aber wenigstens im Umriß skizzieren, was für eine Art von Antwort man als Anhänger einer selektiven realistischen Position geben wird. Man wird zunächst darauf hinweisen, daß man eine völlig verzerrende Darstellung der Wissenschaftsgeschichte liefern würde, wenn man behauptete, daß nach wissenschaftlichen Revolutionen typischerweise die "vorrevolutionären" Theorien als ganze verworfen würden oder auch nur die Teile dieser Theorien vollständig verworfen würden, die von Entitäten, Eigenschaften etc. handeln, von denen in der jeweiligen Nachfolgertheorie nicht mehr die Rede ist. Über diesen deskriptiven Befund über den in den real-existierenden Wissenschaften akzeptierten Gesamtbestand von Theorien, Gesetzen etc. hinaus wird man darauf hinweisen, daß aus der Perspektive einer realistischen Position in der Wissenschaftstheorie die relevante Frage die ist, ob sich durch die Revolution im Hinblick auf die epistemische Rechtfertigung der vorher etablierten Theorien, Gesetze etc. Veränderungen ergeben haben, und die Antwort auf diese Frage hängt i.a. von der Konzeption von epistemischer Rechtfertigung ab, die man akzeptiert und die nicht notwendigerweise mit den Standards übereinstimmen muß, nach denen innerhalb der Wissenschaften Theorien, Gesetze etc. akzeptiert werden oder wurden. Entsprechend stellt der Hinweis auf wissenschaftliche Revolutionen und das Phänomen, daß manchmal in einer nachrevolutionären Theorie von vorher etablierten Entitäten, Eigenschaften etc. nicht mehr die Rede ist, per se keinen Grund für die Annahme dar, daß eine Position, für die ontologische realistische Thesen konstitutiv sind, historisch instabil sein dürfte und jedenfalls keine solchen Thesen über vorrevolutionäre Entitäten, Eigenschaften etc. einschließen darf.

Ein angemessenes Bild der Wissenschaftsgeschichte und insbesondere des Verhältnisses von vor- und nachrevolutionären Theorien zu gewinnen, ist - auch dann, wenn man von Fragen epistemischer Rechtfertigung absieht — ein Projekt von enormem Umfang, das gerade im Bereich physikalischer Theorien komplizierte technische Fragen über die Relationen verschiedener Theorien involviert, die häufig bis heute ungelöst sind. Diese technischen Fragen, die meistens unter dem Stichwort "Reduktion" diskutiert werden, ${ }^{101}$ betreffen u.a.

\footnotetext{
${ }^{100}$ Diese Lesart ist natürlich kontrovers.

${ }^{101}$ Gelegentlich wird hier auch das Stichwort "Emergenz" ins Spiel gebracht; vgl. [Batt02].
} 
auch das Verhältnis der Entitäten, Eigenschaften etc., von denen vorrevolutionäre Theorien handeln, und der Entitäten, Eigenschaften etc. der nachrevolutionären Theorien. Ein Resultat, das sich dabei ergeben kann, ist, daß (zumindest einige) Entitäten, Eigenschaften etc. einer vorrevolutionären Theorie in dem Sinne auf Entitäten, Eigenschaften etc. einer nachrevolutionären Theorie reduzierbar sind, daß unter bestimmten Bedingungen, für bestimmte Wertebereiche bestimmter Größen o.ä. die Entitäten, Eigenschaften etc. der vorrevolutionären Theorie identisch sind mit Entitäten, Eigenschaften etc. der nachrevolutionären Theorie. In solchen Fällen wäre die Tatsache, daß in einer nachrevolutionären Theorie von einigen Entitäten, Eigenschaften etc. der vorrevolutionären Theorie nicht mehr die Rede ist, offenbar nicht darauf zurückzuführen, daß alles, was die vorrevolutionäre Theorie über diese Entitäten, Eigenschaften etc. sagt, falsch ist, da zumindest ein Teil davon auf Aussagen der neuen Theorie reduzierbar ist. ${ }^{102}$ In Fällen, in denen das Verhältnis von vor- und nachrevolutionären Theorien bis heute unklar ist, ist Reduzierbarkeit eine grundsätzlich denkbare Option, so daß Aussagen der alten Theorie jedenfalls nicht allein deswegen als falsch zu betrachten sind, weil es eine Nachfolgetheorie gibt; ein solcher Fall ist gerade das Verhältnis von Quantenmechanik und klassischer Mechanik, in dessen Bereich das oben genannte Beispiel der Bahn des Jupiter fällt.

Fazit dieser Überlegungen ist, daß der Hinweis auf wissenschaftliche Revolutionen und das Phänomen, daß manchmal in einer nachrevolutionären Theorie von vorher etablierten Entitäten, Eigenschaften etc. nicht mehr die Rede ist, ohne weiteres keinen überzeugenden Einwand gegen die Plausibilität und Haltbarkeit einer Position ergibt, für die epistemisch vorsichtige ontologische realistische Thesen konstitutiv sind. Weder wird durch einen solchen Hinweis ohne weiteres plausibel, daß eine realistische Position grundsätzlich nicht Thesen über "vor- und nachrevolutionäre" Entitäten, Eigenschaften etc. zugleich einschließen darf, noch daß sie historisch instabil sein dürfte. Um eine plausible und haltbare realistische Position zu formulieren und zu begründen, für die (epistemisch vorsichtige) ontologische realistische Thesen konstitutiv sind, wird man (u.a.) darauf achten müssen, daß die diversen ontologischen Thesen nicht miteinander konfligieren und daß für sie hinreichend gute epistemische Rechtfertigungsgründe vorliegen, und dabei erfordern das "Kombinieren" von ontologischen realistischen Thesen über vor- und nachrevolutionäre Entitäten, Eigenschaften etc. und das Problem der pessimistischen Induktion vielleicht besondere Aufmerksamkeit. Ob sich dabei in konkreten Fällen Beschränkungen für eine plausible und haltbare Position ergeben und, falls ja, welche, muß im Einzelfall untersucht werden; es scheint aber kein Grund zu der Annahme zu bestehen, daß realistische Positionen, für die epistemisch vorsichtige ontologische realistische Thesen konstitutiv sind, grundsätzlich nicht hinreichend epistemisch vorsichtig sein sollten.

\subsubsection{Die Struktur der Gesamtheit der ontologischen realistischen The- sen, die eine selektive realistische Position konstituieren}

Wenn man sich die für eine selektive realistische Position konstitutiven Thesen explizit zurechtlegt, wird man nicht zu einer unzusammenhängenden Menge disparater ontologischer realistischer Thesen gelangen, sondern zu einer konsistenten und mehr oder weniger

\footnotetext{
${ }^{102}$ Eine Reihe von Kandidaten für solche "Reduktionsverhältnisse", die eingehend zu untersuchen wären, nennt etwa [Rohr97], S.S351ff., z.B. für das Theorienpaar Newtonsche Gravitationstheorie und allgemeine Relativitätstheorie die Beziehung $\gamma=4 \Phi$ (die für kleine Energien gilt) zwischen Newtonschem Gravitationspotential $\Phi$ und der Abweichung $\gamma$ zwischen metrischem Tensor und Minkowki-Metrik und die Beziehung $\Gamma_{00}^{k}=\frac{F^{k}}{m}$ zwischen Newtonscher Gravitationskraft (dividiert durch Masse) und drei Komponenten des Christoffel-Symbols.
} 


\section{kohärenten Gesamtheit.}

Konsistenz wird man als eine vielleicht trivial aussehende Minimalbedingung für eine akzeptable Position verlangen, sie ist jedoch z.B. für die Gesamtheit der derzeit in der Physik akzeptierten Theorien, Gesetze etc. nicht ohne weiteres gegeben - der notorisch kritische Punkt ist das Verhältnis von Quantenmechanik und Relativitätstheorie - und kann daher unter Umständen eine harte Bedingung beim Zurechtlegen einer realistischen Position darstellen, wenn man von dem Bestand an Theorien, Gesetzen etc. ausgeht, der derzeit in der Physik akzeptiert wird. ${ }^{103}$

$\mathrm{Zu}$ einer Position, die ein gewisses Maß an Kohärenz aufweist, wird man zum einen schon deswegen gelangen, weil ontologische realistische Thesen allgemeineren Inhalts solche mit speziellerem Inhalt implizieren. Wichtiger ist, daß für eine selektive realistische Position i.a. ein gewisses Maß an Kohärenz erforderlich ist, weil die epistemische Begründung einer ontologischen realistischen These - je nachdem, was für eine Konzeption epistemischer Rechtfertigung man vertritt — sich in vielen Fällen auf andere ontologische realistische Thesen stützen wird. ${ }^{104}$ Dennoch dürfte eine selektive realistische Position tendenziell weniger Kohärenz aufweisen, als es manche vielleicht (zu Recht oder zu Unrecht) von einer Theorie oder gar einem Theoriegebäude erwarten, insbesondere in der Physik, und stattdessen vielleicht eher dem nahekommen, was Cartwright ein "patchwork of laws" nennt. ${ }^{105}$ Dies liegt aber in der Natur einer selektiven realistischen Position, die die in den Wissenschaften etablierten Theorien eben i.a. nicht en bloc in Form von ontologischen realistischen Thesen übernimmt; welche Gestalt sie genau hat, ist natürlich nur festzustellen, indem man sie sich explizit zurechtlegt.

\footnotetext{
${ }^{103} \mathrm{Vgl}$. [Jose80].

${ }^{104}$ Vgl. Kap.14.2.

${ }^{105}$ Vgl. Fn.161.
} 


\section{Kapitel 14}

\section{Rechtfertigungsgründe und Argumente für ontologische realistische Thesen}

Nachdem im vorigen Kapitel geklärt wurde, welche Gestalt eine selektive realistische Position in der Wissenschaftstheorie hat, ist nun zu untersuchen, wie die ontologischen realistischen Thesen zu begründen sind, die eine solche Position konstituieren, und wie und wieweit antirealistische Diskussionsgegner von diesen Thesen überzeugt werden können.

Wenn man einen Diskussionsgegner von einer ontologischen realistischen These über Unbeobachtbares überzeugen will, können offenbar zwei verschiedene "Argumentationsleistungen" erforderlich sein, gleichsam zwei verschiedene Hindernisse zu überwinden sein. Zum einen kann man mit instrumentalistischen Diskussionsgegnern konfrontiert sein, die jeder ontologischen realistischen These über Unbeobachtbares den Status einer ernsthaften Behauptung absprechen (und einer Begründung einer solchen These i.a. ebenso) und dies durch den Hinweis begründen, daß die zur Formulierung der ontologischen realistischen These verwendeten Ausdrücke bzw. Sätze nicht semantisch vollwertig seien. ${ }^{1}$ Um einen solchen instrumentalistischen Diskussionsgegner von einer ontologischen realistischen These zu überzeugen, muß man ihn zunächst dazu bringen, diese These als ernsthafte Behauptung anzuerkennen. Zum anderen kann man mit Diskussionsgegnern konfrontiert sein, die die zur Debatte stehende ontologische realistische These nicht für epistemisch hinreichend gut begründet halten, um sie zu akzeptieren. ${ }^{2}$ Um einen solchen Diskussionsgegner zu überzeugen, muß man epistemische Rechtfertigungsgründe für die These angeben.

Um für die ontologischen realistischen Thesen zu argumentieren, die eine selektive realistische Position ausmachen, muß man sich mit dem Spektrum der Positionen, die in der wissenschaftstheoretischen Realismusdebatte als antirealistisch auftreten, ${ }^{3}$ nicht im einzelnen auseinandersetzen, denn die Thesen, die für diese Positionen charakteristisch sind, stellen, wenn überhaupt, dann nur in den beiden genannten Weisen (unmittelbar oder mittelbar) ein Hindernis für die Argumentation für ontologische realistische Thesen dar: In der Debatte mit in epistemischer Hinsicht antirealistischen Positionen (wie van Fraassens konstruktivem Empirismus) ist "nur" die zweite der beiden genannten Argumentations-

\footnotetext{
${ }^{1}$ Dies ist die erste der beiden in der Einleitung (S.18) unterschiedenen Formen des Instrumentalismus.

${ }^{2}$ Dazu zählen auch Diskussionsgegner, die zu der fraglichen These eine instrumentalistische Einstellung im Sinne der zweiten der beiden in der Einleitung (S.18) unterschiedenen Formen des Instrumentalismus einnehmen.

${ }^{3}$ Siehe Kap.1.3.2.
} 
leistungen erforderlich. Die verschiedenen in semantischer Hinsicht antirealistischen Positionen thematisieren einen Gegenstandsbereich, über den ontologische realistische Thesen gar nichts aussagen, eben die Semantik der Sprache der Wissenschaften. Eine antirealistische semantische Position kann möglicherweise implizieren oder nahelegen, daß die zu einer ontologischen realistischen These gehörende Unabhängigkeitsklausel falsch ist ${ }^{4}$ oder daß die ontologische realistische These durch eine andere (ihre "Bedeutung" angebende) These zu ersetzen oder in bestimmter Weise zu paraphrasieren ist. ${ }^{5}$ Solchen Einwänden muß man entgegentreten, wenn man für eine ontologische realistische These argumentiert, d.h., man muß ggf. für die ontologische realistische These angebotene Paraphrasierungen zurückweisen und ebenso verifikationistische, operationalistische o.ä. "Ersatzthesen" und Paraphrasierungen. Es ist jedoch nicht erforderlich, die Semantik der ontologischen realistischen These, für die man argumentiert, systematisch zu thematisieren und sich mit antirealistischen Thesen dazu im einzelnen auseinanderzusetzen. ${ }^{6}$ Konstruktivistische Positionen schließlich konfligieren in keiner klar identifizierbaren Weise mit ontologischen realistischen Thesen. ${ }^{7}$

Um zu untersuchen, wie die ontologischen realistischen Thesen zu begründen sind, die eine selektive realistische Position in der wissenschaftstheoretischen Realismusdebatte konstituieren, und wie und wieweit antirealistische Diskussionsgegner von diesen Thesen überzeugt werden können, kann man sich also auf zwei Teilfragen beschränken: Erstens die Frage, ob und wie man Instrumentalisten, die ontologische realistische Thesen über Unbeobachtbares für nicht semantisch vollwertig halten, dazu bringen kann, diese ontologischen realistischen Thesen als ernsthafte Behauptungen anzuerkennen $;^{8}$ zweitens die Frage nach epistemischen Rechtfertigungsgründen und Argumenten für ontologische realistische Thesen über Unbeobachtbares.

\subsection{Die Argumentation gegen instrumentalistische Diskus- sionsgegner}

\subsubsection{Die argumentative Konstellation in der Diskussion zwischen Rea- listen und Instrumentalisten}

Anhänger instrumentalistischer Positionen, die durch bedeutungstheoretische Überzeugungen motiviert sind, sprechen allen Äußerungen, die (nicht nach verifikationistischen, operationalistischen o.ä. Standards definierte) Sätze oder Ausdrücke über Unbeobachtbares verwenden ${ }^{9}$, den Status von ernsthaften Behauptungen ab. Instrumentalisten sind damit auf die Unterscheidung beobachtbar/unbeobachtbar angewiesen, und für Realisten ist

\footnotetext{
${ }^{4}$ Siehe Abschnitt 13.3.1.

${ }^{5}$ Dies gilt für die phänomenalistische und die physikalistische Version des logischen Positivismus; vgl. Abschnitt 1.3.2.

${ }^{6} \mathrm{Vgl}$. S.396.

${ }^{7}$ Siehe Abschnitt 13.2.3.

${ }^{8}$ Hier und im folgenden geht es, wenn von der Argumentation gegen instrumentalistische Diskussionsgegner die Rede ist, um Instrumentalismus im Sinne der ersten der beiden in der Einleitung (S.18) unterschiedenen Formen des Instrumentalismus. Die Argumentation gegen die zweite der beiden unterschiedenen Formen von Instrumentalismus wird bei der Diskussion der — folgenden — Frage nach epistemischen Rechtfertigungsgründen für ontologische realistische Thesen "automatisch" mitbehandelt.

${ }^{9}$ Effektiv sind hier alle in ontologischen realistischen Thesen vorkommenden Sätze bzw. Ausdrücke über Unbeobachtbares relevant, da verifikationistische, operationalistische o.ä. Definitionen (falls solche tatsächlich vorgeschlagen werden sollten) von realistischer Seite zurückgewiesen werden.
} 
eine Möglichkeit, instrumentalistische Positionen anzugreifen, die, zu bestreiten, daß diese Unterscheidung eine für philosophische Zwecke brauchbare Grenzziehung ergibt. ${ }^{10}$ Wenn eine instrumentalistische Position in zufriedenstellender Weise dagegen verteidigt werden soll, muß die Unterscheidung beobachtbar/unbeobachtbar hinreichend präzise erläutert werden.

Von instrumentalistischer Seite kann man dazu die von van Fraassen vorgeschlagene Präzisierung dieser Unterscheidung heranziehen. ${ }^{11}$ Van Fraassen unterscheidet zwischen beobachtbaren und unbeobachtbaren Entitäten, Ereignissen, Sachverhalten etc. und markiert damit eine Unterscheidung auf der Sachebene, nicht, wie für eine instrumentalistische Position erforderlich, eine Unterscheidung auf sprachlicher Ebene. Seine Unterscheidung eröffnet aber mittelbar verschiedene Möglichkeiten, auf sprachlicher Ebene eine Trennlinie zwischen semantisch vollwertigen und "nur" instrumentalistisch aufzufassenden Sätzen bzw. Ausdrücken zu ziehen.

Man kann diese Trennlinie im Anschluß an van Fraassen für Sätze markieren oder für einzelne Ausdrücke. Ersteres hieße, nur solche Sätze als semantisch vollwertig anzuerkennen, die für beobachtbare Sachverhalte stehen, und hätte zur Folge, daß eine große Klasse von Ausdrücken (z.B. 'dreieckig', 'rot' etc.) sowohl in semantisch vollwertigen Sätzen auftreten kann als auch in instrumentalistisch aufzufassenden. Wenn man die Unterscheidung für Ausdrücke vornimmt, gibt es mehrere Möglichkeiten für die Behandlung der genannten Klasse von problematischen Ausdrücken: Als "liberaler" Instrumentalist könnte man einen Ausdruck bereits dann als semantisch vollwertig anerkennen, wenn dieser unter anderem Beobachtbares bezeichnet. ${ }^{12}$ Als vorsichtiger, "konservativer" Instrumentalist dagegen wird man nur Ausdrücke als semantisch vollwertig akzeptieren, die ausschließlich Beobachtbares bezeichnen. Diese konservative Variante des Instrumentalismus liefe Gefahr, wenig oder nichts von der gängigen Sprache der Naturwissenschaften als semantisch vollwertig zurückzubehalten (und auch von der Alltagssprache nur Teile). Der liberalen Variante droht dagegen gleichsam die Verbindung zu ihren positivistischen Wurzeln verloren zu gehen, da sie sicherlich zur Anerkennung einer großen Menge von Sätzen über unbeobachtbare Sachverhalte als semantisch vollwertig führt. Eine dritte denkbare Möglichkeit für Instrumentalisten wäre, eine Sprachreform vorzunehmen, die jeden Ausdruck aus der problematischen Klasse durch zwei Ausdrücke ersetzt, von denen einer nur Beobachtbares, der andere nur Unbeobachtbares bezeichnet, ${ }^{13}$ und von denen entsprechend der erste semantisch vollwertig ist, der zweite nicht. Dies würde allerdings auf massive Eingriffe in die etablierte Sprachpraxis hinauslaufen. Alle genannten Möglichkeiten, im Anschluß an van Fraassen die Unterscheidung beobachtbar/unbeobachtbar zu präzisieren, um eine instrumentalistische Position zu verteidigen, weisen also bestimmte Züge auf, die vielleicht für manchen intuitiv wenig plausibel oder sogar unakzeptabel erscheinen; als Instrumentalist wird man entsprechende Intuitionen jedoch i.a. nicht teilen und die genannten Züge nicht als Nachteile wahrnehmen. Eine Erläuterung der Unterscheidung beobachtbar/unbeobachtbar, die hinreichend präzise ist, um eine instrumentalistische Position zu verteidigen, liefern alle genannten Möglichkeiten. Da es also in der Diskussion zwischen Realisten und Instrumentalisten i.a. nicht reicht, von realistischer Seite auf Mängel und

\footnotetext{
${ }^{10}$ Aus den in Kap.8.1.1 genannten Gründen.

${ }^{11}$ Siehe Abschnitt 8.1.2.

${ }^{12}$ Also einen Individuenausdruck dann, wenn er ein Einzelding bezeichnet, das wenigstens eine beobachtbare Eigenschaft hat, einen Prädikatausdruck, wenn er eine Eigenschaft bezeichnet, deren Vorliegen wenigstens bei einem Einzelding beobachtbar ist, usw.

${ }^{13}$ Siehe S.144.
} 
Ungenauigkeiten der Unterscheidung beobachtbar/unbeobachtbar hinzuweisen, um die instrumentalistische Seite dazu zu bringen, ontologische realistische Thesen über Unbeobachtbares als semantisch vollwertig und damit als ernsthafte Behauptungen anzuerkennen, wird man nach Argumenten anderer Art suchen, um dieses Ziel zu erreichen.

In der Literatur zur wissenschaftstheoretischen Realismusdebatte finden sich, wie die Untersuchungen der vorigen Kapitel ergeben haben, ${ }^{14}$ keine solchen Argumente, jedenfalls keine, die für konsequente, reflektierte Instrumentalisten Überzeugungskraft hätten: Es fanden sich dort Kontinuitätsargumente, die an vortheoretische Intuitionen auf der Sachebene appellieren, die den "merkwürdigen" anthropozentrischen Charakter instrumentalistischer Positionen herausstreichen. ${ }^{15}$ Solche Argumente können jedoch nur für denjenigen Überzeugungskraft entwickeln, der die fraglichen Intuitionen teilt, und das mag in diesem Fall gelegentlich für Personen gelten, die noch keine systematisch reflektierte Position in der Realismusdebatte bezogen haben, aber es gilt sicherlich nicht für konsequente, reflektierte Instrumentalisten. Weiterhin fanden sich in der Literatur einige Argumente (Präsuppositionsargumente, Varianten des Wunderarguments), die (u.a.) darauf zielen, Instrumentalisten von semantischen realistischen Thesen zu überzeugen und die im Erfolgsfall möglicherweise auch dazu führen würden, daß die instrumentalistische Seite entsprechende ontologische realistische Thesen über Unbeobachtbares als semantisch vollwertig und damit als ernsthafte Behauptungen anerkennt. Diese Argumente erwiesen sich jedoch entweder als völlig kraftlos (Präsuppositionsargumente), oder sie nehmen Inferenzschemata in Anspruch, die konsequente, reflektierte Instrumentalisten nicht akzeptieren (Wunderargument). Außerdem, und systematisch wichtiger, zeigte $\operatorname{sich}^{16}$, daß diese Argumente, indem sie unmittelbar auf die Etablierung semantischer realistischer Thesen bzw. semantischer Theorien zielen, in einer Diskussion mit entschlossenen Instrumentalisten nichts ausrichten können, wenn es darum geht, diese davon zu überzeugen, ontologische realistische Thesen über Unbeobachtbares als semantisch vollwertig und damit als ernsthafte Behauptungen anzuerkennen: Ein konsequenter, reflektierter Instrumentalist wird Aussagen, die (von realistischer Seite vertretene) semantische Thesen bzw. Theorien zum Inhalt haben, ebenso als nicht semantisch vollwertig einstufen und zurückweisen wie die ontologischen realistischen Thesen über Unbeobachtbares selbst, deren Semantik durch die fraglichen semantischen Thesen bzw. Theorien erläutert und die dadurch als semantisch vollwertig und als ernsthafte Behauptungen erwiesen werden sollen.

Ergebnis dieser letzten Überlegung, die nicht nur bestimmte Argumente gegen instrumentalistische Positionen betrifft, sondern völlig allgemein ist, ist, daß schwer zu sehen ist, wie es überhaupt möglich sein sollte, ein für konsequente Instrumentalisten überzeugendes Argument für die semantische Vollwertigkeit bestimmter Aussagen bzw. Ausdrücke und Sätze über Unbeobachtbares und damit für den Status ontologischer realistischer Thesen als ernsthafte Behauptungen zu konstruieren: Semantische Thesen bzw. Theorien, die zu diesem Zweck von realistischer Seite herangezogen werden könnten, dürften nur Ausdrücke bzw. Sätze enthalten, die nach instrumentalistischen Standards semantisch vollwertig sind, und dasselbe gilt allgemein für jedes von realistischer Seite ins Feld geführte Argument. Wie ein überzeugungskräftiges Argument, das dieser Anforderung genügt, auch nur im Prinzip funktionieren könnte, ist nicht zu sehen. Dieser Anforderung fällt die auf den ersten Blick vielleicht naheliegendste Möglichkeit zum Opfer, einer instrumentalistischen Einstellung zu bestimmten Aussagen bzw. Ausdrücken und Sätzen entgegenzutreten, nämlich

\footnotetext{
${ }^{14}$ Siehe Teil II, Abschnitt 13.2.1.

${ }^{15} \mathrm{~S}$. Abschnitt 8.2.1.

${ }^{16}$ Siehe S.397ff.
} 
von realistischer Seite eine semantische Theorie zu präsentieren, die diese Aussagen bzw. Ausdrücke und Sätze als semantisch vollwertig erweist; an derselben Anforderung scheinen aber auch alle anderen denkbaren Argumente zu scheitern.

Fazit: Die Suche nach Argumenten, mit deren Hilfe man Instrumentalisten dazu veranlassen kann, ontologische realistische Thesen über Unbeobachtbares als semantisch vollwertig und als ernsthafte Behauptungen anzuerkennen, hat keinen Erfolg gebracht, jedenfalls soweit es um Argumente für die Diskussion mit konsequenten, reflektierten Instrumentalisten geht, und sie hat darüber hinaus sogar Gründe für die Annahme zutage gefördert, daß sich Argumente der gesuchten Art auch in Zukunft nicht finden lassen werden.

Aus realistischer Perspektive ist dies zumindest auf den ersten Blick ein ernüchternder Befund. Für seine Bewertung ist es nützlich, die argumentative Konstellation, die ihm zugrunde liegt, und die Rolle, die die Unterscheidung beobachtbar/unbeobachtbar spielt, mit etwas Abstand zu betrachten. Die argumentative Konstellation in der Diskussion zwischen Instrumentalisten und Realisten weist gewisse Parallelen zu der Konstellation auf, die sich in der Diskussion zwischen Realisten und epistemischen Antirealisten um epistemische Kontinuitätsargumente ergibt: ${ }^{17}$ In beiden Fällen zeigt ein Blick auf die diskutierten Argumente, daß sich sozusagen nichts Wesentliches ändern würde, wenn man in der Position der instrumentalistischen bzw. antirealistischen Seite die Unterscheidung beobachtbar/unbeobachtbar durch eine andere Unterscheidung ersetzte. Wenn von instrumentalistischer Seite die Grenze des semantisch Vollwertigen und damit dessen, was als ernsthafte Behauptungen anerkannt wird, an anderer Stelle gezogen würde, wenn der Instrumentalist diese Grenze also nicht mit der Grenze beobachtbar/unbeobachtbar zusammenfallen ließe, dann würde sich offenbar gegen die resultierende Position von realistischer Seite argumentativ auch nicht mehr ausrichten lassen als gegen eine "gewöhnliche" instrumentalistische Position. Dies wäre auch dann so, wenn die instrumentalistische Seite eine intuitiv "bizarre" Grenzziehung vornähme (etwa nur Sätze als semantisch vollwertig zuließe, über deren Wahrheitswert ein Beobachter aus mindestens zehn Meter Entfernung mit bloßem Auge entscheiden kann o.ä.). Ein konsequenter und reflektierter "bizarrer" Instrumentalist wird alle Aussagen, die sozusagen seine bizarre Grenze überschreiten, als nicht semantisch vollwertig und daher nicht als ernsthafte Behauptungen einstufen, und zwar entsprechende ontologische realistische Thesen genauso wie Argumente für sie, insbesondere wenn diese Argumente semantische Thesen und Theorien enthalten. Der Befund, daß sich keine überzeugungskräftigen Argumente finden lassen, um Instrumentalisten zu veranlassen, ontologische realistische Thesen als semantisch vollwertig und als ernsthafte Behauptungen anzuerkennen, ist also offenbar unabhängig davon, an welcher Stelle von instrumentalistischer Seite die Grenze des semantisch Vollwertigen gezogen wird, und er scheint daher instrumentalistischen Positionen kaum Attraktivität oder Plausibilität zu verleihen.

Für die Bewertung dieses Befundes ist es ferner nützlich, auch die gleichsam entgegengesetzte Frage zu stellen, ob die instrumentalistische Seite ihrerseits über Argumente verfügt, die geeignet wären, einen Realisten davon zu überzeugen, daß ontologische realistische Thesen über Unbeobachtbares nicht semantisch vollwertig sind und daher keine ernsthaften Behauptungen darstellen. Solche Argumente finden sich in der Literatur zur wissenschaftstheoretischen Realismusdebatte ebenfalls nicht. ${ }^{18}$ Für einen Realisten, der

\footnotetext{
${ }^{17}$ Siehe Kap.8.3, bes. S.176ff.

${ }^{18}$ Diese Frage ist in dieser Arbeit nicht eingehend untersucht worden, die Literatur gibt jedoch auch praktisch keinen Stoff für eine solche Untersuchung her: Instrumentalistische Positionen werden dort selten oder nie systematisch entwickelt, sondern eher knapp erwähnt, häufig als eine Option, die man wählen
} 
von den ontologischen realistischen Thesen überzeugt ist, die seine Position konstituieren, spricht daher nichts dagegen, an diesen Thesen, also auch an ihrer semantischen Vollwertigkeit und ihrem Behauptungscharakter festzuhalten und, wenn erforderlich, darauf zu insistieren, ${ }^{19}$ auch wenn er die instrumentalistische Seite nicht davon überzeugen kann.

Fazit dieser Überlegungen ist, daß sich keine Argumente finden lassen, mit deren Hilfe man konsequente, reflektierte Instrumentalisten davon überzeugen kann, ontologische realistische Thesen über Unbeobachtbares als semantisch vollwertig und als ernsthafte Behauptungen anzuerkennen. Dieser Befund scheint jedoch nicht auf einen besonderen Mangel realistischer Positionen hinzudeuten, für die solche ontologischen realistischen Thesen konstitutiv sind, oder gar auf deren Unhaltbarkeit, sondern eher auf prinzipielle Grenzen dessen, was sich mit Hilfe von Argumenten in einer Diskussion mit Instrumentalisten erreichen läßt. Die argumentative Konstellation in der Diskussion zwischen Realisten und Instrumentalisten läuft offenbar auf ein Remis hinaus.

\subsubsection{Eine Argumentationsstrategie für konziliante Realisten und In- strumentalisten: Die Verlagerung der Debatte auf die epistemi- sche Ebene}

Wenn sich als Diskussionsgegner konsequente, reflektierte Realisten und ebensolche Instrumentalisten gegenüberstehen, stellt die beschriebene argumentative Konstellation offenbar das Ende der Debatte dar. Die Argumente der realistischen Seite erreichen gewissermaßen die instrumentalistische Seite gar nicht, geschweige denn, daß sie sie überzeugen könnten, und Argumente "in umgekehrter Richtung" sind ebenfalls nicht in Sicht. Wenn sich als Diskussionsgegner konziliante Realisten und Antirealisten gegenüberstehen, die auch in dieser Situation an einer fruchtbaren Fortsetzung der Debatte interessiert sind, besteht aber die Möglichkeit, daß eine solche Fortsetzung zustande kommt, wenn beide Seiten Hintergrundüberzeugungen in die Diskussion einbeziehen und eventuell zur Disposition stellen, die hinter der Einstufung einer Aussage als ernsthafte Behauptung oder hinter der Zurückweisung dieser Aussage als nicht semantisch vollwertig und keine ernsthafte Behauptung stehen.

Solche Hintergrundüberzeugungen, die vielfach in der Debatte zwischen Instrumentalisten und Realisten wirksam sein dürften, sind zum einen unterschiedliche grundsätzliche Meinungen hinsichtlich der Frage, ob die semantische Vollwertigkeit einer Aussage bzw. eines Ausdrucks oder Satzes und der Status einer Aussage als ernsthafte Behauptung an die epistemische Zugänglichkeit dessen geknüpft ist, was diese Aussage bzw. dieser Ausdruck oder Satz zum Inhalt haben bzw. bezeichnen, zum anderen unterschiedliche speziellere Meinungen dazu, worin genau (hinreichend gute) epistemische Zugänglichkeit besteht und welche Gegenstandsbereiche für Menschen epistemisch zugänglich sind.

kann, wenn man eine verifikationistische, operationalistische o.̈̈. Bedeutungstheorie akzeptiert und zur Kenntnis nehmen muß, daß sich für die Sprache der real-existierenden Wissenschaften selten oder nie verifikationistische, operationalistische o.ä. Definitionen angeben lassen (vgl. S.34).

Aus systematischer Perspektive betrachtet könnte man vielleicht versuchen, eine instrumentalistische Position auszuarbeiten und dabei auch Argumente zu konstruieren, um Realisten davon zu überzeugen, daß ontologische realistische Thesen über Unbeobachtbares keine ernsthaften Behauptungen darstellen, etwa ausgehend von sprachphilosophischen Annahmen und Theorien wie sie Dummett in [Dumm75, Dumm76] propagiert. Solche Ansätze können an dieser Stelle nicht diskutiert werden, festhalten läßt sich jedoch, daß die Chancen nicht gut stehen dürften, auf diese Weise überzeugende Argumente zu gewinnen, da zumindest Dummett von verifikationistischen Prämissen ausgeht, die für Realisten klarerweise nicht akzeptabel sind (vgl. dazu etwa [Loar87]).

${ }^{19} \mathrm{Vgl}$. S.397. 
Instrumentalisten knüpfen vielfach semantische Vollwertigkeit und den Status einer ernsthaften Behauptung in der einen oder anderen Weise an Beobachtbarkeit mit dem bloßen Auge: Sie erkennen, indem sie bestimmte semantische Theorien akzeptieren, als semantisch vollwertig nur Ausdrücke und Sätze an, über deren Erfülltsein bzw. deren Wahrheitswert entweder unmittelbar durch Beobachten mit dem bloßen Auge entschieden werden kann, oder die verifikationistische, operationalistische o.ä. Definitionen haben, über deren Erfülltsein bzw. Wahrheitswert durch Beobachten mit dem bloßen Auge (ergänzt evtl. durch deduktives Schließen) entschieden werden kann, ${ }^{20}$ und sie erkennen als ernsthafte Behauptungen nur entsprechende Aussagen an. Instrumentalisten ziehen also vielfach die Grenze des Bereichs semantisch vollwertiger Rede und damit des Bereichs ernsthafter Behauptungen da, wo ihrer Ansicht nach epistemische Zugänglichkeit nicht mehr gegeben ist, und das ist ihrer Meinung nach dort, wo der Bereich des Beobachtbaren endet. Die instrumentalistische Grenzziehung ist also vielfach durch eine generelle und eine speziellere Überzeugung motiviert: Durch eine generelle Überzeugung über den Zusammenhang zwischen der semantischen Vollwertigkeit einer Aussage bzw. eines Ausdrucks oder Satzes und dem Status einer Aussage als ernsthafte Behauptung einerseits und der epistemischen Zugänglichkeit dessen, was diese Aussage bzw. dieser Ausdruck oder Satz zum Inhalt haben bzw. bezeichnen, andererseits. Außerdem durch die speziellere Überzeugung, daß (hinreichend gute) epistemische Zugänglichkeit in Beobachtbarkeit mit dem bloßen Auge (ergänzt evtl. durch deduktives Schließen) besteht. Diese letztere, speziellere Überzeugung ist es, die die genaue Lage der von instrumentalistischer Seite gezogenen Grenzlinie bestimmt und vor anderen denkbaren Grenzziehungen auszeichnet (etwa auch den oben genannten "bizarren").

Realisten dagegen knüpfen i.a. semantische Vollwertigkeit und den Status einer ernsthaften Behauptung nicht an Beobachtbarkeit mit dem bloßen Auge und darüber hinaus überhaupt nicht an epistemische Zugänglichkeit in irgendeiner Form. Als Realist sieht man i.a. keinen systematischen Zusammenhang zwischen epistemischen Fragen einerseits und der Frage nach der semantischen Vollwertigkeit von Aussagen bzw. Ausdrücken oder Sätzen und dem Status von Aussagen als ernsthafte Behauptungen andererseits, und zu der letzteren Frage braucht man und wird man als Realist i.a. gar keine allgemeine, systematische Überzeugung oder gar so etwas wie eine Theorie zu haben. Andererseits muß man natürlich als Realist keineswegs jeden sprachlichen Ausdruck oder Satz, der in irgendeinem Diskurs verwendet wird oder verwendet werden kann, als semantisch vollwertig und nicht jede Aussage als ernsthafte Behauptung anerkennen, sondern man kann grundsätzlich selbstverständlich der Ansicht sein, daß es Diskursbereiche gibt, zu denen eine instrumentalistische Einstellung angemessen ist. Sofern man als Realist so etwas wie eine Grenze des Bereichs semantisch vollwertiger Rede und damit des Bereichs ernsthafter Behauptungen markieren will, wird man dies aber sicherlich so tun, daß alle Aussagen bzw. Ausdrücke oder Sätze innerhalb dieser Grenze liegen, die etwas epistemisch Zugängliches zum Inhalt haben bzw. bezeichnen, und man wird i.a. nicht die instrumentalistische Überzeugung teilen, daß epistemische Zugänglichkeit in Beobachtbarkeit mit dem bloßen Auge (ergänzt durch deduktives Schließen) besteht, sondern auch andere Mittel und Verfahren anerkennen, (hinreichend gute) epistemische Rechtfertigungsgründe für Aussagen bezüglich bestimmter Gegenstandsbereiche zu gewinnen.

Wenn sich als Diskussionsgegner in der Realismusdebatte konziliante Realisten und Instrumentalisten gegenüberstehen, die in der oben beschriebenen argumentativen Remis-

\footnotetext{
${ }^{20} \mathrm{Vgl}$. Abschnitt 2.1.
} 
Konstellation nach einem Weg suchen, die Debatte in fruchtbarer Weise fortzusetzen, dann ist eine (und vielleicht die) naheliegende Möglichkeit die, auf beiden Seiten die genannten Hintergrundüberzeugungen zumindest teilweise zur Disposition zu stellen, die auf der realistischen Seite hinter der Einstufung ontologischer realistischer Thesen über Unbeobachtbares als ernsthafte Behauptungen stehen bzw. auf der instrumentalistischen Seite hinter der Zurückweisung dieser ontologischen realistischen Thesen als keine ernsthaften Behauptungen, und vielleicht außerdem die Hintergrundüberzeugungen der jeweils anderen Seite zumindest teilweise und/oder für die Zwecke der Diskussion anzuerkennen.

Konkret kann das bedeuten, daß man als konzilianter Instrumentalist an der eigenen generellen Überzeugung festhält, daß die semantische Vollwertigkeit einer Aussage bzw. eines Ausdrucks oder Satzes und der Status einer Aussage als ernsthafte Behauptung an die epistemische Zugänglichkeit dessen geknüpft ist, was diese Aussage bzw. dieser Ausdruck oder Satz zum Inhalt haben bzw. bezeichnen, daß man jedoch die speziellere Überzeugung zur Disposition stellt, daß (hinreichend gute) epistemische Zugänglichkeit Beobachtbarkeit mit dem bloßen Auge (ergänzt durch deduktives Schließen) erfordert, und damit auch die eigene (verifikationistische o.̈̈.) semantische Theorie zur Disposition stellt. Man würde dann als konzilianter Instrumentalist die eigene prinzipielle Ablehnung gegenüber ontologischen realistischen Thesen über Unbeobachtbares gleichsam vorläufig einklammern und mit den fraglichen Sätzen und Ausdrücken vorläufig operieren, als ob sie semantisch vollwertig wären, und die realistische Seite herausfordern, plausibel darzulegen, wie bzw. inwieweit die Entitäten, Eigenschaften etc., von denen die fraglichen Sätze und Ausdrücke handeln, "hinreichend gut" epistemisch zugänglich sind, obwohl Beobachtung mit dem bloßen Auge, Verifikation etc. nicht möglich sind. Eine konziliante instrumentalistische Position könnte darin bestehen, Bereiche von Sätzen oder Ausdrücken über Unbeobachtbares dann tatsächlich "dauerhaft" als semantisch vollwertig anzuerkennen, wenn es der realistischen Seite gelingt, in plausibler und überzeugender Weise darzulegen, daß die Entitäten, Eigenschaften etc., auf die sich die fraglichen Sätze oder Ausdrücke beziehen, epistemisch (hinreichend gut) zugänglich sind, andernfalls jedoch zu einer instrumentalistischen Einstellung zu diesem Bereich von Sätzen und Ausdrücken zurückzukehren.

Auf der anderen Seite kann man als konzilianter Realist an der eigenen Überzeugung festhalten, daß epistemische Zugänglichkeit nicht unbedingt Beobachtbarkeit mit dem bloßen Auge erfordert, jedoch die generelle Überzeugung der instrumentalistischen Seite entweder akzeptieren, oder zumindest für die Debatte mit dem Instrumentalisten vorläufig voraussetzen, daß semantische Vollwertigkeit und der Status einer Aussage als ernsthafte Behauptung an die epistemische Zugänglichkeit dessen geknüpft ist, was diese Aussage bzw. der Ausdruck oder Satz zum Inhalt haben bzw. bezeichnen. Man würde dann die Herausforderung der instrumentalistischen Seite annehmen, plausibel darzulegen, wie bzw. inwieweit die Entitäten, Eigenschaften etc., von denen bestimmte ontologische realistische Thesen über Unbeobachtbares handeln, (hinreichend gut) epistemisch zugänglich sind, obwohl Beobachtung mit dem bloßen Auge, Verifikation etc. nicht möglich sind. Wenn dies in überzeugender Weise gelingt, hätte man damit den Instrumentalisten dazu gebracht, die fraglichen ontologischen realistischen Thesen als ernsthafte Behauptungen anzuerkennen. Ob man als konzilianter Realist "im Mißerfolgsfall" selbst zu einer instrumentalistischen Einstellung zu den fraglichen Thesen übergeht, hängt davon ab, ob man die generelle These, daß semantische Vollwertigkeit und der Status einer Aussage als ernsthafte Behauptung an epistemische Zugänglichkeit geknüpft ist, tatsächlich als Überzeugung akzeptiert, oder ob man sie nur für die Diskussion mit der instrumentalistischen Seite vorausgesetzt hat, sowie evtl. davon, ob man als Realist selbst mit guten Gründen von der epistemischen 
Zugänglichkeit der fraglichen Entitäten, Eigenschaften etc. überzeugt ist ${ }^{21}$. Die Reaktion der realistischen Seite "im Mißerfolgsfall" ist jedoch nur von sekundärem Interesse; damit eine Fortsetzung der Debatte in der oben beschriebenen Remis-Konstellation zustande kommen kann, ist von Seiten des Realisten zunächst nur erforderlich, daß er die Herausforderung der instrumentalistischen Seite annimmt, ein Argument für die epistemische Zugänglichkeit der zur Debatte stehenden Entitäten, Eigenschaften etc. zu geben, obwohl dies seiner Ansicht nach eigentlich für semantische Vollwertigkeit bzw. den Status einer ernsthaften Behauptung entsprechender ontologischer realistischer Thesen nicht erforderlich wäre.

Die skizzierte Strategie, in der beschriebenenen argumentativen Remis-Konstellation zwischen Realisten und Instrumentalisten zu einer fruchtbaren Fortsetzung der Debatte zu gelangen, besteht also darin, über strittige ontologische realistische Thesen über Unbeobachtbares hinaus Hintergrundüberzeugungen beider Seiten in die Diskussion einzubeziehen und dadurch effektiv die Debatte auf die epistemische Ebene zu verlagern, also weg von Argumenten, die direkt und unmittelbar die semantische Vollwertigkeit der jeweils strittigen ontologischen realistischen Thesen und damit ihren Status als ernsthafte Behauptungen betreffen, und hin zu Argumenten, die die epistemische Zugänglichkeit der Entitäten, Eigenschaften etc. betreffen, von denen die ontologischen realistischen Thesen handeln. Konsequente, reflektierte Instrumentalisten und Realisten sind nicht verpflichtet, sich auf diese Verlagerung der Debatte einzulassen, denn es gibt für Instrumentalisten und Realisten sozusagen keinen zwingenden Grund, konziliant zu sein. ${ }^{22}$ Wenn sie es tun, machen sich beide Seiten in gewisser Hinsicht angreifbarer, die instrumentalistische Seite vielleicht in größerem Maße. Beide Seiten können aber dadurch auch an Plausibilität und Überzeugungskraft gewinnen, insofern sie Hintergrundüberzeugungen des jeweiligen Diskussionsgegners berücksichtigen und damit zumindest für konziliante und/oder "weniger konsequente" Anhänger gegnerischer Positionen attraktiver werden.

In systematischer Hinsicht wird durch die skizzierte Strategie die Möglichkeit eröffnet und sogar nahegelegt, die Debatte zwischen Realisten und Instrumentalisten in "lokale" Debatten aufzuteilen, insofern verschiedene Gegenstandsbereiche in verschiedener Weise und unterschiedlich gut epistemisch zugänglich sein können, so daß es sich anbietet, die epistemische Zugänglichkeit verschiedener Gegenstandsbereiche getrennt zu diskutieren und damit auch die Frage nach der semantischen Vollwertigkeit und dem Status als ernsthafte Behauptungen für ontologische realistische Thesen aus verschiedenen Diskursbereichen separat zu behandeln.

\subsubsection{Ein kausales Kriterium im Anschluß an Hacking und Cartwright}

Wenn man von realistischer Seite die im vorigen Abschnitt skizzierte Argumentationsstrategie in der Diskussion mit konzilianten Instrumentalisten verfolgt, muß man effektiv Argumente liefern für die epistemische Zugänglichkeit der Entitäten, Eigenschaften, Sachverhalte etc., von denen die ontologischen realistischen Thesen über Unbeobachtbares handeln, die die eigene realistische Position konstituieren, oder auch für die epistemische Zugänglichkeit eines oder mehrerer Gegenstandsbereiche, die die fraglichen Entitäten, Eigenschaften etc. einschließen.

\footnotetext{
${ }^{21}$ Obwohl man die instrumentalistische Seite nicht davon überzeugen kann — diese Konstellation ist denkbar; dazu s.u.

${ }^{22}$ Außerdem sind natürlich auch Positionen denkbar, die die genannten Hintergrundüberzeugungen nicht haben und bei denen diese Strategie daher nicht greifen kann.
} 
Für eine übersichtliche Darstellung der Resultate einer solchen Argumentation ist es nützlich, wenn man in Form von einem oder mehreren einfachen Kriterien angeben kann, für welche Entitäten, Eigenschaften etc. bzw. für welche Gegenstandsbereiche man von realistischer Seite plausible und überzeugende Gründe für ihre epistemische Zugänglichkeit vorbringen kann, und man damit also Kriterien dafür angeben kann, welche Aussagen bzw. Sätze oder Ausdrücke semantisch vollwertig sind, obwohl solche Kriterien natürlich nicht konstitutiver Teil einer realistischen Position sind. Auch schon für die Argumentation selbst können solche Kriterien hilfreich sein, insofern sie deren Ziel klar formulieren, also angeben, für welche Entitäten, Eigenschaften etc. man sich sozusagen auf realistischer Seite überzeugende Argumente für ihre epistemische Zugänglichkeit zutraut und für welche Aussagen bzw. Sätze oder Ausdrücke man sich damit also überzeugende Argumente für ihre semantische Vollwertigkeit zutraut.

An dieser Stelle läßt sich an die von Hacking und Cartwright ins Spiel gebrachte Idee eines Kriteriums dafür, welcher Teil des Gesamtbestandes der in den Wissenschaften etablierten Theorien, Gesetze etc. sich auf Entitäten, Eigenschaften etc. bezieht, zu denen eine realistische Einstellung einzunehmen ist, anknüpfen, und insbesondere an die in dieser Idee enthaltene (Teil-)Idee eines kausalen Kriteriums dafür, zu welchem Teil des Gesamtbestandes der in den Wissenschaften etablierten Theorien, Gesetze etc. eine instrumentalistische Einstellung nicht angemessen ist. ${ }^{23}$ Bei Hacking und Cartwright selbst bleiben der genaue Inhalt, der Status und die Begründung ihres Kriteriums letzten Endes unklar, dennoch bietet sich ihre Idee an, um im Anschluß daran ein kausales Kriterium für die semantische Vollwertigkeit von Aussagen bzw. Sätzen und Ausdrücken zu formulieren, das zumindest auf den ersten Blick plausibel aussieht, wenn man als Realist die im vorigen Abschnitt skizzierte Strategie in der Diskussion mit konzilianten Instrumentalisten verfolgt.

Um eine angemessen explizite und präzise Formulierung für ein solches kausales Kriterium zu gewinnen, ist es hilfreich, sich daran zu orientieren, wie ein aus instrumentalistischer Perspektive angemessenes Kriterium für semantische Vollwertigkeit aussehen würde. Ein solches instrumentalistisches Kriterium müßte an zentraler Stelle auf die Unterscheidung beobachtbar/unbeobachtbar Bezug nehmen, die, wie oben diskutiert, mit Hilfe der von van Fraassen angegebenen Explikation erläutert werden kann; es müßte lauten:

' $\mathrm{X}$ ' ist semantisch vollwertig, wenn $\mathrm{X}$ beobachtbar ist. ${ }^{24}$

Parallel dazu läßt sich ein aus realistischer Perspektive zumindest prima facie plausibles kausales Kriterium für semantische Vollwertigkeit formulieren, indem man 'beobachtbar' durch eine "kausale Bedingung" ersetzt, die einen größeren Bereich von Aussagen bzw. Sätzen und Ausdrücken erfaßt, die sich aber auf einen noch immer epistemisch hinreichend gut zugänglichen Gegenstandsbereich beziehen. Eine naheliegende Formulierung ist:

' $\mathrm{X}$ ' ist semantisch vollwertig, wenn $\mathrm{X}$ kausal nachweisbar bzw. (im Falle von Größen) meßbar ist.

Dieses kausale Kriterium geht offenbar über das instrumentalistische Kriterium hinaus und erfaßt einen für die wissenschaftstheoretische Debatte zentralen Bereich von Aussagen bzw.

\footnotetext{
${ }^{23}$ Siehe Kap.11, bes. Abschnitt 11.5.

${ }^{24}$ Genaugenommen müßte es heißen: ... wenn $\mathrm{X}$ beobachtbar ist oder ' $\mathrm{X}$ ' verifikationistisch (oder operationalistisch o.ä.) definierbar. Definitionen dieser Art spielen jedoch für die Diskussion ontologischer realistischer Thesen keine Rolle und bleiben daher im folgenden beiseite.

In dieser Formulierung des Kriteriums bleiben außerdem die verschiedenenen oben (S.433) diskutierten Möglichkeiten implizit, van Fraassens Unterscheidung beobachtbar/unbeobachtbar auf die sprachliche Ebene abzubilden.
} 
Sätzen und Ausdrücken, der sozusagen weit über die Grenze beobachtbar/unbeobachtbar hinausreicht, aber es erfaßt andererseits bei weitem nicht alles jenseits dieser Grenze. Die enge Verwandtschaft des instrumentalistischen und des kausalen Kriteriums wird besonders deutlich, wenn man die für sie zentralen Ausdrücke 'beobachtbar' und 'kausal nachweisbar' bzw. 'meßbar' aus der Perspektive eines reliabilistischen Ansatzes in der Erkenntnistheorie ${ }^{25}$ erläutert. Eine reliabilistische Reformulierung von van Fraassens Erläuterung von 'beobachtbar'26 lautet:

$\mathrm{X}$ ist beobachtbar, wenn es Umstände gibt, unter denen das Beobachten mit dem bloßen Auge ein verläßliches epistemisches Verfahren für X ist.

Eine reliabilistische Erläuterung von 'kausal nachweisbar' bzw. 'meßbar' ist:

$\mathrm{X}$ ist kausal nachweisbar bzw. meßbar, wenn es ein kausales epistemisches Verfahren bzw. Meßverfahren sowie Umstände gibt, unter denen dieses Verfahren verläßlich für $\mathrm{X}$ ist.

Von einem reliabilistischen Standpunkt aus betrachtet stellt kausale Nachweisbarkeit bzw. Meßbarkeit offenbar eine Verallgemeinerung von Beobachtbarkeit mit dem bloßen Auge dar, insofern Beobachten mit dem bloßen Auge ein kausales epistemisches Verfahren unter vielen ist, die epistemische Zugänglichkeit sicherstellen können. Das kausale Kriterium für semantische Vollwertigkeit knüpft diese nicht mehr an epistemische Zugänglichkeit durch ein bestimmtes kausales epistemisches Verfahren (eben Beobachten mit dem bloßen Auge), sondern "nur noch" an epistemische Zugänglichkeit durch ein beliebiges kausales epistemisches Verfahren. Die angegebene Erläuterung von 'kausal nachweisbar' bzw. 'meßbar' ist, wie van Fraassens Erläuterung von 'beobachtbar', sinngemäß auf Entitäten, Eigenschaften, Sachverhalte, Ereignisse etc. anwendbar.

Die angegebene Erläuterung von 'kausal nachweisbar' bzw. 'meßbar' teilt mit van Fraassens Erläuterung von 'beobachtbar' die Unschärfe, daß idealerweise präziser angegeben werden sollte, inwieweit die "Umstände", von denen darin die Rede ist, kontrafaktische sein dürfen, d.h. solche, unter denen X beobachtbar bzw. kausal nachweisbar oder meßbar wäre, wenn ein Beobachter bzw. ein Nachweis- bzw. Meßinstrument präsent wäre (oder, allgemeiner, wenn ein kausales epistemisches Verfahren anwendbar wäre), was jedoch aus kontingenten Gründen unwahrscheinlich oder sogar ausgeschlossen ist. Diese Unschärfe überträgt sich sozusagen auf die beiden Kriterien für semantische Vollwertigkeit, insofern zur Erläuterung dieser Kriterien die beiden genannten Erläuterungen von 'beobachtbar' und von 'kausal nachweisbar' bzw. 'meßbar' herangezogen werden. Im Fall der kausalen Nachweisbarkeit oder Meßbarkeit und des entsprechenden Kriteriums für semantische Vollwertigkeit ist die Unschärfe eher noch größer als im Fall der Beobachtbarkeit und des instrumentalistischen Kriteriums, da bei der Erläuterung von 'beobachtbar' "nur" in dem Sinn kontrafaktische Umstände im Spiel sind, daß man gleichsam in Gedanken einen Beobachter an eine faktisch unzugängliche Raum-Zeit-Stelle versetzt (und eventuell mit geeigneten Schutzvorrichtungen versieht, die sein Überleben und "Funktionieren" unter widrigen Bedingungen sicherstellen) o.ä., während bei der Erläuterung von 'kausal nachweisbar' bzw. 'meßbar' zusätzlich die Bedingung, daß es ein kausales Verfahren bzw. Meßverfahren gibt, auf verschiedene Weise gelesen werden kann: Eine enge Lesart dieser Erläuterung im Fall einer Größe wäre etwa, diese nur dann als meßbar gelten zu lassen, wenn ein fertiges Meßgerät dafür sozusagen betriebsbereit im Regal steht, eine etwas

\footnotetext{
${ }^{25} \mathrm{Vgl}$. Kap.8.3.1.

${ }^{26}$ Siehe S.143.
} 
liberalere Lesart, daß ein Meßgerät sicher herstellbar sein muß, eine noch weitere Lesart, daß das Konstruktionsprinzip für ein Meßgerät bekannt, wenn auch mit gegenwärtigen technischen Mitteln noch nicht realisierbar sein muß, usw. ${ }^{27}$ Trotz dieser Unschärfe ist die angegebene Erläuterung von 'kausal nachweisbar' bzw. 'meßbar' jedoch zumindest für paradigmatische, zentrale Fälle kausaler Verfahren sicherlich nicht wesentlich unklarer als die Erläuterung von 'beobachtbar' und ist entsprechend das kausale Kriterium für semantische Vollwertigkeit zumindest für paradigmatische kausale Aussagen bzw. Sätze und Ausdrücke sicherlich nicht wesentlich unschärfer als das instrumentalistische Kriterium.

Das angegebene kausale Kriterium für semantische Vollwertigkeit spezifiziert einen für die wissenschaftstheoretische Realismusdebatte zentralen Bereich von Aussagen bzw. Sätzen und Ausdrücken, für den es aus realistischer Perspektive zumindest prima facie plausibel aussieht, daß man in der Diskussion mit konzilianten Instrumentalisten überzeugende Gründe für die epistemische Zugänglichkeit der Entitäten, Eigenschaften etc. vorbringen kann, auf die sich die Aussagen bzw. Sätze und Ausdrücke beziehen. Ob man dies tatsächlich kann, muß die Detaildiskussion von Argumenten für epistemische Zugänglichkeit erweisen; das im Anschluß an Hacking und Cartwright formulierte kausale Kriterium stellt per se zunächst nur eine — wenn auch plausible - Hypothese über die Resultate einer solchen Diskussion dar sowie vielleicht eine Formulierung eines Argumentationsziels der realistischen Seite.

Aufgrund des beschriebenen Status des kausalen Kriteriums ist klar, daß es als hinreichendes Kriterium für semantische Vollwertigkeit aufzufassen ist, nicht als notwendiges, denn es ist natürlich grundsätzlich möglich, daß sich auch für andere Gegenstandsbereiche überzeugende Argumente für ihre epistemische Zugänglichkeit angeben lassen und sich entsprechende weitere (hinreichende) Kriterien für semantische Vollwertigkeit formulieren lassen — auch wenn dies prima facie vielleicht für nicht kausal nachweisbare Entitäten, Eigenschaften etc., etwa für mathematische, weniger plausibel aussehen mag als für den Gegenstandsbereich, den das kausale Kriterium abdeckt. Ob tatsächlich auch in anderen Bereichen in überzeugender Weise für semantische Vollwertigkeit argumentiert werden kann, muß wiederum die Detaildiskussion von Argumenten für epistemische Zugänglichkeit erweisen.

\subsubsection{Argumente für epistemische Zugänglichkeit}

Wenn man als Realist die im vorletzten Abschnitt skizzierte Argumentationsstrategie verfolgt, um konziliante Instrumentalisten dazu zu bringen, die ontologischen realistischen Thesen über Unbeobachtbares, die konstitutiv für eine realistische Position sind, als semantisch vollwertig anzuerkennen, und man dazu (und darüber hinaus) vielleicht auch

\footnotetext{
${ }^{27}$ Diese Dimension der Unschärfe entfällt beim epistemischen Verfahren Beobachten, denn dort liegt das "Instrument" fertig vor.

Davon, ob man diese Unschärfe durch eine Präzisierung beseitigt und wenn ja, wie, hängt auch ab, ob und inwieweit das angegebene kausale Kriterium für semantische Vollwertigkeit sich mit dem in Hackings Argumentation für seinen experimentellen Realismus identifizierten (Teil-)Kriterium (siehe Kap.11.3.3, bes. S.333) deckt, nach dem eine instrumentalistische Einstellung zu Theorien, Gesetzen etc. zurückzuweisen ist, die Entitäten, Sachverhalten etc. kausale Eigenschaften, kausale Wirksamkeit o.̈̈. zuschreiben. Anders formuliert: Davon, ob man die genannte Unschärfe durch eine Präzisierung beseitigt und wenn ja, wie, hängt auch ab, wieviel der Bereich der kausal nachweisbaren bzw. meßbaren Entitäten, Sachverhalte, Größen etc. vom Bereich der kausal wirksamen, kausale Eigenschaften tragenden etc. Entitäten, Sachverhalte, Größen etc. abdeckt. Daß der erstere Bereich den letzteren komplett abdeckt, dürfte aber in keinem Fall zu erwarten sein, denn man kann sich etwa kausal isolierte Teile des Universums (oder Paralleluniversen) denken, die in keinem erkennbaren Sinn mehr durch kausale epistemische Verfahren für Menschen zugänglich sind.
} 
für die semantische Vollwertigkeit eines ganzen Bereichs von Aussagen bzw. Sätzen und Ausdrücken, wie ihn etwa das im vorigen Abschnitt angegebene kausale Kriterium spezifiziert, argumentieren will, muß man effektiv überzeugende Gründe für die (hinreichend gute) epistemische Zugänglichkeit der Entitäten, Eigenschaften etc. vorbringen, auf die sich die zur Debatte stehenden Thesen und Aussagen bzw. Sätze und Ausdrücke beziehen. Wie sehen überzeugende Argumente für die epistemische Zugänglichkeit bestimmter Entitäten, Eigenschaften etc. aus, d.h. in dem im vorigen Abschnitt genannten Bereich also Argumente für ihre kausale Nachweisbarkeit bzw. Meßbarkeit?

Ob ein Argument Überzeugungskraft entwickeln kann, hängt grundsätzlich und so auch in diesem Fall davon ab, welche Inferenzschemata und Prämissen der jeweilige Diskussionsgegner akzeptiert, und wie überzeugende Argumente für die epistemische Zugänglichkeit bzw. die kausale Nachweisbarkeit oder Meßbarkeit bestimmter Entitäten, Eigenschaften etc. aussehen, hängt insbesondere davon ab, wie im einzelnen erläutert wird, was epistemische Zugänglichkeit bzw. kausale Nachweisbarkeit oder Meßbarkeit ist, und kann daher nicht generell angegeben werden. Wenn man eine reliabilistische Perspektive voraussetzt und die oben genannte reliabilistische Erläuterung, was kausale Nachweisbarkeit oder Meßbarkeit ist, lassen sich aber einige in Frage kommende Arten von Argumenten wenigstens grob skizzieren.

Aus reliabilistischer Perspektive ist ein Argument für die kausale Nachweisbarkeit oder Meßbarkeit einer Entität, Eigenschaft etc. ein Argument dafür, daß es ein kausales epistemisches Verfahren oder Meßverfahren gibt, durch das sich diese Entität, Eigenschaft etc. unter bestimmten Umständen verläßlich nachweisen oder messen läßt, d.h. im Zentrum eines solchen Arguments steht stets ein kausales epistemisches Verfahren oder Meßverfahren und seine Verläßlichkeit. Für die Verläßlichkeit eines solchen Verfahrens für eine bestimmte Entität, Eigenschaft etc. sind verschiedene Arten von Argumenten denkbar.

Ein Argument für die Verläßlichkeit eines kausalen epistemischen Verfahrens oder Meßverfahrens für eine bestimmte Entität, Eigenschaft etc. und damit ein Argument für die kausale Nachweisbarkeit oder Meßbarkeit dieser Entität, Eigenschaft etc. liegt offenbar dann vor, wenn diese Entität, Eigenschaft etc. tatsächlich kausal nachgewiesen oder gemessen werden konnte, genauer: wenn ein Argument vorliegt, daß es sich bei einem bestimmten, tatsächlich durchgeführten Experiment, einer bestimmten, tatsächlich durchgeführten Messung o.ä. um einen kausalen Nachweis oder eine Messung dieser Entität, Eigenschaft etc. handelt. Eine tatsächlich kausal nachgewiesene bzw. gemessene Entität, Eigenschaft etc. ist offenbar auch kausal nachweisbar bzw. meßbar. Ein Argument für die Verläßlichkeit eines kausalen epistemischen Verfahrens oder Meßverfahrens, das bei einem tatsächlich durchgeführten Nachweis oder einer tatsächlich durchgeführten Messung eingesetzt wurde, kann offenbar von verschiedener Art sein: Denkbar ist etwa, daß sich die Verläßlichkeit eines Verfahrens aus einer (auf anderem Weg gewonnenen und begründeten) Theorie herleiten läßt, die eine theoretische Beschreibung des Nachweisgerätes, Meßinstrumentes o.ä. einschließt. Denkbar ist auch, daß sich die Verläßlichkeit eines Verfahrens für eine bestimmte Entität, Eigenschaft etc. durch einen induktiven oder induktiv extrapolierenden Schluß begründen läßt, der an eine Kalibrierung des Verfahrens an (in relevanter Hinsicht) ähnlichen Entitäten, Eigenschaften etc. anschließt, ${ }^{28}$ und denkbar sind schließlich vielleicht auch noch andere Argumente für die Verläßlichkeit eines kausalen epistemischen Verfahrens wie etwa die von Hacking anhand einiger Beispiele angedeuteten, die von der systematischen Übereinstimmung der tatsächlich gewonnenen Resultate mehre-

\footnotetext{
${ }^{28} \mathrm{Vgl}$. Abschnitt 8.3.
} 
rer unabhängiger Nachweis- oder Meßgeräte ausgehen. ${ }^{29}$ Die beiden letztgenannten Arten von Begründungen setzen keine theoretische Beschreibung des Nachweisgerätes, des Meßinstruments o.ä. voraus (zumindest keine, die so detailiert und "vollständig" ist, daß sich aus ihr eine Verläßlichkeitsannahme ableiten ließe).

Im Fall einer Entität, Eigenschaft etc., die tatsächlich (noch) nicht kausal nachgewiesen oder gemessen wurde, sind ebenfalls verschiedenartige Argumente für die Verläßlichkeit eines kausalen epistemischen Verfahrens oder Meßverfahrens für die fragliche Entität, Eigenschaft etc. und damit für ihre kausale Nachweisbarkeit oder Meßbarkeit denkbar: Eine entsprechende Verläßlichkeitsannahme läßt sich grundsätzlich auch dann, wenn die fragliche Entität, Eigenschaft etc. tatsächlich (noch) nicht nachgewiesen oder gemessen wurde, aus einer Theorie herleiten, die eine theoretische Beschreibung des Nachweisgerätes, Meßinstrumentes o.ä. einschließt, oder durch einen an eine Kalibrierung anschließenden induktiven oder induktiv extrapolierenden Schluß begründen (letzteres allerdings nur, sofern es in relevanter Hinsicht ähnliche Entitäten, Eigenschaften etc. gibt und diese für Kalibrierungsexperimente oder -Messungen zur Verfügung stehen). Es macht jedoch einen Unterschied, ob das fragliche epistemische Verfahren oder Meßverfahren bereits realisiert und zum Nachweis oder zur Messung anderer Entitäten, Eigenschaften etc. eingesetzt wurde oder nicht: Nur wenn das so ist, sprich: wenn das entsprechende Nachweisgerät, Meßinstrument o.ä. tatsächlich existiert, können Nachweisexperimente, Messungen etc. vorgenommen werden, die eine Kalibrierung des Gerätes, Instruments etc. ermöglichen und damit auch einen induktiven oder induktiv extrapolierenden Schluß auf dessen Verläßlichkeit für die (noch) nicht kausal nachgewiesene oder gemessene Entität, Eigenschaft o. ̈̈. Dagegen kann aus einer theoretischen Beschreibung eines Nachweisgerätes, Meßinstruments o.ä., wenn eine solche tatsächlich zur Verfügung steht, grundsätzlich auch dann eine Verläßlichkeitsannahme abgeleitet werden, wenn das Gerät, Instrument o.ä. tatsächlich (noch) nicht existiert, sondern nur (mehr oder weniger detailierte) Konstruktionspläne - auch wenn eine solche Ableitung in der Praxis vielleicht nur selten möglich ist.

Wenn eine Verläßlichkeitsannahme aus einer Theorie abgeleitet wird, die eine theoretische Beschreibung des jeweiligen Nachweisgerätes, Meßinstruments o.ä. einschließt, muß i.a. für diese Theorie argumentiert werden. Welche Argumente sich hier vorbringen lassen, muß im Einzelfall und vor dem Hintergrund der jeweils akzeptierten Konzeption epistemischer Rechtfertigung geprüft werden. In Frage kommen könnten etwa Argumente, die eine (mehr oder weniger genau spezifizierte) Form des Schließens auf die beste Erklärung in Anspruch nehmen und auf bestimmte Erklärungsleistungen der fraglichen Theorie in einem anderen als dem für das Nachweisgerät, Meßinstrument o.ä. relevanten Gegenstandsbereich Bezug nehmen.

Daß die hier skizzierten Arten von Argumenten für die kausale Nachweisbarkeit oder Meßbarkeit einer Entität, Eigenschaft etc. tatsächlich die sind, die man plausiblerweise anführen wird, zumindest wenn man eine reliabilistische Konzeption von epistemischer Rechtfertigung voraussetzt, wird deutlich, wenn man die Parallelen zwischen Beobachtbarkeit und kausaler Nachweisbarkeit oder Meßbarkeit in den Blickpunkt rückt bzw. die Tatsache, daß Beobachten mit dem bloßen Auge aus reliabilistischer Perspektive nur ein kausales epistemisches Verfahren unter anderen ist. Wenn man sich die Frage stellt, was sich an Argumenten für die Beobachtbarkeit einer Entität, Eigenschaft etc. anführen läßt, etwa in einer Diskussion mit einem (konzilianten) "Hyperinstrumentalisten", nach dessen Ansicht nicht die Grenze beobachtbar/unbeobachtbar den Bereich des epistemisch

\footnotetext{
${ }^{29}$ Siehe S.327.
} 
Zugänglichen begrenzt, sondern eine noch enger gezogene "bizarre" Grenze, ${ }^{30}$ dann weist die naheliegende Antwort weitgehende Parallelen zu den oben skizzierten Argumenten für kausale Nachweisbarkeit oder Meßbarkeit auf: Im Fall einer Entität, Eigenschaft etc., die tatsächlich bereits beobachtet wurde, wird man darauf hinweisen, daß eine tatsächlich beobachtete Entität, Eigenschaft etc. auch beobachtbar ist, und versuchen, Argumente dafür anzugeben, daß das Beobachten mit dem bloßen Auge ein verläßliches Verfahren für die fragliche Entität, Eigenschaft etc. ist. Nach solchen Argumenten zu suchen ist ein im Zusammenhang mit der wissenschaftstheoretischen Realismusdebatte ungewöhnliches Unternehmen, in Frage kommen aber offenbar am ehesten Argumente, die einen induktiven oder induktiv extrapolierenden Schluß von der Verläßlichkeit des Beobachtens ähnlicher Entitäten, Eigenschaften etc. auf die Verläßlichkeit des Beobachtens im Falle der zur Debatte stehenden Entität, Eigenschaft etc. vorsehen, oder Argumente, die von der systematischen Übereinstimmung der Beobachtungen einer Person mit dem Output anderer kausaler epistemischer Verfahren ausgehen, etwa des Tastsinns dieser Person oder des Sehsinns anderer Personen. Solche Argumente weisen augenscheinlich weitgehende Parallelen zu den oben skizzierten "Kalibrierungsargumenten" und den von Hacking angedeuteten "Übereinstimmungsargumenten" für kausale Nachweisbarkeit oder Meßbarkeit auf. Grundsätzlich in Frage kommt auch ein Argument, das die Verläßlichkeit des Beobachtens mit dem bloßen Auge aus einer theoretischen Beschreibung des Auges bzw. des Sehsinnes herleitet, eine derartige Theorie dürfte jedoch derzeit (noch) nicht verfügbar sein. Im Fall einer Entität, Eigenschaft etc., die tatsächlich noch nicht mit dem bloßen Auge beobachtet wurde (Dinosaurier, Oberflächendetails der Jupitermonde u.ä.), dürften faktisch (derzeit) nur Schlüsse induktiver oder induktiv extrapolierender Art ein Argument für die Verläßlichkeit des Beobachtens mit dem bloßen Auge ergeben. Die Argumente, die man als Realist in der Diskussion mit Instrumentalisten im Rahmen der im vorigen Abschnitt beschriebenen Argumentationsstrategie für die kausale Nachweisbarkeit oder Meßbarkeit einer Entität, Eigenschaft etc. angeben kann, scheinen also von derselben Art zu sein wie die, die sich für die Beobachtbarkeit einer Entität, Eigenschaft etc. angeben lassen und auf die auch ein Instrumentalist in einer Diskussion mit einem "Hyperinstrumentalisten" angewiesen wäre.

Wie sehen überzeugende Argumente für die epistemische Zugänglichkeit bestimmter Entitäten, Eigenschaften etc. aus, die nicht durch ein kausales epistemisches Verfahren epistemisch zugänglich sind, die also keine kausalen Eigenschaften haben, nicht kausal wechselwirken usw. und daher nicht kausal nachweisbar oder meßbar sind? Allgemein läßt sich dies aus analogen Gründen wie im Fall kausal nachweisbarer oder meßbarer Entitäten, Eigenschaften etc. nicht angeben, darüber hinaus ist es aber sogar aus einer reliabilistischen Perspektive schwierig, in Frage kommende Arten von Argumenten auch nur grob zu skizzieren. Beispiele für nicht-kausale bzw. nicht kausal wechselwirkende Entitäten, Eigenschaften etc. sind etwa die der Mathematik, vielleicht auch ethische oder ästhetische Entitäten, Eigenschaften etc. Um Argumente für deren epistemische Zugänglichkeit zu skizzieren, müßte man erläutern, worin hier epistemische Zugänglichkeit besteht, und dabei epistemische Verfahren für die fraglichen Entitäten, Eigenschaften etc. spezifizieren, die keine kausalen Verfahren sind, also nicht auf einer Verursachung der durch das Verfahren gewonnenen Überzeugungen durch die Entitäten, Eigenschaften etc. beruhen, und dann für die Verläßlichkeit dieser nicht-kausalen epistemischen Verfahren argumentieren. Daß sich solche epistemischen Verfahren für nicht-kausale bzw. nicht kausal wechselwir-

\footnotetext{
${ }^{30}$ Siehe S.435.
} 
kende Entitäten, Eigenschaften etc. spezifizieren lassen, ist grundsätzlich denkbar, aber wie sie aussehen könnten, ist nicht offensichtlich und jedenfalls ohne eingehende Untersuchungen der konkreten Fälle bzw. Gegenstandsbereiche nicht zu sehen. ${ }^{31}$ Für Argumente für die Verläßlichkeit solcher nicht-kausaler Verfahren gilt Entsprechendes. Argumente für die epistemische Zugänglichkeit bestimmter Entitäten, Eigenschaften etc. sollten offenbar wiederum dort vorliegen, wo man Argumente für einen tatsächlichen epistemischen $Z u$ gang hat, sprich: tatsächlich Argumente dafür hat, daß eine bestimmte Entität existiert, bestimmte Eigenschaften hat usw., aber wie solche Argumente und damit Argumente für die Verläßlichkeit nicht-kausaler epistemischer Verfahren aussehen und insbesondere, ob sie von derselben oder ähnlicher Art sind wie die oben für den Fall kausaler epistemischer Verfahren skizzierten, ist ohne eingehende Untersuchungen konkreter Fälle bzw. Gegenstandsbereiche nicht zu sehen.

\subsubsection{Fazit}

Zusammenfassend läßt sich Folgendes festhalten. Die argumentative Konstellation in der Diskussion zwischen Realisten und Instrumentalisten läuft offenbar auf ein Remis hinaus, wenn beide Seiten ihre Positionen in hinreichend konsequenter Weise verteidigen. Insbesondere lassen sich von realistischer Seite keine Argumente finden, mit deren Hilfe man konsequente, reflektierte Instrumentalisten davon überzeugen kann, ontologische realistische Thesen über Unbeobachtbares als semantisch vollwertig und als ernsthafte Behauptungen anzuerkennen. Die untersuchten Argumente und soweit erkennbar auch alle, die möglicherweise noch gewonnen werden können, können Überzeugungskraft allenfalls für jemanden haben, der in der Realismusdebatte eine instrumentalistische Position vertritt, die nicht konsequent entwickelt ist, oder der noch gar keine systematisch entwickelte Position einnimmt. Da dieser Befund jedoch unabhängig davon zu sein scheint, wo genau die instrumentalistische Seite die Grenze dessen zieht, was sie als semantisch vollwertig und als ernsthafte Behauptungen anerkennt, scheint er nicht auf einen besonderen Mangel realistischer Positionen hinzuweisen, sondern eher auf prinzipielle Grenzen dessen, was sich mit Hilfe von Argumenten ausrichten läßt.

Wenn in dieser Konstellation dennoch eine fruchtbare Fortsetzung der Debatte zwischen der realistischen und der instrumentalistischen Seite zustandekommen soll, können konziliante Realisten und Instrumentalisten dies erreichen, indem sie die skizzierte Strategie verfolgen, über strittige ontologische realistische Thesen hinaus Hintergrundüberzeugungen beider Seiten in die Diskussion einzubeziehen und dadurch effektiv die Debatte auf die epistemische Ebene zu verlagern. Zumindest vorläufig für die Diskussion wird gemäß dieser Strategie von beiden Seiten vorausgesetzt, daß semantische Vollwertigkeit und der Status einer Aussage als ernsthafte Behauptung an die epistemische Zugänglichkeit der Entitäten, Eigenschaften etc. geknüpft sind, die diese Aussage bzw. der Ausdruck oder Satz zum Inhalt haben bzw. bezeichnen, und daß epistemische Zugänglichkeit nicht Beobachtbarkeit mit dem bloßen Auge (oder Zugänglichkeit auf eine durch eine verifikationistische

\footnotetext{
${ }^{31}$ In diesem Punkt besteht ein deutlicher Unterschied zwischen nicht-kausalen bzw. nicht kausal wechselwirkenden Gegenstandsbereichen wie den Entitäten, Eigenschaften etc. der Mathematik und kausal wechselwirkenden Gegenstandsbereichen, insofern sich viele kausale epistemische Verfahren, die in den letzteren Gegenstandsbereichen für epistemische Zugänglichkeit sorgen, zumindest intuitiv und grob angeben und spezifizieren lassen (etwa Beobachten mit Mikroskopen verschiedener Art, Messung von Gewichten mit einer Waage, Messung von Stromstärken mit einem Amperemeter, Detektion von geladenen Teilchen mit einer Nebelkammer usw.), während in den ersteren Bereichen auch das kaum oder nur schwer möglich zu sein scheint.
} 
o.ä. Definition beschriebene Weise) erfordert. Im Mittelpunkt der Diskussion stehen dann nicht mehr Argumente, die unmittelbar die semantische Vollwertigkeit der jeweils strittigen ontologischen realistischen Thesen und ihren Status als ernsthafte Behauptungen betreffen, sondern Argumente, die die epistemische Zugänglichkeit der Entitäten, Eigenschaften etc. betreffen, von denen die ontologischen realistischen Thesen handeln. Für konsequente, reflektierte Instrumentalisten und Realisten gibt es aber keinen zwingenden Grund, sich auf diese Verlagerung der Debatte einzulassen.

Wie Argumente für die epistemische Zugänglichkeit bestimmter Entitäten, Eigenschaften etc. aussehen, die im Rahmen der beschriebenen Argumentationsstrategie tatsächlich Überzeugungskraft für konziliante Instrumentalisten haben, läßt sich nicht allgemein angeben. Wenn man eine reliabilistische Konzeption von epistemischer Rechtfertigung voraussetzt, lassen sich aber immerhin, wie gezeigt, einige Arten von Argumenten grob skizzieren, die in dem für die Realismusdebatte wichtigen Bereich kausal nachweisbarer oder meßbarer Entitäten, Eigenschaften etc. in Frage kommen. Außerhalb dieses Bereiches stellt sich die Situation aus reliabilistischer Perspektive unübersichtlich dar und überzeugende Argumente für epistemische Zugänglichkeit dürften sich wenn, dann nur aufgrund eingehender Untersuchungen der konkreten Fälle bzw. Gegenstandsbereiche gewinnen lassen. In jedem Fall involviert ein Argument für die epistemische Zugänglichkeit bestimmter Entitäten, Eigenschaften etc. aus reliabilistischer Perspektive stets ein Argument für die Verläßlichkeit eines epistemischen Verfahrens, das den Zugang ermöglicht. Daher ist ein Argument für die epistemische Zugänglichkeit bestimmter Entitäten, Eigenschaften etc. sicherlich dann "automatisch" gegeben, wenn ein Argument dafür vorliegt, daß man zu diesen Entitäten, Eigenschaften etc. tatsächlich epistemischen Zugang hat, sprich ein Argument dafür, daß diese Entitäten tatsächlich existieren, die Eigenschaften tatsächlich vorliegen usw., und damit ein epistemisches Argument, das epistemische Rechtfertigungsgründe involviert. Auch ein Argument für die epistemische Zugänglichkeit von Entitäten, Eigenschaften etc., zu denen man tatsächlich (noch) keinen epistemischen Zugang hat, involviert aber, da man für die Verläßlichkeit eines epistemischen Verfahrens argumentieren muß, ein epistemisches Argument und damit epistemische Rechtfertigungsgründe. Wenn man als Realist in einer Diskussion mit konzilianten Instrumentalisten die skizzierte Argumentationsstrategie verfolgt und damit die Debatte auf die epistemische Ebene verlagert, führt dies also letztlich zum Vorbringen epistemischer Argumente und epistemischer Rechtfertigungsgründe und damit zum Thema des folgenden Abschnitts.

Das im Anschluß an Hacking und Cartwright formulierte kausale Kriterium für semantische Vollwertigkeit spezifiziert einen für die wissenschaftstheoretische Realismusdebatte zentralen Bereich von Aussagen bzw. Sätzen und Ausdrücken, der über den Bereich des Beobachtbaren hinausreicht und für den es prima facie plausibel aussieht, daß man von realistischer Seite in der Diskussion mit konzilianten Instrumentalisten tatsächlich überzeugende Argumente für die epistemische Zugänglichkeit der Entitäten, Eigenschaften etc. vorbringen kann, auf die sich die Aussagen bzw. Sätze und Ausdrücke beziehen. Ob dies tatsächlich so ist, muß aber in der Diskussion konkreter Argumente gezeigt werden; bis dahin stellt das kausale Kriterium stellt lediglich eine - wenn auch plausible - Hypothese über das, was sich von realistischer Seite leisten läßt, dar.

Die skizzierte Argumentationsstrategie stellt eine Möglichkeit dar, die Debatte zwischen Realisten und Instrumentalisten in fruchtbarer Weise fortzusetzen, obwohl die argumentative Konstellation dieser Debatte auf ein Remis hinausläuft, wenn beide Seiten ihre Positionen in hinreichend konsequenter Weise verteidigen. Diese Strategie setzt konziliante Diskussionsgegner voraus; ob es Strategien gibt, die aus der Remis-Konstellation 
herausführen, ohne diese Voraussetzung zu machen, oder überhaupt andere Strategien, die dies leisten, ist hier nicht erörtert worden, es ist jedoch schwer zu erkennen, wie solche Strategien aussehen sollten. Wenn es tatsächlich keine Alternativen gibt, dann ist das, was sich im Rahmen der hier beschriebenen Argumentationsstrategie von realistischer Seite erreichen läßt, offenbar alles, was sich in der vorliegenden Konstellation der Positionen mit argumentativen Mitteln ausrichten läßt, um Instrumentalisten davon zu überzeugen, ontologische realistische Thesen über Unbeobachtbares als semantisch vollwertig und als ernsthafte Behauptungen anzuerkennen.

\subsection{Epistemische Rechtfertigungsgründe und Argumente für ontologische realistische Thesen}

Nachdem im vorigen Abschnitt die Möglichkeiten untersucht worden sind, vom Standpunkt einer selektiven realistischen Position aus gegen instrumentalistische Diskussionsgegner zu argumentieren, ist jetzt die Frage nach epistemischen Rechtfertigungsgründen und Argumenten für ontologische realistische Thesen über Unbeobachtbares zu diskutieren, die von realistischer Seite gegen Diskussionsgegner ins Feld geführt werden können, die eine in epistemischer Hinsicht antirealistische Position vertreten.

Das Fazit der Untersuchung der Argumente, die sich in der Literatur zur wissenschaftstheoretischen Realismusdebatte finden, war, daß alle diese Argumente keine Überzeugungskraft für reflektierte, konsequente Antirealisten haben, daß aber einige dieser Argumente (evtl. in verbesserter Form) unter Umständen dazu dienen können, "nicht-konsequente" Antirealisten zu überzeugen oder Personen, die noch keine systematisch entwickelte Position in der Realismusdebatte bezogen haben. Ferner ergaben sich Hinweise darauf, daß die "Kraftlosigkeit" der untersuchten Argumente in der Diskussion mit konsequenten Antirealisten mit so etwas wie prinzipiellen Grenzen der Möglichkeiten, eine realistische Position argumentativ zu begründen, zu tun haben könnte. ${ }^{32}$ In diesem Abschnitt soll den genannten Hinweisen nachgegangen werden und untersucht werden, was sich evtl. über solche Grenzen sagen läßt; ferner soll vor diesem Hintergrund systematisch erörtert werden, was sich an epistemischen Rechtfertigungsgründen und Argumenten für ontologische realistische Thesen anführen läßt.

\subsubsection{Eine naturalistische und reliabilistische Perspektive}

Wenn man epistemische Rechtfertigungsgründe oder Argumente für bestimmte Thesen anführt und diskutiert, muß (implizit oder explizit) eine Konzeption gerechtfertigter Überzeugungen (oder wenigstens die grobe Skizze einer solchen Konzeption) vorausgesetzt werden, die idealerweise in eine erkenntnistheoretische Gesamtposition integriert ist. Um zu einer adäquaten und zufriedenstellenden erkenntnistheoretischen Position zu gelangen, ist eine Vielzahl von mehr oder weniger allgemeinen Fragen zu beantworten, insbesondere auch von erkenntnistheoretischen Fragen, die über die Zusammenhänge der wissenschaftstheoretischen Realismusdebatte weit hinausgehen; in den Debatten der Erkenntnistheorie ist jedoch selbst zu grundsätzlichen Fragen dieser Art derzeit kein Konsens in Sicht. Da diese Fragen bei weitem zu komplex und zu weitreichend sind, um gleichsam bei der Vorbereitung zur Erörterung einer wissenschaftstheoretischen Fragestellung diskutiert oder gar in zufriedenstellender Weise beantwortet zu werden, ist an dieser Stelle die naheliegendste

\footnotetext{
${ }^{32}$ Siehe Abschnitt13.1.
} 
- und vielleicht die einzig realisierbare - Strategie die, den aussichtsreichsten Ansatz aus den allgemeinen erkenntnistheoretischen Debatten für die wissenschaftstheoretischen Untersuchungen zu übernehmen, ohne ihn alternativen Ansätzen gegenüberzustellen oder im Detail auf seine Vorzüge und Nachteile einzugehen, und vor dem Hintergrund dieses Ansatzes die Fragen der epistemischen Begründung realistischer Thesen über Unbeobachtbares zu diskutieren, um die es in diesem Abschnitt gehen soll. Diese Überlegung führt, wie schon erörtert, ${ }^{33}$ beim gegenwärtigen Stand der erkenntnistheoretischen Debatten zu den bereits vorne skizzierten reliabilistischen Ansätzen. ${ }^{34}$

Einige spezielle Vorzüge, die in der wissenschaftstheoretischen Realismusdebatte mit einer reliabilistischen Position in der Erkenntnistheorie verbunden sind, sollen aber wenigstens genannt werden. Einen reliabilistischen Ansatz für die wissenschaftstheoretische Realismusdebatte vorauszusetzen, bringt einen gewichtigen Vorzug mit sich, wenn man eine bestimmte Intuition hat, die einige, aber keineswegs alle Realisten teilen: Die Intuition ist die, die auch hinter den Kontinuitätsargumenten steht, ${ }^{35}$ nämlich, daß zwischen dem Bereich des Beobachtbaren und dem Bereich des Unbeobachtbaren keine prinzipielle, philosophisch grundlegende Differenz besteht, sondern daß es zwischen beiden Bereichen mehr oder weniger kontinuierliche Übergänge gibt. Diese "Kontinuitätsintuition" besagt u.a., nämlich in erkenntnistheoretischer Hinsicht, daß die Grenze beobachtbar/unbeobachtbar für die epistemische Rechtfertigung von Überzeugungen keine besondere oder gar grundlegende Rolle spielt und daß (hinreichend gute bzw. überzeugende) Rechtfertigungsgründe und Argumente für Überzeugungen auf beiden Seiten der Grenze beobachtbar/unbeobachtbar von der gleichen Art und "Qualität" sein sollten. Diese Intuition ist mit einem reliabilistischen Ansatz verträglich und wird darüber hinaus durch ihn konkretisiert, indem für das, was Wissen, eine gerechtfertigte Überzeugung, ein verläßliches epistemisches Verfahren etc. ist, Erläuterungen gegeben werden, in die die Unterscheidung beobachtbar/unbeobachtbar nicht eingeht, und indem der Grenze beobachtbar/unbeobachtbar auch sonst keinerlei grundlegende Rolle im Zusammenhang mit den epistemischen Verfahren, die für eine reliabilistische Position zentral sind, zugewiesen wird. ${ }^{36}$ Wenn man diese Intuition über eine "allgemeine Eigenschaft" einer adäquaten Konzeption von Wissen, gerechtfertigten Überzeugungen etc. teilt und diese "Eigenschaft" auch ins Spiel bringt, wenn man epistemische Rechtfertigungsgründe und Argumente für ontologische realistische Thesen über Unbeobachtbares vorbringt (wie es etwa die Anhänger epistemischer Kontinutitätsargumente tun), entfernt man sich damit vom Mainstream der wissenschaftstheoretischen Realismusdebatte, in dem die Frage nach epistemischen Rechtfertigungsgründen und Argumenten für Überzeugungen und Thesen über Beobachtbares von Anfang an außerhalb des Blickfeldes bleibt und stattdessen ein Common-sense-Realismus vorausgesetzt wird, nach dessen Begründung oder Rechtfertigung nicht gefragt wird. ${ }^{37}$ Von diesem Mainstream entfernt man sich als Realist, wie sich zeigen wird, insbesondere auch dann, wenn man unter Voraussetzung eines reliabilistischen Ansatzes epistemische Rechtfertigungsgründe und Argumente für ontologische realistische Thesen vorbringt.

Ein weiterer Vorzug eines reliabilistischen Ansatzes für die wissenschaftstheoretische Realismusdebatte ist aus realistischer Perspektive, daß ein solcher Ansatz, wie diskutiert ${ }^{38}$,

\footnotetext{
${ }^{33}$ Siehe S.149f.

${ }^{34}$ Siehe Kap.8.3.1.

${ }^{35}$ Siehe Kap.8.

${ }^{36}$ Siehe S.156.

${ }^{37}$ Siehe S.24ff.

${ }^{38}$ Siehe Kap.8.
} 
einen geeigneten Hintergrund für die Formulierung oder Rekonstruktion von epistemischen Kontinuitätsargumenten darstellt. Für das Wunderargument und seine Varianten gilt Entsprechendes. ${ }^{39}$ Die Argumente und Argumentskizzen aus der Literatur zur wissenschaftstheoretischen Realismusdebatte, die vergleichsweise noch die erfolgversprechendsten sind und (in verbesserter Form) wenigstens in der Diskussion mit "nicht-konsequenten" Antirealisten und Personen ohne systematisch entwickelte Position Überzeugungskraft entwickeln könnten, können also vor einem reliabilistischen Hintergrund rekonstruiert und/oder weiterentwickelt werden. Eine reliabilistische Position erlaubt außerdem, "antiinstrumentalistische" Argumente, die der in den vorigen Abschnitten skizzierten Argumentationsstrategie folgen, so, wie es dort bereits angedeutet wurde, in natürlicher Weise an epistemische Argumente für ontologische realistische Thesen anzuschließen. Schließlich hat eine reliabilistische Position den Vorzug, daß die für sie zentralen Begriffe des epistemischen Verfahrens und der Verläßlichkeit eines Verfahren eine natürliche Beschreibung der epistemischen Praxis real-existierender Naturwissenschaften ergeben, insbesondere auch der Praxis in den experimentellen Teilbereichen der Naturwissenschaften, in denen Beobachtungs-, Nachweis- und Meßinstrumente eine zentrale Rolle spielen und die im "Alltagsgeschäft" für Meßwerte, Gesetze, Modelle etc. vorgebrachten Rechtfertigungsgründe vielfach explizit auf die Verläßlichkeit der zu ihrer Gewinnung eingesetzten Instrumente Bezug nehmen. ${ }^{40}$

Eine grobe Skizze einer reliabilistischen Position, die den Überlegungen zu epistemischen Rechtfertigungsgründen und Argumenten für ontologische realistische Thesen im folgenden zugrundeliegen soll, wurde, wie erwähnt, bereits oben ${ }^{41}$ gegeben. Es ist jedoch nützlich, dieser Skizze noch einige Ergänzungen bzw. Erläuterungen hinzuzufügen.

Eine reliabilistische Position zu formulieren und von einem solchen erkenntnistheoretischen Standpunkt aus Rechtfertigungsgründe und Argumente für bestimmte Aussagen und Thesen anzugeben, erfordert, wie zum Teil schon vorne erwähnt ${ }^{42}$, "reichhaltigere" Beschreibungen der epistemischen Zustände von Personen als in erkenntnistheoretischen Diskussionen üblich, und zwar "reichhaltiger" in dem Sinn, daß nicht nur Überzeugungen erster Ordnung, also Überzeugungen "über die Welt", erfaßt werden, sondern auch Überzeugungen zweiter Ordnung, die Überzeugungen erster Ordnung zum Inhalt haben, ${ }^{43}$ außerdem die Inferenzregeln oder -schemata, denen eine Person folgt, und andere epistemische Verfahren, mit deren Hilfe sie Überzeugungen gewinnt, sowie auch Überzeugungen, die die Verläßlichkeit der Inferenzregeln und anderen epistemischen Verfahren zum Inhalt haben. ${ }^{44}$ Ein bisher noch nicht genanntes Element dieser Liste ist, daß - neben den erwähnten Inferenzregeln und anderen epistemischen Verfahren, mittels derer Überzeugungen erzeugt bzw. stabilisiert werden - ein weiterer Typ von Regeln oder Verfahren erfaßt werden muß, nämlich die Regeln oder Verfahren, denen eine Person folgt, wenn ein Konflikt zwischen verschiedenen Überzeugungen in ihrem Überzeugungssystem entdeckt wird und beseitigt werden muß. ${ }^{45}$

\footnotetext{
${ }^{39}$ Dies wurde in Kap.9 nur am Rande diskutiert, ist aber aus einer reliabilistischen Perspektive betrachtet unschwer zu erkennen; vgl. bes. die Abschnitte 9.9.5 und 9.10.1.

${ }^{40}$ Dazu siehe S.499ff.

${ }^{41}$ Abschnitt 8.3.1.

${ }^{42}$ Vgl. Abschnitt 8.3, S.155 et passim.

${ }^{43}$ Die englischen Termini technici dafür sind '1st-order beliefs' und '2nd-order beliefs' .

${ }^{44}$ Die letzteren Überzeugungen sollen weder zu den Überzeugungen erster Ordnung, noch zu denen zweiter Ordnung zählen.

${ }^{45}$ Diese sind relevant für die Diskussion der Argumente, die in der Debatte zwischen Realisten und Antirealisten für ontologische realistische Thesen vorgebracht werden können; vgl. u.a. S.487.
} 
Bei einem solchen Konflikt kann es sich um eine Inkonsistenz handeln, also um einen logischen Widerspruch zwischen mehreren Überzeugungen, oder "nur" um eine Inkohärenz von der Art, daß eine Überzeugung im Lichte anderer Überzeugungen (mehr oder weniger) unwahrscheinlich erscheint. ${ }^{46}$ Plausible Regeln oder Verfahren, nach denen in solchen Fällen das jeweilige Überzeugungssystem revidiert wird, in einigermaßen genauer Form anzugeben, ist ein schwieriges und komplexes Problem, das in der Erkenntnistheorie erst in neuerer Zeit in Angriff genommen wird, bisher allerdings ohne Resultate, die über allererste Ansätze hinausgehen. ${ }^{47}$ Dieses Problem kann hier im wesentlichen nur genannt und mit dem Hinweis als ungelöst beiseite gelegt werden, daß man sich natürlich in konkreten Fällen auch dann darüber einig sein kann (und es häufig auch ist), auf welchem Weg ein Konflikt auszuräumen ist, wenn man dafür keine expliziten allgemeinen Regeln oder Verfahren angeben kann. Aus reliabilistischer Perspektive scheint lediglich für einige sehr einfache Fälle einigermaßen offensichtlich, was allgemeine Regeln oder Verfahren dort plausiblerweise sagen sollten: Wenn es um einen Widerspruch zwischen zwei durch jeweils ein (mehr oder weniger verläßliches) Erzeugungsverfahren gewonnenen Überzeugungen geht, die nicht auf andere Weise stabilisiert werden, dann dürfte die angemessene Vorgehensweise sein, diejenige der beiden Überzeugungen aufzugeben, die durch das weniger verläßliche Verfahren erzeugt wurde. Wenn die beiden Überzeugungen jeweils durch mehrere voneinander unabhängige Verfahren unterschiedlicher Verläßlichkeit erzeugt wurden bzw. stabilisiert werden, ist die Sachlage bereits schwieriger und es müssen verschieden große Mengen von Rechtfertigungsgründen unterschiedlicher "Qualität" gegeneinander abgewogen werden, möglicherweise, indem man die "Verläßlichkeitswerte" der beiden Überzeugungen jeweils summiert. Wenn es um einen Widerspruch zwischen zwei Überzeugungen geht, die deduktiv aus anderen Überzeugungen folgen, reicht es offenbar nicht, eine der Überzeugungen fallen zu lassen, sondern es muß zusammen mit einer von ihnen ein so großer Teil des Überzeugungssystems aufgegeben werden, daß sie (und damit der Widerspruch) sich nicht aus dem verbleibenden Teil durch ein (noch immer) akzeptiertes Inferenzverfahren zurückgewinnen läßt. ${ }^{48}$ Wie für diesen Typ von Fällen eine plausible Regel aussehen könnte, ist bereits nicht mehr offensichtlich; möglicherweise sollte ein für die Entscheidung zwischen verschiedenen "Revisionsmöglichkeiten" relevanter Aspekt sein, daß (ceteris paribus) möglichst wenige Überzeugungen aufgegeben werden.

Eine weitere, für die Beurteilung eines reliabilistischen Ansatzes wichtige Frage ist die, wie genau sich epistemische Verfahren und ihre Verläßlichkeit charakterisieren und spezifizieren lassen. Als Erläuterung, was ein verläßliches Erzeugungsverfahren ist, war vorne $^{49}$ angegeben worden:

VeEv Ein Erzeugungsverfahren $E V$, das eine Person $A$ verwendet, ist unter den Bedingungen $B$ für das Feld $F$ von Propositionen verläßlich genau dann, wenn gilt:

Wenn 1) $A$ das Verfahren $E V$ einsetzt,

2) die Proposition, daß $P$, zu $F$ gehört und

\footnotetext{
${ }^{46}$ Etwa dadurch, daß letztere als Prämissen eines induktiven Schlusses auf das Gegenteil der ersteren Überzeugung mittels eines mehr oder weniger, aber nicht $100 \%$ ig verläßlichen Inferenzschemas fungieren können.

${ }^{47}$ Siehe dazu [Gard88, Harm86].

${ }^{48}$ Wenn es um Überzeugungen geht, die nicht deduktiv aus anderen Überzeugungen folgen, sondern mittels eines Inferenzschemas, das nicht $100 \%$ ig verläßlich ist, etwa mittels eines induktiven Schemas, gilt Entsprechendes, und zwar nicht unbedingt bei einzelnen "zurückgewinnbaren" Überzeugungen, aber für Fälle, in denen so viele verworfene Überzeugungen "zurückgewinnbar" sind, daß dies mit der Beurteilung der Verläßlichkeit des Inferenzschemas nicht mehr verträglich ist.

${ }^{49} \mathrm{~S} .153$.
} 
3) die Bedingungen $B$ vorliegen ${ }^{50}$, dann gewinnt $A$ eine sehr wahrscheinlich wahre Überzeugung darüber, ob $P$ oder $\neg P$,

als entsprechende Erläuterung, was ein verläßliches Übertragungsverfahren ist:

Ve ̈̈v Ein Übertragungsverfahren $\ddot{U} V$, das eine Person $A$ verwendet, ist unter den Bedingungen $B$ für das Feld $F$ von Propositionen verläßlich genau dann, wenn gilt:

Wenn 1) $A$ das Verfahren $\ddot{U} V$ einsetzt,

2) die Propositionen, daß $P_{1}$, daß $P_{2}$ etc., die Inhalt der als Prämissen verwendeten Überzeugungen sind, zu $F$ gehören,

3) die als Prämissen verwendeten Überzeugungen wahr sind und

4) die Bedingungen $B$ vorliegen ${ }^{51}$,

dann gewinnt $A$ eine neue, sehr wahrscheinlich wahre Überzeugung.

Um ein bestimmtes epistemisches Verfahren mit aller wünschenswerten Genauigkeit zu charakterisieren, sollte idealerweise exakt spezifiziert werden, welches die Bedingungen $B$ und das Feld von Propositionen $F$ sind, für die es sehr wahrscheinlich wahre Überzeugungen liefert, und auch, eine wie hohe Wahrscheinlichkeit als "sehr wahrscheinlich" zählt. Dies ist beim gegenwärtigen Kenntnisstand in Erkenntnistheorie und Kognitionswissenschaften im allgemeinen nicht mit der grundsätzlich wünschenswerten Genauigkeit möglich. Die Charakterisierungen, die derzeit zu haben sind, sind für verschiedene epistemische Verfahren in sehr unterschiedlichem Maße zufriedenstellend. Für ein deduktives Inferenzverfahren wie das Schließen gemäß Modus ponens etwa lassen sich die Bedingungen $B$ und das Feld $F$ einigermaßen genau angeben: Die meisten Personen, deren kognitiver Apparat normal entwickelt ist, können, wenn sie wach und aufmerksam sind, nicht unter Drogen stehen u.ä., verläßlich aus zwei Sätzen $S_{1}$ und $S_{2}$ nach Modus ponens einen Satz $S_{3}$ folgern, wenn es sich um nicht zu lange, sprachlich korrekt formulierte, ansonsten beliebige Sätze der erforderlichen Form handelt. Für das Beobachten mit dem bloßen Auge dagegen lassen sich $B$ und $F$ nicht so einheitlich und randscharf spezifizieren: Personen mit normalem Sehvermögen können unter "Normalbedingungen" jedes Wort ihrer Muttersprache in 11 Punkt großer Druckschrift aus Entfernungen bis ca. 80 Zentimeter verläßlich lesen; Vögel der häufigsten europäischen Arten dagegen können manche Personen bei "normalen" Lichtverhältnissen aus einer Entfernung von bis bis zu ungefähr fünf Metern verläßlich erkennen, jedoch kann kaum jemand alle Arten verläßlich erkennen und verschiedene Personen erkennen i.a. verschiedene Arten, manche Personen auch gar keine, usw.

Notorisch hartnäckige, in der philosophischen Literatur seit langem diskutierte Probleme bereitet die Charakterisierung induktiver Verfahren und Inferenzschemata. Induktive Inferenzverfahren, die, analog zu deduktiven, aus gegebenen Prämissen eine Überzeugung als Output generieren und dies für beliebige Prämissen einer bestimmten Form in verläßlicher Weise tun, sind, wenn die bisherigen Resultate diesbezüglicher Untersuchungen nicht täuschen, nicht zu haben. Induktive Inferenzschemata wie etwa das in der Literatur häufig genannte der enumerativen Induktion

Alle bisher beobachteten $P$ s sind $Q$

Also:

\footnotetext{
${ }^{50}$ Darunter i.a. Bedingungen in bezug auf $P$, etwa: der Gegenstand, von dem $P$ handelt, wird durch Tageslicht beleuchtet.

${ }^{51}$ Darunter i.a. Bedingungen in bezug auf $P_{1}, P_{2}$ etc.
} 
Alle $P$ s sind $Q$

sind offenbar nicht für beliebige Eigenschaften $P$ und $Q$ verläßlich (auch dann nicht, wenn man eine Mindestanzahl von beobachteten Einzelfällen fordert, den für Verläßlichkeit verlangten Wahrscheinlichkeitswert niedrig ansetzt u.ä.); darüber hinaus ist aber auch nicht klar, wie in interessanter (d.h. nicht viel zu spezieller) Weise ein Feld $F$ oder mehrere zu charakterisieren wären, für die ein Inferenzschema dieser Art verläßlich ist. ${ }^{52}$ Gleichzeitig ist es jedoch so, daß Schlüsse induktiver Art für die epistemische Praxis des Alltags und auch der Wissenschaften zweifellos unverzichtbar und auch nichts Außergewöhnliches sind; z.B. liefert der menschliche kognitive Apparat in Situationen, in denen man eine Reihe gleichartiger Einzelfälle beobachtet oder sonstwie von ihnen erfahren hat, vielfach eine Überzeugung, die eine entsprechende Verallgemeinerung zum Inhalt hat, und die auch in vielen Fällen wahr ist. ${ }^{53}$ Andererseits sind solche induktiv gewonnenen Überzeugungen jedoch zweifellos auch in vielen Fällen falsch. Entsprechendes gilt außer für induktive Schlüsse im engeren Sinne auch für die vorne erwähnten induktiven Extrapolationsschlüsse. ${ }^{54}$ Die Situation ist also offenbar die, daß Menschen i.a. eine Art induktives Vermögen oder mehrere solche induktive Vermögen oder Fähigkeiten besitzen, dem bzw. denen man in der Praxis in vielen Fällen traut und auch trauen kann, daß diese Vermögen sich jedoch beim gegenwärtigen Kenntnisstand nicht durch in zufriedenstellender Weise spezifizierte verläßliche epistemische Verfahren beschreiben lassen.

Mit Ungenauigkeiten und ungelösten Problemen dieser Art hinsichtlich der Charakterisierung konkreter epistemischer Verfahren wird man beim gegenwärtigen Stand der Dinge rechnen und auch "leben" müssen, wenn man einen reliabilistischen Ansatz in der Erkenntnistheorie und insbesondere auch im Zusammenhang mit der wissenschaftstheoretischen Realismusdebatte erprobt. U.a. wird man bei der Begründung ontologischer realistischer Thesen auf induktive Schlüsse angewiesen sein, obwohl sich die verwendeten induktiven Inferenzschemata bzw. epistemischen Verfahren nicht in zufriedenstellender Weise spezifizieren lassen. Dies ist aber keine Besonderheit, die nur den Bereich des Unbeobachtbaren betrifft, sondern gilt genauso für den Bereich der beobachtbaren Alltagswelt. Die genannten Charakterisierungsprobleme zu lösen und die epistemischen Verfahren, die man in der epistemischen Praxis der Alltagswelt und der Wissenschaften verwendet, sowie ihre Verläßlichkeit in angemessener, hinreichend präziser Weise zu spezifizieren, ist eine wichtige Teilaufgabe innerhalb des Projektes, eine reliabilistische Position in der Erkenntnisund Wissenschaftstheorie weiterzuentwickeln und auszubauen, allerdings eine Teilaufgabe, die in dieser Arbeit weitgehend beiseite bleiben muß.

Eine Frage, die naheliegt, wenn man für wissenschaftstheoretische Untersuchungen einen reliabilistischen Ansatz aus den allgemeinen erkenntnistheoretischen Debatten übernimmt, die aber hier im wesentlichen ebenfalls beiseite bleiben muß, ist die nach dem Verhältnis der reliabilistischen Konzeption epistemischer Rechtfertigung zu den diversen in der Wissenschaftstheorie gängigen Theorien, Positionen, Modellen etc.: Solche Theorien etc., die Themenbereichen wie "Bestätigungstheorie", "Theoriendynamik", "rationale

\footnotetext{
${ }^{52}$ Einige ziemlich spezielle und nur mäßig verläßliche induktive Verfahren dieser Art könnten sich aber bei gründlicher Suche identifizieren lassen: Man könnte hier an Bauernregeln zur Wetterprognose denken oder an bestimmte Verfahren zur Prognose von Börsenkursen (wie sie Lipton in [Lipt91], S.163 nennt).

${ }^{53}$ Z.B. bin ich nach einer Reihe von entsprechenden Beobachtungen (eigenen und denen anderer Personen) überzeugt, daß alle (einigermaßen frischen) Hühnereier nach fünfzehnminütigem Kochen hart sind, daß sich alle Fettflecken in Baumwollkleidung durch Auswaschen mit Wasser und Gallseife entfernen lassen, u.ä.

${ }^{54}$ Siehe S.161.
} 
Theoriewahl" u.ä. zuzuordnen sind, berühren oder beantworten oftmals (explizit oder implizit) erkenntnistheoretische Fragen oder setzen Antworten auf solche Fragen zumindest implizit voraus. ${ }^{55}$ Diese Theorien, Positionen etc. beantworten i.a. unterschiedliche und unterschiedlich viele erkenntnistheoretische Fragen in sehr verschiedener Weise und stehen daher in sehr unterschiedlichen Beziehungen zum Reliabilismus, so daß diese Beziehungen hier aus Platzgründen nicht im einzelnen diskutiert werden können. Es lassen sich jedoch einige wenige Punkte festhalten, die hilfreich sein könnten, um Mißverständnisse zu vermeiden, und insbesondere, um den auf den ersten Blick vielleicht naheliegenden Eindruck auszuräumen, daß ein reliabilistischer Ansatz in grundlegender Weise und zwangsläufig in einem Konkurrenzverhältnis zu sämtlichen in der Wissenschaftstheorie gängigen Theorien, Positionen etc. stehen muß:

- An formalen Sprachen und/oder empiristischen Ansätzen orientierte Theorien der Bestätigung, der Stützung, des Testens u.ä. wissenschaftlicher Theorien (z.B. Carnaps induktive Logik, Poppers hypothetisch-deduktive Konzeption) versuchen vielfach, durch Relationen zwischen Beobachtungsdaten oder singulären Beobachtungssätzen einerseits, und anderen, vor allem allgemeinen Sätzen, Gesetzen oder Theorien andererseits zu erläutern, worin die Bestätigung, Stützung o.ä. letzterer besteht. Damit wird - wie auch immer im einzelnen — der epistemische Status von (vor allem allgemeinen) Sätzen, Gesetzen und Theorien thematisiert, deren Wahrheitswerte nicht durch Beobachten ermittelt wurde, nicht dagegen die Frage nach dem epistemischen Status der Beobachtungsdaten oder (singulären) Beobachtungssätze, deren Wahrheitswert tatsächlich durch Beobachten gewonnen wurde. Im Gegensatz dazu beschäftigen sich reliabilistische Ansätze mit dem epistemischen Status aller Überzeugungen gleichermaßen, egal auf welche Weise ihr Wahrheitswert ermittelt wird und welchen "Allgemeinheitsgrad" sie haben. Reliabilistische Ansätze sind in diesem Sinn allgemeiner.

- Theorien der Bestätigung, der Stützung, des Testens u.ä. wissenschaftlicher Theorien versuchen häufig, ausschließlich mittels logischer Relationen zwischen Beobachtungssätzen einerseits, und anderen Sätzen oder Theorien andererseits (bzw. zwischen entsprechenden Propositionen) zu erläutern, worin Bestätigung, Stützung u.ä. von Sätzen oder Theorien und damit ein "ausgezeichneter" epistemischer Status von Sätzen oder Theorien (bzw. entsprechenden Propositionen) besteht. Reliabilistische und damit naturalistische Ansätze dagegen erläutern mittels "natürlicher", also kausaler, physikalischer o.̈̈. Eigenschaften und Relationen einer Überzeugung, worin epistemische Rechtfertigung einer Überzeugung besteht. Hinter dieser Differenz steht häufig der grundlegende Unterschied zwischen einem naturalistischen und einem (implizit) nicht-naturalistischen Ansatz in der Erkenntnistheorie, dies ist aber nicht zwangsläufig so. Zumindest einige Theorien der Bestätigung etc. lassen sich grundsätzlich auch aus einer naturalistischen und reliabilistischen Perspektive lesen bzw. rekonstruieren.

- Die meisten theoriendynamische Modelle (z.B. das von Kuhn) und auch einige Theorien der Bestätigung, der Stützung o.ä. zielen darauf ab, die Praxis des Akzeptierens,

\footnotetext{
${ }^{55}$ Wichtige Theorien, Positionen o.ä. dieser Art sind u.a. Carnaps induktive Logik, Bayessche Bestätigungstheorien, die hypothetisch-deduktiven Konzeptionen von Popper und von Hempel, die theoriendynamischen Modelle von Kuhn und Lakatos und Glymours Bootstrapping-Ansatz.
} 
des "Wählens" o.ä. von wissenschaftlichen Theorien und Gesetzen in den Naturwissenschaften deskriptiv genau zu erfassen oder zumindest die zentralen, paradigmatischen Teile dieser Praxis wiederzugeben oder zu rekonstruieren. Über die Frage, ob eine in epistemischer Hinsicht realistische (oder antirealistische) Einstellung zu den gemäß dieser theoriendynamischen oder bestätigungstheoretischen Konzeptionen akzeptierten, gewählten o.ä. Theorien und Gesetzen angemessen ist und begründet oder gerechtfertigt werden kann, ist damit per se nichts gesagt. Reliabilistische Ansätze enthalten eine Konzeption von epistemischer Rechtfertigung, die mit der Frage nach einer in epistemischer Hinsicht realistischen Einstellung zu dem, was gerechtfertigt ist, unmittelbar verknüpft ist: Indem man hinreichende (reliabilistische) Rechtfertigungsgründe für eine Überzeugung hat, hat man hinreichende Rechtfertigungsgründe für eine entsprechende ontologische realistische These. Im Hinblick auf die Realismusdebatte ist die Frage, die an ein theoriendynamisches Modell und an eine Bestätigungstheorie o.ä. zu stellen ist, die, ob die Theorien, Gesetze usw., die gemäß der von diesem Modell bzw. dieser Bestätigungstheorie beschriebenen Kriterien akzeptiert, gewählt o.ä. werden, mit Sicherheit, mit hoher Wahrscheinlichkeit o.ä. wahr sind, der Wahrheit nahe kommen o.ä., bzw. ob sich Gründe für die Annahme angeben lassen, daß dies so ist. Wenn dies so ist, beschreibt das theoriendynamische Modell bzw. die Bestätigungstheorie damit, aus reliabilistischer Perspektive betrachtet, ein verläßliches epistemisches Verfahren und ist damit in einen reliabilistischen Ansatz integrierbar; wenn dies nicht so ist, können theoriendynamische Modelle bzw. Bestätigungstheorien grundsätzlich dennoch mit einem reliabilistischen Ansatz verträglich sein, etwa wenn man das Akzeptieren, Wählen o.ä. von Theorien, Gesetzen etc. gemäß der theoriendynamischen bzw. bestätigungstheoretischen Kriterien als eine Art strategisches Suchverfahren auffaßt, das nicht zu Überzeugungen führt, sondern zum Akzeptieren von Theorien, Gesetzen etc. in van Fraassens Sinn von 'akzeptieren, ${ }^{56}$ Ob von den in diesem Sinn akzeptierten Theorien, Gesetzen etc. einige oder einige Teile (im reliabilistischen Sinn) gerechtfertigt sind (und, falls ja, welche oder welche Teile), zu denen dann eine in epistemischer Hinsicht realistische Einstellung angemessen ist, wären in dieser Lesart Fragen, die ein theoriendynamisches Modell bzw. eine Bestätigungstheorie per se offen läßt.

\subsubsection{Der Zusammenhang zwischen der Eigenschaft einer Überzeu- gung, daß $P$, gerechtfertigt zu sein, Rechtfertigungsgründen und Argumenten für die Überzeugung, daß $P$, und der Überzeugung (zweiter Ordnung), daß die Überzeugung, daß $P$, gerechtfertigt ist}

Eine reliabilistische Konzeption dessen, was eine gerechtfertigte Überzeugung ist, ist eine externalistische, d.h. ihr zufolge ist es i.a. möglich, daß jemand eine Überzeugung hat, die gerechtfertigt ist, ohne daß ihm selbst Rechtfertigungsgründe und/oder Argumente für sie bekannt, bewußt oder sonstwie zugänglich sind. Die Eigenschaft einer Überzeugung, gerechtfertigt zu sein, ist (anders als nach einer internalistischen Konzeption) grundsätzlich unabhängig davon, ob die Person, die diese Überzeugung hat, über (hinreichend gute) Rechtfertigungsgründe für die Überzeugung verfügt. ${ }^{57}$ Es ist aber gemäß einer reliabilisti-

\footnotetext{
${ }^{56}$ Siehe Abschnitt 10.2.3.

${ }^{57}$ Gemäß einer internalistischen Konzeption dagegen ist eine Überzeugung nur dann gerechtfertigt, wenn ihr Träger über (hinreichende) Rechtfertigungsgründe für sie verfügt.
} 
schen Konzeption natürlich auch nicht ausgeschlossen, daß jemand Rechtfertigungsgründe und/oder Argumente für seine Überzeugungen angeben kann.

In der Realismusdebatte geht es für die realistische Seite darum, Argumente für bestimmte ontologische realistische Thesen anzugeben und dadurch die Diskussionsgegner von diesen Thesen zu überzeugen. Erfolgreich für eine These zu argumentieren heißt in einfachen Fällen, daß man den jeweiligen Diskussionsgegner auf bestimmte seiner Überzeugungen hinweist ${ }^{58}$ sowie ihm eventuell neue Überzeugungen verschafft (indem man ihm neue Informationen zur Verfügung stellt, ihn bestimmte Sachverhalte per Augenschein untersuchen läßt o.ä.), und ihn dann darauf hinweist, daß aus diesen Überzeugungen die These nach einer von ihm als verläßlich akzeptierten (deduktiven, induktiven o.ä.) Inferenzregel folgt. Da ein rationaler, kohärenter Reliabilist einem von ihm als verläßlich anerkannten Inferenzverfahren stets selbst folgt, also dessen Output als Überzeugungen akzeptiert ${ }^{59}$, akzeptiert er auch die These, die das Ziel des Arguments darstellt, als neue Überzeugung. ${ }^{60}$ In komplizierteren Fällen kann erfolgreiches Argumentieren für eine These heißen, den Diskussionsgegner zunächst darauf hinzuweisen, daß aus den genannten Überzeugungen eine für die weitere Argumentation benötigte Prämisse folgt oder daß er eine andere seiner Überzeugungen aufgeben sollte, und dann nach vorbereitenden Schritten dieser Art darauf hinzuweisen, daß sich nach einer von ihm akzeptierten Inferenzregel die These gewinnen läßt. In anderen Fällen kann die Anknüpfung der Argumentation an das vorliegende Überzeugungssystem noch komplizierter sein. ${ }^{61}$

Rechtfertigungsgründe für eine Überzeugung, daß $P$, sind gemäß einer reliabilistischen Konzeption andere Überzeugungen, aus denen (gegeben die reliabilistische Erläuterung, was eine gerechtfertigte Überzeugung ist) die Überzeugung (zweiter Ordnung) folgt, daß die Überzeugung, daß P, gerechtfertigt ist. ${ }^{62}$ Hinreichende Rechtfertigungsgründe für eine Überzeugung, daß $P$, schließen also im einfachsten Fall eine Überzeugung (zweiter Ordnung) darüber, durch welches epistemische Verfahren die Überzeugung, daß $P$, erzeugt oder stabilisiert wurde, und eine Überzeugung, daß dieses Verfahren verläßlich ist, ein. Er-

Sofern die reliabilistische Erläuterung dessen, was eine gerechtfertigte Überzeugung ist, durch internalistische Zusatzbedingungen ergänzt wird (vgl. S.155), ist diese Aussage evtl. zu modifizieren. Diese Möglichkeit bleibt im folgenden meistens beiseite.

${ }^{58}$ Üblicherweise auf welche, die man selbst teilt. Argumente ad hominem spielen auf realistischer Seite nur selten eine Rolle, wenn man einen Diskussionsgegner von der eigenen Position überzeugen will; siehe aber Abschnitt 9.10.5.

${ }^{59}$ Vorausgesetzt natürlich, daß er die Prämissen für wahr hält.

${ }^{60}$ Allgemein gilt, daß ein rationaler, kohärenter Reliabilist den Output eines von ihm als verläßlich anerkannten epistemischen Verfahrens (nicht nur eines Übertragungsverfahrens) stets als Überzeugungen akzeptiert. In Fall eines Erzeugungsverfahrens, und insbesondere gerade im Falle des Beobachtens mit dem bloßen Auge, wird die Sachlage jedoch dadurch etwas kompliziert, daß eine Überzeugung, die zwei Diskussionsgegner teilen (bzw. teilen sollen) von ihnen i.a. genaugenommen nicht durch dasselbe Erzeugungsverfahren gewonnen werden: Wenn jemand eine eigene, nur von ihm gemachte Beobachtung berichtet, wird sein Diskussionsgegner eine entsprechende Überzeugung akzeptieren, wenn er ihn (unter den relevanten Bedingungen etc.) für einen verläßlichen Beobachter hält (sowie außerdem seinem Gedächtnis traut etc.), aber er erwirbt die Überzeugung nicht durch (eigenes) Beobachten. Der Diskussionsgegner wird also gleichsam das Beobachten plus die Informationsvermittlung durch seinen Informanten als ein verlässliches Erzeugungsverfahren behandeln. Die Frage, wie ein solches Verfahren genau zu charakterisieren wäre, muß hier jedoch beiseite bleiben.

${ }^{61}$ Siehe dazu S.486ff.

${ }^{62}$ Nicht unbedingt die Überzeugung, daß $P$, selbst. Dies ist relevant für Überzeugungen, die durch Erzeugungsverfahren gewonnen wurden, z.B. durch Beobachtung.

Diese Konzeption von Rechtfertigungsgründen folgt den Hinweisen in [Sosa95], S.226ff.; vgl. auch die (abweichende) Erläuterung in [Alst86], S.11. In der Literatur zum Reliabilismus wird das Thema "Rechtfertigungsgründe" leider kaum oder nur am Rande diskutiert. 
stere soll im folgenden Herkunftsüberzeugung heißen, letztere Verläßlichkeitsüberzeugung. Sofern es sich bei dem epistemischen Verfahren um ein Übertragungsverfahren handelt, schließen hinreichende Rechtfertigungsgründe im einfachsten Fall außerdem die bei der Gewinnung der Überzeugung, daß $P$, als Prämissen fungierenden Überzeugungen ein; ferner werden die Prämissen in diesem Fall auch in der Herkunftsüberzeugung genannt. ${ }^{63}$ In weniger einfachen Fällen bestehen hinreichende Rechtfertigungsgründe für eine Überzeugung, daß $P$, aus Überzeugungen, aus denen erst nach Zwischenschritten die Überzeugung (zweiter Ordnung) folgt, daß die Überzeugung, daß $P$, gerechtfertigt ist. Rechtfertigungsgründe für eine Überzeugung sind also andere Überzeugungen, auf die man einen Diskussionsgegner, der sie teilt, im Verlauf einer Argumentation hinweisen kann, um ihn zu veranlassen, die erstere Überzeugung, genauer: eine entsprechende These als Überzeugung zu akzeptieren. Rechtfertigungsgründe für eine Überzeugung, daß $P$, kann man aber auch unabhängig von Argumentationen und Diskussionsgegnern ins Auge fassen, indem man in interner Reflexion nach Überzeugungen sucht, aus denen folgt, daß die (eigene) Überzeugung, daß $P$, gerechtfertigt ist.

Im Hinblick auf die in den folgenden Abschnitten zu diskutierenden Fragen nach Rechtfertigungsgründen und Argumenten für ontologische realistische Thesen (und möglichen Grenzen für deren Rechtfertigung und argumentative Begründung) ist vor allem ein Aspekt der angegebenen reliabilistischen Konzeption von Rechtfertigungsgründen wichtig: Danach besagt die Tatsache, daß jemand über hinreichende Rechtfertigungsgründe für eine Überzeugung, daß $P$, verfügt, per se noch nichts darüber, ob diese Rechtfertigungsgründe $i h$ rerseits gerechtfertigt sind, und ob er auch über Rechtfertigungsgründe für sie verfügt. Rechtfertigungsgründe für eine Überzeugung, daß $P$, sollen im folgenden auch als direkte Rechtfertigungsgründe für sie bezeichnet werden, Rechtfertigungsgründe für direkte Rechtfertigungsgründe als indirekte Rechtfertigungsgründe für die Überzeugung, daß $P$. Es gilt dann: Die Tatsache, daß jemand über hinreichende Rechtfertigungsgründe für eine Überzeugung, daß $P$, verfügt, besagt per se noch nichts darüber, wie die Gesamtheit der direkten und indirekten Rechtfertigungsgründe aussieht, die er für seine Überzeugung, daß $P$, hat. Offen sind etwa noch (für das Folgende relevante) Fragen nach Umfang und Struktur dieser Gesamtheit, z.B. die Frage, ob es für jeden Rechtfertigungsgrund seinerseits einen Rechtfertigungsgrund gibt, anders formuliert: ob das iterative Zurückverfolgen von Rechtfertigungsgründen irgendwann an "Endpunkte" führt oder in Zirkel o.ä., und wenn ja, wann. Dieser Befund, daß aus der Tatsache, daß jemand über hinreichende Rechtfertigungsgründe für eine Überzeugung, daß $P$, verfügt, per se nichts über die Gesamtheit der (direkten und indirekten) Rechtfertigungsgründe, die er für diese Überzeugung hat, folgt, gilt für Reliabilisten; er ergibt sich aus der reliabilistischen Konzeption von Rechtfertigungsgründen und gerechtfertigten Überzeugungen. Er gilt i.a. nicht für Anhänger anderer Konzeptionen von epistemischer Rechtfertigung. ${ }^{64}$

\footnotetext{
${ }^{63}$ Siehe (Re2) auf S.155. Mögliche internalistische Zusatzbedingungen zur reliabilistische Erläuterung (Re2) (vgl. S.155), bleiben hier und im folgenden beiseite, da sich dadurch für die Argumentation in der Realismusdebatte aus dem vorne angedeuteten Grund nur wenig oder nichts wesentliches ändern dürfte.

${ }^{64}$ In eine Erläuterung dessen, was eine gerechtfertigte Überzeugung ist, können i.a. Bedingungen über die Gesamtheit der Rechtfertigungsgründe, über die der Träger der Überzeugung verfügen muß, "eingebaut" sein. Beispiele liefern etwa bestimmte fundamentalistische und internalistische Konzeptionen von Rechtfertigung: Wenn z.B. eine Überzeugung genau dann gerechtfertigt ist, wenn sie durch Beobachtung mit dem bloßen Auge gewonnen wurde oder deduktiv aus ihrerseits gerechtfertigten Überzeugungen abgeleitet wurde, liegt die Struktur der Gesamtheit der Rechtfertigungsgründe einer gerechtfertigten Überzeugung damit zum Teil fest (bildlich gesprochen: eine "Baumstruktur" mit durch Beobachtung gewonnenen
} 


\subsubsection{Rechtfertigungsgründe und Argumente für ontologische realisti- sche Thesen über Beobachtbares}

Wenn man aus einer reliabilistischen Perspektive Rechtfertigungsgründe und Argumente für ontologische realistische Thesen im Hinblick auf die wissenschaftstheoretische Realismusdebatte untersuchen will, empfiehlt es sich, sich zunächst dem Problem der epistemischen Begründung ontologischer realistischer Thesen über Beobachtbares zuzuwenden, bevor man die entsprechenden Fragen in bezug auf ontologische realistische Thesen über Unbeobachtbares in Angriff nimmt. Diese Vorgehensweise ist im Mainstream der wissenschaftstheoretischen Realismusdebatte nicht üblich. Dort wird der Streit zwischen Realisten und Antirealisten, um Hackings im Einleitungskapitel zitiertes Bild aufzugreifen ${ }^{65}$, als "Kolonialkrieg" geführt, also sozusagen um die unbeobachtbaren Gegenstände, Prozesse etc. aus den Gegenstandsbereichen der Wissenschaften, während der "Bürgerkrieg" um die beobachtbaren Gegenstände, Prozesse etc. der Alltagswelt außerhalb des Blickfeldes bleibt. Es gibt jedoch mehrere Gründe, von dieser Verfahrensweise abzuweichen und zunächst einen Blick auf die Rechtfertigungsgründe und Argumente zu werfen, die einem im Bürgerkrieg zur Verfügung stehen, wenn man eine reliabilistische Konzeption von Rechtfertigung voraussetzt.

Gegeben eine reliabilistische Konzeption von Rechtfertigung ist im Prinzip klar, was als Rechtfertigungsgrund und was als Argument für eine ontologische realistische These bzw. für eine entsprechende Überzeugung zählt, so daß man daran gehen kann, für konkrete ontologische realistische Thesen zu untersuchen, was sich an Rechtfertigungsgründen und Argumenten für sie vorbringen läßt. Bei solchen Untersuchungen kann man (und wird man, wie sich zeigen wird) darauf stoßen, daß die Möglichkeiten, für eine ontologische realistische These Rechtfertigungsgründe oder Argumente anzugeben, in verschiedener Hinsicht Grenzen haben. Daß man bei der Suche nach Rechtfertigungsgründen für eine ontologische realistische These auf solche Grenzen stoßen kann, haben die Überlegungen des vorigen Abschnitts gezeigt: Sie haben ergeben, daß bei einer Überzeugung, die gerechtfertigt ist und für die man hinreichende Rechtfertigungsgründe vorweisen kann, damit noch nicht festliegt, welchen Umfang und welche Struktur die Gesamtheit ihrer (direkten und indirekten) Rechtfertigungsgründe hat, so daß es von daher z.B. möglich ist, daß das iterative Zurückverfolgen der Rechtfertigungsgründe irgendwann an "Endpunkte" oder in Zirkel führt, daß es also in diesem Sinn Grenzen der Rechtfertigung dieser Überzeugung gibt. Gewisse Hinweise, die zumindest darauf hinzudeuten scheinen, daß man bei der Suche nach Argumenten für ontologische realistische Thesen über Unbeobachtbares tatsächlich auf Grenzen stoßen dürfte, haben sich bereits bei der Untersuchung der Kontinuitätsargumente und auch des Wunderarguments aus reliabilistischer Perspektive ergeben. ${ }^{66}$ Wenn man sich nun bei der Suche nach Rechtfertigungsgründen und Argumenten für eine ontologische realistische These über Unbeobachtbares wirklich mit bestimmten Grenzen konfrontiert sieht (und es wird sich zeigen, daß dies so ist), dann ist es aus mehreren Gründen von Vorteil, wenn man sich vorher ein Bild davon verschafft hat, ob solche oder ähnliche Grenzen auch bei der Suche nach Rechtfertigungsgründen und Argumenten für ontologische realistische Thesen über Beobachtbares bestehen, genauer: wenn man sich davon überzeugt hat, daß dies (wie sich zeigen wird) tatsächlich der Fall ist.

Überzeugungen als Astenden), denn es ist dann z.B. nicht möglich, daß iterative Zurückverfolgen von Rechtfertigungsgründen irgendwann in einen Zirkel führt.

${ }^{65}$ Siehe S.24.

${ }^{66}$ Siehe S.180ff., 261ff. 
Ein Grund, der allerdings nur für jemanden besteht, der die Kontinuitätsintuition ${ }^{67}$ teilt, daß Rechtfertigungsgründe und Argumente auf beiden Seiten der Grenze beobachtbar/unbeobachtbar von der gleichen Art und "Qualität" sind, ist der, daß einem die Rechtfertigungsgründe und Argumente, die man "im Beobachtbaren" zur Verfügung hat, dann eine Art Standard dafür geben, was "im Unbeobachtbaren" an Rechtfertigungsgründen und Argumenten zu erwarten ist, und damit auch einen groben Anhaltspunkt dafür, wann man sozusagen gründlich genug nach Rechtfertigungsgründen und Argumenten für ontologische realistische Thesen über Unbeobachtbares geforscht hat und wann die Grenzen, auf die man dabei gestoßen ist, nichts (mehr) mit mangelnder Gründlichkeit bei der Suche und speziellen "Mängeln" der bis dahin gefundenen bzw. konstruierten Rechtfertigungsgründe und Argumente zu tun haben. Wenn man "im Beobachtbaren" auf bestimmte Grenzen gestoßen ist, wird man dann auch "im Unbeobachtbaren" Grenzen der gleichen Art erwarten. ${ }^{68}$

Ein anderer, wichtigerer Grund ist (u.a.) deswegen von Gewicht, weil im Mainstream der wissenschaftstheoretischen Realismusdebatte von Anhängern sowohl realistischer als auch antirealistischer Positionen eine Art Common-sense-Realismus, also eine realistische Einstellung zu den beobachtbaren Gegenständen, Eigenschaften, Prozessen etc. der Alltagswelt, vorausgesetzt wird, gleichzeitig aber die Frage nach der genauen Formulierung der Thesen, die für diesen Common-sense-Realismus konstitutiv sind, und vor allem nach der epistemischen Begründung dieser Thesen systematisch eingeklammert wird: ${ }^{69}$ Wie die Diskussionen um die epistemischen Kontinuitätsargumente und das Wunderargument zeigen, neigen Anhänger solcher Mainstream-Positionen typischerweise dazu, einen Befund, daß die Möglichkeiten, Rechtfertigungsgründe und Argumente für realistische Thesen über Unbeobachtbares anzugeben, bestimmte Grenzen haben, in bestimmter Weise zu bewerten, nämlich dahingehend, daß ein solcher Befund zeigt, daß der Bereich des Unbeobachtbaren nicht in zufriedenstellender Weise epistemisch zugänglich ist, jenseits der Grenzen menschlicher Erkenntnismöglichkeiten liegt o.ä., oder daß jedenfalls keine zufriedenstellenden Gründe für die Annahme angegeben werden können, daß dies nicht so ist. Wenn man zuvor den Bereich des Beobachtbaren in den Blick genommen hat und festgestellt hat, daß man dort mit Grenzen der gleichen Art konfrontiert ist wie im Bereich des Unbeobachtbaren, dann lassen sich ein Befund über Grenzen im Bereich des Unbeobachtbaren und vor allem Bewertungen dieses Befundes wie die genannten gleichsam ins rechte Licht rücken: Wenn man (nach entsprechenden Untersuchungen) darauf hinweisen kann, daß für realistische Thesen auf beiden Seiten der Linie beobachtbar/unbeobachtbar Rechtfertigungsgründe und Argumente der gleichen Art und auch mit den gleichen Grenzen verfügbar sind, ${ }^{70}$ fordert man damit jeden, der für die wissenschaftstheoretische Realismusdebatte eine Form von Common-sense-Realismus voraussetzt, dazu heraus, seine Bewertung des Befundes, daß sich für ontologische realistische Thesen über Unbeobachtbares nur innerhalb dieser Grenzen Rechtfertigungsgründe und Argumente angeben lassen, in ein Verhältnis zu seinem Common-sense-Realismus zu setzen: Wer aus diesem Befund den Schluß zieht, daß der Bereich des Unbeobachtbaren nicht in zufriedenstellender Weise epistemisch zugänglich ist, jenseits der Grenzen menschlicher Erkenntnismöglichkeiten liegt o.ä., oder daß jedenfalls keine zufriedenstellenden Gründe für die Annahme angegeben wer-

\footnotetext{
${ }^{67}$ Vgl. S.449.

${ }^{68}$ Dies ist deswegen "nur" ein Anhaltspunkt, weil man natürlich auch zu dem Schluß kommen kann, daß die Kontinuitätsintuition falsch ist.

${ }^{69}$ Siehe S.24f.

${ }^{70} \mathrm{Daß}$ sich also die Kontinuitätsintuition als zutreffend erweist.
} 
den können, daß dies nicht so ist, wird für den Bereich des Beobachtbaren denselben Schluß ziehen müssen, und das dürfte mit einem Common-sense-Realismus (wie auch immer dieser genau auszuformulieren ist) kaum verträglich sein und für viele dementsprechend sehr kontraintuitiv und unplausibel erscheinen. Die andere Möglichkeit ist, die Bewertung des genannten Befundes falleszulassen, sich also sozusagen mit dem Gedanken anzufreunden, daß die (auf beiden Seiten der Linie beobachtbar/unbeobachtbar) aufgefundenen Grenzen der Möglichkeiten, Rechtfertigungsgründe und Argumente für realistische Thesen anzugeben, in der Natur der Sache liegen und keinen Grund für die Einschätzung darstellen, daß der Bereich des Unbeobachtbaren "nicht in zufriedenstellender Weise epistemisch zugänglich" ist o.ä., und daß man mit diesen Grenzen leben muß und auch gut leben kann und daß sie insbesondere einer realistischen Einstellung nicht im Wege stehen, weder einem Common-sense-Realismus, noch wissenschaftlichem Realismus. ${ }^{71}$

Aus diesen Gründen soll in den folgenden Abschnitten für den Bereich der beobachtbaren Gegenstände, Eigenschaften etc. der Alltagswelt erörtert werden, wie es aus einer reliabilistischen Perspektive um die Möglichkeiten, epistemische Rechtfertigungsgründe und Argumente für ontologische realistische Thesen anzugeben, und auch um die Grenzen dieser Möglichkeiten bestellt ist.

Im folgenden bleiben die Unabhängigkeitsaussagen, die Teil ontologischer realistischer Thesen sind, meistens implizit, und die Frage nach epistemischen Rechtfertigungsgründen und Argumenten für diesen Teil ontologischer realistischer Thesen wird nicht im Detail diskutiert. Es ist kaum jemals kontrovers, ob für die Entitäten, Sachverhalte o.ä., von denen eine ontologische realistische These handelt, eine oder mehrere der vorne durch (UvmE1) bis (UvmE4) unterschiedenen Arten von Unabhängigkeit vorliegt, und wenn ja, welche ${ }^{72}$; im Hinblick auf epistemische Rechtfertigungsgründe und Argumente stellt "der Rest" einer ontologischen realistischen These den "interessanten" und häufig strittigen Teil dar. Für die Unabhängigkeitsaussagen, die zu ontologischen realistischen Thesen gehören, dürften i.a. hinreichende, je nach genauem Inhalt der Unabhängigkeitsaussagen verschiedene Rechtfertigungsgründe induktiver Art sprechen, deren genaue Form, wie oben gesagt, ${ }^{73}$ schwer zu identifizieren ist, über deren Gewicht aber selten oder nie Zweifel bestehen. ${ }^{74}$

\footnotetext{
${ }^{71} \mathrm{Um}$ sich mit diesem Gedanken in bezug auf wissenschaftlichen Realismus anzufreunden, ist es natürlich nicht unbedingt erforderlich, den Bereich des Beobachtbaren in die Diskussion einzubeziehen. Erfahrungsgemäß erleichtert dies aber für viele, die an der wissenschaftstheoretischen Realismusdebatte interessiert sind, die Sache, insofern für sie (wenn auch vielleicht nicht für Philosophen generell) eine Einschätzung, daß der Bereich des Beobachtbaren nicht in zufriedenstellender Weise epistemisch zugänglich ist o.ä., und ein dadurch nahegelegter "Common-sense-Antirealismus" sehr kontraintuitiv und unplausibel erscheinen, jedenfalls in weit höherem Maße als eine entsprechende Einschätzung, daß der Bereich des Unbeobachtbaren nicht in zufriedenstellender Weise epistemisch zugänglich ist o.ä., bzw. "wissenschaftlicher Antirealismus".

${ }^{72}$ Vgl. Kap.1 und S.407ff., 424.

${ }^{73}$ Siehe S.452.

${ }^{74}$ Unabhängigkeitsklauseln der Form (UvmE1) und (UvmE2), also die Aussagen, daß bestimmte Entitäten, Sachverhalte o.ä. auch dann existieren würden, wenn es keine menschliche Erkenntnis gäbe, bzw. daß sie durch menschliche Erkenntnis nicht kausal beeinflußt werden, sind nicht grundsätzlich anders zu rechtfertigen als Aussagen, daß diese Entitäten, Sachverhalte o.ä. auch dann existieren würden, wenn niemand mit dem Finger auf sie zeigen würde, bzw. daß das Zeigen mit dem Finger auf sie sie kausal nicht beeinflußt, und eine naheliegende Möglichkeit, dies festzustellen ist, zu beobachten, ob sich bestimmte Entitäten, Sachverhalte o.ä. verändern, wenn eine Person sie wahrnimmt, Informationen über sie bekommt, oder mit dem Finger darauf zeigt etc.
} 


\section{Zwei Arten von Grenzen der Möglichkeiten, für ontologische realistische The- sen Rechtfertigungsgründe und Argumente anzugeben}

Ob für eine bestimmte These ein erfolgreiches Argument angegeben werden kann, hängt offenbar davon ab, welche Überzeugungen der jeweilige Diskussionsgegner zu Beginn der Diskussion bereits hat, welchen Inferenzregeln er folgt und, allgemeiner, welche epistemischen Verfahren er als verläßlich akzeptiert, denn auf diese Überzeugungen, Regeln und Verfahren muß jedes Argument zurückgreifen. Allein aus dieser Tatsache ergibt sich, daß die Möglichkeiten, erfolgreich für eine These zu argumentieren, Grenzen haben, oder, anschaulich ausgedrückt, daß die Reichweite von Argumenten beschränkt ist: Zwei Diskussionsgegner, deren Positionen in zu grundlegender Weise verschieden sind, die also zu wenig Überzeugungen und insbesondere zu wenig Inferenzregeln und sonstige epistemische Verfahren zur Veränderung ihrer jeweiligen Überzeugungsmengen teilen, sind für Argumente des jeweils anderen nur noch in begrenztem Maße oder gar nicht mehr zugänglich. Bildlich gesprochen finden dann die Argumente des jeweils einen keinen Ansatzpunkt mehr beim anderen und können keine Veränderung in seinen Überzeugungen bewirken. Dieser allgemeine Sachverhalt ist, wie im folgenden diskutiert werden wird, auch für die Realismusdebatte relevant. Auch dort spielt es eine Rolle, daß das, was zwei "zu grundlegend" verschiedene Positionen argumentativ gegeneinander ausrichten können, Grenzen hat.

Auf eine weitere, davon (zumindest prima facie) verschiedene Weise können dem, was sich, gegeben eine reliabilistische Konzeption von Rechtfertigung, mit Argumenten für eine These ausrichten läßt, dadurch Grenzen gesetzt sein, daß die Möglichkeiten, Rechtfertigungsgründe für eine entsprechende Überzeugung anzuführen, begrenzt sind, und zwar unabhängig davon, ob diese Rechtfertigungsgründe als Argument eingesetzt werden sollen oder nicht. Dies kann etwa dadurch zustandekommen, daß Umfang und Struktur der Gesamtheit der (direkten und indirekten) Rechtfertigungsgründe, die demjenigen, der für eine seiner Überzeugungen argumentieren will, selbst zur Verfügung stehen, bestimmte Grenzen mit sich bringen.

Bei der Untersuchung von Rechtfertigungsgründen und Argumenten für ontologische realistische Thesen empfiehlt es sich, diese beiden Arten von Grenzen zu trennen. Daher soll die Frage, welche Rechtfertigungsgründe sich für eine ontologische realistische These anführen lassen, zunächst unabhängig von Fragen der Einsetzbarkeit dieser Rechtfertigungsgründe als Argument ins Auge gefaßt werden. Diese Frage nach Rechtfertigungsgründen läuft auf die Frage hinaus, was sich jemand sozusagen selbst als Rechtfertigungsgründe für eine eigene Überzeugung vorlegen kann, die eine ontologische realistische These zum Inhalt hat, wenn er interne Reflexionen über den epistemischen Status seiner eigenen Überzeugungen anstellt, sich also selbst Rechenschaft über seine Rechtfertigungsgründe für seine Überzeugungen ablegt. Differenzen zwischen Diskussionsgegnern hinsichtlich ihrer Überzeugungen und akzeptierten epistemischen Verfahren und Regeln spielen hier offenbar keine Rolle; es liegt also gleichsam der Grenzfall einer Argumentation vor, durch die jemand anders von der ontologischen realistischen These überzeugt werden soll, und zwar der Grenzfall verschwindender Differenzen hinsichtlich Überzeugungen ${ }^{75}$ und epistemischer Verfahren. Ob und wie weit sich in dieser Konstellation (direkte und indirekte) Rechtfertigungsgründe für ontologische realistische Thesen angeben lassen, soll im folgenden untersucht werden.

\footnotetext{
${ }^{75}$ Bis auf die jeweils in Frage stehende Überzeugung.
} 


\section{Interne Reflexion über den epistemischen Status von Überzeugungen über Beobachtbares}

Direkte Rechtfertigungsgründe für einzelne Überzeugungen Was kann ein Reliabilist, der über den epistemischen Status seiner eigenen Überzeugungen reflektiert, an direkten Rechtfertigungsgründen für eine Überzeugung anführen, die eine ontologische realistische These über Beobachtbares zum Inhalt hat? ${ }^{76}$ Gemäß der oben angegebenen reliabilistischen Konzeption von Rechtfertigungsgründen ${ }^{77}$ sind hinreichende direkte Rechtfertigungsgründe für eine Überzeugung, daß $P$, gegeben durch erstens eine Herkunftsüberzeugung, d.h. eine Überzeugung (zweiter Ordnung), daß die Überzeugung, daß $P$, durch ein bestimmtes epistemisches Verfahren erzeugt wurde oder stabilisiert wird ${ }^{78}$, zweitens eine Verläßlichkeitsüberzeugung, die besagt, daß dieses Verfahren verläßlich ist, und, falls es sich um ein Übertragungsverfahren handelt, drittens, die Überzeugungen, die als Prämissen fungieren.

Wie solche Rechtfertigungsgründe für Überzeugungen (erster Ordnung) über beobachtbare Gegenstände und Sachverhalte der Außenwelt aussehen, illustrieren einige Beispiele: Wenn ich mich nach Rechtfertigungsgründen für meine Überzeugung frage, daß auf der Fensterbank vor meinem Fenster seit mehreren Stunden eine Katze sitzt, ist die offensichtliche Antwort, daß ich dies gesehen habe, meine Überzeugung also durch Beobachten bei Tageslicht und ansonsten guten Sichtverhältnissen aus einer Entfernung von wenigen Metern erzeugt wurde, und daß das Beobachten unter solchen Bedingungen ein verläßliches Verfahren ist, um Katzen, Hunde, Vögel u.ä. Tiere zu erkennen. Wenn ich mich nach Rechtfertigungsgründen für meine Überzeugung frage, daß in meinem Kühlschrank zwei Tüten Milch liegen, finde ich als Antwort, daß sich dies nach Modus ponens aus meinen anderen Überzeugungen schließen läßt, daß ich gestern zwei solche Tüten hineingelegt und seitdem keine herausgenommen habe, daß Milchtüten (wie die meisten festen, "mittelgroßen" materiellen Gegenstände), wenn man sie in einen verschlossenen Schrank legt und niemand sie wieder daraus entfernt (und keine sehr ungewöhnlichen Umstände eintreten, wie eine Explosion des Kühlschrankes o.ä.), darin liegen bleiben, daß außer mir niemand in der Wohnung war, der die Milchtüten hätte nehmen können, und daß auch sonst keine außergewöhnlichen Umstände vorliegen. Dazu kommt, daß ich Schließen nach Modus ponens für ein verläßliches Inferenzverfahren halte. Wenn ich mich nach Rechtfertigungsgründen für meine Überzeugung frage, daß zu Weihnachten in Boston Schnee lag, ist die Antwort, daß mir dies ein Freund erzählt hat und daß ich ihn für einen verläßlichen Beobachter und Informanten (in bezug auf Wetterverhältnisse seiner Umgebung) halte; ein ähnlicher denkbarer Fall wäre, daß ich es in einer Zeitung gelesen habe, die ich für verläßlich halte.

Auf die Frage nach direkten Rechtfertigungsgründen für Verläßlichkeitsüberzeugungen (die ihrerseits als Rechtfertigungsgründe für Überzeugungen erster Ordnung über Beobachtbares fungieren können), sind verschiedene Antworten denkbar. Auf welche Weise eine Verläßlichkeitsüberzeugung tatsächlich erzeugt wurde, dürfte sich bei alltäglichen epistemischen Verfahren wie denen in den obigen Beispielen (Beobachten, deduktives Schließen, Akzeptieren der Berichte eines Freundes über seine Beobachtungen etc.) im allgemeinen nicht rekonstruieren lassen ${ }^{79}$ ein Inferenzverfahren, das eine solche Verläßlichkeitsüber-

\footnotetext{
${ }^{76}$ Rechtfertigungsgründe für die Unabhängigkeitsaussagen, die in ontologischen realistischen Thesen enthalten sind, bleiben hier beiseite; siehe S.460.

${ }^{77}$ Siehe S.456f.

${ }^{78}$ Und falls es ein Übertragungsverfahren ist, mit Hilfe welcher Prämissen.

${ }^{79}$ Auf welche Weise man also zu der Überzeugung gelangt ist, daß man Katzen, Hunde, Vögel etc. verläßlich durch Beobachten erkennen kann, daß Modus ponens ein verläßliches Schlußverfahren ist etc.
} 
zeugung stabilisiert, sollte sich aber vielleicht finden lassen: Eine denkbare Möglichkeit ist, induktiv von den "Produkten" eines Verfahrens auf seine Verläßlichkeit zu schließen: Wenn ich genügend viele Überzeugung erster Ordnung über einen Gegenstandsbereich (sprich: ein Feld $F$ von Propositionen) durch das fragliche Verfahren gewonnen habe und mir dies auch bekannt ist, ich also entsprechende Herkunftsüberzeugungen habe, könnte dies einen induktiven Schluß gestatten, der im Falle eines Erzeugungsverfahrens von den Prämissen

Ich habe die Überzeugung, daß $S_{1}$, die zu $F$ gehört, unter den Bedingungen $B$ durch das Erzeugungsverfahren EV gewonnen und $S_{1}$

Ich habe die Überzeugung, daß $S_{2}$, die zu $F$ gehört, unter den Bedingungen $B$ durch EV gewonnen und $S_{2}$

Ich habe die Überzeugung, daß $S_{3}$, die zu $F$ gehört, unter den Bedingungen $B$ durch EV gewonnen und $S_{3}$

zur Konklusion

EV ist für $F$ unter den Bedingungen $B$ ein verläßliches Erzeugungsverfahren

führt. Im Fall eines Übertragungsverfahrens gilt bei Berücksichtigung der involvierten Prämissen Entsprechendes. Mit Rechtfertigungsgründen dieser Art sind allerdings alle Probleme des induktiven Schließens verbunden, insbesondere die der Spezifikation verläßlicher induktiver Verfahren. ${ }^{80}$ Eine andere Möglichkeit, auf eine Verläßlichkeitsüberzeugung für ein epistemisches Verfahren zu schließen, hätte man dann, wenn man über Überzeugungen über die Funktionsweise dieses Verfahrens verfügt, aus denen seine Verläßlichkeit (unter bestimmten Bedingungen) deduktiv folgt. Dies dürfte jedoch für die gängigen epistemischen Verfahren, mit deren Hilfe man üblicherweise Überzeugungen über Beobachtbares gewinnt, tatsächlich selten oder nie der Fall sein. Über die Mechanismen der visuellen Wahrnehmung ist Einiges bekannt ${ }^{81}$, über die des induktiven Schließens etc. nicht viel Genaues, in jedem Fall aber dürfte es nicht für deduktive Schlüsse auf Verläßlichkeitsüberzeugungen ausreichen. ${ }^{82}$

Auf die Frage nach direkten Rechtfertigungsgründen für Herkunftsüberzeugungen (die ihrerseits als Rechtfertigungsgründe für Überzeugungen erster Ordnung über Beobachtbares fungieren können) dürfte sich ebenfalls in vielen Fällen kaum oder nur schwer eine präzise Antwort geben lassen, die sich auf die Erzeugung der jeweiligen Herkunftsüberzeugung bezieht. Es scheint, daß Menschen im allgemeinen so "konstruiert" sind, daß ihnen ihr

\footnotetext{
${ }^{80}$ Siehe S.452.

${ }^{81}$ Wenn auch i.a. nur Experten, nicht jedem, der sich auf seinen Wahrnehmungsapparat verläßt.

${ }^{82}$ Die Frage nach Rechtfertigungsgründen für Verläßlichkeitsüberzeugungen stellt sich für deduktive Inferenzregeln oder -verfahren, z.B. für Modus ponens, genauso wie für induktive Inferenzregeln und Erzeugungsverfahren, obwohl deduktive Inferenzverfahren prima facie vielleicht "unproblematischer" aussehen. Die Literatur zu dieser sehr grundlegenden Frage (siehe u.a. [Haac76] und Referenzen dort, [Feig50c], [Carn68], S.265f.) kann hier nicht diskutiert werden. Um plausibel zu machen, daß die Antwort darauf keineswegs trivial oder unproblematisch ist, reicht es aber, sich etwa am Beispiel von Modus ponens vor Augen zu führen, daß zum einen induktive Rechtfertigungsgründe für die Verläßlichkeit dieser Inferenzregel von vielen intuitiv als nicht zufriedenstellend und "zu schwach" angesehen werden, und daß zum anderen die Begründung, die in Logiklehrbüchern üblicherweise für deren Verläßlichkeit gegeben wird (Stichwort: Korrektheits- bzw. Adäquatheitsbeweis), ihrerseits eine deduktive ist, d.h. nach deduktiven Schlußregeln — inklusive Modus ponens — von den Prämissen zur Konklusion übergeht (zum damit genannten Problem der Zirkularität von Rechtfertigungsgründen siehe die folgenden Abschnitte).
} 
Wahrnehmungsapparat bewußtes Wahrnehmen ermöglicht, d.h. u.a., daß er nicht nur Überzeugungen erster Ordnung erzeugt, sondern gleichsam automatisch auch Herkunftsüberzeugungen für diese: Wenn ich einen Blick auf die Fensterbank vor meinem Fenster werfe, entsteht in mir nicht nur die Überzeugung, daß dort eine Katze sitzt, sondern gleichzeitig die Überzeugung (zweiter Ordnung), daß ich sehe, daß dort eine Katze sitzt. Entsprechend scheint es bei deduktiven und induktiven Schlüssen zumindest bei Personen, die hinreichend in Logik "trainiert" sind, so zu sein, daß ihr kognitiver Apparat ihnen bei bewußt ausgeführten Schlüssen nicht nur eine Überzeugung liefert, die die Konklusion zum Inhalt hat, sondern zusätzlich eine Herkunftsüberzeugung, die das verwendete Inferenzverfahren (mehr oder weniger genau) spezifiziert. Diese Eigenschaft des (hinreichend trainierten) menschlichen kognitiven Apparates könnte sich vielleicht als epistemisches Verfahren (oder mehrere) beschreiben lassen, das bei bewußtem Beobachten, deduktivem Schließen etc. zum Einsatz kommt; die meisten Menschen dürften jedoch keine expliziten Überzeugungen zu der Frage haben, wo ihre Herkunftsüberzeugungen herkommen. Eine andere Möglichkeit, eine Herkunftsüberzeugung für eine bestimmte Überzeugung erster Ordnung $\mathrm{zu}$ erzeugen oder zu stabilisieren, und dementsprechend auch eine andere Möglichkeit, die Frage nach Rechtfertigungsgründen für diese Herkunftsüberzeugung zu beantworten, bieten induktive Schlüsse: Wenn ich genügend viele "ähnliche", "gleichartige" Überzeugungen (erster Ordnung) durch ein bestimmtes epistemisches Verfahren gewonnen habe und ich auch entsprechende Herkunftsüberzeugungen habe, könnte dies einen induktiven Schluß gestatten, daß eine bestimmte weitere "ähnliche", "gleichartige" Überzeugung (erster Ordnung) ebenfalls durch dasselbe Verfahren gewonnen wurde. Ein Nachteil von Rechtfertigungsgründen dieser Art für eine Herkunftsüberzeugung ist, daß mit ihnen die Probleme induktiver Schlüsse verbunden sind; ein Vorteil ist, daß sie grundsätzlich auch bei unbewußten Beobachtungen, unbewußt ausgeführten Schlüssen etc. gegeben werden können. ${ }^{83}$

Die bisher erwähnten epistemischen Verfahren bilden offenbar keine vollständige Liste, d.h. grundsätzlich können Überzeugungen der verschiedenen Arten auch durch andere epistemische Verfahren als die erwähnten erzeugt oder stabilisiert werden und entsprechende Herkunfts- und Verläßlichkeitsüberzeugungen (plus evtl. erforderliche Prämissen) als direkte Rechtfertigungsgründe für die erzeugten bzw. stabilisierten Überzeugungen fungieren. Weitere Erzeugungsverfahren, die hier in Frage kommen, sind etwa der Gebrauch von Tast- oder Hörsinn (unter bestimmten Bedingungen etc.), weitere Übertragungsverfahren (neben den genannten deduktiven und induktiven Inferenzverfahren) sind z.B. Versionen des Schließens auf die beste Erklärung ${ }^{84}$ und Schemata für induktive Extrapolationsschlüsse $^{85}$. Bemerkenswert, weil aus reliabilistischer Perspektive prima facie unerwartet, ist vielleicht, daß auch Übertragungsverfahren möglich sind, die (hinreichende) direkte Rechtfertigungsgründe für Überzeugungen liefern, die den Output von epistemischen Verfahren darstellen, die nicht (hinreichend) verläßlich sind oder über deren Verläßlichkeit jedenfalls nichts Genaues bekannt ist: Ein wenigstens prima facie plausibles Verfahren dieser Art ist

\footnotetext{
${ }^{83}$ Ein Beispiel: Wenn ich mich während einer langen, routinemäßigen Autofahrt nach Rechtfertigungsgründen für meine Überzeugung frage, daß ich gesehen habe, daß die für mich relevante Ampel an der vorletzten Kreuzung grünes Licht gezeigt hat, obwohl ich, wie meistens bei langweiligen Routinefahrten, mit den Gedanken bei anderen Dingen war und in diesem Sinn die Ampel nicht bewußt wahrgenommen habe, kommt als Antwort offenbar nur eine induktiv erschlossene Überzeugung in Frage: Ich nehme an, daß meine Überzeugung über die fragliche Ampel genauso zustandegekommen ist wie meine meisten anderen "ähnlichen" Überzeugungen über Ampeln o.ä.

${ }^{84}$ Siehe Abschnitt 8.3.5, s.a. Kap.9.

${ }^{85}$ Siehe Abschnitt 8.3.3.
} 
eins, das (innerhalb eines bestimmten Gegenstandsbereichs, unter bestimmten Bedingungen u.ä.) einen Schluß auf eine Überzeugung, daß $P$, gestattet, wenn mehrere voneinander unabängige epistemische Verfahren, die nicht (hinreichend) verläßlich sind oder über deren Verläßlichkeit nichts Genaues bekannt ist, einen übereinstimmenden Output liefern, der besagt, daß $P$. Ein solches Verfahren könnte beispielsweise zur Anwendung kommen, wenn ein Richter zu einer bestimmten, für einen Prozeß relevanten Überzeugung gelangt, weil mehrere voneinander unabhängige Zeugen übereinstimmend eine entsprechende Beobachtung berichtet haben, und zwar Zeugen, die einzeln als nicht hinreichend verläßlich eingeschätzt werden oder deren Verläßlichkeit kaum eingeschätzt werden kann. ${ }^{86}$

Indirekte Rechtfertigungsgründe und die Gesamtheit der Rechtfertigungsgründe für eine einzelne Überzeugung Wenn man die reliabilistische Konzeption von Rechtfertigungsgründen voraussetzt, besagt die Tatsache, daß man über hinreichende direkte Rechtfertigungsgründe für eine Überzeugung verfügt, nichts darüber, ob diese Rechtfertigungsgründe ihrerseits gerechtfertigt sind ${ }^{87}$ Wenn von diesen Rechtfertigungsgründen (wenigstens) einer falsch ist, wird aber durch die Tatsache, daß man über diese Rechtfertigungsgründe für eine Überzeugung verfügt, natürlich nicht sichergestellt, daß die Überzeugung tatsächlich gerechtfertigt ist (und damit zumindest wahrscheinlich wahr). Diese Überlegung legt es vielleicht nahe, daß man sich, wenn man sich in interner Reflexion Rechenschaft über den epistemischen Status einer eigenen Überzeugung ablegt und hinreichende direkte Rechtfertigungsgründe für diese Überzeugung gefunden hat, nicht mit diesem Ergebnis zufriedengibt, sondern auch für die aufgewiesenen (direkten) Rechtfertigungsgründe ihrerseits nach Rechtfertigungsgründen sucht, also nach indirekten Rechtfertigungsgründen für die Überzeugung, bei der die Untersuchung begonnen hat.

Wenn man solche (indirekten) Rechtfertigungsgründe findet, läßt sich die obige Überlegung jedoch auch auf diese (indirekten) Rechtfertigungsgründe anwenden. Wenn man daraufhin auch für diese Rechtfertigungsgründe ihrerseits weitere hinreichende Rechtfertigungsgründe sucht und findet, kann man wiederum fragen, ob letztere gerechtfertigt sind, usw. Die Frage nach Rechtfertigungsgründen läßt sich offenbar iterieren.

Wohin führen Überlegungen dieser Art? Wie weit kann man die beschriebene Strategie sozusagen treiben, die Frage nach Rechtfertigungsgründen immer wieder zu iterieren? ${ }^{88}$

Klar ist aus reliabilistischer Perspektive zunächst, daß sich keine "unhinterfragbaren" Überzeugungen finden lassen, also keine Überzeugungen, bei denen sich die Frage nach Rechtfertigungsgründen nicht mehr stellen läßt, und die deswegen als Fundament oder als "natürliche" Anfangspunkte für Ketten von Rechtfertigungsgründen fungieren könnten. Daß man für eine Überzeugung tatsächlich keine Rechtfertigungsgründe findet (oder zumindest keine hinreichenden), ist selbstverständlich möglich, aber die Frage, ob sie durch ein verläßliches Verfahren erzeugt wurde oder stabilisiert wird (und somit wahrscheinlich wahr ist), läßt sich offenbar für jede Überzeugung stellen. Insbesondere gilt dies auch für

\footnotetext{
${ }^{86}$ In einem solchen Fall könnte man evtl. auch eine Version des Schließens auf die beste Erklärung oder eine Version des Prinzips der gemeinsamen Ursache ins Spiel bringen (vgl. Abschnitt 8.3.4), dies ist jedoch nicht zwingend. Es sind klarerweise auch Inferenzverfahren möglich, die bei übereinstimmendem Output mehrerer unabhängiger epistemischer Verfahren einen Schluß auf den Inhalt dieses Outputs gestatten, ohne auf Erklärungen, Ursachen, Kausalprozesse etc. Bezug zu nehmen; dies deutet Hacking an (vgl. S.327) und auch Wimsatt in [Wims81].

${ }^{87}$ Siehe S.457.

${ }^{88}$ Die Frage nach Umfang und Struktur der Gesamtheit reliabilistischer Rechtfertigungsgründe erörtert Ernest Sosa in [Sosa95], S.226ff.; an dessen Ausführungen lehnt sich das Folgende an. Eine eingehende Diskussion derselben Frage liefert William Alston in [Alst86].
} 
Überzeugungen, die durch Beobachten mit dem bloßen Auge gewonnen wurden. ${ }^{89}$ Es kann daher, gegeben, daß menschliche Gehirne nur endlich groß sind, und ein Mensch daher nur endlich viele Überzeugungen haben kann, offenbar zweierlei passieren, wenn man sich, ausgehend von einer einzelnen Überzeugung, in interner Reflexion nach Rechtfertigungsgründen für diese Überzeugung fragt und die Frage immer wieder iteriert, also bei jeder als Rechtfertigungsgrund in Anspruch genommenen Überzeugung deren Rechtfertigungsgründe zurückverfolgt: Es können Zirkel auftreten, d.h. Konstellationen, in denen man beim sukzessiven Zurückverfolgen von Rechtfertigungsgründen irgendwann eine Überzeugung erreicht, die schon vorher einmal in der bis dahin durchlaufenen Kette von Rechtfertigungsgründen vorgekommen ist, und man kann auf offene Enden stoßen, d.h. auf Überzeugungen, für die sich im Gesamtsystem der eigenen Überzeugungen keine (hinreichenden) Rechtfertigungsgründe mehr finden. Da für eine Überzeugung stets zwei oder mehr andere Überzeugungen als (hinreichende) direkte Rechtfertigungsgründe fungieren, ergibt das iterative Zurückverfolgen aller Rechtfertigungsgründe einer bestimmten einzelnen Überzeugung i.a. eine verzweigte Struktur, in mathematischer Terminologie ausgedrückt: einen Graphen, dessen Knoten Überzeugungen und dessen Kanten Rechtfertigungsrelationen darstellen. Wenn man in einem solchen "Rechtfertigungsgraphen" einer Überzeugung deren Rechtfertigungsgründen in der Weise nachgeht, daß man an jedem Verzweigungspunkt nur einem der Zweige, sprich: der Rechtfertigungsgründe, folgt, findet man als Teilstruktur des gesamten Graphen einen der beiden genannten Fälle, eine Kette mit offenem Ende oder

\footnotetext{
${ }^{89}$ Ebenso gilt es grundsätzlich auch für Überzeugungen, die traditionell häufig als apriori eingestuft werden, etwa für Überzeugungen über mathematische Gegenstände und Sachverhalte, denn auch solche Überzeugungen werden offenbar irgendwie erzeugt bzw. stabilisiert, etwa durch eine Art Vermögen rationaler Intuition o.ä., dessen Verläßlichkeit man hinterfragen kann.

Eine Ausnahme könnten allerdings Überzeugungen bilden, deren Inhalt durch analytisch wahre Sätze gegeben ist. Einen Satz als analytisch wahr zu akzeptieren setzt voraus, daß man eine Beschreibungstheorie der Bedeutung bzw. Referenz akzeptiert (genauer: eine Beschreibungstheorie, nach der jeder kompetente Sprecher die Bedeutung kennen muß, vgl. S.40); die analytisch wahren Sätze sind typischerweise Allsätze wie 'Alle Junggesellen sind unverheiratet', 'Für alle Menschen $X$ und $Y$ gilt: Wenn $X$ die Mutter von $Y$ ist, dann ist $Y$ die Tochter von $X^{\prime}$ u.ä. Damit Überzeugungen, die solchen analytischen Sätzen entsprechen, tatsächlich eine Ausnahme darstellen, ist weiterhin Voraussetzung, daß die Regeln, nach denen man Konflikte innerhalb des eigenen Überzeugungssystems beseitigt (vgl. S.451), die "Eigenschaft" haben, die Überzeugungen "mit analytischem Inhalt", niemals und unter keinen Umständen aufzugeben, komme, was da wolle - ansonsten könnte man offenbar (Quines bekannter Argumentation folgend) nach Gründen für das Beibehalten bzw. Aufgeben solcher Überzeugungen bei Konflikten mit anderen, insbesonder neu gewonnenen Überzeugungen fragen, und es bestünde kein ersichtlicher Unterschied mehr zwischen solchen Gründen und "gewöhnlichen" epistemischen Rechtfertigungsgründen. Wenn beide Voraussetzungen erfüllt sind, können Überzeugungen mit analytischem Inhalt offensichtlich als Anfangspunkte von Ketten von Rechtfertigungsgründen fungieren, für die ihrerseits keine Rechtfertigungsgründe mehr angegeben werden können und brauchen (bzw., wenn man als Rechtfertigungsgrund für eine Überzeugung mit analytischem Inhalt noch die Überzeugung (zweiter Ordnung) angibt, daß erstere analytisch ist, dann fungiert letztere als Anfangspunkt).

Auch dann, wenn Überzeugungen mit analytischem Inhalt in einem Überzeugungssystem als Anfangspunkte von Rechtfertigungsketten fungieren, sind sie für das Gesamtbild, das dieses Überzeugungssystem im Hinblick auf den epistemischen Status seiner Elemente bietet, typischerweise nur von untergeordneter Bedeutung, denn zum einen ist es natürlich möglich, daß sich für eine Überzeugung dieser Art auch andere, zusätzliche Rechtfertigungsgründe anführen lassen (etwa deduktive oder induktive Schlüsse, die von Prämissen ausgehen, die erst nach dem Erwerb der Überzeugung mit dem analytischen Inhalt gewonnen wurden), zum anderen gibt es auch in einem Überzeugungssystem mit "analytischen Anfangspunkten" Rechtfertigungspfade, die in offene Enden oder in Zirkel laufen (schon deswegen, weil die bedeutungskonstituierenden Sätze Allsätze sind, aus denen allein sich keine singulären und Existenzsätze folgern lassen). Für die folgenden Überlegungen hängt daher nichts Wesentliches davon ab, ob es solche analytischen Anfangspunkte gibt; daher wird dieser, ohnehin nur im Zusammenhang mit Beschreibungstheorien relevante Punkt im folgenden vernachlässigt.
} 
einen Zirkel. In beiden Fällen ist die Suche nach Rechtfertigungsgründen damit offenbar an ein Ende gekommen. Wenn man ein solches Ende als unbefriedigend empfindet, kann man natürlich nach neuen, bisher nicht bekannten Rechtfertigungsgründen suchen und "im Erfolgsfall" dem eigenen Überzeugungssystem entsprechende Überzeugungen hinzufügen. Man wird diese Suche bzw. die Ergänzung des eigenen Überzeugungssystems jedoch (aus praktischen Gründen oder jedenfalls, weil das menschliche Gehirn nur endlich groß ist) irgendwann abbrechen müssen, und für das erweiterte Überzeugungssystem gilt dann offenbar dasselbe wie für das vorherige: Ein Pfad durch einen Rechtfertigungsgraphen läuft irgendwann entweder in ein offenes Ende oder in einen Zirkel.

Der erstere der beiden Fälle, der eines offenen Endes, tritt z.B. dann auf, wenn man im Rechtfertigungsgraphen einer Überzeugung einen Pfad verfolgt, der jeweils von einer Überzeugung zu der als Rechtfertigungsgrund für sie fungierenden Herkunftsüberzeugung führt. Dabei stößt man typischerweise spätestens nach wenigen Schritten auf ein offenes Ende, und irgendwann muß man offenbar sogar auf ein solches Ende stoßen, denn man kann, vorausgesetzt die Gesamtzahl der Überzeugungen jedes Menschen ist endlich, nicht zu jeder Überzeugung eine weitere Herkunftsüberzeugung haben.

Der zweite Fall, der eines Zirkels, tritt z.B. häufig dann auf, wenn man in einem Rechtfertigungsgraphen einen Pfad verfolgt, der von einer Überzeugung erster Ordnung zu der Verläßlichkeitsüberzeugung führt, die als (ein) Rechtfertigungsgrund fungiert, von dort weiter zu einem der Rechtfertigungsgründe dieser Verläßlichkeitsüberzeugung usw. und der dabei durch "genügend viele" Verläßlichkeitsüberzeugungen läuft. Vorausgesetzt, daß die Anzahl epistemischer Verfahren, die ein Mensch zur Gewinnung und Stabilisierung seiner Überzeugungen verwendet, endlich ist, muß auf einem solchen Pfad früher oder später (mindestens) ein epistemisches Verfahren, genauer: eine diesbezügliche Verläßlichkeitsüberzeugung, doppelt auftreten, sofern dieser Pfad nicht vorher in ein offenes Ende läuft. Wenn man auf einem solchen Pfad die Rechtfertigungsgründe für die Verläßlichkeitsüberzeugung für das doppelt auftretende epistemische Verfahren zurückverfolgt, findet man also, daß man irgendwann diese Verläßlichkeitsüberzeugung selbst als Rechtfertigungsgrund in Anspruch nimmt.

Daß man tatsächlich häufig auf Zirkel dieser Art stößt, wenn man die Rechtfertigungsgründe für eine Überzeugung iterativ zurückverfolgt, läßt sich anhand konkreter Fälle illustrieren, etwa anhand des oben genannten Beispiels ${ }^{90}$ : Wenn ich nach Rechtfertigungsgründen für meine Überzeugung suche, daß auf der Fensterbank vor meinem Fenster eine Katze sitzt, ist die Antwort, daß ich dies gesehen habe, meine Überzeugung also durch Beobachten mit dem bloßen Auge bei Tageslicht und ansonsten guten Sichtverhältnissen aus einer Entfernung von wenigen Metern erzeugt wurde, und daß das Beobachten unter solchen Bedingungen ein verläßliches Verfahren ist um Katzen, Hunde, Vögel u.ä. Tiere zu erkennen. Wenn ich weiter nach Rechtfertigungsgründen für diese Verläßlichkeitsüberzeugung frage, ist eine mögliche Antwort die, daß sie stabilisiert wird durch einen induktiven Schluß wie den oben ${ }^{91}$ skizzierten: Ich habe eine Reihe von Überzeugungen (erster Ordnung) über Katzen, Hunde, Vögel etc. und außerdem auch entsprechende Überzeugungen (zweiter Ordnung), daß ich die ersteren Überzeugungen durch Beobachten bei Tageslicht etc. gewonnen habe; diese lassen möglicherweise einen induktiven Schluß auf die Konklusion zu, daß das Beobachten bei Tageslicht etc. ein verläßliches Verfahren ist. Ein Zirkel kann bereits auftreten, wenn ich an dieser Stelle weiter nach Rechtfertigungsgründen für die als Prämissen fungierenden Überzeugungen (erster Ordnung) über Katzen, Hunde etc. suche:

\footnotetext{
${ }^{90}$ Siehe S.462.

${ }^{91} \mathrm{~S} .463$.
} 
Wenn ich als Rechtfertigungsgründe für diese Prämissen angebe, daß ich sie durch Beobachten gewonnen habe, und daß Beobachten ein verläßliches Verfahren ist, dann hat sich bereits an dieser Stelle ein Zirkel von Rechtfertigungsgründen geschlossen: Der Rechtfertigungsgraph für die Verläßlichkeitsüberzeugung für das Beobachten bei Tageslicht etc. führt dann bereits nach zwei Schritten zu der Verläßlichkeitsüberzeugung selbst zurück. Denkbar ist jedoch auch, daß ich (zusätzliche) andere Rechtfertigungsgründe für die Prämissen des induktiven Schlusses zur Verfügung habe: Z.B. könnte ich zumindest einige der Prämissen durch Einsatz meines Tastsinnes stabilisiert haben (d.h. mich mit dessen Hilfe zumindest in einigen Fällen vergewissert haben, daß sich dort eine Katze, ein Hund etc. befindet, wo ich eine bzw. einen sehe), und außerdem überzeugt sein, daß mein Tastsinn (unter bestimmten Bedingungen) verläßlich ist. Eine andere Möglichkeit ist, daß zumindest einige der Prämissen dadurch stabilisiert wurden, daß mir eine andere Person, die ich für einen verläßlichen Beobachter halte, übereinstimmende Beobachtungen berichtet. Wenn ich weiter nach Rechtfertigungsgründen für die letzteren Verläßlichkeitsüberzeugungen suche, und wiederum ein induktives Argument der skizzierten Art finde, dessen Prämissen durch Beobachten erzeugt wurden, dann schließt sich an dieser Stelle ein Zirkel von Rechtfertigungsgründen, der etwas größer ist als der erste, oben erwähnte.

Allgemein ist es so, daß man sich bei der Suche nach Rechtfertigungsgründen mit "sehr kleinen" Zirkeln, also mit solchen, die sich — wie der oben beschriebene — schon nach zwei Schritten schließen, dann nicht zufriedengeben muß, wenn man nach Rechtfertigungsgründen für Überzeugungen sucht, die Gegenstandsbereiche betreffen, die durch zwei oder mehr verläßliche epistemische Verfahren zugänglich sind (im Beispiel: Sehsinn und Tastsinn). In solchen Fällen kann nämlich eine Verläßlichkeitsüberzeugung für eines der Verfahren mit Hilfe des Outputs eines anderen Verfahrens erzeugt bzw. stabilisiert werden. Dies ändert jedoch nichts daran, daß aus dem oben genannten allgemeinen Grund jeder Pfad durch einen Rechtfertigungsgraphen irgendwann in einen (größeren) Zirkel laufen muß, wenn er nicht vorher in ein offenes Ende führt.

Die Gesamtheit der (direkten und indirekten) Rechtfertigungsgründe einer Überzeugung, sprich: ihr Rechtfertigungsgraph, enthält also an offenen Enden abbrechende Pfade und - typischerweise - Zirkel als Teilstrukturen. Diese Teilstrukturen sind offenbar mehr oder weniger eng miteinander vernetzt, weil eine Überzeugung als (hinreichende) Rechtfertigungsgründe stets mehrere andere Überzeugungen benötigt und weil eine Überzeugung darüber hinaus i.a. mehrere, voneinander unabhängige (jeweils hinreichende) Mengen von direkten Rechtfertigungsgründen haben kann ${ }^{92}$ und häufig auch hat. ${ }^{93}$

Schwache Gründe für eine Überzeugung und Rechtfertigungsgründe für Mengen von epistemisch zusammenhängenden Überzeugungen Daß eine Überzeugung einen direkten Rechtfertigungsgrund für die Überzeugung, daß $P$, darstellt, heißt gemäß der reliabilistischen Konzeption, daß aus der ersteren Überzeugung zusammen mit anderen Überzeugungen die Überzeugung (zweiter Ordnung) folgt, daß die Überzeugung, daß $P$, gerechtfertigt ist. Ein solcher direkter Rechtfertigungsgrund ist, wie erörtert,

\footnotetext{
${ }^{92}$ Da eine Überzeugung nur einmal, also nur durch ein epistemisches Verfahren erzeugt worden sein kann, müssen dann weitere, unabhängige Mengen von direkten Rechtfertigungsgründen offenbar Verfahren involvieren, die die Überzeugung stabilisiert, nicht (nochmals) erzeugt haben.

${ }^{93}$ Ein Beispiel für solche voneinander unabhängigen (hinreichenden) Mengen von direkten Rechtfertigungsgründen für dieselbe Überzeugung: Meine Überzeugung, daß auf der Fensterbank vor meinem Fenster seit mehreren Stunden eine Katze sitzt, habe ich durch Beobachten gewonnen, aber sie wird außerdem stabilisiert durch einen induktiven Schluß, ausgehend von den Prämissen, daß gestern um dieselbe Zeit eine Katze dort gesessen hat, ebenso vorgestern und jeden Tag in den letzten Wochen.
} 
typischerweise eine Überzeugung erster Ordnung, eine Herkunfts- oder eine Verläßlichkeitsüberzeugung. Intuitiv kann eine Überzeugung jedoch auch dann relevant sein für die Beurteilung des epistemischen Status einer anderen Überzeugung, wenn sie keinen solchen direkten (und auch keinen indirekten) Rechtfertigungsgrund für letztere darstellt, oder dies zumindest prima facie nicht zu tun scheint: Intuitiv kann durch eine Überzeugung auch so etwas wie ein (mehr oder weniger) schwaches Indiz oder ein nicht hinreichender Grund für eine andere Überzeugung gegeben sein; in solchen Fällen soll der Kürze halber im folgenden von einem schwachen Grund für eine Überzeugung die Rede sein.

Daß eine Überzeugung intuitiv einen schwachen Grund für die Überzeugung, daß $P$, darstellt, kann Verschiedenes heißen: Ein schwacher Grund kann darin bestehen, daß die Überzeugung, daß $P$, durch ein Verfahren gewonnen wurde oder werden kann, das mit mehr oder weniger hoher Wahrscheinlichkeit wahren Output liefert, aber nicht mit so hoher Wahrscheinlichkeit, daß es als verläßlich gelten kann. Eine andere Art schwacher Grund für die Überzeugung, daß $P$, ist intuitiv dann gegeben, wenn eine andere Überzeugung eine mehr oder weniger enge Schranke, einen constraint o.ä. für sie darstellt, die bzw. den die Überzeugung, daß $P$, erfüllen muß, wenn also mögliche Alternativen zu $P$ ausgeschlossen werden: Eine Alternative ist im einfachsten Fall $\neg P$; wenn $P$ etwa besagt, daß ein bestimmter Gegenstand rot ist, ist jeder Satz, der diesem Gegenstand eine andere Farbe zuschreibt, eine Alternative, wenn $P$ besagt, daß ein Gegenstand eine bestimmte Größe hat, ist jeder Satz, der ihm eine andere Größe zuschreibt, eine Alternative usw. Gleichsam der Grenzfall dieses Typs eines schwachen Grundes liegt vor, wenn eine Überzeugung sowohl mit der Überzeugung, daß $P$, als auch als auch mit allen Alternativen verträglich ist, also keine der Alternativen ausgeschlossen wird. Solche "bloße" Konsistenz einer Überzeugung mit der Überzeugung, daß $P$, läßt sich intuitiv vielleicht insofern als schwacher Grund für letztere auffassen, als ihr die andere Überzeugung immerhin nicht widerspricht. ${ }^{94}$ Eine weitere denkbare Art schwacher Gründe sind "kombinierte" Fälle, in denen Alternativen "nur" mit mehr oder weniger hoher Wahrscheinlichkeit ausgeschlossen werden, und vielleicht lassen sich auch noch andersartige schwache Gründe aufweisen.

Zumindest prima facie plausible Beispiele für schwache Gründe lassen sich leicht finden: Wenn mir mein Hörsinn (nicht mein Sehsinn) die Überzeugung (bzw. die Vermutung) liefert, daß auf der Fensterbank vor meinem Fenster seit mehreren Stunden eine Katze sitzt, und erfahrungsgemäß das Hören (unter den vorliegenden Bedingungen etc.) ein nur mäßig verläßliches Verfahren ist, eine Überzeugung über Sachverhalte dieser Art zu gewinnen, ist damit intuitiv immerhin ein schwacher Grund für eine entsprechende Überzeugung gegeben (wenn auch kein hinreichender Rechtfertigungsgrund). Einen schwachen (jedoch nicht hinreichenden) Grund für meine Überzeugung, daß es draußen genau -10 Grad Celsius kalt ist, stellt intuitiv meine andere Überzeugung dar, daß die Temperatur draußen unter dem Gefrierpunkt liegt (die ihrerseits etwa durch die Beobachtung gefrorener Pfützen auf der Straße gestützt wird), denn letztere Überzeugung bildet einen constraint für erstere. Sherlock Holmes' Überzeugung, daß der Mörder eine sehr große und kräftige Person war, die die ganze Nacht über im Schloß war, schränkt den Kreis der Verdächtigen auf drei Personen ein und liefert damit intuitiv einen schwachen Grund für seine Überzeugung (bzw. Vermutung), daß es der Butler war. Wenn ich für eine Verläßlichkeitsüberzeugung bezüglich eines bestimmten epistemischen Verfahrens, etwa das Beobachtens mit dem blo-

\footnotetext{
${ }^{94}$ Intuitiv ist dies insbesondere dann ein schwacher Grund, wenn nicht nur eine andere Überzeugung konsistent mit der Überzeugung, daß $P$, ist, sondern zugleich ein ganzes umfangreiches, viele verschiedene Gebiete abdeckendes Überzeugungssystem, das sozusagen leicht in einen Widerspruch zu einer zusätzlichen Überzeugung geraten kann.
} 
ßen Auge (unter bestimmten Bedingungen etc.) oder meines Hörsinns, einen induktiven Schluß der oben ${ }^{95}$ skizzierten Art anführen kann, und Induktionsschlüsse dieser Art für nur mäßig verläßlich halte, stellt dies intuitiv immerhin einen schwachen Grund für die Verläßlichkeitsüberzeugung dar. Andere schwache Gründe für diese Verläßlichkeitsüberzeugungen bezüglich meines Seh- und Hörsinnes sind intuitiv durch die Überzeugungen gegeben, die ich über Licht bzw. Schall und deren Verhalten, die Mechanismen ihrer Ausbreitung sowie über die Funktionsweise des Seh- bzw. Hörsinns habe: Aus letzteren folgen zwar keine Verläßlichkeitsüberzeugungen, aber sie sind mit solchen zumindest konsistent und sie stellen auch bestimmte constraints für sie dar, insofern sie etwas darüber implizieren, unter welchen Bedingungen Seh- bzw. Hörsinn nicht funktionieren bzw. verläßlich sein können. ${ }^{96}$

Auf welche Weise oder in welcher Hinsicht können schwache Gründe aus reliabilistischer Perspektive relevant sein für die Beurteilung des epistemischen Status einer Überzeugung? Auf den ersten Blick scheint es so auszusehen, als könnten schwache Gründe - den genannten Intuitionen zum Trotz — für die Rechtfertigung einer Überzeugung keine Rolle spielen: Entweder man hat für eine Überzeugung hinreichende direkte Rechtfertigungsgründe, ${ }^{97}$ also typischerweise eine Herkunfts- und eine Verläßlichkeitsüberzeugung und, sofern das epistemische Verfahren ein Inferenzverfahren war, als Prämissen fungierende Überzeugungen erster Ordnung, oder man hat keine solchen hinreichenden Rechtfertigungsgründe. Wenn man welche hat, scheint aus reliabilistischer Perspektive betrachtet für (zusätzliche) schwache Gründe keine rechte Funktion zu bleiben; wenn man keine hat, scheint nicht recht zu sehen zu sein, was schwache Gründe in epistemischer Hinsicht wert sein sollten. ${ }^{98}$ Bei etwas genauerer Betrachtung ist jedoch nicht schwer zu erkennen, daß dieser Eindruck täuscht, und daß schwache Gründe auch unter Voraussetzung einer reliabilistischen Position etwas zur Rechtfertigung von Überzeugungen beitragen können.

In einem weiten Sinn können schwache Gründe in mindestens zweierlei Weise relevant sein für die Beurteilung des epistemischen Status einer Überzeugung: Zum einen ist Konsistenz mit dem Rest des eigenen Überzeugungssystems i.a. auch für Reliabilisten Bedingung, um eine Überzeugung beizubehalten, d.h. auch Reliabilisten beseitigen i.a. Inkonsistenzen in ihrem Überzeugungssystem, ${ }^{99}$ und berücksichtigen damit effektiv eine der genannten Arten schwacher Gründe. Zum anderen könnten schwache Gründe für eine Überzeugung zusammen mit anderen schwachen Gründen, die man möglicherweise in Zukunft gewinnt, dann hinreichende Rechtfertigungsgründe "der üblichen Art" für eine Überzeugung darstellen. ${ }^{100}$ Beides ergibt aber klarerweise keine "positiven" Rechtfertigungsgründe, die man als Reliabilist (aktuell) für eine Überzeugung anführen kann, wenn

\footnotetext{
${ }^{95}$ S.463.

${ }^{96} \mathrm{Daß}$ dies intuitiv relevant für die Beurteilung des epistemischen Status der Verläßlichkeitsüberzeugungen zu sein scheint, gewinnt vielleicht an Plausibilität, wenn man sich vor Augen führt, daß für "epistemische Verfahren" wie Gedankenlesen oder Horoskope auf astrologischer Basis keine analogen Konsistenzbedingungen bzw. constraints vorliegen, da in diesen Fällen keine Überzeugungen vorhanden sind, die zumindest grobe, qualitative Beschreibungen der diesen "epistemischen Verfahren" zugrundeliegenden Funktionsmechanismen beinhalten.

${ }^{97}$ Und außerdem vielleicht auch indirekte Rechtfertigungsgründe.

${ }^{98}$ Intuitiv scheint die Forderung plausibel, eine Überzeugung, für die man nur schwache Gründe hat, aufzugeben, etwa in dem obigen Beispiel mit Sherlock Holmes, dem man (sofern er keine anderen Rechtfertigungsgründe hat) nahelegen wird, seine Überzeugung aufzugeben bzw. die Vermutung fallenzulassen, daß der Butler der Mörder ist.

${ }^{99}$ Siehe S.450.

${ }^{100}$ Z.B. könnten mehrere constraints zusammen (jedoch nicht einzeln) eine eindeutig bestimmte Lösung einer Gleichung implizieren u.ä.
} 
man sich in interner Reflexion Rechenschaft über deren epistemischen Status ablegt. Genau diese Funktion als "positive" Rechtfertigungsgründe für eine Überzeugung können jedoch bei genauerem Hinsehen auch schwache Gründe der oben genannten Arten haben: Solche schwachen Gründe können als hinreichende direkte Rechtfertigungsgründe fungieren, und im vorletzten Abschnitt ist auch bereits ein Inferenzverfahren erwähnt worden, das schwache Gründe als Prämissen erfordert, und dessen Einsatz (wenn man es für verläßlich hält) hinreichende Rechtfertigungsgründe für eine Überzeugung liefert:101 Gegeben die Prämissen, daß,

1. mehrere voneinander unabhängige epistemische Verfahren übereinstimmend einen Output geben, der besagt, daß $P$, und daß

2. die Wahrscheinlichkeit, daß der Output dieser Verfahren wahr ist, jeweils (nur) mäßig hoch ist,

liefert dieses Inferenzverfahren die Konklusion, daß $P .{ }^{102}$ Schwache Gründe können also als hinreichende Rechtfertigungsgründe für eine Überzeugung fungieren, indem sie den Input für ein verläßliches Inferenzverfahren bilden, das diese Überzeugung als Output liefert. Dies gilt nicht nur für das genannte Inferenzverfahren, sondern es ist offenbar zumindest denkbar, daß sich auch andere (verläßliche) Inferenzverfahren finden lassen, die schwache Gründe als Prämissen einsetzen.

Solche anderen verläßlichen Inferenzverfahren tatsächlich aufzuweisen und in einigermaßen zufriedenstellender Weise zu spezifizieren, erweist sich als schwierig. Dennoch soll im folgenden versucht werden, ein solches Inferenzverfahren wenigstens zu skizzieren. Das Resultat wird nicht mehr als eine sehr grobe Umrißskizze sein, dem skizzierten Inferenzverfahren kommt aber dennoch zumindest eine gewisse Plausibilität zu, insofern sich einige, von vielen als intuitiv plausibel anerkannte konkrete "Einzelfälle" von Inferenzen angeben lassen, die (im Rahmen dessen, was sich bei den bestehenden Unschärfen sagen läßt) als Anwendungsfälle des skizzierten Inferenzverfahrens aufgefaßt werden können. ${ }^{103}$ Dieses Verfahren ist eines, das bei einer Anwendung nicht (wie die meisten bisher erwähnten Inferenzverfahren ${ }^{104}$ ) eine Überzeugung als Output liefert, sondern eine Menge "epistemisch zusammenhängender"105 Überzeugungen. Es konkretisiert damit die verbreitete Intuition, daß die "Kohärenz" einer Gesamtheit von Überzeugungen ein Indiz für deren Wahrheit darstellt. ${ }^{106}$ Dieses Inferenzverfahren soll trotz aller derzeit nicht behebbaren Ungenau-

\footnotetext{
${ }^{101}$ Siehe S.464.

${ }^{102}$ Der Anwendungsbereich dieses Inferenzverfahrens, die Bedingungen, unter denen es verläßlich ist, etc. sind natürlich erläuterungsbedürftig.

${ }^{103}$ S.u.

${ }^{104}$ Eine Ausnahme ist das Schließen auf die beste Erklärung, zumindest in einigen Varianten bzw. Anwendungsbereichen.

${ }^{105}$ S.u.

${ }^{106}$ Der Begriff der Kohärenz von Überzeugungen (bzw. Mengen von Überzeugungen) steht im Mittelpunkt kohärentistischer Positionen in der Erkenntnistheorie. Die Erläuterungen dafür, was Kohärenz ist, die sich bisher in der Literatur finden, sind notorisch unbefriedigend, dennoch wird er von den Anhängern kohärentistischer Positionen als verständlich genug betrachtet, um ihn schon jetzt ins Zentrum einer erkenntnistheoretischen Position zu stellen (vgl. etwa [Audi98], S.192ff., [BonJ85], Kap.5.3.). Das im folgenden grob skizzierte Inferenzverfahren sollte sich auffassen lassen als Beitrag zu einer genaueren Erläuterung des Begriffes der Kohärenz und vor allem auch der Intuition, daß Kohärenz ein Indiz für Wahrheit ist, vor einem reliabilistischen Hintergrund. In der Literatur ist zwar üblicherweise nur von Kohärenz zwischen Überzeugungen erster Ordnung die Rede, während aus reliabilistischer Perspektive auch Überzeugungen zweiter Ordnung, insbesondere Verläßlichkeitsüberzeugungen, eine Rolle spielen, darin sollte jedoch keine unüberwindliche Differenz liegen (vgl. dazu Sosas Konzeption von "broad coherence" oder "comprehensive coherence" in [Sosa91a, Sosa94b, Sosa95, Sosa97]).
} 
igkeiten wenigstens im groben Umriß skizziert werden, weil ihm eine wichtige Rolle zukommt — oder zumindest zukommen könnte, falls man es für verläßlich hielte und in zufriedenstellender Weise spezifizieren könnte -, wenn man in interner Reflexion nach Rechtfertigungsgründen für die eigenen Überzeugungen sucht. Die Rolle ist folgende.

Wenn man nicht nur nach direkten Rechtfertigungsgründen für die eigenen Überzeugungen sucht, sondern auch nach indirekten, also die Frage nach Rechtfertigungsgründen immer wieder iteriert, stößt man, wie vorne erörtert, irgendwann auf Zirkel und offene Enden. Daher kann es offenbar in einem Überzeugungssystem Teilmengen von Überzeugungen geben, die einen oder mehrere Zirkel einschließen, derart, daß zum einen für die Überzeugungen, die Element eines Zirkels sind, hinreichende direkte Rechtfertigungsgründe aufweisbar sind, die zumindest zum Teil innerhalb der Teilmenge liegen, daß zum anderen jedoch für keine der Überzeugungen in der Teilmenge hinreichende Rechtfertigungsgründe der bisher genannten Art ${ }^{107}$ aufweisbar sind, die ganz außerhalb der Teilmenge liegen. ${ }^{108}$ Man kann sich leicht überlegen, daß es ${ }^{109}$ keine solchen Teilmengen gibt, die für alle ihrer Elemente selbst hinreichende Rechtfertigungsgründe enthalten; es kann aber klarerweise Teilmengen eines Überzeugungssystems geben (und gibt es i.a. auch), für die gilt:

1. Für einen Teil ihrer Elemente, u.a. für die, die in einem Zirkel (oder in mehreren) liegen, gibt es hinreichende Rechtfertigungsgründe, die zumindest zum Teil in der Teilmenge selbst liegen.

2. Der Rest der Teilmenge besteht aus Überzeugungen, die offene Enden von Rechtfertigungsgraphen bilden.

3. Für keine der Überzeugungen in der Teilmenge gibt es hinreichende Rechtfertigungsgründe der bisher genannten Art, die ganz außerhalb der Teilmenge liegen.

Sofern es für die Elemente einer solchen Teilmenge also hinreichende Rechtfertigungsgründe (der bisher genannten Art) gibt, liegen diese (zumindest zum Teil) in der Teilmenge selbst, und ein Teil der Elemente einer solchen Teilmenge (nämlich diejenigen Elemente, die in einem Zirkel liegen) fungiert wechselseitig füreinander als Rechtfertigungsgründe. Eine solche Teilmenge besteht also aus (mehr oder weniger) "epistemisch zusammenhängenden" Überzeugungen, ist aber in dem Sinn vom Rest des gesamten Überzeugungssystems isoliert, daß sich außerhalb der Teilmenge für keines ihrer Elemente hinreichende Rechtfertigungsgründe (der bisher genannten Art) finden.

Wenn man nun in interner Reflexion nach (direkten und indirekten) Rechtfertigungsgründen für eine Überzeugung sucht, die Element einer solchen Teilmenge des eigenen Überzeugungssystems ist, stößt man also mehr oder weniger schnell auf offene Enden und/oder auf einen Zirkel oder ein System zusammenhängender Zirkel, aus dem sozusagen kein Weg hinaus zu außerhalb liegenden hinreichenden Rechtfertigungsgründen führt. Eine mögliche Reaktion darauf ist offenbar, sich damit nicht zufriedenzugeben, weil es zumindest

\footnotetext{
${ }^{107}$ D.h. Rechtfertigungsgründe, die die bisher genannten epistemischen Verfahren involvieren, die (mit Ausnahme des Schließens auf die beste Erklärung) jeweils eine einzelne Überzeugung als Output liefern.

${ }^{108}$ Daß hinreichende Rechtfertigungsgründe für eine Überzeugung "zum Teil" (oder "ganz") innerhalb bzw. außerhalb einer Teilmenge liegen, soll heißen, daß ein Teil der mehreren Überzeugungen, (oder alle Überzeugungen) die zusammen hinreichende Rechtfertigungsgründe für die eine fragliche Überzeugung darstellen, innerhalb bzw. außerhalb der Teilmenge liegen.

${ }^{109}$ Vorausgesetzt, daß hinreichende Rechtfertigungsgründe für eine Überzeugung stets durch mehrere andere Überzeugungen gegeben sind, und zwar durch eine Herkunfts- und eine Verläßlichkeitsüberzeugung plus evtl. Überzeugungen erster Ordnung.
} 
denkbar ist, daß die Überzeugungen der Teilmenge tatsächlich allesamt nicht gerechtfertigt (und sogar falsch) sind, obwohl sich zumindest ein Teil von ihnen (evtl. zusammen mit anderen Überzeugungen "von außerhalb") wechselseitig füreinander als Rechtfertigungsgründe anführen läßt. Da es nach Voraussetzung jedoch für keine der Überzeugungen der Teilmenge ganz außerhalb der Teilmenge liegende hinreichende Rechtfertigungsgründe der bisher genannten Art gibt ${ }^{110}$, scheint man hier zunächst vor einem unlösbaren Problem zu stehen. An dieser Stelle können nun schwache Gründe ins Spiel kommen und eine Rolle bei der Rechtfertigung einer solchen Teilmenge epistemisch zusammenhängender, aber im beschriebenen Sinn vom Rest des Überzeugungssystems isolierter Überzeugungen bekommen.

Schwache Gründe der einen oder anderen Art (also Überzeugungen zweiter Ordnung, daß ein mäßig verläßliches Verfahren eine bestimmte Überzeugung als Output ergibt, constraints u.ä.) lassen sich i.a. für viele oder sogar für die meisten Überzeugungen eines Überzeugungssystems aufweisen, insbesondere auch für Überzeugungen, die in den bisher erörterten Rechtfertigungsgraphen ein offenes Ende bilden oder Element eines Zirkels sind. Wesentlich im Hinblick auf das obige Problem ist, daß sich für die Elemente einer Teilmenge von (im erläuterten Sinn) epistemisch zusammenhängenden, aber vom Rest des Überzeugungssystems isolierten Überzeugungen häufig schwache Gründe aufweisen lassen, die außerhalb der Teilmenge liegen, und die auf diese Weise gleichsam für eine gewisse Anknüpfung dieser Teilmenge "nach außen" an das übrige Überzeugungssystem sorgen. Wenn man vor dem obigen Problem steht, sich also in interner Reflexion nach Rechtfertigungsgründen für alle Elemente einer Teilmenge von (im erläuterten Sinn) epistemisch zusammenhängenden, aber vom Rest des Überzeugungssystems isolierten Überzeugungen fragt, kann sich diese Frage mit Hilfe schwacher Gründe, die außerhalb der Teilmenge liegen, beantworten lassen. Sie läßt sich beantworten, wenn drei Voraussetzungen erfüllt sind: Die erste Voraussetzung ist, daß man ein Inferenzverfahren zur Verfügung hat und für verläßlich hält, das

1. die Prämisse, daß eine bestimmte "hinreichend große" und "geeignet zusammengesetzte" Menge von potentiellen Überzeugungen ${ }^{111}$ oder Überzeugungen intern "hinreichend gut" epistemisch zusammenhängt, und

2. "hinreichend viele" Überzeugungen, die nicht in dieser Menge liegen und "hinreichend gute" schwache Gründe für die Elemente der Menge darstellen, ${ }^{112}$

als Input benötigt, und als Output eine Menge von Überzeugungen liefert, die der in den Voraussetzungen erwähnten Menge von potentiellen Überzeugungen oder Überzeugungen entspricht bzw. mit ihr identisch ist. Die zweite Voraussetzung ist, daß man überzeugt ist, daß die in Frage stehende Teilmenge die in 1. genannten Bedingungen für die Anwendung des Inferenzverfahrens erfüllt. Die dritte Voraussetzung ist schließlich, daß man schwache Gründe für die Elemente der Teilmenge aufweisen kann, die die in 2. genannten Bedingungen erfüllen. Die Überzeugung, daß ein Inferenzverfahren dieser Art verläßlich ist, konkretisiert die Intuition, daß Kohärenz von (potentiellen) Überzeugungen (unter geeigneten Umständen) ein Indikator für deren Wahrheit ist, denn diese Überzeugung besagt,

\footnotetext{
${ }^{110}$ D.h. Rechtfertigungsgründe, die die bisher genannten epistemischen Verfahren involvieren.

${ }^{111}$ D.h. Propositionen, die man erwägt, untersucht u.ä., aber noch nicht als Überzeugung akzeptiert hat.

${ }^{112}$ Die Menge kann, muß aber nicht vom Rest des Überzeugungssystems isoliert sein, d.h. das hier skizzierte Inferenzverfahren ist auch, aber nicht nur auf Mengen anwendbar, die im Hinblick auf hinreichende Rechtfertigungsgründe für einzelne Elemente isoliert sind.
} 
anders und vergröbert formuliert, daß eine Menge von (potentiellen) Überzeugungen, die zum einen untereinander "hinreichend kohärent" sind, und die zum anderen den Rest des eigenen Überzeugungssystems "in hinreichend kohärenter Weise" ergänzen, wahrscheinlich wahr ist. Wenn man ein Inferenzverfahren dieser Art für verläßlich hält, ermöglicht einem dies, das oben genannte Problem zu lösen: Wenn man in interner Reflexion nach Rechtfertigungsgründen für eine Überzeugung sucht, die Element einer im erläuterten Sinn isolierten Teilmenge des eigenen Überzeugungssystems ist, und dabei auf offene Enden und/oder Zirkel oder ein System zusammenhängender Zirkel gestoßen ist, aus dem kein Weg mehr hinaus zu außerhalb liegenden hinreichenden Rechtfertigungsgründen führt, sich aber damit nicht zufriedenzugeben möchte, kann man dieses Inferenzverfahren heranziehen (wenn die genannten Voraussetzungen erfüllt sind). Man kann dann als Rechtfertigungsgründe für die gesamte isolierte Teilmenge erstens die schwachen Gründe, die außerhalb der Teilmenge liegen und für sie sprechen, anführen, zweitens die Überzeugung (zweiter Ordnung), daß dieses Inferenzverfahren (mit diesen schwachen Gründen als Input) die Teilmenge als Output liefert, sowie drittens die Überzeugung, daß dieses Verfahren verläßlich ist.

Ein Inferenzverfahren dieser Art, das es ermöglicht, schwache Gründe als Rechtfertigungsgründe für eine (im erläuterten Sinn) isolierte Menge von Überzeugungen einzusetzen, sollte idealerweise präzise charakterisiert werden, an dieser Stelle kann jedoch, wie bereits erwähnt, nicht mehr als eine sehr grobe Umrißskizze geliefert werden. Dazu sollen einige wenige Erläuterungen zu der obigen Beschreibung des Inferenzverfahrens gegeben werden, die vielleicht andeutungsweise erkennen lassen, woran gedacht ist, wenn von einer "hinreichend großen", "geeignet zusammengesetzten" und "hinreichend gut epistemisch zusammenhängenden" Menge die Rede ist, für die sich "hinreichend viele" und "hinreichend gute" schwache Gründe anführen lassen, die außerhalb der Menge liegen:

- Eine "hinreichend große" und "geeignet zusammengesetzte" Menge von Überzeugungen (oder potentiellen Überzeugungen ${ }^{113}$ ) sollte zum einen eine einigermaßen große Zahl ${ }^{114}$ von Überzeugungen erster Ordnung über einen bestimmten Gegenstandsoder Phänomenbereich o.ä. und entsprechende Herkunftsüberzeugungen enthalten, zum anderen sollte sie Verläßlichkeitsüberzeugungen in bezug auf mehrere (also mindestens zwei) verschiedene, voneinander hinreichend unabhängige Erzeugungsverfahren einschließen.

- In einer "hinreichend gut epistemisch zusammenhängenden" Menge von Überzeugungen sollten sich zu jeder Überzeugung erster Ordnung andere Überzeugungen aufweisen lassen, die - evtl. zusammen mit weiteren Überzeugungen, die außerhalb der Menge liegen — hinreichende Rechtfertigungsgründe für diese Überzeugung erster Ordnung darstellen. Diese Rechtfertigungsgründe werden, anschaulich gesprochen, darauf beruhen, daß die Überzeugungen erster Ordnung entweder durch die Erzeugungsverfahren "innerhalb der Menge" gewonnen wurden oder stabilisiert werden, oder aus so gewonnenen oder stabilisierten Überzeugungen erschlossen wurden oder werden können. Bei den Herkunftsüberzeugungen in einer solchen Menge wird man i.a. offene Enden zulassen müssen. ${ }^{115}$ Dagegen sollten sich zu jeder Verläßlichkeitsüberzeugung, die innerhalb der Menge liegt, andere Überzeugungen in der Menge aufweisen lassen, die - evtl. zusammen mit weiteren Überzeugungen "von außerhalb" — hinreichende Rechtfertigungsgründe für diese Verläßlichkeitsüberzeugung

\footnotetext{
${ }^{113}$ Diese Alternative bleibt im folgenden meistens implizit.

${ }^{114}$ Siehe der nächste Punkt.

${ }^{115}$ Der Grund ist der vorne (S.467) genannte, allgemeine.
} 
darstellen. (Dies liefert einen Anhaltspunkt dafür, was im letzten Punkt mit der Angabe gemeint ist, daß die Menge "eine einigermaßen große Zahl von Überzeugungen erster Ordnung über einen bestimmten Gegenstands- oder Phänomenbereich" einschließen sollte: Diese Zahl sollte groß genug sein, um induktive Schlüsse auf die Verläßlichkeit der Erzeugungsverfahren in der Menge zu ermöglichen. ${ }^{116}$ ) Eine hinreichend gut epistemisch zusammenhängende Menge von Überzeugungen darf sich nicht in zwei (oder mehr) Teilmengen zerlegen lassen, die nicht dadurch verbunden sind, daß (mindestens) ein Element der einen Teilmenge als Rechtfertigungsgrund für ein Element der anderen Teilmenge fungiert (oder umgekehrt). Eine Menge von Überzeugungen hängt (ceteris paribus) umso besser epistemisch zusammen, je mehr Überzeugungen sie einschließt, für die es redundante hinreichende Rechtfertigungsgründe gibt, die (ganz oder zum Teil) innerhalb dieser Menge liegen, d.h. mehrere andere, voneinander unabhängige Überzeugungen, die als voneinander unabhängige hinreichende Rechtfertigungsgründe für die jeweilige eine Überzeugung fungieren können. ${ }^{117}$ Redundante Rechtfertigungsgründe können offenbar insbesondere dadurch zustandekommen, daß mehrere, voneinander unabhängige Erzeugungsverfahren übereinstimmenden Output erzeugen. ${ }^{118}$

- Daß sich für eine Menge von Überzeugungen "hinreichend viele" und "hinreichend gute" schwache Gründe, die außerhalb der Menge liegen, anführen lassen, müßte so erläutert werden, daß das Inferenzverfahren als verläßlich gelten kann, und dazu können ohne eingehende Untersuchungen, die hier nicht möglich sind, kaum genauere Aussagen getroffen werden. Intuitiv ist aber zu erwarten, daß das Inferenzverfahren (ceteris paribus) umso wahrscheinlicher wahren Output liefert, je mehr Elemente der Menge durch schwache Gründe gestützt werden müssen und je besser diese schwachen Gründe sein müssen, wobei für schwache Gründe der beiden oben genannten Typen intuitiv auch naheliegt, was sie (ceteris paribus) zu guten bzw. besseren macht: Daß eine Überzeugung durch ein nur mäßig verläßliches Verfahren erzeugt wurde oder stabilisiert wird, ist ein umso besserer (schwacher) Grund für sie, je höher für dieses Verfahren die Wahrscheinlichkeit ist, daß es wahren Output liefert, und daß eine Überzeugung einen constraint erfüllt, ist ein umso besserer (schwacher) Grund für sie, je mehr Alternativen dieser constraint ausschließt.

Wenn sich diese Andeutungen zu einer einigermaßen zufriedenstellenden Charakterisierung eines Inferenzverfahrens, das schwache Gründe als Input verwendet, ausbauen lassen, sollte damit eine Möglichkeit gegeben sein, Rechtfertigungsgründe für eine ganze, vom Rest des eigenen Überzeugungssytems isolierte Menge von Überzeugungen anzugeben, wenn man in interner Reflexion nach Rechtfertigungsgründen für eine solche Menge sucht.

\footnotetext{
${ }^{116}$ Rechtfertigungsgründe anderer Art für eine Verläßlichkeitsüberzeugung in bezug auf ein Erzeugungsverfahren dürften sich allenfalls selten finden lassen.

${ }^{117}$ Eine denkbare Ergänzung, die hier beiseite bleibt, ist, daß der "epistemischen Zusammenhang" einer Menge von Überzeugungen auch umso besser ist, je mehr Elemente sie einschließt, für die sich (zusätzlich zu den hinreichenden Rechtfertigungsgründen) auch schwache Gründe anführen lassen, die (zum Teil oder ganz) innerhalb der Menge liegen, und je zahlreicher und besser diese schwachen Gründe sind.

${ }^{118}$ Eine Menge von Überzeugungen, die in diesem Sinn gut epistemisch zusammenhängt, ist offenbar robust gegen Irrtümer, d.h., wenn sich eine einzelne Überzeugung später als falsch herausstellen sollte, hat dies nicht automatisch Folgen für die anderen Überzeugungen, für die sie als Rechtfertigungsgrund fungiert; dieser Gedanke wird von verschiedenen Autoren diskutiert, etwa von Wimsatt [Wims81] und Hacking [Hack83a]. Worin genau die Unabhängigkeit verschiedener Rechtfertigungsgründe bzw. insbesondere verschiedener Erzeugungsverfahren besteht, ist offenbar erläuterungsbedürftig; auch diese Frage muß aber an dieser Stelle offen bleiben.
} 
Ein Beispiel soll zum einen illustrieren, was für Fälle den "intendierten Anwendungsbereich" des skizzierten Inferenzverfahrens bilden, zum anderen soll es (soweit dies durch ein Beispiel möglich ist) dazu beitragen, der obigen Umrißskizze Plausibilität zu verleihen, indem es an die Intuition appelliert, daß in dem präsentierten Einzelfall der Schluß plausibel aussieht, den das Inferenzverfahren hier gestattet. Da es um die Suche nach reliabilistischen Rechtfertigungsgründen in interner Reflexion geht, muß man offenbar ein konkretes Überzeugungssystem einer Person in den Blick nehmen, das von den Überzeugungssystemen anderer Personen i.a. abweichen kann und wird. Im folgenden Beispiel ist von meinen eigenen Überzeugungen die Rede; bei vielen anderen werden sich jedoch mehr oder weniger ähnliche Überzeugungen finden, zumindest bei Personen, die eine reliabilistische Position in der Erkenntnistheorie akzeptieren und aus dieser Perspektive über ihre eigenen Überzeugungen reflektieren.

Einen Fall einer epistemisch zusammenhängenden, aber vom Rest meines Überzeugungssystems isolierten Menge stellt eine bestimmte Teilmenge derjenigen meiner Überzeugungen dar, die sich auf die Eigenschaft, rot zu sein, und/oder auf die Eigenschaft, grün zu sein, beziehen, und zwar die Teilmenge, die folgende Überzeugungen einschließt:

1. singuläre Überzeugungen erster Ordnung, daß ein Gegenstand o.ä. rot ist, und singuläre Überzeugungen erster Ordnung, daß ein Gegenstand o.ä. grün ist ${ }^{119}$

2. andere (singuläre und allgemeine) Überzeugungen erster Ordnung, die die Eigenschaft, rot zu sein, und/oder die Eigenschaft, grün zu sein, involvieren, und die sich deduktiv, induktiv o.ä. aus den unter 1. genannten Überzeugungen erschließen lassen (d.h. aus den unter 1. genannten Überzeugungen allein oder aus diesen zusammen mit anderen Überzeugungen "von außerhalb" der Teilmenge), die sich aber nicht aus Überzeugungen "von außerhalb" der Teilmenge allein erschließen lassen (d.h. ohne eine oder mehrere der unter 1. genannten Überzeugungen als Prämissen heranzuziehen $)^{120}$

3. Herkunftsüberzeugungen für die unter 1. und 2. genannten Überzeugungen (also Überzeugungen zweiter Ordnung, daß eine der genannten Überzeugungen erster Ordnung durch eigene Beobachtung gewonnen wurde, durch deduktives oder induktives Schließen, durch Akzeptieren der Aussage eines anderen Beobachters etc.)

4. Verläßlichkeitsüberzeugungen in bezug auf meine Fähigkeiten, durch Beobachten (unter "Normalbedingungen" o.ä.) zu erkennen, ob ein Gegenstand o.ä. rot ist bzw. ob er grün ist, und auch in bezug auf die gleichen Fähigkeiten anderer Personen. ${ }^{121}$

Intuitiv gesprochen ist dies diejenige Teilmenge meiner Überzeugungen, die ich nicht hätte, wenn ich rot und grün nicht erkennen und auseinanderhalten könnte und außerdem auch

\footnotetext{
${ }^{119}$ Die Überzeugung, daß der Kugelschreiber auf meinem Schreibtisch rot ist, die Überzeugung, daß der Bleistift auf meinem Schreibtisch nicht grün ist, u.ä.

${ }^{120}$ Die Überzeugung, daß alle Tomaten, die rot sind, (zumindest halbwegs) reif sind, gehört also zu der Teilmenge, nicht dagegen die Überzeugung, daß die Farbe des Bleistifts auf meinem Schreibtisch, falls sie grün oder blau ist, dann blau ist (denn das folgt zwar aus meiner Überzeugung, daß der Bleistift nicht grün ist - zusammen mit der Überzeugung, daß jeder farbige Gegenstand (zu einem Zeitpunkt, an einer Stelle etc.) eine und nur eine der Farben rot, grün, blau, gelb etc. hat —, aber es folgt auch schon aus meiner außerhalb der Teilmenge liegenden Überzeugung, daß er blau ist).

${ }^{121}$ Unberücksichtigt bleiben hier Verläßlichkeitsüberzeugungen in bezug auf elektronische Detektoren für die Farben rot bzw. grün u.ä. Verläßlichkeitsüberzeugungen für deduktive und induktive Inferenzverfahren sollen nicht zur hier betrachteten Menge zählen.
} 
nicht glauben würde, daß irgendjemand sonst dies kann. Davon, daß diese Teilmenge meiner Überzeugungen die Anwendungsbedingungen des oben skizzierten Inferenzverfahrens erfüllt, kann man sich überzeugen, indem man sich die Elemente der Menge und die für sie aufweisbaren Rechtfertigungsgründe ansieht.

Daß diese Menge "hinreichend groß" und "geeignet zusammengesetzt" ist, dürfte nach ihrer obigen Charakterisierung im wesentlichen unstrittig sein. ${ }^{122}$

Daß sie auch "hinreichend gut epistemisch zusammenhängt", scheint zumindest bei einer kursorischen Betrachtung, wie sie an dieser Stelle nur möglich ist, ebenfalls plausibel: Für singuläre Überzeugungen (erster Ordnung), daß ein bestimmter Gegenstand rot bzw. grün ist o.ä., kann ich als Rechtfertigungsgründe häufig eine Herkunftsüberzeugung, daß ich dies durch eigene Beobachtung festgestellt habe, und eine entsprechende Verläßlichkeitsüberzeugung angeben. In anderen Fällen kann ich zum einen angeben, daß eine solche Überzeugung (erster Ordnung) durch einen induktiven oder deduktiven Schluß gewonnen wurde oder stabilisiert wird, oder dadurch, daß mir jemand anders eine Beobachtung mitteilt, zum anderen eine entsprechende Verläßlichkeitsüberzeugung und, für erschlossene Überzeugungen, die erforderlichen Prämissen. Für allgemeine Überzeugungen (erster Ordnung), daß alle Gegenstände eines Typs rot bzw. grün sind o.ä., kann ich als Rechtfertigungsgründe ebenfalls angeben, daß sie induktiv oder deduktiv erschlossen wurden bzw. werden können, sowie Verläßlichkeitsüberzeugungen in bezug auf die verwendeten Inferenzverfahren und die für den Schluß erforderlichen Prämissen. Für meine Verläßlichkeitsüberzeugung in bezug auf meine Fähigkeit, zu beobachten, ob ein Gegenstand rot ist (bzw. grün), kann ich induktive Rechtfertigungsgründe der vorne ${ }^{123}$ skizzierten Art anführen, ebenso für Verläßlichkeitsüberzeugungen, die die gleiche Fähigkeit einiger anderer Personen betreffen. ${ }^{124}$ Für meine Herkunftsüberzeugungen kann ich (wie vorne erörtert ${ }^{125}$ ) i.a. keine hinreichenden Rechtfertigungsgründe mehr anführen. Daß die zur Debatte stehende Teilmenge meiner Überzeugungen sich nicht in zwei (oder mehr) Teile zerlegen läßt, von denen keiner mindestens einen Rechtfertigungsgrund für den anderen Teil enthält, kann hier nicht im Detail gezeigt werden, sollte aber auch so plausibel sein. ${ }^{126}$

\footnotetext{
${ }^{122}$ Zur Frage, ob die genannten Erzeugungsverfahren tatsächlich voneinander unabhängig sind, s.u. ${ }^{123} \mathrm{~S} .463$.

${ }^{124}$ Ich halte diese Induktionsschlüsse für verläßlich; das Problem der genauen Formulierung induktiver Inferenzverfahren muß hier, wie vorne erläutert, beiseite bleiben.

Ich verfüge nicht über eine Theorie des menschlichen visuellen Apparates, aus der sich Verläßlichkeitsüberzeugungen in bezug auf die Wahrnehmungsfähigkeiten von Menschen deduktiv folgern lassen. Induktive Rechtfertigungsgründe der genannten Art kann ich nur für meine Verläßlichkeitsüberzeugungen in bezug auf die Beobachtungsfähigkeiten einiger (nicht aller) Personen angeben, und zwar solcher Personen, bei denen ich Kenntnis von hinreichend vielen ihrer Beobachtungen habe und diese Beobachtungen mit eigenen Überzeugungen über die beobachteten Gegenstände, Sachverhalte etc. vergleichen kann. (Dies können insbesondere Personen sein, mit denen ich hinreichend viele Beobachtungen gemeinsam angestellt habe.) Andersartigen induktiven Rechtfertigungsgründen für eine Verläßlichkeitsüberzeugung in bezug auf die Beobachtungsfähigkeiten einer Person könnte ein induktiver Schluß vom Vorliegen einer bestimmten Fähigkeit bei einer Reihe von Personen (in einer bestimmten Gruppe) auf das Vorliegen derselben Fähigkeit bei einer weiteren Person (in derselben Gruppe) oder bei allen Menschen zugrundeliegen; angesichts der Tatsache, daß verschiedene Formen der Fehlsichtigkeit, Farbenblindheit u.ä. nicht selten sind, ist aber fraglich, ob ein induktiver Schluß dieser Art als verläßlich gelten kann, und ist damit zweifelhaft, ob dadurch hinreichende Rechtfertigungsgründe für eine entsprechende Verläßlichkeitsüberzeugung gegeben sind.

${ }^{125}$ Siehe S.463, 467.

${ }^{126}$ Nicht offensichtlich ist vielleicht, daß sich die Teilmenge nicht in zwei nicht-zusammenhängende Teile zerlegen läßt, von denen einer nur die Farbe rot involviert, der andere die Farbe grün: Daß dies so ist, sieht man, wenn man sich z.B. klarmacht, daß es Überzeugungen gibt, die eine solche Zerlegung nicht zulassen, etwa meine Überzeugung, daß alle Tomaten rot oder grün sind und (einigermaßen) reif genau dann, wenn sie rot sind.
} 
Im Hinblick auf die Frage nach redundanten Rechtfertigungsgründen ist die Sachlage in dieser Teilmenge meiner Überzeugungen die folgende. Diese Menge enthält mehrere Verläßlichkeitsüberzeugungen in bezug auf Erzeugungsverfahren, die singuläre Überzeugungen liefern, die die Eigenschaft, rot (bzw. grün) zu sein, involvieren: Zum einen die Überzeugung, daß ich selbst (unter "Normalbedingungen" etc.) verläßlich erkennen kann, ob ein Gegenstand o.ä. rot ist (bzw. ob er grün ist), außerdem aber auch entsprechende Überzeugungen, die dieselben Fähigkeiten diversen anderen Personen zuschreiben. Daher kann ich für singuläre Überzeugungen (erster Ordnung) in der fraglichen Menge redundante Rechtfertigungsgründe haben, nämlich dann, wenn der entsprechende Sachverhalt, daß ein Gegenstand o.ä. rot ist (bzw. daß er grün ist), übereinstimmend von mehreren Personen beobachtet worden ist (insbesondere von mir selbst und von anderen). Solche redundanten Rechtfertigungsgründe habe ich für einen Teil meiner singulären Überzeugungen (erster Ordnung), die die Eigenschaft, rot (bzw. grün) zu sein, involvieren, jedoch keineswegs für alle oder auch nur die meisten Überzeugungen dieser Art. ${ }^{127}$ Redundante Rechtfertigungsgründe für diese Art von Überzeugungen können jedoch auch dadurch gegeben sein (und sind es tatsächlich in vielen Fällen), daß eine durch (eigene oder fremde) Beobachtung gewonnene Überzeugung durch einen induktiven oder deduktiven Schluß stabilisiert wird, ${ }^{128}$ oder dadurch, daß eine erschlossene Überzeugung durch einen anderen (von anderen Prämissen ausgehenden) Schluß oder durch eine Beobachtung stabilisiert wird. ${ }^{129}$ Die Möglichkeit, daß eine durch ein Inferenzverfahren gewonnene Überzeugung durch einen davon unabhängigen, anderen Schluß stabilisiert wird (so daß dadurch redundante Rechtfertigungsgründe zur Verfügung stehen) besteht auch für allgemeine Überzeugungen (erster Ordnung) und für Verläßlichkeitsüberzeugungen; tatsächlich dürfte diese Möglichkeit, daß zwei voneinander unabhängige und verläßliche Inferenzverfahren denselben Output ergeben, in der hier zur Debatte stehenden Teilmenge meiner Überzeugungen jedoch selten realisiert sein, insbesondere bei den Verläßlichkeitsüberzeugungen nicht. ${ }^{130}$ Fazit: Soweit sich das bei kursorischer Betrachtung ermitteln läßt, kann ich für einen Teil der Teilmenge meiner Überzeugungen, die sich auf die Eigenschaften, rot bzw. grün zu sein, beziehen, redundante hinreichende Rechtfertigungsgründe vorbringen, insbesondere für einen Teil der singulären Überzeugungen erster Ordnung, jedoch keineswegs für alle Elemente dieser Teilmenge, insbesondere für die Verläßlichkeitsüberzeugungen nicht. Die aufweisbaren (redundanten und nicht-redundanten) Rechtfertigungsgründe sollten ausreichen, um diese Teilmenge als "hinreichend epistemisch zusammenhängend" einzustufen.

Die oben für die verschiedenen Elemente dieser Teilmenge genannten hinreichenden Rechtfertigungsgründe liegen stets zumindest zum Teil in der Teilmenge selbst, und wenn man den Rechtfertigungsgraphen eines Elements dieser Teilmenge verfolgt, stößt man of-

\footnotetext{
${ }^{127}$ Das Beobachten eines Sachverhalts durch verschiedene Beobachter ist insofern eine Anwendung mehrerer unabhängiger Erzeugungsverfahren (und liefert insofern redundante Rechtfertigungsgründe), als verschiedene Beobachter (i.a.) verschiedene Interessen, Vorurteile u.ä. haben, verschiedenen "Störquellen" ausgesetzt sind u.ä. Man könnte einwenden, daß dennoch bestenfalls eine teilweise Unabhängigkeit vorliegt, weil der visuelle und kognitive Apparat der verschiedenen Beobachter weitgehend ähnlich aufgebaut ist und nach weitgehend denselbem Mechanismus funktioniert. Dieser Einwand muß hier offen bleiben; vgl. Fn.118.

${ }^{128}$ Beispiel: Die Beobachtung, daß eine bestimmte Tomate rot ist, wird stabilisiert durch einen (von bisherigen Beobachtungen ausgehenden) induktiven Schluß o.ä.

${ }^{129}$ Sofern hier Induktionsschlüsse im Spiel sind, muß das Problem der genauen Formulierung induktiver Inferenzverfahren und ihrer Verläßlichkeit hier, wie vorne erläutert, beiseite bleiben.

${ }^{130}$ Es ist nicht zu sehen, welche Rechtfertigungsgründe für die Verläßlichkeitsüberzeugungen zu den oben genannten induktiven hinzutreten sollten.
} 
fenbar schnell auf offene Enden und Zirkel. ${ }^{131}$ Hinreichende Rechtfertigungsgründe "von außerhalb" für eine Überzeugung in der Teilmenge gibt es (per Definition der Teilmenge) nicht, so daß diese Teilmenge vom Rest meines Überzeugungssystems isoliert (im vorne erläuterten Sinn) ist. Schwache Gründe "von außen" lassen sich jedoch wenigstens für einige Elemente dieser Teilmenge aufweisen. Einige Beispiele: Mein Überzeugungssystem enthält eine Vielzahl von Überzeugungen erster Ordnung, die sich auf eine Eigenschaft beziehen, eine von rot und grün verschiedene Farbe zu haben, etwa violett, blau, gelb oder orange; solche Überzeugungen können als schwache Gründe für Überzeugungen in der Teilmenge fungieren. So kann eine meiner diversen (außerhalb der Teilmenge liegenden) singulären Überzeugungen (erster Ordnung), daß ein bestimmter Gegenstand o.ä. eine von rot und grün verschiedene Farbe nicht hat (also z.B. nicht blau ist), als constraint für eine (innerhalb der Teilmenge liegende) Überzeugung, daß dieser Gegenstand o.ä. rot (oder grün) ist, fungieren. ${ }^{132}$ Andere Überzeugungen, die als schwache Gründe "von außen" fungieren können sind z.B. allgemeine Überzeugungen wie die, daß ein Stein, der blau ist, dies (seltene Ausnahmen ausgeschlossen) unabhängig vom Wetter, von der Jahreszeit, (in bestimmten Grenzen) von der Temperatur, von der Anwesenheit anderer Steine, von Menschen, Tieren u.ä. in räumlicher Nähe ist und seine Farbe nicht ändert, wenn sich das Wetter, die Jahreszeit etc. ändern, wenn man andere Steine in seine Nähe bringt usw., und entsprechende Überzeugungen in bezug auf die Farben violett, orange, gelb etc. Diese Überzeugungen kann man als einen schwachen induktiven Grund für die entsprechende Überzeugung in bezug auf rote und grüne Steine auffassen. Für meine Verläßlichkeitsüberzeugung in bezug auf meine Fähigkeit, zu erkennen, ob ein Gegenstand o.ä. rot ist, kann ich einen schwachen induktiven Grund von der Art eines induktiven Extrapolationsschlusses ${ }^{133}$ angeben: Die Überzeugungen, daß ich (unter Normalbedingungen etc.) verläßlich erkennen kann, ob ein Gegenstand o.ä. orange ist oder nicht, und daß mutatis mutandis dasselbe für die Farben gelb etc. gilt, kann ich als (vielleicht ziemlich) schwachen Grund für eine entsprechende Verläßlichkeitsüberzeugung in bezug auf das Erkennen von rot anführen. Für Verläßlichkeitsüberzeugungen in bezug auf meine Fähigkeit, grün zu erkennen, und in bezug auf die gleichen Fähigkeiten anderer Personen gilt Entsprechendes. Weitere schwache Gründe für diese Verläßlichkeitsüberzeugungen, und zwar constraints, sind durch verschiedene meiner Überzeugungen über Licht und dessen Verhalten, die Mechanismen seiner Ausbreitung sowie über die Funktionsweise des menschlichen Sehsinns gegeben. ${ }^{134}$ Schwache Gründe für eine Reihe von Überzeugungen erster Ordnung und Verläßlichkeitsüberzeugungen zusammen könnten sich angeben lassen, wenn man über ein wenigstens mäßig verläßliches, "geeignetes" Inferenzschema für Schlüsse auf die beste Erklärung verfügt und plausibel machen kann, daß das Vorliegen etwa der Farbeigenschaft rot bei bestimmten Dingen zusammen mit der Annahme, daß bestimmte Tiere oder Menschen diese Farbe verläßlich erkennen können, die beste Erklärung für bestimmte ihrer Verhaltensweisen liefert. ${ }^{135}$ Gleichsam den Grenzfall eines schwachen Grundes "von außen"

\footnotetext{
${ }^{131}$ Siehe S.467f.

${ }^{132} \mathrm{Da}$ es hier um constraints "von außerhalb" der Teilmenge geht und eine Alternative etwa zu ' $A$ ist rot' nicht schon durch ' $A$ ist nicht blau' ausgeschlossen wird, sondern die weitere Voraussetzung erforderlich ist, daß jeder farbige Gegenstand (zu einem Zeitpunkt, an einer Stelle etc.) eine und nur eine der Farben rot, grün, blau, gelb etc. hat, muß man genau genommen von einem constraint für die Überzeugung, daß $A$ rot ist, falls jeder farbige Gegenstand ..., sprechen (die auch in der Teilmenge liegt).

${ }^{133} \mathrm{Vgl}$. Abschnitt 8.3.3.

${ }^{134}$ Siehe S.470.

${ }^{135}$ Eine (tatsächlich jedoch falsche) Erklärung dieser Art wäre die der Reaktionen der Stiere auf das rote Tuch bei einem Stierkampf; eine andere Erklärung dieser Art, die allerdings nicht die Farben rot und
} 
für die gesamte Teilmenge liefert der ganze Rest meines Überzeugungssytems, insofern er mit der Teilmenge konsistent ist.

Im Falle dieser epistemisch zusammenhängenden, aber vom Rest meines Überzeugungssystems isolierten Teilmenge meiner Überzeugungen sollte ein Schluß intuitiv plausibel aussehen, der von den skizzierten Befunden über den inneren "epistemischen Zusammenhang" der Teilmenge und über die schwachen Gründe "von außen" und vom Rest des Überzeugungssystems als Prämissen auf die Teilmenge selbst als Konklusion führt; zumindest erscheint er mir so. Hinter diesem Eindruck steht die allgemeinere Intuition, daß die Tatsache, daß eine Menge von (potentiellen) Überzeugungen zum einen untereinander "hinreichend kohärent" ist, und zum anderen den Rest eines wahren Überzeugungssystems "in hinreichend kohärenter Weise" ergänzt, ein verläßlicher Indikator dafür ist, daß diese Menge als ganze wahr ist. Wenn man den genannten Schluß im Fall der erörterten Teilmenge als intuitiv plausibel anerkennt, sollte dies dem oben skizzierten Inferenzverfahren zumindest ein Minimum an Plausibilität verleihen (soweit dies eben aufgrund eines Anwendungsfalles möglich ist). Fälle wie die erörterte Teilmenge von Überzeugungen, die die Farben rot und/oder grün involvieren, bilden den "intendierten Anwendungsbereich" des Inferenzverfahrens. Weitere Anwendungsfälle können an dieser Stelle nicht im einzelnen diskutiert werden, es sollten sich jedoch welche finden lassen, indem man in der angegebenen Charakterisierung der erörterten Teilmenge anstelle der Farbeigenschaften rot und grün andere Farbeigenschaften einsetzt oder auch Eigenschaften anderer Art, etwa die Eigenschaften, dreieckig zu sein, rund zu sein u.ä. Als Anwendungsfälle kommen außerdem auch größere Teilmengen von Überzeugungen in Betracht, etwa die Menge von Überzeugungen, die irgendwelche Farbeigenschaften (nicht nur rot und/oder grün) involvieren, oder die Menge von Überzeugungen, die irgendwelche visuell wahrnehmbaren Eigenschaften involvieren, u.ä.; ob das Inferenzverfahren dort noch verläßlich ist, müßte allerdings geprüft werden, da es tendentiell umso weniger und weniger gute schwache Gründe "von außerhalb" der jeweiligen Menge geben dürfte, je größer die Menge im Vergleich zum gesamten Überzeugungssystem ist.

Wenn man das skizzierte Inferenzverfahren (in präzisierter Form) als verläßlich akzeptiert, gestattet es einem (sofern seine Anwendungsbedingungen erfüllt sind) zunächst, das vorne genannte Problem unter Rückgriff auf schwache Gründe zu lösen: Wenn man in interner Reflexion nach Rechtfertigungsgründen für eine Überzeugung sucht, die Element einer Teilmenge des eigenen Überzeugungssystems wie der oben diskutierten ist, und dabei auf offene Enden und/oder Zirkel gestoßen ist, aus denen kein Weg mehr hinaus zu außerhalb liegenden hinreichenden Rechtfertigungsgründen (der bis dahin genannten Art) führt, sich aber damit nicht zufriedenzugeben möchte, kann man dieses Inferenzverfahren heranziehen und damit (sofern dessen Anwendungsbedingungen erfüllt sind) hinreichende Rechtfertigungsgründe für die gesamte Teilmenge angeben - und damit dann doch hinreichende Rechtfertigungsgründe auch für die bis dahin offenen Enden und Zirkel. ${ }^{136}$ Eine prinzipielle Lösung, die einem (zumindest grundsätzlich) Antworten auf alle Fragen liefert, die die vorne beschriebene Strategie generiert, die Frage nach hinreichenden Rechtfertigungsgründen einer Überzeugung immer weiter zu iterieren, erhält man auf diese Weise

grün betrifft, ist die Erklärung bestimmter Verhaltensweisen von Bienen mit Hilfe der Annahme, daß sie eine Farbeigenschaft, ultraviolett zu sein, verläßlich erkennen können, und bestimmte Pflanzen u.ä. diese Eigenschaft haben.

${ }^{136}$ Grundsätzlich ist denkbar, daß es auch andere Inferenzverfahren als das skizzierte gibt, die diese Rolle spielen können, es scheint mir jedoch schwer zu sehen zu sein, wie solche Verfahren plausiblerweise aussehen könnten. 
jedoch klarerweise nicht: Es scheint klar, daß sich diese Strategie auf jede Überzeugung ausdehnen läßt, ${ }^{137}$ sicherlich jedenfalls auf die Überzeugungen, die als schwache Gründe fungieren, und auf eine Verläßlichkeitsüberzeugung in bezug auf das skizzierte Inferenzverfahren. Man kann natürlich nach (hinreichenden) Rechtfertigungsgründen auch für diese Überzeugungen fragen, und für die Möglichkeiten, für sie bzw. für eine auf sie ausgeweitete Menge von Überzeugungen Rechtfertigungsgründe aufzuweisen, gilt (aus den vorne genannten, allgemeinen Gründen) wiederum, daß man früher oder später in Zirkel und/oder offene Enden läuft, wenn man die Frage nach Rechtfertigungsgründen immer weiter iteriert.

Die Grenzen, auf die man stößt, wenn man in interner Reflexion nach Rechtfertigungsgründen für eine Überzeugung sucht Mit den in den vorigen Abschnitten genannten Arten von Rechtfertigungsgründen ist das angegeben, was sich an direkten und indirekten Rechtfertigungsgründen für eine Überzeugung über Beobachtbares finden läßt, wenn man sich in interner Reflexion Rechenschaft über den epistemischen Status dieser Überzeugung ablegen will und einen reliabilistischen Ansatz in der Erkenntnistheorie akzeptiert. Es sind damit aus reliabilistischer Perspektive die Möglichkeiten skizziert, Rechtfertigungsgründe für eine Überzeugung anzugeben, gleichzeitig aber auch die prinzipiellen Grenzen dieser Möglichkeiten. Auf diese Grenzen, nämlich auf die beschriebenen Zirkel und offenen Enden, muß man früher oder später stoßen (und stößt man normalerweise spätestens, nachdem man auch schwache Gründe in der oben beschriebenen Weise in die Überlegungen einbezogen hat), wenn man die Frage nach hinreichenden Rechtfertigungsgründen für eine Überzeugung immer wieder iteriert, wenn man also, sofern man direkte Rechtfertigungsgründe für die Überzeugung gefunden hat, nach Rechtfertigungsgründen für diese fragt usw. Gegeben daß der menschliche kognitive Apparat endlich ist, so daß man "nur" endlich viele Überzeugungen und epistemische Verfahren haben bzw. zur Verfügung haben kann, ergeben sich Grenzen dieser Art zwangsläufig, d.h. ihr Auftreten ist unabhängig davon, wie intensiv man nach weiteren Rechtfertigungsgründen sucht, ob es außer den in den vorigen Abschnitten erörterten Inferenz- und Erzeugungsverfahren noch andere gibt etc.

Welche Konsequenzen sind aus der Existenz von Grenzen dieser Art zu ziehen? Kann und sollte man sich mit Rechtfertigungsgründen für eine Überzeugung, mit denen solche Grenzen verbunden sind, gleichsam zufriedengeben? Oder sind Rechtfertigungsgründe, die früher oder später in Zirkel und offene Enden führen, wenn man die Frage nach Rechtfertigungsgründen auf sie ausweitet und dann immer wieder iteriert, letztlich nichts wert? Kann man angesichts der beschriebenen Grenzen die eigenen Überzeugungen sozusagen guten Gewissens haben und für gerechtfertigt und für wahr halten, oder muß und sollte man der Tatsache ins Gesicht sehen, daß man dafür letzlich keine guten Gründe hat? Diese Fragen berühren mehrere der zentralen, strittigen Probleme und Fragestellungen der Erkenntnistheorie, u.a. all die Fragen, die mit dem Thema "Skeptizismus" zusammenhängen. Dieser Themenkomplex kann an dieser Stelle nicht in der seiner Bedeutung entsprechenden Ausführlichkeit diskutiert werden, es soll aber eine Antwort auf die oben gestellten Fragen aus reliabilistischer Perspektive wenigstens im Umriß skizziert und soweit wie möglich plausibel gemacht werden. ${ }^{138}$

Festhalten sollte man zunächst, daß durch die Tatsache, daß das Iterieren der Frage

\footnotetext{
${ }^{137}$ Siehe aber S.466, Fn.89.

${ }^{138}$ Ich folge hier im wesentlichen Ernest Sosa [Sosa94a, Sosa97]. Sorgfältig formulierte Einwände gegen Sosas Position finden sich in [Stro89, Stro94].
} 
nach Rechtfertigungsgründen stets früher oder später auf offene Enden und/oder Zirkel führt, natürlich nicht ausgeschlossen wird, daß es mehr oder weniger gute (hinreichende) Rechtfertigungsgründe für eine Überzeugung geben kann, daß man also auch bei Überzeugungen, für die man jeweils hinreichende Rechtfertigungsgründe hat, dennoch hinsichtlich der Qualität dieser (hinreichenden) Rechtfertigungsgründe differenzieren kann. Was die Rechtfertigungsgründe, die man für eine Überzeugung anführen kann, zu guten macht bzw. zu besseren als die Rechtfertigungsgründe einer anderen Überzeugung, kann an dieser Stelle nicht im einzelnen diskutiert werden, es lassen sich aber wenigstens zwei Faktoren nennen, die wesentlich für die Qualität der Rechtfertigungsgründe einer Überzeugung sein dürften: ${ }^{139}$ Die Qualität der Rechtfertigungsgründe einer Überzeugung ist (ceteris paribus) sicherlich höher, wenn sie redundant $\operatorname{sind}^{140}$, als wenn sie es nicht sind, und sie ist (ceteris paribus) umso höher, je größer die Zirkel sind, die im Rechtfertigungsgraphen der Überzeugung liegen.

Darüberhinaus ist es eine (wenigstens prima facie) plausible Reaktion, sich mit den für eine Überzeugung verfügbaren Rechtfertigungsgründen nicht schon deswegen zufriedenzugeben, weil sie hinreichend sind, d.h. nicht schon dann, wenn der Rechtfertigungsgraph zumindest eine Teilmenge zusammen hinreichender direkter Rechtfertigungsgründe enthält, sondern nur dann, wenn die verfügbaren Rechtfertigungsgründe außerdem eine bestimmte "Mindestqualität" haben. Dazu ist intuitiv z.B. erforderlich, daß der Rechtfertigungsgraph der Überzeugung keine Überzeugungen erster Ordnung als offene Enden enthält, ${ }^{141}$ und daß er nicht nur aus "zu kleinen", d.h. nur ein Erzeugungsverfahren (genauer: eine diesbezügliche Verläßlichkeitsüberzeugung) involvierenden Zirkeln plus "daran hängenden" Überzeugungen anderer Arten besteht. ${ }^{142}$ Beispiele für Überzeugungen, die die erforderliche Mindestqualität zu haben scheinen, liefert der in den vorigen Abschnitten untersuchte Fall der Überzeugungen über Farbeigenschaften: Die dort skizzierten Rechtfertigungsgraphen von Überzeugungen erster Ordnung, Herkunfts- und Verläßlichkeitsüberzeugungen sehen intuitiv zufriedenstellend aus. ${ }^{143}$

\footnotetext{
${ }^{139}$ In eine präzise allgemeine Erläuterung, was die Qualität von Rechtfertigungsgründen ausmacht, sollten diese intuitiv plausiblen Faktoren eingehen.

${ }^{140}$ Wenn also die Menge der Rechtfertigungsgründe mehrere, jeweils hinreichende, aber voneinander unabhängige Teilmengen enthält; vgl. S.475.

${ }^{141}$ Also keine "inhaltlichen" Überzeugungen, für die man ihrerseits keine hinreichenden Rechtfertigungsgründe mehr angeben kann, informell gesprochen: keine unbegründeten Prämissen.

${ }^{142}$ Der intuitive Grund für diese Bedingung ist, daß solche Rechtfertigungsgründe sozusagen zu leicht zu haben sind, etwa auch für Überzeugungen, die durch Orakel, Kaffeesatzlesen u.ä. gewonnen werden, sofern man durch ein solches "epistemisches Verfahren" hinreichend viele Überzeugungen erster Ordnung gewinnt, um eine Verläßlichkeitsüberzeugung in bezug auf dieses Verfahren induktiv zu erschließen, und diese Überzeugungen erster Ordnung einen Gegenstandsbereich betreffen, der auf keinem anderen Weg epistemisch zugänglich ist (die Stimmungslage der Götter, die Details des Wetters in der letzten Eiszeit o.ä.).

${ }^{143}$ Durch die Rede von "zufriedenstellenden" Rechtfertigungsgründen und -graphen und von deren "Mindestqualität" soll an dieser Stelle keineswegs ein (nicht oder zumindest nicht hinreichend erläuterter) internalistischer Begriff von gerechtfertigter Überzeugung in den reliabilistischen Ansatz eingeschmuggelt werden. Ein Reliabilist hat nur Überzeugungen, deren Rechtfertigungsgründe (seiner Meinung nach) intuitiv zufriedenstellend sind und die erforderliche Mindestqualität aufweisen, da seine Intuitionen hinsichtlich des "Zufriedenstellens" und der Mindestqualität von Rechtfertigungsgründen systematisch mit den von ihm zur Gewinnung und Stabilisierung von Überzeugungen verwendeten epistemischen Verfahren und den zur Beseitigung von Konflikten zwischen verschiedenen Überzeugungen verwendeten Regeln oder Verfahren (vgl. S.450) zusammenhängen: Die von ihm verwendeten Verfahren und Regeln erzeugen und stabilisieren nur Überzeugungen, deren Rechtfertigungsgraph intuitiv zufriedenstellend ist und die erforderliche Mindestqualität aufweist, bzw. belassen bei der Beseitigung eines Konfliktes nur solche Überzeugungen im Überzeugungssystem.
} 
Auch Rechtfertigungsgraphen, die eine - wie auch im einzelnen immer zu erläuternde - Mindestqualität haben, laufen aber irgendwann in Zirkeln und offenen Enden aus, und offenbar tun dies auch Rechtfertigungsgraphen, die "von bester Qualität" sind, also das gesamte Überzeugungssystem erfassen, viel Redundanz aufweisen, nur sehr große Zirkel enthalten etc. (was auch immer "beste Qualität" im einzelnen ausmacht). Dieser Befund allein hat nach Ansicht einiger Autoren zur Folge, daß Rechtfertigungsgründe in der erkenntnistheoretisch relevanten Hinsicht nicht "zufriedenstellen" können. ${ }^{144}$ Nach dieser - von nicht wenigen als intuitiv plausibel betrachteten — Ansicht hat niemand für seine Überzeugungen wirklich gute Gründe, die aus erkenntnistheoretischer Perspektive betrachtet etwas wert sind, und zwar deswegen nicht, weil es die beschriebenen prinzipiellen Grenzen der Rechtfertigung gibt.

Ein wesentliches Motiv für diese Ansicht ist, daß es möglich und vorstellbar erscheint, daß jemand ein Überzeugungssystem hat, das in weiten Teilen, die den gesamten Rechtfertigungsgraphen einer bestimmten Überzeugung einschließen, oder sogar vollständig falsch und nicht gerechtfertigt ist, daß diese Person jedoch, wenn sie sich in interner Reflexion Rechenschaft über den epistemischen Status dieser bestimmten Überzeugung oder sogar ihrer Überzeugungen insgesamt ablegt, für die falsche(n) und nicht gerechtfertigte(n) Überzeugung(en) Rechtfertigungsgründe derselben Art und Qualität aufweisen kann wie jemand, der ein (zum Teil oder völlig) anderes und wahres und vollständig gerechtfertigtes Überzeugungssystem hat, für seine wahren und gerechtfertigten Überzeugungen. Die in den vorigen Abschnitten beschriebenen Rechtfertigungsgraphen und Grenzen der Rechtfertigung scheinen die Möglichkeit offen zu lassen, daß jemand eine Gesamtheit von Überzeugungen erster Ordnung, Verläßlichkeitsüberzeugungen usw. hat, die in weiten Teilen, die den gesamten Rechtfertigungsgraphen einer bestimmten Überzeugung einschließen, oder sogar vollständig falsch und nicht gerechtfertigt ist, obwohl diese Überzeugungen (zum Teil) wechselseitig füreinander als Rechtfertigungsgründe fungieren können, die von guter Qualität o.ä. sind. Insbesondere scheint diese Möglichkeit auch für die eigenen Überzeugungen zu bestehen, denn alles, was man in interner Reflexion an Rechtfertigungsgründen für die eigenen Überzeugungen aufweisen kann, scheint nicht auszuschließen, daß eine bestimmte eigene Überzeugung oder sogar alle eigenen Überzeugungen falsch und nicht gerechtfertigt sind, und dies legt die Ansicht nahe, daß alles, was man in interner Reflexion an Rechtfertigungsgründen aufweisen kann, in der erkenntnistheoretisch relevanten Hinsicht prinzipiell zu wenig leistet und einen daher nicht "zufriedenstellen" kann.

Einer solchen skeptischen Ansicht ist entgegenzuhalten, daß die sie motivierende Beschreibung der Sachlage korrekt ist, die daraus gezogene Konsequenz jedoch nicht folgt und nicht plausibel ist und daher zurückzuweisen ist. Das skizzierte skeptische Szenario eines in weiten Teilen oder vollständig falschen und nicht gerechtfertigten Überzeugungssystems, für dessen Elemente gleichwohl in interner Reflexion Rechtfertigungsgründe guter Qualität vorgebracht werden können, ist aus reliabilistischer Perspektive (zumindest prima facie) verständlich und möglich: Überzeugungen sind etwas, was wahr oder falsch sein kann, egal ob Überzeugungen erster Ordnung, Herkunfts-, Verläßlichkeits- oder sonstige Überzeugungen. Deswegen ist es möglich und denkbar, daß es Personen gibt, die ein Überzeugungssystem haben, dessen Elemente wechselseitig füreinander als Rechtfertigungsgründe fungieren, aber in weiten Teilen oder sogar allesamt falsch und nicht gerechtfertigt sind, weil diese Personen zwar glauben, daß ihre Überzeugungen durch bestimmte verläßliche epistemische Verfahren erzeugt oder stabilisiert worden sind (sofern durch Inferenzverfah-

\footnotetext{
${ }^{144}$ Siehe z.B. [Alst93, Stro94].
} 
ren, mit wahren Prämissen als Input) und daher gerechtfertigt sind, tatsächlich jedoch ihre Überzeugungen (zu weiten Teilen oder sogar alle) nicht durch die angenommenen Verfahren erzeugt bzw. stabilisiert worden sind und/oder die erzeugenden bzw. stabilisierenden Verfahren (zum Teil oder sogar alle) nicht verläßlich sind (und/oder, sofern Inferenzverfahren eingesetzt wurden, die verwendeten Prämissen (zum Teil oder sogar alle) nicht wahr sind). Aus reliabilistischer Perspektive ist es, flapsig gesprochen, kein Wunder, daß ein solches Szenario möglich ist, denn die Rechtfertigungsgründe, mit denen eine Person bei interner Reflexion operiert, sind eben Überzeugungen, also "interne" Entitäten, während die Eigenschaft, gerechtfertigt (oder nicht gerechtfertigt) zu sein, und die Eigenschaft, wahr (oder falsch) zu sein, "externe" Eigenschaften sind. Mit der beschriebenen Möglichkeit wird man sozusagen leben müssen, aber auch können, denn ihr Bestehen ändert natürlich nichts daran, daß ich überzeugt bin, daß ein solches Szenario auf mich nicht zutrifft. Der Befund, daß ein solches Szenario möglich und denkbar ist, stellt kein plausibles Motiv dar, die Rechtfertigungsgründe, die ich tatsächlich für meine Überzeugungen habe, und darüber hinaus grundsätzlich alle Rechtfertigungsgraphen, die irgendwann in Zirkel und offene Enden laufen, als in erkenntnistheoretischer Hinsicht nicht "zufriedenstellend", wertlos o.ä. zu betrachten.

Daß dies so ist, wird klar, wenn man sich die Frage stellt, wie eigentlich Gründe aussehen könnten, die ein skeptisches Szenario der beschriebenen Art ausschließen, und die daher - zusammen mit den bisher erörterten Rechtfertigungsgraphen o.ä. - Rechtfertigungsgründe für eine Überzeugung ergeben, die "in erkenntnistheoretischer Hinsicht zufriedenstellend" sind, nicht wertlos etc. Die Antwort ist, daß es solche Gründe offenbar nicht geben kann: Gründe, die ein solches Szenario ausschließen, müßten offenbar Gründe für die Annahme sein, daß der Teil meiner Überzeugungen, der durch das skeptische Szenario in Frage gestellt wird - also die Teile meines Überzeugungssystems, die den (bzw. die) ganzen Rechtfertigungsgraphen einer bestimmten Überzeugung (bzw. mehrerer Überzeugungen) enthalten, oder sogar das gesamte Überzeugungssystem —, gerechtfertigt ist. Solche Gründe anzugeben hieße also, ein epistemisches Verfahren, vermutlich ein Inferenzverfahren, aufzuweisen, das den in Frage gestellten Teil meiner Überzeugungen erzeugt hat oder stabilisiert (oder auch mehrere epistemische Verfahren, die dies getan haben oder tun), und die dazu erforderlichen Prämissen. Einer Lösung des Problems kommt man so jedoch nicht näher: Entweder zählen die erforderlichen Prämissen, eine Verläßlichkeitsüberzeugung in bezug auf das (oder die) fragliche(n) Verfahren und entsprechende Herkunftsüberzeugungen bereits zur Gesamtheit meiner Überzeugungen, ${ }^{145}$ oder sie tun es nicht. Wenn ja, gehören sie zu den Überzeugungen, die durch das skeptische Szenario gerade in Frage gestellt werden, und können dieses Szenario daher offenbar nicht ausschließen. ${ }^{146}$ Wenn nein, wenn ich also beispielsweise die Prämissen nicht glaube oder nicht glaube, daß das Inferenzverfahren, durch das das skeptische Szenario ausgeschlossen werden soll, verläßlich ist, dann ist nicht ersichtlich, wieso die aufgewiesenen Prämissen etc. für mich Gründe für die Annahme darstellen sollten, daß meine in Frage gestellten Überzeugungen gerechtfertigt sind (geschweige denn "in erkenntnistheoretischer Hinsicht

\footnotetext{
${ }^{145}$ Sie können auch erst im Verlauf der Reflexion über das skeptische Szenario hinzugekommen sein.

${ }^{146}$ Dies gilt nicht, wenn die fraglichen Überzeugungen tatsächlich erst im Verlauf der Reflexion über das skeptische Szenario gewonnen und damit die "ursprünglichen" Rechtfertigungsgraphen um zusätzliche Rechtfertigungsgründe erweitert wurden. Dann läßt sich aber offenbar ein entsprechend erweitertes skeptisches Szenario formulieren, durch das auch die in Verlauf der Reflexion hinzugewonnenen Überzeugungen in Frage gestellt werden. Spätestens wenn sich nach einigen Erweiterungen der ursprünglichen Rechtfertigungsgraphen keine neuen Rechtfertigungsgründe mehr finden lassen, die man als Überzeugung akzeptiert, kommt die oben genannte Alternative zum Tragen.
} 
zufriedenstellende") o.ä., und damit Gründe, die das skeptische Szenario ausschließen. ${ }^{147}$ Ernest Sosa kommentiert diesen Befund, daß es offenbar keine Rechtfertigungsgründe für eigene Überzeugungen geben kann, die skeptische Szenarios der beschriebenen Art ausschließen, in treffender Weise:

"To rue that fact $[. .$.$] is hence like pining for a patron saint of modesty (who$ blesses all and only those who do not bless themselves), once we have seen that there could not possibly be such a saint." 148

Fazit: Wenn man sich in interner Reflexion Rechenschaft über den epistemischen Status der eigenen Überzeugungen ablegt und dabei die Frage nach Rechtfertigungsgründen immer wieder iteriert, stößt man früher oder später auf die beschriebenen offenen Enden und/oder Zirkel, und die Tatsache, daß man irgendwann zwangsläufig auf solche offenen Enden und/oder Zirkel stößt, stellt eine "prinzipielle" Grenze der Rechtfertigungsmöglichkeiten in interner Reflexion dar. Dies und der damit zusammenhängende Befund, daß sich skeptische Szenarios der beschriebenen Art in interner Reflexion nicht ausschließen lassen, stellt jedoch keinen plausiblen Grund dar, die Rechtfertigungsgründe, die sich auf diese Weise aufweisen lassen, grundsätzlich als "in epistemischer Hinsicht nicht zufriedenstellend", wertlos o.ä. zu betrachten. Die aus reliabilistischer Perspektive für die epistemische Bewertung von Überzeugungen wesentlichen Aspekte und Differenzen betreffen die "Qualität" der Rechtfertigungsgründe, die sich für eine Überzeugung aufweisen lassen, und diese Aspekte und Differenzen liegen gleichsam alle diesseits der "prinzipiellen" Grenze der Rechtfertigungsmöglichkeiten.

\section{Debatten mit anderen Personen über Überzeugungen über Beobachtbares}

Nachdem in den vorigen Abschnitten erörtert wurde, wie es um die Möglichkeiten und um die Grenzen der Möglichkeiten bestellt ist, in interner Reflexion Rechtfertigungsgründe für eigene Überzeugungen anzugeben, sollen jetzt die Möglichkeiten und die Grenzen der Möglichkeiten untersucht werden, durch Argumente andere Personen von Thesen zu überzeugen, die man selbst glaubt.

In interner Reflexion Rechtfertigungsgründe für eine eigene Überzeugung aufzuweisen, entspricht, wie schon erwähnt, ${ }^{149}$ in gewisser Weise einem Grenzfall einer Argumentation, durch die eine andere Person dazu gebracht werden soll, dieselbe Überzeugung zu akzeptieren, und zwar dem Grenzfall, in dem die Diskussionsgegner dieselben Überzeugungen haben ${ }^{150}$ und dieselben epistemischen Verfahren und Regeln verwenden. Aus dieser "Grenzfallbetrachtung" ergibt sich bereits einiges über Möglichkeiten und Grenzen der Möglichkeiten, in Debatten mit anderen Personen Argumente für eigene Thesen vorzubringen: Im Hinblick auf Möglichkeiten ergibt sich, daß die Rechtfertigungsgründe, die man in interner Reflexion für eine eigene Überzeugung aufweisen kann, auch in Argumenten eingesetzt werden können, die andere überzeugen sollen. Im Hinblick auf Grenzen der Möglichkeiten ergibt sich, daß das, was man einem Diskussionsgegner präsentieren kann, um für eine eigene Überzeugung zu argumentieren, nicht mehr und "nichts Besseres" ist als eben die Rechtfertigungsgründe, die einem selbst in interner Reflexion zur Verfügung ste-

\footnotetext{
${ }^{147}$ Dieses Argument folgt im wesentlichen [Sosa94a], S.283f.

148 [Sosa94a], S.284.

${ }^{149}$ Siehe S.461.

${ }^{150}$ Bis auf die jeweils in Frage stehende Überzeugung natürlich.
} 
hen: ${ }^{151}$ Über die im vorigen Abschnitt diskutierten Grenzen der Rechtfertigungsmöglichkeiten in interner Reflexion wird man sozusagen auch bei der Suche nach Argumenten nicht hinauskommen, d.h. für Überzeugungen, die im eigenen Überzeugungssystem offene Enden darstellen, kann man auch keine Argumente vorbringen, und dem Befund, daß ein Rechtfertigungsgraph einer Überzeugung Zirkel enthält, entspricht die Tatsache, daß man irgendwann nur noch zirkulär argumentieren kann, wenn man zu einem Argument für eine eigene Überzeugung stets noch ein Argument für dessen Prämissen hinzufügen will. Außerdem bestimmen die Art und "Qualität" der Rechtfertigungsgründe, die man für eine Überzeugung aufweisen kann, auch die Art und "Qualität" der Argumente, die man für sie vorbringen kann, d.h. für eine Überzeugung, für die man "nur" induktive Rechtfertigungsgründe hat, kann man "nur" induktiv argumentieren, (nur) für eine Überzeugung, für die man redundante Rechtfertigungsgründe hat, kann man verschiedene unabhängige Argumente vorbringen usw.

In Debatten mit anderen Personen, in denen Argumente für eigene Überzeugungen eingesetzt werden sollen, liegt natürlich selten oder nie der oben beschriebene Grenzfall vor; vielmehr haben die Diskussionsgegner typischerweise deutlich verschiedene Überzeugungssysteme. Ob ein bestimmter Diskussionsgegner durch ein bestimmtes Argument für eine bestimmte These überzeugt werden kann, hängt aber davon ab, welche Überzeugungen er zu Beginn der Diskussion bereits hat, welche Inferenzregeln und, allgemeiner, welche epistemischen Verfahren er verwendet, denn auf diese Überzeugungen, Regeln und Verfahren muß jedes Argument zurückgreifen. Dies führt, zusammen mit der im vorigen Abschnitt beschriebenen Tatsache, daß der Rechtfertigungsgraph jeder Überzeugung offene Enden und/oder Zirkel enthält, dazu, daß die Rechtfertigungsgründe, die man in interner Reflexion für eine eigene Überzeugung aufweisen kann, nicht in jedem Fall auch ein erfolgreiches Argument für diese Überzeugung ergeben. Vielmehr lassen sich diese Rechtfertigungsgründe nur dann erfolgreich einsetzen, um einen bestimmten Diskussionsgegner zu überzeugen, wenn dieser bereits hinreichend viele der eigenen Überzeugungen, Inferenzregeln und sonstigen epistemische Verfahren und Regeln teilt, insbesondere hinreichend viele der eigenen Rechtfertigungsgründe für die Überzeugung, für die argumentiert werden soll. Den Möglichkeiten, Argumente für eine Überzeugung vorzubringen, sind also zunächst dieselben Grenzen gesetzt wie den Möglichkeiten, in interner Reflexion Rechtfertigungsgründe für diese Überzeugung aufzuweisen; darüber hinaus stößt man aber bei der Suche nach erfolgreichen Argumenten, je nach Diskussionsgegner, i.a. auf noch engere Grenzen. Wie eng diese Grenzen sind, worin sie genau bestehen, und dementsprechend auch, was sich mit Argumenten zugunsten einer Überzeugung ausrichten läßt, hängt davon ab, wie weit die relevanten Gemeinsamkeiten mit dem Diskussionsgegner reichen; es lassen sich hier verschiedene mögliche Konstellationen unterscheiden.

Mögliche Konstellationen bei der Argumentation für eine Überzeugung über
Beobachtbares und die resultierenden Grenzen der Möglichkeiten, erfolgreich
für eine solche Überzeugung zu argumentieren Die einfachste (und praktisch kaum
relevante) Konstellation ist die, in der eine Überzeugung erster Ordnung über Beobachtba-
res zur Diskussion steht, für die zweierlei gilt: Erstens, daß man für sie hinreichende direk-
te Rechtfertigungsgründe (also eine Herkunfts- und eine Verläßlichkeitsüberzeugung sowie

${ }^{151}$ Von Argumenten ad hominem abgesehen, die aber für die Realismusdebatte keine wesentliche Rolle spielen; vgl. S.456, Fn.58. 
evtl. als Prämissen fungierende Überzeugungen) hat, die der Diskussionsgegner teilt; ${ }^{152}$ zweitens, daß das übrige Überzeugungssystem des Diskussionsgegners keinerlei Hindernis für ihn darstellt, eine entsprechende neue Überzeugung desselben Inhalts zu gewinnen. In einem solchen Fall genügt es, den Diskussionsgegner darauf aufmerksam zu machen, daß ein von ihm als verläßlich akzeptiertes Verfahren (evtl. mit einigen seiner Überzeugungen als Prämissen) die zur Diskussion stehende These liefert, um ihn von dieser These zu überzeugen, d.h. einer erfolgreichen Argumentation steht in einem solchen Fall nichts im Wege.

Eine kompliziertere Konstellation liegt bereits vor, wenn die Sachlage wiederum die beschriebene ist, "nur" mit dem Unterschied, daß die zweite der beiden obigen Bedingungen nicht erfüllt ist, weil der Diskussionsgegner eine weitere Überzeugung hat, die mit der zur Diskussion stehenden These konfligiert. In diesem Fall weist man diesen also auf eine bisher implizite Inkonsistenz oder Inkohärenz ${ }^{153}$ in seinem Überzeugungssystem hin und legt ihm nahe, nicht nur die These zu akzeptieren, sondern außerdem die entgegenstehende Überzeugung aufzugeben. Ob diese Argumentation ihr Ziel erreicht, hängt davon ab, welchen Regeln oder Verfahren der Diskussionsgegner folgt, wenn ein Konflikt in seinem Überzeugungssystem zu beseitigen ist, ${ }^{154}$ und vom Rest seines Überzeugungssystems (sofern dieser Rest für die Konfliktbeseitigung relevant ist): Diese Regeln oder Verfahren können dazu führen, daß er dem Argument und der Empfehlung, die mit dessen Konklusion konfligierende Überzeugung fallenzulassen, folgt, sie können aber auch dazu führen, daß er (mindestens) eine der Prämissen des Arguments oder das verwendete epistemische Verfahren aufgibt. Entsprechendes gilt auch für Fälle, in denen für eine These argumentiert wird, die mit mehreren Überzeugungen des Diskussionsgegners konfligiert. Ob ein Argument für eine These erfolgreich ist, die in der beschriebenen Weise mit anderen Überzeugungen des Diskussionsgegners konfligiert, hängt also von den Regeln oder Verfahren ab, die dieser zur Beseitigung von Konflikten verwendet, und vom Rest seines Überzeugungssystems.

Zwei andere, voneinander unterscheidbare Konstellationen können vorliegen, wenn eine Überzeugung erster Ordnung über Beobachtbares zur Diskussion steht, die die zweite der beiden obigen Bedingungen erfüllt, nicht jedoch die erste, genauer: eine Überzeugung, die mit den bisherigen Überzeugungen des Diskussionsgegners nicht konfligiert, und für die man hinreichende direkte Rechtfertigungsgründe hat, jedoch direkten Rechtfertigungsgründe, die der Diskussionsgegner nicht (oder jedenfalls nur zum Teil) teilt. In einem solchen Fall kommt man nicht einfach dadurch zum Argumentationserfolg, daß man den Diskussionsgegner auf die eigenen direkten Rechtfertigungsgründe für die These hinweist, sprich: auf das Verfahren und die Prämissen, die zusammen die These liefern. Man wird in solchen Fällen versuchen, im eigenen Rechtfertigungsgraphen einen Schritt zurückzugehen und dort indirekte Rechtfertigungsgründe zu suchen, die ein Argument für diejenigen direkten Rechtfertigungsgründe liefern, die der Diskussionsgegner nicht teilt. Wenn er diese, als indirekte Rechtfertigungsgründe fungierenden Überzeugungen teilt, steht einer erfolgreichen Argumentation für die zur Diskussion stehende These nichts mehr im Wege. Wenn

\footnotetext{
${ }^{152}$ Implizit bleiben an dieser Stelle die — unproblematischen — "Asymmetrien", die sich bei Überzeugungen ergeben können, die durch ein Erzeugungsverfahren gewonnen wurden, das an eine Person geknüpft ist (Beobachtung mit dem bloßen Auge etc.), so daß andere Personen eine entsprechende Überzeugung genaugenommen durch ein anderes Verfahren (Mitteilen der Beobachtung des Beobachters o.ä.) gewinnen müssen.

${ }^{153}$ Je nachdem, ob die konfligierende Überzeugung der These widerspricht oder ob sie sie "nur" (mehr oder weniger) unwahrscheinlich erscheinen läßt o.ä.

${ }^{154}$ Siehe S.450f.
} 
dies nicht der Fall ist, wird man im eigenen Rechtfertigungsgraphen noch einen Schritt weiter zurückgehen usw. Diese "Suchstrategie" kann zu einem erfolgreichen Argument führen, sie muß es jedoch im allgemeinen nicht, weil, wie in den vorigen Abschnitten erörtert, jeder Rechtfertigungsgraph endlich ist und man daher früher oder später in offene Enden und/oder Zirkel läuft, wenn man die (indirekten) Rechtfertigungsgründe einer Überzeugung immer weiter zurückverfolgt. Je nachdem, ob diese Suchstrategie früher oder später zum Erfolg führt oder nicht, liegen zwei unterscheidbare Konstellationen vor: Wenn die Suche irgendwann auf indirekte Rechtfertigungsgründe führt, die der Diskussionsgegner teilt, kann man ihn unter Hinweis auf diese indirekten Rechtfertigungsgründe von der zur Diskussion stehenden These überzeugen; dies ist eine mögliche Konstellation. Eine andere Konstellation liegt vor, wenn die Suche erfolglos bleibt: Wenn man auf der Suche nach hinreichenden Rechtfertigungsgründen, die der Diskussionsgegner teilt, bereits den gesamten eigenen Rechtfertigungsgraphen für die zur Diskussion stehende Überzeugung durchlaufen hat (und dabei ggf. auch Inferenzverfahren wie das oben ${ }^{155}$ skizzierte berücksichtigt hat, das "schwache Gründe" als Input einsetzt und eine ganze "epistemisch zusammenhängende" Menge von Überzeugungen als Output liefert), ohne auf genügend viele geteilte Überzeugungen gestoßen zu sein, dann muß die Suche nach einem für diesen Diskussionsgegner überzeugungskräftigen Argument erfolglos bleiben. Die Ressourcen, die einem zur Verfügung stehen, um ein Argument zu formulieren, das ihn von der zur Diskussion stehenden These überzeugen könnte, sind dann offenbar erschöpft.

Durch Abwandlung der ersten dieser beiden Konstellationen ergibt sich schließlich eine weitere, nochmals kompliziertere, nämlich dann, wenn eine Überzeugung erster Ordnung über Beobachtbares zur Diskussion steht, für die man hinreichende direkte Rechtfertigungsgründe hat, die der Diskussionsgegner nicht (oder jedenfalls nur zum Teil) teilt, und dann die oben beschriebene Suchstrategie irgendwann auf indirekte Rechtfertigungsgründe führt, die er teilt, die jedoch in Konflikt mit seinem bisherigen Überzeugungssystem stehen. Dieser Konflikt kann an verschiedenen Stellen auftreten: Sowohl die These selbst, für die argumentiert wird, als auch die (direkten und/oder indirekten) Rechtfertigungsgründe, die im Verlauf der Argumentation für die These als Zwischenschritte auftreten, können mit bereits bestehenden Überzeugungen konfligieren. Ob ein Argument für eine These erfolgreich ist, wenn solche mehr oder weniger komplizierten Inkonsistenzen oder Inkohärenzen auftreten, hängt von den Regeln oder Verfahren ab, die der Diskussionsgegner zur Beseitigung von Konflikten verwendet, und vom Rest seines Überzeugungssystems (sofern dies für die Konfliktbeseitigung relevant ist). ${ }^{156}$

Zur Veranschaulichung dieser fünf abstrakt beschriebenen Konstellationen ist es nützlich, sich zumindest einige wenige Beispiele anzusehen.

Ein Fall der ersten, trivialen Art wäre etwa folgender: Ich erwähne in einem Gespräch, daß ich nicht weiß, ob im Norden Deutschlands Wein angebaut wird. Daraufhin überzeugt mich ein Freund davon, daß dies (gelegentlich) vorkommt, indem er mich daran erinnert, daß ich unlängst erzählt habe, daß ich einen kleinen Weinanbau in Kreuzberg in Berlin gesehen habe. Da Berlin im Norden Deutschlands liegt, folgt offensichtlich, daß es auch im Norden Deutschlands Weinanbau gibt.

Ein Fall der zweiten Art liegt vor, wenn ich zunächst zusätzlich die (in meiner Schulzeit erworbene) Überzeugung habe, daß der nördlichste Weinberg Deutschlands in der Nähe von Kassel liegt, denn diese widerspricht, zusammen mit der weiteren Überzeu-

\footnotetext{
${ }^{155}$ Siehe S.468.

${ }^{156}$ Die erforderlichen Abwägungen können hier noch komplizierter sein als bei den im vorletzten Absatz genannten, vergleichsweise einfacheren Konflikten.
} 
gung, daß Kassel nicht im Norden Deutschlands liegt, der Konklusion, daß es im Norden Deutschlands Weinanbau gibt. In diesem Fall akzeptiere ich die Konklusion und gebe die entgegenstehende Überzeugung aus Schulzeiten auf, dies ist jedoch nicht logisch zwingend: Grundsätzlich könnte ich auch (mindestens) eine Prämisse des Arguments und/oder das Inferenzverfahren aufgeben (am ehesten vielleicht die Überzeugung, daß ich einen Weinanbau in Kreuzberg gesehen habe, denn es ist denkbar, daß ich Weinstöcke und damit einen Weinanbau tatsächlich nicht verläßlich erkennen kann, und daß das, was ich gesehen habe, etwas anderes war). Ich kann keine allgemeine Regel zur Beseitigung von Konflikten zwischen Überzeugungen angeben, die in diesem Fall zur Anwendung käme; in diesem Fall gebe ich aber diejenige der konfligierenden Überzeugungen auf, die in der (nach meiner Überzeugung) am wenigsten verläßlichen Weise gewonnen bzw. stabilisiert wurde (Ich glaube, daß ich verläßlich einen Weinberg erkennen kann, und daß die Deutschlandkarten, die ich zur Verfügung habe, verläßlich sind, aber ich halte meinen Erdkundelehrer inzwischen für eine nur mäßig verläßliche Informationsquelle). Hier wie in vielen, vielleicht in den meisten Fällen von Konflikten zwischen Überzeugungen über Beobachtbares dürfte es kaum kontrovers sein, wie der Konflikt innerhalb eines Überzeugungssystems zu beseitigen ist, es gibt jedoch auch Fälle, in denen dies strittig bleibt, und es ist klarerweise auch möglich, daß jemand in konsistenter Weise einer "kontroversen" Regel zur Beseitigung von Konflikten folgt, im Extremfall etwa einer Regel, die auf eine Immunisierungsstrategie für bestimmte Überzeugungen hinauslaufen kann. Beispiele dafür lassen sich im Zusammenhang von Gerichtsverfahren finden, etwa wenn jemand trotz erdrückender Beweislage an der Überzeugung festhält, daß der persönlich eng vertraute Angeklagte unschuldig ist, und (in konsistenter Weise) jedes dem widersprechende Indiz zurückweist und dazu, wenn nötig, auch seine entsprechende Verläßlichkeitsüberzeugung bezüglich des für die Gewinnung des Indizes verantwortlichen epistemischen Verfahrens aufgibt. ${ }^{157}$

Ein Beispiel für eine Fall der dritten der oben genannten Arten erhält man leicht durch Abwandlung des im vorletzten Absatz angegebenen Beispiels für Fälle der ersten, trivialen Art.

Ein Fall der vierten oben genannten Art kann vorliegen, wenn jemand mit Hilfe eines induktiven Schlusses, eines Schlusses auf die beste Erklärung o.ä. für eine Überzeugung erster Ordnung über Beobachtbares argumentieren will, der Diskussionsgegner jedoch das in Anspruch genommene Inferenzverfahren nicht für verläßlich hält und daher nicht akzeptiert und auch sämtliche für dessen Verläßlichkeit ins Feld geführten Rechtfertigungsgründe nicht akzeptiert. Allenfalls sehr selten dürften dagegen Fälle der vierten Art vorkommen, in denen für eine Überzeugung über Beobachtbares argumentiert werden soll, die durch ein Erzeugungsverfahren gewonnen bzw. stabilisiert wurde, sprich: durch Beobachten. Einzelne, zumindest mögliche (wenn auch vielleicht wenig "praxisrelevante") Fälle dieser Art kann man sich aber doch zurechtlegen, und es ist insbesondere im Hinblick auf vergleichbare Konstellationen im Bereich der wissenschaftstheoretischen Realismusdebatte nützlich, zumindest einen oder zwei solche Fälle vor Augen zu haben. Ein solcher Fall könnte vorliegen, wenn jemand zwei Farben, beispielsweise rot und grün, nicht erkennen und nicht

\footnotetext{
${ }^{157}$ An dieser Stelle ist offenbar die in der Literatur geläufige "Quine-Duhem-These" berührt, der zufolge man an jeder Überzeugung festhalten kann, egal was da kommen mag, wenn man anderswo im eigenen Überzeugungssystem "geeignete" Anpassungen vornimmt (vgl. [Quin53c], S.43. [Duhe78], Kap.10). Diese These kann hier nicht eingehend diskutiert werden. Es soll nicht bestritten werden, daß es logisch möglich ist, an einer Überzeugung festzuhalten, komme da was kommen mag; die Behauptung ist "nur", daß in der Praxis über die Beseitigung von Inkonsistenzen weitgehend Einigkeit herrscht (wobei natürlich Erwägungen eingehen, die über deduktive Inferenzregeln hinausgehen), so daß die Quine-Duhem-These für die epistemische Praxis keine wesentlichen Konsequenzen hat.
} 
auseinanderhalten kann, also in bezug auf diese beiden Farben farbenblind ist, ${ }^{158}$ und gleichzeitig nicht glaubt, daß es Dinge gibt, die rot bzw. grün sind, und auch nicht glaubt, daß irgendjemand anders (oder auch irgendein Detektor o.ä.) die Fähigkeit hat, die Eigenschaften, rot bzw. grün zu sein, verläßlich zu erkennen, und wenn ich versuche, diese Person durch ein Argument zu überzeugen, eine meiner Überzeugungen erster Ordnung über rote bzw. grüne Gegenstände zu akzeptieren. Ein weiterer Fall dieser Art könnte vorliegen, wenn eine blinde Person nicht glaubt, daß es Dinge gibt, die irgendeine Farbe haben, und auch nicht glaubt, daß irgendjemand die Fähigkeit hat, irgendeine Farbe verläßlich zu erkennen, und wenn ich versuche, diese Person durch ein Argument dazu zu veranlassen, eine meiner Überzeugungen über farbige Gegenstände zu akzeptieren. ${ }^{159}$

Ein konkretes Beispiel: Ich bin überzeugt, daß es Basilikum mit roten Blättern gibt, und meine direkten Rechtfertigungsgründe für diese Überzeugung sind die Überzeugungen, daß ich vor einiger Zeit rotes Basilikum gesehen habe, ${ }^{160}$ und daß ich verläßlich erkennen kann, ob ein Gegenstand rot ist. Diese Überzeugungen werden von einer farbenblinden oder von einer blinden Person mit den beschriebenen Überzeugungssystemen nicht geteilt und diese können entsprechende Überzeugungen auch nicht selbst durch Beobachtung gewinnen. Auf meine direkten Rechtfertigungsgründe hinzuweisen ergibt daher kein für sie überzeugendes Argument für meine These, daß es rotes Basilikum gibt. Wenn ich daher die oben beschriebene Suchstrategie verfolge, finde ich, daß ich nicht weiß, wie meine Verläßlichkeitsüberzeugung in bezug auf meine Fähigkeit, rot zu erkennen, zustande gekommen ist, daß diese Überzeugung aber stabilisiert wird durch einen induktiven Schluß der oben ${ }^{161}$ skizzierten Art, der von meinen bisher durch eigene Beobachtung gewonnenen Überzeugungen erster Ordnung über rote Dinge (den Kugelschreiber auf meinem Schreibtisch, das Rücklicht meines Fahrrades etc.) und von den zugehörigen Herkunftsüberzeugungen ausgeht, und von dieser "Erfolgsgeschichte" zu der Überzeugung führt, daß ich verläßlich erkennen kann, ob ein Gegenstand rot ist. Auch diese indirekten Rechtfertigungsgründe ergeben kein Argument, das für die beiden genannten Personen Überzeugungskraft hat, da sie die Überzeugungen erster Ordnung, die als Prämissen des induktiven Schlusses fungieren (die Überzeugung, daß der Kugelschreiber auf meinem Schreibtisch rot ist, etc.), nicht teilen. Als Rechtfertigungsgründe für diese Prämissen wiederum kann ich anführen, daß ich einen Teil von ihnen durch eigene Beobachtung gewonnen habe und verläßlich erkennen kann, ob ein Gegenstand rot ist, daß bei einem Teil der Prämissen jemand anders, den ich für einen verläßlichen Beobachter halte, ebenfalls beobachtet und mir mitgeteilt bzw. bestätigt hat, daß der fragliche Gegenstand rot ist, und vielleicht auch, daß einige der Prämissen induktiv erschlossen werden können. Im ersteren Fall schließt sich damit bereits ein Zirkel, denn als Rechtfertigungsgründe gebe ich dann u.a. die Verläßlichkeitsüberzeugung an, für die (seit dem vorletzten Iterationsschritt) ein Argument gesucht wird, so daß sich dieser Teil meines Rechtfertigungsgraphen offenbar als wirkungslos in der Diskussion mit den beiden genannten Gegnern erweist; in den beiden letzteren Fällen ergibt sich ebenfalls kein überzeugungskräftiges Argument, denn die Diskussionsgegner glauben

\footnotetext{
${ }^{158}$ Es kommt an dieser Stelle nicht darauf an, ob es Farbenblindheit genau dieser Art gibt. Unter den diversen Formen von Farbenblindheit, die es gibt, kommt aber eine vor, die der oben beschriebenen ähnlich ist: Bei dieser Form werden rot, grün und grau verwechselt bzw. nicht auseinandergehalten. Das obige Beispiel läßt sich leicht in entsprechender Weise ergänzen.

${ }^{159}$ Vgl. dazu S.476f.

${ }^{160}$ Genauer: Daß ich gesehen habe, daß bestimmte Basilikumpflanzen rote Blätter haben (Daß es sich bei diesen Pflanzen um Basilikum handelt, erkenne ich am Geruch und an der Form der Blätter etc.), und daraus folgt deduktiv, daß es Basilikumpflanzen mit roten Blättern gibt.

${ }^{161}$ S.463.
} 
nicht, das irgendjemand rote Gegenstände erkennen kann, und teilen natürlich auch die Prämissen eines induktiven Schlusses über rote Gegenstände nicht. Wenn ich in den beiden letzteren Fällen weiter meinen Rechtfertigungsgraphen nach indirekten Rechtfertigungsgründen durchsuche, gerate ich auch hier meistens nach wenigen weiteren Schritten in einen Zirkel, weil ich nur wenige Erzeugungsverfahren für Überzeugungen erster Ordnung über die Farben rot bzw. grün für verläßlich halte (eben Beobachten durch menschliche Beobachter).

Alle bisher erwähnten direkten und indirekten Rechtfertigungsgründe für meine Überzeugung, daß es Basilikum mit roten Blättern gibt, gehören offenbar zu einer im vorne erläuterten Sinn ${ }^{162}$ isolierten Teilmenge meiner Überzeugungen, die die beiden Diskussionsgegner nicht mit mir teilen, ${ }^{163}$ und deren Gestalt bereits erörtert wurde, ${ }^{164}$ nämlich zur Menge derjenigen meiner Überzeugungen, die sich auf die Eigenschaft, rot zu sein, und/oder auf die Eigenschaft, grün zu sein, beziehen. Wie ebenfalls bereits erörtert, halte ich diese Menge für "hinreichend groß", "hinreichend gut epistemisch zusammenhängend" und durch "hinreichend viele" und "hinreichend gute" schwache Gründe an mein übriges Überzeugungssystem angeknüpft, um einen Schluß auf diese Menge zu ziehen ${ }^{165}$ (obwohl ich kein präzise spezifiziertes Inferenzverfahren angeben kann, daß diesem Schluß zugrunde liegt); einen Diskussionsgegner, der diese Ansicht teilt (d.h., der hinreichend viele meiner als schwache Gründe fungierenden Überzeugungen sowie die über das "epistemische Zusammenhängen" der Menge teilt, und auch die Ansicht, daß daraus verläßlich auf die Menge geschlossen werden kann), kann ich unter Hinweis darauf von dieser Menge überzeugen, und damit u.a. auch von meiner These, daß es Basilikum mit roten Blättern gibt. Damit sich durch ein solches Argument ein in der beschriebenen Weise farbenblinder bzw. blinder Diskussionsgegner überzeugen läßt, muß dieser also mindestens meine Ansicht teilen, daß die Tatsache, daß es für eine "hinreichend große" und "hinreichend gut epistemisch zusammenhängende" Menge von (potentiellen) Überzeugungen "hinreichend viele" und "hinreichend gute" schwache Gründe gibt, ein verläßlicher Indikator dafür ist, daß diese Menge als ganze wahr ist; außerdem muß er hinreichend viele meiner schwachen Gründe für Überzeugungen, die sich auf die Eigenschaft, rot zu sein, und/oder auf die Eigenschaft, grün zu sein, beziehen, teilen. Die letztere Bedingung kann von einer farbenblinden Person ohne weiteres erfüllt werden, im Fall einer blinden Person mit dem oben angegebenen Überzeugungssystem ist deutlich weniger klar, ob das so ist: Die meisten der vorne genannten schwache Gründe involvieren von rot und grün verschiedene Farben ${ }^{166}$ und werden daher von der beschriebenen blinden Person nicht geteilt; für sie kommen von den vorne genannten schwachen Gründen nur die Konsistenz der Menge mit dem Rest des Überzeugungssystems und evtl. Erklärungsleistungen für "außerhalb der Menge liegende" Sachverhalte in Frage. Wenn ein Diskussionsgegner nicht die Bedingungen dafür erfüllt, daß ein solches Argument für ihn Überzeugungskraft hat, kann ich grundsätzlich noch versuchen, ein entsprechendes Argument für eine noch umfangreichere Teilmenge meiner Überzeugungen (etwa aller Überzeugungen, die sich auf irgendeine Farbeigenschaft beziehen) zu finden, und/oder ein Argument induktiver o.ä. Art dafür zu finden, daß die Tatsache, daß es für eine "hinreichend große" und "hinreichend gut epistemisch zusam-

\footnotetext{
${ }^{162}$ Vgl. S.472f., 476ff.

${ }^{163}$ Oder von denen sie jedenfalls zu wenige teilen, um ein erfolgreiches Argument zu gestatten. Sie könnten möglicherweise einige meiner Herkunftsüberzeugungen teilen, diese Qualifikation bleibt im folgenden beiseite.

${ }^{164}$ Siehe S.476ff.

${ }^{165}$ Siehe S.479f.

${ }^{166}$ Siehe S.479f.
} 
menhängende" Menge von (potentiellen) Überzeugungen "hinreichend viele" und "hinreichend gute" schwache Gründe gibt, ein verläßlicher Indikator dafür ist, daß diese Menge als ganze wahr ist. Die Erfolgschancen dürften jedoch in beiden Fällen gering sein: Daß sich hinreichend viele und gute schwache Gründe für eine derart umfangreiche Menge von Überzeugungen finden lassen, deren Inhalt (Farbeigenschaften) zudem so wenig "Gemeinsamkeiten" oder "Verwandtschaft" mit dem Inhalt anderer Überzeugungen aufweist, und/oder daß sich hinreichend gute induktive Gründe für die genannte Verläßlichkeitsüberzeugung aufweisen lassen, die ein Diskussionsgegner teilt, der die bisher erörterten Rechtfertigungsgründe nicht geteilt hat, dürfte wenig wahrscheinlich sein, sprich: es dürfte wenig wahrscheinlich sein, daß sich auf dieser generellen Ebene noch ein Argument finden läßt, das einen Diskussionsgegner überzeugt, wenn diesen vorher nichts überzeugt hat, und in meinem eigenen Überzeugungssystem finde ich (derzeit) jedenfalls keine hinreichenden Rechtfertigungsgründe, die ich für solche Argumente heranziehen könnte. Die Ressourcen, die mir zur Verfügung stehen, um ein Argument für meine Überzeugung vorzubringen, daß es Basilikum mit roten Blättern gibt, sind jedenfalls sicherlich dann erschöpft, wenn ich meinen gesamten Rechtfertigungsgraphen durchsucht habe, ohne hinreichende (direkte oder indirekte) Rechtfertigungsgründe zu finden, die der Diskussionsgegner teilt, und dies kann bei einem farbenblinden und noch eher bei einem blinden Diskussionsgegner mit dem beschriebenen Überzeugungssystem vorkommen. In einem solchen Fall ergeben sämtliche hinreichenden direkten und indirekten Rechtfertigungsgründe, die ich in interner Reflexion für meine Überzeugung aufweisen kann, kein Argument, das für diese Diskussionsgegner Überzeugungskraft hat.

Fälle der fünften oben genannten, noch komplexeren Art kann man sich zurechtlegen, indem man Beispiele des vierten Typs abwandelt. Ein Beispiel dieser Art, in dem es um die Argumentation für eine Überzeugung erster Ordnung geht, die durch ein Erzeugungsverfahren, sprich: durch Beobachtung, gewonnen wurde, bekommt man etwa, indem man das eben diskutierte dahingehend modifiziert, daß man sich farbenblinde und blinde Personen vorstellt, die "positiv" die Überzeugung haben, daß niemand verläßlich erkennen kann, ob etwas rot oder grün ist bzw. irgendeine Farbe hat. ${ }^{167}$ Für die Möglichkeiten, erfolgreich für eine These wie die, daß es Basilikum mit roten Blättern gibt, zu argumentieren, können sich dadurch zusätzliche Einschränkungen ergeben, nämlich durch die Regeln oder Verfahren, die der jeweilige Diskussionsgegner zur Beseitigung von Konflikten zwischen verschiedenen seiner Überzeugungen verwendet, und den Rest seines Überzeugungssystems (sofern dieser für die Konfliktbeseitigung relevant ist).

Grenzen der Reichweite von Argumenten für eine Überzeugung über Beobachtbares Das Fazit dieser Überlegungen ist das Folgende. Die Möglichkeiten, in einer Debatte mit anderen Personen erfolgreiche Argumente für eine eigene Überzeugung über Beobachtbares vorzubringen, werden durch mehrere zusammenwirkende Faktoren begrenzt. Grundsätzlich stehen einem zur Formulierung eines Arguments für eine Überzeugung alle Rechtfertigungsgründe zur Verfügung, die man in interner Reflexion für diese Überzeugung aufweisen kann, ${ }^{168}$ und bereits damit ist in einer Hinsicht eine Grenze der Möglichkeiten, erfolgreich für diese Überzeugung zu argumentieren, gegeben: Das, was man einem Diskussionsgegner als Argument für eine Überzeugung präsentieren kann, ist

\footnotetext{
${ }^{167}$ Bisher war angenommen worden, daß die Diskussionsgegner dazu keine Meinung haben, also weder glauben, daß andere Personen rot oder grün bzw. irgendwelche Farben verläßlich erkennen können, noch glauben, daß dies nicht der Fall ist.

${ }^{168}$ Argumente ad hominem bleiben hier wiederum beiseite.
} 
nicht mehr und "nichts Besseres" als die (direkten und indirekten) Rechtfertigungsgründe, aus denen der eigene (endliche, offene Enden und/oder Zirkel einschließende) Rechtfertigungsgraph für diese Überzeugung besteht.

Auch in Fällen, in denen man für eine Überzeugung hinreichende Rechtfertigungsgründe "guter Qualität" hat, ${ }^{169}$ kann es jedoch, je nach Diskussionsgegner, vorkommen, daß diese Rechtfertigungsgründe kein erfolgreiches Argument ergeben, d.h. kein Argument, durch das sich dieser Diskussionsgegner dazu bringen läßt, die zur Diskussion stehende Überzeugung zu akzeptieren. Ob dies in einem konkreten Fall so ist, hängt davon ab, ob der Diskussionsgegner genügend viele der eigenen Überzeugungen, epistemischen Verfahren und sonstigen Regeln und Verfahren zur Veränderung des Überzeugungssystems teilt. Wie die obige Diskussion der verschiedenen möglichen argumentativen Konstellationen gezeigt hat, lassen sich zwei Faktoren unterscheiden, die den Möglichkeiten, erfolgreich für eine Überzeugung zu argumentieren, Grenzen ziehen, die noch enger sind als die Grenze, die durch die Beschränkung der "argumentativen Ressourcen" auf die eigenen Rechtfertigungsgründe gegeben ist. Erstens: Wenn der jeweilige Diskussionsgegner nicht hinreichend viele der Überzeugungen teilt, die meinen Rechtfertigungsgraphen für die zur Diskussion stehende Überzeugung bilden, ${ }^{170}$ kann ihn ein Hinweis auf für mich hinreichende Rechtfertigungsgründe nicht überzeugen. Jedes Argument für meine zur Diskussion stehende Überzeugung, das ich mit Hilfe meiner Rechtfertigungsgründe formulieren kann, findet dann gewissermaßen beim Diskussionsgegner keinen Ansatzpunkt, um ihn dazu zu bewegen, dieselbe Überzeugung zu akzeptieren. Zweitens: Wenn meine Argumentation für meine zur Diskussion stehende Überzeugung eine (bisher implizite) Inkonsistenz oder Inkohärenz im Überzeugungssystem des Diskussionsgegners aufdeckt, hängt es von den von ihm zur Beseitigung von Konflikten verwendeten Regeln oder Verfahren und vom Rest seines Überzeugungssystems ab, ob ihn mein Hinweis auf hinreichende Rechtfertigungsgründe für meine zur Diskussion stehende Überzeugung dazu bringt, dieselbe Überzeugung zu akzeptieren (und konfligierende Überzeugungen aufzugeben), oder stattdessen dazu, (mindestens) eine der bisher geteilten Überzeugungen aufzugeben, die als Prämissen meines Arguments fungieren (und an den konfligierenden Überzeugungen festzuhalten).

Für die epistemische Praxis im Bereich der Alltagswelt ${ }^{171}$ spielen die beschriebenen Grenzen der Möglichkeiten, erfolgreich für eine Überzeugung über Beobachtbares zu argumentieren, kaum eine Rolle, d.h. es dürfte allenfalls selten vorkommen, daß mehrere Personen über eine zur Diskussion stehende These über einen beobachtbaren Sachverhalt nicht auf argumentativem Weg zu einem Konsens kommen. ${ }^{172}$ Fälle dieser Art sind aber zumindest denkbar und sie müßten, wie die angeführten Beispiele der farbenblinden bzw. blinden Personen illustrieren, dann auftreten, wenn es zu einer Debatte zwischen Personen kommt, deren Überzeugungssysteme "hinreichend große und grundlegende" Differenzen aufweisen. Solche Fälle illustrieren den allgemeinen (und vielleicht auf den ersten Blick

\footnotetext{
${ }^{169}$ Z.B. redundante Rechtfertigungsgründe, die nicht in "zu kleinen" Zirkeln liegen etc. — was auch immer Rechtfertigungsgründe zu guten macht.

${ }^{170}$ Dies schließt die Bedingung ein, daß er genügend viele der von mir verwendeten epistemischen Verfahren, insbesondere der Inferenzverfahren, ebenfalls verwendet (denn zu den erforderlichen geteilten Überzeugungen zählen u.a. Verläßlichkeitsüberzeugungen, und ein rationaler, kohärenter Reliabilist verwendet die epistemischen Verfahren, die er für verläßlich hält, auch selbst).

${ }^{171}$ D.h. genaugenommen: für die aus reliabilistischer Perspektive betrachtete oder rekonstruierte epistemische Praxis.

${ }^{172}$ Vorausgesetzt natürlich, die Diskussion wird nicht durch interessenbedingte Unaufrichtigkeit (mindestens) einer Seite hinsichtlich dessen, was sie wirklich glaubt, beeinträchtigt, wie es bei Gerichtsverhandlungen, in wirtschaftlichen Kontexten etc. vorkommt.
} 
überraschenden oder jedenfalls nicht selbstverständlichen) Befund, daß die Tatsache, daß man einen Satz hinreichender Rechtfertigungsgründe "guter Qualität" für eine Überzeugung aufweisen kann, nicht impliziert, daß diese Rechtfertigungsgründe ein für jeden Diskussionsgegner überzeugungskräftiges Argument für diese Überzeugung darstellen, ${ }^{173}$ und daß das, was man mit solchen Rechtfertigungsgründen in einer Debatte mit anderen argumentativ ausrichten kann, von den auf Seiten des jeweiligen Diskussionsgegners bereits akzeptierten Überzeugungen, epistemischen Verfahren und sonstigen zur Modifikation seines Überzeugungssystems eingesetzten Regeln und Verfahren abhängt.

\subsubsection{Rechtfertigungsgründe und Argumente für ontologische realisti- sche Thesen über Unbeobachtbares}

\section{Rechtfertigungsgründe und Argumente für Überzeugungen über Beobachtba- res als Orientierungspunkt für die Suche nach und die Bewertung von Rechtfer- tigungsgründen und Argumenten für Überzeugungen über Unbeobachtbares}

Die Überlegungen der vorigen Abschnitte haben gezeigt, wie es aus reliabilistischer Perspektive betrachtet um die Möglichkeiten und um die Grenzen der Möglichkeiten bestellt ist, Rechtfertigungsgründe und Argumente für ontologische realistische Thesen über beobachtbare Gegenstände und Sachverhalte der Alltagswelt anzugeben. Dadurch ist, wie schon vorne erwähnt, ${ }^{174}$ eine Art Orientierungspunkt gegeben sowohl für die Suche nach Rechtfertigungsgründen und Argumenten für ontologische realistische Thesen über Unbeobachtbares, als auch für eine Bewertung der Grenzen, auf die man, wie sich zeigen wird, bei dieser Suche stößt.

Für die Suche nach Rechtfertigungsgründen und Argumenten im Bereich des Unbeobachtbaren gibt einem der Blick auf den Bereich des Beobachtbaren einen groben Anhaltspunkt, was man zu finden erwarten kann (und was nicht) und wann man vermutlich gründlich genug gesucht hat; daß man diesen Anhaltspunkt bekommt, setzt allerdings voraus, daß man die Kontinuitätsintuition teilt, daß Rechtfertigungsgründe und Argumente auf beiden Seiten der Grenze beobachtbar/unbeobachtbar von der gleichen Art und "Qualität" sind. ${ }^{175}$

Für eine Bewertung der Grenzen, auf die man, wie sich zeigen wird, bei der Suche nach Rechtfertigungsgründen und Argumenten im Bereich des Unbeobachtbaren stößt, ist es wichtig oder zumindest hilfreich, zum Vergleich ein Bild von der Sachlage im Bereich des Beobachtbaren vor Augen zu haben, insbesondere ist es im Hinblick auf die wissenschaftstheoretische Realismusdebatte hilfreich: Wenn man dieses Bild zum Vergleich im Blick hat, sieht man, daß die Grenzen, auf die man - wie sich zeigen wird - bei der Suche nach Rechtfertigungsgründen und Argumenten im Bereich des Unbeobachtbaren stößt, zumindest in Teilen dieselben Grenzen bzw. Grenzen derselben Art sind wie die im Bereich des Beobachtbaren. Dies legt es zumindest nahe, daß aus der Existenz solcher Grenzen nicht in den beiden Bereichen unterschiedliche Konsequenzen gezogen werden sollten, und dies wiederum legt es nahe, sorgfältiger zu prüfen, als es im Diskussionszusammenhang der wissenschaftstheoretischen Realismusdebatte häufig geschieht, welche Konsequenzen zu ziehen sind, wenn man bei der Suche nach Rechtfertigungsgründen und Argumenten im Bereich des Unbeobachtbaren auf bestimmte Grenzen stößt.

\footnotetext{
${ }^{173}$ Und zwar auch dann nicht, wenn sich die Diskussionsgegner nicht völlig irrational verhalten o.ä.

${ }^{174}$ Siehe S.459f.

${ }^{175}$ Vgl. S.449.
} 
In der wissenschaftstheoretischen Realismusdebatte ziehen einige Autoren aus der Existenz solcher Grenzen im Bereich des Unbeobachtbaren den Schluß, daß dieser Bereich "nicht in zufriedenstellender Weise epistemisch zugänglich" ist, "jenseits der Grenzen menschlicher Erkenntnismöglichkeiten liegt" o.ä., und daß dies für antirealistische Positionen spricht. Wenn man außerdem, wie viele an der wissenschaftstheoretischen Realismusdebatte beteiligte Autoren es tun, eine Art Common-sense-Realismus akzeptiert, dann legt der Hinweis auf den Befund, daß man bei der Suche nach Rechtfertigungsgründen und Argumenten "im Beobachtbaren" auf die gleichen Grenzen bzw. Grenzen derselben Art stößt wie "im Unbeobachtbaren", nahe, die genannten Konsequenzen für den Bereich des Unbeobachbaren nochmals sorgfältig zu prüfen, denn, gegeben diesen Befund, sollte man offenbar für den Bereich des Beobachtbaren die gleichen Konsequenzen ziehen, und dies wäre mit Common-sense-Realismus nicht verträglich: Obwohl der genaue Gehalt und die epistemische Begründung dessen, was Common-sense-Realismus ausmacht, in der wissenschaftstheoretischen Realismusdebatte üblicherweise eingeklammert werden, ${ }^{176}$ dürfte eine solche Position jedenfalls nicht damit verträglich sein, die genannten Grenzen im Bereich des Beobachtbaren anzuerkennen und dahingehend zu bewerten, daß die beobachtbaren Gegenstände, Eigenschaften etc. der Alltagswelt "nicht in zufriedenstellender Weise epistemisch zugänglich" sind, "jenseits der Grenzen menschlicher Erkenntnismöglichkeiten liegen" o.ä. Die Grenzen im Bereich des Unbeobachtbaren so zu bewerten, legt also zumindest nahe, für den Bereich des Beobachtbaren zur gleichen Bewertung zu kommen und damit den Common-sense-Realismus aufzugeben.

Wenn einem - wie vielen - dieser Schritt kontraintuitiv und unplausibel erscheint, wird man die Gründe, die für ihn sprechen, sorgfältig prüfen, und dabei zeigt sich, wie in den vorigen Abschnitten für den Bereich des Beobachtbaren erörtert, ${ }^{177}$ tatsächlich, daß es keine guten Gründe gibt, aus dem Bestehen der beschriebenen Grenzen dort den Schluß zu ziehen, daß dieser Bereich "nicht in zufriedenstellender Weise epistemisch zugänglich" ist o.ä. Dadurch wird einem nahegelegt, sehr sorgfältig zu prüfen, welche Konsequenzen zu ziehen sind, falls man im Bereich des Unbeobachtbaren Grenzen derselben Art findet, und ggf. daraus jedenfalls nicht in voreiliger Weise antirealistische Schlüsse zu ziehen.

Daß man bei der Suche nach Rechtfertigungsgründen und Argumenten im Unbeobachtbaren tatsächlich (zumindest in Teilen) auf die gleichen Grenzen bzw. Grenzen derselben Art stößt wie im Beobachtbaren, zeigt sich im einzelnen, wenn man die Suche wirklich durchführt. Das oben gewonnene Bild der Sachlage im Beobachtbaren trägt dann in der beschriebenen Weise dazu bei, diese Grenzen im Hinblick auf die wissenschaftstheoretische Realismusdebatte ins rechte Licht zu rücken; in diesem Sinn stellt dieses Bild einen hilfreichen Orientierungspunkt für die Bewertung von Rechtfertigungsgründen und Argumenten für ontologische realistische Thesen über Unbeobachtbares dar.

Im Hinblick auf diese Funktion als Orientierungspunkt sind die folgenden die wesentlichen Züge des in den vorigen Abschnitten gewonnenen Bildes von den Möglichkeiten und den Grenzen der Möglichkeiten, für eine Überzeugung über Beobachtbares Rechtfertigungsgründe und überzeugungskräftige Argumente anzugeben:

- Die Gesamtheit der (direkten und indirekten) Rechtfertigungsgründe, die sich in innerer Reflexion für eine Überzeugung angeben lassen, bildet einen endlich großen Rechtfertigungsgraphen, der offene Enden und/oder Zirkel enthält.

- Die Tatsache, daß der Rechtfertigungsgraph jeder Überzeugung endlich ist, und daß

\footnotetext{
${ }^{176}$ Siehe S.24f.

${ }^{177}$ Vgl. S.481ff., 492ff.
} 
man daher früher oder später auf offene Enden und/oder Zirkel stößt, wenn man die Frage nach Rechtfertigungsgründen für eine Überzeugung immer wieder iteriert, stellt keinen plausiblen Grund dar, die Rechtfertigungsgründe, die deren Rechtfertigungsgraph ausmachen, grundsätzlich als "in epistemischer Hinsicht nicht zufriedenstellend", wertlos o.ä. zu betrachten. Die für die Bewertung des epistemischen Status einer Überzeugung relevanten Fragen, ob man für sie hinreichende Rechtfertigungsgründe aufweisen kann oder nicht, von welcher "Qualität" diese Rechtfertigungsgründe ggf. sind u.ä., lassen sich sozusagen alle diesseits der genannten prinzipiellen Grenze der Rechtfertigungsmöglichkeiten beantworten.

- Die Möglichkeiten, erfolgreich für eine Überzeugung zu argumentieren, werden durch drei Faktoren begrenzt: 1) Zur Formulierung eines Arguments für eine Überzeugung steht mir nicht mehr und "nichts Besseres" als die Elemente meines Rechtfertigungsgraphen der Überzeugung zur Verfügung. 2) Auch Überzeugungen, die für mich hinreichende Rechtfertigungsgründe für die zur Diskussion stehende Überzeugung darstellen, ergeben nur dann ein Argument, das für einen bestimmten Diskussionsgegner Überzeugungskraft hat, wenn dieser genügend viele meiner Rechtfertigungsgründe teilt. 3) Wenn ein Argument für eine Überzeugung eine Inkonsistenz oder Inkohärenz im Überzeugungssystem des Diskussionsgegners aufdeckt, dann hängt der Erfolg eines Arguments zusätzlich von den Regeln oder Verfahren ab, die der Diskussionsgegner zur Beseitigung eines Konflikts verwendet, sowie möglicherweise vom Rest seines Überzeugungssystems.

- Praktisch spielen die drei Faktoren, die die Möglichkeiten, erfolgreich für eine Überzeugung zu argumentieren, begrenzen, kaum eine Rolle. Daß zumindest Fälle denkbar sind, in denen sie eine Rolle spielen, und daß also die Tatsache, daß man hinreichende Rechtfertigungsgründe für eine Überzeugung hat, nicht impliziert, daß diese Rechtfertigungsgründe ein für jeden Diskussionsgegner überzeugungskräftiges Argument für diese Überzeugung ergeben, liegt in der Natur der Sache. Der Status der Rechtfertigungsgründe wird dadurch nicht berührt oder gar beeinträchtigt.

Über das, was bisher gesagt wurde, hinaus kann das durch die obigen vier Punkte charakterisierte Bild von den Möglichkeiten und den Grenzen der Möglichkeiten, für eine Überzeugung über Beobachtbares Rechtfertigungsgründe und Argumente anzugeben, noch in einer weiteren Hinsicht als Orientierungspunkt für die Bewertung entsprechender Möglichkeiten und Grenzen der Möglichkeiten im Bereich des Unbeobachtbaren dienen: Wenn man dort, wie sich zeigen wird, bei der Suche nach Rechtfertigungsgründen und Argumenten auf Grenzen derselben Art stößt wie im Beobachtbaren, und man zu einer wohlerwogenen, gut begründeten Bewertung dieser Grenzen gelangen will, kann man versuchen, sich an den in den vorigen Abschnitten für den Bereich des Beobachtbaren angestellten Überlegungen zu orientieren, deren im zweiten und vierten der vier obigen Punkte zusammengefaßtes Resultat war, daß das Bestehen dieser Grenzen kein Hindernis für eine realistische Einstellung zu den beobachtbaren Gegenständen, Eigenschaften etc. der Alltagswelt, also für Common-sense-Realismus, darstellt. Wenn sich diese Überlegungen auf den Bereich des Unbeobachtbaren übertragen lassen, kann man auf diese Weise eine Begründung dafür gewinnen, daß es kein Hindernis für wissenschaftlichen Realismus darstellt, wenn man bei der Suche nach Rechtfertigungsgründen und Argumenten für ontologische realistische Thesen über Unbeobachtbares auf Grenzen der beschriebenen Art stößt. 
Daß solche prinzipiellen Grenzen — wie sich zeigen wird - existieren, und auch daß diese Grenzen — wie im folgenden plausibel gemacht werden wird - , kein Hindernis für eine realistische Position darstellen, besagt noch nichts darüber, was sich im einzelnen "innerhalb dieser prinzipiellen Grenzen" an Rechtfertigungsgründen und Argumenten für ontologische realistische Thesen über Unbeobachtbares finden läßt, für welche Thesen sich hinreichende Rechtfertigungsgründe angeben lassen, welche Qualität diese ggf. haben etc. und für welche Diskussionsgegner die Argumente, die sich ggf. aus den aufweisbaren Rechtfertigungsgründen gewinnen lassen, Überzeugungskraft haben. Um sicherzustellen, daß die Suche nach Rechtfertigungsgründen und Argumenten im Bereich des Unbeobachtbaren auf ein angemessenes, nicht schon aus prinzipiellen, in der Natur der Sache liegenden Gründen unerreichbares Ziel gerichtet ist, und daß die Rechtfertigungsgründe und Argumente, die diese Suche liefert, nicht nach unangemessenen Standards bewertet werden, die auch im Bereich des Beobachtbaren nicht erfüllt werden und die vor allem gar nicht erfüllbar sind, ist es hilfreich, in der beschriebenen Weise die Möglichkeiten und die Grenzen der Möglichkeiten, Rechtfertigungsgründe und Argumente für ontologische realistische Thesen über Beobachtbares anzugeben, als Orientierungspunkt heranzuziehen.

\section{Interne Reflexion über den epistemischen Status von Überzeugungen über Unbeobachtbares}

Mit den Resultaten, die die Überlegungen der vorigen Abschnitte über Rechtfertigungsgründe und Argumente für ontologische realistische Thesen über Beobachtbares ergeben haben, stehen jetzt alle erforderlichen Voraussetzungen zur Verfügung, um daran gehen zu können, für ontologische realistische Thesen über Unbeobachtbares zu untersuchen, was sich von einem reliabilistischen Standpunkt aus an Rechtfertigungsgründen und Argumenten für sie vorbringen läßt. Das, was hier im einzelnen zu untersuchen ist, und auch das, was sich dabei finden läßt, weist weitreichende Parallelen zu der in den vorigen Abschnitten eingehend erörterten Sachlage im Bereich des Beobachtbaren auf. Eine dieser Parallelen ist, daß auch bei ontologischen realistischen Thesen über Unbeobachtbares zu unterscheiden ist zwischen Rechtfertigungsgründen, die sich in interner Reflexion für eine solche These angeben lassen, und Argumenten, die sich in einer Debatte mit anderen Personen für diese These vorbringen lassen, um die Diskussionsgegner von ihr zu überzeugen. Um erstere soll es hier zunächst gehen. ${ }^{178}$

Die Art von Rechtfertigungsgründen, nach denen man sucht, ist auf beiden Seiten der Grenze beobachtbar/unbeobachtbar dieselbe, da dieser Grenze aus reliabilistischer Perspektive betrachtet keine besondere, irgendwie grundlegende Relevanz zukommt. Wenn man nach Rechtfertigungsgründen für eine Überzeugung über Unbeobachtbares sucht, sucht man — wie im Beobachtbaren — nach hinreichenden direkten Rechtfertigungsgründen, d.h. nach einer Herkunftsüberzeugung, einer Verläßlichkeitsüberzeugung für das erzeugende bzw. stabilisierende epistemische Verfahren und, sofern dies ein Inferenzverfahren ist, nach den als Prämissen erforderlichen Überzeugungen. Wenn man solche direkten Rechtfertigungsgründe gefunden hat, kann man weiter nach Rechtfertigungsgründen für diese suchen, also nach indirekten Rechtfertigungsgründen, usw. ${ }^{179}$

Wenn man die Frage nach Rechtfertigungsgründen für eine Überzeugung über Unbeobachtbares immer wieder iteriert, stößt man, wie bei einer Überzeugung über Beob-

\footnotetext{
${ }^{178} \mathrm{Im}$ folgenden bleibt die Frage nach Rechtfertigungsgründen für die in ontologischen realistischen Thesen enthaltenen Unabhängigkeitsaussagen wiederum beiseite; vgl. S.460.

${ }^{179}$ Siehe S.462ff.
} 
achtbares, früher oder später auf offene Enden und/oder Zirkel. Daß den Möglichkeiten, in interner Reflexion Rechtfertigungsgründe für eine Überzeugung aufzuweisen, auch im Bereich des Unbeobachtbaren in dieser Weise Grenzen gesetzt sind, ist klar, wenn man sich noch einmal ansieht, was dieser Art von prinzipiellen Grenzen im Bereich des Beobachtbaren zugrundeliegt: ${ }^{180}$ Diese Grenzen ergeben sich zwangsläufig dadurch, daß der menschliche kognitive Apparat endlich ist, so daß eine Person nur endlich viele Überzeugungen haben kann und nur endlich viele epistemische Verfahren verwenden kann, und jede Überzeugung einer Person damit nur einen endlichen Rechtfertigungsgraphen haben kann. Für das Zustandekommen dieser Grenzen der Möglichkeiten, Rechtfertigungsgründe für eine Überzeugung aufzuweisen, spielt es also offenbar keine Rolle, ob sich die Überzeugung auf etwas Beobachtbares oder auf etwas Unbeobachtbares bezieht, daher ist unabhängig von der Untersuchung konkreter Beispiele — klar, daß man im Bereich des Unbeobachtbaren ebenso auf diese prinzipiellen Grenzen stoßen muß wie im Bereich des Beobachtbaren, wenn man, ausgehend von einer bestimmten Überzeugung, die Frage nach Rechtfertigungsgründen immer wieder iteriert.

Die Tatsache, daß es solche prinzipiellen Grenzen der Möglichkeiten, in interner Reflexion Rechtfertigungsgründe für eine Überzeugung über Unbeobachtbares aufzuweisen, gibt, stellt jedoch kein Hindernis für wissenschaftlichen Realismus dar. Dies wird klar, wenn man sich noch einmal die vorne ${ }^{181}$ angestellten Überlegungen ansieht, die deutlich machen, daß die Existenz entsprechender prinzipieller Grenzen im Bereich des Beobachtbaren keinen plausiblen Grund darstellt, dort grundsätzlich alle Rechtfertigungsgründe einer Überzeugung als "in epistemischer Hinsicht nicht zufriedenstellend" o.ä. zu betrachten: Auch für diese Überlegungen spielt es keine Rolle, ob es um Überzeugungen über Beobachtbares oder über Unbeobachtbares geht; sie lassen sich daher auf den Bereich des Unbeobachtbaren übertragen und gelten auch dort. Die Tatsache, daß der Rechtfertigungsgraph jeder Überzeugung endlich ist, und daß man daher früher oder später auf offene Enden und/oder Zirkel stößt, wenn man die Frage nach Rechtfertigungsgründen für eine Überzeugung immer wieder iteriert, stellt daher weder im Bereich des Beobachtbaren, noch im Bereich des Unbeobachtbaren einen plausiblen Grund dar, die Rechtfertigungsgründe, die den Rechtfertigungsgraph der Überzeugung ausmachen, grundsätzlich als "in epistemischer Hinsicht nicht zufriedenstellend" o.ä. zu bewerten, und damit stellt sie weder für Common-sense-Realismus, noch für wissenschaftlichen Realismus ein Hindernis dar.

Von den beschriebenen prinzipiellen Grenzen unabhängig sind offenbar auch im Bereich des Unbeobachtbaren die Fragen, ob man für bestimmte Überzeugungen - und damit für bestimmte ontologisch realistische Thesen über Unbeobachtbares - in interner Reflexion hinreichende Rechtfertigungsgründe aufweisen kann oder nicht, von welcher "Qualität" diese Rechtfertigungsgründe ggf. sind u.ä. Die Rechtfertigungsgründe, die man für eine Überzeugung über Unbeobachtbares tatsächlich aufweisen kann, beziehen sich naturgemäß häufig auf andere epistemische Verfahren (bzw. auf deren Verläßlichkeit) als Rechtfertigungsgründe für Überzeugungen über Beobachtbares, eben auf Verfahren, deren Anwendungsbereich nicht diesseits der Grenze beobachtbar/unbeobachtbar liegt, sondern auf beiden Seiten dieser Grenze (wie im Fall des Beobachtens mit einer Lupe und der anderen "grenzüberschreitenden" Verfahren, auf die durch die epistemischen Kontinuitätsargumente hingewiesen wird ${ }^{182}$ ) oder jenseits von ihr (wie im Fall des Messens magnetischer Feldstärken mit Hilfe einer Hall-Sonde u.ä.). Aus reliabilistischer Perspek-

\footnotetext{
${ }^{180}$ Siehe Abschnitt 14.2.3, bes. S.465ff., 481ff.

${ }^{181}$ Siehe S.481ff.

${ }^{182} \mathrm{Vgl}$. Abschnitt 8.3.
} 
tive betrachtet können solche Verfahren im selben Sinn Überzeugungen verursachen oder stabilisieren, verläßlich sein, der Gegenstand von Herkunfts- und Verläßlichkeitsüberzeugungen sein etc. und daher in epistemischer Hinsicht dieselbe Rolle spielen wie die im Bereich des Beobachtbaren gängigen Verfahren.

\section{Ein Programm für die Suche nach epistemischen Rechtfertigungsgründen für eine selektive realistische Position in der wissenschaftstheoretischen Realis- musdebatte}

In interner Reflexion nach Rechtfertigungsgründen für ontologische realistische Thesen über Unbeobachtbares zu suchen ist ein wesentlicher Teil dessen, was sich, aus reliabilistischer Perspektive betrachtet, zur epistemischen Begründung einer selektiven realistischen Position in der wissenschaftstheoretischen Realismusdebatte tun läßt. Um eine solche selektive realistische Position, die man selbst vertritt, epistemisch zu begründen, müßte man sich in interner Reflexion Rechenschaft über ihren epistemischen Status ablegen, d.h. man müßte eine Liste der ontologischen realistischen Thesen bzw. der entsprechenden eigenen Überzeugungen über Unbeobachtbares erstellen, die, wie vorne diskutiert, das Herzstück einer solchen Position bilden, ${ }^{183}$ und man müßte sich dann, so, wie es in den vorigen Abschnitten skizziert wurde, die Rechtfertigungsgraphen all dieser Überzeugungen zurechtlegen, also für jede dieser Überzeugungen die direkten und indirekten Rechtfertigungsgründe, die sich für sie (innerhalb der oben beschriebenen prinzipiellen Grenzen) aufweisen lassen (ggf. bis hin zu Rechtfertigungsgründen, die "schwache Gründe" involvieren ${ }^{184}$ ).

Diese Begründungsaufgabe ist, gegeben den Entwicklungsstand der heutigen Wissenschaften, von einer einzelnen Person offensichtlich nicht mehr erfüllbar, wenn es um die Begründung einer selektiven realistischen Position gehen soll, die, wie es von einer realistischen Position in der wissenschaftstheoretischen Realismusdebatte üblicherweise erwartet wird, eine Aussage zur Gesamtheit der "kognitiven Produkte", also der Theorien, Gesetze, Modelle etc. der Wissenschaften trifft, insbesondere zu dem Teil, der von Unbeobachtbarem handelt: Einer einzelnen Person ist es heute aufgrund der Menge der inzwischen gewonnenen Theorien, Gesetze, Modelle etc. nicht mehr möglich, über den gesamten Kenntnisstand der Wissenschaften informiert zu sein, nicht einmal über den "gut gesicherten", stabilen, in Lehrbuchdarstellungen etc. eingegangenen Teil der inzwischen gewonnenen Theorien, Gesetze etc., sprich: es ist einer einzelnen Person nicht mehr möglich, Überzeugungen zu haben, die den Gesamtbestand der kognitiven Produkte der heutigen Wissenschaften abdecken. Daher ist es einer einzelnen Person auch nicht mehr möglich, eine selektive realistische Position zu vertreten, die zur Gesamtheit dieser kognitiven Produkte, und insbesondere zum gesamten Teil davon, der von Unbeobachtbarem handelt, Stellung bezieht. Eine solche selektive realistische Position auch nur zu formulieren und darüber hinaus Rechtfertigungsgründe für sie anzugeben, ist eine Aufgabe, die allenfalls von einer Gruppe von Personen zusammen, sozusagen in Arbeitsteilung erfüllt werden könnte. Eine einzelne Person kann "nur" einen (mehr oder weniger kleinen) Beitrag zu einem solchen Gesamtprojekt liefern, indem sie für einen Teil der in den Wissenschaften etablierten Theorien, Gesetze etc. über Unbeobachtbares untersucht, was sich für entsprechende ontologische realistische Thesen bzw. für entsprechende Überzeugungen in interner Re-

\footnotetext{
${ }^{183}$ Natürlich gehören i.a. auch entsprechende Thesen bzw. Überzeugungen über Beobachtbares zu einer realistischen Position; diese bleiben aber hier, wie in der wissenschaftstheoretischen Realismusdebatte üblich, beiseite.

${ }^{184}$ Siehe S.468ff.
} 
flexion an Rechtfertigungsgründen anführen läßt. ${ }^{185}$ Eine einzelne Person kann natürlich eine mehr oder weniger große Anzahl von Überzeugungen haben, die ontologische realistische Thesen über Unbeobachtbares zum Inhalt haben, und für diese Überzeugungen so, wie in den vorigen Abschnitten beschrieben, in interner Reflexion Rechtfertigungsgründe anführen, aber eine selektive realistische Position zu vertreten und zu rechtfertigen, die die Rolle ausfüllt, die für eine realistische Position in der wissenschaftstheoretischen Realismusdebatte üblicherweise vorgesehen wird, ist für eine einzelne Person nicht mehr möglich.

Die Aufgabe, einen Beitrag der genannten Art zu einer selektiven realistischen Position in der wissenschaftstheoretischen Realismusdebatte zu liefern, indem man für einzelne oder für einige in den Wissenschaften etablierte Theorien, Gesetze o.ä. über Unbeobachtbares bzw. für entsprechende ontologische realistische Thesen untersucht, was sich in interner Reflexion an Rechtfertigungsgründen für sie angeben läßt, unterscheidet sich in einer Hinsicht von der Aufgabe, sich in interner Reflexion Rechenschaft über den epistemischen Status der eigenen Überzeugungen über beobachtbare Gegenstände, Sachverhalte etc. der Alltagswelt abzulegen, und ist daher i.a. mit mehr Aufwand verbunden: Um eine selektive realistische Position in der wissenschaftstheoretischen Realismusdebatte zu begründen, wird man alles (oder jedenfalls das Beste) an Rechtfertigungsgründen anführen wollen, was die Wissenschaften derzeit zur Verfügung stellen, nicht bloß das, was einer Person kontingenterweise davon bekannt ist. Man wird also für eine bestimmte ontologische realistische These alles (oder jedenfalls das Beste) an Rechtfertigungsgründen angeben wollen, was die Gemeinschaft der Wissenschaftler und insbesondere die mit dem jeweiligen Gebiet beschäftigten Experten, dafür zur Verfügung haben, und das können Rechtfertigungsgründe sein, die i.a. nicht jeder Person und nicht einmal jedem Fachwissenschaftler bekannt sind. Um einen Beitrag zu einer selektiven realistischen Position zu liefern, indem man untersucht, was sich für bestimmte ontologische realistische Thesen in interner Reflexion an Rechtfertigungsgründen angeben läßt, wird man sich also i.a. (d.h. wenn man nicht zufällig gerade "Experte" für das fragliche Gebiet ist) erst alle dafür relevanten Kenntnisse aneignen müssen, ${ }^{186}$ d.h. entsprechende neue Überzeugungen erwerben müssen, bevor man sich die Rechtfertigungsgraphen der Überzeugungen, die die fraglichen ontologischen realistischen Thesen zum Inhalt haben, zurechtlegt. Dies ist bei der Suche nach Rechtfertigungsgründen für eigene Überzeugungen über beobachtbare Gegenstände etc. der Alltagswelt in interner Reflexion nicht so, dort beschränkt man sich (i.a.) auf die kontingenterweise bereits vorhandenen eigenen Überzeugungen.

Mit den obigen Überlegungen ist offenbar ein Programm für die Suche nach epistemischen Rechtfertigungsgründen für eine selektive realistische Position in der wissenschaftstheoretischen Realismusdebatte skizziert, genauer: ein Programm, das beschreibt, was im Prinzip zu tun ist, um für die Gesamtheit der ontologischen realistischen Thesen über Unbeobachtbares, die das Herzstück einer selektiven realistischen Position in der wissenschaftstheoretischen Realismusdebatte bildet, in interner Reflexion das an Rechtfertigungsgründen aufzuweisen, was nach dem heutigen Stand der Wissenschaft verfügbar ist. Dieses Programm setzt offenbar insofern das Zusammenstellen einer Liste der ontologischen realistischen Thesen, die diese Gesamtheit bilden, voraus oder schließt es ein, als die selektive realistische Position, um die es geht, zu allen in den Wissenschaften etablierten Theorien, Gesetzen etc. über Unbeobachtbares eine Aussage treffen soll, und dieses Programm daher eine Suche nach Rechtfertigungsgründen für alle diese Theorien, Gesetze etc. bzw. für alle

\footnotetext{
${ }^{185}$ Vgl. auch Abschnitt 13.4.1.

${ }^{186}$ Durch Lektüre der Fachliteratur, eigene Untersuchungen im fraglichen Gegenstandsbereich usw.
} 
entsprechenden ontologischen realistischen Thesen einschließt. ${ }^{187}$

Das skizzierte Programm ist so umfangreich, daß im Rahmen dieser Arbeit nicht einmal an die Realisierung eines - gemessen am Gesamtumfang — nennenswerten und einigermaßen repräsentativen Teils davon zu denken ist. Was sich hier im Hinblick auf die epistemische Rechtfertigung einer selektiven realistischen Position in der wissenschaftstheoretischen Realismusdebatte tun läßt und getan werden soll, um eine solche Position wenigstens vom Grundsatz her plausibel erscheinen zu lassen, ist zweierlei: Zum einen soll zumindest an einem, gleichsam punktuellen Beispiel aus dem Bereich der Physik untersucht werden, was sich in interner Reflexion an Rechtfertigungsgründen für bestimmte, konkrete ontologische realistische Thesen über Unbeobachtbares vorbringen läßt, auch wenn selbst dies an dieser Stelle nur in unvollständiger Weise und nicht mit der eigentlich wünschenswerten Genauigkeit möglich ist; dies ist das Thema des nächsten Kapitels. ${ }^{188}$ Zum anderen soll ein grober Überblick darüber skizziert werden, was bei einer Umsetzung des Programms zu untersuchen wäre, genauer: welche Art von epistemischen Verfahren im Bereich der Wissenschaften zur Gewinnung oder Stabilisierung ${ }^{189}$ von Überzeugungen über Unbeobachtbares eingesetzt werden und daher für die Rechtfertigung von ontologischen realistischen Thesen über Unbeobachtbares aus dem Bereich der Wissenschaften relevant sind, und welche Art von Rechtfertigungsgründen für die Verläßlichkeit dieser epistemischen Verfahren in Frage kommt und vielleicht plausiblerweise tatsächlich zu finden sein könnte; dies soll im folgenden geschehen.

Zur Gewinnung von Überzeugungen über singuläre unbeobachtbare Sachverhalte wird im Bereich der Wissenschaften eine Vielzahl von Erzeugungsverfahren eingesetzt, die typischerweise (aber nicht ausnahmslos) in alltagsweltlichen Kontexten keine Verwendung finden, nämlich Erzeugungsverfahren, die die Benutzung von Meßgeräten, Nachweis-, Analyse- und Abbildungsinstrumenten und Detektoren der verschiedensten Typen involvieren: Überzeugungen über die Stärke des Erdmagnetfeldes gewinnt man mit Hilfe von Magnetometern, Überzeugungen über die Stärke bestimmter elektrischer Ströme mit Hilfe von Amperemetern, Überzeugungen über Temperaturen mit Hilfe von Thermometern verschiedener Art, die Anzahl roter Blutzellen in Blutproben wird durch Beobachtung mit einem Mikroskop bestimmt, Spektren von Sternen mit Hilfe von Spektrometern und Halbleiterdetektoren für elektromagnetische Strahlung, die Aktivität von Proben radioaktiver Substanzen mittels eines Zählrohrs, der pH-Wert von Wasserproben durch pH-Meter oder Indikatorstreifen etc. Bei den meisten dieser Erzeugungsverfahren liegt ihr Anwendungsbereich ganz im Unbeobachtbaren, es werden aber auch Verfahren eingesetzt, deren Anwendungsbereich auf beiden Seiten der Grenze beobachtbar/unbeobachtbar liegt, z.B. Beobachten mit der Lupe (etwa in der Biologie bei der Bestimmung von Pflanzen und Tieren) und Beobachten mit Hilfe von Hochgeschwindigkeitskameras (etwa bei der Untersuchung der Flugmechanismen von Insekten und des Verhaltens von Flüssigkeitstropfen). Aus reliabilistischer Perspektive betrachtet weist die Gewinnung von Überzeugungen über singuläre Sachverhalte mit Hilfe von Erzeugungsverfahren dieser Art offenbar weitreichen-

\footnotetext{
${ }^{187}$ Vgl. Abschnitt 13.4.1. Grundsätzlich sind Rechtfertigungsgründe natürlich nur für Überzeugungen anzugeben, d.h. nur für ontologische realistische Thesen, die man selbst glaubt. Zu prüfen sind im Rahmen des skizzierten Programms jedoch sämtliche etablierten wissenschaftlichen Theorien, Gesetze etc. bzw. entsprechende ontologische realistische Thesen, da es möglich ist, daß man erst mit dem Erwerb des jeweils relevanten, als Rechtfertigungsgründe fungierenden "Expertenwissens" Überzeugungen erwirbt, die die ontologischen realistischen Thesen zum Inhalt haben.

${ }^{188}$ Siehe Kap. 15.

${ }^{189} \mathrm{Im}$ folgenden ist der Kürze halber wiederum häufig von der Gewinnung von Überzeugungen die Rede, wenn implizit die Gewinnung oder Stabilisierung gemeint ist.
} 
de Parallelen zur Gewinnung von Überzeugungen über singuläre Sachverhalte mit Hilfe menschlicher Sinnesorgane auf, insbesondere dann, wenn es sich um routinemäßig eingesetzte, "robuste" und gut etablierte Verfahren handelt, bei deren Einsatz die Gewinnung einer Überzeugung normalerweise "automatisch" verläuft, d.h., bei deren Einsatz normalerweise kein bewußt ausgeführter, expliziter Inferenzschritt mehr zwischen einem abgelesenen Skalenwert o.ä. und der gewonnenen Überzeugung liegt, so daß sich diese Verfahren gewissermaßen als Erweiterungen des Satzes von Sinnesorganen, mit denen Menschen von Natur aus ausgestattet sind, auffassen lassen. ${ }^{190}$ Überzeugungen über singuläre unbeobachtbare Sachverhalte werden im Bereich der Wissenschaften natürlich auch mit Hilfe von deduktiven und induktiven Inferenzverfahren gewonnen und vielleicht auch mit Hilfe von Übertragungsverfahren von der Art des Schließens auf die beste Erklärung und mit Hilfe des von Salmon skizzierten kausalen Inferenzverfahrens ${ }^{191}$, die sich von den im Bereich der Alltagswelt eingesetzten Verfahren nicht unterscheiden.

Zur Gewinnung von Überzeugungen über allgemeine unbeobachtbare Sachverhalte wird im Bereich der Wissenschaften ebenfalls eine Reihe verschiedener epistemischer (Übertragungs-) Verfahren verwendet. Welches Verfahren für eine bestimmte Überzeugung einsetzbar ist und eingesetzt wird, hängt u.a. davon ab, ob und, wenn ja, inwieweit für die Größen, Eigenschaften o.ä., die der fragliche allgemeine Sachverhalt involviert, Meß-, Nachweis- oder Abbildungsverfahren (und damit "direkt verallgemeinerbare" Überzeugungen über entsprechende singuläre Sachverhalte) verfügbar sind, und auch davon, von welchem "Allgemeinheitsgrad" der fragliche Sachverhalt ist, ob es also um einen eher speziellen Typ von Systemen, Gegenständen, Ereignissen o.ä. und damit um eher niederstufige oder phänomenologische Gesetze geht, wie z.B. bei der Strom-Spannungs-Kennlinie von Nanodrähten aus einem bestimmten Material, oder um einen allgemeineren oder sogar sehr allgemeinen Typ und damit um eher hochstufige oder sogar fundamentale Gesetze, wie z.B. bei den Maxwell-Gleichungen oder bei den Feldgleichungen der allgemeinen Relativitätstheorie. ${ }^{192}$ Überzeugungen, die sich auf einen eher speziellen Typ von Systemen o.ä. beziehen, bzw. niederstufige oder phänomenologische Gesetze können manchmal (wenn man über "geeignete" Prämissen verfügt) deduktiv aus hochstufigeren Gesetzen gewonnen werden; manchmal können solche Überzeugungen bzw. Gesetze induktiv aus Meßdaten o.ä. erschlossen werden, manchmal auch durch eine Kombination deduktiver und induktiver Inferenzverfahren ${ }^{193}$ oder mit Hilfe eines kausalen Inferenzverfahrens oder eines Schlusses von der Art des Schließens auf die beste Erklärung. Schlüsse dieser letzteren Art sind es auch, die in erster Linie zur Gewinnung von Überzeugungen, die sich auf einen allgemeinen oder sehr allgemeinen Typ von Systemen o.ä. beziehen, bzw. von hochstufigen oder fundamentalen Gesetzen eingesetzt werden können oder jedenfalls dafür in Frage kommen (wenn "geeignete" Prämissen vorliegen); ein Inferenzschema, das für solche Schlüsse auf die beste Erklärung einsetzbar ist, (oder auch mehrere) genau zu spezifizieren, ist allerdings, wie vorne diskutiert, schwierig. ${ }^{194}$

\footnotetext{
${ }^{190}$ Auf die Parallelen zwischen Meß-, Nachweis- und Abbildungsverfahren einerseits und den menschlichen Sinnesorganen andererseits weist u.a. Maxwell hin ([Maxw62], S.10f.).

${ }^{191}$ Siehe Abschnitt 8.3.4.

${ }^{192}$ Ein wichtiger Punkt, der bei einer Realisierung des oben skizzierten Programms genau zu diskutierten wäre, der hier jedoch nur genannt werden kann, ist die Frage nach dem Verhältnis von Gesetzen und kontingenten allgemeinen Sätzen und evtl. nach Unterschieden bei der Gewinnung bzw. Rechtfertigung beider Arten allgemeiner Sätze.

${ }^{193}$ Etwa wenn die "Form" eines phänomenologischen Gesetzes deduktiv aus allgemeineren Gesetzen folgt, bestimmte Parameter, Materialkonstanten o.ä. jedoch induktiv aus Messungen erschlossen werden.

${ }^{194}$ Vgl. Abschnitt 8.3.5 und Kap.9, bes. Abschnitt 9.9.7.
} 
Während für die Anwendung deduktiver Inferenzschemata die Unterscheidung beobachtbar/unbeobachtbar keine Rolle spielt, so daß dieselben Inferenzschemata in alltagsweltlichen und in wissenschaftlichen Kontexten eingesetzt werden oder jedenfalls eingesetzt werden können, ist bei induktiven Schlüssen und bei Schlüssen von der Art des Schließens auf die beste Erklärung weniger klar, ob oder inwieweit dasselbe gilt, wenn dies auch grundsätzlich plausibel aussieht: Bei Schlüssen auf die beste Erklärung vertreten zumindest einige Autoren - trotz der genannten "Spezifikationsprobleme" — die Ansicht, daß sie in gleicher Weise auf beiden Seiten der Grenze beobachtbar/unbeobachtbar vorgenommen werden können. ${ }^{195}$ Bei induktiven Schlüssen im alltagsweltlichen Bereich gibt es ähnliche "Spezifikationsprobleme"; sie werden häufig in einer informellen, "intuitiven" Weise gezogen, bei der sich die schließende Person gleichsam auf ihr "induktives Vermögen" verläßt, ohne jedoch ein induktives Inferenzverfahren, das in diesem Fall zur Anwendung kommt, präzise spezifizieren zu können, ${ }^{196}$ und zumindest in "beobachtungsnahen", wenig mathematisierten Teilen der Wissenschaften dürften sich ebenfalls Fälle dieser Vorgehensweise finden lassen. ${ }^{197}$ Dagegen wird in den stärker von mathematischen Methoden durchdrungenen Teilen der Wissenschaften ein umfangreiches, elaboriertes "Regelwerk" eingesetzt, um induktive Schlüsse zu ziehen, vor allem zur Gewinnung niedrigstufiger oder phänomenologischer Gesetze aus Meßwerten, Daten o.ä., die durch systematische Beobachtungen, experimentelle Untersuchungen u.ä. gewonnen wurden (sowie "geeigneten" zusätzlichen Prämissen). Diese statistischen, häufig als Testtheorie o.ä. bezeichneten Verfahren lassen sich aus reliabilistischer Perspektive betrachtet als eine Familie präzise spezifizierter induktiver Inferenzverfahren auffassen. ${ }^{198}$ Zumindest für diese statistischen Inferenzverfahren und ihre Anwendbarkeit spielt die Unterscheidung beobachtbar/unbeobachtbar keine Rolle, und, soweit sich das angesichts der genannten Spezifikationsprobleme beurteilen läßt, dürfte sie auch für die "intuitive" Anwendung eines "induktiven Vermögens" keine Rolle spielen, wenigstens keine prinzipielle. Ebenfalls keine Rolle spielt die Grenze beobachtbar/unbeobachtbar offenbar für das von Salmon skizzierte kausale Inferenzverfahren.

Eine weitere Sorte epistemischer Verfahren, die im Bereich der Wissenschaften bei der Gewinnung von Überzeugungen (sowohl über singuläre, als auch über allgemeine Sachverhalte) eine Rolle spielt, könnte man die Verwendung von Theorien, Modellen etc. als deduktives Orakel nennen: ${ }^{199}$ Theorien, Modelle etc., die man für falsch oder zumindest nicht für wahr hält (unter anderem auch solche, zu denen man eine instrumentalistische Einstellung einnimmt, weil man sie für nicht "semantisch vollwertig" hält ${ }^{200}$ ), kann man grundsätzlich dennoch als verläßliche "Quelle" von Überzeugungen betrachten und behandeln: Aus einer Theorie etwa, die man für (in einem bestimmten Gegenstands-, Größeno.ä. Bereich) empirisch adäquat hält, aber nicht für wahr, kann man dennoch durch deduktives Schließen Überzeugungen über Beobachtbares (in diesem Bereich) gewinnen, und wenn die Theorie tatsächlich empirisch adäquat ist, ist dies ein (in diesem Bereich) verläßliches epistemisches Verfahren. In derselben Weise kann man durch deduktives Schließen

\footnotetext{
${ }^{195}$ Siehe Abschnitt 8.3.5.

${ }^{196}$ Siehe S.451f.

${ }^{197}$ Etwa in der Paläontologie oder in der Anthropologie.

${ }^{198}$ Diese Lesart der von Fisher, Neyman, Pearson und anderen entwickelten Testtheorie skizziert Hacking in [Hack80]. Historisch ist die Testtheorie nicht im Rahmen einer reliabilistischen Position in der Erkenntnistheorie entwickelt worden und auch systematisch ist sie nicht notwendigerweise an eine reliabilistische Position geknüpft, sie läßt sich jedoch zwanglos in eine solche integrieren.

${ }^{199}$ Dies mag gelegentlich, aber sicherlich nicht häufig, auch in "wissenschaftsinfizierten" alltagsweltlichen Kontexten vorkommen.

${ }^{200}$ Siehe S.18.
} 
Überzeugungen aus einer Theorie gewinnen, die man nicht (nur) für empirisch adäquat hält, also nicht (nur) im Beobachtbaren für eine verläßliche "Quelle" von Überzeugungen, sondern in einem anders begrenzten Gegenstands-, Größen- o.ä. Bereich, der ganz oder teilweise jenseits der Grenze beobachtbar/unbeobachtbar liegen kann (z.B. in einem bestimmten Bereich kleiner Geschwindigkeiten, großer Energien o.ä.); auch dies kann ein verläßliches epistemisches Verfahren darstellen. Beispiele für Theorien und Modelle, die in diesem Sinn als deduktives Orakel benutzt werden, sind die Ersatzschaltbilder, die in der Elektrotechnik für den Umgang mit Halbleiterbauelementen gebräuchlich sind, und sämtliche quantenmechanischen Modelle ${ }^{201}$.

Welche Art von Rechtfertigungsgründen kommt für eine Verläßlichkeitsüberzeugung in bezug auf die genannten epistemischen Verfahren in Frage und könnte plausiblerweise tatsächlich aufzuweisen sein, wenn man das vorne skizzierte Programm realisiert? Bei jedem epistemischen Verfahren, das schon "hinreichend oft" eingesetzt worden ist, und dessen Output sich später nicht oder jedenfalls nicht zu häufig als falsch erwiesen hat, sollten sich für eine Verläßlichkeitsüberzeugung induktive Rechtfertigungsgründe der vorne ${ }^{202}$ skizzierten Art anführen lassen, also im wesentlichen der Befund, daß diese Verläßlichkeitsüberzeugung sich induktiv erschließen läßt aus den Überzeugungen, die durch das Verfahren erzeugt oder stabilisiert worden sind, und entsprechenden Herkunftsüberzeugungen. Insbesondere liegen solche induktiven Rechtfertigungsgründe in Fällen vor, in denen zumindest ein Teil der durch ein Verfahren erzeugten rsp. stabilisierten Überzeugungen durch ein weiteres, unabhängiges Verfahren stabilisiert rsp. erzeugt worden sind, so daß die bisherige Erfolgsbilanz des ersteren Verfahrens sozusagen am Output des anderen Verfahrens gemessen und bestätigt wird. ${ }^{203}$ Anschaulich gesprochen beruht ein induktiver Schluß auf eine Verläßlichkeitsüberzeugung dort auf einer Statistik, wie häufig sich der Output des fraglichen epistemischen Verfahrens bisher als wahr (bzw. als falsch) erwiesen hat; in der Praxis wird eine solche Erfolgsstatistik gelegentlich eigens "hergestellt", nämlich in Situationen, in denen ein Meß-, Nachweis- oder Abbildungsinstrument, ein De-

\footnotetext{
${ }^{201}$ Dies gilt etwa dann, wenn man (wie es häufig getan wird) zu einem quantenmechanischen Modell eine instrumentalistische Einstellung einnimmt, aber dennoch daraus klassische Prognosen ableitet und aufgrund dieser Ableitung als Überzeugungen akzeptiert.

${ }^{202}$ Siehe S.463f.

${ }^{203}$ Intuitiv macht es für viele einen wesentlichen Unterschied, ob die durch ein bestimmtes epistemisches Verfahren erzeugten oder stabilisierten Überzeugungen, die einem induktiven Schluß auf eine Verläßlichkeitsüberzeugung in bezug auf dieses Verfahren zugrunde liegen, durch ein weiteres, unabhängiges Verfahren erzeugt oder wenigstens stabilisiert wurden oder nicht (so daß sie im letzteren Fall nur mit Hilfe des Verfahrens selbst gewonnen wurden bzw. stabilisiert werden können, dessen Verläßlichkeit zur Debatte steht). Induktive Rechtfertigungsgründe für eine Verläßlichkeitsüberzeugung in bezug auf dieses Verfahren können sich jedoch offenbar in beiden Fällen aufweisen lassen, nicht nur, wenn die Erfolgsbilanz des Verfahrens am Output eines anderen, unabhängigen Verfahrens gemessen wird.

Die Intuition, daß induktive Rechtfertigungsgründe für eine Verläßlichkeitsüberzeugung nur in der letztgenannten der beiden Sorten von Fällen "zufriedenstellend" sind, "etwas wert sind" o.ä., hängt zusammen mit der vorne bei der Untersuchung indirekter Rechtfertigungsgründe erwähnten Intuition, daß ein Rechtfertigungsgraph einer Überzeugung "nicht zufriedenstellend" ist, "nichts wert" ist o.ä., wenn er lediglich "zu kleine" Zirkel enthält. Beide Intuitionen dürften dadurch motiviert sein, daß diejenigen, die sie teilen (u.a. ich selbst), keine epistemischen Verfahren akzeptieren und zur Gewinnung von Überzeugungen einsetzen, die den Erwerb von Überzeugungen ermöglichen, deren Rechtfertigungsgraph lediglich "zu kleine” Zirkel enthält, und auch keine Regeln oder Verfahren zur Beseitigung von Konflikten in ihrem Überzeugungssystem verwenden, die bei ihrer Anwendung solche Überzeugungen "übrig lassen" (vgl. S.482, Fn.143), so daß sich in ihrem Überzeugungssystem tatsächlich auch keine solchen Überzeugungen finden. Wenn das so ist, sind also die genannten Intuitionen verträglich mit dem Befund, daß man induktive Rechtfertigungsgründe für eine Verläßlichkeitsüberzeugung grundsätzlich in beiden oben unterschiedenen Sorten von Fällen haben kann.
} 
tektor o.ä. mit Hilfe eines anderen Instruments bzw. der durch dieses andere Instrument vermessenen, abgebildeten o.ä. Gegenstände, Systeme o.ä. kalibriert wird. ${ }^{204}$ Wenn man das vorne skizzierte Programm umsetzt, sollten sich induktive Rechtfertigungsgründe für eine Verläßlichkeitsüberzeugung in bezug auf viele Meßgeräte, Nachweis-, Analyse- und Abbildungsinstrumente, Detektoren und ähnliche Erzeugungsverfahren aufweisen lassen, insbesondere in bezug auf in der Praxis schon lange gebräuchliche und etablierte Geräte bzw. Verfahren. Für die Verläßlichkeit deduktiver Inferenzverfahren lassen sich sicherlich ebenfalls induktive Rechtfertigungsgründe angeben, ${ }^{205}$ dagegen wird man bei der Suche nach induktiven Rechtfertigungsgründen für die Verläßlichkeit induktiver Inferenzverfahren zumindest dort auf Schwierigkeiten stoßen, wo diese Verfahren nicht genau genug spezifiziert werden können, ${ }^{206}$ und dies gilt auch für induktive Extrapolationsschlüsse der von Salmon skizzierten Art. ${ }^{207}$ Unklar ist die Lage auch bei Inferenzverfahren von der Art des Schließens auf die beste Erklärung: Für ein allgemeines, kontextunabhängiges Inferenzschema wie (IBE) ${ }^{208}$ sieht die Erfolgsbilanz, wie vorne ${ }^{209}$ unter dem Stichwort "pessimistische Induktion" diskutiert, ungünstig aus; für speziellere, eingeschränktere Inferenzschemata der Form (IBEsp) ${ }^{210}$ könnte sie günstiger aussehen, sofern sich diese Schemata hinreichend genau spezifizieren lassen. Sinngemäß dasselbe gilt, wie vorne bereits erwähnt $^{211}$, für Salmons kausales Inferenzverfahren. Ob die Verwendung einer Theorie, eines Modells o.ä. als deduktives Orakel ein verläßliches Verfahren ist, hängt natürlich vom Einzelfall ab; zumindest im Fall etablierter Verfahren dieser Art (wie der oben genannten Ersatzschaltbilder u.ä.) dürften sich aber induktive Rechtfertigungsgründe für eine Verläßlichkeitsüberzeugung angeben lassen.

Neben induktiven sind auch deduktive Rechtfertigungsgründe für eine Verläßlichkeitsüberzeugung denkbar, und bei einigen Erzeugungsverfahren wie dem Einsatz bestimmter Meßgeräte, Nachweisinstrumente etc. dürften sich auch tatsächlich deduktive Rechtfertigungsgründe für ihre Verläßlichkeit finden lassen. ${ }^{212}$ Solche deduktiven Rechtfertigungsgründe hat man, wenn man über eine theoretische Beschreibung des jeweiligen Meßgeräts, Nachweisinstruments o.ä., also seines Funktionsmechanismus und des Meß-, Nachweiso.ä. Prozesses, verfügt, aus der die Verläßlichkeit des Meß- o.̈̈. Verfahrens (unter bestimmten Bedingungen) näherungsweise (und in seltenen Fällen vielleicht auch exakt) deduktiv folgt. Z.B. sollte sich bei optischen Beobachtungsverfahren (Beobachten mittels Lupe, Mikroskop, Teleskop usw.) häufig eine Verläßlichkeitsüberzeugung aus einer Theorie der Beobachtungsinstrumente bzw. -prozesse näherungsweise ableiten lassen (aus Abbés Theorie des Mikroskops, der Theorie des Kepler-Fernrohres etc.), bei mechanischen

\footnotetext{
${ }^{204}$ Ausführliche Beispiele für die Anwendung von Kalibrierungsstrategien in der Praxis der Physik werden in [Fran97] diskutiert.

${ }^{205}$ Obwohl viele dies intuitiv als nicht angemessene Art von Rechtfertigungsgründen für deduktive Inferenzverfahren betrachten dürften; vgl. S.463, Fn.82.

${ }^{206}$ Vgl. S.452.

${ }^{207}$ Siehe Abschnitt 8.3.3.

${ }^{208}$ Siehe S.168.

${ }^{209}$ Abschnitt 9.10.1.

${ }^{210}$ Siehe S.236.

${ }^{211}$ Siehe S.173.

${ }^{212}$ Genauer: für die Verläßlichkeit der "Abbildung” der zu messenden Größen, nachzuweisenden Entitäten etc. auf Zeigerauslenkungen, ausgegebene Zahlenwerte o.ä. durch das Gerät, Instrument etc. Für die Verläßlichkeit der "Abbildung" der Zeigerauslenkungen etc. auf entsprechende Überzeugungen einer Person durch Beobachten hat man keine deduktiven Rechtfertigungsgründe (s.u.), und daher genaugenommen auch nicht für die Verläßlichkeit der gesamten epistemischen Verfahren, die im Einsatz bestimmter Meßgeräte etc. zur Gewinnung von Überzeugungen bestehen; diese Details bleiben im folgenden implizit.
} 
Waagen sollte aus den Gesetzen der Mechanik eine Verläßlichkeitsüberzeugung folgen, bei (einfachen) Meßinstrumenten für elektrische Spannung oder Stromstärke aus den Gesetzen der klassischen Elektrodynamik und Mechanik ${ }^{213}$ usw. Solche deduktiven Gründe für eine Verläßlichkeitsüberzeugung dürften jedoch keineswegs für alle Meßgeräte, Nachweisinstrumente u.ä. zu finden sein, denn in der Praxis der Wissenschaften werden auch Geräte bzw. Verfahren als (in bestimmten Bereichen) verläßlich anerkannt, bei denen man nicht über eine detaillierte theoretische Beschreibung verfügt, sondern "nur" über so etwas wie eine Skizze der ablaufenden Prozesse: Für das Fernrohr und das Mikroskop etwa hat man heute detaillierte theoretische Beschreibungen, aber sie galten bereits als (in bestimmten Bereichen) verläßliche Abbildungsinstrumente bevor diese Theorien bekannt waren. ${ }^{214}$ Daß deduktive Rechtfertigungsgründe für eine Verläßlichkeitsüberzeugung nicht in bezug auf jedes in der Praxis eingesetzte Meßgerät, Nachweisinstrument etc. erforderlich oder gar unverzichtbar sind, sollte schon deswegen plausibel sein, weil man im Fall des paradigmatischen Erzeugungsverfahrens, des menschlichen Sehapparates, keine derartigen Rechtfertigungsgründe hat. ${ }^{215}$ Für die Verläßlichkeit induktiver, induktiv extrapolierender und kausaler Inferenzverfahren und für die Verläßlichkeit von Inferenzschemata für Schlüsse auf die beste Erklärung sind (zumindest in näherer Zukunft) sicherlich keine deduktiven Rechtfertigungsgründe zu haben. ${ }^{216}$ Deduktive Rechtfertigungsgründe für die Verläßlichkeit einer Theorie oder eines Modells als deduktives Orakel könnten sich dagegen grundsätzlich finden lassen, nämlich dann, wenn man von einer anderen Theorie oder einem anderen Modell überzeugt ist, deren bzw. dessen Gegenstandsbereich den Anwendungsbereich des Orakels einschließt, und die bzw. das nachweislich empirisch äquivalent zu diesem Orakel ist, über dessen Anwendungsbereich nachweislich dieselben Aussagen impliziert o.ä.

Außer induktiven und deduktiven Rechtfertigungsgründen dürften sich für Verläßlichkeitsüberzeugungen häufig auch schwache Gründe der vorne genannten Arten ${ }^{217}$ finden lassen, insbesondere für Verläßlichkeitsüberzeugungen in bezug auf Erzeugungsverfahren wie den Einsatz von Meßgeräten, Nachweisinstrumenten etc. Falls die jeweils zur Diskussion stehende Verläßlichkeitsüberzeugung zu einer "hinreichend gut epistemisch zusammenhängenden" Menge von Überzeugungen gehört, für die sich "hinreichend viele" und "hinreichend gute" schwache Gründe von außen anführen lassen, und man ein Inferenzverfahren der vorne skizzierten Art akzeptiert, das das Schließen auf eine solche Menge gestattet, ${ }^{218}$ kann man diese schwachen Gründe (zusammen mit den anderen für den Schluß erforderlichen Prämissen) als Rechtfertigungsgründe für die Verläßlichkeitsüberzeugung ${ }^{219}$ anführen. Als schwache Gründe für die Verläßlichkeit eines Erzeugungsverfahrens wie der oben genannten dürften sich häufig Überzeugungen erster Ordnung aufweisen lassen, die

\footnotetext{
${ }^{213}$ Dazu siehe Kap.15.

${ }^{214}$ Ein weiteres Beispiel für ein Nachweisverfahren, das bereits als verläßlich galt, bevor eine genaue Theorie dafür vorlag, ist der Einsatz von Photoemulsionen, die in den dreißiger Jahren zum Nachweis kosmischer Strahlung benutzt wurden; siehe [Gali97], Kap.3.2.

${ }^{215}$ Obwohl in wissenschaftstheoretischen Diskussionen gelegentlich die konträre These vertreten wird, daß die Verläßlichkeit eines Meßgerätes, Abbildungsinstruments usw. bzw. mittels eines solchen Gerätes, Instruments etc. gewonnene Überzeugungen in jedem Fall durch eine Theorie des Geräts, Instruments etc. gerechtfertigt werden müssen; vgl. dazu auch [BoWo88], S.326ff., [Fran86, Fran97, Hack83a].

${ }^{216}$ Deduktive Rechtfertigungsgründe für die Verläßlichkeit deduktiver Inferenzverfahren sind denkbar, dieses Thema kann jedoch hier nicht erörtert werden; vgl. S.463, Fn.82.

${ }^{217}$ Siehe S.468ff.

${ }^{218}$ Siehe S.468ff., bes. S.473ff.

${ }^{219}$ Und für den ganzen Rest der epistemisch zusammenhängenden Menge.
} 
(mehr oder weniger spezielle) Gesetze oder das, was Hacking home truths nennt ${ }^{220}$, zum Inhalt haben, und Konsistenzbedingungen oder constraints für die Überzeugung darstellen, daß ein bestimmtes Meßgerät, ein bestimmtes Nachweisinstrument o.ä. "ordnungsgemäß" funktioniert und damit verläßlich ist. Z.B. stellen die Überzeugungen, daß elektromagnetische Felder in metallischen Leitern Ströme induzieren können und daß sie durch geschlossene Hüllen aus Metall (Faraday-Käfige) abgeschirmt werden können, Konsistenzbedingungen für Verläßlichkeitsüberzeugungen in bezug auf Amperemeter (bestimmter Bauart) dar: Eine Überzeugung, daß ein Amperemeter (bestimmter Bauart), das in ein geschlossenes Metallgehäuse eingebaut ist, unter den an der Erdoberfläche heute häufig vorliegenden Bedingungen ("Elektrosmog") verläßlich ist, ist mit den beiden genannten Konsistenzbedingungen verträglich, eine entsprechende Verläßlichkeitsüberzeugung in bezug auf ein Amperemeter ohne abschirmendes Metallgehäuse nicht. Als schwacher Grund für eine Verläßlichkeitsüberzeugung kann auch der Befund fungieren, daß man diese als Output eines nur mäßig verläßlichen Verfahrens erhält, etwa durch einen induktiven Extrapolationsschluß ausgehend von einer Verläßlichkeitsüberzeugung, die sich auf einen engeren Anwendungsbereich bezieht, o.ä.

Diese knappe und sehr grobe Skizze von der Gesamtheit der epistemischen Verfahren, die im Bereich der Wissenschaften zur Gewinnung oder Stabilisierung von Überzeugungen über Unbeobachtbares eingesetzt werden, und von den Arten von Rechtfertigungsgründen, die für Verläßlichkeitsüberzeugungen in bezug auf diese epistemischen Verfahren plausiblerweise zu finden sein könnten, vermittelt vielleicht einen Überblick über das (oder wenigstens einen Eindruck von dem), was zu tun wäre, um das oben umrissene Programm für die Suche nach epistemischen Rechtfertigungsgründen für eine selektive realistische Position in der wissenschaftstheoretischen Realismusdebatte zu realisieren, und damit in interner Reflexion für die Gesamtheit der ontologischen realistischen Thesen über Unbeobachtbares, die das Herzstück einer selektiven realistischen Position in der wissenschaftstheoretischen Realismusdebatte bildet, das an Rechtfertigungsgründen aufzuweisen, was nach dem heutigen Stand der Wissenschaft verfügbar ist. Wie die Gesamtheit der ontologischen realistischen Thesen über Unbeobachtbares aussieht, für die sich im Verlauf der Realisierung des Programms tatsächlich hinreichende Rechtfertigungsgründe aufweisen lassen, welchen Teil des Bestandes der kognitiven Produkte der heutigen Wissenschaften diese Gesamtheit ausmacht, und von welcher Qualität die tatsächlich aufweisbaren Rechtfertigungsgründe sind, läßt sich erst nach Umsetzung des Programms sicher beurteilen, und selbst eine grobe Abschätzung würde die Umsetzung wenigstens wesentlicher Teile des Programms erfordern.

An dieser Stelle lassen sich lediglich einige Vermutungen anstellen, was plausiblerweise vielleicht als Ergebnis der Realisierung des skizzierten Programms zu erwarten ist: Ich vermute, daß sich nicht für alle Theorien, Gesetze, Modelle etc. der heutigen Naturwissenschaften hinreichende Rechtfertigungsgründe aufweisen lassen, auch nicht für alle "gut etablierten", d.h. in Lehrbuchdarstellungen u.ä. eingegangenen, und zwar insbesondere nicht für die abstraktesten, hochstufigsten Theorien etc. bzw. die abstraktesten, hochstufigsten Teile etablierter Theorien. Andererseits erwarte ich nicht, daß sich die Grenze beobachtbar/unbeobachtbar tatsächlich als in irgendeiner Weise epistemisch wichtig erweist: Natürlich endet der Verläßlichkeitsbereich eines epistemischen Verfahrens, eben des Beobachtens mit dem bloßen Auge, an dieser Grenze, aber der Verläßlichkeitsbereich anderer epistemischer Verfahren dürfte nicht dort enden, und zumindest "grenzüberschreitende"

\footnotetext{
${ }^{220}$ Siehe S.309.
} 
Erzeugungsverfahren wie das Beobachten mit der Lupe, dem Mikroskop u.ä. dürften mit dem Beobachten mit bloßem Auge so weitreichende Ähnlichkeiten im Hinblick auf Rechtfertigungsgründe für die gewonnenen Überzeugungen aufweisen, daß sich für Überzeugungen, die durch Beobachtung mit dem bloßen Auge gewonnen wurden, und für Überzeugungen über Unbeobachtbares, die mit Hilfe einer Lupe, eines Mikroskops gewonnen wurden, häufig Rechtfertigungsgründe "derselben Art" aufweisen lassen, d.h. Rechtfertigungsgraphen, die in beiden Fällen nicht nur hinreichende Rechtfertigungsgründe enthalten, sondern darüberhinaus aus Rechtfertigungsgründen in etwa derselben "Qualität" bestehen. ${ }^{221}$ Ich erwarte also, daß sich für ontologische realistische Thesen über Unbeobachtbares zumindest dann, wenn sie Gegenstände, Sachverhalte etc. betreffen, die sozusagen nicht allzuweit jenseits der Grenze beobachtbar/unbeobachtbar liegen, häufig "genauso gute" Rechtfertigungsgründe angeben lassen wie für ontologische realistische Thesen über Beobachtbares, und daß sich also zumindest in dieser Hinsicht die Kontinuitätsintuition als richtig erweist, daß Rechtfertigungsgründe und Argumente auf beiden Seiten der Grenze beobachtbar/unbeobachtbar von der gleichen Art und "Qualität" sind. ${ }^{222}$

\section{Debatten mit anderen Personen über Überzeugungen über Unbeobachtbares}

Zwischen dem Bereich des Beobachtbaren und dem Bereich des Unbeobachtbaren bestehen weitreichende Parallelen nicht nur im Hinblick auf die Möglichkeiten und die Grenzen der Möglichkeiten, in interner Reflexion Rechtfertigungsgründe für Überzeugungen über Gegenstände, Sachverhalte etc. aus dem jeweiligen Bereich aufzuweisen, sondern auch im Hinblick auf die Möglichkeiten und die Grenzen der Möglichkeiten, Argumente anzugeben, mit deren Hilfe sich andere Personen dazu bringen lassen, Überzeugungen über Gegenstände, Sachverhalte o.ä. aus dem jeweiligen Bereich zu akzeptieren.

Gemäß der vorne erwähnten "Grenzfallbetrachtung" entspricht das Aufweisen von Rechtfertigungsgründen für eine eigene Überzeugung in interner Reflexion dem Grenzfall einer Argumentation, durch die eine andere Person dazu gebracht werden soll, die Überzeugung zu akzeptieren, und zwar dem Grenzfall, in dem die Diskussionsgegner dieselben Überzeugungen haben und dieselben epistemischen Verfahren und Regeln verwenden. ${ }^{223}$ Für diese Grenzfallbeziehung spielt es offenbar keine Rolle, ob es um eine Überzeugung über Beobachtbares oder um eine Überzeugung über Unbeobachtbares geht, und daraus folgt, daß nicht nur, wie vorne erörtert, im Bereich des Beobachtbaren, sondern auch im Bereich des Unbeobachtbaren das, was man einem Diskussionsgegner als Argument für eine Überzeugung präsentieren kann, nicht mehr und "nichts Besseres" ist als die Rechtfertigungsgründe, die den eigenen Rechtfertigungsgraphen für diese Überzeugung konstituieren. ${ }^{224}$

Auch ob diese Rechtfertigungsgründe ein überzeugungskräftiges Argument ergeben, hängt offenbar nicht nur, wie vorne erörtert, ${ }^{225}$ im Bereich des Beobachtbaren, sondern ebenso im Bereich des Unbeobachtbaren davon ab, ob der jeweilige Diskussionsgegner hinreichend viele der Rechtfertigungsgründe teilt, sowie evtl. von den Regeln oder Verfahren, die er zur Beseitigung von Konflikten in seinem Überzeugungssystem verwendet, und vom Rest seines Überzeugungssystems: Die in dieser Hinsicht relevanten Konstellationen, die

\footnotetext{
${ }^{221}$ Die also beide nur Zirkel ab einer bestimmten Mindestgröße enthalten, beide etwa dieselbe Menge redundanter Rechtfertigungsgründe, etwa dieselbe Art und Menge offener Enden etc.

${ }^{222}$ Vgl. S.449.

${ }^{223}$ Vgl. S.461, 485f.

${ }^{224}$ Argumente ad hominem bleiben auch hier beiseite.

${ }^{225}$ Siehe S.485ff.
} 
bei der Argumentation für eine Überzeugung vorliegen können, und die daraus resultierenden Grenzen der Möglichkeiten, erfolgreich für eine Überzeugung zu argumentieren, sind im Bereich des Unbeobachtbaren offensichtlich dieselben wie die, die vorne für den Bereich des Beobachtbaren beschrieben wurden. ${ }^{226}$

Für Überzeugungen über Unbeobachtbares gilt somit, genau wie für Überzeugungen über Beobachtbares, daß die Tatsache, daß man hinreichende Rechtfertigungsgründe für eine Überzeugung aufweisen kann (möglicherweise sogar Rechtfertigungsgründe "guter Qualität"), nicht impliziert, daß diese Rechtfertigungsgründe ein für jeden Diskussionsgegner überzeugungskräftiges Argument für diese Überzeugung ergeben. Die drei vorne herausgearbeiteten Faktoren, die den Möglichkeiten, erfolgreich für eine Überzeugung über Beobachtbares zu argumentieren, Grenzen setzen, ${ }^{227}$ begrenzen also in derselben Weise auch die Möglichkeiten, erfolgreich für eine Überzeugung über Unbeobachtbares zu argumentieren. Dadurch sind offenbar prinzipielle Grenzen gegeben, auf die man bei der Suche nach überzeugungskräftigen Argumenten für eine selektive realistische Position in der wissenschaftstheoretischen Realismusdebatte stoßen kann. Es handelt sich jedoch um Grenzen, die in der Natur dessen liegen, was ein Argument und was eine Diskussion zwischen verschiedenen Personen ist, und die den epistemischen Status der realistischen Position und der für sie aufweisbaren Rechtfertigungsgründe nicht berühren.

Das Herzstück einer selektiven realistischen Position in der wissenschaftstheoretischen Realismusdebatte wird durch eine Vielzahl von ontologischen realistischen Thesen über Unbeobachtbares gebildet; für eine solche Position zu argumentieren bedeutet daher, eine ebenso große Vielzahl von Argumenten für einzelne Thesen vorzubringen. Das, was einem maximal zur Verfügung steht, um eine solche Vielzahl von Argumenten zu formulieren, ist die Gesamtheit der Rechtfertigungsgründe, die sich in interner Reflexion für die ontologischen realistischen Thesen aufweisen lassen. Um tatsächlich alles zur Verfügung zu haben, was beim heutigen Stand der Wissenschaften zu haben ist, um für eine selektive realistische Position zu argumentieren, die, wie es von einer realistischen Position in der wissenschaftstheoretischen Realismusdebatte üblicherweise erwartet wird, eine Aussage zu allen "kognitiven Produkten" der Wissenschaften trifft, müßte man also offenbar das oben skizzierte Programm für die Suche nach Rechtfertigungsgründen vollständig realisiert haben. Dies ist aus den erörterten Gründen für eine einzelne Person nicht möglich, daher kann auch die Argumentation für eine selektive realistische Position bestenfalls arbeitsteilig vorgenommen werden. Immerhin hat man aber für die Argumentation für bestimmte einzelne ontologische realistische Thesen über Unbeobachtbares offenbar "schon" dann alles zur Verfügung, was nach dem Stand der Wissenschaften zu haben ist, wenn man sich die Rechtfertigungsgraphen der Überzeugungen zurechtgelegt hat, die diese einzelnen Thesen zum Inhalt haben, also "schon", wenn nur der dafür relevante Bruchteil des skizzierten Programms realisiert ist.

\footnotetext{
${ }^{226} \mathrm{~S} .486 \mathrm{ff}$.

${ }^{227}$ Vgl. S.496.
} 
Grenzen der Reichweite von Argumenten für ontologische realistische Thesen über Unbeobachtbares und die Bedeutung dieser Grenzen für die Argumentation für eine selektive realistische Position in der wissenschaftstheoretischen Realismusdebatte

Die beschriebenen prinzipiellen Grenzen der Möglichkeiten, erfolgreich für eine Überzeugung über Beobachtbares zu argumentieren, spielen, wie bereits erwähnt, ${ }^{228}$ für die epistemische Praxis der Alltagswelt kaum eine Rolle, obwohl man sich zumindest denkbare Fälle zurechtlegen kann, in denen man auf diese Grenzen stößt. ${ }^{229}$ Entsprechend dürften die prinzipiellen Grenzen der Möglichkeiten, erfolgreich für eine Überzeugung über Unbeobachtbares zu argumentieren, in der epistemischen Praxis der Wissenschaften allenfalls selten zum Tragen kommen. Dagegen kommt diesen Grenzen in der wissenschaftstheoretischen Realismusdebatte eine wichtige Rolle zu, denn wenn man von realistischer Seite nach Argumenten sucht, durch die sich die an dieser Debatte beteiligten Anhänger antirealistischer Positionen von einer selektiven realistischen Position, sprich: von ontologischen realistischen Thesen über Unbeobachtbares, überzeugen lassen, stößt man an die beschriebenen prinzipiellen Grenzen.

Um die Bedeutung erörtern zu können, die den beschriebenen Grenzen für die Argumentation für eine selektive realistische Position in der wissenschaftstheoretischen Realismusdebatte zukommt, ist es nicht, wie man vielleicht denken könnte, Voraussetzung, daß das oben skizzierte Programm für die Suche nach Rechtfertigungsgründen vollständig oder auch nur in großen Teilen umgesetzt ist, sondern es genügt, ein Bild von den Rechtfertigungsgraphen einiger typischer ontologischer realistischer Thesen über Unbeobachtbares vor Augen zu haben, und es reicht sogar ein grobes Bild von der Gestalt dieser Rechtfertigungsgraphen.

Für die epistemische Praxis der Wissenschaften spielen die beschriebenen prinzipiellen Grenzen, wie bereits erwähnt, allenfalls selten eine Rolle, denn die in einem Fach arbeitenden Wissenschaftler stimmen normalerweise (in bezug auf den Gegenstandsbereich ihres Fachs) in ihren Überzeugungen und den als verläßlich akzeptierten epistemischen Verfahren so weit überein, daß die prinzipiellen Grenzen in konkreten Fällen allenfalls selten wirksam werden: Ein Wissenschaftler, der für eine bestimmte These über Unbeobachtbares argumentieren will, findet faktisch innerhalb des Rechtfertigungsgraphen, der aus den Rechtfertigungsgründen besteht, die er selbst in interner Reflexion für seine entsprechende Überzeugung aufweisen kann, meistens bereits nach einem oder wenigen Iterationsschritten hinreichende Rechtfertigungsgründe, die seine Fachkollegen teilen und die ein Argument ergeben, um diese zu überzeugen. Daß sein Rechtfertigungsgraph endlich ist und daß es sein könnte, daß ihm kein für die Fachkollegen überzeugungskräftiges Argument für seine These zur Verfügung steht, weil die Kollegen mit ihm zu wenig Überzeugungen teilen oder weil sie aufgrund eines Konfliktes zwischen der zur Debatte stehenden These und anderen von ihren Überzeugungen dem von ihm vorgebrachten Argument nicht folgen, hat für die Praxis höchstens selten irgendwelche Auswirkungen. ${ }^{230}$ Ein Physiker beispielsweise,

\footnotetext{
${ }^{228}$ Vgl. S.493.

${ }^{229}$ Siehe S.489ff.

${ }^{230}$ Dadurch ist natürlich nicht ausgeschlossen, daß es Kontroversen über Themen und Gegenstände gibt, die an einer (zeitgenössischen) Forschungsfront liegen, und deren Untersuchung noch nicht so weit fortgeschritten ist, daß darüber hinreichend gerechtfertigte Überzeugungen existieren (im Unterschied zu Arbeitshypothesen, heuristischen Annahmen u.ä.), die außerdem "konfliktfrei" in die jeweiligen Überzeugungsysteme integriert sind.

Gegen die obige These lassen sich prima facie die Episoden der Wissenschaftsgeschichte ins Feld führen,
} 
der andere Physiker davon überzeugen will, daß das Erdmagnetfeld bestimmten, von ihm gemessenen jahreszeitlichen Schwankungen unterliegt, kann normalerweise voraussetzen, daß seine Fachkollegen die von ihm eingesetzten Meßgeräte und auch die zur Datenauswertung verwendeten statistischen Verfahren für verläßlich halten (jedenfalls wenn es sich um gut etablierte, routinemäßig eingesetzte Standardinstrumente bzw. Auswertungsverfahren handelt), und wenn nicht dies, dann, daß sie mit ihm einig sind, wie die Meßgeräte durch Kalibrierung als verläßlich zu erweisen sind und/oder daß sie sich über die Theorie, die Gesetze o.ä. einig sind, aus denen eine "Theorie der Meßgeräte" abzuleiten ist und damit ein Argument für die Verläßlichkeit dieser Geräte gewonnen werden kann, etc.

Für die wissenschaftstheoretische Realismusdebatte dagegen spielen dieselben prinzipiellen Grenzen eine wichtige Rolle, obwohl es dort nicht um eine andere Art von Thesen oder um eine grundsätzlich andere Art von Argumenten geht, sondern "nur" andere Diskussionsgegner überzeugt werden sollen. Von den vorne bei der Erörterung der Möglichkeiten, für eine ontologische realistische These zu argumentieren, unterschiedenen Konstellationen $^{231}$ sind für die wissenschaftstheoretische Realismusdebatte auch bzw. gerade diejenigen relevant, in denen es kein überzeugungskräftiges Argument gibt, durch das sich der jeweilige Diskussionsgegner dazu bringen ließe, die zur Diskussion stehende These als Überzeugung zu akzeptieren, also diejenigen Konstellationen, in denen man als Realist auf die prinzipiellen Grenzen dessen stößt, was sich mit Argumenten für eine These (für die man hinreichende Rechtfertigungsgründe hat) ausrichten läßt. Die vorne getroffene Unterscheidung der verschiedenen beschriebenen Konstellationen ist hilfreich, um ein systematisches Gesamtbild davon zu gewinnen, was man als Anhänger einer selektiven realistischen Position in der wissenschaftstheoretischen Realismusdebatte mit Hilfe von Argumenten ausrichten kann. Insbesondere ist die vorne getroffene Unterscheidung hilfreich, um ein Bild davon zu bekommen, was man als Realist mit Hilfe von Argumenten ausrichten kann, wenn man versucht, Anhänger antirealistischer Positionen wie van Fraassen von der eigenen realistischen Position zu überzeugen - also Personen, die meinen, daß die Grenze beobachtbar/unbeobachtbar die Grenze des für Menschen epistemisch zugänglichen Teils der Welt markiert —, oder Anhänger "in der Nähe" von van Fraassens Antirealismus liegender und/oder weniger systematisch entwickelter Positionen. In dieses Gesamtbild lassen sich dann auch einige der Resultate einordnen, die die Untersuchung der Kontinuitätsargumente und des Wunderarguments hinsichtlich ihrer Überzeugungskraft und Reichweite geliefert hat; ${ }^{232}$ insbesondere lassen sich vor dem systematischen Hintergrund dieses Bildes die Befunde ins rechte Licht rücken, die sich über die Grenzen dessen ergeben haben, was sich mit Argumenten dieser beiden Typen in der Realismusdebatte ausrichten läßt, und die am Ende der Diskussion dieser beiden Argumenttypen gleichsam isoliert dastanden und ohne einen systematischen Rahmen schwer in angemessener Weise zu bewerten waren.

Von den verschiedenen möglichen Konstellationen, die auftreten können, wenn man als Realist versucht, einen Diskussionsgegner von einer ontologischen realistischen These über Unbeobachtbares, die man selbst glaubt, zu überzeugen und zu diesem Zweck den eigenen Rechtfertigungsgraphen nach einem überzeugungskräftigen Argument durchsucht, ${ }^{233}$ ist die erste und einfachste im Diskussionszusammenhang der Realismusdebatte kaum von Relevanz: Daß man für die zur Diskussion stehende These direkte Rechtfertigungsgründe

die üblicherweise als wissenschaftliche Revolutionen bezeichnet werden. Ob diese tatsächlich gegen die These sprechen, müßte im einzelnen untersucht werden; dies ist an dieser Stelle jedoch nicht möglich.

${ }^{231}$ Siehe S.486ff., S.508.

${ }^{232}$ Siehe Kap.8, 9.

${ }^{233} \mathrm{Vgl}$. S.486ff. 
hat, die der Diskussionsgegner teilt, und daß auch keine andere seiner Überzeugungen ein Hindernis für das Akzeptieren der These darstellt, kommt vor, aber nur wenn der Diskussionsgegner ohnehin eine realistische Position vertritt oder noch gar keine systematisch reflektierte Position in der Realismusdebatte bezogen hat, nicht bei einer Diskussion mit einigermaßen reflektierten Antirealisten oder Anhängern "benachbarter" Positionen. Dieser Befund wird illustriert durch den nur begrenzten Erfolg der von einigen Anhängern epistemischer Kontinuitätsargumente unternommenen Versuche, an vortheoretische Intuitionen zu appellieren, daß bestimmte "grenzüberschreitende" epistemische Verfahren (wie das Beobachten mit einer Lupe, Schließen auf die beste Erklärung u.ä.) auch jenseits der Grenze beobachtbar/unbeobachtbar verläßlich sind, und dadurch für Überzeugungen über Unbeobachtbares zu argumentieren, die mittels dieser Verfahren (also durch Beobachten mit einer Lupe etc.) gewonnen wurden. ${ }^{234}$ Diese Intuitionen — sprich: Verläßlichkeitsüberzeugungen in bezug auf die fraglichen Verfahren, die als direkte Rechtfertigungsgründe fungieren - werden von Realisten meistens geteilt und häufig auch von Personen, die (noch) keine systematische Position in der Realismusdebatte bezogen haben, aber nicht von einigermaßen reflektierten Antirealisten. Antirealisten setzen die in den epistemischen Kontinuitätsargumenten genannten grenzüberschreitenden Verfahren typischerweise selbst zur Gewinnung von Überzeugungen über Beobachtbares ein, ${ }^{235}$ aber eben nur "diesseits" der Grenze beobachtbar/unbeobachtbar, d.h. sie halten diese Verfahren nur für verläßlich, solange ihr Output Beobachtbares zum Inhalt hat, ${ }^{236}$ und glauben also nicht, daß der Verläßlichkeitsbereich dieser Verfahren ein "grenzüberschreitender" ist.

Für die zweite der vorne unterschiedenen Konstellationen gilt im wesentlichen dasselbe. Daß man auf realistischer Seite für eine zur Diskussion stehende These über Unbeobachtbares direkte Rechtfertigungsgründe hat, die der Diskussionsgegner teilt, daß aber irgendeine andere seiner Überzeugungen dem Akzeptieren der These im Weg steht, kommt vor, wenn der Diskussionsgegner eine realistische oder (noch) gar keine systematisch reflektierte Position in der Realismusdebatte vertritt; reflektierte Antirealisten und Anhänger "benachbarter" Positionen dagegen haben i.a. keine Überzeugungen, die als direkte Rechtfertigungsgründe für Überzeugungen über Unbeobachtbares fungieren können. Auf mögliche Ausnahmefälle weist allerdings Friedman in seinem gegen van Fraassen vorgebrachten, vorne diskutierten Einwand hin: ${ }^{237}$ Friedman geht davon aus, daß ein Antirealist wie van Fraassen Überzeugungen (erster Ordnung) haben kann und i.a. auch hat, deren Inhalt Thesen über Beobachtbares sind, die in so "theorieinfizierter" Sprache formuliert sind, daß aus ihnen andere Überzeugungen über Unbeobachtbares deduktiv folgen; da auch Antirealisten deduktive Schlüsse als verläßlich akzeptieren, scheint Friedman damit ein korrektes Argument für (eine Reihe von) Thesen über Unbeobachtbares vorzubringen. Antirealisten,

\footnotetext{
${ }^{234}$ Vgl. Kap.8, bes. S.170f., 173ff. Genaugenommen sind an dieser Stelle wiederum die "Asymmetrien" zu berücksichtigen, die sich dadurch ergeben, daß Überzeugungen durch ein Erzeugungsverfahren gewonnen wurden, das an eine Person geknüpft ist; vgl. S.487, Fn.152.

${ }^{235}$ Denn diese Verfahren spielen (wie in Abschnitt 8.3.6 erörtert) für die epistemische Praxis der Alltagswelt meistens eine wichtige Rolle bei der Gewinnung von Überzeugungen über Beobachtbares, aber tatsächlich nicht Beobachtetes, so daß eine antirealistische Position, die auf sie verzichtet, wenig attraktiv aussieht.

${ }^{236}$ Genauer muß es im Fall von Übertragungsverfahren heißen: solange sie nicht von Prämissen über Beobachtbares auf Konklusionen über Unbeobachtbares führen. (Auch Antirealisten halten üblicherweise z.B. deduktive Inferenzverfahren auch im Bereich des Unbeobachtbaren für verläßlich, d.h. als Verfahren, die aus Prämissen über Unbeobachtbares Konklusionen über Unbeobachtbares erzeugen. Dies ist mit einer antirealistischen Position verträglich, solange sie keine Überzeugungen (erster Ordnung) über Unbeobachtbares einschließt, die als Prämissen fungieren könnten.)

${ }^{237} \mathrm{~S} .302 \mathrm{f}$.
} 
die solche "theorieinfizierten" Überzeugungen haben, lassen sich durch dieses Argument jedoch i.a. nicht überzeugen, van Fraassen selbst jedenfalls nicht, und zwar offenbar, weil die Konklusionen dieses Arguments mit seiner empiristischen Grundüberzeugung konfligieren, der zufolge nur Beobachtbares in Reichweite menschlicher Erkenntnismöglichkeiten liegt. ${ }^{238}$

In einer Konstellation, in der ein solcher Konflikt vorliegt, hängt der Erfolg der Argumentation davon ab, nach welchen Regeln oder Verfahren der Diskussionsgegner Konflikte in seinem Überzeugungssystem beseitigt (und evtl. vom Rest seines Überzeugungssystems, soweit dieser dabei eingeht). ${ }^{239}$ Wenn die zur Konfliktbeseitigung eingesetzten Regeln oder Verfahren sozusagen kontingenterweise ergeben, daß die zur Debatte stehende These über Unbeobachtbares plus eine (oder mehrere) Prämisse(n) des Arguments und/oder das verwendete epistemische Verfahren zu verwerfen sind, und nicht die mit der These konfligierende(n) Überzeugung(en), dann führt das Argument offenbar nicht zum Ziel; erst recht führt es nicht zum Ziel, wenn der Diskussionsgegner zur Konfliktbeseitigung "extreme" Regeln oder Verfahren verwendet, die prinzipiell ausschließen, daß Thesen über Unbeobachtbares akzeptiert werden. Im ersteren Fall kann das Argument doch noch zum Ziel führen, falls man vorher die konfligierende Überzeugung auf anderem Wege "wegargumentieren" kann (oder es können jedenfalls andere Argumente für andere Thesen über Unbeobachtbares erfolgreich sein); im letzteren Fall dagegen ist durch die Regeln oder Verfahren zur Konfliktbeseitigung eine prinzipielle Grenze gegeben, gegen die von realistischer Seite argumentativ nichts auszurichten ist. Die Anhänger antirealistischer Positionen erläutern normalerweise nicht, nach welchen Gesichtspunkten sie Konflikte in ihrem Überzeugungssystem beseitigen, und auch van Fraassen selbst tut das nicht. ${ }^{240}$ Die Rolle, die van Fraassen der empiristischen Grundüberzeugung für seine Position zuweist, legt jedoch die Vermutung zumindest nahe, daß er an dieser Grundüberzeugung festzuhalten bereit ist, komme, was da wolle, d.h., daß er im Falle eines Konflikts dieser Grundüberzeugung mit irgendeiner anderen Überzeugung ${ }^{241}$ prinzipiell immer die letztere verwirft und an der ersteren festhält, und damit Konflikte in seinem Überzeugungssystem nach Regeln beseitigt, die auf eine Immunisierungsstrategie für seine empiristische Grundüberzeugung hinauslaufen. ${ }^{242}$ An einer solchen Strategie ist nichts Inkonsistentes - genauso wenig wie in exakt analogen Fällen, in denen anstelle der empiristischen Grundüberzeugung eine andere Überzeugung (egal ob über Beobachtbares oder Unbeobachtbares) "immunisiert" wird ${ }^{243}$ - es ist jedoch klar, daß es sozusagen in der Natur der Sache liegt, daß gegen eine solche Immunisierungsstrategie, die "hinreichend konsequenten" Antirealisten grundsätzlich offen steht, aus prinzipiellen Gründen durch keinerlei von realistischer Seite vorgebrachte Argumente etwas auszurichten ist, und zwar aus Gründen, die über den epistemischen Status der in der Realismusdebatte zur Diskussion stehenden Thesen über Unbeobachtbares wenig oder nichts implizieren.

\footnotetext{
${ }^{238}$ Vgl. S.175. Worin genau der Konflikt besteht, ist wegen der ungenauen Formulierung der empiristischen Grundüberzeugung nicht zweifelsfrei zu entscheiden; eine denkbare Lesart der von van Fraassen angegebenen Formulierung dieser Grundüberzeugung ist aber eine, nach der sie impliziert, daß Menschen keine gerechtfertigten Überzeugungen über Unbeobachtbares haben können, und dies würde im Widerspruch zu jeder Überzeugung zweiter Ordnung stehen, daß eine bestimmte andere Überzeugung (erster Ordnung) über Unbeobachtbares gerechtfertigt ist, und eine solche Überzeugung zweiter Ordnung geht bei Reliabilisten ohne weiteres mit einer Überzeugung erster Ornung einher.

${ }^{239} \mathrm{Vgl}$. dazu S.450f.

${ }^{240}$ Dasselbe gilt natürlich für Anhänger realistischer und anderer Positionen; vgl. S.450.

${ }^{241}$ Bzw. mit einer potentiellen Überzeugung, sprich: dem Output eines epistemischen Verfahrens.

${ }^{242}$ Vgl. S.173ff. und Abschnitt 10.2.4.

${ }^{243}$ Siehe S.489.
} 
Wenn also jemand eine antirealistische Position vertritt, die tatsächlich Überzeugungen der von Friedman herausgestellten Art einschließt, also Überzeugungen über Beobachtbares, aus denen sich deduktiv Überzeugungen über Unbeobachtbares erschließen lassen, die dann in Konflikt mit einer anderen Überzeugung stehen, dann hängt es von den von ihm zur Beseitigung von Konflikten eingesetzten Regeln oder Verfahren ab, ob die von realistischer Seite vorgebrachten Argumente Erfolg haben können und tatsächlich haben oder nicht. Dasselbe gilt, wenn jemand eine Position vertritt, die Überzeugungen über Beobachtbares einschließt, aus denen sich zwar nicht deduktiv, aber induktiv, durch einen Schluß auf die beste Erklärung o.ä. Überzeugungen über Unbeobachtbares gewinnen lassen, die in Konflikt mit anderen bereits vorhandenen Überzeugungen stehen; dies kommt jedoch nur bei Personen vor, die ohnehin eine realistische Position vertreten, oder bei Personen ohne systematische Position in der Realismusdebatte. In Fällen, die zur zweiten der vorne unterschiedenen Konstellationen zählen, können also prinzipielle Grenzen der Reichweite von Argumenten für eine selektive realistische Position zutage treten, es können aber auch "bloß kontingente" Grenzen auftreten, die sich grundsätzlich und möglicherweise auch tatsächlich überwinden lassen.

Durch die restlichen drei der vorne unterschiedenen Konstellationen werden alle Situationen erfaßt, in denen man als Realist versucht, einen Diskussionsgegner von einer ontologischen realistischen These über Unbeobachtbares zu überzeugen, der nicht hinreichend viele der eigenen direkten Rechtfertigungsgründe teilt, um sich durch diese überzeugen zu lassen. Als Realist durchsucht man dann den eigenen Rechtfertigungsgraphen nach indirekten Rechtfertigungsgründen, die ein für den jeweiligen Diskussionsgegner überzeugungskräftiges Argument ergeben. Dabei findet man entweder hinreichende indirekte Rechtfertigungsgründe für die zur Debatte stehende These, die der Diskussionsgegner teilt, oder man findet im ganzen eigenen Rechtfertigungsgraphen keine solchen Rechtfertigungsgründe; wenn man welche findet, läßt sich aus diesen die These entweder gewinnen, ohne daß sich ein Konflikt mit dem Rest des Überzeugungssystems des Diskussionsgegners ergibt, oder sie läßt sich gewinnen, aber es entsteht dabei ein Konflikt. Die entsprechenden drei Konstellationen sind für die wissenschaftstheoretische Realismusdebatte von größerer Relevanz als die beiden bisher diskutierten.

Die Suche nach indirekten Rechtfertigungsgründen, die ein überzeugungskräftiges Argument ergeben, zielt im wesentlichen auf Rechtfertigungsgründe für Überzeugungen erster Ordnung und für Verläßlichkeitsüberzeugungen. ${ }^{244}$ Die epistemischen Verfahren, die im Bereich der Wissenschaften zur Gewinnung von Überzeugungen (erster Ordnung) über Unbeobachtbares eingesetzt werden, und die Rechtfertigungsgründe, die sich für die Verläßlichkeit dieser Verfahren anführen lassen, sind die der vorne genannten Sorten. ${ }^{245}$ Solche Rechtfertigungsgründe für eine Verläßlichkeitsüberzeugung in bezug auf das Erzeugungsverfahren, durch das eine Überzeugung über Unbeobachtbares gewonnen wurde, können ein überzeugungskräftiges Argument für diese Überzeugung ergeben, wenn der jeweilige Diskussionsgegner diese (indirekten) Rechtfertigungsgründe (genauer: entsprechende Überzeugungen) teilt. Sofern die zur Debatte stehende These durch ein Übertragungsverfahren gewonnen wurde, muß er dazu außerdem die für den Schluß erforderlichen Prämissen oder deren Rechtfertigungsgründe teilen. Als Versuche, indirekte Rechtfertigungsgründe dieser Art für eine Überzeugung (erster Ordnung) über Unbeobachtbares als Argument ins Feld zu führen, lassen sich die von mehreren Anhängern epistemischer Kontinuitätsargumente skizzierten Begründungen für die Verläßlichkeit bestimmter epi-

\footnotetext{
${ }^{244}$ Herkunftsüberzeugungen sind normalerweise nicht strittig.

${ }^{245}$ Siehe S.501ff.
} 
stemischer Verfahren durch einen induktiven oder einen induktiv extrapolierenden Schluß auffassen, ${ }^{246}$ und ebenso die bei der Diskussion des Wunderarguments skizzierten Ansätze, ein Inferenzschema, als dessen Instantiierung sich das Wunderargument rekonstruieren läßt, durch einen induktiven oder einen induktiv extrapolierenden Schluß als verläßlich zu erweisen, ohne eine Petitio Principii zu begehen. ${ }^{247}$ Diese induktiven bzw. induktiv extrapolierenden Argumente haben, wie vorne diskutiert, ${ }^{248}$ Überzeugungskraft nur für jemanden, der die in Anspruch genommenen induktiven oder induktiv extrapolierenden Schlüsse bzw. entsprechende Inferenzschemata akzeptiert, und das tun Realisten und Personen, die noch keine systematische Position in der Realismusdebatte einnehmen, vielfach, aber reflektierte, konsequente Antirealisten tun es nicht. Wenn ein Diskussionsgegner bestimmte indirekte Rechtfertigungsgründe für eine Überzeugung über Unbeobachtbares nicht teilt, so wie konsequente Antirealisten im Fall der epistemischen Kontinuitätsargumente oder des Wunderarguments, dann kommen als Basis eines überzeugungskräftigen Arguments noch die im eigenen Rechtfertigungsgraphen einen Schritt weiter zurückliegenden Überzeugungen in Betracht usw., solange, bis man den gesamten Rechtfertigungsgraph durchsucht hat.

Daß jemand, der nicht hinreichend viele der eigenen direkten Rechtfertigungsgründe für eine Überzeugung über Unbeobachtbares teilt, dennoch hinreichend viele indirekte Rechtfertigungsgründe teilt, kommt vor, etwa in Fällen, in denen die Verläßlichkeit des Meßgerätes, mit dessen Hilfe eine Überzeugung gewonnen wurde, (zunächst) strittig ist, der Diskussionsgegner aber Verläßlichkeitsüberzeugungen in bezug auf andere Meßgeräte teilt, die zur Kalibrierung dienen können, oder Überzeugungen, die Gesetze etc. zum Inhalt haben, aus denen die strittige Verläßlichkeitsüberzeugung abgeleitet werden kann. $\mathrm{Ob}$ diese geteilten indirekten Rechtfertigungsgründe ein überzeugungskräftiges Argument ergeben, hängt dann davon ab, ob sich ein Konflikt mit dem bisherigen Überzeugungssystem des jeweiligen Diskussionsgegners ergibt, und falls ja, von den Regeln oder Verfahren ab, die dieser zur Konfliktbeseitigung einsetzt (und vom dafür evtl. relevanten Teil seines Überzeugungssystems). Beide Konstellationen kommen vor, es kommt aber auch die weitere Konstellation vor, in der ein Diskussionsgegner auch von sämtlichen eigenen indirekten Rechtfertigungsgründen für eine Überzeugung über Unbeobachtbares nicht hinreichend viele teilt und dann hat man kein für ihn überzeugungskräftiges Argument zur Verfügung. Wenn diese letztgenannte Konstellation vorliegt, ist man als Realist offenbar mit einer prinzipiellen Grenze der Reichweite von Argumenten für ontologische realistische Thesen über Unbeobachtbares konfrontiert; wenn die zuvor genannte "Konfliktkonstellation" vorliegt, können, genau wie oben für die zweite der fünf unterschiedenen Konstellationen erörtert, entweder ebenfalls prinzipielle Grenzen der Reichweite von Argumenten für eine selektive realistische Position zutage treten, oder es können "bloß kontingente" Grenzen auftreten, die sich grundsätzlich und möglicherweise auch tatsächlich überwinden lassen.

Um ein angemessenes systematisches Bild davon zu bekommen, was sich in der Realismusdebatte von realistischer Seite mit Hilfe von Argumenten für ontologische realistische Thesen über Unbeobachtbares ausrichten läßt, ist es wichtig zu sehen, daß ein reflektierter Antirealist ein so konsequent restringiertes Überzeugungssystem haben kann, daß für keine einzige Überzeugung (erster Ordnung) über Unbeobachtbares, die irgendjemand hat, gilt, daß dieser Antirealist von sämtlichen für sie aufweisbaren (direkten und indirekten) Rechtfertigungsgründen hinreichend viele teilt, um ein für ihn überzeugungskräftiges Argument

\footnotetext{
${ }^{246}$ Siehe Abschnitt 8.3, bes.8.3.3; s.a. S.504f.

${ }^{247}$ Siehe Abschnitt 9.10.4, bes. S.261ff.

${ }^{248}$ Siehe S.173ff.
} 
für diese Überzeugung zu ermöglichen. Bei einem reflektierten Antirealisten mit einem solchen Überzeugungssystem führt jedes für irgendeine ontologische realistische These über Unbeobachtbares vorgebrachte Argument zu der vierten der fünf oben unterschiedenen Konstellationen, so daß jedes von realistischer Seite vorgebrachte Argument auf eine prinzipielle Grenze stößt. Daß antirealistische Positionen dieser Art möglich sind, ist leicht zu sehen: Jedes Argument für eine These über Unbeobachtbares muß entweder ein Erzeugungsverfahren als verläßlich in Anspruch nehmen, das Output über Unbeobachtbares liefert (z.B. Beobachten mit einer Lupe), oder es muß Prämissen über Unbeobachtbares voraussetzen (aus denen sich z.B. deduktiv Konklusionen über Unbeobachtbares gewinnen lassen), oder es muß ein Übertragungsverfahren in Anspruch nehmen, das aus Prämissen über Beobachtbares Konklusionen über Unbeobachtbares gewinnt, sowie "geeignete" Prämissen über Beobachtbares (z.B. eine Form des Schließens auf die beste Erklärung als Übertragungsverfahren und Überzeugungen über bestimmte beobachtbare Explananda als Prämissen oder deduktive Inferenzschemata als Übertragungsverfahren und die von Friedman genannten "theorieinfizierten" Überzeugungen als Prämissen). Ein Antirealist, der, erstens, kein Erzeugungsverfahren als verläßlich anerkennt, das Output über Unbeobachtbares liefert, und der, zweitens, keine Überzeugungen über Unbeobachtbares hat, und dessen Überzeugungen, drittens, so restringiert und aufeinander abgestimmt sind, daß kein von ihm als verläßlich anerkanntes Übertragungsverfahren mit einer oder mehrerer seiner Überzeugungen (über Beobachtbares) als Input eine Überzeugung über Unbeobachtbares als Output liefert, kann offenbar durch kein Argument von einer These über Unbeobachtbares überzeugt werden. Ein reflektierter Antirealist, dessen Überzeugungssystem die drei genannten Bedingungen erfüllt und bei dem auch sichergestellt ist, daß die von ihm verwendeten Erzeugungsverfahren ihm keine neuen Überzeugungen liefern, aus denen sich durch ein von ihm verwendetes Inferenzverfahren andere Überzeugungen über Unbeobachtbares erschließen lassen, braucht keine empiristische Grundüberzeugung, wie sie von van Fraassen in seinen früheren Arbeiten angegeben wird, zu haben, und er ist nicht auf eine Immunisierungsstrategie angewiesen, die bei Konflikten in seinem Überzeugungssystem wirksam wird. Eine solche antirealistische Position, die durch kein Argument von realistischer Seite erreicht wird, scheint van Fraassen offenbar in seinen späteren Arbeiten im Auge zu haben. ${ }^{249}$

Eine zweite Möglichkeit, eine antirealistische Position einzunehmen, deren Anhänger durch kein Argument von einer ontologischen realistischen These über Unbeobachtbares überzeugt werden können, ist die, die van Fraassen in seinen früheren Arbeiten anzuvisieren scheint: Auch ein Antirealist, der, erstens, kein Erzeugungsverfahren als verläßlich anerkennt, das Output über Unbeobachtbares liefert, und der, zweitens, keine Überzeugungen über Unbeobachtbares hat, und der, drittens, van Fraassens empiristische Grundüberzeugung teilt und eine entsprechende Immunisierungsstrategie verfolgt, wenn Konflikte in seinem Überzeugungssystem auftreten, kann offenbar durch kein Argument von einer These über Unbeobachtbares überzeugt werden — selbst dann nicht, wenn sich herausstellen sollte, daß sich mittels eines von ihm als verläßlich akzeptierten Übertragungsverfahrens aus einer oder mehrerer seiner (evtl. neu gewonnenen) Überzeugungen über Beobachtbares eine Überzeugung über Unbeobachtbares gewinnen läßt. Bei einem Antirealisten, der eine solche Position einnimmt, führt nicht jedes für irgendeine ontologische realistische These über Unbeobachtbares vorgebrachte Argument zu der vierten der fünf oben unterschiedenen Konstellationen, sondern es können auch Konflikte, also die zweite und die fünfte der

${ }^{249}$ Vgl. Abschnitt 10.2.4. 
Konstellationen vorkommen; dennoch stößt auch in der Diskussion mit einem solchen Antirealisten jedes von realistischer Seite vorgebrachte Argument auf eine prinzipielle Grenze, genauer: auf eine der beiden hier wirksamen prinzipiellen Grenzen. ${ }^{250}$

Daß es diese prinzipiellen Grenzen der Reichweite von Argumenten für ontologische realistische Thesen über Unbeobachtbares gibt und daß es daher die zwei beschriebenen Möglichkeiten gibt, eine antirealistische Position zu vertreten, deren Anhänger durch kein von realistischer Seite vorgetragenes Argument von einer These über Unbeobachtbares überzeugt werden können, ist der allgemeine Sachverhalt, unter den sich der vorne bei der Diskussion der epistemischen Kontinuitätsargumente gewonnene Befund subsumieren läßt, daß diese Argumente für einen reflektierten und "hinreichend konsequenten" Antirealisten keine Überzeugungskraft haben. ${ }^{251}$ Der dort konstatierte allgemeinere Befund, daß gegen einen reflektierten und "hinreichend konsequenten" Antirealisten, der durch die epistemischen Kontinuitätsargumente nicht überzeugt werden kann, auch durch kein anderes von realistischer Seite vorgebrachtes Argument etwas ausgerichtet werden kann, ${ }^{252}$ entspricht dem allgemeinen Sachverhalt, der hier bei der Untersuchung der Möglichkeiten, für eine selektive realistische Position zu argumentieren, zutage getreten ist.

Daß es sich bei den bei dieser Untersuchung zutage getretenen prinzipiellen Grenzen der Reichweite von Argumenten für ontologische realistische Thesen über Unbeobachtbares um Grenzen handelt, die in der Natur dessen liegen, was ein Argument ist, und die den epistemischen Status der realistischen Position und der für sie aufweisbaren Rechtfertigungsgründe nicht berühren, wird klar, wenn man sich nochmals die beiden beschriebenen Möglichkeiten ansieht, eine antirealistische Position einzunehmen, gegen die von realistischer Seite mit Argumenten nichts auszurichten ist: Offenbar ist es möglich, exakt "parallele" Positionen zu konstruieren bzw. zu vertreten, die sozusagen anstelle der Grenze beobachtbar/unbeobachtbar eine andere Grenzlinie ziehen, an der die Überzeugungen enden, die ein Anhänger einer solchen Position hat, und wenn man versucht, jemanden, der eine solche Position vertritt, von einer These über etwas "jenseits der Grenzlinie" zu überzeugen, kommt es zu Konstellationen, die exakt "parallel" zu denen in der Diskussion zwischen Realisten und Antirealisten sind, die oben erörtert wurden, d.h., mit Argumenten für Thesen über Gegenstände, Sachverhalte u.ä. "jenseits der Grenzlinie" läßt sich ebenso wenig ausrichten. Ein Beispiel, das diese Sachlage veranschaulicht, ist das oben angegebene, in dem eine farbenblinde Person eine Grenzlinie zieht, die jede Überzeugung ausschließt, die die Farben rot und grün involviert, ${ }^{253}$ also eine Grenzlinie innerhalb des Bereichs des Beobachtbaren. Dadurch wird klar, daß die beschriebenen Grenzen der Reichweite von Argumenten für Thesen über Unbeobachtbares die Grenzlinie beobachtbar/unbeobachtbar nicht in besonderer Weise vor anderen möglichen Grenzlinien auszeichnen, und daß das Bestehen dieser Grenzen der Reichweite von Argumenten daher keinen plausiblen Grund darstellt, um anzunehmen, daß Überzeugungen über den Bereich jenseits der Grenze beobachtbar/unbeobachtbar einen anderen, "defizienten" epistemischen Status hätten, daß der Bereich des Unbeobachtbaren für Menschen nicht epistemisch zugänglich sei o.ä. Einen Hinweis, der dieses Resultat bereits angedeutet hat, stellt der vorne bei der Diskussion der

\footnotetext{
${ }^{250}$ Die beiden hier unterschiedenen Möglichkeiten können natürlich kombiniert werden, d.h., die Überzeugungen eines Antirealisten können so restringiert und aufeinander abgestimmt sind, daß kein von ihm als verläßlich anerkanntes Übertragungsverfahren mit einer oder mehrerer seiner Überzeugungen (über Beobachtbares) als Input eine Überzeugung über Unbeobachtbares als Output liefert, und außerdem kann er die empiristische Grundüberzeugung teilen und eine entsprechende Immunisierungsstrategie verfolgen.

${ }^{251} \mathrm{Vgl}$. S.173ff.

${ }^{252}$ Siehe S.181f.

${ }^{253}$ Siehe S.489f.
} 
epistemischen Kontinuitätsargumente konstatierte, dort etwas isoliert dastehende Befund dar, daß Argumente dieses Typs nicht nur in der Diskussion mit reflektierten, konsequenten Antirealisten keine Überzeugungskraft entwickeln können, sondern ebenso wenig in der Diskussion mit Anhängern analoger Positionen, die anstelle der Grenzlinie beobachtbar/unbeobachtbar eine andere "bizarre" Grenzlinie verteidigen. ${ }^{254}$

Die Tatsache, daß es die beschriebenen prinzipiellen Grenzen der Reichweite von Argumenten für ontologische realistische Thesen über Unbeobachtbares gibt, stellt keinen Grund für die Annahme dar, daß die Suche nach solchen Argumenten grundsätzlich müßig und alles, was sich dabei an Argumenten finden läßt, wertlos ist, denn es ist keineswegs so, daß Argumente für Thesen über Unbeobachtbares nur für Personen Überzeugungskraft entwickeln können, die ohnehin eine realistische Position vertreten. Natürlich können Argumente für eine bestimmte ontologische realistische These über Unbeobachtbares da$\mathrm{zu}$ dienen, jemanden von dieser These zu überzeugen, der bereits von anderen ontologischen realistischen Thesen über Unbeobachtbares überzeugt ist und damit bereits eine selektive realistische Position in der wissenschaftstheoretischen Realismusdebatte vertritt. Dieselben Argumente für eine bestimmte ontologische realistische These über Unbeobachtbares können aber auch dazu dienen, "unvoreingenommene Laien" von dieser These zu überzeugen, also Personen, die bisher keine systematisch reflektierte Position in dieser Debatte einnehmen. Noch wesentlich wichtiger für den Diskussionszusammenhang der wissenschaftstheoretischen Realismusdebatte ist, daß wenigstens ein Teil der Argumente, die von realistischer Seite für ontologische realistische Thesen über Unbeobachtbares vorgebracht werden können, sich grundsätzlich auch eignet, um Antirealisten von diesen Thesen zu überzeugen, die eine "weniger systematisch entwickelte" Position "in der Nähe" von van Fraassens Antirealismus einnehmen, und/oder die "weniger konsequent" an einer empiristischen Grundüberzeugung o.ä. festhalten als etwa van Fraassen dies tut. Solche antirealistischen Positionen sind denkbar und es ist keineswegs inkohärent oder unsinning oder prima facie völlig unplausibel, eine solche "undogmatische" antirealistische Position $\mathrm{zu}$ vertreten.

Eine solche Position könnte etwa eine sein, die weder irgendwelche Überzeugungen erster Ordnung über Unbeobachtbares einschließt, noch irgendwelche Verläßlichkeitsüberzeugungen in bezug auf Erzeugungsverfahren, die Überzeugungen erster Ordnung über Unbeobachtbares liefern (Beobachten mit einem Mikroskop u.ä.), noch Verläßlichkeitsüberzeugungen in bezug auf Inferenzverfahren, die von Überzeugungen erster Ordnung über Beobachtbares (die diese Position einschließt ${ }^{255}$ ) zu Überzeugungen erster Ordnung über Unbeobachtbares führen (Schließen auf die beste Erklärung o.̈̈.). Eine solche "undogmatische" Position wäre in einem gehaltvollen Sinn antirealistisch, insofern jemand, der sie vertritt, keinerlei Überzeugungen erster Ordnung über Unbeobachtbares hat, also von den "kognitiven Produkten" der Wissenschaften, die Unbeobachtbares zum Inhalt haben, nichts glaubt, und auch nicht einfach durch Hinweis auf ein von ihm als verläßlich akzeptiertes epistemisches Verfahren dazu gebracht werden kann, Überzeugungen erster Ordnung über Unbeobachtbares zu gewinnen (z.B. indem man ihn durch eine Lupe oder ein Mikroskop schauen läßt o.ä.). Gleichzeitig könnte eine solche Position eine undogmatische antirealistische sein, indem jemand, der sie vertritt, in irgendeiner Form Inferenzen bzw. Inferenzschemata akzeptiert, durch die er wenigstens grundsätzlich (neue) Verläßlich-

\footnotetext{
${ }^{254}$ Siehe S.180f.

${ }^{255}$ Diese Qualifikation stellt sicher, daß jemand, der eine undogmatische antirealistische Position vertritt, deduktive Inferenzverfahren als verläßlich akzeptieren und verwenden kann, sofern er keine "theorieinfizierten" Überzeugungen der von Friedman herausgestellten Art hat.
} 
keitsüberzeugungen in bezug auf epistemische Verfahren, die Output über Unbeobachtbares liefern, erwerben kann, obwohl er faktisch derzeit kein solches Verfahren für verläßlich $h a ̈ l t{ }^{256}$. Anders ausgedrückt: eine solche Position könnte in dem Sinn eine undogmatische antirealistische sein, daß ein Anhänger dieser Position zumindest grundsätzlich in irgendeiner Form zu einer Bewertung der Verläßlichkeit epistemischer Verfahren, die Output über Unbeobachtbares liefern (und von ihm bisher nicht verwendet werden), gelangen kann und Inferenzen bzw. Inferenzschemata akzeptiert, durch die er zumindest grundsätzlich zu der (für ihn neuen) Überzeugung gelangen kann, daß ein (bisher von ihm nicht für verläßlich gehaltenes und dementsprechend nicht verwendetes) epistemisches Verfahren, das Überzeugungen über Unbeobachtbares liefert, verläßlich ist. Einige zumindest prima facie plausible Kandidaten für Inferenzen bzw. Inferenzschemata, die einen Antirealisten, der sie akzeptiert, in diesem Sinn zu einem undogmatischen Antirealisten machen, sind im Verlauf der bisherigen Untersuchungen schon genannt worden: Man kann als undogmatischer Antirealist zu Verläßlichkeitsüberzeugungen in bezug auf epistemische Verfahren, die Output über Unbeobachtbares liefern, gelangen, wenn man induktive Extrapolationsschlüsse, wie sie Salmon skizziert, als verläßlich akzeptiert, also Inferenzen, die den Verläßlichkeitsbereich eines "grenzüberschreitenden" epistemischen Verfahrens über die Grenze beobachtbar/unbeobachtbar hinaus extrapolieren. ${ }^{257}$ Man kann außerdem als undogmatischer Antirealist zu einer Verläßlichkeitsüberzeugung in bezug auf ein Erzeugungsverfahren, das Output über Unbeobachtbares liefert, gelangen, wenn diese Verläßlichkeitsüberzeugung zu einer "hinreichend gut epistemisch zusammenhängenden" Menge von Überzeugungen gehört, für die sich "hinreichend viele" und "hinreichend gute" schwache Gründe von außen anführen lassen, und man ein Inferenzverfahren der vorne skizzierten Art als verläßlich akzeptiert, das das Schließen auf eine solche Menge gestattet. ${ }^{258}$ Auf diesem letzteren Weg kann man als undogmatischer Antirealist grundsätzlich auch zu Verläßlichkeitsüberzeugungen in bezug auf Erzeugungsverfahren kommen, deren Output - anders als bei grenzüberschreitenden Verfahren — ausschließlich Unbeobachtbares zum Inhalt hat (wie insbesondere im Fall von Meßverfahren für unbeobachtbare Größen wie magnetische Feldstärke u.ä.). Daß ein undogmatischer Antirealismus, der auf diese Weise den Erwerb von (neuen) Verläßlichkeitsüberzeugungen grundsätzlich zuläßt, eine zumindest prima facie plausiblere Position ist als ein konsequenterer Antirealismus wie ihn van Fraassen vertritt, läßt sich vielleicht daran ablesen, daß sich in den vorne skizzierten Beispielen ${ }^{259}$ eine farbenblinde bzw. eine blinde Person von den Fähigkeiten anderer Menschen, rot und grün verläßlich zu erkennen (und damit auch von der Existenz roter und grüner Gegenstände) überzeugen läßt, wenn sie Schlüsse auf eine "hinreichend gut epistemisch zusammenhängenden" Menge von Überzeugungen der beschriebenen Art akzeptiert, während schwer zu sehen ist, wie dies ohne einen Schluß dieser Art möglich sein könnte.

In einer Debatte mit einem Anhänger einer undogmatischen antirealistischen Position oder mit unvoreingenommenen Laien besteht für die realistische Seite zumindest grundsätzlich die Möglichkeit, mit Argumenten für ontologische realistische Thesen über Unbeobachtbares gleichsam innerhalb der oben beschriebenen prinzipiellen Grenzen der

\footnotetext{
${ }^{256}$ Ausgenommen natürlich deduktive Inferenzschemata bei Input über Unbeobachtbares; s.o.

${ }^{257}$ Siehe Abschnitt 8.3.3. Wenn man solche induktiven Extrapolationsschlüsse für nur mäßig verläßlich hält, können dadurch immerhin schwache Gründe für Verläßlichkeitsüberzeugungen gegeben sein, die bei einem Schluß auf eine "epistemisch zusammenhängende" Menge eine Rolle spielen können; siehe dazu das Folgende.

${ }^{258}$ Siehe S.468ff., bes. S.473ff.

${ }^{259}$ S.489ff.
} 
Reichweite solcher Argumente etwas auszurichten. Das, was ein Argument für eine realistische These der Natur der Sache nach leisten kann und was von ihm plausiblerweise zu erwarten oder zu erhoffen ist, spielt sich innerhalb dieser prinzipiellen Grenzen ab.

Vor diesem Hintergrund wird schließlich deutlich, daß die vorne untersuchten epistemischen Kontinuitätsargumente und Versionen des Wunderarguments von ihrer Art her, also abgesehen von den vorne diskutierten speziellen Mängeln und erläuterungsbedürftigen Ungenauigkeiten in der Formulierung (die möglicherweise zu beseitigen sind), Argumente sind, die soviel leisten können, wie plausiblerweise von einem Argument für wissenschaftlichen Realismus zu erwarten ist — obwohl ihre Überzeugungskraft bzw. ihr Erfolg vom jeweiligen Diskussionsgegner abhängt und sie gegen reflektierte, konsequente Antirealisten wirkungslos bleiben. Daß diese Argumente vielen intuitiv als "zu schwach", "nicht überzeugungskräftig genug" o.ä., und deswegen als nicht zufriedenstellend erscheinen, und zwar auch vielen Anhängern realistischer Positionen, läßt sich darauf zurückführen, daß die grundsätzliche Frage nach den Grenzen der Reichweite von Argumenten für realistische Thesen außerhalb des Blickfeldes bleibt, und daß damit auch ausgeblendet bleibt, daß für ontologische realistische Thesen über Beobachtbares in bestimmten Fällen kaum Besseres als analoge Argumente derselben Art zur Verfügung stehen dürfte.

\subsubsection{Fazit}

Die Frage nach epistemischen Rechtfertigungsgründen und Argumenten für ontologische realistische Thesen über Unbeobachtbares, die von realistischer Seite gegen Diskussionsgegner ins Feld geführt werden können, die eine in epistemischer Hinsicht antirealistische Position vertreten, ist hier, aus den vorne genannten Gründen, unter Voraussetzung eines reliabilistischen Ansatzes in der Erkenntnistheorie diskutiert worden. Abweichend von dem, was im Mainstream der wissenschaftstheoretischen Realismusdebatte üblich ist, wurde zunächst untersucht, wie es im Bereich des Beobachtbaren um die Möglichkeiten und um die Grenzen der Möglichkeiten, Rechtfertigungsgründe und Argumente für ontologische realistische Thesen anzuführen, bestellt ist. Dadurch wurde ein Orientierungspunkt für die folgende Untersuchung der entsprechenden Möglichkeiten und Grenzen der Möglichkeiten im Bereich des Unbeobachtbaren gewonnen, und insbesondere auch für eine Bewertung dessen, was diese Untersuchung dort, im Bereich des Unbeobachtbaren, ergeben hat. Zusammenfassend läßt sich das Folgende festhalten.

Es empfiehlt sich in beiden Bereichen zu unterscheiden zwischen den Rechtfertigungsgründen, die man in interner Reflexion für eine eigene Überzeugung bzw. für eine ontologische realistische These, die den Inhalt der Überzeugung darstellt, anführen kann, einerseits, und den Argumenten, die man in einer Debatte mit anderen Personen vorbringen kann, um diese von der ontologischen realistischen These zu überzeugen, andererseits. Die Gesamtheit der (direkten und indirekten) Rechtfertigungsgründe, die man in interner Reflexion für eine ontologische realistische These angeben kann, bildet einen endlich großen Graphen, der offene Enden und/oder Zirkel enthält; diese offenen Enden und Zirkel markieren die Grenzen, auf die man bei der Suche nach Rechtfertigungsgründen für eine ontologische realistische These früher oder später stößt, und zwar im Fall einer These über Beobachtbares genau wie bei einer These über Unbeobachtbares.

Auch wenn man hinreichende Rechtfertigungsgründe für eine ontologische realistische These, die man selbst glaubt, aufweisen kann, impliziert dies nicht, daß diese Rechtfertigungsgründe ein für jeden Diskussionsgegner überzeugungskräftiges Argument ergeben. Die Möglichkeiten, erfolgreich für eine ontologische realistische These zu argumentieren, 
werden durch drei Faktoren begrenzt, im Bereich des Beobachtbaren genau wie im Bereich des Unbeobachtbaren: Erstens steht einem als Realist zur Konstruktion eines Arguments für eine ontologische realistische These, von der man selbst überzeugt ist, nicht mehr als die Überzeugungen zur Verfügung, die den eigenen Rechtfertigungsgraphen der These bilden. Zweitens ergeben (hinreichende) Rechtfertigungsgründe, die man in interner Reflexion für eine ontologische realistische These aufweisen kann, nur dann ein für einen bestimmten Diskussionsgegner überzeugungskräftiges Argument, wenn dieser hinreichend viele dieser Rechtfertigungsgründe teilt. Drittens kann der Erfolg eines Arguments in der Debatte mit einem bestimmten Diskussionsgegner auch noch von den Regeln oder Verfahren abhängen, die dieser zur Beseitigung von Konflikten innerhalb seines Überzeugungssytems verwendet, ${ }^{260}$ nämlich dann, wenn das Argument einen solchen Konflikt aufdeckt.

Wie oben diskutiert, stellt weder die Tatsache, daß man bei der Suche nach Rechtfertigungsgründen für eine ontologische realistische These früher oder später auf die genannten prinzipiellen Grenzen stößt, noch der Befund, daß der Reichweite von (auf den verfügbaren Rechtfertigungsgründen basierenden) Argumenten für eine solche These die beschriebenen prinzipiellen Grenzen gesetzt sind, einen plausiblen Grund für die Annahme dar, daß die verfügbaren Rechtfertigungsgründe "in epistemischer Hinsicht nicht zufriedenstellend", "wertlos" o.ä. seien, und daß dadurch realistische Positionen entwertet werden. Dies gilt für ontologische realistische Thesen über Beobachtbares genauso wie für ontologische realistische Thesen über Unbeobachtbares bzw. für Common-sense-Realismus ebenso wie für wissenschaftlichen Realismus.

Die prinzipiellen Grenzen, die der Reichweite von Argumenten für ontologische realistische Thesen durch die drei genannten Faktoren gesetzt sind, spielen für die alltagsweltliche epistemische Praxis im Bereich des Beobachtbaren selten oder nie eine Rolle, obwohl man sich Fälle (wie die skizzierten über eine farbenblinde bzw. blinde Person) zurechtlegen kann, in denen sie relevant sind. Für die epistemische Praxis der Wissenschaften, auch soweit diese den Bereich des Unbeobachtbaren betrifft, sind diese Grenzen ebenfalls höchstens selten relevant. Für die wissenschaftstheoretische Realismusdebatte dagegen spielen die prinzipiellen Grenzen, die durch die drei Faktoren gegeben sind, eine zentrale Rolle: Diese Grenzen sind dafür verantwortlich, daß ein reflektierter, konsequenter Antirealist wie van Fraassen durch kein von realistischer Seite vorgebrachtes Argument von ontologischen realistischen Thesen über Unbeobachtbares überzeugt werden kann. Die Hinweise, die sich vorne bei der Diskussion der epistemischen Kontinuitätsargumente und des Wunderarguments ergeben hatten, daß die "Kraftlosigkeit" dieser Argumente in der Debatte mit Antirealisten wie van Fraassen nichts mit speziellen Mängeln dieser Argumente zu tun hat, sondern mit so etwas wie prinzipiellen Grenzen der Möglichkeiten, eine realistische Position argumentativ zu begründen, haben sich also hier als korrekt erwiesen. Die prinzipiellen Grenzen, die der Reichweite von Argumenten für ontologische realistische Thesen sowohl über Beobachtbares, als auch über Unbeobachtbares gesetzt sind, liegen, wie sich gezeigt hat, in der Natur dessen, was ein Argument ist, und berühren den epistemischen Status dieser realistischen Thesen nicht. Daß man als wissenschaftlicher Realist einen reflektierten, konsequenten Antirealisten wie van Fraassen nicht von der Existenz unbeobachtbarer Gegenstände oder Sachverhalte überzeugen kann, beeinträchtigt den epistemischen Status einer realistischen Position in der wissenschaftstheoretischen Realismusdebatte ebenso wenig wie die Tatsache, daß sich eine "hinreichend konsequente" farbenblinde bzw. blinde Person nicht durch Argumente von der Existenz farbiger Gegenstände

\footnotetext{
${ }^{260}$ Und, sofern dabei der Rest dieses Überzeugungssystems eingeht, auch von diesem.
} 
überzeugen läßt, den epistemischen Status eines Common-sense-Realismus beeinträchtigt.

Daß man als Anhänger einer realistischen Position in der wissenschaftstheoretischen Realismusdebatte keine Möglichkeiten hat, um reflektierte, konsequente Antirealisten von der eigenen Position zu überzeugen, impliziert nicht, daß Argumente für realistische Thesen keinerlei Funktion in dieser Debatte haben oder daß diese Debatte zwangsläufig jeden Witz verliert: Argumente für realistische Thesen können innerhalb der beschriebenen prinzipiellen Grenzen ihrer Reichweite dazu dienen, Anhänger "undogmatischer" antirealistischer Positionen und unvoreingenommene Laien, also Personen, die bisher keine systematisch reflektierte Position in der Realismusdebatte einnehmen, von einer realistischen Position zu überzeugen. Welche argumentativen Ressourcen auf realistischer Seite zur Verfügung stehen, um solche Diskussionsgegner von bestimmten ontologischen realistischen Thesen und damit von einer selektiven realistischen Position zu überzeugen, läßt sich im einzelnen nur sagen, wenn bzw. soweit wie das oben skizzierte Programm für die Suche nach Rechtfertigungsgründen realisiert ist. Erst wenn dieses Programm umgesetzt ist, hat man nicht nur die Gesamtheit der ontologischen realistischen Thesen über Unbeobachtbares, die das Herzstück einer selektiven realistischen Position in der wissenschaftstheoretischen Realismusdebatte bilden, in der Hand, sondern auch sämtliche Rechtfertigungsgründe für diese Thesen und damit die Gesamtheit der argumentativen Ressourcen, die beim derzeitigen Stand der Wissenschaft verfügbar sind, um für eine selektive realistische Position zu argumentieren.

Dieses Fazit der Suche nach Argumenten für eine selektive realistische Position in der wissenschaftstheoretischen Realismusdebatte, daß ein gleichsam spielentscheidendes Argument, das für alle Diskussionsgegner in dieser Debatte, insbesondere für Antirealisten wie van Fraassen, Überzeugungskraft hat, nicht zu haben ist, und daß darüberhinaus auch die Argumente, die sich von realistischer Seite "innerhalb der prinzipiellen Grenzen der Reichweite von Argumenten" tatsächlich vorbringen lassen, i.a. erst nach der Realisierung wenigstens von Teilen des skizzierten Programms verfügbar sind, ist für jemanden, der einer realistischen Position anhängt oder zumindest "realistische Neigungen" hat, vielleicht ernüchternd oder sogar enttäuschend. Sicherlich ist das, was sich gemäß diesem Fazit mit argumentativen Mitteln in der Realismusdebatte ausrichten läßt, weniger als optimistischere und enthusiastischere Vertreter realistischer Positionen in der wissenschaftstheoretischen Debatte, etwa Putnam und Boyd, nahelegen oder wenigstens hoffen lassen, aber nüchtern betrachtet ist dies die Sachlage, zumindest aus einer reliabilistischen Perspektive betrachtet. Diese Sachlage ist weit weniger enttäuschend als sie auf den ersten Blick vielleicht aussieht, wenn man im Auge behält, daß, um Hackings Bild noch einmal aufzugreifen, ${ }^{261}$ die Dinge im "Bürgerkrieg" um die beobachtbaren Gegenstände, Prozesse etc. der Alltagswelt genauso liegen wie in dem "Kolonialkrieg", den wissenschaftliche Realisten und Antirealisten um die unbeobachtbaren Gegenstände, Prozesse etc. aus den Gegenstandsbereichen der Wissenschaften führen.

\footnotetext{
${ }^{261}$ Siehe S.24.
} 


\section{Kapitel 15}

\section{Ein Baustein für die Realisierung des Programms eines selektiven wissenschaftlichen Realismus}

Ergebnis der Überlegungen zu Rechtfertigungsgründen und Argumenten für eine selektive realistische Position im vorigen Kapitel war, daß dem, was man als Realist in der wissenschaftstheoretischen Realismusdebatte mit Argumenten ausrichten kann, Grenzen prinzipieller Art gesetzt sind, und daß alles, was einem innerhalb dieser Grenzen zur Verfügung steht, um überzeugungskräftige Argumente für eine bestimmte ontologische realistische These über Unbeobachtbares zu formulieren, durch die Gesamtheit der Rechtfertigungsgründe gegeben ist, die man in interner Reflexion für diese These anführen kann, nachdem man sich über den dafür relevanten Kenntnisstand der Wissenschaften informiert hat. Daher hat man alles bzw. das beste, was sich von realistischer Seite an Argumenten für eine selektive realistische Position, die zu sämtlichen "kognitiven Produkten" der Wissenschaften Stellung bezieht, vorbringen läßt, erst dann in der Hand, wenn ein sehr umfangreiches Programm für die "Durchmusterung" der in den Wissenschaften etablierten oder wenigstens diskutierten Theorien, Gesetze, Modelle etc. und der Suche nach Rechtfertigungsgründen für entsprechende ontologische realistische Thesen, die "im Erfolgsfall" das Herzstück der selektiven realistischen Position ausmachen, umgesetzt ist.

Dieses oben beschriebene Programm ist aus den genannten Gründen hier nicht realisierbar. Es soll aber, wie bereits angekündigt, in diesem letzten Kapitel dieser Arbeit wenigstens für ein Fallbeispiel aus dem Bereich der Physik untersucht und in groben Zügen (wenn auch nicht in allen eigentlich wünschenswerten Einzelheiten) skizziert werden, was sich dort an Rechtfertigungsgründen für ontologische realistische Thesen über Unbeobachtbares angeben läßt, um auf diese Weise gleichsam einen Baustein für die Umsetzung des beschriebenen Programms bereitzustellen, und dadurch auch ein etwas anschaulicheres Bild davon zu zeichnen, wie eine weiterreichende Realisierung des vorne in vergleichsweise allgemeiner, abstrakter Weise umrissenen Programms aussehen müßte. Gleichzeitig soll durch dieses Fallbeispiel gezeigt werden, daß sich zumindest für einige ontologische realistische Thesen über Unbeobachtbares tatsächlich hinreichende epistemische Rechtfertigungsgründe "guter Qualität" angeben lassen, daß also der Bereich jenseits der Grenze beobachtbar/unbeobachtbar keineswegs für Menschen epistemisch völlig unzugänglich ist. Dadurch sollte auch der These, daß sich auch für andere ontologische realistische Thesen über Unbeobachtbares und damit für einen "einigermaßen gehaltvollen" selektiven wissen- 
schaftlichen Realismus hinreichende epistemische Rechtfertigungsgründe "guter Qualität" angeben lassen, zumindest eine gewisse Prima-facie-Plausibilität verliehen werden - auch wenn dies im einzelnen erst durch die Umsetzung des skizzierten Programms zu erweisen wäre. Als Fallbeispiel werden im folgenden einige Sätze bzw. Gesetze über elektrische Ströme untersucht. ${ }^{1}$

Dieses Beispiel ist eines aus dem Bereich der Physik, das im Hinblick auf die Realismusdebatte insofern von zentralem Interesse ist, als es Eigenschaften oder Größen bzw. Entitäten betrifft, die in allen Ausprägungen und ganz unbeobachtbar sind (sofern sie existieren $^{2}$ ) — im Unterschied zu Eigenschaften oder Größen, die in beobachtbaren und in unbeobachtbaren Ausprägungen vorkommen, ${ }^{3}$ bzw. Entitäten eines Typs, die beobachtbar oder unbeobachtbar sein können. Daß sich für ontologische realistische Thesen über unbeobachtbare physikalische Entitäten, Eigenschaften, Größen etc. der letzteren Art, also für ontologische realistische Thesen, die sozusagen den Bereich kurz hinter der Grenze beobachtbar/unbeobachtbar betreffen (z.B. Kristalle im Mikrometerbereich, Zellgewebe und Bakterien und deren Farbe, Form und Struktur), hinreichende Rechtfertigungsgründe "guter Qualität" aufweisen lassen, ist vielleicht intuitiv und vor allem auch angesichts der von Maxwell skizzierten Kontinuitätsargumente, die "grenzüberschreitende" Erzeugungsverfahren wie Beobachten mit Lupe und Mikroskop involvieren, einigermaßen plausibel. Für ontologische realistische Thesen, die diesen Grenzbereich betreffen, dürften sich am ehesten und häufig hinreichende Rechtfertigungsgründe finden lassen, jedenfalls soll dieser Bereich, der die aus reliabilistischer Perspektive vielleicht naheliegendsten und am leichtesten "zu behandelnden" Beispiele enthält, hier nicht untersucht werden, sondern stattdessen der genannte "interessantere" Beispielfall.

Eine wichtige Hintergrundprämisse für die folgende Untersuchung bildet das in den Diskussionen vorne gewonnene Resultat, daß sich ein verläßliches Inferenzverfahren von der Art des Schließens auf die beste Erklärung, das einen Schluß von Beobachtungen und Meßresultaten (oder von daraus induktiv verallgemeinerten Sätzen oder phänomenologischen Gesetzen) auf "hochstufige" Theorien wie die klassische Elektrodynamik, die Quantenmechanik oder die Quantenelektrodynamik gestatten würde, derzeit nicht identifizieren läßt. Es ist nicht ausgeschlossen, daß sich ein solches Inferenzverfahren im Verlauf zukünftiger Untersuchungen spezifizieren lassen könnte; solche Untersuchungen können an dieser Stelle jedoch nicht durchgeführt werden, daher wird im folgenden kein Inferenzverfahren für Schlüsse auf die beste Erklärung als verläßlich vorausgesetzt.

Ergebnis der folgenden Erörterungen wird sein, daß sich zumindest für einige Gesetze bzw. Sätze über elektrische Ströme bzw. für entsprechende ontologische realistische Thesen hinreichende Rechtfertigungsgründe "guter Qualität" angeben lassen.

\subsection{Elektrische Ströme und Spannungen}

In diesem Fallbeispiel soll für einige vergleichsweise niederstufige oder phänomenologische Gesetze bzw. Sätze über elektrische Ströme und Spannungen (in metallischen Leitern und Halbleitern) untersucht und in groben Zügen skizziert werden, was sich für entsprechen-

\footnotetext{
${ }^{1}$ Die Frage nach den Unabhängigkeitsaussagen, die in entsprechenden ontologischen realistischen Thesen enthalten sind, und nach Rechtfertigungsgründen für diese Unabhängigkeitsaussagen wird hier nicht explizit erörtert; vgl. S.407f., 460.

${ }^{2}$ Diese Qualifikation bleibt im folgenden häufig implizit.

${ }^{3}$ Z.B. die Farbe rot, je nach Größe des roten Gegenstands, und die Länge eines Gegenstands, je nachdem, wie lang dieser ist.
} 
de Überzeugungen an Rechtfertigungsgründen anführen läßt, welche Gestalt also deren Rechtfertigungsgraph hat, und zwar für die folgenden Gesetze bzw. Sätze: ${ }^{4}$

1. In einem Metalldraht der Länge $l$ und der Querschnittsfläche $A$ fließt bei angelegter Spannung $U$ ein Strom der Stromstärke $I=\frac{U * A}{\rho * l}$, wobei $\rho$ eine Materialkonstante ist, der spezifische Widerstand (Ohmsches Gesetz). Für Kupfer beispielsweise ist (bei einer Temperatur von $273 K) \rho=0.0156 * 10^{-6} \Omega m .{ }^{5}$

2. In einer Silizium-Gleichrichterdiode eines bestimmten Typs fließt bei angelegter Spannung $U$ ein Strom, dessen Stromstärke $I$ durch folgende Kennlinie gegeben ist $^{6}$ :

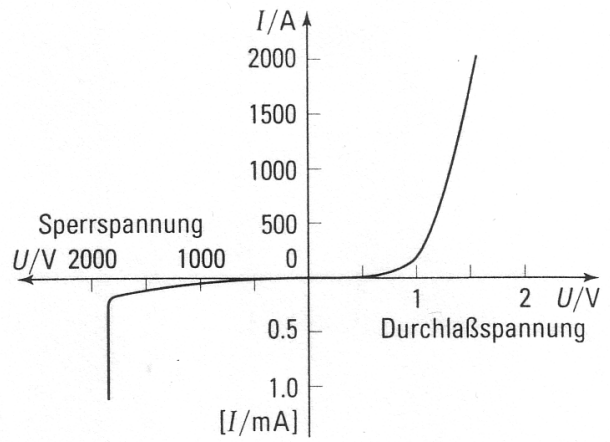

3. Wenn durch eine Leiterplatte der Dicke $d$ und der Breite $b$ von einer Schmalseite zur gegenüberliegenden ein Strom der Stärke $I$ fließt und ein Magnetfeld $B$ senkrecht zur Platte und zum Strom anliegt, dann liegt zwischen den beiden Längsseiten der Platte eine Spannung $U_{\text {Hall }}=R_{H} \frac{B * I}{d}$ an. Dabei ist $R_{H}$ eine Materialkonstante, der Hall-Koeffizient (Hall-Effekt). Für Kupfer beispielsweise ist (bei Zimmertemperatur) $R_{H}=54 \cdot 10^{-6} \frac{\mathrm{cm}}{\mathrm{As}} \cdot 7$

Rechtfertigungsgründe für diese Gesetze bzw. Sätze sind in allen drei Fällen durch Messungen der durch die Gleichungen bzw. die Kennlinie miteinander verknüpften Größen gewonnen worden, aus deren Resultaten sich der jeweilige allgemeine Satz durch einen induktiven Schluß ergibt: ${ }^{8}$ Im Fall des Ohmschen Gesetzes durch Messungen der Länge

\footnotetext{
${ }^{4}$ Alle drei Gesetze bzw. Sätze könnten strenggenommen genauer formuliert werden, etwa im Hinblick auf Strom- und Spannungsbereiche, in denen sie gelten, "Fehlerbalken" für Größenwerte und Materialkonstanten, Zusammensetzung, Homogenität etc. der Leiter und Halbleiter, vorausgesetzte Randbedingungen wie Umgebungstemperatur, Hintergrundfelder diverser Arten etc. Diese Spezifikationen bleiben hier aus Gründen der Übersichtlichkeit implizit, denn für die Argumentation hängt davon nichts wesentliches ab.

${ }^{5}$ Siehe z.B. [AsMe76], S.6ff., [AlFi67], S.585f., [Gert82], S.271.

${ }^{6}$ [Rait99], S.566; vgl. auch [Gert82], S.716. Der genaue Verlauf der Kennlinie hängt vom Typ der Diode bzw. den Materialeigenschaften des pn-Übergangs ab, auf die es hier nicht ankommt; "echte", durch Messungen ermittlte Kennlinien finden sich z.B. in [SaNS57].

${ }^{7}$ Siehe z.B. [Kitt88], S.186, [AsMe76], S.11ff., [Rait99], S.502ff., 548ff., [Gert82], S.308f.

${ }^{8} \mathrm{Im}$ folgenden werden die "Komplikationen" übergangen, die sich dadurch ergeben können, daß bestimmte Überzeugungen durch ein Erzeugungsverfahren, etwa mit Hilfe eines Meßgerätes, gewonnen wurden, dessen "direkter" Output (sprich: Meßwerte, Daten o.ä.) nur der messenden Person zugänglich ist (oder jedenfalls nur einem engen Kreis von "Experten"), so daß andere Personen eine entsprechende Über-
} 
und des Querschnitts von Kupferdrähten und Messungen des Stromes bei verschiedenen, durch kleine Intervalle getrennten konstanten Spannungswerten, im Fall der Diodenkennlinie und des Hall-Effekts ebenfalls durch Strom- und Spannungsmessungen sowie (beim Hall-Effekt) durch Messungen des $B$-Feldes und der Dicke der Metall- bzw. Halbleiterplatten. Der induktive Schluß von den Meßwerten auf das phänomenologische Gesetz bzw. den allgemeinen Satz kommt im ersten und dritten Fall durch Anpassung einer Regressionsgraden zustande, im zweiten Beispiel durch Anpassung einer Spline-Funktion o.ä. Induktive Inferenzverfahren, als deren Instantiierungen sich die drei konkreten Schlüsse auffassen lassen, mit präzise definiertem Verläßlichkeitsbereich genau zu spezifizieren, ist, wie vor$n \mathrm{e}^{9}$ diskutiert, ein notorisch schwieriges Problem, in diesen konkreten Fällen sollte jedoch (genügend dicht liegende Meßpunkte vorausgesetzt) unkontrovers sein, daß der Übergang zu den allgemeinen Sätzen gerechtfertigt ist, daß es also verläßliche induktive Inferenzverfahren gibt, die die fraglichen Schlüsse instantiieren, auch wenn diese Inferenzverfahren und insbesondere ihr Verläßlichkeitsbereich derzeit nicht genau spezifiziert werden können.

Direkte Rechtfertigungsgründe für die Meßwerte, die als Prämissen der induktiven Schlüsse fungieren, sind Herkunfts- und Verläßlichkeitsüberzeugungen, die sich auf das jeweilige Meßgerät beziehen: Die Werte der Stromstärke wurden durch Einsatz eines Amperemeters, Spannungswerte mit einem Voltmeter, B-Felder durch ein Magnetometer etc. gemessen, die (in bestimmten Meßbereichen) verläßlich sind.

Verfolgt man die Rechtfertigungsgraphen der drei phänomenologischen Gesetze bzw. allgemeinen Sätze weiter zurück, so stellt sich als nächstes die Frage nach Rechtfertigungsgründen für die Verläßlichkeitsüberzeugungen in bezug auf die Meßgeräte. Hier läßt sich in allen Fällen ein induktiver Schluß der vorne skizzierten Art angeben, dem zufolge sich die Verläßlichkeit des jeweiligen Meßgerätes aus dessen bisheriger Erfolgsbilanz ergibt. ${ }^{10}$ Industriell hergestellte Ampere-, Volt- und Magnetometer etwa werden üblicherweise nach Abschluß der Produktion durch einige Messungen an bekannten, standardisierten Systemen (Stromquellen etc.) getestet; solche Messungen, zusammen mit zusätzlichen Kalibrierungs- oder Testmessungen und, soweit im konkreten Fall vorliegend, der Erfolgsbilanz des jeweiligen Gerätes in der Laborpraxis, liefern induktive Rechtfertigungsgründe für eine Verläßlichkeitsüberzeugung. Andere, nämlich deduktive Rechtfertigungsgründe für eine solche Verläßlichkeitsüberzeugung sind in einigen Fällen durch eine theoretische Beschreibung der Funktionsweise des jeweiligen Meßgeräts gegeben (s.u.).

Die Strom- bzw. Spannungs- bzw. B-Werte, die einer Erfolgsbilanz und damit der induktiven Rechtfertigung der Verläßlichkeit eines Meßgeräts zugrundeliegen, werden ihrerseits durch Messungen gewonnen oder erschlossen. ${ }^{11}$ In beiden Fällen stößt man i.a. beim Weiterverfolgen des Rechtfertigungsgraphen wiederum auf Verläßlichkeitsüberzeugungen

zeugung genaugenommen durch ein anderes Verfahren (Mitteilen der gemessenen Daten oder sogar nur der erschlossenen Resultate o.ä.) gewinnen müssen. Diese Komplikationen können die Berücksichtigung zusätzlicher Verläßlichkeitsannahmen erforderlich machen, sind aber grundsätzlich unproblematisch; vgl. dazu auch S.487, Fn.152.

${ }^{9} \mathrm{~S} .452$.

${ }^{10}$ Siehe S.463f., 504f.

${ }^{11}$ Dies gilt auch dann, wenn man ein Meßgerät an einem "Normal" eicht, das als "Definition" von Maßeinheiten dient (also etwa ein Voltmeter an einem Spannungsnormal), denn ein bestimmtes physikalisches System wird nur dann zum Normal erklärt (etwa ein bestimmter Typ einer elektrochemischen Zelle oder ein bestimmter Typ Josephson-Tunnelelement zum Spannungsnormal), wenn man gute Gründe für die Annahme hat, daß dieses System einen bestimmten, sehr stabilen, reproduzierbaren, von Umwelteinflüssen unabhängigen Wert der fraglichen Größe instantiiert, und solche guten Gründe involvieren üblicherweise Messungen mit den besten (zum jeweiligen Zeitpunkt) existierenden Instrumenten. Normale für elektrische Einheiten werden beschrieben in [Brau90, Gobe97]. 
in bezug auf Meßgeräte (im ersteren Fall sofort im nächsten Schritt, im letzteren Fall früher oder später, wenn man die Rechtfertigungsgründe der Prämissen des Schlusses verfolgt $\left.{ }^{12}\right)$. Bei diesen Meßgeräten kann es sich im Prinzip um Geräte desselben Typs handeln wie die, die die Meßdaten für den induktiven Schluß auf die drei Gesetze bzw. allgemeinen Sätze geliefert haben; es stehen aber zur Messung von elektrischen Strömen und Spannungen und von B-Feldern (zumindest in bestimmten Meßbereichen) jeweils Geräte mehrerer Typen zur Verfügung, die sich nicht nur durch Details der Konstruktion unterscheiden, sondern deren Funktion auf verschiedenen physikalischen Mechanismen basiert, und i.a. wird zur Kalibrierung eines Meßgerätes ein Gerät einer anderen Bauart herangezogen.

Für die Messung von Stromstärken gibt es u.a.

- elektronische Amperemeter,

- Drehspulamperemeter, bei denen die Kraft ausgenutzt wird, die auf eine stromdurchflossene Spule in einem konstanten Magnetfeld wirkt,

- Hitzdrahtamperemeter, bei denen der gemessene Strom einen Draht erwärmt und die daraus resultierende Längenausdehnung ausgenutzt wird,

- elektrochemische Meßapparaturen, bei denen der Strom durch eine Elektrolytlösung geführt wird und daraus (je nach Lösung) Gas oder Metall abscheidet, deren Menge als Maß für den geflossenen Strom dient. ${ }^{13}$

Zur Messung von Spannungen gibt es neben elektronischen Voltmetern u.a. Drehspulvoltmeter, bei denen die gemessene Spannung einen kleinen Strom durch das Instrument hervorruft, der dann gemessen wird, und elektrostatische (also ohne Stromfluß arbeitende) Geräte, die zur Messung die Kraftwirkung zwischen Metallplatten ausnutzen, zwischen denen eine Spannung liegt. ${ }^{14}$ B-Felder lassen sich u.a. durch Magnetometer messen, die auf ihrer Induktionswirkung in bewegten Leitern beruhen, durch Magnetometer, die ausnutzen, daß sie auf kleine Magneten ein Drehmoment ausüben und durch Hall-Sonden, die den Hall-Effekt zur Messung nutzen. ${ }^{15}$

Für die Verläßlichkeit eines Meßinstruments lassen sich, wie im vorletzten Absatz bereits erwähnt, häufig auch deduktive Rechtfertigungsgründe angeben, d.h. eine Verläßlichkeitsüberzeugung folgt (näherungsweise) deduktiv aus einer theoretischen Beschreibung des Funktionsmechanismus des jeweiligen Geräts. Rechtfertigungsgründe dieser Art können hier jedoch (aus Platzgründen) nur für drei der genannten Arten von Amperemetern skizziert werden. ${ }^{16}$

\footnotetext{
${ }^{12}$ Denn ein verläßliches Inferenzverfahren, das Konklusionen über die Größen Stromstärke, Spannung und magnetische Feldstärke ohne Prämissen über diese Größen liefert, ist nicht in Sicht.

${ }^{13}$ In der Laborpraxis werden heute meistens elektronische Geräte eingesetzt. Die beiden zuletzt genannten Meßmethoden werden heute praktisch nicht mehr benutzt, waren aber historisch eine zeitlang für bestimmte Umstände und Meßbereiche gebräuchlich. Detaillierte Beschreibungen dieser verschiedenen Instrumenttypen (und anderer) finden sich in [DrJo52] und [Bald73], kurze Beschreibungen in [Gert82], S.353ff. Zur historischen Entwicklung der Messung elektrischer Ströme siehe [Hump37, StVa83].

${ }^{14}$ Siehe z.B. [Bald73, DrJo52].

${ }^{15}$ Siehe z.B. [Bald73], Kap.16, bes. S.309.

${ }^{16}$ Elektronische Amperemeter, Voltmeter und Magnetometer bleiben hier beiseite.
} 
Den Aufbau eines typischen Drehspulamperemeters zeigt die folgende Skizze ${ }^{17}$ : Der
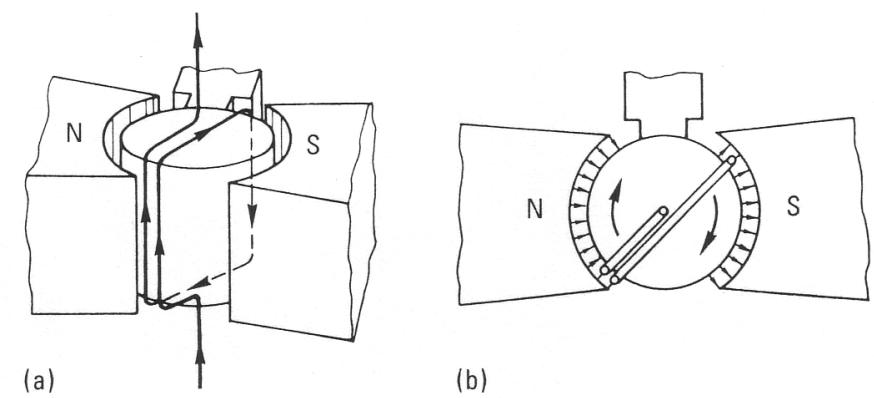

skizzierte Aufbau aus den Polen eines Permanentmagneten und einem Zylinder aus Weicheisen sorgt für ein um die Zylinderachse radialsymmetrisches B-Feld. Um den Zylinder ist in der skizzierten Weise eine Spule gewickelt, durch die der zu messende Strom fließt; Zylinder und Spule sind an einem Torsionsfaden drehbar aufgehängt. Diese Anordnung ist als Amperemeter verwendbar, weil auf jeden stromdurchflossenen Draht in einem Magnetfeld eine Kraft wirkt, die hier ein auf die Spule wirkendes Drehmoment um die Aufhängungsachse ergibt. Dieses Drehmoment ist proportional zum Strom, daher kann ein an der Spule bzw. dem Zylinder befestigter Zeiger als Anzeige der Stromstärke benutzt werden.

Die über diese qualitative Beschreibung hinausgehende, quantitative "Theorie des Drehspulamperemeters" lautet in den Grundzügen wie folgt ${ }^{18}$ : Allgemein gilt, daß auf ein (gerades) Drahtstück der Länge $l$, durch das ein Strom $I$ fließt, in einem Magnetfeld $\underline{B}$ eine Kraft $\underline{F}=I \cdot \underline{l} \times \underline{B}$ wirkt. ${ }^{19}$ Auf die beiden Seiten der Spule, die sich an den flachen Zylinderflächen befinden, wirkt keine Kraft, da dort $\underline{l}$ stets parallel zu $\underline{B}$ ist. Für die beiden anderen Seiten der Spule ist $\underline{l}$ stets senkrecht zu $\underline{B}$, daher wirkt dort jeweils eine Kraft vom Betrag $F=I \cdot l \cdot B$ in die Richtung senkrecht zum Draht und zum Magnetfeld auf jede Spulenwindung, bei $w$ Windungen der Spule also $F=w \cdot I \cdot l \cdot B$. Beide Spulenseiten zusammen sorgen daher bezüglich der Drehachse von Spule und Zylinder für ein Drehmoment vom Betrag $M_{I}=w \cdot s \cdot l \cdot I \cdot B,{ }^{20}$ oder, wenn man $w, s, l$ und $B$ zu einer Gerätekonstante $g$ zusammenfaßt, $M_{I}=g \cdot I$.

Die (klassisch-mechanische) Bewegungsgleichung für die Spule erhält man, indem man in $M=\theta \ddot{\varphi}$ für das Gesamtdrehmoment $M$ die Summe aller Beiträge einsetzt. ${ }^{21}$ Dazu tragen, neben $M_{I}$, die Verdrillung des Torsionsfadens einen Term $M_{T}=-k \varphi$ bei und die Reibung der Spule bei Bewegung ${ }^{22}$ und der in der Spule bei Bewegung induzierte Strom jeweils einen Term proportional zur Winkelgeschwindigkeit $\dot{\varphi}$ bei. Durch Lösen der Bewegungsgleichung (mit den jeweils vorliegenden Anfangsbedingungen) erhält man die

\footnotetext{
${ }^{17}$ [Rait99], S.169; vgl. auch [AlFi67], S.514.

${ }^{18}$ Zur Theorie des Drehspulamperemeters siehe u.a. [Bald73], Kap.2, [DrJo52], Kap.3, [West74], S.318ff.

${ }^{19}$ Unterstrichene Buchstaben bezeichnen Vektoren. $\underline{l}$ steht für den Vektor mit der Richtung des Stromes und der Länge $l$.

${ }^{20} s$ ist die Seitenlänge der Spule an den flachen Zylinderflächen.

${ }^{21} \varphi$ ist der Auslenkungswinkel der Spule, gemessen von der Ruhelage aus, $\theta$ ist das Trägheitsmoment von Spule und Zylinder.

${ }^{22}$ Luft- und evtl. Lagerreibung.
} 
Beschreibung der Bewegung der Spule und damit auch eines mit ihr verbundenen Zeigers. Die je nach Geräteparametern $(w, s, l, B, \theta$ etc.) verschiedenartigen Lösungen brauchen hier nicht diskutiert zu werden; für den Fall der Messung eines konstanten Gleichstroms reicht es zu sehen, daß im Gleichgewichtszustand (der nach Einschalten eines zu messenden Stroms mehr oder weniger schnell erreicht wird) $M_{I}$ allein durch $M_{T}$ kompensiert wird ${ }^{23}$, so daß $\varphi=\frac{g}{k} \cdot I$. Der Auslenkungswinkel der Spule bzw. eines daran befestigten Zeigers ist also proportional zum gemessenen (konstanten) Strom.

Den Aufbau eines Hitzdrahtamperemeters zeigt die folgende Skizze ${ }^{24}$ : Ein Metalldraht,

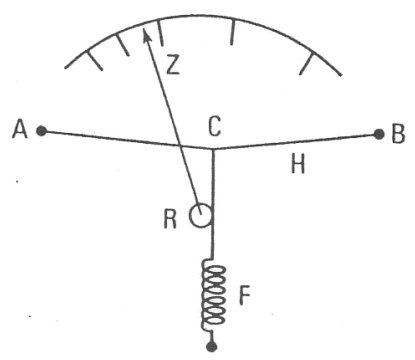

durch den der zu messende Strom fließt, ist zwischen zwei Enden fest eingespannt. In der Mitte des Drahtes greift eine Feder an, die den Draht in die skizzierte, dreieckig abgewinkelte Form zieht, falls seine Länge zunimmt. Wenn eine solche Längenzunahme zustandekommt, verändert sich die Auslenkung der Feder aus ihrer Ruhelage um den Betrag, den der Draht dann "durchhängt"; diese Änderung der Auslenkung wird durch einen mechanisch an die Feder gekoppelten Zeiger angezeigt. Dieser Aufbau ist als Amperemeter einsetzbar, weil ein zu messender Strom den Draht, durch den er fließt, erwärmt und sich dieser Draht dadurch ausdehnt. Die mechanisch angezeigte Verlängerung des Drahtes ist daher ein Maß für die Stromstärke. ${ }^{25}$

Die quantitative "Theorie des Hitzdrahtamperemeters" lautet in den Grundzügen folgendermaßen $^{26}$ : Ein Strom $I$, der durch einen Ohmschen Leiter mit dem Widerstand $R$ fließt, heizt diesen mit einer Leistung $P=I^{2} R$ (Joulesches Gesetz). Bei den in realen Hitzdrahtamperemetern vorliegenden Größenordnungen von Drahtquerschnitt, -länge, gemessener Stromstärke etc. stellt sich kurz nach dem Einschalten des zu messenden (konstanten) Stromes eine konstante Temperatur des Drahtes ein, die etwas größer ist als die Umgebungstemperatur. Unter diesen Bedingungen gilt (näherungsweise) Newtons Abkühlungsgesetz, das besagt, daß ein Körper der Temperatur $T_{1}$, der mit einer Oberfläche $A$ an eine Umgebung (Luft, Kühlflüssigkeit o.ä.) der Temperatur $T_{2}$ grenzt, an diese Umgebung eine Wärmeleistung $P=\alpha A\left(T_{1}-T_{2}\right)$ abgibt. Dabei ist $\alpha$ (für kleine Temperaturdifferenzen) eine Materialkonstante. ${ }^{27}$ Bei stationärer Temperaturdifferenz gilt also $T_{1}-T_{2}=\frac{R}{\alpha A} I^{2}$,

\footnotetext{
${ }^{23}$ Die anderen Terme sind proportional zu $\dot{\varphi}$, verschwinden also im Gleichgewicht.

${ }^{24}$ [Rait99], S.105; vgl. auch [Pohl75], S.6, [DrJo52], S.508,[Gert82], S.355.

${ }^{25}$ Weitere, mechanisch kompliziertere Bauformen des Hitzdrahtamperemeters findet man in [DrJo52], S.8f. und Kap.9.

${ }^{26}$ Siehe [DrJo52], S.500ff.

${ }^{27}$ S.a. [Gert82], S.192.
} 
d.h. die Temperaturdifferenz zwischen Draht und Umgebung ist proportional zum Quadrat der Stromstärke. Für die Abhängigkeit der Länge eines Drahtes von seiner Temperatur gilt (in guter Näherung), wie für viele Festkörper, $l-l_{0}=l_{0} a\left(T-T_{0}\right)$, wobei $a$ eine Materialkonstante ist, der lineare Ausdehnungskoeffizient. ${ }^{28}$ Da der Draht vor dem Einschalten des zu messenden Stroms die Temperatur $T_{0}$ der Umgebung hat, folgt $l-l_{0}=\frac{l_{0} a R}{\alpha A} I^{2}$, d.h. die Längenausdehnung des Drahtes aufgrund des gemessenen Stromes ist proportional zum Quadrat der Stromstärke und stellt also ein Maß für diese dar. Die oben skizzierte Anordnung, in der die Längenzunahme des Drahtes in ein "Durchhängen" und dadurch in eine Änderung der Auslenkung der Feder umgesetzt wird, hat den Sinn, die bei den zur Verfügung stehenden Materialien sehr kleinen Längenzunahmen des Drahtes in größere und damit leichter ablesbare Längendifferenzen zu transformieren. ${ }^{29}$

Meßinstrumente, die die elektrochemischen Wirkungen des elektrischen Stromes nutzen, werden, wie bereits erwähnt, heute nicht mehr verwendet. ${ }^{30}$ In solchen Instrumenten wird der zu messende Strom durch eine elektrolytische Lösung geleitet, wo er eine chemische Zersetzung bewirkt, was, je nach Gerät, zur Abscheidung von Metall oder zur Freisetzung von Gas an den Elektroden führt. Die Menge des pro Zeiteinheit abgeschiedenen Metalls bzw. des pro Zeiteinheit freigesetzten Gases ist ein Maß für die Stromstärke. Praktisch wird Geräten dieser Art die in einem (mit einer Uhr bestimmten) Zeitintervall $T_{2}-T_{1}$ abgeschiedene bzw. freigesetzte Substanzmenge gemessen und damit die in diesem Zeitintervall geflossene Ladung $Q$. Wenn die Stromstärke konstant ist, erhält man ihren Wert als $I=\frac{Q}{T_{2}-T_{1}}$, wenn sie es nicht ist, erhält man auf diesem Weg "nur" die über das Zeitintervall gemittelte Stromstärke. Die quantitative "Theorie" dieser Geräte besteht im wesentlichen nur aus Faradays Gesetz, das besagt, daß die Masse der bei einer Elektrolyse abgeschiedene Substanz proportional zur geflossenen Ladung ist, egal welcher Elektrolyt verwendet wird. ${ }^{31}$

Die skizzierten "Theorien" der drei Arten von Amperemetern können hier nicht im Detail erörtert werden, es sollte aber plausibel sein, daß sich zumindest in bezug auf einige konkrete Amperemeter eine Verläßlichkeitsüberzeugung aus einer theoretischen Beschreibung dieser Instrumente näherungsweise deduktiv erschließen läßt. Im Fall des Drehspulamperemeters läßt sich, gegeben eine korrekte Spezifikation der Materialkonstanten, Anfangsbedingungen etc., aus der skizzierten "Theorie" (näherungsweise) deduktiv schließen, daß ein Instrument dieser Art (unter bestimmten angebbaren Bedingungen) ein verläßliches Meßverfahren für die Stärke elektrischer Ströme (bestimmter Größenordnung) in Stromkreisen, die aus metallischen Leitern oder Halbleitern gebildet werden, darstellt. Im Fall des Hitzdrahtamperemeters ist vielleicht weniger klar, ob sich aus der skizzierten "Theorie" auf die Verläßlichkeit eines real-existierenden Instruments dieser Art schließen läßt, weil keine "Bewegungsgleichung" für die Temperatur des Drahtes angegeben wurde und die Annahmen einer stationären Temperaturdifferenz zwischen Draht und Umgebung und das Newtonsche Abkühlungsgesetz allenfalls grobe, praktisch kaum kontrollierbare Näherungen darstellen. Mit hinreichend großem Forschungsaufwand könnte man die "Theorie" des Gerätes aber vielleicht so "vervollständigen" und die Anfangsbedingungen etc. für bestimmte Anwendungsfälle so genau bestimmen, daß sich daraus Verläßlichkeitsüberzeugungen in bezug auf konkrete Instrumente erschließen lassen. Im Fall der

\footnotetext{
${ }^{28}$ Siehe z.B. [Gert82], S.169.

${ }^{29} \mathrm{Daß}$ dies auf diese Weise erreicht wird, läßt sich durch elementare geometrische Überlegungen zeigen; siehe [DrJo52], S.508f.

${ }^{30}$ Siehe z.B. [DrJo52], S.11.

${ }^{31}$ Siehe z.B. [Gert82], S.282f., [Rait99], S.730f.
} 
elektrochemischen Instrumente läßt sich aus der skizzierten "Theorie" in trivialer Weise ableiten (vorausgesetzt, die Methoden der Massenbestimmung für die abgeschiedenen Substanzen sind verläßlich), daß diese verläßliche Verfahren zur Bestimmung der in einem Zeitintervall geflossenen Ladung darstellen. Wenn vorausgesetzt werden kann, daß der Strom konstant ist, folgt, daß dessen Stärke verläßlich gemessen werden kann, wenn nicht, folgt "nur", daß die mittlere Stromstärke gemessen werden kann. Im Hinblick auf die Gestalt des Rechtfertigungsgraphen der phänomenologischen Gesetze, um die es in diesem Abschnitt geht, ist festzuhalten, daß jede angegebene "Theorie des Amperemeters" (eines bestimmten Typs) mindestens ein Gesetz enthält, das die Größe elektrische Stromstärke involviert, d.h., daß zu den skizzierten deduktiven Rechtfertigungsgründen für die Verläßlichkeit der Amperemeter (als Prämissen des Schlusses) Überzeugungen erster Ordnung zählen, die elektrische Ströme und deren Stärke zum Inhalt haben: Im Fall des Drehspulamperemeters die Überzeugung, daß auf ein gerades, stromdurchflossenes Drahtstück im Magnetfeld eine Kraft $\underline{F}=I \cdot \underline{l} \times \underline{B}$ wirkt, im Fall des Hitzdrahtamperemeters das Joulesche Gesetz und im Fall der elektrolytischen Instrumente die Überzeugung, daß die pro Zeiteinheit abgeschiedene Masse proportional zur Stromstärke ist.

Um ein adäquates Bild von der Gestalt der Rechtfertigungsgraphen der drei phänomenologischen Gesetze bzw. Sätze, um die es in diesem Abschnitt geht, zu gewinnen, ist es offenbar noch erforderlich, zu prüfen, ob sich für diese Gesetze bzw. Sätze und auch für die Gesetze, die in den "Theorien" der oben erwähnten Meßinstrumente auftreten, (neben den bereits erwähnten induktiven) auch deduktive Rechtfertigungsgründe angeben lassen. Insbesondere sind hier die für die entsprechenden Phänomene oder Sachverhalte in der Physik verfügbaren theoretischen Erklärungen zu untersuchen, die eine (näherungsweise oder vielleicht auch exakte) deduktive Herleitung dieser Gesetze bzw. Sätze involvieren könnten. In der physikalischen Literatur finden sich für all diese Gesetze bzw. Sätze theoretische Modelle und Erklärungen, meistens sogar mehrere. Diese Erklärungen sind allesamt atomistisch, d.h. sie gehen davon aus, daß ein elektrischer Strom ein Prozeß der Bewegung elektrischer Ladung ist, genauer: der Bewegung von bestimmten Ladungsträgern, und zwar von Elektronen in Metallen und von Ionen in Elektrolyten. An dieser Stelle können aus Platzgründen nur die Modelle für die Leitungsvorgänge in Metallen erörtert werden, aus denen sich die derzeit verfügbaren Erklärungen für das Ohmsche Gesetz, das Joulesche Gesetz, das Gesetz über die Kraft auf einen stromdurchflossenen Draht im Magnetfeld und der Ausdruck für die Hall-Spannung ergeben, und auch diese Modelle und Erklärungen können nur in den allergröbsten Grundzügen umrissen werden. Dies sollte aber genügen, um plausibel zu machen, daß die derzeit verfügbaren theoretischen Erklärungen und Modelle keine hinreichenden Rechtfertigungsgründe für die genannten Gesetze bzw. Sätze über elektrische Ströme einschließen oder liefern. Bei den hier relevanten Modellen handelt es sich um ein klassisches und um mehrere halbklassische oder quantenmechanische Modelle.

Das klassische Modell geht auf Paul Drude zurück. ${ }^{32}$ Diesem Modell zufolge besteht ein (reines) Metall aus Atomen des jeweiligen Elements, die in ungeordneter Weise und unbeweglich zusammengelagert sind. Von jedem Atom haben sich (je nach Element) ein oder mehrere Elektronen, die Valenzelektronen, gelöst; sie können sich frei zwischen den dadurch zu Ionen gewordenen Metallatomen bewegen und verhalten sich wie ein Gas. Die zentrale Idee von Drudes Modell ist, daß sich dieses Elektronengas so verhält wie es ein "gewöhnliches" Gas gemäß der kinetischen Gastheorie tut: Ein freies Elektron wird durch

\footnotetext{
${ }^{32}$ Für eine moderne Darstellung siehe [AsMe76], Kap.1.; vgl. auch [Purc83], S.88ff.
} 
andere Elektronen und durch die Metallionen nur dann beeinflußt, wenn es mit ihnen zusammenstößt; ansonsten bewegt es sich gemäß den Newtonschen Bewegungsgleichungen, also gleichförmig auf einer geradlinigen Bahn, wenn keine äußeren elektrischen oder Magnetfelder anliegen, bzw. auf einer entsprechend veränderten Bahn, wenn ein äußeres elektrisches oder Magnetfeld anliegt. Ein Elektron stößt in einem Zeitintervall $d t$ mit einer Wahrscheinlichkeit $\frac{1}{\tau} d t$ mit einem Ion oder einem anderen Elektron zusammen ( $\tau$ heißt Relaxationszeit). Ein Stoß ist ein instantanes Ereignis, bei dem sich die Geschwindigkeit des Elektrons abrupt ändert. Die Bewegungsrichtung eines Elektrons nach einem Stoß ist gleichmäßig über alle Raumrichtungen zufallsverteilt und nicht mit seiner Richtung vor dem Stoß korreliert. Die Stöße sorgen dafür, daß das Elektronengas im thermodynamischen Gleichgewicht ist. Mit Hilfe dieses Modells lassen sich vergleichsweise anschauliche Erklärungen für das Ohmsche Gesetz, das Joulesche Gesetz, den Hall-Effekt und das Gesetz über die Kraft auf einen stromdurchflossenen Draht im Magnetfeld geben.

Das Ohmsche Gesetz für Metalle wird aufgrund dieses klassischen Modells wie folgt erklärt. Wenn kein äußeres Feld anliegt, haben die Elektronen des Elektronengases (wie die Moleküle eines idealen Gases) gleichmäßig zufällig verteilte Bewegungsrichtungen im Raum, daher ist ihre mittlere Geschwindigkeit null. Wenn dagegen ein elektrisches Feld $E$ anliegt, wie es in einem stromdurchflossenen Metalldraht der Fall ist, wird jedes Elektron zwischen zwei Stößen durch das Feld (gemäß den Newtonschen Bewegungsgleichungen) beschleunigt: Ein Elektron, das direkt nach seinem letzten Stoß die Geschwindigkeit $v_{0}$ hatte, hat, wenn seitdem die Zeit $t$ vergangen ist, ohne daß es zu einem weiteren Stoß gekommen ist, die Geschwindigkeit $v=v_{0}-\frac{e E}{m} t{ }^{33}$ Die mittlere Geschwindigkeit aller Elektronen ergibt sich daher als $\bar{v}=\overline{v_{0}}-\frac{e E}{m} \bar{t}$. Der Mittelwert der $v_{0}$ ist null, weil die Bewegungsrichtungen der Elektronen nach einem Stoß, gemäß der obigen Annahme, über alle Raumrichtungen gleichverteilt sind; der Mittelwert der $t$ ist die Relaxationszeit $\tau$. Die mittlere Geschwindigkeit der Elektronen bei anliegendem Feld $E$ ist also $\bar{v}=-\frac{e E}{m} \tau$. Aus diesem Resultat ergibt sich nun auf elementare Weise das Ohmsche Gesetz: Wenn sich die freien Elektronen in einem Draht mit der mittleren Geschwindigkeit $\bar{v}$ bewegen, dann ist dies ein Strom in Richtung von $\bar{v}$. Wenn $n$ die Dichte der Elektronen ist, fließt dann durch eine Fläche der Größe $A$ senkrecht zu $\bar{v}$ pro Zeiteinheit die Ladung $-n e \bar{v} A^{34}$, durch den Draht fließt also ein Strom $I=\frac{n e^{2} E \tau}{m} A$. Da der Spannungsabfall entlang des Drahtes linear ist $(U=E l)$, erhält man also, indem man die Materialkonstanten als $\rho:=\frac{m}{n e^{2} \tau}$ zusammenfaßt, schließlich $I=\frac{U A}{\rho l}$. Daß ein konstantes äußeres elektrisches Feld nicht, wie vielleicht prima facie zu erwarten, wenn die Newtonschen Bewegungsgleichungen eine Rolle spielen, $\mathrm{zu}$ einer konstanten Beschleunigung der Elektronen führt, sondern zu einer konstanten Geschwindigkeit, sprich: zu einem konstanten Strom, liegt also nach diesem Modell daran, daß die durch das elektrische Feld gewonnene Geschwindigkeit in Feldrichtung nach kurzer Zeit immer wieder durch Stöße mit den Ionen zufällig über alle Raumrichtungen gleichverteilt und so gleichsam zunichte gemacht wird, so daß als resultierender Strom "nur" der (im Mittel) zwischen zwei Stößen gewonnene Anteil bleibt.

Das Joulesche Gesetz für metallische Leiter läßt sich in ähnlicher Weise mit Hilfe des klassischen Modells von Drude erklären, indem man den mittleren Energieverlust der Elektronen bei Stößen errechnet. ${ }^{35}$

\footnotetext{
${ }^{33} m$ ist die Masse des Elektrons, - $e$ seine Ladung.

${ }^{34} \bar{v} d t$ ist die Strecke, die ein "mittleres" Elektron in der Zeit $d t$ zurücklegt, $\bar{v} d t A$ also das "Volumen von Elektronen", das in der Zeit $d t$ durch die Fläche $A$ tritt.

${ }^{35}$ Siehe z.B. [AsMe76], S.26.
} 
Die Erklärung des Hall-Effektes mit Hilfe des klassischen Modells ist in den Grundzügen die folgende ${ }^{36}$ : Solange kein äußeres Magnetfeld anliegt, bewegen sich die Elektronen in einer stromdurchflossenen Leiterplatte, wie oben erläutert, mit der mittleren Geschwindigkeit $\bar{v}$ in Richtung des E-Feldes. Wenn ein Magnetfeld anliegt, wirkt auf die Elektronen zusätzlich die Lorentzkraft, die senkrecht zu $E$ und zu $v$ steht, also im Mittel senkrecht zu $E$ und zu $\bar{v}$ steht und damit in Richtung der einen Längsseite der Leiterplatte weist (auch unter Berücksichtigung der Stöße). Die mittlere Bewegungsrichtung der Elektronen wird also eine Komponente in Richtung der einen Längsseite der Leiterplatte bekommen, sofern die Lorentzkraft nicht durch eine andere Kraft kompensiert wird. Eine solche Gegenkraft wird sich jedoch im Gleichgewicht schnell einstellen: Da Elektronen, die sich unter dem Einfluß der Lorentzkraft bewegen, nicht am einen Ende der Leiterplatte aus dieser austreten können, kommt es dort zu einem Ladungsüberschuß, der ein E-Feld verursacht. Im Gleichgewicht ist dieses E-Feld gerade so groß, daß die Kraft, die es auf ein Elektron ausübt, genauso groß ist wie die (mittlere) Lorentzkraft: $-e E=-e \bar{v} B$. Mit dem obigen Ausdruck für den Strom und $U_{H}=E b$ folgt daraus $U_{H}=-\frac{1}{n e} \frac{B I}{d}$ und, wenn man noch $R_{H}:=-\frac{1}{n e}$ setzt, das oben für die Hall-Spannung angegebene Gesetz.

Die Erklärung für das Gesetz über die Kraft auf einen stromdurchflossenen Draht im Magnetfeld mit Hilfe des Modells von Drude lautet ${ }^{37}$ : In einem Drahtstück der Länge $l$ und des Querschnitts $A$ befinden sich $n l A$ freie Elektronen, die zum Stromfluß beitragen, wenn eine Spannung anliegt. Für die Stromstärke $I$ gilt (s.o.) $I=-n e \bar{v} A$. Auf jedes Elektron wirkt im Magnetfeld $B$ die Lorentzkraft $\underline{F}=-e \underline{v} \times \underline{B}$, auf alle zum Strom beitragenden Elektronen im Draht zusammen wirkt daher die Kraft $\underline{F}=-e n l A \underline{\bar{v}} \times \underline{B}$. Da $\underline{\bar{v}}$ in Richtung des Drahtes weist, folgt für die Kraft, die auf die Gesamtheit der Elektronen im Magnetfeld wirkt, $\underline{F}=I \cdot \underline{l} \times \underline{B}$. Daß diese Kraft, die auf die Elektronen wirkt, zu einer gleich großen Kraft auf den stromdurchflossenen Draht als Ganzen führt, wird in der gleichen Weise erklärt wie der Hall-Effekt: Die dort beschriebene Ablenkung der fließenden Elektronen durch die Lorentzkraft tritt nicht nur in Leiterplatten auf, sondern auch in einem stromdurchflossenen Draht im Magnetfeld (auch wenn die Gesetzmäßigkeiten für den Zusammenhang von Strom, B-Feld und Hall-Spannung komplizierter werden), d.h. auch dort tritt ein E-Feld der beschriebenen Art auf, das die Auswirkungen der Lorentzkraft auf die (mittlere) Bewegungsrichtung der Elektronen kompensiert. Diese E-Feld wirkt aber nicht nur auf die Elektronen, sondern auch auf die Metallionen des Drahtes, daher hat die Lorentzkraft auf die Gesamtheit der Elektronen eines stromdurchflossenen Drahtes im Magnetfeld eine genauso große Kraft auf den ganzen Draht zur Folge.

Neben Drudes klassischem Modell werden in der physikalischen Literatur zur Erklärung von Leitungsvorgängen in Metallen im wesentlichen drei Modelle bzw. theoretische Ansätze herangezogen, die in unterschiedlichem Maß quantenmechanische Beschreibungselemente enthalten: Sommerfelds Theorie der Metalle, das sogenannte semiklassische Modell und Herleitungen im Rahmen der quantenstatistischen Mechanik des Nichtgleichgewichts. Sommerfelds Theorie der Metalle ${ }^{38}$ unterscheidet sich von Drudes Modell lediglich dadurch, daß für die Geschwindigkeiten der Elektronen im thermodynamischen Gleichgewicht eine andere Verteilungsfunktion angenommen wird, nämlich anstelle der Maxwell-BoltzmannVerteilung die Fermi-Dirac-Verteilung der Quantenstatistik, was für die oben skizzierten Erklärungen des Ohmschen Gesetzes etc. keinen Unterschied macht, wohl aber für die Erklärung anderer Phänomene und Eigenschaften von Metallen (etwa ihrer Wärmeleitfähig-

\footnotetext{
${ }^{36}$ Siehe [AsMe76], S.11ff.; s.a. [Purc83], S.162ff., [Gert82], S.308.

${ }^{37}$ Siehe z.B. [Gert82], S.306f., [AlFi67], S.510ff., [Purc83], S.162.

${ }^{38}$ Siehe z.B. [AsMe76], Kap.2.
} 
keit).

Das semiklassische Modell wird in den heutigen Lehrbüchern der Festkörperphysik üblicherweise zur Erklärung von elektrischen Strömen, Wärmeleitung und anderen Transportphänomenen in Metallen herangezogen. ${ }^{39}$ Bei der Konstruktion dieses Modells geht man (anders als bei Drudes Modell) zunächst von einer quantenmechanischen Beschreibung der Leitungselektronen eines Metalls aus und motiviert dadurch gewisse "klassisch aussehende", das Modell definierende Bewegungsgleichungen für die Leitungselektronen eines Metalls unter dem Einfluß äußerer Felder. Ein elektrischer Strom in einem Metall wird dann als Bewegung von Elektronen beschrieben, die zum einen gemäß dieser Bewegungsgleichungen durch ein äußeres E-Feld bestimmt wird, zum anderen durch Stöße der Elektronen. Mit diesem Ansatz kann man für die Leitungselektronen eine BoltzmannGleichung aufstellen, also eine Gleichung, die die Verteilungsfunktion der Elektronen im Phasenraum beschreibt. Daraus lassen sich dann Erklärungen für das Ohmsche Gesetz und einige andere Phänomene im Rahmen einer sogenannten "Theorie der linearen Antwort" gewinnen, d.h. als Resultat einer Rechnung, die von der Annahme ausgeht, daß die an einem Leiter angelegte Spannung eine "kleine" Störung des thermodynamischen Gleichgewichts des Elektronengases darstellt. Etwas genauer hat es mit dem semiklassischen Modell und den mit seiner Hilfe gewonnenen Erklärungen Folgendes auf sich. ${ }^{40}$

Bei der Konstruktion des semiklassischen Modells geht man vom allgemeineren Bändermodell für Metalle (und andere kristalline Festkörper) aus: Ein Metall besteht danach aus positiven Ionen, die ein periodisches Kristallgitter bilden, und dem Elektronengas der Leitungselektronen. Die Elektronen werden durch quantenmechanische Zustandsfunktionen beschrieben, die der Schrödinger-Gleichung unterliegen, die positiven Ionen werden klassisch beschrieben, d.h., sie sorgen für ein periodisches Potential, das in die SchrödingerGleichung für die Elektronen eingeht. Da die Vielteilchen-Schrödinger-Gleichung für das gesamte Elektronengas praktisch nicht lösbar ist, macht man die Modellannahme, daß die Wechselwirkung der Leitungselektronen untereinander näherungsweise durch ein effektives Potential beschrieben werden kann, das auf ansonsten unabhängige Elektronen wirkt; dieses effektive Potential hat dieselbe Periodizität wie das Kristallgitter. Die VielteilchenSchrödinger-Gleichung zerfällt daher in Ein-Teilchen-Schrödinger-Gleichungen

$$
\left(-\frac{\hbar}{2 m} \underline{\partial}^{2}+\mathcal{U}(\underline{x})\right) \psi=\mathcal{E} \psi
$$

mit periodischem (aus Gitterpotential und effektivem Potential zusammengesetztem) Potentialterm $\mathcal{U}(\underline{x})$, d.h. es ist $\mathcal{U}(\underline{x})=\mathcal{U}(\underline{x}+\underline{R})$ für alle Gittervektoren $\underline{R}$. Eine Lösung der Vielteilchen-Gleichung erhält man als Produkt aus Lösungen der Einteilchen-Gleichung. Es läßt sich zeigen (Blochsches Theorem), daß jede Lösung von (15.1) die Form $\psi(\underline{x})=$ $e^{i \underline{k x}} u(\underline{x})$ hat, wobei $u(\underline{x})$ die Periodizität des Gitters hat. Die Gesamtheit der Lösungen von (15.1) besteht aus Zustandsfunktionen der Form

$$
\psi_{n \underline{k}}(\underline{x})=e^{i \underline{k x}} u_{n \underline{k}}(\underline{x}),
$$

wobei $n$ die natürlichen Zahlen durchläuft und $\underline{k}$ für jedes feste $n$ eine bestimmte Vielzahl diskreter, durch die Gestalt des Gitters festgelegter Werte annimmt. Die Energieeigenwerte $\mathcal{E}_{n}(\underline{k})$, die zu den zu einem festen $n$ existierenden $\psi_{n \underline{k}}$ gehören, unterscheiden sich für verschiedene $\underline{k}$, und zwar liegen sie so zwischen einer oberen und einer unteren Schranke,

\footnotetext{
${ }^{39}$ Siehe u.a. [AsMe76, Zima72, Harr70, Kitt88].

${ }^{40}$ Siehe [Zima72], Kap.7, s.a. [AsMe76], Kap.8, 12, 13, [Harr70], S.252ff.
} 
daß sie das Intervall dazwischen sozusagen eng nebeneinanderliegend ausfüllen. Die zu einem $n$ gehörenden $\psi_{n \underline{k}}$ werden als ein Band bezeichnet, $n$ als dessen Bandindex. Zwischen den Energiebereichen, die durch verschiedene Bänder abgedeckt werden, liegen i.a. Bandlücken, d.h. Bereiche ohne Eigenwerte bzw. zugehörige Zustände. Den Grundzustand eines Elektronengases aus $N$ Elektronen erhält man als Produkt aus den $N$ EinteilchenZuständen mit den niedrigsten Energieeigenwerten. In einem Metall ist die Struktur der Zustände so, daß die am Grundzustand "beteiligten" Einteilchen-Zustände bzw. die entsprechenden Energieeigenwerte "im Inneren" eines Bandes liegen, das also sozusagen nur teilweise aufgefüllt ist; dieses heißt Leitungsband.

Ausgehend von diesem Bändermodell, das in der Festkörperphysik die Grundlage für die Erklärung einer Vielzahl verschiedener Phänomene und Gesetze ist, ist speziell für die Erklärung des Verhaltens der Leitungselektronen von Metallen unter dem Einfluß äußerer elektrischer und magnetischer Felder das semiklassische Modell konstruiert worden. Quantenmechanisch wäre für diesen Fall eigentlich die Schrödinger-Gleichung mit einem Hamilton-Operator zu verwenden, der um einen Term für die äußeren Felder ergänzt ist, diese Gleichung ist jedoch praktisch nicht lösbar. Man geht daher an dieser Stelle zu einer Beschreibung über, in der die äußeren Felder auf andere Weise berücksichtigt werden: Die Idee des semiklassischen Modells ist, daß sich das Verhalten der Elektronen durch Wellenpakete aus Bloch-Zuständen beschreiben läßt, also durch Zustände der Form

$$
\psi_{n}(\underline{x}, t)=\sum_{\underline{k}^{\prime}} g\left(\underline{k}^{\prime}\right) \psi_{n \underline{k^{\prime}}}(\underline{x}) e^{-\frac{i}{\hbar} \mathcal{E}_{n}\left(\underline{k}^{\prime}\right) t}
$$

(wobei $g\left(\underline{k}^{\prime}\right) \approx 0$ für alle $\underline{k}^{\prime}$ mit $\left|\underline{k}^{\prime}-\underline{k}\right|>\Delta \underline{k}$ ), und daß sich das Verhalten dieser Wellenpakete (unter gewissen Bedingungen) durch zwei "klassisch aussehende" Bewegungsgleichungen beschreiben läßt, eine für die (räumliche) Bewegung des Maximums des Wellenpakets und eine für $\underline{k}$ : Aus der Quantenmechanik ist bekannt, daß sich das Maximum eines solchen Wellenpakets mit der Geschwindigkeit

$$
\underline{v}_{n}=\frac{1}{\hbar} \frac{\partial \mathcal{E}_{n}(\underline{k})}{\partial \underline{k}}
$$

bewegt; dadurch ist die erste Bewegungsgleichung des Modells gegeben, nämlich die für die Bewegung des Maximums ${ }^{41}$. Es liegt nahe, die Bewegung des Maximums des Wellenpakets sozusagen als die Bewegung des Elektrons aufzufassen, durch die es die Wirkung von klassisch beschriebenen äußeren elektrischen oder magnetischen Feldern, sprich: die Lorenzkraft, spürt. Die zweite Bewegungsgleichung des Modells implementiert diesen Gedanken in Form einer Newtonschen Bewegungsgleichung für $\underline{k}$; diese zweite Gleichung lautet:

$$
\hbar \underline{\dot{k}}=-e\left(\underline{E}+\underline{v}_{n} \times \underline{B}\right) .
$$

Sie läßt sich nicht streng aus einer quantenmechanischen Beschreibung, wie sie das Bändermodell liefert, ableiten, sondern nur in heuristischer Weise motivieren. ${ }^{42}$

Mit Hilfe der Bewegungsgleichungen des semiklassischen Modells kann man Erklärungen für verschiedene Phänomene bzw. phänomenologische Gesetze geben, u.a. für den Hall-Effekt und das Ohmsche Gesetz in Metallen, von denen hier nur die letztere skizziert werden kann. ${ }^{43}$ Man stellt zu diesem Zweck eine Boltzmann-Gleichung für die zeitliche

\footnotetext{
${ }^{41}$ Die durch die Abhängigkeit $\frac{\partial \mathcal{E}_{n}(\underline{\underline{k}})}{\partial \underline{k}}$ bei den Bloch-Zuständen festgelegt ist.

${ }^{42}$ Siehe [Zima72], Kap.6, [AsMe76], S.214ff.

${ }^{43}$ Zum Hall-Effekt siehe [AsMe76], Kap.12, [Zima72], Kap.7, [Harr70], S.252ff.
} 
Entwicklung der Verteilungsfunktion $f(\underline{x}, \underline{k}, t)$ der Elektronen des Leitungsbandes im Phasenraum auf: ${ }^{44} \mathrm{Zu}$ zeitlichen Veränderungen von $f$ können mehrere Faktoren beitragen, nämlich Streuung der Leitungselektronen (an Fehlstellen oder Gitterschwingungen ${ }^{45}$ oder an anderen Elektronen), die Bewegung der Elektronen unter dem Einfluß äußerer Felder und Diffusion, d.h. die Bewegung der Elektronen gemäß ihrer Bewegungsgleichung ohne Stöße und äußere Felder: $\frac{\partial f}{\partial t}=\left(\frac{\partial f}{\partial t}\right)_{\text {Streuung }}+\left(\frac{\partial f}{\partial t}\right)_{\text {Felder }}+\left(\frac{\partial f}{\partial t}\right)_{\text {Diffusion }}$. Die beiden letzten Beiträge lassen sich mit Hilfe der semiklassischen Bewegungsgleichungen (15.3) und (15.4) errechnen: Gäbe es keine Streuung, so wären alle Elektronen, die zum Zeitpunkt $t$ am Phasenraumort $(\underline{x}, \underline{k})$ sind, gemäß der Bewegungsgleichungen in der Zeit $d t$ dorthin gelangt, d.h., es würde gelten: $f(\underline{x}, \underline{k}, t)=f\left(\underline{x}-\underline{v} d t, \underline{k}-\frac{e}{\hbar}(\underline{E}+\underline{v} \times \underline{B}) d t, t-d t\right)$. Durch Taylor-Entwicklung erhält man damit die Boltzmann-Gleichung, die in dem für das Ohmsche Gesetz relevanten Fall $\underline{B}=0$ lautet:

$$
\frac{\partial f}{\partial t}+\underline{v} \frac{\partial f}{\partial \underline{x}}-\frac{e}{\hbar} \underline{E} \frac{\partial f}{\partial \underline{k}}=\left(\frac{\partial f}{\partial t}\right)_{\text {Streuung }} .
$$

Um sie für den Fall des Ohmschen Gesetzes zu lösen, macht man mehrere Annahmen: Man beschreibt ein System, in dem ein Strom fließt, durch eine stationäre Verteilungsfunktion, also eine, für die $\frac{\partial f}{\partial t}=0$ ist, und man nimmt weiter an, daß diese Verteilungsfunktion sich nur wenig von der Fermi-Dirac-Verteilung $f_{F D}$ im thermodynamischen Gleichgewicht unterscheidet: $f(\underline{x}, \underline{k}, t)=f_{F D}(\underline{x}, \underline{k}, t)+g(\underline{x}, \underline{k}, t)$. Schließlich nimmt man an, daß Stöße der Elektronen das System nicht vom thermodynamischen Gleichgewicht wegführen, sondern ohne äußeres Feld dafür sorgen würden, daß Abweichungen vom Gleichgewicht mit exponentieller Abhängigkeit von $t$ verschwinden: $\left(\frac{\partial f}{\partial t}\right)_{\text {Streuung }}=-\frac{1}{\tau} g$ (RelaxationszeitNäherung). Mit diesen Annahmen erhält man als Lösung von (15.5):

$$
g(\underline{k})=e \underline{E} \underline{v}(\underline{k}) \tau\left(\frac{\partial f_{F D}}{\partial \mathcal{E}}\right) .
$$

Aus dieser Lösung läßt sich das Ohmsche Gesetz ableiten: Elektrischer Strom in einem Metall besteht aus der Bewegung der Leitungselektronen, daher ist die Stromdichte $\underline{j}=-\frac{e}{4 \pi^{3}} \int d \underline{k} \underline{v}(\underline{k}) g(\underline{k})$; in diesem Integral steht $g$ (nicht $f$ ), weil im thermodynamischen Gleichgewicht kein Strom fließt, also nur der "Nichtgleichgewichtsanteil" der Verteilungsfunktion einen Beitrag gibt. Einsetzen der obigen Lösung liefert

$$
\underline{j}=\underline{\underline{\sigma}} \underline{\underline{E}}
$$

wobei der Leitfähigkeitstensor

$$
\underline{\underline{\sigma}}=-\frac{e^{2}}{4 \pi^{3}} \int d \underline{k} \tau \underline{v}(\underline{k}) \underline{v}(\underline{k})\left(\frac{\partial f_{F D}}{\partial \mathcal{E}}\right)_{\mathcal{E}=\mathcal{E}(\underline{k})}
$$

ist. Für kubische Kristalle (wie z.B. Kupfer) wird dieser Tensor diagonal und die Diagonalelemente identisch, so daß $\underline{j}=\sigma \underline{E}$, und daraus erhält man schließlich durch Integration

\footnotetext{
${ }^{44}$ Siehe etwa [Zima72], Kap.7, [AsMe76] , S.244ff, 319ff. Was genau im Fall des semiklassischen Modells unter dem Phasenraum zu verstehen ist, ist eine der notorisch schwierigen, bis heute nicht befriedigend gelösten Fragen über den Grenzbereich zwischen Quantenmechanik und klassischer Mechanik, über die man in der Festkörperphysik in der Regel mit dem Hinweis auf einige "hand-waving arguments" hinweggeht.

${ }^{45}$ Nicht jedoch an den Gitterionen, solange das Gitter nicht thermisch angeregt ist, denn dieser "Einfluß" auf die Elektronen wird durch das Gitterpotential in der Schrödinger-Gleichung berücksichtigt.
} 
über die Stirnfläche eines Drahtes (und mit $\sigma=\frac{1}{\rho}$ ) das Ohmsche Gesetz in der vorne angegebenen Form; den Wert von $\rho$ liefert diese Ableitung jedoch (noch) nicht. Man kann versuchen, die im obigen Ausdruck für $\sigma$ enthaltenen materialabhängigen Größen $\tau$ und $\frac{\partial f_{F D}}{\partial \mathcal{E}}$ ihrerseits aus Annahmen über die relevanten Streuprozesse bzw. über die Bandstruktur herzuleiten, dies ergibt aber allenfalls im Einzelfall numerisch die durch Messung gewonnenen Werte. ${ }^{46}$

Die Erklärungen, die mit Hilfe des semiklassischen Modelle, wie hier skizziert, für das Ohmsche Gesetz und auch für andere Transportphänomene in Metallen gegeben werden, unterscheiden sich offenbar grundsätzlich von denen, die auf Drudes klassischem Modell beruhen: Leitungselektronen werden durch quantenmechanische Wellenpakete modelliert (statt als klassische Punktteilchen) und ihre für das Transportverhalten relevanten Stoßprozesse involvieren Fehlstellen und Gitterschwingungen (nicht Gitterionen in Ruhe).

Außer den skizzierten Erklärungen, die sich mit Hilfe dieser beiden Modelle geben lassen, findet sich schließlich in der Literatur noch eine Erklärung für das Ohmsche Gesetz, die sich sozusagen ganz im Rahmen der quantenstatistischen Mechanik des Nichtgleichgewichts bewegt, und auch entsprechende Erklärungen für einige andere Transportphänomene. ${ }^{47}$ Diese Erklärungen sind zu komplex, um sie hier zu erörtern, dies ist jedoch auch nicht erforderlich.

Das Gesagte sollte ausreichen, um plausibel zu machen, daß die genannten theoretischen Erklärungen für das Ohmsche Gesetz, den Hall-Effekt und die anderen erwähnten phänomenologischen Gesetze oder Sätze über elektrische Ströme und Spannungen bzw. die Modelle, die diesen Erklärungen zugrunde liegen, keine deduktiven Rechtfertigungsgründe für diese Gesetze oder Sätze liefern. Damit die erklärenden Prämissen bzw. das jeweilige Modell als deduktive Rechtfertigungsgründe fungieren können, müßte man, erstens, entweder von ihnen überzeugt sein, oder man müßte sie in irgendeiner Form für verläßliche deduktive Orakel im vorne erläuterten $\operatorname{Sinn}^{48}$ halten, und zweitens müßte man die zu rechtfertigenden Gesetze bzw. Sätze tatsächlich deduktiv aus ihnen ableiten können. Bei jemandem, der sich über den derzeitigen Kenntnisstand der Physik informiert hat, dürfte jedoch im Fall der genannten Erklärungen und Modelle mindestens eine dieser Bedingungen nicht erfüllt sein. Daß eine solche Person nicht von diesen Erklärungen und Modellen überzeugt ist, liegt zumindest nahe, wenn sich (wie vorne erläutert) ein verläßliches Inferenzschema von der Art des Schließens auf die beste Erklärung derzeit nicht identifizieren läßt, das einen Schluß auf entsprechende Überzeugungen aufgrund der für das Ohmsche Gesetz, den Hall-Effekt etc. gelieferten Erklärungen gestatten würde; es ist allerdings grundsätzlich denkbar, daß solche Überzeugungen auf anderem Weg gewonnen werden, und die hier in Frage kommenden Möglichkeiten können an dieser Stelle nicht untersucht werden. Unabhängig davon lassen sich aber im Fall der skizzierten Erklärungen und Modelle Gründe angeben, die dagegen sprechen, von den erklärenden Prämissen und Modellen überzeugt zu sein oder sie als verläßliche deduktive Orakel zu betrachten, und daß sich die erklärten Gesetze bzw. Sätze deduktiv ableiten lassen, trifft, wie am Rande schon erwähnt, auch nur in Einzelfällen und/oder in einem eingeschränkten Sinn zu, insofern etwa beim Ohmschen Gesetz "nur" der lineare Zusammenhang von Strom und Spannung abgeleitet wird, nicht dagegen der Wert des spezifischen Widerstands.

Im Fall des auf Drude zurückgehenden klassischen Modells spricht die Tatsache, daß es neben den skizzierten Erklärungserfolgen auch eine Reihe von Mißerfolgen aufweist,

\footnotetext{
${ }^{46}$ Vgl. dazu [Zima72], Kap.7, [AsMe76], Kap.16, 26.

${ }^{47}$ Siehe dazu [Bren89, Jack78].

${ }^{48}$ Siehe S.503.
} 
dagegen, die Modellannahmen bzw. erklärenden Prämissen als Überzeugungen zu akzeptieren oder auch nur als verläßliches deduktives Orakel zu betrachten, und bei genauerer Betrachtung stellen auch die skizzierten Erklärungen nicht alle tatsächlich Erfolge dar: Das abgeleitete Resultat für die Hall-Konstante, $R_{H}=-\frac{1}{n e}$, etwa ist von Temperatur und Magnetfeldern unabhängig und kann offenbar nur negative Werte annehmen, Messungen, die mit Instrumenten ausgeführt wurden, die allgemein für verläßlich gehalten werden, ergeben jedoch temperatur- und magnetfeldabhängige und bei einigen Materialien auch positive Hall-Konstanten. Der Widerstand von Metallen sollte gemäß dem klassischen Modell unabhängig von äußeren Magnetfeldern sein, was ebenfalls im Widerspruch zu den Resultaten von Messungen steht, die als verläßlich gelten. Das Verhältnis von Wärmeleitfähigkeit und elektrischer Leitfähigkeit eines Metalls sollte proportional zur Temperatur sein, Messungen liefern dieses Resultat jedoch nur für hohe Temperaturen. Diese und einige weitere Mißerfolge, d.h. Fälle, in denen (näherungsweise) deduktive Konsequenzen aus den Modellannahmen des klassischen Modells im Widerspruch zu Meßergebnissen stehen, die durch Verfahren gewonnen wurden, die für verläßlich gehalten werden, sprechen deutlich dagegen, diese Modellannahmen als Überzeugungen zu akzeptieren oder als verläßliches Orakel zu betrachten. ${ }^{49}$

Beim semiklassischen Modell treten weniger solche Widersprüche zu verläßlich gewonnenen Meßergebnissen auf und mehr Erklärungserfolge, insofern stellt es zwar sicherlich einen wesentlichen, bedeutenden Fortschritt dar, aber auch hier sprechen die Mißerfolge des Modells deutlich dagegen, die Modellannahmen als Überzeugungen zu akzeptieren. Beim Hall-Effekt etwa ergibt das semiklassische Modell einen Ausdruck für $R_{H}$, der eine Abhängigkeit vom Magnetfeld einschließt und, je nach Material auch positiv sein kann. Für den Widerstand von Metallen liefert das semiklassische Modell einen magnetfeldabhängigen Ausdruck, der aber nicht die gemessenen Werte reproduziert, für das Verhältnis von Wärmeleitfähigkeit und elektrischer Leitfähigkeit eines Metalls liefert es im wesentlichen dasselbe wie das klassische Modell. ${ }^{50}$

Unabhängig von diesen und anderen Konflikten mit Meßergebnissen tritt beim semiklassischen Modell jedoch ein weiteres Hindernis auf, das dem Akzeptieren der Modellannahmen als Überzeugungen im Weg steht. Das semiklassische Modell beschreibt die Leitungselektronen von Metallen quantenmechanisch — auch wenn die Bewegungsgleichungen "klassisch aussehen" und sich in Anwendungen des Modells gelegentlich auch heuristische Formulierungen finden, die von den Elektronen ein Bild klassischer Teilchen mit klassischen Bahnen nahelegen. ${ }^{51}$ Dabei ist zunächst, wie oben erwähnt, das Verhältnis der Wellenpakete und deren semiklassischen Bewegungsgleichungen zu einer "vollständigen" quantenmechanischen Beschreibung eines Metalls nicht völlig geklärt, so daß man auch schon aus diesem Grund Zweifel anmelden könnte, ob man die Modellannahmen tatsächlich als Überzeugungen akzeptieren sollte, es mag sich aber vielleicht durch zukünftige Untersuchungen spezifizieren lassen, in welchem Sinn genau die Modellannahmen eine Näherung einer vollständigen quantenmechanischen Beschreibung darstellen. Wichtiger ist jedoch, daß auch dann, wenn diese Frage zufriedenstellend beantwortet sein sollte, dem Akzeptieren der Modellannahmen als Überzeugungen noch immer all die Hindernisse im Weg stehen, die notorisch mit dem Akzeptieren quantenmechanischer Gesetze, Modelle

\footnotetext{
${ }^{49}$ Siehe dazu z.B. [AsMe76], Kap.1, 2.

${ }^{50} \mathrm{Zu}$ den Erfolgen und Mißerfolgen des semiklassischen Modells siehe [AsMe76], Kap.12, 13.

${ }^{51}$ Solche Formulierungen sind also nicht wörtlich gemeint bzw. entsprechende Äußerungen nicht als wörtlich gemeinte Behauptungen aufzufassen (vgl. S.402ff., 417.). Deutlich wird dieser Punkt z.B. in [AsMe76], S.217ff., bes. S.217, Fn.8 festgehalten.
} 
etc. als Überzeugungen verbunden sind, genauer: mit dem Akzeptieren von ontologischen realistischen Thesen, die quantenmechanische Gesetze etc. zum Inhalt haben, als Überzeugungen. Diese Schwierigkeiten können hier nicht diskutiert werden, es dürfte derzeit jedoch kaum kontrovers sein, daß es derzeit keine hinreichenden Rechtfertigungsgründe gibt, solche ontologischen realistischen Thesen als Überzeugungen zu akzeptieren.

Diese zuletzt genannten Hindernisse betreffen auch die (oben nur kurz erwähnten) theoretischen Erklärungen im Rahmen der Quantenstatistik des Nichtgleichgewichts bzw. die zugrundeliegenden Annahmen. Herleitungen dieser Art liefern ${ }^{52}$, anders als die beiden erörterten Modelle, bisher nichts, was im Widerspruch zu verläßlich gewonnenen Meßresultaten steht (oder jedenfalls nicht ohne daß bei der Herleitung Näherungen im Spiel sind, für die plausibel ist, daß sie für Konflikte mit und Abweichungen von gemessenen Resultaten verantwortlich sind), so daß man die zugrundeliegenden Prämissen in irgendeiner Weise als verläßliches deduktives Orakel betrachten könnte. Ob dies in überzeugender Weise möglich ist, muß hier offen bleiben; es müßte jedenfalls spezifiziert werden, was genau zum Orakel zählt, und wenn dies so etwas wie die grundlegenden Annahmen der Quantenstatistik des Nichtgleichgewichts sein sollen, dürfte es schwierig sein, diese tatsächlich als verläßlich zu erweisen, da die Anzahl der phänomenologischen Gesetze, die sich auf diesem Wege herleiten läßt, derzeit relativ klein ist (deutlich kleiner als bei den beiden erörterten Modellen), und daher die Basis für eine induktive Begründung einer Verläßlichkeitsannahme schmal ist.

Fazit ist also, daß die in der physikalischen Literatur verfügbaren theoretischen Erklärungen für das Ohmsche Gesetz, den Hall-Effekt und die anderen erwähnten Gesetze oder Sätze über elektrische Ströme und Spannungen bzw. die Modelle, die diesen Erklärungen zugrunde liegen, keine deduktiven Rechtfertigungsgründe für diese Gesetze oder Sätze liefern - jedenfalls soweit dies hier untersucht werden konnte und mit der möglichen Ausnahme, daß sich die Quantenstatistik des Nichtgleichgewichts als verläßliches deduktives Orakel erweisen läßt. Die letztere Möglichkeit wird im folgenden eingeklammert.

Mit dem bisher Gesagten ist offenbar noch kein einigermaßen genaues und vollständiges Bild von dem gegeben, was sich beim gegenwärtigen Kenntnisstand der Physik an Rechtfertigungsgründen für die drei zu Anfang dieses Abschnitts genannten phänomenologischen Gesetze bzw. Sätze angeben läßt, es sollten aber wesentliche Teile davon grob erfaßt sein, und insbesondere sollten die wesentlichen "Arten" von Elementen eines Rechtfertigungsgraphen genannt sein, den eine Person, die sich über den Kenntnisstand der Physik informiert hat, mit diesen drei Gesetzen bzw. Sätzen verbindet, nämlich Überzeugungen, die Meßresultate und phänomenologische Gesetze und allgemeine Sätze zum Inhalt haben, und Verläßlichkeitsüberzeugungen in bezug auf Meßinstrumente für Stromstärke, Spannung etc. ${ }^{53} \mathrm{Ob}$ die drei Rechtfertigungsgraphen einer solchen Person weitere, insbesondere im Hinblick auf die Realismusdebatte wichtige Elemente enthalten, und wenn ja, welche, wird i.a. von den erkenntnistheoretischen, wissenschaftshistorischen etc. Überzeugungen der Person abhängen.

Daß weitere Elemente der Rechtfertigungsgraphen, die zu den bisher genannten hinzutreten, im Hinblick auf die Realismusdebatte wichtig sein können, sieht man, wenn man sich eine Gemeinsamkeit der bisher genannten Arten von Rechtfertigungsgründen vor Augen führt: Jedes der drei zur Debatte stehenden phänomenologischen Gesetze handelt

\footnotetext{
${ }^{52}$ Meines Wissens.

${ }^{53} \mathrm{Zu}$ einem solchen Rechtfertigungsgraphen gehören natürlich auch Herkunftsüberzeugungen, Verläßlichkeitsüberzeugungen für deduktive Inferenzverfahren etc.; diese werden im folgenden meistens nicht explizit genannt, weil mit ihnen keine besonderen Probleme verbunden sind.
} 
(u.a.) von elektrischen Strömen, genauer von deren Stromstärke, und jeder aus den bisher genannten Arten von Rechtfertigungsgründen zusammengestellte Satz hinreichender (direkter oder indirekter) Rechtfertigungsgründe für eins der drei Gesetze enthält entweder eine Verläßlichkeitsüberzeugung für ein Amperemeter, oder (mindestens) eine Prämisse (für einen Schluß induktiver oder deduktiver Art), die von der Größe Stromstärke handelt. Für die Größe elektrische Spannung gilt Entsprechendes, und (im Fall des Gesetzes über den Hall-Effekt) auch für die Größe magnetische Feldstärke. Sofern die Rechtfertigungsgraphen für die drei zur Debatte stehenden Gesetze "nur" aus Elementen der bisher genannten Arten bestehen, wird man also, wenn man die Frage nach Rechtfertigungsgründen für eines der drei Gesetze immer wieder iteriert, früher oder später auf Zirkel oder offene Enden stoßen, ohne daß man zuvor hinreichende Rechtfertigungsgründe gefunden hätte, die nicht eine Verläßlichkeitsüberzeugung in bezug auf ein Amperemeter oder eine Überzeugung (erster Ordnung) über Stromstärken involvieren. Da der Rechtfertigungsgraph einer Überzeugung das umfaßt, was man maximal als Argumente ins Feld führen kann, um einen Diskussionsgegner dazu zu bringen, die gleiche Überzeugung zu akzeptieren, steht einem in diesem Fall also kein Argument zur Verfügung, mit dessen Hilfe man jemanden von den drei Gesetzen überzeugen könnte, der nicht glaubt, daß es elektrische Ströme gibt und daß diese eine bestimmte Stromstärke aufweisen (und auch nicht, daß es Instrumente gibt, mit denen man verläßlich Stromstärken messen kann).

Sofern der Rechtfertigungsgraph einer Person für eins der drei zur Debatte stehenden Gesetze "nur" aus Elementen der bisher genannten Arten besteht, gehört dieses Gesetz also offenbar zu mehreren im vorne beschriebenen Sinn 54 "epistemisch zusammenhängenden" Mengen von Überzeugungen dieser Person, die vom Rest des Überzeugungssystems isoliert sind: Das Ohmsche Gesetz etwa gehört, intuitiv gesprochen, zum einen zur (epistemisch zusammenhängenden und isolierten) Menge derjenigen Überzeugungen, die die Person nicht hätte, wenn es keine verläßlichen Amperemeter gäbe (oder wenn sie keins für verläßlich hielte), zum anderen zur (epistemisch zusammenhängenden und isolierten) Menge derjenigen Überzeugungen, die die Person nicht hätte, wenn es keine verläßlichen Voltmeter gäbe (oder wenn sie keins für verläßlich hielte). Genauer umfaßt die erstere Menge alle singulären Überzeugungen erster Ordnung, daß ein bestimmter Strom eine bestimmte Stromstärke hat, weiterhin alle singulären und allgemeinen Überzeugungen erster Ordnung, die Stromstärken involvieren und sich mit Hilfe der ersteren Überzeugungen erschließen lassen, aber nicht allein aus Überzeugungen "von außerhalb" der Menge, und schließlich Herkunftsüberzeugungen für die bisher genannten Überzeugungen und Verläßlichkeitsüberzeugungen in bezug auf Amperemeter. ${ }^{55}$ Die zweite Menge enthält die analogen Überzeugungen, die elektrische Spannungen involvieren, und für Überzeugungen, die magnetische Feldstärken etc. involvieren, lassen sich offenbar entsprechende (epistemisch zusammenhängende und isolierte) Mengen spezifizieren.

Als zusätzliche und im Hinblick auf die Realismusdebatte "interessante" Elemente der Rechtfertigungsgraphen, die eine Person mit den drei zur Debatte stehenden phänomenologischen Gesetzen verbindet, scheinen vor allem zwei "Arten" in Frage zu kommen: Wenn man ein Inferenzverfahren von der Art des Schließens auf die beste Erklärung für verläßlich hält, könnte dieses in irgendeiner Form einen Schluß von Beobachtungsda-

\footnotetext{
${ }^{54}$ Siehe S.472ff.

${ }^{55}$ Siehe dazu S.476. Die dort spezifizierten Mengen aller Überzeugungen, die eine Person nicht hätte, wenn sie rot und grün nicht erkennen könnte und außerdem auch nicht glauben würde, daß irgendjemand sonst dies kann, bzw. wenn sie gar keine Farben erkennen könnte und auch nicht glauben würde, daß irgendjemand sonst dies kann, sind offenbar analog zu den hier relevanten Mengen.
} 
ten $^{56}$ auf Überzeugungen erster Ordnung, die von elektrischen Stromstärken etc. handeln, ermöglichen $;{ }^{57}$ wie vorne erörtert, läßt sich jedoch derzeit kein verläßliches Inferenzschema dieser Art identifizieren. Unter diesen Umständen könnte man zusätzliche, für die Realismusdebatte wichtige Rechtfertigungsgründe für die zur zur Debatte stehenden Gesetze zur Verfügung haben, wenn man ein Inferenzverfahren der vorne umrissenen Art ${ }^{58}$ als verläßlich akzeptiert, das einen Schluß auf eine "hinreichend große" und "hinreichend gut epistemisch zusammenhängende" Menge von (potentiellen) Überzeugungen ermöglicht, für die man "hinreichend viele" und "hinreichend gute" schwache Gründe hat, die außerhalb der Menge liegen. Zusätzliche Rechtfertigungsgründe anderer Art sind grundsätzlich natürlich denkbar, es ist jedoch schwer zu sehen, wie solche Rechtfertigungsgründe im Fall der drei Gesetze aussehen sollten.

Ob die genannten epistemisch zusammenhängenden und isolierten Mengen von Überzeugungen die Anwendungsbedingungen eines Inferenzschemas erfüllen, das einen Schluß auf eine ganze solche Menge gestattet, läßt sich allenfalls so genau prüfen wie das Inferenzschema spezifiziert ist. Wenn die vorne skizzenhaften Formulierungen für solche Anwendungsbedingungen ${ }^{59}$ nicht ganz falsch sind, sollte aber vielleicht plausibel sein, daß die genannten epistemisch zusammenhängenden und isolierten Mengen darunter fallen, jedenfalls in etwa genauso plausibel wie im Fall der vorne untersuchten Menge aller Überzeugungen, die jemand nicht hätte, wenn er keine Farben erkennen könnte. ${ }^{60}$ Z.B. sollte die Menge der Überzeugungen, die eine Person nicht hätte, wenn es keine verläßlichen Amperemeter gäbe, "hinreichend groß" sein, insofern sie neben vielen Überzeugungen erster Ordnung über Stromstärken auch Verläßlichkeitsüberzeugungen in bezug auf mehrere, voneinander unabhängige Erzeugungsverfahren, sprich: Amperemeter, einschließt, und sie sollte auch "hinreichend gut epistemisch zusammenhängend" im vorne angedeuteten Sinn sein, insofern die darin enthaltenen Überzeugungen erster Ordnung und Verläßlichkeitsüberzeugungen wechselseitig füreinander als Rechtfertigungsgründe fungieren und in manchen Fällen auch redundante Rechtfertigungsgründe vorhanden sind (insbesondere auch redundante Rechtfertigungsgründe, die durch voneinander unabhängige Erzeugungsverfahren, sprich: durch verschiedene Meßinstrumente, geliefert werden, deren Funktion auf verschiedenen "Mechanismen" beruht); außerdem sollten die im vorausgehenden gegebene Beschreibung von Teilen der Rechtfertigungsgraphen des Ohmschen Gesetzes und "verwandter" phänomenologischer Gesetze vielleicht plausibel werden lassen, daß es in der Menge nicht mehr und nicht völlig andersartige offene Enden gibt als in der vorne untersuchten Menge aller Überzeugungen, die jemand nicht hätte, wenn er keine Farben erkennen könnte. Auch an schwachen Gründen "von außerhalb der Menge" lassen sich zumindest einige finden: Die Menge ist konsistent mit dem restlichen Überzeugungssystem. ${ }^{61}$ Wenn man das von Sal-

\footnotetext{
${ }^{56}$ Also von Überzeugungen, die durch Beobachten mit dem bloßen Auge gewonnen wurden (und daher keine Ströme zum Inhalt haben), etwa Überzeugungen über leuchtende Glühbirnen, Zeigerstellungen o.ä.

${ }^{57}$ Sei es auf phänomenologische Gesetze wie das Ohmsche Gesetz oder auf hochstufigere Gesetze, aus denen erstere (näherungsweise) folgen.

${ }^{58}$ Siehe S.473ff.

${ }^{59}$ Siehe S.474.

${ }^{60} \mathrm{Vgl}$. S.476ff.

${ }^{61}$ Dies ist i.a. keineswegs eine triviale, sozusagen leicht erfüllbare Bedingung. Ein Beispiel, das dies illustriert: Das Joulsche Gesetz und die für bestimmte konkrete Systeme gemessenen Werte für Stromstärken und Widerstände sind konsistent mit dem Energieerhaltungssatz und den sonstigen Überzeugungen über die diversen Energieformen; dies könnte jedoch leicht anders sein: Bei einem experimentellen Aufbau etwa, in dem durch einen Generator mechanische Energie in elektrische umgewandelt wird, die dann durch einen Strom durch einen Heizdraht eine Flüssigkeit heizt, könnte man die "hineingesteckte" mechanische Leistung kennen und die ausgehende Wärmeleistung und außerdem Strom-, Spannungs- und Widerstands-
} 
mon vorgeschlagene Prinzip der gemeinsamen Ursache für verläßlich oder zumindest für mäßig verläßlich hältt, ${ }^{62}$ hat man schwache Gründe für manche singuläre Überzeugungen über Ströme, nämlich in Situationen, in denen Korrelationen zwischen dem Umlegen eines Lichtschalters und dem Aufleuchten einer Lampe vorliegen oder ähnliches, und in denen dieses Prinzip der gemeinsamen Ursache einen Schluß auf die Existenz eines verbindenden Kausalprozesses gestattet, und diese Existenzannahme dann einen constraint darstellt, der durch die Überzeugung erfüllt wird, daß ein elektrischer Strom (einer bestimmten Stärke) fließt. Weitere schwache Gründe für ein phänomenologisches Gesetz wie das Ohmsche Gesetz hat man etwa dann, wenn man das oben skizzierte semiklassische Modell (zwar nicht für wahr, aber) wenigstens für ein mäßig verläßliches deduktives Orakel im vorne erläuterten Sinn hält. An schwachen Gründen dieser und ähnlicher Arten lassen sich noch einer Reihe weiterer angeben, und dasselbe gilt auch für die anderen erwähnten epistemisch zusammenhängenden und isolierten Mengen, das Gesagte sollte aber vielleicht ausreichen, um jeweils einen Schluß auf diese Menge plausibel erscheinen zu lassen, der von den skizzierten Befunden über den "inneren epistemischen Zusammenhang" der Menge und über die schwachen Gründe "von außen" und vom Rest des eigenen Überzeugungssystems als Prämissen auf die Menge als Konklusion führt.

Mit dem, was gesagt wurde, ist wenigstens in groben Zügen, aber natürlich keineswegs in zufriedenstellender Vollständigkeit das skizziert, was sich vom Standpunkt einer selektiven realistischen Position an Rechtfertigungsgründen für die drei zu Anfang dieses Abschnitts genannten Gesetze über elektrische Ströme und damit für entsprechende ontologische realistische Thesen aufweisen läßt. ${ }^{63}$ Wie skizziert sind Überzeugungen, die diese Gesetze zum Inhalt haben, Teil einer Menge von Überzeugungen über elektrische Ströme, die wechselseitig füreinander (unter "Mitwirkung" anderer Überzeugungen) als hinreichende Rechtfertigungsgründe fungieren können. Wenn man nach Rechtfertigungsgründen für diese Menge als ganze sucht, wird man (vorausgesetzt, man verfügt nicht über ein hier einsetzbares verläßliches Inferenzverfahren von der Art des Schließens auf die beste Erklärung) nur dann fündig, wenn man, wie beschrieben, einen Schluß auf eine "hinreichend große" und "hinreichend gut epistemisch zusammenhängende" Menge von (potentiellen) Überzeugungen, für die man "hinreichend viele" und "hinreichend gute" schwache Gründe "von außen" hat, als verläßlich akzeptiert, oder, anders und anschaulicher ausgedrückt, wenn man die Tatsache, daß eine Menge von Überzeugungen zum einen intern "hinreichend kohärent" ist, und zum anderen den Rest des eigenen Überzeugungssystems "in hinreichend kohärenter Weise" ergänzt, als verläßlichen Indikator für die Wahrheit der Menge anerkennt. Andere Rechtfertigungsgründe für die ganze genannte Menge sind grundsätzlich natürlich denkbar, es ist jedoch schwer zu sehen, wie solche Rechtfertigungsgründe in diesem konkreten Fall aussehen sollten.

Man verfügt also im Fall der drei zu Anfang genannten Gesetze, die von elektrischen Strömen handeln (und damit von einer unbeobachtbaren Größe bzw. unbeobachtbaren Sachverhalten, die sozusagen nicht nur knapp hinter der Grenze beobachtbar/unbeobachtbar liegen) über hinreichende epistemische Rechtfertigungsgründe, und wenn man zum Vergleich den mehrfach erwähnten Fall der Überzeugungen über die Farben von Gegenständen

werte messen. Daß das Joulesche Gesetz in einem solchen Fall sozusagen genau in die Energiebilanz paßt, ist nicht trivial.

${ }^{62}$ Siehe Abschnitt 8.3.4.

${ }^{63} \mathrm{Wie}$ vorne erwähnt, ist die Frage nach den Unabhängigkeitsaussagen, die in diesen ontologischen realistischen Thesen enthalten sind, und nach Rechtfertigungsgründen für diese Unabhängigkeitsaussagen hier nicht explizit erörtert worden, da sie unkontrovers sind; vgl. S.407f., 460. 
aus dem Bereich der Alltagswelt im Blick hat, zeigt sich, daß die Rechtfertigungsgründe, die in beiden Fällen vorliegen, von vergleichbarer Art und "guter Qualität" sind. 


\title{
Zusammenfassung und Fazit
}

\begin{abstract}
Time is running short now, and I mustn't waste any more words than I have to. In the beginning, I didn't think it would take very long - a few days to give you the essentials, and that would be it. Now the entire notebook has almost been filled, and I have barely even skimmed the surface. [...] I've been trying to fit everything in, trying to get to the end before it's too late, but I see now how badly I've deceived myself. Words do not allow such things. The closer you come to the end, the more there is to say. The end is only imaginary, a destination you invent to keep yourself going, but a point comes when you realize you will never get there. You might have to stop, but that is only because you have run out of time. You stop, but that does not mean you have come to the end. ${ }^{64}$
\end{abstract}

Diese Arbeit beschäftigt sich mit der Realismusdebatte in der Wissenschaftstheorie und mit der Frage, wie eine intuitiv plausible und haltbare Form des wissenschaftlichen Realismus aussieht und durch welche Rechtfertigungsgründe und Argumente eine solche realistische Position in möglichst überzeugungskräftiger Weise begründet werden kann.

Es wurde untersucht, welche Thesen in der Realismusdebatte als konstitutiv für wissenschaftlichen Realismus betrachtet werden und wie diese Thesen präzise zu erläutern sind, es wurden die Argumente, die in dieser Debatte zugunsten realistischer Positionen ins Feld geführt werden, analysiert und auf ihre Überzeugungskraft geprüft, und es wurden drei neuere Positionen untersucht, die in der Debatte als Konkurrenten des wissenschaftlichen Realismus auftreten.

Vor dem Hintergrund des so gewonnenen Bildes vom Stand der Dinge in der Realismusdebatte wurde der Umriß einer realistischen Position erarbeitet, der durch eine Vielzahl von Einzelthesen über unbeobachtbare Gegenstände und Sachverhalte aus den Themenbereichen der Wissenschaften auszufüllen ist. Damit ist der Weg skizziert, auf dem sich eine präzise formulierte, wenn auch kaum durch ein einfaches Kriterium spezifizierbare realistische Position gewinnen läßt, die als selektiver wissenschaftlicher Realismus bezeichnet wurde.

Es wurde sodann untersucht, welche Art von Rechtfertigungsgründen und Argumenten

\footnotetext{
${ }^{64}$ Paul Auster; In the country of last things, New York, 1987, S.182/183.
} 
für die Thesen vorgebracht werden kann, die eine solche realistische Position konstituieren, um die beiden wesentlichen Gruppen von antirealistischen Diskussionsgegnern von diesen Thesen zu überzeugen, nämlich Anhänger instrumentalistischer Positionen und Anhänger von in epistemischer Hinsicht antirealistischen Positionen. Für diese Untersuchung der Möglichkeiten, Rechtfertigungsgründe und Argumente für realistische Thesen anzugeben, wurde - wie (mindestens implizit) bei jeder Suche nach Rechtfertigungsgründen und Argumenten - eine Konzeption von epistemischer Rechtfertigung vorausgesetzt, und zwar wurde hier eine reliabilistische Konzeption gewählt, die in den allgemeinen erkenntnistheoretischen Debatten außerhalb der Wissenschaftstheorie derzeit den aussichtsreichsten Ansatz darstellt. Aus dieser reliabilistischen Perspektive konnte ein klares Bild der Möglichkeiten gewonnen werden, für eine selektive realistische Position überzeugungskräftige Argumente vorzubringen. Insbesondere wurde aus dieser Perspektive deutlich sichtbar, daß es prinzipielle Grenzen der Reichweite von Argumenten für realistische Thesen gibt, und daß die Existenz dieser Grenzen dafür verantwortlich ist, daß in der wissenschaftstheoretischen Realismusdebatte der realistischen Seite keine Argumente zur Verfügung stehen können, die für "hinreichend konsequente" antirealistische Diskussionsgegner Überzeugungskraft haben. Deutlich sichtbar wurde ferner, daß innerhalb der prinzipiellen Grenzen grundsätzlich viele und verschiedenartige Argumente für realistische Thesen entwickelt werden können, die für "weniger konsequente" Antirealisten Überzeugungskraft haben können, und auch für Personen, die noch keine systematisch reflektierte Position in der Realismusdebatte bezogen haben.

Den Umriß einer selektiven realistischen Position tatsächlich mit Einzelthesen auszufüllen und sich gleichzeitig die Rechtfertigungsgründe und Argumente zu verschaffen, die für solche Thesen zu haben sind, erfordert die Umsetzung eines umfangreichen Programms, das eine "Durchmusterung" der in den Wissenschaften etablierten oder wenigstens diskutierten Theorien, Gesetze etc. und der dort für diese vorliegenden Begründungen einschließt. Dieses Programm wurde skizziert, und es wurde außerdem an einem Fallbeispiel in groben Zügen vorgeführt, wie eine weiterreichende Umsetzung auszusehen hätte.

Im einzelnen sind die wesentlichen Ergebnisse der Untersuchungen dieser Arbeit die Folgenden.

In der wissenschaftstheoretischen Realismusdebatte wird unter dem Titel "Realismus" eine Vielzahl verschiedener, teils unscharf formulierter Thesen diskutiert, und es gibt keinen Konsens darüber - nicht einmal unter den Autoren, die sich selbst als Realisten verstehen - , welche der diversen Thesen konstitutiv für wissenschaftlichen Realismus sind. Hinter den meisten als realistisch auftretenden Thesen und Positionen läßt sich jedoch so etwas wie eine verbindende allgemeine Intuition erkennen, nämlich die "zweiteilige" Intuition, daß die Welt einerseits unabhängig vom menschlichen Geist und menschlicher Erkenntnis ist, daß Menschen aber andererseits dennoch (zumindest in Teilbereichen) Wissen über sie haben können und tatsächlich haben. Die meisten der realistischen Thesen lassen sich nach vier Arten klassifizieren oder zumindest im Sinne einer präzisierenden Explikation durch Thesen dieser vier Arten rekonstruieren: Dies sind ontologische, semantische, epistemische und axiologische realistische Thesen. Ontologische realistische Thesen besagen, grob gesprochen, daß bestimmte Entitäten unabhängig von menschlicher Erkenntnis existieren und bestimmte Eigenschaften haben. Semantische realistische Thesen besagen, daß bestimmte Sätze oder Theorien Wahrheitswerte haben, und zwar unabhängig von menschlichen epistemischen Mitteln zum Erkennen dieser Wahrheitswerte, und daß die Sätze oder Theorien wörtlich zu nehmen sind. Epistemische realistische Thesen sagen, daß bestimmte Sätze oder Theorien wahr (oder annähernd wahr) sind, und axiologische 
realistische Thesen, daß das Ziel der Wissenschaften wörtlich zu nehmende und wahre Theorien, Gesetze etc. sind. Sowohl ontologische, als auch semantische realistische Thesen enthalten eine "Unabhängigkeitsaussage"; im ersteren Fall werden bestimmte Entitäten und Eigenschaften als "unabhängig" charakterisiert, im letzteren Fall dagegen semantische Eigenschaften oder Relationen bestimmter Sätze und Theorien. In beiden Fällen kann in mehreren verschiedenen Weisen erläutert werden, worin diese Unabhängigkeit besteht. Die "zweiteilige" allgemeine realistische Intuition kann einerseits durch ontologische realistische Thesen konkretisiert werden (in diesem Fall entspricht den beiden "Teilen" der Intuition einerseits die Unabhängigkeitsaussage, andererseits die Aussage über die Existenz von Entitäten und ihre Eigenschaften bzw. der durch sie zum Ausdruck gebrachte Wissensanspruch), andererseits kann sie durch semantische und epistemische realistische Thesen zusammen konkretisiert werden (die dann je einem "Teil" der Intuition entsprechen).

Realistische Thesen der unterschiedenen Arten finden sich, mit Ausnahme axiologischer Thesen, auch in anderen philosophischen Debatten außerhalb der Wissenschaftstheorie. Obwohl die Debatte um wissenschaftlichen Realismus meistens von den anderen Debatten abgekoppelt geführt wird, stellt also der Gegenstand der wissenschaftstheoretischen Realismusdebatte - wenn man von den axiologischen Thesen absieht - ein "Spezialgebiet" unter vielen dar, die in den anderen Debatten behandelt werden.

Für die Sprache der Wissenschaften sind in der Literatur eine Reihe verschiedener Bedeutungs-, Referenz- und Wahrheitstheorien vorgeschlagen worden, und zwar verschiedene im Zusammenhang mit dem logischen Positivismus entwickelte semantische Theorien, mehrere Kontexttheorien, die kausalen Referenz- und Bedeutungstheorien und schließlich Hybridtheorien. Für die Realismusdebatte können diese Theorien in zweierlei Weise relevant sein: Die eine besteht darin, daß semantische realistische Thesen - und damit auch realistische Positionen, für die solche Thesen konstitutiv sind - durch eine Wahrheitstheorie und eventuell durch eine Bedeutungstheorie und/oder eine Referenztheorie ergänzt werden müssen, wenn die Unabhängigkeitsaussagen, die sie einschließen, in präziser, zufriedenstellender Weise erläutert werden sollen. Die Untersuchung der genannten semantischen Theorien hat ergeben, daß sich mehrere davon eignen, um eine solche Ergänzung zu liefern.

In einer zweiten Weise sind semantische Theorien dadurch für die Realismusdebatte relevant, daß sie eine Rolle für die Argumentation für oder gegen eine realistische Position spielen können, und zwar auch dann, wenn sie nicht als konstitutiver Teil dieser Position betrachtet werden: Eine bestimmte semantische Theorie zu akzeptieren, bringt im allgemeinen auch in diesem Fall verschiedene Konsequenzen für die Argumentation für und gegen eine realistische Position mit sich, insbesondere dadurch, daß das Akzeptieren einer bestimmten semantischen Theorie i.a. Folgen für das Bild hat, das man von dem Verhältnis bekommt, in dem wissenschaftliche Theorien zueinander stehen, die einander im Laufe der Geschichte der Wissenschaften ablösen. Die Untersuchung der vorliegenden semantischen Theorien hat ergeben, daß mit Tarskis Korrespondenztheorie zwar eine Wahrheitstheorie zur Verfügung steht, die im Hinblick auf die Argumentation für und gegen eine realistische Position keine besonderen Nachteile aufweist, daß aber derzeit keine Bedeutungstheorie und keine Referenztheorie existiert, die nicht deutliche Probleme für die Rechtfertigung ontologischer oder epistemischer realistischer Thesen mit sich bringt.

Die Argumente, die in der wissenschaftstheoretischen Realismusdebatte für realistische Positionen vorgebracht worden sind, lassen sich nach drei Arten klassifizieren, die als Präsuppositionsargumente, Kontinuitätsargumente und Varianten des Wunderarguments 
bezeichnet wurden.

In Präsuppositionsargumenten wird auf bestimmte Elemente der Praxis der Wissenschaften oder bestimmte dieser Praxis zugrundeliegende Methoden, bestimmte "Arten des Umgangs" mit Theorien, Experimenten etc. hingewiesen, um dann Voraussetzungen herauszuarbeiten, unter denen diese Praxis eine rationale ist. Insofern diese Voraussetzungen durch realistische Thesen beschrieben werden, soll dadurch ein Argument für wissenschaftlichen Realismus gegeben sein. Argumenten dieses Typs kommt aus wenigstens zwei Gründen keine Überzeugungskraft zu: Zum einen bleibt bei den in der Literatur präsentierten Argumenten die Frage unbeantwortet, ob die jeweils genannten, durch realistische Thesen beschriebenen Voraussetzungen die einzigen sind, unter denen die aufgewiesenen "Arten des Umgangs" mit Theorien, Experimenten etc. in der Praxis der Wissenschaften rational sind. Zum anderen bleibt bei Präsuppositionsargumenten völlig offen, wieso die Tatsache, daß eine Praxis unter bestimmten Voraussetzungen rational ist, ein Argument für diese Voraussetzungen darstellen soll.

Kontinuitätsargumente entwickeln in unterschiedlicher Weise die Idee, daß der Bereich des Beobachtbaren und der Bereich des Unbeobachtbaren in mehr oder weniger kontinuierlicher Weise ineinander übergehen, daß also zwischen beiden Bereichen keineswegs, wie Antirealisten typischerweise meinen, eine prinzipielle, fundamentale Differenz besteht. Diskutiert wurden verschiedene Arten von Kontinuitätsargumenten: Zum einen ein "destruktives" Kontinuitätsargument, durch das bestritten wird, daß die Unterscheidung beobachtbar/unbeobachtbar überhaupt eine für philosophische Zwecke brauchbare Grenzziehung ergibt; zum zweiten "positive" Kontinuitätsargumente, in denen an vortheoretische Intuitionen über Folgen von Gegenständen, deren Größe "kontinuierlich" bis zur Unsichtbarkeit abnimmt, u.ä und an Intuitionen über den "merkwürdigen" anthropozentrischen Charakter des Weltbildes eines Antirealisten appelliert wird; zum dritten epistemische Kontinuitätsargumente, in denen auf Beobachtungsverfahren (wie z.B. Beobachten mit der Lupe) und Inferenzschemata, die Überzeugungen über Beobachtbares und über Unbeobachtbares liefern, hingewiesen wird, und die Verläßlichkeit dieser "grenzüberschreitenden" Beobachtungsverfahren und Inferenzschemata induktiv oder durch eine Art induktive Extrapolation begründet wird. Das "destruktive" Kontinuitätsargument läßt sich durch eine Präzisierung der Unterscheidung beobachtbar/unbeobachtbar entkräften. Kontinuitätsargumente der beiden letzteren Typen können möglicherweise dazu beitragen, jemanden von realistischen Thesen zu überzeugen, der die Intuitionen teilt bzw. die Inferenzschemata als verläßlich akzeptiert, die von diesen Argumenten in Anspruch genommen werden; konsequente, reflektierte Antirealisten tun dies jedoch nicht, und daher haben diese Argumente für sie keine Überzeugungskraft.

Beim Wunderargument und seinen Varianten handelt es sich um Argumente, deren gemeinsame Idee ist, mit Hilfe von Erklärungen für bestimmte Erfolge oder Leistungen, die wissenschaftliche Theorien erzielen oder ermöglichen, für realistische Thesen zu argumentieren. Hauptsächlich bilden Prognose- oder Handlungserfolge den Ausgangspunkt dieser Argumente. Es zeigte sich, daß bei genauerer Betrachtung ein ganzer Cluster von verschiedenen Argumentvarianten auseinanderzuhalten ist, die sich untereinander teilweise deutlich unterscheiden hinsichtlich der Explananda, der Explanantia, der Art von Erklärung, die letztere für erstere liefern, und der in Anspruch genommenen Inferenzschemata. Sämtliche Varianten lassen sich jedoch als Argumente irgendeiner Art eines Schlusses auf die beste Erklärung auffassen. Eine Bewertung des Wunderarguments und seiner Varianten fällt uneinheitlich aus und ist derzeit nur teilweise möglich, weil für eine fundierte Beurteilung detaillierte wissenschaftshistorische und philosophische Detailuntersuchungen nötig 
wären, die (noch) nicht vorliegen. Einige der Varianten des Wunderargumentes werden durch Einwände entkräftet, vor allem durch den, der das Wunderargument mit dem Theorienwandel im Verlauf der Wissenschaftsgeschichte konfrontiert; dies betrifft in erster Linie Varianten, die sich auf ein sehr allgemeines Explanandum beziehen, etwa auf Prognoseerfolge nicht näher spezifizierter Art, und dafür ein sehr umfassendes, allgemeines Explanans vorsehen, etwa die (annähernde) Wahrheit aller derzeit akzeptierten wissenschaftlichen Theorien. Für Varianten des Wunderarguments, die sich auf ein enger spezifiziertes Explanandum beziehen, etwa auf genauer spezifizierte Prognoseerfolge einer Theorie, und ein "eingeschränkteres" Explanans vorsehen, ist mangels hinreichender wissenschaftshistorischer Studien derzeit nicht fundiert zu beurteilen, inwieweit sie von den diskutierten Einwänden getroffen werden. Für alle Varianten des Wunderarguments gilt aber, daß sie irgendein Inferenzschema für Schlüsse auf die beste Erklärung in Anspruch nehmen, und da konsequente, reflektierte Antirealisten Inferenzschemata dieser Art i.a. nicht akzeptieren, haben die Varianten des Wunderarguments zumindest für solche Antirealisten keine Überzeugungskraft.

Die Analyse der Argumente, die in der wissenschaftstheoretischen Realismusdebatte zugunsten realistischer Positionen ins Feld geführt werden, ergibt also den — aus realistischer Perspektive betrachtet ernüchternden — Befund, daß allen diesen Argumenten in einer Diskussion mit konsequenten, reflektierten Antirealisten keine Überzeugungskraft zukommt, auch dann nicht, wenn man von Detailproblemen absieht. Epistemische Kontinuitätsargumente und einige Varianten des Wunderarguments könnten sich allerdings zumindest eignen, um "weniger konsequente" Antirealisten von realistischen Thesen zu überzeugen, sowie außerdem Personen, die noch keinen systematischen Standpunkt in der Realismusdebatte bezogen haben.

Als Gegner realistischer Positionen treten in der Realismusdebatte Anhänger verschiedener Positionen auf, die realistische Thesen in unterschiedlichem Ausmaß und aus unterschiedlichen Gründen zurückweisen. Als - für die neuere Realismusdebatte einigermaßen repräsentative - Auswahl solcher Gegenpositionen wurden Bas van Fraassens konstruktiver Empirismus, Ian Hackings und Nancy Cartwrights experimenteller Realismus und Andrew Pickerings Sozialkonstruktivismus diskutiert.

Van Fraassen hat eine zeitgemäße Position in der Traditionslinie des Empirismus entwickelt, die in konsequenter Weise eine "Haltung" artikuliert, deren Kern ein bestimmtes Ideal epistemischer Rationalität darstellt: Danach gibt es für Überzeugungen über Unbeobachtbares (und damit für ontologische, epistemische und auch für axiologische realistische Thesen) für Menschen keine Rechtfertigungsgrundlage. Ergebnis der Untersuchung von van Fraassens Standpunkt ist, daß dieser zwar im Hinblick auf seine innere Konsistenz nicht frei von Problemen ist, aber mit "hinreichend konsequenten" Modifikationen gegen alle von realistischer Seite ins Feld geführten Argumente und Einwände verteidigt werden kann. Für Personen, die noch keinen systematisch entwickelten Standpunkt in der Realismusdebatte eingenommen haben, dürfte der Übergang zu van Fraassens Position i.a. die Aufgabe einer großen Zahl vortheoretischer Intuitionen erfordern; daher dürften viele kaum zu diesem Schritt zu bringen sein, aber wer ihn einmal getan hat, kann seine Position dann erfolgreich gegen alle Argumente verteidigen, die für realistische Thesen vorgebracht werden. Aus der Gegenperspektive betrachtet enthält oder liefert van Fraassens Position allerdings — von Einwänden gegen einzelne Argumente für realistische Thesen abgesehen - auch keine überzeugungskräftigen Argumente gegen wissenschaftlichen Realismus, also keine Argumente, durch die konsequente, reflektierte Realisten dazu gebracht werden könnten, ihre Position aufzugeben. 
Hacking und Cartwright lehnen einen "unfragmentierten" wissenschaftlichen Realismus, wie ihn etwa Richard Boyd vertritt, ab, also eine Position, die realistische Thesen in bezug auf alle gegenwärtig etablierten wissenschaftlichen Theorien, Gesetze etc. einschließt, sie skizzieren dann aber den Grundriß einer moderateren realistischen Position, die gleichsam zwischen einem "unfragmentierten" Realismus und einer konsequent antirealistischen Position wie der von van Fraassen liegt. Hacking und Cartwright schlagen ein grobes Kriterium vor, durch das im Gesamtbestand der in den Wissenschaften etablierten Theorien, Modelle, Gesetze etc. eine Teilmenge von phänomenologischen, niederstufigen Gesetzen, und "experimentnahen" Entitäten ausgezeichnet wird, zu denen ihrer Ansicht nach eine realistische Einstellung angemessen ist. Sie motivieren ihre Position durch Hinweise auf Parallelen zwischen Alltagswelt und Wissenschaften und auch durch einige, für viele intuitiv sehr plausibel aussehende Beispiele aus der Praxis der Physik, die unter ihr Kriterium fallen. Eine genaue Untersuchung ihrer Argumentation zeigt jedoch, daß sie keine einigermaßen stringenten und überzeugungskräftigen Argumente für ihre moderaten realistischen Thesen liefern - auch wenn ihr Kriterium nicht unplausibel aussieht, sofern man es als hinreichendes (nicht als notwendiges) für eine realistische Einstellung auffaßt. Dennoch stellt der experimentelle Realismus von Hacking und Cartwright dadurch, daß sie intuitiv plausible Beispielfälle aus der Praxis der Physik ins Zentrum der Realismusdebatte rücken und ihre Position daran orientieren, einen attraktiven Anknüpfungspunkt für die Suche nach einem moderaten — im Gegensatz zu einem "unfragmentierten" wissenschaftlichen Realismus dar.

Pickering hat mehrere Studien zur Geschichte der modernen Physik vorgelegt und in Verbindung damit zwei Modelle für eine soziologische Erklärung der Gewinnung und Etablierung von Theorien, Gesetzen etc. in der Physik vorgeschlagen. Er knüpft an diese Modelle und die mit deren Hilfe gegebenen Erklärungen eine Reihe von Thesen, die auf eine Art Sozialkonstruktivismus hinauslaufen, und legt durch seine Formulierungen und den Duktus seiner Studien den Eindruck nahe, daß seine Erklärungen und Analysen in Konflikt oder wenigstens in einem Spannungsverhältnis zu realistischen Thesen und Positionen stehen. Bei genauerer Betrachtung zeigt sich jedoch, daß dies nicht der Fall ist, und daß seine wissenschaftshistorischen und -soziologischen Studien zur Realismusdebatte nichts Nennenswertes beitragen.

Im Anschluß an eine Bilanz der im ersten Teil dieser Arbeit durchgeführten ausführlichen Analyse der Thesen, Argumente und Positionen, die in der wissenschaftstheoretischen Realismusdebatte diskutiert worden sind, wurde im zweiten Teil versucht, im Lichte der zuvor gewonnenen Resultate eine plausible und haltbare realistische Position zu formulieren, für die möglichst überzeugungskräftige Rechtfertigungsgründe und Argumente angegeben werden können. Dazu wurde zunächst untersucht, welche der vier unterschiedenen Arten von realistischen Thesen konstitutiv für eine intuitiv angemessene realistische Position sind. Ergebnis einer eingehenden Abwägung der Gründe, Intuitionen und Motive, die im Fall der einzelnen Arten realistischer Thesen dafür oder dagegen sprechen, daß diese in angemessener Weise eine realistische Einstellung zum Ausdruck bringen, ist, daß ontologische realistische Thesen das Herzstück einer realistischen Position bilden sollten, nicht etwa semantische (plus epistemische) realistische Thesen, wie von einer Reihe von Autoren angenommen, und auch nicht axiologische realistische Thesen. Ontologische realistische Thesen stellen demnach die angemessene Weise dar, die allgemeine realistische Intuition zu konkretisieren, daß die Welt unabhängig vom menschlichen Geist und menschlicher Erkenntnis ist, daß Menschen aber andererseits dennoch Wissen über sie haben können und tatsächlich haben. Damit ist nicht ausgeschlossen, daß semantische Thesen oder Theorien 
eine realistische Position ergänzen und eventuell eine nützliche Rolle bei der Begründung oder Verteidigung einer solchen Position spielen können; unverzichtbar sind semantische Thesen und Theorien dafür jedoch kaum, so daß der zuvor erwähnte Befund, daß es derzeit keine in jeder Hinsicht zufriedenstellenden Bedeutungs- und Referenztheorien für die Sprache der Wissenschaft gibt, eine realistische Position der hier konzipierten Art nicht beeinträchtigt.

Die ontologischen realistischen Thesen, die eine realistische Position der anvisierten Art konstituieren, sind Aussagen derselben Art, wie sie (u.a.) innerhalb der Wissenschaften über Entitäten, Phänomene, Ereignisse etc., insbesondere über mit dem bloßen Auge unbeobachtbare, getroffen werden, ergänzt um eine Unabhängigkeitsaussage. Ontologische realistische Thesen können von sehr unterschiedlichem Allgemeinheitsgrad sein: Sie können die Existenz und die Eigenschaften bestimmter raumzeitlich lokalisierter Entitäten oder Ereignisse betreffen oder mehr oder weniger allgemeine oder völlig universelle Sachverhalte, Phänomene usw. Ontologische realistische Thesen können auch in "epistemisch vorsichtiger" Weise formuliert werden, indem sie einer Entität, einem Sachverhalt o.ä. statt genauer Eigenschaften oder Werten von Größen ungefähre, angenäherte oder nur innerhalb bestimmter Grenzen spezifizierte Eigenschaften oder Werte von Größen zuschreiben. Eine realistische Position der konzipierten Art kann und wird eine Vielzahl ontologischer realistischer Thesen verschiedensten Inhalts einschließen. Sie wird nicht für alle in den Wissenschaften etablierten Theorien, Gesetze etc. ontologische realistische Thesen entsprechenden Inhalts einschließen, sondern nur für einen Teil davon, der sich auf Entitäten, Phänomene etc. bezieht, für die Unabhängigkeitsaussagen gelten, und für den hinreichend gute epistemische Rechtfertigungsgründe vorliegen. In diesem Sinn handelt es sich bei der anvisierten Position um eine selektive realistische Position.

Bei der Argumentation für die ontologischen realistischen Thesen, die eine solche selektive realistische Position konstituieren, kann man sich auf zwei wesentliche Diskussionsgegner beschränken. Jemanden von einer ontologischen realistischen These über Unbeobachtbares zu überzeugen, kann offenbar zwei verschiedene "Argumentationsleistungen" erfordern: Zum einen kann man mit instrumentalistischen Diskussionsgegnern konfrontiert sein, die jeder ontologischen realistischen These über Unbeobachtbares den Status einer "ernsthaften" Behauptung absprechen und dies durch den Hinweis begründen, daß die zur Formulierung der These verwendeten Ausdrücke bzw. Sätze nicht "semantisch vollwertig" seien, also keinerlei Bedeutung, Referenz oder Wahrheitswerte hätten. Einen solchen Instrumentalisten muß man dazu bringen, die These als ernsthafte Behauptung anzuerkennen. Zum anderen kann man mit Diskussionsgegnern konfrontiert sein, die die zur Debatte stehende ontologische realistische These nicht für epistemisch hinreichend gut begründet halten, um sie zu akzeptieren. Einen solchen Gegner muß man durch die Angabe epistemischer Rechtfertigungsgründe von der These überzeugen.

Ergebnis der Suche nach Argumenten, die ersteres leisten, ist, daß sich keine Argumente finden lassen, mit deren Hilfe konsequente, reflektierte Instrumentalisten davon überzeugt werden können, ontologische realistische Thesen über Unbeobachtbares als semantisch vollwertig und als ernsthafte Behauptungen anzuerkennen. Ein wesentlicher Grund dafür ist, daß konsequente Instrumentalisten semantischen Thesen und Theorien, die von realistischer Seite angeführt werden können, um für die Anerkennung bestimmter ontologischer realistischer Thesen als semantisch vollwertig zu argumentieren, i.a. denselben Status zuschreiben wie den ontologischen Thesen selbst. Lediglich für "weniger konsequente" Instrumentalisten können von realistischer Seite vorgebrachte Argumente Überzeugungskraft haben. Eine Möglichkeit dazu besteht dann, wenn die instrumentalistische Seite ihre 
Grundüberzeugungen über den Zusammenhang von semantischer Vollwertigkeit und Beobachtbarkeit zur Disposition stellt, und semantische Vollwertigkeit z.B. "nur noch" an epistemische Zugänglichkeit in einem weiteren Sinn geknüpft wird. In diesem Fall kann die Diskussion auf eine epistemische Ebene verlagert werden, also hin zu Argumenten für oder gegen die epistemische Zugänglichkeit bestimmter Gegenstände oder Gegenstandsbereiche.

Die Suche nach epistemischen Rechtfertigungsgründen und Argumenten für ontologische realistische Thesen findet, wenn man eine reliabilistische Konzeption epistemischer Rechtfertigung voraussetzt, vor einem systematischen Hintergrund statt, der die Möglichkeiten, solche Rechtfertigungsgründe und Argumente aufzuweisen bzw. zu konstruieren, und vor allem auch die Grenzen dieser Möglichkeiten klarer sichtbar werden läßt, als man sie vielfach in den Diskussionen der wissenschaftstheoretischen Realismusdebatte vor $\mathrm{Au}-$ gen hat.

Einer reliabilistischen Konzeption von Rechtfertigung zufolge sind Rechtfertigungsgründe einer Überzeugung durch andere Überzeugungen gegeben, nämlich durch die Überzeugung zweiter Ordnung, daß die erstere Überzeugung mittels eines verläßlichen Beobachtungs-, Inferenz- oder sonstigen epistemischen Verfahrens gewonnen wurde, sowie durch die dabei eingesetzten Prämissen, falls die Überzeugung mittels eines Inferenzverfahrens gewonnen wurde. Die Gesamtheit der für eine bestimmte Überzeugung zur Verfügung stehenden Rechtfertigungsgründe schließt außer deren direkten Rechtfertigungsgründen auch Rechtfertigungsgründe für die letzteren ein, außerdem deren Rechtfertigungsgründe usw. Diese Gesamtheit kann man sich bildlich als einen — naturgemäß endlich großen Graphen vorstellen, dessen Knoten Überzeugungen und dessen Kanten Rechtfertigungsrelationen darstellen, und der offene Enden und Zirkel aufweist. Iteriert man die Frage nach Rechtfertigungsgründen für eine Überzeugung immer wieder, so stößt man früher oder später auf diese offenen Enden und Zirkel. Wenn man diese Sachlage im Blick hat, ist klar, daß die Möglichkeiten, als Realist erfolgreich für eine ontologische realistische These zu argumentieren, in prinzipieller Weise begrenzt sind. Es lassen sich drei begrenzende Faktoren unterscheiden: Erstens steht einem zur Konstruktion eines Arguments für eine ontologische realistische These, von der man selbst überzeugt ist, nicht mehr als die Überzeugungen zur Verfügung, die den eigenen Rechtfertigungsgraphen der These bilden. Zweitens ergeben Rechtfertigungsgründe, die man für eine ontologische realistische These aufweisen kann, nur dann ein für einen bestimmten Diskussionsgegner überzeugungskräftiges Argument, wenn nicht nur man selbst, sondern auch dieser Diskussionsgegner von hinreichend vielen dieser Rechtfertigungsgründe bereits überzeugt ist. Drittens kann der Erfolg eines Arguments in der Debatte mit einem bestimmten Diskussionsgegner auch noch von den Regeln oder Verfahren abhängen, die dieser zur Beseitigung von Konflikten innerhalb seiner Gesamtheit von Überzeugungen verwendet (nämlich dann, wenn eine Konklusion des Arguments mit vorhandenen Überzeugungen in Konflikt steht). Auch wenn man selbst hinreichende Rechtfertigungsgründe für eine Überzeugung hat, impliziert dies also nicht, daß diese Rechtfertigungsgründe ein für jeden Diskussionsgegner überzeugungskräftiges Argument ergeben. Dies gilt für Überzeugungen über Gegenstände und Sachverhalte im Bereich des Beobachtbaren genau wie im Bereich des Unbeobachtbaren, und es gilt insbesondere auch für Überzeugungen, die ontologische realistische Thesen zum Inhalt haben.

Sowohl die Tatsache, daß man früher oder später auf Grenzen stößt, wenn man die Frage nach den eigenen Rechtfertigungsgründen für eine ontologische realistische These immer wieder iteriert (nämlich, bildlich gesprochen, auf die Zirkel oder offenen Enden des Rechtfertigungsgraphen), als auch die Tatsache, daß die Reichweite von Argumenten für eine solche These durch die drei genannten Faktoren begrenzt ist, liegen in der Natur 
der Sache, also in der Natur des menschlichen Erkenntnisapparates bzw. dessen, was ein Argument ist. Keiner dieser beiden Befunde stellt bei genauer Betrachtung einen plausiblen Grund für die gelegentlich dadurch motivierte Annahme dar, daß die verfügbaren Rechtfertigungsgründe "in epistemischer Hinsicht nicht zufriedenstellend", "wertlos" o.ä. seien, und daß dadurch realistische Thesen und Positionen entwertet werden - obwohl dies auf den ersten Blick vielleicht so erscheinen könnte. Dies gilt für ontologische realistische Thesen über Beobachtbares ebenso wie für ontologische realistische Thesen über Unbeobachtbares.

Praktisch spielen die prinzipiellen Grenzen der Reichweite von Argumenten selten oder nie eine Rolle, weder für die alltagsweltliche epistemische Praxis im Bereich des Beobachtbaren, noch für die epistemische Praxis der Wissenschaften. Nichtsdestoweniger kann man sich aber Fälle zurechtlegen, in denen diese Grenzen im Bereich des Beobachtbaren wirksam werden: Ein solcher konstruierter Fall wäre der, in dem man versucht, eine farbenblinde bzw. eine blinde Person, die nicht glaubt, daß es farbige Dinge gibt, von einer bestimmten Aussage über die Farbe eines Gegenstandes zu überzeugen, und zwar eine "hinreichend konsequente" farbenblinde bzw. blinde Person, die auch nicht glaubt, daß irgendjemand Farbeigenschaften erkennen kann, und die auch sonst kein Schlußverfahren akzeptiert, das Überzeugungen über Farbeigenschaften liefern kann. Daß es dazu parallele Fälle gibt, in denen dieselben Grenzen der Reichweite von Argumenten im Bereich des Unbeobachtbaren wirksam werden, ist aus reliabilistischer Perspektive betrachtet nicht überraschend. Konstellationen dieser Art sind es nun aber gerade, die in der wissenschaftstheoretischen Realismusdebatte eine zentrale Rolle spielen: Die durch die drei genannten Faktoren beschriebenen Grenzen der Reichweite von Argumenten sind dafür verantwortlich, daß ein reflektierter, konsequenter Antirealist durch kein von realistischer Seite vorgebrachtes Argument von ontologischen realistischen Thesen über Unbeobachtbares überzeugt werden kann; daß Kontinuitätsargumente und Varianten des Wunderarguments für ihn keine Überzeugungskraft haben, ist ein Spezialfall dieses allgemeinen Befundes. Daß man als wissenschaftlicher Realist einen reflektierten, konsequenten Antirealisten nicht von ontologischen realistischen Thesen über Unbeobachtbares, also von der Existenz unbeobachtbarer Gegenstände oder Sachverhalte überzeugen kann, trägt aus reliabilistischer Perspektive betrachtet gegen wissenschaftlichen Realismus genauso viel oder genauso wenig aus wie die Tatsache, daß sich eine "hinreichend konsequente" farbenblinde bzw. blinde Person nicht durch Argumente von der Existenz farbiger Gegenstände überzeugen läßt, gegen eine realistische Einstellung zu beobachtbaren Gegenständen der Alltagswelt austrägt.

Aus reliabilistischer Perspektive betrachtet können innerhalb der beschriebenen prinzipiellen Grenzen der Reichweite von Argumenten, je nach zur Debatte stehender ontologischer realistischer These, grundsätzlich verschiedenartige epistemische Rechtfertigungsgründe und Argumente für eine solche These vorgebracht werden, um Anhänger "weniger konsequenter" antirealistischer Positionen und unvoreingenommene Laien, also Personen, die bisher keine systematisch reflektierte Position in der Realismusdebatte einnehmen, davon zu überzeugen, und in einer Diskussion mit solchen Diskussionsgegnern auch zum Erfolg führen. In Frage kommen hier sowohl (präzisierte und verbesserte) Kontinuitätsargumente und Versionen des Wunderarguments, als auch eine Vielzahl speziellerer, "lokalerer" Argumente.

Um im einzelnen spezifizieren zu können, was sich für eine bestimmte ontologische realistische These an Argumenten anführen läßt, muß man sich die beim derzeitigen Kenntnisstand der Wissenschaften (einschließlich der Wissenschaftsgeschichte) dafür je- 
weils verfügbaren Rechtfertigungsgründe verschaffen. Wenn spezifiziert werden soll, was sich für eine selektive realistische Position in der wissenschaftstheoretischen Realismusdebatte an Argumenten ins Feld führen läßt, gilt Entsprechendes in bezug auf alle ontologischen realistischen Thesen, die diese Position konstituieren. Den skizzierten Umriß einer selektiven realistischen Position tatsächlich mit Einzelthesen auszufüllen und sich gleichzeitig die Argumente zu verschaffen, die für solche Thesen zu haben sind, erfordert also die Umsetzung eines umfangreichen Programms, das eine "Durchmusterung" der in den Wissenschaften etablierten oder wenigstens diskutierten Theorien, Gesetze etc. und der dort für diese vorliegenden Begründungen einschließt. Erst wenn dieses Programm umgesetzt ist, hat man alle ontologischen realistischen Thesen über Unbeobachtbares in der Hand, die eine selektive realistische Position bilden, die, wie es traditionell von einer Position in der wissenschaftstheoretischen Realismusdebatte erwartet wird, zum Status aller Theorien, Gesetze, Modelle etc., die in den Wissenschaften etabliert sind, Stellung nimmt. Erst dann hat man auch alle Ressourcen in der Hand, die beim derzeitigen Stand der Wissenschaft verfügbar sind, um für eine solche selektive realistische Position zu argumentieren.

Dieses Programm konnte in dieser Arbeit nur skizziert werden, es wurde jedoch an einem Fallbeispiel in groben Zügen vorgeführt, wie eine weiterreichende Umsetzung auszusehen hätte. Gleichzeitig wurde in diesem Fallbeispiel gezeigt, daß zumindest für einige ontologische realistische Thesen über Unbeobachtbares, nämlich über elektrische Ströme, hinreichende Rechtfertigungsgründe "guter Qualität" angegeben werden können.

Fazit der Suche nach Argumenten für eine selektive realistische Position in der wissenschaftstheoretischen Realismusdebatte ist also, daß keine Argumente zu haben sind, die für "hinreichend konsequente" Anhänger instrumentalistischer oder in epistemischer Hinsicht antirealistischer Positionen Überzeugungskraft haben, und daß darüberhinaus auch die Argumente, die sich gleichsam innerhalb der beschriebenen prinzipiellen Grenzen der Reichweite von Argumenten von realistischer Seite vorbringen lassen, i.a. erst nach der Umsetzung wenigstens von Teilen des skizzierten Programms verfügbar sind. Diese Einsicht mag für jemanden, der zu einer realistischen Position neigt oder zumindest eine allgemeine realistische Intuition teilt, zunächst ernüchternd wirken, insbesondere wenn man sie den zum Teil verlockend "einfach" und stringent aussehenden und von "Detailproblemen" bestimmter Gegenstandsbereiche ganz abstrahierenden Argumenten gegenüberstellt, die von Realisten in der Debatte mit einiger Zuversicht vorgetragen werden. Nüchtern betrachtet ist diese Sachlage jedoch weit weniger enttäuschend als sie auf den ersten Blick vielleicht aussieht, wenn man im Auge behält, daß für realistische Thesen in bezug auf die beobachtbaren Gegenstände und Sachverhalte der Alltagswelt nichts prinzipiell Besseres oder Andersartiges an Argumenten zu haben ist. 


\section{Literaturverzeichnis}

[AcBa69] Peter Achinstein, Stephen F.Barker (eds.); The legacy of logical positivism, Baltimore, 1969

[AcHa85] Peter Achinstein, Owen Hannaway (eds.); Observation, Experiment, and Hypothesis in Modern Physical Science, Cambridge, MA, 1985

[Achi68] Peter Achinstein; Concepts of Science, Baltimore, 1968

[Acke89] Robert Ackermann; The New Experimentalism, British Journal for the Philosophy of Science 40 (1989), 185-190

[Adam81] Douglas Adams; Per Anhalter durch die Galaxis, Frankfurt, 1981

[Adam82] Douglas Adams; Das Restaurant am Ende des Universums, Frankfurt, 1982

[AlFi67] Marcelo Alonso, Edward J.Finn; Fundamental university physics, Vol.II, Fields and waves, Reading, MA, 1967

[Alle89] Sture Allén (ed.); Possible Worlds in Humanities, Arts and Sciences, Berlin, 1989

[Allp93] Philip P.Allport; Are the laws of physics 'economical with the truth'?, Synthese 94 (1993), 245-290

[Alst86] William P.Alston; Epistemic Circularity, Philosophy and Phenomenological Research 47 (1986), 1-30

[Alst93] William P.Alston; The Reliability of Sense Perception, Ithaca, NJ, 1993

[Alst95] William P.Alston; How to Think about Reliability, Philosophical Topics 23 (1995), 1-29

[Anto87] Louise M.Antony; Naturalized epistemology and the study of language, in: [ShNa87], 235-257

[AsGi81] Peter D.Asquith, Ronald N.Giere (eds.); PSA 1980, Vol.2, East Lansing, MI, 1981

[AsMe76] Neil W.Ashcroft, N.David Mermin; Solid State Physics, Philadelphia, 1976

[AsNi83] Peter D.Asquith, Thomas Nickles (eds.); PSA 1982, Vol.2, East Lansing, MI, 1983

[Audi98] Robert Audi; Epistemology, London, 1998

[Ayer36] Alfred J.Ayer; Language, Truth and Logic, London, 1936

[Bald73] C.T.Baldwin; Fundamentals of Electrical Measurements, 2nd ed., London, 1973

[Batt02] Robert W.Batterman; The devil in the details, Oxford, 2002

[BeKr86] K.Berka, L.Kreiser (Hg.); Logik-Texte, Berlin, 1986

[Beda93] Katherine Bedard; Partial Denotations of Theoretical Terms, Noûs 27 (1993), 499-511

[BenM90] Yemima Ben-Menahem; The inference to the best explanation, Erkenntnis 33 (1990), 319-344

[Bena73] Paul Benacerraf; Mathematical truth, Journal of Philosophy 70 (1973), 661-680

[Berk88] George Berkeley; Principles of Human Knowledge and Three Dialogues between Hylas and Philonous, London, 1988

[Bier87] Peter Bieri (Hg.); Analytische Philosophie der Erkenntnis, Frankfurt, 1987

[Blac50] Max Black (ed.); Philosophical Analysis, Ithaca, NY, 1950

[Blac80] Simon Blackburn; Truth, Realism, and the Regulation of Theory, in: [FrUW80], 353-371

[Blac84] Simon Blackburn; Spreading the Word, Oxford, 1984

[Blac93a] Simon Blackburn; Essays in Quasi-Realism, New York, 1993

[Blac93b] Simon Blackburn; Knowledge, Truth, and Reliability, in: [Blac93a], 35-51 
[BoGT91] Richard Boyd, Philip Gasper, J.D.Trout (eds.); The Philosophy of Science, Cambridge, 1991

[BoWo88] James Bogen, James Woodward; Saving the phenomena, The Philosophical Review 97 (1988), $303-352$

[BonJ85] Laurence BonJour; The Structure of Empirical Knowledge, Cambridge, MA, 1985

[Bool90] George Boolos (ed.); Meaning and Method, Cambridge, 1990

[Boyd73] Richard Boyd; Realism, Underdetermination, and a Causal Theory of Evidence, Noûs 7 (1973), $1-12$

[Boyd79] Richard Boyd; Metaphor and Theory Change: What is "Metaphor" a Metaphor for?, in: [Orto79], 356-408

[Boyd81] Richard Boyd; Scientific Realism and Naturalistic Epistemology, in: [AsGi81], 613-662

[Boyd85a] Richard Boyd; Observations, Explanatory Power, and Simplicity: Toward a Non-Humean Account, in: [AcHa85], 47-94

[Boyd85b] Richard Boyd; Lex Orandi est Lex Credendi, in: [ChHo85], 3-34

[Boyd88] Richard Boyd; How to Be a Moral Realist, in: [SaMC88], 181-228

[Boyd89] Richard Boyd; What Realism Implies and What it Does Not, Dialectica 43 (1989), 5-29

[Boyd90a] Richard Boyd; Realism, Approximate Truth, and Philosophical Method, in: [Sava90], 355-391

[Boyd90b] Richard Boyd; Realism, conventionality, and "realism about", in: [Bool90], 171- 195

[Boyd91] Richard Boyd; On the Current Status of Scientific Realism, in: [BoGT91], 195-221, (zuerst in: Erkenntnis 19 (1983), 45-90)

[BrCo81] Marilynn B.Brewer, Barry E.Collins (eds.); Scientific Inquiry and the Social Sciences, San Francisco, 1981

[Brau90] E.Braun; Mikrochips werden Normale, Physikalische Blätter 46 (1990), 58-60

[Bren89] Wilhelm Brenig; Statistical Theory of Heat, Berlin, 1989

[Brid27] Percy W.Bridgman; The logic of modern physics, New York, 1927

[Brow85] James Robert Brown; Ist der Erfolg der Wissenschaft erklärbar?, Ratio 27 (1985), 42-57

[BuWa01] Jed Z.Buchwald, Andrew Warwick (eds.); Histories of the Electron, Cambridge, MA, 2001

[Buch95] Jed Buchwald (ed.); Scientific Practice, Chicago, 1995

[Bung64] Mario Bunge (ed.); The Critical Approach to Science and Philosophy, London, 1964

[Bung67] Mario Bunge (ed.); Quantum Theory and Reality, Berlin, 1967

[Buri90] Richard M.Burian; Review: Andrew Pickering, Constructing Quarks, Synthese 82 (1990), 163174

[Ca36/37] Rudolf Carnap; Testability and Meaning, Philosophy of Science 3 (1936), 419-471 und 4 (1937), $1-40$

[CaJo91] Nancy Cartwright, Martin Jones; How to hunt quantum causes, Erkenntnis 35 (1991), 205-231

[Carn28] Rudolf Carnap; Der logische Aufbau der Welt, Berlin, 1928

[Carn31] Rudolf Carnap; Überwindung der Metaphysik durch logische Analyse der Sprache, Erkenntnis 2 (1931), 219-241

[Carn32] Rudolf Carnap; Die physikalische Sprache als Universalsprache der Wissenschaft, Erkenntnis 2 (1932), 432-465

[Carn36] Rudolf Carnap; Wahrheit und Bewährung, in: [Skir77], 89-95 (zuerst in: Actes du Congrès International de Philosophie Scientifique, fasc.4, Paris, 1936, 1823)

[Carn39] Rudolf Carnap; Foundations of Logic and Mathematics, (Otto Neurath et al. (eds.); International Encyclopedia of Unified Science, Vol.I, No.3 (1939)), Chicago, 1939

[Carn49] Rudolf Carnap; Logical Foundations of the Unity of Science, in: [FeSe49], 408-423, (zuerst in: Otto Neurath et al. (eds.); International Encyclopedia of Unified Science, Vol.I, No.1 (1938), 42-62)

[Carn56a] Rudolf Carnap; The Methodological Character of Theoretical Concepts, in: [FeSc56], 38-76 
[Carn56b] Rudolf Carnap; Meaning and Necessity, 2nd. ed., Chicago, 1956

[Carn56c] Rudolf Carnap; Meaning and synonymy in natural languages, in: [Carn56b], 233-247, (zuerst in: Philosophical Studies 7 (1955), 33-47)

[Carn58] Rudolf Carnap; Beobachtungssprache und theoretische Sprache, Dialectica 12 (1958), 236-248

[Carn63a] Rudolf Carnap; Intellectual Autobiography, in: [Schi63], 1-84

[Carn63b] Rudolf Carnap; Replies and Systematic Expositions, in: [Schi63], 859-1013

[Carn66] Rudolf Carnap; Philosophical Foundations of Physics, New York, 1966

[Carn68] Rudolf Carnap; Inductive logic and inductive intuition, in: [Laka68], 258-267

[Carr91] Martin Carrier; What is wrong with the miracle argument?, Studies in History and Philosophy of Science 22 (1991), 23-36

[Carr93] Martin Carrier; What is Right with the Miracle Argument: Establishing a Taxonomy of Natural Kinds, Studies in History and Philosophy of Science 24 (1993), 391-409

[Carr98] Martin Carrier; New Experimentalism and the Changing Significance of Experiments: On the Shortcomings of an Equipment-Centered Guide to History, in: [HeSt98], 175-191

[Cart83] Nancy Cartwright; How the laws of physics lie, Oxford, 1983

[Cart89a] Nancy Cartwright; Nature's Capacities and their Measurement, Oxford, 1989

[Cart89b] Nancy Cartwright; Capacities and Abstractions, in: [KiSa89], 349-356

[Cart92] Nancy Cartwright; Aristotelian Natures and the Modern Experimental Method, in: [Earm92a], $44-71$

[Cart93a] Nancy Cartwright; Marks and probabilities: two ways to find causal structure, in: [Stad93], $113-119$

[Cart93b] Nancy Cartwright; Is natural science 'natural' enough?: A reply to Philip Allport, Synthese 94 (1993), 291-301

[Cart94] Nancy Cartwright; Fundamentalism vs. The Patchwork Of Laws, Proceedings of the Aristotelian Society 94 (1994), 279-292

[Cart95a] Nancy Cartwright; Reply to Eells, Humphreys and Morrison, Philosophy and Phenomenological Research 55 (1995), 177-187

[Cart95b] Nancy Cartwright; Causal structures in econometrics, in: [Litt95], 63-74

[Cart97] Nancy Cartwright; What Is a Causal Structure?, in: [McTu97], 343-357

[Cauc86] Venant Cauchy (ed.); Philosophy and Culture, Montreal, 1986

[ChCa93] Hasok Chang, Nancy Cartwright; Causality and realism in the EPR experiment, Erkenntnis 38 (1993), 169-190

[ChHo85] Paul M.Churchland, Clifford A.Hooker (eds.); Images of Science, Chicago, 1985

[Chur85] Paul M.Churchland, The Ontological Status of Observables: In Praise of the Superempirical Virtues, in: [ChHo85], 35-47

[ClLe89] Marjorie Clay, Keith Lehrer (eds.); Knowledge and Skepticism, Boulder, CO, 1989

[ClMS87] Frank Close, Michael Marten, Christine Sutton; The Particle Explosion, New York, 1987

[CoWa65] Robert S.Cohen, Marx W.Wartofsky (eds.); Boston Studies in the Philosophy of Science, Vol.2, Dordrecht, 1965

[Cohe82] L.Jonathan Cohen et al. (eds.); Logic, Methodology and Philosophy of Science VI, Amsterdam, 1982

[Colo65] Robert G.Colodny (ed.); Beyond the edge of certainty, Englewood Cliffs, NJ, 1965

[Coll85] Harry Collins; Changing Order: Replication and Induction in Scientific Practice, London, 1985

[Crai90] Edward Craig; Knowledge and the State of Nature, Oxford, 1990

[Cram87] Konrad Cramer et al. (Hg.); Theorie der Subjektivität, Frankfurt, 1987

[CuDG84] James T.Cushing, C.F.Delaney, Gary M.Gutting (eds.); Science and Reality, Notre Dame, 1984

[Cumm92] D.Cummiskey; Reference Failure and Scientific Realism: a Response to the Meta-induction, British Journal for the Philosophy of Science 43 (1992), 21-40 
[DaKi94] Timothy Day, Harold Kincaid; Putting inference to the best explanation in its place, Synthese 98 (1994), 271-295

[DaSo92] Jonathan Dancy, Ernest Sosa (eds.); A Companion to Epistemology, Oxford, 1992

[Danc85] Jonathan Dancy; An Introduction to Contemporary Epistemology, Oxford, 1985

[DeLi97] Don DeLillo; Underworld, New York, 1997

[Desc72] René Descartes; Meditationen über die Grundlagen der Philosophie mit sämtlichen Einwänden und Erwiderungen, Hamburg, 1972

[Devi81] Michael Devitt; Designation, New York, 1981

[Devi84] Michael Devitt; Realism and Truth, Princeton, 1984

[Devi91] Michael Devitt; Aberrations of the realism debate, Philosophical Studies 61 (1991), 43-63

[Devi96] Michael Devitt; Coming to Our Senses, Cambridge, 1996

[Dewe88] John Dewey; The Quest for Certainty, (The Later Works, 1925-1953, Vol.4), Carbondale, IL, 1988

[Diek86] D.Dieks; Physics and the direction of causation, Synthese 25 (1986), 85-110

[Donn74] Keith Donnellan; Speaking of Nothing, Philosophical Review 83 (1974), 3-31

[Douv99] Igor Douven; Inference to the Best Explanation Made Coherent, Philosophy of Science 66 (1999), S424-S435

[DrJo52] C.V.Drysdale, A.C.Jolley; Electrical Measuring Instruments, Part One, 2nd ed., London, 1952

[Dret92] Fred Dretske; Perceptual knowledge, in: [DaSo92], 333-338

[DuGu90] J.M.Dunn, A.Gupta (eds.); Truth or Consequences, Dordrecht, 1990

[Duer81] Hans-Peter Duerr (Hg.); Versuchungen. Aufsätze zur Philosophie Paul Feyerabends, Bd.2, Frankfurt, 1981

[Duhe78] Pierre Duhem; Ziel und Struktur physikalischer Theorien, Hamburg, 1978

(französisches Original: La Théorie physique: Son object, Sa structure, Paris, 1906)

[Dumm75] Michael Dummett; What is a theory of meaning?, in: [Gutt75], 97-138 (auch in: [Dumm93a], 1-33)

[Dumm76] Michael Dummett; What is a theory of meaning? (II), in: [EvMc76], 67-137 (auch in: [Dumm93a], 34-93)

[Dumm78a] Michael Dummett; Truth and Other Enigmas, London, 1978

[Dumm78b] Michael Dummett; Realism, in: [Dumm78a], 145-165

[Dumm78c] Michael Dummett; The Philosophical Basis of Intuitionistic Logic, in: [Dumm78a], 215-247

[Dumm78d] Michael Dummett; Can Analytical Philosophy be Systematic, and Ought it to Be?, in: [Dumm78a], 305-326

[Dumm93a] Michael Dummett; The Seas of Language, Oxford, 1993

[Dumm93b] Michael Dummett; Realism and Anti-Realism, in: [Dumm93a], 462-478

[Dumm93c] Michael Dummett; Realism, in: [Dumm93a], 230-276 (zuerst in: Synthese 52 (1982), 55-112)

[Dupr81] John Dupré; Natural kinds and biological taxa, Philosophical Review 90 (1981), 66-90

[EaFi77] John Earman, Arthur Fine; Against Indeterminacy, Journal of Philosophy 74 (1977), 535-538

[Earm83] John Earman (ed.); Testing Scientific Theories, (Minnesota Studies in the Philosophy of Science, vol.X), Minneapolis, 1983

[Earm92a] John Earman (ed.); Inference, Explanation, and other Frustrations, Berkeley, 1992

[Earm92b] John Earman; Bayes or Bust?, Cambridge, MA, 1992

[Earm93] John Earman; Underdetermination, Realism, and Reason, in: [FrUW93], 19-38

[Eddi29] Arthur S.Eddington; The Nature of the Physical World, New York, 1929

[Elli85] Brian Ellis; What Science aims to Do, in: [ChHo85], 48-74

[Elsa94] Mohamed Elsamahi; Could Theoretical Entities Save Realism?, in: [HuFB94], 173-180 
[EnBr86] The New Encyclopaedia Britannica, Vol.17, Chicago, 1985

[Engl73] Jane English; Underdetermination: Craig and Ramsay, Journal of Philosophy 70 (1973), 453462

[Engl78] Jane English; Partial interpretation and meaning change, Journal of Philosophy 75 (1978), $57-76$

[EvMc76] Gareth Evans, John McDowell (eds.); Truth and Meaning, Oxford, 1976

[Evan73] Gareth Evans; The Causal Theory of Names; Aristotelian Society Supplementary Volume 47 (1973), 187-208

[Evan82] Gareth Evans; Varieties of Reference, Oxford, 1982

[FeBr53] Herbert Feigl, May Brodbeck (eds.); Readings in the Philosophy of Science, New York, 1953

[FeMa62] Herbert Feigl, Grover Maxwell (eds.); Scientific Explanation, Space, and Time, (Minnesota Studies in the Philosophy of Science, vol.III), Minneapolis, 1962

[FeSM58] Herbert Feigl, Michael Scriven, Grover Maxwell (eds.); Concepts, Theories, and the Mind-Body Problem, (Minnesota Studies in the Philosophy of Science, vol.II), Minneapolis, 1958

[FeSc56] Herbert Feigl, Michael Scriven (eds.); The Foundations of Science and the Concepts of Psychology and Psychoanalysis, (Minnesota Studies in the Philosophy of Science, vol.I), Minneapolis, 1956

[FeSe49] Herbert Feigl, Wilfrid Sellars (eds.); Readings in Philosophical Analysis, New York, 1949

[Feig50a] Herbert Feigl; Existential hypotheses, Philosophy of Science 17 (1950), 35-62 (auch in: [Feig81], 192-223)

[Feig50b] Herbert Feigl; Logical Reconstruction, realism and pure semiotic, Philosophy of Science 17 (1950), 186-195

[Feig50c] Herbert Feigl; De principiis non disputandum ... ?, in: [Blac50], 119-156 (auch in: [Feig81], 237-268)

[Feig70] Herbert Feigl; The "Orthodox" View of Theories: Remarks in Defence as well as Critique, in: [RaWi70], 3-16

[Feig81] Herbert Feigl; Inquiries and Provocations, Dordrecht, 1981

[Fetz88] James H.Fetzer (ed.); Probability and Causality, Dordrecht, 1988

[Feye60a] Paul Feyerabend; Das Problem der Existenz theoretischer Entitäten, in: [Topi60], 35-72

[Feye60b] Paul Feyerabend; Patterns of discovery, Philosophical Review 69 (1960), 247-252

[Feye65] Paul Feyerabend; Problems of Empiricism, in: [Colo65], 145-260

[Feye81a] Paul Feyerabend; Realism, rationalism and scientific method, Philosophical papers Vol.1, Cambridge, 1981

[Feye81b] Paul Feyerabend; Explanation, reduction and empiricism, in: [Feye81a], 44-96 (zuerst in: [FeMa62], 28-97)

[Feye81c] Paul Feyerabend; Reply to criticism, in: [Feye81a], 104-131 (zuerst in: [CoWa65], 223-261)

[Feye81d] Paul Feyerabend; Realism and instrumentalism, in: [Feye81a], 176-202 (zuerst in: [Bung64], 280-308)

[Feyn65] Richard Feynman; The Character of Physical Law, Cambridge, MA, 1965

[FiFW90] Arthur Fine, Micky Forbes, Linda Wessels (eds.); PSA 1990, vol.1, East Lansing, MI, 1990

[FiMa86] Arthur Fine, Peter Machamer (eds.); PSA 1986, vol.1, East Lansing, MI, 1986

[Fiel72] Hartry Field; Tarski's theory of truth, Journal of Philosophy 69 (1972), 347-375

[Fiel73] Hartry Field; Theory change and the indeterminacy of reference, Journal of Philosophy $\mathbf{7 0}$ (1973), 462-481

[Fiel78] Hartry Field; Mental representation, Erkenntnis 13 (1978), 9-61

[Fine75] Arthur Fine; How to Compare Theories: Reference and Change, Noûs 9 (1975), 17-32

[Fine84a] Arthur Fine; The Natural Ontological Attitude, in: [Lepl84], 83-107 (auch in: [Fine86a], 112-135) 
[Fine84b] Arthur Fine; And Not Anti-Realism Either, Noûs 18 (1984), 51-65 (auch in: [Fine86a], 136-150)

[Fine86a] Arthur Fine; The Shaky Game, Chicago, 1986

[Fine86b] Arthur Fine; Unnatural Attitudes: Realist and Instrumentalist Attachments to Science, Mind 95 (1986), 149-179

[Fine96] Arthur Fine; Science Made Up: Constructivist Sociology of Scientific Knowledge, in: [GaSt96], $231-254$

[Fodo84] Jerry Fodor; Observation reconsidered, Philosophy of Science 51 (1984), 23-43

[Fors88] Malcolm R.Forster; Unification, explanation, and the composition of causes in Newtonian mechanics, Studies in History and Philosophy of Science 19 (1988), 55-101

[FrUW80] Peter A.French, Theodore E.Uehling, Jr., Howard K.Wettstein (eds.); Studies in Epistemology, (Midwest Studies in Philosophy, Vol.V), Minneapolis, 1980

[FrUW93] P.A.French, T.E.Uehling, jr., H.K.Wettstein (eds.); Philosophy of Science, (Midwest Studies in Philosophy, Vol.XVIII), Notre Dame, IN, 1993

[FrUW94] Peter A.French, Theodore E.Uehling, Jr., Howard K.Wettstein (eds.); Philosophical Naturalism, (Midwest Studies in Philosophy, Vol.XIX), Notre Dame, IN, 1994

[FrWe99] Peter A.French, Howard K.Wettstein (eds.); New Directions in Philosophy, (Midwest Studies in Philosophy, Vol.XXIII), Boston, 1999

[FrZe83] Gerhard Frey, Josef Zelger (Hg.); Der Mensch und die Wissenschaften vom Menschen, (Beiträge des XII. Deutschen Kongresses für Philosophie in Innsbruck, 29.9.-3.10.1981), Bd.2, Innsbruck, 1983

[Fran32] Philipp Frank; Das Kausalgesetz und seine Grenzen, Wien, 1932

[Fran86] Allan Franklin; The neglect of experiment, Cambridge, 1986

[Fran88] Allan Franklin; How Nancy Cartwright Tells the Truth, British Journal for the Philosophy of Science 39 (1988), 527-529

[Fran90] Allan Franklin; Experiment, right or wrong, Cambridge, 1990

[Fran97] Allan Franklin; Calibration, Perspectives on Science 5 (1997), 31-80

[Freg62a] Gottlob Frege; Funktion, Begriff, Bedeutung, Göttingen, 1962

[Freg62b] Gottlob Frege; Über Sinn und Bedeutung, in: [Freg62a], 40-65

[Frie79] Michael Friedman; Truth and confirmation, Journal of Philosophy 76 (1979), 361-382

[Frie81] Michael Friedman; Theoretical explanation, in: [Heal81], 1-16

[Frie82] Michael Friedman; Review: The Scientific Image, Journal of Philosophy 79 (1982), 274-283

[Frie83] Michael Friedman; Foundations of Space-Time Theories, Princeton, 1983

[GaSt96] Peter Galison, David Stump (eds.); The Disunity of Science, Stanford, 1996

[Gali86] Peter Galison; Review of: Ian Hacking; Representing and Intervening, Isis 77 (1986), 118-120

[Gali87] Peter Galison; How Experiments End, Chicago, 1987

[Gali95a] Peter Galison; Context and Constraints, in: [Buch95], 13-41

[Gali95b] Peter Galison; Theory Bound and Unbound: Superstrings and Experiment, in: [Wein95], 369408

[Gali97] Peter Galison; Image and Logic, Chicago, 1997

[Garb83] Daniel Garber; Old Evidence and Logical Omniscience in Bayesian Confirmation Theory, in: [Earm83], 99-131

[Gard88] Peter Gärdenfors; Knowledge in Flux, Cambridge, MA, 1988

[Gert82] Christian Gerthsen; Physik: Ein Lehrbuch zum Gebrauch neben Vorlesungen/Gerthsen; Kneser; Vogel, 14.Aufl. (neubearbeitet und erweitert von H.Vogel), Berlin, 1982

[GiSc86] Yves Gingras, Silvan S.Schweber; Constraints on Construction, Social Studies of Science 16 (1986), 372-383

[Gibb84] Peter Gibbins; Nancy Cartwright's new philosophy of physics, British Journal for the Philosophy of Science 35 (1984), 390-401 
[Gier88] Ronald N.Giere; Explaining Science, Chicago, 1988

[Ging97] Yves Gingras; The New Dialectics of Nature, Social Studies of Science 27 (1997), 317-334

[Glym84] Clark Glymour; Explanation and Realism, in: [Lepl84], 173-192, (auch in: [ChHo85], 99-117)

[GoPS89] David Gooding, Trevor Pinch, Simon Shaffer (eds.); The Uses of Experiment: Studies of Experimentation in the Natural Sciences, Cambridge, 1989

[Gobe97] E.O.Göbel; Quantennormale im SI-Einheitensystem, Physikalische Blätter 53 (1997), 217-223

[Gold79] Alvin I.Goldman; What is justified belief?, in: [Papp79], 1-23

[Gold86] Alvin I.Goldman; Epistemology and Cognition, Cambridge, MA, 1986

[Gold88] Alan Goldman; Empirical Knowledge, Berkeley, 1988

[Gold94] Alvin I.Goldman; Naturalistic Epistemology and Reliabilism, in: [FrUW94], 301-320

[Good55] Nelson Goodman; Fact, Fiction and Forecast, Cambridge, MA, 1955

[Good78] Nelson Goodman; Ways of Worldmaking, Indianapolis, 1978

[Good80] Nelson Goodman; On starmaking, Synthese 45 (1980), 211-215

[Gros90] Alan Gross; Reinventing Certainty: The Significance of Ian Hacking's Realism, in: [FiFW90], $421-431$

[Gutt75] Samuel Guttenplan (ed.); Mind and Language, Oxford, 1975

[HaAs78] Ian Hacking, Peter Asquith (eds.); PSA 1978, vol.1, East Lansing, MI, 1978

[HaDa72] Gilbert Harman, Donald Davidson (eds.); Semantics of Natural Language, Dordrecht, 1972

[HaSc86] Lewis E.Hahn, Paul A.Schilpp (eds.); The Philosophy of W.V.Quine, La Salle, IL., 1986

[Haac76] Susan Haack; The justification of deduction, Mind 85 (1976), 112-119

[Haac87] Susan Haack; "Realism", Synthese 73 (1987), 275-299

[Hack75] Ian Hacking; Why Does Language Matter to Philosophy?, Cambridge, 1975

[Hack80] Ian Hacking; The theory of probable inference: Neyman, Peirce and Braithwaite, in: [Mell80], $141-160$

[Hack81] Ian Hacking; Spekulation, Berechnung und die Erschaffung von Phänomenen, in: [Duer81], $126-158$

[Hack82a] Ian Hacking; Experimentation and Scientific Realism, in: [BoGT91], 247-260, (zuerst in: Philosophical Topics 13 (1982), 71-87, auch in: [Lepl84], 154-172)

[Hack82b] Ian Hacking; Language, Truth and Reason, in: [HoLu82], 48-66

[Hack83a] Ian Hacking; Representing and Intervening, Cambridge, 1983

[Hack83b] Ian Hacking; The Accumulation of Styles of Scientific Reasoning, in: [Henr83], 453-465

[Hack89] Ian Hacking; Extragalactic Reality: The Case of Gravitational Lensing, Philosophy of Science 56 (1989), 555-581

[Hack92a] Ian Hacking; 'Style' for Historians and Philosophers, Studies in History and Philosophy of Science 23 (1992), 1-20

[Hack92b] Ian Hacking; The Self-Vindication of the Laboratory Sciences, in: [Pick92], 29-64

[Hack92c] Ian Hacking; Statistical language, statistical truth and statistical reason: the self-authentification of a style of scientific reasoning, in: [McMu92], 130-157

[Hamm80] R.W.Hamming; The unreasonable effectiveness of mathematics, American Mathematical Monthly 87 (1980), 81-90

[Hans58] Norwood R.Hanson; Patterns of Discovery, Cambridge, 1958

[Hard54] John A.Hardon; The concept of miracle from St.Augustine to modern apologetics; Theological Studies 15 (1954), 229-257

[Harm65] Gilbert Harman; The Inference to the Best Explanation, The Philosophical Review 74 (1965), 88-95

[Harm73] Gilbert Harman; Thought, Princeton, 1973 
[Harm86] Gilbert Harman; Change in View, Cambridge, MA, 1986

[Harr70] Walter A.Harrison; Solid State Theory, New York, 1970

[Harv80] Bill Harvey; The effects of social context on the process of scientific investigation: experimental tests of quantum mechanics, in: [KnKW80], 139-163

[Harv81] Bill Harvey; Plausibility and the Evaluation of Knowledge: A Case-Study of Experimental Quantum Mechanics, Social Studies of Science 11 (1981), 95-130

[HeSt98] Michael Heidelberger, Friedrich Steinle (Hg.); Experimental Essays — Versuche zum Experiment, Baden-Baden, 1998

[Heal81] Richard Healey (ed.); Reduction, time and reality, Cambridge, 1981

[Heal94] Richard Healey; Nonseparable Processes and Causal Explanation, Studies in History and Philosophy of Science 25 (1994), 337-374

[Heid92] Michael Heidelberger; Kausalität. Eine Problemübersicht, Neue Hefte für Philosophie 32/33 (1992), 130-153

[Hell83] Geoffrey Hellman; Realist principles, Philosophy of Science 50 (1983), 227-249

[Hell97] Geoffrey Hellman; Bayes and Beyond, Philosophy of Science 64 (1997), 191-221

[Hemp35] Carl G.Hempel; On the Logical Positivists' Theory of Truth, Analysis 2 (1935), 49-59

[Hemp50] Carl G.Hempel; A note on semantic realism, Philosophy of Science 17 (1950), 169-173

[Hemp52] Carl G.Hempel; Fundamentals of Concept Formation in Empirical Science, (Otto Neurath et al. (eds.); International Encyclopedia of Unified Science, Vol.II, No.7 (1952)), Chicago, 1952

[Hemp63] Carl G.Hempel; Implications of Carnap's work for the philosophy of science, in: [Schi63], 685709

[Hemp65a] Carl G.Hempel; Aspects of Scientific Explanation, New York, 1965

[Hemp65b] Carl G.Hempel; Empiricist Criteria of Cognitive Significance: Problems and Changes, in: [Hemp65a], 101-122

[Hemp65c] Carl G.Hempel; The Theoretician's Dilemma: A Study in the Logic of Theory Construction, in: [Hemp65a], 173-226, (zuerst in: [FeSM58], 37-98)

[Hemp65d] Carl G.Hempel; Aspects of Scientific Explanation, in: [Hemp65a], 331-496

[Hemp66] Carl G.Hempel; Philosophy of Natural Science, Englewood Cliffs, NJ, 1966

[Hemp70] Carl G.Hempel; On the "Standard Conception" of Scientific Theories, in: [RaWi70], 142-163

[Hemp73] Carl G.Hempel; The meaning of theoretical terms: A critique of the standard empiricist construal, in: [Supp73], 367-378

[Henr83] Dieter Henrich (Hg.); Kant oder Hegel? (Stuttgarter Hegel-Kongreß 1981), Stuttgart, 1983

[Hilg94] Jan Hilgevoord (ed.); Physics and our view of the world, Cambridge, 1994

[Hitc92] Christopher Read Hitchcock; Causal explanation and scientific realism, Erkenntnis 37 (1992), $151-178$

[HoLu82] M. Hollis, S.Lukes (eds.); Rationality and Relativism, Oxford, 1982

[HoRo94] Carl Hoefer, Alexander Rosenberg; Empirical equivalence, underdetermination, and systems of the world, Philosophy of Science 61 (1994), 592-607

[HoUr93] Colin Howson, Peter Urbach; Scientific Reasoning: The Bayesian Approach, 2nd ed., Chicago, 1993

[Holl65] R.F.Holland; The miraculous, American Philosophical Quarterly 2 (1965), 43-51

[Horw82a] Paul Horwich; Three forms of realism, Synthese 51 (1982), 181-201

[Horw96] Paul Horwich; Realism and Truth, in: [Tomb96], 187-197

[Hows97] Colin Howson; A Logic of Induction, Philosophy of Science 64 (1997), 268-290

[Hoyn93] Paul Hoyningen-Huene; Reconstructing scientific revolutions, Chicago, 1993

[HuFB94] David L.Hull, M.Forbes, Richard M.Burian (eds.); PSA 1994, vol.1, East Lansing, MI, 1994

[HuFO93] D.Hull, M.Forbes, K.Okruhlik (eds.); PSA 1992, vol.2, East Lansing, MI, 1993 
[Hump37] A.W.Humphreys; The development of the conception and measurement of electric current, Annals of Science 2 (1937), 164-178

[Hutt96] Andreas Hüttemann; Idealisierungen und das Ziel der Physik: eine Untersuchung zum Realismus, Empirismus und Konstruktivismus in der Wissenschaftstheorie, Berlin, 1996

[JaTe85] Peter Janich, Holm Tetens; Protophysik. Eine Einführung, Philosophia Naturalis 22 (1985), $3-21$

[Jack78] Josef Jäckle; Einführung in die Transporttheorie, Braunschweig, 1978

[Jose80] Geoffrey Joseph; The many sciences and the one world, Journal of Philosophy 77 (1980), $773-791$

[KaAc87] Robert Kargon, Peter Achinstein (eds.); Kelvin's Baltimore Lectures and Modern Theoretical Physics, Cambridge, MA, 1987

[KeSc00] Geert Keil, Herbert Schnädelbach (Hg.); Naturalismus, Frankfurt, 2000

[KiSa89] Philip Kitcher, Wesley Salmon (eds.); Scientific Explanation, (Minnesota Studies in the Philosophy of Science, vol. XIII), Minneapolis, 1989

[Kim77] Jaegwon Kim; Perception and reference without causality, Journal of Philosophy 74 (1977), 606-620

[Kim84] Jaegwon Kim; Concepts of Supervenience, Philosophy and Phenomenological Research 45 (1984), 153-176 (auch in: [Kim93], 53-78)

[Kim93] Jaegwon Kim; Supervenience and Mind, Cambridge, 1993

[Kitc83] Philip Kitcher; The Nature of Mathematical Knowledge, New York, 1983

[Kitc92] Philip Kitcher; The Naturalists Return, The Philosophical Review 101 (1992), 53-114

[Kitc93] Philip Kitcher; The Advancement of Science, New York, 1993

[Kitt88] Charles Kittel; Einführung in die Festkörperphysik, 7.Auflage, München, 1988 (englisches Original: Introduction to Solid State Physics, 6th edition, New York, 1986)

[KlMa86] A.David Kline, Carl A.Matheson; How the laws of physics don't even fib, in: [FiMa86], 33-41

[KnKW80] Karin Knorr, Roger Krohn, Richard Whitley (eds.); The Social Process of Scientific Investigation. Sociology of the Sciences, Vol.IV, Dordrecht, 1980

[Knor95] Karin Knorr-Cetina; How Superorganisms Change: Consensus Formation and the Social Ontology of High-Energy Physics Experiments, Social Studies of Science 25 (1995), 119-147

[Krip71] Saul A.Kripke; Identity and Necessity, in: [Muni71], 135-164

[Krip80] Saul A.Kripke; Naming and Necessity, Oxford, 1980, (zuerst in: [HaDa72], 253-355)

[Krip86] Saul A.Kripke; A problem in the theory of reference: the linguistic division of labor and the social character of naming,

in: [Cauc86], 241-247

[Kroo85] Frederick W.Kroon; Theoretical terms and the causal view of reference, Australasian Journal of Philosophy 63 (1985), 143-166

[Krug81] Lorenz Krüger; Vergängliche Erkenntnis der beharrenden Natur, in: [Pose81], 223-249

[Krug83] Lorenz Krüger; Empirismus oder Realismus — eine Alternative in der Wissenschaftstheorie?, in: [FrZe83], 569-587

[Krug89] Lorenz Krüger; Materie für uns und an sich — Was sind primäre Eigenschaften?, Jahrbuch der Akademie der Wissenschaften in Göttingen 1989, 69-89

[Kuhn70] Thomas S.Kuhn; The Structure of Scientific Revolutions, 2nd. ed., (Otto Neurath et al. (eds.); International Encyclopedia of Unified Science, Vol.II, No.2 (1970)), Chicago, 1970

[Kuhn77a] Thomas S.Kuhn; The Essential Tension, Chicago, 1977

[Kuhn77b] Thomas S.Kuhn; The Relations between the History and the Philosophy of Science, in: [Kuhn77a], 3-20

[Kuhn89] Thomas S.Kuhn; Possible Worlds in History of Science, in: [Alle89], 9-32 
[Kuhn90] Thomas S.Kuhn; Dubbing and Redubbing: The Vulnerability of Rigid Designation, in: [Sava90], $298-318$

[Kukl94] André Kukla; Scientific Realism, Scientific Practice, and the Natural Ontological Attitude, British Journal for the Philosophy of Science 45 (1994), 955-975

[Kukl96] André Kukla; The Theory-Observation Distinction, The Philosophical Review 105 (1996), $173-230$

[LaJo80] Goerge Lakoff, Mark Johnson; Metaphors We Live By, Chicago, 1980

[LaLe91] Larry Laudan, Jarrett Leplin; Empirical equivalence and underdetermination, Journal of Philosophy 88 (1991), 449-472

[Laka68] Imre Lakatos (ed.); The Problem of Inductive Logic, Amsterdam, 1968

[Lako87] George Lakoff; Women, Fire, and Dangerous Things, Chicago, 1987

[Lato88] Bruno Latour; A Relativistic Account of Einstein's Relativity, Social Studies of Science 18 (1988), 3-44

[Laud81] Larry Laudan; A confutation of convergent realism, Philosophy of Science 48 (1981), 19-49

[Laud84] Larry Laudan; Explaining the Success of Science: Beyond Epistemic Realism and Relativism, in: [CuDG84], 83-105

[Laud87] Larry Laudan; Progress or rationality? The prospects for normative naturalism, American Philosophical Quarterly 24 (1987), 19-31

[Laym89] Ronald Laymon; Cartwright and the lying laws of physics, Journal of Philosophy 86 (1989), 353-372

[LeSa95] Paolo Leonardi, Marco Santambrogio (eds.); On Quine, Cambridge, 1995

[Leed94] Stephen Leeds; Constructive Empiricism, Synthese 101 (1994), 187-221

[Leed97] Stephen Leeds; Incommensurability and Vagueness, Noûs 31 (1997), 385-407

[Lepl84] Jarrett Leplin (ed.); Scientific Realism, Berkeley, 1984

[Lep197] Jarrett Leplin; A Novel Defense of Scientific Realism, New York, 1997

[Lewi72] David Lewis; Psychophysical and theoretical identifications, Australasian Journal of Philosophy 50 (1972), 249-258

[Lewi83a] David Lewis; Philosophical Papers, vol.1, Oxford, 1983

[Lewi83b] David Lewis; How To Define Theoretical Terms, in: [Lewi83a], 78-95, (zuerst in: Journal of Philosophy 67 (1970), 427-446)

[Lipt91] Peter Lipton; Inference to the best explanation, London, 1991

[Litt95] Daniel Little (ed.); On the reliability of economic models, Dordrecht, 1995

[Loar87] Brian Loar; Truth beyond all verification, in: [Tayl87], 81-116

[Mahe93] Patrick Maher; Betting on Theories, New York, 1993

[Mate78] Benson Mates; Elementare Logik, 2.Aufl., Göttingen, 1978

[Math98] Carl Matheson; Why the no-miracles argument fails, International Studies in the Philosophy of Science 12 (1998), 263-279

[Maxw62] Grover Maxwell; The Ontological Status of Theoretical Entities, in: [FeMa62], 3-27

[McCu89] Gregory McCulloch; The Game of the Name, Oxford, 1989

[McLa93] Peter McLaughlin; Der neue Experimentalismus in der Wissenschaftstheorie, in: [RhHa93], 207-218

[McMu78] Ernan McMullin; Structural Explanation, American Philosophical Quarterly 15 (1978), 139147

[McMu83] Ernan McMullin; Values in Science, in: [AsNi83], 3-28

[McMu84] Ernan McMullin; A Case for Scientific Realism, in: [Lepl84], 8-40

[McMu91] Ernan McMullin; Selective Anti-Realism, Philosophical Studies 61 (1991), 97-108

[McMu92] Ernan McMullin (ed.); The Social Dimensions of Science, Notre Dame, IN, 1992

[McMu94] Ernan McMullin; Enlarging the known world, in: [Hilg94], 79-113 
[McTu97] Vaughn R.McKim, Stephen P.Turner (eds.); Causality in Crisis?, Notre Dame, IN, 1997

[Megg97] Georg Meggle (ed.); Analyomen 2, vol.I, Berlin, 1997

[Mell77] D.Hugh Mellor; Natural Kinds, British Journal for the Philosophy of Science 28 (1977), 299312

[Mell80] D.H.Mellor (ed.); Science, belief and behaviour, Cambridge, 1980

[Mill74] David Miller; Popper's qualitative theory of verisimilitude, British Journal for the Philosophy of Science 25 (1974), 166-177

[Mitt95] Jürgen Mittelstraß (Hg.); Enzyklopädie Philosophie und Wissenschaftstheorie, Stuttgart, 1995

[Morr90a] Margaret Morrison; Theory, Intervention and Realism, Synthese 82 (1990), 1-22

[Morr94] Margaret Morrison; Causes and Contexts: The Foundations of Laser Theory, British Journal for the Philosophy of Science 45 (1994), 127-151

[MuUn74] Milton K.Munitz, Peter K.Unger (eds.); Semantics and Philosophy, New York, 1974

[Muni71] Milton Munitz (ed.); Identity and Individuation, New York, 1971

[Musg74] Alan Musgrave; Logical versus Historical Theories of Confirmation, British Journal for the Philosophy of Science 25 (1974), 1-23

[Musg85] Alan Musgrave; Realism versus constructive empiricism, in: [ChHo85], 197-221

[Musg88] Alan Musgrave; The ultimate argument for scientific realism, in: [Nola88], 229-252

[Nage50] Ernest Nagel; Science and semantic realism, Philosophy of Science 17 (1950), 174-181

[Nage79] Ernest Nagel; The structure of science, Indianapolis, 1979

[Nage86] Thomas Nagel; The view from nowhere, Oxford, 1986

[MeSm78] William Newton-Smith; The underdetermination of theory by data, Aristotelian Society Supplementary Volume 52 (1978), 71-91

[NeSm81] William Newton-Smith; The Rationality of Science, London, 1981

[Need91] Paul Needham; Duhem and Cartwright on the truth of laws, Synthese 89 (1991), 89-109

[Nels94] Alan Nelson; How Could Scientific Facts be Socially Constructed?, Studies in History and Philosophy of Science 25 (1994), 535-547

[Ners87] Nancy Nersessian (ed.); The Process of Science, Dordrecht, 1987

[Nick78] Thomas Nickles; Scientific Problems and Constraints, in: [HaAs78], 134-148

[Nick80a] Thomas Nickles (ed.); Scientific Discovery, Logic, and Rationality, Dordrecht, 1980

[Nick80b] Thomas Nickles; Can scientific constraints be violated rationally?, in: [Nick80a], 285-315

[Niin87] Ilkka Niiniluoto; Truthlikeness, Dordrecht, 1987

[Niin97a] Ilkka Niiniluoto; Theoretical Reference and Truthlikeness, in: [Megg97], 439-452

[Niin97b] Ilkka Niiniluoto; Reference Invariance and Truthlikeness, Philosophy of Science 64 (1997), 546-554

[Nola80] Robert Nola; Fixing the reference of theoretical terms, Philosophy of Science 47 (1980), 505531

[Nola88] Robert Nola (ed.); Relativism and Realism in Science, Dordrecht, 1988

[Nort94] John Norton; Science and Certainty, Synthese 99 (1994), 3-22

[Oddi86] Graham Oddie; Likeness to Truth, Dordrecht, 1986

[Orto79] Andrew Ortony (ed.); Metaphor and Thought, Cambridge, 1979

[Pais82] Abraham Pais; 'Subtle is the Lord ...', Oxford, 1982

[Pais86] Abraham Pais; Inward Bound, Oxford, 1986

[Papi93] David Papineau; Philosophical Naturalism, Oxford, 1993

[Papp79] George S.Pappas (ed.); Justification and Knowledge, Dordrecht, 1979

[Peir34a] Charles Sanders Peirce; Collected Papers of Charles Sanders Peirce, vol.V (ed. by Charles Hartshorne, Paul Weiss), Cambridge, MA, 1934

[Peir34b] Charles Sanders Peirce; Lectures on Pragmatism, in: [Peir34a], 13-131 
[Peir98] Charles Sanders Peirce; The essential Peirce: Selected philosophical writings, vol.2, Bloomington, IN, 1998

[Pett91] Philip Pettit; Realism and Response-Dependence, Mind 100 (1991), 587-626

[Pick80] Andrew Pickering; The role of interests in high-energy physics, in: [KnKW80], 107-138

[Pick84] Andrew Pickering; Constructing Quarks, Edinburgh, 1984

[Pick90] Andrew Pickering; Knowledge, Practice and Mere Construction, Social Studies of Science 20 (1990), 682-729

[Pick92] Andrew Pickering (ed.); Science As Practice And Culture, Chicago, 1992

[Pick95a] Andrew Pickering; Beyond Constraint: The Temporality of Practice and the Historicity of Knowledge, in: [Buch95], 42-55

[Pick95b] Andrew Pickering; The Mangle of Practice, Chicago, 1995

[Pinc86] Trevor Pinch; Confronting Nature: The Sociology of Solar Neutrino Detection, Dordrecht, 1986

[Pitt85] Joseph C.Pitt (ed.); Change and Progress in Modern Science, Dordrecht, 1985

[Plan49a] Max Planck; Vorträge und Erinnerungen, 5.Auflage, Stuttgart, 1949

[Plan49b] Max Planck; Die Einheit des physikalischen Weltbildes, in: [Plan49a], 28-51

[PoEc77] Karl R.Popper, John C.Eccles; The Self and Its Brain, Berlin, 1977

[Pohl75] Robert Wichard Pohl; Elektrizitätslehre, 21.Auflage, Berlin, 1975

[Polk86] John Polkinghorne; One world, Princeton, NJ, 1986

[Popp63a] Karl R.Popper; Conjectures and Refutations, London, 1963

[Popp63b] Karl R.Popper; Truth, Rationality, and the Growth of Scientific Knowledge, in: [Popp63a], $215-250$

[Popp67] Karl R.Popper; Quantum Mechanics without "The Observer", in: [Bung67], 7-44

[Pose81] Hans Poser (Hg.); Wandel des Vernunftbegriffs, Freiburg, 1981

[Psil95] Stathis Psillos; Is Structural Realism the Best of Both Worlds?, Dialectica 49 (1995), 15-46

[Psil96] Stathis Psillos; Scientific realism and the 'pessimistic induction', Philosophy of Science 63 (1996), (Proceedings), S306-S314

[Psil99] Stathis Psillos; Scientific Realism, London, 1999

[Purc83] Edward M.Purcell; Elektrizität und Magnetismus, 3.Auflage, Braunschweig, 1983 (englisches Original: Electricity and Magnetism, New York, 1965)

[Putn71] Hilary Putnam; Philosophy of Logic, New York, 1971 (wiederabgedruckt in [Putn75a], 323-357)

[Putn75a] Hilary Putnam; Mathematics, Matter and Method, Philosophical Papers, Vol.1, Cambridge, 1975

[Putn75b] Hilary Putnam; Mind, Language, and Reality, Philosophical Papers, Vol.2, Cambridge, 1975

[Putn75c] Hilary Putnam; What is mathematical truth?, in: [Putn75a], 60-78

[Putn75d] Hilary Putnam; What theories are not, in: [Putn75a], 215-227

[Putn75e] Hilary Putnam; The analytic and the synthetic, in: [Putn75b], 33-69

[Putn75f] Hilary Putnam; How not to talk about meaning, in: [Putn75b], 117-131

[Putn75g] Hilary Putnam; Is semantics possible?, in: [Putn75b], 139-152

[Putn75h] Hilary Putnam; Explanation and reference, in: [Putn75b], 196-214

[Putn75i] Hilary Putnam; The meaning of "meaning", in: [Putn75b], 215-271

[Putn75j] Hilary Putnam; Language and reality, in: [Putn75b], 272-290

[Putn78] Hilary Putnam; Meaning and the Moral Sciences, London, 1978

[Putn81] Hilary Putnam; Reason, Truth and History, Cambridge, 1981

[Putn83a] Hilary Putnam; Realism and Reason, Philosophical Papers, Vol.3, Cambridge, 1983

[Putn83b] Hilary Putnam; Models and reality, in: [Putn83a], 1-25 
[Putn83c] Hilary Putnam; Reference and truth, in: [Putn83a], 69-86

[Putn83d] Hilary Putnam; Why there isn't a ready-made world, in: [Putn83a], 205-228

[Putn87a] Hilary Putnam; The Many Faces of Realism, La Salle, IL, 1987

[Putn87b] Hilary Putnam; Meaning Holism and Epistemic Holism, in: [Cram87], 251-277

[Putn88] Hilary Putnam; Representation and Reality, Cambridge, MA, 1988

[Putn90a] Hilary Putnam; Realism with a Human Face, Cambridge, MA, 1990

[Putn90b] Hilary Putnam; Is Water Necessarliy $\mathrm{H}_{2} \mathrm{O}$ ?, in: [Putn90a], 54-79

[Putn90c] Hilary Putnam; Meaning Holism, in: [Putn90a], 278-302, (zuerst in: [HaSc86], 405-426)

[Putn92] Hilary Putnam; Renewing Philosophy; Cambridge, MA, 1992

[QuU170] Willard Van Orman Quine, J.S.Ullian; The Web of Belief, New York, 1970

[Quin53a] Willard Van Orman Quine; From a logical point of view, Cambridge, MA, 1953

[Quin53b] Willard Van Orman Quine; On what there is, in: [Quin53a], 1-19

[Quin53c] Willard Van Orman Quine; Two dogmas of empiricism, in: [Quin53a], 20-46

[Quin60] Willard Van Orman Quine; Word and Object, Cambridge, MA, 1960

[Quin75] Willard Van Orman Quine; On empirically equivalent systems of the world, Erkenntnis 9 (1975), 313-328

[Quin76a] Willard Van Orman Quine; The Ways of Paradox and Other Essays, revised edition, Cambridge, MA, 1976

[Quin76b] Willard Van Orman Quine; Carnap and Logical Truth, in: [Quin76a], 107-132

[Quin76c] Willard Van Orman Quine; Posits and Reality, in: [Quin76a], 246-254

[Quin81a] Willard Van Orman Quine; Theories and Things, Cambridge, MA, 1981

[Quin81b] Willard Van Orman Quine; Things and Their Place in Theories, in: [Quin81a], 1-23

[Quin81c] Willard Van Orman Quine; Empirical content, in: [Quin81a], 24-30

[Quin81d] Willard Van Orman Quine; Success and Limits of Mathematization, in: [Quin81a], 148-155

[Quin91] Willard Van Orman Quine; Two Dogmas in Retrospect, Canadian Journal of Philosophy 21 (1991), 265-274

[RaCh01] Nicolas Rasmussen, Alan Chalmers; The Role of Theory in the Use of Instruments; or, How Much Do We Need To Know about Electrons to Do Science with an Electron Microscope?, in: [BuWa01], 467-502

[RaWi70] Michael Radner, Stephen Winokur (eds.); Analyses of Theories and Methods of Physics and Psychology, (Minnesota Studies in the Philosophy of Science, vol. IV), Minneapolis, 1970

[Rait99] Wilhelm Raith; Lehrbuch der Experimentalphysik/Bergmann; Schaefer, Band 2, Elektromagnetismus, Berlin, 1999

[RePi95] Richard Reiner, Robert Pierson; Hacking's Experimental Realism: An Untenable Middle Ground, Philosophy of Science 62 (1995), 60-69

[Reic30] Hans Reichenbach; Atom und Kosmos, Berlin, 1930

[Reic53] Hans Reichenbach; The Verificability Theory of Meaning, in: [FeBr53], 93-102, (zuerst in: Proceedings of the American Academy of Arts and Sciences 80 (1951), 46-60)

[Reic56] Hans Reichenbach; The Direction of Time, Berkeley, 1956

[Resn94] David Resnik; Hacking's Experimental Realism, Canadian Journal of Philosophy 24 (1994), 395-412

[Rey98] Georges Rey; A naturalistic apriori, Philosophical Studies 92 (1998), 25-43

[RhHa93] Hans-Jörg Rheinberger, Michael Hagner (Hg.); Die Experimentalisierung des Lebens, Berlin, 1993

[RoBa90] Paul Roth, Robert Barrett; Deconstructing Quarks, Social Studies of Science 20 (1990), 579632

[Rohr97] Fritz Rohrlich; Cognitive Emergence, Philosophy of Science 64 (1997), S346-S358 
[Russ18a] Bertrand Russell; Mysticism and Logic, New York, 1918

[Russ18b] Bertrand Russell; The Relation of Sensa-data to Physics, in:[Russ18a], 140-172

[Russ18c] Bertrand Russell; On the Notion of Cause, in: [Russ18a], 173-199

[Russ18d] Bertrand Russell; Knowledge by Acquaintance and Knowledge by Description, in: [Russ18a], 200-221

[Ryle49] Gilbert Ryle; The concept of mind, London, 1949

[SaMC88] Geoffrey Sayre-McCord (ed.); Essays on Moral Realism, Ithaka, NY, 1988

[SaNS57] Chih-Tang Sah, Robert N.Noyce, William Shockley; Carrier Generation and Recombination in $P-N$ Junctions and $P-N$ Junction Characteristics, Proceedings of the IRE 45 (1957), 1228-1243

[Salm84] Wesley Salmon; Scientific Explanation and the Causal Structure of the World, Princeton, 1984

[Salm92] Merrliee H. Salmon et al.; Introduction to the Philosophy of Science, Englewood Cliffs, NJ, 1992

[Salm94] Wesley Salmon; Causality without counterfactuals, Philosophy of Science 61 (1994), 297-312

[Sava90] C.Wade Savage (ed.); Scientific Theories, (Minnesota Studies in the Philosophy of Science, vol.XIV), Minneapolis, 1990

[Schi63] Paul A.Schilpp (ed.); The Philosophy of Rudolf Carnap, La Salle, IL, 1963

[Schl38a] Moritz Schlick; Gesammelte Aufsätze, Wien, 1938

[Schl38b] Moritz Schlick; Die Kausalität in der gegenwärtigen Physik, in: [Schl38a], 41-82 (zuerst in: Die Naturwissenschaften 19 (1931), 145-162)

[Schl38c] Moritz Schlick; Meaning and verification, in: [Schl38a], 337-367 (zuerst in: Philosophical Review 44 (1936), 339-369)

[Seag95] William Seager; Groud truth and virtual reality: Hacking vs. van Fraassen, Philosophy of Science 62 (1995), 459-478

[Sell63] Wilfrid Sellars; Science, perception and reality, Atascadero, CA, 1963

[ShNa87] Abner Shimony, Debra Nails (eds.); Naturalistic Epistemology, Dordrecht, 1987

[Shap69] Dudley Shapere; Notes toward a post-positivistic interpretation of science, in: [AcBa69], 115160

[Shap82a] Dudley Shapere; Reason, reference, and the quest for knowledge, Philosophy of Science 49 (1982), 1-23

[Shap82b] Dudley Shapere; The concept of observation in science and philosophy, Philosophy of Science 49 (1982), 485-525

[Shap89] Dudley Shapere; Evolution and continuity in scientific change, Philosophy of Science 56 (1989), 419-437

[Shap93] Dudley Shapere; Astronomy and Antirealism, Philosophy of Science 60 (1993), 134-150

[Sism93] Sergio Sismondo; Some Social Constructions, Social Studies of Science 23 (1993), 515-553

[Skir77] Gunnar Skirbekk (Hg.); Wahrheitstheorien, Frankfurt am Main, 1977

[Smar63] John J.C.Smart; Philosophy and Scientific Realism, London, 1963

[Smar68] John J.C.Smart; Between Science and Philosophy, New York, 1968

[Smar87a] John J.C.Smart; Essays Metaphysical and Moral, Oxford, 1987

[Smar87b] John J.C.Smart; Difficulties for Realism in the Philosophy of Science, in: [Smar87a], 132-144 (zuerst in: [Cohe82], 363-375)

[Smit98] Peter Smith; Approximate Truth and Dynamical Theories, British Journal for the Philosophy of Science 49 (1998), 253-277

[SoTo93] Ernest Sosa, Michael Tooley (eds.); Causation, Oxford, 1993

[Sobe84] Elliott Sober; Common cause explanation, Philosophy of Science 51 (1984), 212-241

[Sobe88] Elliott Sober; The principle of the common cause, in: [Fetz88], 211-228

[Sosa91a] Ernest Sosa; Knowledge in Perspective, Cambridge, 1991 
[Sosa94a] Ernest Sosa; Philosophical scepticism and epistemic circularity, Proceedings of the Aristotelian Society Suppl. 68 (1994), 263-290

[Sosa94b] Ernest Sosa; Virtue Perspectivism: A Response to Foley and Fumerton, in: [Vill94], 29-50

[Sosa95] Ernest Sosa; Perspectives in virtue epistemology: A response to Dancy and Bonjour, Philosophical Studies 78 (1995), 221-235

[Sosa97] Ernest Sosa: Reflective knowledge in the best circles, Journal of Philosophy 94 (1997), 410-430

[Sosa99] Ernest Sosa; Existential Relativity, in: [FrWe99], 132-143

[SpGS93] Peter Spirtes, Clark Glymour, Richard Scheines (eds.); Causation, Prediction, and Search, New York, 1993

[StVa83] John T.Stock, Denys Vaughan; The Development of Instruments to Measure Electric Current, London, 1983

[Stad93] Friedrich Stadler (ed.); Scientific Philosophy: Origins and Developments, Dordrecht, 1993

[Stal74] Robert C.Stalnaker; Pragmatic Presuppositions, in: [MuUn74], 197-213

[Stap94] Timothy J.Stapledon (ed.); The Question of Hermeneutics, Dordrecht, 1994

[Steg70] Wolfgang Stegmüller; Probleme und Resultate der Wissenschaftstheorie und Analytischen Philosophie, Band II, Theorie und Erfahrung, Berlin, 1970

[Stei87] Howard Stein; After the Baltimore Lectures: Some Philosophical Reflections on Subsequent and Modern Theoretical Physics, in: [KaAc87], 375-398

[Stei89] Howard Stein; Yes, but... Some Sceptical Remarks on Realism and Anti-Realism, Dialectica 43 (1989), 47-65

[Stra71a] Peter F.Strawson; Logico-Linguistic Papers, London, 1971

[Stra71b] Peter F.Strawson; On Referring, in: [Stra71a], 1-27

(zuerst in: Mind 59 (1950), 320-344)

[Stro68] Barry Stroud; Transcendental arguments, Journal of Philosophy 65 (1968), 241-256

[Stro89] Barry Stroud; Understanding Human Knowledge in General, in: [ClLe89], 31-50

[Stro94] Barry Stroud; Scepticism, 'externalism', and the goal of epistemology, Proceedings of the Aristotelian Society Suppl. 68 (1994), 292-307

[Supp73] Patrick Suppes et al. (eds.); Logic, Methodology and Philosophy of Science IV, Amsterdam, 1973

[Supp72] Frederick Suppe; What's wrong with the Received View on the structure of scientific theories?, Philosophy of Science 39 (1972), 1-19

[Supp74] Frederick Suppe (ed.); The Structure of Scientific Theories, Urbana, IL, 1974

[Tars35] Alfred Tarski; Der Wahrheitsbegriff in den formalisierten Sprachen, Studia Philosophica 1 (1935), 261-405 (auch in: [BeKr86], 445-546)

[Ta43/44] Alfred Tarski; The semantic conception of truth, Philosopy and Phenomenological Research 4 (1943/44), 341-375

[Tayl87] Barry Taylor (ed.); Michael Dummett, Dordrecht, 1987

[Tell83] Paul Teller; A poor man's guide to supervenience and determination, Southern Journal of Philosophy 22 (1983), Supplement, 137-167

[Tete87] Holm Tetens; Experimentelle Erfahrung, Hamburg, 1987

[Tomb87] James E.Tomberlin (ed.); Philosophical Perspectives, 1, Metaphysics, Atascadero, CA, 1987

[Tomb96] James E.Tomberlin (ed.); Philosophical Perspectives, 10, Metaphysics, (Supplement to Noûs), Cambridge, MA, 1996

[Topi60] Ernst Topitsch (Hg.); Probleme der Wissenschaftstheorie, Wien, 1960

[Traw88] Sharon Traweek; Beamtimes and Lifetimes, Cambridge, MA, 1988

[Trou92] J.D.Trout; Theory-Conjunction and Mercenary Reliance, Philosophy of Science 59 (1992), $231-245$ 
[Tsch93] Frank Tschepke; Verisimilitudo oder Wahrscheinlichkeit? - über formale Präzisierungen des wissenschaftlichen Fortschritts, Magisterarbeit, Göttingen, 1993

[vDal83] Dirk van Dalen; Logic and Structure, 2nd. ed., Berlin, 1983

[vFra80] Bas van Fraassen; The Scientific Image, Oxford, 1980

[vFra85] Bas van Fraassen; Empiricism in the Philosophy of Science, in: [ChHo85], 245-308

[vFra87] Bas van Fraassen; The Semantic Approach to Scientific Theories, in: [Ners87], 105-124

[vFra89a] Bas van Fraassen; Laws and Symmetry, Oxford, 1989

[vFra90] Bas van Fraassen; Figures in a probability landscape, in: [DuGu90], 345-356

[vFra91] Bas van Fraassen; Quantum Mechanics: An Empiricist View, Oxford, 1991

[vFra92] Bas van Fraassen; From Vicious Circle to Infinite Regress, and Back Again, in: [HuFO93], 6-29

[vFra94a] Bas van Fraassen; Against transcendental empiricism, in: [Stap94], 309-335

[vFra94b] Bas van Fraasen; The world of empiricism, in: [Hilg94], 114-134

[vFra95] Bas van Fraassen; Against Naturalized Epistemology, in: [LeSa95], 68-88

[vFra98] Bas van Fraassen; The agnostic subtly probabilified, Analysis 58 (1998), 212-220

[vWri71] Georg Henrik von Wright; Explanation and Understanding, Ithaca, NY, 1971

[vWri93] Georg Henrik von Wright; On the logic and epistemology of the causal relation, in: [SoTo93], 105-124

(zuerst in: [Supp73], 293-312)

[Vill94] Enrique Villanueva (ed.); Truth and Rationality, (Philosophical Issues 5), Atascadero, CA, 1994

[Wais30] Friedrich Waismann; Logische Analyse des Wahrscheinlichkeitsbegriffs, Erkenntnis 1 (1930), 228-248

[Wald84] Robert M.Wald; General Relativity, Chicago, 1984

[Wein95] Friedel Weinert (ed.); The Laws of Nature, Berlin, 1995

[West74] Wilhelm H.Westphal; Physikalisches Praktikum, 13.Auflage, Braunschweig, 1974

[West92] Thomas Weston; Approximate truth and scientific realism, Philosophy of Science 59 (1992), $53-74$

[Whew47] William Whewell; The Philosophy of the Inductive Sciences, Founded upon their History, 2nd ed., London, 1847

[Wign79a] Eugene P.Wigner; Symmetries and Reflections, Woodbridge, CT, 1979

[Wign79b] Eugene P.Wigner; The Unreasonable Effectiveness of Mathematics in the Natural Sciences, in: [Wign79a], 222-237

[Wilk93] T.E.Wilkerson; Species, essences and the names of natural kinds, Philosophical Quarterly 43 (1993), 1-19

[Wims81] William C.Wimsatt; Robustness, Reliability, and Overdetermination, in: [BrCo81], 124-163

[Witt67] Ludwig Wittgenstein; Ludwig Wittgenstein und der Wiener Kreis, Aufzeichnungen von Friedrich Waismann, (Schriften 3), Frankfurt, 1967

[Wolt87] Nicholas Wolterstorff; Are concept-users world-makers?, in: [Tomb87], 233-267

[Worr84] John Worrall; An Unreal Image, British Journal for the Philosophy of Science 35 (1984), 65-80

[Worr85] John Worrall; Scientific discovery and theory-confirmation, in: [Pitt85], 301-331

[Worr89] John Worrall; Structural Realism: The Best of Both Worlds?, Dialectica 43 (1989), 99-124

[Wrig92] Crispin Wright; Truth and Objectivity, Cambridge, MA, 1992

[Wrig93] Crispin Wright; Scientific Realism and Observation Statements, International Journal of Philosophical Studies 1 (1993), 231-254

[Wrig91] John Wright; Science and the Theory of Rationality, Aldershot, 1991

[Zema76] Eddy M.Zemach; Putnam's theory on the reference of substance terms, Journal of Philosophy 73 (1976), 116-127

[Zima72] John M.Ziman; Principles of the Theory of Solids, 2nd. ed., London, 1972 
Hiermit versichere ich an Eides statt, daß ich die eingereichte Dissertation "Wissenschaftlicher Realismus" selbständig und ohne unerlaubte Hilfe verfaßt habe. Anderer als der von mir angegebenen Hilfsmittel und Schriften habe ich mich nicht bedient. Alle wörtlich oder sinngemäß den Schriften anderer Autorinnen oder Autoren entnommenen Stellen habe ich kenntlich gemacht. Die Abhandlung ist noch nicht veröffentlicht worden und noch nicht Gegenstand eines Promotionsverfahrens gewesen. 